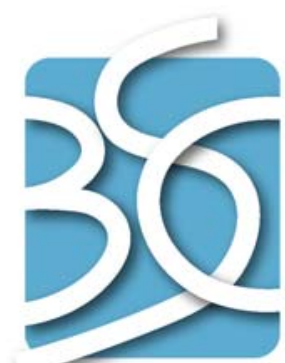

BECHTEL SAIC COMPANYLC
QA: QA

MDL-NBS-HS-000011 REV 02

November 2004

\title{
Saturated Zone Site-Scale Flow Model
}

Prepared for:

U.S. Department of Energy

Office of Civilian Radioactive Waste Management

Office of Repository Development

1551 Hillshire Drive

Las Vegas, Nevada 89134-6321

Prepared by:

Bechtel SAIC Company, LLC

1180 Town Center Drive

Las Vegas, Nevada 89144

Under Contract Number

DE-AC28-01RW12101 


\section{DISCLAIMER}

This report was prepared as an account of work sponsored by an agency of the United States Government. Neither the United States Government nor any agency thereof, nor any of their employees, nor any of their contractors, subcontractors or their employees, makes any warranty, express or implied, or assumes any legal liability or responsibility for the accuracy, completeness, or any third party's use or the results of such use of any information, apparatus, product, or process disclosed, or represents that its use would not infringe privately owned rights. Reference herein to any specific commercial product, process, or service by trade name, trademark, manufacturer, or otherwise, does not necessarily constitute or imply its endorsement, recommendation, or favoring by the United States Government or any agency thereof or its contractors or subcontractors. The views and opinions of authors expressed herein do not necessarily state or reflect those of the United States Government or any agency thereof. 
QA: QA

Saturated Zone Site-Scale Flow Model

MDL-NBS-HS-000011 REV 02

November 2004 


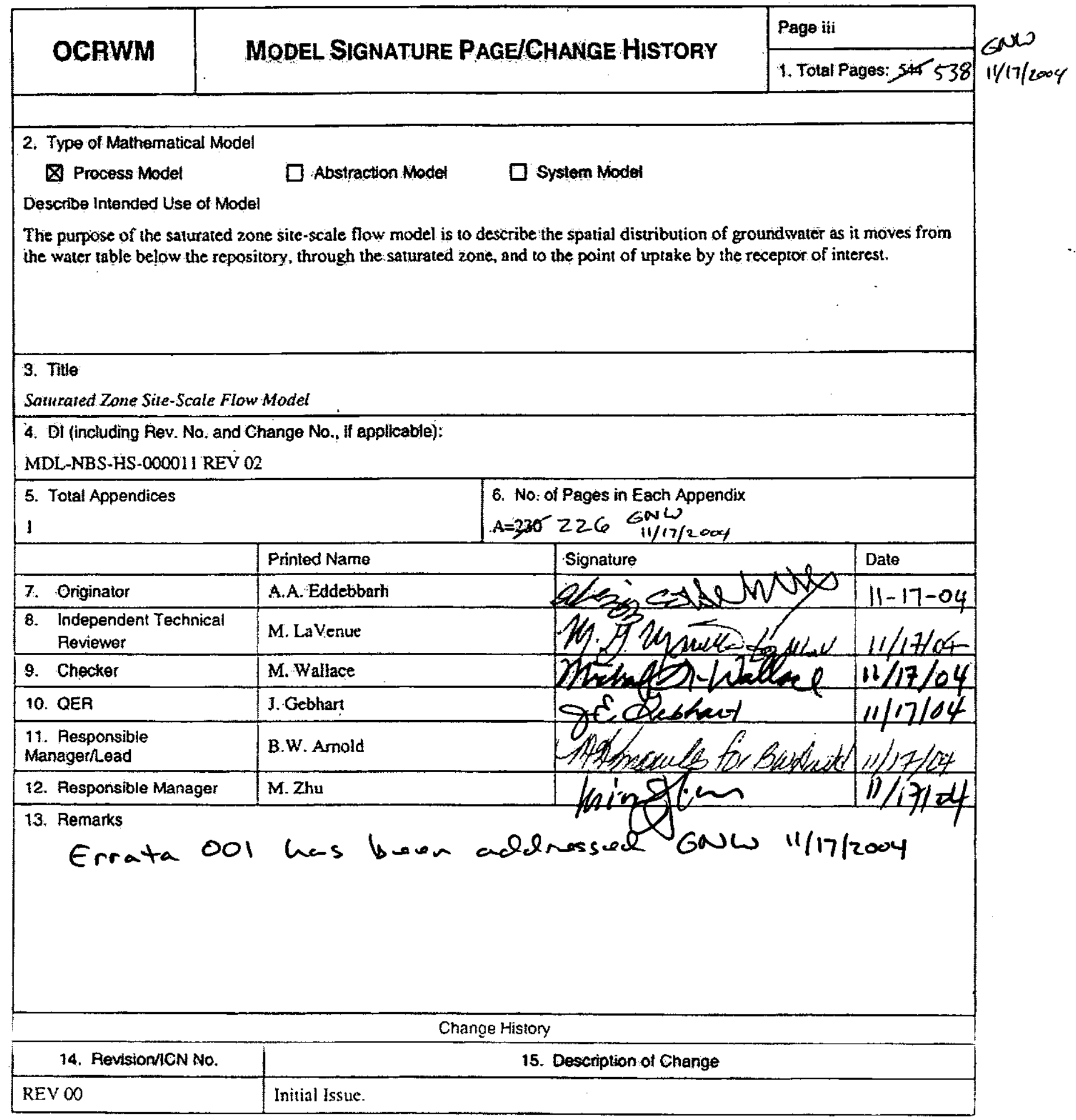




\begin{tabular}{|l|l|}
\hline REV 00, ICN 01 & $\begin{array}{l}\text { Change bars were used in REV 00, ICN 01, to indicate corrections to the original } \\
\text { document. }\end{array}$ \\
\hline REV 01 & $\begin{array}{l}\text { Change bars are not used in REV 01 because there were extensive changes to the } \\
\text { original document. }\end{array}$ \\
\hline REV 01 ERRATA 1 & Response to CR 2234. \\
\hline REV 02 & $\begin{array}{l}\text { Description and presentation of alternative model. The alternate models are developed } \\
\text { to evaluate the impact of new data and analyses on the saturated zone site-scale model } \\
\text { predictions. The new data include a revised and reinterpreted HFM conceptual model, } \\
\text { boundary fluxes and recharge derived from the 2001 regional flow model and the 2004 } \\
\text { UZ flow model, and the latest Nye County water-level data. The alternative models also } \\
\text { include the incorporation of different conceptualization of site-scale features including } \\
\text { the large hydraulic gradient, Solitario canyon fault, anisotropy etc. The revision also } \\
\text { contains as Appendix A the analysis titled "Geochemical and Isotopic Constraints on } \\
\text { Groundwater Flow." } \\
\text { This report addresses CR-1873D resulting from BSC Surveillance No. BQA-SI-04-002: } \\
\text { This report addresses comments from the Regulatory Integration Team. The entire } \\
\text { model documentation was revised, because the changes were too extensive to indicate } \\
\text { individual changes. }\end{array}$ \\
\hline
\end{tabular}




\section{CONTENTS}

Page

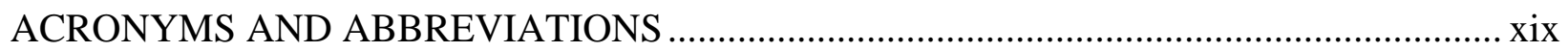

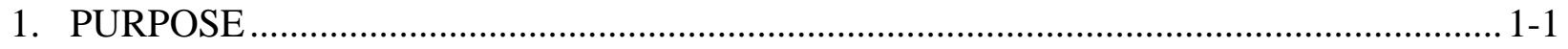

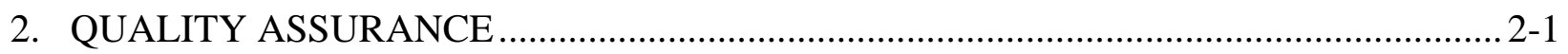

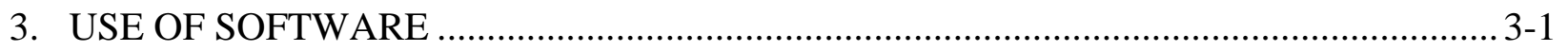

3.1 SOFTWARE TRACKED BY CONFIGURATION MANAGEMENT ........................ 3-1

3.1.1 Parameter Optimization ............................................................................... 3-3

3.1.2 Flow Modeling...................................................................................... 3-3

3.1.3 Particle Tracking ........................................................................... 3-3

3.1.4 Grid Generation ................................................................................... 3-4

3.1.5 Framework Translation...................................................................... 3-4

3.1.6 Corrections of ${ }^{14} \mathrm{C}$ Ages in Field Data ....................................................... 3-4

3.2 EXEMPT SOFTWARE ................................................................................... 3-4

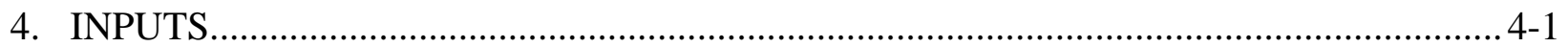

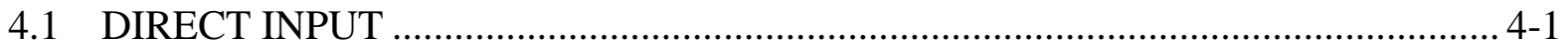

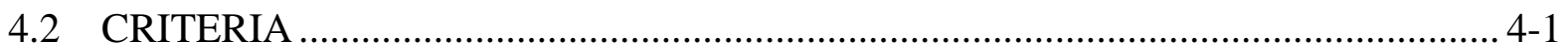

4.3 CODES, STANDARDS, AND REGULATIONS ........................................................ 4-4

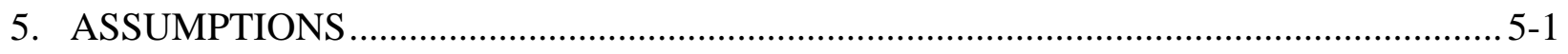

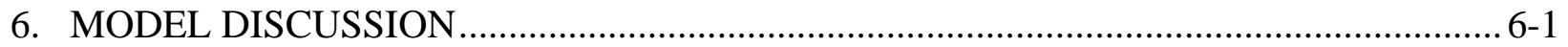

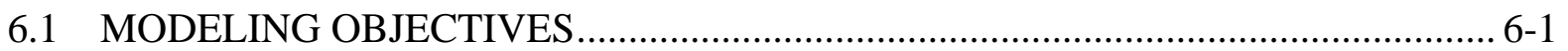

6.2 FEATURES, EVENTS, AND PROCESSES CONSIDERED IN MODEL …............. 6-1

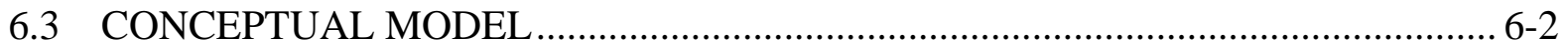

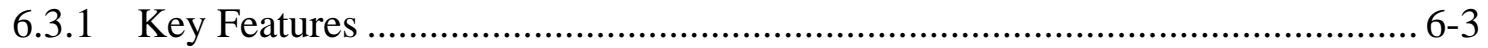

6.3.2 Components of the Base Case Conceptual Model............................................. 6-4

6.3.2.1 Groundwater Occurrence and Flow ……………………………...... 6-6

6.3.2.2 Hydrologic Features ......................................................................... 6-8

6.3.2.3 Flow Field.......................................................................... 6-11

6.3.2.4 Large, Moderate, and Small Hydraulic Gradients............................ 6-13

6.3.2.5 Vertical Gradients.................................................................. 6-14

6.3.2.6 Lateral Boundary Conditions ..................................................... 6-16

6.3.2.7 Recharge ................................................................................. 6-17

6.3.2.8 Discharge .................................................................................6-19

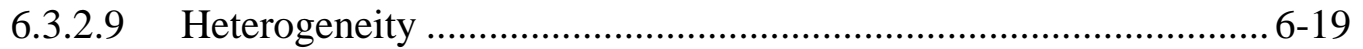

6.3.2.10 Role of Faults .............................................................................. 6-21

6.3.3 Groundwater Flow Processes.................................................................. 6-22

6.4 CONSIDERATION OF ALTERNATIVE CONCEPTUAL MODELS ……….......... 6-26

6.4.1 Large Hydraulic Gradient ........................................................................ 6-27

6.4.2 Solitario Canyon Fault .................................................................................. 6-30 


\section{CONTENTS (Continued)}

Page

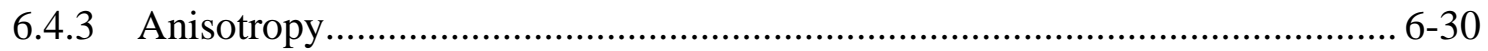

6.4.3.1 Vertical Anisotropy ...................................................................... 6-30

6.4.3.2 Horizontal Anisotropy .................................................................... 6-31

6.4.4 Potentiometric Surface (Horizontal Hydraulic Gradient) and

Water-Level Data

6.4.4.1 Water-Level Data Analysis for the SZ Site-Scale Flow Model

(Base Case Model) …………………………………………........ 6-33

6.4.4.2 Updated Water-Level Data Analysis for the SZ Site-Scale Flow Model ............................................................................... 6-34

6.4.4.3 Unsaturated Zone Flow Model Lower Boundary for the

Unsaturated Zone Flow Model...................................................... 6-36

6.4.5 Water Table Rise.................................................................................. 6-36

6.4.5.1 Water Table Rise beneath Repository ............................................. 6-36

6.4.5.2 Incorporation of Water Table Rise into the SZ Flow and

Transport Models ........................................................................ 6-39

6.4.5.2.1 Estimating Water Table Rise from Climate

Change ...................................................................... 6-40

6.4.5.2.2 Water Table Rise in the SZ Site-Scale Flow

Model .......................................................................... 6-44

6.4.6 Alternate SZ Site-Scale Flow Model (Hydrogeologic Framework Model

Reinterpretation and Additional Data)......................................................... 6-44

6.4.6.1 Alternative Conceptual Model .......................................................6-46

6.4.6.2 Alternate Flow Model Formulation............................................... 6-47

6.4.6.2.1 Grid Generation......................................................... 6-47

6.4.6.2.2 Hydrogeologic Framework Model............................... 6-49

6.4.6.2.3 Features ……………………………………......... 6-54

6.4.6.2.4 Boundary Conditions ………………………............. 6-54

6.4.6.2.5 Recharge................................................................ 6-54

6.4.6.3 Calibration of Alternate SZ Site-Scale Flow Model ....................... 6-56

6.4.6.3.1 Calibration Targets...................................................... 6-56

6.4.6.3.2 Calibration Parameters ................................................. 6-60

6.4.6.3.3 Calibration Results: Heads and Fluxes ....................... 6-62

6.4.6.3.4 Calibration Results: Permeability and

Permeability Multipliers ................................................ 6-70

6.4.6.3.5 Calibration Results: Potentiometric Surface and

Flow Path Lines ........................................................ 6-75

6.4.6.3.6 Calibration Results: Sensitivity.................................... 6-86

6.4.6.3.7 Calibration Results: Specific Discharge ..................... 6-91

6.4.6.3.8 Calibration Results: Flux Uncertainty......................... 6-91

6.4.6.4 Comparison of Boundary Target Fluxes ....................................... 6-92

6.4.6.5 Conclusions from Alternate Flow Models ....................................... 6-95

6.4.7 Summary of the Alternative Conceptual Models............................................ 6-95

6.5 MODEL FORMULATION OF CONCEPTUAL MODEL ……………................... 6-97

6.5.1 Mathematical Description of Conceptual Model.............................................. 6-97 


\section{CONTENTS (Continued)}

\section{Page}

6.5.2 Computational Model

6-100

6.5.3 Saturated Zone Site-Scale Model Inputs.

6-101

6.5.3.1 Hydrogeologic Framework Model Overview ............................... 6-101

6.5.3.2 Grid Generation ...................................................................... 6-103

6.5.3.3 Hydrogeologic Properties............................................................ 6-109

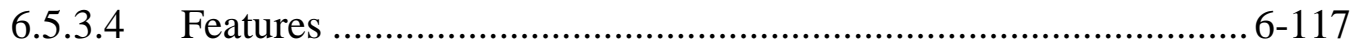

6.5.3.5 Boundary and Initial Conditions ................................................. 6-118

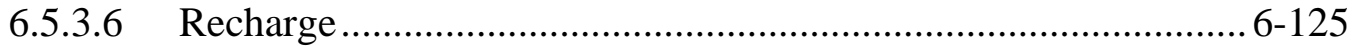

6.5.3.7 Nodal Hydrogeologic Properties ................................................ 6-125

6.6 SZ SITE-SCALE FLOW MODEL RESULTS.............................................. 6-128

6.6.1 Model Calibration ................................................................................... 6-128

6.6.1.1 Calibration Criteria................................................................ 6-129

6.6.1.2 Parameter Optimization Procedure …………………………...... 6-129

6.6.1.3 Calibration Targets ....................................................................... 6-131

6.6.1.4 Calibration Parameters ............................................................... 6-136

6.6.2 Calibration Results............................................................................... 6-139

6.6.2.1 Water Levels......................................................................... 6-139

6.6.2.2 Comparing Fluxes Derived from the Regional Model with

Fluxes Calculated from the Calibrated Model ............................... 6-143

6.6.2.3 Predicted Flow Paths .................................................................... 6-144

6.6.2.4 Specific Discharge....................................................................... 6-145

6.7 EVALUATION OF ALTERNATIVE MODELS ………....................................... 6-147

6.7.1 Large Hydraulic Gradient Alternative Conceptual Model.............................. 6-147

6.7.1.1 Overview ............................................................................ 6-147

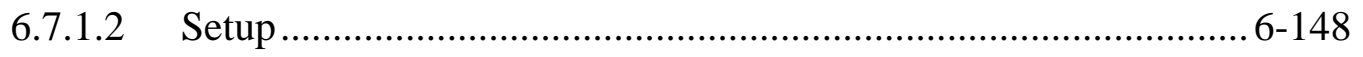

6.7.1.3 Results ............................................................................... 6-148

6.7.1.4 Assessment ........................................................................... 6-155

6.7.2 Solitario Canyon Fault Depth Alternative Conceptual Model........................ 6-156

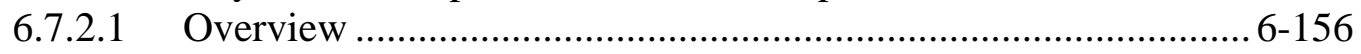

6.7.2.2 Setup .................................................................................... 6-156

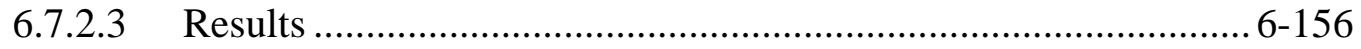

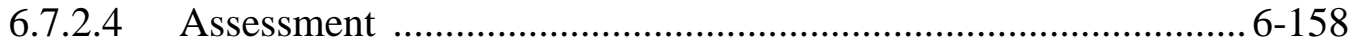

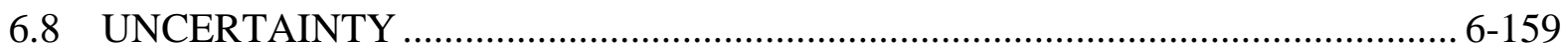

6.8.1 Large Hydraulic Gradient ........................................................................ 6-159

6.8.2 Perched Water on Flow Paths and Specific Discharge .................................... 6-165

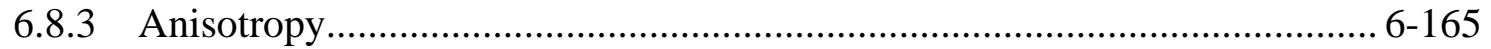

6.8.3.1 Vertical Anisotropy ................................................................. 6-165

6.8.3.2 Horizontal Anisotropy …………………………......................... 6-166

6.8.4 Representing Faults with Enhanced Permeability Grid Blocks ..................... 6-166

6.8.5 Quantification of Groundwater Specific Discharge...................................... 6-167

6.8.5.1 Discussion of the Effect of Hydrogeologic Contact

Uncertainty on Specific Discharge..................................................6-168

6.8.5.2 Specific Discharge Uncertainty Range........................................... 6-169

6.8.5.3 Remaining Uncertainties in Specific Discharge Estimates ........... 6-172 


\section{CONTENTS (Continued)}

6.8.6 Scaling Issues.

6.8.7 Description of Barrier Capability

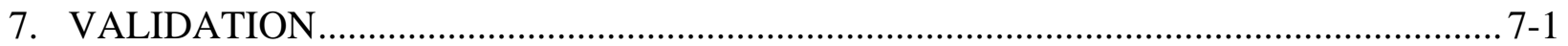

7.1 VALIDATION CRITERIA …………………................................................

7.1.1 Confidence Building during Model Development to Establish Scientific

Basis and Accuracy for Intended Use .............................................................. 7-2

7.1.2 Confidence Building after Model Development to Support the Scientific Basis of the Model ........................................................................................ 7-4

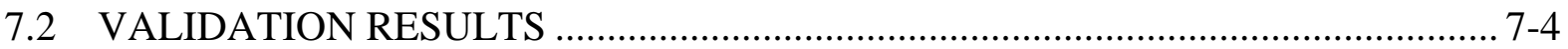

7.2.1 Comparison of Observed and Predicted Nye County Water Levels.................. 7-6

7.2.2 Comparison of Specific Discharge Based On Permeability Data and

Alluvial Testing Complex Tracer Test Results............................................... 7-10

7.2.2.1 Newer Permeability Data ……………………………………...... 7-12

7.2.2.1.1 Calico Hills ............................................................. 7-13

7.2.2.1.2 Alluvial Testing Complex ............................................ 7-13

7.2.2.1.3 Apache Leap …………………………………......... 7-14

7.2.2.1.4 Ghost Dance Fault...................................................... 7-15

7.2.2.1.5 Tuffaceous Formations …………………………..... 7-16

7.2.2.2 Implications of Permeability Data on Specific Discharge

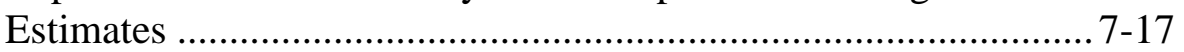

7.2.2.3 Permeability Data from the Yucca Mountain Area.......................... 7-18

7.2.2.3.1 Single-Hole Tests ....................................................... 7-18

7.2.2.3.2 Cross-Hole Tests ........................................................ 7-19

7.2.2.4 Permeability Data from the Nevada Test Site ................................. 7-21

7.2.2.4.1 Lower Carbonate Aquifer (Unit 4)............................... 7-21

7.2.2.4.2 Valley Fill Aquifer (Unit 20) ....................................... 7-23

7.2.2.4.3 Welded Tuff Aquifer (Unit 16).................................... 7-24

7.2.2.4.4 Lava Flow Aquifer (Unit 17) ..................................... 7-25

7.2.2.5 Inferences about Permeability from Regional Observations........... 7-26

7.2.2.5.1 Lower Clastic Aquitard (Unit 3) .................................. 7-26

7.2.2.5.2 Upper Clastic Aquitard (Unit 5).................................. 7-27

7.2.2.5.3 Faults ....................................................................... 7-28

7.2.2.6 Comparing Permeability Data to Calibrated Permeability

Values.

7.2.3 Comparison of Hydrochemical Data Trends with Calculated

Particle Pathways ......................................................................................... 7-33

7.2.4 Thermal Modeling ............................................................................... 7-34

7.2.4.1 Conduction-Only Modeling ........................................................... 7-35

7.2.4.1.1 Temperature and Thermal Properties Data .................. 7-36

7.2.4.1.2 Thermal Conduction Model Setup ............................... 7-41

7.2.4.1.2.2 Thermal Boundary Conditions on the Lower Boundary ............................................................... 7-44

7.2.4.1.3 Thermal Model Calibration........................................... 7-45 


\section{CONTENTS (Continued)}

7.2.4.1.4 Sensitivity to Thermal Conductivity in the Alluvium ……………................................................ 7-49

7.2.4.1.5 Results and Discussion of Conduction-Only Thermal Modeling....................................................... 7-50

7.2.4.2 Coupled Thermal Modeling ......................................................... 7-50

7.2.4.2.1 SZ Site-Scale Coupled Thermal Model Setup ............. 7-50

7.2.4.2.2 Results and Discussion of Coupled Thermal Modeling .................................................................. 7-53

7.3 VALIDATION SUMMARY …………………................................................... 7-55

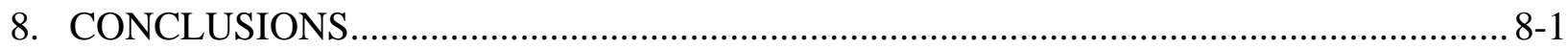

8.1 SUMMARY OF MODELING ACTIVITIES …………...................................... 8-2

8.1.1 SZ Flow Characterization ........................................................................ 8-2

8.1.2 Conceptual Model of SZ Site-Scale Flow ………........................................ 8-3

8.1.3 Mathematical Model and Numerical Approach.............................................. 8-4

8.1.4 Model Validation and Confidence Building..................................................... 8-4

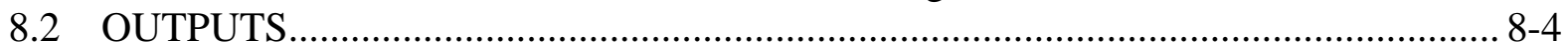

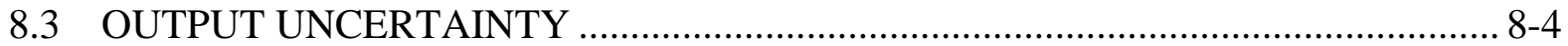

8.3.1 Specific Discharge Uncertainty Range ........................................................ 8-5

8.3.2 Flow Paths Uncertainty............................................................................... 8-6

8.4 HOW THE APPLICABLE ACCEPTANCE CRITERIA ARE ADDRESSED............ 8-6

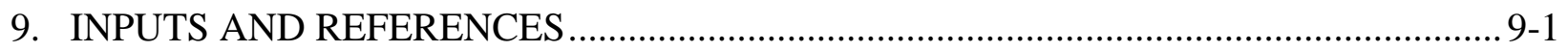

9.1 DOCUMENTS CITED ..................................................................................... 9-1

9.2 CODES, STANDARDS, REGULATIONS, AND PROCEDURES ........................... 9-19

9.3 SOURCE DATA, LISTED BY DATA TRACKING NUMBER …............................ 9-19

9.4 OUTPUT DATA, LISTED BY DATA TRACKING NUMBER ………................. 9-28

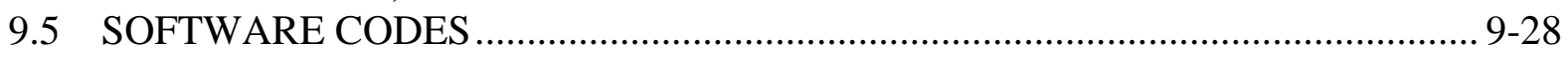

APPENDIX A - GEOCHEMICAL AND ISOTOPIC CONSTRAINTS ON GROUNDWATER FLOW ………………………………………….... A-1 


\section{INTENTIONALLY LEFT BLANK}




\section{FIGURES}

1-1. Generalized Flow of Information Among Reports Pertaining to Flow and Transport in the SZ

6-1. Important Physiographic Features Near Yucca Mountain Including Boundaries of the SZ Site-Scale Flow Model

6-2. Potentiometric Surface Map and Gradient Areas Developed Using Water-Level Data from 1993

6-3. Location of Faults in the Yucca Mountain Region

6-4. Potentiometric Surface and Inferred Flow Directions for Yucca Mountain and Vicinity

6-5. Features of the SZ Site-Scale Flow Model with East-West Barrier Included. 6-28

6-6. Features of the LHG-ACM SZ Site-Scale Flow Model without the East-West Barrier

6-7. Horizontal Anisotropy Is Applied to the Blue Crosshatched Area. 6-32

6-8. Contour Plot of Water-Level Data for the SZ Flow and Transport Model 6-35

6-10. Plan-View Schematic Showing Boreholes, Contoured Water Table (Elevation in Meters), UZ Model Boundary, Repository outline, ESF, and Enhanced Characterization of the Repository Block Cross-Drift

6-11. Estimated Water-Table Elevations for Future Glacial Transition Conditions ............... 6-42

6-12. Estimated Depth to the Water Table for Future Glacial-Transition Conditions ............ 6-43

6-13. Hydrogeologic Framework Model Units at the Water Table for Present Conditions 6-45

6-14. Hydrogeologic Framework Model Units at the Water Table for Estimated Future Glacial Transition Conditions 6-46

6-15. Hydrogeology and Selected Particle Paths at the Water Table for Base Case and Alternate Models.

6-16. Geologic Features in the SZ Area for the Alternate Flow Models 6-55

6-17. Location and Weights of Observation Wells for SZ Site-Scale Flow Model and Alternate Flow Models $6-58$

6-18a. Residual Heads for Base case and Alternate Flow Model AM0 .................................. 6-67

6-18b. Residual Heads for Alternate Flow Models AM1 and AM2....................................... 6-68

6-18c. Residual Heads for Alternate Flow Models AM3 and AM4 ......................................... 6-69

6-19. Flow Paths from the Repository with Simulated Hydraulic Head Contours for SZ Site-Scale Flow Model and Alternate Flow Model AM0. 6-76

6-20. Flow Paths from the Repository with Simulated Hydraulic Head Contours for Alternate Flow Models AM1 and AM2.

6-21. Flow Paths from the Repository with Simulated Hydraulic Head Contours for Alternate Flow Models AM3 and AM4.

6-22. Head Contours, for SZ Site-Scale Flow Model, and Alternate Flow Models AM0, AM1, AM2, AM3, and AM4, at Elevation 500 meters and Water Table.

6-23. View of Hydrostratigraphy Along Particle Path 50 for Alternate Flow Model AM0 . $6-80$ 


\section{FIGURES (Continued)}

Page

6-24. View of Hydrostratigraphy Along Particle Path 50 for SZ Site-Scale Flow Model...... 6-81

6-25. Views of Hydrostratigraphy Along Particle Path 50 for Alternate Flow Models AM1 and AM2

6-26. Views of Hydrostratigraphy Along Particle Path 50 for Alternate Flow Models AM3 and AM4

6-27. Top of 500m Computational Grid. 6-104

6-28. View of the 500-meter Computational Grid (3x Vertical Exaggeration) Showing Node Points Colored by Hydrogeologic Unit Values from the HFM-19

6-29. Close-up View of Computational Grid (3x Vertical Exaggeration) Showing Cut Away at UTM Easting $=549000$ and UTM Northing $=4078000$ Through the Yucca Mountain Repository .....

6-30. Composition of HFM-19 and SZ Site-Scale Flow Model Units Thickness for Units 2, 3, 4 .

6-31. Composition of HFM-19 and SZ Site-Scale Flow Model Units Thickness for Units 5, 6, 7

6-32. Composition of HFM-19 and SZ Site-Scale Flow Model Units Thickness for Units 8. 9, 10

6-33. Composition of HFM-19 and SZ Site-Scale Flow Model Units Thickness for Units 11, 12, 13

6-34. Composition of HFM-19 and SZ Site-Scale Flow Model Units Thickness for Units 14, 15, 16

6-35. Composition of HFM-19 and SZ Site-Scale Flow Model Units Thickness for Units 17, 18, 19

6-36. Composition of HFM-19 and SZ Site-Scale Flow Model Units Thickness for Unit 20

6-37. Geologic Features in the Area of the SZ Site-Scale Flow Model.

6-38. Comparison of Recharge Data (Left Panel) with Those Used as Input in the SZ Site-Scale Flow Model Data (Right Panel).

6-39. Map of Modeled Temperature at the Water Table for the SZ Site-Scale Flow Model Domain

6-40. Location of Observation Wells 6-141

6-41. Contour Plot of Water-Level Data (left panel) and Simulated Water-Level Data with Residual Heads (right panel).

6-42. Flux Zones Used for Comparing Death Valley Regional Flow System Flow Model and Site-Scale Flow Model Fluxes.

6-43. Flow Paths from the Repository and Hydraulic Head Contours Simulated with the SZ Site-Scale Flow Model

6-44. Predicted Flow Paths from the Water Table beneath the Repository for the Altered, No Fault Alternative Model.

6-45. Predicted Flow Paths from the Water Table beneath the Repository for the Altered, with Fault Alternative Model. 6-152

6-46. Predicted Flow Paths from the Water Table Beneath the Repository for the Altered with Fault/Ghost Dance Fault Alternative Model.... 6-153 


\section{FIGURES (Continued)}

Page

6-47. Groundwater Flow Paths in SZ Interpreted from Groundwater Chemistry and Isotope Compositions

6-48. Simulated Groundwater Flow Paths from Beneath the Repository for the SZ Site-Scale Flow Model Deep Solitario Canyon Fault....

6-49. Simulated Groundwater Flow Paths from the West Side of Solitario Canyon Fault for the SZ Site-Scale Flow Model Deep Solitario Canyon Fault.

6-50. Simulated Groundwater Flow Paths from Beneath the Repository for the Alternative Case (Shallow Solitario Canyon Fault) SZ Site-Scale Flow Model

6-51. Simulated Groundwater Flow Paths from the West Side of Solitario Canyon Fault for the Alternative Conceptual Model of the Shallow Solitario Canyon Fault.

7-1. Locations of Nye County Early Warning Drilling Program Wells............................... 7-7

7-2. $\quad$ Measured and Simulated Head Along Flow Path ................................................ 7-11

7-3. Comparison of Unsaturated Zone and SZ Permeabilities......................................... 7-17

7-4. $\quad$ Logarithms of Permeabilities Estimated during Model Calibration Compared to Mean Logarithms of Permeability Determined from Pump-Test Data from Yucca Mountain

7-5. Logarithms of Permeabilities Estimated during Model Calibration Compared to Mean Logarithms of Permeability Determined from Pump-Test Data from the NTS

7-6. Transport Pathways Deduced from Hydrochemistry Data, Shown in Red, Compared to Particle Pathways Calculated for the SZ Site-Scale Transport Model..... 7-35

7-7. Computed Average Annual Surface Temperature for the SZ Site-Scale Thermal

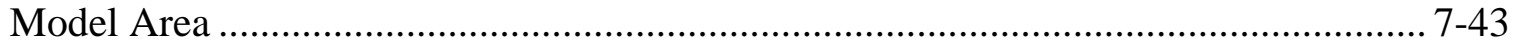

7-8. Depth to the Water Table in the SZ Site-Scale Flow Model Area............................... 7-44

7-9. Simulated Temperatures at the Water Table for the Thermal Conduction Model ........ 7-46

7-10. Simulated Temperatures Versus Observed Temperatures for the Thermal Conduction Model

7-11. Histogram of Residuals in Simulated Temperature for the Thermal Conduction Model.....

7-12. Residuals in Simulated Temperature at the Water Table for the Thermal Conduction Model

7-13. Simulated Temperatures at the Water Table for the Coupled Thermal Model.

7-14. Simulated Temperatures Versus Observed Temperatures for the Coupled Thermal Model.

7-15. Residuals in Simulated Temperature at the Water Table for the Coupled Thermal Model

A6-1. Important Physiographic Features near Yucca Mountain....

A6-2. Selected Geologic and Hydrogeologic Units for the SZ at Yucca Mountain 


\section{FIGURES (Continued)}

A6-3. Potentiometric Surface and Inferred Flow Directions for Yucca Mountain and Vicinity

A6-4. Effects of Different Processes on Delta Deuterium and Delta Oxygen-18 Composition of Subsurface Water.....

A6-5. Locations of Boreholes in the Vicinity of Yucca Mountain and the Northern Amargosa Desert.

A6-6. Trilinear and Scatter Plots for Samples that Surround Yucca Mountain But Are Generally North of the Amargosa Valley

A6-7. Trilinear and Scatter Plots for Samples from the Yucca Mountain Area

A6-8. Trilinear and Scatter Plots for Samples from Groupings in the Amargosa Desert Region.

A6-9. Plots of Selected Hydrochemical Constituents for the Different Depth Intervals of Boreholes NC-EWDP-19D and -19P.

A6-10. Plots of Selected Hydrochemical Constituents for the Different Depth Intervals of Borehole NC-EWDP-9SX

A6-11. Plots of Selected Hydrochemical Constituents for the Different Depth Intervals of Boreholes NC-EWDP-1S and -1DX

A6-12. Plots of Selected Hydrochemical Constituents for the Different Depth Intervals of Boreholes NC-EWDP-3S and NC-EWDP-3D

A6-13. Plots of Selected Hydrochemical Constituents for the Different Depth Intervals of Boreholes NC-EWDP-12PA, -12PB and NC-EWDP-12PC

A6-14. Areal Distribution of $\mathrm{pH}$ in Groundwater. A-100

A6-15. Areal Distribution of Chloride in Groundwater. A-102

A6-16. Areal Distribution of Sulfate in Groundwater A-103

A6-17. Areal Distribution of Bicarbonate in Groundwater A-105

A6-18. Areal Distribution of Fluoride in Groundwater A-106

A6-19. Areal Distribution of Silica in Groundwater. A-107

A6-20. Areal Distribution of Calcium in Groundwater A-108

A6-21. Areal Distribution of Magnesium in Groundwater A-109

A6-22. Areal Distribution of Sodium in Groundwater A-110

A6-23. Areal Distribution of Potassium in Groundwater A-112

A6-24. Areal Distribution of Delta Deuterium in Groundwater..... A-113

A6-25. Areal Distribution of Delta Oxygen-18 in Groundwater A-114

A6-26. Areal Distribution of Delta Sulfur-34 in Groundwater. A-115

A6-27. Areal Distribution of Delta Carbon-13 in Groundwater. A-117

A6-28. Areal Distribution of Carbon-14 in Groundwater A-118

A6-29. Areal Distribution of Uranium in Groundwater. A-120

A6-30. Areal Distribution of ${ }^{234} \mathrm{U} /{ }^{238} \mathrm{U}$ Activity Ratios (AR) in Groundwater . A-121

A6-31. Areal Distribution of Strontium in Groundwater.

A6-32. Areal Distribution of Delta Strontium-87 in Groundwater. A-124

A6-33. Comparison between Measured Dissolved Aluminum Concentrations and Dissolved Aluminum Concentrations Calculated by PHREEQC Assuming Equilibrium with Kaolinite . 


\section{FIGURES (Continued)}

A6-35. Areal Distribution of Dissolved Inorganic Carbon in Groundwater.

A-140

A6-36. Areal Distribution of Dissolved Carbon-Dioxide Partial Pressure in Groundwater... A-142

A6-37. Areal Distribution of Calcite Saturation Index in Groundwater.

A6-38. Areal Distribution of Smectite Saturation Index in Groundwater

A6-39. Areal Distribution of Calcium Clinoptilolite Saturation Index in Groundwater ........ A-145

A6-40. Areal Distribution of K-Feldspar Saturation Index in Groundwater .......................... A-146

A6-41. Uranium Isotopic Compositions and Schematic Evolutionary Trends at Yucca Mountain

A6-42. Scatter Plot Comparing Sulfate and Chloride Compositions of Perched Waters and SZ Groundwaters

A6-43. Scatter Plot Comparing Delta Carbon-13 and Dissolved Inorganic Carbon Compositions of Perched Waters and SZ Groundwaters.

A6-44. Scatter Plot Comparing Delta Deuterium and Delta Oxygen-18 Data for Perched Water and Groundwater near Yucca Mountain .

A6-45. ${ }^{14} \mathrm{C}$ Activity versus Delta ${ }^{13} \mathrm{C}$ of Perched Water and Groundwater near Yucca Mountain

A6-46. Scatter Plot Comparing Calcium and Sodium Compositions of Perched Waters and SZ Groundwaters

A6-47. Chloride Mass-Balance Method for Estimating Infiltration ...

A6-48. Delta Deuterium and Delta ${ }^{18} \mathrm{O}$ Data for Borehole UZ-14 Unsaturated Zone Pore Water, Perched Water, and Groundwater near Yucca Mountain

A6-50. Cross Correlation Plot of Sulfate versus Chloride for Samples in the Amargosa Desert Region.

A6-51. Scatter Plot of Delta ${ }^{34}$ S versus Inverse Sulfate for Samples in the Amargosa Desert Region.

A6-52. Geologic Units Defined in the SZ Flow Model

A6-53. Steady-State Distribution of the Percentage of Yucca Mountain Recharge in Downgradient Groundwater Calculated Using the SZ Flow Model

A6-54. Map View of Steady-State Distribution of the Percentage of Inflow through the Pre-Tertiary Units of Northwest Crater Flat Groundwater Calculated Using the SZ Flow Model

A6-55. Cross Sectional View of Steady-State Distribution of the Percentage of Inflow through the Pre-Tertiary Units of Northwest Crater Flat Groundwater Calculated Using the SZ Flow Model

A6-56. Steady-State Distribution of the Percentage of Inflow through the Tertiary Units of Northwest Crater Flat Groundwater Calculated Using the Saturated Zone Flow Model.

A6-57. Steady-State Distribution of the Percentage of Shallow Timber Mountain Area Groundwater through the Tertiary Units Calculated Using the SZ Flow Model.

A6-58. Map View of Steady-State Distribution of the Percentage of Shallow Upper Fortymile Wash Area Groundwater through the Pre-Tertiary Units Calculated Using the SZ Flow Model. 


\section{FIGURES (Continued)}

Page

A6-59. Cross Sectional View of Steady-State Distribution of the Percentage of Shallow Upper Fortymile Wash Area Groundwater through the Pre-Tertiary Units Calculated Using the SZ Flow Model.

A6-60. Steady-State Distribution of the Percentage of Shallow Upper Fortymile Wash Area Groundwater through the Tertiary Units Calculated Using the SZ Flow Model

A6-61. Steady-State Distribution of the Percentage of Pre-Tertiary Rocks of the Skeleton Hills Area Groundwater Calculated Using the SZ

Flow Model.

A6-62. Regional Flow Paths Inferred from Hydrochemical and Isotopic Data..... 


\section{TABLES}

Page

3-1. Computer Codes Used in the SZ Site-Scale Flow Model............................................ 3-1

4-1. Direct Input Data Sources ..................................................................................... 4-1

4-2. Project Requirements and YMRP Acceptance Criteria Applicable to This Model Report.................................................................................................................... 4-1

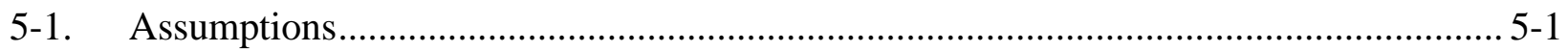

6-1. Features, Events, and Processes Included in TSPA-LA and Relevant to this Model Report........................................................................................................ 6-2

6-2. $\quad$ Alternate SZ Site-Scale Flow Model and SZ Site-Scale Flow Model Size Comparison ........................................................................................................ 6-48

6-3. Correlation of Alternate SZ Site-Scale Flow Model HFM-27 and SZ Site-Scale Flow Model HFM-19 Units

6-4. Comparison of Grid Hydrogeologic Unit Volume: Alternate SZ Site-Scale Model vs. SZ Site-Scale Flow Model ............................................................................ 6-51

6-5. Alternate SZ Site-Scale Flow Models Descriptions .......................................................... 6-59

6-6. Hydrological Features in the SZ Alternate Flow Model................................................ 6-61

6-7. Calibration Results: Observed Water-Level Elevation vs. Calibrated Head for Alternate SZ Site-Scale Flow Models AM0, AM1, AM2, AM3, and AM4

6-8. Calibration Permeability and Permeability Ranges for the Alternate SZ Site-Scale Flow Models ...................................................................................................... 6-71

6-9. Parameter Sensitivity Over All Observation Groups..................................................... 6-86

6-10. Parameter Sensitivity Over Observation Group Path .................................................... 6-90

6-11. Specific Discharge ................................................................................................... 6-91

6-12. Calibration Results: Comparison of Flux Target with Flux Calibrated Values.............. 6-93

6-13. Alternative Conceptual Models Considered ............................................................ 6-96

6-14. Bounding Box ..................................................................................................... 6-105

6-15. Vertical Grid Spacing Used in the SZ Site-Scale Flow Model..................................... 6-106

6-16. Number of Gridblocks per Hydrogeologic Unit ......................................................... 6-117

6-17. Hydrological Features in the SZ Site-Scale Flow Model ............................................. 6-119

6-18. Comparison of Observed Weighting of Hydraulic Heads from the SZ Site-Scale Flow Model and Model Computed Head Data ......................................................... 6-132

6-19. Calibration Parameters Used in the SZ Site-Scale Flow Model................................. 6-138

6-20a. Comparison of Regional and Site-Scale Fluxes.......................................................... 6-144

6-20b Comparison of Fluxes at the Site-Scale Boundaries Predicted by the 1997 and 2001 Regional Flow Models................................................................................... 6-145

6-21. SZ Site-Scale Flow Model Compared with Alternative Conceptual Models Selected Residuals from Models.

6-22. Comparison of Selected Parameter Values for Alternate Conceptual Models ............. 6-150

6-23. Observed and Computed Head Data Compared to Shallow Solitario Canyon Fault Alternative Conceptual Model 6-157 


\section{TABLES (Continued)}

Page

6-36. Statistical Summary of Permeabilities Calculated from Single-Hole and Cross-Hole Tests at Yucca Mountain

7-1. Nye County EWDP Wells Used as Calibration Targets in the SZ Site-Scale Model Calibration with Observed and Predicted Water Levels.

7-2. Comparison of Water Levels Observed and Predicted at Nye County EWDP

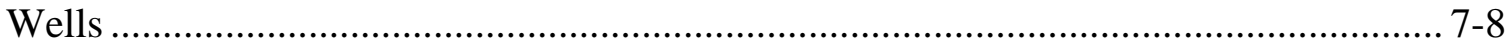

7-3. Predicted and Observed Hydraulic Gradient for Identified Wells .................................. 7-12

7-4. Transmissivities, Hydraulic Conductivities, and Permeabilities Determined in the Single-Well Hydraulic Tests Conducted in the Alluvium in NC-EWDP-19D1 between July and November 2000

7-5. Permeabilities Calculated for the Lower Carbonate Aquifer....................................... 7-22

7-6. $\quad$ Permeability Estimates for the Valley Fill Aquifer ...................................................... 7-24

7-7. Permeability Estimates for the Welded Tuff Aquifer …………………………………... 7-25

7-8. Permeabilities of the Lava Flow Aquifer ................................................................. 7-26

7-9. Temperature Data from Boreholes................................................................. 7-36

7-10. Thermal Conductivity of SZ Hydrogeologic Units ..................................................... 7-39

A3-1. Software Used in Support of this Scientific Analysis.................................................... A-2

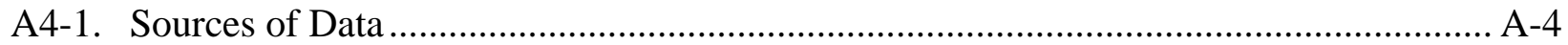

A4-2. Sources of Data and Other Information .................................................................. A-7

A4-3. Summary of Groundwater Wells and Data Sources ……........................................... A-10

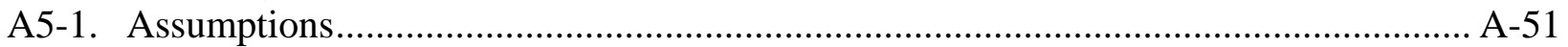

A6-1. Field Parameters and Major Ion Composition ............................................................ A-64

A6-2. Isotope and Trace Element Composition...................................................................... A-73

A6-3. Calculated Geochemical Parameters of Groundwater Samples Used in this Report A-127

A6-4. Yucca Mountain Mineral Phase Compositions and Thermodynamic Data Used in PHREEQC Analyses.

A6-5. Chemical and Isotopic Composition of Perched Water at Yucca Mountain 10 $0^{-5}$....... A-149

A6-6. Recharge Rates Based on the Chloride Mass Balance Method .................................... A-164

A6-7. Chemistry and Ages of Groundwaters from Seven Boreholes at Yucca Mountain ... A-170

A6-8. Sensitivity of the Permissible Fraction of Young Water Present in Groundwater to Dissolved Inorganic Carbon Concentration Assumed for the Old Component of the Mixed Groundwater..... A-172

A6-9. Sensitivity of the Permissible Fraction of Young Water Present in Groundwater to the Assumed ${ }^{14} \mathrm{C}$ Activity of the Old Component of the Mixed Groundwater.

A6-10. Mineral Phases and Exchange Reactions Considered in the PHREEQC Inverse Analyses

A6-11. Calculated Groundwater Transit Times (in years) between Well WT-3 and Various Depth Zones in Well NC-EWDP-19D 


\section{ACRONYMS AND ABBREVIATIONS}

ACM alternative conceptual model

ANF altered, no fault (ACM)

AR

Amargosa River: group of boreholes located on the west side of Amargosa Desert

AR/FMW Group of boreholes located near the confluence of the Amargosa River and Fortymile Wash drainages

ATC Alluvial Testing Complex

AWF altered, with fault (ACM)

CMB

chloride mass balance

CRWW

Coffer Ranch Windmill Well

CVFE

control-volume finite element

DFGP Desert Farms Garlic Plot

DIC Dissolved inorganic carbon

DTN data tracking number

DVRFS Death Valley Regional Flow System

ESF Exploratory Studies Facility

FEHM finite-element heat and mass transfer numerical analysis computer code

FEPs features, events, and processes

FMW-E Fortymile Wash-East: group of boreholes in the Amargosa Desert east of Fortymile Wash

FMW-N $\quad$ Fortymile Wash-North: group of boreholes east and northeast of Yucca Mountain

FMW-S Fortymile Wash-South: group of boreholes along or near the main channel of Fortymile Wash in Amargosa Desert

FMW-W $\quad$ Fortymile Wash-West: group of boreholes in the Amargosa Desert west of Fortymile Wash

GDF Ghost Dance fault

GF Gravity Fault: group of boreholes located on east side of the Amargosa Desert

HFM hydrogeologic framework model

HFM-19 original hydrogeologic framework model (DTN: GS030208312332.001)

HFM-27 revised hydrogeologic framework model (DTN: GS021008312332.002)

LA license application

LANL Los Alamos National Laboratory

LHG large hydraulic gradient (ACM)

LM Levenberg-Marquardt (optimization algorithm for PEST)

LW Amargosa Valley (formerly Lathrop Wells): group of boreholes located along U.S. Highway 95 


\section{ACRONYMS AND ABBREVIATIONS (Continued)}

MVA middle volcanic aquifer

NAD North American Datum

NC-EWDP Nye County Early Warning Drilling Program

OV/NWA Oasis Valley/Northwest Amargosa Valley: group of boreholes located in that region

PA performance assessment

QARD Quality Assurance Requirements and Description

SCM Software Configuration Management

SCW Solitario Canyon Wash: western group of boreholes

SSD sum-of-squares difference

SZ saturated zone

TDS total dissolved solids

TM Timber Mountain: group of boreholes north of Yucca Mountain

TSPA total system performance assessment

UZ unsaturated zone

YMP Yucca Mountain Project

YMRP Yucca Mountain Review Plan, Final Report

\section{HYDROGEOLOGIC UNITS AND CHEMICAL ELEMENTS}

Tac Calico Hills formation

Tcb Bullfrog tuff of the Crater Flat Group

Tcp Prow Pass tuff of the Crater Flat Group

Tct Tram tuff of the Crater Flat Group

Tlr $\quad$ Lithic Ridge tuffs

$\delta^{13} \mathrm{C} \quad$ delta carbon-13

$\delta \mathrm{D} \quad$ delta hydrogen-2, or delta deuterium

$\delta^{18} \mathrm{O} \quad$ delta oxygen-18

$\delta^{34} \mathrm{~S} \quad$ delta sulfur-34

$\delta^{87} \mathrm{Sr} \quad$ delta strontium-87 


\section{PURPOSE}

The purpose of this model report is to document the components of the saturated zone (SZ) site-scale flow model at Yucca Mountain, Nevada, in accordance with AP-SIII.10Q, Models. This report provides validation and confidence in the flow model that was developed for site recommendation and will be used to provide flow fields in support of the total system performance assessment (TSPA) for the license application (LA). The output from this report provides the flow model used in the site-scale SZ transport model, which provides output to the SZ flow and transport model abstraction. In particular, the output from the SZ site-scale flow model, containing the flow fields, flow paths and specific discharge, is used by the SZ site-scale transport model to simulate the groundwater flow pathways and radionuclide transport to the accessible environment for use in the TSPA calculations. Figure 1-1 shows the relationship of this report to other SZ reports that also pertain to the SZ flow and transport. The figure also depicts the relationship between SZ models and analyses. It should be noted that Figure 1-1 does not contain a complete representation of the data and parameter inputs and outputs of all SZ reports, nor does it show inputs external to this suite of SZ reports.

Since the development, calibration, and validation of the SZ site-scale flow model, "Calibration of the Site-Scale Saturated Zone Flow Model” (BSC 2001 [DIRS 155974]), more data have been gathered and analyses have been completed. The data include new stratigraphic and water-level data from Nye County wells, single- and multiple-well hydraulic testing data, and new hydrochemistry data. New analyses include the 2001 Death Valley Regional Flow System (DVRFS) model (D'Agnese et. al 2002 [DIRS 158876]), the creation of an alternative Hydrogeologic Framework Model (HFM), (BSC 2004 [DIRS 170008]), and a revised unsaturated zone (UZ) flow model (BSC 2004 [DIRS 169861]). The new data and analyses were used to construct alternative SZ flow models that are presented in this report to evaluate the impact of the new data and analyses on the predictions of the SZ site-scale flow model.

The intended use of this work is to provide a flow model that generates flow fields that are used to simulate radionuclide transport in saturated porous rock and alluvium under natural or forced gradient flow conditions. The SZ site-scale flow model simulations were completed using the three-dimensional, finite-element heat and mass transfer computer code, FEHM V2.20, STN: 10086-2.20-00 (LANL 2003 [DIRS 161725]). Concurrently, the process-level transport model and methodology for calculating radionuclide transport in the SZ at Yucca Mountain using FEHM are described in Site-Scale Saturated Zone Transport (BSC 2004 [DIRS 170036]). The velocity fields are calculated by the flow model, described herein, independent of the transport processes, and are then used as inputs to the transport model. Justification for this abstraction is presented in Saturated Zone Flow and Transport Model Abstraction (BSC 2004 [DIRS 170042]). 


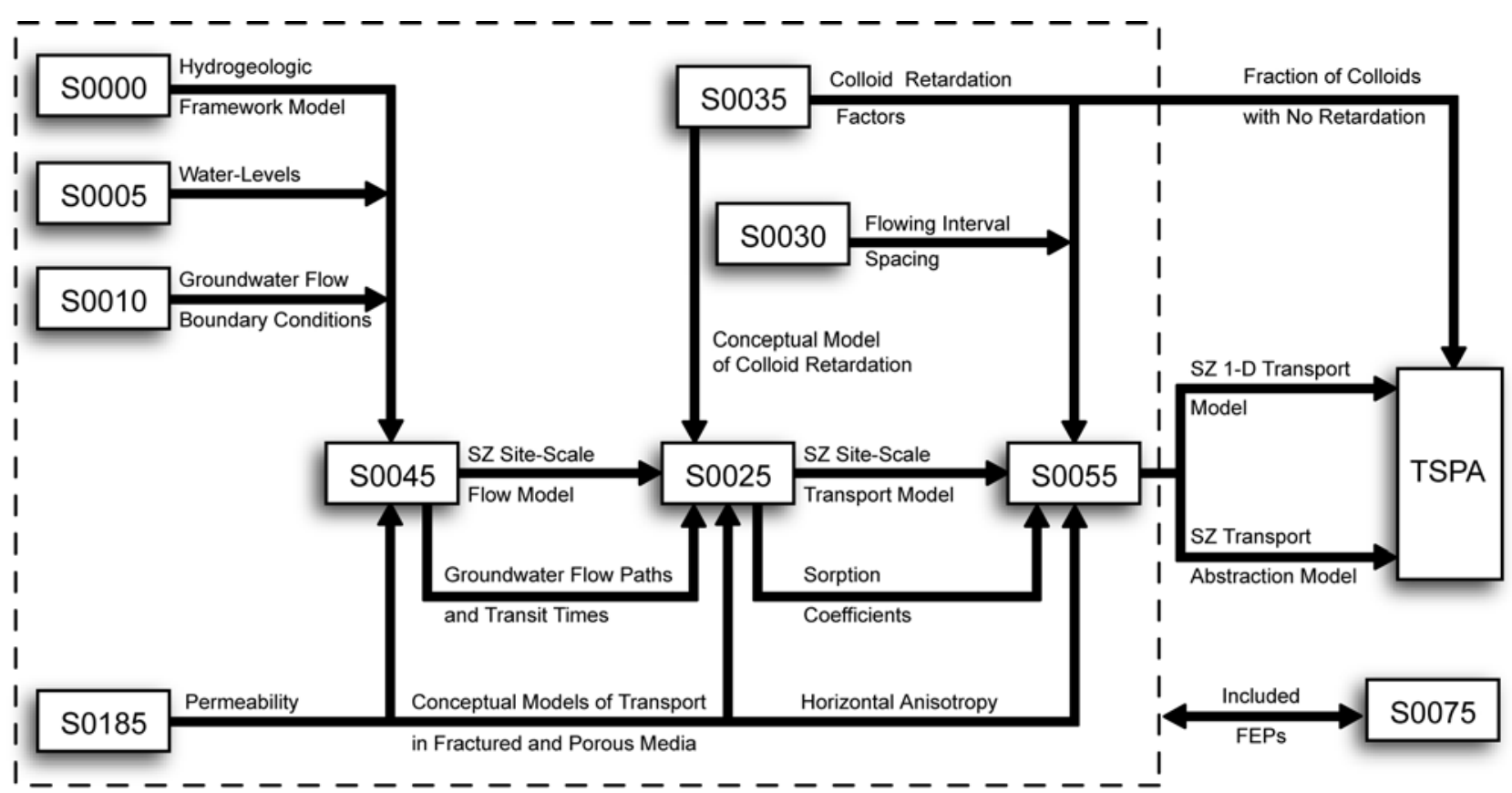

\section{Legend}

S0000 - Hydrogeologic Framework Model

MDL-NBS-HS-000024

S0005 - Water-Level Data Analysis

ANL-NBS-HS-000034

S0010 - Recharge and Lateral Groundwater Flow Boundary Conditions

S0025 - Site-Scale Saturated Zone Transport

ANL-NBS-MD-000010

S0030 - Probability Distribution for Flowing Interval Spacing

MDL-NBS-HS-000010

S0035 - Saturated Zone Colloid Transport

ANL-NBS-MD-000003

S0045 - Site-Scale Saturated Zone Flow Model

S0055 - Saturated Zone Flow and Transport Model Abstraction

ANL-NBS-HS-000031

MDL-NBS-HS-000011

MDL-NBS-HS-000021

S0075 - Features, Events, and Processes in SZ Flow and Transport

ANL-NBS-MD-000002

S0185 - Saturated Zone In-Situ Testing

ANL-NBS-HS-000039

NOTE: This figure is a simplified representation of the flow of information among SZ reports. See the Document Input Reference System (DIRS) of each report for a complete listing of data and parameter inputs. This figure does not show inputs external to this suite of SZ reports.

FEPS = features, events, and processes; SZ = saturated zone; TSPA = total system performance assessment.

Figure 1-1. Generalized Flow of Information Among Reports Pertaining to Flow and Transport in the SZ 
This model report is governed by the Office of Civilian Radioactive Waste Management Technical Work Plan for: Natural System - Saturated Zone Analysis and Model Report Integration (BSC 2004 [DIRS 171421], Work Package ARTM01). All activities listed in the technical work plan (TWP) that are appropriate to the SZ site-scale flow model are documented in this report.

Model-validation activities presented in this report lead to increased confidence that the model is a reasonable representation of groundwater flow likely to occur at Yucca Mountain near the repository site. Model-validation activities consist of comparison between observed data and model predictions. Comparisons are presented between:

- Predicted and observed hydraulic heads

- Hydraulic properties obtained from model calibrations and those obtained from hydraulic field and laboratory testing

- Groundwater temperature data predicted by the model and those measured in wells

- Flow path lines obtained from the model and those inferred from analysis of field hydrochemistry and isotopic data.

Alternative conceptual models and the implications of these models for flow field, flow paths, and transport times predictions are evaluated relative to the SZ site-scale flow model.

A number of relevant features, events, and processes (FEPs) are addressed in this report (Section 6.2).

Uncertainty inherent in the input parameters is discussed in Section 4 and, as appropriate, propagated in Section 8. Uncertainty inherent to conceptualization and modeling is discussed in Section 6 and propagated, as appropriate, in Section 8.

The SZ site-scale flow model is limited to steady state use for TSPA purposes. When using the SZ site-scale flow model for TSPA calculations, there are limitations that must be noted in regard to the following: changes to input parameter values, useable path-line distances, and overall model recharge fluxes. These are discussed more fully in Section 8.

Important technical issues addressed by this model report, and the sections in which they are discussed, include:

- Horizontal and vertical anisotropy, reasonable range for uncertainty (Sections 6.4.3 and 6.8.3.2)

- Updated potentiometric data (Section 6.4.4)

- Alternative conceptual flow model for Solitario Canyon fault (Section 6.7.2) 
- Validation of SZ site-scale flow model (Section 7)

- Comparison of fluxes with those of the Death Valley regional flow model (Section 6.6.2.2)

Modeling objectives addressed in this model report include:

- Reflect the current understanding of the SZ flow

- Enhance model validation and uncertainty analyses

- Incorporate new data collected since the TSPA-SR (CRWMS M\&O 2000 [DIRS 153246]).

This report is cited by Features, Events, and Processes in SZ Flow and Transport, (BSC 2004 [DIRS 170013]) and Engineered Barrier System Features, Events, and Processes, (BSC 2004 [DIRS 170900]).

One variation from the technical work plan (TWP) (BSC 2004 [DIRS 171421]) was required to complete this work. The change from the TWP concerned the inclusion of the FEP 22.03.02.0A, "Rock properties of Host Rock and other Units". This was made to be consistent with results of SZ FEP identification and screening process as documented in the SZ FEPs report. This is an implicit rather than explicit inclusion carried forward from the upstream reports. 


\section{QUALITY ASSURANCE}

Development of this model report and the supporting modeling activities are subject to the Office of Civilian Radioactive Waste Management quality assurance program as indicated in the TWP (BSC 2004 [DIRS 171421], Work Package ARTM01). Approved quality assurance procedures identified in Section 4 of the TWP have been used to conduct and document the activities described in this model report. Section 8 of the TWP also identifies the methods used to control the electronic management of data.

This model report provides calibrated values for hydrologic properties of the SZ portion of the lower natural barrier (i.e., UZ below the repository horizon and SZ below and downgradient from the repository), which is important to the demonstration of compliance with the postclosure performance objectives prescribed in 10 CFR 63.113 [DIRS 156605]. Therefore, the lower natural barrier is classified on the Q-List (BSC 2004 [DIRS 168361], Table A-2) as "SC" (Safety Category), reflecting its importance to waste isolation, as defined in AP-2.22Q, Classification Analyses and Maintenance of the Q-List. This report contributes to the analysis and modeling data used to support performance assessment; the conclusions do not directly impact engineered features important to safety, as defined in AP-2.22Q. 


\section{INTENTIONALLY LEFT BLANK}




\section{USE OF SOFTWARE}

\subsection{SOFTWARE TRACKED BY CONFIGURATION MANAGEMENT}

The computer codes used directly in the SZ site-scale flow model are summarized in Table 3-1. The qualification status of the software is indicated in the Software Configuration Management (SCM) database. All software was obtained from SCM and is appropriate for the application. Qualified codes were used only within the range of validation as required by LP-SI.11Q-BSC, Software Management.

All computer codes listed in Table 3-1 were selected for use in the analysis report because they satisfy at least one of the following conditions:

- Were developed specifically for the tasks considered in this report (these codes are denoted with * in the Table 3-1 footnote)

- Were developed for the Yucca Mountain Project (YMP) (these codes are denoted with ** in the Table 3-1 footnote)

- Were best available codes for modeling conditions specific to the YMP.

The codes developed specifically for the tasks considered in this report and for the YMP were validated for the parameter ranges expected for Yucca Mountain. The range of use and the limitations on output of each code are specified in the Software Management Report (SMR) of each code. As it can be concluded from these SMRs, the limitations on input and output should only be considered when these codes are used outside of YMP. Otherwise, no special limitations on input and output exist. The codes that fall into the best category are described in Sections 3.1.1 through 3.1.6.

Table 3-1. Computer Codes Used in the SZ Site-Scale Flow Model

\begin{tabular}{|c|c|c|c|c|}
\hline $\begin{array}{c}\text { Software Name and } \\
\text { Version (V) }\end{array}$ & $\begin{array}{c}\text { Software } \\
\text { Tracking } \\
\text { Number } \\
\text { (STN) }\end{array}$ & Description & $\begin{array}{c}\text { Computer Type, Platform, } \\
\text { and Location }\end{array}$ & $\begin{array}{c}\text { Date } \\
\text { Baselined }\end{array}$ \\
\hline $\begin{array}{l}\text { FEHM } \\
\text { V2.20 LANL (2003 } \\
\text { [DIRS 161725]) }\end{array}$ & $10086-2.20-00$ & $\begin{array}{l}\text { Flow modeling / flow and } \\
\text { transport modeling } \\
\text { (particle tracking) }\end{array}$ & $\begin{array}{l}\text { Sun Ultra Sparc with Sun } \\
\text { Solaris } 5.7 \text { or } 5.8 \text { operating } \\
\text { system at LANL }\end{array}$ & $1 / 28 / 03$ \\
\hline $\begin{array}{l}\text { LaGriT } \\
\text { V1.0 LANL (2001 } \\
\text { [DIRS 149148]) }\end{array}$ & $10212-1.0-00$ & $\begin{array}{l}\text { Software package for } \\
\text { grid generation, analysis, } \\
\text { and visualization. }\end{array}$ & $\begin{array}{l}\text { Sun Ultra Sparc with Sun } \\
\text { OS } 2.7 \text { operating system at } \\
\text { LANL }\end{array}$ & $8 / 8 / 01$ \\
\hline $\begin{array}{l}\text { NETPATH } \\
\text { V2.13 LANL (2001 } \\
\text { [DIRS 149910]) }\end{array}$ & $10303-2.13-00$ & $\begin{array}{l}\text { Groundwater age } \\
\text { correction for figures in } \\
\text { document }\end{array}$ & $\begin{array}{l}\text { PC with Windows DOS } \\
\text { operating system at LANL }\end{array}$ & 8/8/01 \\
\hline $\begin{array}{l}\text { PEST } \\
\text { V5.5 Watermark } \\
\text { Computing (2002 } \\
\text { [DIRS 161564]) }\end{array}$ & $10289-5.5-00$ & $\begin{array}{l}\text { Preconditioning and } \\
\text { parameter optimization } \\
\text { for FEHM (LANL 2003 } \\
\text { [DIRS 161725]) runs }\end{array}$ & $\begin{array}{l}\text { Sun Ultra Sparc with Sun } \\
\text { Solaris } 5.7 \text { or } 5.8 \text { operating } \\
\text { system at LANL }\end{array}$ & $12 / 3 / 02$ \\
\hline
\end{tabular}


Table 3-1. Computer Codes Used in the SZ Site-Scale Flow Model (Continued)

\begin{tabular}{|c|c|c|c|c|}
\hline $\begin{array}{c}\text { Software Name and } \\
\text { Version (V) }\end{array}$ & $\begin{array}{c}\text { Software } \\
\text { Tracking } \\
\text { Number } \\
\text { (STN) }\end{array}$ & Description & $\begin{array}{c}\text { Computer Type, Platform, } \\
\text { and Location }\end{array}$ & $\begin{array}{c}\text { Date } \\
\text { Baselined }\end{array}$ \\
\hline $\begin{array}{l}\text { * prepare_- } \\
\text { features_for_- } \\
\text { surfer V1.0 } \\
\text { [DIRS 171911] }\end{array}$ & $11091-1.0-00$ & $\begin{array}{l}\text { Postprocessor to write } \\
\text { visualization for Surfer }\end{array}$ & $\begin{array}{l}\text { Sun Ultra Sparc with Sun } \\
\text { OS } 2.7 \text { or } 2.8 \text { operating } \\
\text { system at LANL }\end{array}$ & 6/23/03 \\
\hline $\begin{array}{l}\text { STRAT2AVS } \\
\text { V1.0 LANL }(2003 \\
\text { [DIRS 163069]) }\end{array}$ & $11028-1.0-00$ & $\begin{array}{l}\text { Preprocessor used to } \\
\text { extract hydrogeologic } \\
\text { surface data from the } \\
\text { USGS HFM. }\end{array}$ & $\begin{array}{l}\text { SGI with Irix64 operating } \\
\text { system at LANL }\end{array}$ & $3 / 3 / 03$ \\
\hline $\begin{array}{l}{ }^{*} \text { READPATHS V1.0 } \\
\text { LANL }(2000 \\
\text { [DIRS 150459]) }\end{array}$ & $11089-1.0-00$ & $\begin{array}{l}\text { Postprocessor for FEHM } \\
\text { (LANL } 2003 \\
\text { [DIRS 161725]) to view } \\
\text { flow lines }\end{array}$ & $\begin{array}{l}\text { Sun Ultra Sparc with Sun } \\
\text { OS } 2.7 \text { or } 2.8 \text { operating } \\
\text { system at LANL }\end{array}$ & $6 / 23 / 03$ \\
\hline $\begin{array}{l}\text { * write_temps } \\
\text { V1.0 } \\
\text { [DIRS 171891] }\end{array}$ & $11090-1.0-00$ & $\begin{array}{l}\text { Preprocessor for FEHM } \\
\text { (LANL } 2003 \\
\text { [DIRS 161725]) to adjust } \\
\text { viscosity values }\end{array}$ & $\begin{array}{l}\text { Sun Ultra Sparc with Sun } \\
\text { Solaris } 5.7 \text { or } 5.8 \text { operating } \\
\text { system at LANL }\end{array}$ & $6 / 27 / 03$ \\
\hline $\begin{array}{l}{ }^{\star \star} \text { Extract } \\
\text { V1.0 SNL (2002 } \\
\text { [DIRS 163070]) }\end{array}$ & $10955-1.0-00$ & $\begin{array}{l}\text { Pre/postprocessor used } \\
\text { to extract lateral flow } \\
\text { data from the USGS } \\
\text { regional flow model }\end{array}$ & $\begin{array}{l}\text { Sun UltraSPARC - SunOS } \\
5.7 \text { operating system at } \\
\text { SNL }\end{array}$ & $12 / 11 / 02$ \\
\hline $\begin{array}{l}{ }^{\star \star} \text { Extract } \\
\text { V1.1 SNL (2002 } \\
\text { [DIRS 163071]) }\end{array}$ & $10955-1.1-00$ & $\begin{array}{l}\text { Pre/postprocessor used } \\
\text { to extract lateral flow } \\
\text { data from the USGS } \\
2001 \text { regional flow model }\end{array}$ & $\begin{array}{l}\text { Sun UltraSPARC - SunOS } \\
5.7 \text { operating system at } \\
\text { SNL }\end{array}$ & $12 / 11 / 02$ \\
\hline 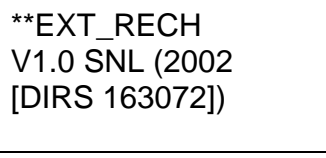 & $10958-1.0-00$ & $\begin{array}{l}\text { Pre/postprocessor used } \\
\text { to extract recharge data } \\
\text { from the USGS regional } \\
\text { flow model }\end{array}$ & $\begin{array}{l}\text { Sun UltraSPARC - SunOS } \\
5.7 \text { operating system at } \\
\text { SNL }\end{array}$ & $12 / 11 / 02$ \\
\hline $\begin{array}{l}\text { **Mult_Rech } \\
\text { V1.0 SNL (2002 } \\
\text { [DIRS 163073]) }\end{array}$ & $10959-1.0-00$ & $\begin{array}{l}\text { Pre/postprocessor that } \\
\text { scales recharge data } \\
\text { from the USGS regional } \\
\text { flow model and maps the } \\
\text { data to a new grid }\end{array}$ & $\begin{array}{l}\text { Sun UltraSPARC - SunOS } \\
5.7 \text {, Solaris } 2.7 \text { operating } \\
\text { system at SNL }\end{array}$ & $12 / 18 / 02$ \\
\hline $\begin{array}{l}\star \star \text { WTCONVYD } \\
\text { V1.00 SNL (2002 } \\
\text { [DIRS 163835]) }\end{array}$ & $10815-1.00-00$ & $\begin{array}{l}\text { Used to calculate the } \\
\text { estimated elevation of } \\
\text { the water table for wetter } \\
\text { climatic conditions }\end{array}$ & PC with Windows 98 at SNL & $7 / 15 / 02$ \\
\hline $\begin{array}{l}\text { **Xread_Distr_Rech } \\
\text { V1.0 SNL }(2002 \\
\text { [DIRS 163074]) }\end{array}$ & $10960-1.0-00$ & $\begin{array}{l}\text { Pre/postprocessor used } \\
\text { to extract recharge data } \\
\text { from the USGS } 1999 \\
\text { regional flow model }\end{array}$ & $\begin{array}{l}\text { Sun UltraSPARC - SunOS } \\
5.7 \text { operating system at } \\
\text { SNL }\end{array}$ & $12 / 11 / 02$ \\
\hline $\begin{array}{l}\text { **Xread_Distr_Rech_- } \\
\text { UZ V1.0 SNL (2002 } \\
\text { [DIRS 163075]) }\end{array}$ & $10961-1.0-00$ & $\begin{array}{l}\text { Pre/postprocessor that } \\
\text { maps recharge data onto } \\
\text { a new grid excluding the } \\
\text { UZ flow model region }\end{array}$ & $\begin{array}{l}\text { Sun UltraSPARC - SunOS } \\
5.7 \text { operating system at } \\
\text { SNL }\end{array}$ & $12 / 11 / 02$ \\
\hline $\begin{array}{l}\text { **Xread_- } \\
\text { Reaches } \\
\text { V1.0 SNL (2002 } \\
\text { [DIRS 163076]) }\end{array}$ & $10962-1.0-00$ & $\begin{array}{l}\text { Pre/postprocessor that } \\
\text { maps local recharge from } \\
\text { four stream channels } \\
\text { onto a new grid }\end{array}$ & $\begin{array}{l}\text { Sun UltraSPARC - SunOS } \\
5.7 \text { operating system at } \\
\text { SNL }\end{array}$ & $12 / 11 / 02$ \\
\hline
\end{tabular}


Table 3-1. Computer Codes Used in the SZ Site-Scale Flow Model (Continued)

\begin{tabular}{|c|c|c|c|c|}
\hline $\begin{array}{c}\text { Software Name and } \\
\text { Version (V) }\end{array}$ & $\begin{array}{l}\text { Software } \\
\text { Tracking } \\
\text { Number } \\
\text { (STN) }\end{array}$ & Description & $\begin{array}{c}\text { Computer Type, Platform, } \\
\text { and Location }\end{array}$ & $\begin{array}{c}\text { Date } \\
\text { Baselined }\end{array}$ \\
\hline $\begin{array}{l}\text { **Xwrite_Flow_ } \\
\text { New } \\
\text { V1.0-125 SNL (2002 } \\
\text { [DIRS 163077]) }\end{array}$ & $\begin{array}{l}10963-1.0-125- \\
00\end{array}$ & $\begin{array}{l}\text { Used both to map the } \\
\text { combined UZ and SZ } \\
\text { site-scale fluxes onto a } \\
125-m \text { grid and to create } \\
\text { a flux file that is } \\
\text { compatible with FEHM } \\
\text { LANL } 2003 \\
\text { [DIRS 161725]) flow } \\
\text { macros }\end{array}$ & $\begin{array}{l}\text { Sun UltraSPARC - SunOS } \\
5.7 \text { operating system at } \\
\text { SNL }\end{array}$ & $12 / 11 / 02$ \\
\hline $\begin{array}{l}* * \text { Zone } \\
\text { V1.0 SNL (2002 } \\
\text { [DIRS 163078]) }\end{array}$ & $10957-1.0-00$ & $\begin{array}{l}\text { Used to extract zonal } \\
\text { designation data from the } \\
\text { USGS } 2001 \text { regional flow } \\
\text { model. }\end{array}$ & $\begin{array}{l}\text { Sun UltraSPARC - SunOS } \\
5.7 \text { operating system at } \\
\text { SNL }\end{array}$ & $12 / 11 / 02$ \\
\hline
\end{tabular}

NOTE: * These codes were developed specifically for the tasks considered in this report

** These codes were developed for the YMP

DOS=disk operating system; HFM = hydrogeologic framework model; LANL=Los Alamos National Laboratory; PC=personal computer; SNL=Sandia National Laboratories; SZ=saturated zone; USGS=U.S. Geological Survey; UZ=unsaturated zone.

\subsubsection{Parameter Optimization}

In this report, the parameter estimation code PEST V5.5, STN: 10289-5.5-00 (Watermark Computing 2002 [DIRS 161564]) is used to perform the parameter optimization for the hydrogeologic and feature permeabilities. The PEST code is based on the Levenberg-Marquardt (LM) algorithm. This software was not used to generate any model output. It is used to calibrate the flow model by minimizing the difference between observed and predicted head and boundary fluxes values.

\subsubsection{Flow Modeling}

The FEHM code V2.20, STN: 10086-2.20-00 (LANL 2003 [DIRS 161725]) is used to solve for a steady-state flow solution and to provide model output. The range of validation for the FEHM code was developed with the YMP specific data. Consequently, the input and output parameters are within their validation ranges.

\subsubsection{Particle Tracking}

The FEHM code is used within its validated range to determine the streamlines (particle tracks) with the steady-state flow solution (see Section 3.1.2). FEHM has two different particle-tracking routines. This study uses the sptr macro for particle tracking. The particle-tracking portion of FEHM has been verified in Site-Scale Saturated Zone Transport (BSC 2004 [DIRS 170036], Section 6.4.2). 


\subsubsection{Grid Generation}

The Los Alamos grid generation software package LaGriT, V1.0, STN: 10212-1.0-00 (LANL 2001 [DIRS 149148]) is used within its validation limits for creation, analysis, and visualization of grids. LaGriT is a set of software macros that uses the HFM conceptual model data to create computational grids. The software macros translate the coordinate and attribute information into a form that is valid for finite-element heat and mass compilations (FEHM).

\subsubsection{Framework Translation}

The software STRAT2AVS V1.0, STN: 11028-1.0-00 (LANL 2003 [DIRS 163069]) is used within its validated range to read stratamodel geocellular modeling files representing a three-dimensional hydrogeologic framework and then write ASCII surface files with $x, y, z$ coordinate locations and quadrilateral element connectivity. These binary stratamodel geocellular modeling files are both written and read by STRATAMODEL and represent the HFM. This HFM provides the geologically defined internal geometry for flow and transport process models and can be converted into a mesh for use in groundwater flow and transport modeling codes.

\subsubsection{Corrections of ${ }^{14} \mathrm{C}$ Ages in Field Data}

NETPATH V2.13, STN: 10303-2.13-00 (LANL 2001 [DIRS 149910]) is a public-domain geochemical software, which was used within its validation range in this report to correct ${ }^{14} \mathrm{C}$ ages for the effects of chemical reactions. The results of all calculations using NETPATH were checked with order-of-magnitude estimations.

\subsection{EXEMPT SOFTWARE}

Commercial, off-the-shelf software used in support of this modeling analysis to create data plots is exempt from the qualification requirements of LP-SI.11Q-BSC, Software Management but meets the acceptance criteria of being able to correctly produce plots of acceptable graphic quality in formats suitable for incorporation into this model report.

- EXCEL 98-SR-1 was used to preprocess data from the U.S. Geological Survey (USGS) traces for FEHM zone definitions. The calculation of basic statistics was used with standard functions only.

- SURFER for Windows, V7.0 was used for plotting and visualization of analysis results in figures shown in this report. The results were visually checked for correctness.

- TECPLOT, V8.0 was used for plotting and visualization of analysis results in figures shown in this report. The results were visually checked for correctness.

- FORTNER PLOT SUN Workstations V1.3 was used for visualizations in this analysis and documentation for plotting graphs.

- GMV and Adobe Illustrator V10 were used to visualize and illustrate the computational mesh and related data. 
- AquaChem, V3.7, was used to create trilinear diagrams showing proportions of major ions in groundwater and $x-y$ scatter plots.

- Adobe Illustrator was used to create flow-path maps.

The output from SURFER, TECPLOT, Excel, Adobe Illustrator, and AquaChem were visually checked for correctness. This output can be found in the Technical Data Management System within data packages that have been assigned data tracking number (DTN) numbers. The DTNs are identified in appropriate places throughout Section 6 of this model report to allow the independent reviewer to reproduce or verify results by visual inspection or hand calculation. 


\section{INTENTIONALLY LEFT BLANK}




\section{INPUTS}

\subsection{DIRECT INPUT}

Input information used in this model report comes from several sources, which, along with their DTNs, are summarized in Table 4-1. The data referenced in Table 4-1 contain information necessary to construct the numerical model, set boundary conditions, calibrate the model, and check the calibration. The data are fully appropriate for the SZ site-scale flow model. All data listed in Table 4-1 are qualified.

Table 4-1. Direct Input Data Sources

\begin{tabular}{|l|l|l|}
\hline \multicolumn{1}{|c|}{ Data Description } & \multicolumn{1}{c|}{ Data Tracking Number } & \multicolumn{1}{c|}{ File Name } \\
\hline Water level and head distributions & GS000508312332.001 [DIRS 149947] & All \\
\hline Borehole data from water-level data analysis & GS010908312332.002 [DIRS 163555] & All \\
\hline $\begin{array}{l}\text { HFM for SZ site-scale flow and transport } \\
\text { model, containing unit surfaces }\end{array}$ & GS030208312332.001 [DIRS 163087] & All \\
\hline Distribution of recharge flux & SN9908T0581999.001 [DIRS 132867] & $\begin{array}{l}\text { Boundaries.xIs, } \\
\text { Combined.xls }\end{array}$ \\
\hline Feature and fault distributions & GS010908314221.001 [DIRS 162874] & All \\
\hline Plots of temperature profiles in wells & MO0102DQRBTEMP.001 [DIRS 154733] & All \\
\hline
\end{tabular}

$\mathrm{HFM}=$ hydrogeologic framework model; SZ=saturated zone.

The data listed in Table 4-1 are direct model inputs, after appropriate manipulation by the software listed in Table 3-1. The indirect input includes the lateral fluxes that are stored in the same DTN as the distribution of recharge fluxes in Table 4-1.

\subsection{CRITERIA}

The general requirements to be satisfied by the TSPA are stated in 10 CFR 63.114 [DIRS 156605]. Technical requirements to be satisfied by the TSPA are identified in the Project Requirements Document (Canori and Leitner 2003 [DIRS 166275]). The acceptance criteria that will be used by the U.S. Nuclear Regulatory Commission to determine whether the technical requirements have been met are identified in the Yucca Mountain Review Plan, Final Report (YMRP) (NRC 2003 [DIRS 163274]). The requirements and criteria, which had been identified for this report, are summarized in Table 4-2.

Table 4-2. Project Requirements and YMRP Acceptance Criteria Applicable to This Model Report

\begin{tabular}{|c|c|c|c|}
\hline $\begin{array}{l}\text { Requirement } \\
\text { Number }^{\mathrm{a}}\end{array}$ & Requirement Title ${ }^{a}$ & $\begin{array}{c}10 \text { CFR Part } 63 \\
\text { Link }\end{array}$ & $\begin{array}{l}\text { YMRP Acceptance } \\
\text { Criteria }^{\mathrm{b}}\end{array}$ \\
\hline PRD-002/T-015 & Requirements for Performance Assessment & $\begin{array}{l}10 \text { CFR } 63.114 \\
\text { [DIRS 156605] }\end{array}$ & 2.2.1.3.8.3, criteria 1 to 4 \\
\hline
\end{tabular}

a from Canori and Leitner (2003 [DIRS 166275]).

${ }^{b}$ from NRC (2003 [DIRS 163274]).

YMRP =Yucca Mountain Review Plan, Final Report 
The applicable acceptance criteria in the YMRP (NRC 2003 [DIRS 163274], Section 2.2.1.3.8.3) are given below. How they are addressed by this report is described in Section 8.4.

\section{Acceptance Criterion 1: System Description and Model Integration Are Adequate.}

(1) Total system performance assessment adequately incorporates important design features, physical phenomena, and couplings, and uses consistent and appropriate assumptions, throughout the flow paths in the SZ abstraction process;

(2) The description of the aspects of hydrology, geology, geochemistry, design features, physical phenomena, and couplings, that may affect flow paths in the $\mathrm{SZ}$, is adequate. Conditions and assumptions in the abstraction of flow paths in the SZ are readily identified, and consistent with the body of data presented in the description;

(4) Boundary and initial conditions used in the total system performance assessment abstraction of flow paths in the SZ are propagated throughout its abstraction approaches. For example, abstractions are based on initial and boundary conditions consistent with site-scale modeling and regional models of the Death Valley ground-water flow system;

(5) Sufficient data and technical bases to assess the degree to which features, events, and processes have been included in this abstraction are provided;

(6) Flow paths in the SZ are adequately delineated, considering natural site conditions;

(7) Long-term climate change, based on known patterns of climatic cycles during the Quaternary period, particularly the last 500,000 years, and other paleoclimate data, are adequately evaluated;

(8) Potential geothermal and seismic effects on the ambient SZ flow system are adequately described and accounted for;

(9) The impact of the expected water table rise on potentiometric heads and flow directions, and consequently on repository performance, is adequately considered; and

(10) Guidance in NUREG-1297 and NUREG-1298 (Altman, et al., 1988a,b), or other acceptable approaches for peer review and data qualification is followed.

\section{Acceptance Criterion 2: Data Are Sufficient for Model Justification.}

(1) Geological, hydrological, and geochemical values used in the license application to evaluate flow paths in the SZ are adequately justified. 
Adequate descriptions of how the data were used, interpreted, and appropriately synthesized into the parameters are provided;

(2) Sufficient data have been collected on the natural system to establish initial and boundary conditions for the abstraction of flow paths in the SZ;

(3) Data on the geology, hydrology, and geochemistry of the SZ used in the total system performance assessment abstraction are based on appropriate techniques. These techniques may include laboratory experiments, sitespecific field measurements, natural analogue research, and process-level modeling studies. As appropriate, sensitivity or uncertainty analyses, used to support the U.S. Department of Energy total system performance assessment abstraction, are adequate to determine the possible need for additional data; and

(4) Sufficient information is provided to substantiate that the proposed mathematical groundwater modeling approach and proposed model(s) are calibrated and applicable to site conditions.

\section{Acceptance Criterion 3: Data Uncertainty Is Characterized and Propagated Through the Model Abstraction.}

(1) Models use parameter values, assumed ranges, probability distributions, and bounding assumptions that are technically defensible, reasonably account for uncertainties and variabilities, and do not result in an underrepresentation of the risk estimate;

(2) Uncertainty is appropriately incorporated in model abstractions of hydrologic effects of climate change, based on a reasonably complete search of paleoclimate data;

(3) Uncertainty is adequately represented in parameter development for conceptual models, process-level models, and alternative conceptual models, considered in developing the abstraction of flow paths in the SZ. This may be done either through sensitivity analyses or through use of conservative limits. For example, sensitivity analyses and/or similar analyses are sufficient to identify SZ flow parameters that are expected to significantly affect the abstraction model outcome; and

(4) Where sufficient data do not exist, the definition of parameter values and conceptual models is based on appropriate use of expert elicitation, conducted in accordance with NUREG-1563 (Kotra, et al., 1996 [DIRS 100909]). If other approaches are used, the U.S. Department of Energy adequately justifies their uses. 


\section{Acceptance Criterion 4: Model Uncertainty Is Characterized and Propagated Through the Model Abstraction.}

(1) Alternative modeling approaches of features, events, and processes are considered and are consistent with available data and current scientific understanding, and the results and limitations are appropriately considered in the abstraction;

(2) Conceptual model uncertainties are adequately defined and documented, and effects on conclusions regarding performance are properly assessed. For example, uncertainty in data interpretations is considered by analyzing reasonable conceptual flow models that are supported by site data, or by demonstrating through sensitivity studies that the uncertainties have little impact on repository performance;

(3) Consideration of conceptual model uncertainty is consistent with available site characterization data, laboratory experiments, field measurements, natural analogue information and process-level modeling studies; and the treatment of conceptual model uncertainty does not result in an under-representation of the risk estimate; and

(4) Appropriate alternative modeling approaches are consistent with available data and current scientific knowledge, and appropriately consider their results and limitations, using tests and analyses that are sensitive to the processes modeled.

\subsection{CODES, STANDARDS, AND REGULATIONS}

No codes, standards, or regulations other than those identified in the project requirements document (Canori and Leitner 2003 [DIRS 166275], Table 2-3) and determined to be applicable (Table 4-4) were used in this model report. 


\section{ASSUMPTIONS}

A list of the assumptions used in this model report is provided in Table 5-1. The rationale and confirmation status for each status assumption is also provided. The upstream assumptions associated with the rationale below do not impact the results of the model.

Table 5-1. Assumptions

\begin{tabular}{|c|c|c|c|c|}
\hline Number & Assumption & Rationale & $\begin{array}{c}\text { Confirmation } \\
\text { Status }\end{array}$ & $\begin{array}{l}\text { Location in } \\
\text { this Report }\end{array}$ \\
\hline 1 & $\begin{array}{l}\text { A horizontal to vertical } \\
\text { anisotropy ratio of } 10: 1 \text { is } \\
\text { appropriate for most of the } \\
\text { hydrogeologic units in the SZ } \\
\text { site-scale flow model. }\end{array}$ & $\begin{array}{l}\text { This assumption is justified by common } \\
\text { usage among groundwater modelers } \\
\text { including the DVRFS, Yucca Mountain, } \\
\text { and Nevada Test Site (NTS); and by the } \\
\text { Yucca Mountain Expert Elicitation Panel } \\
\text { (CRWMS M\&O 1998 [DIRS 100353], } \\
\text { Table 3-2). The 10:1 ratio is the } \\
\text { geometric mean of the 1:1 To 100:1 } \\
\text { range given by the experts }\end{array}$ & $\begin{array}{l}\text { This } \\
\text { assumption } \\
\text { does not } \\
\text { require } \\
\text { confirmation } \\
\text { for LA } \\
\text { submittal. }\end{array}$ & $\begin{array}{l}\text { Used } \\
\text { throughout } \\
\text { this report. }\end{array}$ \\
\hline 2 & $\begin{array}{l}\text { The hydrogeologic properties } \\
\text { for all units in the SZ } \\
\text { site-scale flow model may be } \\
\text { represented as } \\
\text { homogeneous values. }\end{array}$ & $\begin{array}{l}\text { This assumption is introduced due to the } \\
\text { lack of information on the areal } \\
\text { heterogeneity within the SZ. The flow } \\
\text { model is designed to simulate the } \\
\text { groundwater flow field at a scale of many } \\
\text { kilometers. For simulating flow at that } \\
\text { scale, effective flow parameters are } \\
\text { generally acceptable. Thus, the use of } \\
\text { homogeneous properties within a } \\
\text { particular flow unit is acceptable. The } \\
\text { calibration process provides "best fit" } \\
\text { parameters for the SZ model. Where } \\
\text { appropriate, additional zones or } \\
\text { parameters are supplied to represent } \\
\text { spatial differences in hydrogeology. } \\
\text { These zones are justified in the sections } \\
\text { in which they are used (see, for example, } \\
\text { Sections 6.5.3.1 and 6.5.3.4). }\end{array}$ & $\begin{array}{l}\text { This } \\
\text { assumption } \\
\text { does not } \\
\text { require } \\
\text { confirmation } \\
\text { for LA } \\
\text { submittal. }\end{array}$ & $\begin{array}{l}\text { Used } \\
\text { throughout } \\
\text { this report. }\end{array}$ \\
\hline
\end{tabular}

DVRFS = Death Valley Regional Flow System; LA=license application; NTS = Nevada Test Site; SZ=saturated zone. 


\section{INTENTIONALLY LEFT BLANK}




\section{MODEL DISCUSSION}

\subsection{MODELING OBJECTIVES}

The purpose of the SZ site-scale flow model is to describe the steady-state flow of groundwater as it moves from the water table below the repository, through the SZ, and to the accessible environment. The flow model describes the SZ advective processes that control the movement of groundwater and the movement of dissolved radionuclides and colloidal particles that might be present.

The current SZ site-scale flow model was developed in support of the TSPA-LA. The current model was built upon the model used for the TSPA-SR (CRWMS M\&O 2000 [DIRS 153246]) but includes a number of modifications to (1) reflect the current understanding of the SZ flow, (2) enhance model validation and uncertainty analyses, and (3) incorporate new data collected since the TSPA-SR. Changes introduced since the TSPA-SR iteration include the following:

- Use of field and laboratory tests (hydraulic and tracer data collected since TSPA-SR) to establish and confirm the conceptual model for flow, constrain model parameter calibration, and provide data for model validation and confidence building.

- Use of thermal data for model validation.

- For validation purposes, use of recently collected hydraulic and geologic data that were obtained from the Nye County Early Warning Drilling Program (NC-EWDP).

This modeling analysis is a direct feed to Site-Scale Saturated Zone Transport (BSC 2004 [DIRS 170036]) as it provides the SZ flow fields and specific discharge in transport calculations.

\subsection{FEATURES, EVENTS, AND PROCESSES CONSIDERED IN MODEL}

As stipulated in the Technical Work Plan for: Natural System - Saturated Zone Analysis Model Report Integration (BSC 2004 [DIRS 171421]) this model report addresses the SZ FEPs pertaining to SZ flow that are included (i.e., Included FEPs) for TSPA-LA (Table 6-1). SZ FEPs that were excluded (i.e., Excluded FEPs) for TSPA-LA are described in Features, Events, and Processes in SZ Flow and Transport (BSC 2004 [DIRS 170013]). Table 6-1 provides a list of FEPs that are relevant to this model analysis in accordance with their assignment in the LA FEP list (DTN: MO0407SEPFEPLA.000 [DIRS 170760]). Specific reference to the various sections within this document where issues related to each FEP are addressed is provided in the table. The detailed discussion of these FEPs, and their implementation in TSPA-LA are documented in the Features, Events, and Processes in SZ Flow and Transport (BSC 2004 [DIRS 170013]). 
Table 6-1. Features, Events, and Processes Included in TSPA-LA and Relevant to this Model Report

\begin{tabular}{|c|c|c|c|}
\hline FEP No. & FEP Name & $\begin{array}{l}\text { Sections Where } \\
\text { Disposition is } \\
\text { Described }\end{array}$ & $\begin{array}{c}\text { Discussed in Supporting } \\
\text { AMRs }\end{array}$ \\
\hline 1.2.02.01.0A & Fractures & $\begin{array}{l}\text { Sections } 6.3 .3,6.5 .1 \\
8.3 .2,8.3 .1\end{array}$ & $\begin{array}{l}\text { Upstream Feeds }{ }^{\mathrm{a}} \text { BSC } \\
2004 \text { [DIRS 170014] (BSC } \\
2004 \text { [DIRS 170008]) } \\
\text { Corroborating }{ }^{\mathrm{b}} \text { BSC } 2004 \\
\text { [DIRS 170010] }\end{array}$ \\
\hline $1.2 .02 .02 .0 \mathrm{~A}$ & Faults & $\begin{array}{l}\text { Sections } 6.3,6.5,6.3 .2 \text {, } \\
\text { 6.5.3.1; Table 6-6 }\end{array}$ & $\begin{array}{l}\text { Upstream Feeds }{ }^{\mathrm{a}} \text { BSC } \\
2004 \text { [DIRS 170008] } \\
\text { Corroborating }^{\mathrm{b}} \text { BSC } 2004 \\
\text { [DIRS 170010] }\end{array}$ \\
\hline 1.3.07.02.0A & Water table rise affect SZ & Section 6.4.5.1 & $\begin{array}{l}\text { Upstream Feeds }{ }^{a} \text { BSC } \\
2004 \text { [DIRS 170009] }\end{array}$ \\
\hline 2.2.03.01.0A & Stratigraphy & $\begin{array}{l}\text { Sections 6.5.3.1, } \\
6.5 .3 .4,6.5 .3,6.3 .2\end{array}$ & $\begin{array}{l}\text { Upstream Feeds }^{a} \text { BSC } \\
2004 \text { [DIRS 170008] ; } \\
\text { Corroborating }{ }^{b} \text { BSC } 2004 \\
\text { [DIRS 170014] BSC } 2004 \\
\text { [DIRS 170010] }\end{array}$ \\
\hline $2.2 .03 .02 .0 \mathrm{~A}$ & $\begin{array}{l}\text { Rock properties of host rock } \\
\text { and other units }\end{array}$ & $\begin{array}{l}\text { Sections } 6.5 .3,6.5 .3 .4, ; \\
\text { Table 6-6 }\end{array}$ & $\begin{array}{l}\text { Upstream Feeds }{ }^{\mathrm{a}} \text { BSC } \\
2004 \text { [DIRS 170008] } \\
\text { Corroborating }^{\mathrm{b}} \text { BSC } 2004 \\
\text { [DIRS 170010] }\end{array}$ \\
\hline 2.2.07.12.0A & $\begin{array}{l}\text { Saturated groundwater flow in } \\
\text { the geosphere }\end{array}$ & $\begin{array}{l}\text { Sections } 6.2,6.3,6.3 .1, \\
6.3 .2,6.3 .2 .7,6.3 .2 .10, \\
6.5 ; \text { Figure } 6-1 ; \text { A-6.7.6, } \\
\text { A-6.7.7, A-6.7.8, A- } \\
\text { 6.7.9, and A-6.7.11 }\end{array}$ & $\begin{array}{l}\text { Upstream Feeds }^{\mathrm{a}} \text { BSC } \\
2004 \text { [DIRS 170015] ; } \\
\text { Corroborating }{ }^{\mathrm{b}} \text { BSC } 2004 \\
\text { [DIRS 170014] BSC } 2004 \\
\text { [DIRS 170010] }\end{array}$ \\
\hline 2.2.07.13.0A & $\begin{array}{l}\text { Water-conducting features in } \\
\text { the SZ }\end{array}$ & $\begin{array}{l}\text { Sections } 6.3,6.3 .2,6.5 \\
\text { 6.5.3.4; Figure 6-4; } \\
\text { Table 6-6 }\end{array}$ & $\begin{array}{l}\text { Upstream Feeds }{ }^{\mathrm{a}} \text { BSC } \\
2004 \text { [DIRS 170008] ; } \\
\text { Corroborating }{ }^{\mathrm{b}} \text { BSC } 2004 \\
\text { [DIRS 170014] BSC } 2004 \\
\text { [DIRS 170010] }\end{array}$ \\
\hline 2.2.07.15.0A & $\begin{array}{l}\text { Advection and dispersion in } \\
\text { the SZ }\end{array}$ & Sections 6.3-6.8, 8 & $\begin{array}{l}\text { Upstream Feeds }{ }^{a} \text { BSC } \\
2004 \text { [DIRS 170015] } \\
\text { Corroborating }^{b} \text { BSC } 2004 \\
\text { [DIRS 170010] }\end{array}$ \\
\hline 2.2.08.01.0A & Chemical Characteristics & $\begin{array}{l}\text { Section A-7.1.2; Tables } \\
\text { A-10, A-11 }\end{array}$ & $\begin{array}{l}\text { Corroborating }^{\mathrm{b}} \text { BSC } 2004 \\
\text { [DIRS 170042], BSC } 2004 \\
\text { [DIRS 170036] }\end{array}$ \\
\hline 2.2.10.03.0A & $\begin{array}{l}\text { Natural geothermal effects on } \\
\text { flow in the SZ }\end{array}$ & Sections 6.5.3.7, 7.4 & $\begin{array}{l}\text { This report } \\
\text { Upstream Feeds }{ }^{a} \text { NA } \\
\text { Corroborating NA }\end{array}$ \\
\hline
\end{tabular}

AMRs = analysis model reports; FEP = features, events, and processes; $\mathrm{SZ}=$ saturated zone.

\subsection{CONCEPTUAL MODEL}

The SZ site-scale flow model presented in this section describes our current state of knowledge of the saturated flow system. The original hydrogeologic framework model (HFM-19) used in the base case model is shown in Section 6.5.3.2 (see Figure 6-28). This figure displays a 
three-dimensional representation of the hydrogeologic units used in the HFM and is useful in visualizing the region modeled in this report. Additional information that corroborates the base case model is presented in Appendix A.

The general conceptual model of SZ flow in the SZ site-scale flow model area is that groundwater flows southerly from recharge areas of higher precipitation at higher elevations north of Yucca Mountain, through the Fortymile Wash and toward the Amargosa Desert. Within the site-scale model area, recharge occurs from infiltration of both precipitation and flood-flows from Fortymile Wash and its tributaries. In the southeastern part of the model area (within the Ash Meadows groundwater basin), considerable flows enter and exit the area in the lower carbonate aquifer system (BSC 2004 [DIRS 170015], Section 6.2). This aquifer system is believed to underlie much of the Alkali Flat-Furnace Creek groundwater basin based on inferences from Death Valley regional groundwater flow data as explained below. However, the flow patterns of groundwater in this area and their relationship to flow in the Ash Meadows flow system are poorly understood. Outflow from the SZ site-scale flow model area mostly occurs across the southern boundary of the model. The boundary conditions on the southern boundary include discharge by irrigation wells in the Amargosa Farms area.

\subsubsection{Key Features}

Within the boundaries of the site-scale flow model area, there are several components that strongly affect the local flow system and potential radionuclide transport. Those are:

- Solitario Canyon fault

- Recharge on Yucca Mountain

- Crater Flat tuff hydrogeologic units

- Shallow alluvial aquifer of Fortymile Wash

- Regional carbonate aquifer.

The Solitario Canyon fault is important because it provides a fast vertical flow path from the surface to the SZ. It also can provide a barrier for water flowing laterally under Yucca Mountain that originated in Crater Flat. Recharge to the SZ is important because the transport time of potential radionuclides is directly dependent on it. The Crater Flat tuffs, particularly the Bullfrog unit, are likely to be the most permeable hydrogeologic units near the repository and, thus, are the most likely paths for potential radionuclide transport. The shallow alluvial aquifer in Fortymile Wash is important because it both contains the likely flow paths for fluid leaving the repository area and has desirable retardation characteristics for many radionuclides. The regional carbonate aquifer underlies the likely flow area for fluid leaving the repository area. This aquifer also provides an upward gradient that keeps the flow lines shallow and, effectively, isolates the local Yucca Mountain system from the regional carbonate aquifer.

Hydrochemical studies conducted at and near Yucca Mountain over the last 25 years are summarized in Appendix A. The appendix provides an analysis of groundwater recharge rates, flow directions and velocities, and mixing proportions of water from different source areas based on analyses of the geochemistry and isotopic constraints. It also provides an evaluation of data to determine chemical reactions in the groundwater system, the evolution of groundwater as it moves along the flow pathway, groundwater-mixing relationships, and chemical controls on 
strontium and uranium. The appendix also examines groundwater residence times based on corrected ${ }^{14} \mathrm{C}$ ages and evaluates water/rock interactions to provide a basis for the ${ }^{14} \mathrm{C}$ age corrections. The appendix provides a comparison of patterns of groundwater movement outlined by the SZ flow model with flow patterns inferred strictly from hydrochemical and isotopic data. In this way, the analysis documented in the appendix provides an independent means of corroborating the SZ site-scale flow model.

The HFM is a conceptual model providing a three-dimensional interpretation of the hydrostratigraphic unit locations and structure within the site-scale SZ flow and transport model domain for use in the SZ flow and transport numerical models. The HFM does not provide any hydraulic parameter, rather it provides a conceptualization of hydrogeologic units which serves as the basis for assigning upper and lower bounds for hydraulic parameters used in flow model calibration.

\subsubsection{Components of the Base Case Conceptual Model}

Yucca Mountain is located in the Great Basin about $150 \mathrm{~km}$ northwest of Las Vegas, Nevada. The mountain consists of a series of fault-bounded blocks of ash-flow and ash-fall tuffs and a smaller volume of lava deposited between 14 and 11 Ma (one million years (refers to age)) from a series of calderas located a few to several tens of kilometers to the north (Sawyer et al. 1994 [DIRS 100075]). Yucca Mountain itself extends southward from the Pinnacles Ridge toward the Amargosa Desert, where the tuffs thin and pinch out beneath the alluvium (Figure 6-1). The tuffs dip 5 to 10 degrees to the east over most of Yucca Mountain.

Crater Flat is west of Yucca Mountain and separated from it by Solitario Canyon, which is the surface expression of the Solitario Canyon fault-a steeply dipping scissors fault with down-to-the-west displacement of as much as $500 \mathrm{~m}$ in southern Yucca Mountain (Day et al. 1998 [DIRS 100027], pp. 6 to 7). Underlying Crater Flat is a thick sequence of alluvium, lavas, and tuffs that has been locally cut by faults and volcanic dikes. East of Yucca Mountain, and separated from it by Fortymile Wash, is Jackass Flats, which is underlain by a thick sequence of alluvium and volcanic rocks. Timber Mountain, approximately $25 \mathrm{~km}$ to the north of the repository area, is a resurgent dome within the larger caldera complex that erupted the tuffs at Yucca Mountain.

The central block of Yucca Mountain, into which waste would be emplaced if the site were licensed, is bounded by Drill Hole Wash on the north, the Solitario Canyon fault on the west, the Bow Ridge fault on the east, and is dissected by the Ghost Dance and Dune Wash faults (Figure 6-3). Topography is highly variable and, north of the central block, is controlled by long, northwest-trending, fault-controlled washes. Within and south of the central block, washes are shorter and trend eastward. Topography in the southern part of Yucca Mountain is controlled by south-trending faults. 


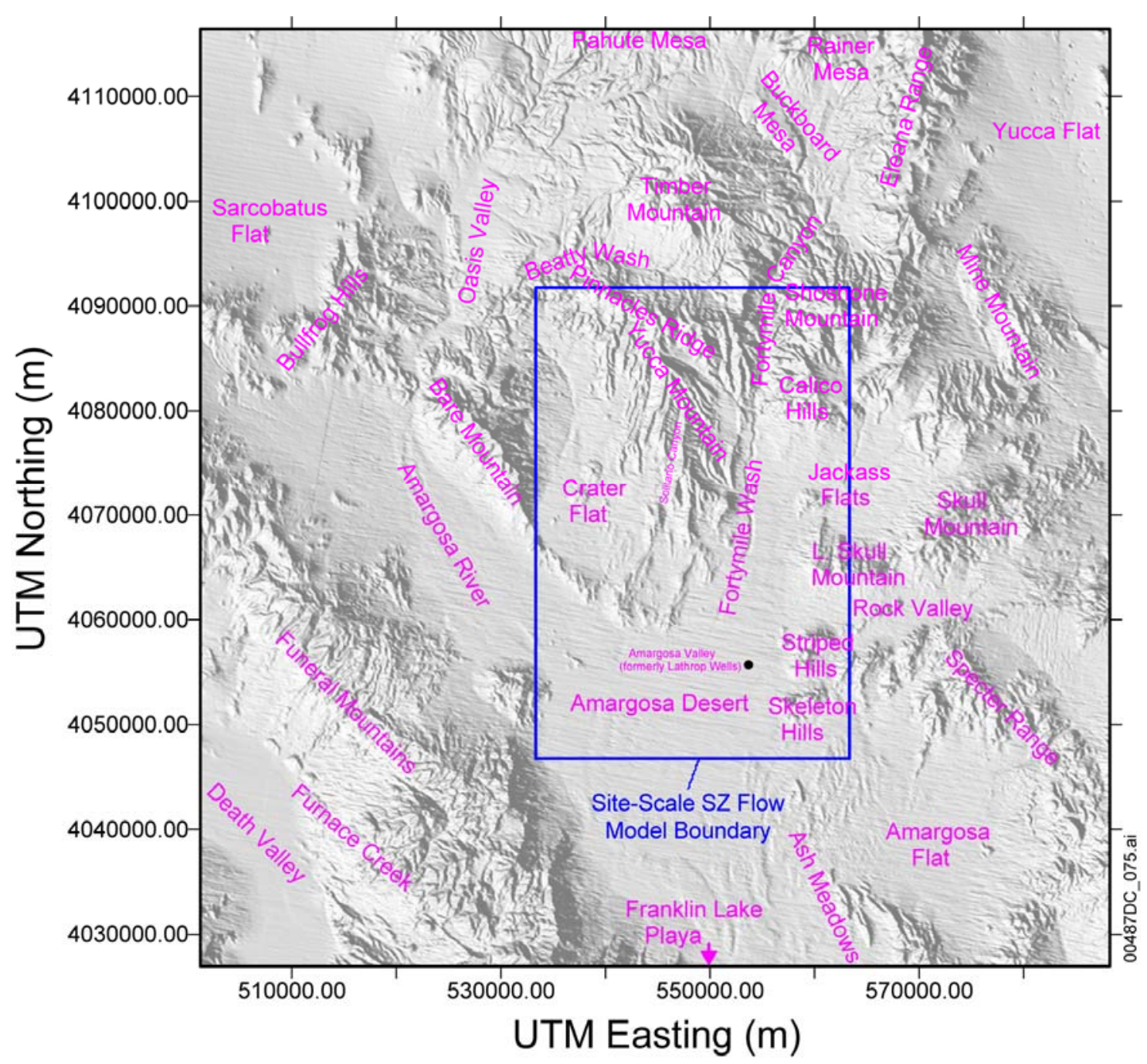

Source: DTN: GS991208314221.001 (DIRS 145263).

NOTE: The blue rectangle is the boundary of the numerical model for SZ flow and transport.

SZ = saturated zone; UTM = Universal Transverse Mercator.

Figure 6-1. Important Physiographic Features Near Yucca Mountain Including Boundaries of the SZ Site-Scale Flow Model

The boundaries of the numerical models for SZ flow and transport are labeled as the SZ site-scale flow boundary in Figure 6-1. The domain was selected to be: (1) coincident with grid cells in the DVRFS model (DTN: GS960808312144.003 [DIRS 105121]) such that the base of the site model is consistent with the base of the regional model (2,750 m below a smoothed version of the potentiometric surface); (2) sufficiently large to reduce the effects of boundary conditions on estimating permeability values and calculated flow fields at Yucca Mountain; (3) sufficiently large to assess groundwater flow at distances beyond the 18-km compliance boundary from the repository area; (4) small enough to minimize the model size for computational uses; (5) thick enough to include part of the regional Paleozoic carbonate aquifer; and (6) large enough to include borehole control in the Amargosa Desert at the southern end of the modeled area. The hydrogeologic setting of the SZ flow system in the vicinity of Yucca 
Mountain was summarized by Luckey et al. (1996 [DIRS 100465], p. 13). Yucca Mountain is part of the Alkali Flat-Furnace Creek subbasin of the Death Valley groundwater basin, as described by Waddell (1982 [DIRS 101062], pp. 15 to 16). Discharge within the subbasin occurs at Alkali Flat (Franklin Lake Playa) and, possibly, Furnace Creek in Death Valley (Figure 6-1). Water inputs to the subbasin include groundwater inflow along the northern boundary of the subbasin, recharge from precipitation in high-elevation areas of the subbasin, and recharge from surface runoff in Fortymile Canyon and Fortymile Wash. North and northeast of Yucca Mountain, recharge from precipitation also probably occurs at Timber Mountain, Pahute Mesa, Rainier Mesa, and Shoshone Mountain (Luckey et al. 1996 [DIRS 100465], p. 13).

\subsubsection{Groundwater Occurrence and Flow}

As described by Luckey et al. (1996 [DIRS 100465], p. 17), the Tertiary volcanic section at Yucca Mountain consists of a series of ash flow and bedded ash fall tuffs that contain minor amounts of lava and flow breccia. Individual ash flow tuffs may be several hundred meters thick, whereas bedded ash fall tuffs generally are less than a few tens of meters thick. Ash flow tuffs range from nonwelded to densely welded, and the degree of welding varies both horizontally and vertically in a single flow unit. Nonwelded ash flow tuffs, when unaltered, have moderate to low matrix permeability but high porosity. Permeability is decreased by secondary alteration, and fractures are infrequent and often closed in the low-strength nonwelded tuffs. Consequently, these rocks generally constitute laterally extensive SZ confining units in the Yucca Mountain area. The properties of partly welded tuffs vary between those of fractured, welded tuffs and those of altered, nonwelded tuffs. The densely welded tuffs generally have minimal primary porosity and water-storage capacity, but they can be highly fractured. Where interconnected, fractures can easily transmit water, and highly fractured units function as aquifers. In general, the bedded ash fall tuffs have high primary porosity and can store large amounts of water. Their matrix permeability is moderate to low, depending on the degree of alteration. North of Yucca Mountain the Claim Canyon caldera have been the subject of thermal alteration. The bedded ash fall tuffs generally function as confining units, at least when compared to less porous but densely fractured ash flow tuffs. Lavas, flow breccias, and other minor rock types are neither thick nor widely distributed in the Yucca Mountain area. Their hydraulic properties probably are as variable as the properties of the ash flow tuffs, but the relatively limited spatial distribution of these minor rock types makes them generally unimportant to the hydrology of Yucca Mountain.

Luckey et al. (1996 [DIRS 100465], p. 17) state that even fractured tuffs and lavas may not easily transmit water because lithostatic loading keeps the fractures closed. In addition, where volcanic glass has been partly replaced by zeolites and clays, particularly in the originally glassy nonwelded tuffs, these secondary minerals substantially decrease permeability and slow groundwater flow through the rock. The degree of alteration can affect the water-transmitting characteristics of the volcanic sequence. Alteration, particularly in the Calico Hills Formation, increases toward the north of Yucca Mountain and probably accounts for the apparent decrease in hydraulic conductivity to the north. Alteration also tends to increase with depth and is pervasive below the Calico Hills Formation.

Fractures vary in length, orientation, connectivity, aperture width, and amounts and types of coatings, all of which may affect the flow of water. The physical parameters of fractures are 
characterized by outcrop mapping, borehole logging, and mapping in the Exploratory Studies Facility. In the UZ, seeps of water have not been observed in outcrop mapping or in mapping in the Exploratory Studies Facility.

Fractures at Yucca Mountain originated as a result of initial cooling of the volcanic deposits and as a result of tectonic activity. For example, in the Tiva Canyon welded hydrologic unit, two sets of vertically orientated cooling fractures were observed dipping nearly vertically and striking towards the northwest and northeast. A third set of tectonic joints commonly abuts the cooling joints, and these three sets of joints form an orthogonal, three-dimensional network. An extensive discussion of fractures in the Yucca Mountain area is presented in the Yucca Mountain Site Description (BSC 2004 [DIRS 169734], Section 3.5).

Fracture aperture characteristics are poorly known from direct observation, and for modeling, reliance is placed on indirect effects such as changes in air and water permeability. In general, the stress due to overburden loading across high-angle fractures will be less than across low-angle fractures, resulting in higher vertical than horizontal permeability. Stratification effects will also be present in many units. This will tend to have the opposite effect; that is, the horizontal permeability will be larger than the vertical permeability.

The volcanic rocks consist of alternating layers of welded and nonwelded ash flow and ash fall (bedded) tuff deposits. Each of the ash flow units is underlain by an associated bedded tuff layer. The ash flow units vary in degree of welding (or recrystallization) with the maximum welding generally found near the center of the flow, where heat was retained the longest, and the degree of welding decreasing upward and downward toward the flow boundaries.

The welded units typically have low matrix porosities and high fracture densities, whereas the nonwelded and ash fall have relatively higher matrix porosities and lower fracture densities. The fracture density is correlated with the degree of welding of the volcanic rocks.

Where glassy tuff has been saturated for long periods (e.g., beneath the water table), the original glassy material generally has been altered to zeolite or clay minerals. Such alteration does not affect porosity greatly because it does not fill the pore spaces, but the permeability of the rocks is greatly reduced by alteration of the connections between the pore spaces. Alteration of silica to zeolites or clay minerals is not an important factor in densely welded zones because cooling fractures dominate permeability.

The SZ flow system to the south of Yucca Mountain transitions from a fractured tuff aquifer to a valley-fill (alluvium) aquifer before reaching the approximately 18-km performance compliance boundary at the southern boundary of the Nevada Test Site (NTS). Underlying Crater Flat is a thick sequence of alluvium, lavas, and tuffs that have been locally cut by faults and volcanic dikes. East of Yucca Mountain, and separated from it by Fortymile Wash, is Jackass Flats, which is underlain by a thick sequence of alluvium and volcanic rocks. Characterization of the valley-fill system was conducted just outside the southwest corner of NTS at the Alluvial Testing Complex (ATC), which is the site of well NC-EWDP-19D/D1. Multiple-well hydraulic tests, single-well hydraulic tests, and tracer tests were conducted in NC-EWDP-19D/D1. This test well location is shown Figure 7-1. These tests indicated producing zones with permeabilities consistent with other alluvial systems $\left(1\right.$ to $\left.10 \times 10^{-12} \mathrm{~m}^{2}\right)$ interbedded with lower permeability 
$\left(10^{-15} \mathrm{~m}^{2}\right)$ clay-rich zones. In addition to flow in the volcanic rocks and alluvium in the SZ, groundwater also flows in the carbonate rocks of the lower carbonate aquifer.

In general, it is believed that the matrix porosity of the ancient marine limestones and dolomites of the lower carbonate aquifer is negligible (Winograd and Thordarson 1975 [DIRS 101167], p. C14), and that the large discharge from that aquifer system at Ash Meadows is due to flow through solution-enlarged fractures and along faults (Dudley and Larson 1976 [DIRS 103415], pp. 5 and 9). One borehole, UE-25 p\#1 (labeled as P\#1 in Figure 6-2), penetrates the lower carbonate aquifer near Yucca Mountain. Another deep well, NC-EWDP-2DB was completed in the carbonate aquifer as part of the NC-EWDP. These deep wells helped improve the understanding of hydrologic conditions in the aquifers, including the deep carbonate aquifer, and helped to confirm the direction and magnitude of groundwater flow in that aquifer. Large groundwater volumetric flow has been modeled in the carbonate aquifer by D'Agnese et al. (1997 [DIRS 100131], Figures 46 to 47, p. 90) in the Death Valley regional groundwater flow model within the southern part of the site-scale flow model. These results are discussed in Section 6.3.2.4.

\subsubsection{Hydrologic Features}

The HFM for the SZ site-scale flow model (HFM-19) (BSC 2004 [DIRS 170008], Section 6.3.3) represents faults and other hydrogeologic features (Figure 6-3) such as zones of hydrothermal alteration that affect SZ flow. Information on faults includes fault trace maps, which show both faults on cross sections and locations where faults intersect the land surface. Faults in the model area dip at various angles, but most are high-angle faults. Faults deemed important to flow near Yucca Mountain are modeled explicitly in the numerical SZ site-scale flow model. Given software constraints and the numerical flow model resolution, faulting in the area was simplified in the numerical model, and the faults were treated as vertical features. Section 6.5.3.1 discusses how these features were constructed in the HFM. 

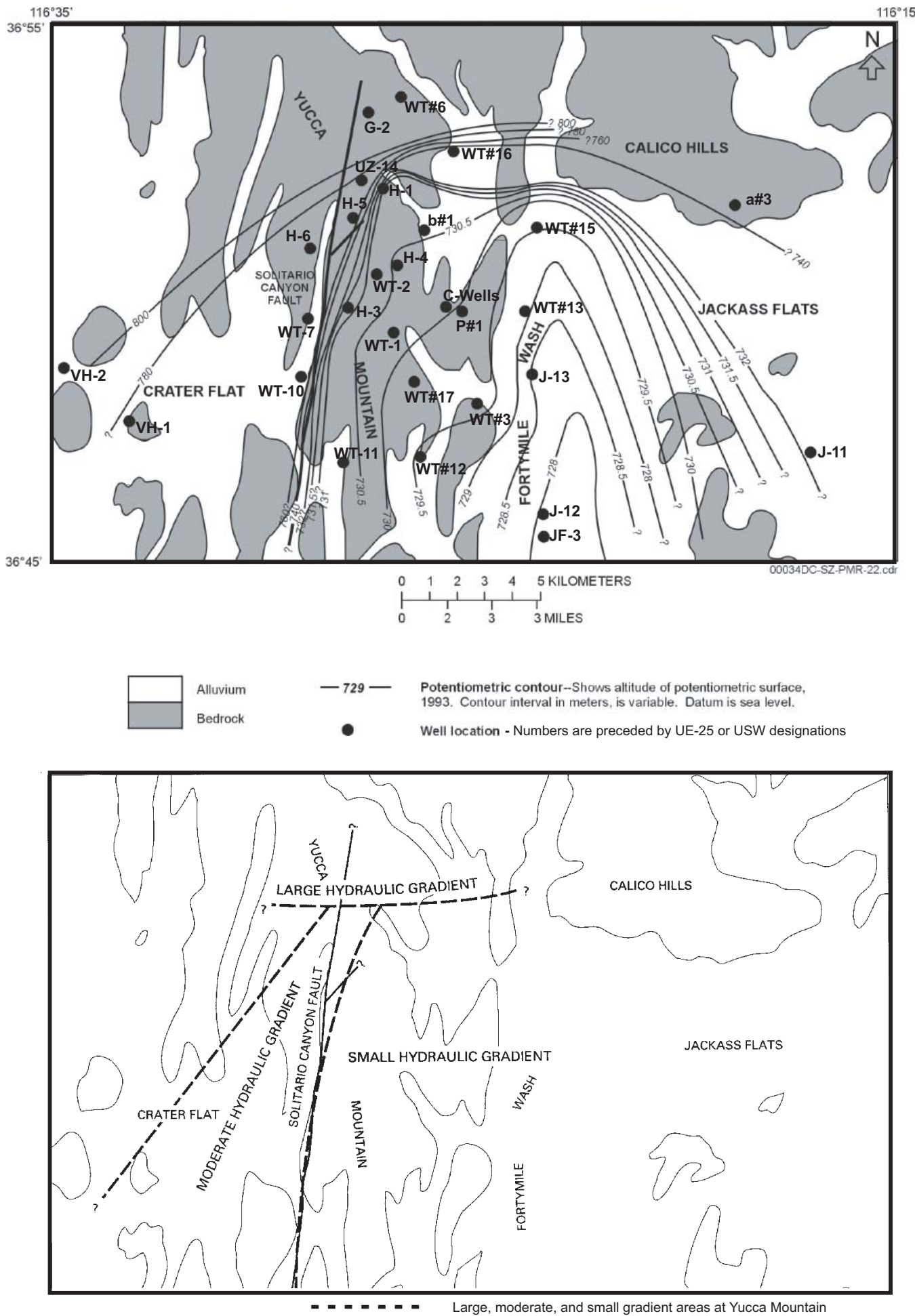

Source: Tucci and Burkhardt (1995 [DIRS 101060], Figures 2, 4, and 5).

Figure 6-2. Potentiometric Surface Map and Gradient Areas Developed Using Water-Level Data from 1993 


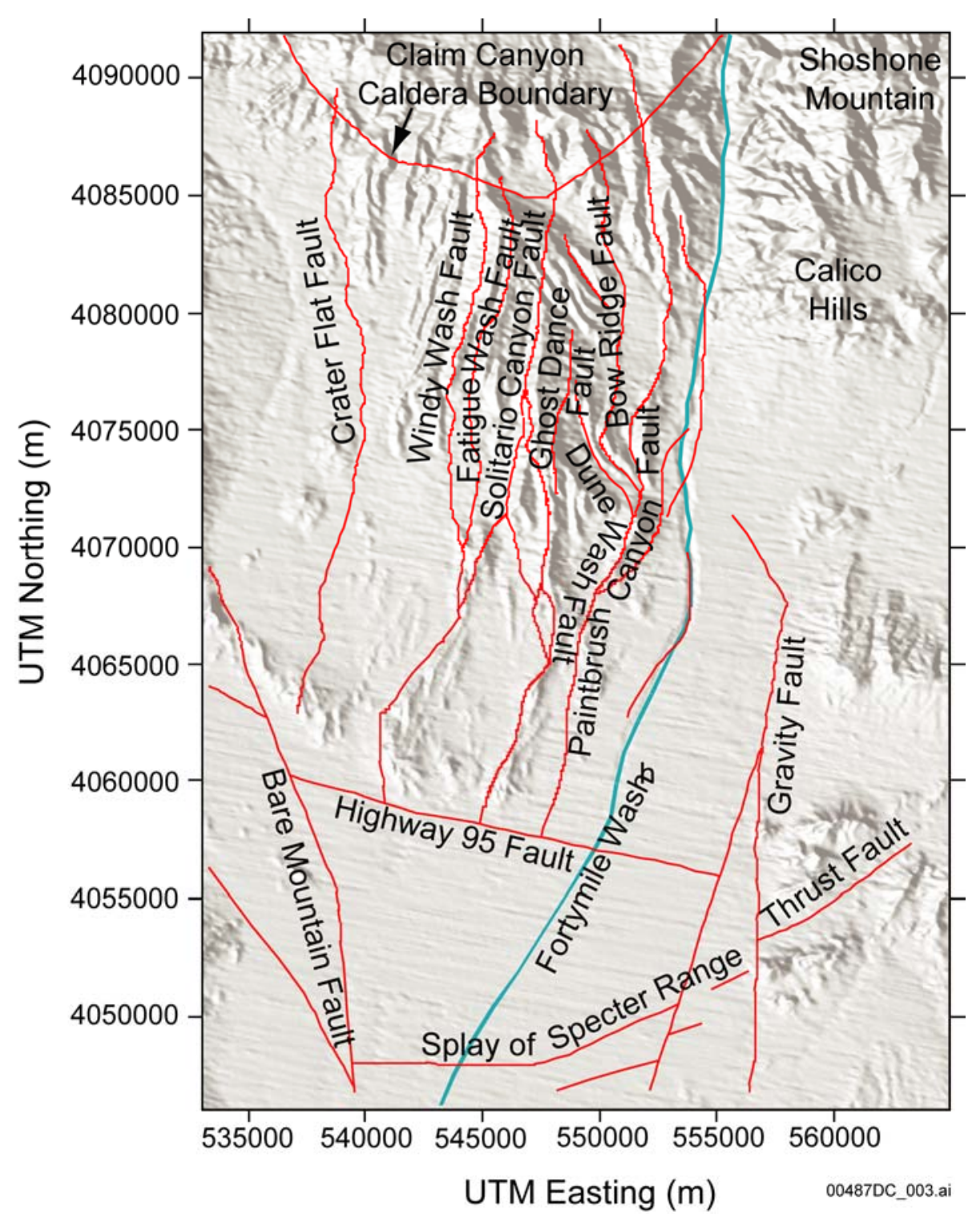

Source: DTN: GS991208314221.001 (DIRS 145263) (Tertiary Faults).

NOTE: The geographic coordinates and the name of the different geologic features shown in this figure are the results of interpretation of the geologic map, including geologic cross-sections, and lithostratigraphic and structural data from boreholes as it is described in detail in BSC (2004 [DIRS 170008]). The conversion of the geographic coordinates was done using standard Geographic System Information (GIS) functions. See BSC (2004 [DIRS 170008], Figure 6-3) for an example showing both, the latitude/longitude and UTM coordinates of the site-scale model and some of the features shown in Figure 6-37.

UTM = Universal Transverse Mercator.

Figure 6-3. Location of Faults in the Yucca Mountain Region 


\subsubsection{Flow Field}

Using the potentiometric surface map (Figure 6-4) and the supposition that hydraulic conductivity is horizontally isotropic, the general direction of groundwater flow within the SZ site-scale flow and transport model area can be deduced as being from north to south. Under this supposition, the direction of flow is perpendicular to the water-level contours. Under the BSC (2004 [DIRS 170008], Section 6.3.6) interpretation of the water-level data, the water table exhibits a steep gradient throughout the northern part of the model area (north of the repository) and the contours curve southward to the west of Crater Flat.

Several faults (Figure 6-4) are interpreted as barriers to groundwater flow, as indicated by offsets of contours where they cross faults. This interpretation is supported only by field data at the Solitario Canyon fault, west of the repository, which is interpreted as causing a differential of about $45 \mathrm{~m}$ (148 ft) in the potentiometric surface. In Crater Flat and on the southern part of Yucca Mountain, the flow direction is nearly easterly toward Fortymile Wash. A more detailed water-level map of the immediate vicinity of Yucca Mountain (Figure 6-2) indicates that flows from the west and east converge at Fortymile Wash and turn southward toward the Amargosa Desert. The cause of the easterly gradient in Crater Flat and southern Yucca Mountain is not evident, but it suggests that a groundwater barrier exists near the northern margin of the Amargosa Desert. In any event, the potentiometric surface upgradient of the $725-\mathrm{m}(2,379-\mathrm{ft})$ contour and the U.S. Highway 95 fault appears to have little north-south flow over an area of about $259 \mathrm{~km}^{2}\left(100 \mathrm{mi}^{2}\right)$. Note that Figure 6-2 is a water-level map using 1993 data. Newer data do not contradict any of the discussion of this paragraph.

As discussed in Section 6.3.2.5, the potentiometric level in well UE-25 p\#1, which penetrates the lower carbonate aquifer, is about $752 \mathrm{~m}(2,467 \mathrm{ft}), 21 \mathrm{~m}(69 \mathrm{ft})$ higher than in nearby wells tapping the lower volcanic aquifer. This result indicates a potential for upward flow from the lower carbonate aquifer; however, other lines of evidence suggest that such flow is small. The direction of flow and hydraulic gradient cannot be determined from a single well; however, regional relationships suggest that the general direction of flow in the lower carbonate aquifer should be southerly to southeasterly in the SZ site-scale flow model domain (NRC 1998 [DIRS 107770], p. 109). South of the site-scale model domain, there is geochemical evidence for a westward component of flow in the carbonate aquifer (Appendix A).

Most monitoring wells in the Yucca Mountain area show little variation in water level over time (Luckey et al. 1996 [DIRS 100465], p. 29). In contrast, water levels in the heavily pumped Amargosa Farms area have declined substantially since intensive irrigation development began in the 1950s. Kilroy (1991 [DIRS 103010], p. 18) reported a water level decline of as much as

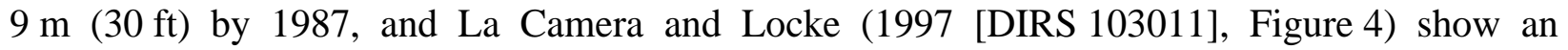

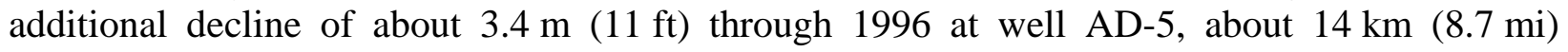
southwest of the Amargosa Valley. 


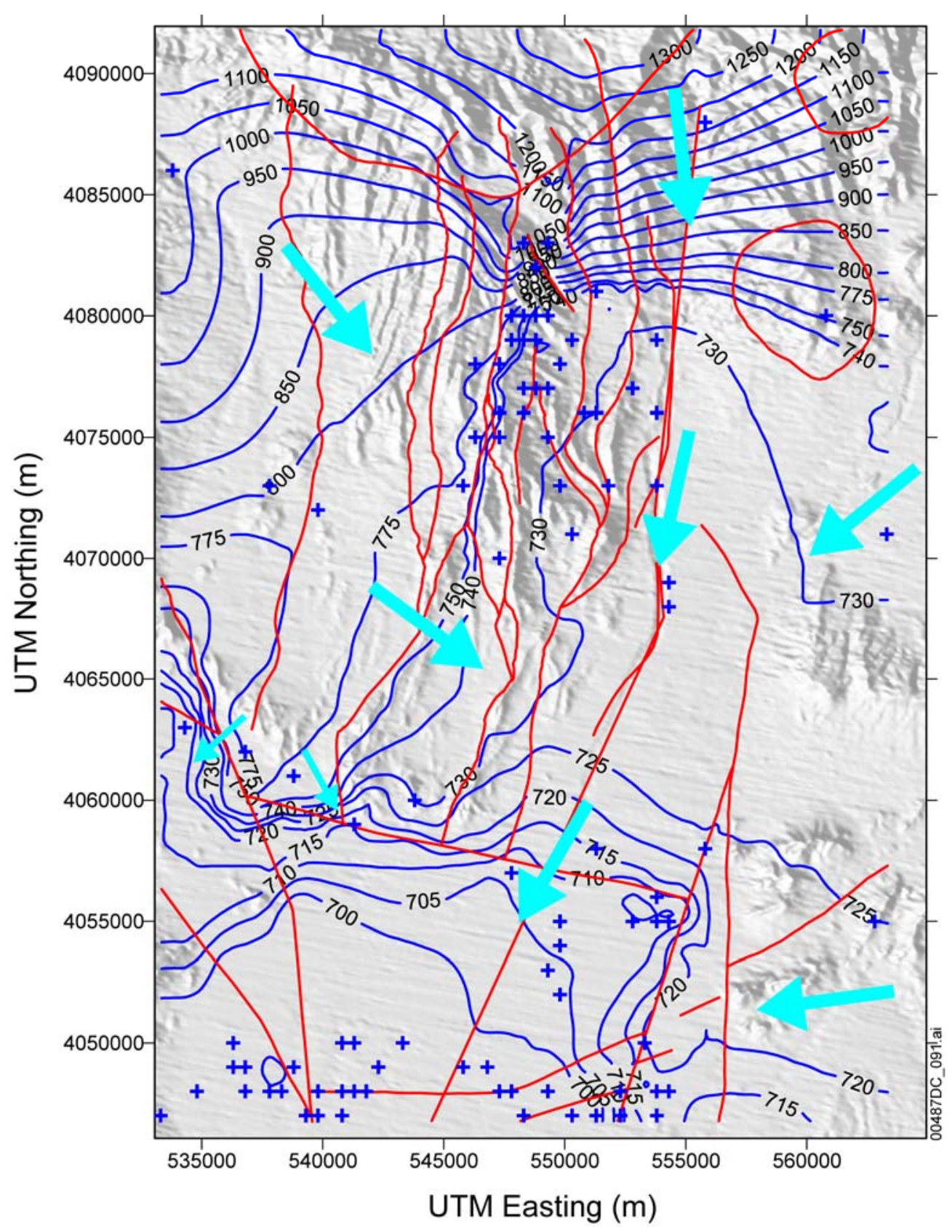

Source: DTN: GS991208314221.001 (DIRS 145263) (Tertiary faults); GS00050812332.001 (DIRS 149947) (Water-level contours.) USGS (2001 (DIRS 154625), Figure 1-2).

NOTE: The inferred groundwater flow directions are based on Assumption 1 in Appendix A (see Table A5-1). The circular areas outlined in red near the Calico Hills in the northeast corner of the map are zones of hydrothermal alteration associated with granitic intrusions (Table 6-17). The semicircular area along the central northern portion of the map is the southern boundary of the Claim Canyon caldera (Table 6-17). The other red lines are selected faults; blue crosses indicated the location of hydraulic head measurements. Potentiometric Surface and Inferred Flow Directions are indicated by light blue arrows.

UTM = Universal Transverse Mercator projection system of coordinates.

Figure 6-4. Potentiometric Surface and Inferred Flow Directions for Yucca Mountain and Vicinity 


\subsubsection{Large, Moderate, and Small Hydraulic Gradients}

Three distinctive hydraulic gradients of the potentiometric surface at Yucca Mountain are recognized: (1) a large hydraulic gradient of 0.13 between water-level altitudes of $1,030 \mathrm{~m}$

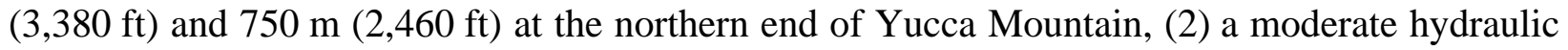
gradient of 0.05 west of the crest of Yucca Mountain, and (3) a small hydraulic gradient of 0.0001 to 0.0003 extending from Solitario Canyon to Fortymile Wash. These gradients have been portrayed on detailed potentiometric surface maps presented by Ervin et al. (1994 [DIRS 100633]), and Tucci and Burkhardt (1995 [DIRS 101060]), as well as on the maps with large contour intervals compiled by D’Agnese et al. (1997 [DIRS 100131]). The large contour-interval maps do not portray the small or moderate gradients adequately because of limitations imposed by contour intervals; however, the large gradient is recognizable on all of these maps.

Luckey et al. (1996 [DIRS 100465]) present detailed descriptions of these gradient features and discuss interpretations of their causes. The large hydraulic gradient has been the subject of numerous theories and could be the results of the Claim Canyon caldera and their associated thermal alteration. The large gradient is discussed in Luckey et al. (1996 [DIRS 100465], pp. 21 to 25):

- The gradient is the result of flow through the upper volcanic confining unit, which is nearly $300 \mathrm{~m}$ (984 ft) thick near the large gradient. This large thickness of low permeability material creates a barrier to flow that causes water to back up behind it, raising hydraulic head to the north, and leading to the large gradient.

- The gradient represents a semi-perched system in which flow in the upper and lower aquifers is predominantly horizontal, whereas flow in the upper confining unit would be predominantly vertical. In this scenario, the large hydraulic gradient is a manifestation of water leaking out of the upper aquifer, through the confining unit, and into the lower aquifer. Farther south, water has drained out of the perched aquifer and now only the lower heads of the deeper aquifer are measured. The difference in heads between the northern-perched water levels and the southern deeper aquifer levels appears as a large hydraulic gradient.

- The gradient represents a drain down a buried fault from the volcanic aquifers to the lower carbonate aquifer. In this case water levels drop quickly as the feature is approached from the north much in the same way water levels drop into the cone of depression caused by a pumping well. In this case, the feature is linear; the result is a region of steep hydraulic gradient rather than a cone of depression around a single well. 
- The gradient represents a spillway in which a fault marks the effective northern limit of the lower volcanic aquifer. In this scenario, water flows more readily in lower volcanic aquifer, which is located south of the LHG. This effectively "drains off" the high hydraulic heads and established a lower water level. North of this location, the lower permeabilities create a barrier to flow that keeps water levels high.

- The large gradient results from the presence at depth of the Eleana formation, a part of the Paleozoic upper confining unit, which overlies the lower carbonate aquifer in much of the Death Valley region. The Eleana formation is absent at Borehole UE-25 p\#1 at Yucca Mountain, which penetrated the lower carbonate aquifer directly beneath the lower volcanic confining unit.

The cause of the moderate hydraulic gradient is less controversial than that of the large gradient, and Luckey et al. (1996 [DIRS 100465], p. 25) suggest that the Solitario Canyon fault and its splays function as a barrier to flow from west to east due to the presence of low-permeability fault gouge or to the juxtaposition of more permeable units against less permeable units.

The small hydraulic gradient occupies most of the repository area and the downgradient area eastward to Fortymile Wash. Over a distance of $6 \mathrm{~km}(3.7 \mathrm{mi})$, the hydraulic head declines only about $2.5 \mathrm{~m}(8.2 \mathrm{ft})$ between the crest of Yucca Mountain and Fortymile Wash. The small gradient could indicate highly transmissive rocks, little groundwater flow in this area, or a combination of both causes (Luckey et al. 1996 [DIRS 100465], p. 27).

The potentiometric map (BSC 2004 [DIRS 170009], Section 6.4), which includes head data from the recently drilled NC-EWDP boreholes, indicates that the small hydraulic gradient extends southward to an east-west fault located approximately along U.S. Highway 95 (see BSC 2004 [DIRS 170009], Figure 6-1).

\subsubsection{Vertical Gradients}

Information on vertical hydraulic gradients in the SZ is available near Yucca Mountain, from the Nye County Early Warning Wells (BSC 2004 [DIRS 170009]), and from Kilroy (1991 [DIRS 103010]) for wells in the Amargosa Desert. The following discussion of vertical gradients is extracted from Luckey et al. (1996 [DIRS 100465], pp. 27 to 29) and BSC (2004 [DIRS 170009], Sections 6.3.1 and 7.1.1).

BSC (2004 [DIRS 170009], Section 6.3.2)report on potentiometric level measurements in multiple depth intervals in 17 boreholes at Yucca Mountain. Differences in potentiometric levels at different depth intervals in the same borehole ranged from as little as $0.10 \mathrm{~m}(0.33 \mathrm{ft})$ in Borehole USW H-4 to as much as $54.7 \mathrm{~m}$ (180 ft) in USW H-1 (BSC 2004 [DIRS 170009], Table 6-4). The largest differences were between the lower carbonate aquifer or the adjoining lowermost lower volcanic confining unit and the overlying lower volcanic aquifer and at the well NC-EWDP-1DX location along U.S. Highway 95 south of Crater Flat. Between the upper part of the lower volcanic confining unit and the lower volcanic aquifer, the differences in potentiometric levels generally were $1 \mathrm{~m}(3.3 \mathrm{ft})$ or less. 
Potentiometric levels generally were higher in the lower intervals of the volcanic rocks than in the upper intervals, indicating a potential for upward groundwater movement. However, at seven boreholes (USW G-4, USW H-1, USW H-6, UE-25 J-13, NC-EWDP-1DX, NC-EWDP-3S, and UE-25 b\#1), potentiometric levels in the volcanic rocks were slightly higher in the uppermost intervals than in the next lower intervals. Overall, it appears that an upward gradient between the lower and upper volcanic aquifer is maintained at these locations nearest Yucca Mountain (USW G-4, USW H-1, USW H-6, and UE-25 b\#1). Away from Yucca Mountain the direction of the vertical hydraulic gradient varies from location to location. For example, at locations UE-25 J-13, NC-EWDP-1DX, and NC-EWDP-3S, there is a consistent downward gradient in the upper portion of the volcanic units. For wells in the lower Fortymile Wash, such as NC-EWDP-2D/-2DB, NC-EWDP-4PA/-4PB, NC-EWDP-9SX, NC-EWDP-12PA/-12PB/-12PC, and NC-EWDP-19P/-19D, the gradient is consistently upward.

Potentiometric levels in the Paleozoic carbonate aquifer in Borehole UE-25 p\#1 are about

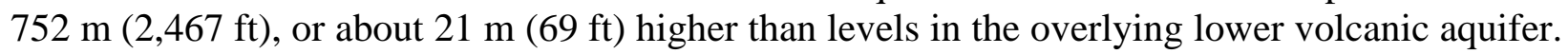
The potentiometric levels in the Paleozoic carbonate aquifer in borehole NC-EWDP-2DB is about $7.2 \mathrm{~m}$ higher than the overlying volcanic unit at NC-EWDP-2D. A potential for upward groundwater movement from the Paleozoic rocks to the volcanic rocks was, therefore, indicated. Because of the large difference in potentiometric levels in these two aquifers, they seem to be hydraulically separated (Luckey et al. 1996 [DIRS 100465], p. 28). Testing at the C-wells complex in 1984 suggested a hydraulic connection between the lower volcanic aquifer and the carbonate aquifer; however, testing in 1995 and 1996, using more reliable water-level measurement equipment, did not confirm the hydraulic connection (Luckey et al. 1996 [DIRS 100465], p. 28).

In borehole UE-25 p\#1, the lowermost $70 \mathrm{~m}$ (230 ft) of the older tuffs (lower volcanic confining unit) had potentiometric levels similar to those in the carbonate aquifer, indicating a hydraulic connection between the lowermost part of the lower volcanic confining unit and the carbonate aquifer. Such a connection could be expected in the hanging-wall rocks adjacent to a fault; and, this type of connection is supported by calcification of the basal tuffs in the borehole. The remaining $237 \mathrm{~m}$ (778 ft) of the lower volcanic confining unit had a potentiometric level similar to that of the lower volcanic aquifer (Luckey et al. 1996 [DIRS 100465], p. 28). The upward hydraulic gradient observed in wells NC-EWDP-2D/-2DB supports the conceptual model that water levels in the carbonate aquifer are higher than in the overlying volcanic units throughout a large portion of the SZ site-scale flow model area (BSC 2004 [DIRS 170009], Section 7.1.1).

No obvious spatial patterns in the distribution of vertical hydraulic gradients around Yucca Mountain are apparent; however, some generalizations can be made as to the distribution of potentiometric levels in the lower sections of the volcanic rocks. Potentiometric levels in the lower volcanic confining unit are relatively high (altitude greater than $750 \mathrm{~m}[2,460 \mathrm{ft}]$ ) in the western and northern parts of Yucca Mountain and are relatively low (altitude about $730 \mathrm{~m}$ $[2,395 \mathrm{ft}]$ ) in the eastern part of Yucca Mountain. Based on potentiometric levels that were measured in borehole UE-25 p\#1 and NC-EWDP-2D/-2DB, the potentiometric levels in the lower volcanic confining unit in boreholes USW H-1, USW H-3, USW H-5 and USW H-6 may reflect the potentiometric level in the carbonate aquifer. Boreholes UE-25 b\#1 and USW G-4 do not seem to fit the pattern established by the other boreholes. These two boreholes penetrated only $31 \mathrm{~m}$ (102 ft) and $64 \mathrm{~m}(210 \mathrm{ft})$, respectively, into the lower volcanic confining unit and had 
potentiometric levels (about $730 \mathrm{~m}[2,395 \mathrm{ft}]$ ) that were similar to potentiometric levels in the lower volcanic aquifer. Penetration of the other four boreholes into the lower volcanic confining unit ranged from $123 \mathrm{~m}$ (403 ft) in borehole USW H-3 to $726 \mathrm{~m}$ (2,382 ft) in borehole USW H-1. Only in boreholes USW H-1, USW H-3, USW H-5, and USW H-6 are the potentiometric levels in the lower volcanic confining unit influenced by the potentiometric level in the carbonate aquifer (Luckey et al. 1996 [DIRS 100465], p. 29).

At several wells, including USW $\mathrm{H}-1$ and USW H-6, small hydraulic gradient reversals at several depths are observed (see BSC 2004 [DIRS 170009], Table 6-4). These small reversals may be explained by small-scale heterogeneities in the hydrostratigraphic units or measurement errors (BSC 2004 [DIRS 170009], Section 6.3.2). The confidence in the vertical hydraulic head differences is greatest for the locations with the largest hydraulic head differences.

Vertical hydraulic gradients could have an important impact on the analysis of the effectiveness of the SZ as a barrier to radionuclide transport in that they keep the flow path from the potential repository in the shallow groundwater. Based on available data, a spatially extensive upward gradient can be inferred between the carbonate aquifer and the volcanic aquifers, which indicates that, at least for the immediate Yucca Mountain area, radionuclide transport would be restricted to the volcanic system (BSC 2004 [DIRS 170009], Section 7.1.1).

Kilroy (1991 [DIRS 103010], pp. 11 to 16, Table 3) presents vertical gradient data for 21 nested piezometers, 1 well cluster, and 1 river and well pair in the Amargosa Desert area. However, none of these locations is within the area of the SZ site-scale model, so the results are not discussed in detail here. Upward gradients generally were associated with freshwater limestones, carbonate rock outcrops, and structural features (Kilroy 1991 [DIRS 103010], p. 16). The association with carbonate rocks is attributed to a hydraulic connection with the carbonate aquifer regional flow system and, especially, to the Spotted Range-Mine Mountain fault zone, which is a conduit for flow from the carbonate aquifer to the basin fill.

\subsubsection{Lateral Boundary Conditions}

The boundary conditions used in the SZ site-scale flow model are derived from hydraulic heads predicted by the DVRFS model and measured water levels (DTN: GS000508312332.001 [DIRS 149947]). The data are used to form fixed-head boundary conditions on the lateral sides of the model. These fixed heads, it is meant that the heads may vary in space along the boundary but not in the vertical direction or with time. Because of constant vertical head, this condition produces no vertical flow at the boundary. This model contrasts with a known upward gradient in the area near well UE-25 p\#1. Nevertheless, some upward gradient can be obtained away from the boundaries with the present boundary conditions. This is because permeability differences between the hydrogeologic units propagate the head for the higher permeability carbonate rocks farther into the model interior than the lower permeability volcanic confining unit overlaying the carbonate rocks. A discussion of the impact of the boundary conditions on predicted vertical gradients is presented in Section 6.2.1. Of special note is the southern boundary of the model, which is near a large number of wells in the Amargosa Valley. The water levels at the southern boundary reflect the influence of lower water levels caused by drawdown in the Amargosa Valley wells. 
Here there are a variety of measurements over the time of usage. Some of the earlier measurements represent predevelopment states, and the later measurements generally represent water levels that show the effects of pumping. The boundary conditions represent water levels with pumping and are described in BSC (2004 [DIRS 170015], Sections 6.5 and 6.7). (See Section 6.4.4 for a discussion of the water level used in this report and the other analyses that are available.)

Most of the inflows to, and outflows from, the SZ site-scale flow model occur as groundwater flows across the lateral boundaries. The best estimates of flow rates are the cell-by-cell fluxes calculated by the 1997 Death Valley regional flow model. These fluxes are compiled in four tables (BSC 2004 [DIRS 170015], Tables 6-5, 6-6, 6-7, and 6-8) corresponding to each boundary of the SZ site-scale flow model. The flows are compiled by the three depth layers ( 0 to $500 \mathrm{~m}$ [0 to 1,640 ft], 500 to 1,250 m [1,640 to 4,100 ft], and 1,250 to 2,750 m [4,100 to 9,020 ft] below the water table) of the regional flow model (D’Agnese et al. 1997 [DIRS 100131], p. 75).

The lateral boundary fluxes from the regional-scale flow model were used in the calibration of the SZ site-scale flow model. Lateral boundary fluxes play an important role in the SZ site-scale flow model. These fluxes provide some communication with the regional-scale flow model, which is based on a regional mass balance and calibrated to spring flow data. There are differences between the SZ site-scale flow model and the regional model largely due to the HFMs used for the two models. These differences are exacerbated because the two models also used different grid resolutions and methods to simulate hydrogeology. Thus it was necessary to average the fluxes over many grid blocks on each side of the model. Output from the regional flow model is linked to the SZ site-scale flow model through the calibration code PEST V5.5, STN: 10289-5.5-00 (Watermark Computing 2002 [DIRS 161564]). Averaged fluxes derived from the regional flow model were used for calibration targets in the SZ site-scale flow model calibration process in much the same way water levels were used for targets. (The regional flow model is not a direct input but is cited as the reference for the DTN for recharge and lateral fluxes in Table 4-1.) These targets were weighted differently based on the importance of a given average flux to the SZ site-scale flow model. Because of the differences in the two models, only general agreement regarding fluxes is expected, and obtained, between the two models.

Consistent with the regional flow model, the bottom boundary condition of the SZ site-scale flow model was "no-flow." Direct evapotranspiration from the water table is not considered in this analysis because depth to water is too great for this process to be important. The top boundary condition was a specified flux recharge map described in Section 6.3.2.7 and derived from the regional model, the UZ model and evapotranspiration studies along Forty-Mile wash. Because the flow model is a steady-state model, there are no boundary condition temporal variation requirements.

\subsubsection{Recharge}

The recharge to the site-scale flow model was derived from three sources (site-scale UZ model, regional-scale SZ model, and Fortymile Wash data) that take different forms and are combined into a single result (see Table 6-12 for the complete list of fluxes). Recharge from the site-scale UZ model (percolation flux) was taken as the flow through the base of that model, the domain of which includes approximately $40 \mathrm{~km}^{2}\left(19.3 \mathrm{mi}^{2}\right)$ that encompasses only the footprint of Yucca 
Mountain, a very small fraction of the SZ model domain. The UZ flow model uses dual permeability; accordingly, the output includes fluxes for fracture and matrix flow. These data are combined into a total volumetric flow rate and an average percolation flux (BSC 2004 [DIRS 170015], Table 6-4 and Figure 6-4).

Estimates of recharge from the infiltration of surface flows in Fortymile Wash are given by linear reaches along the wash. Recharge estimates were interpolated to a 500-m (1,640-ft) wide recharge zone for most of the wash and a broader area of distributary channels in the Amargosa Desert (BSC 2004 [DIRS 170015], Table 6-3, Figure 6-6), since the SZ flow model is a single continuum model (Section 6.3.3). The recharge through each node of the UZ flow model is extracted and the corresponding recharge to the SZ site-scale flow model node was calculated (the UZ flow model grid is finer than the site-scale SZ grid).

The distributed vertical recharge, limited to the northern-most portion of the SZ site-scale flow model area, was extracted from the Death Valley regional groundwater flow model (D'Agnese et al. 1997 [DIRS 100131]). No recharge within the UZ flow model area was included from the regional flow model as this was accounted for separately (see above). A plot of distributed recharge from the regional-scale SZ flow model is provided by BSC (2004 [DIRS 170015], Figure 6-1). The details are considered in Recharge and Lateral Groundwater Flow Boundary Conditions for the Saturated Zone Site-Scale Flow and Transport Model (BSC 2004 [DIRS 170015]).

Estimated recharge from all three sources is displayed in Recharge and Lateral Groundwater Flow Boundary Conditions for the Saturated Zone Site-Scale Flow and Transport Model (BSC 2004 [DIRS 170015], Figure 6-8 and Section 6.2.4).

Total recharge was about $1.54 \times 10^{6} \mathrm{~m}^{3} / \mathrm{yr}(1,250$ acre-ft/yr). Of this total, about $2.11 \times 10^{5} \mathrm{~m}^{3} / \mathrm{yr}(171 \mathrm{acre}-\mathrm{ft} / \mathrm{yr})$ was attributed to flux from the UZ flow model area and about $9.47 \times 10^{4} \mathrm{~m}^{3} / \mathrm{yr}(76.8 \mathrm{acre}-\mathrm{ft} / \mathrm{yr})$ was attributed to infiltration along Fortymile Wash, leaving a remainder of about $1.24 \times 10^{6} \mathrm{~m}^{3} / \mathrm{yr}(1,000 \mathrm{acre}-\mathrm{ft} / \mathrm{yr})$ from distributed recharge. The recharge in each node of the regional model was extracted and the corresponding recharge in the site-scale model node was calculated (the regional model grid has a resolution of 1,500 $\mathrm{m}$ which is coarser than the site-scale model grid resolution).

Groundwater inflows approximately along the eastern, northern, and western boundaries of the SZ site-scale flow model total $17.7 \times 10^{6} \mathrm{~m}^{3} / \mathrm{yr}(14,400$ acre-ft/yr $), 6.18 \times 10^{6} \mathrm{~m}^{3} / \mathrm{yr}$ (5,000 acre-ft/yr), and $3.75 \times 10^{6} \mathrm{~m}^{3} / \mathrm{yr} \quad(3,040 \mathrm{acre}-\mathrm{ft} / \mathrm{yr})$, respectively (BSC 2004 [DIRS 170015], pp. 6-27 to 6-29). These inflows, totaling $27.75 \times 10^{6} \mathrm{~m}^{3} / \mathrm{yr}(22,500 \mathrm{acre}-\mathrm{ft} / \mathrm{yr})$, represent nearly 18 times the estimated recharge from the surface in the model area. Of the total inflow for the eastern boundary, $17.5 \times 10^{6} \mathrm{~m}^{3} / \mathrm{yr}(14,200 \mathrm{acre}-\mathrm{ft} / \mathrm{yr})$, or 99 percent, occurs in the southern sector, nearest the Amargosa Desert (BSC 2004 [170015]), and nearly all of that occurs in layers 2 and 3 of the regional-scale flow model (BSC 2004 [DIRS 170015], Table 6-6) and represents flows in the lower carbonate aquifer (D’Agnese et al. 1997 [DIRS 100131], p. 90, Figures 46 and 47). 


\subsubsection{Discharge}

At the present time, there is no measurable natural discharge (i.e., springs or evapotranspiration within the SZ site-scale flow model domain); therefore, natural discharge to the surface is not represented in the SZ SS Flow Model.

\subsubsection{Heterogeneity}

Physical and chemical heterogeneity of the rocks and water in the SZ can affect groundwater flow and the transport of contaminants in the SZ. The principal forms of heterogeneity in the SZ site-scale model area are physical and may be primary (i.e., related to the formation of the rocks) or secondary (i.e., related to events subsequent to their formation).

The most obvious form of primary heterogeneity is the mode of origin (i.e., volcanic rocks, clastic rocks, carbonate rocks, and alluvial deposits), which is the primary basis for subdividing the rocks into hydrogeologic units. Within each major category, further subdivisions are possible. Probably the major form of primary heterogeneity affecting groundwater flow in the SZ site-scale model area results from the origin of the volcanic rocks (i.e., ash flow or air fall pyroclastic deposits, lava flows, and volcanic breccias). The pyroclastic rocks (termed tuffs) primarily are nonwelded to densely welded, vitric to devitrified ash flow deposits separated by nonwelded vitric air fall deposits. Thus, the primary heterogeneity in physical character relates to whether the deposits resulted from massive eruptions of hot volcanic ash from volcanic centers that moved downslope as flows of fragmental material, or whether they resulted from explosive eruptions that injected volcanic fragments into the air to fall out as bedded ash fall tuffs.

The thicker flow deposits, up to several hundred meters thick, were very hot, resulting in welding of the fragments into a dense mass. Thinner flows retained heat less effectively, resulting in partly welded to nonwelded ash flow tuffs. Ash fall tuffs, generally less than tens of meters thick, are cooled in the atmosphere and characteristically glassy (vitric) (Luckey et al. 1996 [DIRS 100465], p. 17).

The mode of origin controls the porosity and permeability of the volcanic rocks. The densely welded tuffs generally have minimal primary porosity and water-storage capacity but commonly are highly fractured and function as aquifers (Luckey et al. 1996 [DIRS 100465], p. 17). Nonwelded ash flow tuffs, when unaltered, have moderate to low matrix permeability but high porosity, and commonly constitute confining units. Ash fall tufts have high primary porosity and moderate to low permeability, and they generally function as confining units.

As the tuff deposits cooled, they were subjected to secondary processes, including formation of cooling fractures, recrystallization or devitrification, and alteration of the initial glassy fragments to zeolite minerals and clay minerals, all of which affect the hydrologic properties of the rocks. Beginning with deposition and throughout their subsequent history, the rocks have been subjected to tectonic forces resulting in further fracturing and faulting. They also have been subject to changes in the position of the water table, which greatly affects the degree of alteration of the initially glassy deposits. 
The forms of secondary heterogeneity most affecting the SZ are fracturing, faulting, and alteration of glassy materials to zeolites and clay minerals. Fractures, where interconnected, transmit water readily, which accounts for the permeable character of the welded tuffs. Cooling fractures, which are pervasive in welded tuffs, tend to be strata-bound that is, confined to the welded portions of flows, whereas tectonic fractures tend to cut through stratigraphic units, as do faults.

Nonwelded deposits are less subject to fracturing and more subject to alteration of the initial glassy deposits to zeolites and clay minerals, both of which reduce permeability. The presence of perched-water bodies in the UZ is attributed to the ubiquitous presence of a smectite-zeolite interval at the base of the Topopah Spring tuff, which, in the absence of through-going fractures, essentially stops the vertical movement of water (Luckey et al. 1996 [DIRS 100465], p. 46).

The heterogeneity in permeability of different types of deposits led to the subdivision of the Yucca Mountain geologic section into five basic SZ hydrologic units: upper volcanic aquifer, upper volcanic confining unit, lower volcanic aquifer, lower volcanic confining unit, and lower carbonate aquifer. To accommodate the more extensive area of the SZ flow model, the HFM-19 (BSC 2004 [DIRS 170008], Table 6-3) includes several additional units above and below these basic five units. Near Yucca Mountain, volcanic deposits generally form laterally extensive stratigraphic units; however, due to physical heterogeneity, porosity and permeability are highly variable both laterally and vertically.

In the southern part of the SZ site-scale flow model domain, the volcanic deposits thin and inter-finger with valley fill deposits. The latter are heterogeneous (sand and gravel) because of their mode of deposition (Walker and Eakin 1963 [DIRS 103022], p. 14), but are not subject to the fracturing, faulting, and alteration types of heterogeneity that affect the volcanic rocks.

Within the SZ site-scale model area, little specific information is available on the lower carbonate aquifer. However, information from nearby areas (D'Agnese et al. 1997 [DIRS 100131], p. 90, Figures 46 and 47) suggests that the lower carbonate aquifer is highly and uniformly permeable, and that the high permeability is attributed to pervasive solution enlarged fractures.

Heterogeneity in material properties is a common characteristic of hydrogeologic units through which groundwater flows at the Yucca Mountain site. The heterogeneity exists at many different scales ranging from the pore scale to the regional scale. The larger scale heterogeneity, at scales of kilometers to 10s of kilometers, is effectively addressed via the different units within the HFM (BSC 2004 [DIRS 170008]) and incorporation of specific hydrogeologic features (e.g., faults and structural zones), and anisotropy. The pore scale heterogeneities are averaged via the concept of macroscopic parameters defined on the basis of a representative elementary volume (Freeze and Cherry 1979 [DIRS 101173], pp. 69 to 70). The governing equations used to model the groundwater flow use parameters defined on the basis of the representative elementary volume. For predominantly porous units such as bedded tuffs and alluvium, the size of the representative elementary volume may be on the order of a few cubic centimeters (De Marsily 1986 [DIRS 100439], p. 15). For fractured rocks (volcanics and carbonates), the size of the representative elementary volume is less well defined but is accepted to be related to the density of fracturing and is generally much larger than for granular material (Freeze and Cherry 
[DIRS 101173], p. 73). The 500-m grid spacing used for the flow model is sufficiently large to allow the use of representative elementary volume defined parameters for groundwater flow. In fact, the grid spacing is large enough that sub-grid scale heterogeneity needs to be considered with regard to radionuclide transport. This sub-grid heterogeneity has been shown to lead to an enhancement of dispersion with increasing scales of transport (De Marsily 1986 [DIRS 100439], pp. 247 to 248). Additionally, the uncertainty in the density of fracturing at the sub-grid scale leads to uncertainty in the groundwater velocity and the process of matrix diffusion. The groundwater modeling accounts for sub-grid heterogeneity by defining scaled dispersivities and flowing interval spacing (BSC 2004 [DIRS 170014]) in the transport abstraction modeling (BSC 2004 [DIRS 170042], Section 6.5.2) as random variables characterized by probability density functions.

The heterogeneity at intermediate scales between the grid size of $500 \mathrm{~m}$ and the large-scale features of the HFM are addressed using uncertainty in the anisotropy of hydraulic conductivity. A primary concern related to intermediate scale heterogeneity is the possibility of a fast pathway along a relatively continuous path. In the fractured volcanic aquifers beneath Yucca Mountain, the fast path, if it exists, is likely to be related to a fracture or structural feature. The hydraulic testing at the C-well complex (BSC 2004 [DIRS 170010], Section 6.2) demonstrated that at a large scale (about $1 \mathrm{~km}^{2}$ ) the hydraulic conductivity can be characterized as homogeneous, but anisotropic. The direction of anisotropy is likely related to the dominant direction of fractures and faulting. The impact of possible fast paths at an intermediate scale of heterogeneity is included in the transport simulations via the probability distributions of specific discharge, horizontal anisotropy in permeability, and flowing interval spacing (BSC 2004 [DIRS 170042], Section 6.5.2). The aggregate uncertainty in these and other parameters related to radionuclide transport result in simulated SZ transport times for nonsorbing species of less than 100 years in some Monte Carlo realizations of the SZ system (BSC 2004 [DIRS 170042], Figure 6-28).

As noted previously, the properties of each hydrogeologic unit is taken as uniform, but uncertain, with the value being established during the calibration process. The model is still complex because of the lateral distribution of the hydrogeologic units. Heterogeneity of material properties at a variety of scales is still included in the model via several different mechanisms. First, large-scale heterogeneity is defined by the distribution of units in the HFM and the discrete hydrogeologic features incorporated in the SZ site-scale flow model. Sub-grid heterogeneity is included in the transport simulations through the probability distributions for flowing interval spacing and dispersivities. Finally, intermediate scale heterogeneity, which is most likely to be reflected in possible fast paths at scales up to several kilometers, is included as uncertainty in anisotropy. The uncertainty in the HFM is discussed in Section 6.4.6, where the different alternative models developed using different HFM are considered and compared.

\subsubsection{Role of Faults}

Faults and fault zones are hydrogeologic features that require special treatment in the SZ site-scale flow and transport models. Faulting and fracturing are pervasive at Yucca Mountain, and they greatly affect groundwater flow patterns because they may act as preferred conduits or barriers to groundwater flow. The role that faults play in facilitating or inhibiting groundwater flow depends on the nature of the fault (i.e., whether the faults are in tension, compression, or 
shear) and other factors such as the juxtaposition of varying geologic units along the fault plane, the rock types involved, fault zone materials, and depth below land surface.

Faunt (1997 [DIRS 100146]) investigated the effect of faulting on groundwater movement in the Death Valley region and developed a map of fault traces (Faunt 1997, [DIRS 100146] Figure 10) and developed diagrams (Faunt 1997 [DIRS 100146], Figure 11) showing the orientation of faults within the principal structural provinces of region. Faunt (1997 [DIRS 100146], p. 38) grouped the faults into three categories depending on their orientations relative to the present-day stress field (i.e., those in relative tension, compression, or shear).

Faults in relative tension are more likely to be preferential conduits for groundwater, and faults in shear or compression are more likely to deflect or block groundwater movements. Within the SZ site-scale flow model area, faults modeled to have the most evident effects on groundwater movement, such as effects on potentiometric contours, include the Solitario Canyon, U.S. Highway 95, Crater Flat, and Bare Mountain faults (Figure 6-3), all of which appear to act as barriers to groundwater flow. Faults within the SZ site-scale model area of hydrologic importance include the Spotted Range-Mine Mountain shear zone (Figure 6-37), which Faunt (1997 [DIRS 100146], p. 34) describes as a major high-permeability zone in the lower carbonate aquifer. The following features are given special treatment is accorded in the SZ site-scale flow model: Crater Flat fault, Solitario Canyon fault, U.S. Highway 95 fault, Bare Mountain fault, Imbricate fault zone (between the Ghost Dance and Paintbrush Canyon faults at Yucca Mountain), Fortymile Wash zone (which may not be a fault), and the east-west barrier (which is shown on Figure 6-37 and appears to cause the large hydraulic gradient north of Yucca Mountain). These features fall into three categories depending on their hydrologic impacts: (1) zones of permeability enhancement parallel to faults and zones of permeability reduction perpendicular to faults (Crater Flat and Solitario Canyon faults), (2) zones of permeability enhancement (Bare Mountain fault, Imbricate fault zone, Fortymile Wash zones, and Spotted Range-Mine Mountain zone) (Figure 3-37), and (3) zones of uncertain behavior (U.S. Highway 95 fault).

\subsubsection{Groundwater Flow Processes}

Modeling simplifications used in modeling the groundwater flow process include those of the regional scale models and the SZ site-scale flow models, and those made in estimating parameters that are used as input to these models. For the following reasons, the effective continuum representation of fracture permeability is used.

- On the scale represented by the SZ site-scale flow model, the site is well represented by a continuum flow model. Aquifer hydraulic tests show evidence of fracture flow near Yucca Mountain (Geldon et al. 1997 [DIRS 100397]). Numerical modeling of fracture properties is done in one of three ways: discrete fracture models, effective continuum models, or dual-continuum models. Dual-continuum models are not needed because transient simulations are not performed. For steady-state SZ flow calculations, dual-continuum formulations are equivalent to single-continuum formulations. Discrete fracture models represent each fracture as a distinct object within the modeling domain. Although a discrete fracture model might reproduce the flow system more accurately, 
flow modeling is adequately conducted using a continuum model for the following reasons:

- At Yucca Mountain, studies of the density and spacing of flowing intervals generally indicate that flow occurs through fracture zones (BSC 2004 [DIRS 170014], Figure 6-2). The fractures or fracture zones are located in various geological units, and in most cases, no single zone dominates the flow through a well. Geochemical studies (see Figure A6-62) independently confirm a south-southeasterly trace of the particle flow path. For the limited set of wells (Luckey et al. 1996 [DIRS 100465], Figure 11), flow appears to be carried through fracture zones separated by a few tens of meters rather than by a few individual fractures.

- Part of the flow system is an alluvium unit for which flow and transport is appropriately modeled using a continuum model.

- The drawdown response to pumping at wells surrounding the C-wells complex in multiwell pump tests indicates a well-connected fracture network in the Miocene tuffaceous rocks in this area (Geldon et al. 1998 [DIRS 129721], p. 31).

The following assumptions also apply to the continuum modeling approach used in the SZ site-scale flow model for supporting the TSPA-LA.

- Estimates of discharge from the volcanic aquifer, elicited from the SZ expert elicitation panel, are applicable to the entire flow path from the repository to the accessible environment. The estimates of specific discharge from the SZ expert elicitation (CRWMS M\&O 1998 [DIRS 100353], p. 3-8) primarily were based on data from hydraulic testing in wells in volcanic units and the hydraulic gradient inferred from water-level measurements. The relative values of groundwater flux in the volcanic aquifer and along the flow path farther to the south are constrained by the calibration of the SZ site-scale flow model; that is, the limits of permeability values of important hydrological units that allow reasonable calibration are used to set limits on specific discharge. It is reasonable to extrapolate the degree of uncertainty in the absolute value of groundwater flux from the volcanic aquifer to the flow path farther to the south. 
- Horizontal anisotropy in permeability is adequately represented by a permeability tensor that is oriented in the north-south and east-west directions. In support of the TSPA-LA, horizontal isotropy and anisotropy are considered for radionuclide transport in the SZ (BSC 2004 [DIRS 170010]). The numerical grid of the SZ site-scale flow model is aligned north-south and east-west, and values of permeability may be specified only in directions parallel to the grid. Analysis of the probable direction of horizontal anisotropy shows that the direction of maximum transmissivity is $\mathrm{N} 33^{\circ} \mathrm{E}$ (Winterle and La Femina 1999 [DIRS 129796], p. iii), indicating that the anisotropy applied on the SZ site-scale model grid is within approximately $30^{\circ}$ of the inferred anisotropy. Horizontal isotropy was assumed in the calibrated flow model, but sensitivity analyses were performed to assess the impact of uncertainty in the anisotropy and presented in Saturated Zone Flow and Transport Model Abstraction (BSC 2004 [DIRS 170042], Section 6.5.2).

- Horizontal anisotropy in permeability applies to the fractured and faulted volcanic units of the SZ system along the groundwater flow paths that run from the repository to points south and east of Yucca Mountain. The inferred flow path from beneath the repository extends to the south and east. This is the area in which potential anisotropy could have an important impact on radionuclide transport in the SZ. Given the conceptual basis for the anisotropy model, it is appropriate to apply anisotropy only to those hydrogeologic units that are dominated by groundwater flow in fractures. The more detailed discussion of anisotropy is provided in Section 6.4.3.

- Anisotropy in permeability represents an alternative conceptual model of groundwater flow at the Yucca Mountain site. Sufficient uncertainty in the analysis of horizontal anisotropy exists to warrant consideration of two possible conceptual models: one with anisotropy and one without anisotropy (i.e., isotropic permeability).

- Changes in the water-table elevation (due to future climate changes) will have negligible effect on the direction of the groundwater flow near Yucca Mountain although the magnitude of the groundwater flux will change. This supposition has been studied in regional-scale (D’Agnese et al. 1999 [DIRS 120425]) and subregional-scale (Czarnecki 1984 [DIRS 101043]) flow models. These studies found that the flow direction did not change significantly under increased recharge scenarios. The studies were based on two-dimensional confined aquifer models that did not take into account the free surface boundary at the water table or the saturation of geological units that currently are in the UZ overlying the present-day SZ. These UZ tuffs generally have a lower permeability than those in the SZ, and as such, UZ units are not likely to introduce faster fluxes (BSC 2004 [DIRS 169861] Appendix A).

- Future water supply wells that might be drilled near Yucca Mountain (including outside the regulatory boundary) will have a negligible effect on the hydraulic gradient. Water levels at the southern boundary of the SZ site-scale flow and transport models (in the Amargosa Valley) currently reflect the effect of well pumpage (Luckey et al. 1996 [DIRS 100465], p. 41). 
- In the analysis presented in this report, temperature is modeled to be approximately proportional to the depth below the ground surface. Modeling a uniform temperature gradient with depth is equivalent to a model of uniform geothermal heat flux through a medium of homogeneous thermal conductivity. In addition, the temperature at the ground surface is modeled to be equal to a uniform value. The data on temperature in boreholes presented in Sass et al. (1988 [DIRS 100644], Figures 4 to 8, Figure 10) indicate that there is significant variability in the temperature gradient at different locations and within individual wells, presumably due to advective redistribution of heat from infiltration and vertical groundwater flow. However, these data also indicate that the temperature gradients generally become more linear with increasing depth below the water table. It is important to note that the goal of assigning temperature variations with depth in the SZ site-scale flow model is to account for resulting variations in fluid viscosity at different depths in the SZ. The viscosity of water changes by a factor of only about 3.3 over the temperature range of $20^{\circ} \mathrm{C}$ to $100^{\circ} \mathrm{C}$ (Streeter and Wylie 1979 [DIRS 145287], p. 536) that is expected within the range of depths in the SZ site-scale model domain. Thus, the linear approximation of the temperature gradient is adequate to capture the general effects of variations in groundwater viscosity with depth in the SZ site-scale flow model. The density also varies with temperature, but the effect is much smaller than viscosity. Over the temperature range of $20^{\circ} \mathrm{C}$ to $100^{\circ} \mathrm{C}$, water density varies only a few percent. Using a variable viscosity allows the calibration of intrinsic permeability to be made instead of hydraulic conductivity. The former is a rock property, whereas the latter is a rock and fluid property. This approach, in turn, allows for more accurate flux calculations on the boundaries of the model.

- The confined-aquifer solution approach is used in the SZ site-scale flow model. The approach treats the upper boundary as if there is no UZ and, therefore, solves a simplified and computationally more efficient numerical model. In the numerical model, the top surface has boundary conditions of applied recharge flux. The confined aquifer solution was enforced in the FEHM code by adding a large artificial head to the numerical solution. This artificial head was later subtracted after the computer run to recover the true solution. Because none of the fluid or rock properties depend on head, no changes to the true solution occur other than forcing the bookkeeping coding in FEHM to model the system as fully saturated conditions. If this procedure were not adopted, small variations in head around the water-level value would result in FEHM testing for an air phase, thus decreasing the efficiency. The negative side of this approach is that the top surface of the numerical model corresponds to the measured water-table surface and may be inconsistent with the model-derived water table surface. This discrepancy affects the flux through the model domain. The error is generally small because the flowing area is proportional to the thickness of the model in the north-south direction, and the weighted root mean square residual between the calibrated and measured heads is $16 \mathrm{~m}$ (see Section 6.1.2), compared to a model thickness of approximately 3,000 m. Furthermore, the discrepancy can be checked after the model is run. The numerical model weighted root mean square residual was about $16 \mathrm{~m}$ for the more than 100 head observations. Assuming that the water table solution is in error by this amount, error for the "flow area" for the horizontal head gradient is small. Care was taken in the calibration process to model the low head gradient area to the south and east 
of Yucca Mountain accurately. Specified head boundary conditions on the lateral boundaries were set with no vertical gradient. It should be noted that the model allows for vertical flows that arise from recharge and heterogeneity. The numerical approach used is similar to the classical Dupuit-Forcheimer method.

\subsection{CONSIDERATION OF ALTERNATIVE CONCEPTUAL MODELS}

The SZ site-scale flow model is used in the performance assessment calculations to evaluate the potential risks to groundwater users downgradient from the repository area. The results of these performance assessment calculations depend strongly on the specific discharge of groundwater leaving the repository area, as well as on the flow paths and the distribution of flow among the various hydrostratigraphic units that carry, deflect, or otherwise affect the flow. The alternative conceptual models (ACMs) presented here were investigated because they represented a well-publicized hydrologic concern such as large hydraulic gradient (LHG) or were related to a model feature (anisotropy or fault), or conceptualization (potentiometric surface), that had a possibility of strongly affecting the specific discharge calculations. Thus, it is important to understand how ACMs and their representations may affect the specific discharge and flow paths. This section presents analyses of the ACMs, their representation in the numerical model, and a discussion about possible impacts on the model outputs (specific discharge and flow paths). ACMs affecting model outputs are discussed in Section 6.7, and their associated uncertainty is propagated to the stochastic generation of radionuclide breakthrough curves in the TSPA calculations.

The SZ site-scale flow model described in detail in Section 6.5 also provides the basis for the ACMs discussed here. That is, the same numerical grid and HFM conceptual model were used throughout this section. Various parameterization schemes were used to define the ACMs. For example, the LHG HFM conceptual model used a different feature set (without the east-west barrier) from the SZ site-scale flow model. Otherwise, the models are the same. The following ACMs were evaluated:

- Large Hydraulic Gradient: This ACM deals with the presence and absence of the LHG.

- Solitario Canyon Fault: This ACM deals with the vertical extent of Solitario Canyon fault.

- Anisotropy: This ACM deals with anisotropy in permeability.

- Potentiometric Surface (Horizontal Hydraulic Gradient) and Water-Level Data: This ACM deals with different interpretations of water level elevation and water level contouring alternatives.

- Water Table Rise: This ACM deals with future water table rise.

- Alternate SZ Site-scale Flow Model (HFM Reinterpretation, HFM-27 and Additional Data): This ACM deals with the impact of data acquired and analyses performed since the development of the SZ site-scale flow model on radionuclide transport predictions in the SZ. 


\subsubsection{Large Hydraulic Gradient}

It is important to understand how the presence or absence of the LHG and its representation in the numerical model affect estimates of groundwater specific discharge and flow paths. Absence of the LHG means that the high heads and/or high gradients are an artifact of interpreting water levels as the regional water table when they are representing a perched water body. In the alternative conceptual models of the LHG that follow, the absence of the LHG are implicitly accounted for by assigning a low weight (relative to other observations) in the numerical calibrations to those wells that are suspected of being perched.

The LHG north of Yucca Mountain is a feature of the flow system near Yucca Mountain that has been the subject of interest over the years (Figures 6-2 and 6-4). Compared to the very gentle gradient from the repository to points south, the gradient north of the site is much larger. Potential causes of this gradient are discussed in Section 6.3.2.4. To model the LHG, a low-permeability east-west feature has been incorporated into the base case conceptual model of SZ flow north of Yucca Mountain. Because there is little field evidence for the presence of this feature, alternative conceptualizations are plausible. The Claim Canyon Caldera, north of Yucca Mountain, is an area of extensive hydrothermal alteration, which may result in a generalized reduction in permeability in the hydrogeologic units in this area. Permeability changes in similar environments have been studied by economic geologists (Norton and Knapp 1977 [DIRS 147379]).

Because the LHG occurs north of Yucca Mountain, the change in the model's simulated potentiometric surface due to the LHG conceptualization is minimal if the downstream gradients of Yucca Mountain are modeled accurately. The different model-generated potentiometric surfaces, though similar, lead to considerable differences in flow paths for fluid particles leaving the repository as well as large differences in flow directions for groundwater entering the repository area. These different conceptualizations are important to the overall understanding of the flow system, and, thus, a detailed evaluation of the ACMs is warranted.

The SZ site-scale flow model has been used to evaluate three different conceptual models of the LHG. In addition to the original conceptualization described above, a second conceptual model was evaluated that models the apparent LHG to be a result of low-permeability, hydrothermally altered rock north of Yucca Mountain. A third conceptual model of the LHG was evaluated that takes into account not only the area of hydrothermally altered rock north of Yucca Mountain but also the observed faults in the northwest-southeast trending washes in northern Yucca Mountain. These models are referred to as the "altered, no fault" (ANF) and "altered, with fault" (AWF) models, respectively. The feature sets for the alternative conceptual models of the LHG are shown in Figures 6-5 and 6-6 (see a more detailed discussion of these feature sets in Section 6.5.3.4). Regardless of their conductivity, these faults tend to divert water along their strike and have the potential for segregating flow regimes near Yucca Mountain. Section 6.7.1.3 shows that the flow paths generated with the LHG ACMs are consistent with the SZ site-scale flow model. 


\section{Features in the Base-Case SZ Model (E-W Barrier Included)}

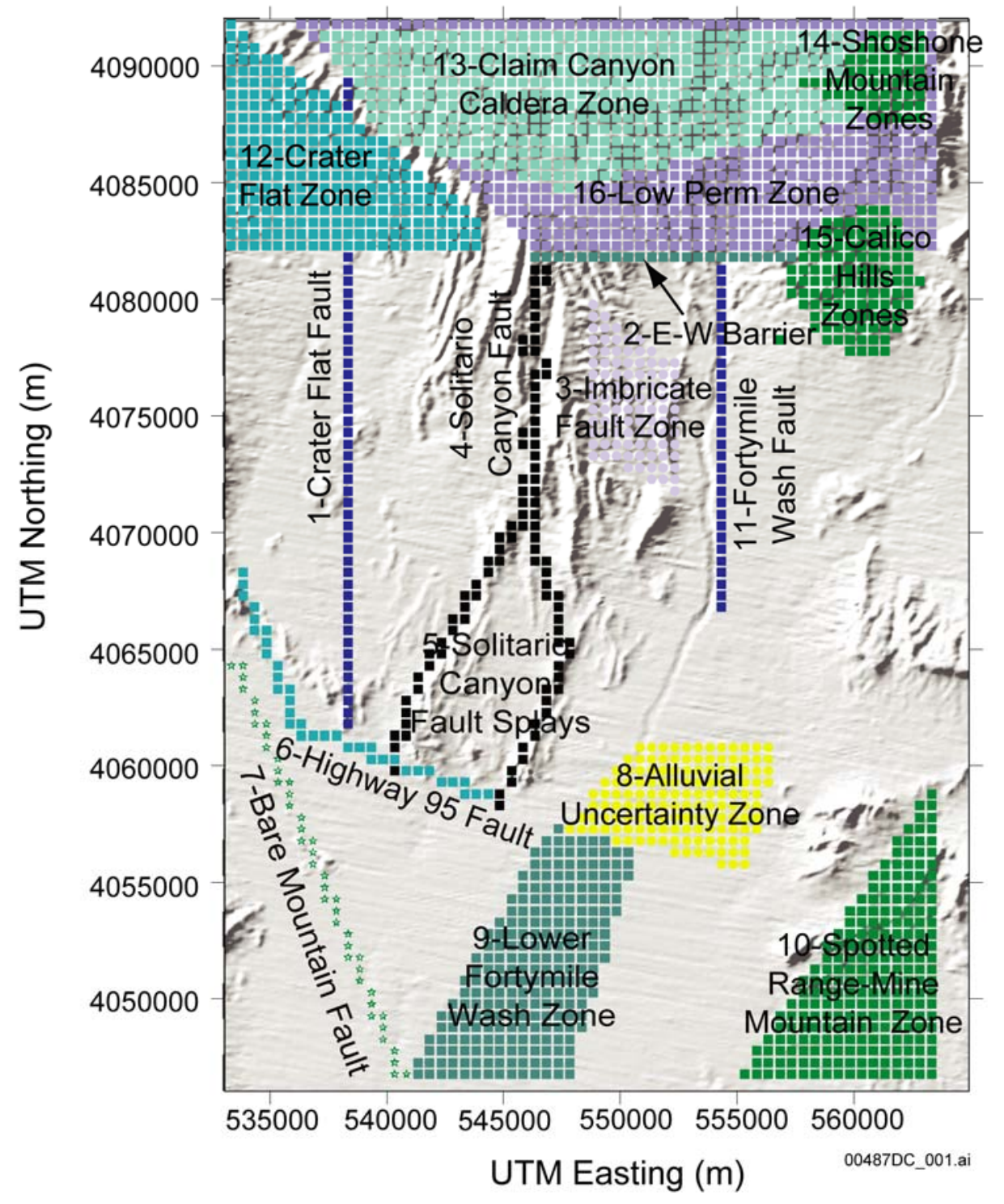

Source: Zyvoloski et al. 2003 (DIRS 163341), Figure 2b.

$\mathrm{UTM}=$ Universal Transverse Mercator.

Figure 6-5. Features of the SZ Site-Scale Flow Model with East-West Barrier Included 


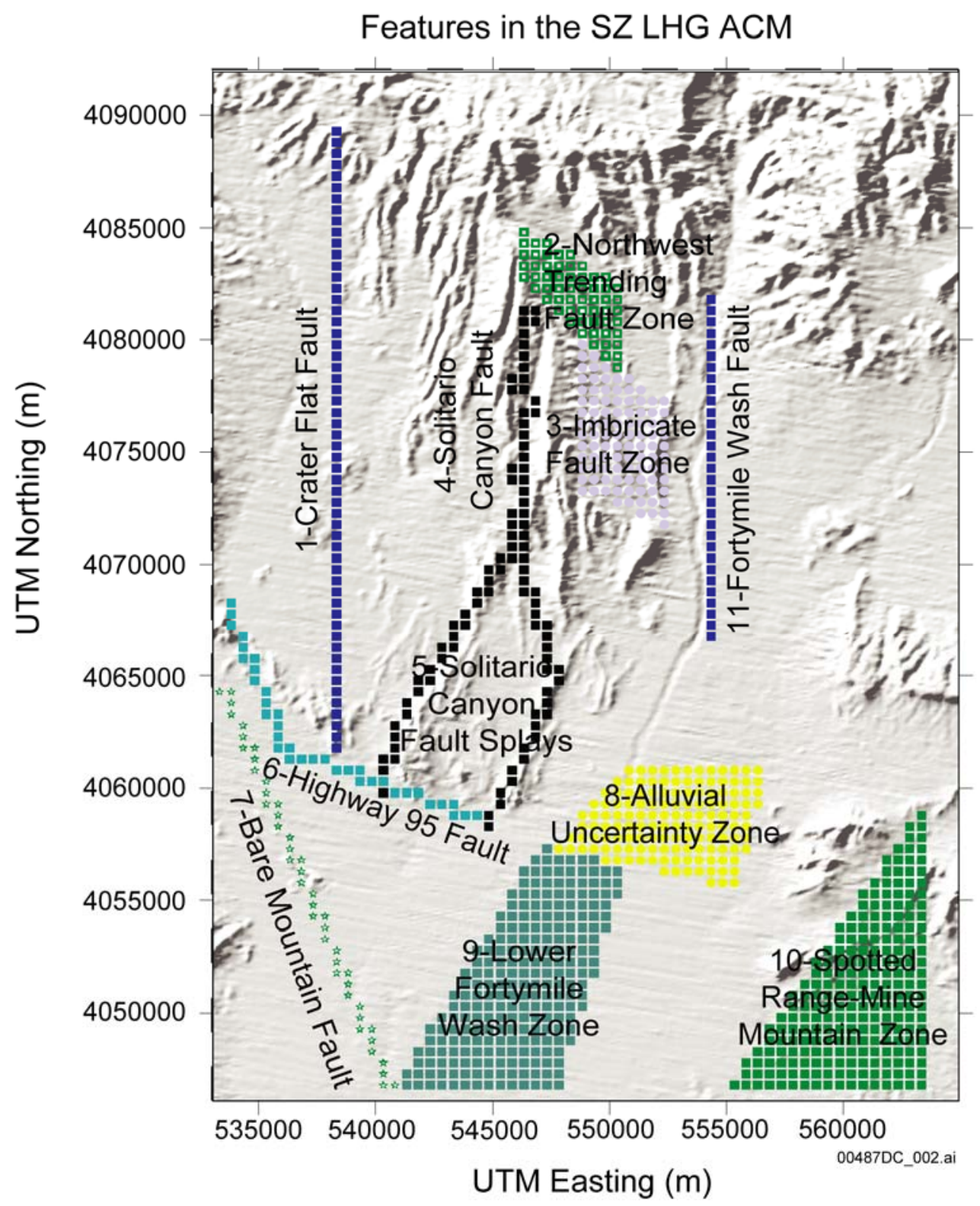

Source: Zyvoloski et al. 2003 (DIRS 163341), Figure 2c.

UTM = Universal Transverse Mercator.

Figure 6-6. Features of the LHG-ACM SZ Site-Scale Flow Model Without the East-West Barrier 


\subsubsection{Solitario Canyon Fault}

The Solitario Canyon fault separates Crater Flat from Yucca Mountain (Figure 6-2). The representation of the Solitario Canyon fault is an important part of the SZ site-scale flow model because it potentially can control flow from Crater Flat to Fortymile Wash in the area of the repository. The impact on the model of these features is to generate a higher hydraulic gradient to the west of Yucca Mountain and to impede flow from Crater Flat to Yucca Mountain. This in turn affects the eastern extent of travel of fluid leaving the repository area. Thus, the conceptual model of the Solitario Canyon fault influences the path length in the alluvial material of groundwater that originated from beneath the repository region.

While the Solitario Canyon fault has been identified as a major fault in the SZ site-scale flow model region, conceptual uncertainty remains in the HFM-27 as to the depth of this fault (Potter et al. 2002 [DIRS 160060]). This uncertainty translates into uncertainty regarding the likely hydraulic behavior of this feature at depth. The SZ site-scale flow model includes the Solitario Canyon fault as a discrete feature that extends from the bottom of the model to the top of the water table. The fault is modeled as an anisotropic feature with greater permeability along the plane of the fault than across it. It is possible that this treatment of the anisotropy is inappropriate where it cuts the carbonate aquifer deep in the model domain. To investigate the importance of the Solitario Canyon fault depth, an alternative conceptualization has been simulated in which the fault extends from the water table only to the top of the carbonate aquifer.

\subsubsection{Anisotropy}

Anisotropy occurs when hydraulic properties have different values in the three different directions: vertical, horizontal along the direction of maximum permeability, and horizontal along the direction of minimum permeability. This ratio of horizontal to vertical permeability is in the general accepted range as given by the expert elicitation panel (CRWMS M\&O 1998 [DIRS 100353], Table 3-2).

\subsubsection{Vertical Anisotropy}

A fractured or porous media exhibits anisotropy when hydraulic properties are not uniform in all directions. For Yucca Mountain, anisotropic permeability potentially affects the specific discharge, the flow paths, and the flow path lengths in the volcanic tuffs and alluvium. The SZ site-scale flow model includes a horizontal to vertical anisotropy ratio of 10:1, a typical value, in many of the units. For the SZ site-scale flow model, anisotropy ratios generally were kept constant during the analysis of the groundwater flow regime. Some units were modeled with isotropic permeability. These units were the granite confining, the clastic units, the upper volcanic confining unit, the lava-flow aquifer, and the limestone aquifer. Faults and features were generally modeled with anisotropic permeability, though not with the same horizontal to vertical ratio as the hydrogeologic units. Conceptual models both with and without vertical anisotropy are considered. 


\subsubsection{Horizontal Anisotropy}

The faults in the SZ site-scale flow model include both vertically and horizontally anisotropic features that have high conductivity in the strike and vertical directions and low conductivity in the direction across the fault. In general, the $\mathrm{x}$ direction permeability of major faults was calibration parameter. However, the anisotropy ratios were kept constant during the calibration process. In addition, the predominant north-south trending faults near Yucca Mountain were investigated using an ACM with variable horizontal anisotropy ratios (north-south to east-west permeability change).

The predominately north-south trending faults near Yucca Mountain were investigated using an ACM with variable horizontal anisotropy ratios (north-south to east-west permeability changes). The area to which the anisotropy ratio was applied is bounded by a quadrilateral shown in Figure 6-7. This effect was investigated by re-running the SZ calibrated model with a 5:1 permeability ratio and checking the sensitivity of the calibration. A detailed description of the development of the horizontal anisotropy distribution used in this model is found in Saturated Zone In-Situ Testing (BSC 2004 [DIRS 170010], Section 6.2.6). The TSPA calculations generated flow fields with that distribution, illustrated in Figure 6.2-3 of the in situ testing report (BSC 2004 [DIRS 170010], Section 6.2.6). Incorporating the 5:1 permeability anisotropy in the area of the north-south trending faults at Yucca Mountain into the calibrated model resulted in predicted hydraulic heads that were slightly closer to the observed heads than for the model calibration without anisotropy. The differences in predicted heads and their impacts on the specific discharge, the flow-path direction, and flow-path lengths in volcanic tuffs and alluvium were within the uncertainty ranges used in the TSPA (BSC 2004 [DIRS 170042], Sections 6.4 and 6.5.2.10). Because horizontal anisotropy impacts model results, this parameter has been included in the TSPA analysis and, thus, is fully accounted for in terms of effect on repository performance.

\subsubsection{Potentiometric Surface (Horizontal Hydraulic Gradient) and Water-Level Data}

Water-level data are important parameters for model development. Measured water levels were used directly as calibration targets in this model report and to construct potentiometric surfaces used to derive horizontal and vertical hydraulic gradients (BSC 2004 [DIRS 170009]). Additionally, water-level responses to pumping were used to estimate a distribution of horizontal anisotropies for certain model zones (BSC 2004 [DIRS 170010], Section 6.2). 


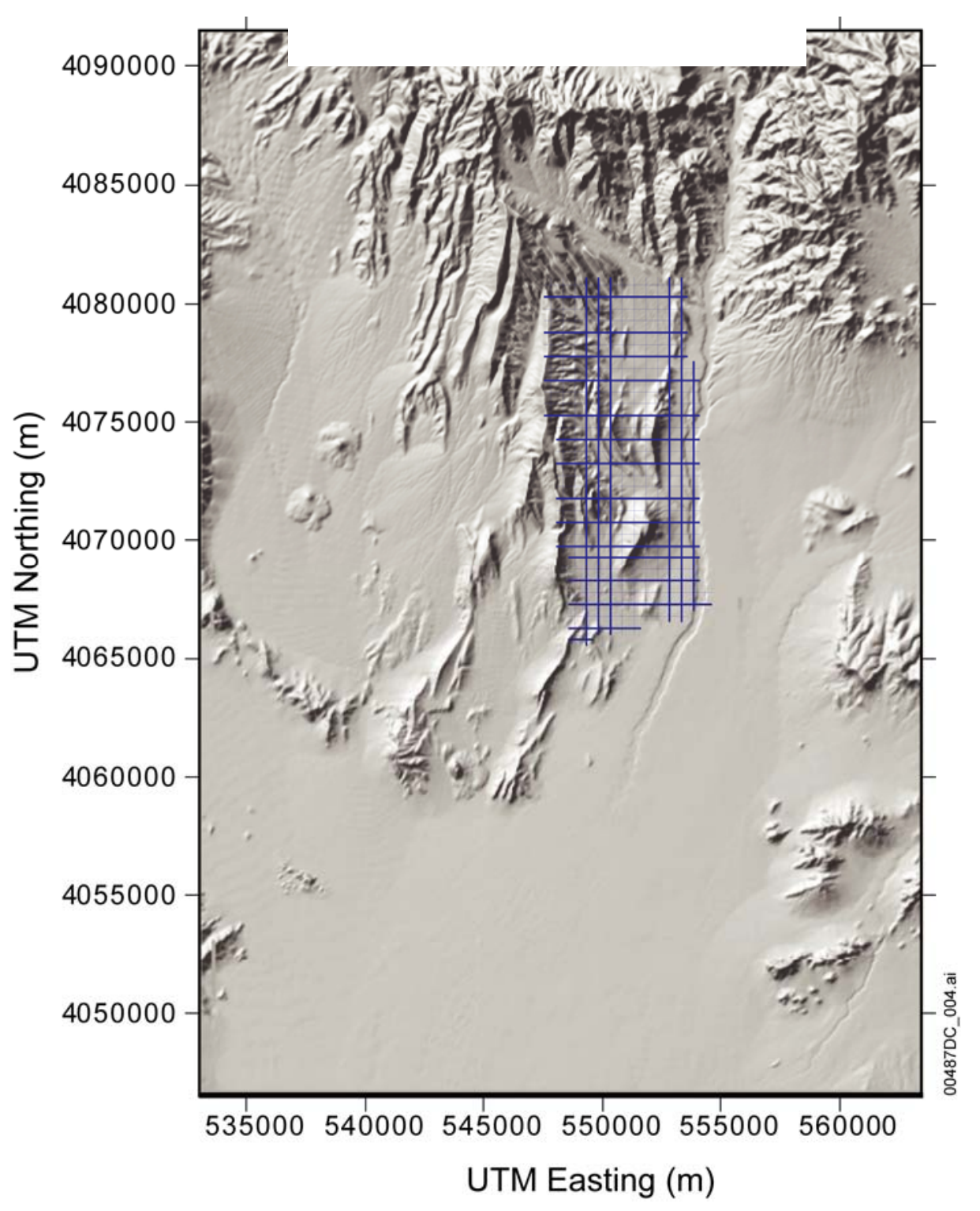

Output DTN: LA0304TM831231.002.

UTM = Universal Transverse Mercator.

Figure 6-7. Horizontal Anisotropy Is Applied to the Blue Crosshatched Area 
The purpose of this section is to compare four versions of the potentiometric surface of the uppermost part of the SZ for the SZ site-scale flow and transport model domain. There are differences in the potentiometric surface represented in each of these versions because of differences in purpose, assumptions, conceptual models, and methods by which the surfaces were constructed. Three potentiometric surfaces were derived from the following four sources:

1. Water-Level Data Analysis for the Saturated Zone Site-Scale Flow and Transport Model (USGS 2001 [DIRS 154625], Section 6.2)

2. Water-Level Data Analysis for the Saturated Zone Site-Scale Flow and Transport Model (USGS 2001 [DIRS 157611], Section 6.2)

3. Water-Level Data Analysis for the Saturated Zone Site-Scale Flow and Transport Model (BSC 2004 [DIRS 170009], Section 6.4)

4. Development of Numerical Grids for UZ Flow and Transport Modeling (BSC 2004 [DIRS 169855], Section 6.2).

These are not the only versions of the potentiometric surface produced for this area; however, model comparisons will be limited to Sources 1, 3, and 4, all of which have been developed since the year 2000. Items 1 and 2 are summarized in the revised report, Water-Level Data Analysis for the Saturated Zone Site-Scale Flow and Transport Model (BSC 2004 [DIRS 170009]). Item 2, Water-Level Data Analysis for the Saturated Zone Site-Scale Flow and Transport Model (USGS 2001 [DIRS 157611]), is not compared because all of its features are also included in Item 3.

The SZ site-scale flow model calibration described in this report used a relatively low weighting for observations in the high-head, LHG area because of the uncertainty associated with those observations. Some of these uncertainties are due to the water-level data in wells USW G-2 and UE-25 WT-24.

\subsubsection{Water-Level Data Analysis for the SZ Site-Scale Flow Model (Base Case Model)}

A potentiometric surface map (Figure 6-4) was presented in Water-Level Data Analysis for the Saturated Zone Site-Scale Flow and Transport Model (USGS 2001 [DIRS 154625], Figures 1-1 and 1-2). The purpose of the analysis documented in this USGS report was to provide the SZ site-scale flow model with the configuration of the potentiometric surface and target water-level data for model calibration. This analysis was used to support the site recommendation. The source data consisted of water-level data from boreholes within the SZ site-scale flow model domain and from one borehole (UE-25 J-11) adjacent to the SZ site scale flow model domain. The SZ site-scale flow model domain coordinates range from Universal Transverse Mercator Easting of 533,340 meters to 563,340 meters and from Universal Transverse Mercator Northing of 4,046,782 meters to 4,091,782 meters (Zone 11, North American Datum 1927) (BSC 2004 [DIRS 170009], Figure 1-2).

Water levels were used from a number of wells in the northern part of the domain that defined a region of the LHG. An important assumption for this analysis was that, while the wells defining the LHG were suspected to represent perched water (USW G-2, UE-25 WT-24), there were 
insufficient data to exclude these water levels from the analysis. The output of this analysis (DTN: GS000508312332.001 [DIRS 149947]) was used to construct the potentiometric surface using gridding software.

\subsubsection{Updated Water-Level Data Analysis for the SZ Site-Scale Flow Model}

An updated potentiometric surface map was presented in Water-Level Data Analysis for the Saturated Zone Site-Scale Flow and Transport Model (BSC 2004 [DIRS 170009], Section 6). The purpose of the analysis documented in BSC (2004 [DIRS 17009]) was to provide the SZ site-scale flow model with an updated configuration of the potentiometric surface. The updated water-level data included water levels obtained from the NC-EWDP and data from borehole USW WT-24. Source data included data used for the USGS water-level data analysis described in Section 6.4.4.1 (USGS 2001 [DIRS 157611], Sections 6.2 and 7.2), and the potentiometric surface was constructed for the same domain. An ACM was considered in this revision by incorporating the following two assumptions:

- Water levels in boreholes USW G-2 and UE-25 WT\#6 in the northern part of Yucca Mountain and in borehole NC-EWDP-7S in southern Crater Flat represent perched conditions.

- Water levels in USW WT-24, at approximately $840 \mathrm{~m}$ above sea level, represent the regional potentiometric level.

The output of this analysis was a potentiometric surface map assuming perched conditions north of Yucca Mountain (DTN: GS010608312332.002 [DIRS 163555]). The method used to construct this potentiometric surface differed from that used for the map discussed in the preceding section (USGS 2001 [DIRS 154625]). Automatic gridding software was used for the original USGS water-level data analysis (USGS 2001 [DIRS 154625]), while contours for BSC (2004 [DIRS 170009], Section 6.4) were hand drawn by project hydrologists.

The potentiometric surface maps developed in the water-level data analyses (USGS 2001 [DIRS 154625], Figure 1-1; BSC 2004 [DIRS 170009], Figure 6-1) are compared in Water-Level Data Analysis for the Saturated Zone Site-Scale Flow and Transport Model (BSC 2004 [DIRS 170009]). Because the two maps were based on similar data, the general characteristics of the surfaces were similar. The most significant difference noted is the representation of the LHG area north of Yucca Mountain. Exclusion of water-level data from boreholes USW G-2 and UE-25 WT \#6 considered to represent perched conditions reduced the LHG significantly. Another difference noted is that potentiometric contours in Water-Level Data Analysis for the Saturated Zone Site-Scale Flow and Transport Model (BSC 2004 [DIRS 170009]) are no longer offset where they cross faults. Offsets in the water-level map of USGS (2001 [DIRS 154625]) were noted in the water-level data analysis of BSC (2004 [DIRS 170009]) and were described as unexpected where contours are perpendicular or nearly perpendicular to faults. The contour interval for this map (Figure 6-8) is variable. 


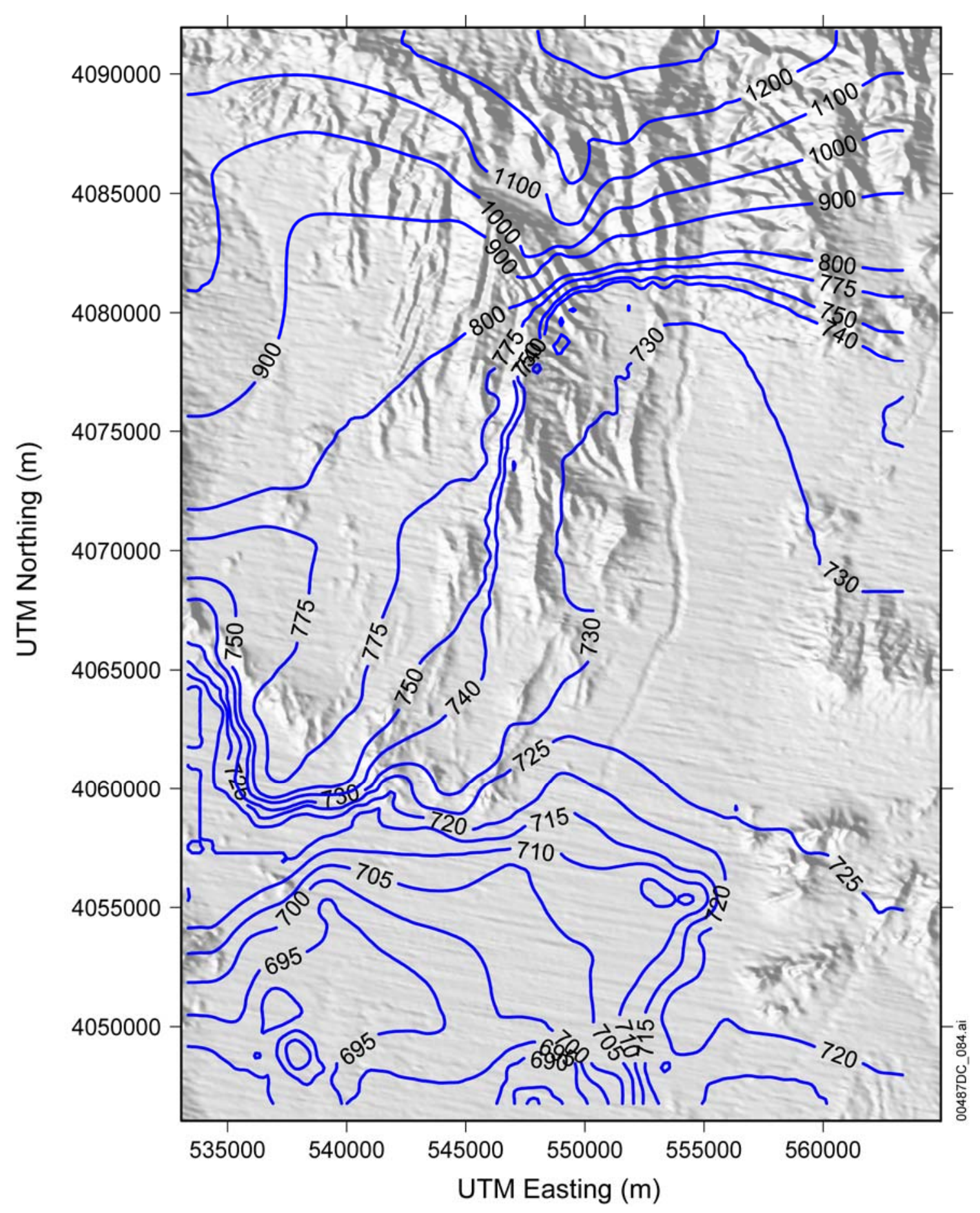

Source: DTN: GS000508312332.002 [DIRS 149947]; BSC 2004 [DIRS 170009], Figure 6-1. UTM = Universal Transverse Mercator.

Figure 6-8. Contour Plot of Water-Level Data for the SZ Flow and Transport Model 


\subsubsection{Flow Model Lower Boundary for the UZ Flow Model}

The development of numerical grids of the unsaturated hydrogeologic system beneath Yucca Mountain is described in Development of Numerical Grids for UZ Flow and Transport Modeling (BSC 2004 [DIRS 169855]). A representation of the potentiometric surface was an output of the UZ flow model report analysis report because this surface defined the lower UZ model boundary (Figure 6-10 Note: Figure 6-9 was deleted.]). The domain for this interpretation of the potentiometric surface is smaller than the SZ site-scale flow model domain encompassing approximately $40 \mathrm{~km}^{2}$ (BSC 2004 [DIRS 169855], Section 6.2) as compared to the approximately 1,350 $\mathrm{km}^{2}$ of the SZ site-scale flow model domain (USGS 2001 [DIRS 154625], Figures 1-1 and 1-2).

The lower boundary for the UZ model was established using water levels consistent with the perched water interpretation of the water-level data analysis (BSC 2004 [DIRS 170009]). Two gridding steps were used to create a reference horizon file representing the lower boundary. This gridding process was noted in Development of Numerical Grids for UZ Flow and Transport Modeling (BSC 2004 [DIRS 169855], Sections 6.4.2 and 6.9.1) as producing small deviations in the resulting potentiometric surface with respect to the original digitized potentiometric surface. These deviations were considered to be relatively minor (i.e., less than 5 meters near the repository footprint). Larger differences of up to 60 meters between the output potentiometric surface and the potentiometric surface discussed in the report (BSC 2004 [DIRS 170009]) were attributed to errors associated with contour digitization before generation of the potentiometric surface (BSC 2004 [DIRS 169855], Sections 6.4.2 and 6.9.1).

Because of the UZ's smaller domain, comparison of the surface derived from the SZ site-scale flow model calibration to Development of Numerical Grids for UZ Flow and Transport Modeling (BSC 2004 [DIRS 169855]) is limited. Differences in potentiometric surfaces can be attributed to differences in purpose, assumptions, conceptual models, and methods by which the surfaces were constructed. The discussion of the different potentiometric surfaces is presented in BSC (2004 [DIRS 170009], Section 6.5).

\subsubsection{Water Table Rise}

\subsubsection{Water Table Rise Beneath Repository}

In addition to modeling SZ Flow under current conditions, it is also necessary to consider conditions over the next 10,000 years, as the climate changes. A higher water table is expected in the Yucca Mountain region for future wetter climatic conditions. A rise in the water table could impact flow paths from beneath the repository in the SZ, but is handled in a simplified, conservative manner, as explained below. A higher water table has clear impacts on radionuclide transport in the UZ by shortening the transport distance between the repository and the water table. SZ modeling analyses considered in this report indicate that a rise in the water table will cause flow paths from beneath the repository to the accessible environment to be in units with lower permeabilities than the ones under the current water table conditions which will result in longer radionuclides transport time through the SZ. 


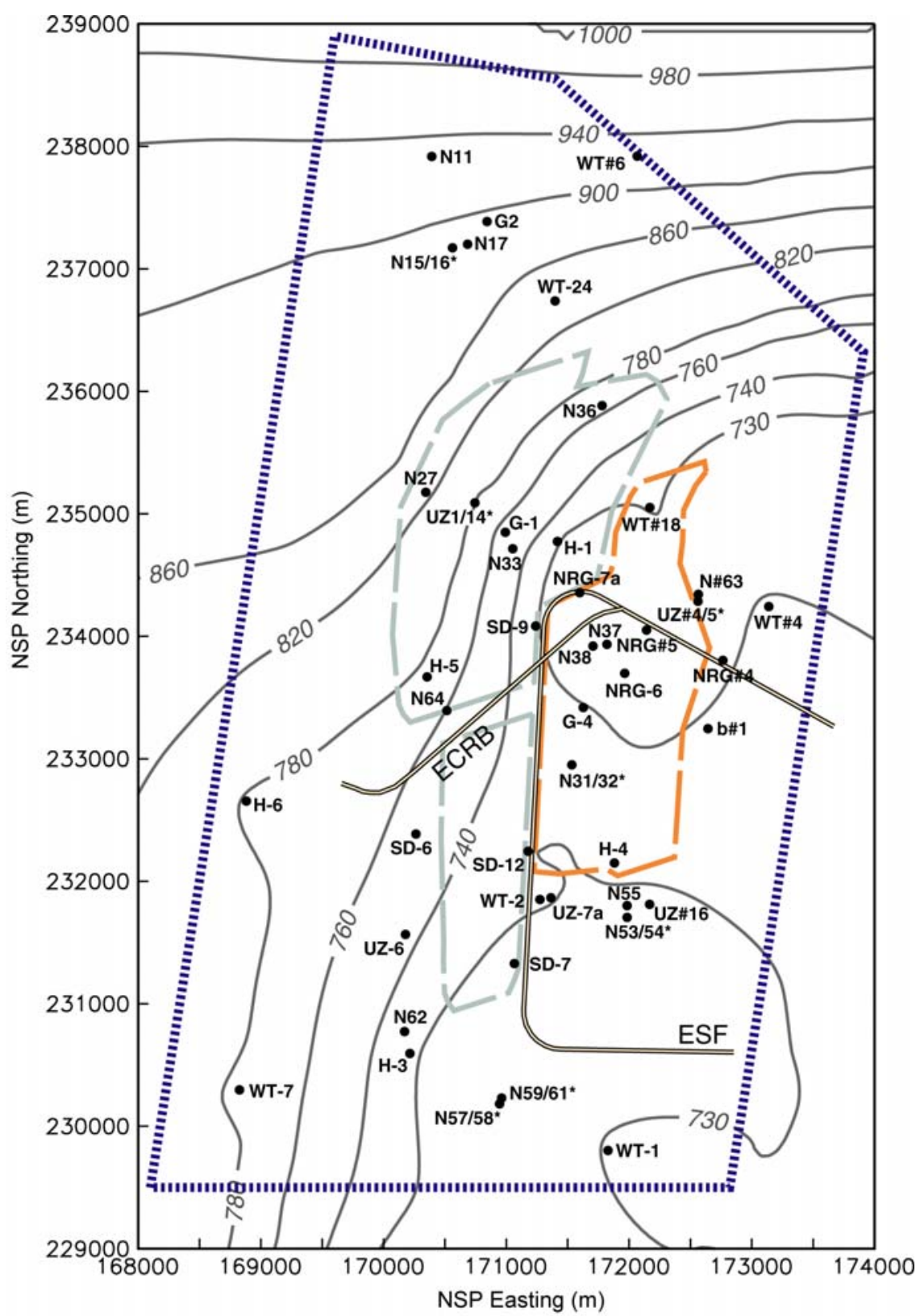

\begin{tabular}{|c|c|}
\hline \multicolumn{2}{|l|}{ LEGEND } \\
\hline 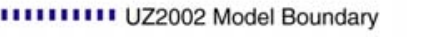 & - 900 — Water Table Elevation Contours \\
\hline 2002 Repository Boundary & UZ\#16 Boreholes \\
\hline $\begin{array}{l}=2002 \text { Repository Lower Block } \\
\end{array}$ & $\begin{array}{l}\text { Note: } \begin{array}{l}\text { * Denotes single location used for } \\
\text { adjacent boreholes. }\end{array}\end{array}$ \\
\hline
\end{tabular}

Source: BSC 2004 (DIRS 169855), Figure 6-2.

NOTE: Figure 6-9 was deleted. Figures were not renumbered due to figure cross-referencing in other documents. NSP $=$ Nevada State Plane Coordinate System.

Figure 6-10. Plan-View Schematic Showing Boreholes, Contoured Water Table (Elevation in Meters), UZ Model Boundary, Repository Outline, ESF, and Enhanced Characterization of the Repository Block Cross-Drift 
Several independent lines of evidence are available for estimating the magnitude of rise in the water table beneath the repository at Yucca Mountain under previous glacial-transition climatic conditions (Forester et al. 1999 [DIRS 109425], pp. 56 and 57. Mineralogic alteration (zeolitization and tridymite distribution) in the UZ at Yucca Mountain shows no evidence that the water table has risen more than $60 \mathrm{~m}(200 \mathrm{ft})$ above its present position in the geologic past (Levy 1991 [DIRS 100053], p. 477). Analyses of ${ }^{87} \mathrm{Sr} /{ }^{86} \mathrm{Sr}$ ratios in calcite veins of the UZ and SZ at Yucca Mountain indicated previous water table positions of $85 \mathrm{~m}$ (279 ft) higher than present (Marshall et al. 1993 [DIRS 101142], p. 1948). Recently completed wells at paleospring discharge locations near the southern end of Crater Flat revealed shallower-than-expected groundwater (Paces and Whelan 2001 [DIRS 154724]; BSC 2004 [DIRS 168473], Table I-1), with depths of only 17 to $30 \mathrm{~m}$ (56 to $100 \mathrm{ft}$ ) to the water table. These findings indicate that the water table rise during the Pleistocene at these paleospring locations could not have been more than about $30 \mathrm{~m}$ (100 feet) due to the development of discharge locations. The results of the mineralogical and geochemical studies showing maximum water table rise of up to $85 \mathrm{~m}$ reflected evolution of past climates of up to 1 million years, which included the effects of glacial climates. The maximum water table rise under monsoon and glacial-transition climates for the next 10,000 years is, therefore, expected to be smaller because the monsoon and glacial-transition climates are warmer and dryer than the glacial climate (Sharpe 2003 [DIRS 161591]).

Interpretation of the water levels in wells at the southern end of Crater Flat, in relation to water table rise, is complicated by several factors. The paleospring discharge locations at the southern end of Crater Flat are not along the flow path from Yucca Mountain. Also, a higher groundwater flow rate is expected under future wetter climatic conditions and the principles of hydrogeology indicate that a uniform rise in the water table is not expected to occur unless the higher water table leads to a corresponding increase in the transmissivity (due to increased saturated thickness). A higher groundwater flow rate implies a higher hydraulic gradient, a larger transmissivity, or both along any given flow line. Thus, the water table at upgradient locations would be expected to rise more than the water table at downgradient locations, resulting in a nonuniform rise in the water table across the flow system.

Groundwater flow modeling of the response to a doubling of the mean annual precipitation indicated a maximum increase of $130 \mathrm{~m}(430 \mathrm{ft})$ of the water table in the vicinity of Yucca Mountain (Czarnecki 1985 [DIRS 160149]). This water table was overestimated because the analysis by Czarnecki (1985 [DIRS 160149]) was limited to two dimensions. In addition, average precipitation under monsoon and glacial-transition climates is less than twice the present-day value in the Yucca Mountain area, and the percolation flux resulting from the precipitation increase by Czarneck (1985 [DIRS 160149]) was also conservatively modeled. More recent groundwater flow modeling of the regional flow system under paleoclimate conditions simulated water levels of 60 to $150 \mathrm{~m}$ (200 to $490 \mathrm{ft}$ ) higher than present beneath Yucca Mountain (D’Agnese et al. (1999 [DIRS 120425], p. 2). Coarse resolution of the numerical grid used by the D’Agnese et al. (1999 [DIRS 120425]) flow modeling is believed to have resulted in an overestimate of water table rise $(150 \mathrm{~m})$.

Alternatively, an approximate calculation illustrates how the increased groundwater flow rate inferred for glacial-transition climate conditions could result in a higher water table at Yucca Mountain. Consider a groundwater flow line from beneath Yucca Mountain to near the southern 
boundary of the SZ site-scale flow model domain. Simulations of groundwater flow under past glacial-transition climate conditions in D’Agnese et al. (1999 [DIRS 120425], Figure 13) show that groundwater discharge would be initiated at the toe of the Fortymile Wash system, near the southern boundary of the SZ site-scale flow model domain. The present water table elevation at this location is about 700 meters (2,300 feet), and the water table beneath Yucca Mountain is at about 730 meters (2,400 feet) elevation. The drop in hydraulic head along this groundwater flow line is about 30 meters (100 feet). It is estimated that the groundwater flux along this flow line would be greater by a factor of about 4 for glacial-transition climate conditions (BSC 2003 [DIRS 170042], Table 6-5). Attributing increases in groundwater flux to increases in the hydraulic gradient only (i.e., no increase in transmissivity), the head drop along the flow path would have to increase from 30 meters (100 feet) to four times 30 meters, or 120 meters (400 feet). Furthermore, for groundwater discharge to be initiated near the southern end of the flow line, the water table would have to rise by about 30 meters (100 feet) at that location. Therefore, the water table elevation beneath Yucca Mountain would have to be 700 meters + 30 meters +120 meters $(2,300$ feet +100 feet +400 feet), or a value of 850 meters (2,800 feet) for glacial-transition climate conditions, based on this simplified calculation. A water table elevation of 850 meters (2,800 feet) beneath Yucca Mountain constitutes a rise of about 120 meters (400 feet) relative to present conditions.

For the TSPA-LA calculations, a conservative approach in which a rise in the water table of 120 meters (400 feet) is imposed in the UZ transport model for monsoon and glacial-transition climatic conditions (BSC 2004 [DIRS 170041], Section 6.4.8). This effectively decreases the length of the flow path of radionuclides in the UZ by about 120 meters. The 120-meter (400-foot) rise in the water table due to climate change is a conservative estimate that minimizes the transport time in the UZ. In addition, the 120-meter (400-foot) rise in the water table is assumed to occur immediately following the change to wetter climatic conditions. In reality, there could be a significant period of adjustment in the SZ flow system in response to increased recharge related to climate change.

Overall, the treatment of water table rise due to climate change in the TSPA-LA tends to underestimate the transport times of radionuclides through the natural system. However, given the differing estimates and lack of definitive information on the magnitude and timing of water table rise, it constitutes a reasonable bounding approximation.

\subsubsection{Incorporation of Water Table Rise into the SZ Flow and Transport Models}

The effects of climate change on radionuclide transport simulations in the SZ are incorporated into the TSPA analyses by scaling the simulated SZ breakthrough curves by a factor representative of the alternative climate state (BSC 2004 [DIRS 170042], Section 6.5). The scaling factor used in this approach is the ratio of average SZ groundwater flux under the future climatic conditions to the flux under present conditions. This approach approximates the impacts of future, wetter climatic conditions in which the SZ groundwater flux will be greater. However, this approach implicitly models the same flow path for radionuclide transport through the SZ under wetter climatic conditions of the future. In reality, significant rise in the water table due to climatic changes would result in different flow paths through the SZ system, including the potential for encountering different hydrogeologic units by radionuclides during transport. 
The objective of this modeling task is to adapt the SZ site-scale flow model to include the effects of estimated water table rise and to compare the results of particle-tracking simulations using this adapted model to the simple flux scaling approach used in TSPA analyses. Flow modeling for this task is presented in this report and the transport simulations are presented in BSC (2004 [DIRS 170036], Sections 6.5 and 6.8). Based on qualitative arguments, the flux scaling approach to simulation of climate change is deemed to be conservative with regard to radionuclide transport in the SZ, relative to the more realistic situation in which water table rise is included in the modeling (BSC 2004 [DIRS 170042], Section 6.5). The purpose of this section is to both verify that assumption and provide an upper bound on the future climate fluxes.

\subsection{Estimating Water Table Rise from Climate Change}

Rise in the water table during wetter glacial transition conditions at Yucca Mountain is a complex function of greater recharge to the SZ and changes to the amount and spatial distribution of discharge from the regional SZ system. Simulations of groundwater flow under wetter, monsoonal conditions with the SZ regional-scale flow model (D'Agnese et al. 1999 [DIRS 120425]) indicate that groundwater flow paths from beneath Yucca Mountain do not change much under monsoonal conditions. These simulations also show that groundwater surface discharge from the SZ for the wetter monsoonal conditions would not occur along the flow path from Yucca Mountain at any location closer than the regulatory limit of approximately 18 kilometers south of the repository.

The estimated elevation of the water table under wetter, glacial transition conditions within the domain of the SZ site-scale flow model was calculated using the software code WTCONVYD V.1.00 STN: 10815-1.00-00 (SNL 2002 [DIRS 163835]). This software code uses an algorithm that incorporates qualitative information on the paleoflow system, an estimate of increased groundwater flux under glacial conditions based on known patterns of climatic cycles during the Quaternary period, particularly the last 500,000 years, and other paleoclimate data, and physical limits to the position of the water table. The software code calculates the estimated rise in the water table using this algorithm, along with data on the present water table surface and the elevations of the topographic surface.

Estimates of the elevation of the water table under Yucca Mountain for wetter, glacial-transition climatic conditions indicate that the water table could have been on the order of 100 meters higher under these conditions based on the discussion in Section 6.4.5.1. The water table was calculated by the software code WTCONVYD assuming that water levels will rise approximately 100 meters higher than present conditions in the area beneath Yucca Mountain. In those areas of the model domain where the present water table has an elevation greater than 730 meters (the approximate water level observed beneath Yucca Mountain), the software code also calculates the elevation of the water table under monsoonal conditions to be 100 meters higher than present conditions, except where the topographic surface is less than 100 meters above the present water table. This exception occurs in the canyon of Fortymile Wash in the northern part of the model domain where the software code calculates the water table under monsoonal conditions to occur within 1 meter of the topographic surface. There is little information upon which to base estimates of the water table configuration under monsoonal conditions in the area to the north of Yucca Mountain in the SZ site-scale flow model domain. 
However, the approach used in the software code WTCONVYD is reasonable and has little impact on the flow system downgradient of Yucca Mountain in the SZ site-scale flow model.

Simulations of groundwater flow under wetter, glacial transition conditions with the SZ regional-scale flow model (D’Agnese et al. 1999 [DIRS 120425]) indicate that the groundwater flux in the area of Yucca Mountain would be approximately four times greater than at present (see Section 6.6). The software code WTCONVYD calculates the higher water table elevations for monsoonal conditions such that the approximate hydraulic gradient would be greater by a factor of four for locations in the model domain where the present water table is between 700 meters and 730 meters elevation. This range of water table elevations covers that portion of the SZ flow system along the flow path from beneath the repository to the regulatory limit of approximately 18 kilometers south of the repository. The approximation that the software code uses in this approach counts upon the average permeability along the flow path not differing significantly between present conditions and the monsoonal conditions and that a four-fold increase in the gradient would result in an approximately four-fold increase in the groundwater flux. Finally, the software code increases the elevation of the water table by a uniform value of 10 meters for locations within the model domain where the present water table is less than 700 meters elevation. This condition occurs only in the southern part of the SZ site-scale flow model domain where the water table is located in the valley-fill alluvium unit and the hydraulic gradient is relatively low. The elevation of the water table under monsoonal conditions is relatively unimportant with regard to the hydrogeologic unit configuration because of the thick alluvium in this area of the model domain.

The software code WTCONVYD also limits the estimated rise in the water table under monsoonal conditions to within one meter of the topographic surface, which constitutes a physical limit to the rise in the water table within the domain of the SZ site-scale flow model. Rise of the water table to within one meter of the surface would induce significant groundwater discharge by evapotranspiration and the formation of local springs.

The estimated elevations of the water table under wetter, monsoonal conditions, as calculated by the WTCONVYD are shown in Figure 6-11. Note that the pattern of the contours for the water table surface is generally similar to the present water table, with the exception of the area in Fortymile Canyon in the northern part of the model domain and in some areas in the south-central and southwestern parts of the model domain. These areas, in which the contours of the estimated higher water table are more irregular, are areas of shallow groundwater under monsoonal conditions. 


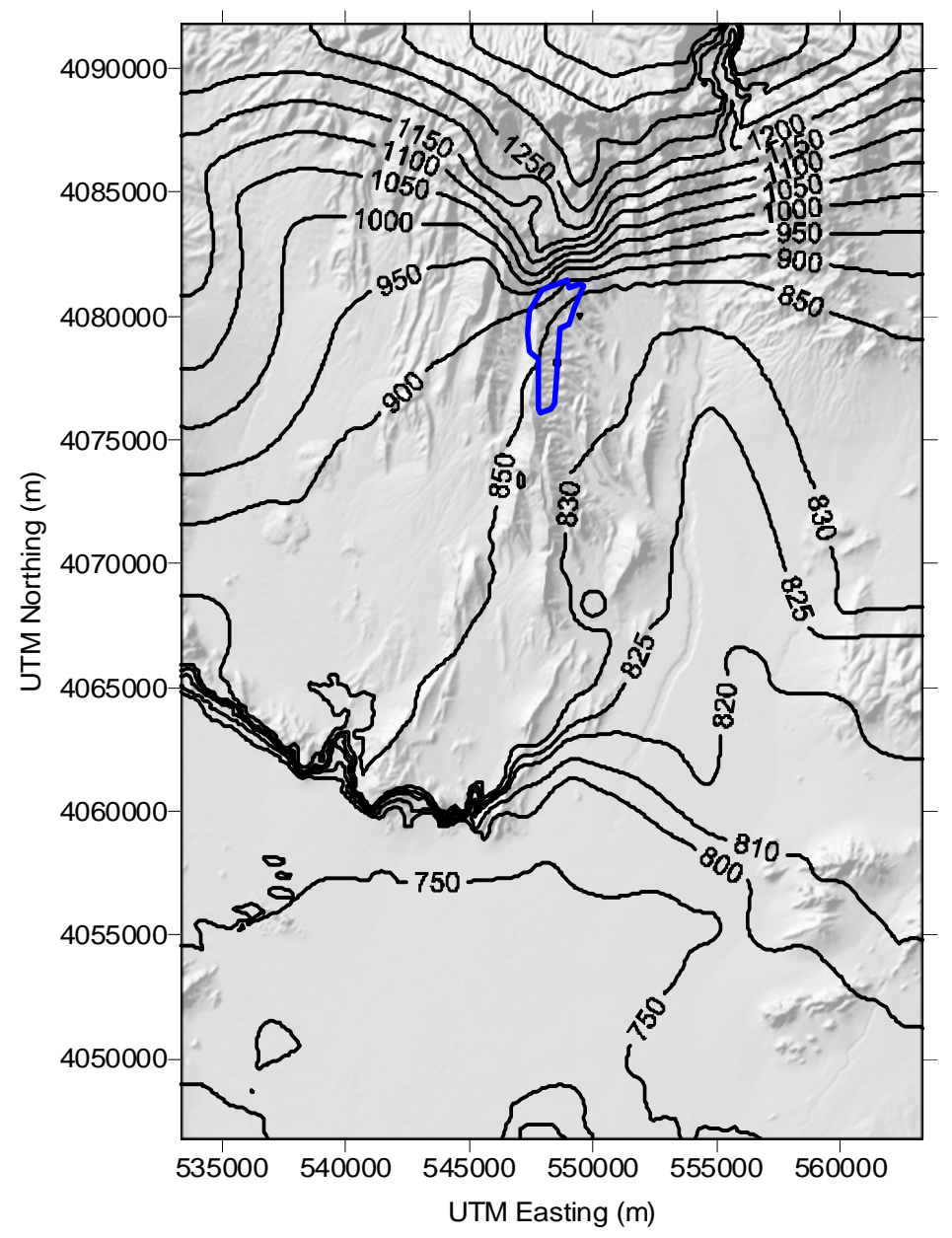

Source for repository outline: BSC 2003 (DIRS 162289). For illustration purposes only

NOTE: Repository outline shown with bold blue line.

UTM = Universal Transverse Mercator

Figure 6-11. Estimated Water-Table Elevations for Future Glacial Transition Conditions

Figure 6-12 shows the estimated depth to the water table under wetter, glacial transition climate conditions, as calculated by the WTCONVYD. The areas in which the estimated water table is within 5 meters of the topographic surface are shown with the light blue shading. The larger light-blue area of shallow estimated groundwater in the southwestern part of the domain contains the three areas of paleospring deposits located along U.S. Highway 95 and at the southern end of Crater Flat. This shows a certain degree of consistency between the estimated higher water table and the geologic features associated with Pleistocene spring discharge. The specific paleospring locations are probably controlled by structural features that are below the resolution of the analysis of the estimated water table elevation under monsoonal conditions. The other site of shallow estimated groundwater shown in Figure 6-12 is Fortymile Canyon. Although paleospring deposits are not observed in Fortymile Canyon, it is reasonable to postulate that such deposits would not be preserved in this geomorphic location. In any event, the large block sizes of the numerical model would average out heterogeneities of this scale. 


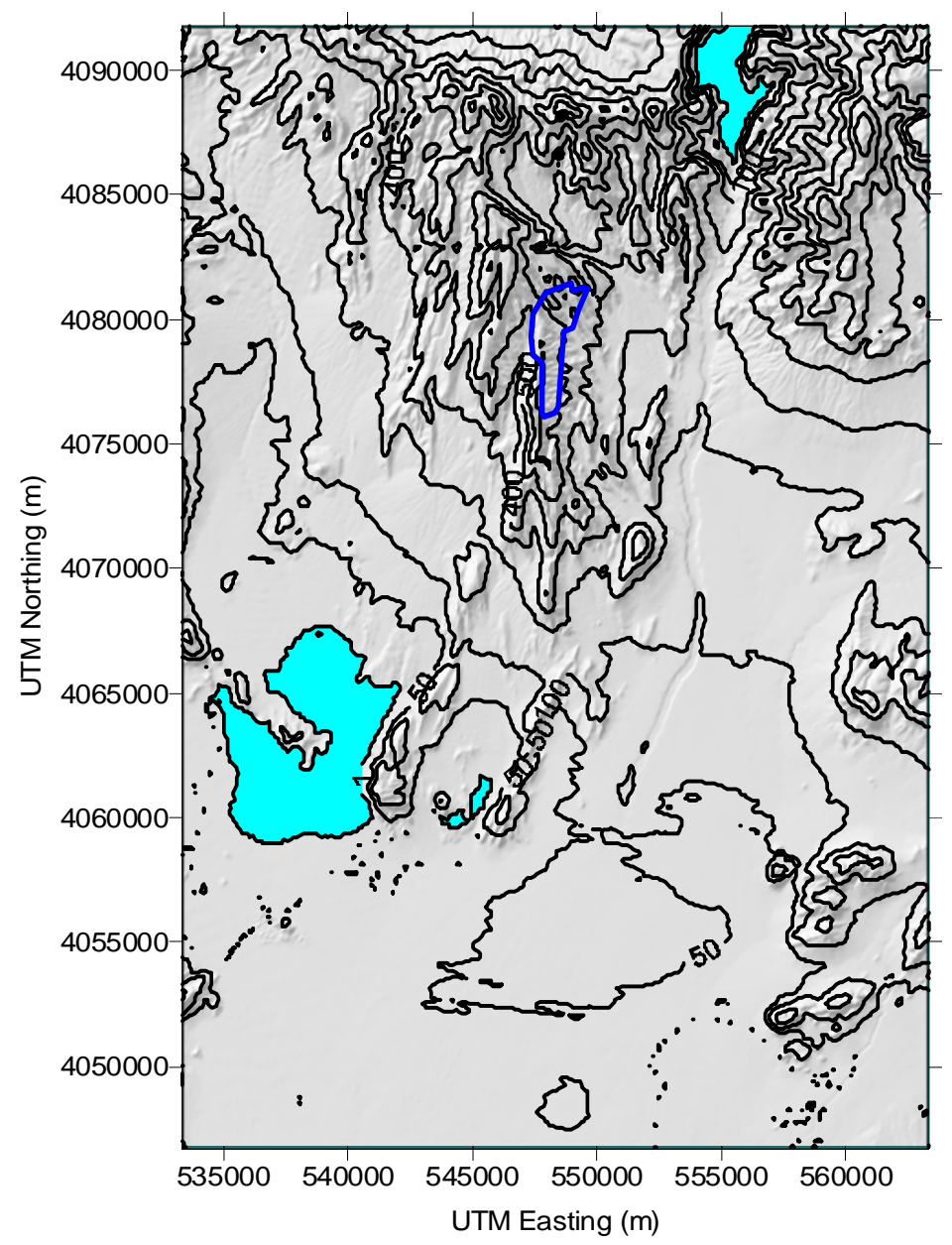

Source for repository outline: BSC 2003 (DIRS 162289). For illustration purposes only.

NOTE: Repository outline shown with bold blue line. Areas with estimated depth to the water table of less than $5 \mathrm{~m}$ are shown with light blue shading.

UTM = Universal Transverse Mercator

Figure 6-12. Estimated Depth to the Water-Table for Future Glacial Transition Conditions

In summary, a reasonable estimate of the water table elevation under wetter, glacial transition conditions is developed for the SZ site-scale flow model domain. The estimated rise in the water table is consistent with the estimated increase in groundwater flux along the inferred flow path from beneath the repository because the rise produces an approximately four-fold increase in hydraulic gradient. In addition, the pattern of the estimated rise in the water table is generally consistent with the locations of paleospring deposits within the domain. 


\subsection{Water Table Rise in the SZ Site-Scale Flow Model}

The SZ site-scale flow model is adapted to the higher estimated water table for glacial transition conditions by creating a new grid with an upper surface corresponding to the higher water table. The lateral and bottom boundary locations remain the same in this adaptation of the model. The spatial distributions of hydrogeologic units at the water table in the flow model under present conditions and in the adapted model with the higher estimated water table are shown in Figures 6-13 and 6-14, respectively.

Comparison of Figures 6-13 and 6-14 indicates potentially significant differences in the hydrogeologic units present in the shallow SZ beneath the repository and along the inferred flow path to the south and east of the repository at depths corresponding to the position of the water table at the different climatic conditions. The upper volcanic confining unit is much more widely distributed at the water table beneath the repository under estimated future monsoonal conditions than it is under present conditions, particularly under the northern and eastern parts of the repository. To the south and east of the repository, the alluvium unit is present at the water table over a broad area under estimated future conditions, where this unit is absent under the present conditions.

The site-scale transport simulations with the higher water table are considered in BSC (2004 [DIRS 170036], Section 6.6 and Appendix E1). Comparison of these simulations with the simplified approach used in TSPA abstraction shows that the site-scale transport model results in longer simulated transport times. The simplified TSPA approach is thus a conservative representation of transport in the SZ under wetter monsoonal conditions with regard to more realistic approach in which water table rise is included in modeling.

\subsubsection{Alternate SZ Site-scale Flow Model (Hydrogeologic Framework Model Reinterpretation and Additional Data)}

Additional data and analyses have become available after the SZ site-scale flow model was developed. These additional data and analyses include additional water-level data, a reinterpreted HFM, revised recharge distribution, updated boundary fluxes, additional permeability data, the use of 15 new Nye County head targets in some calibrations (DTN: MO0405NYE05819.215 [DIRS 170539]), and further evaluation of alternative conceptual models. To evaluate the impact of this additional knowledge on the modeling of the SZ site-scale flow system, an alternate SZ site-scale flow model has been formulated and calibrated. 


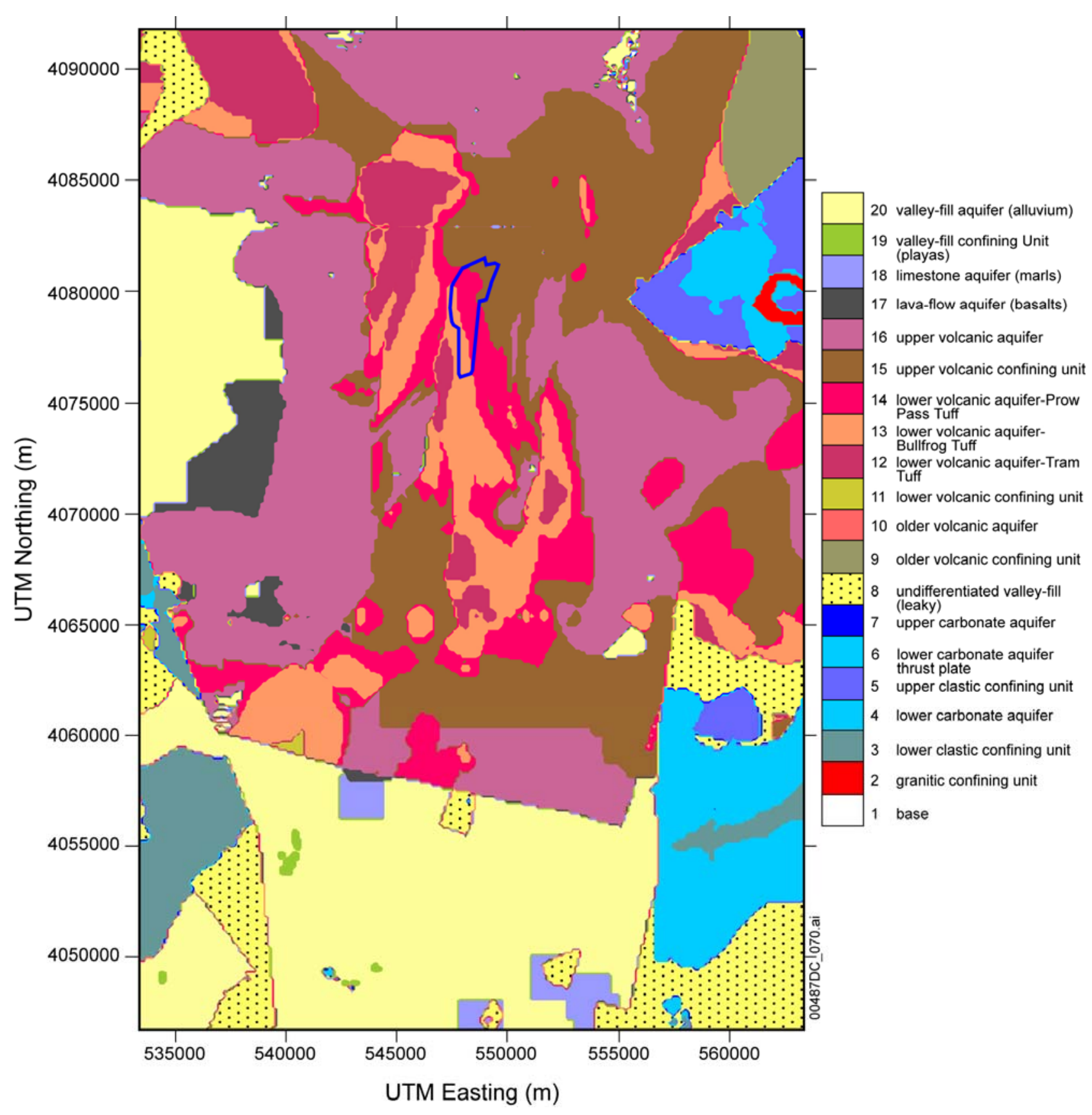

Source for repository outline: BSC 2003 (DIRS 162289). For illustration purposes only.

NOTE: Repository outline shown with bold blue line.

UTM = Universal Transverse Mercator

Figure 6-13. Hydrogeologic Framework Model Units at the Water Table for Present Conditions 


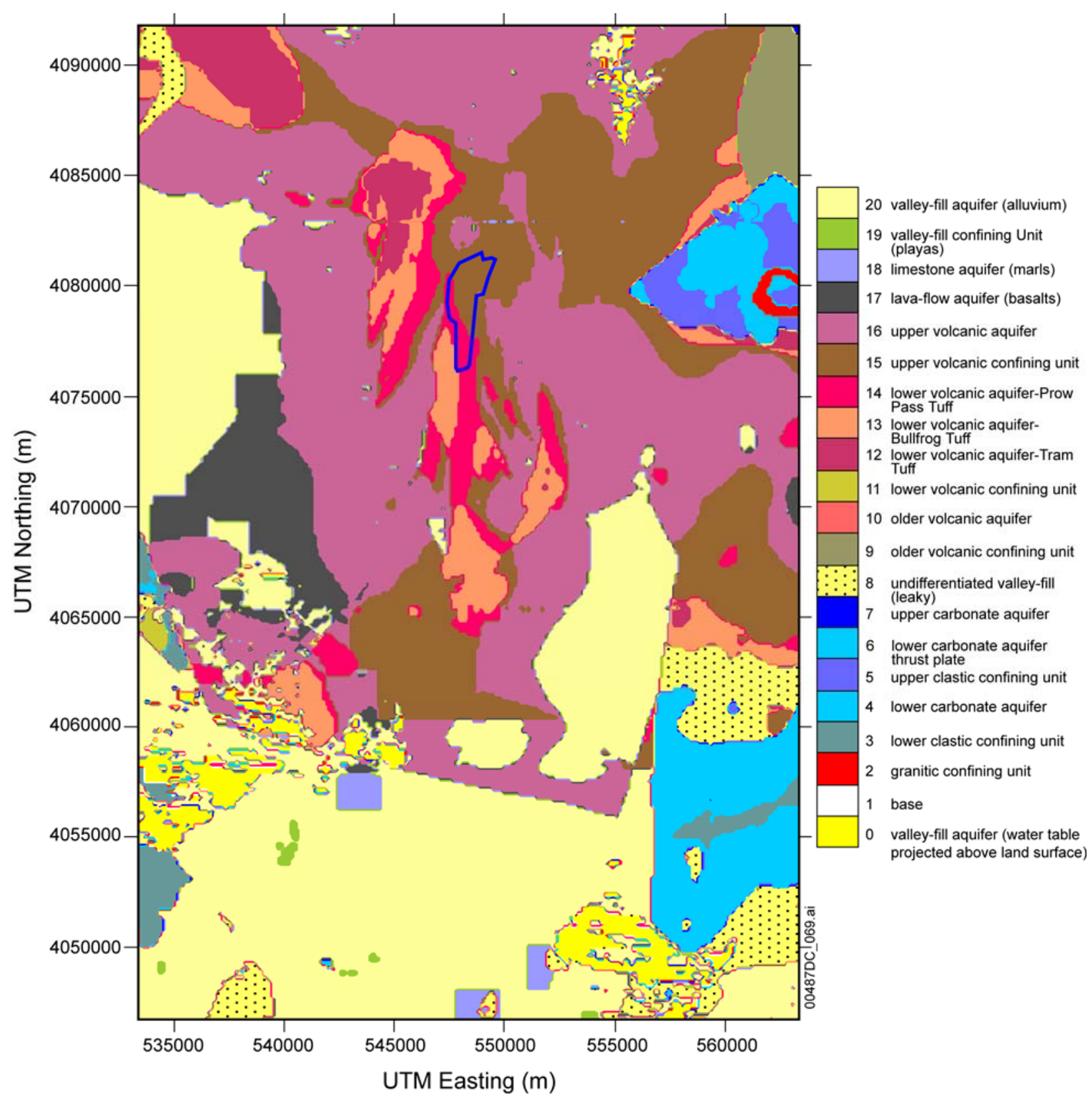

Source for repository outline: BSC 2003 [DIRS 162289]. For illustration purposes only.

NOTE: Repository outline shown with bold blue line.

UTM = Universal Transverse Mercator

Figure 6-14. Hydrogeologic Framework Model Units at the Water Table for Estimated Future Glacial Transition Conditions

\subsubsection{Alternative Conceptual Model}

The conceptual model used in the alternate flow model has been modified from that used in the SZ site-scale flow model. Many of these changes are due to changes from the SZ site-scale flow model HFM conceptualization (DTN: GS030208312332.001 [DIRS 163087]) referred to as 
HFM-19, which has 19 hydrogeologic units, to an updated version of the HFM conceptualization (DTN: GS021008312332.002 [DIRS 164363]) referred to as HFM-27 with 27 hydrogeologic units. The HFM-27 involves work associated with updates to the Death Valley regional flow model. In particular, a subset of the regional model was resampled and rebuilt at a finer resolution to be used for site-scale flow modeling. The Yucca Mountain HFM-19 has been reinterpreted with data obtained from the NC- EWDP and with the reinterpretation of existing data from other areas, including geophysical data in the northern area of the site. These changes are discussed in Section 6.4.6.2.3.

The conceptual model used in the alternate flow model has also changed from that used in the SZ site-scale flow model, through the incorporation of an ACM for the LHG area north of Yucca Mountain. As discussed in Sections 6.4.1 and 6.7.1, a low-permeability east-west feature has been incorporated into the SZ site-scale conceptual model north of Yucca Mountain to simulate the LHG area reflecting the postulated presence of a zone of hydrothermal alteration. However, there is little field evidence for the presence of this feature; but the Claim Canyon Caldera does exist north of Yucca Mountain. The Claim Canyon caldera is an area of extensive hydrothermal alteration that may result in a generalized reduction in permeability in the hydrogeologic units in this area. Alternate conceptualizations have been investigated that remove the extensive set of features north of Yucca Mountain but that divide the model domain along the Claim Canyon caldera into northern and southern zones, allowing different permeabilities to be assigned in the north versus the south within the same hydrogeologic unit. By creating a distributed region of lower permeability in the northern portion of the model, the LHG can be simulated in the flow domain. Using this basic conceptualization, several different conceptual models have been evaluated for the SZ site-scale flow model, but the conceptualization incorporating the northwest-southeast-trending fault zone just north of Yucca Mountain and the Ghost Dance fault and the Dune Wash fault has been found to best reproduce water levels and flow paths from the repository. This alternative conceptualization has been identified as the "altered with fault/Ghost Dance fault" (AWF/GDF) conceptualization and has been used in the alternate flow model. A more detailed discussion regarding the evaluation of alternative conceptualizations is available in Section 6.7.

\subsubsection{Alternate Flow Model Formulation}

The mathematical formulation used in the alternate SZ site-scale flow model (Section 6-5) is identical to that used in the SZ site-scale flow model. The FEHM code (Zyvoloski et al. 1997 [DIRS 100615]) was used in the SZ site-scale flow model to obtain a numerical solution to the mathematical equation describing groundwater flow. FEHM was used in the alternate flow model. However, the inputs used in the alternate flow model have been updated to reflect the increased data and analyses now available for formulating the SZ site-scale flow model. These changes in the model inputs are discussed below.

\subsection{Grid Generation}

The computational grid established for use in the alternate SZ site-scale flow model has been modified from that used in the SZ site-scale flow model (Section 6-6). The 500-meter horizontal grid spacing used in the SZ site-scale flow model has been retained in the alternate flow model. The grid is offset by 340 meters to the west and expanded by 500 meters in the east-west 
direction. The grid is offset by 280 meters to the south. The alternate flow model grid now coincides with even multiples of 100 meters in the UTM coordinate system. The result is a slightly larger grid.

The grid for the alternate flow model has also been extended along the vertical coordinate to the ground surface, although those nodes located above the water table are not computationally active. A confined aquifer solution using the water table elevation to define the top of the flow system continues to be implemented as it was in the SZ site-scale flow model (Section 6-6). However, extension of the grid to the ground surface allows, if necessary, the simulation of a dynamic water table. The depth of the alternate flow model grid has also been extended to 4,000 meters below sea level to match the depth of the HFM-27, which increased primarily to include more of the regional carbonate aquifer. Similar to the way in which the nodes above the water table are made computationally inactive, nodes a distance of 2,200 meters or greater below the variable-elevation water table are also removed from the computation. Thus, the active bottom of the alternate model grid varies from the north, where the water table is approximately 1,200 meters above mean sea level, to the south, where the water table is approximately 700 meters above mean sea level. This computational strategy was adopted in an effort to match the Death Valley regional flow model, which consists of three model layers, each with a constant thickness below a variable-elevation water table (D’Agnese et al. 1997 [DIRS 100131], p 75).

The vertical grid spacing of the alternate flow model is also equivalent to that of the site-scale flow model. Gridblocks higher than the 1,200 meters mentioned in Table 6-2, simply continue the 50-meter spacing listed for the top zone. Gridblocks lower than -600 meters have the 400-meter vertical spacings. The gridblocks (nodes) increase from 142,853 nodes in the SZ site-scale flow model to 228,237 nodes in the alternate SZ site-scale flow model. This increase in number is due to the extension of the alternate SZ site-scale flow model grid to ground surface and its deeper extent.

Table 6-2. Alternate SZ Site-Scale Flow Model and SZ Site-Scale Flow Model Size Comparison

\begin{tabular}{|l|l|l|l|l|}
\hline & \multicolumn{1}{|c|}{$\begin{array}{c}\text { Alternate Flow } \\
\text { Model } \\
\text { HFM-27 }\end{array}$} & $\begin{array}{c}\text { Alternate Flow } \\
\text { Model } \\
\text { Grid }\end{array}$ & $\begin{array}{c}\text { SZ Site-Scale } \\
\text { Flow Model } \\
\text { HFM-19 }\end{array}$ & \multicolumn{1}{|c|}{$\begin{array}{c}\text { SZ Site-Scale } \\
\text { Flow Model Grid }\end{array}$} \\
\hline $\begin{array}{l}\boldsymbol{X} \text { min/max (UTM } \\
\text { Easting, meters) }\end{array}$ & $533000-563500$ & $533000-563500$ & $533340-563340$ & $533340-563340$ \\
\hline $\begin{array}{l}Y \\
\min / \max \text { (UTM } \\
\text { Northing, meters) }\end{array}$ & $4046500-4091875$ & $4046500-4091500$ & $4046780-4091780$ & $4046780-4091780$ \\
\hline $\begin{array}{l}Z \\
\text { min/max (datum mean } \\
\text { seal level, meters) }\end{array}$ & $-4100-2156$ & $-4000-2150$ & $-2355-1343$ & $-2200-1200$ \\
\hline Nodes & 2140320 & 228237 & 1827021 & 142853 \\
\hline
\end{tabular}

Source DTN: GS021008312332.002 [DIRS 164363], SZ site-scale flow model HFM-27

DTN: GS030208312332.001 [DIRS 163087], SZ site-scale flow model HFM-19

DTN: LA0304TM831231.002 [DIRS 163788] SZ site-scale flow model grid.

NOTE: HFM = hydrogeologic framework model; SZ = saturated zone; UTM = Universal Transverse Mercator 


\subsection{Hydrogeologic Framework Model}

Since the development of the HFM-19 used in the SZ site-scale flow model, the Yucca Mountain HFM has been reinterpreted with data recently obtained from the EWDP and through the reinterpretation of existing data from other areas, including geophysical data in the northern area of the site. The major changes in the southern part of the model are the depths and extent of the alluvial layers. The HFM for the northern part of the model domain has also changed substantially. This is largely the result of reinterpretation of geophysical data regarding the depth of the carbonate aquifer. The reinterpretation results in the shape and extent of the carbonate aquifer changing significantly. In particular, the carbonate aquifer is no longer believed to intersect the northern boundary of the SZ site-scale flow model.

Because of the reinterpretation of the HFM-19, the number and distribution of hydrogeologic units has been modified in the HFM-27 that is used in the alternate flow model. A comparison of the hydrogeologic units identified in the HFMs used in the SZ site-scale flow model and alternate flow models is provided in Table 6-3, which indicates that while there were 19 hydrogeologic units in the SZ site-scale flow model HFM-19, there are 27 hydrogeologic units in the alternate HFM-27. Four of the 27 units present in the regional model are not represented in the site-scale HFM because these units are pinched out by adjacent units. The alternate grid covers a slightly larger area horizontally and extends from the surface to a deeper elevation than the SZ site-scale flow model grid. In order to compare the alternate and site-scale grids, the larger alternate is subset to the volume occupied by the full SZ site-scale flow model grid. Because the two grids do not have elements aligned, there is a minimum subset, fully enclosed by the SZ site-scale flow model grid, and a maximum subset, slightly larger than the volume of the SZ site-scale flow model grid. Table 6-4 lists the number of nodes in each unit for the grids. This table also gives the percentage volume for each of the hydrogeologic units.

To provide a better understanding of the changes in the HFM-27 used for the alternate SZ site-scale flow model, discussions comparing the differences in the hydrogeology at the water table, in the area of Nye County, and along the anticipated flow path from the repository are provided in the next sections.

Table 6-3. Correlation of Alternate SZ Site-Scale Flow Model HFM-27 and SZ Site-Scale Flow Model HFM-19 Units

\begin{tabular}{|c|c|c|c|c|}
\hline \multirow[b]{2}{*}{ Abbreviation } & \multicolumn{2}{|l|}{ Alternate Flow Model } & \multicolumn{2}{|r|}{ SZ Site-Scale Flow Model } \\
\hline & Hydrogeologic Name & Unit & Unit & Hydrogeologic Name \\
\hline Base & Base $(-4000 \mathrm{~m})$ & 1 & 1 & Base (bottom of regional flow model) \\
\hline ICU & Intrusive Confining Unit & 2 & 2 & Granitic confining unit (granites) \\
\hline $\mathrm{XCU}$ & Crystalline Confining Unit & 3 & 3 & Lower Clastic Confining Unit (Iccu) \\
\hline LCCU & Lower Clastic Confining Unit & 4 & 3 & Lower Clastic Confining Unit (Iccu) \\
\hline LCA & Lower Carbonate Aquifer & 5 & 4 & Lower Carbonate Aquifer (Ica) \\
\hline UCCU & Upper Clastic Confining Unit & 6 & 5 & $\begin{array}{l}\text { Upper Clastic Confining Unit, Upper Clastic } \\
\text { Confining Unit - thrust } 2 \text { (uccu, uccut2) }\end{array}$ \\
\hline UCA & Upper Carbonate Aquifer & 7 & 7 & NA \\
\hline LCCU_T1 & $\begin{array}{l}\text { Lower Clastic Confining Unit - } \\
\text { thrust }\end{array}$ & 8 & NA & Lower Clastic Confining Unit - thrust 1 (Iccut1) \\
\hline
\end{tabular}


Table 6-3. Correlation of Alternate SZ Site-Scale Flow Model HFM-27 and SZ Site-Scale Flow Model HFM-19 Units (Continued)

\begin{tabular}{|c|c|c|c|c|}
\hline \multirow[b]{2}{*}{ Abbreviation } & \multicolumn{2}{|l|}{ Alternate flow model } & \multicolumn{2}{|r|}{ SZ site-scale flow model } \\
\hline & Hydrogeologic Name & Unit & Unit & Hydrogeologic Name \\
\hline LCA_T1 & $\begin{array}{l}\text { Lower Carbonate Aquifer - } \\
\text { thrust }\end{array}$ & 9 & 6 & $\begin{array}{l}\text { Lower Carbonate Aquifer thrusts } 1 \text { and } 2 \\
\text { (Icat1, Icat2) }\end{array}$ \\
\hline $\mathrm{SCU}$ & $\begin{array}{l}\text { Sedimentary Confining Unit } \\
\text { (none in site area) }\end{array}$ & NA & NA & NA \\
\hline VSU Lower & $\begin{array}{l}\text { Lower Volcanic and } \\
\text { Sedimentary Units }\end{array}$ & 11 & 8 & Undifferentiated valley-fill (leaky) \\
\hline OVU & Older Volcanic Units & 12 & $9,10,11$ & $\begin{array}{l}\text { Older Volcanic Confining Unit, Older Volcanic } \\
\text { Aquifer, Lower Volcanic Confining Unit (Ivcu, } \\
\text { Iva, mvcu) }\end{array}$ \\
\hline BRU & $\begin{array}{l}\text { Belted Range Unit (none in site } \\
\text { area) }\end{array}$ & NA & NA & NA \\
\hline CFTA & Crater Flat - Tram Aquifer & 14 & 12 & Lower Volcanic Aquifer - Tram Tuff (tct) \\
\hline CFBCU & $\begin{array}{l}\text { Crater Flat - Bullfrog Confining } \\
\text { Unit }\end{array}$ & 15 & 13 & Lower Volcanic Aquifer -Bullfrog Tuff (tcb) \\
\hline CFPPA & Crater Flat - Prow Pass Aquifer & 16 & 14 & Lower Volcanic Aquifer -Prow Pass Tuff (tcp) \\
\hline WVU & Wahmonie Volcanic Unit & 17 & 15 & Upper Volcanic Confining Unit (uvcu) \\
\hline $\mathrm{CHVU}$ & Calico Hills Volcanic Unit & 18 & 15 & Upper Volcanic Confining Unit (uvcu) \\
\hline PVA & Paintbrush Volcanic Aquifer & 19 & 16 & Upper Volcanic Aquifer (uva) \\
\hline TMVA & $\begin{array}{l}\text { Timber Mountain Volcanic } \\
\text { Aquifer }\end{array}$ & 20 & 16 & Upper Volcanic Aquifer (uva) \\
\hline \multirow[b]{2}{*}{ Abbreviation } & \multicolumn{2}{|l|}{ Alternate flow model } & \multicolumn{2}{|c|}{ SZ site-scale flow model } \\
\hline & Hydrogeologic Name & Unit & Unit & Hydrogeologic Name \\
\hline VSU & $\begin{array}{l}\text { Volcanic and Sedimentary } \\
\text { Units }\end{array}$ & 21 & 8 & Undifferentiated valley-fill (leaky) \\
\hline YVU & $\begin{array}{l}\text { Young Volcanic Units (none in } \\
\text { site area) }\end{array}$ & NA & NA & NA \\
\hline LFU & Lavaflow Unit & 23 & 17 & Lava-flow Aquifer (basalts) \\
\hline LA & Limestone Aquifer & 24 & 18 & Limestone Aquifer (amarls) \\
\hline OACU & $\begin{array}{l}\text { Older Alluvial Confining Unit } \\
\text { (none in site area) }\end{array}$ & NA & NA & NA \\
\hline OAA & Older Alluvial Aquifer & 26 & 20 & $\begin{array}{l}\text { Valley-fill Aquifer (alluvium), Undifferentiated } \\
\text { valley-fill (leaky) }\end{array}$ \\
\hline YACU & Young Alluvial Confining Unit & 27 & 19 & Valley-fill Confining Unit (playas) \\
\hline YAA & Young Alluvial Aquifer & 28 & 20 & Valley-fill Aquifer (alluvium) \\
\hline
\end{tabular}

NOTE: These units do not have a one-to-one correlation. This table approximately relates the alternate HFM hydrogeologic units to the SZ site-scale flow model HFM hydrogeologic units. Four units do not occur in the site-scale HFM (OACU, YVU, BRU, and SCU) but are included to maintain the relationship to the regional model.

Sources for these data are: DTN: GS021008312332.002 [DIRS 164363] for HFM-27 (alternate conceptual models HFM) and DTN: GS030208312332.001 [DIRS 163087] for HFM-19 (base case HFM). The details of implementations are provided in BSC (2004 [DIRS 170008]).

$\mathrm{HFM}=$ hydrogeologic framework model; N/A = not applicable; SZ = saturated zone 
Table 6-4. Comparison of Grid Hydrogeologic Unit Volume: Alternate SZ Site-Scale Model vs. SZ SiteScale Flow Model

\begin{tabular}{|c|c|c|c|c|c|c|}
\hline \multirow[t]{2}{*}{ Unit Name } & \multicolumn{3}{|c|}{ Alternate flow model } & \multicolumn{3}{|c|}{ SZ site-scale flow model } \\
\hline & Unit ID & Nodes & Fractional Volume & Unit ID & Nodes & Fractional Volume \\
\hline ICU & 2 & 5304 & 0.06155 & 2 & 608 & 0.00668 \\
\hline $\mathrm{XCU}$ & 3 & 2470 & 0.02863 & & & \\
\hline LCCU & 4 & 12726 & 0.13700 & 3 & 13259 & 0.17918 \\
\hline LCA & 5 & 31835 & 0.34402 & 4 & 27097 & 0.39315 \\
\hline UCCU & 6 & 10648 & 0.03995 & 5 & 5923 & 0.05606 \\
\hline UCA & 7 & 1278 & 0.00150 & 7 & 23 & 0.00001 \\
\hline LCCU_T1 & 8 & 5074 & 0.04009 & NA & 0 & 0 \\
\hline LCA_T1 & 9 & 9000 & 0.06111 & 6 & 1192 & 0.01087 \\
\hline VSU Lower & 11 & 21411 & 0.11172 & & & \\
\hline VSU Upper & 21 & 9435 & 0.00850 & 8 & 21578 & 0.14526 \\
\hline OVU & 12 & 5663 & 0.02432 & $\begin{array}{c}9 \\
10 \\
11\end{array}$ & $\begin{array}{c}11012 \\
210 \\
9142\end{array}$ & $\begin{array}{l}0.06112 \\
0.00238 \\
0.03868\end{array}$ \\
\hline CFTA & 14 & 22626 & 0.04429 & 12 & 11676 & 0.03551 \\
\hline CFBCU & 15 & 12829 & 0.01708 & 13 & 6472 & 0.01373 \\
\hline CFPPA & 16 & 6185 & 0.00698 & 14 & 5666 & 0.01101 \\
\hline WVU & 17 & 4484 & 0.00412 & & & \\
\hline $\mathrm{CHVU}$ & 18 & 15403 & 0.01892 & 15 & 7845 & 0.01261 \\
\hline PVA & 19 & 33544 & 0.03709 & 16 & 13831 & 0.02389 \\
\hline TMVA & 20 & 6083 & 0.00608 & & & \\
\hline LFU & 23 & 2104 & 0.00175 & 17 & 891 & 0.00095 \\
\hline LA & 24 & 1050 & 0.00044 & 18 & 227 & 0.00042 \\
\hline YACU & 27 & 286 & 0.00010 & 19 & 13 & 0.00002 \\
\hline OAA & 26 & 5024 & 0.00319 & & & \\
\hline YAA & 28 & 3775 & 0.00157 & 20 & 6188 & 0.00846 \\
\hline
\end{tabular}

NOTE: These units do not have a one-to-one correlation. Table 6-3 provides further detail of the units correlation. This table relates the alternate HFM hydrogeologic units to the SZ site-scale flow model HFM hydrogeologic units.

Sources for these data are: DTN GS021008312332.002 [DIRS 164363] for HFM-27 (alternate conceptual models HFM) and DTN GS030208312332.001 [DIRS 163087] for HFM-19 (base- case HFM). The details of implementations are provided in BSC (2004 [DIRS 170008]).

$\mathrm{HFM}=$ hydrogeologic framework model; N/A = not applicable; SZ = saturated zone 


\subsection{Comparison of Hydrogeology at the Water Table}

A comparison of hydrogeologic units present at the water table in the site-scale flow model HFM-27 is presented in Figure 6-15. As shown in both parts of this figure, major differences are evident in the southern part of the model where the volcanic and sedimentary units replace the valley-fill aquifer as the most pervasive unit in the revised HFM-27. The -most zone, called the alluvial uncertainty zone, represents a transition zone from the volcanic to the alluvial aquifer system. It replaces the older HFM-19 because, based on logs from well NC-EWDP-19-D, the alluvial aquifer extended north farther than what is presented in the HFM-19. The permeability associated with this zone is a calibration parameter and, thus, can represent either aquifer system. A second zone, the lower Fortymile Wash zone, was inserted to achieve a better calibration in the alternate model. It represents a distinct subset of the alluvial aquifer that is characterized by the higher proportion of gravels in the lower-most portion of Fortymile Wash. The Calico Hills volcanic unit has replaced the upper volcanic confining unit in the HFM-27. In the HFM-27, there is no longer any of this Calico Hills material separating the upper and lower portions of the Fortymile Wash. Further north, the Paintbrush volcanic aquifer replaces the upper volcanic aquifer as the dominant unit, at least near the water table. The Yucca Mountain block remains comprised of the Crater Flat group: Prow Pass, Bullfrog, and Tram units. The Crater Flat units are more continuous to the north and west of Yucca Mountain in the HFM-27 than in the HFM-19. Because the Crater Flat group has relatively high permeability, the new representation may provide a high-permeability flow path at the water table to Yucca Mountain that was not present in the earlier model. To be able to examine flow paths through the geologic units only three particles P1, P50, and P100 for the left figure and P6, P50, and P100 for the right figure are used to compare the flow paths at the water table. One of the revealed differences between the two HFMs and their respective flow models is that particle P1 did not travel along the water table in the alternate model as it did in the case of the SZ site-scale flow model. Another particle P6 was used in the alternate model. The purpose of tracking the 3 particles is to show clear single paths in units through which the flow paths travel which is not possible to do when showing all 100-particle paths.

\subsection{Comparison of Nye County Hydrogeology}

The most pronounced difference between HFM-19 and HFM-27 is the relative abundance of the Crater Flat group (given by the reds and yellows) to the west of Yucca Mountain in the HFM-27. The Crater Flat group represents relatively high permeability rock. However, the flow paths of fluid particles leaving the repository area are expected to be to the east of Yucca Mountain. Thus, this change in the HFM may not significantly influence the alternate SZ site-scale flow model's ability to replicate the flow paths predicted by the SZ site-scale flow model. In the HFM-27, the Crater Flat group is more continuous on the east side of Yucca Mountain, possibly influencing the calibration and specific discharge predictions of the alternate flow model. 


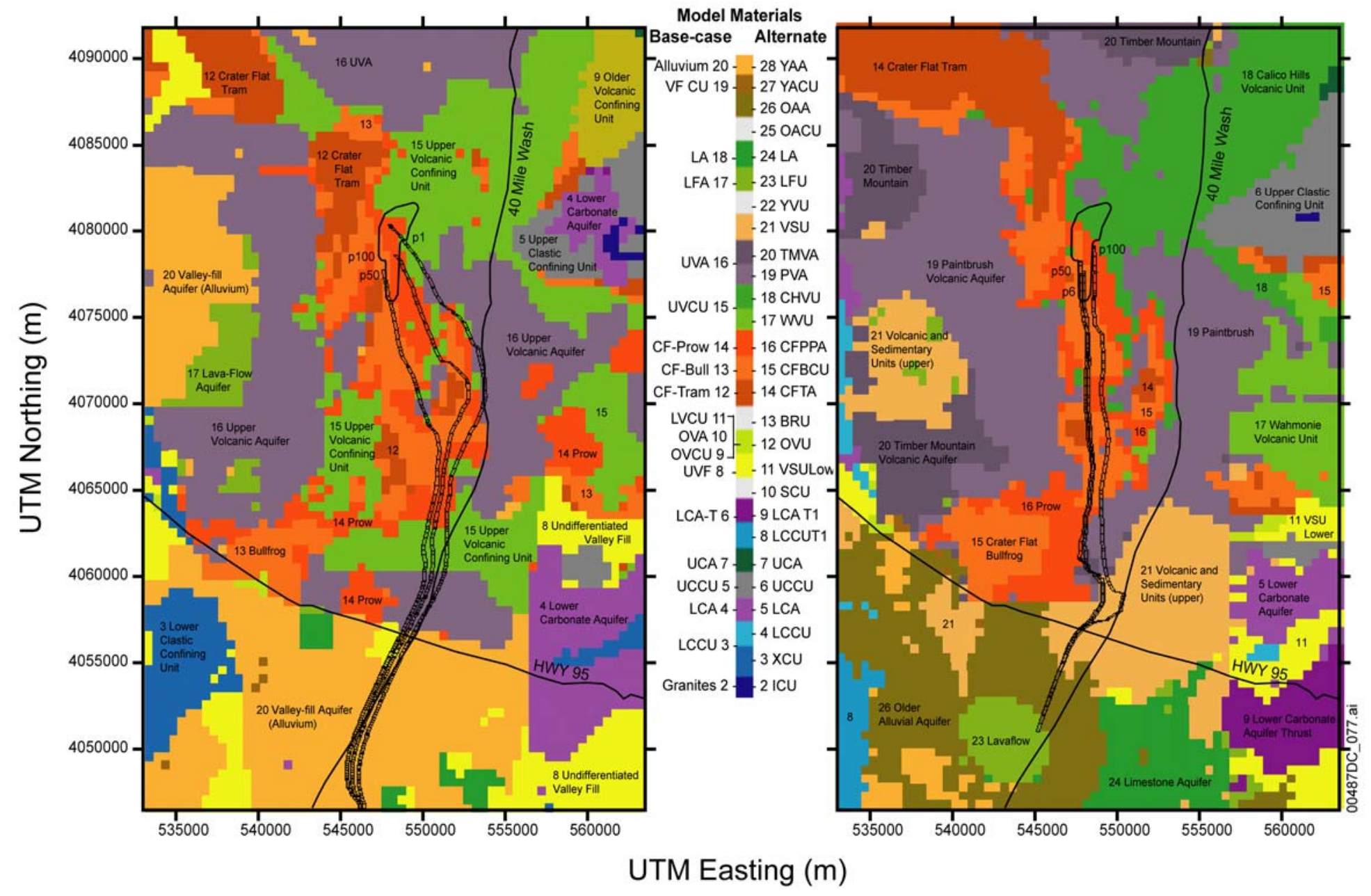

UTM Easting (m)

Source: DTN: GS030208312332.001 (DIRS 163087); DTN: GS021008312332.002 (DIRS 164363).

NOTE: The material units in these two models do not have a one-to-one correlation an approximate relationship is inferred with the color bar and unit names. See also Table 6-3.

UTM = Universal Transverse Mercator

Figure 6-15. Hydrogeology and Selected Particle Paths at the Water Table for Base Case and Alternate Models 


\subsection{Features}

A set of 17 hydrogeologic features was incorporated into the SZ site-scale flow model. In the alternate SZ site-scale flow model, these features have been modified, largely due to changes necessary to incorporate an ACM for the LHG north of Yucca Mountain. The alternative conceptualization, which is referred to as the AWF/GDF conceptualization of the LHG area in Section 6.7.1, has been used in the alternate SZ site-scale flow model. The AWF/GDF conceptualization does not make use of the extensive feature set north of Yucca Mountain, and these have been removed from the model grid, thereby simplifying the grid used in the alternate SZ site-scale flow model. Instead, the hydrogeologic units have been divided into northern and southern zones at the Claim Canyon caldera boundary to represent a zone of hydrothermal alteration in the area of the caldera. Differ permeabilities can be assigned in each zone to each hydrogeologic unit. In addition, a zone has been added to represent the northwest-southeast trending fault zone just north of Yucca Mountain, and features have been added to account for the Ghost Dance fault and the Dune Wash fault. Although there are fewer discrete features in the alternate SZ site-scale flow model than in the SZ site-scale flow model, there are actually a greater number of calibration parameters. This increase in the number of parameters is a result of breaking the hydrogeologic units into northern and southern zones. In addition, the alluvial uncertainty zone has been removed as a feature in the alternate SZ site-scale flow model. The location of each of these features is depicted in Figure 6-16. The gray zones were defined for the SZ site-scale flow model and are described in Table 6-6. The table also describes the colored zones added to represent features in the alternate flow model.

\subsection{Boundary Conditions}

The boundary conditions were established in the alternate SZ site-scale flow model in the same manner as in the SZ site-scale flow model (Section 6-6). Constant head boundaries were established around the periphery of the model at each boundary node. However, in the case of the alternate flow model, the updated 2001 potentiometric surface (BSC 2004 [DIRS 170009]) has been used to identify the water levels specified at each boundary node. Identical to the SZ site-scale flow model, the heads remain constant with depth at each boundary nodal point and, consequently, vertical flow is not allowed along the boundary of the alternate SZ site-scale flow model.

\subsection{Recharge}

Recharge was applied to the top surface of the computational grid as a flux boundary condition in the alternate flow model in a manner to that in the SZ site-scale flow model. However, an updated recharge distribution (DTN: SN0407T0504404.002 [DIRS 170929]) as described in BSC (2004 [DIRS 170015]) has been used in the alternate SZ site-scale flow model. The update recharge distribution results in similar recharge to the alternate SZ site-scale flow model. 

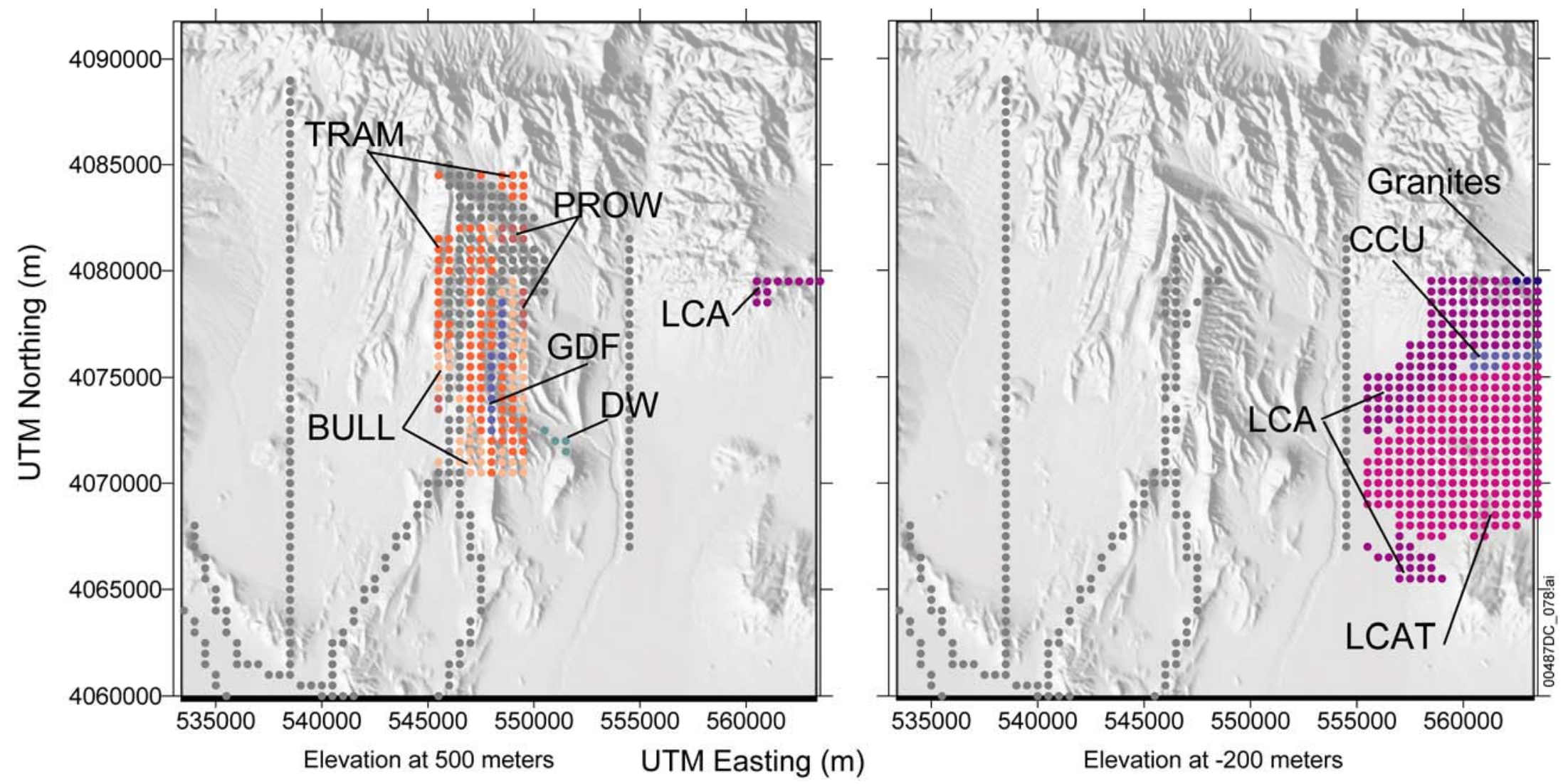

Sources: DTN GS021008312332.002 (DIRS 164363) for HFM-27 (revised HFM) and DTN GS030208312332.001 (DIRS 163087 ) for HFM-19 (base case HFM) The details of implementations are provided in the HFM report (BSC 2004 [DIRS 170008]).

NOTE: $\quad$ SZ model representation of features zoomed in to the area north of $\mathrm{Y}=4060000$. The gray zones were defined for the SZ site-scale flow model and are described in Table 6-6. These colored zones are added to represent features in the alternate flow models and are described in Table 6-6.

SZ = saturated zone; UTM = Universal Transverse Mercator.

Figure 6-16. Geologic Features in the SZ Area for the Alternate Flow Models 


\subsubsection{Calibration of Alternate SZ Site-Scale Flow Model}

The alternate SZ site-scale flow model was calibrated with consideration of the full range of currently available data, including field data for water levels and hydraulic heads, permeability data from field and laboratory tests, locations of known faults and other geologic data, and hydrochemical data. Calibration is the process by which values of important model parameters are estimated and optimized to produce the best fit between the model output and the observed data. Following the same philosophy used to calibrate the SZ site-scale flow model; the alternate SZ site-scale flow model was calibrated to deliver a model that is realistic where data exist and conservative where data are lacking. Besides these objectives, the alternate SZ site-scale flow model was also used to address parameter sensitivity, the impact of the new Nye County water-level data, and the uncertainty in groundwater flux in the model and the propagation of uncertainty from the regional DVRFS to the site scale flow model. A total of five calibrations were necessary to address these issues. The calibration of the alternate flow model was automated using the PEST code in a manner similar to that used during the calibration of the SZ site-scale flow model.

\subsection{Calibration Targets}

In a manner similar to the calibration of the SZ site-scale flow model (Section 6-6), water levels and boundary fluxes were used as calibration targets during the calibration of the alternate SZ site-scale flow model. However, during the alternate SZ site-scale flow model calibration, the water levels used as calibration targets during the SZ site-scale flow model calibration were augmented by new water-level data obtained from wells recently installed as part of the EWDP. The location of these new wells is shown in Figure 6-17. A total of 26 water-level measurements are now available in Nye County, bringing the number of water-level measurements used as targets during the calibration of the alternate SZ site-scale flow model to 130. Uncertainty resulting from the spatial distribution of observation wells is discussed in the hydrogeologic framework model report (BSC 2004 [DIRS 170008]).

Because of the potential importance of flux and fluid path lines on specific discharge (and by inference on radionuclide transport), additional effort is expended on flux targets.

Fluxes around the boundary of the model domain have again been used as calibration targets during the calibration of the alternate SZ site-scale flow model. The fluxes used in the site-scale flow model were based on fluxes derived from the 1997 DVRFS model (D’Agnese et al. 1997 [DIRS 100131]). However, since 1997, the DVRFS model has been updated and undergone significant improvements, including an increased resolution in the vertical dimension, with the number of vertical layers increasing from 3 in the 1997 model to 15 in the updated 2001 DVRFS model (D’Agnese et al. 2002 [DIRS 158876]). In addition, the 1997 DVFRS model used a concept of permeability classes, while node-specific values of permeability are assigned in the updated DVRFS model. Due to these and other enhancements, the updated 2001 DVRFS model offers improved estimates of fluxes along the boundary of the SZ site-scale flow model and has been used to establish boundary flux targets for the alternate SZ site-scale flow model. A comparison of the boundary fluxes used in the SZ site-scale flow model and alternate SZ site-scale flow models is presented in Section 6.4.6.4. 
As shown in Section 6.4.6.4, the flux targets have changed from the SZ site-scale flow model to the alternate SZ site-scale flow model. The biggest differences occur on the east and west sides of the SZ site-scale flow model. In particular, the thrust zone in the southeastern corner of the model has been removed in D'Agnese et al. (2002 [DIRS 158876]). As a result, the flux target has decreased from $-555 \mathrm{~kg} / \mathrm{s}\left(-1.8 \times 10^{7} \mathrm{~m}^{3} / \mathrm{yr}\right)$ to $-69.7 \mathrm{~kg} / \mathrm{s}\left(-2.2 \times 10^{6} \mathrm{~m}^{3} / \mathrm{yr}\right)$ in the southern-most zone on the eastern boundary. Overall, the flow out of the southern boundary in the alternate SZ site-scale flow model is approximately one-half (430/918) of the flux in the SZ site-scale flow model. The large differences in the flux targets can be traced to the evolution of the DVRFS model.

At the time the SZ site-scale flow model was developed and calibrated, the DVRFS model consisted of three vertical layers (D'Agnese et al. 1997 [DIRS 100131]). The SZ site-scale flow model had 39 vertical layers. This fact, and the fact that the HFMs used to generate the 1997 DVRFS and the SZ site-scale flow models were different, made it difficult to match flux targets in the SZ site-scale flow model. For example, on the southwestern side of the SZ site-scale flow model, the SZ site-scale flow model HFM showed a large quantity of clastic confining material that made it difficult to match the $-71 \mathrm{~kg} / \mathrm{s}\left(-2.2 \times 10^{6} \mathrm{~m}^{3} / \mathrm{yr}\right)$ (west boundary, SZ site-scale flow model) derived from the regional model. The vertical resolution of the DVRFS model (D'Agnese et al. 2002 [DIRS 158876]) has now increased dramatically, and the HFMs used in the site-scale and regional flow models are now much closer. It is also important to note, however, that the HFM-27 has undergone considerable checking and revision, resulting in changes in the HFM-27 in the areas of upper and lower Fortymile Wash that may affect flows within the SZ site-scale flow model. Despite these differences, the flux targets listed in Section 6.4.6.4 for the alternate flow model should be more realistic and, consequently, more achievable than those for the SZ site-scale flow model because the regional and site-scale HFMs are more compatible. The eastern boundary fluxes were extracted at 563,000 meters instead of the model boundary of 563,500 meters. This is 500 meters west of the actual model boundary. The error in the fluxes boundary value caused by the offset is proportional to the change in gradient between the two locations. A visual examination of the potentiometric surface indicates small gradient variation between the two locations. The boundary flux error is within the uncertainty in the boundary flux that was investigated.

In order to address uncertainty in flow path lines due to uncertainty in the boundary fluxes, different arrangement of flux targets were investigated in the calibrations (Table 6-5). The uncertainty was addressed by using the changes in the fluxes derived from the DVRFS as surrogates for the flux uncertainty. 


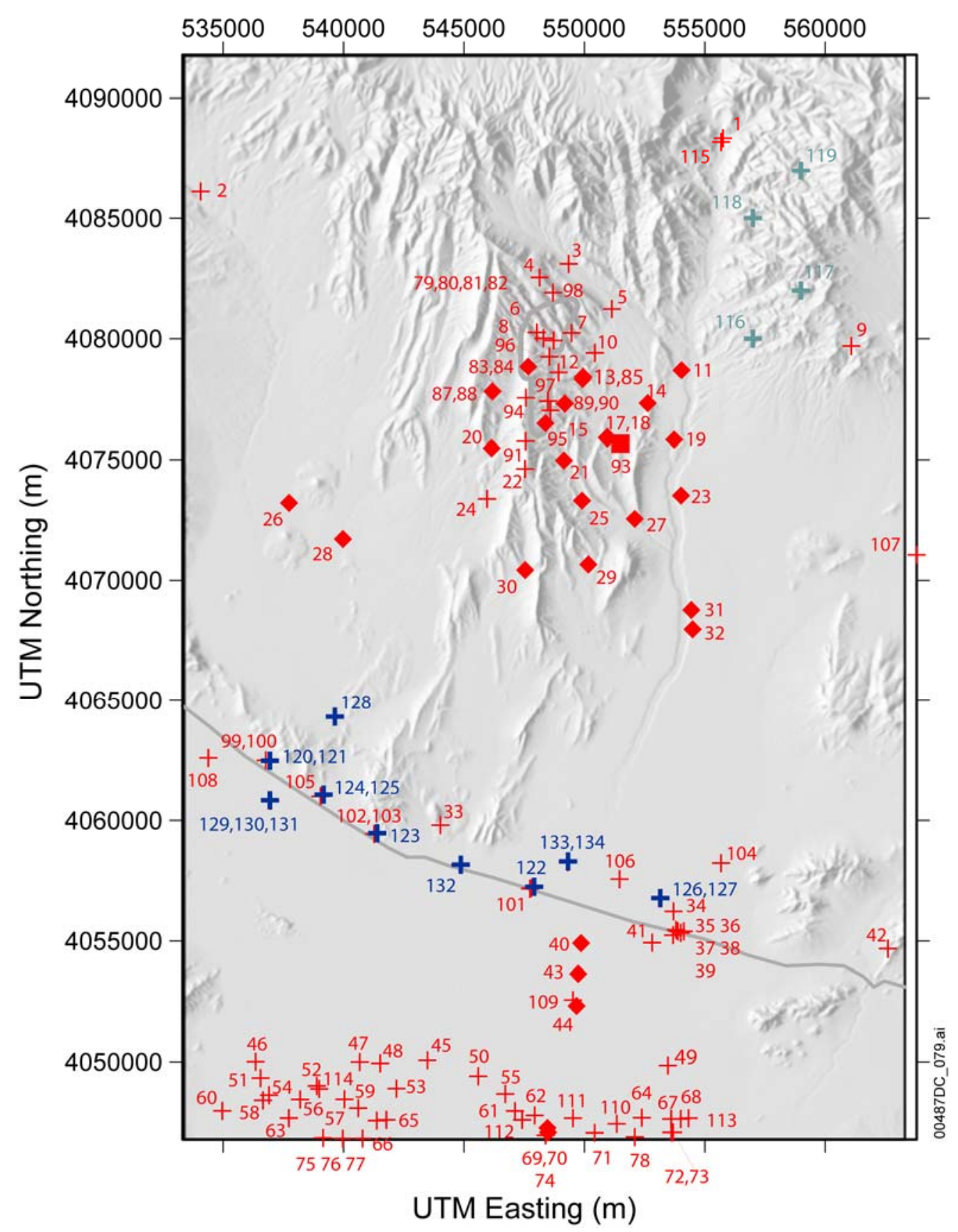

Source DTN: GS010908312332.002 (DIRS 163555).

NOTE: Numbers in the figure refer to the well numbers listed in the second column of Table 6-7 Red symbols are wells used for the SZ site-scale flow model. Wells added to the Alternate flow models are the green Northeast constraining wells, and blue Nye-County wells (phase 1 and 2) numbers 120 to 134 . The crosses indicate weights of 1 , diamonds are weights 4 and 9, and the square at well 93 is weight 10.

UTM = Universal Transverse Mercator.

Figure 6-17. Location and Weights of Observation Wells for SZ Site-Scale Flow Model and Alternate Flow Models 
Table 6-5. Alternate SZ Site-Scale Flow Models Descriptions

\begin{tabular}{|l|l|l|l|l|l|l|}
\hline \multicolumn{1}{|c|}{ Flow Model } & \multicolumn{1}{c|}{ Base Case } & \multicolumn{1}{c|}{ AM0 } & \multicolumn{1}{c|}{ AM1 } & \multicolumn{1}{c|}{ AM2 } & \multicolumn{1}{c|}{ AM3 } & \multicolumn{1}{c|}{ AM4 } \\
\hline $\begin{array}{l}\text { Nye County Wells } \\
\text { Used in Calibration }\end{array}$ & HFM-19 & \multicolumn{1}{c|}{ HFM-27 } & \multicolumn{1}{c|}{ HFM-27 } & \multicolumn{1}{c|}{ HFM-27 } & \multicolumn{1}{c|}{ HFM-27 } & \multicolumn{1}{c|}{ HFM-27 } \\
\hline $\begin{array}{l}\text { Boundary Flux, } \\
\text { single or multiple } \\
\text { targets per side }\end{array}$ & Multiple & Yes & No & Yes & Yes & Yes \\
\hline Boundary Flux & $\begin{array}{l}\text { Table 6-12 } \\
\text { values }\end{array}$ & $\begin{array}{l}\text { Table 6-12 } \\
\text { values }\end{array}$ & $\begin{array}{l}\text { Table 6-12 } \\
\text { values, }\end{array}$ & $\begin{array}{l}\text { Table 6-12 } \\
\text { values, }\end{array}$ & $\begin{array}{l}\text { Table 6-12 } \\
\text { values } \\
\text { except west } \\
\text { side target } \\
\text { of -119 } \mathrm{kg} / \mathrm{s}\end{array}$ & $\begin{array}{l}\text { Table 6-12 } \\
\text { values } \\
\text { except east } \\
\text { side target } \\
\text { of -96 kg/s }\end{array}$ \\
\hline
\end{tabular}

Sources: DTNs: GS021008312332.002 (DIRS 164363) for HFM-27 (alternate conceptual models HFM) and GS030208312332.001 (DIRS 163087) for HFM-19 (base case HFM). The details of the HFM implementations are provided in the HFM (BSC 2004 [DIRS 170008]).

$\mathrm{AM}=$ alternate model; HFM = hydrogeologic framework model.

AM0 Alternate Site-Scale Flow Model 0: This model is the standard in which the fluxes listed in Section 6.4.6.4 are used for the alternate SZ site-scale flow model. There is one major difference. Instead of using the spatially distributed zones listed in the table, the fluxes on each side boundary were summed and used as a single target for each side. This was justified by the very large uncertainty and differences in gridding. The multiple flux target model is evaluated in alternate flow model 2.

AM1 Alternate Site-Scale Flow Model 1, Nye County Targets: This model is the same as AM0, however it does not use the 15 new Nye County well water levels that were available after the SZ site-scale flow model was created. It quantifies how these additional data affect the alternate flow model (by comparison to AM0) and by inference, the SZ site-scale flow model.

AM2 Alternate Site-Scale Flow Model 2, Multiple Flux Targets: This model is the same as AM0, only it uses the distributed flux targets given in Section 6.4.6.4. This calibration distinguishes the differences between one per side flux targets of AM0 and the multiple targets of this calibration.

AM3 Alternate Site-Scale Flow Model 3, West Flux Changed: The SZ site-scale flow model did not use flux targets on the west side because of differences between the site HFM and regional HFM. We note here that the flux changed from $-119 \mathrm{~kg} / \mathrm{s}$ (in) to $125 \mathrm{~kg} / \mathrm{s}$ (out), a change of 200 percent. This fact necessitated the exploration of flux uncertainty on the west side. AM3 uses a flux target on the west side of $-11 \mathrm{~kg} / \mathrm{s}$ instead of $125 \mathrm{~kg} / \mathrm{s}$ that is used on AM0.

AM4 Alternate Site-Scale Flow Model 4, Small East Flux: The flux on the east side has potentially a large impact on the flow path lines since the SZ site-scale flow model has path lines (starting from the repository) that traverse parts of Fortymile Wash. This alternate flow model uses a flux target of $-96 \mathrm{~kg} / \mathrm{s}$ instead of the $-209 \mathrm{~kg} / \mathrm{s}$. 
Figure 6-17 shows the wells used for the calibration targets of the alternate flow model. In the figure, the Nye County targets are highlighted. Section 6.4.6.4 summarizes the flux targets for each of the alternate flow model calibrations.

As was the case for the SZ site-scale flow model, calibration targets along the potential flow path are given higher weights. However, in the alternate flow model moderate gradient wells, and those in lower Fortymile Wash, if they were along the flow path, were given higher weights as well as the low gradient wells (which were the only higher-weighted wells in the SZ site-scale flow model). Other weightings were similar to the SZ site-scale flow model, DTN: GS010908312332.001 [DIRS 163087] (see Section 6.6.1.3).

The higher weights were given to wells that were thought to be in the possible flow path. The weighting was changed between the base case and the alternate flow models AM0 and AM4 largely because of additional data collected from the Nye county wells. More wells were added by Nye County along the projected "flow path".

\subsection{Calibration Parameters}

In a manner similar to the SZ site-scale flow model (Section 6-6), permeability was optimized during calibration of the alternate SZ site-scale flow model. Permeability zones were created for hydrogeologic units identified in HFM-27 and for specific hydrogeologic features established in the model. In the SZ site-scale flow model, a permeability zone was established for each hydrogeologic unit, with the exception of the basal unit that served as a lower boundary for the model. The permeability parameters used in the alternate SZ site-scale flow models are those described in Section 6.4.1, on the LHG ACM. The alternate SZ site-scale flow model also uses additional zones and features for purposes of calibration and exploration of flow path line uncertainty. These are summarized below.

- A permeability zone was created for each hydrogeologic unit present in the Claim Canyon caldera to allow for modifying unit permeabilities in this area. This modification was necessary to implement the ACM used to simulate the LHG area in the north of the model domain (see Section 6.4.6.2.4).

- A permeability zone was created for each member of the Crater Flat group (Tram, Bullfrog, and Prow Pass) near Yucca Mountain. This modification was used to explore spatial differences in this hydrogeologic group between the low head gradient area east of Yucca Mountain and the Yucca Mountain area itself.

- Permeability zones were created for several of the deeper units near the east side of the SZ site-scale flow model. The affected units are the intrusive (granitic confining), lower carbonate, lower clastic, and lower carbonate thrust. These zones were created in order to study flux uncertainty on the east boundary of the site model.

It should also be noted that the alluvial uncertainty zone, an important zone in SZ site-scale flow model, has been removed for the alternate SZ site-scale flow model. The rationale for using the zone, an inability of HFM-19 to represent the hydrogeology near the Alluvial Testing Complex, has been corrected. 
Upper and lower bounds were placed on each permeability variable during parameter optimization, as occurred in the SZ site-scale flow model. The upper and lower bounds for the permeabilities and permeability multipliers were chosen to reflect maximum and minimum field values (permeability) or a reasonably realistic range of values (permeability multipliers). These limits reflected all data available at the time of model calibration, including new permeability data obtained since the calibration of the SZ site-scale flow model. A list of permeability zones, including the parameter type assigned to each zone, the upper and lower bounds specified for the parameter, and an identification of the parameters optimized during calibration, is provided in Table 6-8. In a manner similar to the SZ site-scale flow model, the vertical anisotropy was assigned a value of 10:1 (horizontal to vertical) in the volcanic and valley-fill units in the alternate SZ site-scale flow model. The location of each of these features is depicted in Figure 6-16. The gray zones were defined for the site-scale flow model and are described in Table 6-6. The table also describes the colored zones added to represent features in the alternate flow models.

Table 6-6. Hydrological Features in the SZ Alternate Flow Model

\begin{tabular}{|c|c|c|c|}
\hline $\begin{array}{c}\text { Feature Name and } \\
\text { Description }\end{array}$ & $\begin{array}{c}\text { Geometric Definition } \\
\text { (x, y UTM meters, } \\
\text { z, elevation above msl, meters) }\end{array}$ & $\begin{array}{c}\text { Hydrogeological } \\
\text { Characteristics }\end{array}$ & Impact on Model \\
\hline $\begin{array}{l}\text { 1. Eastern Flux } \\
\text { Zone } \\
\text { This region } \\
\text { adjacent to the } \\
\text { eastern boundary } \\
\text { allows the } \\
\text { properties of some } \\
\text { of the regional } \\
\text { hydrogeologic units } \\
\text { to vary spatially. }\end{array}$ & $\begin{array}{l}x \min =555000 \\
x \max =563500 \\
y \min =4065000 \\
y \max =4080000 \\
z=\text { entire model }\end{array}$ & $\begin{array}{l}\text { This zone affects the flux } \\
\text { entering the model on the } \\
\text { east side. }\end{array}$ & $\begin{array}{l}\text { Although it does not } \\
\text { strongly influence the flow } \\
\text { model, it is expected to be } \\
\text { important to performance } \\
\text { assessment calculations } \\
\text { due to its effect on solute } \\
\text { transport. }\end{array}$ \\
\hline $\begin{array}{l}\text { 2. Yucca } \\
\text { Mountain Crater } \\
\text { Flat Zone } \\
\text { Due to different } \\
\text { geologic } \\
\text { environments near } \\
\text { Yucca Mountain } \\
\text { and removed from } \\
\text { Yucca Mountain. } \\
\text { The Tram, Bullfrog, } \\
\text { and Prow Pass } \\
\text { units are allowed } \\
\text { different parameter } \\
\text { values near Yucca } \\
\text { Mountain. }\end{array}$ & $\begin{array}{l}x \min =544000 \\
x \max =548000 \\
y \min =4070000 \\
y \max =4085000 \\
z=\text { entire model }\end{array}$ & $\begin{array}{l}\text { These parameters are } \\
\text { important to flow near } \\
\text { Yucca Mountain. }\end{array}$ & $\begin{array}{l}\text { It allows representation of } \\
\text { permeability near Yucca } \\
\text { Mountain that may be } \\
\text { different from other areas of } \\
\text { the site scale model. }\end{array}$ \\
\hline $\begin{array}{l}\text { 3.Dune Wash } \\
\text { Fault } \\
\text { This fault is } \\
\text { potentially } \\
\text { important to flow } \\
\text { near Yucca } \\
\text { Mountain. }\end{array}$ & $\begin{array}{l}x \min =548800 \\
x \max =551400 \\
y \min =4076000 \\
y \max =4072000 \\
z \min =400 \\
z \max =\text { top of model }\end{array}$ & $\begin{array}{l}\text { Possible control of fluid } \\
\text { pathways near Yucca } \\
\text { Mountain. }\end{array}$ & $\begin{array}{l}\text { Fault is a possible } \\
\text { preferential flow path. }\end{array}$ \\
\hline
\end{tabular}


Table 6-6. Hydrological Features in the SZ Alternate Flow Model (Continued)

\begin{tabular}{|c|c|c|c|}
\hline $\begin{array}{c}\text { Feature Name and } \\
\text { Description }\end{array}$ & $\begin{array}{c}\text { Geometric Definition } \\
\text { (x, y UTM meters, } \\
\text { z, elevation above msl, meters) }\end{array}$ & $\begin{array}{l}\text { Hydrogeological } \\
\text { Characteristics }\end{array}$ & Impact on Model \\
\hline $\begin{array}{l}\text { 4.Ghost Dance } \\
\text { Fault } \\
\text { Linear feature that } \\
\text { intersects the } \\
\text { repository area. }\end{array}$ & $\begin{array}{l}x \min =547960 \\
x \max =548210 \\
y \min =4072000 \\
y \max =4080000 \\
z \min =400 \\
z \max =\text { top of model }\end{array}$ & $\begin{array}{l}\text { Control of fluid pathways } \\
\text { near the repository. }\end{array}$ & $\begin{array}{l}\text { Fault is a possible } \\
\text { preferential flow path. }\end{array}$ \\
\hline
\end{tabular}

Source for these data is: DTN GS021008312332.002 [DIRS 164363] for HFM-27 (alternate conceptual models HFM). The details of implementations are provided in BSC (2004 [170008]).

NOTE: $\mathrm{msl}=$ mean sea level; UTM = Universal Transverse Mercator

\subsection{Calibration Results: Heads and Fluxes}

Calibrations were achieved for all alternate SZ site-scale flow models (AM0, AM1, AM2, AM3, and AM4). The calibration results are presented in Table 6-7 for the head comparisons and Table 6-12 for the boundary flux comparisons. Ten target observations that fall above the simulated water table are noted in Table 6-7. Because of the fine resolution of the grid at the water table, the elevations of these points fall above the water table and therefore were eliminated from use as calibration targets. These observation points are located next to other observation points used as calibration targets; therefore, their elimination did not diminish the accuracy of the calibration. The SZ site-scale flow model assigned these target positions to the top layer of the model.

Table 6-7. Calibration Results: Observed Water-Level Elevation vs. Calibrated Head for Alternate SZ Site-Scale Flow Models AM0, AM1, AM2, AM3, and AM4

\begin{tabular}{|l|l|l|l|l|l|l|l|}
\hline \multicolumn{1}{|c|}{ Site Name } & $\begin{array}{c}\text { Well } \\
\text { Number }\end{array}$ & $\begin{array}{c}\text { Water } \\
\text { Level } \\
(\mathbf{m})\end{array}$ & $\begin{array}{c}\text { Head } \\
\text { Model } \\
\text { AM0 }(\mathbf{m})\end{array}$ & $\begin{array}{c}\text { Head } \\
\text { Model } \\
\text { AM1 }(\mathbf{m})\end{array}$ & $\begin{array}{c}\text { Head } \\
\text { Model } \\
\text { AM2 }(\mathbf{m})\end{array}$ & $\begin{array}{c}\text { Head } \\
\text { Model } \\
\text { AM3 }(\mathbf{m})\end{array}$ & $\begin{array}{c}\text { Head } \\
\text { Model } \\
\text { AM4 (m) }\end{array}$ \\
\hline UE-29 a \#2 & 1 & 1187.7 & 1249.24 & 1251.17 & 1226.44 & 1243.7 & 1240.59 \\
\hline GEXA Well 4 & 2 & 1008 & 1005.72 & 1005.69 & 1001.38 & 1008.33 & 1009.37 \\
\hline UE-25 WT\#6 & 3 & 1034.6 & 740.68 & 741.33 & 749.84 & 747.35 & 747.73 \\
\hline USW G-2 & 4 & 1020.2 & 748.26 & 749.45 & 753.93 & 756.1 & 753.99 \\
\hline UE-25 WT \#16 & 5 & 738.3 & 735.74 & 735.93 & 741.07 & 740.24 & 740.57 \\
\hline USW UZ-14 & 6 & 779 & AWT & AWT & AWT & AWT & AWT \\
\hline UE-25 WT \#18 & 7 & 730.8 & 735.88 & 736.29 & 737.22 & 738.94 & 738.04 \\
\hline USW G-1 & 8 & 754.2 & 749.96 & 750.75 & 750.93 & 754.06 & 751.07 \\
\hline UE-25 a \#3 & 9 & 748.3 & 750.16 & 749.93 & 750.21 & 751.99 & 749.84 \\
\hline UE-25 WT \#4 & 10 & 730.8 & 732.53 & 732.68 & 734.7 & 735.08 & 734.51 \\
\hline UE-25 WT \#15 & 11 & 729.2 & 729.65 & 729.53 & 729.76 & 730.08 & 729.34 \\
\hline USW G-4 & 12 & 730.6 & 729.88 & 729.91 & 729.83 & 730.79 & 729.87 \\
\hline UE-25 a \#1 & 13 & 731 & 730.09 & 730.12 & 730.33 & 731.19 & 730.25 \\
\hline UE-25 WT \#14 & 14 & 729.7 & 729.7 & 729.63 & 729.96 & 730.42 & 729.71 \\
\hline
\end{tabular}


Table 6-7. Calibration Results: Observed Water-Level Elevation vs. Calibrated Head for Alternate SZ Site-Scale Flow Models AM0, AM1, AM2, AM3, and AM4 (Continued)

\begin{tabular}{|c|c|c|c|c|c|c|c|}
\hline Site Name & $\begin{array}{c}\text { Well } \\
\text { Number }\end{array}$ & $\begin{array}{c}\text { Water } \\
\text { Level } \\
(\mathrm{m})\end{array}$ & $\begin{array}{c}\text { Head } \\
\text { Model } \\
\text { AM0 }(\mathrm{m}) \\
\end{array}$ & $\begin{array}{c}\text { Head } \\
\text { Model } \\
\text { AM1 }(\mathrm{m}) \\
\end{array}$ & $\begin{array}{c}\text { Head } \\
\text { Model } \\
\text { AM2 }(\mathrm{m}) \\
\end{array}$ & $\begin{array}{c}\text { Head } \\
\text { Model } \\
\text { AM3 }(\mathrm{m}) \\
\end{array}$ & $\begin{array}{c}\text { Head } \\
\text { Model } \\
\text { AM4 }(\mathrm{m}) \\
\end{array}$ \\
\hline USW WT-2 & 15 & 730.6 & 729.7 & 729.71 & 729.61 & 730.6 & 729.75 \\
\hline UE-25 c \#1 & 16 & 730.3 & $729.62^{a}$ & $729.59^{a}$ & $729.77^{\mathrm{a}}$ & $730.51^{\mathrm{a}}$ & $729.81^{a}$ \\
\hline UE-25 c \#3 & 17 & 730.3 & $729.62^{a}$ & $729.59^{a}$ & $729.77^{\mathrm{a}}$ & $730.51^{a}$ & $729.81^{a}$ \\
\hline UE-25 c \#2 & 18 & 730.2 & 729.62 & 729.58 & 729.77 & 730.51 & 729.8 \\
\hline UE-25 WT \#13 & 19 & 729.1 & 729.53 & 729.42 & 729.6 & 730 & 729.3 \\
\hline USW WT-7 & 20 & 775.8 & 778.79 & 780.17 & 779.59 & 785.39 & 779.49 \\
\hline USW WT-1 & 21 & 730.4 & 729.47 & 729.42 & 729.57 & 730.34 & 729.59 \\
\hline USW G-3 & 22 & 730.5 & 730.06 & 730.04 & 730.08 & 730.97 & 730.28 \\
\hline UE-25 J-13 & 23 & 728.4 & 729.31 & 729.22 & 729.34 & 729.84 & 729.22 \\
\hline USW WT-10 & 24 & 776 & 771.23 & 772.85 & 772.67 & 779.35 & 772.03 \\
\hline UE-25 WT \#17 & 25 & 729.7 & 729.12 & 729.03 & 729.25 & 729.88 & 729.34 \\
\hline USW VH-2 & 26 & 810.5 & 806.09 & 807.6 & 807.5 & 810.68 & 808.49 \\
\hline UE-25 WT \#3 & 27 & 729.6 & 729.08 & 728.97 & 729.16 & 729.63 & 729.03 \\
\hline USW VH-1 & 28 & 779.4 & 775.93 & 777.42 & 776.42 & 784.9 & 775.4 \\
\hline UE-25 WT \#12 & 29 & 729.5 & 728.48 & 728.33 & 728.66 & 729.07 & 728.61 \\
\hline USW WT-11 & 30 & 730.7 & 728.46 & 728.27 & 728.82 & 729.21 & 728.95 \\
\hline UE-25 J-12 & 31 & 727.9 & 729.01 & 728.93 & 728.99 & 729.38 & 728.81 \\
\hline UE-25 JF \#3 & 32 & 727.8 & 728.94 & 728.87 & 728.92 & 729.29 & 728.73 \\
\hline Cind-R-Lite Well & 33 & 729.8 & 720.51 & 719.29 & 718.22 & 721.79 & 721.24 \\
\hline Ben Bossingham & 34 & 718.4 & 715.46 & 715.32 & 712.73 & 714.34 & 712.97 \\
\hline Fred Cobb & 35 & 702.8 & $710.47^{\mathrm{a}}$ & $710.42^{\mathrm{a}}$ & $709.26^{a}$ & $710.03^{a}$ & $709.49^{a}$ \\
\hline Bob Whellock & 36 & 704.1 & $710.47^{\mathrm{a}}$ & $710.42^{a}$ & $709.26^{a}$ & $710.03^{\mathrm{a}}$ & $709.49^{a}$ \\
\hline Louise Pereidra & 37 & 705.6 & 710.5 & 710.46 & 709.28 & 710.06 & 709.52 \\
\hline Joe Richards & 38 & 701.7 & 710.47 & 710.42 & 709.26 & 710.03 & 709.49 \\
\hline NDOT Well & 39 & 705.3 & 713.8 & 713.67 & 711.76 & 713.1 & 711.87 \\
\hline James H. Shaw & 40 & 706.7 & 708.48 & 708.4 & 708.56 & 709.2 & 708.25 \\
\hline Airport Well & 41 & 705.5 & 713.57 & 713.44 & 711.61 & 712.93 & 711.71 \\
\hline TW-5 & 42 & 725.1 & 722.08 & 722.08 & 722.06 & 722.08 & 722.06 \\
\hline Richard Washburn & 43 & 707.7 & 705.14 & 705.05 & 705.27 & 705.73 & 705.14 \\
\hline Richard Washburn & 44 & 704.4 & 703.81 & 703.71 & 703.78 & 704.24 & 703.79 \\
\hline $\begin{array}{l}\text { Nye County } \\
\text { Develop. Co. }\end{array}$ & 45 & 694.4 & 697.47 & 697.37 & 697.38 & 697.56 & 697.57 \\
\hline Fred Wooldridge & 46 & 691.9 & 699.66 & 699.38 & 699.67 & 699.58 & 700.65 \\
\hline Fred J. Keefe & 47 & 694.3 & 698.53 & 698.37 & 698.92 & 698.75 & 699.33 \\
\hline Leslie Nickels & 48 & 694.4 & 698.07 & 697.92 & 698.29 & 698.27 & 698.65 \\
\hline L. Mason & 49 & 722.1 & 711.55 & 711.52 & 711.22 & 711.47 & 711.19 \\
\hline Unknown & 50 & 697.8 & 697.45 & 697.36 & 697.19 & 697.43 & 697.38 \\
\hline Davidson Well & 51 & 690.2 & 698.36 & 698.12 & 698.37 & 698.3 & 699.21 \\
\hline $\begin{array}{l}\text { Eugene J. } \\
\text { Mankinen }\end{array}$ & 52 & 707.4 & 698.22 & 698.04 & 698.4 & 698.3 & 698.98 \\
\hline Donald O. Heath & 53 & 698.1 & 696.51 & 696.38 & 696.39 & 696.62 & 696.65 \\
\hline Elvis Kelley & 54 & 691 & 695.68 & 695.53 & 695.68 & 695.65 & 696.21 \\
\hline
\end{tabular}


Table 6-7. Calibration Results: Observed Water-Level Elevation vs. Calibrated Head for Alternate SZ Site-Scale Flow Models AM0, AM1, AM2, AM3, and AM4 (Continued)

\begin{tabular}{|c|c|c|c|c|c|c|c|}
\hline Site Name & $\begin{array}{c}\text { Well } \\
\text { Number }\end{array}$ & $\begin{array}{l}\text { Water } \\
\text { Level } \\
(\mathrm{m})\end{array}$ & $\begin{array}{c}\text { Head } \\
\text { Model } \\
\text { AM0 }(\mathrm{m})\end{array}$ & $\begin{array}{c}\text { Head } \\
\text { Model } \\
\text { AM1 }(\mathrm{m}) \\
\end{array}$ & $\begin{array}{c}\text { Head } \\
\text { Model } \\
\text { AM2 }(\mathrm{m}) \\
\end{array}$ & $\begin{array}{c}\text { Head } \\
\text { Model } \\
\text { AM3 (m) }\end{array}$ & $\begin{array}{c}\text { Head } \\
\text { Model } \\
\text { AM4 (m) }\end{array}$ \\
\hline Manuel Rodela & 55 & 693.6 & 696.16 & 696.07 & 695.72 & 695.96 & 695.94 \\
\hline $\begin{array}{l}\text { Charles C. DeFir } \\
\text { Jr. }\end{array}$ & 56 & 706.9 & 696.46 & 696.3 & 696.5 & 696.45 & 697 \\
\hline William R. Monroe & 57 & 699 & 696.79 & 696.67 & 696.86 & 696.86 & 697.19 \\
\hline DeFir Well & 58 & 691.3 & 695.31 & 695.15 & 695.28 & 695.26 & 695.82 \\
\hline Edwin H. Mankinen & 59 & 695.2 & 695.69 & 695.61 & 695.68 & 695.72 & 695.88 \\
\hline Bill Strickland & 60 & 689.2 & 691.31 & 691.18 & 690.84 & 691.1 & 691.26 \\
\hline M. Meese & 61 & 686.4 & 695.37 & 695.29 & 694.84 & 695.08 & 695.07 \\
\hline Theo E. Selbach & 62 & 696.2 & 695.62 & 695.54 & 695.1 & 695.34 & 695.33 \\
\hline C.L. Caldwell & 63 & 691.4 & 693.58 & 693.5 & 693.57 & 693.56 & 693.82 \\
\hline Leonard Siegel & 64 & 709 & 709.26 & 709.25 & 709.18 & 709.24 & 709.18 \\
\hline James K. Pierce & 65 & 690.4 & 694.4 & 694.34 & 694.09 & 694.24 & 694.26 \\
\hline James K. Pierce & 66 & 705.7 & 694.29 & 694.23 & 694.08 & 694.2 & 694.2 \\
\hline Cooks West Well & 67 & 717.2 & 712.79 & 712.78 & 712.71 & 712.77 & 712.69 \\
\hline Cooks East Well & 68 & 718.8 & 713.53 & 713.52 & 713.44 & 713.5 & 713.42 \\
\hline $\begin{array}{l}\text { Nye County Land } \\
\text { Co. }\end{array}$ & 69 & 690.1 & AWT & AWT & AWT & AWT & AWT \\
\hline $\begin{array}{l}\text { Amargosa Town } \\
\text { Complex }\end{array}$ & 70 & 688.9 & 693.27 & 693.24 & 693.01 & 693.11 & 693.11 \\
\hline $\begin{array}{l}\text { Nye County } \\
\text { Develop. Co. }\end{array}$ & 71 & 691.2 & 697.34 & 697.34 & 697.32 & 697.35 & 697.33 \\
\hline Lewis C. Cook & 72 & 717.4 & 714 & 713.99 & 713.95 & 713.99 & 713.95 \\
\hline Lewis C. Cook & 73 & 714.8 & 714.01 & 714 & 713.96 & 714 & 713.96 \\
\hline $\begin{array}{l}\text { Amargosa Valley } \\
\text { Water }\end{array}$ & 74 & 701.4 & 693.28 & 693.24 & 693.02 & 693.12 & 693.12 \\
\hline Earl N. Selbach & 75 & 696.5 & 694.18 & 694.15 & 694.15 & 694.17 & 694.23 \\
\hline Lewis N. Dansby & 76 & 694.2 & 694.96 & 694.93 & 694.96 & 694.97 & 695.04 \\
\hline $\begin{array}{l}\text { Edwin } \mathrm{H} . \\
\text { Mankinen }\end{array}$ & 77 & 694 & 693.9 & 693.87 & 693.8 & 693.84 & 693.85 \\
\hline Willard Johns & 78 & 699.5 & 705.79 & 705.79 & 705.76 & 705.79 & 705.76 \\
\hline USW H-1 tube 1 & 79 & 785.5 & 752.06 & 752.91 & 752.79 & 757.23 & 753.14 \\
\hline USW H-1 tube 2 & 80 & 736 & 750.03 & 750.85 & 750.9 & 753.89 & 751.02 \\
\hline USW H-1 tube 3 & 81 & 730.6 & 751.41 & 752.45 & 751.63 & 754.44 & 751.82 \\
\hline USW H-1 tube 4 & 82 & 730.9 & 752.34 & 753.51 & 752.19 & 755.06 & 752.47 \\
\hline USW H-5 upper & 83 & 775.5 & 772.63 & 772.7 & 777.69 & 780.09 & 775.16 \\
\hline USW H-5 lower & 84 & 775.6 & 772.71 & 772.76 & 777.97 & 780.15 & 775.23 \\
\hline UE-25 b \#1 lower & 85 & 729.7 & 730.88 & 730.95 & 731.2 & 732.13 & 731.12 \\
\hline UE-25 b \#1 upper & 86 & 730.7 & 730.06 & 730.12 & 730.18 & 731.16 & 730.21 \\
\hline USW H-6 upper & 87 & 776 & 773.26 & 774.42 & 775.7 & 781.52 & 774.04 \\
\hline USW H-6 lower & 88 & 775.9 & 771.99 & 773.07 & 774.46 & 779.96 & 772.79 \\
\hline USW H-4 upper & 89 & 730.4 & 729.77 & 729.79 & 729.67 & 730.69 & 729.79 \\
\hline USW H-4 lower & 90 & 730.5 & 732.58 & 732.62 & 733.03 & 733.89 & 732.67 \\
\hline USW H-3 upper & 91 & 731.5 & 729.57 & 729.56 & 729.48 & 730.44 & 729.66 \\
\hline
\end{tabular}


Table 6-7. Calibration Results: Observed Water-Level Elevation vs. Calibrated Head for Alternate SZ Site-Scale Flow Models AM0, AM1, AM2, AM3, and AM4 (Continued)

\begin{tabular}{|c|c|c|c|c|c|c|c|}
\hline Site Name & $\begin{array}{c}\text { Well } \\
\text { Number }\end{array}$ & $\begin{array}{c}\text { Water } \\
\text { Level } \\
(\mathrm{m})\end{array}$ & $\begin{array}{c}\text { Head } \\
\text { Model } \\
\text { AM0 }(\mathrm{m}) \\
\end{array}$ & $\begin{array}{c}\text { Head } \\
\text { Model } \\
\text { AM1 }(\mathrm{m}) \\
\end{array}$ & $\begin{array}{c}\text { Head } \\
\text { Model } \\
\text { AM2 }(\mathrm{m}) \\
\end{array}$ & $\begin{array}{c}\text { Head } \\
\text { Model } \\
\text { AM3 (m) }\end{array}$ & $\begin{array}{c}\text { Head } \\
\text { Model } \\
\text { AM4 (m) }\end{array}$ \\
\hline USW H-3 lower & 92 & 755.9 & 730.61 & 730.64 & 730.58 & 731.6 & 730.75 \\
\hline $\begin{array}{l}\text { UE-25 p \#1 (Lwr } \\
\text { Intrvl) }\end{array}$ & 93 & 752.4 & 752.26 & 752.29 & 752.47 & 753.31 & 752.41 \\
\hline USW & 94 & 731.2 & 729.77 & 729.77 & 729.67 & 730.62 & 729.77 \\
\hline USW SD-7 & 95 & 727.6 & 729.65 & 729.65 & 729.58 & 730.54 & 729.72 \\
\hline USW SD-9 & 96 & 731.1 & 743.47 & 744.3 & 742.86 & 744.32 & 742.28 \\
\hline USW SD-12 & 97 & 730 & 729.74 & 729.76 & 729.64 & 730.65 & 729.77 \\
\hline WT-24 & 98 & 839.8 & 834.14 & 830.07 & 834.12 & 822.91 & 837.54 \\
\hline NC-EWDP-1D & 99 & 785.8 & 793.9 & 796.43 & 781.89 & 797.02 & 784.43 \\
\hline $\begin{array}{l}\text { NC-EWDP-1S } \\
\text { probe } 1\end{array}$ & 100 & 786.7 & 794.8 & 797.03 & 785.59 & 797.8 & 786.29 \\
\hline NC-EWDP-2D & 101 & 706.3 & 707.63 & 707.5 & 707.4 & 708.19 & 707.55 \\
\hline NC-EWDP-3D & 102 & 717.1 & 716.77 & 715.73 & 714.25 & 716.51 & 717.59 \\
\hline $\begin{array}{l}\text { NC-EWDP-3S } \\
\text { probe } 2\end{array}$ & 103 & 718.7 & AWT & AWT & AWT & AWT & AWT \\
\hline NC-EWDP-5SB & 104 & 724.1 & 717.45 & 717.38 & 714.57 & 716.27 & 714.78 \\
\hline $\begin{array}{l}\text { NC-EWDP-9SX } \\
\text { probe } 2\end{array}$ & 105 & 766 & 771.81 & 774.3 & 762.84 & 780.09 & 763.05 \\
\hline NC-Washburn-1X & 106 & 714.6 & 714.96 & 714.79 & 712.36 & 713.94 & 712.56 \\
\hline UE-25 J-11 & 107 & 732.2 & 731.52 & 731.52 & 731.52 & 731.52 & 731.52 \\
\hline BGMW-11 & 108 & 715.9 & 714.56 & 714.35 & 714.3 & 714.34 & 715 \\
\hline Richard Washburn & 109 & 704.1 & AWT & AWT & AWT & AWT & AWT \\
\hline L. Cook & 110 & 713.3 & AWT & AWT & AWT & AWT & AWT \\
\hline Unknown & 111 & 689.5 & AWT & AWT & AWT & AWT & AWT \\
\hline Amargosa Water & 112 & 690.4 & AWT & AWT & AWT & AWT & AWT \\
\hline Lewis C. Cook & 113 & 715.7 & AWT & AWT & AWT & AWT & AWT \\
\hline Unknown & 114 & 690.8 & AWT & AWT & AWT & AWT & AWT \\
\hline USW UZ-N91 & 115 & 1186.8 & 1247.27 & 1249.4 & 1222.65 & 1241.94 & 1239.23 \\
\hline $\begin{array}{l}\text { NC-EWDP- } \\
\text { 1DX,deep }\end{array}$ & 120 & 748.8 & 789.57 & $792.09^{b}$ & 779.16 & 793.01 & 780.62 \\
\hline NC-EWDP-1S,P2 & 121 & 786.8 & 794.81 & $797.03^{b}$ & 785.59 & 797.8 & 786.29 \\
\hline NC-EWDP-2DB & 122 & 713.3 & 712.63 & $712.48^{\mathrm{b}}$ & 711.81 & 712.75 & 712.26 \\
\hline NC-EWDP-3S,P3 & 123 & 719.4 & 715.83 & $714.77^{b}$ & 713.35 & 715.39 & 716.79 \\
\hline NC-EWDP-9SX,P1 & 124 & 766.7 & 771.73 & $774.25^{\mathrm{b}}$ & 762.66 & 780.02 & 762.93 \\
\hline NC-EWDP-9SX,P4 & 125 & 766.8 & 771.9 & $774.37^{b}$ & 763.03 & 780.17 & 763.2 \\
\hline NC-EWDP-4PA & 126 & 717.9 & 716.08 & $715.93^{\mathrm{b}}$ & 713.08 & 714.77 & 713.34 \\
\hline NC-EWDP-4PB & 127 & 723.6 & 716.12 & $715.97^{b}$ & 713.08 & 714.78 & 713.35 \\
\hline NC-EWDP-7S & 128 & 830.1 & AWT & $A W T^{b}$ & AWT & AWT & AWT \\
\hline NC-EWDP-12PA & 129 & 722.9 & 713.82 & $712.32^{\mathrm{b}}$ & 715.11 & 712.5 & 718.64 \\
\hline NC-EWDP-12PB & 130 & 723 & 713.82 & $712.32^{\mathrm{b}}$ & 715.11 & 712.5 & 718.64 \\
\hline NC-EWDP-12PC & 131 & 720.7 & 713.83 & $712.34^{\mathrm{b}}$ & 715.06 & 712.51 & 718.62 \\
\hline NC-EWDP-15P & 132 & 722.5 & AWT & $A W T^{b}$ & AWT & AWT & AWT \\
\hline
\end{tabular}


Table 6-7. Calibration Results: Observed Water-Level Elevation vs. Calibrated Head for Alternate SZ Site-Scale Flow Models AM0, AM1, AM2, AM3, and AM4 (Continued)

\begin{tabular}{|c|c|c|c|c|c|c|c|}
\hline Site Name & $\begin{array}{c}\text { Well } \\
\text { Number }\end{array}$ & $\begin{array}{c}\text { Water } \\
\text { Level } \\
(\mathrm{m})\end{array}$ & $\begin{array}{c}\text { Head } \\
\text { Model } \\
\text { AM0 }(\mathrm{m}) \\
\end{array}$ & $\begin{array}{c}\text { Head } \\
\text { Model } \\
\text { AM1 (m) }\end{array}$ & $\begin{array}{c}\text { Head } \\
\text { Model } \\
\text { AM2 }(\mathrm{m}) \\
\end{array}$ & $\begin{array}{c}\text { Head } \\
\text { Model } \\
\text { AM3 }(\mathrm{m}) \\
\end{array}$ & $\begin{array}{c}\text { Head } \\
\text { Model } \\
\text { AM4 }(\mathrm{m}) \\
\end{array}$ \\
\hline NC-EWDP-19P & 133 & 707.5 & 713.64 & $713.48^{\mathrm{b}}$ & 711.58 & 713.19 & 712.1 \\
\hline NC-EWDP-19D & 134 & 712.8 & 713.87 & $713.72^{b}$ & 711.89 & 713.42 & 712.29 \\
\hline RSME, m & & $16^{\mathrm{c}}$ & 9.29 & 9.21 & 8.56 & 9.40 & 8.79 \\
\hline
\end{tabular}

Output DTNs: LA0409GZ831231.001, LA0409GZ831231.002, LA0409GZ831231.003, LA0409GZ831231.004, LA0409GZ831231.005

NOTE: Entries marked AWT have head measurement higher than the top of the model and are not used in calibration. $\mathrm{AM}=$ alternate model; RSME = Root Squared Mean Error.

a Entries are data where the wells are so close together that they are associated with the same FEHM computational node.

b Entries do not use the head data as calibration targets.

${ }^{\mathrm{c}}$ See Section 6.6.2.1

Figures 6-18a, 6-18b, and 6-18c show the comparison of simulated heads versus measured water-level elevations. The root mean squared error values in residual heads are summarized in the last row of Table 6-7 for each alternate model considered to provide a basis for the quantitative comparison among them. From the figures and the root mean squared error values it can be seen that the alternate flow model calibrations are slightly better than that of the SZ site-scale flow model and that the calibration of all the alternate flow models is also similar to each other. The improvement in the alternate model root mean squared error is due in part to improvements in the model components (HFM, recharge, fluxes, etc.). However, the comparison is for illustrative purposes only because the number of wells and weights are not the same between the base case and ACM.

The following observations can be made:

- The moderate water-level targets, those between 740 meters to 780 meters, are much better simulated with the alternate flow models than with the SZ site-scale flow model

- The alternate flow models produced lower head values at WT-6 and G-2, wells suspected of being perched, than the SZ site-scale flow model. The SZ site-scale flow model prediction was 100 meters low, while the alternate SZ site-scale flow model prediction was $\sim 290$ meters low

- The upward gradient is more accurately replicated with the alternate SZ site-scale flow models than with the SZ site-scale flow model. This includes the predictions at UE-25 p \#1 and EWDP-2DB

- The calibration, in regards to the head data, was relatively independent of the flux targets on the sides of the SZ site-scale flow model. In fact, using a single flux target on a side proved as effective as using the spatially distributed targets 

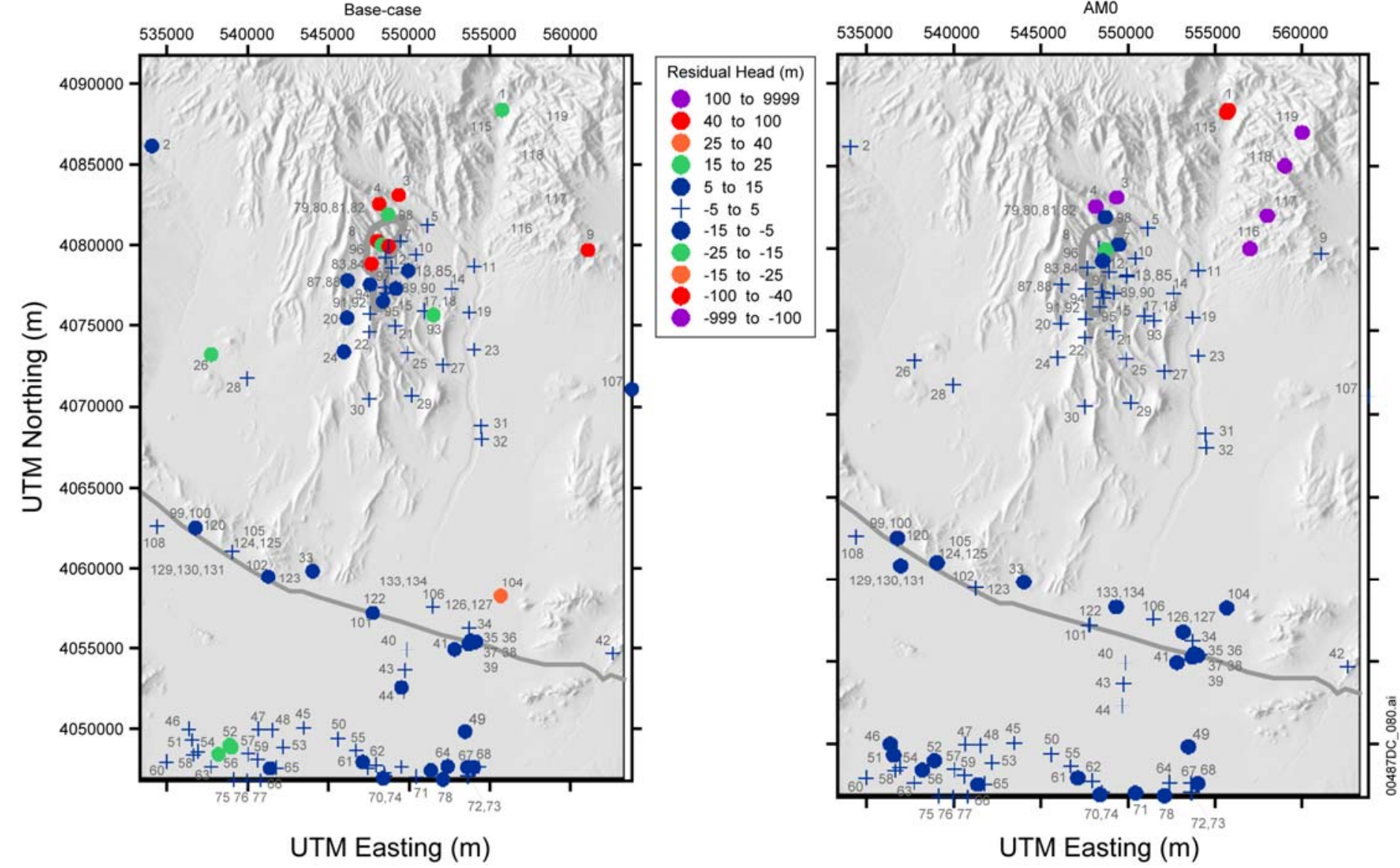

Output DTNs: LA0409GZ831231.001, LA0409GZ831231.002.

NOTE: Symbols represent well locations and their residuals (measured water level - simulated head). The blue crosses represent acceptable values within 5 meters of the measured heads. The numbers represent well numbers. Well numbers above 115 are new wells that were not used in the SZ site-scale flow model calculations. See Table 6-7 for a full list of wells, locations, and head results. This alternative conceptualization is included in DTN: LA0409GZ831231.001. 

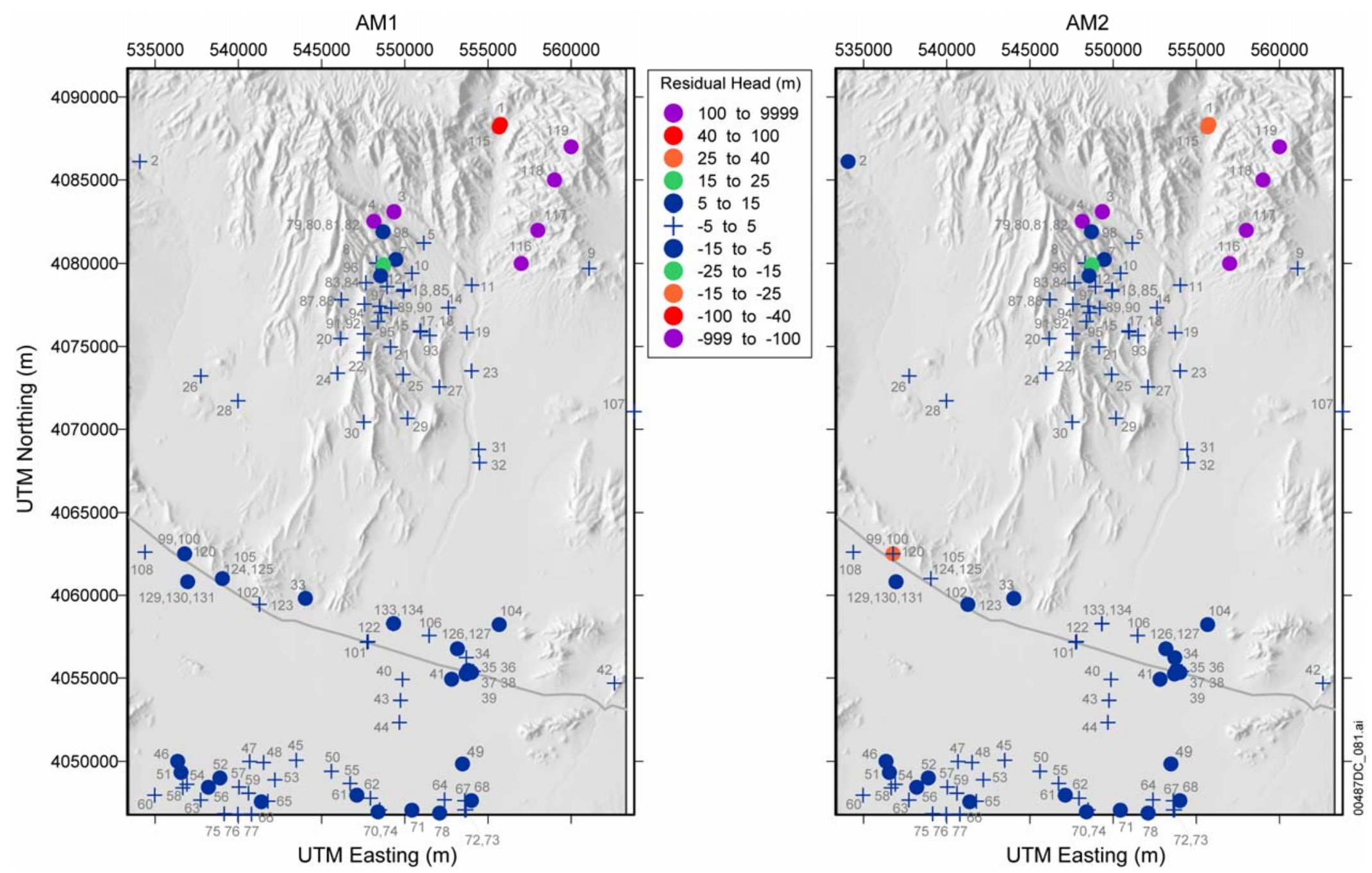

옹

Output DTNS: LA0409GZ831231.001; LA0409GZ831231.002; LA0409GZ831231.003; LA0409GZ831231.004; and LA0409GZ831231.005. UTM = Universal Transverse Mercator

Figure 6-18b. Residual Heads for Alternate Flow Models AM1 and AM2 

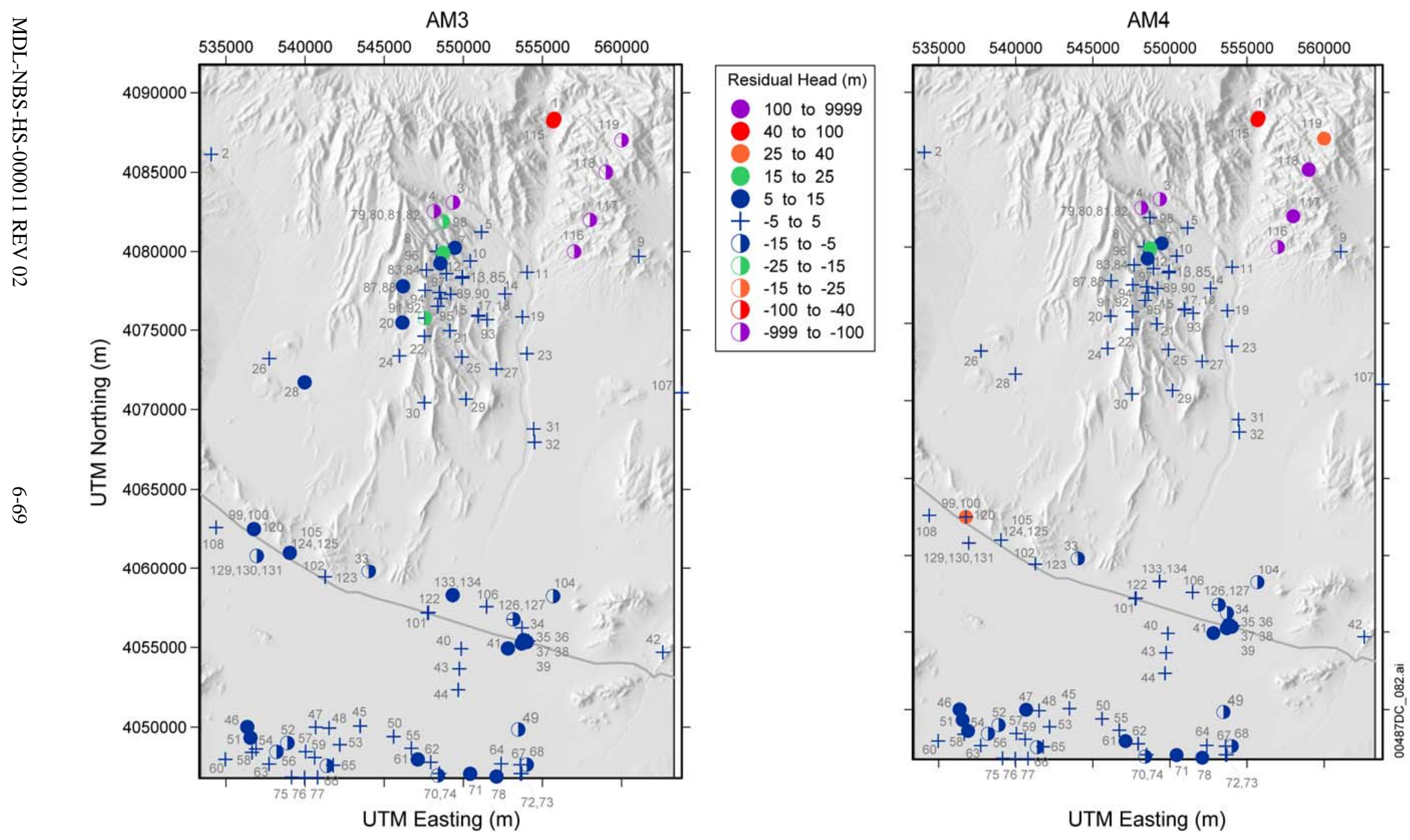

Output DTNs: LA0409GZ831231.004 and LA0409GZ831231.005.

UTM = Universal Transverse Mercator.

Figure 6-18c. Residual Heads for Alternate Flow Models AM3 and AM4. 
- The flux targets were more accurately matched with the alternate SZ site-scale flow model, including AM2, which provided distributed fluxes similar to the SZ site-scale flow model

- The inclusion of additional Nye County targets did not improve either the overall calibration or the match at the Nye County wells.

The flux targets and calibrated fluxes are presented in Section 6.4.6.4. The alternate flow models produced a better match between the targets and calibrated values than the SZ site-scale flow model. The northernmost value on the western boundary $(-271 \mathrm{~kg} / \mathrm{s})$ was difficult to match for the distributed flux case (AM2). It should be noted that specific discharge estimates (see Section 6.4.6.3.7, Table 6-11) are lower for the alternate SZ site-scale flow model. In addition, transport analyses (BSC 2004 [DIRS 170036], Appendix E2) indicated that the transport times estimated using the alternate SZ site-scale flow model are longer. Therefore, using the SZ site-scale flow model for TSPA-LA is conservative and will yield breakthrough curves.

\subsection{Calibration Results: Permeability and Permeability Multipliers}

It can be seen from Table 6-8 that the calibration of the alternate SZ site-scale flow model produced similar permeability values to those from the site-scale flow model. The calibrated permeability is generally lower in the alternate flow model above the flow path from the repository to the compliance boundary. Observations are summarized below.

- The permeability for the Crater Flat group, Tram, Bullfrog, and Prow Pass, are lower in the alternate SZ site-scale flow models than in the SZ site-scale flow model. The spatial distribution of these parameters is larger in the alternate SZ site-scale flow model

- Additional spatially distributed zones for the Crater Flat group produced different permeability values for this group near Yucca Mountain. These permeability values were lower than those along the flow path in Fortymile Wash. They were approximately an order of magnitude smaller near Yucca Mountain than in the Fortymile Wash area

- The alternate SZ site-scale flow models permeability values for the Solitario canyon fault were different from those of the SZ site-scale flow model. The alternate flow models permeability values were consistent with Solitario Canyon fault values between $5 \times 10^{-15}$ to $6 \times 10^{-16} \mathrm{~m}^{2}$ for the most permeable segment of the fault. The SZ site-scale flow model permeability value for the Solitario Canyon was $1 \times 10^{-18} \mathrm{~m}^{2}$

- With few exceptions discussed below, the calibration was independent of the parameter bounds used by PEST.

Fixed bounds were used for the following parameters: bull (Bullfrog), wa40 (Fortymile Wash), bully (Bullfrog near Yucca Mountain), tramy (Tram near Yucca Mountain), prowy (Prow near Yucca Mountain), wash (lower Fortymile Wash), and ghos (Ghost Dance fault). The permeability depth relationships (i.e., the deeper member of the Crater Flat group have lower permeability) were considered when setting the permeability limits for the units. For this reason the tramy permeability values were limited to values lower than and up to the bully values. 
Likewise, the prowy permeability values were limited to values equal to or higher than the bull values. The permeability values for the bully and other parameters listed above did not reach the fixed bounds in any of the alternate SZ site-scale flow models.

The calibrations were relatively insensitive to the Ghost Dance fault parameter. Yet, this parameter had a measurable effect on the path lines as discussed further in subsequent sections.

Table 6-8. Calibration Permeability and Permeability Ranges for the Alternate SZ Site-Scale Flow Models

\begin{tabular}{|c|c|c|c|c|c|c|c|c|c|}
\hline Name & $\begin{array}{c}\text { Geologic Unit } \\
\text { or Feature }\end{array}$ & $\begin{array}{l}\text { Calibrated } \\
\text { Value } \\
\text { AM0 }\left(\mathrm{m}^{2}\right)\end{array}$ & $\begin{array}{c}\begin{array}{c}\text { Calibrated } \\
\text { Value AM1 } \\
\left(\mathrm{m}^{2}\right)\end{array} \\
\end{array}$ & $\begin{array}{c}\text { Calibrated } \\
\text { Value AM2 } \\
\left(\mathrm{m}^{2}\right)\end{array}$ & $\begin{array}{c}\text { Calibrated } \\
\text { Value AM3 } \\
\left(\mathrm{m}^{2}\right)\end{array}$ & $\begin{array}{c}\text { Calibrated } \\
\text { Value AM4 } \\
\left(\mathrm{m}^{2}\right)\end{array}$ & P/M & \begin{tabular}{|c|}
$\begin{array}{c}\text { Minimum } \\
\text { Value } \\
\left(\mathrm{m}^{2}\right)\end{array}$ \\
\end{tabular} & $\begin{array}{c}\text { Maximum } \\
\text { Value } \\
\left(\mathrm{m}^{2}\right)\end{array}$ \\
\hline intr & $\begin{array}{l}\text { (S)Intrusive } \\
\text { Confining }\end{array}$ & 3.41E-18 & 3.39E-18 & 4.03E-18 & 3.89E-18 & 4.55E-18 & $\mathbf{P}$ & 1.00E-18 & 1.00E-10 \\
\hline gran & $\begin{array}{l}\text { (S)Granitic } \\
\text { Confining }\end{array}$ & 5.43E-17 & $5.38 \mathrm{E}-17$ & 5.69E-18 & 4.14E-17 & 3.69E-17 & $\mathbf{P}$ & $1.00 \mathrm{E}-18$ & 1.00E-10 \\
\hline Icla & $\begin{array}{l}\text { (S)Crystaline } \\
\text { Confining }\end{array}$ & 3.61E-18 & 3.57E-18 & 3.35E-18 & 4.11E-18 & 3.96E-18 & $\mathbf{P}$ & 1.00E-19 & $1.00 \mathrm{E}-10$ \\
\hline Icar & \begin{tabular}{|l} 
(S)Lower \\
Carbonate \\
Aquifer
\end{tabular} & 2.12E-16 & $1.94 \mathrm{E}-16$ & 2.88E-16 & 5.62E-16 & 9.94E-16 & $\mathbf{P}$ & 1.00E-18 & 1.00E-10 \\
\hline ucla & $\begin{array}{l}\text { (S)Upper } \\
\text { Clastic } \\
\text { Confining } \\
\text { Unit } \\
\end{array}$ & 8.00E-19 & 1.08E-19 & 6.88E-19 & 2.92E-19 & 1.18E-18 & $\mathbf{P}$ & 1.00E-19 & 1.00E-10 \\
\hline ucar & \begin{tabular}{|l} 
(S)Lower \\
Carbonate \\
Aquifer \\
Thrust \\
\end{tabular} & 3.47E-15 & 2.39E-15 & 3.65E-15 & 3.86E-15 & 8.90E-15 & $\mathbf{P}$ & 1.00E-18 & 1.00E-10 \\
\hline Iclat & $\begin{array}{l}\text { (S)Lower } \\
\text { Clastic } \\
\text { Confining } \\
\text { Thrust } \\
\end{array}$ & 1.02E-17 & $9.69 \mathrm{E}-18$ & $9.21 \mathrm{E}-18$ & 1.34E-17 & 1.24E-17 & $\mathbf{P}$ & 1.00E-18 & 1.00E-10 \\
\hline Icart & \begin{tabular}{|l} 
(S)Lower \\
Carbonate \\
Aquifer \\
Thrust \\
\end{tabular} & 1.34E-12 & 1.05E-12 & 1.65E-12 & 1.23E-12 & 8.44E-13 & $\mathbf{P}$ & 1.00E-18 & 5.00E-10 \\
\hline scon & $\begin{array}{l}\text { (S)Sedimenta } \\
\text { ry Confining } \\
\text { Unit }\end{array}$ & 2.03E-15 & 1.99E-15 & 1.56E-15 & 2.13E-15 & 1.98E-15 & $\mathbf{P}$ & 1.00E-18 & 1.00E-10 \\
\hline vsul & \begin{tabular}{|l} 
(S)Lower \\
Volcanic and \\
Sedimentary
\end{tabular} & 5.05E-19 & 4.95E-19 & 4.53E-19 & 5.30E-19 & 5.06E-19 & $\mathbf{P}$ & 1.00E-19 & 1.00E-10 \\
\hline ovoa & $\begin{array}{l}\text { (S)Older } \\
\text { Volcanic }\end{array}$ & 4.30E-15 & 3.93E-15 & 3.63E-15 & 7.32E-15 & 1.19E-14 & $\mathbf{P}$ & 1.00E-18 & $1.00 \mathrm{E}-10$ \\
\hline belt & $\begin{array}{l}\text { (S)Belted } \\
\text { Range } \\
\end{array}$ & 2.33E-14 & 2.30E-14 & 2.09E-14 & 2.46E-14 & 2.43E-14 & $\mathbf{P}$ & 5.00E-18 & $1.00 \mathrm{E}-10$ \\
\hline tram & $\begin{array}{l}\text { (S)Crater Flat- } \\
\text { Tram } \\
\end{array}$ & 1.10E-11 & 1.21E-11 & 1.22E-11 & 1.20E-11 & 8.12E-12 & $\mathbf{P}$ & 1.00E-18 & 1.00E-10 \\
\hline bull & $\begin{array}{l}\text { (S)Crater Flat- } \\
\text { Bullfrog }\end{array}$ & 9.11E-13 & 1.00E-12 & 3.93E-13 & 1.27E-12 & 9.73E-13 & $\mathbf{P}$ & 1.00E-12 & 3.00E-11 \\
\hline
\end{tabular}


Table 6-8. Calibration Permeability and Permeability Ranges for the Alternate SZ Site-Scale Flow Models (Continued)

\begin{tabular}{|c|c|c|c|c|c|c|c|c|c|}
\hline Name & $\begin{array}{c}\text { Geologic Unit } \\
\text { or Feature }\end{array}$ & $\begin{array}{c}\text { Calibrate } \\
\text { d Value } \\
\text { AMO }\left(\mathrm{m}^{2}\right)\end{array}$ & $\begin{array}{c}\text { Calibrated } \\
\text { Value AM1 } \\
\left(\mathrm{m}^{2}\right)\end{array}$ & \begin{tabular}{|c} 
Calibrated \\
Value AM2 \\
$\left(\mathrm{m}^{2}\right)$
\end{tabular} & $\begin{array}{c}\text { Calibrated } \\
\begin{array}{c}\text { Value AM3 } \\
\left(\mathrm{m}^{2}\right)\end{array} \\
\end{array}$ & $\begin{array}{c}\text { Calibrated } \\
\begin{array}{c}\text { Value AM4 } \\
\left(\mathbf{m}^{2}\right)\end{array} \\
\end{array}$ & $\mathbf{P} / \mathbf{M}$ & \begin{tabular}{|c|}
$\begin{array}{c}\text { Minimum } \\
\text { Value } \\
\left(\mathrm{m}^{2}\right)\end{array}$ \\
\end{tabular} & \begin{tabular}{|c}
$\begin{array}{c}\text { Maximum } \\
\text { Value } \\
\left(\mathrm{m}^{2}\right)\end{array}$ \\
\end{tabular} \\
\hline prow & \begin{tabular}{|l|} 
(S)Crater Flat- \\
Prow Pass
\end{tabular} & 0.22 & 0.19 & 0.64 & 0.23 & 0.38 & $\mathbf{M}$ & 1.00E-05 & 1.00E+00 \\
\hline wahm & \begin{tabular}{|l} 
(S)Wahmonie \\
Volcanic
\end{tabular} & 1.17E-14 & 1.16E-14 & 1.16E-14 & 1.74E-14 & 1.70E-14 & $\mathbf{P}$ & 1.00E-18 & 3.00E-10 \\
\hline cali & (S)Calico Hills & $6.99 \mathrm{E}-17$ & 7.39E-17 & 7.42E-17 & 8.89E-17 & 7.10E-17 & $\mathbf{P}$ & $1.00 \mathrm{E}-18$ & $1.00 \mathrm{E}-10$ \\
\hline pain & (S)Paintbrush & 1.21E-13 & 1.32E-13 & 1.04E-13 & 1.99E-13 & 3.38E-13 & $\mathbf{P}$ & 1.00E-18 & 1.00E-10 \\
\hline timb & $\begin{array}{l}\text { (S)Timber } \\
\text { Mountain } \\
\text { Volcanic }\end{array}$ & 4.13E-11 & 3.57E-11 & 8.90E-12 & 2.10E-11 & 2.10E-11 & $\mathbf{P}$ & 1.00E-18 & 5.00E-10 \\
\hline vose & $\begin{array}{l}\text { (S)Volcanic } \\
\text { and } \\
\text { Sedimentary }\end{array}$ & $5.06 \mathrm{E}-12$ & 4.98E-12 & $1.62 \mathrm{E}-11$ & 1.15E-11 & 1.08E-11 & $\mathbf{P}$ & 1.00E-18 & $4.00 \mathrm{E}-10$ \\
\hline uvoa & $\begin{array}{l}\text { (S)Upper } \\
\text { Volcanic } \\
\text { Aquifer }\end{array}$ & 7.96E-16 & 7.89E-16 & 7.39E-16 & 7.92E-16 & 8.47E-16 & $\mathbf{P}$ & 5.00E-18 & 1.00E-10 \\
\hline lava & $\begin{array}{l}\text { (S)Lavaflow } \\
\text { Unit }\end{array}$ & 3.20E-11 & 3.28E-11 & 2.44E-11 & 4.54E-11 & 4.00E-11 & $\mathbf{P}$ & 1.00E-18 & 1.00E-10 \\
\hline lime & $\begin{array}{l}\text { (S) Limestone } \\
\text { Aquifer }\end{array}$ & 1.89E-17 & 1.87E-17 & $1.73 \mathrm{E}-17$ & 3.78E-17 & 4.55E-17 & $\mathbf{P}$ & 1.00E-18 & 1.00E-10 \\
\hline oalc & $\begin{array}{l}\text { (S)Older } \\
\text { Alluvial } \\
\text { Confining }\end{array}$ & $1.20 \mathrm{E}-14$ & 1.20E-14 & $1.08 \mathrm{E}-14$ & $1.20 \mathrm{E}-14$ & 1.30E-14 & P & 1.00E-18 & 1.00E-10 \\
\hline oala & $\begin{array}{l}\text { (S)Older } \\
\text { Alluvial Aquifer }\end{array}$ & 4.38E-13 & 4.42E-13 & 3.39E-13 & 6.48E-13 & 7.62E-13 & $\mathbf{P}$ & 5.00E-18 & 1.00E-11 \\
\hline yalc & $\begin{array}{l}\text { (S)Young } \\
\text { Alluvial } \\
\text { Confining } \\
\end{array}$ & $5.40 \mathrm{E}-14$ & 5.37E-14 & 4.85E-14 & 5.48E-14 & 6.05E-14 & $\mathbf{P}$ & 1.00E-18 & 1.00E-10 \\
\hline yala & \begin{tabular}{|l|} 
(S)Young \\
Alluvial Aquifer
\end{tabular} & 4.94E-13 & 4.92E-13 & 4.41E-13 & 4.51E-13 & 4.55E-13 & P & 1.00E-18 & 1.00E-10 \\
\hline intrm & $\begin{array}{l}\text { (N)Intrusive } \\
\text { Confining }\end{array}$ & 30.4 & 30.5 & 34.0 & 28.5 & 33.9 & & 1.00E-05 & $1.00 \mathrm{E}+04$ \\
\hline granm & (N)Granites & 1955 & 1961 & 198 & 1481 & 1430 & M & 1.00E-05 & $1.00 \mathrm{E}+06$ \\
\hline Iclam & $\begin{array}{l}\text { (N)Crystaline } \\
\text { Confining }\end{array}$ & 69.6 & 69.2 & 61.4 & 57.1 & 57.3 & M & $1.00 \mathrm{E}-05$ & $1.00 \mathrm{E}+04$ \\
\hline Icarm & \begin{tabular}{|l} 
(N)Lower \\
Carbonate \\
Aquifer
\end{tabular} & 0.21 & 0.21 & 0.22 & 0.19 & 0.20 & M & 1.00E-05 & 100 \\
\hline uclam & \begin{tabular}{|l|} 
(N)Upper \\
Clastic \\
Confining Unit
\end{tabular} & 0.56 & 0.56 & 0.51 & 0.50 & 0.52 & $\mathbf{M}$ & 1.00E-05 & 100 \\
\hline ucarm & \begin{tabular}{|l|} 
(N)Lower \\
Carbonate \\
Aquifer Thrust
\end{tabular} & 0.97 & 0.70 & 1.26 & 1.11 & 2.99 & $\mathbf{M}$ & 1.00E-05 & 100 \\
\hline Iclatm & $\begin{array}{l}\text { (N)Lower } \\
\text { Clastic } \\
\text { Confining } \\
\text { Thrust } \\
\end{array}$ & 17.4 & 17.2 & 16.3 & 15.4 & 15.6 & M & 1.00E-05 & 100 \\
\hline
\end{tabular}


Table 6-8. Calibration Permeability and Permeability Ranges for the Alternate SZ Site-Scale Flow Models (Continued)

\begin{tabular}{|c|c|c|c|c|c|c|c|c|c|}
\hline Name & $\begin{array}{l}\text { Geologic Unit } \\
\text { or Feature }\end{array}$ & $\begin{array}{c}\text { Calibrate } \\
\text { d Value } \\
\text { AM0 }\left(\mathrm{m}^{2}\right)\end{array}$ & $\begin{array}{c}\begin{array}{c}\text { Calibrated } \\
\text { Value AM1 } \\
\left(\mathrm{m}^{2}\right)\end{array} \\
\end{array}$ & $\begin{array}{c}\text { Calibrated } \\
\text { Value AM2 } \\
\left(\mathrm{m}^{2}\right)\end{array}$ & $\begin{array}{c}\begin{array}{c}\text { Calibrated } \\
\text { Value AM3 } \\
\left(\mathrm{m}^{2}\right)\end{array} \\
\end{array}$ & $\begin{array}{c}\begin{array}{c}\text { Calibrated } \\
\text { Value AM4 } \\
\left(\mathrm{m}^{2}\right)\end{array} \\
\end{array}$ & $\mathbf{P} / \mathbf{M}$ & $\begin{array}{c}\text { Minimum } \\
\text { Value } \\
\left(\mathrm{m}^{2}\right)\end{array}$ & \begin{tabular}{|c} 
Maximum \\
Value \\
$\left(\mathbf{m}^{2}\right)$
\end{tabular} \\
\hline Icartm & \begin{tabular}{|l} 
(N)Lower \\
Carbonate \\
Aquifer Thrust \\
\end{tabular} & 1.97 & 1.96 & 1.84 & 1.74 & 1.77 & M & 1.00E-05 & 100 \\
\hline sconm & $\begin{array}{l}\text { (N)Sedimentary } \\
\text { Confining Unit }\end{array}$ & 2.76 & 2.74 & 2.58 & 2.45 & 2.50 & M & 1.00E-05 & 100 \\
\hline vsulm & $\begin{array}{l}\text { (N)Lower } \\
\text { Volcanic and } \\
\text { Sedimentary } \\
\end{array}$ & 1.41E-04 & 1.40E-04 & 1.33E-04 & 1.49E-04 & $1.55 \mathrm{E}-04$ & M & 1.00E-05 & 100 \\
\hline ovoam & $\begin{array}{l}\text { (N)Older } \\
\text { Volcanic }\end{array}$ & 7.65E-04 & 7.60E-04 & 7.15E-04 & 6.51E-04 & 6.56E-04 & M & 1.00E-05 & 100 \\
\hline beltm & $\begin{array}{l}\text { (N)Belted } \\
\text { Range }\end{array}$ & 1.04E-04 & 1.03E-04 & 9.70E-05 & 9.16E-05 & 9.33E-05 & M & 1.00E-05 & 100 \\
\hline tramm & $\begin{array}{l}\text { (N)Crater Flat- } \\
\text { Tram }\end{array}$ & 1.06E-04 & 7.14E-05 & 8.55E-04 & 2.62E-04 & 4.11E-04 & M & 1.00E-05 & 100 \\
\hline bullm & $\begin{array}{l}\text { (N)Crater Flat- } \\
\text { Bullfrog }\end{array}$ & 3.41E-05 & 3.30E-05 & 3.01E-05 & 2.53E-05 & 1.90E-05 & M & 1.00E-08 & 100 \\
\hline prowm & $\begin{array}{l}\text { (N)Crater Flat- } \\
\text { Prow Pass }\end{array}$ & 4.19E-06 & 4.10E-06 & 3.98E-06 & 5.26E-06 & 5.89E-06 & M & 1.00E-06 & 100 \\
\hline $\begin{array}{l}\text { wahm } \\
\mathrm{m}\end{array}$ & $\begin{array}{l}\text { (N)Wahmonie } \\
\text { Volcanic }\end{array}$ & 0.509197 & 0.495458 & 0.472581 & 0.426208 & 0.449338 & M & 1.00E-05 & 100 \\
\hline calim & (N)Calico Hills & 10.9 & 15.3 & 10.8 & 20.2 & 11.4 & M & 1.00E-05 & 100 \\
\hline painm & (N)Paintbrush & 3.53E-07 & 3.81E-07 & 1.54E-07 & 5.74E-07 & 6.19E-07 & M & 1.00E-07 & 100 \\
\hline timbm & $\begin{array}{l}(\mathrm{N}) \text { Timber } \\
\text { Mountain } \\
\text { Volcanic }\end{array}$ & 7.31 & 7.84 & 2.93E-03 & 6.34 & 5.91 & M & 1.00E-05 & 10000 \\
\hline vosem & $\begin{array}{l}\text { (N)Volcanic } \\
\text { and } \\
\text { Sedimentary }\end{array}$ & 1.26 & 1.23 & 1.18 & 1.01 & 1.06 & M & 1.00E-05 & 100 \\
\hline uvoam & $\begin{array}{l}\text { (N) Upper } \\
\text { Volcanic } \\
\text { Aquifer }\end{array}$ & 0.76 & 0.74 & 0.71 & 0.66 & 0.68 & M & 1.00E-05 & 100 \\
\hline lavam & $\begin{array}{l}\text { (N) Lavaflow } \\
\text { Unit }\end{array}$ & 1.03 & 1.05 & 0.96 & 0.90 & 1.05 & M & 1.00E-05 & 100 \\
\hline limem & $\begin{array}{l}\text { (N) Limestone } \\
\text { Aquifer }\end{array}$ & 0.11 & 0.11 & 0.11 & 9.69E-02 & 9.99E-02 & M & 1.00E-05 & 100 \\
\hline oalcm & \begin{tabular}{|l|} 
(N) Older \\
Alluvial \\
Confining
\end{tabular} & 7.65E-02 & 7.88E-02 & 7.25E-02 & 7.85E-02 & 6.44E-02 & M & 1.00E-05 & 100 \\
\hline oalam & $\begin{array}{l}\text { (N) Older } \\
\text { Alluvial Aquifer }\end{array}$ & 1.97 & 1.90 & 1.84 & 1.99 & 2.20 & M & 1.00E-05 & 100 \\
\hline yalcm & \begin{tabular}{|l} 
(S)Young \\
Alluvial \\
Confining
\end{tabular} & 3.83 & 3.76 & 3.22 & 2.70 & 1.38 & M & 1.00E-05 & 100 \\
\hline yalam & $\begin{array}{l}\text { (S)Young } \\
\text { Alluvial Aquifer }\end{array}$ & 1.24 & 1.20 & 1.08 & 1.02 & 0.66 & M & 1.00E-05 & 100 \\
\hline nsba & $\begin{array}{l}\text { Solitario Fault } \\
\text { Component } 1\end{array}$ & $6.00 \mathrm{E}-15$ & 5.86E-15 & 4.25E-15 & 7.97E-15 & 1.02E-14 & $\mathbf{P}$ & $1.00 \mathrm{E}-20$ & $1.00 \mathrm{E}-13$ \\
\hline
\end{tabular}


Table 6-8. Calibration Permeability and Permeability Ranges for the Alternate SZ Site-Scale Flow Models (Continued)

\begin{tabular}{|c|c|c|c|c|c|c|c|c|c|}
\hline Name & $\begin{array}{c}\text { Geologic Unit } \\
\text { or Feature }\end{array}$ & $\begin{array}{c}\text { Calibrate } \\
\text { d Value } \\
\text { AMO }\left(\mathrm{m}^{2}\right) \\
\end{array}$ & \begin{tabular}{|c|}
$\begin{array}{c}\text { Calibrated } \\
\text { Value AM1 } \\
\left(\mathrm{m}^{2}\right)\end{array}$ \\
\end{tabular} & \begin{tabular}{|c|}
$\begin{array}{c}\text { Calibrated } \\
\text { Value AM2 } \\
\left(\mathrm{m}^{2}\right)\end{array}$ \\
\end{tabular} & $\begin{array}{c}\text { Calibrated } \\
\text { Value AM3 } \\
\left(\mathrm{m}^{2}\right)\end{array}$ & $\begin{array}{c}\begin{array}{c}\text { Calibrated } \\
\text { Value AM4 } \\
\left(\mathrm{m}^{2}\right)\end{array} \\
\end{array}$ & P/M & \begin{tabular}{|c|} 
Minimum \\
Value \\
$\left(\mathrm{m}^{2}\right)$
\end{tabular} & \begin{tabular}{|c|}
$\begin{array}{c}\text { Maximum } \\
\text { Value } \\
\left(\mathrm{m}^{2}\right)\end{array}$ \\
\end{tabular} \\
\hline nssb & $\begin{array}{l}\text { Solitario Fault } \\
\text { Component } 2\end{array}$ & 9.87E-17 & $9.97 \mathrm{E}-17$ & $9.60 \mathrm{E}-17$ & 9.18E-17 & 8.41E-17 & $\mathbf{P}$ & 1.00E-20 & 1.00E-13 \\
\hline nsym & $\begin{array}{l}\text { Solitario Fault } \\
\text { Component } 3\end{array}$ & $6.57 \mathrm{E}-18$ & $6.67 \mathrm{E}-18$ & $6.41 \mathrm{E}-18$ & 5.88E-18 & $6.61 \mathrm{E}-18$ & $\mathbf{P}$ & 1.00E-18 & $1.00 \mathrm{E}-13$ \\
\hline nszm & $\begin{array}{l}\text { Solitario Fault } \\
\text { Component } 4\end{array}$ & 7.72E-16 & 7.23E-16 & 7.72E-16 & $1.01 \mathrm{E}-15$ & $8.61 \mathrm{E}-16$ & $\mathbf{P}$ & $1.00 \mathrm{E}-18$ & 1.00E-11 \\
\hline scfs & $\begin{array}{l}\text { Solitario Fault } \\
\text { Component } 5\end{array}$ & 3.52E-16 & 2.84E-16 & $6.10 \mathrm{E}-16$ & $5.12 \mathrm{E}-16$ & 7.42E-16 & $\mathbf{P}$ & 1.00E-18 & 1.00E-13 \\
\hline wa40 & $\begin{array}{l}\text { Forty Mile } \\
\text { Wash }\end{array}$ & 85.9 & 93.6 & 95.4 & 69.2 & 75.8 & & 1.00E-05 & $1.00 \mathrm{E}+02$ \\
\hline tramy & $\begin{array}{l}\text { (YM) Crater } \\
\text { Flat-Tram }\end{array}$ & 200 & 100 & 1192 & 114 & 267 & M & 1.00E-5 & $1.00 E+02$ \\
\hline bully & \begin{tabular}{|l|} 
(YM)Crater \\
Flat-Bullfrog
\end{tabular} & $1.24 \mathrm{E}-13$ & $1.72 \mathrm{E}-13$ & 8.07E-14 & 3.44E-13 & 4.39E-13 & $\mathbf{P}$ & $1.00 \mathrm{E}-13$ & $1.00 \mathrm{E}-10$ \\
\hline prowy & \begin{tabular}{|l|} 
(YM)Crater \\
Flat-Prow Pass
\end{tabular} & 0.55 & 0.71 & 0.26 & 0.1 & 0.1 & M & $1.00 \mathrm{E}-5$ & $1.00 \mathrm{E}+02$ \\
\hline intre & $\begin{array}{l}\text { (E)Intrusive } \\
\text { Confining }\end{array}$ & 3.31E-17 & $3.35 \mathrm{E}-17$ & $2.90 \mathrm{E}-17$ & 3.16E-17 & 3.12E-17 & $\mathbf{P}$ & 1.00E-18 & 1.00E-10 \\
\hline Icare & $\begin{array}{l}\text { (E)Lower } \\
\text { Carbonate } \\
\text { Aquifer }\end{array}$ & $2.53 \mathrm{E}-15$ & $2.50 \mathrm{E}-15$ & 2.89E-15 & 3.30E-15 & $5.48 \mathrm{E}-15$ & $\mathbf{P}$ & 1.00E-18 & 1.00E-10 \\
\hline Iclate & \begin{tabular}{|l|} 
E)Lower \\
Clastic \\
Confining \\
Thrust
\end{tabular} & 1.53E-14 & $1.55 \mathrm{E}-14$ & $1.34 \mathrm{E}-14$ & $1.25 \mathrm{E}-14$ & $45 \mathrm{E}-14$ & $\mathbf{P}$ & 1.00E-18 & $1.00 \mathrm{E}-10$ \\
\hline Icarte & \begin{tabular}{|l|} 
E)Lower \\
Carbonate \\
Aquifer Thrust \\
\end{tabular} & 9.64E-12 & 1.02E-11 & 2.85E-12 & 8.52E-12 & 8.48E-12 & $\mathbf{P}$ & 1.00E-18 & 5.00E-10 \\
\hline cffz & \begin{tabular}{|l|} 
Crater Flat \\
Fault 1
\end{tabular} & 3.49E-15 & $3.72 \mathrm{E}-15$ & 9.38E-16 & 8.77E-15 & 7.96E-15 & $\mathbf{P}$ & 1.00E-17 & $5.00 \mathrm{E}-12$ \\
\hline Cff1 & \begin{tabular}{|l|} 
Crater Flat \\
Fault 2
\end{tabular} & $1.27 \mathrm{E}-15$ & $1.38 \mathrm{E}-15$ & 6.86E-16 & $1.75 \mathrm{E}-15$ & 2.30E-15 & $\mathbf{P}$ & 1.00E-17 & 5.00E-11 \\
\hline Hy95 & $\begin{array}{l}\text { U.S. Highway } \\
\text { 95 Fault Zone }\end{array}$ & $9.82 \mathrm{E}-16$ & $6.98 \mathrm{E}-16$ & 3.01E-15 & 1.32E-15 & 5.19E-15 & $\mathbf{P}$ & 1.00E-17 & 5.00E-11 \\
\hline wash & \begin{tabular}{|l} 
Lower \\
Fortymile \\
Wash Zone
\end{tabular} & $1.11 \mathrm{E}-11$ & $1.12 \mathrm{E}-11$ & $1.41 \mathrm{E}-11$ & 1.37E-11 & 1.40E-11 & $\mathbf{P}$ & 1.00E-11 & 5.00E-10 \\
\hline nwtf & \begin{tabular}{|l|} 
North West \\
Trending Fault \\
Zone
\end{tabular} & 3.66E-16 & 3.23E-16 & 4.99E-16 & 4.22E-16 & $64 \mathrm{E}-16$ & $\mathbf{P}$ & 1.00E-16 & 1.00E-10 \\
\hline dune & $\begin{array}{l}\text { Dune Wash } \\
\text { Fault Zone }\end{array}$ & $5.24 \mathrm{E}-12$ & 5.34E-12 & 4.66E-12 & 5.42E-12 & $5.73 \mathrm{E}-12$ & $\mathbf{P}$ & 1.00E-12 & $5.00 \mathrm{E}-10$ \\
\hline ghos & \begin{tabular}{|l|} 
Ghost Dance \\
Fault Zone
\end{tabular} & 1.08E-11 & 1.03E-11 & 1.17E-11 & 2.19E-11 & 2.40E-11 & $\mathbf{P}$ & 1.00E-12 & 1.00E-11 \\
\hline
\end{tabular}

Output DTNs: LA0409GZ831231.001; LA0409GZ831231.002; LA0409GZ831231.003; LA0409GZ831231.004; LA0409GZ831231.005

NOTE: $\quad(P)=$ parameter; $(M)=$ multiplier; $(N)=$ northern zone; $(S)$ = southern zone; $(E)$ = eastern zone; $(\mathrm{YM})=$ Yucca Mountain zone. If parameter is of type M, table entry is a unit-less multiplier. Values have been rounded for consistency of presentation. $\mathrm{AM}=$ alternate model 


\subsection{Calibration Results: Potentiometric Surface and Flow Path Lines}

The results of the calibration are shown in Figure 6-19 through 6-22. These figures were plotted using graphical software SURFER for Windows (see Section 3.2). The output from FEHM was processed with post-processing code prepare_features_for_surfer V1.0 STN: 11091-1.0-00 (Los Alamos National Laboratory 2003 [DIRS 171911]). As a result, the coordinates of the nodes at the specified elevation/water table, corresponding heads, saturation, temperature, and other output parameters were written into a file in the format required by SURFER. These files are provided with the corresponding DTNs (see figure footnotes).

Shown in Figures 6-19 through 6-22 are the potentiometric surface and flow path lines for the five alternate SZ site-scale flow models. The similarity between the five alternate SZ site-scale flow model outputs is evident.

Figures 6-19, 6-20, and 6-21 show different particle paths originating from the repository area. These paths represent fluid leaving from the southern, central, and northern parts of the repository. Figure 6-22 shows the path lines for AM0 through AM4 at elevation 500 meters and at the water table. Figure 6-23 through 6-26 show the hydrostratigraphy along the flow paths for the SZ site-scale flow model and the alternate models AM0 through AM4. The fluid particles travel downward until they reach the Crater Flat Bullfrog unit (colored red). Because of the high permeability of the Bullfrog unit, the particles remain in that unit until it ends. Particles leaving the northern part of the repository experience a more tortuous transition between the volcanic and alluvial aquifers. With the SZ site-scale flow model particles travel in a short transition zone consisting of the upper volcanic confining unit until they reach the alluvial part of the flow system. This consists of an "alluvial uncertainty zone” and the lower Fortymile Wash zone. In the alternate SZ site-scale flow model, the particles start similarly and travel to the Bullfrog unit. However, the top panels of these figures show that the newer rendition of the Bullfrog unit in the alternate SZ site-scale flow model is somewhat thinner and more continuous in the north-south direction and transitions to the volcanic and sedimentary units (the alluvial aquifer) without going through the Calico Hills volcanic unit. Because the Calico Hills unit has a relatively low permeability, this could have implications on the flow field.

The differences along the flow path from the repository can be summarized as follows. The flow near the repository area in the alternate SZ site-scale flow model is likely to be very similar to that in the SZ site-scale flow model because the HFM changes were small in this portion of the model. Flow in the upper Fortymile Wash, in the area also known as the low-gradient area, might be expected to change because the character of the Bullfrog unit is different in the two HFMs. The alternate SZ site-scale flow model fluid path lines are narrower in width and more continuous. Flow in the lower Fortymile Wash is also expected to be somewhat different. The changes in the extent of the alluvial aquifer are the major difference. The alluvial uncertainty zone included in the SZ site-scale flow model, however, has mitigated some of this difference.

The flow paths may be impacted by the low permeability of Calico Hills which may prevent the flow paths from going more east as in the SZ site-scale flow model thus going in more north south direction than the SZ site-scale flow model. 


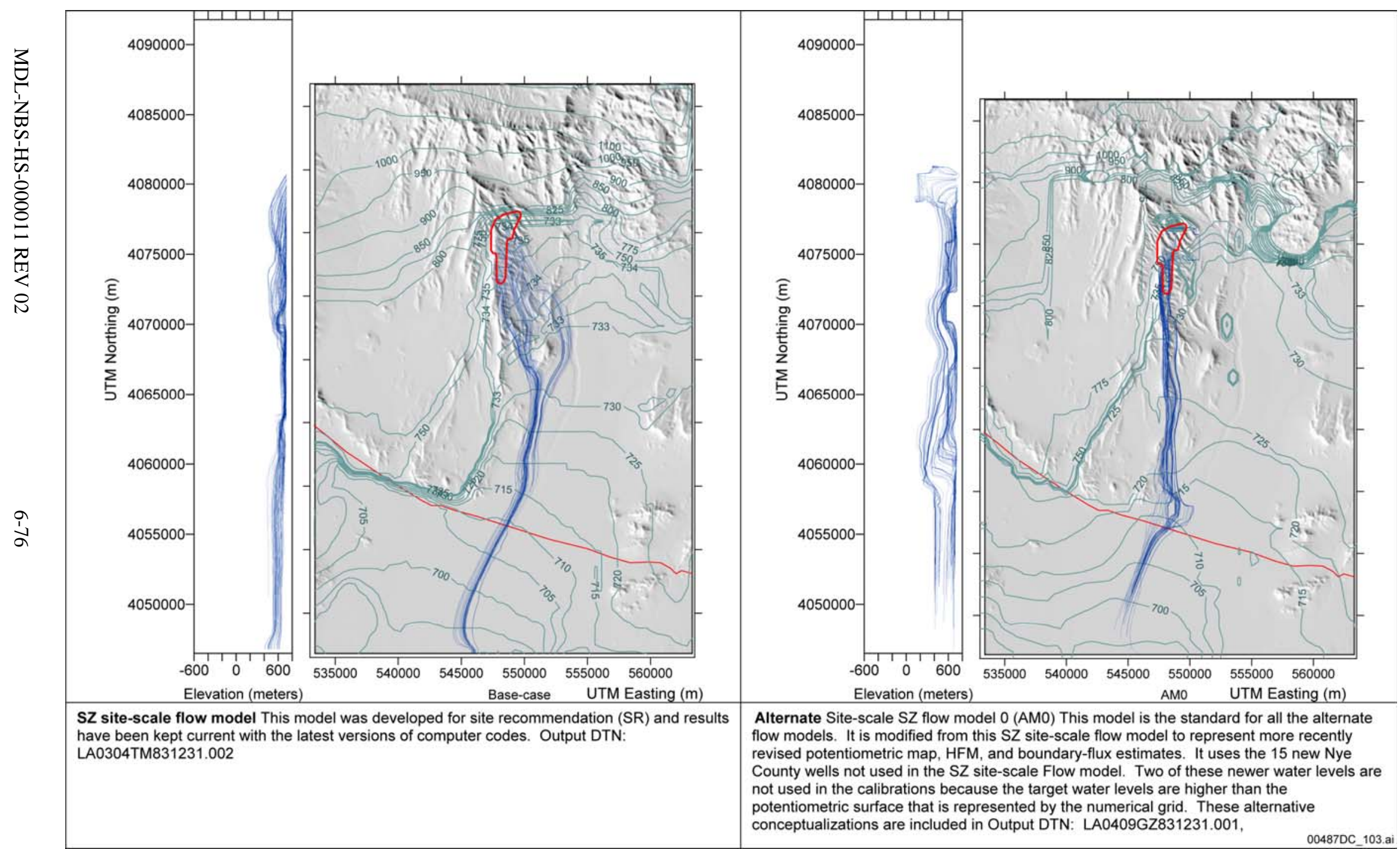

NOTE: Green lines refer to head contours; blue lines refer to the particle paths, and the red lines indicate locations of the Repository and U.S. Highway 95

UTM = Universal Transverse Mercator

Figure 6-19. Flow Paths from the Repository with Simulated Hydraulic Head Contours for SZ Site-Scale Flow Model and Alternate Flow Model $\mathrm{AMO}$ 


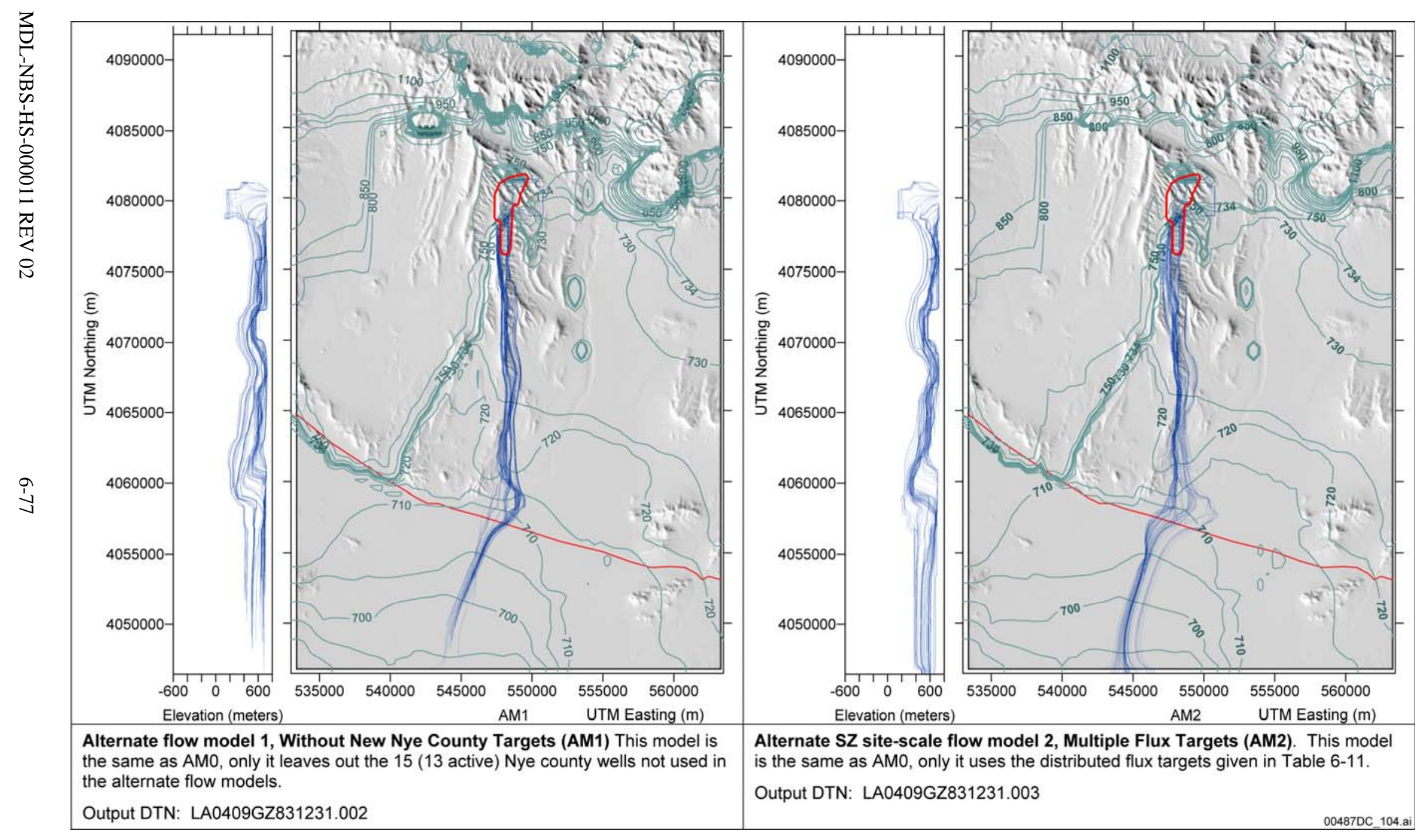

NOTE: Green lines refer to head contours; blue lines refer to the particle paths, and the red lines indicate locations of the Repository and U.S. Highway 95. UTM = Universal Transverse Mercator.

Figure 6-20. Flow Paths from the Repository with Simulated Hydraulic Head Contours for Alternate Flow Models AM1 and AM2 


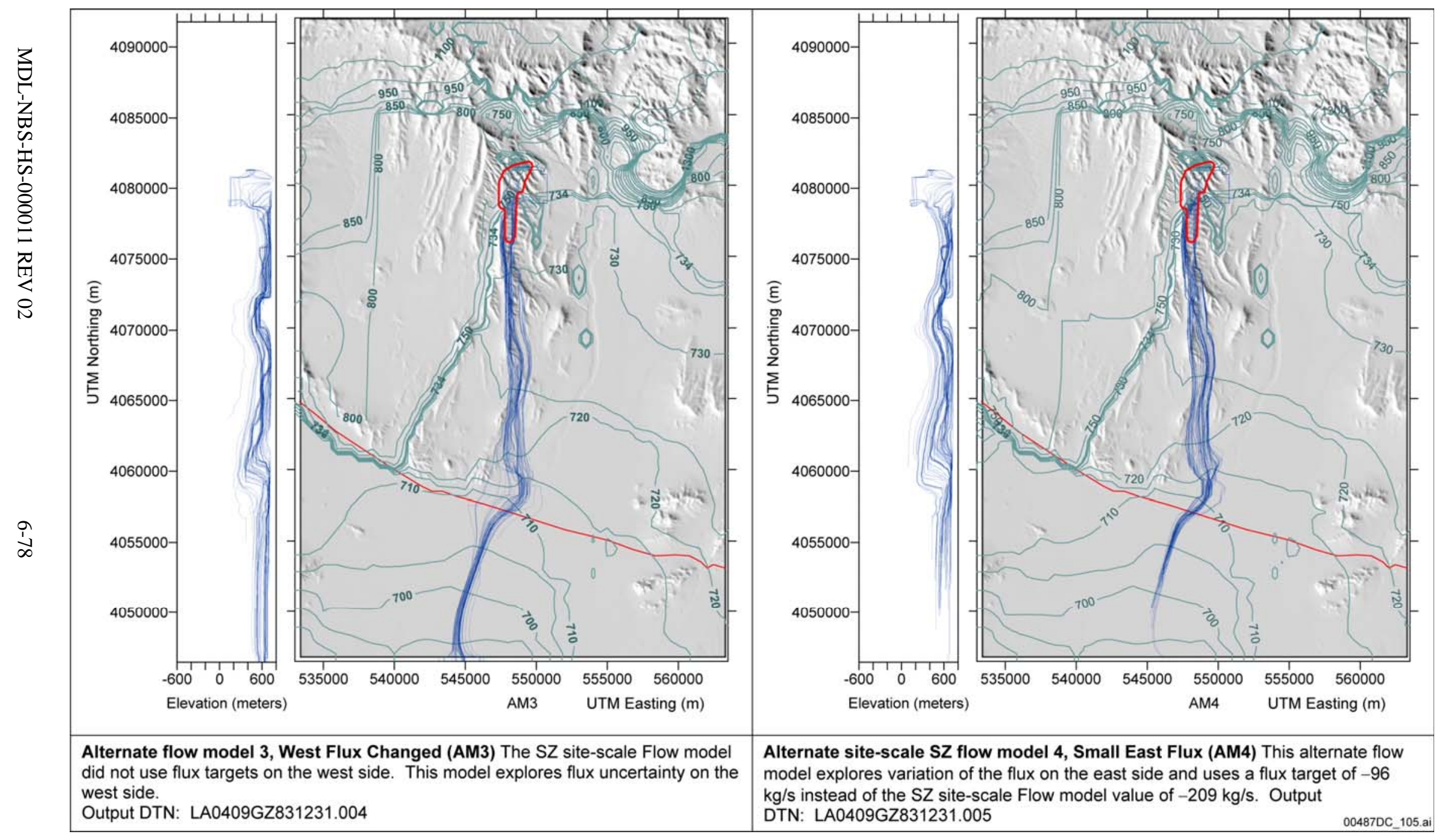

NOTE: Green lines refer to head contours; blue lines refer to the particle paths, and the red lines indicate locations of the Repository and U.S. Highway 95. 


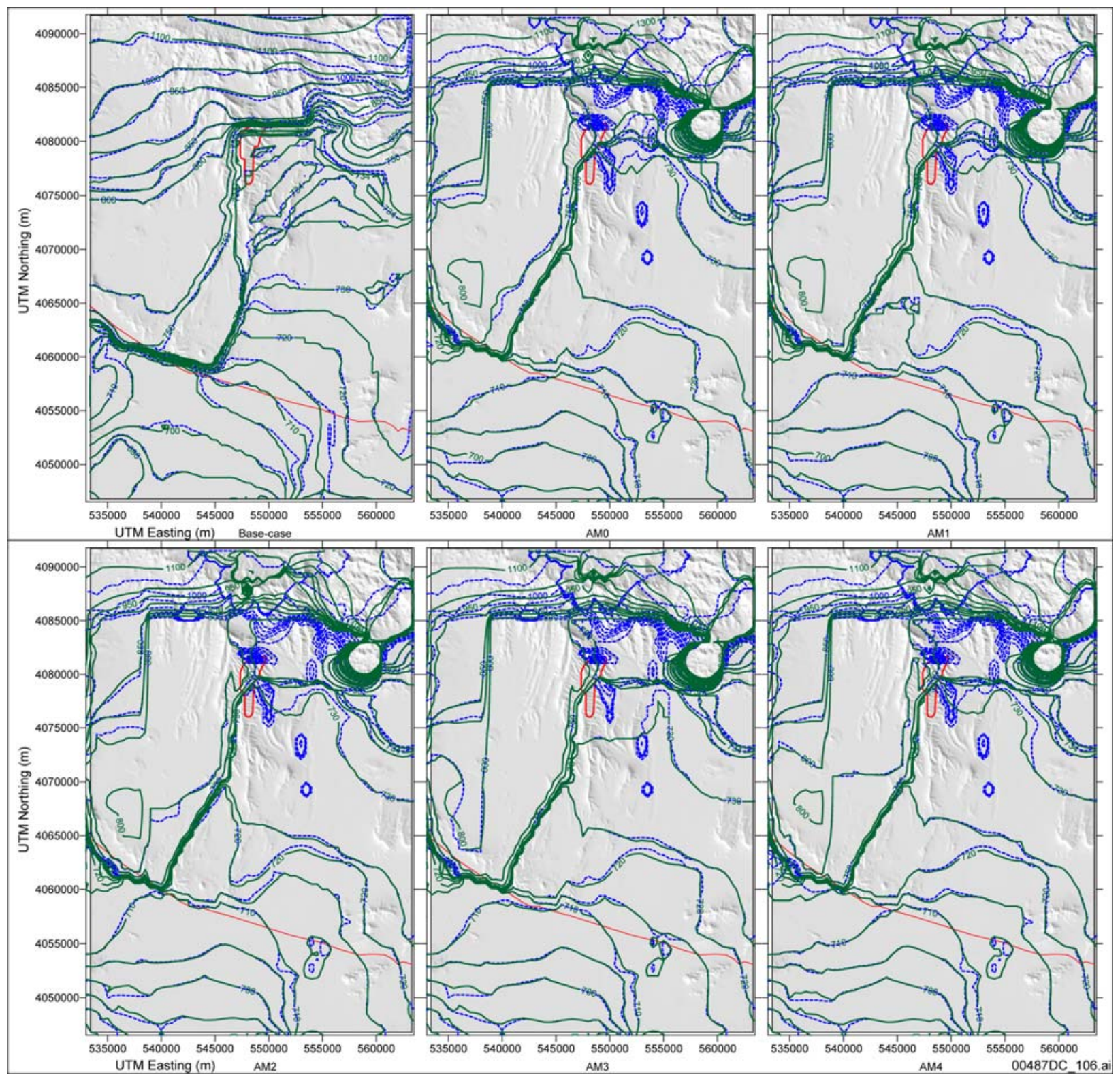

Output DTN: LA034TM831231.002, alternative conceptualizations are included in Output DTNs: LA0409GZ831231.001, LA0409GZ831231.002, LA0409GZ831231.003, LA0409GZ831231.004, LA0409GZ831231.005.

NOTE: Green lines refer to head contours at elevation 500 meters; blue dotted lines refer to head contours at the water table. Repository outline and U.S. Highway 95, in red, are included for reference. The data used for plotting head contours at the water table are located in file "sur1002_1002.txt". The data used for plotting head contours at the elevation 500 meters are located in file "sur1003_1002.txt". Each DTN listed above includes both files with these names.

UTM = Universal Transverse Mercator.

Figure 6-22. Head Contours, for SZ Site-Scale Flow Model, and Alternate Flow Models AM0, AM1, AM2, AM3, and AM4, at Elevation 500 meters and Water Table 


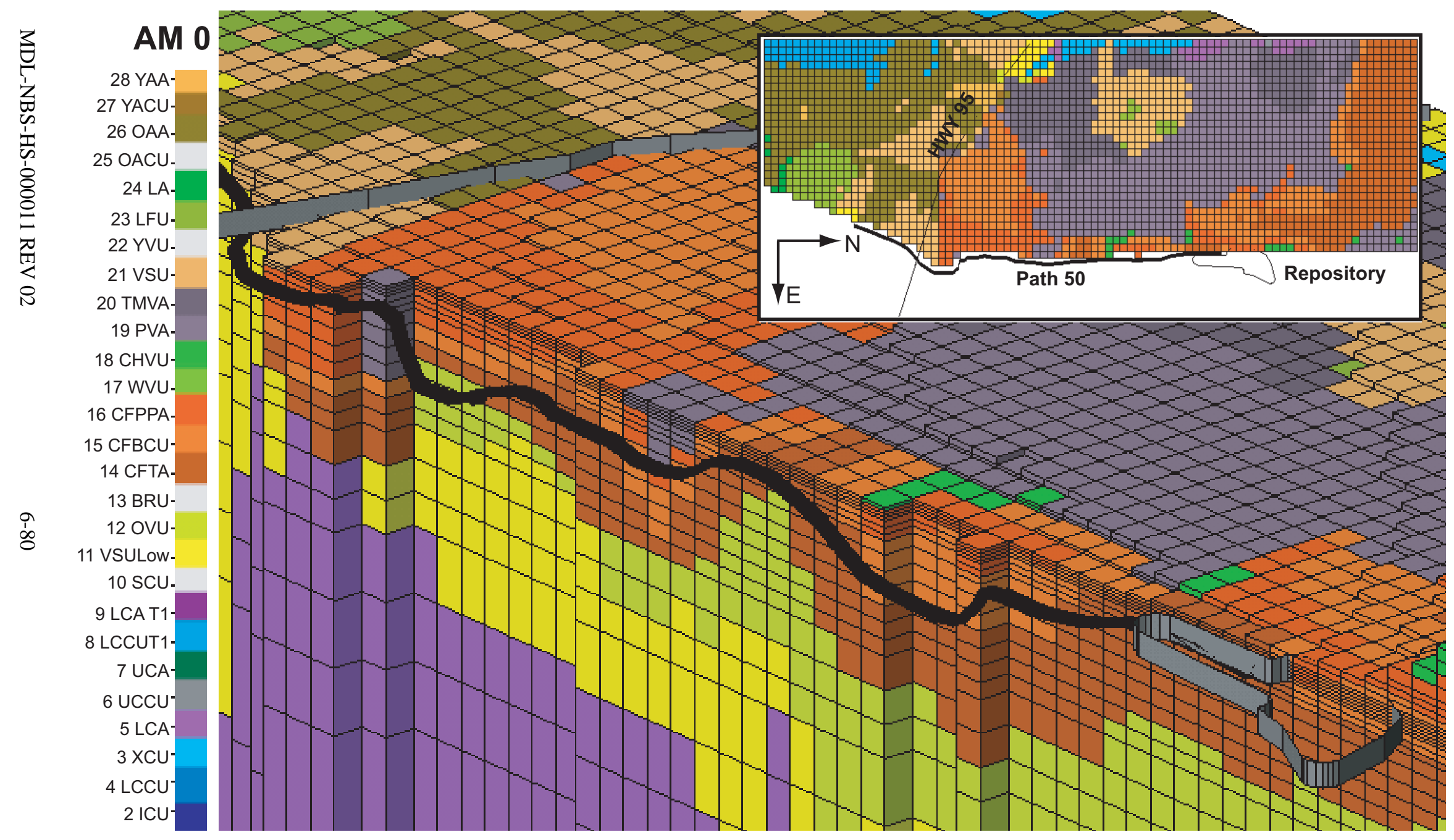

NOTE: For illustration purposes only. This alternative conceptualization is included in Output DTN: LA0409GZ831231.001. 


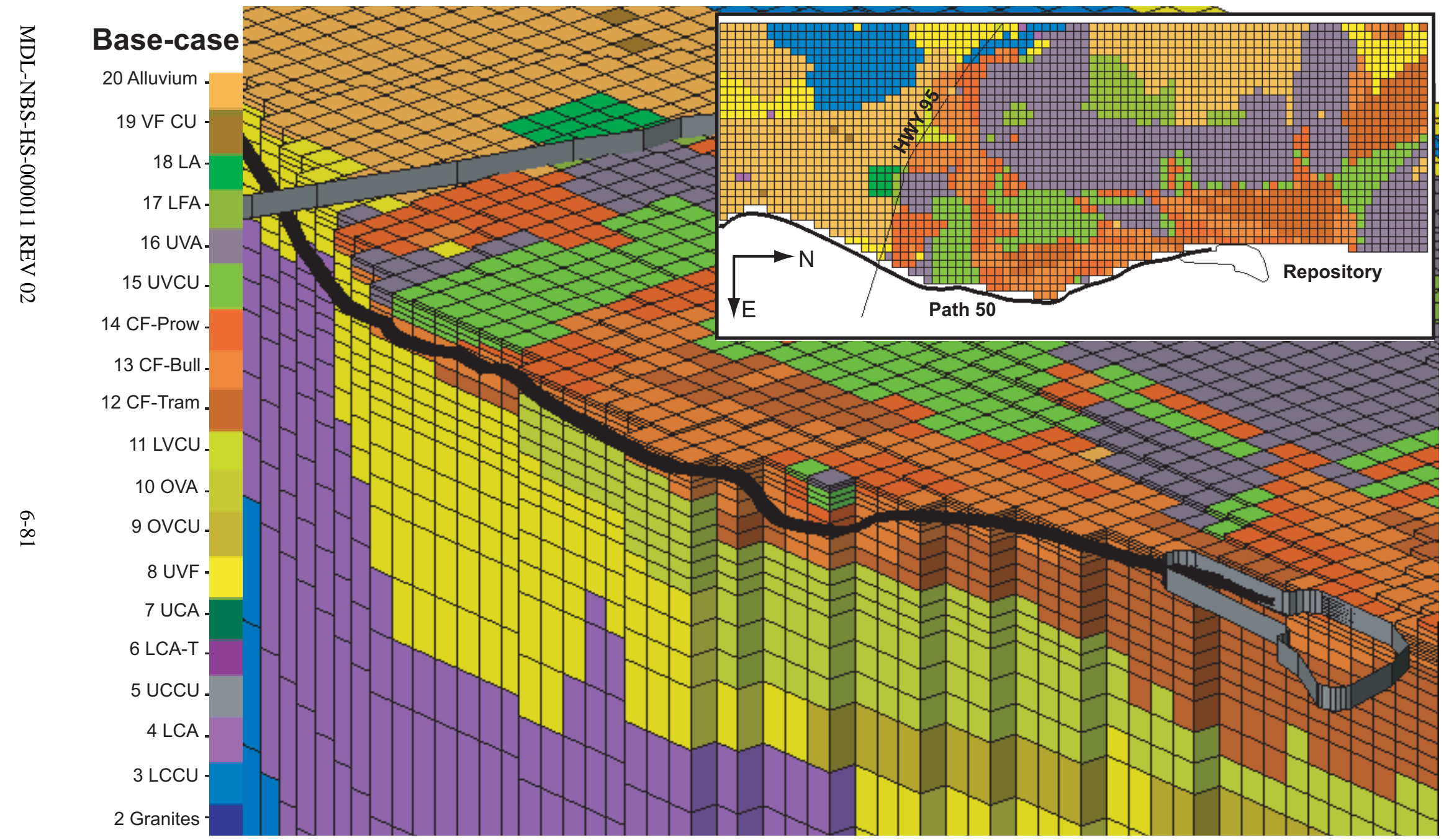

Output DTN: LA034TM831231.002. 


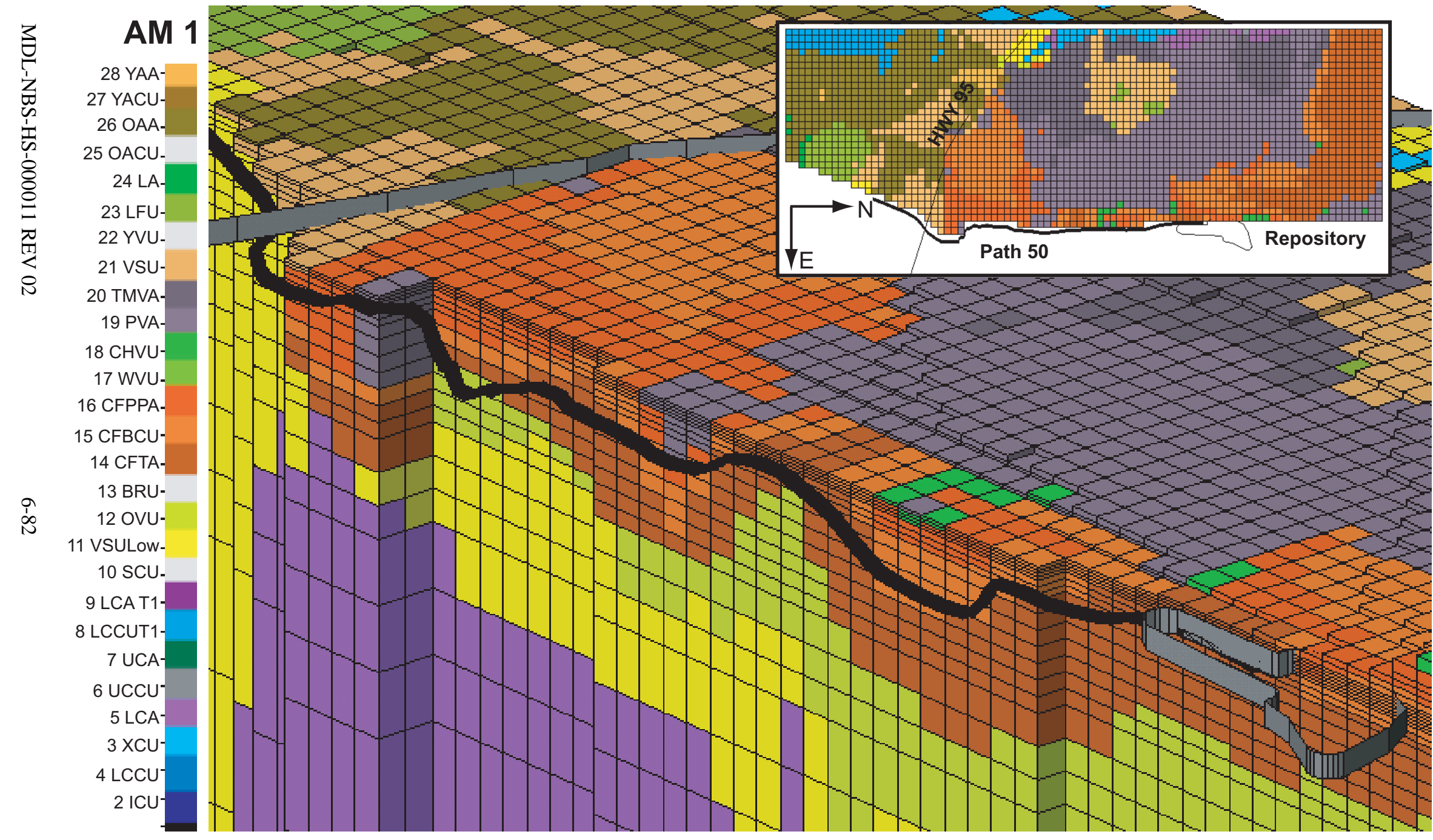

Output DTNs: LA0409GZ831231.002, LA0409GZ831231.003.

NOTE: For illustration purposes only.

UTM = Universal Transverse Mercator.

Figure 6-25. Views of Hydrostratigraphy Along Particle Path 50 for Alternate Flow Models AM1 and AM2 


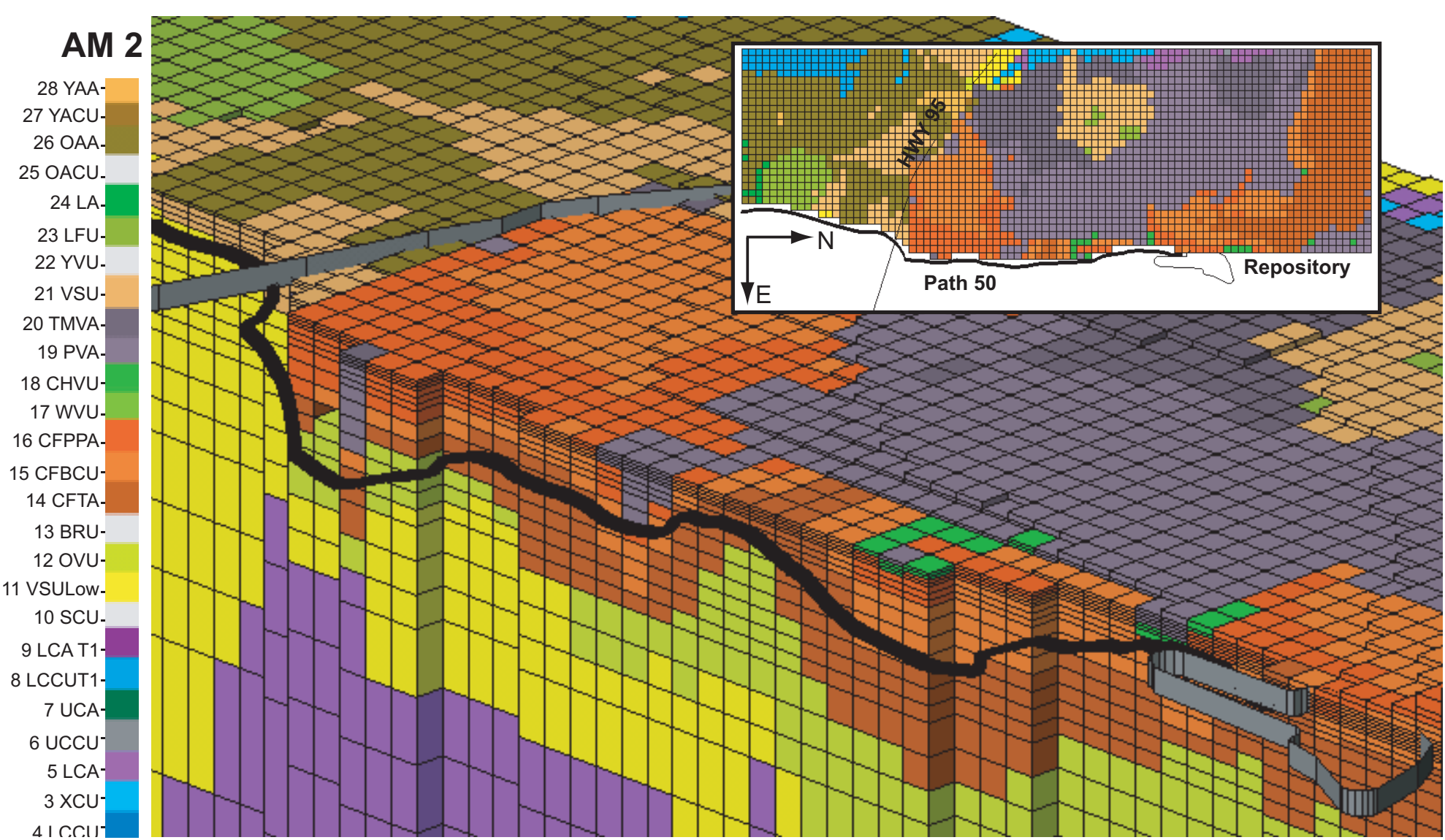

Output DTNs: LA0409GZ831231.002, LA0409GZ831231.003.

NOTE: For illustration purposes only. These views were created by selecting particle path number 50 from each set of model results. The computational grid is sliced along the path and blocks west of the path are removed. Grid blocks above the water table surface are removed. The location of 95 and the repository are included for reference and both objects sit at elevation 700 meters. The view is looking south and west with the particle path shown as a black ribbon along the vertical face of the grid and originating near the repository outline. The grid elevation has been exaggerated $5 x$ for easier viewing. Colors in these images represent the hydrogeologic units as defined by the input HFM and do not include additional zones defined for the models.

UTM = Universal Transverse Mercator

Figure 6-25. Views of Hydrostratigraphy Along Particle Path 50 for Alternate Flow Models AM1 and AM2 (Continued) 


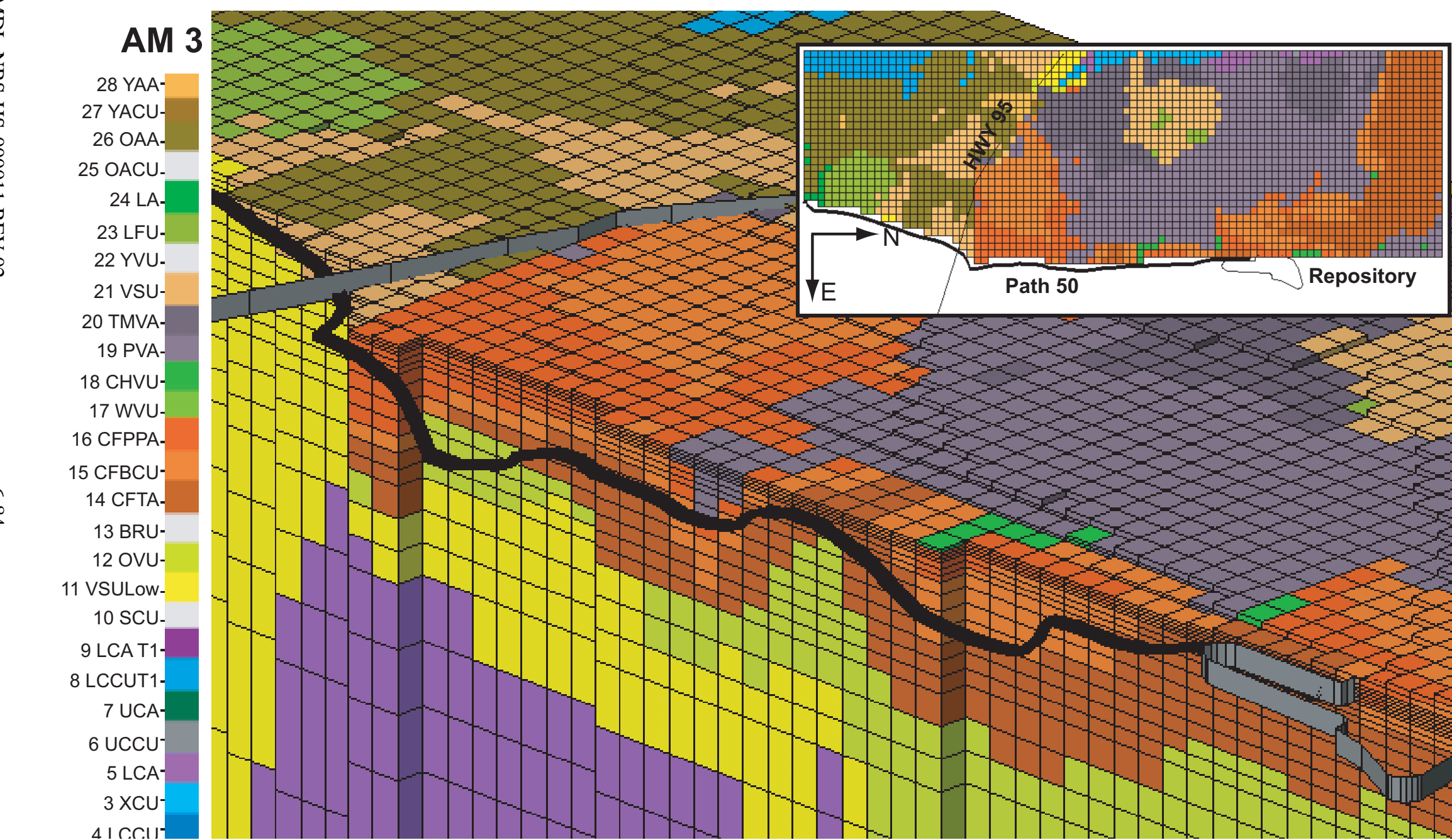




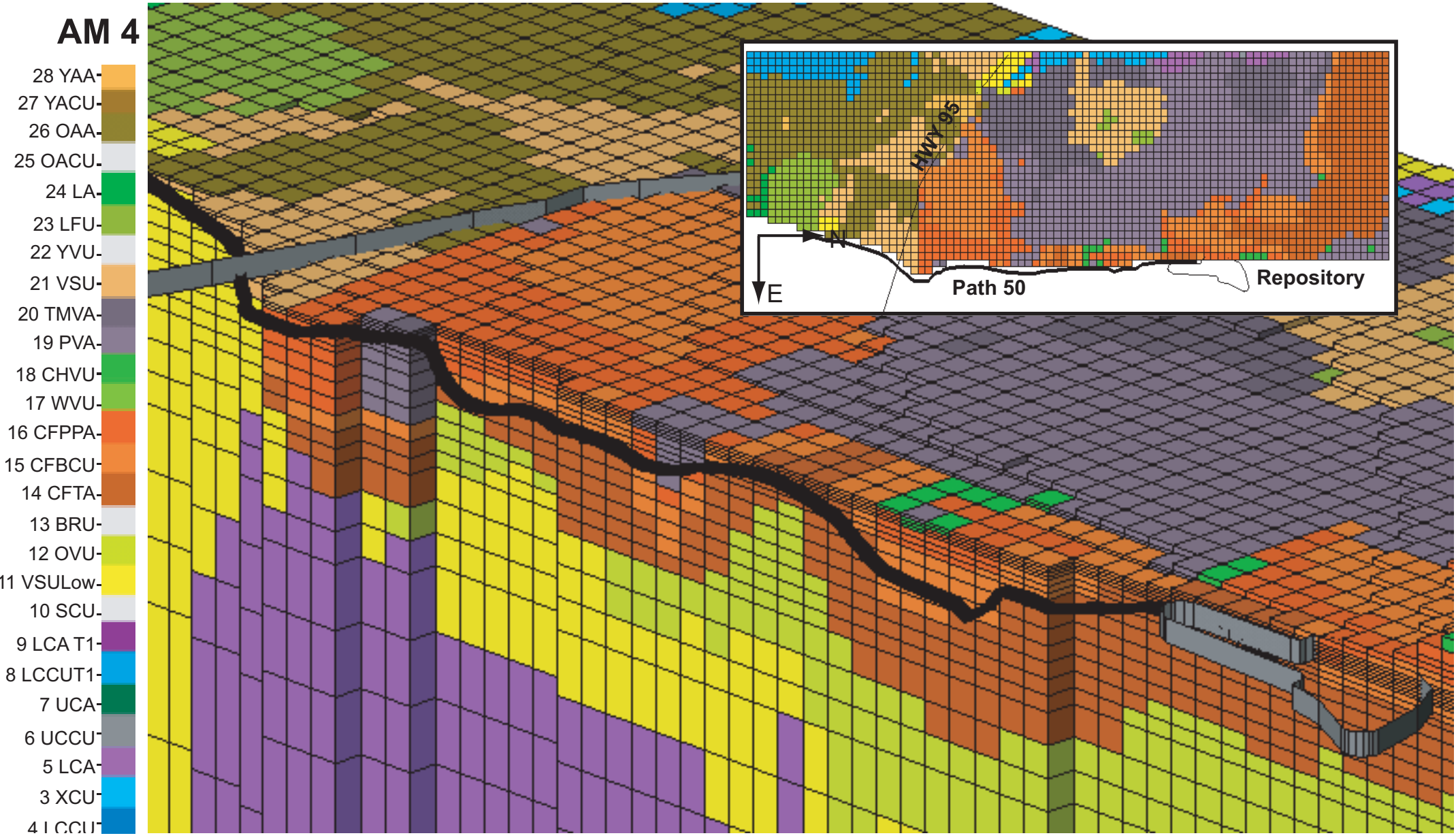

Output DTNs: LA0409GZ831231.004, LA0409GZ831231.005.

NOTE: These views were created by selecting particle path number 50 from each set of model results. The computational grid is sliced along the path and blocks west of the path are removed. Grid blocks above the water table surface are removed. The location of Hwy 95 and the repository are included for reference and both objects sit at elevation 700 meters. The view is looking south and west with the particle path shown as a black ribbon along the vertical face of the grid and originating near the repository outline. The grid elevation has been exaggerated $5 x$ for easier viewing. Colors in these images represent the hydrogeologic units as defined by the input HFM and do not include additional zones defined for the models.

UTM = Universal Transverse Mercator.

Figure 6-26. Views of Hydrostratigraphy along Particle Path 50 for Alternate Flow Models AM3 and AM4 (Continued) 


\subsection{Calibration Results: Sensitivity}

Parameter sensitivity is defined as the ratio of changes in calibration head in response to change in a given calibration parameter. Tables 6-9 and 6-10 present calibration sensitivity to the calibration parameters used to rank the importance of the parameters to model calibration for the alternate flow models.

Because hydrostratigraphic units are broken into northern and southern groups, there are 34 model parameters that have sensitivities greater than 0.1 . If northern and southern parameters are grouped, the 34 model parameters are reduced to 28 parameters with sensitivity greater than 0.1 .

Table 6-9. Parameter Sensitivity Over All Observation Groups

\begin{tabular}{|c|c|c|c|c|c|}
\hline \multirow[b]{2}{*}{ Parameter Name } & \multicolumn{5}{|c|}{ Sensitivity over all observation groups } \\
\hline & AMO & AM1 & AM2 & AM3 & AM4 \\
\hline Intr & $5.295 \mathrm{E}-01$ & 5.569E-01 & $5.469 \mathrm{E}-01$ & 5.795E-01 & 5.892E-01 \\
\hline Gran & 3.477E+00 & $3.718 \mathrm{E}+00$ & 4.638E-02 & $2.030 \mathrm{E}+00$ & $1.762 \mathrm{E}+00$ \\
\hline Lcla & 1.199E-02 & $1.850 \mathrm{E}-02$ & 8.787E-03 & 7.786E-03 & 6.125E-03 \\
\hline Lcar & 1.793E-01 & 1.450E-01 & $1.369 \mathrm{E}-01$ & 1.842E-01 & $2.524 \mathrm{E}-01$ \\
\hline Ucla & $2.018 \mathrm{E}-01$ & $1.545 \mathrm{E}+00$ & 2.663E-02 & 1.197E-02 & 1.356E-01 \\
\hline Ucar & 1.106E-01 & $9.434 \mathrm{E}-02$ & $1.341 \mathrm{E}-01$ & 1.477E-01 & 7.343E-01 \\
\hline Lclat & $1.266 \mathrm{E}-01$ & $1.402 \mathrm{E}-01$ & 8.945E-02 & 7.971E-02 & 4.410E-02 \\
\hline Lcart & 8.223E-01 & 7.103E-01 & 7.270E-01 & 7.438E-01 & 5.178E-01 \\
\hline Scon & 4.740E-03 & 6.389E-02 & $4.505 \mathrm{E}-03$ & 4.798E-03 & 4.741E-03 \\
\hline Vsul & $1.689 \mathrm{E}-01$ & 1.883E-01 & $1.126 \mathrm{E}-01$ & 7.515E-02 & 4.218E-02 \\
\hline Ovoa & $1.540 \mathrm{E}-01$ & $1.368 \mathrm{E}-01$ & 1.970E-01 & 1.957E-01 & $2.268 \mathrm{E}-01$ \\
\hline Belt & 4.739E-03 & 4.794E-02 & 4.505E-03 & 4.739E-03 & 4.739E-03 \\
\hline Tram & $1.122 \mathrm{E}+00$ & 1.167E+00 & $3.048 \mathrm{E}+00$ & $1.436 \mathrm{E}+00$ & $1.264 \mathrm{E}+00$ \\
\hline Bull & $1.043 \mathrm{E}+00$ & $1.187 \mathrm{E}+00$ & $5.989 \mathrm{E}-01$ & $1.091 \mathrm{E}+00$ & $6.854 \mathrm{E}-01$ \\
\hline Prow & $1.355 \mathrm{E}-01$ & $2.128 \mathrm{E}+00$ & 7.830E-02 & $9.138 \mathrm{E}-02$ & $9.072 \mathrm{E}-02$ \\
\hline Wahm & 7.067E-03 & $1.527 \mathrm{E}-02$ & $9.086 \mathrm{E}-03$ & 1.036E-02 & 1.393E-02 \\
\hline Cali & $1.034 \mathrm{E}+00$ & $1.085 \mathrm{E}+00$ & $9.608 \mathrm{E}-01$ & $1.021 \mathrm{E}+00$ & $1.038 \mathrm{E}+00$ \\
\hline Pain & 3.785E-01 & 4.427E-01 & $5.179 \mathrm{E}-01$ & 5.824E-01 & 9.589E-01 \\
\hline Timb & 4.006E-01 & $5.540 \mathrm{E}-01$ & $1.182 \mathrm{E}+00$ & $9.980 \mathrm{E}-01$ & $8.716 \mathrm{E}-01$ \\
\hline Vose & 9.742E-01 & $1.455 \mathrm{E}+00$ & $1.032 \mathrm{E}+00$ & 8.369E-01 & 7.914E-01 \\
\hline Uvoa & 4.739E-03 & $5.840 \mathrm{E}-02$ & 1.303E-01 & $2.555 \mathrm{E}-01$ & 4.739E-03 \\
\hline Lava & 2.563E-02 & $6.683 \mathrm{E}-02$ & $2.436 \mathrm{E}-02$ & 3.977E-02 & 4.367E-02 \\
\hline Lime & 4.746E-03 & 5.536E-02 & $4.511 \mathrm{E}-03$ & 4.744E-03 & 4.743E-03 \\
\hline Oalc & 4.740E-03 & 5.535E-02 & 4.505E-03 & 4.748E-03 & 4.741E-03 \\
\hline Oala & 1.516E-02 & 6.354E-02 & $1.242 \mathrm{E}-02$ & 2.160E-02 & 2.214E-02 \\
\hline Yalc & 4.739E-03 & $5.350 \mathrm{E}-02$ & 4.505E-03 & 4.739E-03 & 4.739E-03 \\
\hline Yala & $4.741 \mathrm{E}-03$ & $5.349 \mathrm{E}-02$ & 4.557E-03 & 4.740E-03 & $4.763 \mathrm{E}-03$ \\
\hline
\end{tabular}


Table 6-9. Parameter Sensitivity Over All Observation Groups (Continued)

\begin{tabular}{|c|c|c|c|c|c|}
\hline \multirow[b]{2}{*}{ Parameter Name } & \multicolumn{5}{|c|}{ Sensitivity over all observation groups } \\
\hline & AMO & AM1 & AM2 & AM3 & AM4 \\
\hline Intrm & $5.257 \mathrm{E}-01$ & $5.531 \mathrm{E}-01$ & $5.421 \mathrm{E}-01$ & $5.775 \mathrm{E}-01$ & $5.866 \mathrm{E}-01$ \\
\hline Granm & $3.476 \mathrm{E}+00$ & $3.706 \mathrm{E}+00$ & 4.601E-02 & $2.031 \mathrm{E}+00$ & $1.762 \mathrm{E}+00$ \\
\hline Lclam & $5.591 \mathrm{E}-03$ & 4.393E-02 & $4.585 \mathrm{E}-03$ & $5.404 \mathrm{E}-03$ & $5.599 \mathrm{E}-03$ \\
\hline Lcarm & 4.438E-01 & 4.807E-01 & 4.334E-01 & 4.383E-01 & 4.249E-01 \\
\hline Uclam & $5.042 \mathrm{E}-03$ & 4.377E-02 & 4.556E-03 & 4.790E-03 & 4.799E-03 \\
\hline Ucarm & 1.105E-01 & 8.839E-02 & $1.341 \mathrm{E}-01$ & $1.476 \mathrm{E}-01$ & 7.343E-01 \\
\hline Lclatm & 4.739E-03 & 4.385E-02 & 4.505E-03 & 4.739E-03 & 4.739E-03 \\
\hline Lcartm & $4.739 \mathrm{E}-03$ & 4.385E-02 & 4.505E-03 & $4.739 \mathrm{E}-03$ & $4.739 \mathrm{E}-03$ \\
\hline sconm & 4.739E-03 & 4.385E-02 & $4.505 \mathrm{E}-03$ & $4.739 \mathrm{E}-03$ & 4.739E-03 \\
\hline vsulm & 4.739E-03 & 4.384E-02 & 4.505E-03 & 4.739E-03 & 4.739E-03 \\
\hline ovoam & 4.748E-03 & 4.376E-02 & 4.511E-03 & 4.761E-03 & 4.799E-03 \\
\hline beltm & $4.739 \mathrm{E}-03$ & 4.375E-02 & $4.505 \mathrm{E}-03$ & $4.739 \mathrm{E}-03$ & $4.739 \mathrm{E}-03$ \\
\hline tramm & $5.766 \mathrm{E}-01$ & 4.316E-01 & $4.070 \mathrm{E}+00$ & $1.191 \mathrm{E}+00$ & $1.214 \mathrm{E}+00$ \\
\hline bullm & 7.952E-03 & $5.119 \mathrm{E}-02$ & $5.864 \mathrm{E}-03$ & 6.073E-03 & $5.286 \mathrm{E}-03$ \\
\hline prowm & $4.827 \mathrm{E}-03$ & 8.917E-02 & 4.510E-03 & $4.790 \mathrm{E}-03$ & 4.809E-03 \\
\hline wahmm & $4.739 \mathrm{E}-03$ & 7.661E-02 & $4.505 \mathrm{E}-03$ & $4.739 \mathrm{E}-03$ & 4.739E-03 \\
\hline calim & $2.976 \mathrm{E}-01$ & 4.395E-01 & 3.862E-01 & 6.668E-01 & 3.824E-01 \\
\hline painm & $8.235 \mathrm{E}-03$ & $2.144 \mathrm{E}-01$ & 7.227E-03 & 4.936E-03 & 5.551E-03 \\
\hline timbm & 8.233E-02 & $2.000 \mathrm{E}-01$ & 5.713E-01 & $2.539 \mathrm{E}-02$ & 6.395E-03 \\
\hline vosem & 3.776E-02 & 4.994E-02 & 4.505E-03 & 6.791E-02 & 3.590E-01 \\
\hline uvoam & 6.078E-02 & 4.993E-02 & $4.505 \mathrm{E}-03$ & 1.313E-02 & $2.072 \mathrm{E}-01$ \\
\hline lavam & $6.543 \mathrm{E}-02$ & 6.627E-02 & $4.505 \mathrm{E}-03$ & $2.976 \mathrm{E}-02$ & $1.083 \mathrm{E}-02$ \\
\hline limem & 5.607E-02 & $5.821 \mathrm{E}-02$ & 4.505E-03 & $5.468 \mathrm{E}-03$ & 3.181E-02 \\
\hline oalcm & $1.522 \mathrm{E}-02$ & $9.416 \mathrm{E}-02$ & 4.505E-03 & 2.632E-02 & 7.004E-03 \\
\hline oalam & $6.104 \mathrm{E}-03$ & $5.219 \mathrm{E}-02$ & $4.505 \mathrm{E}-03$ & $5.839 \mathrm{E}-03$ & 4.819E-03 \\
\hline yalcm & 5.667E-02 & 5.617E-02 & $4.505 \mathrm{E}-03$ & $6.805 \mathrm{E}-03$ & $3.884 \mathrm{E}-02$ \\
\hline yalam & 3.719E-02 & $5.139 \mathrm{E}-02$ & 4.505E-03 & $1.509 \mathrm{E}-02$ & 4.619E-02 \\
\hline nsba & 7.034E-01 & 7.678E-01 & 5.950E-01 & 7.227E-01 & 7.034E-01 \\
\hline nssb & 1.277E-02 & 4.966E-02 & $6.119 \mathrm{E}-03$ & $2.024 \mathrm{E}-02$ & 4.873E-03 \\
\hline nsym & 4.853E-03 & 4.908E-02 & 4.576E-03 & $4.825 \mathrm{E}-03$ & 4.786E-03 \\
\hline nszm & 7.614E-01 & 4.069E-01 & 8.646E-01 & 5.332E-01 & $1.991 \mathrm{E}-01$ \\
\hline scfs & $1.688 \mathrm{E}-01$ & 2.413E-01 & 2.124E-01 & $1.802 \mathrm{E}-01$ & $1.820 \mathrm{E}-01$ \\
\hline wa40 & $5.422 \mathrm{E}-01$ & $5.989 \mathrm{E}-01$ & 5.778E-01 & $6.215 \mathrm{E}-01$ & 6.339E-01 \\
\hline tramy & $1.680 \mathrm{E}-01$ & $2.521 \mathrm{E}-01$ & 8.637E-02 & $2.124 \mathrm{E}-01$ & $9.845 \mathrm{E}-02$ \\
\hline bully & $3.450 \mathrm{E}-01$ & 7.163E-01 & 3.643E-01 & 4.572E-01 & $9.565 \mathrm{E}-02$ \\
\hline prowy & 8.589E-02 & $1.568 \mathrm{E}-01$ & 4.802E-02 & $6.939 \mathrm{E}-02$ & 5.122E-02 \\
\hline Intre & 5.837E-03 & $1.094 \mathrm{E}-01$ & 5.107E-03 & $5.121 \mathrm{E}-03$ & 4.927E-03 \\
\hline Icare & $2.869 \mathrm{E}-01$ & 3.151E-01 & $2.787 \mathrm{E}-01$ & 3.962E-01 & 3.578E-01 \\
\hline Iclate & $1.230 \mathrm{E}-02$ & 1.070E-01 & $1.372 \mathrm{E}-02$ & $2.062 \mathrm{E}-02$ & $2.569 \mathrm{E}-02$ \\
\hline Icarte & 8.464E-02 & 1.094E-01 & 1.342E-01 & 7.147E-02 & $4.148 \mathrm{E}-02$ \\
\hline
\end{tabular}


Table 6-9. Parameter Sensitivity Over All Observation Groups (Continued)

\begin{tabular}{|c|c|c|c|c|c|}
\hline \multirow[b]{2}{*}{ Parameter Name } & \multicolumn{5}{|c|}{ Sensitivity over all observation groups } \\
\hline & AMO & AM1 & AM2 & AM3 & AM4 \\
\hline $\mathrm{Cffz}$ & 8.493E-01 & 9.063E-01 & 1.163E-01 & $9.740 \mathrm{E}-01$ & 6.927E-01 \\
\hline $\mathrm{cff1}$ & $1.510 \mathrm{E}+00$ & $1.628 \mathrm{E}+00$ & $7.122 \mathrm{E}-01$ & $1.234 \mathrm{E}+00$ & $1.531 \mathrm{E}+00$ \\
\hline hy95 & $5.468 \mathrm{E}-01$ & 4.817E-01 & $1.280 \mathrm{E}+00$ & 5.979E-01 & 9.705E-01 \\
\hline wash & $1.651 \mathrm{E}+00$ & $1.825 \mathrm{E}+00$ & $1.691 \mathrm{E}+00$ & $1.862 \mathrm{E}+00$ & $1.865 \mathrm{E}+00$ \\
\hline nwtf & 7.590E-02 & $1.045 \mathrm{E}-01$ & 4.944E-02 & $6.217 \mathrm{E}-02$ & 4.962E-02 \\
\hline dune & $5.176 \mathrm{E}-03$ & 7.213E-02 & 4.687E-03 & 4.967E-03 & 5.714E-03 \\
\hline ghos & $1.248 \mathrm{E}-02$ & $7.410 \mathrm{E}-02$ & $6.323 \mathrm{E}-03$ & $1.910 \mathrm{E}-02$ & $6.737 \mathrm{E}-03$ \\
\hline Intr & $1.715 \mathrm{E}-01$ & 3.864E-02 & $2.413 \mathrm{E}-01$ & 1.096E-01 & 1.558E-01 \\
\hline Gran & $6.772 \mathrm{E}-02$ & $1.640 \mathrm{E}+00$ & $1.394 \mathrm{E}-01$ & 1.179E-01 & 3.272E-02 \\
\hline Lcla & $9.092 \mathrm{E}-02$ & $1.385 \mathrm{E}-01$ & $2.038 \mathrm{E}-03$ & $2.466 \mathrm{E}-03$ & 1.685E-02 \\
\hline Lcar & 3.586E-01 & 2.302E-01 & $2.555 \mathrm{E}-01$ & $2.461 \mathrm{E}-01$ & 1.444E-01 \\
\hline Ucla & 8.955E-02 & 1.295E-01 & $2.090 \mathrm{E}-02$ & 7.396E-03 & 6.732E-02 \\
\hline Ucar & $9.454 \mathrm{E}-02$ & 1.150E-01 & 4.015E-04 & 5.933E-04 & 7.011E-02 \\
\hline Lclat & 1.593E-01 & 1.070E-01 & $5.210 \mathrm{E}-03$ & 3.371E-03 & 7.300E-02 \\
\hline Lcart & $1.201 \mathrm{E}+00$ & $1.067 \mathrm{E}+00$ & $1.425 \mathrm{E}+00$ & 6.986E-01 & 5.394E-02 \\
\hline Scon & $1.277 \mathrm{E}-02$ & $1.538 \mathrm{E}-01$ & 5.334E-01 & 1.100E-03 & 5.464E-02 \\
\hline Vsul & 3.412E-01 & 1.277E-01 & 5.723E-02 & 7.174E-03 & $5.330 \mathrm{E}-02$ \\
\hline Ovoa & $5.438 \mathrm{E}-01$ & 8.890E-01 & $6.380 \mathrm{E}-01$ & 8.701E-01 & $1.031 \mathrm{E}+00$ \\
\hline Belt & 1.677E-01 & 1.574E-01 & $6.918 \mathrm{E}-05$ & 1.033E-05 & 5.380E-02 \\
\hline Tram & $5.883 \mathrm{E}+00$ & $1.238 \mathrm{E}+01$ & $7.835 \mathrm{E}+00$ & $5.106 \mathrm{E}+00$ & $4.839 \mathrm{E}+00$ \\
\hline Bull & $1.559 \mathrm{E}+00$ & $1.971 \mathrm{E}+00$ & $6.223 \mathrm{E}+00$ & 7.125E-01 & $1.906 \mathrm{E}+00$ \\
\hline Prow & $9.502 \mathrm{E}-01$ & 4.720E-01 & 6.777E-01 & 5.857E-01 & 4.860E-01 \\
\hline wahm & 3.148E-01 & 3.979E-01 & $3.657 \mathrm{E}-02$ & 4.039E-02 & 3.470E-01 \\
\hline Cali & $1.206 \mathrm{E}+00$ & $2.316 \mathrm{E}+00$ & $2.247 \mathrm{E}+00$ & $4.023 E+00$ & $3.999 \mathrm{E}+00$ \\
\hline Pain & $1.097 \mathrm{E}+00$ & $2.468 \mathrm{E}+00$ & $1.528 \mathrm{E}+00$ & $1.302 \mathrm{E}+00$ & $1.233 \mathrm{E}+00$ \\
\hline Timb & $1.039 \mathrm{E}+00$ & $2.495 E+00$ & 7.026E-01 & 2.373E-01 & $1.859 \mathrm{E}+00$ \\
\hline Vose & $4.628 \mathrm{E}+00$ & $1.830 \mathrm{E}+01$ & $3.512 \mathrm{E}+00$ & $4.661 \mathrm{E}+00$ & $6.033 \mathrm{E}+00$ \\
\hline Uvoa & $2.444 \mathrm{E}-01$ & 3.331E-02 & $1.299 \mathrm{E}-04$ & 3.156E-05 & $6.024 \mathrm{E}-02$ \\
\hline Lava & 3.191E-01 & 3.797E-02 & $8.208 \mathrm{E}-02$ & 1.134E-01 & 1.190E-01 \\
\hline Lime & 3.104E-01 & 3.502E-02 & $7.532 \mathrm{E}-05$ & 1.309E-04 & 1.221E-01 \\
\hline Oalc & 3.104E-01 & $3.508 \mathrm{E}-02$ & 3.655E-04 & 1.043E-03 & 1.223E-01 \\
\hline Oala & 3.075E-01 & $6.581 \mathrm{E}-01$ & $2.552 \mathrm{E}-03$ & 5.403E-03 & 1.343E-01 \\
\hline Yalc & $3.025 \mathrm{E}-01$ & 1.249E-01 & $2.144 \mathrm{E}-04$ & $1.571 \mathrm{E}-04$ & 1.435E-01 \\
\hline Yala & $3.024 \mathrm{E}-01$ & 1.243E-01 & $2.385 \mathrm{E}-05$ & 3.135E-05 & $1.436 \mathrm{E}-01$ \\
\hline Intrm & 1.963E-01 & 1.186E-01 & $2.562 \mathrm{E}-01$ & 1.349E-01 & 9.985E-02 \\
\hline granm & $2.147 \mathrm{E}-01$ & $1.615 \mathrm{E}+00$ & $1.292 \mathrm{E}-01$ & 1.160E-01 & 4.193E-02 \\
\hline Lclam & 2.203E-01 & $2.632 \mathrm{E}-01$ & 3.910E-04 & 3.039E-04 & $9.866 \mathrm{E}-02$ \\
\hline Icarm & 1.863E-01 & $2.348 \mathrm{E}-01$ & $5.866 \mathrm{E}-02$ & 3.744E-02 & 1.097E-01 \\
\hline uclam & $2.249 \mathrm{E}-01$ & 1.886E-01 & 1.187E-04 & $1.272 \mathrm{E}-04$ & $8.425 \mathrm{E}-02$ \\
\hline ucarm & 2.293E-01 & 1.649E-01 & 3.097E-04 & 3.263E-04 & 7.883E-02 \\
\hline
\end{tabular}


Table 6-9. Parameter Sensitivity Over All Observation Groups (Continued)

\begin{tabular}{|c|c|c|c|c|c|}
\hline \multirow[b]{2}{*}{ Parameter Name } & \multicolumn{5}{|c|}{ Sensitivity over all observation groups } \\
\hline & AMO & AM1 & AM2 & AM3 & AM4 \\
\hline Iclatm & 2.329E-01 & $1.516 \mathrm{E}-01$ & $1.611 \mathrm{E}-05$ & $1.110 \mathrm{E}-05$ & 7.386E-02 \\
\hline Icartm & 2.329E-01 & $1.509 \mathrm{E}-01$ & 4.041E-05 & $1.319 \mathrm{E}-05$ & 7.377E-02 \\
\hline sconm & $2.330 \mathrm{E}-01$ & 1.502E-01 & 1.146E-04 & 1.994E-05 & $7.350 \mathrm{E}-02$ \\
\hline vsulm & $2.331 \mathrm{E}-01$ & 1.496E-01 & $2.911 \mathrm{E}-05$ & 1.863E-05 & 7.336E-02 \\
\hline ovoam & 2.342E-01 & $1.441 \mathrm{E}-01$ & 3.465E-03 & $1.830 \mathrm{E}-04$ & 7.148E-02 \\
\hline beltm & 2.349E-01 & $1.390 \mathrm{E}-01$ & 6.656E-06 & 3.694E-06 & 6.966E-02 \\
\hline tramm & $1.586 \mathrm{E}+00$ & $2.321 \mathrm{E}-01$ & $1.159 \mathrm{E}+01$ & $3.148 \mathrm{E}+00$ & $4.288 \mathrm{E}+00$ \\
\hline bullm & 1.820E-01 & 2.154E-01 & $2.918 \mathrm{E}-03$ & $5.622 \mathrm{E}-03$ & 2.661E-01 \\
\hline prowm & 1.819E-01 & $2.016 \mathrm{E}-01$ & $2.209 \mathrm{E}-04$ & $6.004 \mathrm{E}-04$ & 4.220E-02 \\
\hline wahmm & $1.824 \mathrm{E}-01$ & 1.913E-01 & $1.101 \mathrm{E}-06$ & 3.821E-06 & 3.834E-02 \\
\hline calim & $1.084 \mathrm{E}+00$ & $1.864 \mathrm{E}+00$ & $1.999 \mathrm{E}+00$ & $3.870 \mathrm{E}+00$ & $3.784 \mathrm{E}+00$ \\
\hline painm & 5.414E-01 & $1.878 \mathrm{E}-01$ & 4.688E-02 & $2.374 \mathrm{E}-02$ & 1.604E-01 \\
\hline timbm & 4.767E-01 & $1.354 \mathrm{E}-01$ & $3.954 \mathrm{E}-01$ & 4.029E-01 & $1.561 \mathrm{E}-01$ \\
\hline vosem & 4.718E-01 & 1.346E-01 & 3.680E-05 & 4.942E-05 & 1.409E-01 \\
\hline uvoam & 4.711E-01 & $1.341 \mathrm{E}-01$ & 1.429E-04 & $5.285 \mathrm{E}-05$ & $1.408 \mathrm{E}-01$ \\
\hline lavam & 4.707E-01 & $1.335 \mathrm{E}-01$ & $2.125 \mathrm{E}-04$ & 3.153E-05 & 1.407E-01 \\
\hline limem & 4.703E-01 & 1.331E-01 & 4.692E-04 & $6.032 \mathrm{E}-04$ & 1.406E-01 \\
\hline oalcm & 4.623E-01 & $1.326 \mathrm{E}-01$ & $1.081 \mathrm{E}-04$ & $2.021 \mathrm{E}-04$ & $1.390 \mathrm{E}-01$ \\
\hline oalam & 4.620E-01 & $1.318 \mathrm{E}-01$ & 1.815E-04 & $1.595 \mathrm{E}-03$ & 1.389E-01 \\
\hline yalcm & 4.592E-01 & $1.314 \mathrm{E}-01$ & 4.657E-04 & $6.248 \mathrm{E}-05$ & 1.376E-01 \\
\hline yalam & 4.587E-01 & 1.307E-01 & 7.668E-05 & 8.647E-05 & 1.375E-01 \\
\hline nsba & $3.035 \mathrm{E}+00$ & 2.331E-01 & $2.214 \mathrm{E}+00$ & $1.931 \mathrm{E}+00$ & $2.332 \mathrm{E}+00$ \\
\hline nssb & 5.162E-01 & $1.101 \mathrm{E}-01$ & 4.438E-02 & $1.435 \mathrm{E}-02$ & $9.249 \mathrm{E}-02$ \\
\hline nsym & $2.256 \mathrm{E}-01$ & 1.063E-01 & 6.594E-02 & 2.137E-02 & $9.386 \mathrm{E}-02$ \\
\hline nszm & 5.617E-01 & $1.005 \mathrm{E}-01$ & $1.774 \mathrm{E}+00$ & 8.866E-01 & 4.426E-01 \\
\hline scfs & 3.450E-01 & 3.637E-01 & 3.786E-01 & 4.396E-01 & $2.660 \mathrm{E}-01$ \\
\hline Wa40 & 4.836E-01 & $1.540 \mathrm{E}+00$ & $5.721 \mathrm{E}+00$ & 4.564E-01 & 4.409E-01 \\
\hline tramy & $1.710 \mathrm{E}+00$ & 8.188E-01 & $5.722 \mathrm{E}+00$ & $1.113 \mathrm{E}+00$ & $6.546 \mathrm{E}-01$ \\
\hline bully & $3.558 \mathrm{E}+00$ & 9.273E-01 & $1.731 \mathrm{E}+00$ & $1.306 \mathrm{E}+00$ & $1.701 \mathrm{E}+00$ \\
\hline prowy & 8.141E-01 & $2.201 \mathrm{E}-01$ & $6.336 \mathrm{E}+00$ & 2.011E-01 & $1.714 \mathrm{E}+00$ \\
\hline intre & 2.867E-01 & 4.121E-02 & $3.128 \mathrm{E}-03$ & 3.742E-03 & 2.843E-01 \\
\hline Icare & $2.956 \mathrm{E}-01$ & $4.289 \mathrm{E}-02$ & $6.589 \mathrm{E}-03$ & $6.968 \mathrm{E}-03$ & 2.790E-01 \\
\hline Iclate & 2.917E-01 & $4.255 \mathrm{E}-02$ & $2.714 \mathrm{E}-03$ & $1.178 \mathrm{E}-02$ & $2.715 \mathrm{E}-01$ \\
\hline Icarte & 5.963E-01 & $5.685 \mathrm{E}-02$ & $1.046 \mathrm{E}+00$ & 5.986E-01 & $1.596 \mathrm{E}-01$ \\
\hline cffz & $7.380 \mathrm{E}-01$ & $1.369 \mathrm{E}+00$ & $3.021 \mathrm{E}-01$ & $1.272 \mathrm{E}+00$ & $1.216 \mathrm{E}+00$ \\
\hline Cff1 & $2.465 \mathrm{E}+00$ & $2.221 \mathrm{E}+01$ & $2.070 \mathrm{E}+00$ & $3.084 \mathrm{E}+00$ & $4.195 E+00$ \\
\hline hy95 & $1.693 E+00$ & $1.954 \mathrm{E}+00$ & 3.844E-01 & 5.661E-01 & $1.568 \mathrm{E}+00$ \\
\hline wash & $1.241 \mathrm{E}+01$ & $1.075 \mathrm{E}+00$ & $1.228 \mathrm{E}+01$ & $1.322 \mathrm{E}+01$ & $1.591 \mathrm{E}+01$ \\
\hline
\end{tabular}


Table 6-9. Parameter Sensitivity Over All Observation Groups (Continued)

\begin{tabular}{|c|c|c|c|c|c|}
\hline \multirow{2}{*}{ Parameter Name } & \multicolumn{5}{|c|}{ Sensitivity over all observation groups } \\
\cline { 2 - 6 } & AM0 & AM1 & AM2 & AM3 & AM4 \\
\hline nwtf & $2.143 \mathrm{E}-01$ & $9.561 \mathrm{E}-02$ & $6.586 \mathrm{E}-02$ & $6.843 \mathrm{E}-02$ & $1.522 \mathrm{E}-01$ \\
\hline dune & $1.883 \mathrm{E}-01$ & $9.673 \mathrm{E}-02$ & $3.708 \mathrm{E}-02$ & $1.534 \mathrm{E}-02$ & $1.235 \mathrm{E}-01$ \\
\hline ghos & $2.532 \mathrm{E}-01$ & $2.028 \mathrm{E}-01$ & $5.929 \mathrm{E}+00$ & $1.045 \mathrm{E}-01$ & $1.243 \mathrm{E}-01$ \\
\hline
\end{tabular}

Output DTNs: LA0409GZ831231.001, LA0409GZ831231.002, LA0409GZ831231.003, LA0409GZ831231.004, LA0409GZ831231.005

$\mathrm{AM}=$ alternate model

Table 6-10. Parameter Sensitivity Over Observation Group Path

\begin{tabular}{|c|c|c|c|c|c|}
\hline \multirow{2}{*}{ Parameter Name } & \multicolumn{5}{|c|}{ Sensitivity over observation group PATH } \\
\cline { 2 - 6 } & AM0 & AM1 & AM2 & AM3 & AM4 \\
\hline Lcart & $1.201 \mathrm{E}+00$ & $1.067 \mathrm{E}+00$ & $1.425 \mathrm{E}+00$ & $6.986 \mathrm{E}-01$ & $5.394 \mathrm{E}-02$ \\
\hline Tram & $5.883 \mathrm{E}+00$ & $1.238 \mathrm{E}+01$ & $7.835 \mathrm{E}+00$ & $5.106 \mathrm{E}+00$ & $4.839 \mathrm{E}+00$ \\
\hline Prow & $9.502 \mathrm{E}-01$ & $4.720 \mathrm{E}-01$ & $6.777 \mathrm{E}-01$ & $5.857 \mathrm{E}-01$ & $4.860 \mathrm{E}-01$ \\
\hline Cali & $1.206 \mathrm{E}+00$ & $2.316 \mathrm{E}+00$ & $2.247 \mathrm{E}+00$ & $4.023 \mathrm{E}+00$ & $3.999 \mathrm{E}+00$ \\
\hline Pain & $1.097 \mathrm{E}+00$ & $2.468 \mathrm{E}+00$ & $1.528 \mathrm{E}+00$ & $1.302 \mathrm{E}+00$ & $1.233 \mathrm{E}+00$ \\
\hline Timb & $1.039 \mathrm{E}+00$ & $2.495 \mathrm{E}+00$ & $7.026 \mathrm{E}-01$ & $2.373 \mathrm{E}-01$ & $1.859 \mathrm{E}+00$ \\
\hline Vose & $4.628 \mathrm{E}+00$ & $1.830 \mathrm{E}+01$ & $3.512 \mathrm{E}+00$ & $4.661 \mathrm{E}+00$ & $6.033 \mathrm{E}+00$ \\
\hline tramm & $1.586 \mathrm{E}+00$ & $2.321 \mathrm{E}-01$ & $1.159 \mathrm{E}+01$ & $3.148 \mathrm{E}+00$ & $4.288 \mathrm{E}+00$ \\
\hline calim & $1.084 \mathrm{E}+00$ & $1.864 \mathrm{E}+00$ & $1.999 \mathrm{E}+00$ & $3.870 \mathrm{E}+00$ & $3.784 \mathrm{E}+00$ \\
\hline nsba & $3.035 \mathrm{E}+00$ & $2.331 \mathrm{E}-01$ & $2.214 \mathrm{E}+00$ & $1.931 \mathrm{E}+00$ & $2.332 \mathrm{E}+00$ \\
\hline tramy & $1.710 \mathrm{E}+00$ & $8.188 \mathrm{E}-01$ & $5.722 \mathrm{E}+00$ & $1.113 \mathrm{E}+00$ & $6.546 \mathrm{E}-01$ \\
\hline bully & $3.558 \mathrm{E}+00$ & $9.273 \mathrm{E}-01$ & $1.731 \mathrm{E}+00$ & $1.306 \mathrm{E}+00$ & $1.701 \mathrm{E}+00$ \\
\hline Cff1 & $2.465 \mathrm{E}+00$ & $2.221 \mathrm{E}+01$ & $2.070 \mathrm{E}+00$ & $3.084 \mathrm{E}+00$ & $4.195 \mathrm{E}+00$ \\
\hline hy95 & $1.693 \mathrm{E}+00$ & $1.954 \mathrm{E}+00$ & $3.844 \mathrm{E}-01$ & $5.661 \mathrm{E}-01$ & $1.568 \mathrm{E}+00$ \\
\hline wash & $1.241 \mathrm{E}+01$ & $1.075 \mathrm{E}+00$ & $1.228 \mathrm{E}+01$ & $1.322 \mathrm{E}+01$ & $1.591 \mathrm{E}+01$ \\
\hline
\end{tabular}

Output DTNs: LA0409GZ831231.001, LA0409GZ831231.002, LA0409GZ831231.003, LA0409GZ831231.004, LA0409GZ831231.005.

$\mathrm{AM}=$ alternate model

The following observations can be made of the parameter sensitivity analysis:

- The most important parameters for the overall calibration were the permeabilities of gran, tram, prow, cali, vose, granm, cff1, hy95, and wash. The gran and granm are the granite units and are important to the estimation of the boundary flux targets. The parameter vose refers to the shallow volcanic and sedimentary unit that was not represented in the SZ site-scale flow model. The cff1 is a segment of the crater flat fault and is important in matching the flux boundary conditions on the west side.

- It is noted that the potentiometric surfaces for all alternative conceptual models AM0 through AM4 indicate limited mound in scattered areas along Fortymile Wash (Figures 6-19 to 6-21). The mounds are the results of recharge along Fortymile Wash. 
The figures indicate that the mounds dissipate downward as shown by the potentiometric surface at the 500-meter elevation. There are no observation wells along Fortymile Wash to confirm or refute the existence of the mounds. The mounds are localized, are small in areal extent, and do not appear to impact the flow paths from the water table below the repository to the accessible environment. There is no sinks in the potentiometric surface.

- The most important parameters for calibration along the flow 'path' were lcart, tram, prow, cali, pain, timb, vose, tramm, calim, nsba, tramy, bully, cff1, hy95, and wash. The observations along the flow path have different sensitivities than the overall sensitivities. The sensitivities include more parameters that are near Yucca Mountain. In particular, there are now sensitivities to nsba, a portion of the Solitario Canyon fault.

The sensitivity of parameter along the flow path is studied because of the importance of calibration along the flow path to predicted particle path lines.

\subsection{Calibration Results: Specific Discharge}

The calibrated specific discharge for the SZ site-scale flow model and alternate flow models results are presented in Table 6-11. Specific discharge is computed by calculating the transport time of the 50th particle of 100 particles, all released at the same time, to cross the 18-kilometer compliance boundary. The velocity does not account for any tortuosity in the particle path and is computed as the 18-kilometer distance divided by transport time. The alternate SZ site-scale flow models (AM0-AM4) produce specific discharge values in the range of 0.459 to $0.653 \mathrm{~m} / \mathrm{yr}$ compared to the SZ site-scale flow model specific discharge of $1.3 \mathrm{~m} / \mathrm{yr}$ at the 18-kilometer boundary. The reasons for the difference are that the calibrated permeabilities values for some of the units that dominate the flow paths are lower in the alternate SZ site-scale flow models.

Table 6-11. Specific Discharge

\begin{tabular}{|c|c|c|c|c|c|}
\hline SZ Site-Scale Flow model & AM0 & AM1 & AM2 & AM3 & AM4 \\
\hline 1.317 & $0.51 \mathrm{~m} / \mathrm{yr}$ & $0.459 \mathrm{~m} / \mathrm{yr}$ & $0.630 \mathrm{~m} / \mathrm{yr}$ & $0.591 \mathrm{~m} / \mathrm{yr}$ & $0.653 \mathrm{~m} / \mathrm{yr}$ \\
\hline
\end{tabular}
Output DTNs: LA0409GZ831231.001, LA0409GZ831231.002, LA0409GZ831231.003,
LA0409GZ831231.004, LA0409GZ831231.005.

AM - alternate model; SZ = saturated zone.

\subsection{Calibration Results: Flux Uncertainty}

Groundwater flow fields are the major output of the SZ site-scale flow model. These flow fields are used in transport calculations that support TSPA. Quantification of uncertainty in groundwater flux is thus very important. The flux through the model has a local and regional component. The local component results from recharge near Yucca Mountain and the regional component results from flux entering the model boundaries. These boundary fluxes are obtained from the 2001 DVRFS as described previously. Even though the local recharge is only about 10 percent of the total flux leaving the model's southern boundary, it is important to flow paths originating in the repository area. In this section, the impact of uncertainty in the boundary fluxes on the flow paths is investigated. 
The five different scenarios represented by the alternate SZ site-scale flow model runs can be used to evaluate the effect of flux uncertainty on groundwater flow field specific discharge and flow paths. Using the change in flux targets derived from 2001 DVRFS as a surrogate of flux uncertainty, it is noted (Table 6-12) that the flux flowing into the north boundary of the site scale model changed about 30 percent. The flux flowing into the west boundary changed about 220 percent and actually reversed directions. The flux flowing into the east north boundary was not changed between the different alternate SZ site-scale flow models.

The east side used a smaller flux target in AM3 than AM0. This was done because the HFM-27 did not incorporate a highly permeable thrust zone in the southeast corner of the model that was present in the SZ site-scale flow model and the 1997 DVRFS. This high flow entered and left in the extreme southeast corner and effectively doubled the flow through the southern boundary.

The discussion of the calibration results noted the following:

- The various combinations of fluxes are matched well with the alternate flow models

- The degree of calibration is similar for all the alternate flow models

- The flow paths are equivalent for all the alternate SZ site-scale flow models

- The parameter estimates were similar for all the alternate SZ site-scale flow models

- It is concluded, at least for the particle paths and flow field, that the alternate site-scale model is insensitive to the uncertainty in the boundary fluxes derived from the 2001 DVRFS.

Some important path line sensitivities were discovered during the analysis of the alternate models. The most important was the Ghost Dance fault parameter ghos. This was the only bounded parameter in all the alternate models. The presented results use a bounded ghos of $1 \times 10^{-12} \mathrm{~m}^{2}$. By bounding this parameter at $1 \times 10^{-11} \mathrm{~m}^{2}$, the flow path changes. The comparison of flow paths is shown in Figures 6-19 to 6-21

\subsubsection{Comparison of Boundary Target Fluxes}

A comparison of target fluxes and the fluxes derived from the SZ site-scale flow model and alternate flow models are presented in Table 6-12. As indicated in Table 6-12, the SZ site-scale flow model compared well to the 1997 regional flow model target boundary fluxes when integrated on each boundary. The exception was the west boundary where the fluxes were not used as targets, because differences in hydrostratigraphy between the SZ site-scale flow model and the 1997 DVRFS model (D’Agnese et al. 1997 [DIRS 100131]) would not allow meaningful comparison. A similar match between target and calibrated flux values in the alternate flow model has been achieved. 


\begin{tabular}{|c|c|c|c|c|c|c|c|c|c|c|c|c|}
\hline & \multicolumn{2}{|c|}{ AM0 Flux (kg/s) } & \multicolumn{2}{|c|}{ AM1 Flux (kg/s) } & \multicolumn{2}{|c|}{ AM2 Flux (kg/s) } & \multicolumn{2}{|c|}{ AM3 Flux (kg/s) } & \multicolumn{2}{|c|}{ AM4 Flux (kg/s) } & \multicolumn{2}{|c|}{$\begin{array}{l}\text { Base-Case Flux } \\
(\mathrm{kg} / \mathrm{s})\end{array}$} \\
\hline & Target & Calibrate & Target & Calibrate & Target & Calibrate & Target & Calibrate & Target & Calibrate & Target & Calibrate \\
\hline \multirow{5}{*}{$\stackrel{\bar{d}}{3}^{\overline{8}}$} & \multirow{5}{*}{125.00} & \multirow{5}{*}{$\begin{array}{l}-120.89 \\
(4.11)\end{array}$} & \multirow{5}{*}{125.00} & \multirow{5}{*}{$\begin{array}{l}99.05 \\
(-25.96)\end{array}$} & 213.30 & $\begin{array}{l}.05197 \\
(-213.248)\end{array}$ & \multirow{5}{*}{-119.00} & \multirow{5}{*}{$\begin{array}{l}-57.06 \\
(61.94)\end{array}$} & \multirow{5}{*}{-119.00} & \multirow{5}{*}{$\begin{array}{l}-112.84 \\
(6.16)\end{array}$} & \multirow{5}{*}{$-118.7^{*}$} & \multirow{5}{*}{$\begin{array}{l}-2.69 \\
(116.02)\end{array}$} \\
\hline & & & & & -.081 & $\begin{array}{l}-15.08 \\
(-14.999)\end{array}$ & & & & & & \\
\hline & & & & & -56.10 & $\begin{array}{l}-48.87 \\
(7.23)\end{array}$ & & & & & & \\
\hline & & & & & -1.26 & $\begin{array}{l}-12.35 \\
(-11.09)\end{array}$ & & & & & & \\
\hline & & & & & -28.10 & $\begin{array}{l}-4.055 \\
(24.045)\end{array}$ & & & & & & \\
\hline \multirow{5}{*}{ 㤎 } & \multirow{5}{*}{$\begin{array}{l}-209.0 \\
0\end{array}$} & \multirow{5}{*}{$\begin{array}{l}-207.77 \\
(1.23)\end{array}$} & \multirow{5}{*}{-209.00} & \multirow{5}{*}{$\begin{array}{l}-211.10 \\
(-2.10)\end{array}$} & -71.32 & $\begin{array}{l}-61.86 \\
(9.46)\end{array}$ & \multirow{5}{*}{-209.00} & \multirow{5}{*}{$\begin{array}{l}-189.52 \\
(19.48)\end{array}$} & \multirow{5}{*}{-96.00} & \multirow{5}{*}{$\begin{array}{r}-89.70 \\
(6.30)\end{array}$} & \multirow{5}{*}{-561.3} & \multirow{5}{*}{$\begin{array}{l}-513.68 \\
(47.65)\end{array}$} \\
\hline & & & & & -0.023 & $\begin{array}{l}-13.696 \\
(-13.673)\end{array}$ & & & & & & \\
\hline & & & & & -147.67 & $\begin{array}{l}-148.51 \\
(-0.84)\end{array}$ & & & & & & \\
\hline & & & & & 0.120 & $\begin{array}{l}0.154 \\
(0.034)\end{array}$ & & & & & & \\
\hline & & & & & -1.53 & $\begin{array}{l}10.31 \\
(11.84)\end{array}$ & & & & & & \\
\hline
\end{tabular}


Table 6-12. Calibration Results: Comparison of Flux Target with Flux Calibrated Values (Continued)

\begin{tabular}{|c|c|c|c|c|c|c|c|c|c|c|c|c|}
\hline & \multicolumn{2}{|c|}{ AMO Flux (kg/s) } & \multicolumn{2}{|c|}{ AM1 Flux (kg/s) } & \multicolumn{2}{|c|}{ AM2 Flux $(\mathrm{kg} / \mathrm{s})$} & \multicolumn{2}{|c|}{ AM3 Flux $(\mathrm{kg} / \mathrm{s})$} & \multicolumn{2}{|c|}{ AM4 Flux $(\mathrm{kg} / \mathrm{s})$} & \multicolumn{2}{|c|}{$\begin{array}{c}\text { Base-Case Flux } \\
(\mathrm{kg} / \mathrm{s})\end{array}$} \\
\hline & Target & Calibrate & Target & Calibrate & Target & Calibrate & Target & Calibrate & Target & Calibrate & Target & Calibrate \\
\hline \multirow{4}{*}{$\frac{5}{z}$} & \multirow{4}{*}{-271.00} & \multirow{4}{*}{$\begin{array}{l}-283.43 \\
(-12.43)\end{array}$} & \multirow{4}{*}{-271.00} & \multirow{4}{*}{$\begin{array}{l}-272.23 \\
(-1.23)\end{array}$} & -217.67 & $\begin{array}{l}-208.04 \\
(9.63)\end{array}$ & \multirow{4}{*}{-271.00} & \multirow{4}{*}{$\begin{array}{l}-274.28 \\
(-3.28)\end{array}$} & \multirow{4}{*}{-271.00} & \multirow{4}{*}{$\begin{array}{l}-284.37 \\
(-13.37)\end{array}$} & \multirow{4}{*}{-195.8} & \multirow{4}{*}{$\begin{array}{l}-168.8 \\
(26.99)\end{array}$} \\
\hline & & & & & -56.57 & $\begin{array}{l}-44.24 \\
(12.33)\end{array}$ & & & & & & \\
\hline & & & & & 6.91 & $\begin{array}{l}19.09 \\
(12.18)\end{array}$ & & & & & & \\
\hline & & & & & -1.32 & $\begin{array}{l}4.25 \\
(5.57) \\
\end{array}$ & & & & & & \\
\hline 苟 & 403.6 & $\begin{array}{l}419.37 \\
(5.77)\end{array}$ & 403.6 & $\begin{array}{l}433.20 \\
(29.60)\end{array}$ & 410.51 & $\begin{array}{l}572.05 \\
(161.536)\end{array}$ & 648.2 & $\begin{array}{l}570.59 \\
(-77.61)\end{array}$ & 535.2 & $\begin{array}{l}535.82 \\
(0.62)\end{array}$ & $789.6^{*}$ & $\begin{array}{l}733.75 \\
(-55.85)\end{array}$ \\
\hline
\end{tabular}

DTN: SN9908T0581999.001 [DIRS 132867] - base case model target fluxes, file 02_calib.pest.

DTN: $\quad$ LA0409GZ831231.001; LA0409GZ831231.002; LA0409GZ831231.003; LA0409GZ831231.004; LA0409GZ831231.005 - alternate model calibrated fluxesLA0304TM831231.002 - base case model calibrated fluxes, files named sz_site_2004.pest.

NOTE: Location of AM2 distributed fluxes are given in Table 6-11.

South boundary flux is not a calibration target in the alternate models. It is calculated as the negative of the sum of west, east and north boundary fluxes and infiltration flux.

${ }^{*}$ These fluxes (west and south) were not used as targets in SZ site-scale flow model calibration. The sum of the target boundary fluxes and infiltration flux is not zero (BSC 2004 [DIRS 170015], Section 6.5.1).

Numbers in the parentheses are residuals between the corresponding target fluxes and calibrated fluxes.

$\mathrm{AM}=$ alternate model 


\subsubsection{Conclusions from Alternate Flow Models}

Based on the updated and improved HFM-27, more consistent flux targets from the 2001 DVRFS model, and additional water-level calibration targets from the Nye County drilling program, the alternate model (AM0, AM1, AM2, AM3, AM4) provide similar representations of the SZ flow system near Yucca Mountain. Results indicate that the important parameters in the SZ site-scale flow model are again the most sensitive parameters in the alternate SZ site-scale flow model. Probable flow paths, considering the differences between HFM-19 and HFM-27, are similar in both models. The following conclusions are noted:

- Alternate SZ site-scale flow models result in hydraulic heads generally consistent with the SZ site-scale flow model. Parameter values are consistent in the alternative models and fall within the range of measured data where available.

- Specific discharge values are lower $(0.459-0.653 \mathrm{~m} / \mathrm{yr})$ in the alternate SZ site-scale flow models than in the SZ site-scale flow model ( $1.3 \mathrm{~m} / \mathrm{yr})$.

- Particle paths are more north/south with less east/west deviation in the alternate SZ site-scale flow models than in the SZ site-scale flow model and thus shorter between the repository and the 18-kilometer compliance boundary.

- Particle paths are insensitive to range of boundary fluxes used. Thus, the large uncertainty of fluxes derived from the 2001 DVRFS has little impact on the site-scale flow model predictions.

\subsubsection{Summary of the Alternative Conceptual Models}

Table 6-13 summarizes the ACMs considered and their screening status. Compared to the SZ site-scale flow model, the alternate mode produces lower seepage velocity that will result in slower transport and therefore larger transport times. On the other hand, the alternate flow model predicts shorter flow paths that may result in faster transport and therefore smaller transport times. The combined effects were investigated in the transport simulations (BSC 2004 [DIRS 170036]) which shows that transport time predicted by the alternate model are larger than the SZ site-scale flow model and therefore that using the SZ site-scale flow model yields conservative results for TSPA-LA. Based on this result the SZ site-scale flow model discussed in this model report was determined to be an appropriate and conservative model for use in TSPA-LA calculations. 
Table 6-13. Alternative Conceptual Models Considered

\begin{tabular}{|c|c|c|c|}
\hline $\begin{array}{c}\text { Alternative } \\
\text { Conceptual Model }\end{array}$ & Key Assumptions & $\begin{array}{c}\text { Screening Assessment and } \\
\text { Basis }\end{array}$ & $\begin{array}{c}\text { Uncertainty } \\
\text { Propagation Forward }\end{array}$ \\
\hline $\begin{array}{l}\text { Large hydraulic } \\
\text { gradient }\end{array}$ & $\begin{array}{l}\text { The large hydraulic gradient is a } \\
\text { result of perched water or a } \\
\text { result of low permeability or } \\
\text { large head }\end{array}$ & $\begin{array}{l}\text { Different conceptualizations of } \\
\text { a LHG do not result in } \\
\text { different flow field or specific } \\
\text { discharge results. This is } \\
\text { based on analysis of the } \\
\text { various conceptualizations of } \\
\text { the LHG }\end{array}$ & $\begin{array}{l}\text { This is not necessary } \\
\text { to propagate forward }\end{array}$ \\
\hline Solitario Canyon & $\begin{array}{l}\text { Solitario Canyon goes deep into } \\
\text { the carbonate aquifer or it only } \\
\text { goes to the top of the carbonate } \\
\text { aquifer }\end{array}$ & $\begin{array}{l}\text { Different conceptualizations of } \\
\text { the role of Solitario Canyon } \\
\text { do not result in different flow } \\
\text { field or specific discharge } \\
\text { results. This is based on } \\
\text { computer analysis and } \\
\text { simulation of the } \\
\text { representation of Solitario } \\
\text { Canyon. See Section 6.7.2.1 }\end{array}$ & $\begin{array}{l}\text { This is not necessary } \\
\text { to propagate forward }\end{array}$ \\
\hline Vertical anisotropy & $\begin{array}{l}\text { Vary the range of the vertical to } \\
\text { horizontal permeability }\end{array}$ & $\begin{array}{l}\text { The range of vertical to } \\
\text { horizontal permeability affects } \\
\text { the flow field and the specific } \\
\text { discharge }\end{array}$ & $\begin{array}{l}\text { This is not necessary } \\
\text { to propagate forward }\end{array}$ \\
\hline $\begin{array}{l}\text { Horizontal } \\
\text { anisotropy }\end{array}$ & $\begin{array}{l}\text { Vary the range of the horizontal } \\
\text { maximum to horizontal minimum } \\
\text { permeability }\end{array}$ & $\begin{array}{l}\text { The range of horizontal } \\
\text { maximum to horizontal } \\
\text { minimum permeability does } \\
\text { not significantly affect the flow } \\
\text { field and the specific } \\
\text { discharge }\end{array}$ & $\begin{array}{l}\text { This uncertainty needs } \\
\text { to be propagated in the } \\
\text { generation of } \\
\text { breakthrough curves }\end{array}$ \\
\hline $\begin{array}{l}\text { Potentiometric } \\
\text { surface }\end{array}$ & $\begin{array}{l}\text { Different potentiometric } \\
\text { interpretations of water-level } \\
\text { data }\end{array}$ & $\begin{array}{l}\text { Compare model predictions of } \\
\text { potentiometric surface to the } \\
\text { different interpretations. The } \\
\text { different interpretations do not } \\
\text { affect the flow field or specific } \\
\text { discharge results }\end{array}$ & $\begin{array}{l}\text { This is not necessary } \\
\text { to propagate forward }\end{array}$ \\
\hline $\begin{array}{l}\text { Water table rise } \\
\text { due to future } \\
\text { climates }\end{array}$ & $\begin{array}{l}\text { Future climates can change } \\
\text { water table levels }\end{array}$ & $\begin{array}{l}\text { Compare model predictions of } \\
\text { using different water table } \\
\text { levels. The different } \\
\text { interpretations do not affect } \\
\text { the flow-field spatial } \\
\text { distribution (only the } \\
\text { magnitude) }\end{array}$ & $\begin{array}{l}\text { This is not necessary } \\
\text { to propagate forward. } \\
\text { Specific discharge } \\
\text { calculations involve } \\
\text { only the scaling of } \\
\text { site-scale flow model } \\
\text { results }\end{array}$ \\
\hline $\begin{array}{l}\text { Alternate SZ } \\
\text { site-scale flow } \\
\text { models }\end{array}$ & $\begin{array}{l}\text { Reinterpreted HFM, boundary } \\
\text { fluxes and recharge from the } \\
2002 \text { regional model and } 2004 \\
\text { UZ model, and additional Nye } \\
\text { County water-level data }\end{array}$ & $\begin{array}{l}\text { Specific discharge smaller } \\
\text { than that of the SZ site-scale } \\
\text { flow model. However the flow } \\
\text { paths are North-South and } \\
\text { may be shorter than those in } \\
\text { the SZ site-scale flow model }\end{array}$ & $\begin{array}{l}\text { The uncertainty which } \\
\text { results in shorter flow } \\
\text { paths needs to be } \\
\text { evaluated in transport } \\
\text { simulations }\end{array}$ \\
\hline
\end{tabular}

HFM = hydrogeologic framework model; LHG = large hydraulic gradient; SZ = saturated zone;

$\mathrm{UZ}=$ unsaturated zone. 


\subsection{MODEL FORMULATION OF CONCEPTUAL MODEL}

\subsubsection{Mathematical Description of Conceptual Model}

An effective continuum approach is adopted for simulating groundwater flow through the fractured rock and alluvial materials within the domain of the SZ site-scale flow model. Based on this conceptualization, the equations governing groundwater flow can be derived by combining the equations describing the conservation of fluid mass and Darcy's Law (Freeze and Cherry 1979 [DIRS 101173], Section 2.11). The equations presented below are for an isotropic, isothermal medium. The conservation of fluid mass is:

$$
\frac{\partial A_{\text {mass }}}{\partial t}+\bar{\nabla} \cdot \bar{f}_{\text {mass }}+q_{\text {mass }}=0
$$

where

$\bar{\nabla}$ is first derivative,

$A_{\text {mass }}$ is the fluid mass per unit volume given by:

$$
A_{\text {mass }}=\phi \rho_{l}
$$

$\bar{f}_{\text {mass }}$ is the fluid mass flux given by:

$$
\bar{f}_{\text {mass }}=\rho_{l} \bar{v}
$$

$\phi$ is the porosity in the system (dimensionless),

$\rho_{l}$ is the fluid density $\left(\mathrm{kg} / \mathrm{m}^{3}\right)$,

$\bar{v}$ is the fluid velocity $(\mathrm{m} / \mathrm{s})$,

$q_{\text {mass }}$ is the fluid mass source $(\mathrm{kg} / \mathrm{s})$.

The velocity of the fluid can be expressed by Darcy's Law:

$$
\bar{v}=-\frac{k}{\mu}\left(\bar{\nabla} P-\rho_{l} g\right)
$$

where

$\mu$ is the dynamic viscosity of the fluid $(\mathrm{kg} / \mathrm{m} / \mathrm{s})$,

$P$ is the fluid pressure $(\mathrm{Pa})$,

$k$ is the permeability $\left(\mathrm{m}^{2}\right)$,

$g$ is the acceleration resulting from gravity $\left(\mathrm{m}^{2} / \mathrm{s}\right)$. 
Equations 6-1 and 6-4 can be combined to yield:

$$
-\bar{\nabla} \cdot D_{\text {mass }} \frac{\bar{\nabla} P}{g}+q_{m}+\frac{\partial}{\partial z} D_{\text {mass }} \rho_{l}+\frac{\partial A_{\text {mass }}}{\partial t}=0,
$$

where

$$
D_{\text {mass }} \text { is hydraulic conductivity. }
$$

Equation 6-5 is the fundamental equation describing groundwater flow. Here $z$ is oriented in the direction of gravity and the hydraulic conductivity is given by:

$$
D_{\text {mass }}=\frac{k \rho_{l} g}{\mu}
$$

Groundwater flow is simulated in the SZ site-scale flow model by obtaining a numerical solution to this equation. Solution of this equation requires the specification of the pressure at the boundaries of the solution domain. For steady-state calculations, solution of this equation does not require specification of initial conditions (initial pressure distribution throughout the solution domain), because Equation 6-5 (at very large times) represents steady-state flow, which is independent of initial conditions.

Conservation of fluid-rock energy is expressed by the equation:

$$
\frac{\partial A_{e}}{\partial t}+\bar{\nabla} \cdot \overline{f_{e}}+q_{e}=0
$$

where the energy per unit volume, $A_{e}$, is given by:

$$
A_{e}=(1-\phi) \rho_{r} u_{r}+\phi \rho_{l} u_{l}
$$

with $u_{r}=c_{p r} T$, and the energy flux, $\overline{f_{e}}$, is given by:

$$
\overline{f_{e}}=\rho_{l} h_{l} \bar{v}-K \bar{\nabla} T
$$

Here,

the subscript $r$ refers to the rock matrix, the subscript $l$ refers to the liquid, the subscript $e$ refers to energy, $u_{r}$ and $u_{l}$ are specific internal energies, $c_{p r}$ is the specific heat,

$h_{l}$ is specific enthalpy, $K$ is an effective thermal conductivity, 
$T$ is the temperature, and

$q_{e}$ is the energy contribution from sources and sinks.

Equations (6-6) and (6-4) can be combined to yield:

$$
-\bar{\nabla} \cdot\left(D_{e} \bar{\nabla} P\right) / g-\bar{\nabla} \cdot(K \bar{\nabla} T)+q_{e}+\frac{\partial}{\partial z} D_{e} \rho_{l}+\frac{\partial A_{e}}{\partial t}=0
$$

where the transmissivity term is given by;

$$
D_{e}=h_{l} D_{\text {mass }} .
$$

It is assumed that a steady-state model is sufficient for calibration purposes and the intended use of the SZ site-scale flow model. There are two potential causes of transient flow that are relevant to this assumption: (1) changes in climate over the past 15,000 years, and (2) pumping from wells south of the model domain during approximately the last 40 years. Use of the steady-state assumption requires that the modern-day flow system has had sufficient time to completely equilibrate to both of these perturbations to the natural system. It is noted that transient tests (C-wells and Alluvial Testing Complex) were performed and that derived permeability values from those tests were considered in the validation of the numerical model. It is not expected that the model can reproduce the transient tests, largely due to the 500-m gridblocks. Because transient pumping is not used in any Yucca Mountain radionuclide migration simulations and steady-state gradients are modeled accurately with the model, this does not invalidate the steady-state assumption. Climate change and other transient impacts are incorporated in the SZ flow and transport abstractions (BSC 2004 [DIRS 170042], Section 6.5)

The conceptual model of the long-term groundwater flow in this region holds that recharge rates and, consequently, the elevation of the water table and groundwater flow rates were larger during the last glacial pluvial period. The time required for the flow system to equilibrate to a more arid climate depends mainly on the hydraulic conductivity of the rocks and the amount of water that must be drained from storage in order to lower the water table.

It is likely that equilibration to the drier climate has occurred given (1) the long time (thousands of years) since the climate change was completed, (2) the relatively small amount of water stored (small specific yield) in fractured volcanic rocks that make up much of the model domain near the water table, and (3) the relatively large hydraulic conductivity of the fractured volcanic rocks.

The time required for the flow field to arrive at steady-state with respect to pumping from wells is much shorter than the time required for equilibration to climate change. It depends mainly on the time required for changes in water level to be transmitted through the SZ. Fast transmittal is expected in fractured volcanic rocks because of their relatively large hydraulic conductivity and small specific storage. The fact that the modern-day flow system has equilibrated to pumping is supported by the lack of consistent, large-magnitude variations in water levels observed in wells near Yucca Mountain (Luckey et al. 1996 [DIRS 100465], pp. 29 to 32). A transient response to pumping would be expected, instead, to result in a continued decrease in water levels. 


\subsubsection{Computational Model}

The FEHM software code is used in site-scale SZ modeling to obtain a numerical solution to the mathematical equation describing groundwater flow (Equation 6-5). FEHM is a nonisothermal, multiphase flow and transport code that simulates the flow of water and air and the transport of heat and solutes in two-dimensional and three-dimensional saturated or partially saturated heterogeneous porous media. The code includes comprehensive reactive geochemistry and transport modules and a particle-tracking capability. Fractured media can be simulated using an equivalent-continuum, discrete-fracture, dual-porosity, or dual-permeability approach. A subset of the FEHM code capabilities was used in the SZ site-scale flow model. Single-phase, isothermal flow was simulated in the SZ site-scale flow model.

Particle tracking is a numerical technique that is acceptable for simulating the transport of fluid particles in the SZ at Yucca Mountain. Particle-tracking techniques have a long history of use in such applications (e.g., Pollock 1988 [DIRS 101466]; Tompson and Gelhar 1990 [DIRS 101490]; Wen and Gomez-Hernandez 1996 [DIRS 130510]), thereby justifying this assumption.

The control-volume finite element (CVFE) method is used in FEHM to obtain a numerical solution to the groundwater flow equation over the model domain. Finite-element methods are based on the assumption that a continuum may be modeled as a series of discrete elements. For each element, equations based on a discretized form of the groundwater flow equation are written that describe the interaction of that element with its neighbors. These equations describe the hydrologic behavior of the elements. This discretization leads to a set of equations that must be solved numerically to obtain the values of groundwater pressure at each node throughout the model domain.

The CVFE method has been used extensively in petroleum reservoir engineering (Forsyth 1989 [DIRS 144110]). The CVFE method treats the potentials in a finite-element approach while the control-volume aspect allows local mass conservation and upstream weighting (Verma and Aziz 1997 [DIRS 143606]). Quadrilaterals and triangles in two dimensions and hexahedra and tetrahedra in three dimensions are divided into volumes associated with gridblocks and areas associated with interblock distances. The gridblock volumes are the Voronoi volumes (Forsyth 1989 [DIRS 144110]) associated with each gridblock. Voronoi volumes are also called perpendicular bisector volumes. The Voronoi volume is formed by boundaries that are orthogonal to the lines joining adjacent gridblocks and that intersect the midpoints of the lines (Verma and Aziz 1997 [DIRS 143606]). Any point within a Voronoi volume is closer to its associated gridblock than to any other node in the grid. The CVFE method can be shown on simple elements with constant properties to be equivalent to traditional finite-element methods.

The stiffness coefficients (e.g., elements of the stiffness matrix) of the traditional finite-element method can be interpreted as a linear function of the area through which the fluid passes traveling from one node to its neighbor. A stiffness coefficient uses the area of the boundary of the Voronoi volume that intersects the line joining adjacent nodes. LaGriT V1.0 STN: 10212-1.0-00 (LANL 2001 [DIRS 149148]) is designed to produce CVFE grids. 
These terms are used to form control-volume difference equations for the conservation equations. This method is not traditional because equation parameters are defined by node, not element, but the method leads to an intuitive understanding of the numerical method.

In FEHM, the nodal definition of equation parameters leads naturally to a separation of the nonlinear and purely geometric parts. This separation is explained in detail by Zyvoloski (1983 [DIRS 101171]) and is valid over lower-order elements. The nonlinear part uses average inverse kinematic viscosity,

$$
D=\frac{\rho}{\mu}
$$

between two nodes, which is usually taken to be the upstream nodal value. The result is a much more stable code for solving nonlinear problems while still retaining much of the geometric flexibility of finite elements. This method has been used in FEHM since 1983 (Zyvoloski 1983 [DIRS 101171]) and has been extensively verified. A harmonic weighting of the intrinsic permeability is used. It is noted that even though the SZ site-scale flow model is linear, the fact that it uses spatially varying viscosity terms (due to spatially varying temperatures), upwinding the viscosity terms is the standard way of modeling the interblock fluid fluxes. The Newton-Raphson iteration is applied to the system of equations, which is solved with a multidegree of freedom and preconditioned, conjugate gradient methods using generalized minimum residual method or biconjugate gradient-squared acceleration techniques.

\subsubsection{SZ Site-Scale Flow Model Inputs}

The development of the base case SZ site-scale flow model involves the input of data from a number of sources, including water level and head distributions, definition of the hydrogeologic units, distribution of recharge flux and lateral fluxes into the model domain, feature and fault distribution, temperature profiles in wells, and boundary conditions. The data sources for these inputs are identified in Table 4-1.

Incorporation of these inputs into the SZ site-scale flow model first requires the generation of a hydrogeologic framework conceptualization and a computational grid. The HFM conceptualization and known features of the site were used to design a grid for flow modeling. Once a computational grid is formulated, these data inputs were used to assign the hydrogeologic units and features, recharge fluxes, hydrogeologic properties, and boundary conditions at node points throughout the computation grid. Each of these elements of model development is discussed below.

\subsubsection{Hydrogeologic Framework Model Overview}

The HFM (BSC 2004 [DIRS 170008]) is a conceptual model providing a three-dimensional interpretation of the hydrostratigraphic unit locations and structure within the site-scale SZ flow and transport model domain for use in the SZ flow and transport numerical models.

The geometry of geologic units is defined in STRATAMODEL V4.1.1, STN: 10121-4.1.1-00 (Landmark Graphics 1998 [DIRS 153238]) framework files (DTN: GS030208312332.001 
[DIRS 163087]) known as HFM-19, which characterize a three-dimensional geocellular model of the site base case HFM for the SZ (output from BSC 2004 [DIRS 170008]). In depth, the HFM domain extends from the interpreted potentiometric surface (DTN: GS000508312332.001 [DIRS 149947]) to the base of the 1997 regional groundwater flow model (D'Agnese et al. 1997 [DIRS 100131]). The data in the STRATAMODEL framework files conform to the geologic framework model (GFM) (BSC 2004 [DIRS 170008], Section 6.3.2) in areas where the GFM is valid and comprises additional information for the other areas of the SZ model. The HFM-19 is constructed by combining a set of structural contour maps representing the tops of hydrogeologic units using the software product STRATAMODEL. The construction of the HFM-19 includes data from geologic maps and sections, borehole data, geophysical data, and existing geologic models. This representation enables the computational grid to be populated with an initial set of hydrologic properties for the calibration of the SZ site-scale flow model. The HFM-19 and its development are documented in Hydrogeologic Framework Model for the Saturated-Zone Site-Scale Flow and Transport Model (USGS 2004 [DIRS 170008]). It is noted that the base case HFM also includes, as its top surface, the base case water table definition.

The HFM grid consists of a rectangular array of nodes with a spacing of $125 \mathrm{~m}$. This selection simplifies the available data near the repository and extrapolates from very widely spaced data in other areas of the model domain. The three-dimensional HFM-19 was constructed by stacking the set of structure contour maps using "geologic rules" of the software STRATAMODEL. The software allows for the specification of sedimentary depositional units, as well as truncation and faulting. Stratigraphic intrusions are included by arranging the order of the stacking sequence. This ordering begins at a depth that is the same as the base of the HFM used to support the regional flow model (DTN: GS960808312144.003 [DIRS 105121]) and the granitic intrusions as the first geologic unit. The lower clastic confining unit was input and truncated where the granitic intrusions were above this grid. The remaining units were entered in order onto the lower clastic confining unit and intrusions, and a special surface was placed within the sequence to represent the thrust-faulted geometries. The valley-fill aquifer and confining units were then emplaced in the valleys.

The HFM-19 was constructed to represent faults and other hydrogeologic features (such as zones of hydrothermal alteration) that affect SZ flow. Information on faults included fault trace maps, which show faults on cross sections and the locations where faults intersect the land surface. Faults in the model area can dip at almost any angle, but most are high-angle faults. Given software constraints and the numerical flow model resolution, faulting in the area was simplified, and the faults were treated as vertical features. Faults deemed important to flow near Yucca Mountain were modeled explicitly in the numerical SZ site-scale flow model. The hydrogeologic features that influence the flow field are identified separately (DTN: GS010908314221.000 [DIRS 162874]) and discussed in Section 6.5.3.4. These features are included in the SZ numerical model by permeability zones in FEHM.

Important thrust faults were represented by repeating hydrogeologic units in the HFM-19. When geologic structural or stratigraphic surfaces are stored as arrays, they cannot have multiple $z$-values at one location. This limitation means that thrust faults and mushroom-shaped intrusions cannot be represented by an array. To deal with these problems, simplifying techniques were used. Where units were repeated by thrust faults, two different grids were created for the same hydrogeologic unit. A unit boundary map was then added to define an 
outline for the perimeter of the thrust sheet. Within this boundary, hydrogeologic structural altitude values were treated as defining unique additional hydrogeologic unit(s). Where units were continuous across this boundary, altitudes of surfaces are the same on each side of the boundary, making the boundary "invisible." Because of the large number of faults in the SZ site-scale model area and limitations in modeling technology, only those faults and other features of hydrologic importance were constructed in the HFM-19 (BSC 2004 [DIRS 170008], Figure 6-2).

Most of the special features are defined as extending from the top of the carbonate aquifer to the top of the model (water table). Exceptions to this generalization are the Spotted Range-Mine Mountain zone, which extends from the top of the model to the bottom; the alluvial uncertainty zone, which extends from the top of the model down through the undifferentiated valley fill; and the Imbricate fault zone, which extends from the top of the model to the top of the undifferentiated valley fill (see Section 6.5.3.4, Table 6-17).

The top of the HFM-19 is truncated by the 2000 potentiometric surface as described in Water-Level Data Analysis for the Saturated Zone Site-Scale Flow and Transport Model (BSC 2004 [DIRS 170008], Section 6.2). The surface contour map was constructed using potentiometric data from various borehole locations (BSC 2004 [DIRS 170008], Figure 6-2, p. 27). Data from the uppermost-completed borehole intervals were used. Borehole data for this HFM were estimated from the digital elevation model for data model consistency. The elevations were derived from USGS 3-arc-second 1-by-1 degree digital elevation model files. The water table forms the upper surface of the HFM-19 with grid values sampled from the potentiometric map to 125-m spacing coincident to the HFM. These water-level data have been updated as described in Water-Level Data Analysis for the Saturated Zone Site-Scale Flow and Transport Model (BSC 2004 [DIRS 170008]). The revision consists of additional borehole water-level data and a different interpretation of the large hydraulic gradient. The 2001 potentiometric-surface map resulting from the revision represent an alternative conceptual model as described in Section 6.7.

\subsubsection{Grid Generation}

The computational grid for the SZ site-scale flow model was developed using LaGriT grid-generation software. The computational grid was designed so that the horizontal grid is coincident with the grid cells in the 1997 flow model. The extent of the computational grid is shown in Figure 6-27 and Table 6-14. The depth of the computational grid is approximately the same as depth of DVRFS flow model. The top of the computational grid begins at the water table surface and extends to a depth of 2,750 m (9,020 ft) below sea level. 


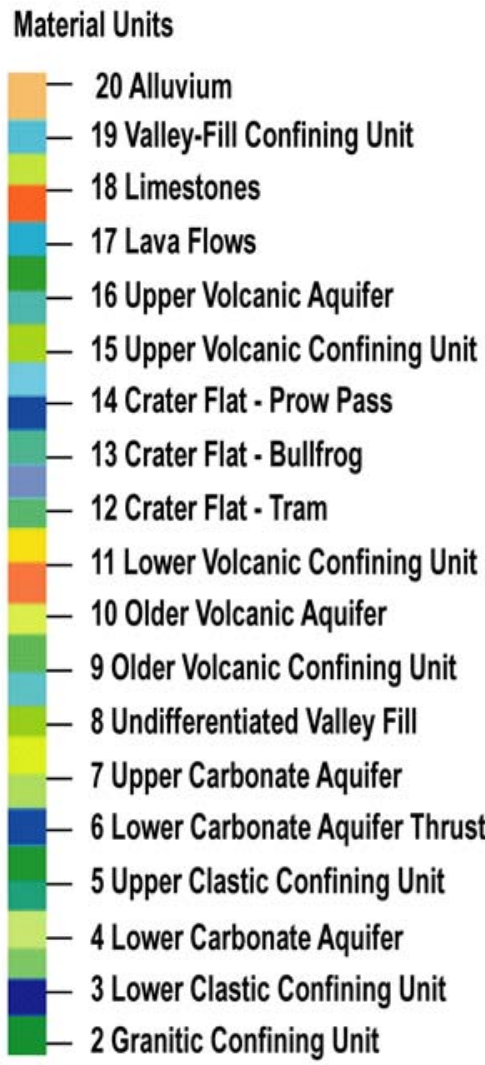

2 Granitic Confining Unit

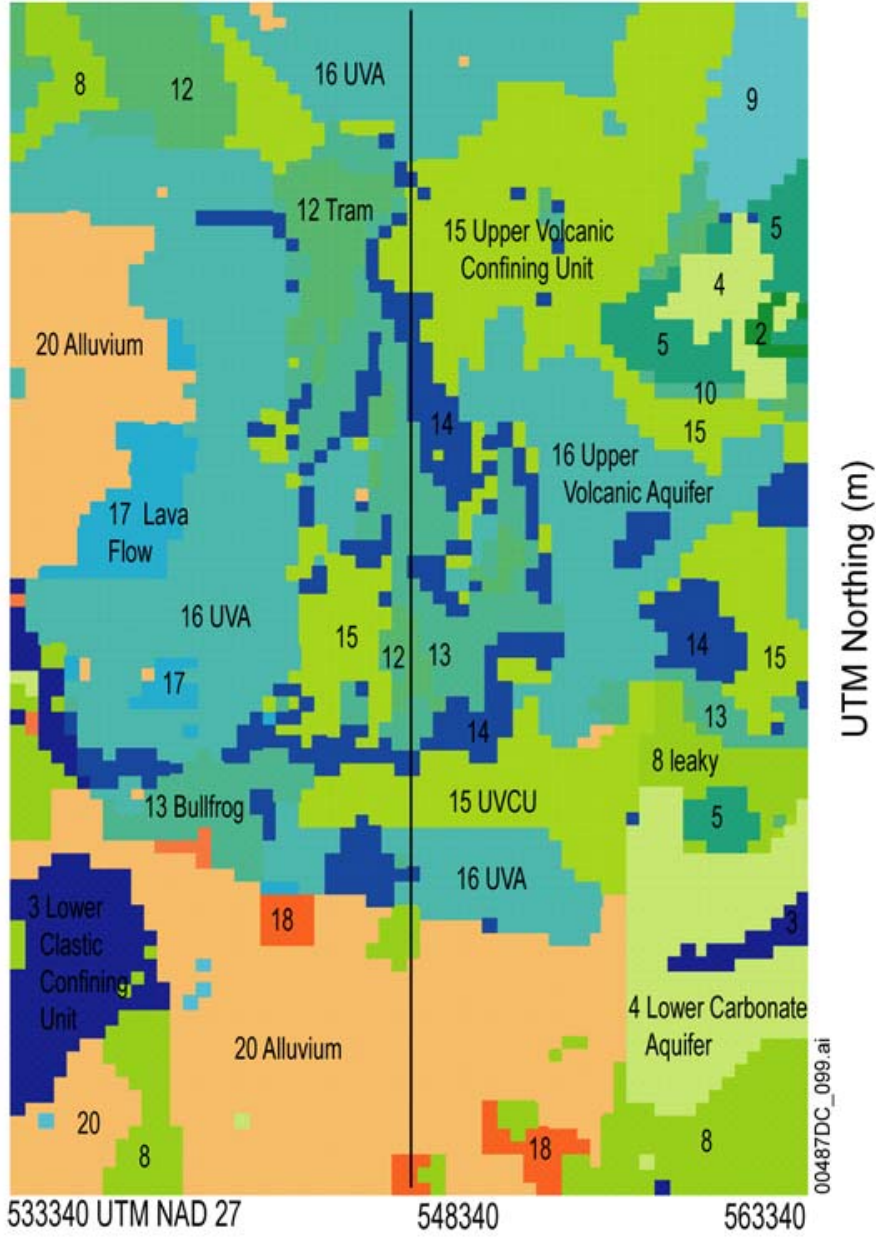

UTM Easting (m)

Source: DTN: GS030208312332.001 [DIRS 163087].

NOTE: For Illustration purposes only. This view is showing the top of the 500-m computational grid. The different colors in the figure show the material units as defined by hydrogeologic surfaces. The black vertical line is half way between the east and west boundaries and is for reference only. The grid top is the water table surface.

UTM = Universal Transverse Mercator projection system of coordinates; UVA = Upper Volcanic Aquifer; UVCU = Upper Volcanic Confining Unit.

Figure 6-27. Top of 500m Computational Grid 
Table 6-14. Bounding Box

\begin{tabular}{|l|c|}
\hline \multicolumn{1}{|c|}{ Box Direction } & UTM coordinates (m) \\
\hline West to east & 533,340 to 563,340 \\
\hline South to north & $4,046,780$ to $4,091,780$ \\
\hline Bottom to water table & $-2,200$ to 1,200 \\
\hline
\end{tabular}

Source: BSC (2004 [DIRS 170008]).

A structural grid using orthogonal hexahedral elements is chosen for the SZ site-scale flow model. Previous models (Czarnecki et al. 1997 [DIRS 100377]) of Yucca Mountain SZ flow and transport have used both unstructured (finite element) meshes and structured orthogonal grids. However, the principal reason structured grids are used for this work is to allow for the use of the streamline particle-tracking transport capability of FEHM. Although the structured meshes are not as flexible as unstructured meshes in fitting complex geometry, tests have shown that they provide accurate solutions as long as there is adequate resolution to represent the geometry of the different materials in each hydrogeologic layer. Moreover, there must be enough resolution to account for any large gradients present in the flow or transport model. The adequacy of grid resolution is investigated by running a flow model using various grids of differing resolutions. If little difference is found among model results using grids of increasing resolution, those resolutions at which the model differences become minimal can be used to identify suitable grid resolutions. A study (Bower et al. 2000 [DIRS 149161]) of the accuracy of both the flow and transport solution was performed on 10 grids with horizontal resolutions ranging from $500 \mathrm{~m}$ to $10,000 \mathrm{~m}$ to determine the appropriate horizontal grid resolution for the SZ site-scale flow model. Although the study was based on an earlier HFM, the results show that the 500-m grid is entirely adequate to meet the objectives of the SZ site-scale flow model. Consequently, a horizontal grid spacing of $500 \mathrm{~m}$ is used in this model.

The grid resolution in the vertical dimension is important for adequately representing groundwater flow and transport in the SZ. Each layer in the structured grid is horizontal, but the layers of the physical hydrogeologic units are gently sloping with approximately 7 percent dip to the east. Therefore, a finer and nonuniform grid resolution is used in the vertical dimension, and this is sufficient to capture the geometry of the hydrogeologic units. The vertical grid spacing is selected to provide the resolution for accurately representing flow and transport along critical flow and transport pathways in the SZ. A finer resolution is used at shallower portions of the model, and a progressively coarser resolution is used for deeper portions of the aquifer. The vertical grid spacing ranges from $10 \mathrm{~m}(33 \mathrm{ft})$ near the water table to $550 \mathrm{~m}(1,805 \mathrm{ft})$ at the bottom of the model domain. The vertical dimension of the model domain is divided into 11 zones, and constant vertical grid spacing is adopted in each of these zones. The structure of the vertical layering used in the site-scale SZ flow and transport model grid is summarized in Table 6-15 and shown in the full three-dimensional view Figure 6-28. In total, 38 layers are included in the vertical dimension that extends from $+1,200 \mathrm{~m}(4,100 \mathrm{ft})$ to $-2,750 \mathrm{~m}(-9,020 \mathrm{ft})$ elevation. Figure 6-29 shows a close-up view of the horizontal and vertical resolution in the grid. The material properties were assigned to the intersections of the grid lines. At the locations where grid is coarse, some of the HFM-19 layers were not represented. However, in the areas of most interest, the grid is very fine and the resolution of the HFM-19 is on the same level as the resolution of the grid. 
Table 6-15. Vertical Grid Spacing Used in the SZ Site-Scale Flow Model

\begin{tabular}{|c|c|c|c|c|}
\hline \multicolumn{2}{|c|}{$\begin{array}{c}\text { Gridblock Elevation Zone } \\
\text { Boundaries }(\mathrm{m})\end{array}$} & \multirow{2}{*}{$\begin{array}{l}\text { Grid } \\
\text { Spacing } \\
\text { (m) }\end{array}$} & \multirow{2}{*}{$\begin{array}{c}\text { Zone Width } \\
\text { (m) }\end{array}$} & \multirow{2}{*}{$\begin{array}{l}\text { Grid Lines } \\
\text { per Zone }\end{array}$} \\
\hline Upper & Lower & & & \\
\hline 1200 & 1000 & 50 & 200 & 4 \\
\hline 1000 & 840 & 40 & 160 & 4 \\
\hline 840 & 760 & 20 & 80 & 4 \\
\hline 760 & 700 & 10 & 60 & 6 \\
\hline 700 & 640 & 20 & 60 & 3 \\
\hline 640 & 600 & 40 & 40 & 1 \\
\hline 600 & 300 & 50 & 300 & 6 \\
\hline 300 & 0 & 100 & 300 & 3 \\
\hline 0 & -600 & 200 & 600 & 3 \\
\hline-600 & -2200 & 400 & 1600 & 4 \\
\hline \multirow[t]{2}{*}{-2200} & -2750 & 550 & 550 & 1 \\
\hline & & & & Total: 39 \\
\hline
\end{tabular}

Output DTN: LA0304TM831231.002.

NOTE: Of the 39 grid lines, one defined the lower boundary of the model and, thus, was not considered in the model. Therefore, there were only 38 grid lines in the model.

Anisotropy in the horizontal permeability field (north-south and east-west components) is assumed to be sufficient to represent fracture sets at the sub-grid scale. The use of just the principal values of permeability without cross terms is justified because this form of anisotropy is to represent the predominately north-south trending faults east of Yucca Mountain and west of Fortymile Wash (BSC 2004 [DIRS 170015], Figure 6-6). Because of the fault direction (see Section 6.6.1.3), they only enhance the north-south flow in that region (for illustration purposes only).

A three-dimensional representation of the computational grid is provided in Figure 6-28. Not all unit layers extend throughout the entire horizontal extent of the model domain. Because the model domain is both truncated at the water table and the water table exhibits some variation in altitude over the model domain ( $700 \mathrm{~m}$ to 1,200 m), those layers in the higher water table areas (i.e., to the north of the model domain) are truncated as the water table decreases in altitude toward the south. 


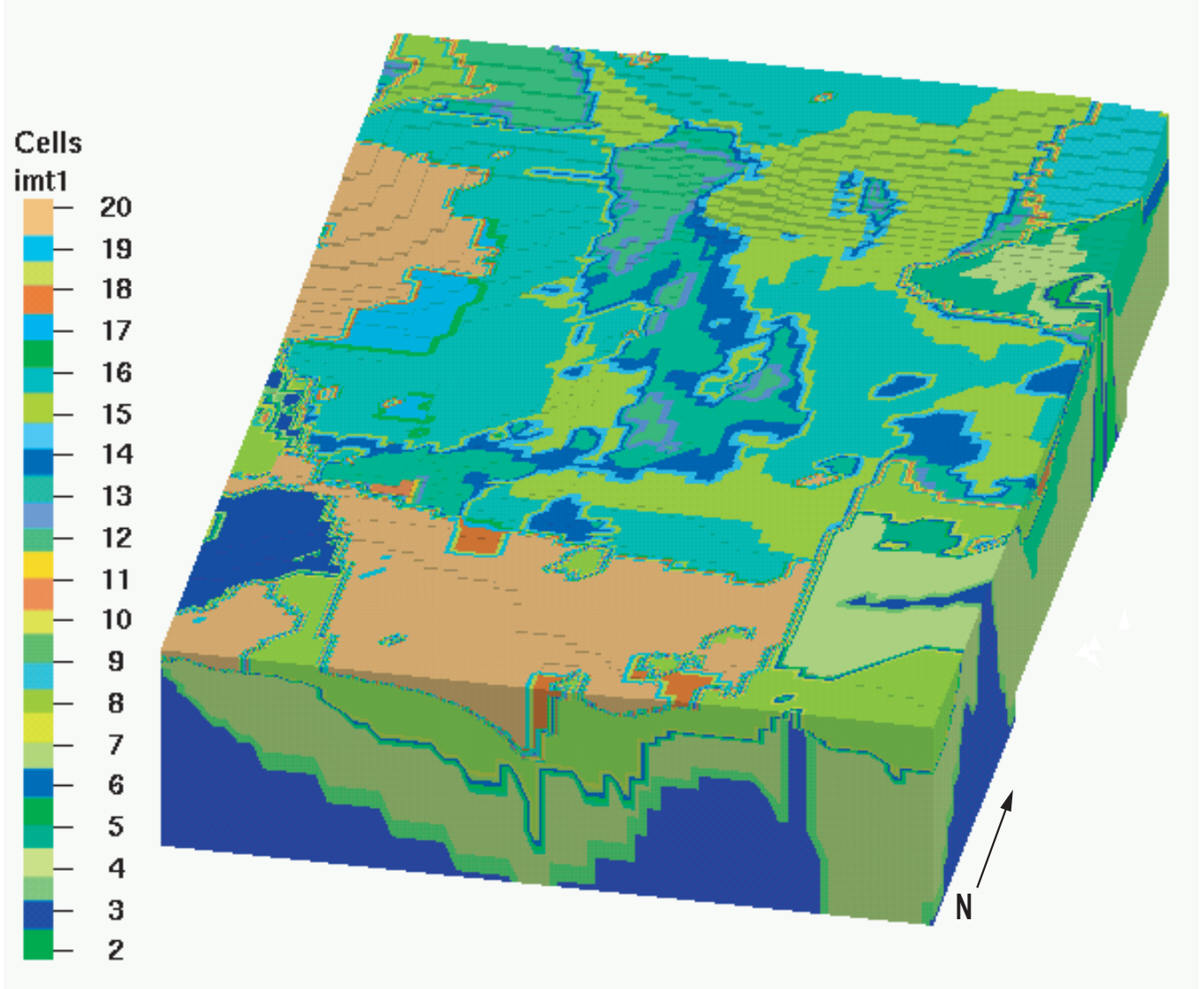

Source: DTN: GS030208312332.001 (DIRS 163087).

NOTE: The grid is truncated at the water table surface, which is at $1,200 \mathrm{~m}$ in the north and $700 \mathrm{~m}$ in the south. The grid extends 533,340 to $563,340 \mathrm{~m}$ in the east and west, and 4,046,780 to 4,091,780 $\mathrm{m}$ north and south (Coordinates UTM North American Datum 27).

Figure 6-28. View of the 500m Computational Grid (3x Vertical Exaggeration) Showing Node Points Colored by Hydrogeologic Unit Values from the HFM-19 


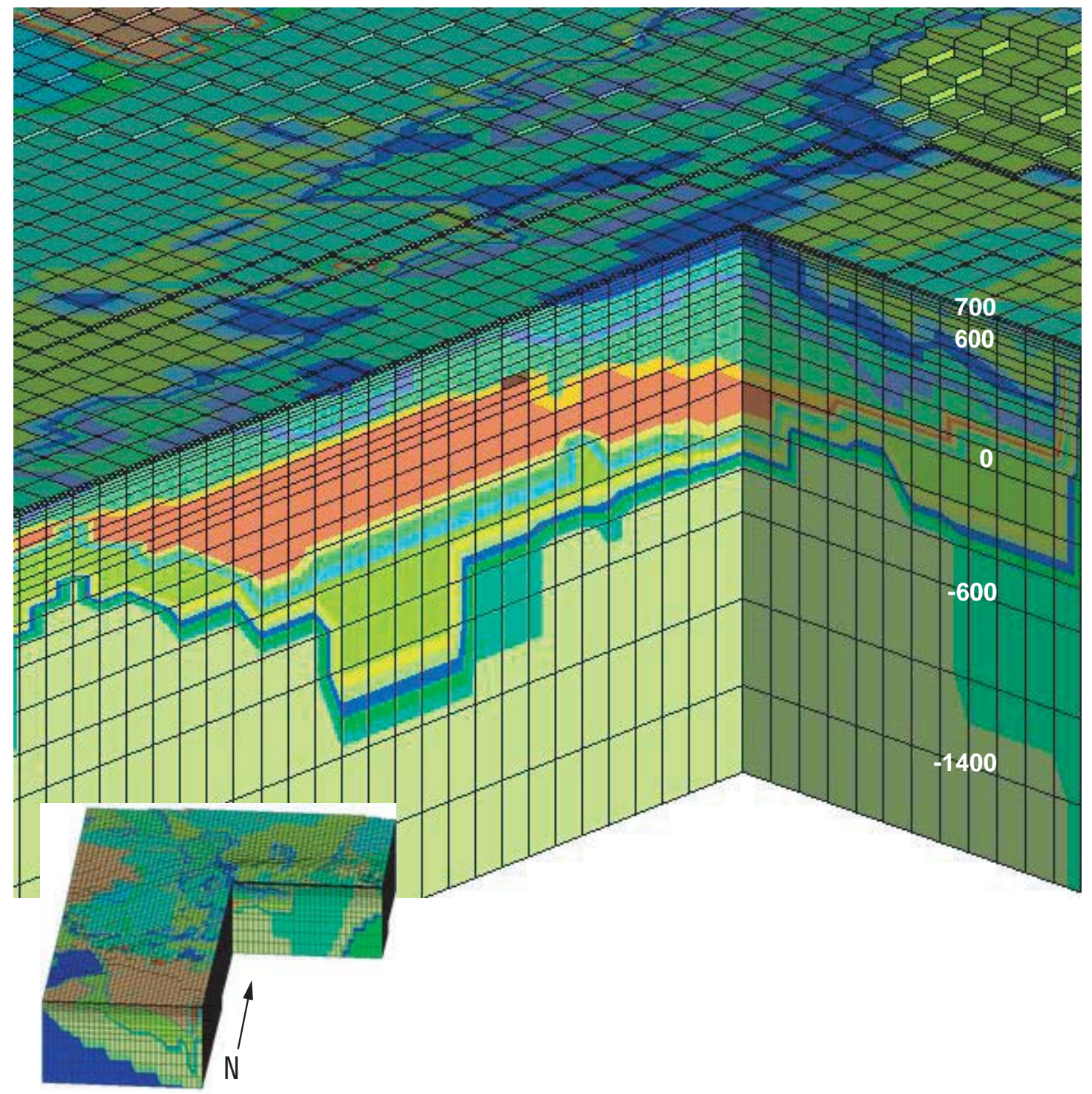

Source: DTN: GS030208312332.001 (DIRS 163087).

NOTE: For illustration purposes only. Grid spacing at the bottom of the grid is at $400 \mathrm{~m}$, then $200,100,50,40,20$, with $10 \mathrm{~m}$ near an elevation of $700 \mathrm{~m}$. Spacing then increases with elevation from $10 \mathrm{~m}$ to 20 and $40 \mathrm{~m}$, with 50-m spacing near the higher elevations in the north. The inset at the bottom of the image shows the location of the cut out in relation to the full grid. The grid points are colored with the values of the Hydrogeologic Units 2 through 20. Elevations are denoted in the figure from $-1,400$ to $700 \mathrm{~m}$ above mean sea level.

UTM = Universal Transverse Mercator

Figure 6-29. Close-Up View of Computational Grid (3x Vertical Exaggeration) Showing Cut Away at UTM Easting $=549000$ and UTM Northing $=4078000$ Through the Yucca Mountain Repository 


\subsubsection{Hydrogeologic Properties}

After establishing the grid, the physical hydrogeologic unit present at each node in the computational grid was established. The HFM-19 Stratamodel files were converted to advanced visualization system quadrilateral surfaces (Output DTN: LA0304TM831231.001) using STRAT2AVS V1.0 STN: 11028-1.0-00, (LANL 2003 [DIRS 163069]). These surface files represent the top surface of each hydrogeologic layer in the Stratamodel framework. The structured grid and the advanced visualization system surfaces that define the hydrogeologic layers were imported into LaGriT and were used to identify the hydrogeologic layer designation for each node and cell of the computational grid. Cells above the water table and below the bottom unit were removed from the grid. Once the grid geometry conforms to the HFM, FEHM input files were generated. These files include the mesh geometry, lists of nodes on external boundaries, and node lists sorted by material property.

Quality checks were performed to ensure that the final grid is correct. These include histograms of element volume and element aspect ratio. The details of this analysis can be found in Bower et al. (2000 [DIRS 149161]). All nodes were automatically and visually checked to ensure that they were assigned the correct material identification corresponding to the input HFM. Lists of the number of nodes associated with each material were compared to the volume of each material in the Stratamodel framework to confirm that the hydrogeologic units are identified correctly.

The grid units were checked and compared visually to HFM-19 units. Figure 6-27 shows the top of the grid with the nodes colored by each of the 19 hydrogeologic units. This image compares favorably with the same view of the HFM-19 in the Hydrogeologic Framework Model for the Saturated-Zone Site-Scale Flow and Transport Model (BSC 2004 [DIRS 170008], Figure 6-7). Further comparisons can be made with each individual unit by comparing HFM-19 layer thickness (isopach) to the shape of the grid nodes for each hydrogeologic unit (Figures 6-30 to 6-36). Both sets of images are views looking straight down at the top, with south towards the page bottom.

These images are for visual comparison of unit shapes. The shapes of the HFM-19 units and the grid units compare reasonably given that the grid resolution is $500 \mathrm{~m}$ and the HFM-19 is $125 \mathrm{~m}$. These unit shapes are used as reference during the flow calibration process to give the modeler some idea what the underlying HFM units look like. For further information on each unit, the HFM-19 is colored by unit thickness, and the grid units are colored by top surface elevation. These are not for comparison, but are used by modelers as information about the units.

The HFM isopach images are formed using LaGriT to read each of two surfaces defining the top and bottom of a unit. LaGriT then calculates the thickness at each $x, y$ point. The images show the HFM unit thickness with zero thickness removed. Images for the computational grid show all points within each selected unit, colored by the node elevation. A comparison of each unit shows that the grid units correspond adequately with the HFM unit images. Note that each unit distribution is also shown in the model report (BSC 2004 [DIRS 170008], Figures 6-6a to 6-6q), but before being clipped by the water table surface. The images (in Figures 6-30 to 6-36) still compare favorably with USGS images, with some differences in the upper units as they approach the top surface and are clipped by the water table. 

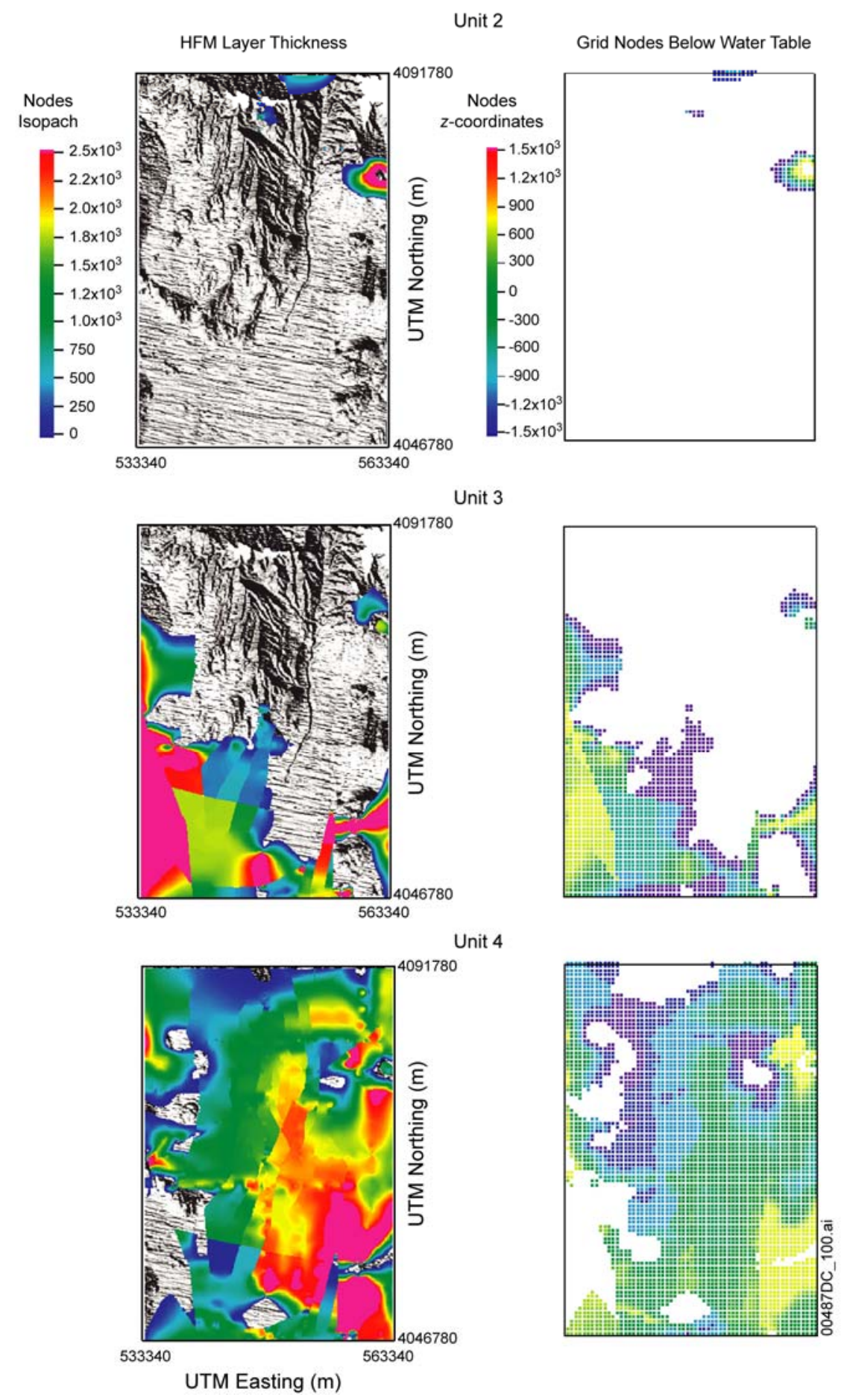

Output DTN: LA0304TM831231.002.

NOTE: See notes following Figure 6-36.

HFM = Hydrogeologic Framework Model; UTM = Universal Transverse Mercator

Figure 6-30. Composition of HFM-19 and SZ Site-Scale Flow Model Units Thickness for Units 2, 3, 4 

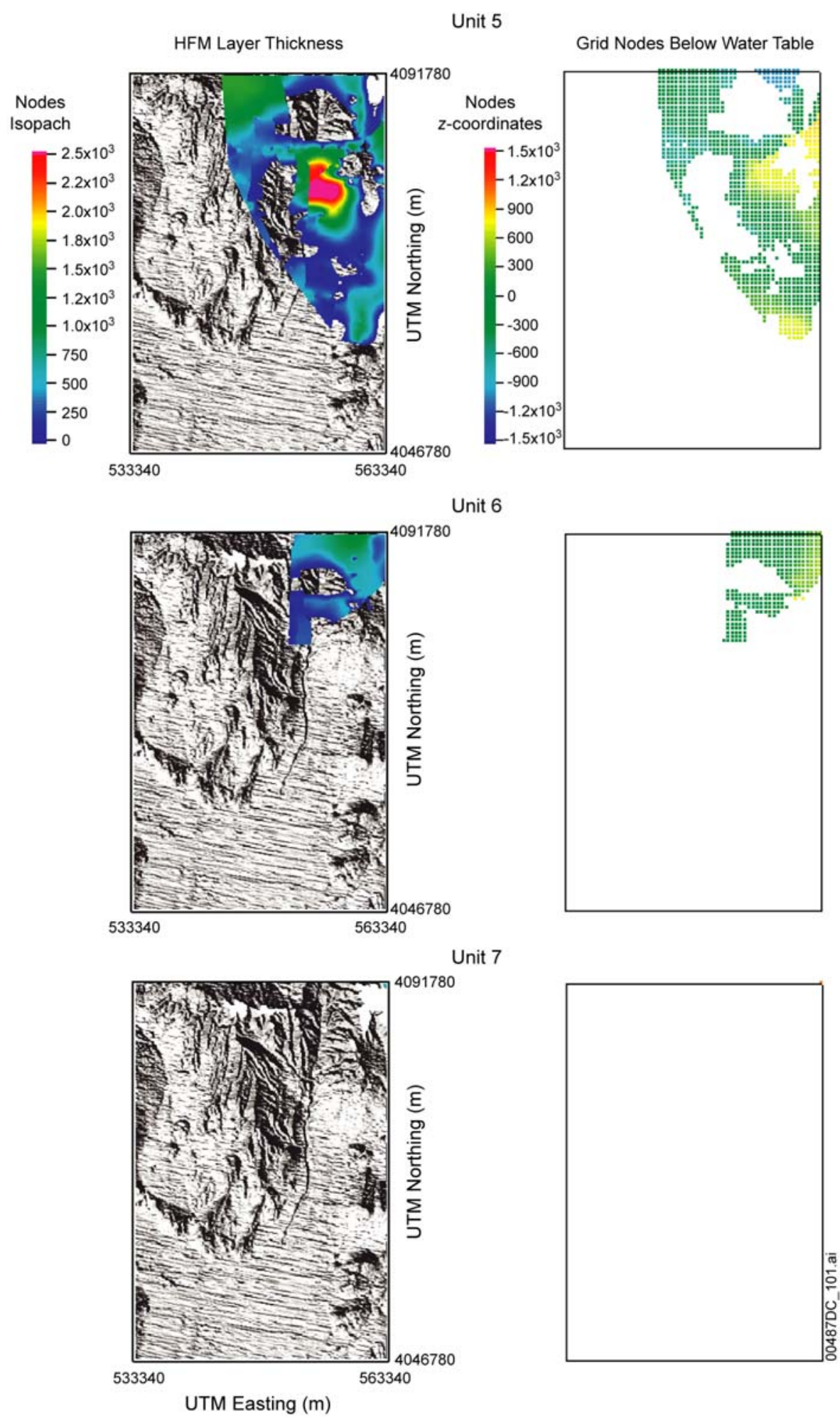

Output DTN: LA0304TM831231.002

NOTE: See notes following Figure 6-36.

HFM = Hydrogeologic Framework Model $;$ UTM = Universal Transverse Mercator.

Figure 6-31. Composition of HFM-19 and SZ Site-Scale Flow Model Units Thickness for Units 5, 6, 7 

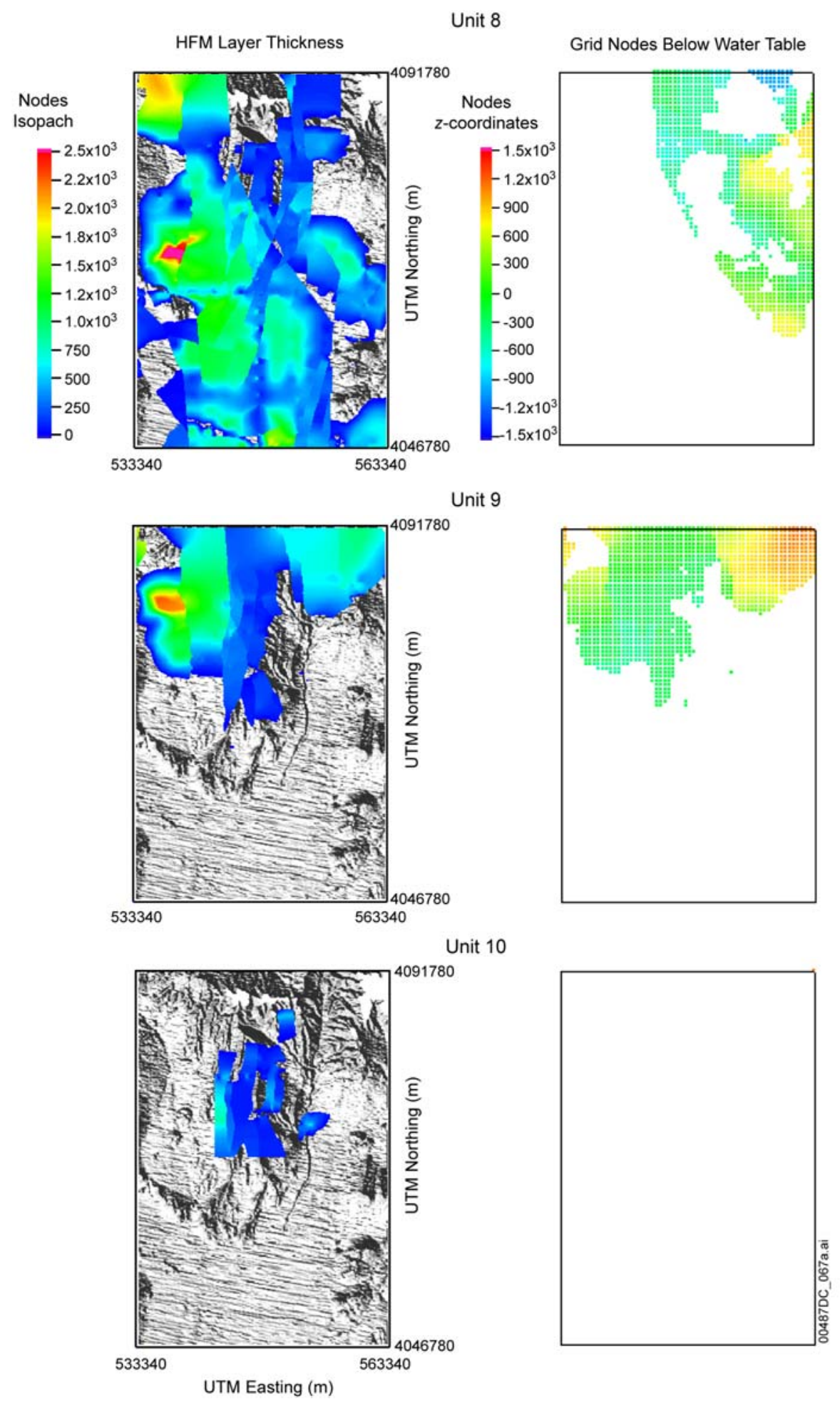

Output DTN: LA0304TM831231.002.

NOTE: See notes following Figure 6-36

HFM = Hydrogeologic Framework Model ; UTM = Universal Transverse Mercator.

Figure 6-32. Composition of HFM-19 and SZ Site-Scale Flow Model Units Thickness for Units 8. 9, 10 


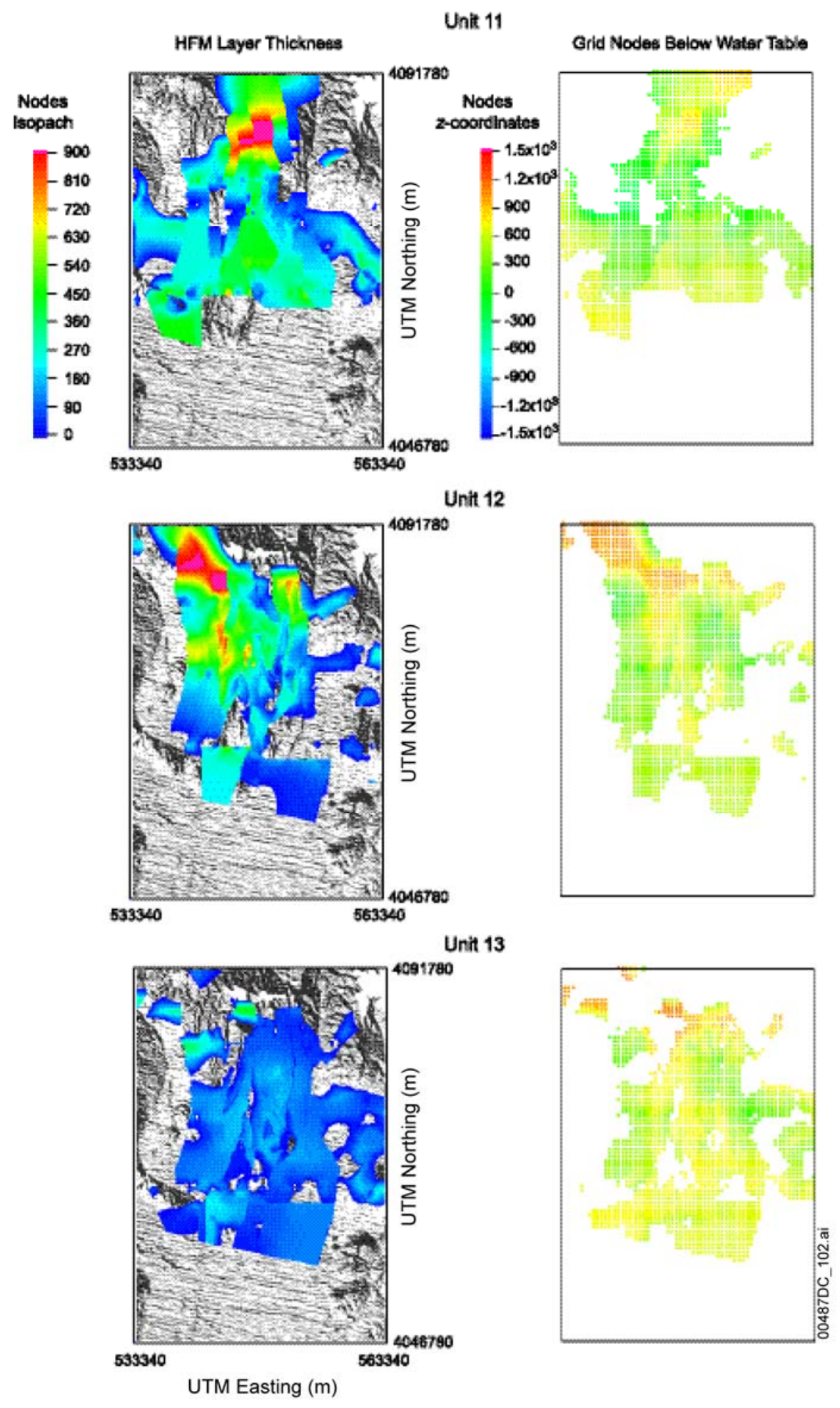

Output DTN: LA0304TM831231.002.

NOTE: See notes following Figure 6-36.

HFM = Hydrogeologic Framework Model; UTM = Universal Transverse Mercator.

Figure 6-33. Composition of HFM-19 and SZ Site-Scale Flow Model Units Thickness for Units 11, 12, 13 

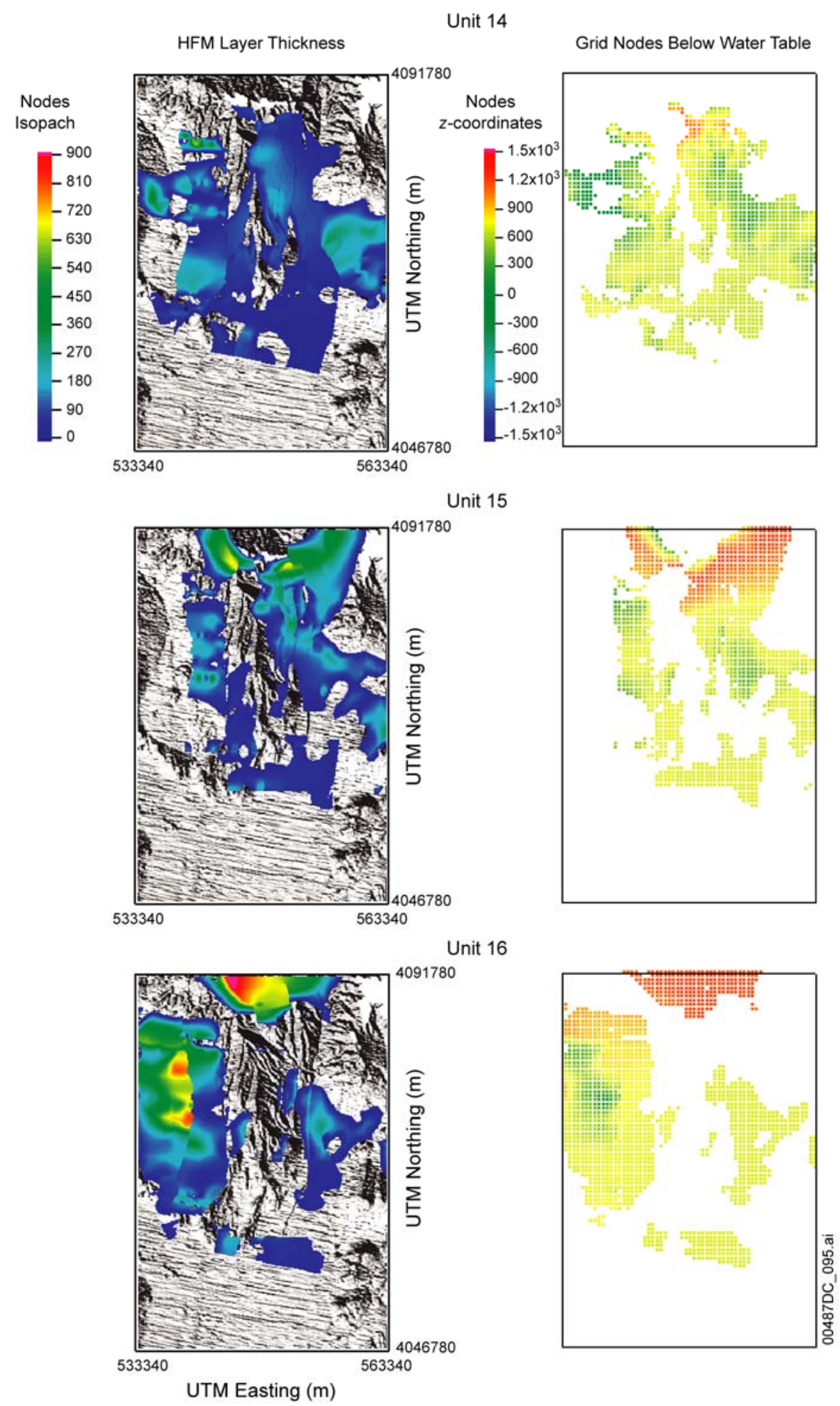

Output DTN: LA0304TM831231.002.

NOTE: See notes following Figure 6-36.

HFM = Hydrogeologic Framework Model; UTM = Universal Transverse Mercator

Figure 6-34. Composition of HFM-19 and SZ Site-Scale Flow Model Units Thickness for Units 14, 15, 16 

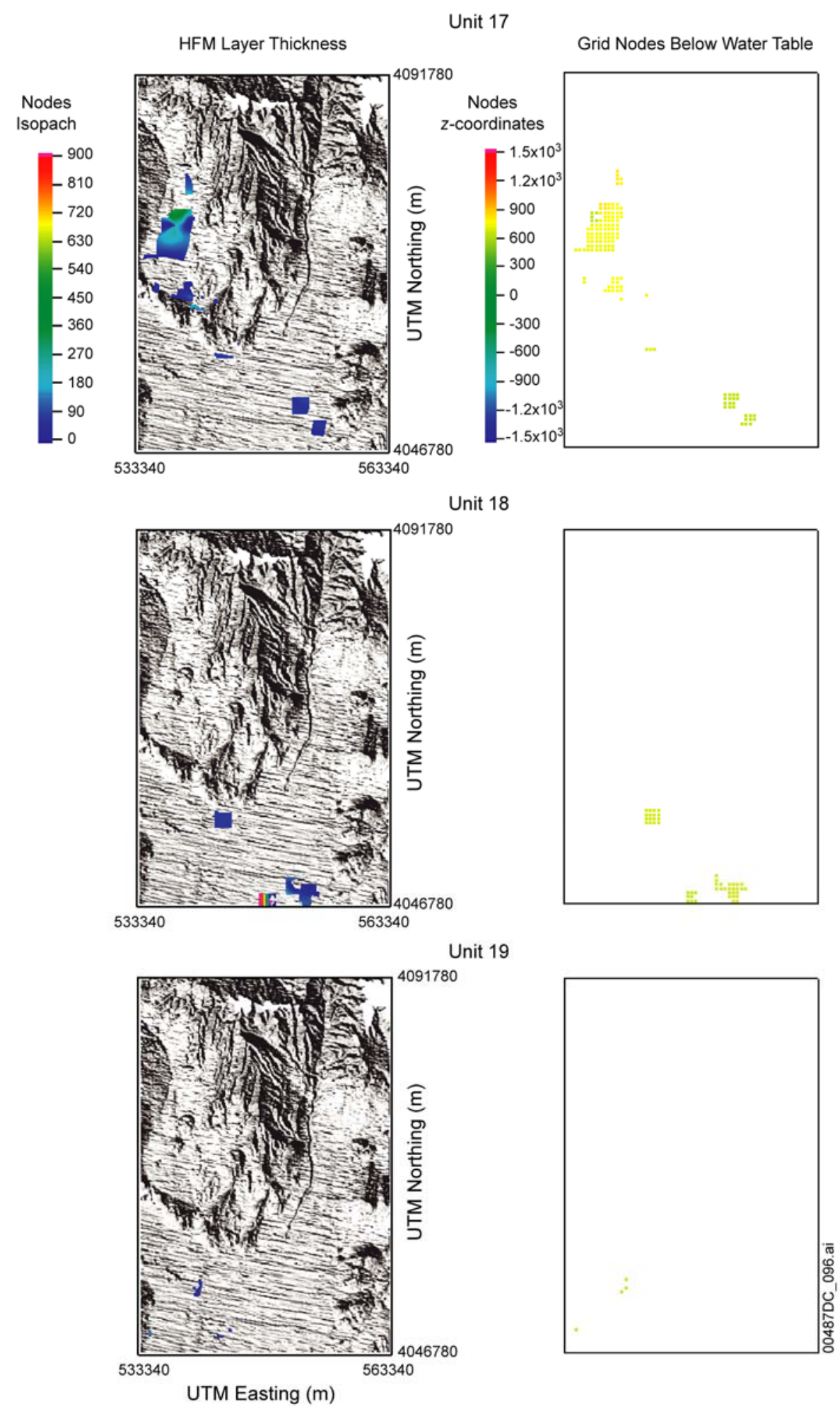

Output DTN: LA0304TM831231.002.

NOTE: See notes following Figure 6-36.

HFM = Hydrogeologic Framework Model; UTM = Universal Transverse Mercator.

Figure 6-35. Composition of HFM-19 and SZ Site-Scale Flow Model Units Thickness for Units 17, 18, 19 


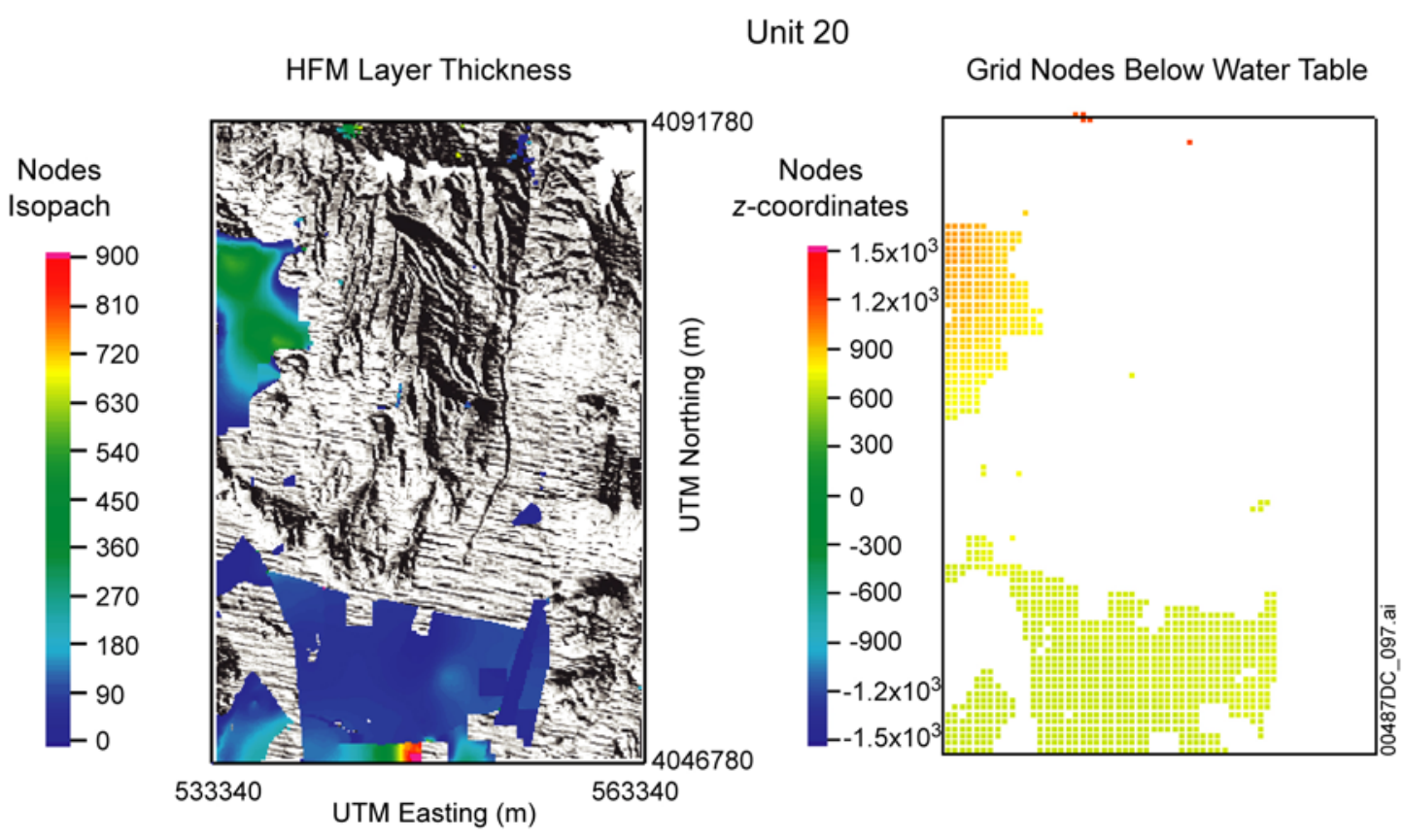

Output DTN: LA0304TM831231.002.

NOTE: Left panels of HFM-19 Layer Thicknesses: Color in the grid indicates vertical thickness between each of two unit surfaces. Each image is a plan view of the input HFM-19 and is formed by the surfaces extracted from the HFM-19. The bottom surface of each hydrogeologic unit is subtracted from the top surface resulting in the unit thickness at each point. Points of zero thickness have been removed, and the points are shown in relation to the topographic surface. These points are at a resolution of $125 \mathrm{~m}$, the same as the HFM (BSC 2004 [DIRS 170008], Section 6.1).

Right panels of Grid Nodes by Hydrogeologic Unit: Color in the grid indicates elevation at the top of the unit. Each image is a view looking down at the 500-m computational grid. Images are formed by selecting node points for each of the unit numbers 2 through 20 . There are no points where the units are truncated. Output DTN: LA0304TM831231.002

Correspondence between hydrostratigraphic unit numbers and unit names is listed in Figure 6-14.

HFM = Hydrogeologic Framework Model; UTM = Universal Transverse Mercator.

Figure 6-36. Composition of HFM-19 and SZ Site-Scale Flow Model Units Thickness for Unit 20

The LaGriT code writes FEHM input files; these files include the mesh geometry, lists of nodes on external boundaries, and node lists sorted by hydrogeologic unit. The number of nodes assigned to each hydrogeologic unit is presented in Table 6-16. 
Table 6-16. Number of Gridblocks per Hydrogeologic Unit

\begin{tabular}{|c|l|r|}
\hline $\begin{array}{c}\text { Surface } \\
\text { Number }\end{array}$ & \multicolumn{1}{|c}{ Hydrogeologic Units } & $\begin{array}{c}\text { Number of } \\
\text { Gridblocks }\end{array}$ \\
\hline 20 & Alluvium (Valley-Fill Aquifer) & 6,188 \\
\hline 19 & Valley-Fill Confining Unit & 13 \\
\hline 18 & Limestones & 227 \\
\hline 17 & Lava Flows & 891 \\
\hline 16 & Upper Volcanic Aquifer & 13,831 \\
\hline 15 & Upper Volcanic Confining Unit & 7,845 \\
\hline 14 & Crater Flat - Prow Pass & 5,666 \\
\hline 13 & Crater Flat - Bullfrog & 6,472 \\
\hline 12 & Crater Flat - Tram & 11,676 \\
\hline 11 & Lower Volcanic Confining Unit & 9,142 \\
\hline 10 & Older Volcanic Aquifer & 210 \\
\hline 9 & Older Volcanic Confining Unit & 11,012 \\
\hline 8 & Undifferentiated Valley Fill & 21,578 \\
\hline 7 & Upper Carbonate Aquifer & 23 \\
\hline 6 & Lower Carbonate Aquifer Thrust & 1,192 \\
\hline 5 & Upper Clastic Confining Unit & 5,923 \\
\hline 4 & Lower Carbonate Aquifer & 27,097 \\
\hline 3 & Lower Clastic Confining Unit & 13,259 \\
\hline 2 & Granitic confining unit & 608 \\
\hline 1 & Base & 0,853 \\
\hline & Total Number of Gridblocks & \\
\hline
\end{tabular}

Output DTN: LA0304TM831231.002.

\subsubsection{Features}

To represent discrete features and regions having distinct hydrological properties within the model domain, a set of 17 hydrogeologic features complementary to the HFM were identified and incorporated into the flow model. The hydrogeologic features included in the SZ site-scale flow model primarily represent faults, fault zones, and areas of mineralogical alteration. The features described here are essentially vertical: some being linear in the horizontal extent, and some being of areal extent. These features are distinct from the subhorizontal geological formations, which form zones with distinct geometry and material properties and are described in Section 6.5.3.3. Each of the features described in this report includes multiple geologic formations and represents zones of altered permeability within the individual formations: enhanced permeability, reduced permeability, or anisotropic permeability. Each feature has a significant impact on the SZ site-scale flow model. The geometric definition, description, nature of permeability alteration, and impact on the model for each of these features are described in Table 6-17. In the table, the numbers in the parentheses refer to zone numbers in the input file for FEHM. The features are shown in Figure 6-37, which is based on the Yucca Mountain area geologic map (DTN: GS010908314221.001 [DIRS 162874]) and shows feature representation in the SZ site-scale flow model. Also shown in the figure are the zone numbers used in the input files for FEHM. The permeability values associated with the features described in Table 6-17 are presented and discussed in Section 6.6.1.4. Because of their importance to 
TSPA, two proposed zones in the alluvium deserve special consideration. These zones are (1) the alluvial uncertainty zone and (2) the lower Fortymile Wash zone. The alluvial uncertainty zone was added to incorporate the new geology obtained with the recently drilled NC-EWDP-2D and Washburn wells (DTN: MO9909NYEEWDP0.000 [DIRS 119613]). This data source is not direct input to the SZ site-scale flow model. It is cited only to support the assertion that the base case HFM does not accurately represent the volcanic alluvium contact in the vicinity of the above-mentioned wells. The location of this zone is given in Table 6-17. The drilling records of these wells show that alluvium extends further north and east than the geologic model (created without benefit of the two wells) indicates. Because of the importance to TSPA, the alluvial uncertainty zone was added to the model. The lower Fortymile Wash zone was added because of the distinct character of the Fortymile Wash in the southern part of the model. Field observations indicate possible channelization with attendant textural contrasts with surrounding alluvial material (Oatfield and Czarnecki 1989 [DIRS 149438]).

The Claim Canyon, Calico Hills, Shoshone Mountain fault zones (known collectively as the northern low permeability zone), and the east-west barrier deserve additional comment because they form the LHG zone (Luckey et al. 1996 [DIRS 100465]) north of Yucca Mountain. The east-west barrier was required to have a low permeability $\left(10^{-18} \mathrm{~m}^{2}\right)$ during the calibration in order to separate the high heads in the north from the lower heads near Yucca Mountain. This feature has no other geologic significance. Though there are several theories proposed to explain the large hydraulic gradient, the expert elicitation panel (CRWMS M\&O 1998 [DIRS 100353], pp. 3-5 to 3-6) favored the idea of semi-perched water in that area. If several of the wells were semi-perched to the north of Yucca Mountain, then the hydraulic head gradient in the SZ would be smaller. This would likely result in different calibrated values for the northern low permeability zone and the east-west barrier than those obtained with the present model.

\subsubsection{Boundary and Initial Conditions}

The lateral boundary conditions are described in Section 6.3.2.6. It should be noted that, historically, groundwater has been extracted from wells in the Amargosa Valley south of the site-scale model domain. Drawdown from the wells is represented in the 2000 potentiometric surface map that was used to establish southern boundary head conditions. Consequently, the effect of pumping on flow within the model domain is accounted for by the head values specified along the southern boundary. A small amount of pumping also has occurred from the southern portion of the site-scale model. This pumping was included in the DVRFS model, but not the site-scale model. Ignoring this pumping is assumed to have very little effect on the calculated flow paths and flow times to compliance boundaries.

The initial conditions (initial pressure or head distribution) are not relevant since the SZ site-scale flow model and all the alternative models are formulated for steady-state flow. 


\section{Feature Name and Description}

\section{Northern Zone (Entire Claim Canyon,}

\section{Calico Hills, and Shoshone Mountain.; \#81)}

This zone is wedge-shaped, spanning almost the entire

northern boundary (except the western corner of the northern

boundary) and approximately the upper fourth of the eastern boundary. Vertically, it extends from the top to the bottom o

\section{Northern Crater Flat Zone (\#82)}

This wedge-shaped zone is at the northern third of the western boundary of the model. Vertically, it extends from the top to the bottom of the model, and its areal extent is shown by the four points.

\section{Fortymile Wash Zones (\#57 and \#58)}

These two north-south linear features are located

approximately halfway between Yucca Mountain and the

\section{eastern model boundary. Vertically, they extend from the top $x=554330, y=4081790$, and}

to the bottom of the model, and their areal extent is shown by the four points.

\section{Spotted Range-Mine Mountain Zone (\#59)}

This triangular feature is in the southeast corner of the model. Vertically, it extends from the top of the model down

to the bottom. Its areal extent is shown by the four points.

\begin{tabular}{|c|c|}
\hline $\begin{array}{c}\text { Geometric Definition } \\
\text { (UTM) }\end{array}$ & $\begin{array}{l}\text { Hydrogeological } \\
\text { Characteristics }\end{array}$ \\
\hline $\begin{array}{l}x=546436, y=4082110 \\
x=563657, y=4082110 \\
x=563549, y=4092080, \\
x=535832, y=4092020, \text { and } \\
z=\text { top to bottom of model. }\end{array}$ & $\begin{array}{l}\text { It represents the general region } \\
\text { of lowered permeability caused } \\
\text { by hydrothermal alteration } \\
\text { associated with the Claim } \\
\text { Canyon caldera. }\end{array}$ \\
\hline $\begin{array}{l}x=533077, y=4074580, \\
x=544206, y=4074530, \\
x=544103, y=4083490, \\
x=532974, y=4092230, \text { and } \\
z=\text { top to bottom of model. }\end{array}$ & $\begin{array}{l}\text { It is a permeability reduction } \\
\text { zone, representing a } \\
\text { hydrothermally altered area } \\
\text { associated with the Claim } \\
\text { Canyon caldera. }\end{array}$ \\
\hline $\begin{array}{l}x=554330, y=4066770 \\
x=554350, y=4066770 \\
x=554350, y=4081790 \\
x=554330, y=4081790, \\
z=\text { top to bottom of model. }\end{array}$ & $\begin{array}{l}\text { It is an enhanced permeability } \\
\text { zone representing the faulted } \\
\text { area associated with the wash. }\end{array}$ \\
\hline $\begin{array}{l}x=555000, y=4046770 \\
x=563350, y=4046770 \\
x=563350, y=4059000, \\
x=563310, y=4059000, \text { and } \\
z=\text { top to bottom of model. }\end{array}$ & $\begin{array}{l}\text { It is a zone of enhanced } \\
\text { permeability associated with } \\
\text { the Spotted Range thrust } \\
\text { region }\end{array}$ \\
\hline
\end{tabular}

\section{Impact on Model}

Impact of the model on this zone is mainly to control the flow of water into the model from the north boundary.

Impact of the model on this zone is to control influx from the northwest corner of the model.

Impact on the model is to channel the flow of the east-central portion of the model in the Jackass Flats area in a southern direction, lower the hydraulic gradient in the area, and act as a regional drain.

Impact on the model is to control the water flow into the model from the southern end of the east boundary and water flow out of the model of the eastern end of the southern boundary. 


\begin{tabular}{|c|c|c|c|}
\hline Feature Name and Description & $\begin{array}{c}\text { Geometric Definition } \\
\text { (UTM) }\end{array}$ & $\begin{array}{l}\text { Hydrogeological } \\
\text { Characteristics }\end{array}$ & Impact on Model \\
\hline $\begin{array}{l}\text { 5. Claim Canyon Caldera (East and West, } \# \mathbf{6 1} \text { and \#62) } \\
\text { These zones span much of the northern boundary of the } \\
\text { model, extending south as triangular shapes and terminating } \\
\text { north of the Yucca Wash. Vertically, they extend from the } \\
\text { top to the bottom of the model, and their areal extent is } \\
\text { shown by the eight points. These zones are part of the } \\
\text { northern low perm zone used in calibration. }\end{array}$ & $\begin{array}{l}x=536800, y=4091760 \\
x=540000, y=4086700 \\
x=547600, y=4084700 \\
x=547600, y=4091760 ; \\
x=547677, y=4091760 \\
x=547631, y=4084710 \\
x=560000, y=4087660 \\
x=560000, y=4091760, \text { and } \\
z=\text { top to bottom of model. }\end{array}$ & $\begin{array}{l}\text { These are zones of reduced } \\
\text { permeability due to the } \\
\text { hydrothermal alteration } \\
\text { associated with the caldera; but } \\
\text { the permeability reduction is } \\
\text { somewhat less than the rest of } \\
\text { the northern zone, probably due } \\
\text { to faulting associated with the } \\
\text { vertical movement due to caldera } \\
\text { collapse and the greater } \\
\text { thickness of welded zones within } \\
\text { the caldera. }\end{array}$ & $\begin{array}{l}\text { Impact on the model is } \\
\text { mainly to control the water } \\
\text { flow into the model from the } \\
\text { northern boundary. }\end{array}$ \\
\hline $\begin{array}{l}\text { 6. Shoshone Mountain Zone (North and South, \#63 and } \\
\text { \#64) } \\
\text { These two zones are in the northeastern corner of the model. } \\
\text { They extend from the top of the carbonate aquifer up to the } \\
\text { top of the model. Vertically, they extend from the top to the } \\
\text { bottom of the model, and their areal extent is shown by the } \\
\text { eight points. These zones are part of the northern low perm } \\
\text { zone used in calibration. }\end{array}$ & $\begin{array}{l}x=560634, y=4091530 \\
x=559362, y=4089570 \\
x=563090, y=4089620 \\
x=563044, y=4091480 ; \\
x=557045, y=4089620 \\
x=560953, y=4087480 \\
x=563137, y=4087750 \\
x=563090, y=4089620, \text { and } \\
z=\text { top to bottom of model. }\end{array}$ & $\begin{array}{l}\text { These are zones of permeability } \\
\text { reduction due to hydrothermal } \\
\text { alteration associated with the } \\
\text { Claim Canyon caldera. }\end{array}$ & $\begin{array}{l}\text { Impact on the model is } \\
\text { mainly to control the water } \\
\text { flow into the model from the } \\
\text { northern portion of the } \\
\text { eastern boundary. }\end{array}$ \\
\hline $\begin{array}{l}\text { 7. Calico Hills Zone (North and South \#65 and \#66) } \\
\text { These two zones are near the eastern end of the model, } \\
\text { south of the Shoshone Mountain zones, at approximately the } \\
\text { same northing as the Yucca Wash. Vertically, they extend } \\
\text { from the top to the bottom of the model, and their areal } \\
\text { extent is shown by the eight points. These zones are part of } \\
\text { the northern low perm zone used in calibration. }\end{array}$ & $\begin{array}{l}x=556864, y=4081020 \\
x=562957, y=4081020 \\
x=561499, y=4084070 \\
x=558589, y=4083430 ; \\
x=556818, y=4081020 \\
x=558821, y=4078070 \\
x=561273, y=4077160 \\
x=563142, y=4080980, \text { and } \\
z=\text { top to bottom of model. }\end{array}$ & $\begin{array}{l}\text { These are zones of permeability } \\
\text { reduction due to hydrothermal } \\
\text { alteration associated with the } \\
\text { Calico Hills }\end{array}$ & $\begin{array}{l}\text { Impact on the model is } \\
\text { mainly to control the water } \\
\text { flow into the model from the } \\
\text { northern portion of the } \\
\text { eastern boundary. }\end{array}$ \\
\hline
\end{tabular}




\begin{tabular}{|c|c|c|c|}
\hline Feature Name and Description & $\begin{array}{c}\text { Geometric Definition } \\
\text { (UTM) }\end{array}$ & $\begin{array}{l}\text { Hydrogeological } \\
\text { Characteristics }\end{array}$ & Impact on Model \\
\hline $\begin{array}{l}\text { 8. Crater Flat Fault (North-1, North-2, South-3, and } \\
\text { South-4, \#69, \#70,\#71, and \#72) } \\
\text { This is a linear feature running north-south in the western } \\
\text { half of the model, starting to the south of the Claim Canyon } \\
\text { and terminating near U.S. Highway } 95 \text {, almost halfway } \\
\text { between the western boundary and the Solitario Canyon. } \\
\text { Vertically, it extends from the top to the bottom of the model, } \\
\text { and its areal extent is shown by the sixteen points. }\end{array}$ & $\begin{array}{l}x=538330, y=4083800, \\
x=538350, y=4083800, \\
x=538350, y=4089430, \\
x=538330, y=4089430 ; \text { and } \\
x=538330, y=4074750, \\
x=538350, y=4074750, \\
x=538350, y=4083800, \\
x=538330, y=4083800 ; \text { and } \\
x=538330, y=4066500, \\
x=538350, y=4066500, \\
x=538350, y=4074750, \\
x=538330, y=4074750 ; \text { and } \\
x=538330, y=4061400, \\
x=538350, y=4061400, \\
x=538350, y=4066500, \\
x=538330, y=4066500 ; \text { and } \\
z=\text { top to bottom of model. }\end{array}$ & $\begin{array}{l}\text { These are zones of permeability } \\
\text { reduction normal to the fault } \\
\text { orientation and permeability } \\
\text { enhancement parallel to the fault } \\
\text { orientation. }\end{array}$ & $\begin{array}{l}\text { Impact on the model of these } \\
\text { zones is to generate a } \\
\text { somewhat high head gradient } \\
\text { in the western half of the } \\
\text { model and control the influx } \\
\text { coming from the western } \\
\text { boundary, and to restrict the } \\
\text { flow towards the eastern half } \\
\text { of the model. }\end{array}$ \\
\hline $\begin{array}{l}\text { 9. Solitario Canyon Fault (\#74, \# } 83 \text { and \#84) } \\
\text { These are generally north-south trending linear features just } \\
\text { to the west of Yucca Mountain. Vertically, they extend from } \\
\text { the bottom of the model to the top of the model. Their areal } \\
\text { extent is shown by the twelve points. }\end{array}$ & $\begin{array}{l}x=546451, y=4077540, \\
x=545632, y=4073550, \\
x=546384, y=4073550, \\
x=547018, y=4077540 ; \text { and } \\
x=546451, y=4077540, \\
x=545632, y=4077520, \\
x=546384, y=4081580, \\
x=547018, y=4081580 ; \text { and } \\
x=545638, y=4071110, \\
x=546379, y=4071080, \\
x=546647, y=4073550, \\
x=546008, y=4073520 ; \text { and } \\
z=\text { top to bottom of model. }\end{array}$ & $\begin{array}{l}\text { These are zones of permeability } \\
\text { enhancement in the vertical and } \\
\text { fault-parallel direction and } \\
\text { permeability reduction normal to } \\
\text { the fault. }\end{array}$ & $\begin{array}{l}\text { Impact on the model of these } \\
\text { features is to generate a } \\
\text { higher head gradient to the } \\
\text { west of Yucca Mountain and } \\
\text { to impede flow from Crater } \\
\text { Flat to Yucca Mountain. }\end{array}$ \\
\hline $\begin{array}{l}\text { 10. Solitario Canyon Fault, East Branch }(\# 75, \# 76) \\
\text { These are generally north-northeast trending linear features } \\
\text { just to the west of Yucca Mountain. Vertically, they extend } \\
\text { from the bottom of the model to the top of the model. Their } \\
\text { areal extent is given by the eight points. }\end{array}$ & $\begin{array}{l}x=545632, y=4071110 \\
x=547450, y=4064680 \\
x=547996, y=4064680 \\
x=546384, y=4071090 ; \text { and } \\
x=547450, y=4064680 \\
x=544520, y=4058330 \\
x=545040, y=4058150 \\
x=548022, y=4064680 ; \text { and } \\
z=\text { top to bottom of model. }\end{array}$ & $\begin{array}{l}\text { These are zones of permeability } \\
\text { enhancement in the vertical and } \\
\text { fault-parallel direction and } \\
\text { permeability reduction normal to } \\
\text { the fault. }\end{array}$ & $\begin{array}{l}\text { Impact on the model of these } \\
\text { features is to generate a } \\
\text { higher head gradient to the } \\
\text { west of Yucca Mountain and } \\
\text { to impede flow from Crater } \\
\text { Flat to Yucca Mountain. }\end{array}$ \\
\hline
\end{tabular}




\begin{tabular}{|c|c|c|c|}
\hline Feature Name and Description & $\begin{array}{c}\text { Geometric Definition } \\
\text { (UTM) }\end{array}$ & $\begin{array}{l}\text { Hydrogeological } \\
\text { Characteristics }\end{array}$ & Impact on Model \\
\hline $\begin{array}{l}\text { 11. Solitario Canyon Fault, West Branch }(\# 77, \# 78) \\
\text { These are generally north-northeast trending linear features } \\
\text { just to the west of Yucca Mountain. Vertically, they extend } \\
\text { from the bottom of the model to the top of the model. Their } \\
\text { areal extent is given by the eight points. }\end{array}$ & $\begin{array}{l}x=545632, y=4061090 \\
x=540452, y=4062590 \\
x=541018, y=4062610 \\
x=546384, y=4071060 ; \text { and } \\
x=540426, y=4062590 \\
x=540132, y=4059720 \\
x=540699, y=4059470, \\
x=541018, y=4062590 ; \text { and } \\
z=\text { top to bottom of model. }\end{array}$ & $\begin{array}{l}\text { These are zones of permeability } \\
\text { enhancement in the vertical and } \\
\text { fault-parallel direction and } \\
\text { permeability reduction normal to } \\
\text { the fault. }\end{array}$ & $\begin{array}{l}\text { Impact on the model of these } \\
\text { features is to generate a } \\
\text { higher head gradient to the } \\
\text { west of Yucca Mountain and } \\
\text { to impede flow from Crater } \\
\text { Flat to Yucca Mountain. }\end{array}$ \\
\hline $\begin{array}{l}\text { 12. U.S. Highway } 95 \text { Fault (West, \#79) } \\
\text { This is a linear feature in the lower half of the western portion } \\
\text { of the model. It is east-southeast trending. Vertically, it } \\
\text { extends from the bottom of the model to the top of the model. } \\
\text { Its areal extent is given by the four points. }\end{array}$ & $\begin{array}{l}x=536625, y=4061240 \\
x=544355, y=4058380 \\
x=544716, y=4058330 \\
x=536486, y=4061840, \text { and } \\
z=\text { top to bottom of model. }\end{array}$ & $\begin{array}{l}\text { This is a zone of permeability } \\
\text { enhancement in the vertical and } \\
\text { fault-parallel direction and } \\
\text { permeability reduction normal to } \\
\text { the fault. }\end{array}$ & $\begin{array}{l}\text { Impact on this model is to } \\
\text { restrict flow in the north-south } \\
\text { direction and support high } \\
\text { head gradients in that portion } \\
\text { of the model. }\end{array}$ \\
\hline $\begin{array}{l}\text { 13. Bare Mountain Fault ( } \# \mathbf{8 0} \text { and } \# \mathbf{9 0} \text { ) } \\
\text { This is a northwest- to southeast-trending linear feature in } \\
\text { the southwestern corner of the model. Vertically, it extends } \\
\text { from the bottom of the model to the top of the model. Its } \\
\text { areal extent is given by the eight points. }\end{array}$ & $\begin{array}{l}x=533628, y=4067570 \\
x=536126, y=4061020 \\
x=536672, y=4061250 \\
x=533628, y=4068980, \text { and } \\
x=540330, y=4046780 \\
x=540850, y=4046780 \\
x=533850, y=4064290 \\
x=533330, y=4064290 ; \text { and } \\
z=\text { top to bottom of model. }\end{array}$ & $\begin{array}{l}\text { This is a zone of permeability } \\
\text { enhancement representing the } \\
\text { Bare Mountain fault. }\end{array}$ & $\begin{array}{l}\text { Impact on the model is to } \\
\text { drain the flow from Crater } \\
\text { Flat to the Amargosa Desert. }\end{array}$ \\
\hline $\begin{array}{l}\text { 14. Alluvial Uncertainty Zone (Expected Case, \#88) } \\
\text { This is a roughly rectangular region to the south of Yucca } \\
\text { Mountain in the southern half of the model. Vertically, it } \\
\text { extends from the top of the model down through the } \\
\text { undifferentiated units. Its areal extent is given by the four } \\
\text { points. }\end{array}$ & $\begin{array}{l}x=547622, y=4057310 \\
x=555503, y=4055420 \\
x=556740, y=4062060 \\
x=550691, y=4062060, \text { and } \\
z=\text { top of model to }+400\end{array}$ & $\begin{array}{l}\text { This zone represents uncertainty } \\
\text { in the border between the } \\
\text { alluvium and tuff. }\end{array}$ & $\begin{array}{l}\text { Although it does not strongly } \\
\text { influence the SZ site-scale } \\
\text { flow model, it is expected to } \\
\text { be important to TSPA } \\
\text { calculations due to its effect } \\
\text { on solute transport. }\end{array}$ \\
\hline $\begin{array}{l}\text { 15. Imbricate Fault Zone (\#91) } \\
\text { This is a highly faulted area bounded in the west by the } \\
\text { Ghost Dance fault, south by the Dune Wash, east by the } \\
\text { Paintbrush Canyon fault, and to the north by the Drill Hole } \\
\text { Wash. Vertically, it extends from the top of the model down } \\
\text { through the middle volcanics to the top of the undifferentiated } \\
\text { units. Its areal extent is given by the four points. }\end{array}$ & $\begin{array}{l}x=548830, y=4073270 \\
x=552350, y=4071770 \\
x=552350, y=4077290 \\
x=548830, y=4079790, \text { and } \\
z=\text { top of model to }+400\end{array}$ & $\begin{array}{l}\text { This is a region of permeability } \\
\text { enhancement. }\end{array}$ & $\begin{array}{l}\text { It allows the model to } \\
\text { represent higher } \\
\text { permeabilities due to faulting } \\
\text { while retaining regional scale } \\
\text { permeability values of the } \\
\text { middle volcanic layers in the } \\
\text { expected range. }\end{array}$ \\
\hline
\end{tabular}




\begin{tabular}{|c|c|c|c|}
\hline Feature Name and Description & $\begin{array}{c}\text { Geometric Definition } \\
\text { (UTM) }\end{array}$ & $\begin{array}{l}\text { Hydrogeological } \\
\text { Characteristics }\end{array}$ & Impact on Model \\
\hline $\begin{array}{l}\text { 16. East-West Barrier (\#56) } \\
\text { This linear feature runs east-west just to the north of Yucca } \\
\text { Mountain, starting at the western edge of Yucca Mountain } \\
\text { and extending eastwards but short of the Calico Hills. } \\
\text { Vertically, it extends from the bottom of the model to the top } \\
\text { of the model. Its areal extent is given by the four points. }\end{array}$ & $\begin{array}{l}x=546000, y=4081440 \\
x=559000, y=4081440 \\
x=559000, y=4082000 \\
x=546000, y=4082000, \text { and } \\
z=\text { top to bottom of model. }\end{array}$ & $\begin{array}{l}\text { This is a zone of permeability } \\
\text { reduction. }\end{array}$ & $\begin{array}{l}\text { The impact of this barrier on } \\
\text { the model is mainly to create } \\
\text { the steep hydraulic gradient } \\
\text { to the north of Yucca } \\
\text { Mountain between the wells } \\
\text { G2, WT6 to the north and the } \\
\text { wells WT18, H1 to the south. }\end{array}$ \\
\hline $\begin{array}{l}\text { 17. Lower Fortymile Wash Zone (\#45) } \\
\text { This quadrilateral feature (plan view) encompasses the lower } \\
\text { Fortymile Wash part of the model. The depth of the zone } \\
\text { includes the alluvium unit to the top of the model. Its areal } \\
\text { extent is given by the four points. }\end{array}$ & $\begin{array}{l}x=546965, y=4057460 \\
x=550691, y=4056450 \\
x=547893, y=4046760 \\
x=540833, y=4046760 \\
z=400 m \text { to top. }\end{array}$ & $\begin{array}{l}\text { This is a zone of permeability } \\
\text { enhancement. }\end{array}$ & $\begin{array}{l}\text { The impact on the model of } \\
\text { this barrier is mainly to create } \\
\text { the low hydraulic gradient } \\
\text { observed in the Fortymile } \\
\text { wash area where it intersects } \\
\text { the southern boundary. }\end{array}$ \\
\hline
\end{tabular}

Sousre : DTN: GS010908314221.001 (DIRS 162874); Output DTN: LA0304TM831231.002.

NOTE: $\quad$ The geologic map in DTN GS010908314221.001 [DIRS 162874] is an essential input used to construct a site-scale three-dimensional hydrologic framework model (HFM), (BSC 2004 [DIRS 170008]). The geographic coordinates and the name of the different geologic features shown in this table are the results of interpretation of the geologic map, including geologic cross-sections, and lithostratigraphic and structural data from boreholes as it is described in detail in BSC (2004 [DIRS 170008]). The conversion of the geographic coordinates was done using standard Geographic Information System (GIS) functions. An example shows both the latitude/longitude and UTM coordinates of the site-scale model and some of the features shown in Figure 6-37 (BSC 2004 [DIRS 170008], Figure 6-3).

TSPA=total system performance assessment; UTM = Universal Transverse Mercator 


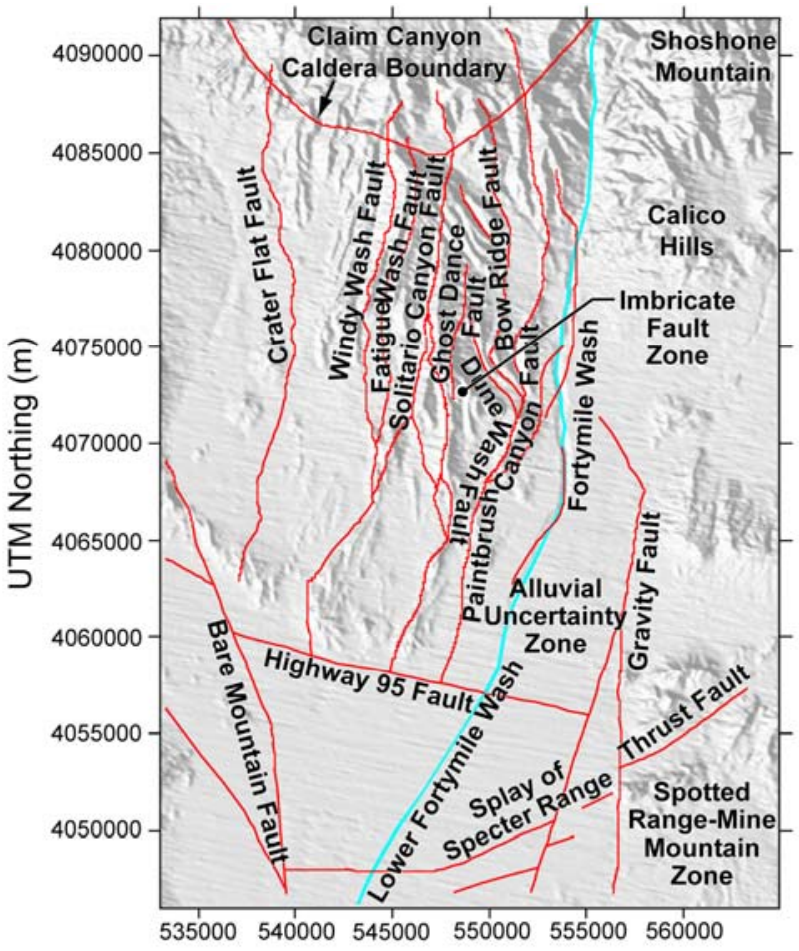

UTM Easting $(\mathrm{m})$

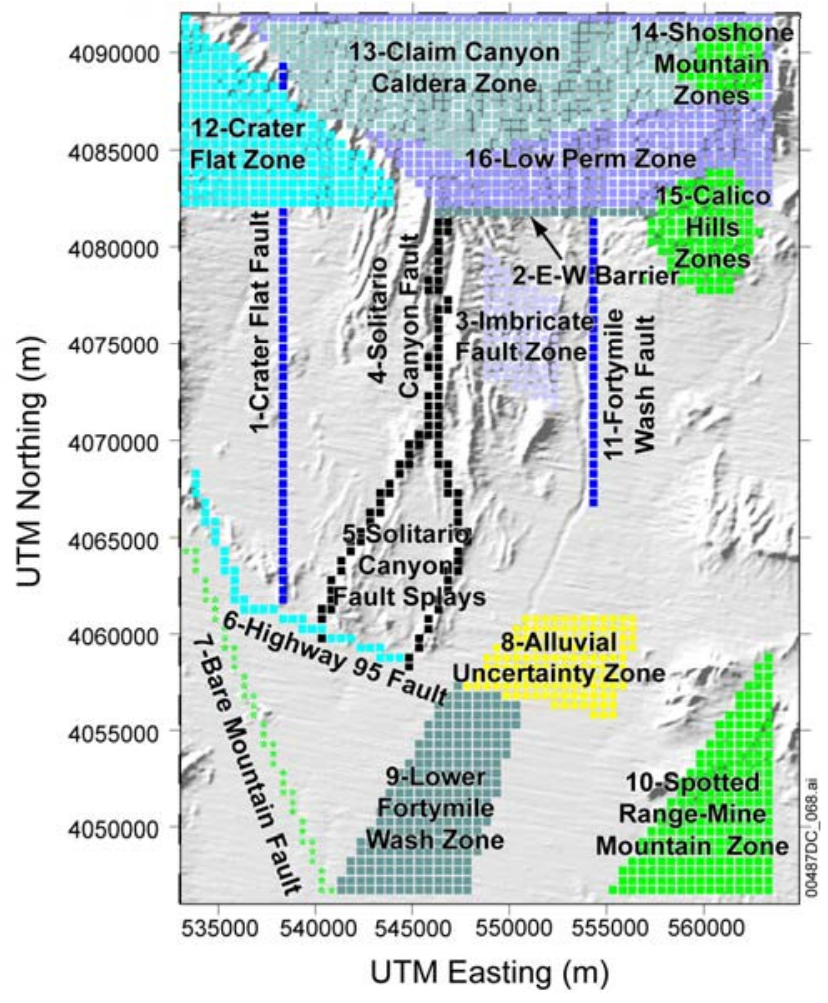

UTM Easting $(\mathrm{m})$

Source: DTN: GS010908314221.001 (left panel) [DIRS 162874]. Output DTN: LA0304TM831231.002 (right panel).

NOTE: Fault traces are on the left panel, and the SZ model representation is on the right panel. Numbers designate the following regions: 45 - lower Fortymile Wash zone; 56 -east-west Barrier zone; 57 and 58 - Fortymile Wash zones; 59 - Spotted Range-Mine Mountain zone; 61 and 62 - Claim Canyon caldera zones; 63 and 64 - Shoshone Mountain zones; 65 and 66 - Calico Hills zones; 69, 70, 71, and 72 - Crater Flat fault zones; 74, 83, and 84 - Solitario Canyon fault zones; 75 and 76 - Solitario Canyon fault zones (east branch); 77 and 78 - Solitario Canyon fault zones (west branch); 79 - U.S. Highway 95 fault zone; 80 and 90 - Bare Mountain fault zones; 81 - northern zone; 82 - northern Crater Flat zone; 88 - alluvial uncertainty zone (expected case); 91 Imbricate fault zone.

The geologic map in DTN GS010908314221.001 [DIRS 162874] is an essential input used to construct the site-scale three-dimensional hydrologic framework model (HFM-19), (BSC 2004 [DIRS 170008]). The geographic coordinates and the name of the different geologic features shown in this figure are the results of interpretation of the geologic map, including geologic cross-sections, and lithostratigraphic and structural data from boreholes as it is described in detail in BSC (2004 [DIRS 170008]). The conversion of the geographic coordinates was done using standard Geographic System Information (GIS) functions. See Figure 6-3 in BSC (2004 [DIRS 170008]) an example showing both, the latitude/longitude and UTM coordinates of the site-scale model and some of the features shown in Figure 6-37.

UTM = Universal Transverse Mercator

Figure 6-37. Geologic Features in the Area of the SZ Site-Scale Flow Model 


\subsubsection{Recharge}

Recharge was applied to the top surface of the computational grid as a flux boundary condition. The recharge map in Recharge and Lateral Groundwater Flow Boundary Conditions for the Saturated Zone Site-Scale Flow and Transport Model (BSC 2004 [DIRS 170015], Section 6.2) was mapped (with changes to be described later) to the top surface of the numerical grid described in this report. An important characteristic of the recharge data is that they were developed with the assumption that they are applied at the land's surface. The recharge data required as impacts to the SZ site-scale flow model are the penetration rate at the water table infiltration. The exception is the recharge in the area of the UZ model domain, where the actual output of the UZ model was used. Thus, except for the area beneath the UZ model domain, redistribution of infiltration in the $\mathrm{UZ}$ is likely to produce recharge at the water table that is different from that described in Recharge and Lateral Groundwater Flow Boundary Conditions for the Saturated Zone Site-Scale Flow and Transport Model (BSC 2004 [DIRS 170015]). Because most of the recharge occurs at higher elevations in rocks that are less permeable than in other regions, there are nodes at the top of the model (i.e., at the water table surface) where the permeability is too small to accept the recharge developed for the land surface at that location. This has necessitated the increase in the permeability of the top layer in the SZ model in some areas. This change allows the flow to redistribute locally and avoid artificially high heads. This method conserved recharge mass flux and was deemed better than any procedure that would modify the spatial distribution of the recharge. Sensitivity to this procedure on calibration and flow direction is small because this procedure was applied to the low permeability rocks that exist to the north of Yucca Mountain. The effect on the flow field to the south and east of Yucca Mountain, provided the heads and gradients are well matched, is therefore minimal.

To assign recharge values to the top surface of the computational grid, an infiltration map (DTN: SN9908T0581999.001 [DIRS 132867]) was interpolated onto the computational mesh to provide the top surface flux boundary condition. The interpolation procedure was designed to ensure that the local small-scale features of the infiltration map are represented in the boundary conditions and that the total flux is preserved. This procedure is accomplished by first providing the infiltration map (DTN: SN9908T0581999.001 [DIRS 132867]) as an ASCII file with two coordinates, $x$ and $y$, for each data point, the area associated with that point, and the infiltration rate for each point. The computational mesh has a regular point distribution with points spaced at 500-m horizontal intervals. However, the mesh numbering was irregular. A geometric sorting program was used to identify each point in the infiltration data with the corresponding gridlock in the computational mesh. This step is equivalent to determining the gridblock number for the 500-m mesh and determining to which node each point of the infiltration map belongs. Figure 6-38 shows a comparison of the data in the above-mentioned DTN and that recharge used in the FEHM input files for the SZ site-scale flow model. They are identical, thus proving that the mapping used preserves the recharge distribution.

\subsubsection{Nodal Hydrogeologic Properties}

Hydrogeologic properties must be specified for each node in the computational grid. Using the hydrogeologic unit sets created in the grid-building process, flow parameters such as permeability, viscosity, and porosity are assigned to each node.

The parameter values for viscosity depend on the temperature at each node, and a uniform temperature gradient is assumed. This assumption of a uniform temperature gradient with depth 
is equivalent to assuming uniform geothermal heat flux through a medium of homogeneous thermal conductivity. In addition, the temperature at the ground surface is assumed to be equal to a uniform value. The data on temperature in boreholes presented by Sass et al. (1988 [DIRS 100644]; DTN: MO0102DQRBTEMP.001 [DIRS 154733], Figures 4, 5, 6, 7, 8, and 10) indicate that there is significant variability in the temperature gradient at different locations and within individual wells, presumably from advective redistribution of heat from infiltration and vertical groundwater flow. The data were used to estimate an approximate average temperature gradient and representative surface temperature for the site. As noted by Sass et al. (1988 [DIRS 100644], p. 2), there is considerable variability (about $15^{\circ} \mathrm{C} / \mathrm{km}$ to nearly $60^{\circ} \mathrm{C} / \mathrm{km}$ ) in the temperature gradients among the wells. However, the approximately average value of the temperature gradient in the wells is $25^{\circ} \mathrm{C} / \mathrm{km}$, and the average surface temperature is about $19^{\circ} \mathrm{C}$. However, these data also indicate that the temperature gradients generally become more linear with increasing depth below the water table. It is important to note that the goal of assigning temperature variations with depth in the SZ site-scale flow model is to account for resulting variations in fluid viscosity at different depths in the SZ. The viscosity of water changes by a factor of only about 3.3 over the temperature range of $20^{\circ} \mathrm{C}$ to $100^{\circ} \mathrm{C}$ (Streeter and Wylie 1979 , [DIRS 145287], p. 536) that is expected within the range of depths in the SZ site-scale model domain. Thus, the linear approximation of the temperature gradient is adequate to capture the general effects of variations in groundwater viscosity with depth in the SZ site-scale flow model.

The density also varies with temperature, but the effect is much smaller than that of viscosity. Over the temperature range of $20^{\circ} \mathrm{C}$ to $100^{\circ} \mathrm{C}$, water density varies only a few percent, and therefore density was treated as a constant. Using a variable viscosity allows the calibration of intrinsic permeability to be made instead of hydraulic conductivity. The former is a rock property, whereas the latter is both a rock and fluid property. This approach, in turn, allows for more accurate flux calculations on the boundaries of the model.

The approach taken to the incorporation of groundwater temperature in the SZ site-scale model was to evaluate the average temperature gradient using temperature measurements in boreholes and to use that temperature gradient to specify temperature at grid nodes in the SZ site-scale flow model. As implemented in the SZ site-scale flow model, temperatures remain fixed at the specified value, and the heat-transport equations are not solved in the simulation. Thus, the specified values of temperatures were used to calculate the local groundwater viscosity, but temperature variations do not result in any variable-density flow processes as the density in all calculations was treated as a constant.

The temperature at the water table at the different locations was calculated as the sum of the representative temperature at the surface $\left(19^{\circ} \mathrm{C}\right)$ and the product of the average temperature gradient $\left(25^{\circ} \mathrm{C} / \mathrm{km}\right)$ and the depth to the water table. The depth to water table in the different boreholes was calculated as the difference in the surface elevation of the borehole and the calculated average ground water table altitude. The data on the borehole locations, surface elevations, and the average groundwater table altitudes were taken from DTN: GS010908312332.002 [DIRS 163555]. The map in Figure 6-39 shows spatial distribution of the temperatures at the water table generated from the point temperatures at the water table calculated at the borehole locations. The lower temperatures in this figure correspond to areas of relatively small-unsaturated thickness, and the higher temperatures correspond to a thick UZ. 


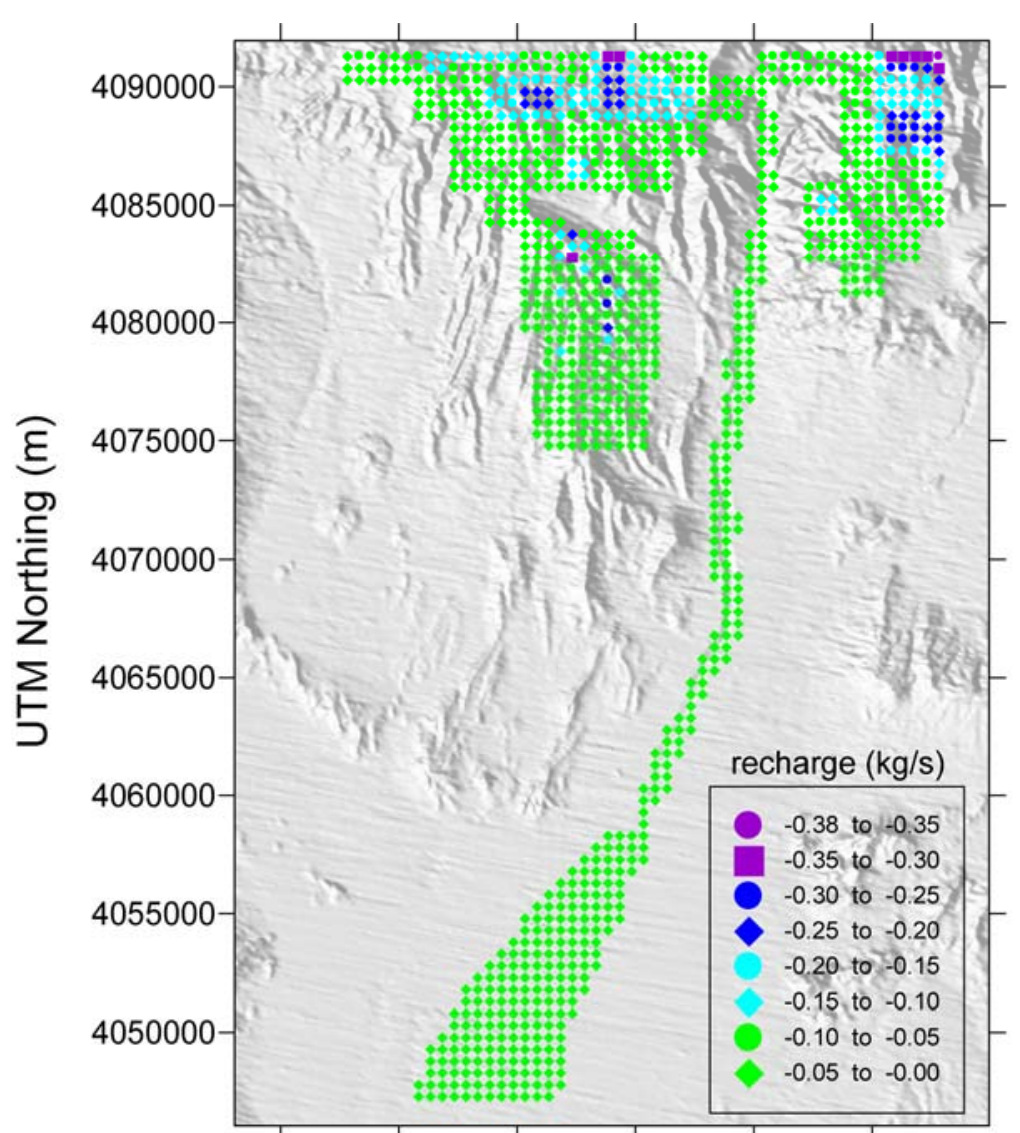

535000540000545000550000555000560000

UTM Easting $(\mathrm{m})$

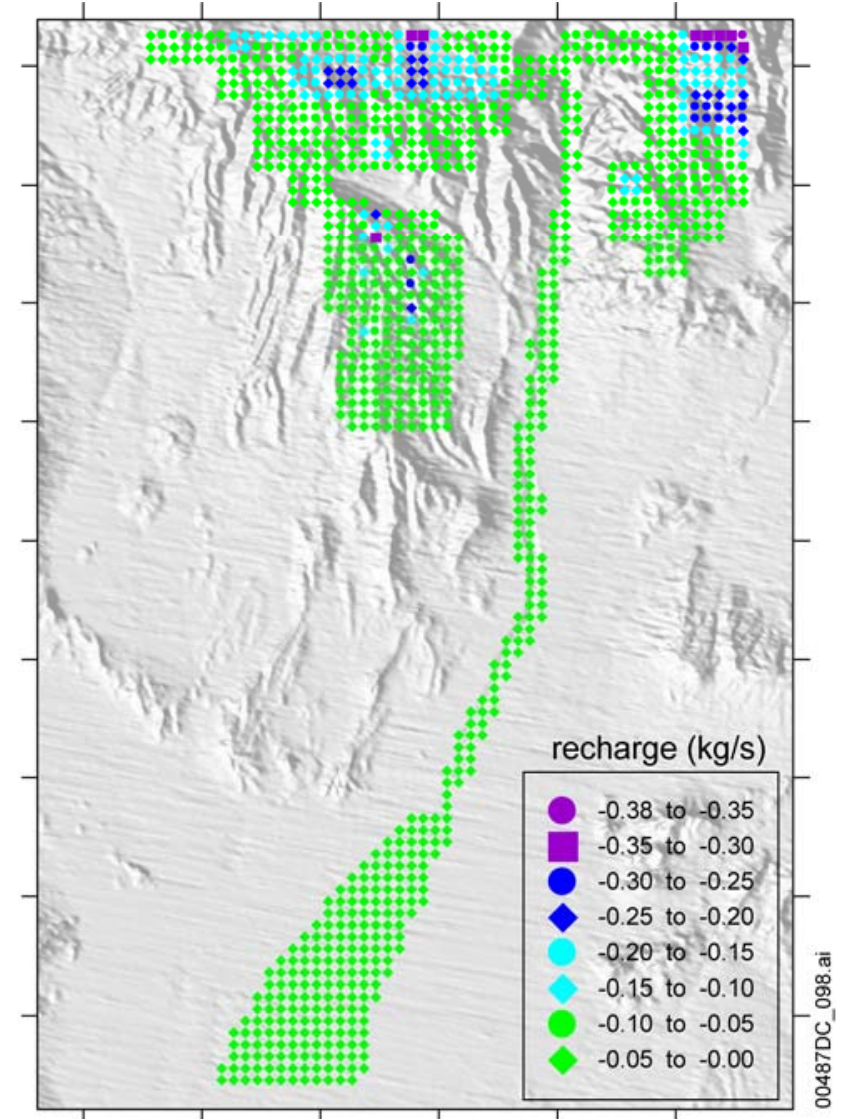

535000540000545000550000555000560000

UTM Easting (m)

Source DTN: SN9908T0581999.001 [DIRS 132867] (left panel). Output DTN: LA0304TM831231.002 (right panel).

NOTE: The contoured recharge rate refers to an area of $500 \times 500 \mathrm{~m}^{2}$, and that a recharge rate of $0.2 \mathrm{~kg} / \mathrm{s}$ corresponds to a recharge flux of approximately $25 \mathrm{~mm} / \mathrm{yr}$.

UTM = Universal Transverse Mercator

Figure 6-38.Comparison of Recharge Data (Left Panel) with Those Used as Input in the SZ Site-Scale Flow Model Data (Right Panel) 


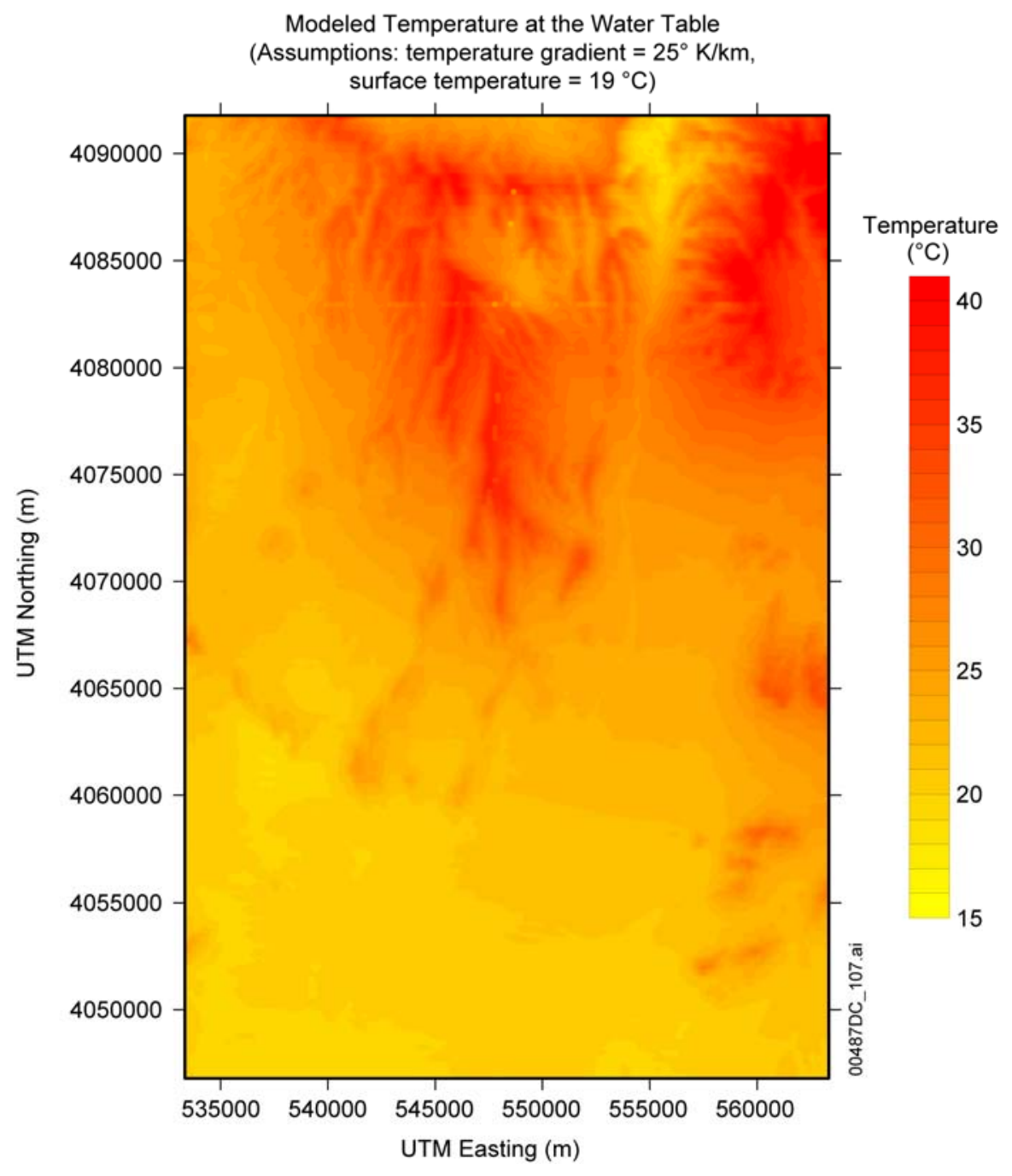

Source: DTN: MO0102DQRBTEMP.001 [DIRS 154733].

NOTE: UTM = Universal Transverse Mercator

Figure 6-39. Map of Modeled Temperature at the Water Table for the SZ Site-Scale Flow Model Domain

\subsection{SZ SITE-SCALE FLOW MODEL RESULTS}

\subsubsection{Model Calibration}

Calibration is the process by which values of important model parameters are estimated and optimized to produce the best fit between the model output and the observed data. Calibration generally is accomplished by adjusting model input parameters (e.g., permeability) to minimize the difference between observed and simulated conditions (in this case, comparing predicted and observed head values and lateral boundary fluxes). Model calibration may be performed through manual methods or automated optimization procedures. Automated optimization procedures generally employ a carefully prescribed mathematical process that selects the optimal set of parameters based on minimizing an objective function describing the difference between observed and simulated conditions. These procedures generally provide the most structured and 
thorough means of calibrating a model, and, frequently, they provide useful additional information regarding model sensitivity to parameters and other useful statistical measures. Consequently, an automated optimization procedure is used to calibrate the SZ site-scale flow model. However, manual adjustments to the calibration are also performed to ensure an accurate representation of fluxes in the low-head gradient portion of Fortymile Wash in the numerical model.

Discussed below are the criteria used to guide calibration, optimization procedures used during calibration, those model outputs for which the difference between predicted and observed values were minimized (calibration targets) during calibration, and those parameters that were optimized during calibration.

\subsubsection{Calibration Criteria}

Proper calibration of the SZ site-scale flow model requires consideration of the full range of available data, which include field data for water levels and hydraulic heads, permeability data from field and laboratory tests, locations of known faults and other geologic data, and hydrochemical data. Opinions expressed during the expert elicitation process (CRWMS M\&O 1998 [DIRS 100353]) also must be considered. The goal during development of the SZ site-scale flow model was to deliver to performance assessment a model that is realistic where data exist and is conservative where data are lacking.

\subsubsection{Parameter Optimization Procedure}

Calibration of the SZ site-scale flow model was accomplished with the groundwater flow, heat, and transport computer code, FEHM (Zyvoloski et al. 1997 [DIRS 100615]) and commercial parameter estimation code PEST. PEST is a Levenberg-Marquardt (LM)-based optimization algorithm. The LM package is a well-established algorithm (Press et al. 1992 [DIRS 103316], pp. 678 to 683), very robust, and widely applicable. It will search for the minima of a multidimensional function. In this case, the "function" is the sum-of-squares difference (SSD) between a set of observations (the heads in 114 wells in the Yucca Mountain region plus side-boundary fluxes from the regional flow model) and the solution to the partial differential equation that describes SZ flow at Yucca Mountain. PEST computes the derivatives of the SSD function with respect to the various parameters. As discussed below in Section 6.6.1.3, those parameters optimized during calibration are the intrinsic permeability of each of the various hydrogeologic units and the permeability multipliers for some of the hydrogeologic features established in the model. An initial estimate or guess for each unknown parameter is specified at the beginning of the fitting process:

1. FEHM computes the resulting heads for the initial estimate of parameters.

2. The results are returned to the PEST code. 
3. Through a series of FEHM simulations with perturbations in the parameters, the LM package of PEST computes the derivative of the SSD function with respect to each of the parameters.

4. The LM package of PEST then determines the amount to change each parameter's current value to improve the fit to the data. It does this through a mathematical process that combines gradient information and second derivative (approximated) information.

This process is repeated until the fit to data is within a prescribed tolerance or until no further improvement is possible. This coupling between PEST and FEHM allows any variable in FEHM to be considered as a fitting parameter, if desired, whether a flow-related or transport-related parameter. PEST will find local minima of the target function. To enable the PEST code to search for the global minimum, a procedure is attached to the code that carries out a simulated annealing process, which allows the PEST code to move from one local minimum to another, better local minimum. This process is repeated until no further improvement occurs. The simulated annealing process (Press et al. 1992 [DIRS 103316], pp. 436 to 448) is simple in principle. The approach is to reject an improved solution occasionally, move to a new location in parameter space, and continue the search. Theory indicates that this will eventually find the global or a near-global minimum. In the Yucca Mountain case, the procedure involves resetting the value of the LM step-size parameter after each local minimum is found.

In addition to the PEST optimization described above, several manual adjustments were made to the model. These were made to improve the model in ways that were not possible during the PEST run. The most important adjustment was to ensure that the specific discharge near Yucca Mountain was realistic with respect to the estimates given by the SZ expert elicitation panel (CRWMS M\&O 1998 [DIRS 100353]). Because the specific discharge was calculated with the particle-tracking feature of FEHM after the flow calculations were performed, this adjustment could not be incorporated easily in the PEST optimization. The specific discharge was adjusted by changing the permeability of the Bullfrog unit. Because of the large permeability of that unit, the specific discharge could be manipulated by changing the unit's permeability without adversely affecting the heads in the low-gradient area near Yucca Mountain. Adjustments also were made to the permeability in the lower Fortymile Wash area so water levels in the NC-EWDP-2D and Washburn wells in lower Fortymile Wash would be more consistent with those in the upper Fortymile Wash area, thus preserving the observed head gradient. These well locations will be discussed in Section 6.6.1.3. Adjustments to the permeability of the alluvial uncertainty zone and the permeability of the valley-fill aquifer also were made to better match eastern boundary fluxes of the regional model.

Although the SZ model was calibrated with the application of the PEST code, the final product (a suite of FEHM files) does not include any PEST files. Thus, the SZ site-scale flow model may be used for performance assessment or other purposes without the inclusion of the PEST executable code or related files. 


\subsubsection{Calibration Targets}

The SZ site-scale flow model was calibrated to achieve a minimal difference between observed water levels and predicted water levels, as well as between fluxes along specific boundary segments predicted by the regional model and the SZ site-scale model. For calibration targets, 114 water level and head measurements were used. This was the complete set of wells available at the time of calibration. The measurements (DTN: GS000508312332.001 [DIRS 149947]) represent water levels and deeper head measurements. The deeper measurements represent average values over "open" or "packed-off" intervals, and the coordinates of the observations represent midpoints of the interval. The calibration targets also represent steady-state values. Where pumping is taking place, as in the Amargosa Valley, current water levels are used. When comparing simulated water levels to target water levels, the model represents water levels at the target locations by assigning the target head value to the nearest gridblock that is in the same hydrostratigraphic unit as the measurement.

During the calibration process, emphasis was given to minimizing the difference between observed and simulated water levels at selected target locations based on probable flow pathways. This was accomplished by multiplying the squared differences at that location by a weighting factor. A weighting factor of 1 (i.e., standard importance) normally was applied to calibration targets. However, a preferential weighting factor (20) was applied to approximately 30 calibration targets in the low-gradient region to the south and east of Yucca Mountain. These calibration targets were given high weighting, because they are in the likely groundwater pathway leaving the repository site and because small changes in head in this area could produce a large effect on the flow direction. Calibration targets north of Yucca Mountain are given a low weighting ( 0.05 , i.e., little importance). The five wells in this category are given low weights primarily because of the possibility of perching and the attendant uncertainty in water-level measurements in this region. For the base case model, the moderate gradient wells or those wells that provide a transition between the high and low gradients proved to be relatively unimportant. The east-west barrier incorporated in the base case model to establish the LHG was the primary reason for this behavior. Other ACMs of the LHG without the east-west barrier were more sensitive to the moderate gradient wells and additional parameters were required for these models. The head measurement in the carbonate aquifer UE-25 (p \#1) was given a preferential weighting factor (5) because of the importance of this calibration target for reproducing an upward gradient in the calibrated model. The inclusion of an upward gradient within the calibrated SZ site-scale flow model is considered to be important for generating a realistic model because an upward gradient tends to force flow along shallower path lines as indicated by geochemical data. A complete listing of all target water-level values, target locations, and the weighting applied to each target is provided in Table 6-18. 
Table 6-18. Comparison of Observed Weighting of Hydraulic Heads from the SZ Site-Scale Flow Model and Model Computed Head Data

\begin{tabular}{|c|c|c|c|c|c|c|c|c|}
\hline $\begin{array}{c}\text { Site } \\
\text { Name }\end{array}$ & $\begin{array}{l}\text { Fig. } \\
6-40\end{array}$ & $\begin{array}{c}\text { Node } \\
\text { Number }\end{array}$ & $\begin{array}{c}x(\text { UTM) } \\
(\mathrm{m})\end{array}$ & $\begin{array}{c}y \text { (UTM) } \\
(\mathrm{m})\end{array}$ & $\begin{array}{c}z \\
\text { (elevation) } \\
(\mathrm{m})\end{array}$ & \begin{tabular}{|c|} 
Measured \\
Water Level \\
Head Data* \\
$(\mathrm{m})$
\end{tabular} & $\begin{array}{c}\text { Modeled } \\
\text { Head) }\end{array}$ & Weight \\
\hline UE-29 a \#2 & 1 & 121034 & 555753 & 4088351 & 990.8 & 1187.7 & 1165.98 & 0.05 \\
\hline GEXA Well 4 & 2 & 69302 & 534069 & 4086110 & 859.2 & 1009.0 & 1017.91 & 0.05 \\
\hline UE-25 WT\#6 & 3 & 120881 & 549352 & 4083103 & 983.2 & 1034.6 & 945.38 & 0.05 \\
\hline USW G-2 & 4 & 84692 & 548143 & 4082542 & 371.5 & 1020.2 & 933.91 & 0.05 \\
\hline UE-25 WT \#16 & 5 & 117338 & 551146 & 4081234 & 714.1 & 738.3 & 734.62 & 1 \\
\hline USW UZ-14 & 6 & 113564 & 548032 & 4080260 & 793.4 & 779.0 & 735.00 & 1 \\
\hline UE-25 WT \#18 & 7 & 117980 & 549468 & 4080238 & 722.1 & 730.8 & 734.78 & 20 \\
\hline USW G-1 & 8 & 81935 & 548306 & 4080016 & 125.7 & 754.2 & 735.11 & 1 \\
\hline UE-25 a \#3 & 9 & 39729 & 561084 & 4079697 & 681.4 & 748.3 & 799.00 & 1 \\
\hline UE-25 WT \#4 & 10 & 117286 & 550439 & 4079412 & 709 & 730.8 & 734.57 & 20 \\
\hline UE-25 WT \#15 & 11 & 116632 & 554034 & 4078694 & 698.7 & 729.2 & 733.98 & 20 \\
\hline USW G-4 & 12 & 103508 & 548933 & 4078602 & 542.2 & 730.6 & 734.61 & 20 \\
\hline UE-25 a \#1 & 13 & 109866 & 549925 & 4078330 & 584 & 731.0 & 734.47 & 1 \\
\hline UE-25 WT \#14 & 14 & 127094 & 552630 & 4077330 & 703.6 & 729.7 & 733.90 & 20 \\
\hline USW WT-2 & 15 & 112088 & 548595 & 4077028 & 702 & 730.6 & 734.29 & 20 \\
\hline UE-25 c \#1 & 16 & 102578 & 550955 & 4075933 & 473.2 & 730.2 & 734.03 & 20 \\
\hline UE-25 c \#3 & 17 & 102578 & 550930 & 4075902 & 474.3 & 730.2 & 734.03 & 20 \\
\hline UE-25 c \#2 & 18 & 109378 & 550955 & 4075871 & 553.2 & 730.2 & 734.02 & 20 \\
\hline UE-25 WT \#13 & 19 & 127059 & 553730 & 4075827 & 703.8 & 729.1 & 733.47 & 20 \\
\hline USW WT-7 & 20 & 118658 & 546151 & 4075474 & 740.9 & 775.8 & 768.13 & 1 \\
\hline USW WT-1 & 21 & 112500 & 549152 & 4074967 & 708.4 & 730.4 & 733.97 & 20 \\
\hline USW G-3 & 22 & 83665 & 547543 & 4074619 & 318.1 & 730.5 & 735.06 & 20 \\
\hline UE-25 J-13 & 23 & 101936 & 554017 & 4073517 & 354.8 & 728.4 & 732.87 & 20 \\
\hline USW WT-10 & 24 & 129857 & 545964 & 4073378 & 734.2 & 776.0 & 781.49 & 1 \\
\hline UE-25 WT \#17 & 25 & 112470 & 549905 & 4073307 & 705.4 & 729.7 & 733.69 & 20 \\
\hline USW VH-2 & 26 & 122026 & 537738 & 4073214 & 282.8 & 810.4 & 794.36 & 1 \\
\hline UE-25 WT \#3 & 27 & 106625 & 552090 & 4072550 & 705.8 & 729.6 & 733.20 & 20 \\
\hline USW VH-1 & 28 & 123007 & 539976 & 4071714 & 490.5 & 779.4 & 783.69 & 1 \\
\hline UE-25 WT \#12 & 29 & 116452 & 550168 & 4070659 & 702.6 & 729.5 & 733.02 & 20 \\
\hline USW WT-11 & 30 & 116439 & 547542 & 4070428 & 691.9 & 730.7 & 733.80 & 20 \\
\hline UE-25 J-12 & 31 & 110744 & 554444 & 4068774 & 659.6 & 727.9 & 731.60 & 20 \\
\hline UE-25 JF \#3 & 32 & 105329 & 554498 & 4067974 & 662.7 & 727.8 & 731.32 & 20 \\
\hline $\begin{array}{c}\text { Cind-R-Lite } \\
\text { Well }\end{array}$ & 33 & 127537 & 544027 & 4059809 & 710.2 & 729.8 & 737.46 & 20 \\
\hline $\begin{array}{c}\text { Ben } \\
\text { Bossingham }\end{array}$ & 34 & 126439 & 553704 & 4056228 & 697.4 & 718.4 & 714.91 & 1 \\
\hline Fred Cobb & 35 & 139338 & 553808 & 4055459 & 675.6 & 702.8 & 713.17 & 1 \\
\hline Bob Whellock & 36 & 139338 & 553883 & 4055398 & 682 & 704.1 & 713.17 & 1 \\
\hline $\begin{array}{l}\text { Louise } \\
\text { Pereidra }\end{array}$ & 37 & 139875 & 554131 & 4055399 & 698 & 705.6 & 713.71 & 1 \\
\hline Joe Richards & 38 & 139338 & 554008 & 4055337 & 679.3 & 701.6 & 713.17 & 1 \\
\hline
\end{tabular}


Table 6-18. Comparison of Observed Weighting of Hydraulic Heads from the SZ Site-Scale Flow Model and Model Computed Head Data (Continued)

\begin{tabular}{|c|c|c|c|c|c|c|c|c|}
\hline $\begin{array}{l}\text { Site } \\
\text { Name }\end{array}$ & $\begin{array}{l}\text { Fig. } \\
6-40\end{array}$ & $\begin{array}{c}\text { Node } \\
\text { Number }\end{array}$ & $\begin{array}{c}x \text { (UTM) } \\
(\mathrm{m})\end{array}$ & $\begin{array}{c}y \text { (UTM) } \\
(\mathrm{m})\end{array}$ & $\begin{array}{c}z \\
\text { (elevation) } \\
\text { (m) }\end{array}$ & $\begin{array}{c}\text { Measured } \\
\text { Water Level } \\
\text { Head Data* } \\
(\mathrm{m})\end{array}$ & $\begin{array}{l}\text { Modeled } \\
\text { Head) }\end{array}$ & Weight \\
\hline NDOT Well & 39 & 139338 & 553685 & 4055242 & 682.1 & 705.4 & 713.17 & 1 \\
\hline $\begin{array}{c}\text { James H. } \\
\text { Shaw }\end{array}$ & 40 & 138458 & 549863 & 4054911 & 664.3 & 706.7 & 707.18 & 1 \\
\hline Airport Well & 41 & 137742 & 552818 & 4054929 & 636.5 & 705.3 & 711.26 & 1 \\
\hline TW-5 & 42 & 39571 & 562604 & 4054686 & 688.7 & 725.1 & 726.67 & 1 \\
\hline $\begin{array}{c}\text { Richard } \\
\text { Washburn }\end{array}$ & 43 & 138403 & 549746 & 4053647 & 669.9 & 707.7 & 705.75 & 1 \\
\hline $\begin{array}{c}\text { Richard } \\
\text { Washburn }\end{array}$ & 44 & 139149 & 549679 & 4052322 & 675.3 & 704.4 & 703.72 & 1 \\
\hline $\begin{array}{l}\text { Nye County } \\
\text { Develop. Co. }\end{array}$ & 45 & 137506 & 543481 & 4050069 & 638.6 & 694.3 & 696.59 & 1 \\
\hline $\begin{array}{c}\text { Fred } \\
\text { Wooldridge }\end{array}$ & 46 & 138950 & 536350 & 4050006 & 673.8 & 691.9 & 688.06 & 1 \\
\hline Fred J. Keefe & 47 & 138957 & 540673 & 4049994 & 676.7 & 694.3 & 696.09 & 1 \\
\hline Leslie Nickels & 48 & 138146 & 541518 & 4049937 & 654.7 & 694.3 & 696.30 & 1 \\
\hline L. Mason & 49 & 67776 & 553471 & 4049848 & 699.2 & 722.1 & 711.61 & 1 \\
\hline Unknown & 50 & 138123 & 545596 & 4049403 & 667.6 & 697.8 & 695.93 & 1 \\
\hline Davidson Well & 51 & 138915 & 536552 & 4049329 & 672 & 690.1 & 688.07 & 1 \\
\hline $\begin{array}{l}\text { Eugene J. } \\
\text { Mankinen }\end{array}$ & 52 & 67243 & 538889 & 4049000 & 678.6 & 707.4 & 691.82 & 1 \\
\hline $\begin{array}{c}\text { Donald O. } \\
\text { Heath }\end{array}$ & 53 & 138086 & 542194 & 4048892 & 651.6 & 694.1 & 694.47 & 1 \\
\hline Elvis Kelley & 54 & 138883 & 536903 & 4048621 & 685.1 & 691.0 & 688.16 & 1 \\
\hline $\begin{array}{l}\text { Manuel } \\
\text { Rodela }\end{array}$ & 55 & 138899 & 546718 & 4048669 & 686.7 & 693.6 & 695.25 & 1 \\
\hline $\begin{array}{c}\text { Charles C. } \\
\text { DeFir Jr. }\end{array}$ & 56 & 67220 & 538196 & 4048442 & 685.7 & 706.9 & 691.09 & 1 \\
\hline $\begin{array}{l}\text { William R. } \\
\text { Monroe }\end{array}$ & 57 & 138051 & 540035 & 4048450 & 669.5 & 693.7 & 694.78 & 1 \\
\hline DeFir Well & 58 & 138854 & 536655 & 4048405 & 671.1 & 690.2 & 688.21 & 1 \\
\hline $\begin{array}{l}\text { Edwin H. } \\
\text { Mankinen }\end{array}$ & 59 & 138053 & 540608 & 4048083 & 662.8 & 695.2 & 694.38 & 1 \\
\hline Bill Strickland & 60 & 138820 & 534967 & 4047966 & 677 & 689.2 & 687.22 & 1 \\
\hline M. Meese & 61 & 138036 & 547120 & 4047963 & 664.6 & 686.4 & 693.44 & 1 \\
\hline $\begin{array}{l}\text { Theo E. } \\
\text { Selbach }\end{array}$ & 62 & 136554 & 547941 & 4047782 & 673.3 & 696.2 & 693.97 & 1 \\
\hline C.L. Caldwell & 63 & 66654 & 537727 & 4047670 & 654.5 & 691.4 & 690.70 & 1 \\
\hline $\begin{array}{c}\text { Leonard } \\
\text { Siegel }\end{array}$ & 64 & 138042 & 552390 & 4047685 & 667.2 & 709.0 & 703.69 & 1 \\
\hline $\begin{array}{l}\text { James K. } \\
\text { Pierce }\end{array}$ & 65 & 138025 & 541778 & 4047596 & 664 & 690.4 & 693.40 & 1 \\
\hline $\begin{array}{l}\text { James K. } \\
\text { Pierce }\end{array}$ & 66 & 138828 & 541381 & 4047563 & 677.1 & 705.6 & 693.63 & 1 \\
\hline $\begin{array}{c}\text { Cooks West } \\
\text { Well }\end{array}$ & 67 & 136594 & 553609 & 4047631 & 690.2 & 720.1 & 712.20 & 1 \\
\hline
\end{tabular}


Table 6-18. Comparison of Observed Weighting of Hydraulic Heads from the SZ Site-Scale Flow Model and Model Computed Head Data (Continued)

\begin{tabular}{|c|c|c|c|c|c|c|c|c|}
\hline $\begin{array}{l}\text { Site } \\
\text { Name }\end{array}$ & $\begin{array}{l}\text { Fig. } \\
6-40\end{array}$ & $\begin{array}{c}\text { Node } \\
\text { Number }\end{array}$ & $\begin{array}{c}x(\text { UTM) } \\
(\mathrm{m})\end{array}$ & $\begin{array}{c}y \text { (UTM) } \\
(\mathrm{m})\end{array}$ & $\begin{array}{c}z \\
(\text { elevation) } \\
(\mathrm{m})\end{array}$ & $\begin{array}{c}\text { Measured } \\
\text { Water Level } \\
\text { Head Data* } \\
\text { (m) }\end{array}$ & $\begin{array}{l}\text { Modeled } \\
\text { Head) }\end{array}$ & Weight \\
\hline $\begin{array}{c}\text { Cooks East } \\
\text { Well }\end{array}$ & 68 & 136594 & 554006 & 4047633 & 693.4 & 718.9 & 712.20 & 1 \\
\hline $\begin{array}{l}\text { Nye County } \\
\text { Land Co. }\end{array}$ & 69 & 136550 & 548466 & 4047261 & 715.4 & 690.1 & 693.27 & 1 \\
\hline $\begin{array}{c}\text { Amargosa } \\
\text { Town } \\
\text { Complex }\end{array}$ & 70 & 136512 & 548492 & 4047077 & 668.3 & 688.8 & 693.27 & 1 \\
\hline $\begin{array}{l}\text { Nye County } \\
\text { Develop. Co. }\end{array}$ & 71 & 137090 & 550431 & 4047057 & 615.4 & 691.2 & 694.88 & 1 \\
\hline Lewis C. Cook & 72 & 136591 & 553612 & 4047076 & 702.5 & 717.4 & 714.00 & 1 \\
\hline Lewis C. Cook & 73 & 136553 & 553687 & 4047077 & 688.7 & 714.8 & 714.01 & 1 \\
\hline $\begin{array}{c}\text { Amargosa } \\
\text { Valley Water }\end{array}$ & 74 & 136545 & 548393 & 4046953 & 673.9 & 701.3 & 691.81 & 1 \\
\hline $\begin{array}{l}\text { Earl N. } \\
\text { Selbach }\end{array}$ & 75 & 67149 & 539147 & 4046844 & 672.1 & 696.5 & 694.05 & 1 \\
\hline $\begin{array}{l}\text { Lewis N. } \\
\text { Dansby }\end{array}$ & 76 & 137961 & 539968 & 4046817 & 664.7 & 694.2 & 695.22 & 1 \\
\hline $\begin{array}{l}\text { Edwin H. } \\
\text { Mankinen }\end{array}$ & 77 & 138767 & 540788 & 4046821 & 686.2 & 694.0 & 693.64 & 1 \\
\hline Willard Johns & 78 & 138786 & 552097 & 4046882 & 678.9 & 699.5 & 708.82 & 1 \\
\hline $\begin{array}{c}\text { USW H-1 } \\
\text { tube } 1\end{array}$ & 79 & 118456 & 548727 & 4079926 & -495.5 & 785.5 & 830.84 & 1 \\
\hline $\begin{array}{l}\text { USW H-1 } \\
\text { tube } 2\end{array}$ & 80 & 91032 & 548727 & 4079926 & 193 & 736.0 & 734.79 & 1 \\
\hline $\begin{array}{c}\text { USW H-1 } \\
\text { tube } 3\end{array}$ & 81 & 103512 & 548727 & 4079926 & 562.5 & 730.6 & 734.74 & 20 \\
\hline $\begin{array}{l}\text { USW H-1 } \\
\text { tube } 4\end{array}$ & 82 & 111633 & 548727 & 4079926 & 680.5 & 730.8 & 734.76 & 20 \\
\hline $\begin{array}{l}\text { USW H-5 } \\
\text { upper }\end{array}$ & 83 & 106331 & 547668 & 4078841 & 704.2 & 775.5 & 734.76 & 1 \\
\hline $\begin{array}{l}\text { USW H-5 } \\
\text { lower }\end{array}$ & 84 & 94198 & 547668 & 4078841 & 446.4 & 775.6 & 734.77 & 1 \\
\hline $\begin{array}{l}\text { UE-25 b \#1 } \\
\text { lower }\end{array}$ & 85 & 81208 & 549949 & 4078423 & -8.8 & 729.7 & 735.63 & 20 \\
\hline $\begin{array}{l}\text { UE-25 b \#1 } \\
\text { upper }\end{array}$ & 86 & 102018 & 549949 & 4078423 & 366.2 & 730.6 & 734.45 & 20 \\
\hline $\begin{array}{l}\text { USW H-6 } \\
\text { upper }\end{array}$ & 87 & 105485 & 546188 & 4077816 & 662.9 & 776.0 & 764.14 & 1 \\
\hline $\begin{array}{l}\text { USW H-6 } \\
\text { lower }\end{array}$ & 88 & 91691 & 546188 & 4077816 & 315.8 & 775.9 & 763.99 & 1 \\
\hline $\begin{array}{l}\text { USW H-4 } \\
\text { upper }\end{array}$ & 89 & 93378 & 549188 & 4077309 & 395.5 & 730.4 & 734.36 & 20 \\
\hline
\end{tabular}


Table 6-18. Comparison of Observed Weighting of Hydraulic Heads from the SZ Site-Scale Flow Model and Model Computed Head Data (Continued)

\begin{tabular}{|c|c|c|c|c|c|c|c|c|}
\hline $\begin{array}{l}\text { Site } \\
\text { Name }\end{array}$ & $\begin{array}{l}\text { Fig. } \\
6-40\end{array}$ & $\begin{array}{c}\text { Node } \\
\text { Number }\end{array}$ & $\begin{array}{c}x \text { (UTM) } \\
(\mathrm{m})\end{array}$ & $\begin{array}{c}y \text { (UTM) } \\
(\mathrm{m})\end{array}$ & $\begin{array}{c}z \\
\text { (elevation) } \\
\text { (m) }\end{array}$ & $\begin{array}{c}\text { Measured } \\
\text { Water Level } \\
\text { Head Data* } \\
(\mathrm{m})\end{array}$ & $\begin{array}{l}\text { Modeled } \\
\text { Head) }\end{array}$ & Weight \\
\hline $\begin{array}{l}\text { USW H-4 } \\
\text { lower }\end{array}$ & 90 & 81182 & 549188 & 4077309 & 45 & 730.5 & 735.20 & 20 \\
\hline $\begin{array}{l}\text { USW H-3 } \\
\text { upper }\end{array}$ & 91 & 96228 & 547562 & 4075759 & 576.9 & 731.5 & 734.59 & 20 \\
\hline $\begin{array}{l}\text { USW H-3 } \\
\text { lower }\end{array}$ & 92 & 84647 & 547562 & 4075759 & 343.2 & 755.9 & 734.62 & 1 \\
\hline $\begin{array}{l}\text { UE-25 p \#1 } \\
\text { (Lwr Intrvl) }\end{array}$ & 93 & 28770 & 551501 & 4075659 & -410.3 & 752.4 & 739.73 & 5 \\
\hline USW SD-7 & 95 & 104836 & 548384 & 4076499 & 637.7 & 727.6 & 734.24 & 20 \\
\hline USW SD-9 & 96 & 111629 & 548550 & 4079256 & 678.3 & 731.1 & 734.75 & 20 \\
\hline USW SD-12 & 97 & 106315 & 548492 & 4077415 & 696.7 & 730.0 & 734.42 & 20 \\
\hline USW WT-24 & 98 & 50635 & 548697 & 4081909 & 734.8 & 840.1 & 742.01 & 1 \\
\hline $\begin{array}{l}\text { NC-EWDP- } \\
\text { 1DX, shallow }\end{array}$ & 99 & 84963 & 536768 & 4062502 & 413.5 & 786.8 & 763.89 & 1 \\
\hline $\begin{array}{l}\text { NC-EWDP-1S } \\
\text { probe } 1\end{array}$ & 100 & 113410 & 536771 & 4062498 & 747.8 & 787.1 & 773.29 & 1 \\
\hline NC-EWDP-2D & 101 & 63142 & 547744 & 4057164 & 507.2 & 706.1 & 709.21 & 1 \\
\hline NC-EWDP-3D & 102 & 84914 & 541273 & 4059444 & 376.7 & 718.3 & 703.75 & 1 \\
\hline $\begin{array}{l}\text { NC-EWDP-3S } \\
\text { probe } 2\end{array}$ & 103 & 106390 & 541269 & 4059445 & 719.1 & 719.8 & 702.40 & 1 \\
\hline $\begin{array}{l}\text { NC-EWDP- } \\
5 \text { SB }\end{array}$ & 104 & 103618 & 555676 & 4058229 & 603.9 & 723.6 & 717.45 & 1 \\
\hline $\begin{array}{l}\text { NC-EWDP- } \\
\text { 9SX probe } 2\end{array}$ & 105 & 89328 & 539039 & 4061004 & 721.2 & 767.3 & 732.42 & 1 \\
\hline $\begin{array}{c}\text { NC- } \\
\text { Washburn-1X }\end{array}$ & 106 & 104959 & 551465 & 4057563 & 668.8 & 714.6 & 714.01 & 1 \\
\hline UE-25 J-11 & 107 & 125874 & 563799 & 4071058 & 687.2 & 732.2 & 731.57 & 20 \\
\hline BGMW-11 & 108 & 67494 & 534386 & 4062600 & 673.4 & 715.9 & 724.53 & 1 \\
\hline $\begin{array}{c}\text { Richard } \\
\text { Washburn }\end{array}$ & 109 & 139739 & 549529 & 4052567 & 739.9 & 704.0 & 703.85 & 1 \\
\hline L. Cook & 110 & 138814 & 551348 & 4047432 & 704.1 & 713.2 & 699.01 & 1 \\
\hline Unknown & 111 & 67200 & 549532 & 4047668 & 691.8 & 689.5 & 695.01 & 1 \\
\hline $\begin{array}{c}\text { Amargosa } \\
\text { Water }\end{array}$ & 112 & 138840 & 547420 & 4047594 & 714.3 & 690.4 & 693.44 & 1 \\
\hline
\end{tabular}


Table 6-18. Comparison of Observed Weighting of Hydraulic Heads from the SZ Site-Scale Flow Model and Model Computed Head Data (Continued)

\begin{tabular}{|c|c|c|c|c|c|c|c|c|}
\hline $\begin{array}{c}\text { Site } \\
\text { Name }\end{array}$ & $\begin{array}{c}\text { Fig. } \\
\mathbf{6 - 4 0}\end{array}$ & $\begin{array}{c}\text { Node } \\
\text { Number }\end{array}$ & $\begin{array}{c}\boldsymbol{x}(\mathbf{U T M}) \\
(\mathbf{m})\end{array}$ & $\begin{array}{c}\boldsymbol{y}(\mathbf{U T M}) \\
(\mathbf{m})\end{array}$ & $\begin{array}{c}\boldsymbol{z} \\
(\mathbf{e l e v a t i o n )} \\
(\mathbf{m})\end{array}$ & $\begin{array}{c}\text { Measured } \\
\text { Water Level } \\
\text { Head Data } \\
(\mathbf{m})\end{array}$ & $\begin{array}{c}\text { Modeled } \\
\text { Head) }\end{array}$ & Weight \\
\hline Lewis C. Cook & 113 & 68127 & 554329 & 4047666 & 735.5 & 715.7 & 713.64 & 1 \\
\hline Unknown & 114 & 67243 & 538989 & 4048877 & 710.1 & 690.8 & 691.82 & 1 \\
\hline USW UZ-N91 & 115 & 121579 & 555680 & 4088196 & 1180.6 & 1186.7 & 1165.80 & 0.05 \\
\hline
\end{tabular}

Source: DTN: GS010908312332.002 [DIRS 163555].

Output DTN: LA0304TM831231.002.

*Head data refers to the observed mean water-level altitude (m). UTM = Universal Transverse Mercator

NOTE: The "Figure. 6-40" label in the second column of the table refers to the well numbers given in Figure 6-40.

The information on site name, UTM coordinates easting and northing, and measured heads is from DTN: GS010908312332.002 [DIRS 163555]. The measured heads in Table 6-18 correspond to the average water table altitude data in DTN: GS010908312332.002 [DIRS 163555]. Mean water-level altitudes were calculated as time-averages over the period of available measurements and were rounded to the nearest tenth of a meter.

The elevation Z shown in Table 6-18 is from DTN: LA0304TM831231.002 [DIRS 163788]. These data are stored in file pest_new.macro. This file provides elevation per each well along with UTM coordinates.

The model heads shown in Table 6-18 are from DTN: LA0304TM831231.002 [DIRS 163788]. The calibrated heads are stored in file 02_calib.pest. This file provides initial, intermediate, and final values of all the calibrated parameters. The final heads are located at the end of this file and correspond to the simulation time equal to $0.36525 \mathrm{E}+17$ days. Each well is represented by specific node. The relationship between the wells and the nodes is provided in Table 6-18. There are 119 nodes in the output file. The last 4 nodes are not shown in Table 6-18 since they do not represent any of the observation wells. These 4 points were added to the calibration targets to condition the results, so that the heads would stay reasonable (in agreement with the potentiometric surface defined) in the areas with no data. The heads in Table 6-18 can be obtained from the corresponding heads shown in the output file by subtracting 5000 from the later ones. For example, the well UE-25 WT\#6, shown in Figure 6-40 by number 3 is assigned to node number 120881 . The head in this node is in the output file 5945.38. The head shown for this well in Table 6-18 is $5945.38-5000=945.38 \mathrm{~m}$.

Location 94, which is well USW SD-6 is not used. This reduces the number of observation points to 114.

In addition to water levels, fluxes around certain boundary segments were used as calibration targets. Fluxes from all boundary segments on the eastern and northern boundaries of the SZ site-scale flow model domain were used as calibration targets during parameter optimization. Fluxes from the five western boundary segments were not used during parameter optimization (see Section 6.6.2.2, Table 6-20a). Preliminary calibration runs indicated that it was difficult to match the fluxes along these segments predicted by the SZ site-scale flow model with those predicted by the DVRFS model (see Section 6.6.2.2, Table 6-20a). This difficulty largely was a result of the different HFMs used in the site-scale and regional-scale flow models. The goal of ensuring that the total flux through the SZ site-scale flow model domain is close to that predicted by the regional-scale model was achieved by not forcing a close match along those boundary segments for which the rock types (because of differences in the grid resolution and the HFMs) were different in the two models. Thus, a weighting scheme was used with the target fluxes. Zero weight was applied to the western boundary segments and weights between one and two were used for the eastern and northern segments. 


\subsubsection{Calibration Parameters}

Calibration of permeability was optimized during calibration of the SZ site-scale flow model. The model formulation and the FEHM code allow for the specification of a permeability value at each node. However, there are not sufficient water level and permeability data to warrant identifying a specific value of permeability for each individual node during calibration. Consequently, sets of nodes are grouped into specific permeability zones based on similar permeability characteristics. A single permeability value is assigned to each zone. These zonal values of permeability serve as the parameters that are optimized during model calibration. Permeability zones were created for hydrogeologic units identified in the HFM-19 conceptual model and for specific hydrogeologic features. With the exception of the basal unit that serves as a lower boundary for the model, a permeability zone was established for each hydrogeologic unit. All of the nodes within a specific hydrogeologic unit were assigned to that permeability zone unless they are included in one of the permeability zones established for specific hydrogeologic features. The zone sizes were fixed, largely based on the HFM-19. Some of the uncertainty associated with geologic contacts is discussed in Section 6.8.5.1.

For permeability, vertical anisotropy is assigned a value of 10:1 (horizontal to vertical) in the volcanic and valley-fill units in the SZ site-scale flow model. Relatively lower permeability in the vertical direction may occur in stratified media, and the ratio of 10:1 is in the generally accepted range (CRWMS M\&O 1998 [DIRS 100353], Table 3-2). Furthermore, the relatively high vertical gradient observed in well UE-25p\#1 suggests that vertical permeability is lower than horizontal permeability. Well NC-EWDP-2D also exhibited a vertical gradient. The uncertainty associated with the vertical anisotropy is discussed in Section 6.8.3.1.

Specific hydrogeologic features that were thought to potentially impact groundwater flow also were classified as permeability zones. The permeability variable or permeability multiplication factor used for a specific feature was assigned to all of the nodes within that feature. The hydrogeologic features for which special permeability zones were established are primarily faults, fault zones, and areas of chemical alteration (Section 6.5.2). As previously discussed, these features are distinct from the subhorizontal hydrogeologic units identified in the HFM-19 conceptual model. Each of the identified hydrogeologic features includes multiple geologic formations and represents zones of altered permeability within the individual formations.

Twenty-seven permeability zones were established for model calibration. In addition, permeability multipliers were assigned to four zones containing geologic features that penetrate a number of hydrogeologic units. The permeability multipliers were used to modify the permeability values assigned to the hydrogeologic units in the area of the geologic features. Although the permeability parameter or multiplier values for most zones were optimized during calibration, permeability for the upper carbonate aquifer was assigned a constant value because sensitivity analyses indicate that the model is not sensitive to this parameter value.

The parameters used in the calibration of the SZ site-scale flow model are a combination of permeabilities of hydrogeologic units, permeabilities of faults and other features, and permeability multipliers of faults and features. Permeabilities of the 18 hydrogeologic units were chosen as calibration parameters because of the importance of the parameter in the flow system and each of the units was identified in the HFM-19 conceptual model. The parameters that 
represent these features were added because they were identified as important structural features (e.g., the Solitario Canyon fault), were in the regional-scale model (e.g., the Spotted Range-Mine Mountain zone), or were necessary for some conceptual feature, such as the LHG north of Yucca Mountain (east-west barrier). The number of parameters represents a computationally tractable set.

Upper and lower bounds were placed on each permeability variable during parameter optimization. The upper and lower bounds for the permeabilities and permeability multipliers were chosen to reflect maximum and minimum field values (permeability) or a reasonably realistic range of values (permeability multipliers) (See Sections 7.2.2.4.1 to 7.2.2.4.4). For example, when the multiplier represents flow in the plane of a fault, the multiplier is allowed to take on values between 1 and 100; when the multiplier represents geochemical alteration, the multiplier is allowed to take values between 0.00001 and 0.50000 . The upper bounds for permeability for faults were generally higher than the hydrostratigraphic unit where the fault was situated. The final calibrated values of the parameters are not sensitive to initial parameter values within the range specified, thus giving confidence that the calibration values are unique within the specified bounds of permeability.

A list of permeability zones, including the parameter type assigned to each zone, the upper and low bounds specified for the parameter, and an identification of the parameters optimized during calibration, are provided in Table 6-19.

Table 6-19. Calibration Parameters Used in the SZ Site-Scale Flow Model

\begin{tabular}{|c|c|c|c|c|c|}
\hline $\begin{array}{c}\text { Parameter } \\
\text { Name }\end{array}$ & $\begin{array}{l}\text { Geologic Unit } \\
\text { or Feature }\end{array}$ & $\begin{array}{c}\text { Calibrated } \\
\text { Value }\end{array}$ & $\begin{array}{l}\text { Parameter } \\
\text { Type }\end{array}$ & $\begin{array}{l}\text { Minimum } \\
\text { Value }\end{array}$ & $\begin{array}{l}\text { Maximum } \\
\text { Value }\end{array}$ \\
\hline gran & Granitic Confining Unit & $1.96 \times 10^{-16}$ & Permeability & $1.00 \times 10^{-17}$ & $1.00 \times 10^{-14}$ \\
\hline Icla & Lower Clastic Confining Unit & $1.00 \times 10^{-16}$ & Permeability & $1.00 \times 10^{-16}$ & $1.00 \times 10^{-14}$ \\
\hline Ica2 & Lower Carbonate Aquifer & $5.00 \times 10^{-14}$ & Permeability & $5.00 \times 10^{-14}$ & $1.00 \times 10^{-12}$ \\
\hline ucla & Upper Clastic Confining Unit & $1.00 \times 10^{-16}$ & Permeability & $1.00 \times 10^{-16}$ & $1.00 \times 10^{-14}$ \\
\hline Ica1 & Lower Carbonate Aquifer Thrust & $1.00 \times 10^{-14}$ & Permeability & $1.00 \times 10^{-14}$ & $1.00 \times 10^{-12}$ \\
\hline ucar & Upper Carbonate Aquifer & $4.08 \times 10^{-14}$ & Permeability (fixed) & $4.08 \times 10^{-14}$ & $4.08 \times 10^{-14}$ \\
\hline udif & Undifferentiated Valley Fill & $5.00 \times 10^{-15}$ & Permeability & $5.00 \times 10^{-15}$ & $1.00 \times 10^{-12}$ \\
\hline OVOC & Older Volcanic Confining Unit & $2.00 \times 10^{-16}$ & Permeability & $2.00 \times 10^{-16}$ & $1.00 \times 10^{-11}$ \\
\hline ovoa & Older Volcanic Aquifer & $5.00 \times 10^{-16}$ & Permeability & $3.00 \times 10^{-16}$ & $1.00 \times 10^{-12}$ \\
\hline IVOC & Lower Volcanic Confining Unit & $2.00 \times 10^{-15}$ & Permeability & $1.00 \times 10^{-15}$ & $1.00 \times 10^{-11}$ \\
\hline tram & Crater Flat-Tram & $2.36 \times 10^{-13}$ & Permeability & $1.00 \times 10^{-13}$ & $1.00 \times 10^{-11}$ \\
\hline bull & Crater Flat-Bullfrog & $1.54 \times 10^{-11}$ & Permeability & $1.00 \times 10^{-13}$ & $8.00 \times 10^{-11}$ \\
\hline prow & Crater Flat-Prow Pass & $8.00 \times 10^{-12}$ & Permeability & $1.00 \times 10^{-13}$ & $5.00 \times 10^{-11}$ \\
\hline uvoc & Upper Volcanic Confining Unit & $5.00 \times 10^{-14}$ & Permeability & $4.00 \times 10^{-14}$ & $1.00 \times 10^{-12}$ \\
\hline uvoa & Upper Volcanic Aquifer & $8.00 \times 10^{-14}$ & Permeability & $8.00 \times 10^{-14}$ & $1.00 \times 10^{-11}$ \\
\hline lava & Lava Flow Aquifer & $1.00 \times 10^{-12}$ & Permeability & $1.00 \times 10^{-16}$ & $2.00 \times 10^{-12}$ \\
\hline lime & Limestone Aquifer & $1.00 \times 10^{-12}$ & Permeability & $1.00 \times 10^{-15}$ & $1.00 \times 10^{-11}$ \\
\hline vala & Valley Fill Aquifer & $5.00 \times 10^{-12}$ & Permeability & $1.00 \times 10^{-13}$ & $8.00 \times 10^{-12}$ \\
\hline ewba & East-West Barrier & $1.05 \times 10^{-18}$ & Permeability & $1.00 \times 10^{-18}$ & $1.00 \times 10^{-15}$ \\
\hline nsba & Solitario Canyon Fault & $1.00 \times 10^{-18}$ & Permeability & $1.00 \times 10^{-18}$ & $1.00 \times 10^{-15}$ \\
\hline fpb1 & Fortymile Wash Fault & 10 & Multiplier & 2 & 100 \\
\hline fpb2 & $\begin{array}{l}\text { Spotted Range-Mine Mountain } \\
\text { Zone }\end{array}$ & 11.7789 & Multiplier & 1 & 70 \\
\hline fpb3 & $\begin{array}{l}\text { Northern Low Permeability } \\
\text { Zone }\end{array}$ & $7.11 \times 10^{-2}$ & Multiplier & $1.00 \times 10^{-5}$ & 0.5 \\
\hline
\end{tabular}


Table 6-19. Calibration Parameters Used in the SZ Site-Scale Flow Model (Continued)

\begin{tabular}{|l|l|l|l|l|l|}
\hline $\begin{array}{c}\text { Parameter } \\
\text { Name }\end{array}$ & \multicolumn{1}{|c|}{$\begin{array}{c}\text { Geologic Unit } \\
\text { or Feature }\end{array}$} & $\begin{array}{c}\text { Calibrated } \\
\text { Value }\end{array}$ & \multicolumn{1}{|c|}{$\begin{array}{c}\text { Parameter } \\
\text { Type }\end{array}$} & $\begin{array}{c}\text { Minimum } \\
\text { Value }\end{array}$ & $\begin{array}{c}\text { Maximum } \\
\text { Value }\end{array}$ \\
\hline fpb4 & Imbricate Fault Zone & 1 & Multiplier & 1 & 100 \\
\hline $\mathrm{cffz}$ & Crater Flat Fault & $5.00 \times 10^{-14}$ & Permeability & $1.00 \times 10^{-15}$ & $5.00 \times 10^{-13}$ \\
\hline allu & Alluvial Uncertainty Zone & $3.20 \times 10^{-12}$ & Permeability & $1.00 \times 10^{-13}$ & $1.00 \times 10^{-11}$ \\
\hline wash & Lower Fortymile Wash Zone & $5.00 \times 10^{-12}$ & Permeability & $1.00 \times 10^{-14}$ & $8.00 \times 10^{-12}$ \\
\hline
\end{tabular}

Output DTN: LA0304TM831231.002. Minimum and Maximum values are indirect input.

NOTE: Permeability listed is the geometric mean and is in the units of $\mathrm{m}^{2}$. The water levels predicted by the calibrated SZ site-scale flow model along with the observed water level at each of the calibration target locations are presented in Table 6-18.

\subsubsection{Calibration Results}

\subsubsection{Water Levels}

The water levels predicted by the calibrated SZ site-scale flow model along with the observed water level at each of the calibration target locations are presented in Table 6-19. The location of each target observation well is shown in Figure 6-40. The calibration targets (water levels) are from DTN: GS000508312332.001 [DIRS 149947] and updated in DTN: GS010908312332.002 [DIRS 163555]. The water-level data from Faunt (2001 [DIRS 154625], Attachment I) were used in the development of the site-scale flow model. The potentiometric surface (Faunt 2001 [DIRS 154625], Figure 1-2) as provided in DTN: GS000508312332.001 [DIRS 149947] was used to truncate the top of the flow model grid and provide the water levels supplied as boundary conditions around the perimeter of the model. The water levels presented by Faunt (2001 [DIRS 154625], Attachment I) as provided in DTN: GS000508312332.001 [DIRS 149947] were specified as water-level target values for calibration. During the process of calibration, additional water-level data from Tucci (2004 DIRS 168473], Attachment I) became available and were used to supplement the data from Faunt. Specifically, an additional water-level location, USW WT-24, was added and the eight water-level locations corresponding to the NC-EWDP) in Faunt (2001 [DIRS 154625]) were replaced by equivalent locations from Tucci (2004 [DIRS 168473]). The remaining 15 Nye County locations presented by Tucci (2004 [DIRS 168473]) were not added to the calibration targets, but rather were saved and used for validation (see Table 7-2). Of the final 114 water-level calibration targets presented Table 6-18, 105 values were obtained from DTN: GS000508312332.001 [DIRS 149947] and nine values were obtained from DTN: GS010908312332.002 [DIRS 163555]. The calibration targets are discussed in Section 6.6.1.3. The distribution of residuals, along with the measured and simulated water-level surfaces, resulting from the calibrated model is provided in Figure 6-41. The actual water levels (not the interpolated surface) in each well are used for comparison. In the more recent interpretations, such as DTN: GS010608312332.001 ([DIRS 155307]), potentiometric surface map output from Water-Level Data Analysis for the Saturated Zone Site-Scale Flow and Transport Model (USGS 2001 [DIRS 157611]), the head contours have been smoothed in the area near wells WT-24 and G-2 to reflect perched conditions. The different interpretations of the water table surface, that is, whether or not wells WT-24 and G-2 are perched, have little impact on the results. This is because those wells were given a low weight (owing to their suspect levels) and do not affect the calibration. Interestingly, the model 
consistently reports simulated levels in WT-24 and G-2 that are closer to the perched interpretations than the original high water table values.

A weighting scheme was used in conjunction with the PEST code to focus the calibration in areas where the confidence in the data was high (i.e., the low gradient area) or importance to the TSPA calculations was great (i.e., along the flow path). A low weighting on a target value will cause PEST to essentially ignore the value, and high value will cause PEST to respect the target value at the expense of other observations.

The calibrated SZ site-scale flow model has a sum-squared, weighted residual of approximately 27,600, which translates into approximately a 16-m (weighted) residual for each observation. Without weighting, the sum-squared residual is approximately 90,000, which corresponds to the approximately 30-m average residual for each observation. Compared to the overall head drop of approximately $500 \mathrm{~m}$ in the SZ site-scale flow model, the $30-\mathrm{m}$ average residual amounts to a 6 percent error.

As can be seen in Figure 6-41, the largest head residuals $(\sim 80 \mathrm{~m})$ are in the northern part of the model in the high-head gradient area near the east-west barrier. In the figure, a negative residual means that the calibrated value was lower than the target data. These head values are largely the result of the low weighting factor of (0.05) and the uncertainty in these measurements, possibly due to perched conditions. The next highest group of head residuals borders the east-west barrier and the Solitario Canyon fault. These residuals $(\sim 50 \mathrm{~m})$ are most likely the result of 500-m grid blocks not being able to resolve the 780-m to 730-m drop in head in the very short distance just east of the above-mentioned features. There may well be additional complicating factors such as the changing character in the Solitario Canyon fault along its north-south transect. The fault is modeled as a barrier with only one calibration parameter. This may be inadequate to represent the behavior locally of such a long feature. For example, well H-5, about $1,000 \mathrm{~m}$ from the Solitario Canyon fault, has discrepancy between measured and simulated heads of $41 \mathrm{~m}$. The measured head for this well $(775 \mathrm{~m})$, located on the east side of the fault, is closer to measured head values on the west side of the fault. Because the majority of wells on the east side are approximately $735 \mathrm{~m}$, the simulated head for H-5 was close to that value. Luckey et al. (1996 [DIRS 100465], p. 25) discuss potential causes for the high-head measurements at H-5 located just to the east of the Solitario Canyon fault. When the predicted and the observed water-level surfaces were compared, it should be noted that both water table surfaces are contoured and that the data distribution for both surfaces is not uniform. Evident in the comparison is the low-gradient region in the Fortymile Wash region, the high-gradient region north of Yucca Mountain, and the flow disruption caused by the Solitario Canyon fault. These results indicate that the model adequately represents the current water table near Yucca Mountain.

The recharge map used in the calibration process is described in Recharge and Lateral Groundwater Flow Boundary Conditions for the Saturated Zone Site-Scale Flow and Transport Model (BSC 2004 [DIRS 170015], Section 6.2). During performance assessment (TSPA-SR) calculations (CRWMS M\&O 2000 [DIRS 139440]), a revised recharge map was used than the one used here. The older map was used for calibration purposes, because it was the only map available at the time of calibration. The only differences are in the area of the model associated with the UZ model, and in that area, the changes were small. The complete details of the newer 
recharge map are described in Input and Results of the Base Case Saturated Zone Flow and Transport Model for TSPA (CRWMS M\&O 2000 [DIRS 139440]).

The important aspect to be addressed in this report is the effect of the newer recharge map on the calibrated SZ site-scale flow model. The differences are given in Table 6-18 with tenths of a meter difference at most. Thus, it is appropriate for the TSPA to use either recharge map.

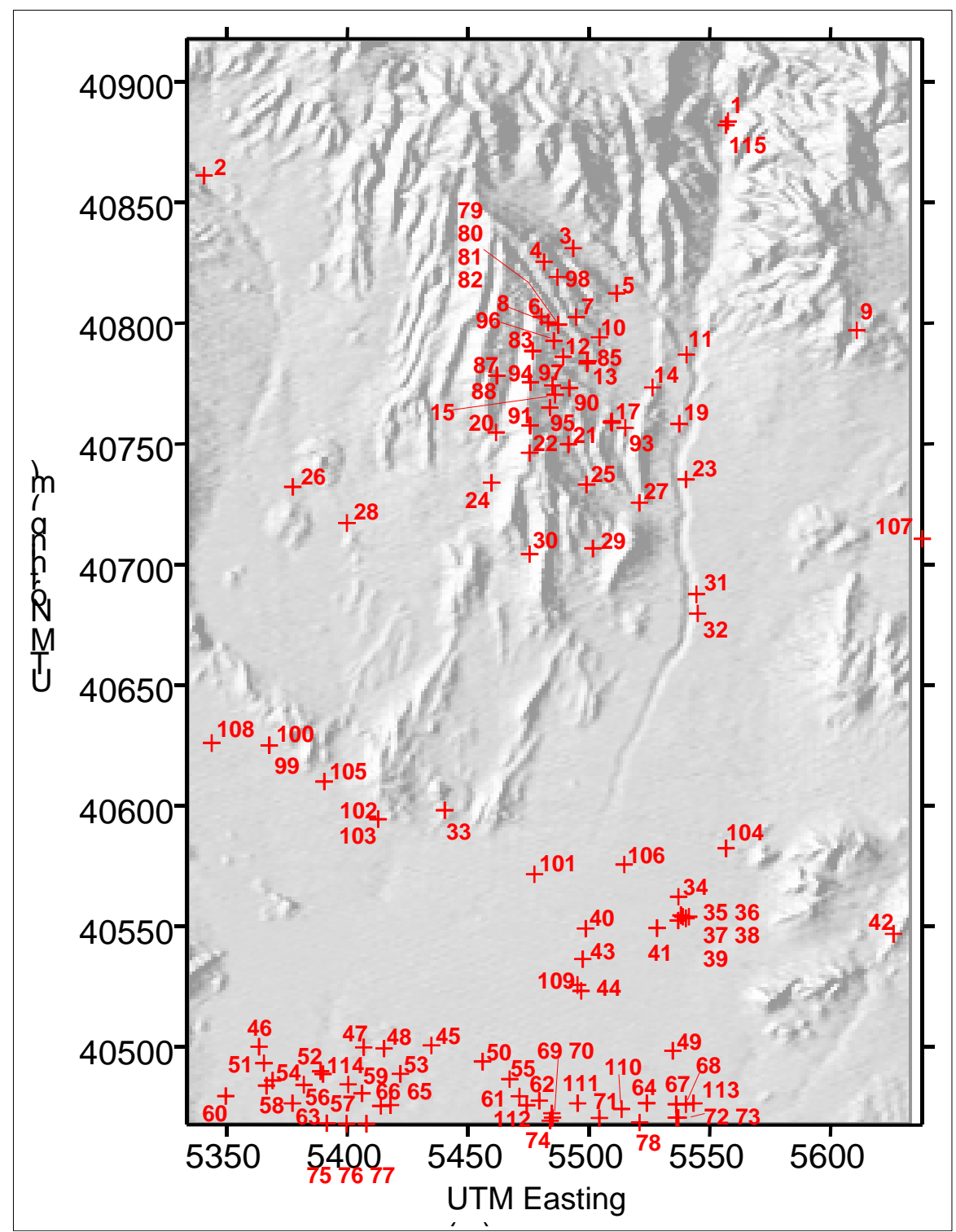

DTN: GS010908312332.002 [DIRS 163555].

NOTE: Numbers in the figure refer to the well numbers also listed in the second column of Table 6-18; UTM = Universal Transverse Mercator

Figure 6-40. Location of Observation Wells 

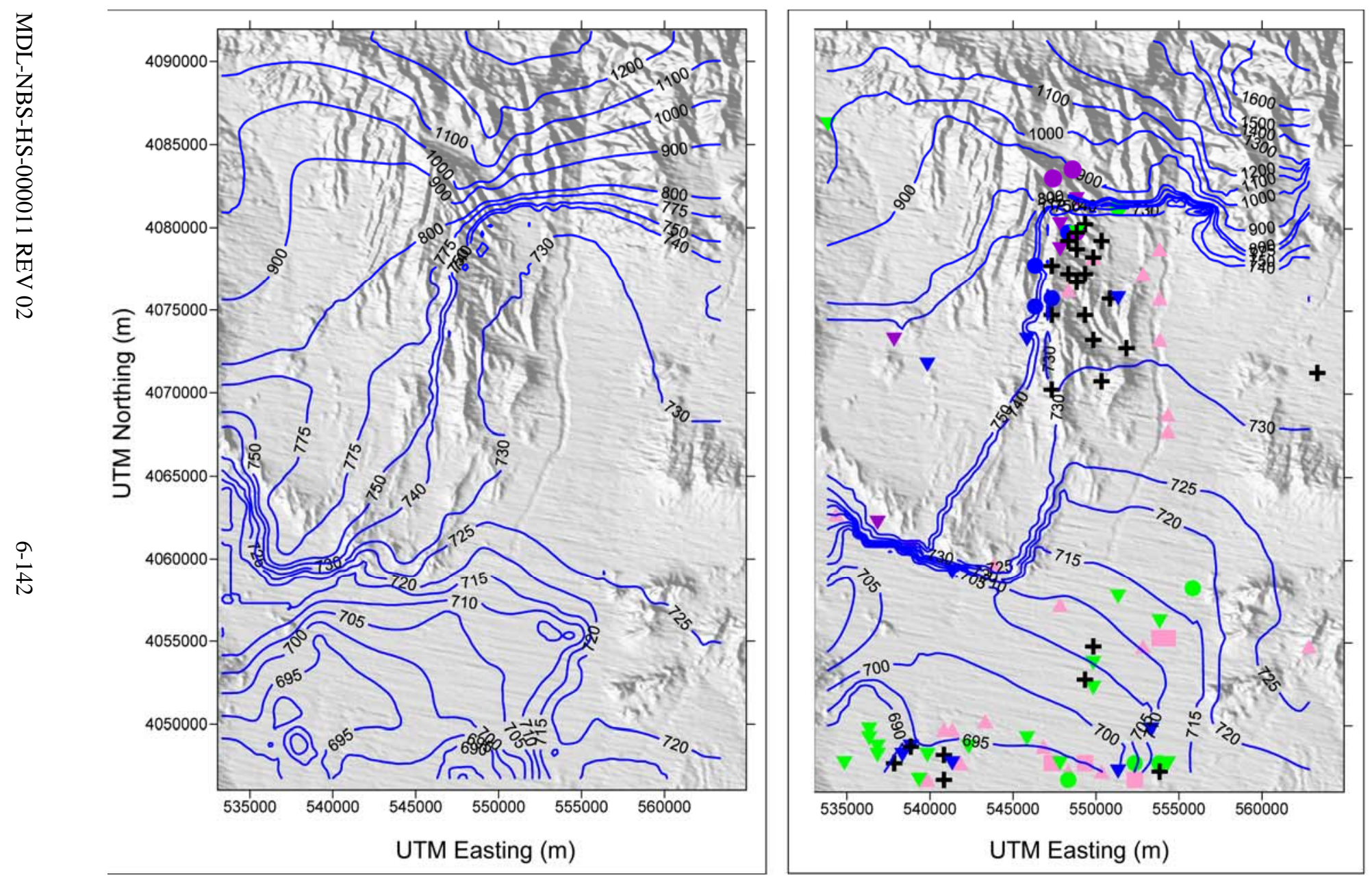

-89.26 to -50.00

-50.00 to -30.00

-30.00 to -20.00

-20.00 to -10.00

-10.00 to -5.00

-5.00 to -1.00

+-1.00 to 1.00

1.00 to 5.00

5.00 to 10.00

A 10.00 to 20.00

20.00 to 30.00

30.00 to 40.00

40.00 to 50.70

00487DC_092.ai

Source: DTN: GS000508312332.001 [DIRS 149947], left panel; Output DTN: LA0304TM831231.002, right panel.

NOTE: Symbols in right panel represent well locations; UTM = Universal Transverse Mercator

Figure 6-41. Contour Plot of Water-Level Data (Left Panel) and Simulated Water-Level Data with Residual Heads (Right Panel) 


\subsubsection{Comparing Fluxes Derived from the Regional Model with Fluxes Calculated from the Calibrated Model}

The SZ site-scale flow model describes a small part of the Death Valley regional groundwater flow system. By comparing the SZ site-scale flow model with the regional flow model, additional constraints can be applied to the SZ site-scale flow model. The comparison between the two models was also suggested by the Expert Elicitation Panel (CRWMS 1998 [DIRS 100353]). The numerical model of the regional flow system models a closed system and contains data from spring discharges to help fix the water flux through the system (D'Agnese et al. 1997 [DIRS 100131]). Thus, it is appropriate to compare the fluxes in the two models.

The regional model uses a 1997 regional HFM, which is described by D'Agnese et al. (1997 [DIRS 100131]). The SZ site-scale flow model uses the HFM-19, which is described in Hydrogeologic Framework Model for the Saturated-Zone Site-Scale Flow and Transport Model (BSC 2004 [DIRS 170008].

In Section 6.6.1.4, the methodology for applying fixed-head boundary conditions on the sides of the SZ site-scale flow model was described. With fixed-head boundary conditions, the flux through the boundary is a function of the permeabilities. A comparison of fluxes derived from the regional model and fluxes derived from the calibrated site-scale flow model are shown in Table 6-20a. In this table, the zones with " $\mathrm{N}$ " in the label refer to the northern boundary, those with an "E," the eastern boundary, and so on. The zones are depicted graphically in Figure 6-42. The comparison is reasonable on the northern and eastern boundaries. The northern boundary, for instance, has a total flux of $189 \mathrm{~kg} / \mathrm{s}\left(6.0 \times 10^{6} \mathrm{~m}^{3} / \mathrm{yr}\right)$ across it in the regional model and $169 \mathrm{~kg} / \mathrm{s}\left(5.3 \times 10^{6} \mathrm{~m}^{3} / \mathrm{yr}\right)$ across it in the SZ calibrated model. As can be seen in Table 6-20a and Figure 6-42, the distribution is different, which is not unexpected because the regional and SZ calibrated models are based on different hydrogeologic models. The target calibration fluxes are a little different from those extracted from the regional model (Table 6-20b). Those differences did not affect the calibration results. Table 6-20b shows the fluxes extracted from a comparison of the 1997 regional model and 2001 regional model. The match was good on the eastern side of the model with the lower thrust area, E1. The other zones showed small flows in both models. The match between the two models was poor on the western boundary. The southern boundary flux, which is simply a sum of the other boundary fluxes plus the recharge, is also a good match. The difference in southern fluxes (shown as Zone $\mathrm{S}$ in Table 6-20a) is about 21 percent.

Several factors affect the flux match between the two models: the horizontal and vertical resolution, the hydrologic framework model, and the permeability distribution. The horizontal resolution of the site-scale flow model is nine times finer than the regional model (500-m versus 1,500-m grid block size). The vertical resolution of the SZ site-scale flow model is an order of magnitude finer than the regional model (39 versus 3 layers). The increased resolution of the site scale means that fluxes calculated by the SZ site-scale flow model may depend more strongly on a few units than on the regional-scale model. This fact is important when considering that many of the unit permeabilities in the SZ site-scale flow model are constrained by field data. The HFM-19 used in the SZ site-scale flow model differs considerably from the 1997 regional HFM used in the 1997 DVRFS model, which is why the matching requirements for the fluxes were relaxed for the western boundary and the flux distribution is different on the northern boundary. 
The last factor affecting the flux distribution in the regional model is the use of permeability classes. In the regional model, permeabilities associated with specific units are not defined (D'Agnese et al. 1997 [DIRS 100131]). Rather, the permeabilities are grouped into classes, which are assigned to a particular grid block based on the percentages of the rock types contained in the grid block. Thus, although the DVRFS model was based on a complex HFM, the actual model used only four permeability classes. That method of assigning permeabilities made it difficult to reproduce the distribution of fluxes on the side of the SZ site-scale flow model, if done on a unit-by-unit basis. In turn, this discrepancy makes it difficult to reproduce vertical flow or head gradients if they existed in the regional model because this would require a flux distribution on the lateral boundaries assigned by hydrogeologic unit. Never the less, the difference in the total flux across the southern boundary between the SZ site-scale flow model and the regional model is well within the range considered acceptable by the Expert Elicitation Panel (CRWMS M\&O 1998 [DIRS 100353]). This water table is propagated through the distribution of specific discharge used in the transport abstraction.

Table 6-20a. Comparison of Regional and Site-Scale Fluxes

\begin{tabular}{|c|c|c|c|c|c|}
\hline \multirow{2}{*}{$\begin{array}{c}\text { Boundary } \\
\text { Zone }\end{array}$} & \multicolumn{2}{|c|}{ Regional Flux } & \multicolumn{2}{|c|}{ Site-Scale Flux } & \multirow{2}{*}{$\begin{array}{c}\text { Calibration } \\
\text { Target? }\end{array}$} \\
\hline & $\mathrm{kg} / \mathrm{s}$ & $\mathrm{m}^{3} / \mathrm{yr}$ & $\mathrm{kg} / \mathrm{s}$ & $\mathrm{m}^{3} / \mathrm{yr}$ & \\
\hline $\mathrm{N} 1$ & -102 & $-3.2 \times 10^{6}$ & -60.0 & $-1.9 \times 10^{6}$ & Yes \\
\hline N2 & -16.5 & $-5.9 \times 10^{5}$ & -33.4 & $-1.0 \times 10^{6}$ & Yes \\
\hline N3 & -53.0 & $-2.0 \times 10^{6}$ & -30.6 & $-1.0 \times 10^{6}$ & Yes \\
\hline N4 & -18.4 & $-3.3 \times 10^{5}$ & -44.8 & $-1.4 \times 10^{6}$ & Yes \\
\hline W5 & 3.45 & $1.1 \times 10^{5}$ & 4.17 & $1.5 \times 10^{5}$ & No \\
\hline W4 & -71 & $-2.2 \times 10^{6}$ & -0.007 & $-2.3 \times 10^{2}$ & No \\
\hline W3 & -6.9 & $-2.2 \times 10^{6}$ & -0.000008 & -0.2 & No \\
\hline W2 & 2.73 & $8.6 \times 10^{4}$ & -0.00002 & -0.7 & No \\
\hline W1 & -47.0 & $-1.5 \times 10^{6}$ & -6.85 & $-2.2 \times 10^{4}$ & No \\
\hline E1 & -555. & $-1.8 \times 10^{7}$ & -554 & $-1.7 \times 10^{7}$ & Yes \\
\hline E2 & -5.46 & $-1.7 \times 10^{5}$ & 3.53 & $1.1 \times 10^{5}$ & Yes \\
\hline E3 & 2.65 & $8.3 \times 10^{4}$ & 16.5 & $5.2 \times 10^{5}$ & Yes \\
\hline E4 & -3.07 & $-3.7 \times 10^{4}$ & 16.8 & $5.3 \times 10^{5}$ & Yes \\
\hline $\mathrm{S}$ & 918 & $2.5 \times 10^{7}$ & 724 & $2.3 \times 10^{7}$ & No \\
\hline
\end{tabular}

Source: BSC 2004 [DIRS 170015], pp. 26-30; Output DTN: LA0304TM831231.002.

NOTE: A negative value indicates flow into the model. Values were rounded to two or three significant digits. Target flux values for N2, N3, N4, and S are different from the DVRFS model. However; these differences did not affect the calibration results.

\subsubsection{Predicted Flow Paths}

The particle-tracking capability of FEHM was used to demonstrate flow paths predicted by the calibrated SZ site-scale flow model. One hundred particles were distributed uniformly over the area of the repository and allowed to migrate until they reached the model boundary (Figure 6-43). The pathways generally leave the repository and travel in a south-southeasterly direction to the $18-\mathrm{km}$ compliance boundary. From the $18-\mathrm{km}$ boundary to the end of the model, the flow paths trend to the south-southwest and generally follow Fortymile Wash. Most of the pathways pass through the designated Imbricate zone (Zone 91 of Figure 6-37). Some of the pathways follow fault zones along Fortymile Wash (Zones 57 and 58 of Figure 6-37). The 
hydrogeologic units through which the flow leaving the repository layer passes consist of the Crater Flat group (Bullfrog, Tram, and Prow Pass) with most of the flow in the Bullfrog unit, the upper volcanic aquifer, the upper volcanic confining unit, the valley fill unit, and the undifferentiated valley-fill unit. Figure 6-43 shows a vertical cross section of the path lines. Evident in the figure is the shallow depth of the path lines, which is consistent with data supporting an upward head gradient. In Section 7, the fluid pathways are compared with those inferred from geochemical data.

\subsubsection{Specific Discharge}

Using the calibrated SZ site-scale flow model, specific discharge was estimated for a nominal fluid path leaving the repository area and traveling 0 to $5 \mathrm{~km}, 5$ to $20 \mathrm{~km}$, and 20 to $30 \mathrm{~km}(0,3$, 12.5, and 18.6 miles). The specific discharge simulated by the SZ site-scale flow model for each segment of the flow path from the repository was determined using the median transport time (50th particle) for a group of particles released beneath the repository. By dividing the distance between the boundaries (shown in Figure 6-43) by the median transport time, values for specific discharge of $0.67 \mathrm{~m} / \mathrm{yr}, 2.3 \mathrm{~m} / \mathrm{yr}$, and $2.5 \mathrm{~m} / \mathrm{yr}(2.2,7.5$, and $8.2 \mathrm{ft} / \mathrm{yr})$ were obtained, respectively, for the three segments of the flow path. The expert elicitation panel (CRWMS $\mathrm{M} \& O 1998$ [DIRS 100353], Figure 3-2e) estimated a median specific discharge of $0.71 \mathrm{~m} / \mathrm{yr}$ $(2.3 \mathrm{ft} / \mathrm{yr})$ for the $5-\mathrm{km}(3-\mathrm{mi})$ distance. Thus, good agreement is found between the specific discharge predicted by the calibrated SZ site-scale flow model and that estimated by the expert elicitation panel for this distance. The expert elicitation committee did not consider other travel distances. Mass balance error for all runs was zero.

Table 6-20b Comparison of Fluxes at the Site-Scale Boundaries Predicted by the 1997 and 2001 Regional Flow Models

\begin{tabular}{|c|c|c|c|c|}
\hline \multirow[b]{2}{*}{ Boundary Zone } & \multicolumn{2}{|c|}{$\begin{array}{c}1997 \\
\text { Regional Flux }\end{array}$} & \multicolumn{2}{|c|}{$\begin{array}{c}2001 \\
\text { Regional Flux }\end{array}$} \\
\hline & $\left(\mathrm{m}^{3} / \mathrm{yr}\right)^{\mathrm{b}}$ & $\mathrm{kg} / \mathrm{s}^{\mathrm{a}}$ & $\left(m^{3} / y r\right)^{b}$ & $\mathrm{~kg} / \mathrm{s}^{\mathrm{a}}$ \\
\hline N1 & $-3.2 \times 10^{6}$ & -102 & $-6.9 \times 10^{6}$ & -219 \\
\hline N2 & $-5.9 \times 10^{5}$ & -18.9 & $-1.8 \times 10^{6}$ & -57.1 \\
\hline N3 & $-2.0 \times 10^{6}$ & -64.7 & $2.2 \times 10^{5}$ & 6.9 \\
\hline N4 & $-3.3 \times 10^{5}$ & -10.6 & $-4.3 \times 10^{5}$ & -1.37 \\
\hline Subtotal of North Boundary Fluxes & $-6.2 \times 10^{6}$ & -196 & $-8.5 \times 10^{6}$ & -271 \\
\hline W5 & $1.1 \times 10^{5}$ & 3.45 & $6.6 \times 10^{6}$ & 210 \\
\hline W4 & $-2.2 \times 10^{5}$ & -71 & $-2.5 \times 10^{3}$ & -0.08 \\
\hline W3 & $-2.2 \times 10^{5}$ & -6.9 & $-1.8 \times 10^{6}$ & -56.1 \\
\hline W2 & $8.6 \times 10^{4}$ & 2.73 & $-4.1 \times 10^{4}$ & -1.31 \\
\hline W1 & $-1.5 \times 10^{6}$ & -48.0 & $-8.9 \times 10^{5}$ & -28.4 \\
\hline Subtotal of West Boundary Fluxes & $-3.7 \times 10^{6}$ & -119 & $3.9 \times 10^{6}$ & 124 \\
\hline E1 & $-1.8 \times 10^{7}$ & -555 & $-2.2 \times 10^{6}$ & -69.7 \\
\hline E2 & $-1.7 \times 10^{5}$ & -5.46 & $-3.2 \times 10^{2}$ & -0.01 \\
\hline E3 & $8.3 \times 10^{4}$ & 2.65 & $4.4 \times 10^{6}$ & 138.1 \\
\hline
\end{tabular}


Table 6-20b. Comparison of Fluxes at the Site-Scale Boundaries Predicted by the 1997 and 2001 Regional Flow Models (Continued)

\begin{tabular}{|c|c|c|c|c|}
\hline \multirow[b]{2}{*}{ Boundary Zone } & \multicolumn{2}{|c|}{$\begin{array}{c}1997 \\
\text { Regional Flux }\end{array}$} & \multicolumn{2}{|c|}{$\begin{array}{c}2001 \\
\text { Regional Flux }\end{array}$} \\
\hline & $\left(\mathrm{m}^{3} / \mathrm{yr}\right)^{\mathrm{b}}$ & $\mathrm{kg} / \mathrm{s}^{\mathrm{a}}$ & $\left(m^{3} / y r\right)^{b}$ & $\mathrm{~kg} / \mathrm{s}^{\mathrm{a}}$ \\
\hline E4 & $-9.7 \times 10^{4}$ & -3.07 & $-4.8 \times 10^{4}$ & -1.53 \\
\hline Subtotal of East Boundary Fluxes & $-1.8 \times 10^{7}$ & -561 & $-6.6 \times 10^{6}$ & -209 \\
\hline$S$ & $2.5 \times 10^{7}$ & 790 & $1.4 \times 10^{7}$ & 430 \\
\hline
\end{tabular}

NOTE: Negative values indicate flow into the model. Values were rounded to two or three significant digits.

Source: ${ }^{a}$ DTN: SN0407T0504404.002 [DIRS 170929], pp. 6-26 and 6-27.

$$
{ }^{\mathrm{b}} \text { Conversion factor: } \mathrm{m}^{3} / \mathrm{yr}=\frac{\mathrm{m}^{3}}{1,000 \mathrm{~kg}} \bullet \frac{86,400 \mathrm{~s}}{\text { day }} \bullet \frac{365 \text { day }}{\mathrm{yr}} \bullet \frac{\mathrm{kg}}{\mathrm{s}}
$$

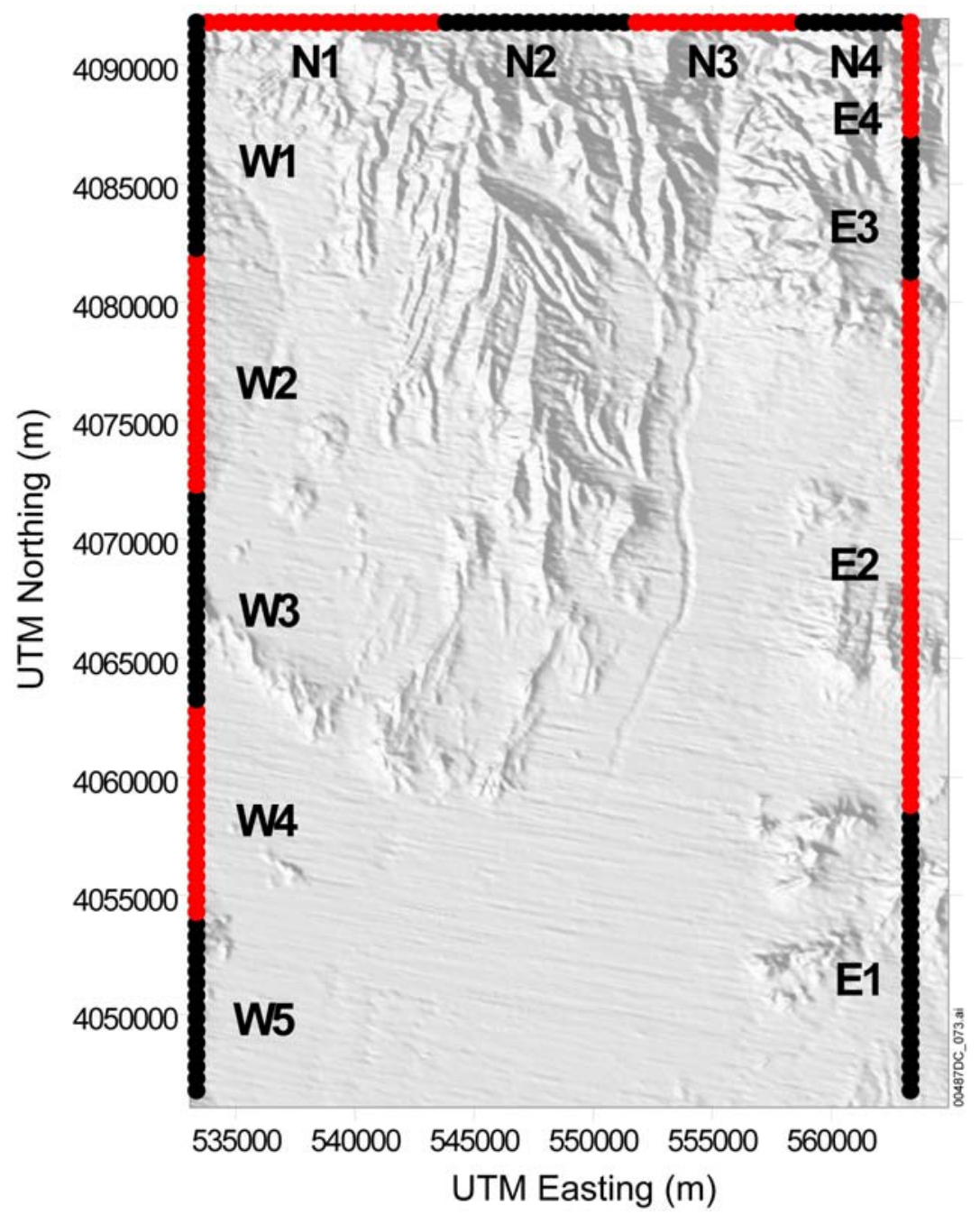

Source: Previous version of this model report (BSC 2001 [DIRS 155974]).

NOTE: Colors are used only to discriminate among flux zones. UTM = Universal Transverse Mercator.

Figure 6-42. Flux Zones Used for Comparing Death Valley Regional Flow System Flow Model and Site-Scale Flow Model Fluxes 

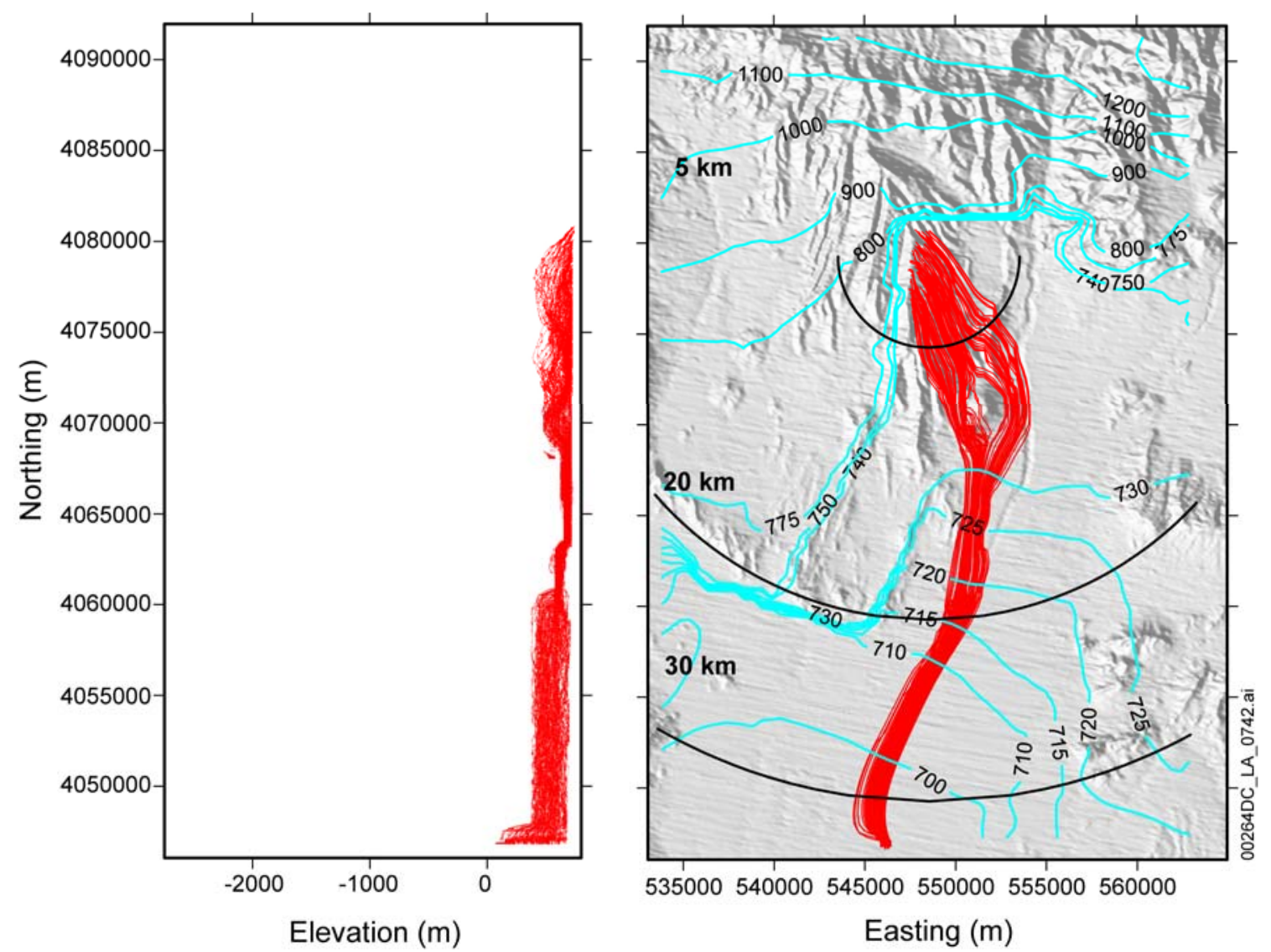

Output DTN: LA0304TM831231.002.

NOTE: Blue lines refer to head contours; red lines refer to particles. Arcs correspond to distances of 5-km, 20-km, and $30-\mathrm{km}$ from the repository. The left panel plots all flow paths projected onto a north-south vertical plane the right panel is the flow paths in plan view. The 0 in the left panel corresponds to the mean sea level.

Figure 6-43. Flow Paths from the Repository and Hydraulic Head Contours Simulated with the SZ Site-Scale Flow Model

\subsection{EVALUATION OF ALTERNATIVE MODELS}

\subsubsection{Large Hydraulic Gradient Alternative Conceptual Model}

An overview of the large hydraulic gradient (LHG) ACM is presented below, followed by discussions of the model setup used in evaluating the ACM and of the results of the evaluation. The section concludes with an assessment of the impact of the LHG ACM on the SZ site-scale flow model. The evaluation of ACMs associated with the LHG is taken from "The Site-Scale SZ Flow Model for Yucca Mountain: Calibration of Different Conceptual Models and Their Impact on Flow Paths" (Zyvoloski et al. 2003 [DIRS 163341]).

\subsubsection{Overview}

Alternative conceptualizations have been formulated, which remove the extensive set of features north of Yucca Mountain but divide the model domain along the Claim Canyon caldera into northern and southern zones, allowing different permeabilities to be assigned in the north versus 
the south within the same hydrogeologic unit. By creating a distributed region of lower permeability in the northern portion of the model, the LHG can be simulated in the flow domain. Using this basic conceptualization, different models incorporating the northwest-southeast trending fault zone just north of Yucca Mountain, the Ghost Dance fault, and the Dune Wash fault have been formulated to evaluate the sensitivity of the base case model to different conceptualizations of the LHG.

\subsubsection{Setup}

The alternative conceptualizations of the LHG do not make use of the extensive feature set north of Yucca Mountain, and these have been removed from the base case model grid (Figure 6-6), thereby simplifying the grid in the alternative conceptualizations considered for the LHG. Instead, the hydrogeologic units have been divided into northern and southern zones at the Claim Canyon caldera boundary. Differing permeabilities can be assigned in each zone to each hydrologic unit. Two variants of this basic approach are considered: one uses only the alteration zone, whereas the other includes the alteration zone and a zone to represent the northwest-southeast trending fault zone just north of Yucca Mountain (Feature 2 in Figure 6-6). These models are referred to as the "altered, no fault" (ANF) and "altered, with fault" (AWF) models, respectively. Although there are fewer discrete features in the altered models than in the base case model, there are actually a greater number of calibration parameters. This increase is a result of breaking the hydrogeologic units into independent northern and southern zones. A third alternative model, which adds features to the AWF model to account for the Ghost Dance fault and the Dune Wash fault, was formulated to improve the calibration obtained with the AWF conceptual models. This third alternative conceptual model is referred to as the AWF/GDF model.

The alternative models resulted only in changes to the computation grid that was necessary to implement these alternative formulations of the hydrogeology. The alternative models were calibrated in a manner identical to that previously described for the SZ site-scale flow model. Water-level contour maps and particle tracks were generated based on the water levels predicted by the alternative models in a manner similar to that previously described for the SZ site-scale flow model.

\subsubsection{Results}

Water levels predicted by the SZ site-scale flow model and the LHG model at selected observation points are presented in Table 6-21. The calibrated permeability values, the SZ site-scale flow model, and the LHG model are presented in Table 6-22. All models adequately reproduced the gradient in the flow path downstream of the repository, and each model has similar sum-of-the-squared residuals on an overall basis. However, the simulations of the conceptual models that include the altered zone in the north matched better water-level observations in the low-gradient region than the simulation with the SZ site-scale flow model. In addition, all models capture the upward gradient from the carbonate aquifer. The close agreement of the calibrated permeabilities of the Bullfrog Tuff from each model also suggests that there are no significant differences in the specific discharge beneath the repository for the various conceptualizations. 
The flow paths resulting from the simulations with the various conceptual models are shown in Figures 6-44 (ANF), 6-45 (AWF), and 6-46 (AWF/GDF). Although the flow paths predicted by the ANF and AWF conceptual models are similar to one another, they are noticeably different from the flow paths predicted by the simulations of the SZ site-scale flow model. The SZ site-scale flow model produces flow paths that trend in a southeasterly direction from the repository site (see Figure 6-43). Further analysis of the flow paths indicates that the fluid particles travel in the same units, predominantly the Bullfrog tuff and the alluvial units, regardless of the model, and do not reach the carbonate aquifer. This is because of the pervasive upward gradient and confining unit that separates the alluvial units and the carbonate aquifer. Because the transport times are directly proportional to the permeability values, a qualitative transport-time comparison with SZ site-scale flow model results per unit can be inferred from the calibrated permeabilities in Table 6-22. The Bullfrog tuff has a calibrated value about 30 percent higher in the AWF/GDF model than in the SZ site-scale flow model. This is within the uncertainty range for specific discharge discussed in Section 6.8.5.2.

Table 6-21. SZ Site-Scale Flow Model Compared with Alternative Conceptual Models Selected Residuals from Models

\begin{tabular}{|c|c|c|c|c|c|c|}
\hline & & & duals (M & el - Meas & d), $\mathrm{m}$ & \\
\hline Well ID & $\begin{array}{c}\text { Measured } \\
\text { Head, (masl) }\end{array}$ & $\begin{array}{c}\text { SZ SS } \\
\text { Flow } \\
\text { Model }\end{array}$ & $\begin{array}{c}\text { ANF } \\
\text { Model }\end{array}$ & $\begin{array}{l}\text { AWF } \\
\text { Model }\end{array}$ & $\begin{array}{c}\text { AWFIGDF } \\
\text { Model }\end{array}$ & $\begin{array}{c}\text { Characteristic } \\
\text { of Head Measurement }\end{array}$ \\
\hline UE-25 WT \#18 & 730.8 & 3.83 & 6.20 & 1.58 & 2.75 & Low gradient \\
\hline UE-25 WT \#4 & 730.8 & 3.63 & 0.23 & 0.41 & 2.65 & Low gradient \\
\hline UE-25 WT \#15 & 729.2 & 4.65 & 1.57 & 1.62 & 4.15 & Low gradient \\
\hline USW G-4 & 730.6 & 4.38 & 0.65 & 0.78 & 3.36 & Low gradient \\
\hline USW SD-6 & 731.2 & 3.61 & -0.37 & -0.28 & 2.24 & Low gradient \\
\hline USW SD-7 & 727.6 & 6.50 & 3.05 & 3.16 & 5.68 & Low gradient \\
\hline USW SD-9 & 731.1 & 3.51 & -0.29 & -0.17 & 2.41 & Low gradient \\
\hline UE-25 J-11 & 732.2 & -0.63 & -0.63 & -0.63 & -0.57 & Low gradient \\
\hline USW UZ-14 & 779.0 & -44.10 & -47.60 & -48.20 & -45.40 & Moderate gradient \\
\hline USW G-1 & 754.2 & -19.20 & -23.00 & -23.30 & -18.60 & Moderate gradient \\
\hline USW WT-7 & 775.8 & -7.70 & -17.50 & -17.80 & -7.80 & Moderate gradient \\
\hline USW WT-10 & 776.0 & 5.50 & -3.01 & -2.91 & -39.80 & Moderate gradient \\
\hline USW H-5 upper & 775.5 & -40.90 & -45.20 & -45.30 & -42.00 & Moderate gradient \\
\hline USW H-6 lower & 775.9 & -12.00 & -10.20 & -10.30 & 13.50 & Moderate gradient \\
\hline UE-25 WT \#6 & 1034.6 & -89.34 & -211.76 & -289.47 & -297.20 & Possibly perched \\
\hline USW G-2 & 1020.2 & -86.41 & -209.63 & -283.92 & -286.40 & Possibly perched \\
\hline $\begin{array}{l}\text { UE-25 p \#1 (Lwr } \\
\text { Intrvl) }\end{array}$ & 752.4 & -12.73 & -13.90 & -14.89 & -17.60 & Upward gradient \\
\hline
\end{tabular}

Output DTN: LA0304TM831231.002.

Source: Zyvoloski et al. (2003 [DIRS 163341], Table 1).

NOTE: *ANF = altered, no fault; AWF = altered, with fault; AWF/GDF = altered, with fault/Ghost Dance fault; masl $=$ meters above sea level; $\mathrm{SS}=$ site-scale $; \mathrm{SZ}$ = saturated zone 
Table 6-22. Comparison of Selected Parameter Values for Alternate Conceptual Models

\begin{tabular}{|c|c|c|c|c|}
\hline \multirow[t]{2}{*}{ Hydrogeologic Unit or Feature } & \multicolumn{4}{|c|}{ Permeability $\left(\mathrm{m}^{2}\right)$ or Permeability Multiplication Factor $\left.{ }^{(* *}\right)$} \\
\hline & Base Case & ANF* & AWF* & AWF/GDF* \\
\hline Lower Carbonate Aquifer & $5.00 \times 10^{-14}$ & $3.29 \times 10^{-14}$ & $3.30 \times 10^{-14}$ & $1.96 \times 10^{-14}$ \\
\hline Older Volcanic Confining Unit & $2.00 \times 10^{-16}$ & $1.03 \times 10^{-16}$ & $1.00 \times 10^{-16}$ & $5.70 \times 10^{-16}$ \\
\hline Older Volcanic Aquifer & $5.00 \times 10^{-16}$ & $1.00 \times 10^{-15}$ & $1.00 \times 10^{-15}$ & $1.52 \times 10^{-14}$ \\
\hline Lower Volcanic Confining Unit & $2.00 \times 10^{-15}$ & $1.28 \times 10^{-16}$ & $1.54 \times 10^{-16}$ & $1.79 \times 10^{-13}$ \\
\hline Crater Flat-Tram & $2.36 \times 10^{-13}$ & $2.23 \times 10^{-13}$ & $1.73 \times 10^{-13}$ & $3.38 \times 10^{-14}$ \\
\hline Crater Flat-Bullfrog & $1.54 \times 10^{-11}$ & $2.00 \times 10^{-11}$ & $2.00 \times 10^{-11}$ & $2.02 \times 10^{-11}$ \\
\hline Crater Flat-Prow Pass & $8.00 \times 10^{-12}$ & $1.01 \times 10^{-13}$ & $1.00 \times 10^{-13}$ & $7.19 \times 10^{-14}$ \\
\hline Upper Volcanic Confining Unit & $5.00 \times 10^{-14}$ & $1.52 \times 10^{-15}$ & $1.87 \times 10^{-15}$ & $1.55 \times 10^{-14}$ \\
\hline Upper Volcanic Aquifer & $8.00 \times 10^{-14}$ & $1.00 \times 10^{-14}$ & $1.00 \times 10^{-14}$ & $8.25 \times 10^{-15}$ \\
\hline Lava Flow Aquifer & $1.00 \times 10^{-12}$ & $4.85 \times 10^{-12}$ & $4.89 \times 10^{-12}$ & $7.81 \times 10^{-12}$ \\
\hline Limestone Aquifer & $1.00 \times 10^{-12}$ & $1.87 \times 10^{-11}$ & $1.94 \times 10^{-11}$ & $8.26 \times 10^{-11}$ \\
\hline Valley Fill Aquifer & $5.00 \times 10^{-12}$ & $5.00 \times 10^{-14}$ & $5.01 \times 10^{-14}$ & $4.93 \times 10^{-14}$ \\
\hline Lower Carbonate Aquifer (North) & - & $3.30 \times 10^{-16}$ & $2.18 \times 10^{-16}$ & $5.00 \times 10^{-16}$ \\
\hline Older Volcanic Confining Unit (North) & - & $9.59 \times 10^{-16}$ & $1.27 \times 10^{-15}$ & $5.64 \times 10^{-19}$ \\
\hline Older Volcanic Aquifer (North) & - & $3.28 \times 10^{-16}$ & $3.32 \times 10^{-16}$ & $2.20 \times 10^{-16}$ \\
\hline Lower Volcanic Confining Unit (North) & - & $1.00 \times 10^{-16}$ & $1.00 \times 10^{-16}$ & $1.08 \times 10^{-15}$ \\
\hline Crater Flat-Tram (North) & - & $1.00 \times 10^{-16}$ & $1.00 \times 10^{-16}$ & $2.14 \times 10^{-15}$ \\
\hline Crater Flat-Bullfrog (North) & - & $2.55 \times 10^{-13}$ & $1.00 \times 10^{-13}$ & $1.34 \times 10^{-14}$ \\
\hline Crater Flat-Prow Pass (North) & - & $6.12 \times 10^{-15}$ & $5.00 \times 10^{-15}$ & $2.83 \times 10^{-14}$ \\
\hline Upper Volcanic Confining Unit (North) & - & $8.04 \times 10^{-16}$ & $8.00 \times 10^{-16}$ & $9.83 \times 10^{-16}$ \\
\hline Upper Volcanic Aquifer (North) & - & $3.00 \times 10^{-15}$ & $3.00 \times 10^{-15}$ & $2.52 \times 10^{-14}$ \\
\hline Lava Flow Aquifer (North) & - & $2.96 \times 10^{-12}$ & $2.99 \times 10^{-12}$ & $1.06 \times 10^{-11}$ \\
\hline Limestone Aquifer (North) & - & $4.31 \times 10^{-13}$ & $4.42 \times 10^{-13}$ & $5.87 \times 10^{-12}$ \\
\hline Fortymile Wash Fault** & 10 & 5.6 & 5.6 & - \\
\hline Spotted Range-Mine Mountain Zone ${ }^{\star \star}$ & 11.8 & 18.3 & 18.2 & - \\
\hline Imbricate Fault Zone ${ }^{\star \star}$ & 1 & 5 & 5 & - \\
\hline Crater Flat Fault & $5.00 \times 10^{-14}$ & $3.19 \times 10^{-14}$ & $3.47 \times 10^{-14}$ & $4.57 \times 10^{-13}$ \\
\hline Crater Flat Fault (North) & - & $3.56 \times 10^{-14}$ & $4.52 \times 10^{-14}$ & $1.21 \times 10^{-12}$ \\
\hline U.S. Highway 95 Fault & - & $9.36 \times 10^{-15}$ & $9.60 \times 10^{-15}$ & $1.21 \times 10^{-14}$ \\
\hline Alluvial Uncertainty Zone & $3.20 \times 10^{-12}$ & $3.00 \times 10^{-12}$ & $3.00 \times 10^{-12}$ & $3.13 \times 10^{-11}$ \\
\hline Lower Fortymile Wash Zone & $5.00 \times 10^{-12}$ & $5.95 \times 10^{-12}$ & $5.39 \times 10^{-12}$ & $6.81 \times 10^{-12}$ \\
\hline Northwest Trending Fault Zone & - & - & $3.87 \times 10^{-13}$ & $1.55 \times 10^{-11}$ \\
\hline
\end{tabular}

Source: Zyvoloski et al. (2003 [DIRS 163341], Table 2). Output DTN: LA0304TM831231.002.

NOTE: *ANF "altered, no fault."

AWF "altered, with fault."

AWF/GDF "altered, with fault/Ghost Dance fault."

** Permeability Multiplication Factor is used to multiply the permeability in the grid macro that has the multiplier 


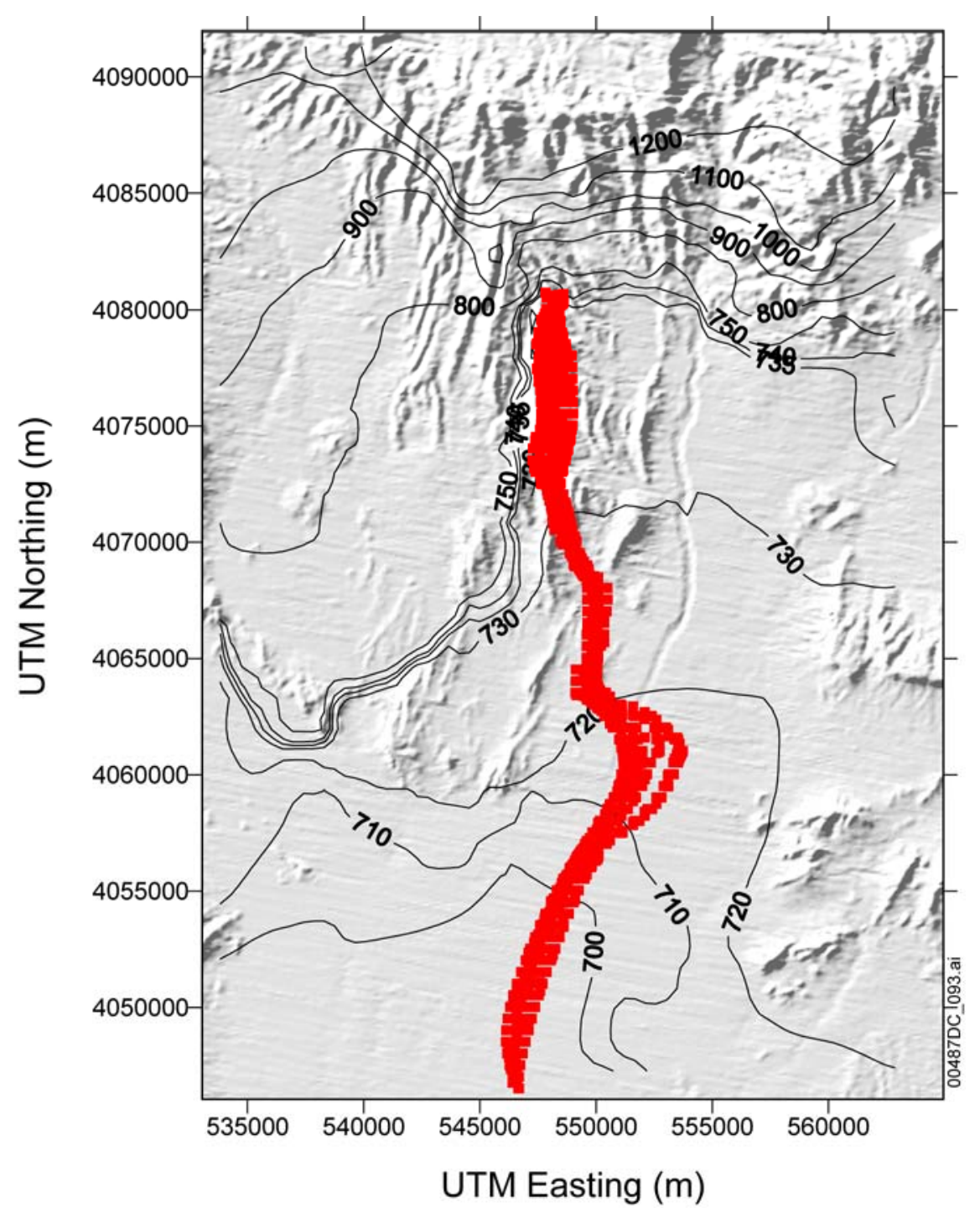

Source: Zyvoloski et al. (2003 [DIRS 163341], Figure 6).

NOTE: The red lines indicate flow paths.

UTM = Universal Transverse Mercator.

Figure 6-44. Predicted Flow Paths from the Water Table beneath the Repository for the Altered, No Fault Alternative Model 


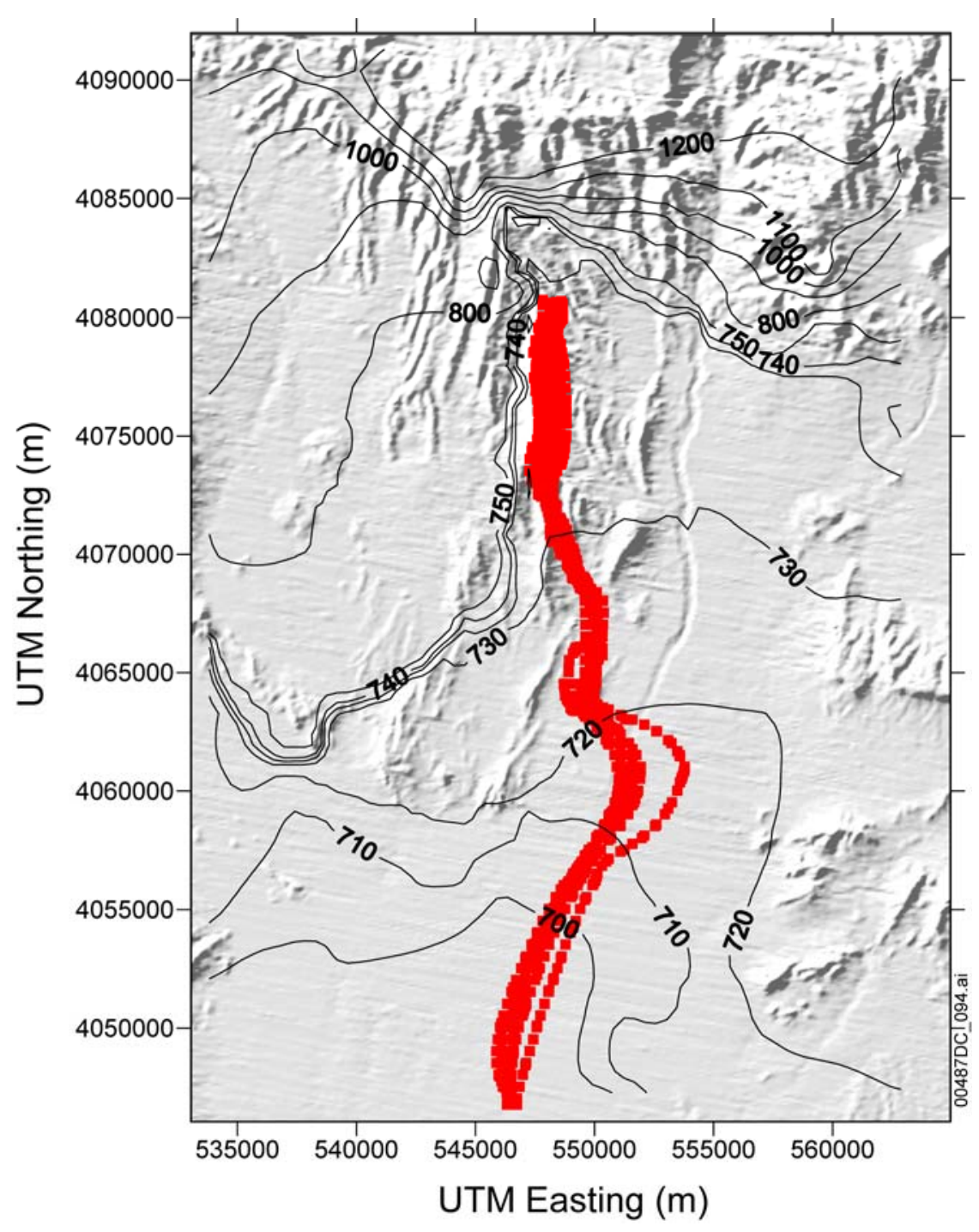

Source: Zyvoloski et al. (2003 [DIRS 163341], Figure 7).

NOTE: The red lines indicate flow paths.

UTM = Universal Transverse Mercator

Figure 6-45. Predicted Flow Paths from the Water Table beneath the Repository for the Altered, with Fault Alternative Model 


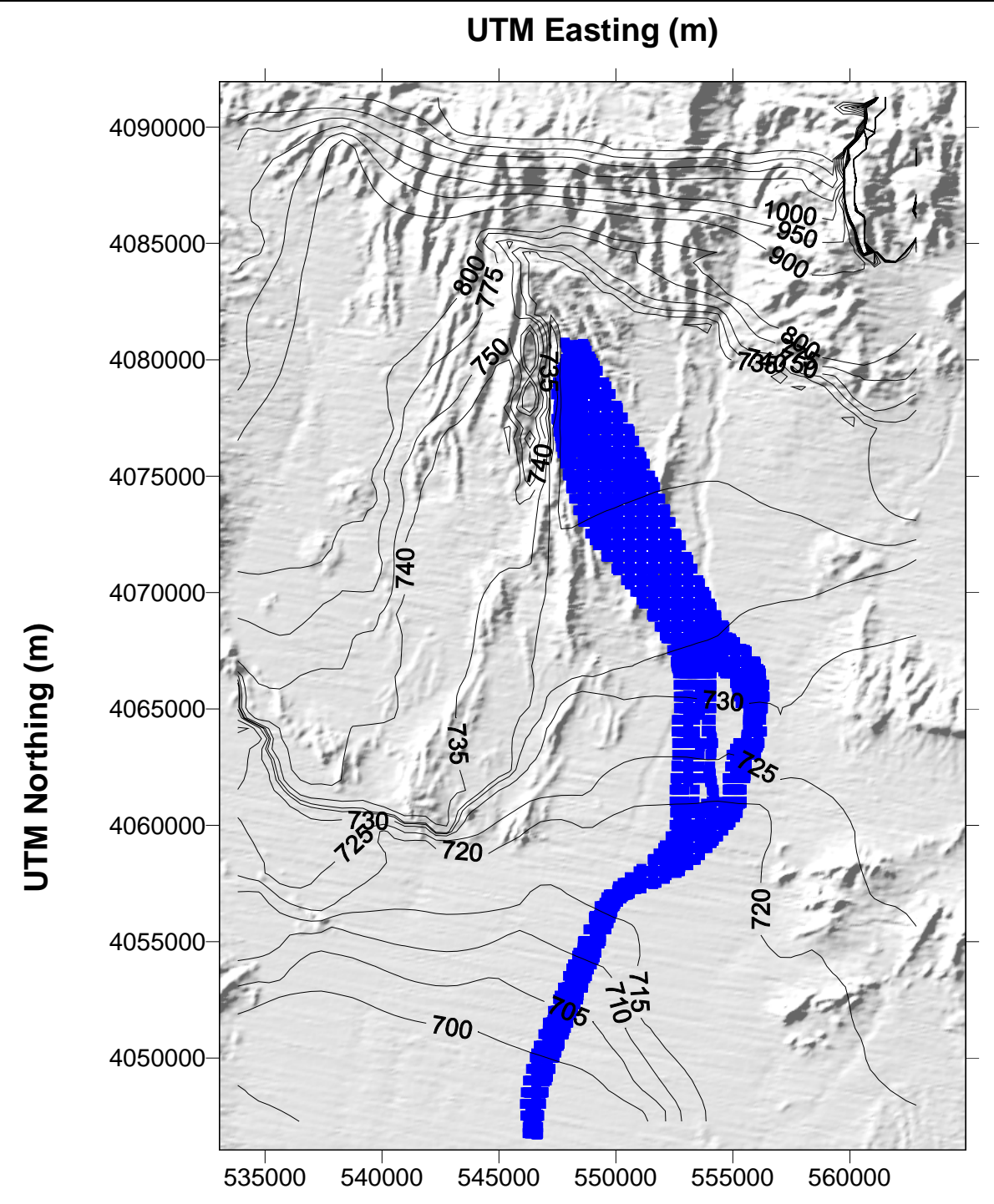

Source: Zyvoloski et al. (2003 [DIRS 163341], Figure 8).

NOTE: The blue lines indicate flow paths.

Figure 6-46. Predicted Flow Paths from the Water Table Beneath the Repository for the Altered with Fault/Ghost Dance Fault Alternative Model

As described in Section 7.3, the flow paths predicted by the SZ site-scale flow model are consistent with the flow paths inferred from geochemical and isotopic data shown in Figures 6-47 and 7-6. The ANF and AWF alternative models produce flow paths of particles leaving the repository that are more southerly in direction than those of the SZ site-scale flow model and, arguably, significantly different from the interpreted flow paths from the geochemistry. The more southeasterly direction predicted by the SZ site-scale flow model is due to the east-west barrier feature that is not present in the ANF and AWF conceptual models. This feature acts as a dam to keep the head elevated in the north, but in the process, also blocks water flow from the north. 

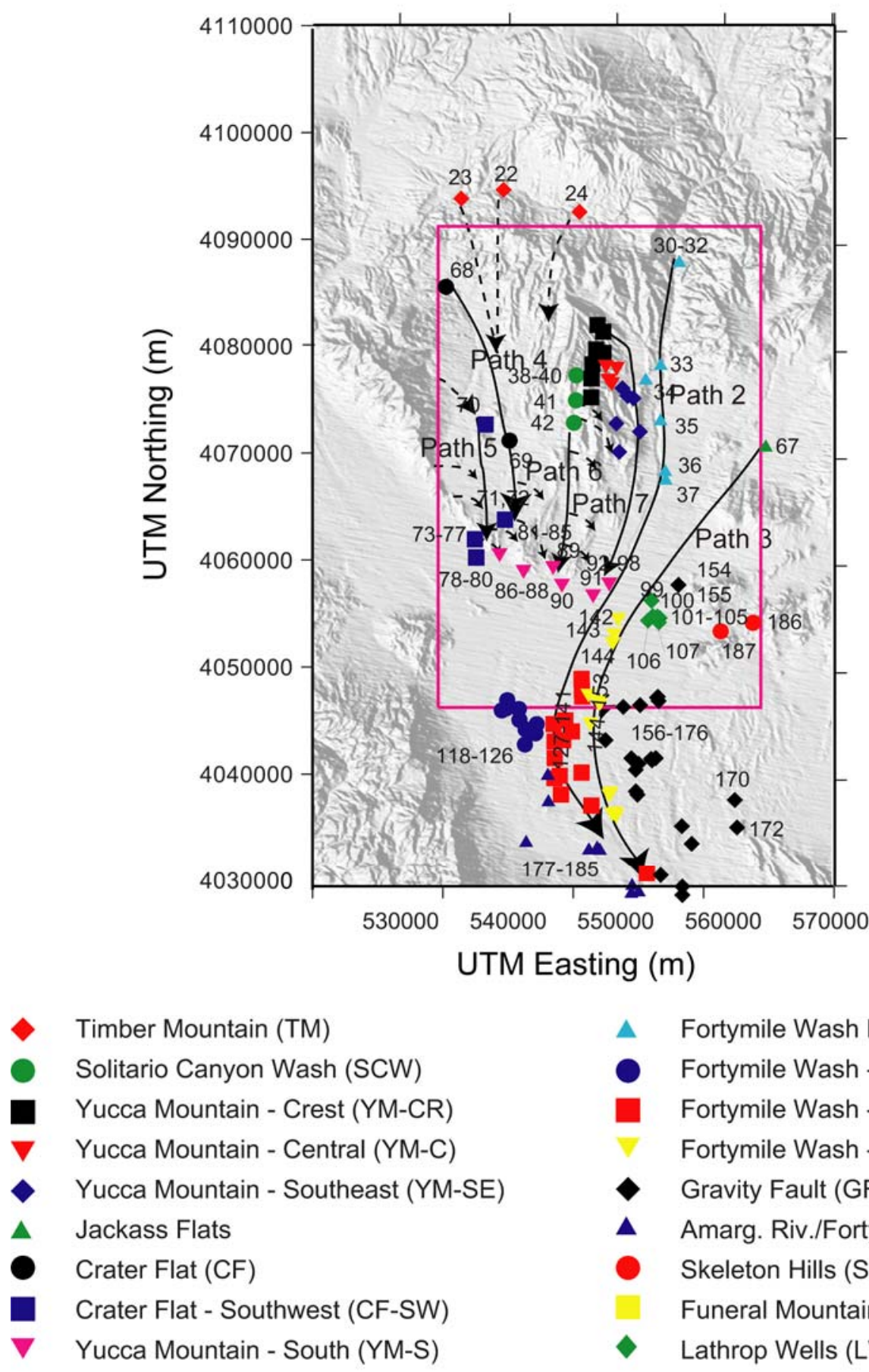

Fortymile Wash North (FMW-N)

- Fortymile Wash - West (FMW-W)

Fortymile Wash - South (FMW-S)

Fortymile Wash - East (FMW - E)

- Gravity Fault (GF)

A Amarg. Riv./Fortymile W (AR/FMW)

- Skeleton Hills (SH)

Funeral Mountains (FMt)

$\checkmark \quad$ Lathrop Wells (LW)

00487DC_083.ai

Source: See Appendix A, Figure A6-62.

NOTE: Base map shows borehole designators and inserts; for reference see Figure A6-5 and Table A4-3. UTM = Universal Transverse Mercator

Figure 6-47. Groundwater Flow Paths in SZ Interpreted from Groundwater Chemistry and Isotope Compositions 
Because the ANF and AWF models are forced to honor the available head data, the calibration process adjusts for this blockage by determining permeability distributions that allow water from Crater Flat (west of Yucca Mountain) to enter the repository area. Although the alternative conceptual models produced a level of calibration equal to or better than the original model, this adjustment results in the calibration of these alternative models not achieving as good a match as the SZ site-scale flow model in those few moderate gradient water-level wells (750 m to $780 \mathrm{~m}$ ) just to the west of Yucca Mountain.

To correct these deficiencies in the ANF and AWF alternative models, the AWF/GDF model was formulated. The AWF/GDF model augments the structures present in the AWF model with two permeability features, the Ghost Dance fault and the Dune Wash fault, and an additional four parameters associated with the moderate gradient region. The Ghost Dance fault runs parallel and to the east of the Solitario Canyon fault. The Dune Wash fault is a northwest-southeast trending fault splay of the Ghost Dance fault. Both features are shown in Figure 6-3. Calibration with the additional parameters noticeably improves the model in the moderate gradient region, with little deterioration of the overall fit. The more accurate match to the heads in the moderate gradient region results in particle flow paths (Figures 6-44 to 6-46) that more closely resemble those inferred from geochemistry. Therefore, the AWF/GDF model is considered a plausible alternative model to the SZ base-scale flow model and an improvement over the other two models, which assume only altered rock of lower permeability north of Yucca Mountain. The predicted flow paths and overall flux were similar between the base case and AWF/GDF models.

\subsubsection{Assessment}

The SZ site-scale flow model and three alternative conceptual models representing a variety of approaches for interpreting the cause of the LHG north of Yucca Mountain were investigated using calibration to water-level data, followed by a comparison of predicted flow paths from the repository. Although the calibrations may not be unique, several important data sets were matched by all of the conceptual models. The low hydraulic gradient in the area to the south-southeast of Yucca Mountain was modeled accurately in all models, with the alternative conceptual models producing better head matches.

The largest potential differences observed between the SZ site-scale flow and alternative conceptual models are found in the flow paths predicted by the models. The analyses of the base case, ANF, and AWF models show that the flow path could be sensitive to the conceptual model of the LHG. To address the difficulties encountered by the ANF and Altered, with fault models in matching heads near the Solitario Canyon fault, the AWF/GDF model was evaluated. The AWF/GDF model contains additional parameters designed to capture the moderate gradient more accurately. With the additional parameterization, this model produced flow paths similar to the SZ site-scale flow model.

The similarity of the SZ site-scale flow and AWF/GDF models suggests that the conceptualization of the LHG has little effect on the SZ site-scale flow model results. Apparent differences in flow paths in the ANF and AWF models are most likely due to not representing accurately the moderate gradient head observations and do not represent important differences in hydrologic conditions for the different conceptual models of the LHG. Thus, the SZ site-scale 
flow model, in its role as a TSPA tool, is adequate. The uncertainty associated with the LHG models is discussed in Section 6.8.1.

\subsubsection{Solitario Canyon Fault Depth Alternative Conceptual Model}

An overview of the Solitario Canyon fault ACM is presented below followed by discussions of the model setup used in evaluating the ACM and of the results of the evaluation. The section concludes with an assessment of the impact of the Solitario Canyon fault ACM on the SZ site-scale flow model.

\subsubsection{Overview}

The Solitario Canyon fault and its east and west branches make up three of the 17 discrete geologic features and regions represented with distinct hydrological properties in the SZ site-scale flow model. The Solitario Canyon fault separates Crater Flat from Yucca Mountain and is shown in Figure 6-3. The Solitario Canyon fault consists of generally north-south trending features just to the west of Yucca Mountain. Both east and west branches consist of generally north-northeast trending linear features, also just to the west of Yucca Mountain. The representation of the Solitario Canyon fault is an important part of the SZ site-scale flow model because it can potentially control flow from Crater Flat to Fortymile Wash. The impact on the model of these features is to generate a higher hydraulic gradient to the west of Yucca Mountain and to impede flow from Crater Flat to Yucca Mountain. This effect on flow is important in determining the amount of alluvial material that groundwater flowing from beneath the repository region passes through en route to the accessible environment.

\subsubsection{Setup}

The SZ site-scale flow model includes the Solitario Canyon fault as a discrete feature that extends from the top of the water table to the bottom of the model. To investigate the importance of Solitario Canyon fault depth, an alternative conceptualization was simulated in which the fault extends from the water table only to the top of the carbonate aquifer. This alternative was identical to the SZ site-scale flow model in all other respects except for the Solitario Canyon fault properties. The alternative resulted only in changes to the computation grid that was necessary to implement this alternative formulation of the fault. The alternative model was calibrated in a manner identical to that previously described for the SZ site-scale flow model (see Section 6.6). Water-level contour maps and particle tracks were generated based on the water levels predicted by the alternative model in a manner similar to that previously described for the SZ site-scale flow model.

\subsubsection{Results}

The Solitario Canyon fault depth, is referred to as the shallow fault alternative model. This alternative is identical to the SZ site-scale flow model (Section 6.6) in all respects except for the Solitario Canyon fault properties. Table 6-23 compares the modeled head values from the shallow fault alternative model for the 32 wells in the low-gradient region to the south and east of Yucca Mountain with measured values and values from the base case model. Locations of the wells in Table 6-23 are shown in Figure 6-17. This area was chosen for comparison because of its influence on the specific discharge $5 \mathrm{~km}$ from the repository, which is an important 
performance assessment measure. To provide a quantitative measure of the calibration of the shallow fault alternative model versus the SZ site-scale flow model, modeled heads at selected wells and water-level contours over the model domain can be compared. As seen from the comparison of modeled heads in Table 6-23, this simulation produced essentially the same result as the original SZ site-scale flow model with the deeper fault zone. For the shallow fault case, however, the calibrated permeability for the fault was approximately 25 percent lower than the permeability for the original deeper fault.

Table 6-23. Observed and Computed Head Data Compared to Shallow Solitario Canyon Fault Alternative Conceptual Model

\begin{tabular}{|c|c|c|c|c|c|c|c|c|}
\hline $\begin{array}{c}\text { Site } \\
\text { Name }\end{array}$ & $\begin{array}{l}\text { Fig. } \\
6-40 \\
\text { Label }\end{array}$ & $\begin{array}{c}\text { (UTM) } \\
\text { (m) }\end{array}$ & $\begin{array}{c}\text { (UTM) } \\
\text { (m) }\end{array}$ & $\begin{array}{c}z \\
\text { (elevation) } \\
(\mathrm{m})\end{array}$ & $\begin{array}{c}\text { Observed } \\
\text { Head } \\
\text { Data } \\
(\mathrm{m}) \\
\end{array}$ & $\begin{array}{c}\text { SZ SS Flow } \\
\text { Model } \\
\text { Results (m) }\end{array}$ & $\begin{array}{c}\text { Shallow } \\
\text { Fault Model } \\
\text { Results (m) }\end{array}$ & Weigh \\
\hline $\begin{array}{l}\text { UE-25 } \\
\text { WT \#18 }\end{array}$ & 7 & 549468 & 4080238 & 722.1 & 730.8 & 734.67 & 734.93 & 20 \\
\hline $\begin{array}{l}\text { UE-25 } \\
\text { WT \#4 }\end{array}$ & 10 & 550439 & 4079412 & 709 & 730.8 & 734.46 & 734.70 & 20 \\
\hline $\begin{array}{l}\text { UE-25 } \\
\text { WT \#15 }\end{array}$ & 11 & 554034 & 4078694 & 698.7 & 729.2 & 733.87 & 734.02 & 20 \\
\hline $\begin{array}{l}\text { USW G- } \\
4\end{array}$ & 12 & 548933 & 4078602 & 542.2 & 730.6 & 734.5 & 734.77 & 20 \\
\hline $\begin{array}{l}\text { UE-25 } \\
\text { WT \#14 }\end{array}$ & 14 & 552630 & 4077330 & 703.6 & 729.7 & 733.79 & 733.95 & 20 \\
\hline $\begin{array}{l}\text { USW } \\
\text { WT-2 }\end{array}$ & 15 & 548595 & 4077028 & 702 & 730.6 & 734.18 & 734.46 & 20 \\
\hline $\begin{array}{l}\text { UE-25 c } \\
\# 1\end{array}$ & 16 & 550955 & 4075933 & 473.2 & 730.2 & 733.92 & 734.11 & 20 \\
\hline $\begin{array}{l}\text { UE-25 c } \\
\# 3\end{array}$ & 17 & 550930 & 4075902 & 474.3 & 730.2 & 733.92 & 734.11 & 20 \\
\hline $\begin{array}{l}\text { UE-25 c } \\
\# 2\end{array}$ & 18 & 550955 & 4075871 & 553.2 & 730.2 & 733.9 & 734.10 & 20 \\
\hline $\begin{array}{l}\text { UE-25 } \\
\text { WT \#13 }\end{array}$ & 19 & 553730 & 4075827 & 703.8 & 729.1 & 733.35 & 733.47 & 20 \\
\hline $\begin{array}{l}\text { USW } \\
\text { WT-1 }\end{array}$ & 21 & 549152 & 4074967 & 708.4 & 730.4 & 733.86 & 734.05 & 20 \\
\hline $\begin{array}{l}\text { USW G- } \\
3\end{array}$ & 22 & 547543 & 4074619 & 318.1 & 730.5 & 734.96 & 738.02 & 20 \\
\hline $\begin{array}{l}\text { UE-25 } \\
\mathrm{J}-13\end{array}$ & 23 & 554017 & 4073517 & 354.8 & 728.4 & 732.74 & 732.83 & 20 \\
\hline $\begin{array}{l}\text { UE-25 } \\
\text { WT \#17 }\end{array}$ & 25 & 549905 & 4073307 & 705.4 & 729.7 & 733.58 & 733.70 & 20 \\
\hline $\begin{array}{l}\text { UE-25 } \\
\text { WT \#3 }\end{array}$ & 27 & 552090 & 4072550 & 705.8 & 729.6 & 733.08 & 733.18 & 20 \\
\hline $\begin{array}{l}\text { UE-25 } \\
\text { WT \#12 }\end{array}$ & 29 & 550168 & 4070659 & 702.6 & 729.5 & 732.92 & 732.89 & 20 \\
\hline $\begin{array}{l}\text { USW } \\
\text { WT-11 }\end{array}$ & 30 & 547542 & 4070428 & 691.9 & 730.7 & 733.71 & 733.43 & 20 \\
\hline $\begin{array}{l}\text { UE-25 } \\
\mathrm{J}-12\end{array}$ & 31 & 554444 & 4068774 & 659.6 & 727.9 & 731.44 & 731.48 & 20 \\
\hline
\end{tabular}


Table 6-23. Observed and Computed Head Data Compared to Shallow Solitario Canyon Fault Alternative Conceptual Model (Continued)

\begin{tabular}{|c|c|c|c|c|c|c|c|c|}
\hline $\begin{array}{c}\text { Site } \\
\text { Name }\end{array}$ & $\begin{array}{l}\text { Fig. } \\
6-40 \\
\text { Label }\end{array}$ & $\begin{array}{c}x \\
\text { (UTM) } \\
\text { (m) }\end{array}$ & $\begin{array}{c}y \\
\text { (UTM) } \\
\text { (m) }\end{array}$ & $\begin{array}{c}z \\
\text { (elevation) } \\
(\mathrm{m})\end{array}$ & $\begin{array}{c}\text { Observed } \\
\text { Head } \\
\text { Data } \\
(\mathrm{m})\end{array}$ & $\begin{array}{c}\text { SZ SS Flow } \\
\text { Model } \\
\text { Results (m) }\end{array}$ & $\begin{array}{c}\text { Shallow } \\
\text { Fault Model } \\
\text { Results (m) }\end{array}$ & Weigh \\
\hline $\begin{array}{l}\text { UE-25 } \\
\text { JF-3 }\end{array}$ & 32 & 554498 & 4067974 & 662.7 & 727.8 & 731.15 & 731.19 & 20 \\
\hline $\begin{array}{l}\text { Cind-R- } \\
\text { Lite } \\
\text { Well }\end{array}$ & 33 & 544027 & 4059809 & 710.2 & 729.8 & 737.49 & 735.75 & 20 \\
\hline $\begin{array}{l}\text { USW H- } \\
1 \text { tube } 3\end{array}$ & 81 & 548727 & 4079926 & 562.5 & 730.6 & 734.63 & 734.89 & 20 \\
\hline $\begin{array}{l}\text { USW H- } \\
1 \text { tube } 4\end{array}$ & 82 & 548727 & 4079926 & 680.5 & 730.8 & 734.65 & 734.92 & 20 \\
\hline $\begin{array}{l}\text { UE-25 b } \\
\# 1 \text { lower }\end{array}$ & 85 & 549949 & 4078423 & -8.8 & 729.7 & 735.53 & 735.84 & 20 \\
\hline $\begin{array}{l}\text { UE-25 b } \\
\# 1 \\
\text { upper }\end{array}$ & 86 & 549949 & 4078423 & 366.2 & 730.6 & 734.34 & 734.58 & 20 \\
\hline $\begin{array}{l}\text { USW H- } \\
4 \text { upper }\end{array}$ & 89 & 549188 & 4077309 & 395.5 & 730.4 & 734.25 & 734.51 & 20 \\
\hline $\begin{array}{l}\text { USW H- } \\
4 \text { lower }\end{array}$ & 90 & 549188 & 4077309 & 45 & 730.5 & 735.1 & 735.48 & 20 \\
\hline $\begin{array}{l}\text { USW H- } \\
3 \text { upper }\end{array}$ & 91 & 547562 & 4075759 & 576.9 & 731.5 & 734.48 & 736.23 & 20 \\
\hline $\begin{array}{l}\text { USW } \\
\text { SD-6 }\end{array}$ & 94 & 547578 & 4077550 & 725.9 & 731.2 & 734.84 & 735.21 & 20 \\
\hline $\begin{array}{l}\text { USW } \\
\text { SD-7 }\end{array}$ & 95 & 548384 & 4076499 & 637.7 & 727.6 & 734.13 & 734.43 & 20 \\
\hline $\begin{array}{l}\text { USW } \\
\text { SD-9 }\end{array}$ & 96 & 548550 & 4079256 & 678.3 & 731.1 & 734.64 & 734.91 & 20 \\
\hline $\begin{array}{l}\text { USW } \\
\text { SD-12 }\end{array}$ & 97 & 548492 & 4077415 & 696.7 & 730.0 & 734.31 & 734.61 & 20 \\
\hline $\begin{array}{l}\text { UE-25 } \\
\mathrm{J}-11\end{array}$ & 107 & 563799 & 4071058 & 687.2 & 732.2 & 731.57 & 731.57 & 20 \\
\hline
\end{tabular}

Output DTN: LA0304TM831231.002.

SS = site-scale; SZ = saturated zone; UTM = Universal Transverse Mercator.

Groundwater flow paths in the base case SZ site-scale flow model and in the alternative shallower Solitario Canyon fault model were evaluated using particle tracking. Particle paths from beneath the repository show similarity between those in the alternative model to those in the SZ site-scale flow model; however, the flow paths in the cross section indicate that the paths crossing the southern branches of the Solitario Canyon fault do not extend to depths as great as in the SZ site-scale flow model (Figures 6-48 to 6-51).

\subsubsection{Assessment}

An analysis of flow paths in the SZ beneath Yucca Mountain was completed using an alternative representation of the Solitario Canyon fault. The results of the analysis were compared to 
SZ site-scale flow model representation of the Solitario Canyon fault. The comparison resulted in the following.

- Bothconceptualizations of the Solitario Canyon fault yield the same flow paths from the water table underneath the repository to the accessible environment.

- Particles started to the west of the Solitario Canyon fault do not extend to a depth as great as in the SZ site-scale flow model (see Figures 6-49 and 6-51).

- For the shallow-fault ACM, the calibrated permeability for the fault was approximately 25 percent lower than for the fault in the SZ site-scale flow model. Thus, transport times for the ACM will not be shorter than for the SZ site-scale flow model.

- Based on this SZ subsystem analysis, which yielded similar flow path for both conceptualizations of the Solitario Canyon fault, it is concluded that the alternative representation of the Solitario Canyon fault will not change the SZ barrier performance, and therefore does not need to be propagated into TSPA.

\subsection{UNCERTAINTY}

Characterizing and understanding the flow through the SZ is important for assessing the overall containment strategy for safely storing radioactive materials at the Yucca Mountain repository. Uncertainty in flow modeling arises from a number of sources including, but not limited to, the conceptual model of the processes affecting groundwater flow, water-level measurements and simplifications of the model geometry, boundary conditions, hydrogeologic unit extent and depth, and the values of permeability assigned to hydrogeologic units. This section discusses and attempts to quantify uncertainties in the SZ site-scale flow model. In addition to the discussion in this section, parameter uncertainty is addressed in the model abstraction document (BSC 2004 [DIRS 170042]). This document includes additional quantitative analysis on horizontal anisotropy in permeability and groundwater specific discharge. Saturated Zone In-Situ Testing (BSC 2004 [DIRS 170010]) addresses the uncertainty related to the spatial distribution of the observation wells.

\subsubsection{Large Hydraulic Gradient}

An area of a LHG north of the high-level radioactive waste repository at Yucca Mountain has been inferred from previous hydraulic head measurements. To simulate this feature in the Yucca Mountain SZ site-scale flow model reported in the previous revision to this model report, a low-permeability east-west feature was incorporated into the model domain north of Yucca Mountain. The presence of this feature has yet to be confirmed by field investigations. Data that are more recent appear to indicate that the gradient in this area may be significantly lower than originally thought (BSC 2004 [DIRS 170009]), although high gradients still appear to be present in which a low-permeability east-west feature is incorporated into the model domain north of Yucca Mountain. 

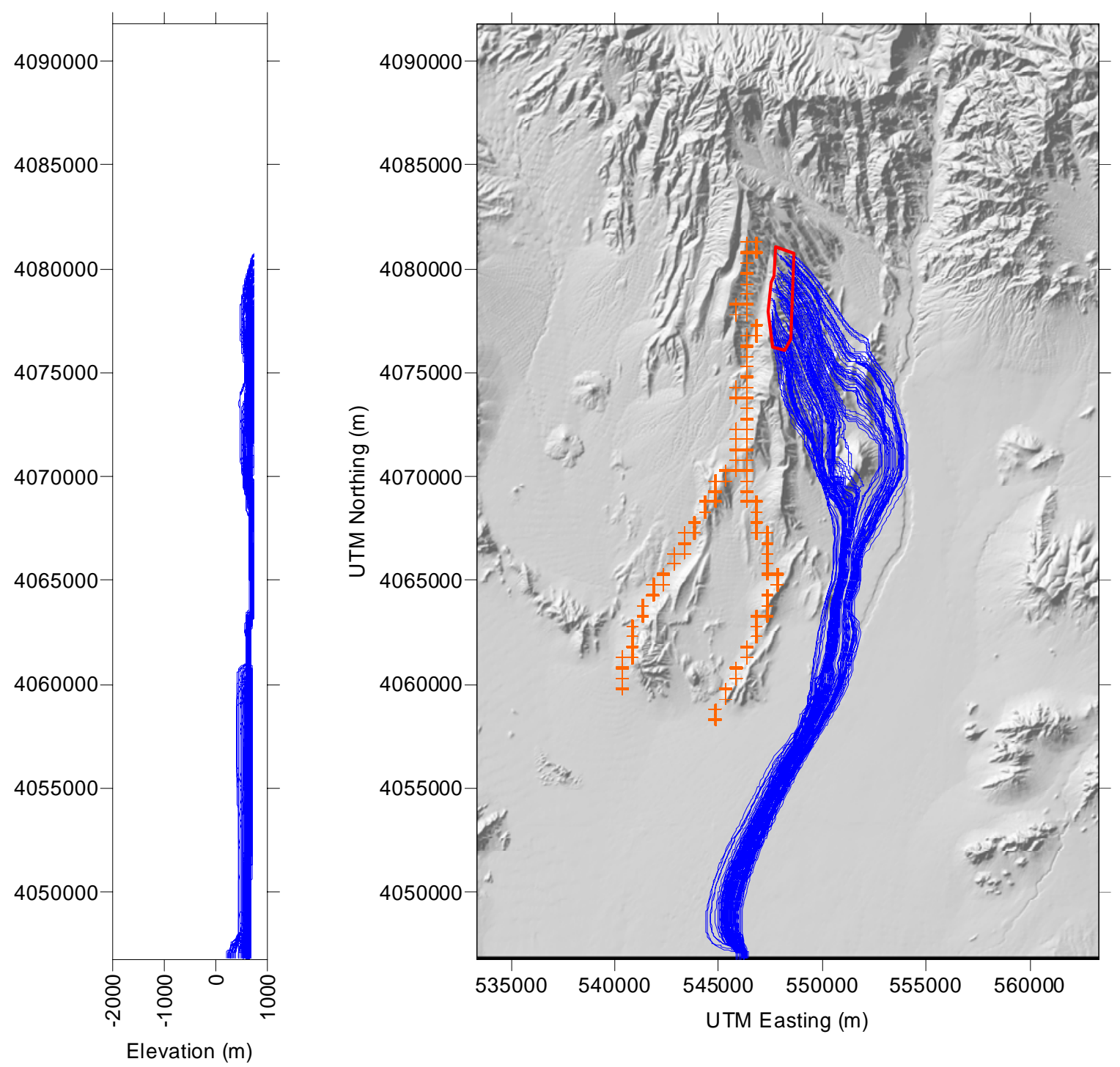

Output DTN: LA0304TM831231.002.

NOTE: Repository outline (shown with the bold red line) and nodes along the Solitario Canyon fault (shown with orange crosses). The left panel plots cross section of all flow paths projected onto a north-south vertical plane; the right panel is the flow paths in plan view. The 0 in the left panel corresponds to the mean sea level. Blue lines indicate simulated groundwater flow paths from beneath the repository.

UTM = Universal Transverse Mercator

Figure 6-48. Simulated Groundwater Flow Paths from Beneath the Repository for the SZ Site-Scale Flow Model Deep Solitario Canyon Fault 

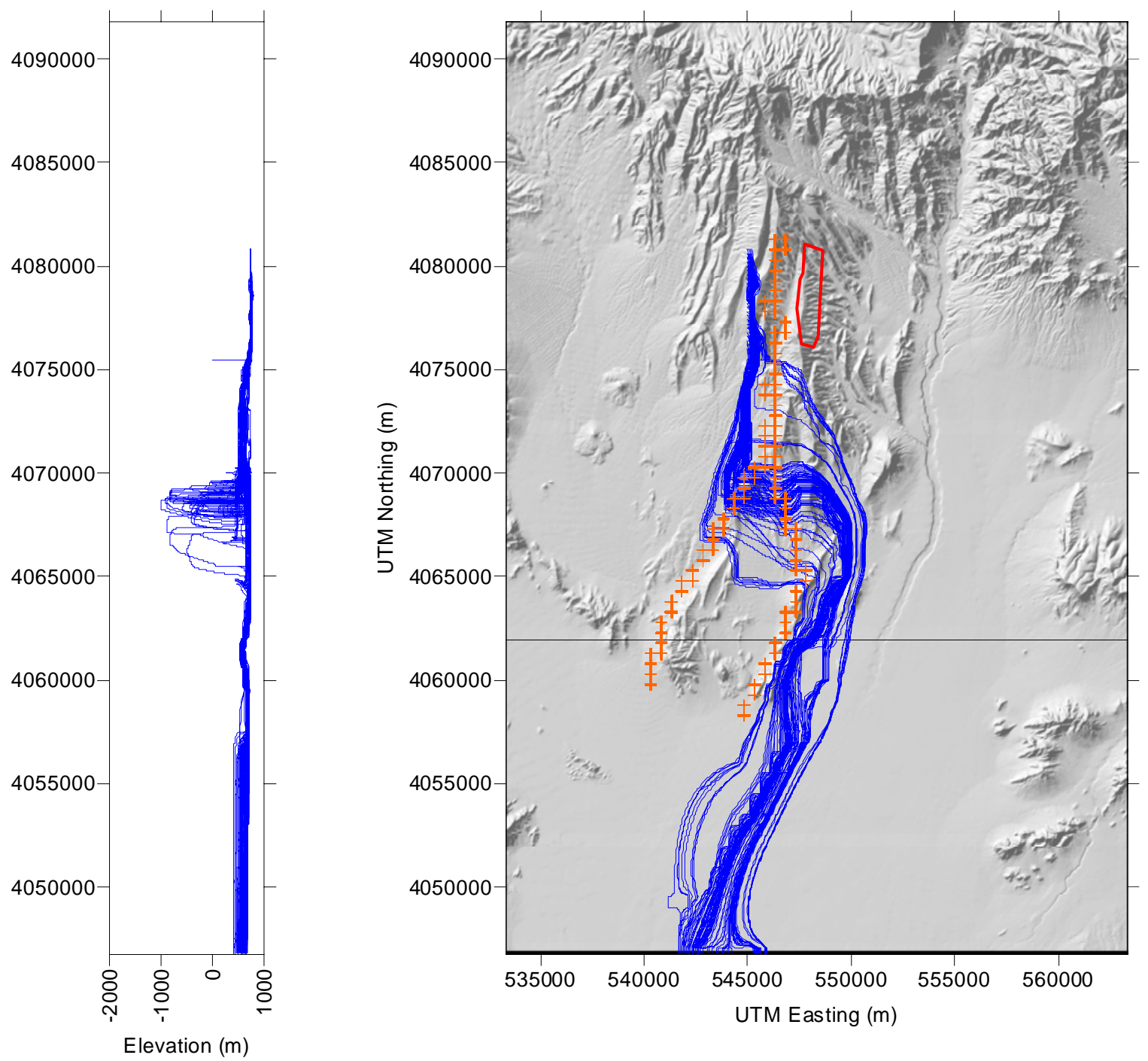

Output DTN: LA0304TM831231.002

NOTE: Repository outline (shown with the bold red line) and nodes along the Solitario Canyon fault (shown with orange crosses). The left panel plots cross section of all flow paths projected onto a north-south vertical plane; the right panel is the flow paths in plan view. The 0 in the left panel corresponds to the mean sea level. Blue lines indicate simulated groundwater flow paths from the west side of the Solitario Canyon Fault.

UTM = Universal Transverse Mercator

Figure 6-49. Simulated Groundwater Flow Paths from the West Side of Solitario Canyon Fault (Blue Lines) for the SZ Site-Scale Flow Model Deep Solitario Canyon Fault 

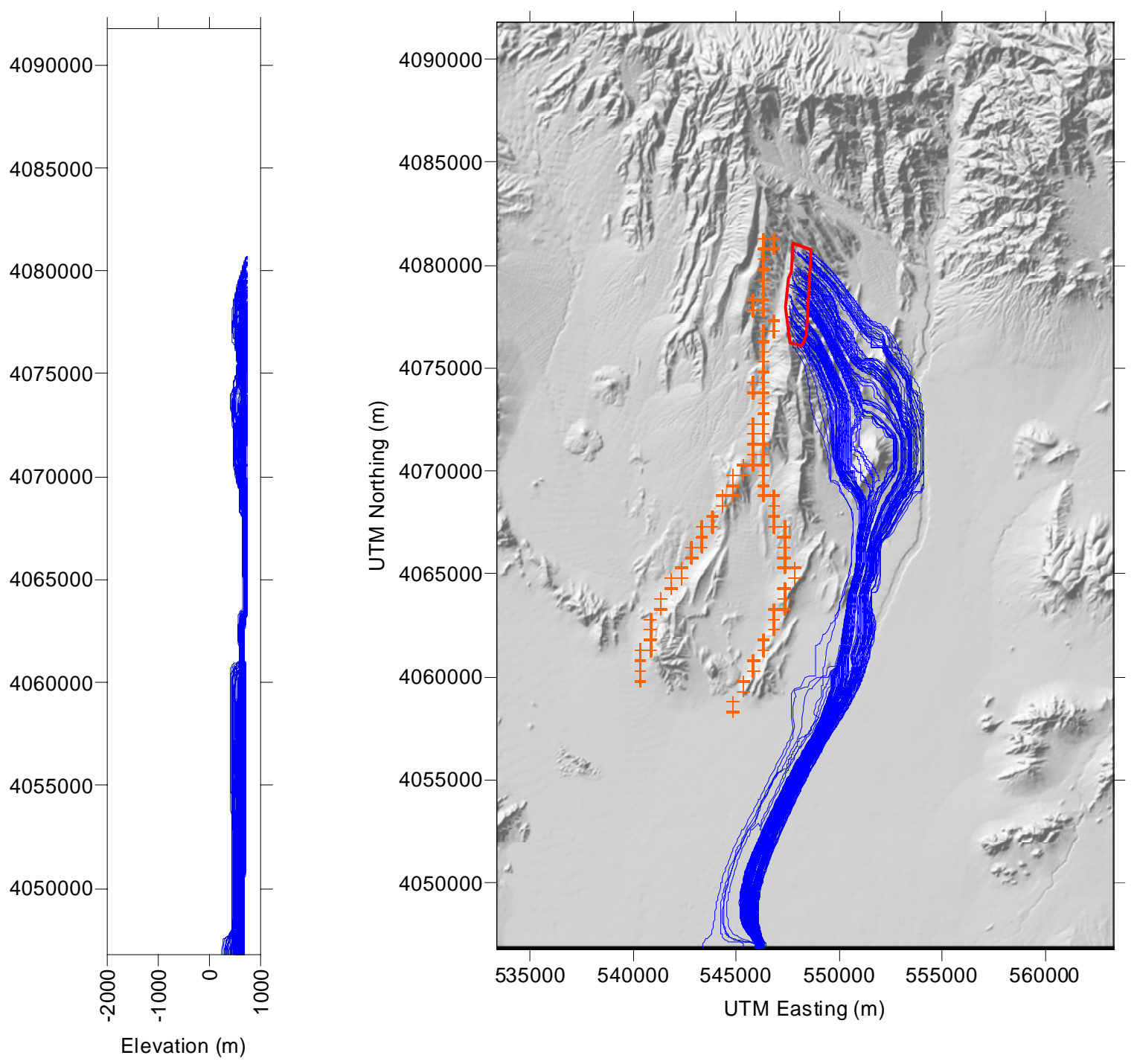

Output DTN: LA0304TM831231.002.

NOTE: Repository outline (shown with the bold red line) and nodes along the Solitario Canyon fault (shown with orange crosses). The left panel plots cross section of all flow paths projected onto a north-south vertical plane; the right panel is the flow paths in plan view. The 0 in the left panel corresponds to the mean sea level. Blue lines indicate simulated groundwater flow paths from beneath the repository.

UTM = Universal Transverse Mercator

Figure 6-50. Simulated Groundwater Flow Paths from Beneath the Repository for the Alternative Case (Shallow Solitario Canyon Fault) SZ Site-Scale Flow Model 

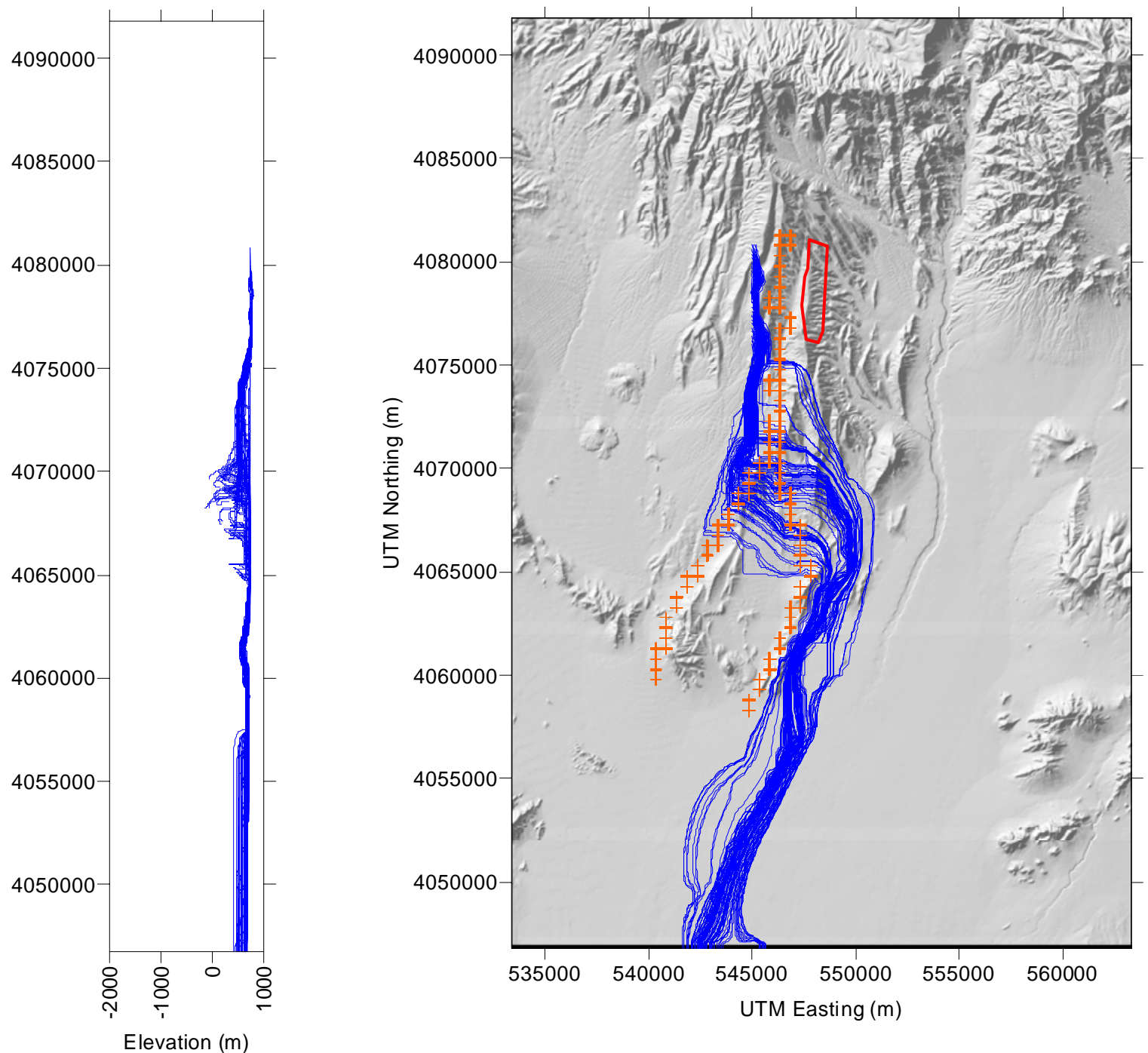

Output DTN: LA0304TM831231.002.

NOTE: Repository outline (shown with the bold red line) and nodes along the Solitario Canyon fault (shown with orange crosses). The left panel plots cross section of all flow paths projected onto a north-south vertical plane; the right panel is the flow paths in plan view. The 0 in the left panel corresponds to the mean sea level. Blue lines indicate simulated groundwater flow paths from the west side of Solitario Canyon Fault.

UTM = Universal Transverse Mercator

Figure 6-51. Simulated Groundwater Flow Paths from the West Side of Solitario Canyon Fault for the Alternative Conceptual Model of the Shallow Solitario Canyon Fault 
The sensitivity of the estimated groundwater flow paths and specific discharge to each of the conceptual models of the LHG has been investigated by both recalibrating the numerical model to fit conditions appropriate to each conceptual model and noting the resulting changes in the groundwater flow regime. The SZ site-scale flow model uses the uniform permeability of the hydrogeologic units plus permeabilities (or permeability multipliers) associated with features as calibration parameters. As discussed above, the SZ site-scale flow model calibration included low permeability zones and an east-west barrier north of Yucca Mountain to simulate the high gradient area (Figure 6-5). The alternative conceptualizations of the LHG do not make use of the extensive feature set north of Yucca Mountain, and these have been removed in the alternative models (Figure 6-6). To incorporate the area of extensive hydrothermal alteration in the Claim Canyon Caldera north of Yucca Mountain, the hydrogeologic units have been divided into distinct northern and southern zones. The AWF and AWF/GDF models differ from each other only by the inclusion of a zone that represents the northwest-southeast trending fault zone just north of Yucca Mountain (Feature 2 in Figure 6-6).

Although the number of features used in the alternative models is less than in the original SZ site-scale flow model, the number of calibration parameters has been increased. This increase is a consequence of dividing the hydrogeologic units into northern and southern zones. The list of calibrated versus measured observations for selected observation points (calibration targets) is given in Table 6-18. In general, the simulations of the alternative conceptual models better match observations in the low gradient region than the simulation within the original SZ site-scale flow model. The inclusion of the additional northwest-southeast trending fault zone in the second of the alternative conceptual models does not seem to improve the calibration.

The flow paths resulting from the simulation of the alternative conceptual models and original model are shown in Figures 6-44 to 6-46. Although the flow paths predicted by the simulation of the alternative conceptual models are similar, they are noticeably different from the flow paths predicted by the simulations of the original SZ site-scale conceptual model. The original model produces flow paths that trend in a southeasterly direction from the repository site (Figure 6-44). This result is consistent with the path lines inferred from geochemical shown in Figure 6-47. The AWF and AWF/GDF models produce path lines of particles leaving the repository that are more southerly in direction than those of the original model (Figures 6-45 and 6-46). An indepth analysis of the path lines indicates that the fluid particles travel in the same units-basically the Bullfrog tuff and the alluvial units-regardless of the model, and do not reach the carbonate aquifer. The net result of the flow paths from the alternative conceptualization is a relatively shorter traverse through the alluvial units compared to the paths for the original model. It should be noted that the more southeasterly component of the original model is due to the east-west barrier feature that is not present in the alternative models. This feature not only acts as a dam to keep the head elevated in the north but also blocks water from the north, thus allowing water from Crater Flat to enter the repository area. The alternative models lack this feature and allow the water to flow directly south. Because the flow paths and overall flux were smaller between the AWF/GDF and the SZ site-scale flow model, the uncertainty in the LHG is captured in the range of uncertainty associated with the horizontal anisotropy (Section 6.8.3) and included in the SZ flow and transport abstraction model (BSC 2004 [DIRS 170042]). 


\subsubsection{Perched Water on Flow Paths and Specific Discharge}

Perched water was not explicitly modeled in the SZ site-scale flow model, although it is noted here that all three conceptualizations of the LHG produced water levels in wells UE-25 WT\#6 and UE-25 G-2 (suspected to be perched) that were much lower than the reported water levels. From Table 6-21, it can be seen that the original model is about $80 \mathrm{~m}$ to $90 \mathrm{~m}$ low, indicating a water level of about $930 \mathrm{~m}$ in this area to the north of Yucca Mountain; this is consistent with the latest water-level interpretation in that area (BSC 2004 [DIRS 170009]. The alternative models of the LHG yield water levels in the UE-25 WT\#6, UE-25 G-2 area that are $130 \mathrm{~m}$ lower than the SZ site-scale conceptual model, indicating a much more abrupt change in head. This area has the steepest hydraulic gradient in the model; thus, it is not surprising that such differences in the models occur. As these hydraulic gradients occur over only several elements, addition discretization may be needed to quantify possible effects on flow direction and specific discharge. Fortunately, the LHG is upgradient of the repository and only minimally affect particle flow paths and transport times (see Figure 6-46). Therefore; uncertainty due to perched water on flow paths and specific discharge is not propagated forward into the SZ flow and transport abstraction model (BSC 2004 [DIRS 170042]).

\subsubsection{Anisotropy}

Both vertical and horizontal anisotropy can affect the flow path, flow direction, and specific discharge.

\subsubsection{Vertical Anisotropy}

The SZ site-scale flow model was calibrated using 114 head measurements from wells within the model domain as described in Section 6.6. Removing background vertical anisotropy from the model had the following effects on computed heads for these wells and lateral boundary fluxes. The difference between heads computed for the target wells with and without background vertical anisotropy was less than the difference between heads computed using the model and measured heads except for seven of the 114 measurements.

- Well UE-29a-2 Hydraulic Test Hole is located in the high-gradient region north of Yucca Mountain. Removing background vertical anisotropy resulted in a computed head $23 \mathrm{~m}$ lower than the model with vertical anisotropy.

- Wells USW WT-10 and USW VH-1 are located west of Yucca Mountain. Removing background vertical anisotropy resulted in computed heads $12 \mathrm{~m}$ and $13 \mathrm{~m}$ lower than the model with vertical anisotropy.

- Wells James H. Shaw, Richard Washburn (1), NC-Washburn-1X, and Richard Washburn (3) are located in the Amargosa Desert. Removing background vertical anisotropy resulted in computed heads approximately $1 \mathrm{~m}$ higher than the model with vertical anisotropy.

Differences in fluxes through the boundary flux zones defined in Figure 6-42 exceeded 30 percent for only two of the zones, W1 and W4, both of which are located on the western 
boundary of the SZ site-scale flow model boundary. Overall, 10:1 vertical anisotropy yielded better flow calibration and was therefore kept unchanged in the SZ site-scale flow model

\subsubsection{Horizontal Anisotropy}

Incorporating anisotropy in the area of the north-south trending faults at Yucca Mountain into the SZ site-scale flow model discussed in Section 6.6 resulted in predicted hydraulic heads that were slightly closer to the observed heads than for the model calibration without anisotropy. The differences in predicted heads and their impacts on the specific discharge, the flow path direction, and flow path lengths in volcanic tuffs and alluvium were within the uncertainty ranges used in the TSPA (BSC 2004 [DIRS 170042]). More detailed analyses (including pathline analyses) were conducted to study the impact of horizontal anisotropy on specific discharge and flow path direction and length, (BSC 2004 [DIRS 170042], Section 6.5.1.2). These analyses use the anisotropy distribution specified in Saturated Zone In-Situ Testing (BSC 2004 [DIRS 170010], Section 6.2.6).

\subsubsection{Representing Faults with Enhanced Permeability Grid Blocks}

Computational limitations (i.e., insufficient memory and/or processor speed) preclude the implementation of a finite-element model of the SZ model domain that explicitly models individual fractures and faults on a one-to-one scale. For example, if the exact location, orientation, and dimensions were known for each fracture/fault in the system, the number of elements (and computation time) required to model the system would increase by several orders of magnitude. Therefore, major faults are conceptualized in the SZ site-scale flow model as zones of enhanced permeability that simulate preferential flow in faults with grid blocks that are nominally $500 \times 500 \mathrm{~m}$ in the horizontal directions. The situation is somewhat different in the vertical direction. Here, element depth is typically on the order of tens of meters at the fault termination depth (often the top of the regional carbonate aquifer). Thus, the depth of a fault zone is as accurate as the available geologic information. Nevertheless, fault properties are necessarily volume-averaged throughout an element. On the one hand, representing faults with $500 \times 500 \mathrm{~m}$ elements certainly accounts for the uncertainties in their geographic location. The discussion of the observed relationship between the pumping test and faults is provided in BSC (2004 [DIRS 170010]). On the other hand, the hydrogeologic properties are "smeared" across a relatively large area, precluding the use of some fault-specific site data in the calibration targets. Finally, it should be noted that Bower et al. (2000 [DIRS 149161]) studied 10 different grids generated from the same HFM (similar to that used in the SZ site-scale flow model) and found that model calibrations were sufficient with 500-m horizontal elements, and that further refinement produced little change in fluxes.

Volume-averaged representations of faults are commonly used in numerical modeling. For example, studies of different conceptual models of the LHG have shown that its (modeled) representation had little impact on resulting flow paths as long as the system potentiometric surface was matched. Furthermore, because element permeability values are calibrated to field observations that are several grid blocks away from faults, it is believed that the large grid block representation is adequate for the purpose of flow modeling "away" from the fault. While the precise flow regime within the fault may not be representative, overall flow through the system, particularly at the model boundaries, is not significantly affected by the volume-averaged 
approach. These studies give confidence that the representation of faults is adequate in the SZ site-scale flow model.

\subsubsection{Quantification of Groundwater Specific Discharge}

The specific discharge downgradient from the repository at Yucca Mountain, along with effective transport porosity, determines the rate at which groundwater and radionuclides move away from Yucca Mountain. The specific discharge, in turn, is a function of both the permeability of the rocks and alluvium and of the hydraulic gradient in this area. The hydraulic gradient, as discussed above, is sufficiently characterized to provide well-constrained input to the transport calculations. The purpose of this section is to discuss the permeability data for the volcanic rocks at Yucca Mountain and elsewhere at the NTS and the application of these data to calculations of specific discharge.

As discussed in Section 6.4, several conceptual models have been evaluated with the common goal of reducing the uncertainty in specific discharge near the repository and downgradient in the alluvial aquifer. These efforts include:

- Studying different conceptualizations of the Solitario Canyon fault

- Studying different conceptualizations of the LHG

- Mapping the vertical gradient

- Investigating anisotropy effects

- Investigating repository temperature effects.

Investigating different conceptualizations of the Solitario Canyon fault is important because this fault regulates flow from Crater Flat (west of the fault) to Fortymile Wash (east of the fault). Conceptualizations include a shallower representation of the fault that terminates at the top of the carbonate aquifer (it originally went to the bottom of the SZ site-scale flow model, well into the carbonate aquifer). In the shallow fault model, neither the calibrated permeability of the fault nor the resulting path lines for fluid leaving the repository area change significantly. In both models, the flow remains primarily in the volcanic units due to an upward gradient in the carbonate aquifer. Furthermore, varying the ratio of vertical to horizontal permeabilities also has little effect. The important fault property is the east-west (across the fault) permeability.

Different conceptualizations of the LHG are important because all previous models of the SZ near Yucca Mountain required a low permeability feature north of Yucca Mountain to explain the abrupt drop in heads in this area (from 1,200 m to $730 \mathrm{~m}$ ). As discussed in Section 6.4.1, an excellent potentiometric surface calibration was obtained by modeling the large head change with geochemical alteration and ring faulting as a consequence of the formation on the Claim Canyon caldera north of Yucca Mountain. In all models of the LHG, fluid path lines and specific discharge are similar, primarily because this feature is upgradient of any flow that might originate from the repository at Yucca Mountain. The important conclusion to draw is that if the water-level calibration is accurate, the conceptualization of the LHG has little effect on specific discharge or flow path.

The mapping of the vertical gradient at the contact between the volcanic and/or alluvial aquifer and the Carbonate Aquifer shows that the vertical gradient is upward along the fluid path lines 
originating from the repository area. It can be inferred that for all reasonable climate scenarios, the flow paths will lie in the most permeable volcanic unit (likely the Bullfrog tuff), until they reach (and remain in) the alluvial aquifer. Therefore, it is important to carry forward a conceptualization of the vertical gradient in the SZ site-scale flow model.

The SZ site-scale flow model included a vertical anisotropy ratio of 10:1 in many of the units as described in Section 6.4.3. Included faults were generally modeled as anisotropic features highly conductive along the fault (strike), and vertically of low conductivity in the direction across the fault (Figure 6-1). Results indicated that the effect of individual fault anisotropy is relatively unimportant. When a fault zone is calibrated to its minimum directional permeability (across the fault), even significant changes in the other directional permeabilities (vertical and strike) contribute little variation in the model results. For example, the Solitario Canyon fault zone is calibrated to its across-the-fault permeability. Increasing the vertical permeability by factors of 10 and 1,000 times the across-the-fault value has little effect on model calibrations.

There is an area of special concern in the SZ site-scale flow model with predominately north-south trending faults in the vicinity of Yucca Mountain. This zone is bounded by a quadrilateral with points $(548712,4065570)$, (554390, 4067050), (553647, 4080900), (547317, $4081090)$ in UTM coordinates $\left(\sim 88 \mathrm{~km}^{2}\right)$ and has a north-south to east-west anisotropy ratio in permeability. A detailed analysis of the anisotropy distribution applied to this zone can be found in Saturated Zone In-Situ Testing (BSC 2004 [DIRS 170010], Section 6.2.6). In the SZ site-scale flow model the effect of horizontal anisotropy in this area was incorporated with a 5:1 anisotropy ratio. Calibration results were slightly closer to targets with this implementation of anisotropy. Although particle tracking was not performed, it is likely that the fluid path lines leaving the repository will have a more north-south trajectory than the original isotropic model. Particle path-line changes subject to the latest distribution of horizontal anisotropy in this zone will be studied in more detail in this model report.

Incorporating increases in saturated-zone water temperature changes the specific discharge in a predictable manner. Creating a zone of elevated temperature near the repository simply decreases the transport time (and, thus, the specific discharge) in proportion to the decrease in the fluid viscosity due to temperature change. Increasing the average temperature from $30^{\circ} \mathrm{C}$ to $80^{\circ} \mathrm{C}$ along a 5-km path decreases both the viscosity and transport time by a factor of two. The temperature impacts on groundwater flow are within the range of uncertainty in specific discharge considered in the SZ flow and transport simulations for TSPA (Section 6.5)

\subsubsection{Discussion of the Effect of Hydrogeologic Contact Uncertainty on Specific Discharge}

The HFM conceptual model for the SZ site-scale flow model was created from a variety of field data and exists in electronic form as Stratamodel surfaces (BSC 2004 [DIRS 170008]). There is uncertainty in the spatial positions of these surfaces primarily due to lack of data. These surfaces were used to generate the finite-element mesh such that each element is assigned those hydrogeologic properties found at the center of the element. There is interest in how uncertainties in the representation of hydrogeologic-unit horizontal locations affect flux or specific discharge calculations. Due to the coarseness of the finite-element mesh, some horizontal uncertainty in the HFM can be entertained. As long as the horizontal spatial 
ambiguity in the location of hydrogeologic contacts is less than $250 \mathrm{~m}$ (one-half the grid block dimension), there is essentially no impact on model specific discharge or flux calculations.

Because flow leaving the repository area is confined to a few of the most permeable units, the vertical dimension deserves special consideration. From the SZ site-scale flow model, it is known that the fluid leaves the repository area through the Bullfrog tuff and migrates to alluvial units. The flow paths in areal and vertical views are reproduced in Figure 6- 43. Note that the vertical thickness of the flowing zone varies between 100 and $400 \mathrm{~m}$, and the elevation changes from 300 to $700 \mathrm{~m}$ above sea level. From Table 6-15, the spacing in this part of the finite element mesh varies from 10 to $50 \mathrm{~m}$. Consider, for example, that the uncertainty in the vertical contact location of the Bullfrog tuff is $50 \mathrm{~m}$ in the portion of the model where the flow path is 300 to $400 \mathrm{~m}$ thick. Changing a single element's hydrogeologic designation, either to or from Bullfrog tuff would result in a change to the local specific discharge by no more than a factor of $50 / 300$ (17 percent). This is well within the overall specific discharge uncertainty range. Unfortunately, the thin flow path between UTM Northing coordinates 4,070,000 and 4,060,000 $\mathrm{m}$ (Figure 6-43) can be problematic. Here the fluid flow is vertically constrained to $100 \mathrm{~m}$. If the bottom contact of the Bullfrog tuff were to change by $50 \mathrm{~m}$, this could result in a change to the specific discharge flux in that area of up to 50 percent. Fortunately, integrated specific discharge calculations will be affected to a lesser degree. The impacts of hydrogeologic contact location uncertainty are summarized below.

- Sensitivity to uncertainty in the hydrogeologic contact surfaces in the horizontal directions is much less than in the vertical direction due to the averaging effect of $500-\mathrm{m}$ grid block spacing.

- The change in specific discharge due to the 50-m uncertainty in the vertical hydrogeologic surface can produce up to a 17 percent change in the local specific discharge near the repository and in the alluvial flow regions.

- 50-m uncertainty in the vertical hydrogeologic surface can produce up to a 50 percent change in the local specific discharge in the transitional zone (UTM Northing coordinates 4,070,000 to 4,060,000 m).

Because of the averaging effect across elements in the integrated specific-discharge calculations ( 0 to $5 \mathrm{~km}, 0$ to $20 \mathrm{~km}$ ), a 50 percent regional change in a relatively small portion of the 0 - to $20-\mathrm{km}$ compliance boundary affects model results only moderately. The range of uncertainty considered for specific discharge in the SZ flow and transport abstractions model is significantly greater than the uncertainty in the HFM (BSC 2004 [DIRS 170042], Section 6.5.2.1).

\subsubsection{Specific Discharge Uncertainty Range}

In previous transport models of the SZ, the specific discharge has varied from one-tenth of its nominal value to ten times its nominal value in performance assessment calculations (BSC 2001 [DIRS 157132], Section 6.2.5). Based on recent calibration experience and the evaluation of permeability data from Yucca Mountain and other sites presented above, the range for the majority of the uncertainty in specified discharge may be limited to one-third of its nominal value to three times the nominal value. The nominal value was obtained from the calibration of 
the SZ site-scale flow model (Section 6.6). Because of the linearity of the numerical model, the calibration of the model can be preserved by scaling the fluxes, recharge, and permeabilities in exactly the same manner. In the discussion below, we focus on the Bullfrog tuff unit because calibration experience has shown that, for all reasonable scenarios, the fluid particles leaving the repository area travel predominantly in this unit until the transition to the alluvial aquifer.

From the reevaluation of the permeability data described above and the statistical summary of the permeability data given in Table 6-24, three important facts emerge. The first is that the upper 95 percent confidence interval for the mean permeability of the Bullfrog tuff from the cross-hole tests $\left(3.4 \times 10^{-11} \mathrm{~m}^{2}\right)$ is approximately three times the mean value $\left(1.4 \times 10^{-11} \mathrm{~m}^{2}\right)$. The mean value, in turn, is very close to the nominal calibration value of $1.5 \times 10^{-11} \mathrm{~m}^{2}$ obtained for the SZ site-scale flow model. Second, alternative conceptual models developed since the SZ site-scale flow model was calirated have resulted in a range of estimates for the permeability of the Bullfrog tuff that vary less than 100 percent from the nominal permeability value. Third, the permeability data from Yucca Mountain had a practical maximum of $8.0 \times 10^{-11} \mathrm{~m}^{2}$ for individual tests in highly fractured intervals in volcanic rock. Although this value exceeds the nominal value by a factor of five, uncertainty in the geometric-mean permeability is a more relevant measure of the uncertainty that should be considered in the numerical model because all units in that model are considered to be homogeneous and should have site-averaged rather than local permeabilities. Large values were measured in cross-hole tests in the C-wells complex near the Midway Valley fault, and, as discussed above, proximity to the fault was probably responsible for these permeability measurements. Based on this evidence, upper limits for permeabilities of the Bullfrog tuff (and, by inference, other units that are three times the nominal values) are realistic and appropriate. By similar reasoning, because the lower 95 percent confidence interval of the geometric-mean permeability of the Bullfrog tuff is approximately $\Sigma$ of the mean value, this ratio is recommended for the lower limit in performance assessment calculations.

In the 18-km compliance region (Figure 6-43), performance assessment calculations are also strongly influenced by travel of fluid in the alluvial aquifer. Recently, estimates of groundwater specific discharge in the SZ have been obtained from field-testing at the ATC (BSC 2004 [DIRS 170010], Section 6.5.5). The ATC is approximately located at the boundary of the accessible environment, as specified in regulations for the Yucca Mountain Project, 10 CFR 63.302 (10 CFR Part 63 [DIRS 156605]). The location of the ATC is approximately $18 \mathrm{~km}$ from Yucca Mountain, and testing was performed in the alluvium aquifer. Estimates of groundwater specific discharge at the ATC range from $1.2 \mathrm{~m} / \mathrm{yr}$ to $9.4 \mathrm{~m} / \mathrm{yr}$ (DTN: LA0303PR831231.002 [DIRS 163561]). The simulated average specific discharge in this region of the SZ system, using the SZ transport abstraction model, ranges from $1.9 \mathrm{~m} / \mathrm{yr}$ to $3.2 \mathrm{~m} / \mathrm{yr}$ for differing values of horizontal anisotropy in permeability. Correspondingly, the simulated average specific discharge in the volcanic aquifer near Yucca Mountain using the SZ transport abstraction model ranges from $0.31 \mathrm{~m} / \mathrm{yr}$ to $0.87 \mathrm{~m} / \mathrm{yr}$ for differing values of horizontal anisotropy in permeability. These results show that the average groundwater specific discharge tends to increase along the flow path from beneath Yucca Mountain to the south. This increase in the specific discharge is due to convergent groundwater flow in this region of the SZ system. These results also indicate that there is general consistency between the simulated specific discharge and the median values of uncertainty ranges estimated for the volcanic aquifer and the alluvial aquifer along the flow path. 
Table 6-36. Statistical Summary of Permeabilities Calculated from Single-Hole and Cross-Hole Tests at Yucca Mountain

Single-Hole Tests

\begin{tabular}{|c|c|c|c|c|c|c|c|c|c|c|c|}
\hline Unit & $\begin{array}{c}\text { Topopah } \\
\text { Spring Tuff }\end{array}$ & $\begin{array}{l}\text { Calico Hills } \\
\text { Formation }\end{array}$ & $\begin{array}{c}\text { Prow Pass } \\
\text { Tuff }\end{array}$ & $\begin{array}{c}\text { Bullfrog } \\
\text { Tuff }\end{array}$ & Tram Tuff & $\begin{array}{l}\text { Lava } \\
\text { Flows }\end{array}$ & $\begin{array}{c}\text { Lithic } \\
\text { Ridge Tuff }\end{array}$ & $\begin{array}{c}\text { Pre-Lithic } \\
\text { Ridge Tuff } \\
\text { (Older } \\
\text { Tuff) }\end{array}$ & $\begin{array}{l}\text { Middle } \\
\text { Volcanic } \\
\text { Aquifer }\end{array}$ & Mixed Tuffs & $\begin{array}{c}\text { Carbonate } \\
\text { Aquifer }\end{array}$ \\
\hline Number of Tests & 1 & 9 & 14 & 19 & 34 & 0 & 15 & 5 & 10 & 30 & 24 \\
\hline Mean & $7.84 \times 10^{-13}$ & $9.38 \times 10^{-14}$ & $2.85 \times 10^{-13}$ & $3.07 \times 10^{-14}$ & $1.00 \times 10^{-14}$ & - & $1.09 \times 10^{-14}$ & $4.52 \times 10^{-16}$ & $5.59 \times 10^{-14}$ & $1.34 \times 10^{-15}$ & $7.17 \times 10^{-14}$ \\
\hline $\begin{array}{l}\text { Lower } 95 \% \\
\text { Confidence Interval } \\
\text { for Mean }\end{array}$ & - & $4.45 \times 10^{-14}$ & $8.13 \times 10^{-14}$ & $9.98 \times 10^{-15}$ & $4.03 \times 10^{-15}$ & - & $2.57 \times 10^{-15}$ & $1.87 \times 10^{-18}$ & $6.19 \times 10^{-15}$ & $4.56 \times 10^{-16}$ & $4.69 \times 10^{-14}$ \\
\hline $\begin{array}{l}\text { Upper } 95 \% \\
\text { Confidence Interval } \\
\text { for Mean }\end{array}$ & - & $1.97 \times 10^{-13}$ & $9.95 \times 10^{-13}$ & $9.45 \times 10^{-14}$ & $2.49 \times 10^{-14}$ & - & $4.60 \times 10^{-14}$ & $1.09 \times 10^{-13}$ & $5.05 \times 10^{-13}$ & $3.95 \times 10^{-15}$ & $1.10 \times 10^{-13}$ \\
\hline Minimum & - & $2.72 \times 10^{-14}$ & $7.77 \times 10^{-15}$ & $2.28 \times 10^{-16}$ & $2.35 \times 10^{-16}$ & - & $8.35 \times 10^{-17}$ & $1.84 \times 10^{-18}$ & $1.85 \times 10^{-16}$ & $1.72 \times 10^{-18}$ & $1.69 \times 10^{-14}$ \\
\hline Maximum & - & $4.19 \times 10^{-13}$ & $1.40 \times 10^{-11}$ & $1.67 \times 10^{-12}$ & $1.18 \times 10^{-12}$ & - & $1.22 \times 10^{-12}$ & $4.49 \times 10^{-14}$ & $1.40 \times 10^{-12}$ & $3.53 \times 10^{-13}$ & $1.40 \times 10^{-12}$ \\
\hline
\end{tabular}

Cross-Hole Tests

\begin{tabular}{|l|l|l|l|l|l|}
\hline & $\begin{array}{c}\text { Calico } \\
\text { Hills } \\
\text { Formation }\end{array}$ & $\begin{array}{c}\text { Prow Pass } \\
\text { Tuff }\end{array}$ & $\begin{array}{c}\text { Mullfrog } \\
\text { Tuff }\end{array}$ & Tram Tuff & $\begin{array}{c}\text { Middle } \\
\text { Volcanic } \\
\text { Aquifer }\end{array}$ \\
\hline Number of Tests & 6 & 8 & 13 & 1 & 6 \\
\hline Mean & $1.68 \times 10^{-13}$ & $2.77 \times 10^{-12}$ & $1.37 \times 10^{-11}$ & $5.39 \times 10^{-11}$ & $1.78 \times 10^{-11}$ \\
\hline $\begin{array}{l}\text { Lower 95\% } \\
\text { Confidence Interval } \\
\text { for Mean }\end{array}$ & $1.25 \times 10^{-13}$ & $1.78 \times 10^{-12}$ & $5.61 \times 10^{-12}$ & - & $8.33 \times 10^{-12}$ \\
\hline $\begin{array}{l}\text { Upper 95\% } \\
\text { Confidence Interval } \\
\text { for Mean }\end{array}$ & $2.26 \times 10^{-13}$ & $4.31 \times 10^{-12}$ & $3.36 \times 10^{-11}$ & - & $3.81 \times 10^{-11}$ \\
\hline Minimum & $1.08 \times 10^{-13}$ & $1.44 \times 10^{-12}$ & $1.08 \times 10^{-12}$ & - & $7.19 \times 10^{-12}$ \\
\hline Maximum & $2.52 \times 10^{-13}$ & $7.19 \times 10^{-12}$ & $7.55 \times 10^{-11}$ & - & $5.75 \times 10^{-11}$ \\
\hline
\end{tabular}

Source: DTN: SNT05082597001.003 [DIRS 129714].

NOTE: Permeability values are given in units of meters-squared $\left(\mathrm{m}^{2}\right)$. The Topopah Spring tuff corresponds to the upper volcanic aquifer (unit 16); the Calico Hills Formation corresponds to the upper volcanic confining unit (unit 15); and portions of the lithic ridge and pre-lithic ridge tuffs correspond to the lower volcanic confining unit (unit 11), the older volcanic aquifer (unit 10), and the older volcanic confining unit (unit 9). The middle volcanic aquifer includes the Prow Pass, Bullfrog, and Tram tuffs and associated bedded units (Luckey et al. 1996 [DIRS 100465], Figure 7). Other units correspond to hydrogeologic units of the same name. 
The additional data from the ATC both constitute new information on the specific discharge in the SZ and significantly reduce uncertainty in the specific discharge relative to the assessment by the expert elicitation panel. The range of estimated specific discharge at the ATC spans about a factor of 7.8 (i.e., $1.2 \mathrm{~m} / \mathrm{yr}$ to $9.4 \mathrm{~m} / \mathrm{yr}$ ). This indicates a range of uncertainty in specific discharge that is somewhat less than one order of magnitude, which is considerably less than the degree of uncertainty of a factor 10 from the SZ Expert Elicitation Project (CRWMS M\&O 1998 [DIRS 100353], p. 3-43). Consequently, the uncertainty distribution for the groundwater specific discharge is reevaluated to reflect the reduced uncertainty. From this information, an uncertainty distribution in specific discharge is constructed, in which 80 percent of the probability is between one-third and three times the nominal value of specific discharge and the remaining 20 percent probability extending the range to $1 / 30$ and 10 times the best estimate of the specific discharge. Note that the details, including figures, of the specific discharge distribution and associated sampling techniques are contained in Saturated Zone Flow and Transport Model Abstraction (BSC 2004 [DIRS 170042], Section 6.5.2.1).

\subsubsection{Remaining Uncertainties in Specific Discharge Estimates}

The analyses and corresponding assignment of an uncertainty range for the groundwater specific discharge assumes that the porous continuum approach is appropriate for the fractured volcanic tuffs. A remaining uncertainty is whether or not the continuum approach can be employed at the scale of the model. An alternative conceptual model not yet explicitly examined is one in which most of the flow from Yucca Mountain moves through faults rather than through the unfaulted rock. To test this alternative model, the known faults need to be included explicitly in the numerical grid of the SZ site-scale flow and transport models. Although the grid-generation and flow-calculation capabilities exist to do this, the need to calibrate the model efficiently and perform particle-tracking transport simulations has taken priority and led to the adoption of structured grids that make explicit inclusion of faults difficult. Important faults are included in the model to capture their impact on flow and transport. Furthermore, the adoption of a range that includes larger specific discharge values and smaller effective porosities introduces realizations that replicate the behavior of a fault-dominated flow and transport system. Therefore, the suite of performance assessment transport simulations currently used likely encompasses the range of behavior that will be obtained with a fault-based flow and transport model.

\subsubsection{Scaling Issues}

Scaling issues are some of the most complex modeling problems to overcome, and it is an active field of contemporary research in geohydrology (Neuman 1990 [DIRS 101464]). Although there are many approaches that address the effects of scaling on model results, none has been widely accepted as the "best" method. Transport models are particularly sensitive to scaling issues in both space and time. For example, distribution coefficients measured on the order of hours to months in the laboratory for a performance assessment model are dubiously applied to transport of contaminants over millennia. However, flow modeling is much less sensitive to scaling issues in both space and time. First, time scales are relatively unimportant because hydrogeologic properties change little over the course of millennia. While water-level data and infiltration rates may change over such long time-periods, any flow model can easily account for these changes given appropriate boundary conditions. Second, while hydrogeologic properties 
measured through borehole pumping tests may not be appropriate to apply at distances far from the sample site (distance scaling), the SZ site-scale flow model described here does not use these measured properties directly. Instead, they are used as calibration targets and to describe parameter estimation limits. Therefore, although it may be inappropriate to assign geologic properties based on distant measurements, the calibration techniques used in this SZ site-scale flow model moderate the negative impact of such scaling issues.

\subsubsection{Description of Barrier Capability}

This model report is a compilation of information and processes affecting flow in the SZ around Yucca Mountain. As such, it provides a description of the SZ barrier flow component. The two main features of the barrier described here are: (1) the specific discharge, which affects the transport time of the radionuclides that may be released at the water table beneath the repository horizon and travel to the accessible environment; and (2) the flow paths that will affect the travel length and, therefore, transport times.

The base case result for specific discharge ranges from $0.5 \mathrm{~m} / \mathrm{yr}$ to $3 \mathrm{~m} / \mathrm{yr}$, depending on the part of the flow path. The average particle flow path itself is likely to travel southeast as it leaves the repository area and follow Fortymile Wash, where it encounters large amounts of alluvial material. Transport times are expected in the thousands of years (BSC 2004 [DIRS 170042], Sections 6.6 and 6.7).

Uncertainty affects the permeability range and the flow paths. These parameters, with the head gradient, comprise the components of the specific discharge calculations. The largest uncertainty range for permeability was that of the Bullfrog Tuff in which the mean value, $1.4 \times 10^{-11} \mathrm{~m}^{2}$, varied by a factor of 3 . The flow paths proved to be relatively independent of the ACM provided the moderate and low gradient observations were adequately represented in the calibrated numerical model.

Outputs from this model report are used in the SZ site-scale transport model report (BSC 2004 [DIRS 170036]) to generate both concentrations-versus-time and concentrations-versus-distance curves that are needed to demonstrate the capabilities of the SZ flow and the transport barrier. 


\section{INTENTIONALLY LEFT BLANK}




\section{VALIDATION}

Model validation is the process of testing the appropriateness of the conceptual, mathematical, and numeric representation of the system being modeled. The SZ site-scale flow model is designed to provide an analysis tool that facilitates understanding of flow in the aquifer beneath and downgradient from the repository. The flow model is also a computational tool to provide the flow fields for performing radionuclide migration predictions in the SZ. For these predictions to be credible, the SZ site-scale flow model has been validated for its intended use. This statement means that there is established "confidence that a mathematical model and its underlying conceptual model adequately represents with sufficient accuracy the phenomenon, process, or system in question." Based on the material presented in these sections, this requirement is considered satisfied.

The validation criteria are provided in Section 7.1; the validation results are discussed in Section 7.2; and the summary of the validation effort is presented in Section 7.3.

The data used in validation activities are discussed in the following sections and are summarized below.

- Observed hydraulic heads not used for model development and calibration. This includes the potentiometric data not available at the time when model calibration was conducted (DTN: GS010908312332.002 [DIRS 163555]).

- Hydraulic parameters derived from hydraulic testing at the C-wells, Alluvial Testing Complex, and single-well testing at other wells (BSC 2004 [DIRS 170010]).

- Temperature measured in the wells (DTN: MO0102DQRBTEMP.001 [DIRS 154733]).

- Flow paths derived from hydrochemistry and isotope analysis (Appendix A).

\subsection{VALIDATION CRITERIA}

The current Technical Work Plan For: Natural System - Saturated Zone Analysis and Model Report Integration (BSC 2004 [DIRS 171421], Section 2.2.1.1) states that model validation was completed following criteria in the previous version of the technical work plan. Model validation presented in Section 7 follows the Technical Work Plan for: Saturated Zone Flow and Transport Modeling and Testing (BSC 2003 [DIRS 166034], Section 2.5). Section 2.5 of the 2003 technical work plan states that Level II validation will be achieved through confidence building during model development and implementing one or more postdevelopment validation methods. In the case of the SZ site-scale flow model, the chosen postdevelopment method was the corroboration of the model results to observed data on water-level elevation, permeability and specific discharge data, temperature data, and flow paths interpreted from geochemistry and isotope data.

The acceptance criteria for validation of the SZ site-scale flow model are the following:

- A favorable qualitative comparison between the simulated SZ flow paths and those deduced from the hydrochemistry and isotope data. The flow paths simulated by the SZ 
site scale flow model are enveloped by those deducted from the hydrochemical and isotope data.

- A favorable quantitative comparison of:

- Model simulated water-level data with observed water-level data

- Model simulated temperature data and observed temperature data

- Calibrated permeability data and data obtained from field and laboratory testing

- Model simulated specific discharge and those derived from field-testing data.

These acceptance criteria reflect the essential functions of the SZ system with regard to the transport time and radionuclide mass delivery to the accessible environment.

\subsubsection{Confidence Building During Model Development to Establish Scientific Basis and Accuracy for Intended Use}

For Level II validation, the development of the model should be documented in accordance with the requirements of Section 5.3.2(b) of AP-SIII.10Q. The development of the SZ site-scale flow model was conducted according to the following criteria (italicized). The paragraphs following each criterion describe how it was satisfied.

1. Selection of input parameters and/or input data, and a discussion of how the selection process builds confidence in the model [AP-SIII.10Q, 5.3.2(b)(1) and AP-2.27Q Attachment 3, Level I (a)].

The inputs to the SZ site-scale flow model have all been obtained from controlled sources (see Table 4-1). Model assumptions have been described in Section 5. Detailed discussion about model concepts can be found in Section 6.3. Further studies of flow based on field observations are presented in Section 7, leading to increased confidence in the parameters that are used in the SZ site-scale flow model presented in this report. Two assumptions were made in Section 5: (1) concerning vertical to horizontal anisotropy and (2) concerning homogeneous representation of hydrogeologic properties for all units.

2. Description of calibration activities, and/or initial boundary condition runs, and/or run convergences, simulation conditions set up to span the range of intended use and avoid inconsistent outputs, and a discussion of how the activity or activities build confidence in the model. Inclusion of a discussion of impacts of any nonconvergence runs [(AP-SIII.10Q 5.3.2(b)(2) and AP-2.27Q Attachment 3 Level I (e)].

The SZ site-scale flow model uses the water-level potentiometric surface (BSC 2004 [DIRS 170009]) as a starting point. The model was calibrated to water-level elevations measured from 114 wells. Recharge and lateral boundary fluxes were developed from the DVRFS flow model and the UZ site-scale flow model (Section 6.3) Initial conditions were not required for the steady state model. Sections 6.6 and 6.7 provide detailed discussion of various model results (i.e., those of convergence runs). All runs discussed in this report have converged. 
3. Discussion of the impacts of uncertainties to the model results including how the model results represent the range of possible outcomes consistent with important uncertainties [(AP-SIII.10 Q 5.3.2(b)(3) and AP-2.27Q Attachment 3 Level 1 (d) and $(f)]$.

A discussion of model uncertainties is provided in Section 8.3. Sensitivity of the output (specific discharge and flow paths) to each of the uncertain input parameters is discussed in Sections 8.3.1 through 8.3.2.

4. Formulation of defensible assumptions and simplifications [AP-2.27Q Attachment 3 Level I (b)].

Discussion of assumptions and simplifications are provided in Sections 5 and 6.3. The conceptual model of flow in the SZ and the components of the model are discussed in Section 6.3. As discussed in detail in Section 7, further confidence building in submodel components of the SZ site-scale flow model was conducted through comparison of the conceptual model of SZ flow with the results of field tests conducted at the C-wells complex, the ATC. These following observations were made from testing at both the $\mathrm{C}$-wells and ATC regarding the two assumptions:

- Testing at the ATC indicated that hydrogeologic properties could be represented as homogeneous values.

- Testing at the $\mathrm{C}$-wells indicated that the volcanic tuffs are a fractured dominated system.

Long term testing resulted in responses that could be fitted with effective continuum physical equations and homogeneous hydrologic properties. Thus, this requirement is considered satisfied.

5. Consistency with physical principles, such as conservation of mass, energy, and momentum [AP-2.27Q Attachment 3 Level I (c)]

Consistency with physical principles is demonstrated by the conceptual and mathematical formulation in Sections 6.3 and 6.5, and the selection and use of the FEHM Code in Section 3. The governing equations for nonisothermal flow implemented in FEHM are based on conservation of mass and energy and Darcy's law. As discussed in detail in Section 7.2 further confidence building in the SZ site-scale flow model was conducted through comparison of the conceptual model of SZ flow and model results with the results of field tests conducted at the C-wells complex and the ATC. Testing at the C-wells indicated that:

- The volcanic tuffs are a fractured dominated system.

- Long term testing resulted in responses that could be fitted with effective continuum physical equations and homogeneous hydrologic properties. 
- The testing at the ATC confirmed that the flow system behaves as a porous media.

These tests therefore validated that the SZ can be modeled as an effective continuum with homogeneous properties. Thus, this requirement is considered satisfied.

\subsubsection{Confidence Building After Model Development to Support the Scientific Basis of the Model}

Model validation requires mathematical models be validated by one or more of several methods given in Section 5.3.2(c and d) of AP-SIII.10Q [DIRS 171760]. Validation of the SZ site-scale flow model is documented in Section 7 of this report and is related to the procedural requirements as follows.

1. AP-SIII.10Q 5.3.2(c), Method 1: Corroboration of model results with the laboratory, field experiments, analog studies, or other relevant observations, not previously used to develop or calibrate the model.

The SZ site-scale flow model was validated by comparing results from this model with the laboratory and field experiment and other observations. The validation criteria, testing, and results are described in detail in Section 7.2 of this report. Based on material presented in these sections this requirement is considered satisfied.

2. AP-SIII.10Q 5.3.2(d): Technical review through publication in a refereed professional journal. Although this is not required by the TWP, this post development validation activity adds to the confidence in the SZ site-scale flow model.

The SZ site-scale flow model and its results are described in the referenced professional publications of Eddebbarh et al. (2003 [DIRS 163577]) and Zyvoloski et al. [(2003 [DIRS 163341]). These publications demonstrate additional confidence in the model, when taken in conjunction with the model validation activity described in item 1 above.

\subsection{VALIDATION RESULTS}

The validation activities for the SZ site-scale flow model are carried out according to the Technical Work Plan for: Natural System - Saturated Zone Analysis and Model Report Integration (BSC 2004 [DIRS 170115]), Section 2.2), which requires Level II model validation of the SZ site-scale flow model based on its relative importance to the performance of the repository system. The technical work plan states that the validation activities will include confidence building activities implemented during model development. In addition, the technical work plan states that postmodel development validation will consist of a comparison of simulated flow paths with those derived from hydrochemistry and isotope analyses, plus one or more other comparisons as indicated in the technical work plan. 
The following comparisons were completed between:

- Predicted and observed hydraulic heads not used during model development and calibration, including recently available potentiometric data.

- Simulated and observed hydraulic properties. These include permeability and hydraulic gradient. At locations where sufficient new data are available, the validation has been extended to a comparison of the specific discharge calculated using predicted and observed values of both hydraulic gradient and permeability. Observed specific discharge is deduced (1) from permeability data derived from hydraulic testing at locations where the hydraulic data and resulting parameter values were not used during model development and calibration, and (2) ATC tracer test results. Simulated specific discharges are deducted from calibrated hydraulic conductivity and simulated hydraulic gradient.

- Flow path derived from hydrochemistry and isotope analysis and those predicted by the SZ site-scale flow model.

- Predicted and observed temperatures in SZ wells. A thermal model based on the SZ site-scale flow model is used to predict temperatures in the SZ wells.

For purposes of postmodel development validation, a comparison of predicted and observed water levels for all the new water level data is presented in Section 7.2.1. This comparison focuses on the Phase II water level data obtained as part of the Nye County Early Warning Drilling Program (NC-EWDP) (DTN: MO9909NYEEWDP0.000 [DIRS 119613. A comparison of predicted and observed gradients along the flow path from the repository is also presented to evaluate the impact of the difference between observed and predicted water levels on the computation of specific discharge. Specific discharge is directly proportional to the hydraulic gradient. As previously established in the SZ technical work plan (BSC 2004 [DIRS 170115], Section 2.2), validation is considered acceptable if the differences between simulated and observed hydraulic gradients are not greater than 50 percent of the observed hydraulic gradient along the flow path from the water table directly beneath the repository to the compliance boundary at the accessible environment (differences may be greater than 50 percent away from this flow path). The 50 percent criterion used here is within the range (a factor of 3 smaller or larger) used for representing uncertainty in the specific discharge for calculations used directly by TSPA.

The comparison of specific discharges based on calibrated hydraulic parameters (permeability values) and those derived from hydraulic testing is presented in Section 7.2.2. This section summarizes the data from Yucca Mountain and nearby areas available for determining the permeability of the hydrogeologic units represented in the SZ site-scale flow model. These data are compared to the permeability values established during the calibration of the SZ site-scale flow model. However, because the permeability data were used to constrain permeability parameters during model calibration, the comparisons are not suitable for formal, postmodel development validation. Rather, these comparisons are provided in support of model validation as a confidence-building activity. 
New permeability measurements are available from the Alluvial Testing Complex (BSC 2004 [DIRS 170010], Section 6). These permeability measurements were not used during model development and calibration and, as such, are suitable for postmodel development validation. The measurements were taken along the flow path from the repository. Section 7.2.2 compares these measurements with calibrated permeabilities. In addition, because new water-level data and permeability measurements are available at the ATC, predicted and observed values of hydraulic gradient and permeability at this location are used to calculate specific discharge. These calculated values are compared to the model-simulated specific discharge for the test location for purposes of postmodel development validation. Furthermore, the ATC tracer test also independently provides estimates of specific discharge from groundwater flow velocity for a range of flowing porosity (DTN: LA0303PR831231.002 [DIRS 163561]; BSC 2004 [DIRS 170010], Section 6.4); a comparison also was made between the calibrated and the testderived specific discharge values at the ATC. As previously established in the SZ technical work plan (BSC 2004 [DIRS 170115], Section 2.2), validation is considered acceptable if the differences between specific discharge values are within the factor of 3 used in TSPA simulations.

The comparison of the predicted flow pathways with those derived from the hydrochemistry and isotope analysis is presented in Section 7.2.3. The hydrochemistry and isotope analysis was not used during model development and calibration and, consequently, is suitable for post-model development validation. The flow-path comparison is considered acceptable if the flow paths predicted by the model are enveloped by those flow paths inferred from hydrochemical and isotope analyses (Appendix A).

The comparison of predicted and observed temperatures in SZ wells is presented in Section 7.2.4. A thermal model based on the SZ site-scale flow model is used to predict temperatures in the SZ wells. This validation method involves the evaluation of the model's ability to simulate the magnitudes and spatial distribution of temperature differences observed in wells in the SZ. This activity constitutes postmodel development validation of the SZ site-scale flow model because the temperature data represent an independent data set that was not used in construction or calibration of the model. The validation criteria consist of a quantitative comparison between the measured and simulated temperatures in wells and qualitative comparison of spatial patterns for observed wells (BSC 2004 [DIRS 171421], Section 2). The calibration target of $\pm 10^{\circ} \mathrm{C}$ was selected because of the wide range of temperature variations observed in the SZ near Yucca Mountain.

\subsubsection{Comparison of Observed and Predicted Nye County Water Levels}

Since the calibration of the SZ site-scale model, 15 additional wells have been installed as part of the Nye County EWDP. These additions include wells installed at new locations and wells completed at depths different from those previously available at existing locations. Comparison of the water levels observed in the new Nye County EWDP wells with water levels predicted by the SZ site-scale flow model at these new locations and depths offers an opportunity to validate the model. In addition, water-level measurements from the new Nye County EWDP wells provide additional data for use in comparing the measured and predicted hydraulic gradients along the flow path from the repository. This comparison can be used to validate the SZ site-scale model quantitatively. 
The SZ site-scale model was calibrated using 114 water level and head measurements from wells within the model domain, as described in Section 6.6.1.3. Eight of these measurements were from wells drilled and completed as part of the Nye County EWDP. Measured and predicted heads for these wells, along with their coordinates, are shown in Table 7-1. The locations of these wells are shown in Figure 7-1.

Table 7-1. Nye County EWDP Wells Used as Calibration Targets in the Saturated Zone Site-Scale Model Calibration with Observed and Predicted Water Levels

\begin{tabular}{|l|l|l|l|l|l|l|}
\hline \multicolumn{1}{|c|}{ Well ID } & \multicolumn{1}{|c|}{$\begin{array}{c}\text { Easting } \\
(\mathbf{U T M}) \\
(\mathbf{m})\end{array}$} & $\begin{array}{c}\text { Northing } \\
(\mathbf{U T M}) \\
(\mathbf{m})\end{array}$ & $\begin{array}{c}\mathbf{z}(\text { elevation) } \\
(\mathbf{m})\end{array}$ & $\begin{array}{c}\text { Observed } \\
\text { Head }(\mathbf{m})\end{array}$ & $\begin{array}{c}\text { Modeled } \\
\text { Head } \\
(\mathbf{m})\end{array}$ & \multicolumn{1}{|c|}{$\begin{array}{c}\text { Residual } \\
\text { Error }(\mathbf{m})\end{array}$} \\
\hline $\begin{array}{l}\text { NC-EWDP-1DX } \\
\text { shallow }\end{array}$ & 536768 & 4062502 & 413.5 & 786.8 & 763.9 & -22.9 \\
\hline $\begin{array}{l}\text { NC-EWDP-1S } \\
\text { probe 1 }\end{array}$ & 536771 & 4062498 & 747.8 & 787.1 & 773.3 & -13.8 \\
\hline NC-EWDP-2D & 547744 & 4057164 & 507.2 & 706.1 & 709.3 & -3.2 \\
\hline NC-EWDP-3D & 541273 & 4059444 & 376.7 & 718.3 & 703.9 & -14.4 \\
\hline $\begin{array}{l}\text { NC-EWDP-3S } \\
\text { probe 2 }\end{array}$ & 541269 & 4059445 & 719.1 & 719.8 & 702.5 & -17.3 \\
\hline NC-EWDP-5SB & 555676 & 4058229 & 603.9 & 723.6 & 718.0 & -5.6 \\
\hline $\begin{array}{l}\text { NC-EWDP-9SX } \\
\text { probe 2 }\end{array}$ & 539039 & 4061004 & 721.2 & 767.3 & 732.5 & -34.8 \\
\hline $\begin{array}{l}\text { NC-Washburn- } \\
1 X\end{array}$ & 551465 & 4057563 & 668.8 & 714.6 & 714.6 & 0.0 \\
\hline
\end{tabular}

Source DTN: GS010908312332.002. (DIRS 163555).

UTM = Universal Transverse Mercator

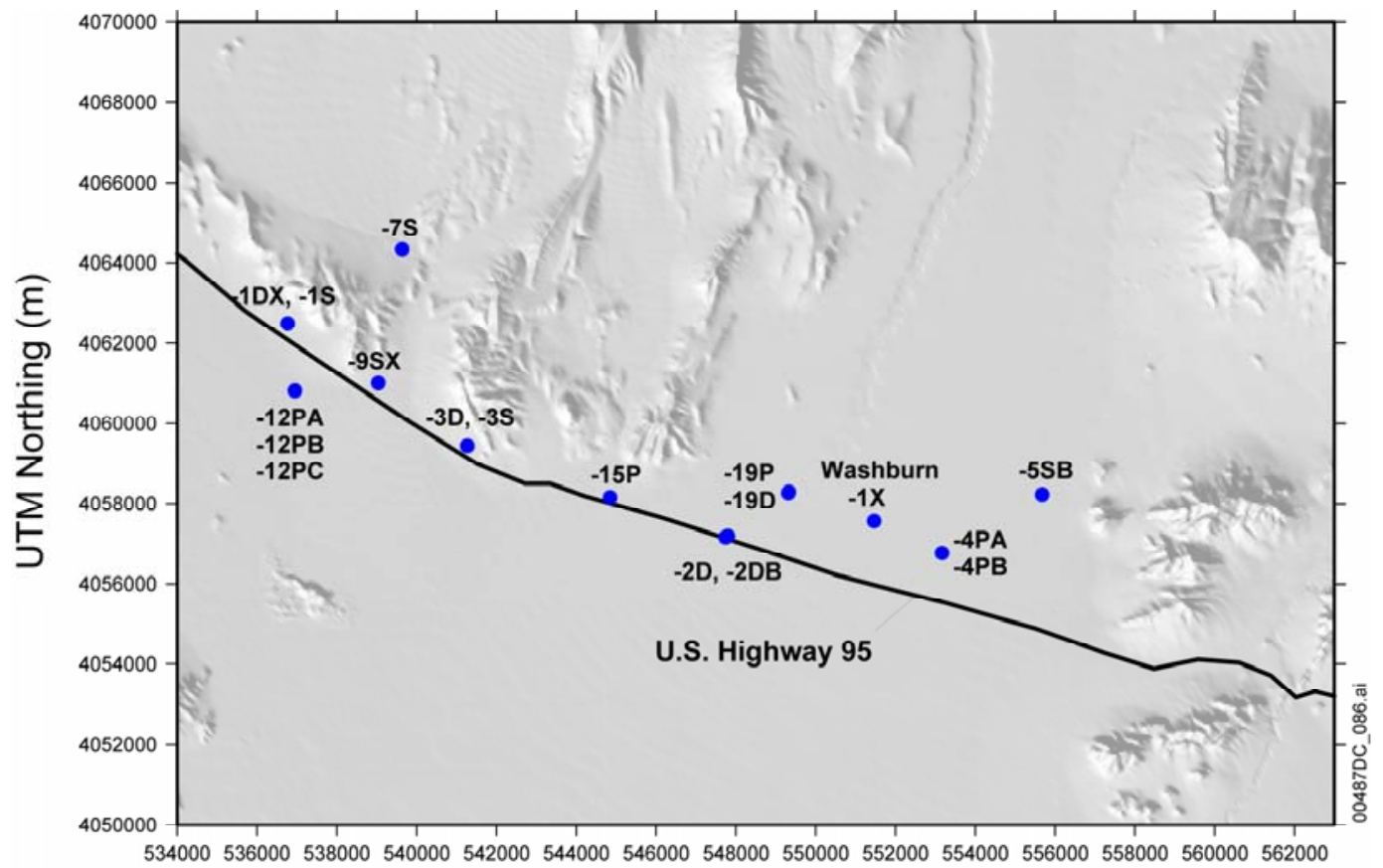

UTM Easting $(\mathrm{m})$

Source DTN: $\quad$ GS010908312332.002 [DIRS 163555] (coordinates for well locations).

NOTE: The coordinates for well locations can be found in Table 7-2. UTM = Universal Transverse Mercator

Figure 7-1. Locations of Nye County EWDP Wells 
With the addition of the new EWDP wells, the number of water-level observations available in the Nye County area has increased to 26. These wells are identified in Table 7-2, and the location of these wells is shown in Figure 7-1. As indicated in Table 7-2, water-level data from new completion intervals at previously existing well locations are now available and, for the purpose of this comparison, are replacing water levels previously available at this location. It should also be noted that although NC-EWDP-2D, NC-EWDP-3D, and NC-Washburn-1X were previously used as calibration targets for the SZ site-scale model, water levels from these wells are included in Table 7-2. All these wells were assigned the same weight equal to 1.

Examination of the residuals reported in Table 7-2 indicates that the errors in predicted water levels are highly dependent on their location within the site-scale model domain. Well clusters NC-EWDP-1, -9, and -12 are in the western portion of the Nye County study area, along U.S. Highway 95 and south of Crater Flat. The residuals observed in this cluster range from $+13.9 \mathrm{~m}$ to $-35.6 \mathrm{~m}$. Comparing Figure 6-3 and Figure 7-1 shows that these wells are located in an area of rapid water-level changes, along the U.S. Highway 95 fault, and the model is not able to replicate fully the steep head gradients observed in this area. Similar residual errors were observed using the water-level data available during model calibration. The new data indicate significant vertical gradients at the NC-EWDP-1 well cluster, which the calibrated model is not able to reproduce. NC-EWDP-7S is located north of these wells. The residual observed here was $-60.5 \mathrm{~m}$, but this well is located on a paleospring deposit at the southern end of Crater Flat. All of these wells are located in the southern portion of the Crater Flat flow system. Consequently, the errors observed in this area of the model domain are not likely to influence significantly the flow system from the repository. A residual of $-19.9 \mathrm{~m}$ was also observed for well NC-EWDP-1P, which is located northeast of well NC-EWDP-7S in the lower Solitario fault area. This area is also one of significant water level change.

Table 7-2. Comparison of Water Levels Observed and Predicted at Nye County EWDP Wells

\begin{tabular}{|l|c|c|c|c|c|c|}
\hline \multicolumn{1}{|c|}{ Site Name } & $\begin{array}{c}\text { Easting (UTM) } \\
(\mathbf{m})\end{array}$ & $\begin{array}{c}\text { Northing } \\
\mathbf{( U T M )} \\
(\mathbf{m})\end{array}$ & $\begin{array}{c}\mathbf{z} \text { (elevation) } \\
\mathbf{( m )}\end{array}$ & $\begin{array}{c}\text { Observed } \\
\text { Head }(\mathbf{m})\end{array}$ & $\begin{array}{c}\text { Modeled } \\
\text { Head (m) }\end{array}$ & $\begin{array}{c}\text { Residual } \\
\text { Error }(\mathbf{m})\end{array}$ \\
\hline NC-EWDP-1DX, shallow & 536768 & 4062502 & 585.7 & 786.8 & 756.7 & -30.1 \\
\hline NC-EWDP-1DX, deep & 536768 & 4062502 & 133.1 & 748.8 & 762.7 & 13.9 \\
\hline NC-EWDP-1S, P1 & 536771 & 4062498 & 751.8 & 787.1 & 767.3 & -19.8 \\
\hline NC-EWDP-1S, P2 & 536771 & 4062498 & 730.8 & 786.8 & 767.3 & -19.5 \\
\hline NC-EWDP-2DB & 547800 & 4057195 & -77.0 & 713.3 & 717.0 & 3.7 \\
\hline NC-EWDP-2D & 547744 & 4057164 & 507.1 & 706.1 & 709.2 & 3.1 \\
\hline NC-EWDP-3D & 541273 & 4059444 & 377.9 & 718.3 & 703.7 & -14.6 \\
\hline NC-EWDP-3S, P2 & 541269 & 4059445 & 682.8 & 719.8 & 702.5 & -17.3 \\
\hline NC-EWDP-3S, P3 & 541269 & 4059445 & 642.3 & 719.4 & 702.6 & -16.8 \\
\hline NC-EWDP-5SB & 555676 & 4058229 & 707.8 & 723.6 & 718.0 & -5.6 \\
\hline NC-EWDP-9SX, P1 & 539039 & 4061004 & 765.3 & 766.7 & 731.7 & -35.0 \\
\hline NC-EWDP-9SX, P2 & 539039 & 4061004 & 751.3 & 767.3 & 731.7 & -35.6 \\
\hline NC-EWDP-9SX, P4 & 539039 & 4061004 & 694.8 & 766.8 & 731.7 & -35.1 \\
\hline NC-Washburn-1X & 551465 & 4057563 & 687.0 & 714.6 & 714.5 & -0.1 \\
\hline NC-EWDP-4PA & 553167 & 4056766 & 687.0 & 717.9 & 715.5 & -2.4 \\
\hline NC-EWDP-4PB & 553167 & 4056766 & 582.5 & 723.6 & 715.5 & -8.1 \\
\hline
\end{tabular}


Table 7-2. Comparison of Water Levels Observed and Predicted at Nye County EWDP Wells (Continued)

\begin{tabular}{|l|c|c|c|c|c|c|}
\hline \multicolumn{1}{|c|}{ Site Name } & $\begin{array}{c}\boldsymbol{x}(\mathbf{U T M}) \\
(\mathbf{m})\end{array}$ & $\begin{array}{c}\boldsymbol{y}(\mathbf{U T M}) \\
(\mathbf{m})\end{array}$ & $\begin{array}{c}\boldsymbol{z}(\text { elevation) } \\
(\mathbf{m})\end{array}$ & $\begin{array}{c}\text { Observed } \\
\text { Head }(\mathbf{m})\end{array}$ & $\begin{array}{c}\text { Modeled } \\
\text { Head }(\mathbf{m})\end{array}$ & $\begin{array}{c}\text { Residual } \\
\text { Error }(\mathbf{m})\end{array}$ \\
\hline NC-EWDP-7S & 539638 & 4064323 & 826.6 & 830.1 & 769.6 & -60.5 \\
\hline NC-EWDP-12PA & 536951 & 4060814 & 666.7 & 722.9 & 705.3 & -17.6 \\
\hline NC-EWDP-12PB & 536951 & 4060814 & 666.7 & 723.0 & 705.3 & -17.7 \\
\hline NC-EWDP-12PC & 536951 & 4060814 & 713.7 & 720.7 & 704.3 & -16.4 \\
\hline NC-EWDP-15P & 544848 & 4058158 & 716.9 & 722.5 & 711.0 & -11.5 \\
\hline NC-EWDP-19P & 549329 & 4058292 & 694.7 & 707.5 & 713.2 & 5.7 \\
\hline NC-EWDP-19D & 549317 & 4058270 & 549.7 & 712.8 & 713.2 & 0.4 \\
\hline
\end{tabular}

DTN: GS010908312332.002 [DIRS 163555] (first five columns);

Output DTN: LA0304TM831231.002.

NOTE: z-elevation refers to the mid point of the monitored open interval of an uncased well. UTM $=$ Universal Transverse Mercator

The observed residuals tend to improve as the wells are located further to the east. The residual errors at the NC-EWDP-3 well cluster range from $-14.6 \mathrm{~m}$ to $-17.3 \mathrm{~m}$. With an observed residual of $-11.5 \mathrm{~m}$ at NC-EWDP-15P, the residuals decrease in well locations further east. At the NC-EWDP-19 cluster location (the ATC), the residuals improve further, with observed values of only $+0.4 \mathrm{~m}$ and $+5.7 \mathrm{~m}$. The residuals in this general area at NC-Washburn-1X, NE-EWDP-4, and NC-EWDP-5 are similarly low. These wells are in the predicted flow path from the repository. Thus, these additional water-level data confirm the SZ site-scale model's capability to predict water levels accurately in this portion of the flow path from the repository.

To further validate the SZ site-scale flow model, a comparison of the hydraulic gradients along the flow path from the repository observed through field data and predicted by the model has been performed. These gradients have a direct impact on the prediction of specific discharge along the flow path from the repository and can be used to determine whether the model meets the validation criterion of having an effect not greater than 50 percent on the specific discharge.

The water-level data from a series of six wells extending from the immediate area of the repository to the new Nye County EWDP well 19P is presented in Figure 7-2. The predicted and observed hydraulic gradient among the identified wells is presented in Table 7-3. The location of these wells is shown in Figures 6-40 and Figure 7-1. Only the hydraulic gradient calculated for the last segment actually involves new water-level data not previously used during the SZ site-scale flow model development and calibration. Consequently, only a comparison of predicted and observed hydraulic gradients from this segment meets the requirement of postmodel development validation. The comparison of predicted and observed hydraulic gradients along the remainder of the flow path from the repository is presented as a confidence-building activity.

As Figure 7-2 and Table 7-3 indicate, the observed and predicted gradients along the flow path are in good agreement, except in the northernmost part of the flow path. The wells were selected because they were on or close to the predicted flow path and included wells that were on the east and west of the Solitario Canyon fault. Another candidate well not selected, H-5, is discussed in 
Section 6.6.2.1. The discrepancies in water levels observed and predicted between wells H-6 and WT-2 are the result of the manner in which the model accounts for the effect of the splay of the Solitario Canyon fault, which lies in the general area of these wells. However, while the model does not accurately predict the precise location for the drop in head across the fault, largely because of the 500-m grid blocks, the overall hydraulic gradient predicted between H- 6 and WT-2 agrees reasonably well with the value (34 percent). Regarding the segment between WT-2 and WT-1, for which simulated hydraulic gradient differs from the observed by 60 percent, in absolute terms the difference between the observed and simulated hydraulic gradients is very close to zero. The water table is very flat in that area, and the accuracy of land surface altitude is $0.1 \mathrm{~m}$ BSC 2004 [DIRS 170009]). Overall, the comparisons between simulated and observed hydraulic gradients along the flow path are deemed acceptable and in compliance with the 50 percent validation criterion of the 2003 technical work plan (BSC 2004 [DIRS 171421], Section 2.2).

\subsubsection{Comparison of Specific Discharge Based On Permeability Data and Alluvial Testing Complex Tracer Test Results}

The numerical model was calibrated by adjusting permeability values for individual hydrogeologic units in the model until the sum of the weighted-residuals squared (the objective function) was minimized. The residuals include the differences between the measured and simulated hydraulic heads and the differences between the groundwater fluxes simulated with the regional- and the site-scale models. Permeabilities estimated from hydraulic tests were neither formally included in the calibration as prior information nor were considered in the calculation of the objective function. The field-derived permeabilities were instead used to guide the selection of bounds on the permissible range of permeabilities to be considered during the calibration and to check on the reasonableness of the final permeability estimates produced by the calibration. However, since these permeability data were used to constrain permeability parameters during model calibration, these measurements are not suitable for formal postmodel-development validation. Rather, they are presented and discussed below in support of model validation as a confidence-building activity. New permeability measurements are available from the ATC. These permeability measurements were not previously used during model development and calibration and, as such, are suitable for postmodel-development validation. A comparison of calibrated permeability values with those newly obtained values from the ATC is presented below. The impact of the differences between these values on the determination of specific discharge is also evaluated. In addition, an analysis of the combined impact of differences between predicted and observed hydraulic gradients and permeabilities at the ATC on specific discharge is presented below. 

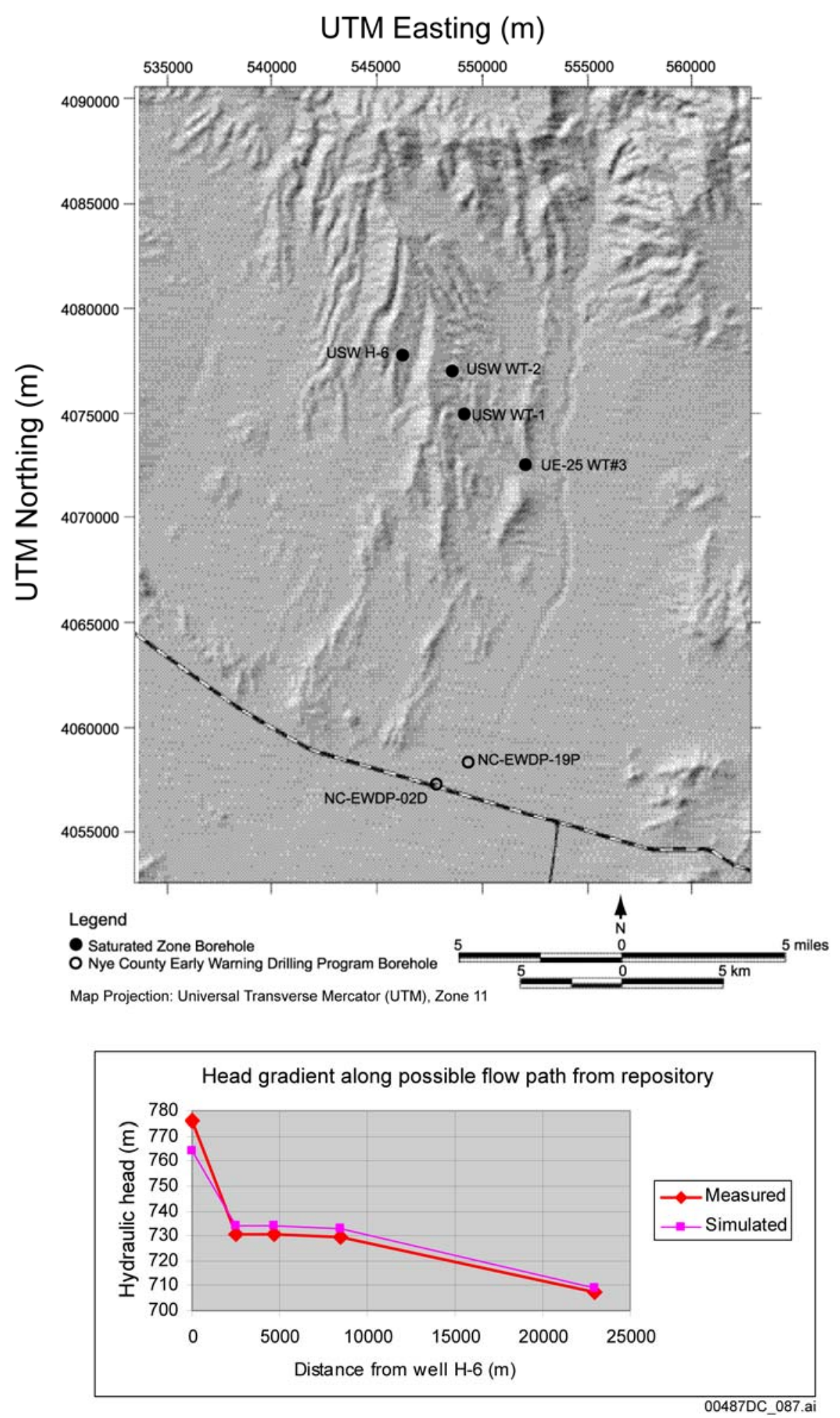

Source DTN: $\quad$ GS000508312332.001 [DIRS 149947]. Output DTN: LA0304TM831231.002. NOTE: Data results computed from Table 6-20.

UTM = Universal Transverse Mercator

Figure 7-2. Measured and Simulated Head Along Flow Path 
Table 7-3. Predicted and Observed Hydraulic Gradient for Identified Wells

\begin{tabular}{|l|l|l|}
\hline \multicolumn{1}{|c|}{ Flow Segment } & \multicolumn{1}{c|}{$\Delta \mathrm{H} / \Delta \mathrm{L}$ (Measured) } & \multicolumn{1}{c|}{$\Delta \mathrm{H} / \Delta \mathrm{L}$ (Simulated) } \\
\hline H-6 to WT-2 & 0.0118 & 0.0078 \\
\hline WT-2 to WT-1 & 0.000094 & 0.00015 \\
\hline WT-1 to WT-3 & 0.00021 & 0.00021 \\
\hline WT-3 to $19 P / 2 D$ & 0.0015 & 0.0016 \\
\hline
\end{tabular}

DTN: GS000508312332.001 [DIRS 149947].

Source Output DTN: LA0304TM831231.002.

NOTE: Data results computed from Table 6-20.

Discussions of the permeability data from the Yucca Mountain Area and nearby NTS as well as the Apache Leap site in Arizona are presented in the following subsections. A discussion of the general inferences about permeability that can be drawn from regional observations is also presented. Following these discussions, a comparison of calibrated with measured permeability values is presented, including the analysis of the potential impact of calibrated permeability values on groundwater specific discharge.

In the following discussion, the permeability values will be cited with $10^{-12} \mathrm{~m}^{2}$ as the base exponent for comparison purposes.

\subsubsection{Newer Permeability Data}

Information contained in Section 7.2.2.1 was acquired or accepted since the calibration of the SZ site-scale flow model.

Many factors can be expected to affect the permeability of the volcanic rocks at Yucca Mountain, including: (1) the tendency of the rock either to fracture or to deform plastically in response to stress; (2) the ability of the rock to maintain open fractures, which is a function of the strength of the rock and overburden stress; (3) proximity to major zones of deformation, such as fault zones; and, (4) the degree of mineralization or alteration that would tend to seal fractures and faults. Other factors being equal, rocks that tend to fracture are at shallow depth, have high compressive strength, are located in a fault zone, or are unmineralized and would be expected to have high permeabilities compared to rocks that do not possess these attributes. In addition to actual variations in permeability, the scale of measurement may also influence the permeability value determined by a test. This effect is most often observed when results of permeability tests conducted on cores that do not contain fractures are compared to the results of tests conducted in boreholes that contain fractured intervals. At Yucca Mountain, the relatively high permeabilities estimated from cross-hole tests compared to single-hole tests in the same rock unit have also been attributed to the effects of scale (Geldon et al. 1998 [DIRS 129721]). In this case, the cause of the permeability increase in the cross-hole tests is attributed to the greater likelihood of including relatively rare but highly transmissive and continuous features in the larger rock volume sampled by the cross-hole tests. This assumption is reevaluated below based on recent analyses of air-injection tests conducted at the Apache Leap test site near Globe, Arizona. Permeability data from single- and multiple-borehole hydraulic tests at Yucca Mountain and single-borehole tests elsewhere at the NTS have been compiled and compared to permeabilities estimated during calibration of the SZ site-scale flow model. Several aspects of the data merit further discussion. 


\subsection{Calico Hills}

First, the mean permeability estimated for the Calico Hills Formation from single-hole tests $\left(k=7.8 \times 10^{-14} \mathrm{~m}^{2}\right)$ is of the same order as that estimated from cross-hole tests $(k=1.7 \mathrm{x}$ $10^{-13} \mathrm{~m}^{2}$ ). This observation indicates that factors other than the test method and the scale of the test are influencing results. One such factor may be proximity to faults. Several of the single-hole tests conducted in the Calico Hills Formation were performed in the highly faulted area near borehole UE-25 b\#1, whereas faults were present only at deeper stratigraphic horizons at the C-wells where the cross-hole tests were done (Geldon et al. 1998 [DIRS 129721], Figure 3). Nonetheless, geologic contacts with open partings may also have enhanced permeability in the Calico Hills Formation at the C-wells (Geldon et al. 1998 [DIRS 129721], Figure 5). Second, both estimates of the mean Calico Hills Formation permeability are either larger than the mean permeability estimated for the carbonate aquifer from Yucca Mountain data $\left(k=0.072 \times 10^{-12} \mathrm{~m}^{2}\right)$ or comparable to mean permeabilities estimated for the carbonate aquifer from data elsewhere at the NTS $\left(k=0.6 \times 10^{-12} \mathrm{~m}^{2}\right)$. Although the permeability of the Calico Hills Formation may be locally higher than the mean permeability of the carbonate aquifer, it is unlikely that this relation between the two formation permeabilities can exist in general. The carbonate aquifer, along with the alluvial aquifers, is widely viewed as a major water-supply source in Southern Nevada (Dettinger 1989 [DIRS 154690]). In contrast, the Calico Hills Formation has properties similar to those of rocks deemed suitable for nuclear weapons tests below the water table at Pahute Mesa. The rocks at Pahute Mesa had properties (low intrinsic permeability due to zeolitization and sparse, poorly connected fractures) that were predicted, and later observed, to result in only small amounts of seepage into open test chambers during their construction (Blankennagel and Weir 1973 [DIRS 101233], pp. B30 to B31). Similar rocks in the unsaturated zone at Rainier Mesa produced perched water from isolated fault zones during construction of tunnels into the mesa; however, because the fault zones drained quickly and fault zones intersected later during tunneling also initially produced water, the fault zones were inferred to be relatively isolated both horizontally and vertically (Thordarson 1965 [DIRS 106585], pp. 42 to 43). At Yucca Mountain, the apparently widespread presence of perched water on top of the zeolitic Calico Hills Formation in northern Yucca Mountain (Patterson 1999 [DIRS 158824]) indicates that the formation generally has low permeability compared to the rate of water percolation through the unsaturated zone, which has been estimated to average $1 \mathrm{~mm} / \mathrm{yr}$ to $10 \mathrm{~mm} / \mathrm{yr}$ in the vicinity of the repository under the present climate (Flint 1998 [DIRS 100033]). Water flowing under a unit gradient at a rate of $10 \mathrm{~mm} / \mathrm{yr}$ $\left(3.17 \times 10^{-10} \mathrm{~m} / \mathrm{s}\right)$ would pass through a rock having a permeability of $3.23 \times 10^{-17} \mathrm{~m}^{2}$ (assuming a viscosity of $0.001 \mathrm{~N}-\mathrm{s} / \mathrm{m}^{2}$ and a water density of $1000 \mathrm{~kg} / \mathrm{m}^{3}$ ); so the field-scale vertical permeability of the Calico Hills Formation, which includes the effects of fracturing, presumably has permeabilities less than this value. The geometric-mean hydraulic conductivity for the zeolitic Calico Hills Formation, based on core measurements, is $4.5 \times 10^{-11} \mathrm{~m} / \mathrm{s}$ (Flint 1998 [DIRS 100033], Table 7), comparable to the low hydraulic conductivity value $\left(3.23 \cdot 10^{-17} \mathrm{~m}^{2}\right)$ previously thought as necessary for perched water.

\subsection{Alluvial Testing Complex}

From July through November 2000, pumping tests were conducted in well NC-EWDP-19D1. The first test involved production from the entire saturated thickness of $136 \mathrm{~m}$ (446 feet). The results indicated a transmissivity of about $21 \mathrm{~m}^{2} /$ day $\left(223 \mathrm{ft}^{2} /\right.$ day $)$ and an average hydraulic 
conductivity of $0.5 \mathrm{ft} /$ day, approximately equivalent to a permeability of $0.2 \times 10^{-12} \mathrm{~m}^{2}$. Subsequently, four screened intervals having a combined thickness of $84 \mathrm{~m}(276 \mathrm{ft})$ were tested individually. The combined transmissivities of these intervals totaled about $145 \mathrm{~m}^{2} /$ day $\left(1,600 \mathrm{ft}^{2} /\right.$ day $)$, far exceeding the transmissivity determined for the initial open-hole test. There are at least two likely causes for the discrepancy. First, pumping apparently resulted in further well development, as fine materials were drawn into the well and discharged with the water. Second, the screened intervals are probably interconnected hydraulically, consistent with the complexity of fluvial-alluvial depositional environments, so that actual thicknesses of the producing zones were significantly greater than the screened intervals. The average permeability of the section is probably greater than the initial permeability determined from the open-hole test $\left(0.2 \times 10^{-12} \mathrm{~m}^{2}\right)$ but less than those calculated for the two deeper screened intervals, $1.5 \times 10^{-12} \mathrm{~m}^{2}$ and $3.3 \times 10^{-12} \mathrm{~m}^{2}$. Although thin, discontinuous zones may locally have higher permeabilities, these results indicate that significantly thick (greater than $10 \mathrm{~m}$ ) and areally extensive zones at NC-EWDP-19D1 probably have average permeabilities between $0.1 \times 10^{-12}-1 \times 10^{-12} \mathrm{~m}^{2}$.

\subsection{Apache Leap}

Fractured welded tuffs and relatively unfractured nonwelded tuffs occur both above and below the water table. Permeabilities measured in the unsaturated zone at Yucca Mountain using air may, therefore, have some relevance to the permeability values of similar rocks located below the water table. In the unsaturated zone, air-injection tests have been conducted from surface-based boreholes in both welded and nonwelded tuffs (LeCain 1997 [DIRS 100153]) and from test alcoves in and adjacent to the Ghost Dance fault zone in the densely welded Topopah Spring tuff (LeCain et al. 2000 [DIRS 144612]). At Yucca Mountain, no water-injection tests were done in these same intervals to directly compare to the results of the air-injection tests. However, some understanding of the probable relation between permeabilities estimated from air- and water-injection tests at Yucca Mountain can be made on the basis of tests in nonwelded to partially welded tuff at the Apache Leap experimental site in Arizona, where borehole air- and water-injection tests were made at ambient moisture conditions in the same depth intervals (Rasmussen et al. 1993 [DIRS 154688]). The Apache Leap data (Rasmussen et al. 1993, Figure 5b [DIRS 154688]) showed a somewhat complex relation between permeabilities calculated from the two types of tests. Air-injection tests resulted in lower permeabilities than water-injection tests in borehole intervals for which permeabilities calculated using both fluids indicated that fractures were sparse or absent. In these intervals, matrix pore water probably obstructed air movement. However, in test intervals for which air and water permeabilities were both relatively high, the air-injection tests resulted in permeabilities comparable to or higher than permeabilities from the water-injection tests. In these intervals, both fluids probably moved into drained fractures. Additionally, because gravitational influences on air are not as pronounced as for water in the unsaturated zone, air had more possible pathways for movement than water, so air permeabilities were often higher than water permeabilities. Overall, the correlation between air and water permeabilities from the borehole injection tests at Apache Leap was $r=0.876$ (Rasmussen et al. 1993 [DIRS 154688], Figure 5b).

The test data from Apache Leap indicate that permeabilities calculated from air-injection test data in the unsaturated zone at Yucca Mountain probably provide good approximations to the water permeabilities, particularly in the densely welded intervals where drained fractures 
dominate the overall air permeability. The surface-based tests in four boreholes at Yucca Mountain showed that the highest air permeabilities (up to $54.0 \cdot 10^{-12} \mathrm{~m}^{2}$ ) were present at depths less than $50 \mathrm{~m}$ in the Tiva Canyon tuff, presumably because low lithostatic stresses at these depths allowed fractures to open (LeCain 1997 [DIRS 100153], Figures 7 to 10). However, permeabilities in the Tiva Canyon tuff typically decreased rapidly with depth, so that the permeabilities at depths greater than $50 \mathrm{~m}$ were less than $10^{-11} \mathrm{~m}^{2}$. The geometric-mean permeabilities of the Tiva Canyon tuff in the four boreholes varied between $3.4 \cdot 10^{-12} \mathrm{~m}^{2}$ and $8.4 \cdot 10^{-12} \mathrm{~m}^{2}$ (LeCain 1997 [DIRS 100153], Table 1), with an overall geometric-mean permeability of $4.7 \cdot 10^{-12} \mathrm{~m}^{2}$ based on a total of 23 tests. Geometric-mean permeabilities of the Topopah Spring tuff at the four boreholes varied between $0.3 \cdot 10^{-12} \mathrm{~m}^{2}$ and $1.7 \cdot 10^{-12} \mathrm{~m}^{2}$ (LeCain 1997 [DIRS 100153], Table 5) with an overall geometric-mean permeability of $0.75 \cdot 10^{-12} \mathrm{~m}^{2}$ based on the results of 153 tests.

Recent work by Vesselinov et al. (2001 [DIRS 154706]) at the Apache Leap site has demonstrated that permeabilities determined from multiple single-well air-injection tests and simultaneous numerical inversion of multiple cross-hole air-injection tests provided comparable estimates of the mean permeability of the test volume. However, when the cross-hole tests were analyzed individually with an approach equivalent to type-curve analyses, which requires the assumption of a uniform permeability field and a particular flow geometry (spherical), the resulting mean permeability estimated for the test volume was several orders of magnitude higher than the mean permeability estimated from the single-hole analyses or the more detailed simultaneous numerical inversion of the cross-hole tests. The simultaneous numerical inversion of the cross-hole tests did result in larger calculated variance in permeabilities than was estimated from the multiple single-hole tests, a result that may have been caused by round-off error associated with the numerical inversion. The conclusions of this work relevant to the present analysis are that the mean permeabilities would not be a function of test methodology (single-hole or cross-hole analyses) except for the inability of standard cross-hole type-curve methods to account for heterogeneity and departures of the actual flow field from the assumed flow geometry.

\subsection{Ghost Dance Fault}

Cross-hole air-injection tests conducted in and adjacent to the Ghost Dance fault resulted in geometric-mean permeability values of $4.1 \times 10^{-12} \mathrm{~m}^{2}$ for the hanging wall of the fault, $14.6 \times 10^{-12} \mathrm{~m}^{2}$ for the main fault zone (defined by a zone of significantly higher fracture density), and $7.8 \times 10^{-12} \mathrm{~m}^{2}$ for the footwall (LeCain et al. 2000 [DIRS 144612], Table 13). These permeabilities were higher than the permeabilities measured in the same units elsewhere from the surface-based boreholes and 2 to 10 times higher than the permeabilities estimated for the Ghost Dance fault and adjacent rock from single-hole tests conducted from an exploratory borehole drilled before alcove excavation (LeCain et al. 2000 [DIRS 144612], p. 26).

Air permeabilities have also been estimated at Yucca Mountain from measured subsurface pneumatic pressure changes that occur in response to barometric changes at land surface (Kwicklis 1999 [DIRS 157414]; Ahlers et al. 1999 [DIRS 109715]). Because subsurface pneumatic pressure changes are described by a diffusivity equation (Weeks 1978 [DIRS 108841]), assumptions need to be made about the effective air-filled porosity to estimate permeability to air. Ahlers et al. (1999 [DIRS 109715]) calculated only air diffusivity. 
Assuming the entire drained porosity of the matrix to be the effective air-filled porosity for airflow, Kwicklis (1999 [DIRS 157414]) estimated permeabilities for the Tiva Canyon tuff to be between $0.2 \times 10^{-12} \mathrm{~m}^{2}$ and $10.0 \times 10^{-12} \mathrm{~m}^{2}$ and for the Topopah Spring tuff to be between $1.0 \times 10^{-12} \mathrm{~m}^{2}$ and $50.0 \times 10^{-12} \mathrm{~m}^{2}$ (Kwicklis 1999 [DIRS 157414], Tables 9 to 12). The value of $50.0 \times 10^{-12} \mathrm{~m}^{2}$ was estimated for a thin $(22 \mathrm{~m})$ interval at borehole NRG-6 that fracture $\operatorname{logs}$ indicated were highly fractured. Generally, however, permeabilities of about $10.0 \times 10^{-12} \mathrm{~m}^{2}$ were adequate to match the subsurface pneumatic pressure response in the Topopah Spring tuff. The differences between the permeabilities obtained for the Tiva Canyon tuff and the Topopah Spring tuff by LeCain (1997 [DIRS 100153]) and by Kwicklis (1999 [DIRS 157414]) may be due to anisotropy, scale effects, or to assumptions made by Kwicklis (1999 [DIRS 157414]) about air-filled porosity.

\subsection{Tuffaceous Formations}

The Prow Pass tuff, Bullfrog tuff, and Tram tuff of the Crater Flat group contain both nonwelded to partially welded margins and partially to densely welded interiors (Bish and Chipera 1989 [DIRS 101195]; Loeven 1993 [DIRS 101258]). The initially vitric nonwelded to partially welded margins of these units have been largely altered to zeolites during hydrothermal events as a result of their thermodynamically unstable glass composition and their initially high permeabilities (Broxton et al. 1987 [DIRS 102004]). The partially to densely welded parts of these units have devitrified to mostly quartz and feldspar and have higher matrix permeabilities than the nonwelded to partially welded zeolitized margins (Loeven 1993 [DIRS 101258]; Flint 1998 [DIRS 100033]). Additionally, because the welded parts of the tuffs have a greater tendency to fracture, the densely welded parts of these units generally have higher secondary permeability. Thus, unless faults are locally present, the densely welded parts of the Prow Pass tuff, Bullfrog tuff, and Tram tuff are expected to have substantially higher permeability than the nonwelded margins.

The densely welded parts of the Prow Pass tuff, Bullfrog tuff, and Tram tuff are likely to have mean permeabilities that are less than the mean air permeabilities of the Tiva Canyon $\left(k=4.7 \times 10^{-12} \mathrm{~m}^{2}\right)$ or Topopah Spring $\left(k=0.75 \times 10^{-12} \mathrm{~m}^{2}\right)$ tuffs estimated from air-permeability tests. This likelihood is because greater lithostatic stresses at depth tend to close fractures and successive hydrothermal events have caused increasing degrees of alteration with depth (Broxton et al. 1987 [DIRS 102004]). Figure 7-3 shows the geometric-mean permeabilities from the single-hole air-permeability tests for the Tiva Canyon and Topopah Spring tuffs and the Geometric-mean single-hole water permeabilities calculated for the Calico Hills Formation and the Prow Pass, Bullfrog, Tram, and Lithic Ridge tuffs as a function of relative stratigraphic position. The single-hole permeabilities show the expected trends with depth. Conversely, the trends in the cross-hole permeability data from the C-wells (see Section 7.2.2.3.2 and Section 7.2.2.6, Figure 7-4) are exactly opposite the trends one would expect to see based on geologic reasoning; these trends do, however, reflect the proximity of each hydrogeologic unit to the Midway Valley fault, which intersects the C-wells in the upper part of the Tram tuff (Geldon et al. 1998 [DIRS 129721], Figure 3). Thus, it appears that permeability trends with depth at the C-wells are controlled by local conditions and do not reflect general trends in permeability established by the single-hole tests and expected from geologic reasoning. 


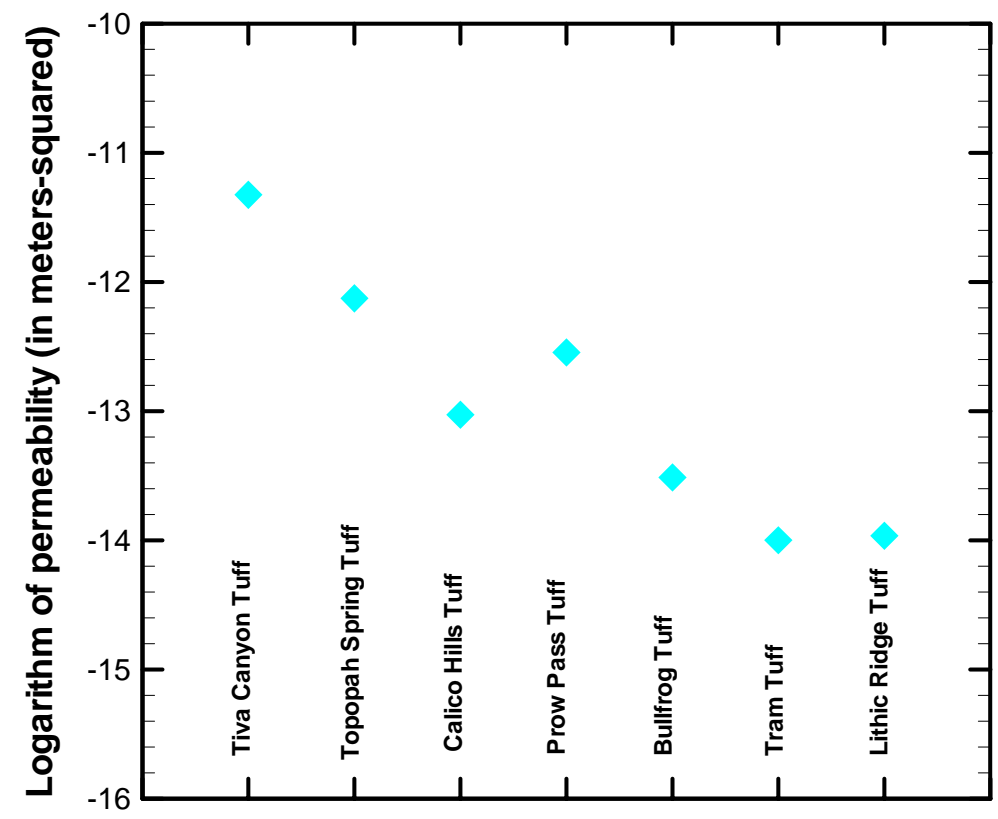

Increasing stratigraphic depth

Source DTNs:GS960908312232.012 [DIRS 114124] (Tiva and Topopah units); DTN: SNT05082597001.003 ([DIRS 129714]) (All other units). Used for corroboration only.

Figure 7-3. Comparison of UZ and SZ Permeabilities

Overall, an upper limit of $60 \times 10^{-12} \mathrm{~m}^{2}$ in the most critical alluvial formations is expected, and this value is used in the PEST model calibrations of the SZ SS flow model.

\subsubsection{Implications of Permeability Data on Specific Discharge Estimates}

The depth-dependent trends in mean hydrogeologic-unit permeabilities indicated by the combined air-permeability data from the unsaturated zone and the water-permeability data from the SZ (Section 7.2.2.3.2 and Section 7.2.2.6, Figure 7-4) are consistent with the trends expected as higher lithostatic stresses and more intense hydrothermal alterations close fractures at increasing depths. Conversely, permeabilities measured from cross-hole tests at the C-wells (Section 7.2.2.3.2 and Section 7.2.2.6, Figure 7-4) indicate trends that reflect proximity to the Midway Valley fault. Recent studies at the Apache Leap site in Arizona have indicated that single-hole and cross-hole tests should yield the same mean permeabilities once heterogeneity and departures from idealized flow geometries are properly taken into account. Therefore, except for the Calico Hills Formation, the single-hole permeabilities reflect the true permeabilities of the hydrogeologic units in unfaulted areas and can be used to represent the hydrogeologic-unit permeabilities in specific-discharge calculations or in numerical models, provided the effects of faults are also accounted for in some manner. The geometric-mean permeability estimated for the Calico Hills Formation was probably unduly biased toward that of faulted locations by data from boreholes UE-25 b\#1 and UE-25 J-13. In unfaulted areas, the Calico Hills Formation permeability is probably several orders of magnitude less than the geometric-mean permeability calculated from the single-hole tests. The similarity of 
geometric-mean permeability values from cross-hole air-permeability testing in the Ghost Dance fault $\left(k=14.6 \times 10^{-12} \mathrm{~m}^{2}\right)$ and the maximum permeabilities from cross-hole testing at the C-wells $\left(54.0 \times 10^{-12} \mathrm{~m}^{2}\right)$ indicate that values of $10.0 \times 10^{-12}$ to $50.0 \times 10^{-12} \mathrm{~m}^{2}$ may be appropriate as fault zone properties in numerical models so long as the modeled width reflects the true width of the fault; otherwise, the permeabilities in the model should be adjusted to preserve the overall transmissivity of the faults. The maximum permeability values that have been calculated for faulted locations at the $\mathrm{C}$-wells and alcoves in the Ghost Dance fault provide upper bounds on the permeability values that would be representative of the tuffs at unfaulted locations $\left(k=50.0 \times 10^{-12} \mathrm{~m}^{2}\right)$. The expected values of the tuffs are provided by the geometric means calculated from the single-hole tests and are one to several orders of magnitude less than this likely upper bound.

\subsubsection{Permeability Data from the Yucca Mountain Area}

Permeability data from single-hole and cross-hole tests were collected in the Yucca Mountain area from the early 1980s to the present day Nye County wells. The test results published up to 1997 were compiled in DTN: SNT05082597001.003 [DIRS 129714] (for reference only). A statistical analysis of this data set is presented in this section. In addition to permeability data previously available during the development of the SZ site-scale model, additional permeability measurements are now available from the ATC. These data are reported below as well.

\subsection{Single-Hole Tests}

The statistical analysis that follows required that the test results be grouped. This grouping was done by first compiling the permeability estimates for individual hydrogeologic units, where possible, and by considering progressively more general groupings for those cases in which the test interval spanned several hydrogeologic units. For instance, in cases in which the test interval was in the Prow Pass tuff, with or without some portion of the adjacent ash fall, the test results were grouped with other permeability estimates for the Prow Pass tuff. If other units within the middle volcanic aquifer (MVA), as defined by Luckey et al. (1996 [DIRS 100465], Figure 7), were also present in the test interval along with the Prow Pass tuff, the test results were considered to represent the MVA. If hydrogeologic units other than those in the MVA were present in the test interval along with the Prow Pass tuff, the permeability estimate for the test was grouped with the most general category, which is mixed tuffs. The mixed-tuff category includes data for all tests that would not fit into a more restrictive category. All tuffs older than the Lithic Ridge tuff are listed as Pre-Lithic Ridge tuffs ("older tuffs"). The other categories were named for the hydrogeologic unit to which they pertain and are believed to be self-explanatory.

There were several instances in which several kinds of hydraulic tests (injection, drawdown, or recovery) were conducted in the same depth interval in the same borehole. The results of these tests could have been treated in several different ways. For example, (1) the data for a particular depth interval could have been averaged and only the single average value considered in the statistical summary, in which case the statistical uncertainty could be interpreted as reflecting only the effects of spatial variability, or (2) all of the permeabilities that resulted from testing of the interval could have been used to calculate the summary statistics, which was done in this report. By considering multiple measurements from the same test interval, this statistical 
analysis attempts to reflect the effects of measurement uncertainty as well as the effects of spatial variability.

The base-10 logarithms of the permeabilities were calculated (Section 6-8) and a statistical analysis was performed on the log-transformed values for each category (CRWMS M\&O [DIRS 139582]). The antilogarithms of the statistical parameters for each category were calculated and are listed in Table 6-24. The analysis indicates that the deepest tuffs, which are the Pre-Lithic Ridge tuffs (Pre-Tlr), and the mixed tuff group has the lowest permeabilities, and the Topopah Spring tuff and Prow Pass tuff have the largest permeabilities. Where they could be calculated, the 95 percent confidence limits indicate that the mean permeability values are constrained within relatively narrow limits, except for the Pre-Lithic Ridge tuffs.

The results also indicate that the Calico Hills Formation, which is a zeolitized tuff that functions as the upper volcanic confining unit (Luckey et al. 1996 [DIRS 100465], Figure 7), has a higher permeability than the Bullfrog tuff and the carbonate aquifer. This paradoxical result may reflect the fact that, because it is unsaturated in the western half of Yucca Mountain, the Calico Hills Formation could be hydraulically tested only in the highly faulted eastern half of Yucca Mountain, whereas the other units were also tested in less intensely faulted areas to the west.

Single-well hydraulic testing of the saturated alluvium in well NC-EWDP-19D1 of the ATC was conducted between July 2000 and November 2000. During this testing, a single-well test of the alluvium aquifer to a depth of 812 feet $(247.5 \mathrm{~m})$ below land surface was initiated to determine the transmissivity and hydraulic conductivity of the entire alluvium system at the NC-EWDP19D1 location. In addition, each of the four intervals in the alluvium in NC-EWDP-19D1 were isolated and hydraulically tested to obtain transmissivity and associated hydraulic conductivity. This interval-testing program was initiated in an effort to evaluate heterogeneity in hydraulic properties over the thickness of the alluvium at the NC-EWDP-19D1 location to help determine the conceptual model of flow in the saturated alluvium south of Yucca Mountain. The results of this testing are presented in Table 7-4.

\subsection{Cross-Hole Tests}

Permeability data from cross-hole tests were compiled, grouped, and analyzed in a manner similar to the permeability data for the single-hole tests (see Table 6-24). The cross-hole data originate from tests conducted at the $\mathrm{C}$-wells complex. Whereas the permeabilities of the Calico Hills formation are similar for both the single- and cross-hole tests, the permeabilities of the Prow Pass tuff, Bullfrog tuff, Tram tuff of the Crater Flat group, and the MVA calculated from the cross-hole tests are one to several orders of magnitude greater than the mean permeabilities calculated from the single-hole tests. The differences in the mean permeability values between the single- and cross-hole tests generally have been attributed to the larger volume of rock affected by the cross-hole tests (Geldon et al. 1997 [DIRS 100397]), which allows a larger number of possible flow paths, including relatively rare, high-transmissivity flow paths, to be sampled during the test. However, some of the increase in permeability attributed to the effects of scale may also be due to the presence of a breccia zone associated with the Midway Valley fault in the Bullfrog tuff and Tram tuff at boreholes UE-25 c\#2 and UE-25 c\#3 (Geldon et al. 1997 [DIRS 100397], Figure 3). Thus, some of the difference in the mean permeabilities 
calculated for the single-hole and cross-hole tests may be due both to local conditions in the vicinity of the $\mathrm{C}$-wells and to scale.

Table 7-4. Transmissivities, Hydraulic Conductivities, and Permeabilities Determined in the Single-Well Hydraulic Tests Conducted in the Alluvium in NC-EWDP-19D1 Between July and November 2000

\begin{tabular}{|c|c|c|c|c|c|}
\hline $\begin{array}{l}\text { Test Interval } \\
\text { (ft below }^{\text {land }} \\
\text { surface) } \\
\text { surfa }^{\mathrm{a}}\end{array}$ & $\begin{array}{c}\text { Apparent } \\
\text { Transmissivity } \\
\text { of Interval }^{\mathrm{b}} \\
\text { (ft }^{2} \text { /day) }\end{array}$ & $\begin{array}{c}\text { Apparent } \\
\text { Transmissivity of } \\
\text { Total Saturated } \\
\text { Alluvium }^{c} \\
\text { (ft }{ }^{2} / \text { day) } \\
\end{array}$ & $\begin{array}{c}\text { Hydraulic } \\
\text { Conductivity } \\
\text { Based on Sand } \\
\text { Pack Thickness } \\
\text { (ft/day) } \\
\end{array}$ & $\begin{array}{c}\text { Hydraulic } \\
\text { Conductivity } \\
\text { Based on } \\
\text { Distance from } \\
\text { Water Table } \\
\text { (ft/day) } \\
\end{array}$ & $\begin{array}{c}\text { Permeability } \\
\left(\mathrm{m}^{2}\right)\end{array}$ \\
\hline \multicolumn{6}{|c|}{ Combined-Interval Test } \\
\hline $\begin{array}{l}\text { Four } \\
\text { combined } \\
\text { intervals }\end{array}$ & 223 & 223 & 0.5 & 0.5 & $2.7 \times 10^{-13}$ \\
\hline \multicolumn{6}{|c|}{ Isolated-Interval Tests } \\
\hline \#1: $412-437$ & 66 & 335 & 2.0 & 0.75 & $2.71 \times 10^{-13}$ \\
\hline \#2: $490-519$ & 7.5 & $\mathrm{~N} / \mathrm{A}$ & 0.23 & 0.04 & $1.44 \times 10^{-14}$ \\
\hline \#3: $568-691$ & 223 & 291 & 1.74 & 0.65 & $2.35 \times 10^{-13}$ \\
\hline \#4. $717-795$ & 300 & 300 & 3.57 & 0.67 & $2.42 \times 10^{-13}$ \\
\hline
\end{tabular}

Source: BSC 2004 [DIRS 170010], Appendix F.

${ }^{a}$ Depths correspond to upper and lower extent of sand packs.

b Transmissivity, as obtained directly from applying the Neuman (1975 [DIRS 150321]) solution to the drawdown in the interval tested, of the saturated alluvium from the water table to the bottom of the screen being tested. Ignoring screen \#2, which is affected by a local clay layer, these transmissivities increase monotonically as the depth of the screen being tested increases.

${ }^{c}$ Transmissivity calculated from the screens $\# 1, \# 3$, and \#4 interval tests for the entire saturated alluvium thickness tested by multiplying the transmissivity value in the second column, which is for the interval from the water table to the bottom of the screen being tested, by the ratio of 446 feet (the total saturated alluvium thickness tested) over the depth from the water table to the bottom of the screen being tested. Thus, for screen \#1, $66 \times(446 / 88)=334.5$ $\approx 335 \mathrm{ft}^{2} /$ day. For screen $\# 3,223 \times(446 / 342)=290.8 \approx 291 \mathrm{ft}^{2} /$ day. No corrections are needed for the combinedinterval test or for the screen $\# 4$ test.

${ }^{d}$ Assumes that interval thickness is the thickness of the interval sand pack.

${ }^{\mathrm{e}}$ Assumes that interval thickness is the distance from the water table to the bottom of the screened interval being pumped.

A cross-hole hydraulic test was also conducted at the ATC in January 2002. During this test, borehole NC-EWDP-19D1 was pumped in the open-alluvium section, while IM1 and IM2 were used as monitoring wells. IM1 was packed off, isolating each of four intervals in the alluvium section, while IM2 had only one packer inflated, isolating the alluvium section from the intervals below it. The analyses of the drawdown data from IM2 resulted in an estimated transmissivity value of $3,300 \mathrm{ft}^{2} /$ day $\left(0.00355 \mathrm{~m}^{2} / \mathrm{s}\right)$. The transmissivity estimate is approximately an order-of-magnitude higher than the $300-\mathrm{ft}^{2} /$ day $\left(0.000322-\mathrm{m}^{2} / \mathrm{s}\right)$ value obtained from single-hole testing in 19D1. The differences between cross-hole and single-well tests are likely the result of large head losses in the single-hole testing due to the well efficiency of 19D1. The tested interval in IM2, from the water table to the bottom of screen \#4, is 438 feet $(133.5 \mathrm{~m})$. Therefore, the intrinsic permeability measured in this test is $2.7 \times 10^{-12} \mathrm{~m}^{2}$. 


\subsubsection{Permeability Data from the Nevada Test Site}

Data from reports pertaining to the NTS were examined to help constrain permeability estimates for hydrogeologic units that were either not tested or that underwent minimal testing at Yucca Mountain. These permeability data, as well as more qualitative observations concerning the permeability of some of the hydrogeologic units in the site-scale model area, are summarized in the following sections. Additionally, these reports, including Blankennagel and Weir (1973 [DIRS 101233]), Winograd and Thordarson (1975 [DIRS 101167]), and Laczniak et al. (1996 [DIRS 103012]), describe the hydrogeologic controls on groundwater movement at the NTS, thereby providing a regional perspective for groundwater flow at Yucca Mountain. Assessments of permeability data from the NTS for the lower carbonate aquifer, the valley fill aquifer, the welded tuff aquifer, and the lava flow aquifer are presented below.

\subsection{Lower Carbonate Aquifer (Unit 4)}

The results of hydraulic tests in the lower carbonate aquifer were reported for eight boreholes by Winograd and Thordarson (1975 [DIRS 101167], Table 3). For two of the boreholes, only transmissivity estimates based on specific capacity were made. At boreholes for which permeability estimates based on drawdown curves were also available, the estimates based on specific capacity were much lower than the estimates based on the drawdown curves. At five boreholes where both drawdown and recovery tests were conducted, the permeabilities estimated from recovery tests were several times higher than those estimated from drawdown tests. Both the drawdown and recovery data exhibited complex responses to pumping that were attributed to test conditions as well as to aquifer properties. These responses were manifested on log-linear plots of time versus drawdown as straight-line segments with distinct breaks in slope. Because they were unable to explain the differences in the results from the drawdown and recovery tests, Winograd and Thordarson (1975 [DIRS 101167], p. C25) advised against the use of the transmissivities estimated from the recovery tests. The transmissivities estimated from drawdown tests in the lower carbonate aquifer are listed for six boreholes in Table 7-5 along with thicknesses of the test intervals and the calculated permeabilities. The permeabilities in $\mathrm{m}^{2}$ were calculated from the hydraulic conductivity values using a viscosity of 0.001 Pascal seconds, a density of $1,000 \mathrm{~kg} / \mathrm{m}^{3}$, and a gravitation acceleration of $9.81 \mathrm{~m} / \mathrm{s}^{2}$. These viscosity and density values are appropriate for test temperatures of about $25^{\circ} \mathrm{C}$. The actual test temperatures were not reported by Winograd and Thordarson (1975 [DIRS 101167]) but may have been substantially higher (greater than $50^{\circ} \mathrm{C}$ ) than the temperatures assumed in this calculation, in which case the calculated permeabilities may overestimate the true permeabilities measured by the tests by a factor of 2 to 3 . A statistical analysis of the base-10 logarithms of the permeabilities listed in Table 7-4 resulted in an estimated mean permeability for the carbonate aquifer of $6.0 \times 10^{-13} \mathrm{~m}^{2}$. The 95 percent lower and upper confidence limits for the mean permeability were $1.39 \times 10^{-13} \mathrm{~m}^{2}$ and $2.58 \times 10^{-12} \mathrm{~m}^{2}$, respectively. 
Table 7-5. Permeabilities Calculated for the Lower Carbonate Aquifer

\begin{tabular}{|c|c|c|c|c|}
\hline Well & $\begin{array}{c}\text { Thickness } \\
\text { (ft) }\end{array}$ & $\begin{array}{c}\text { Transmissivity }^{\mathbf{a}} \\
(\mathrm{gpd} / \mathrm{ft})^{\mathbf{b}}\end{array}$ & $\begin{array}{c}\text { Hydraulic } \\
\text { Conductivity } \\
\left(\text { gpd/ft } \mathrm{ft}^{2}\right)\end{array}$ & $\begin{array}{c}\text { Permeability } \\
\left(\mathrm{m}^{2}\right)\end{array}$ \\
\hline $67-73$ & 281 & 20,000 & 71.2 & $3.44 \times 10^{-12}$ \\
\hline $67-68$ & 996 & 39,000 & 39.2 & $1.89 \times 10^{-12}$ \\
\hline $66-75$ & 753 & 11,000 & 14.6 & $7.05 \times 10^{-13}$ \\
\hline $88-66$ & 872 & 1,300 & 1.49 & $7.19 \times 10^{-14}$ \\
\hline $75-73$ & 750 & 3,800 & 5.07 & $2.45 \times 10^{-13}$ \\
\hline $84-68$ & 205 & 2,400 & 11.7 & $5.65 \times 10^{-13}$ \\
\hline
\end{tabular}

Source: Winograd and Thordarson 1975 (DIRS 101167), Table 3.

NOTE: Statistics for the logarithm of permeability $(\log k)$ are

Mean $=-12.224$

Standard deviation $=0.605$

Median $=-12.999$

Lower 95 percent confidence level for mean $=-12.858$

Upper 95 percent confidence level for mean $=-11.5887$.

a These transmissivities were estimated by Winograd and Thordarson (1975 [DIRS 101167], Table 3) from drawdown curves.

${ }^{b}$ gpd is gallons per day.

In addition to providing quantitative estimates of the permeability, Winograd and Thordarson (1975 [DIRS 101167]) made several qualitative observations regarding the distribution of permeability within the carbonate aquifers.

The permeability data for the carbonate aquifer showed no systematic decrease either with depth beneath the top of the aquifer or beneath the land surface (Winograd and Thordarson (1975 [DIRS 101167], p. C20). The inference that groundwater may circulate freely within the entire thickness of the lower carbonate aquifer is not negated by chemical data, which indicate no significant increase in the dissolved-solids content to depths of several thousand feet (Winograd and Thordarson (1975 [DIRS 101167], p. C103).

No major caverns were detected during drilling in the lower carbonate aquifer, despite the fact that approximately 16,000 feet $(4877 \mathrm{~m})$ of the lower carbonate aquifer was penetrated in 26 holes drilled in 10 widely separated areas, including over 5,000 feet $(1524 \mathrm{~m})$ at 13 holes beneath the Tertiary/pre-Tertiary unconformity, where caverns might be expected to exist (Winograd and Thordarson (1975 [DIRS 101167], p. C19). Drill-stem tests in three holes in the Rock Valley and Yucca Flat indicated negligible to moderate permeability immediately below the unconformity (Winograd and Thordarson (1975 [DIRS 101167], p. C20). Outcrop evidence indicates that klippen, which are the upper plates of low-angle thrust faults and gravity slump faults, have a higher intensity of fracturing and brecciation than rock below the fault planes and may have above-average porosity and permeability (pp. C19 to C20). Specific capacity data for five wells penetrating the upper plates of low-angle faults in southern Yucca Flat and the northwestern Amargosa Desert indicated relatively high transmissibilities for these plates (Winograd and Thordarson (1975 [DIRS 101167] p. C28).

The presence of hydraulic barriers within the lower carbonate aquifer is indicated in the hydraulic response in two-thirds of the wells pumped, indicating that zones of above-average 
transmissivity may often not be connected to each other (Winograd and Thordarson (1975 [DIRS 101167], p. C116). However, this observation needs to be reconciled with hydraulic and chemical evidence supporting the existence of a "mega channel" extending over 40 miles $(64 \mathrm{~km})$ between southern Frenchman Flat and the discharge area at Ash Meadows (Winograd and Pearson 1976 [DIRS 108882]).

\subsection{Valley Fill Aquifer (Unit 20)}

The valley fill aquifer, as defined by Winograd and Thordarson (1975 [DIRS 101167], Table 1, p. C37) is composed of alluvial fan, fluvial, fanglomerate, lakebed, and mudflow deposits in depressions created by post-Pliocene block faulting. Thus defined, the valley fill aquifer of Winograd and Thordarson (1975 [DIRS 101167]) probably includes the valley fill aquifer (Unit 20), the valley-fill confining unit (Unit 19), and the undifferentiated valley fill (Unit 8) defined for the present study.

Transmissivity estimates for the valley-fill aquifer were made at six boreholes in Emigrant Valley, Yucca Flat, and Frenchmen Flat (Winograd and Thordarson 1975 [DIRS 101167], Table 3). For two of the boreholes, only transmissivity estimates based on specific capacity data were available. However, these estimates are considered unreliable because of the lack of agreement with transmissivity estimates based on drawdown or recovery curves at boreholes in which both types of estimates were made. The transmissivity estimates made from drawdown and recovery curves were consistent with each other at wells where both types of tests were conducted, in which case the transmissivity values from the drawdown and recovery curves were averaged to produce the transmissivity estimates listed in Table 7-6. Values used for the viscosity, density, and gravity terms in the expression for permeability are the same as those used for the lower carbonate aquifer. Based on a statistical analysis of the logarithm of the permeabilities listed in Table 7-5, the mean permeability of the valley fill is $1.57 \times 10^{-12} \mathrm{~m}^{2}$, and the 95 percent lower and upper confidence limits for the mean permeability are $1.61 \times 10^{-13}$ and $1.54 \times 10^{-11} \mathrm{~m}^{2}$, respectively. The relatively high mean permeability calculated for the valley fill is probably more reflective of the permeability of the valley-fill aquifer (Unit 20) and, possibly, the undifferentiated valley fill (Unit 8) of this study than of the valley-fill confining unit (Unit 19). 
Table 7-6. Permeability Estimates for the Valley Fill Aquifer

\begin{tabular}{|c|c|c|c|c|}
\hline Well & $\begin{array}{c}\text { Thickness } \\
(\mathbf{f t})\end{array}$ & $\begin{array}{c}\text { Transmissivity } \\
(\mathbf{g p d} / \mathbf{f t})\end{array}$ & $\begin{array}{c}\text { Hydraulic Conductivity } \\
\left(\mathbf{g} \mathbf{p d} / \mathbf{f t}^{\mathbf{2}}\right)\end{array}$ & $\begin{array}{c}\text { Permeability } \\
\left(\mathbf{m}^{\mathbf{2}}\right)\end{array}$ \\
\hline $74-70^{\mathrm{b}}$ & 511 & $2,200^{\mathrm{a}}$ & 4.31 & $2.08 \times 10^{-13}$ \\
\hline $74-70^{\mathrm{a}}$ & 217 & $9,350^{\mathrm{b}}$ & 43.1 & $2.08 \times 10^{-12}$ \\
\hline $83-68$ & 264 & $12,700^{\mathrm{b}}$ & 48.1 & $2.32 \times 10^{-12}$ \\
\hline $91-74$ & 264 & $33,500^{\mathrm{c}}$ & 126.9 & $6.12 \times 10^{-12}$ \\
\hline
\end{tabular}

Source: Winograd and Thordarson 1975 (DIRS 101167), Table 3.

NOTE: $\quad$ Permeability estimates based on transmissivity data from Winograd and Thordarson (1975 [DIRS 101167], Table 3).

Statistics for the logarithm of permeability $(\log k)$ are

Mean $=-11.803$

Standard deviation $=0.623$

Median $=-11.658$

Lower 95 percent confidence level for mean $=-12.794$

Upper 95 percent confidence level for mean $=-10.812$.

${ }^{a}$ Average is the arithmetic sum of the results of one drawdown and two recovery tests.

${ }^{b}$ Average is the arithmetic sum of the results of one drawdown and one recovery test.

${ }^{\mathrm{c}}$ Representative Value is the result of one recoverytest.

gpd=gallons per day

In addition to providing the quantitative estimates of the permeability of the valley fill summarized in this section, Winograd and Thordarson 1975 [DIRS 101167]) also made numerous observations regarding the permeability of the valley fill at particular locations in the area of the NTS. Of special interest to this report are those observations made for the valley fill in the Amargosa Desert. Winograd and Thordarson (1975 [DIRS 101167], pp. C84 to C85) noted that hydraulic head contours south of Amargosa Valley (formerly called Lathrop Wells) probably reflect the effects of upward leakage from the lower carbonate aquifer into poorly permeable valley fill along the Gravity fault and associated faults and of the drainage of this water to more permeable sediments farther west. Immediately west of the Gravity fault, gravity data indicate that downward displacement of the pre-Tertiary rocks west of the fault is 500 to $1,500 \mathrm{ft}$ (152.4 to $457.2 \mathrm{~m})$ at a location one mile east of Amargosa Valley and 1,200 to 2,200 ft (365.8 to $670.6 \mathrm{~m}$ ) at a point one mile southeast of the inferred intersection of the Specter Range Thrust fault and the Gravity fault. The low permeability of the valley fill immediately west of the Gravity fault was indicated by drillers' logs, which showed that the valley fill in this area was mainly clay, and also by analogy with the lakebed sediments southwest of the spring line at Ash Meadows, where groundwater discharging from the lower carbonate aquifer into the sediments across the Gravity fault is forced to the land surface by the low permeability of the sediments. Winograd and Thordarson (1975 [DIRS 101167], p. C85) argued that the discharge across the Gravity fault near Amargosa Valley was probably small because only the lower-most part of the lower carbonate aquifer is present in the area and the lower clastic aquitard, which underlies the carbonate aquifer at shallow depths, would probably not transmit much water.

\subsection{Welded Tuff Aquifer (Unit 16)}

The welded tuff aquifer corresponds to the upper volcanic aquifer (Unit 16) of Table 6-3. Results of hydraulic tests conducted in the welded tuff aquifer were reported by Winograd and Thordarson (1975 [DIRS 101167], Table 3) for four wells, but only two wells, both in Jackass 
Flats, had transmissivity estimates based on drawdown curves. Well 74-57 tested the Topopah Spring tuff and well 74-61 tested both the Topopah Spring tuff and the Basalt of Kiwi Mesa. Permeabilities calculated from the drawdown curves at these wells are listed in Table 7-7. The geometric mean permeability, based on the estimated permeabilities in Table 7-7, is $5.3 \times 10^{-12} \mathrm{~m}^{2}$.

Table 7-7. Permeability Estimates for the Welded Tuff Aquifer

\begin{tabular}{|c|c|c|c|c|}
\hline Well & $\begin{array}{c}\text { Thickness } \\
\text { (ft) }\end{array}$ & $\begin{array}{c}\text { Transmissivity } \\
\text { (gpd/ft) }\end{array}$ & $\begin{array}{l}\text { Hydraulic Conductivity } \\
\left(\mathrm{gpd} / \mathrm{ft}^{2}\right)\end{array}$ & $\begin{array}{c}\text { Permeability } \\
\left(\mathrm{m}^{2}\right)\end{array}$ \\
\hline $74-61$ & 290 & 28,000 & 96.6 & $4.7 \times 10^{-12}$ \\
\hline $74-57$ & 547 & 68,000 & 124.3 & $6.0 \times 10^{-12}$ \\
\hline
\end{tabular}

Source: Winograd and Thordarson 1975 (DIRS 101167), Table 3.

NOTE: Permeability estimates based on transmissivities determined from drawdown curves (Winograd and Thordarson 1975 [DIRS 101167], Table 3). Statistics: The geometric mean permeability is $5.3 \times 10^{-}$ $12 \mathrm{~m}^{2}$.

gpd = gallons per day .

\subsection{Lava Flow Aquifer (Unit 17)}

Rhyolitic lavas and welded and nonwelded tuffs fill the Silent Canyon caldera complex, which now lies buried beneath Pahute Mesa by younger tuffs, erupted from the Timber Mountain caldera complex to the south (Blankennagel and Weir 1973 [DIRS 101233], p. 6; Laczniak et al. 1996 [DIRS 103012], p. 36). The permeabilities of the lava flows beneath Pahute Mesa are assumed to be an appropriate analogue for the Lava Flows (Unit 17) near Yucca Mountain.

A qualitative comparison of the water-producing attributes of the lavas and tuffs based on the concept of specific capacity (in $\mathrm{gal} / \mathrm{min} / \mathrm{ft}$ of drawdown) indicated that despite considerable overlap in their water-yield potential, the lavas generally were the most transmissive rocks tested, followed by the welded tuffs and, finally, the zeolitized nonwelded tuffs (Blankennagel and Weir 1973 [DIRS 101233], Figure 4). Pumping tests were conducted in 16 boreholes at Pahute Mesa, including 14 in which the major water production came from the rhyolitic lava flows (Blankennagel and Weir 1973 [DIRS 101233], Table 3). The borehole names, uncased saturated thickness, measured transmissivities, and calculated hydraulic conductivities and permeabilities associated with these 14 tests are given in Table 7-8. The mean permeability of the rhyolitic lava is estimated to be $2.67 \times 10^{-13} \mathrm{~m}^{2}$, with 95 percent lower and upper confidence limits of $9.18 \times 10^{-14} \mathrm{~m}^{2}$ and $7.76 \times 10^{-13} \mathrm{~m}^{2}$, respectively. However, these estimates should be viewed as approximate lower bounds because other, less permeable rocks (welded and nonwelded tuffs) are present in the test interval, and these less permeable rocks would cause the transmissivity to be lower than the transmissivity that would be expected if only lava had been present. Resistivity logs indicated that nonwelded tuffs could constitute as much as 73 percent of the upper $2000 \mathrm{ft}$ of saturated rock at the boreholes listed in (Blankennagel and Weir 1973 [DIRS 101233], Table 2). Because most of the water pumped from the lava enters the wells from zones that constitute only 3 to 10 percent of the total saturated thickness (Blankennagel and Weir 1973 [DIRS 101233], p. 11), permeabilities in the lava may be locally much higher than the calculated mean value. 
Table 7-8. Permeabilities of the Lava Flow Aquifer

\begin{tabular}{|c|c|c|c|c|}
\hline Well & $\begin{array}{l}\text { Uncased, Saturated } \\
\text { Thickness (ft) }^{\mathrm{a}}\end{array}$ & $\begin{array}{c}\text { Transmissivity } \\
\text { (gpd/ft) }^{\mathbf{b}}\end{array}$ & $\begin{array}{c}\text { Hydraulic Conductivity } \\
\left(\mathrm{gpd} / \mathrm{ft}^{2}\right)\end{array}$ & $\begin{array}{c}\text { Permeability } \\
\left(\mathrm{m}^{2}\right)\end{array}$ \\
\hline UE-18r & 3,375 & 23,000 & 6.82 & $3.28 \times 10^{-13}$ \\
\hline TW-8 & 4,422 & 185,000 & 41.8 & $2.01 \times 10^{-12}$ \\
\hline UE19b-1 & 2,310 & 56,000 & 24.2 & $1.17 \times 10^{-12}$ \\
\hline UE19c & 2,099 & 12,000 & 5.72 & $2.75 \times 10^{-13}$ \\
\hline UE-19d & 5,129 & 20,000 & 3.90 & $1.88 \times 10^{-13}$ \\
\hline UE-19fs & 2,214 & 11,000 & 4.97 & $2.39 \times 10^{-13}$ \\
\hline UE-19gs & 1,858 & 30,000 & 16.1 & $7.77 \times 10^{-13}$ \\
\hline UE-19h & 1,383 & 140,000 & 101.0 & $4.87 \times 10^{-12}$ \\
\hline UE-19I & 5,104 & 1,400 & 0.274 & $1.32 \times 10^{-14}$ \\
\hline U-20a-2 & 2,434 & 18,000 & 7.40 & $3.56 \times 10^{-13}$ \\
\hline UE-20d & 2,047 & 44,000 & 21.5 & $1.03 \times 10^{-12}$ \\
\hline UE-20e-1 & 4,573 & 8,300 & 1.82 & $8.73 \times 10^{-14}$ \\
\hline UE-20f & 9,230 & 1,000 & 0.108 & $5.21 \times 10^{-15}$ \\
\hline UE-20h & 4,701 & 11,000 & 2.34 & $1.13 \times 10^{-13}$ \\
\hline
\end{tabular}

Source: Blankennagel and Weir 1973 [DIRS 101233], Table 3.

NOTE: Statistics for the logarithm of permeability $(\log k)$ are:

Mean $=-12.574$

Standard deviation $=0.803$

Median $=-12.521$

Lower 95 percent confidence level for mean $=-13.037$

Upper 95 percent confidence level for mean $=-12.110$

a Uncased, saturated thickness was calculated as the depth to water or depth of casing, whichever was greater, minus the depth of the well. The depth to water was used for TW-8, where the casing was perforated.

${ }^{\mathrm{b}} \mathrm{gpd}$ is gallons per day

\subsubsection{Inferences About Permeability from Regional Observations}

In addition to the permeability values from the NTS summarized in the previous section, Winograd and Thordarson (1975 [DIRS 101167]) made numerous qualitative evaluations of the relative magnitude of permeability for different hydrogeologic units. These evaluations were based on examination of core for fractures and mineral infilling, the geologic setting and the magnitude of discharge of springs in the region, and the correspondence between changes in hydraulic gradients and the underlying hydrogeologic unit. Sections 7.2.2.5.1 through 7.2.2.5.3 focus on qualitative assessments of hydrogeologic units that have little actual test data and for which the qualitative evaluations, thus, assume relatively more importance.

\subsection{Lower Clastic Aquitard (Unit 3)}

The Lower Clastic Aquitard of Winograd and Thordarson (1975 [DIRS 101167], Table 1) corresponds to the lower clastic confining unit (Unit) of Table 6-3. According to Winograd and Thordarson (1975 [DIRS 101167], p. C43), the large-scale transmissivity of the lower clastic aquitard is probably controlled by its interstitial permeability, which, based on the hydraulic conductivity of 18 cores (Winograd and Thordarson 1975 [DIRS 101167], Table 4), ranges from 
$3.4 \times 10^{-20} \mathrm{~m}^{2}$ to $4.8 \times 10^{-18} \mathrm{~m}^{2}$ and has a median value of $9.7 \times 10^{-20} \mathrm{~m}^{2}$. Although the lower clastic aquitard is highly fractured, Winograd and Thordarson (1975 [DIRS 101167], p. C43) argued that fractures probably do not augment the interstitial permeability of the unit on a regional scale to the same degree as in the lower carbonate aquifer for the following reasons:

- The argillaceous formations within the unit have a tendency to deform plastically, that is, by folding, rather than by fracturing. Thus, fracture continuity across the lower clastic aquitard is disrupted by the argillaceous layers.

- Micaceous partings and argillaceous laminae tend to seal the fractures in the brittle quartzite parts of the unit, reducing or eliminating the ability of the fractures to transmit water.

- The clastic rocks that constitute the unit have a low solubility; therefore, solution channels, which can further enhance permeability along fractures in carbonate rocks, are not likely to be present in this unit.

The low permeability of the lower clastic aquitard compared to the carbonate rocks also was indicated by the observation that, in the Spring Mountains, the total discharge issuing from the lower clastic aquitard is only a small fraction of the total discharge of the springs in the lower carbonate aquifer (Winograd and Thordarson 1975 [DIRS 101167], pp. C42 to C43, C53). The comparatively low permeability of the Clastic Aquitard also is indicated by a head drop across the lower clastic aquitard of $2000 \mathrm{ft}(609.6 \mathrm{~m})$ over a distance of less than 8 miles $(12.8 \mathrm{~km})(\mathrm{an}$ apparent hydraulic gradient of $250 \mathrm{ft} / \mathrm{mile}(47.6 \mathrm{~m} / \mathrm{km})$ ) in the hills northeast of Yucca Flat (Winograd and Thordarson 1975 [DIRS 101167], Plate 1). In contrast, the hydraulic gradient in the carbonate aquifer ranges from $5.9 \mathrm{ft} / \mathrm{mile}(1.12 \mathrm{~m} / \mathrm{km})$ or less along the axis of the potentiometric trough in Yucca Flat to $20 \mathrm{ft} / \mathrm{mile}(3.8 \mathrm{~m} / \mathrm{km})$ along the flanks of the trough (Winograd and Thordarson 1975 [DIRS 101167], p. C71).

\subsection{Upper Clastic Aquitard (Unit 5)}

The upper clastic aquitard is equivalent to the upper clastic confining unit (Unit 5) of Table 6-18. The upper clastic aquitard corresponds to the Eleana formation, which consists of argillite, quartzite, conglomerate, and limestone (Winograd and Thordarson 1975 [DIRS 101167], Table 1). The upper two-thirds of the unit consists mainly of argillite, whereas the lower one-third of the unit is principally quartzite (Winograd and Thordarson 1975 [DIRS 101167], p. C118). Winograd and Thordarson (1975 [DIRS 101167], p. C43) argued that fractures were unlikely to remain open in the rock at depth because of the plastic deformation behavior of the rock, which is evidenced by tight folds, and the fact that the formation serves as a glide plane for several thrust faults at the NTS. No core-scale permeability measurements exist, but based on analogy with the lower clastic aquitard, its interstitial permeability probably is less than $1 \times 10^{-4} \mathrm{gpd} / \mathrm{ft}^{2}\left(4.8 \times 10^{-18} \mathrm{~m}^{2}\right.$ ) (Winograd and Thordarson 1975 [DIRS 101167], p. C43). In the hills northwest of Yucca Flat, an approximately 2,000-ft (607.6-m) drop in hydraulic head in the pre-Tertiary rocks over a distance of less than 10 miles (an apparent hydraulic gradient of $200 \mathrm{ft} / \mathrm{mile}(38 \mathrm{~m} / \mathrm{km}))$ suggests a comparatively low regional permeability for the upper clastic aquitard. However, because land-surface elevation changes abruptly over this same distance and because water table elevations often mimic ground-surface elevations, it is not possible to isolate the effects of permeability from the effects of topography on the head gradient in this area. 


\subsection{Faults}

A summary of the possible effects of faults on groundwater movement in the Death Valley region is presented by Faunt (1997 [DIRS 100146]). The transmissivity of faults was described by Faunt (1997 [DIRS 100146], p. 30) to be a function of many factors:

- The orientation of the fault relative to the minimum horizontal stress in the region.

- The amount and type of fill material in the fault.

- The relative transmissivities of hydrogeologic units juxtaposed by offset across the fault.

- The solubility and deformation behavior of the rock adjacent to the fault.

- Recent seismic history.

\subsection{Orientation of Faults Relative to the Minimum Horizontal Stress in the Region}

In the vicinity of Yucca Mountain, the mean azimuth of the minimum horizontal stress is $306 \pm 11$ degrees (Faunt 1997 [DIRS 100146], Table 4-4), so that faults with traces oriented north-northeast are expected to be more open and permeable than faults with traces oriented in directions that place them in either a shear or a compressive state. Faults oriented northwest, or perpendicular to the maximum horizontal stress direction, would be expected to be least transmissive, all other factors being equal. One example cited by Faunt (1997 [DIRS 100146], pp. 34 to 35) to illustrate the northeast-southwest trending structures that may have relatively high transmissivity is the "megachannel" formed in the Spotted Range-Mine Mountain shear zone between Frenchman Flat and Ash Meadows. The presence of a highly transmissive zone in the carbonate aquifer was indicated by a potentiometric trough in this area and relatively young carbon-14 ages of groundwater discharging from springs at the distal end of the trough (Winograd and Pearson 1976 [DIRS 108882]).

\subsection{Amount and Type of Infilling Material in the Fault}

Fine-grained gouge or clayey infilling material can cause faults to become poorly transmissive, even if their orientation relative to the stress field indicates they have the potential to be highly transmissive. The effects of deformation behavior, solubility, and infilling material in the clastic aquitards and carbonate aquifer were discussed in Section 7.2.2.5.1 and Section 7.2.2.5.2. Solution channels along faults in the carbonate rock have the potential to further enhance the transmissivity of faults in this unit.

\subsection{Relative Transmissivities of Hydrogeologic Units Juxtaposed by Offset Across the Fault}

Where faults juxtapose hydrogeologic units with contrasting permeabilities, the hydrologic effects caused by juxtaposition may be difficult to isolate from the effects of the fault properties themselves. As indicated in Faunt (1997 [DIRS 100146], Figure 16), an increase in the local head gradient compared to the regional gradient can occur across a fault if:

- The fault is closed, thereby blocking flow.

- The fault is open, thereby redirecting flow. 
- The permeability of the material downgradient of the fault is low compared to the upgradient material, so that flow across the fault is blocked.

- The permeability of the material downgradient of the fault is high compared to the upgradient material, so that flow can drain away from the fault faster than it can be delivered by the upgradient material.

Evidence that springs in Ash Meadows are caused by the juxtaposition of poorly permeable sediments and rocks downgradient of the carbonate aquifer across the Gravity fault was presented in Winograd and Thordarson (1975 [DIRS 101167], p. C82). Hydraulic data in southern Indian Springs Valley were interpreted by Winograd and Thordarson (1975 [DIRS 101167], p. C67 to C68) to indicate the presence of two hydraulic barriers related to the Las Vegas shear zone: (1) a northern barrier caused by the juxtaposition of the lower clastic aquitard and lower carbonate aquifer; and (2) a southern barrier, which was attributed to the presence of gouge along a major fault zone.

\subsection{Recent Seismic History}

The seismic history of the faults may indicate which faults have undergone recent movement. Recent movement on a fault may serve to break calcite or silica cement or other material that may have closed the fault. A map showing which faults or fault segments near Yucca Mountain have undergone recent movement was developed by Simonds et al. (1995 [DIRS 101929]). Of the faults that have been mapped near the repository area, only the Solitario Canyon fault and short segments of the Bow Ridge fault near Exile Hill show evidence of late Quaternary (or more recent) movement.

\subsubsection{Comparing Permeability Data to Calibrated Permeability Values}

To check if the permeabilities estimated by PEST61564]) during the calibration of the SZ site-scale model are reasonable, the logarithms of permeabilities estimated during calibration of the model are compared to the mean logarithms of permeability estimated from pump-test data from Yucca Mountain in Figure 7-4 and to data from elsewhere at the NTS in Figure 7-5. Where they could be estimated, the 95 percent confidence limits for the mean logarithm of the permeability data also are shown in Figures 7-4 and 7-5. For the Calico Hills Formation, the Prow Pass tuff, the Bullfrog tuff, the Tram tuff, and the MVA, permeabilities are shown for both the single-hole and for the cross-hole tests at the C-wells complex.

The calibrated permeabilities for the Calico Hills Formation, the Pre-Lithic Ridge tuffs, and the carbonate aquifer are within the 95 percent confidence limits of the mean permeabilities estimated from single-hole pump test analyses at Yucca Mountain (Figure 7-4). The calibrated permeability for the Bullfrog tuff is within the 95 percent confidence limits of the mean-measured permeability determined from the cross-hole tests. The calibrated permeability of the Prow Pass tuff is slightly higher than the mean permeability estimated from the cross-hole tests, whereas the calibrated permeability of the Tram tuff is between the mean permeabilities estimated for the unit from the single-hole and cross-hole tests (Figure 7-4). 


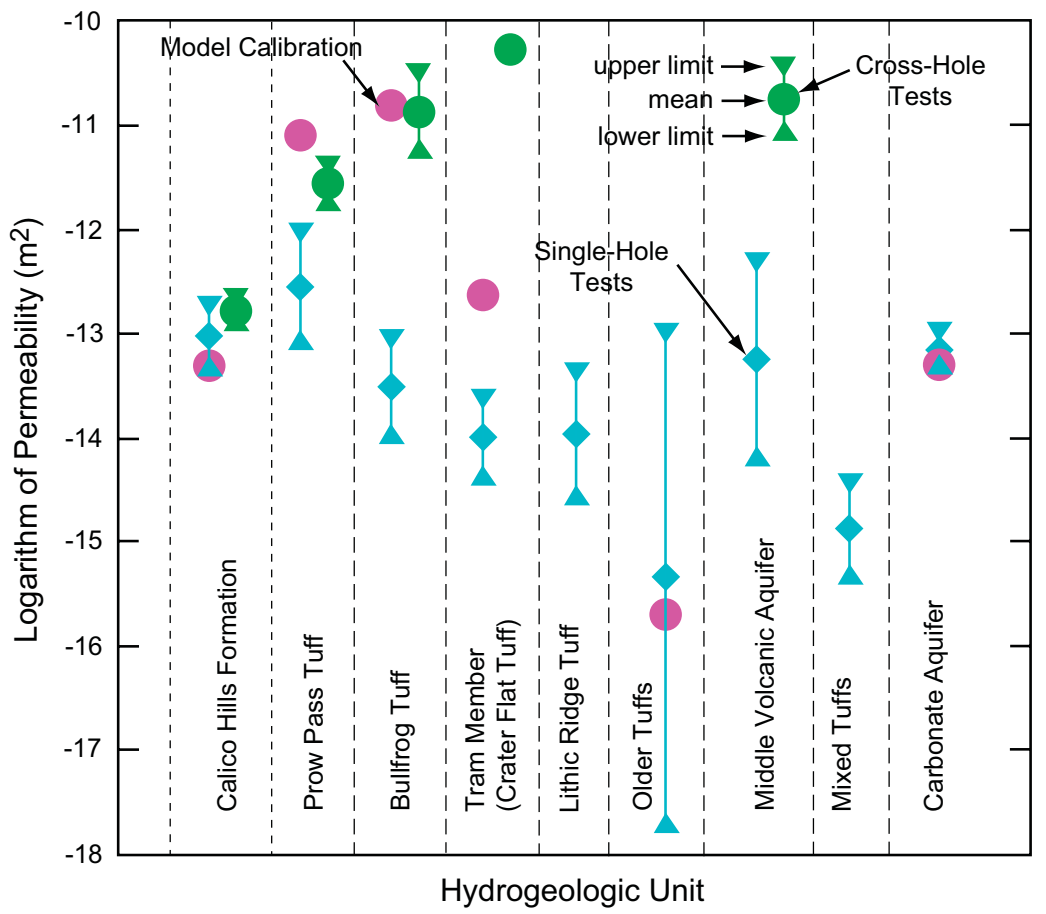

Source DTN: SNT05082597001.003 [DIRS 129714].

Figure 7-4. Logarithms of Permeabilities Estimated During Model Calibration Compared to Mean Logarithms of Permeability Determined from Pump-Test Data from Yucca Mountain

The mean measured permeability of the carbonate aquifer is higher elsewhere at the NTS than either the mean-measured permeability at Yucca Mountain or the calibrated permeability for the carbonate aquifer (Figures 7-4 and 7-5). The calibrated permeabilities for the alluvial aquifer and the lava flow aquifer are within or very close to the 95 percent confidence limits for the mean permeabilities of these units. The calibrated permeability for the upper volcanic aquifer is about two orders of magnitude less than the mean-measured permeability of this unit.

Overall, the calibrated permeabilities are consistent with most of the permeability data from Yucca Mountain and elsewhere at the NTS, except for the upper volcanic aquifer. The calibrated permeability of the Tram tuff is lower than the mean permeability derived from the cross-hole tests but higher than the permeability estimated from the single-hole tests. The relatively high permeability estimated for the Tram tuff from the cross-hole tests may be at least partially attributable to local conditions at the site of these tests. A breccia zone is present in the Tram tuff at boreholes UE-25 c\#2 and UE-25 c\#3 (Geldon et al. 1997 [DIRS 100397], Figure 3), which is a factor that may have caused a local enhancement in the permeability of the Tram tuff.

The permeability data recently obtained from single-hole and cross-hole testing in the Alluvial Testing Complex have not been included in Figure 7-5. As indicated in Section 7.2.2.1, while the permeabilities reported from the single-hole tests for the alluvial materials are about an order of magnitude less than the calibrated value, the cross-hole tests yield a permeability measurement similar to the calibrated permeability values for the alluvial aquifer. 


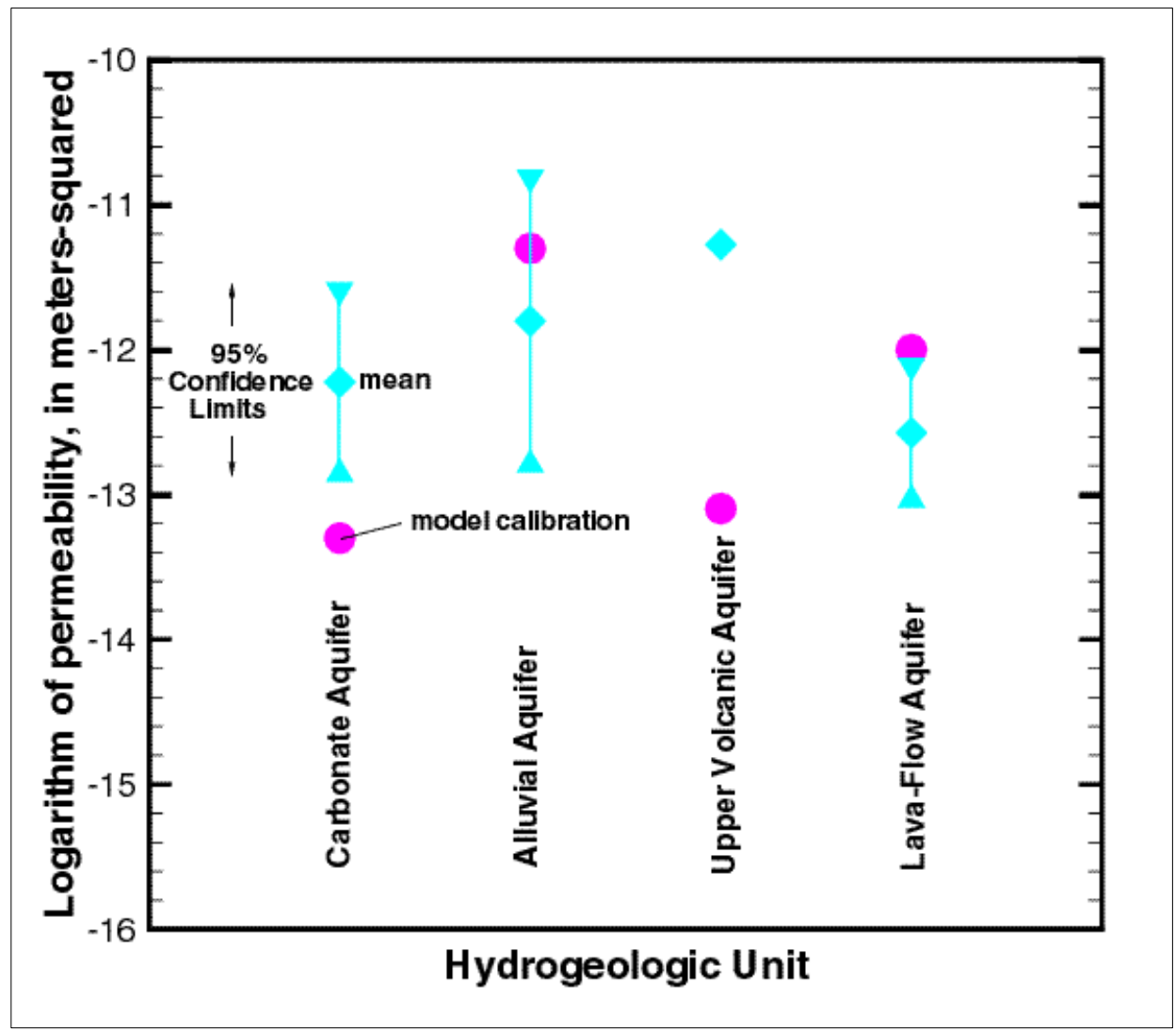

DTN: SNT05082597001.003 [DIRS 129714].

Figure 7-5. Logarithms of Permeabilities Estimated During Model Calibration Compared to Mean Logarithms of Permeability Determined from Pump-Test Data from the NTS

While the calibrated permeability of the many geologic units and features represented in the SZ site-scale flow model may indirectly influence to a limited extent the specific discharge predicted by the SZ site-scale model, the calibrated permeabilities of those geologic units along the flow path from the repository to the compliance boundary most directly determine the specific discharge predicted by the SZ site-scale model. Particle tracking using the SZ site-scale model (see Section 7.2.3.1) indicates that fluid particles migrating from the repository generally travel downward until they reach the Crater Flat Bullfrog unit. Because of the high permeability of the Bullfrog unit, the particles remain in that unit until reaching the southern end. At this point, fluid particles generally enter the alluvial portion of the flow system after briefly transitioning the upper volcanic confining unit. The flow path through the alluvial deposits is represented in the SZ site-scale model by the alluvial uncertainty zone and the lower Fortymile Wash zone. Thus, those calibrated permeabilities that most directly control the prediction of specific discharge by the SZ site-scale model are those for the Bullfrog unit and the alluvial uncertainty and lower Fortymile Wash zones.

The calibrated value for the Bullfrog unit was $1.54 \times 10^{-11} \mathrm{~m}^{2}$ (see Table 6-21). As shown in Table 6-24, the mean permeability for the cross-hole measurements of the Bullfrog unit at Yucca 
Mountain was $1.37 \times 10^{-11} \mathrm{~m}^{2}$. Thus, the calibrated permeability for the Bullfrog unit was only 12 percent greater than the mean of the measured value.

As indicated in Section 7.2.2.3.2, cross-hole tests have been performed in the alluvial material at the ATC in borehole NC-EWDP-19D. Borehole NC-EWDP-19D is located in the southern portion of the alluvial uncertainty zone established in the SZ site-scale model. The calibrated permeability for the alluvial uncertainty zone was $3.20 \times 10^{-12} \mathrm{~m}^{2}$. The permeability measured during the cross-hole tests at NC-EWDP-19D was $2.7 \times 10^{-12} \mathrm{~m}^{2}$. Thus, the calibrated permeability for the alluvial uncertainty zone was only 19 percent greater than the measured value.

Because new water-level data and permeability measurements are available at the ATC, predicted and observed values of hydraulic gradient and permeability at this location can be used to calculate specific discharge. These calculated specific discharge values can be compared to evaluate their combined impact on specific discharge for purposes of postmodel development validation. As previously discussed in Section 7.1, the predicted hydraulic gradient between WT-3 and 19P/2D is only 7 percent greater that the observed gradient between these two locations (see Table 7-3). As indicated above, the calibrated permeability for the Alluvial Uncertainty Zone was 19 percent greater than the measured value at the ATC. Since the combined effect of the differences between predicted and observed values of these parameters on specific discharge is the product of their individual impacts, the calculated specific discharge based on the predicted value of hydraulic gradient and the calibrated value of permeability is only 27 percent greater than the value calculated using the respective observed values of these parameters. This result meets the validation criteria of being within a factor of 3 (BSC 2004 [DIRS 170115], Section 2.2) used in the SZ transport abstraction model.

The 18-km compliance region described in Section 6.8.5.2 and the SZ transport abstraction model (BSC 2004 [DIRS 170042]) are strongly influenced by groundwater flow in alluvium. Estimates of groundwater-specific discharge in the SZ were recently obtained from field-testing at the ATC (BSC 2004 [DIRS 170010], Section 6.5.5). The ATC is located approximately $18 \mathrm{~km}$ from Yucca Mountain at the boundary of the accessible environment as specified in 10 CFR 63.302 (10 CFR Part 63 [DIRS 156605]). The ATC testing was performed in the alluvium aquifer. Estimates of groundwater specific discharge at the ATC range from $1.2 \mathrm{~m} / \mathrm{yr}$ to $9.4 \mathrm{~m} / \mathrm{yr}$. For the details of flow porosity in alluvium, see DTN: LA0303PR831231.002 ([DIRS 163561]) and BSC (2004 [DIRS 170010], Section 6.4). For the expected flow porosity in the alluvium of 0.18 , the test-derived specific discharge ranges from $2.4 \mathrm{~m} / \mathrm{yr}$ to $7.3 \mathrm{~m} / \mathrm{yr}$. The simulated average specific discharge in this region of the SZ system, using the SZ transport abstraction model, ranges from $1.9 \mathrm{~m} / \mathrm{yr}$ to $3.2 \mathrm{~m} / \mathrm{yr}$ for differing values of horizontal anisotropy in permeability ranging from 0.05 to 20 (BSC 2004 [DIRS 170010], Section 6.2.6). For the mean horizontal anisotropy, the simulated average specific discharge is approximately $2.8 \mathrm{~m} / \mathrm{yr}$ for the ATC test location (BSC 2004 [DIRS 170042], Section 6.5.1.2). This specific discharge is within a factor of 1.2 of the lower end of test-derived value $(2.4 \mathrm{~m} / \mathrm{yr})$ and a factor 2.6 of the upper end value $(7.3 \mathrm{~m} / \mathrm{yr})$, which meets the validation criterion of being within a factor of 3 (BSC 2004 [DIRS 170115], Section 2.2). Therefore, the data from the ATC field-testing both constitute new specific discharge in the SZ information and significantly reduce uncertainty in the specific discharge relative for use in SZ transport abstraction model. The remaining uncertainty is propagated accordingly into the SZ transport abstraction model (BSC 2004 
[DIRS 170042]), Section 6.5.2). Specifically, an uncertainty distribution in specific discharge is constructed, in which 80 percent of the probability is between one-third and three times the best estimate of specific discharge, with an additional 10 percent assigned to the lower tail of 1/30 of the expected value and 10 percent to the upper tail of 10 times the expected value of specific discharge. Additionally, the uncertainty in effective porosity is captured through the use of a truncated normal distribution as used in the SZ transport abstraction model (BSC 2004 [DIRS 170042], Section 6.5.2). The details of the uncertainty distributions of specific discharge and effective porosity in the alluvium and their associated sampling techniques are contained in the abstraction model, Sections 6.5.2.1 and 6.5.2.3, respectively.

\subsubsection{Comparison of Hydrochemical Data Trends with Calculated Particle Pathways}

The SZ transport model was used to simulate the movement of a conservative tracer from various segments along the boundaries in the model. The location of these boundary segments and their numerical designations in the model are shown in Figure 6-42. The goal of these simulations was to provide an understanding of where groundwater at any location in the flow system may have originated and to what extent groundwaters originating from various locations may mix. These simulation results are then qualitatively evaluated in the context of the understanding gained from the analysis of the hydrochemical and isotopic data discussed in detail in Appendix A.

Groundwater flow paths and mixing zones were identified in the analyses of the areal distributions of measured and calculated geochemical and isotopic parameters, scatterplots, and inverse mixing and reaction models with PHREEQC (BSC 2002 [DIRS 157837]). This summary describes the basis for the flow paths drawn in Section 7.2.3.1.

Flow paths of tracer particles were calculated for the SZ site-scale transport model. The particles were started in the vicinity of the repository footprint and allowed to transport downstream to the compliance boundary. These flow pathways are compared to flow paths deduced from hydrochemistry data in Figure 7-6. Flow paths deduced from hydrochemistry data were deduced in the context of the hydraulic gradient and considering the possibility that flow paths can be oblique to the potentiometric gradient because of anisotropy in permeability. Theses flow paths were drawn by first using chemical and isotopic constituents generally considered to behave conservatively in groundwater such as the chloride $\left(\mathrm{Cl}^{-}\right)$, sulphate $\left(\mathrm{SO}_{4}{ }^{2-}\right)$ ions. However, because no single chemical or isotopic species varies sufficiently to determine flow paths everywhere in the study area, multiple lines of evidence were used to construct the flow paths. This evidence includes the areal distribution of chemical and isotopic species, sources of recharge, groundwater ages and evaluation of mixing/groundwater evolution through scatterplots, and inverse mixing and reaction models as presented in the previous sections. The derivation of flow pathways from hydrochemical data is developed in detail in Appendix A and summarized in Section A6.6.11

Of particular interest are the flow paths labeled \#2 and \#7 from this analysis (Figure 7-6). Flow Path \#7, originates in the vicinity of the repository footprint and overlaps the model-calculated flow paths Figure 7-6. Flow Path \#2 is also of interest here, although it originates northeast of the repository, because it closely bounds Flow Path \#7 to the east. Although flow pathways 
derived from hydrochemical data do not originate in the exact same location as particle tracks drawn using the site scale model, the paths converge east and south of the repository.

\subsubsection{Thermal Modeling}

Measurements of temperature in the SZ constitute an independent data set that was not used in the calibration of the SZ site-scale flow model and may be used to support the validation of the flow model. The transport of heat in the geosphere occurs generally upward toward the Earth's surface, leading to higher temperatures with depth. However, heat is also redistributed by groundwater flow, and temperature can potentially serve as a tracer for the movement of groundwater in the SZ. To evaluate heat transport in the SZ, modeling of heat transport through conduction only and through conduction with convective transport was undertaken. The validation of the SZ site-scale flow model using simulations of heat transport and measured values of temperature in the SZ is documented in the following section. Modeling of heat transport through conduction only is presented first, followed by a presentation of modeling of heat transport through both conduction and convection. The direct comparison of temperature with groundwater movement is complicated by spatial uncertainty in thermal properties, overburden thickness, and heat flux. Despite these inherent limitations, an acceptable comparison between observed and simulated temperatures was achieved. The work presented in this section is taken from the paper Arnold et al. (2003 [DIRS 164473]) and is not used for any other purpose than to provide additional insight into the SZ site-scale flow model. 


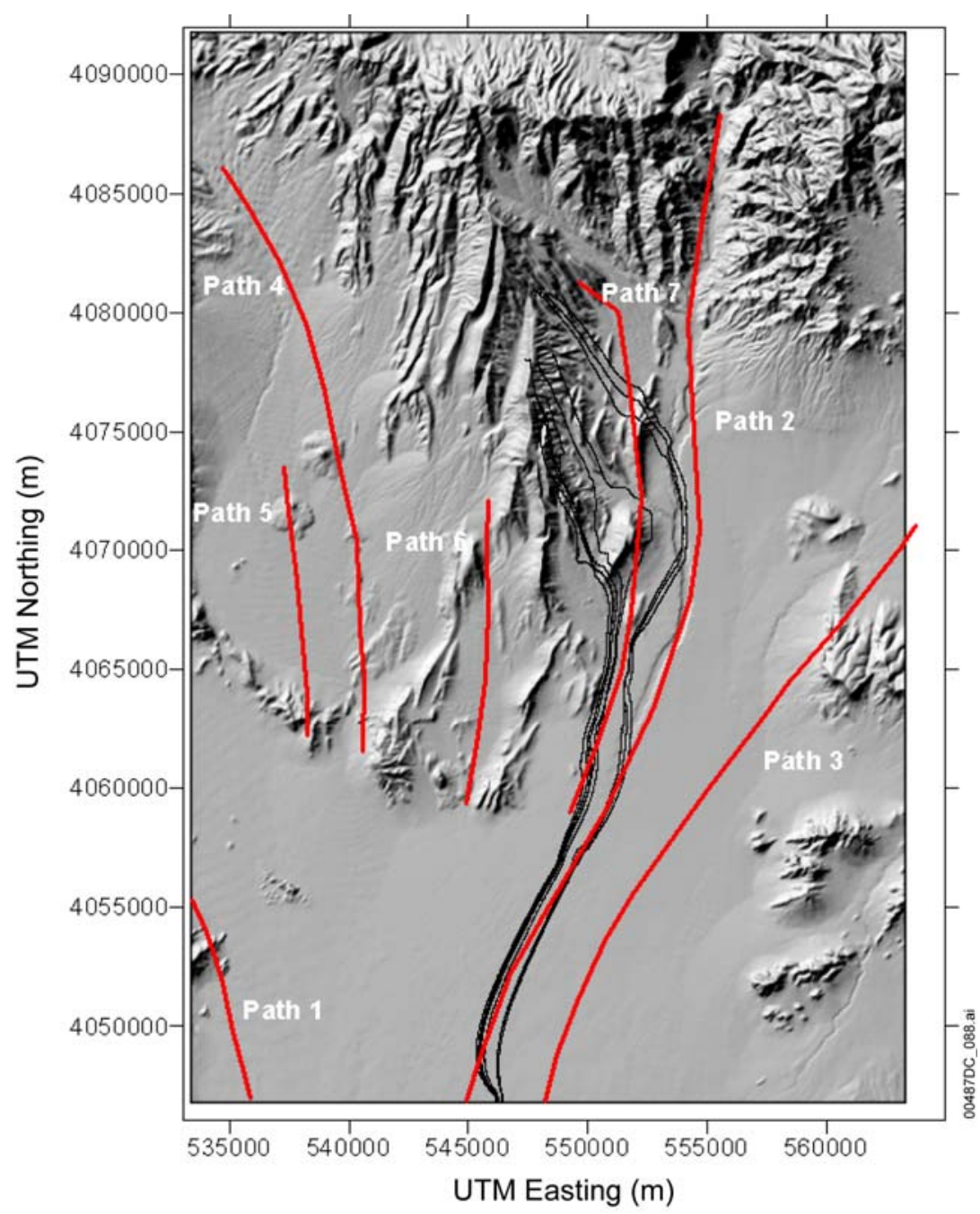

Source: See Appendix A, Figure A6-62

NOTE: In red, flow paths calculated from hydrochemistry data; in black, flow paths calculated for tracer particles starting at the repository footprint. UTM = Universal Transverse Mercator

Figure 7-6. Transport Pathways Deduced from Hydrochemistry Data, Compared to Particle Pathways Calculated for the Saturated Zone Site-Scale Transport Model

\subsubsection{Conduction-Only Modeling}

Heat transport in the geosphere is a function of thermal conduction and advective movement with groundwater flow. Simulation of coupled groundwater flow and heat transport in the SZ is a more complete description of natural geothermal processes in the SZ system. Simulations of heat conduction alone are used to assess the relative importance of conduction with regard to the observed temperatures in the system. In addition, the conduction-only model of the SZ is calibrated with respect to observed temperatures and provides a starting point for coupled thermal simulations that have been optimized with regard to thermal conduction.

The SZ site-scale flow model is used as the basis for the modeling of heat conduction. The model domain and definitions of the hydrogeologic units are retained from the SZ site-scale flow model. Values of thermal conductivity are designated on a unit-by-unit basis. The thermal 
boundary conditions on the bottom and top boundaries of the SZ site-scale flow model are defined and adjusted in the thermal calibration process.

\subsection{Temperature and Thermal Properties Data}

Data on temperatures in the SZ are taken from temperature profiles measured in wells within the SZ site-scale flow model area. These data are from Yucca Mountain Project wells and from the newer Nye County Early Warning Drilling Program wells and are compiled in Table 7-9. The temperature data in Table 7-9 were extracted at 200-m intervals from these temperature $\operatorname{logs}$, starting at the water table. A total of 94 observed temperatures in 35 wells were obtained.

Table 7-9. Temperature Data from Boreholes

\begin{tabular}{|c|c|c|c|c|c|}
\hline $\begin{array}{c}\text { Well } \\
\text { ID }\end{array}$ & $\begin{array}{l}\text { UTM Easting } \\
(\mathrm{m})\end{array}$ & $\begin{array}{l}\text { UTM Northing } \\
(\mathrm{m})\end{array}$ & $\begin{array}{c}\text { Elevation } \\
\text { (m) elative } \\
\text { to mean sea } \\
\text { level }\end{array}$ & $\begin{array}{c}\text { Temperature } \\
\text { (C) }\end{array}$ & $\begin{array}{c}\text { Data Tracking } \\
\text { Number* }\end{array}$ \\
\hline USWG-1 & 548306 & 4080016 & 754 & 29.6 & GS950408318523.001 \\
\hline USWG-1 & 548306 & 4080016 & 554 & 35.8 & GS950408318523.001 \\
\hline USWG-1 & 548306 & 4080016 & 354 & 39.2 & GS950408318523.001 \\
\hline USWG-1 & 548306 & 4080016 & 154 & 44.9 & GS950408318523.001 \\
\hline USWG-1 & 548306 & 4080016 & -46 & 50.4 & GS950408318523.001 \\
\hline USWG-1 & 548306 & 4080016 & -246 & 55.7 & GS950408318523.001 \\
\hline USWG-1 & 548306 & 4080016 & -446 & 62.1 & GS950408318523.001 \\
\hline USWG-2 & 548143 & 4082542 & 1028 & 29.6 & GS950408318523.001 \\
\hline USWG-2 & 548143 & 4082542 & 828 & 32.3 & GS950408318523.001 \\
\hline USWG-2 & 548143 & 4082542 & 628 & 38.4 & GS950408318523.001 \\
\hline USWG-2 & 548143 & 4082542 & 428 & 46.6 & GS950408318523.001 \\
\hline USWG-2 & 548143 & 4082542 & 228 & 55.1 & GS950408318523.001 \\
\hline USWG-3 & 547543 & 4074619 & 729 & 33 & GS950408318523.001 \\
\hline USWG-3 & 547543 & 4074619 & 529 & 35.3 & GS950408318523.001 \\
\hline USWG-3 & 547543 & 4074619 & 329 & 39.7 & GS950408318523.001 \\
\hline USWG-3 & 547543 & 4074619 & 129 & 43 & GS950408318523.001 \\
\hline USWG-4 & 548933 & 4078602 & 729 & 30 & GS950408318523.001 \\
\hline USWG-4 & 548933 & 4078602 & 529 & 34.5 & GS950408318523.001 \\
\hline USWH-1 & 548727 & 4079926 & 730 & 32.8 & GS950408318523.001 \\
\hline USWH-1 & 548727 & 4079926 & 530 & 35.4 & GS950408318523.001 \\
\hline USWH-1 & 548727 & 4079926 & 330 & 39.3 & GS950408318523.001 \\
\hline USWH-1 & 548727 & 4079926 & 130 & 44.2 & GS950408318523.001 \\
\hline USWH-1 & 548727 & 4079926 & -70 & 50.1 & GS950408318523.001 \\
\hline USWH-1 & 548727 & 4079926 & -270 & 56.2 & GS950408318523.001 \\
\hline USWH-1 & 548727 & 4079926 & -470 & 61.6 & GS950408318523.001 \\
\hline USWH-3 & 547562 & 4075759 & 732 & 33.3 & GS950408318523.001 \\
\hline USWH-3 & 547562 & 4075759 & 532 & 37.2 & GS950408318523.001 \\
\hline USWH-3 & 547562 & 4075759 & 332 & 41.1 & GS950408318523.001 \\
\hline USWH-4 & 549188 & 4077309 & 730 & 30.7 & GS950408318523.001 \\
\hline USWH-4 & 549188 & 4077309 & 530 & 32.8 & GS950408318523.001 \\
\hline
\end{tabular}


Table 7-9. Temperature Data from Boreholes (Continued)

\begin{tabular}{|c|c|c|c|c|c|}
\hline $\begin{array}{l}\text { Well } \\
\text { ID }\end{array}$ & $\begin{array}{l}\text { UTM Easting } \\
(\mathrm{m})\end{array}$ & $\begin{array}{l}\text { UTM Northing } \\
(\mathrm{m})\end{array}$ & $\begin{array}{c}\text { Elevation } \\
(\mathrm{m}) \text { elative } \\
\text { to mean sea } \\
\text { level }\end{array}$ & $\begin{array}{c}\text { Temperature } \\
\left.\text { ( }{ }^{\circ} \mathrm{C}\right)\end{array}$ & $\begin{array}{c}\text { Data Tracking } \\
\text { Number* }\end{array}$ \\
\hline USWH-4 & 549188 & 4077309 & 330 & 33.7 & GS950408318523.001 \\
\hline USWH-4 & 549188 & 4077309 & 130 & 38.3 & GS950408318523.001 \\
\hline USWH-4 & 549188 & 4077309 & 30 & 40.2 & GS950408318523.001 \\
\hline USWH-5 & 547668 & 4078841 & 774 & 35.1 & GS950408318523.001 \\
\hline USWH-5 & 547668 & 4078841 & 574 & 37.1 & GS950408318523.001 \\
\hline USWH-5 & 547668 & 4078841 & 374 & 40.3 & GS950408318523.001 \\
\hline USWH-6 & 546188 & 4077816 & 776 & 34 & GS950408318523.001 \\
\hline USWH-6 & 546188 & 4077816 & 576 & 36.1 & GS950408318523.001 \\
\hline USWH-6 & 546188 & 4077816 & 376 & 44 & GS950408318523.001 \\
\hline USWH-6 & 546188 & 4077816 & 176 & 51.2 & GS950408318523.001 \\
\hline UE-25b1H & 549949 & 4078423 & 731 & 31.8 & GS950408318523.001 \\
\hline UE-25b1H & 549949 & 4078423 & 531 & 34.6 & GS950408318523.001 \\
\hline UE-25b1H & 549949 & 4078423 & 331 & 35.4 & GS950408318523.001 \\
\hline UE-25b1H & 549949 & 4078423 & 131 & 39.2 & GS950408318523.001 \\
\hline UE-25p1 & 551501 & 4075659 & 730 & 33.6 & GS950408318523.001 \\
\hline UE-25p1 & 551501 & 4075659 & 530 & 38.2 & GS950408318523.001 \\
\hline UE-25p1 & 551501 & 4075659 & 330 & 41.9 & GS950408318523.001 \\
\hline UE-25p1 & 551501 & 4075659 & 130 & 48.1 & GS950408318523.001 \\
\hline UE-25p1 & 551501 & 4075659 & -70 & 55.6 & GS950408318523.001 \\
\hline UE-25p1 & 551501 & 4075659 & -270 & 57.5 & GS950408318523.001 \\
\hline UE-25p1 & 551501 & 4075659 & -470 & 55.4 & GS950408318523.001 \\
\hline USWVH-1 & 539976 & 4071714 & 898 & 27 & GS930208318523.001 \\
\hline USWVH-1 & 539976 & 4071714 & 698 & 32 & GS930208318523.001 \\
\hline USWVH-1 & 539976 & 4071714 & 498 & 35 & GS930208318523.001 \\
\hline USWVH-1 & 539976 & 4071714 & 298 & 36 & GS930208318523.001 \\
\hline USWVH-2 & 537738 & 4073214 & 811 & 27 & GS930208318523.001 \\
\hline USWVH-2 & 537738 & 4073214 & 611 & 30 & GS930208318523.001 \\
\hline USWVH-2 & 537738 & 4073214 & 411 & 35 & GS930208318523.001 \\
\hline USWVH-2 & 537738 & 4073214 & 211 & 36 & GS930208318523.001 \\
\hline USWVH-2 & 537738 & 4073214 & 11 & 38 & GS930208318523.001 \\
\hline USWVH-2 & 537738 & 4073214 & -189 & 52 & GS930208318523.001 \\
\hline J-13WW & 554017 & 4073517 & 729 & 30.2 & GS950408318523.001 \\
\hline J-13WW & 554017 & 4073517 & 529 & 30.7 & GS950408318523.001 \\
\hline J-13WW & 554017 & 4073517 & 329 & 33.1 & GS950408318523.001 \\
\hline J-13WW & 554017 & 4073517 & 129 & 35.8 & GS950408318523.001 \\
\hline USWWT-1 & 549152 & 4074967 & 731 & 30.1 & GS950408318523.001 \\
\hline USWWT-2 & 548595 & 4077028 & 730 & 31.5 & GS950408318523.001 \\
\hline UE-25WT3 & 552090 & 4072550 & 730 & 33.1 & GS950408318523.001 \\
\hline UE-25WT4 & 550439 & 4079412 & 728 & 31.4 & GS950408318523.001 \\
\hline UE-25WT6 & 549352 & 4083103 & 1029 & 28.4 & GS950408318523.001 \\
\hline USWWT-7 & 546151 & 4075474 & 776 & 33.8 & GS950408318523.001 \\
\hline
\end{tabular}


Table 7-9. Temperature Data from Boreholes (Continued)

\begin{tabular}{|c|c|c|c|c|c|}
\hline $\begin{array}{l}\text { Well } \\
\text { ID }\end{array}$ & $\begin{array}{l}\text { UTM Easting } \\
(\mathrm{m})\end{array}$ & $\begin{array}{l}\text { UTM Northing } \\
(\mathrm{m})\end{array}$ & $\begin{array}{c}\text { Elevation } \\
(\mathrm{m}) \text { elative } \\
\text { to mean sea } \\
\text { level }\end{array}$ & $\begin{array}{c}\text { Temperature } \\
\left({ }^{\circ} \mathrm{C}\right)\end{array}$ & $\begin{array}{c}\text { Data Tracking } \\
\text { Number* }\end{array}$ \\
\hline USWWT-10 & 545964 & 4073378 & 775 & 38.8 & GS950408318523.001 \\
\hline USWWT-11 & 547542 & 4070428 & 730 & 35.2 & GS950408318523.001 \\
\hline UE-25WT12 & 550168 & 4070659 & 730 & 32.9 & GS950408318523.001 \\
\hline UE-25WT13 & 553730 & 4075827 & 729 & 28.5 & GS950408318523.001 \\
\hline UE-25WT14 & 552630 & 4077330 & 730 & 29.9 & GS950408318523.001 \\
\hline UE-25WT15 & 554034 & 4078694 & 729 & 27.5 & GS950408318523.001 \\
\hline UE-25WT16 & 551146 & 4081234 & 737 & 32.3 & GS950408318523.001 \\
\hline UE-25WT17 & 549905 & 4073307 & 729 & 31.1 & GS950408318523.001 \\
\hline UE-25WT18 & 549468 & 4080238 & 731 & 31.2 & GS950408318523.001 \\
\hline NC-EWDP-1S & 536771 & 4062498 & 787 & 21.7 & MO0008NYE02997.033 \\
\hline $\begin{array}{l}\text { NC-EWDP- } \\
\text { 2DB }\end{array}$ & 547744 & 4057164 & 706 & 24.1 & MO0101NYE03692.071 \\
\hline NC-EWDP-3D & 541273 & 4059444 & 717 & 26.6 & MO0008NYE02997.033 \\
\hline NC-EWDP-3D & 541273 & 4059444 & 517 & 26.3 & MO0008NYE02997.033 \\
\hline NC-EWDP-3D & 541273 & 4059444 & 317 & 28.4 & MO0008NYE02997.033 \\
\hline NC-EWDP-3D & 541273 & 4059444 & 117 & 42.3 & MO0008NYE02997.033 \\
\hline $\begin{array}{l}\text { NC-EWDP- } \\
5 S B\end{array}$ & 555676 & 4058229 & 724 & 29.2 & MO0101NYE03452.061 \\
\hline NC-EWDP-7S & 539558 & 4064317 & 830 & 24.5 & MO0101NYE03456.065 \\
\hline NC-EWDP-7S & 539558 & 4064317 & 630 & 31.7 & MO0101NYE03456.065 \\
\hline $\begin{array}{l}\text { NC-EWDP- } \\
12 P A\end{array}$ & 536905 & 4060766 & 723 & 32.7 & MO0101NYE03453.062 \\
\hline $\begin{array}{l}\text { NC-EWDP- } \\
12 \mathrm{PC}\end{array}$ & 536871 & 4060808 & 721 & 29.5 & MO00101NYE03455.064. \\
\hline $\begin{array}{l}\text { NC-EWDP- } \\
19 P\end{array}$ & 549237 & 4058265 & 713 & 26.2 & MO0409NYE06210.225 \\
\hline UE-25a\#1 & 549925 & 4078330 & 731 & 31.5 & GS950408318523.001 \\
\hline UE-25a\#1 & 549925 & 4078330 & 531 & 34.1 & GS950408318523.001 \\
\hline
\end{tabular}

NOTE: The DTNs listed in the table: DTN: GS950408318523.001 [DIRS 107244];

DTN: MO0008NYE02997.033 [DIRS 155290]; DTN: GS930208318523.001 [DIRS 145763]; and the Nye Co. web site Nye County Nuclear Waste Repository Project Office 2000 [DIRS 149364] are the sources of information for each entry. Five different parts of [DIRS 149364] provide data used in this table. This table is used as reference only.

UTM = Universal Transverse Mercator

Values of thermal conductivity for the hydrogeologic units in the conduction-only model are taken from a variety of sources and are listed in Table 7-10. For hydrogeologic units that are generally stratified and for which multiple thermal conductivity measurements are available, vertical and horizontal thermal conductivity are estimated separately. Harmonic averaging is appropriate for effective conductivity in the vertical direction in which stratified variations in conductivity occur in series. Arithmetic averaging is appropriate for effective conductivity in the horizontal direction in which variations in conductivity generally occur in parallel. 
Table 7-10. Thermal Conductivity of SZ Hydrogeologic Units

\begin{tabular}{|c|c|c|c|c|}
\hline $\begin{array}{l}\text { Model } \\
\text { Zone } \\
\text { Number }\end{array}$ & Hydrogeologic Unit & $\begin{array}{c}\text { Horizontal } \\
\text { Thermal } \\
\text { Conductivity } \\
\text { (W/mK) }\end{array}$ & $\begin{array}{c}\text { Vertical } \\
\text { Thermal } \\
\text { Conductivity } \\
\text { (W/mK) }\end{array}$ & $\begin{array}{c}\text { Reference of } \\
\text { Corroborative Data }\end{array}$ \\
\hline 2 & Granite & 2.40 & 2.40 & $\begin{array}{l}\text { Sass et al. 1984, Table 1, p. } 17 \\
\text { [DIRS 153174] }\end{array}$ \\
\hline 3 & Lower Clastic Confining Unit & 2.49 & 2.49 & $\begin{array}{l}\text { Sekiguchi 1984, Table 1, p.73 } \\
\text { [DIRS 163363] }\end{array}$ \\
\hline 4 & Lower Carbonate Aquifer & 4.95 & 4.55 & $\begin{array}{l}\text { Sass et al. 1988, Section 3-5, } \\
\text { p.118 [DIRS 100644] }\end{array}$ \\
\hline 5 & Upper Clastic Confining Unit & 2.49 & 2.49 & $\begin{array}{l}\text { Sekiguchi 1984, Table 1, p.73 } \\
\text { [DIRS 163363] }\end{array}$ \\
\hline 6 & $\begin{array}{l}\text { Lower Carbonate Aquifer } \\
\text { (Thrust) }\end{array}$ & 4.95 & 4.55 & $\begin{array}{l}\text { Sass et al. 1988, Section 3-5, } \\
\text { p.118 [DIRS 100644] }\end{array}$ \\
\hline 7 & Upper Carbonate Aquifer & 3.61 & 3.03 & $\begin{array}{l}\text { Ryder 1997, Section 3.2, p.10 } \\
\text { [DIRS 163364] }\end{array}$ \\
\hline 8 & $\begin{array}{l}\text { Undifferentiated Valley Fill } \\
\text { (North) }\end{array}$ & 1.60 & 1.60 & * \\
\hline 9 & Older Volcanic Confining Unit & 1.87 & 1.86 & $\begin{array}{l}\text { Sass et al. 1988, Tables 3-1, 3-2, } \\
\text { and 3-3, pp. 107, 110, } 113 \\
\text { [DIRS 100644] }\end{array}$ \\
\hline 10 & Older Volcanic Aquifer & 2.00 & 2.00 & $\begin{array}{l}\text { Sass et al. 1988, Tables 3-1, 3-2, } \\
\text { and 3-3, pp. 107, 110, } 113 \\
\text { [DIRS 100644] }\end{array}$ \\
\hline 11 & Lower Volcanic Confining Unit & 1.87 & 1.86 & $\begin{array}{l}\text { Sass et al. 1988, Tables 3-1, 3-2, } \\
\text { and 3-3, pp. 107, 110, 113 } \\
\text { [DIRS 100644] }\end{array}$ \\
\hline 12 & Tram Tuff & 1.75 & 1.72 & $\begin{array}{l}\text { Sass et al. 1988, Tables 3-1, 3-2, } \\
\text { and 3-3, pp. 107, 110, } 113 \\
\text { [DIRS 100644] }\end{array}$ \\
\hline 13 & Bullfrog Tuff & 1.63 & 1.60 & $\begin{array}{l}\text { Sass et al. 1988, Tables 3-1, 3-2, } \\
\text { and 3-3, pp. 107, 110, } 113 \\
\text { [DIRS 100644] }\end{array}$ \\
\hline 14 & Prow Pass Tuff & 1.45 & 1.43 & $\begin{array}{l}\text { Sass et al. 1988, Tables 3-1, 3-2, } \\
\text { and 3-3, pp. 107, 110, } 113 \\
\text { [DIRS 100644] }\end{array}$ \\
\hline 15 & Upper Volcanic Confining Unit & 1.21 & 1.20 & $\begin{array}{l}\text { Sass et al. 1988, Tables 3-1, 3-2, } \\
\text { and 3-3, pp. 107, 110, } 113 \\
\text { [DIRS 100644] }\end{array}$ \\
\hline 16 & Upper Volcanic Aquifer & 1.67 & 1.56 & $\begin{array}{l}\text { Brodsky et al. 1997, Table A-3, } \\
\text { p.A12 [DIRS 100653] }\end{array}$ \\
\hline 17 & Lava Flow Aquifer & 2.09 & 2.09 & $\begin{array}{l}\text { Lagedrost and Capps 1983, } \\
\text { Table 26, p. } 70 \text { [DIRS 163366] }\end{array}$ \\
\hline 18 & Limestone Aquifer & 3.61 & 3.03 & $\begin{array}{l}\text { Ryder 1997, Section 3.2, Table 1, } \\
\text { p. } 10 \text { [DIRS 163364] }\end{array}$ \\
\hline 20 & Valley Fill Aquifer & 1.00 & 1.00 & $\begin{array}{l}\text { Wollenberg et al. } 1983 \text { p. } 9 \\
\text { [DIRS 163359] }\end{array}$ \\
\hline 23 & $\begin{array}{l}\text { Undifferentiated Valley Fill } \\
\text { (South) }\end{array}$ & 1.00 & 1.00 & $\begin{array}{l}\text { Wollenberg et al. 1983, p. } 97 \\
\text { [DIRS 163359] }\end{array}$ \\
\hline
\end{tabular}

NOTE: *Estimate based on unit consisting predominantly of volcanic material. $(\mathrm{W} / \mathrm{m}-\mathrm{K})=$ watts per meter-degree kelvin

This table is for reference only. 
Sass et al. (1984 [DIRS 153174]) investigated thermal conductivity measurements on several rock types, including granite, using the steady state divided bar, line source, and half-space probe techniques. Two thermal conductivities are given for granite, at $23^{\circ} \mathrm{C}$ (Sass et al. (1984 [DIRS 153174]), p. 17); one derived using the divided bar technique, $2.40 \mathrm{~W}-\mathrm{m}^{-1} \mathrm{~K}^{-1}$, and the other, $2.27 \mathrm{~W}-\mathrm{m}^{-1} \mathrm{~K}^{-1}$, using the half-space probe technique. The authors suggest thermal conductivity values using the divided bar technique be used for materials that are easily machineable, anisotropic, and nonfriable materials. Granite falls within this category. For this reason, the YMP regional heat flow model uses $2.40 \mathrm{~W}-\mathrm{m}^{-1} \mathrm{~K}^{-1}$ as the thermal conductivity of granite.

Sekiguchi (1984 [DIRS 163363]) presents thermal conductivities for several rock types, including silty-sandstone, based on three empirical equations, all a function of porosity, fluid type, and mineralogy. He determined a thermal conductivity range for "silty-sandstone" of which a value listed as the primary thermal conductivity for silty-sandstone is bounded (Sekiguchi 1984 [DIRS 163363], Table 1). Consequently, it is believed that $2.49 \mathrm{~W} / \mathrm{mK}$ (watts per meter-degree kelvin), which is the primary thermal conductivity for silty-sandstone given in Sekiguchi (1984 [DIRS 163363]), is appropriate for the regional scale geothermal simulations.

Site-specific thermal conductivity data are reported for dolomite by Sass et al. (1988 [DIRS 100644]). Thirteen Lone Mountain dolomite core samples were taken from borehole UE-25 p\#1 at depths $1310.4 \mathrm{~m}$ to $1801.6 \mathrm{~m}$. Sass et al. (1988 [DIRS 100644] Appendix 3, p. 118, Table 3-5) derived thermal conductivity measurements at ambient room temperatures of about $25^{\circ} \mathrm{C}$. From these values, an harmonic-averaged and an arithmetic effective thermal conductivity are developed. The harmonic-averaged thermal conductivity, $4.55 \mathrm{~W} / \mathrm{mK}$, is to be used for heat flow in the vertical direction; the arithmetic-averaged value, $4.95 \mathrm{~W} / \mathrm{mK}$, is to be used for heat flow in the horizontal direction.

There are no site-specific thermal conductivity measurements for limestone. Consequently, limestone thermal conductivity derived from similar rock types is used. Limestone has been considered as one of the material components to be included in a backfill mixture for Yucca Mountain and has been discussed in Ryder (1997 [DIRS 163364], Section 3.2, p. 10). The range listed in Ryder's 1997 report is based on the author's literature search. Values appropriate for temperatures below $50^{\circ} \mathrm{C}$ for limestone thermal conductivity $(3.03-3.61 \mathrm{~W} / \mathrm{mK})$ are used in the site-scale heat flow model for the vertical and horizontal thermal conductivities.

There are numerous site-specific thermal conductivity measurements for the various tuff units incorporated in the analysis. These values are reported by Sass et al. (1988 [DIRS 100644]) and Brodsky (1997 [DIRS 100653]). Two effective thermal conductivities are derived, one in the vertical direction, the other in the horizontal direction, from cores lithologies representative of each hydrogeologic unit. Thermal conductivity in the vertical direction is derived by first harmonically averaging thermal conductivities for each individual borehole. Then the harmonic averages from individual boreholes are arithmetically averaged. Thermal conductivity in the horizontal direction is derived by simply arithmetically averaging data from the same hydrogeologic units. The number of samples used in the analysis ranged from 7 for the Prow Pass tuff to 58 for the upper volcanic aquifer. 
Thermal conductivity measurements for 11 core samples from three boreholes drilled through the Pomona Member Basalt, located in Washington State, are used to derive an effective basalt thermal conductivity. Thermal conductivity measurements were taken at temperatures ranging between $21^{\circ} \mathrm{C}$ to $50^{\circ} \mathrm{C}$. To derive a thermal conductivity for $30^{\circ} \mathrm{C}$, a simple linear interpolation for thermal conductivity values measured at $\sim 22^{\circ} \mathrm{C}$ to $50^{\circ} \mathrm{C}$ is used. The 11 interpolated values are arithmetically averaged resulting in a thermal conductivity of $2.09 \mathrm{~W} / \mathrm{mK}$.

There are no site-specific data on the thermal conductivity of saturated alluvium. Smyth et al. (1979 [DIRS 163360]) report values of thermal conductivity ranging from 0.5 to 1 . W/mK for soils, indurated, and unconsolidated alluvium at varying degrees of saturation. Wollenberg et al. (1983 [DIRS 163359], p. 97) give an estimated value of $1.0 \mathrm{~W} / \mathrm{mK}$ for the thermal conductivity of typical alluvium under saturated or near-saturated conditions. For the units that are predominantly alluvium, $1.0 \mathrm{~W} / \mathrm{mK}$ is taken as a representative estimate of the thermal conductivity. Because considerable uncertainty exists in the thermal conductivity of alluvium in the SZ site-scale flow model domain, sensitivity analyses were conducted to evaluate the impact of this parameter on the calibration of the conduction-only model, as described later.

\subsection{Thermal Conduction Model Setup}

The FEHM input files for the SZ site-scale flow model are used as the starting point for the SZ site-scale thermal conduction model. Input macros related to fluid flow are removed from the input file, a heat-conduction-only solution is indicated, and thermal boundary conditions are added. The lateral boundaries of the SZ site-scale thermal conduction model are set as no thermal flow. This is appropriate, given the primarily vertical nature of geothermal heat transport and the relatively thin dimension of the model in the vertical direction $(2.75 \mathrm{~km}$ thick $\mathrm{x}$ $30 \mathrm{~km} \times 45 \mathrm{~km}$ ). The bottom boundary is specified heat flux to reflect upward heat transport from the deeper crust. The upper boundary condition is temperature-dependent heat flux, in which the heat flux to the land surface is calculated as a function of the simulated temperature at the water table and the specified temperature at the land surface.

\subsection{Thermal Boundary Conditions on the Upper Boundary}

The thermal boundary condition at the upper boundary of the SZ site-scale thermal conduction model requires that the temperature at the land surface and the effective conductance from the water table to the land surface be specified. The temperature at the land surface is specified based on an estimate of the average annual surface temperature. The effective thermal conductance of the UZ is a function of several factors, including thickness of the UZ, rock type, and downward percolation of groundwater through the UZ; however, only thickness of the UZ is included here. The spatially varying effective thermal conductance of the UZ is estimated in the calibration process, as explained later.

The average annual surface temperature for the SZ site-scale thermal model domain is estimated using a relationship relating temperature to elevation (Section 6.5.3.7). This simple linear relationship for average surface temperature is:

$$
T_{s}=T_{\text {ref }}-\lambda\left(Z_{s}-Z_{r e f}\right)
$$


where

$T_{s}$ is the average surface temperature

$T_{r e f}$ is the average temperature at a reference location

$\lambda$ is the rate of change in temperature with elevation

$Z_{s}$ is the surface elevation

$Z_{\text {ref }}$ is the surface elevation at the reference location.

Using values of mean surface temperature and elevations from the locations of boreholes NRG-6 and NRG-7 (DTN: GS950208312232.003 [DIRS 105572]), the value of $\lambda$ is $0.009^{\circ} \mathrm{C} / \mathrm{m}$ (Section 6.5). The reference average surface temperature and reference elevation at the location of borehole NRG- 6 are $18.23^{\circ} \mathrm{C}$ and $1231 \mathrm{~m}$, respectively.

This relationship is applied to the SZ site-scale thermal model domain to estimate the average annual surface temperature, as shown in Figure 7-7. Estimated average surface temperature varies as a function of elevation from about $10^{\circ} \mathrm{C}$ in northern parts of the area to greater than $22^{\circ} \mathrm{C}$ at the lower elevations in the southern part of the domain. The spatially varying values of estimated average surface temperature shown in Figure 7-7 are used as the upper boundary condition of the SZ site-scale thermal model.

The thermal conductance of the UZ at the upper boundary of the SZ site-scale thermal conduction model is inversely proportional to the thickness of the UZ, which varies considerably across the area of the model. The UZ acts as a thermal "blanket" to geothermal heat flow from the SZ, so the higher conductance occurs where the UZ is thin and lower conductance occurs where the UZ is relatively thick. Figure 7-8 shows a plot of the thickness of the UZ, which varies from less than $50 \mathrm{~m}$ in the south and in Fortymile Canyon to greater than $1,000 \mathrm{~m}$ in the north. The values of UZ thickness shown in Figure 7-8 are used to calculate spatially varying values of thermal conductance for the upper boundary condition in the SZ site-scale thermal conduction model.

Considerable uncertainty exists in the effective thermal conductivity of the UZ. In addition, thermal conductivity of the UZ varies as a function of rock type and heat flow may be influenced by downward percolation of groundwater in the UZ, as noted above. Because of these uncertainties, the effective thermal conductance at the upper boundary is treated as a calibration parameter in the heat conduction-only modeling for the SZ. The inverse proportionality to UZ thickness is preserved in the calibration process, but the overall effective thermal conductance is adjusted proportionally during thermal calibration. 


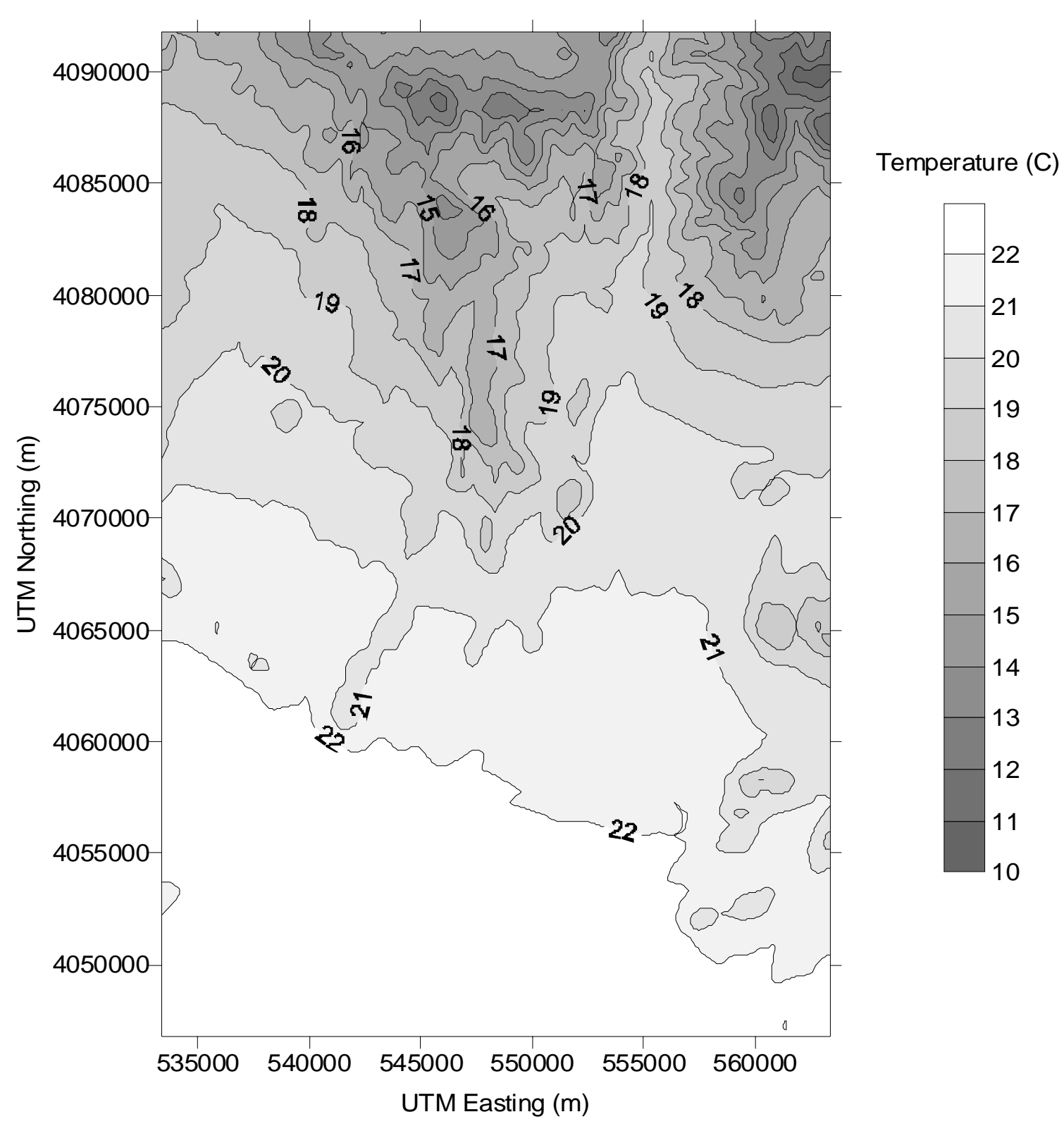

Source: Arnold et al. 2003 [DIRS 164473].

UTM = Universal Transverse Mercator

Figure 7-7. Computed Average Annual Surface Temperature for the SZ Site-Scale Thermal Model Area 


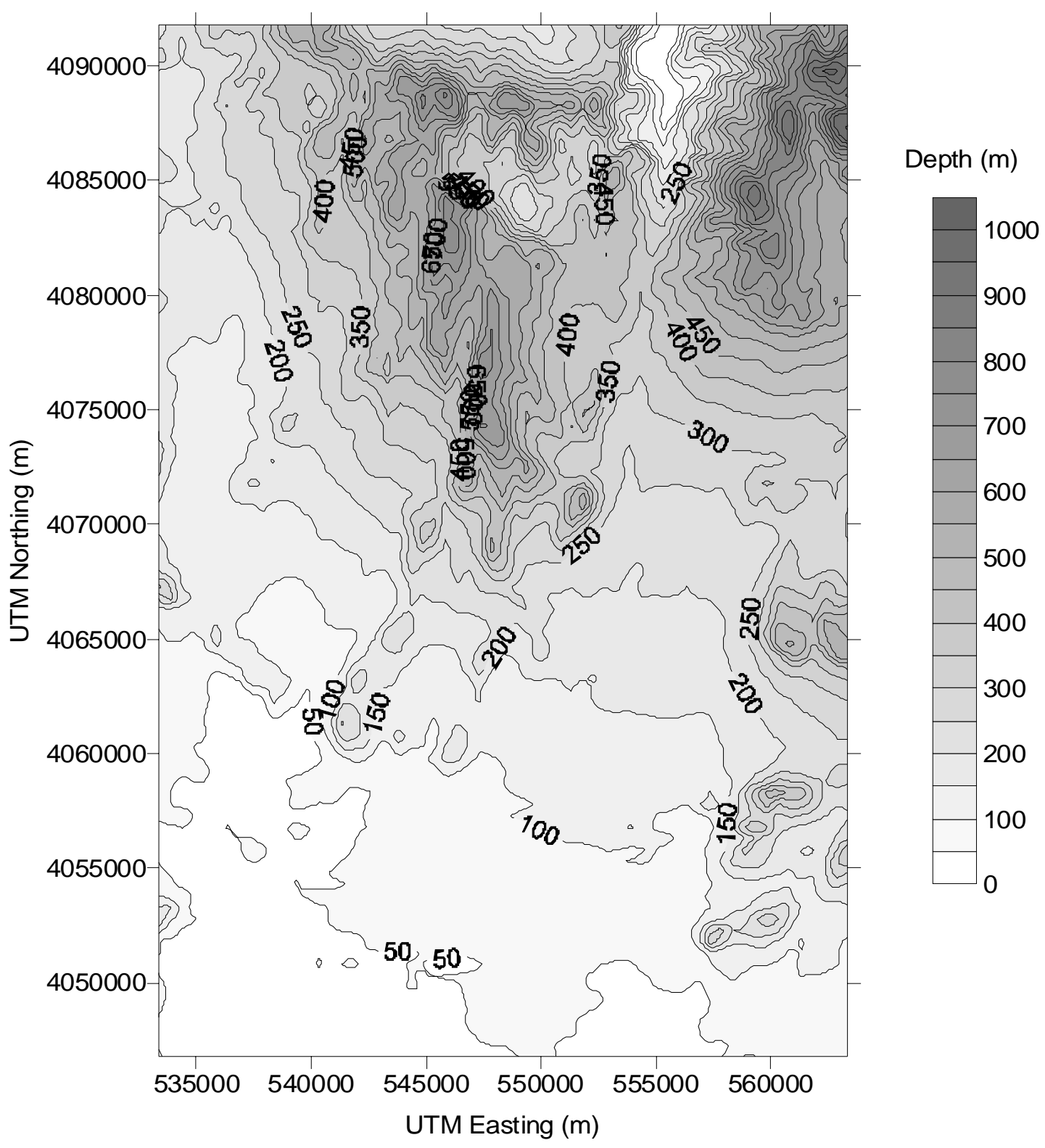

Source: Arnold et al. 2003 [DIRS 164473].

UTM = Universal Transverse Mercator

Figure 7-8. Depth to the Water Table in the SZ Site-Scale Flow Model Area

\subsection{Thermal Boundary Conditions on the Lower Boundary}

The lower thermal boundary condition of the SZ site-scale thermal conduction model is assigned a uniform value of specified heat flux. Variations in the geothermal heat flux may occur at the scale of the SZ site-scale flow model domain; however, there is not sufficient information on variations in deep heat flow to justify assigning spatial variations in heat flux at the bottom boundary of the model. The lower boundary of the SZ site-scale thermal conduction model is relatively deep at $2,750 \mathrm{~m}$ below the water table, so variations in heat flux due to topographic effects and groundwater flow are significantly less than at shallower depths. 
The estimated geothermal heat flux from measurements of temperature profiles in wells at Yucca Mountain is about $40 \mathrm{~mW} / \mathrm{m}^{2}$ (Sass et al. 1988, p. 2 [DIRS 100644]). This value of heat flux is considerably lower than the regional average of about $85 \mathrm{~mW} / \mathrm{m}^{2}$. Because there is considerable uncertainty in the appropriate value of heat flux at the lower boundary of the SZ site-scale thermal conduction model, this parameter is varied in the thermal calibration process to match the observed temperatures.

\subsection{Thermal Model Calibration}

The SZ site-scale thermal conduction model was calibrated by adjusting the upper and lower thermal boundary conditions in a trial-and-error method. (The simulated temperatures at the water table in the calibrated conduction-only model are shown in Figure 7-9.) The model was run to steady-state thermal conditions and the simulated temperatures were compared to the observed temperatures in a cross plot, such as shown in Figure 7-10. The calibration process sought to minimize the coefficient of determination $\left(R^{2}\right)$ for this cross plot. The calibration also attempted to place the least-squares line fit to the cross plot along a $45^{\circ}$ line, as shown by the dashed red line in Figure 7-10. Precise optimization of the conduction-only model was not required for the purposes of this analysis because the ultimate goal was to examine coupled groundwater flow and heat transport.

The best calibration of the SZ site-scale thermal conduction model is obtained with a uniform heat flux of $35 \mathrm{~mW} / \mathrm{m}^{2}$ at the lower boundary and an equivalent thermal conductivity of $0.3 \mathrm{~W} / \mathrm{mK}$ for the $\mathrm{UZ}$ at the upper boundary. The calibrated value of the heat flux at the lower boundary of $35 \mathrm{~mW} / \mathrm{m}^{2}$ is somewhat lower than the estimate from Sass et al. (1988 [DIRS 100644], Section 2-17), but is within the estimated range of error $\left(40 \pm 9 \mathrm{~mW} / \mathrm{m}^{2}\right)$ from that study. The calibrated value of the equivalent thermal conductivity for the UZ is quite low relative to the units in the SZ. However, this equivalent value may also account for the effects of unsaturated conditions, variations in rock type, and percolation of groundwater.

As mentioned above, the simulated temperatures at the water table in the calibrated conduction-only model are shown in Figure 7-9. The values of simulated temperature are projected onto -the water table surface, and the topographic surface is shown in this figure. There is considerable variation in the simulated temperature at the water table, primarily as a function of the UZ.

The higher simulated temperatures correspond to the relatively thick UZ under Yucca Mountain in the north-central portion of the area and under the Calico Hills in the northeastern part of the model. The lower simulated temperatures occur in areas where the water table is closer to the land surface, in the southern part of the model, and under Fortymile Canyon in the north. The pattern of simulated temperatures at the water table is influenced to a lesser extent by refraction of heat flow in the lower carbonate aquifer with its higher thermal conductivity. 


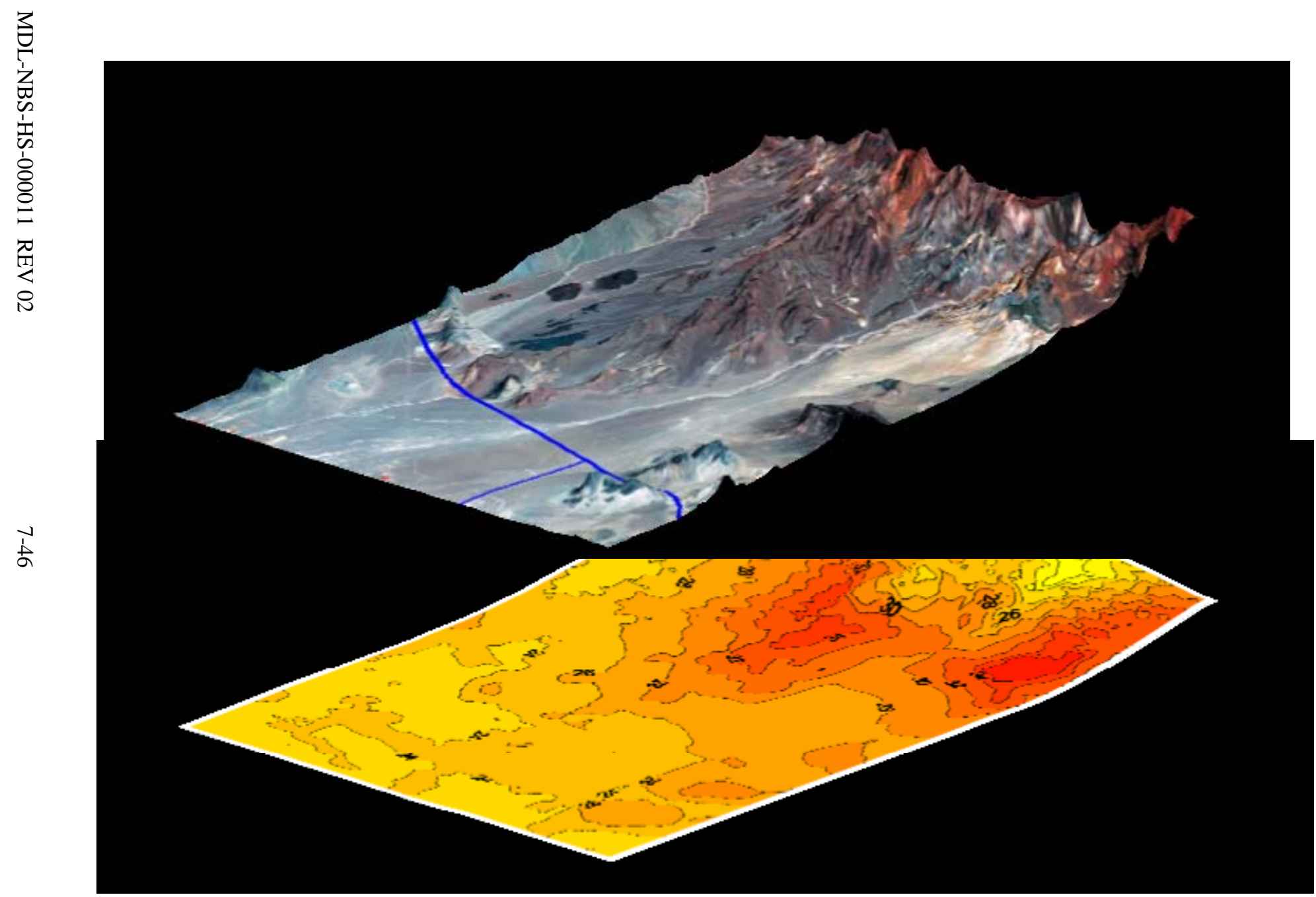

Temperature (C)

Source: Arnold et al. 2003 (DIRS 164473)

NOTE: Temperature is in ${ }^{\circ} \mathrm{C}$

Figure 7-9. Simulated Temperatures at the Water Table for the Thermal Conduction Model 


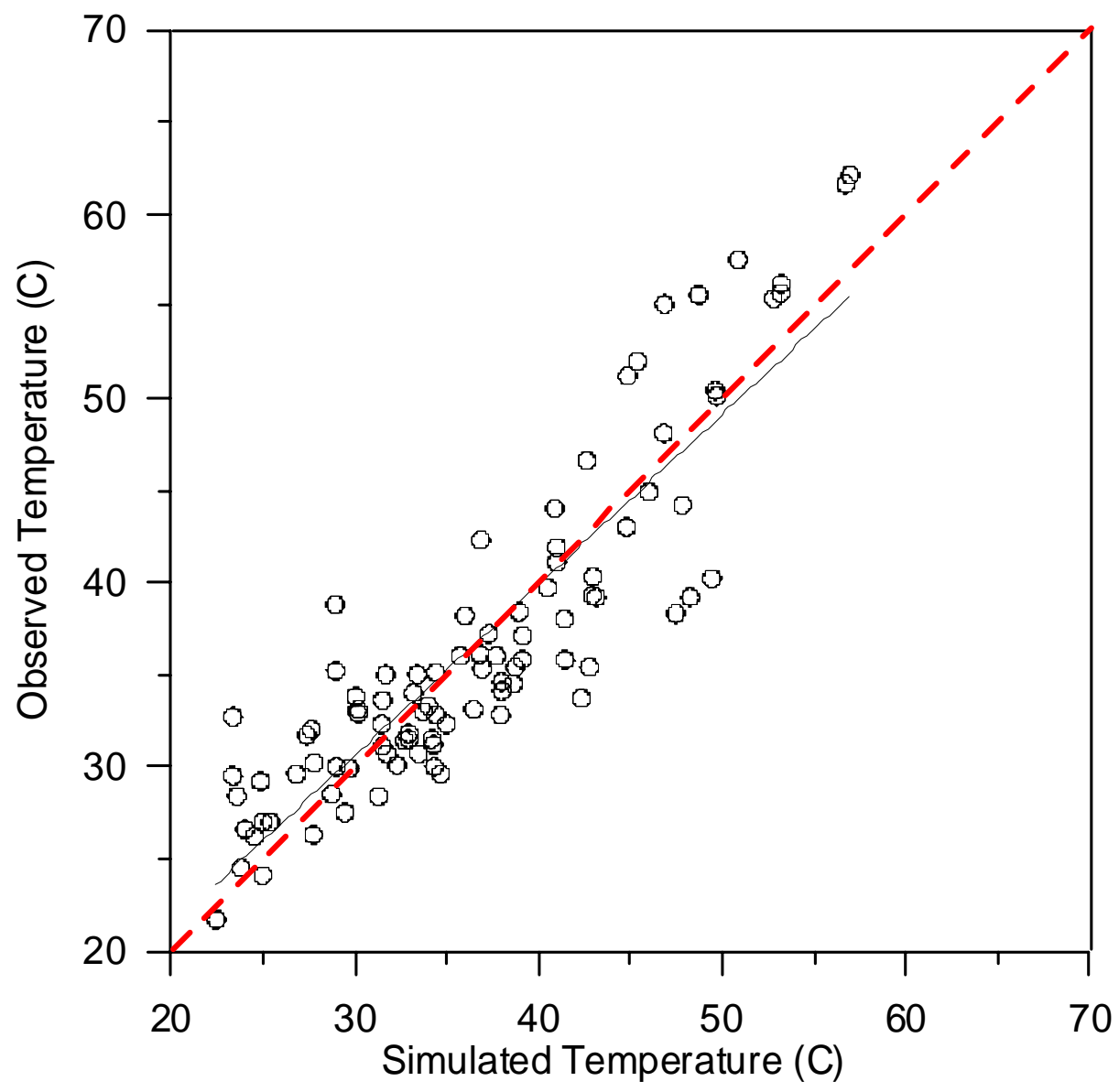

Source: Arnold et al. 2003 [DIRS 164473].

NOTE: Temperatures are in ${ }^{\circ} \mathrm{C}$.

Figure 7-10. Simulated Temperatures vs. Observed Temperatures for the Thermal Conduction Model

A plot of the 94 observations of temperatures in wells versus simulated temperatures for the calibrated thermal conduction model is shown in Figure 7-10. This cross plot indicates that there is generally good agreement between observed and simulated temperatures in the model. The $R^{2}$ value for these results is 0.80 . There is an apparent tendency for the calibrated model to underestimate temperatures between $20^{\circ} \mathrm{C}$ and $35^{\circ} \mathrm{C}$, to overestimate temperatures between $35^{\circ} \mathrm{C}$ and $50^{\circ} \mathrm{C}$, and to underestimate temperatures over $50^{\circ} \mathrm{C}$.

The residuals in simulated temperature are defined as the simulated temperature minus the observed temperature at a given location. A histogram of the residuals in simulated temperature in the calibrated SZ site-scale conduction-only model is shown in Figure 7-11. These residuals are approximately normally distributed, with maximum errors in simulated temperature of less than $10^{\circ} \mathrm{C}$. The average residual is $-0.3^{\circ} \mathrm{C}$. A majority of the simulated temperatures is within $3^{\circ} \mathrm{C}$ of the observed temperature at that location. These characteristics of the residuals indicate that the calibrated heat conduction-only model is fairly accurate and unbiased with regard to errors in simulated temperature. 


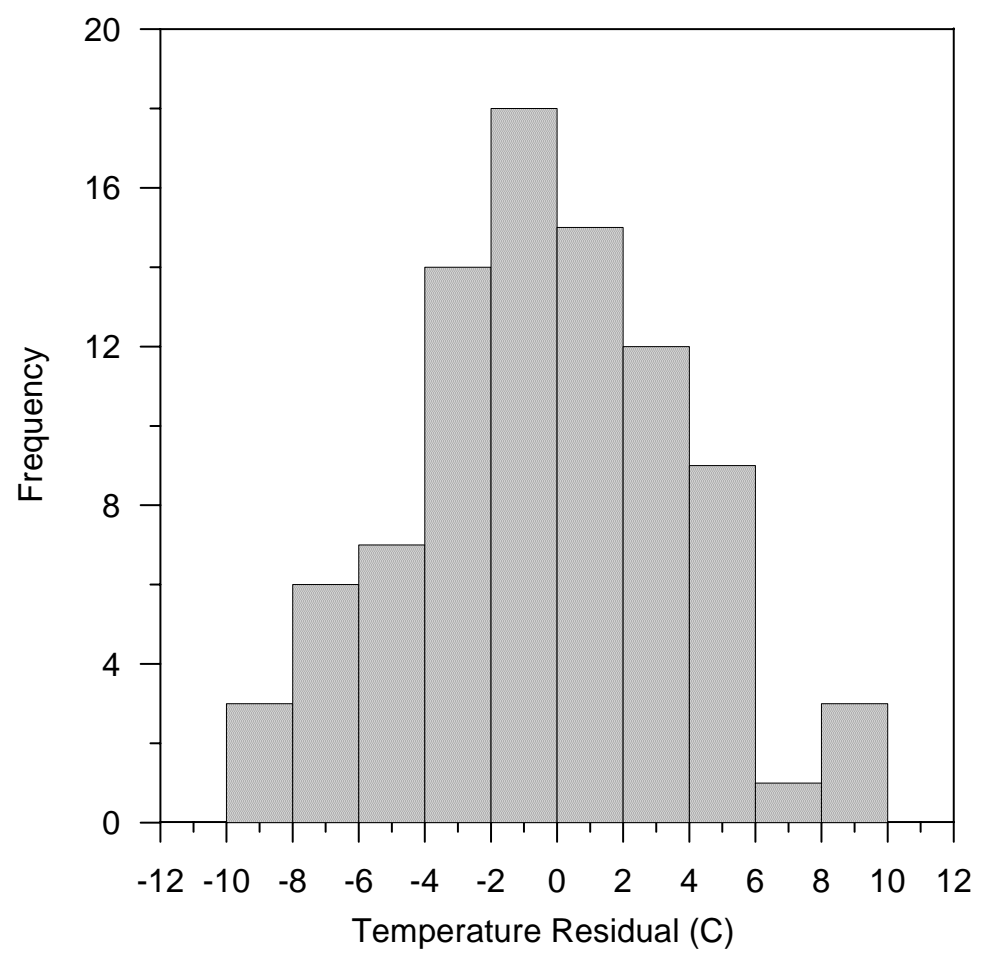

Source: Arnold et al. 2003 (DIRS 164473).

NOTE: Temperature is in ${ }^{\circ} \mathrm{C}$.

Figure 7-11. Histogram of Residuals in Simulated Temperature for the Thermal Conduction Model

The spatial distribution of residuals in simulated temperature at the water table is examined in the map shown in Figure 7-12. This figure indicates that there is some systematic pattern to the spatial distribution of residuals in simulated temperature. The positive residuals tend to cluster near and to the east of Yucca Mountain; whereas, the residuals farther to the south and immediately to the north of Yucca Mountain tend to be negative. The positive residuals indicate that the simulated temperature at the water table is too high.

One explanation for the clustering of positive residuals near the crest of Yucca Mountain is that these are locations of significant downward percolation of groundwater through the UZ. Downward percolating groundwater tends to suppress the geothermal gradient and would cause lower temperatures at the water table. Because the heat conduction-only model does not account for this process at the upper boundary, it tends to overestimate the temperature at these locations, leading to the positive residuals. The negative residuals may correspond to locations at which groundwater flow in the SZ is upward. This process is also not accounted for in the heat conduction-only model. Consequently, the simulated temperatures would be too low at these locations. 


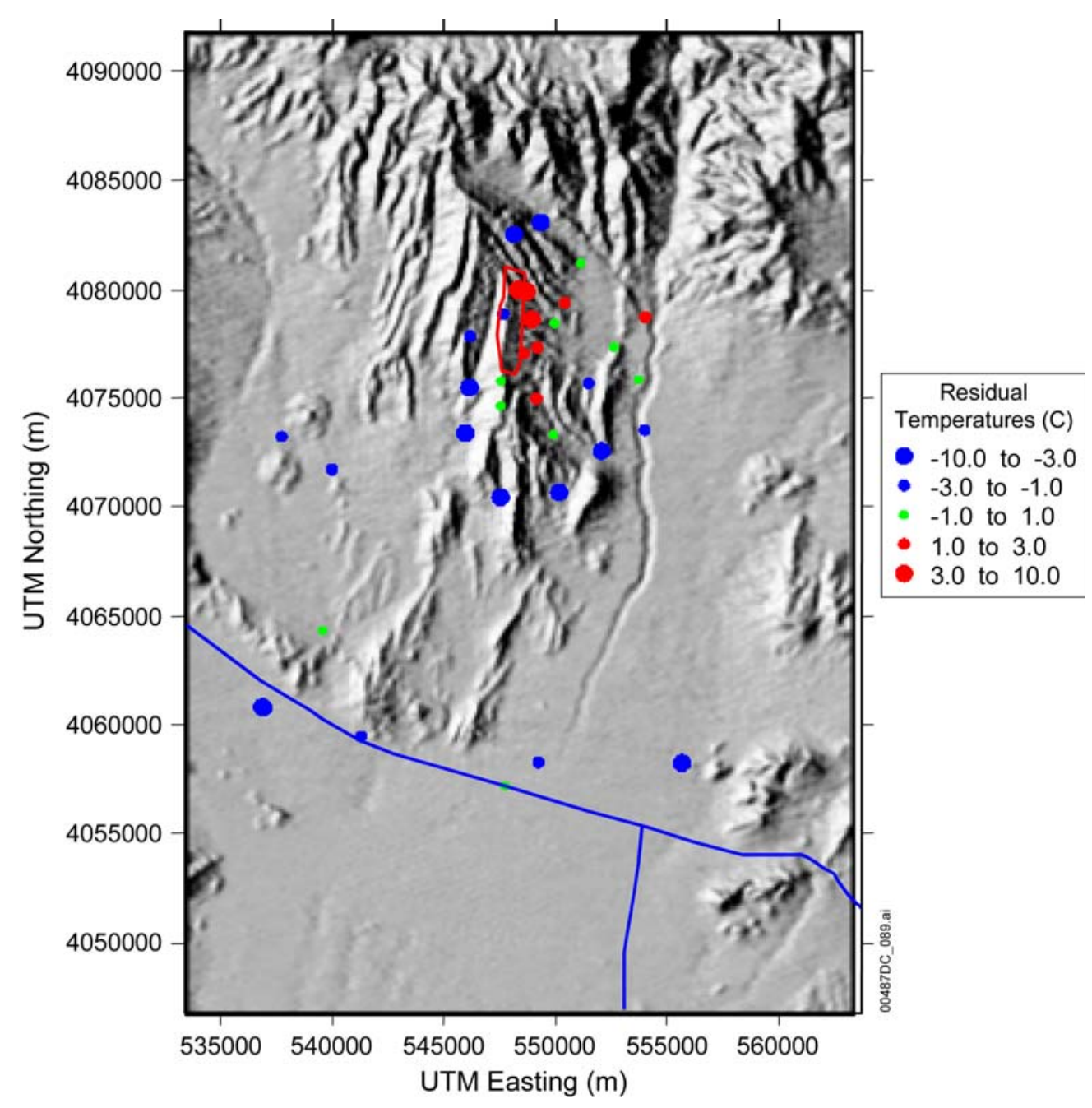

Source: Arnold et al. 2003 (DIRS 164473).

NOTES: Temperatures are in ${ }^{\circ} \mathrm{C}$. UTM $=$ Universal Transverse Mercator

Figure 7-12. Residuals in Simulated Temperature at the Water Table for the Thermal Conduction Model

\subsection{Sensitivity to Thermal Conductivity in the Alluvium}

Sensitivity of the SZ site-scale heat conduction-only model to the thermal conductivity of the alluvium was evaluated using a higher value $(1.6 \mathrm{~W} / \mathrm{mK})$ and a lower value $(0.5 \mathrm{~W} / \mathrm{mK})$ for this parameter. The results indicate relatively little sensitivity of the model calibration to this parameter, with the $R^{2}$ varying from 0.777 to 0.783 over this range of parameter values. Simulated temperatures near the water table are not very sensitive to the thermal conductivity of the alluvium below them, but simulated temperatures deeper in the valley-fill regions of the model are significantly higher for the lower value of thermal conductivity of the alluvium (and vice versa for the higher value). This low sensitivity to the thermal conductivity in the alluvium is primarily due to the general lack of deep temperature observations in wells in the alluvium that would constrain temperatures. 


\subsection{Results and Discussion of Conduction-Only Thermal Modeling}

Steady-state heat conduction in the SZ site-scale flow model domain is simulated to assess heat transport by conduction only. The resulting calibrated SZ site-scale thermal conduction model provides a relatively accurate, unbiased match to the observed temperatures in wells in the Yucca Mountain area. Comparison of observed temperatures to simulated temperatures results in a value of 0.80 for the $R^{2}$. The approximately normal statistical distribution of residuals in simulated temperature indicates that errors in the model are essentially random and not reflective of any systematic misrepresentation of the thermal transport processes in the SZ. There are some systematic spatial variations in the residuals in simulated temperatures, but these are generally understandable in terms of the coupled groundwater flow and heat transport processes that are not included in the conduction-only model.

Thermal transport in the SZ is dominated by conductive geothermal heat flow at the scale of the SZ site-scale flow model domain. The results of the calibration of the conduction-only model indicate that at least 80 percent of the variability in the observed temperatures can be explained by thermal conduction, based on the coefficient of determination from observed versus simulated temperatures. The remaining 20 percent of variability not accounted for in the thermal conduction model is probably due to the spatial discretization of the SZ model or spatial variability that is not represented in the model.

The spatial distribution of observations of temperature may limit the interpretation and modeling of heat transport in the SZ site-scale flow model area. Most of the temperature logs from wells are concentrated near Yucca Mountain, and almost all the measurements at depths of greater than a few hundred meters below the water table are in this area. Conclusions regarding the heat flux at the bottom boundary of the SZ site-scale flow model are most accurate for the area near Yucca Mountain but may be much less applicable elsewhere in the model domain.

\subsubsection{Coupled Thermal Modeling}

Coupled thermal modeling of groundwater flow and heat transport provides a more complete representation of thermal transport processes in the SZ than the conduction-only modeling. Groundwater flow redistributes heat in both the lateral and vertical directions. In addition, variations in the density and viscosity of groundwater as a function of temperature influence the groundwater flow field. These coupled processes result in a more challenging numerical modeling task for the coupled thermal model, relative to the conduction-only model.

\subsection{SZ Site-Scale Coupled Thermal Model Setup}

The SZ site-scale flow model and the SZ site-scale thermal conduction model are used as the basis for the modeling of coupled thermal transport. The calibrated upper and lower thermal boundary conditions from the conduction-only model are used in the coupled thermal model. The lateral groundwater flow boundary conditions of the SZ site-scale flow model are adjusted for use in the coupled thermal model. The specified head boundary conditions at the lateral boundaries of the SZ site-scale flow model are converted to values of specified pressure for the coupled thermal model. The temperature of groundwater flowing into the coupled thermal model at the lateral boundaries is specified to be equal to the simulated temperatures at those 
nodes in the SZ site-scale thermal conduction model. Similarly, the specified groundwater flux from recharge on the upper boundary of the coupled thermal model is specified to be at the simulated temperatures from the conduction-only model.

The SZ site-scale coupled thermal model is run to steady-state thermal and flow conditions for comparison to the observed temperatures in wells. Joint calibration of the coupled thermal model to water level and temperature measurements was not possible given the long computer run-times necessary to achieve a steady-state solution. Ideally, joint calibration of the SZ site-scale model would provide explicit constraints on the groundwater flow field. Nonetheless, the uncalibrated coupled heat and groundwater flow model can provide independent validation of the flow model and subjective indications to improve the flow model.

The resulting steady state, simulated temperatures at the water table for coupled groundwater flow and thermal transport are shown in Figure 7-13. Simulated temperatures at the water table for the coupled model differ significantly from the conduction-only model in the area directly to the east of Yucca Mountain and in a small area in Crater Flat. The simulated temperatures are generally higher in the area between Yucca Mountain and Fortymile Wash in the coupled model, indicating significant upward vertical advective heat transfer in this area of the model. The smaller area of higher simulated temperatures in Crater Flat indicates another area of simulated upward groundwater flow.

Results of combining the calibrated SZ site-scale flow model and the calibrated thermal conduction model indicate a significant reduction in the $R^{2}$ of observed and simulated temperatures from the conduction-only model (0.62 versus 0.80$)$. A plot of simulated temperatures versus observed temperatures for the coupled heat and groundwater flow model is shown in Figure 7-14. The statistical distribution of residuals in simulated temperature for the coupled model has a broader range than for the conduction-only model with an average of $0.13^{\circ} \mathrm{C}$. Note in Figure 7-14 that the simulated temperatures for the deeper, higher temperature measurement locations have both positive and negative residuals from the coupled model, whereas, the conduction-only model consistently underestimated the temperatures at these locations (Figure 7-10).

The spatial distribution of residuals in simulated temperature at the water table for the SZ coupled thermal model is examined in the map shown in Figure 7-15. The largest positive residuals generally occur in the area to the east and southeast of Yucca Mountain and in a relatively small area in Crater Flat. The largest negative residuals occur to the north of Yucca Mountain. 


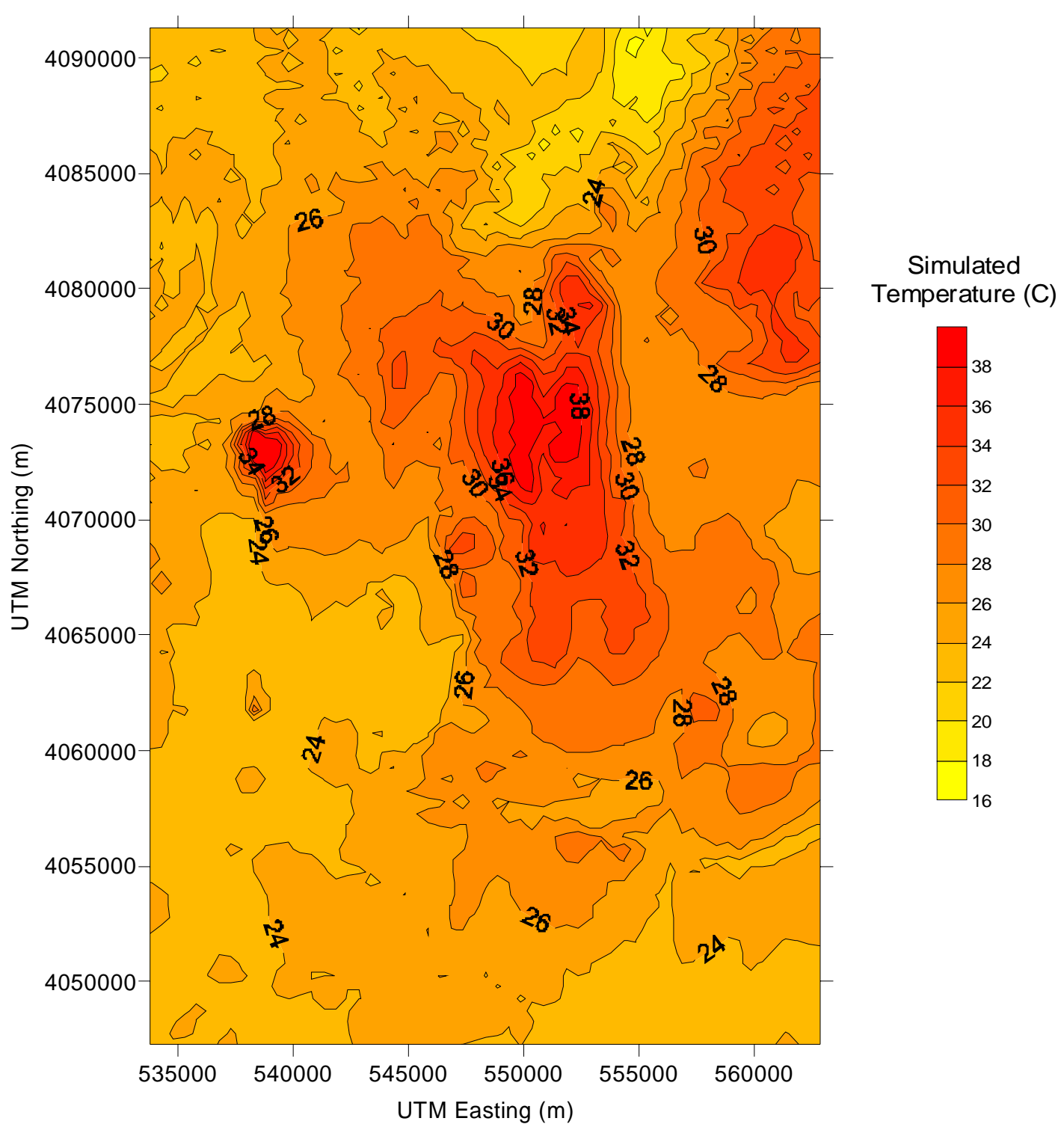

Source: Arnold et al. 2003 (DIRS 164473).

NOTES: Temperatures are in ${ }^{\circ} \mathrm{C}$. UTM $=$ Universal Transverse Mercator

Figure 7-13. Simulated Temperatures at the Water Table for the Coupled Thermal Model 


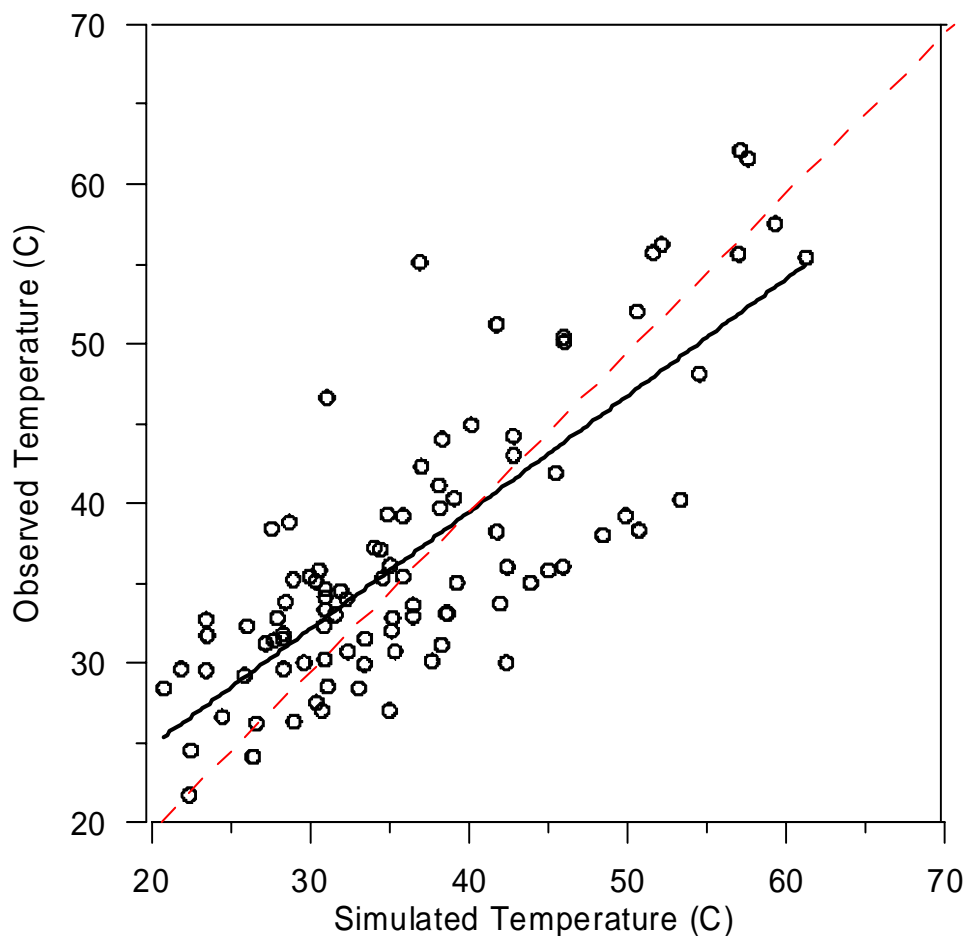

Source: Arnold et al. 2003 (DIRS 164473).

NOTE: Temperatures are in ${ }^{\circ} \mathrm{C}$.

Figure 7-14. Simulated Temperatures vs. Observed Temperatures for the Coupled Thermal Model

\subsection{Results and Discussion}

The calibrated SZ site-scale thermal conduction model provides a relatively accurate, unbiased match to the observed temperatures in wells in the Yucca Mountain area. The approximately normal statistical distribution of residuals in simulated temperature indicates that errors in the model are essentially random and not reflective of any systematic misrepresentation of the thermal transport processes in the SZ.

Thermal transport in the SZ is dominated by conductive, predominantly vertical, geothermal heat flow at the scale of the SZ site-scale flow model domain. The results of the calibration of the conduction-only model indicates that at least 80 percent of the variability in the observed temperatures can be explained by thermal conduction, based on the coefficient of determination from observed versus simulated temperatures.

The results of the coupled thermal transport model show that this jointly uncalibrated model is unbiased, but less accurate than the heat conduction-only model. The pattern of residuals in simulated temperatures suggests that the groundwater flow model overestimates upward groundwater flow in the region to the east and southeast of Yucca Mountain and in one area of Crater Flat, leading to larger positive residuals. The groundwater flow model also apparently overestimates downward groundwater flow to the north of Yucca Mountain and the large hydraulic gradient, resulting in larger negative residuals in this area. The results of the coupled thermal modeling provide additional confidence in the SZ site-scale flow model in a general sense. 


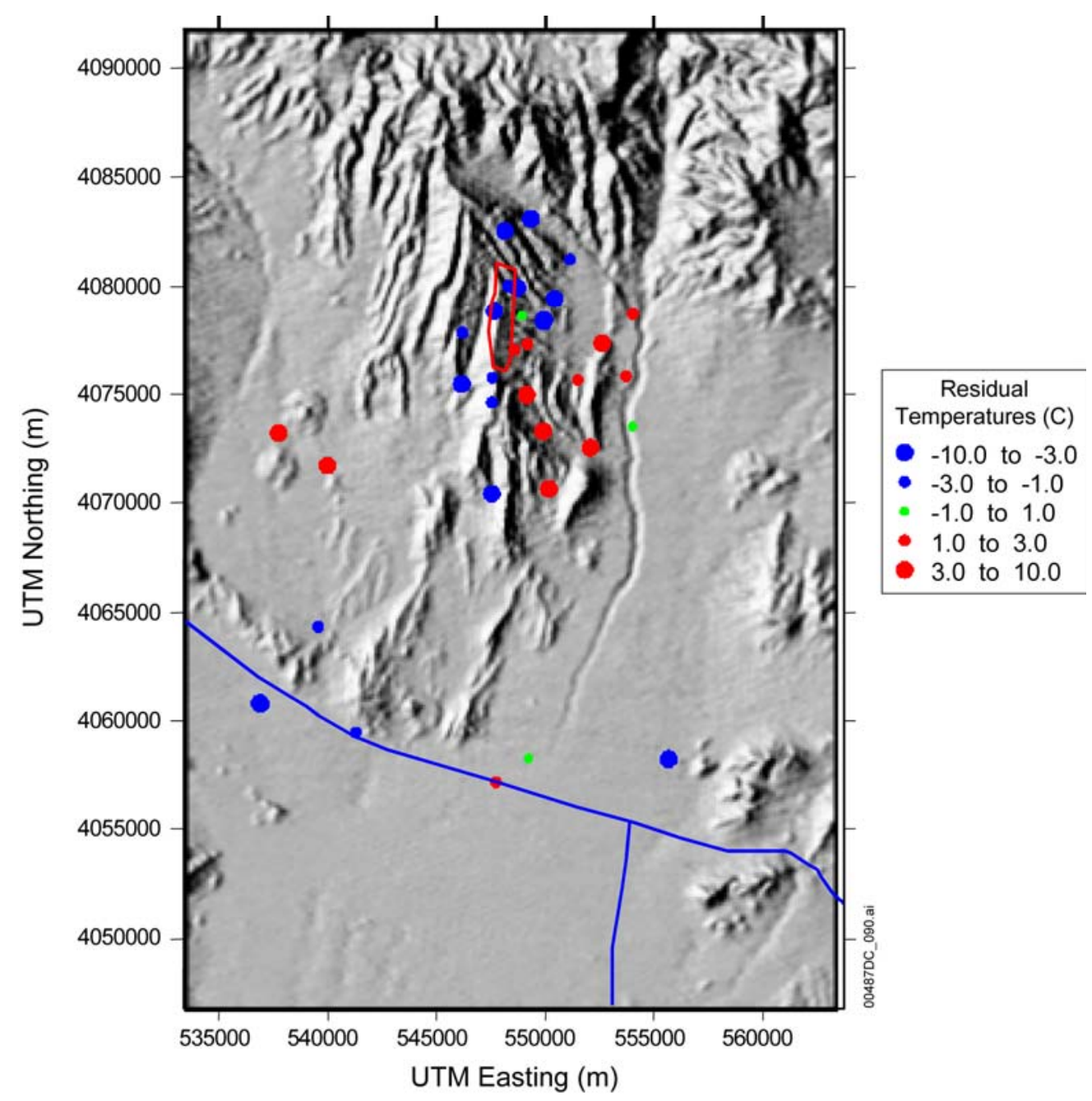

Source: Arnold et al. 2003 (DIRS 164473).

NOTES: Temperatures are in ${ }^{\circ} \mathrm{C}$. UTM $=$ Universal Transverse Mercator

Figure 7-15. Residuals in Simulated Temperature at the Water Table for the Coupled Thermal Model

In the technical work plan governing this modeling task, a criterion was established for the independent validation of the SZ site-scale flow model with the ambient temperature data (BSC 2004 [DIRS 171421]). This criterion stated that the coupled model would constitute an independent validation of the flow model if the simulated temperatures were within $10^{\circ} \mathrm{C}$ of the measured temperatures. The uncalibrated coupled thermal transport model of the SZ does meet this criterion ( 85 of the 94 simulated temperatures are within $10^{\circ} \mathrm{C}$ of the measured temperatures). Thus, the validation criteria are generally met. The SZ site-scale flow model overestimates the upward vertical flow of groundwater in the area to the east and southeast of Yucca Mountain, and this flow could be controlled by reducing the vertical permeability in this area. The anomalously high, simulated temperatures in a small area of Crater Flat in the coupled model are apparently the result of an unrealistic discontinuity in the HFM that strongly focuses groundwater flow upward in this region. 


\subsection{VALIDATION SUMMARY}

The SZ site-scale flow model has met the validation criteria established for the validation activities completed to date. A comparison of the predicted and recently obtained water levels from the newly installed Nye County EWDP wells demonstrates that the SZ site-scale flow model can reliably predict the water levels and gradients along the flow path from the repository. An analysis of the impact of the differences between observed and predicted hydraulic gradients on the specific discharge along the flow path from the repository has identified only a minimal impact on the specific discharge, which easily meets the validation criteria previously established for this comparison.

A comparison of the permeability measurements from the ATC with the calibrated permeability value for the alluvium has similarly indicated close agreement between calibrated and measured values. An analysis of the impact of differences between calibrated and measured permeability on the specific discharge along the flow path from the repository also has demonstrated only a minimal impact on the specific discharge, which easily meets the validation criteria previously established for this comparison. An analysis of the combined impact on the specific discharge of the difference between observed and predicted hydraulic gradients and permeability values in the area of the ATC have similarly indicated minimal impact that easily meets the validation criteria previously established for this comparison.

The comparison between the flow paths predicted by the SZ site-scale flow model and those indicated by hydrochemical analysis has demonstrated close agreement between these flow paths, with the flow paths derived from hydrochemical analysis generally enveloping those predicted by the SZ site-scale flow model. The thermal model developed from the SZ site-scale flow model is capable of modeling thermal transport in the SZ reasonably well, and comparisons of the predicted with the observed temperatures generally meet the validation criteria previously established for the thermal modeling. The successful meeting of the validation criteria required for a Level II model validation provides the appropriate level of confidence required for the use of the SZ site-scale flow model in the overall total system performance assessment of the repository system.

The SZ site-scale flow model has been validated by applying acceptance criteria based on an evaluation of the model's relative importance to the potential performance of the repository system. Activities for confidence building during model development have been satisfied (Section 7.1.1). Also, all postdevelopment validation requirements defined in the technical work plan (BSC 2004 [DIRS 171421], Section 2.2.2) have been fulfilled (with justification for changes in the validation criteria), including corroboration of model results with hydrochemical data, temperature data, and water-level data that were not used in the model development (Sections 7.2.1, 7.2.3, and 7.2.4). The model development activities and the postdevelopment validation activities described the scientific basis for the SZ site-scale flow model. No future activities need to be accomplished for model validation. The model validation activities have determined that the SZ site-scale flow model is adequate and sufficiently accurate for the stated and intended purpose. 


\section{INTENTIONALLY LEFT BLANK}




\section{CONCLUSIONS}

The SZ site-scale flow model is the culmination of enormous efforts incorporating volumes of geologic, hydrologic-testing, and geochemistry data into a coherent representation of flow through the SZ near Yucca Mountain. This model is based upon a three-dimensional finite element mesh with $500 \mathrm{~m} \times 500 \mathrm{~m}$ horizontal elements, which grid convergence studies have shown to represent the hydrogeologic framework adequately without introducing significant numerical error. Additionally, the model's vertical resolution varies from 10 to $500 \mathrm{~m}$; the higher resolution is near the water table in the area under Yucca Mountain. This model is calibrated to and faithfully reproduces two important data sets: the observed potentiometric surface (water-level data) and boundary fluxes obtained from the SZ regional-scale flow model. In addition, the SZ site-scale flow model matches other data quantitatively and qualitatively. These data include permeability values derived from single-well and multiple-well tests, hydrochemical data, temperature data, and specific-discharge values estimated by the expert elicitation panel (CRWMS M\&O 1998 [DIRS 100353], Section 3.2).

The SZ site-scale flow model matches much of the existing SZ-related data, particularly with respect to the inferred fluid pathways below the repository area. Although the model is meant to represent the SZ accurately, when parameter uncertainty could not be further resolved, parameter values were selected to err on the side of conservatism. The hydrochemical data were used as a quality check for path-line direction. The SZ model produced path lines from the repository area that agree with those inferred from geochemical information. However, there was a bias in the calibration, notably in the low-gradient area where the calibrated heads were consistently 3-4 m higher than the observations.

When using the SZ site-scale flow model for TSPA calculations, three limitations must be noted:

- Changes to calibration parameter values. Some calibration parameters can be varied over a moderate range, and the overall calibration is not adversely affected. For example, calibration was performed assuming isotropic horizontal permeabilities, while the PA model runs incorporate a range of anisotropic permeabilities. Incorporating anisotropy improved calibration.

- Usable path-line distances. The continuum approach used for the SZ site-scale flow model requires large grid blocks that effectively average fracture and rock matrix properties. To produce meaningful results, the flow path should be long compared to the grid block size. Because the grid block size is $500 \mathrm{~m}$, a minimum distance of $2 \mathrm{~km}$ is recommended for path lines used in PA calculations.

- Overall model recharge fluxes. Because the SZ site-scale flow model is linear, recharge fluxes may be changed to reflect uncertainty in specific discharge, so long as the boundary fluxes and permeabilities are changed proportionally. 


\subsection{SUMMARY OF MODELING ACTIVITIES}

The SZ site-scale flow model was developed in several stages. First, the hydrogeology of a region around Yucca Mountain was numerically characterized with the Death Valley regional flow system model (SZ regional-scale model). Second, a detailed conceptual model of flow processes was developed for a smaller region (i.e., the site-scale) appropriate for TSPA-LA calculations. Third, a numerical model of groundwater flow was developed and calibrated (i.e., the SZ site-scale flow model). Fourth, a series of validation activities were completed to provide confidence in the SZ site-scale flow model and its output. Finally, results of this model were provided and the associated uncertainties were discussed (required before the start of TSPA-LA calculations).

\subsubsection{Saturated Zone Flow Characterization}

Much information is available about the regional-scale hydrogeology at Yucca Mountain, both from site characterization activities as well as from numerous additional hydrogeologic studies that have been conducted at the NTS. Specifically, sufficient information is available to describe the stratigraphy, structure, and hydraulic properties of component media, recharge and discharge regions, and groundwater flow paths.

The climate in the Yucca Mountain area is arid, and the water table varies from hundreds of meters below ground surface in the northern part of the model to tens of meters below ground surface in the southern part of the model. Natural recharge to the SZ is from precipitation percolating through the unsaturated zone. Recharge occurs primarily in mountainous areas where there is more snow and rainfall (i.e., Yucca Mountain, including regions of higher elevation to the north and northeast, and the Spring Mountains 31 miles $(50 \mathrm{~km})$ southeast of Yucca Mountain). Estimates of recharge rates at the regional scale are based on empirical relationships, and the SZ regional-scale model ensures equal SZ recharge and discharge. Flow paths in the SZ are well characterized at the regional scale, because numerous water-level measurements are available.

The fluxes from the SZ regional-scale flow model were used as targets, because this model represents a comprehensive water balance of the Death Valley hydrologic system with fluxes constrained by data from spring flows and infiltration rates. Boundary fluxes can help link the SZ site-scale flow model to other global-water-balance data, if necessary. The SZ site-scale flow model reasonably matched the flux data from the SZ regional scale flow model.

In the area near Yucca Mountain, water-level measurements, hydraulic testing in wells and geochemical analyses provide additional information about groundwater flow in the SZ. Water-level measurements indicate considerable differences in the magnitude of the hydraulic gradient between areas to the north (large hydraulic gradient), west (moderate hydraulic gradient), and southeast (low hydraulic gradient) of Yucca Mountain. The hydraulic gradient drives flow from the repository to the south and southeast. A vertical, upward hydraulic gradient from the underlying carbonate aquifer and the deeper volcanic units is also observed immediately downgradient of Yucca Mountain. Data on groundwater chemistry indicate significant spatial variability in geochemical and isotopic composition that results from differences in flow paths, recharge locations, and groundwater age. 
Because the performance of the Yucca Mountain repository is evaluated over a long period, the possible impacts of a future wetter climate must be considered. The general locations of areas of recharge and discharge depend primarily on the topography of the land surface. Modeling studies suggest that increased recharge would result in a higher water table and steeper hydraulic gradients. Field mapping of the occurrence of zeolites and paleospring deposits has confirmed that a higher water table existed during past wetter climates and supports numerical simulations of the possible impacts of climate change. Consequently, wetter climates in the future are expected to result in faster groundwater flow rates along present-day flow paths. The impacts of increased water table are discussed in the SZ transport model report (BSC 2004 [DIRS 170036], Section 6.6 and Appendix E1).

As groundwater in the Death Valley system moves from recharge to discharge areas, flow rates and paths depend largely on the hydraulic properties of the media along the flow paths. Geologic studies have identified the important rock types and their spatial distribution. The rock types that play the largest role in regional hydrogeology are Paleozoic carbonates, Quaternary-Tertiary volcanic rocks, and Quaternary-Tertiary sediments and volcanic tuffs that fill structural depressions (referred to as valley-fill material in portions of this report). Relatively shallow flow occurs in the volcanic rocks and valley fill (primarily alluvium), and deeper flow occurs in the regionally extensive carbonate aquifer. Along the inferred shallow flow path, groundwater flow paths originate in volcanic rocks near the repository site and continue into younger valley-fill deposits at greater distances.

The permeability of the volcanic rocks near Yucca Mountain is increased by the presence of fractures. An extensive suite of field observations, interpretations of borehole logs, boreholes hydrologic tests, lab-scale tests, and field tracer tests (C-wells complex) confirm that fractures dominate groundwater flow in the volcanic rocks. However, flow in the alluvium occurs through the primary porosity of these sediments.

\subsubsection{Conceptual Model of SZ Site-Scale Flow}

The SZ site-scale conceptual model is a synthesis of what is known about flow processes at the scale required for TSPA-LA calculations. This knowledge builds upon, and is consistent with, information that has accumulated at the regional scale, but it is more detailed because a higher density of data is available at the site-scale.

Information from geologic maps and cross sections, borehole data, fault-trace maps, and geophysical data were used to construct the HFM, a three-dimensional interpretation of the hydrostratigraphy and geologic structure of the SZ site-scale flow model. Rock stratigraphies within the framework model are grouped into 18 hydrogeologic units that are classified as having either relatively large permeability (aquifers) or relatively small permeability (confining units). The framework model specifies the position and geometry of these hydrogeologic units. In addition, the framework model identifies major faults that affect groundwater flow.

The source of most of the groundwater flow in the SZ site-scale flow model is lateral flow through the western, northern, and eastern boundaries. A small portion (approximately 5 percent) of the total flux through the SZ site-scale flow model is from precipitation and surface runoff infiltrating along Fortymile Wash. Outflow from the site-scale region is chiefly through 
the southern boundary. A small amount of water is removed by pumping wells located in the Amargosa Valley near the southern boundary of the model domain. As groundwater moves away from the repository, it first flows through a series of welded and nonwelded volcanic tuffs. These flow paths pass into alluvium.

\subsubsection{Mathematical Model and Numerical Approach}

The mathematical basis (and associated numerical approaches) of the SZ site-scale flow model is designed to assist in quantifying the uncertainty in the permeability of rocks in the geologic framework model and to represent accurately all included flow process. An automated parameter estimation approach is used to obtain the distribution of rock permeabilities yielding hydraulic heads that best matched measured values, as well as lateral-flow rates across model boundaries that are compatible with results from the SZ regional-scale flow model.

Calculations of groundwater flow (specific-discharge field) are made under steady-state assumptions. The approach of not explicitly representing fractures in the volcanic rocks is reasonable at the scale required for the TSPA-LA (tens of kilometers) but is not accurate at length scales shorter than the dimensions of model grid blocks (less than $500 \mathrm{~m}$ ).

\subsubsection{Model Validation and Confidence Building}

Confidence in the results of the mathematical model was built by comparing: (1) calculated to observed hydraulic heads; (2) predicted to measured permeabilities and therefore specific discharge; and (3) predicted and measured groundwater temperatures. In addition, it was confirmed that the flow paths leaving the region of the repository are consistent with those inferred both from gradients of measured head and from independent water-chemistry data.

\subsection{OUTPUTS}

The technical output from this model comprises the SZ site-scale flow model and associated input and output files (base case flow files). Output from the SZ site-scale flow model consists of the flow fields for the site-scale area that will be integrated into the SZ transport model and used to generate radionuclide breakthrough curves. Specifically, the output from the SZ site-scale flow model contains the specific discharge and the flow paths from the water table beneath the repository horizon to the accessible environment.

The computer files associated with the SZ site-scale flow model are contained in SZ Flow and Transport Model, Hydrogeologic Surface Files (output DTN: LA0304TM831231.001) and SZ Site-Scale Flow Model, FEHM Files for Base Case (DTN: LA0304TM831231.002 [DIRS 163788]).

\subsection{OUTPUT UNCERTAINTY}

This section describes remaining uncertainties with the two technical outputs of this model report: specific discharge and flow paths. The section also recommends how the uncertainty associated with the outputs should be considered. 


\subsubsection{Specific Discharge Uncertainty Range}

In previous SZ site-scale flow models for PA calculations, the specific discharge was varied from one-tenth of its nominal value to 10 times its nominal value. Since the uncertainty in permeability directly translates into the uncertainty in specific discharge, assuming a constant head gradient, experience gained in investigating permeability values during calibration is applicable to specific discharge. Based on recent calibration experience and the evaluation of permeability data from Yucca Mountain and other sites, this range may extend from one-third of its nominal value to three times the nominal value. The nominal value was obtained from the calibration effort described in this model report. Because the model is linear, calibration is preserved by scaling the fluxes, recharge, and permeabilities proportionally. It should also be noted that this scaling does not cause any permeabilities to exceed the limits imposed in the calibration process for any hydrogeologic unit along the flow path. In the discussion below, the focus is on the Bullfrog tuff unit because calibration experience has shown that, for all reasonable scenarios, the fluid particles leaving the repository area travel primarily through this unit before entering the alluvial aquifer.

From the re-evaluation of the permeability data described above and the statistical summary of the permeability data given in Table 6-24, three important facts emerge. First, the upper 95 percent confidence interval for the mean permeability of the Bullfrog tuff from the cross-hole tests $\left(3.4 \times 10^{-11} \mathrm{~m}^{2}\right)$ is approximately three times the mean value $\left(1.1 \times 10^{-11} \mathrm{~m}^{2}\right)$. The mean value, in turn, is very close to the nominal calibration value of $1.5 \times 10^{-11} \mathrm{~m}^{2}$ obtained for the SZ site-scale flow model. Second, alternative conceptual models implemented in the numerical model since the previous version of this report (BSC 2001 [DIRS 155974]) have resulted in a range of estimates for the permeability of the Bullfrog tuff that vary by less than 100 percent of the nominal permeability value. Third, the permeability data from Yucca Mountain had a practical maximum of $7.6 \times 10^{-11} \mathrm{~m}^{2}$ from individual tests (see Table 6-26) in highly fractured intervals in volcanic rock. Although this value exceeds the nominal value by a factor of five, uncertainty in the geometric-mean permeability is a more relevant measure of the uncertainty. Additionally, the intrinsic model formulation requires homogeneity within an element (volume-averaged permeability). Recall that large permeability measurements from the C-wells complex were probably due to their proximity to the Midway Valley fault. Overall, these arguments support the range of permeabilities being within three times the nominal value. Similarly, because the lower 95 percent confidence interval of the geometric-mean permeability of the Bullfrog tuff is approximately one-third of the mean value, this ratio is recommended for the lower limit in PA calculations. It should be noted that low permeabilities do not negatively impact modeled performance at this location. When the SZ site-scale model was run with permeabilities of three times and one-third of the nominal value, overall model calibration remained within acceptable tolerances.

In the 18-km compliance region, performance assessment calculations are strongly influenced by travel of fluid particles in the alluvial aquifer. Recent aquifer tests in well NC-EWDP-19D (Table 7-4) and permeability data for the NTS suggest that the variability of the alluvial aquifer permeability is less than that of the volcanic rocks. In particular, three of the four tests produced permeability values that were within a factor of 2 of the mean value. Thus, the permeability ratio ranges derived from the Bullfrog tuff analysis described above should be sufficient to bound the uncertainty in the alluvial aquifer permeability for the $18-\mathrm{km}$ compliance calculations. 


\subsubsection{Flow Paths Uncertainty}

The flow paths from the water table beneath the repository to the accessible environment directly affect breakthrough curves and associated radionuclide transport times. Because the flow paths are close to the water table and transition from the volcanic tuffs to the alluvium, flow-path uncertainty directly affects the length of flow in the volcanic tuffs and in the alluvium.

Uncertainty in flow paths is affected by anisotropy in hydraulic properties of the volcanic tuffs. Large-scale anisotropy and heterogeneity were implemented in the SZ site-scale flow model through direct incorporation of known hydraulic features, faults, and fractures. Small-scale anisotropy was derived from analysis of hydraulic testing at the C-wells (BSC 2004 [DIRS 170010], Section 6.2.6). This scientific analysis report also recommends an uncertainty range in anisotropy that should be used in the SZ site-scale flow model to account for uncertainty in the flow paths. For isotropic permeability, flow-path length is approximately $24.5 \mathrm{~km}$. For anisotropy ratios of 20 and 0.05 , flow path lengths are 22 and $27 \mathrm{~km}$, respectively. This is an acceptable range of variability in model results.

The alternate model developed to assess the impact of new data and analyses made available since the development of the SZ site-scale flow model indicates a straight north-to-south flow path. These alternate flow paths were incorporated in transport simulations (BSC 2004 [DIRS 170036]) to assess their effect on radionuclide transport.

The model is adequate for its intended use of providing flow field predictions as input to the SZ site-scale transport model necessary to generate radionuclide breakthrough curves.

\subsection{HOW THE APPLICABLE ACCEPTANCE CRITERIA ARE ADDRESSED}

This section describes how the acceptance criteria in the YMRP (NRC 2003 [DIRS 163274], Section 2.2.1.3.8.3, Flow Paths in the Saturated Zone, are addressed by this report.

\section{Acceptance Criteria from Section 2.2.1.3.8.3, Flow Paths in the Saturated Zone}

\section{Acceptance Criterion 1: System Description and Model Integration Are Adequate.}

Subcriterion (1): Section 1 explains that this model generates SZ velocity fields which are used as inputs for the model of transport in the SZ and are abstracted in the TSPA. The important physical phenomena are adequately incorporated in the SZ abstraction process as described in the following subsections: hydraulic gradients (Section 6.3.2.4); vertical gradients (Section 6.3.2.5); lateral boundary conditions (Section 6.3.2.6); Recharge (Section 6.3.2.7); Discharge (Section 6.3.2.8); heterogeneity (Section 6.3.2.9); faults (Section 6.3.2.10); and groundwater flow processes (Section 6.3.3.). The discussion of groundwater table rise in Section 6.4.5.1 uses consistent and appropriate assumptions about climate change.

Subcriterion (2): Aspects of hydrology, geology and geochemistry that may affect flow paths in the SZ are described adequately in Section 6.3 and Appendix A.

Subcriterion (4): Section 4.1 states that: (1) the SZ flow model uses the same recharges as used in the 1997 DVRFS model in the area represented by the site scale model; (2) the lateral 
boundary fluxes from the DVRFS are used to calibrate the site-scale flow model; and (3) the fluxes from the DVRFS were averaged and used as calibration targets for the SZ site-scale model. The SZ site-scale flow model uses appropriate recharge values from flow in the unsaturated zone.

Subcriterion (5): Section 6.2 provides sufficient data and technical bases to assess the degree to which FEPs have been included in the flow paths.

Subcriterion (6): Flow paths in the SZ are adequately delineated, considering site conditions, as described in Section 6.6.2.3 and Appendix A. Section 6.8 shows how the flow model that was developed generates flow fields that simulate radionuclide transport in saturated porous rock and alluvium under natural and forced gradient conditions.

Subcriterion (7): The effect of climate on flow paths is evaluated adequately in Section 6.4.5.1.

Subcriterion (8): Section 6.5.3.7 explains how the linear approximation of the temperature gradient captures the effect of geothermal heat flux on groundwater viscosity.

Subcriterion (9): The impact of the expected water table rise on potentiometric heads and flow directions, and consequently on repository performance, is adequately considered in Section 6.4.5.1.

Subcriterion (10): This report was prepared in accordance with the Quality Assurance Requirements and Description (QARD) (DOE 2004 [DIRS 171539]), which commits to this U.S. Nuclear Regulatory Commission guidance. Compliance with the QARD was determined through multiple reviews.

\section{Acceptance Criterion 2: Data Are Sufficient for Model Justification.}

Subcriterion (1): Section 4.1 identifies the geological, hydrological, and geochemical values used in this model to evaluate flow paths in the SZ and adequately justifies those values by identifying their reliable sources. Section 6.5.3 adequately describes how the data were used, interpreted, and appropriately synthesized into parameters by explaining how water level and head distributions, definitions of the hydrogeologic units, the distribution of recharge flux and lateral fluxes into the model domain, feature and fault distribution, temperature profiles in wells, and boundary conditions were incorporated into the site-scale model for SZ flow. Section 6.5.3.1 describes the development of the hydrogeologic framework, which, with the known features of the site is used to design a grid for flow modeling. Section 6.5.3.2 describes the generation of the grid, which enables the data to be assigned to hydrogeologic units and features, recharge fluxes, hydrogeologic properties, and boundary conditions at node points. Section 6.5.3.3 describes the use of hydrogeologic properties, Section 6.5.3.4 describes the representation of features, Section 6.5.3.5 describes the use of the boundary conditions described in Section 6.3.2.6, Section 6.5.3.6 describes recharge, and Section 6.5.3.7 describes how the hydrogeologic properties are specified for each node in the computational grid. Section 7.2.4 describes the permeability data obtained at the NTS, including the lower carbonate aquifer (Section 7.2.4.1), the valley fill aquifer (Section 7.2.4.2), the welded tuff aquifer (Section 7.2.4.3), and the lava flow aquifer (Section 7.2.4.4). 
Subcriterion (2): The sufficiency of the data collected on the natural system to establish boundary conditions on flow paths in the SZ is demonstrated in Section 6.3.2. Section 6.3.2 describes the hydrogeologic setting of the SZ flow system near Yucca Mountain. Section 6.3.2.1 relates the geologic features to flow in the SZ. Section 6.3.2.2 describes the HFM that includes faults, zones of hydrothermal alteration, and other features that affect flow in the SZ. Section 6.3.2.3 uses the potentiometric surface map to determine the general direction of groundwater flow. Section 6.3.2.4 describes the hydraulic gradients and Section 6.3.2.5 describes the vertical gradients. Section 6.3.2.6 explains how the boundary conditions are derived from regional water level and head data form fixed-head boundary conditions on the lateral sides of the model. Section 6.3.2.7 describes the three components of recharge and Section 6.3.2.8 reports that no natural discharge is observed. Section 6.3.2.9 describes the observed physical and chemical heterogeneity of the rocks and water in the SZ. Section 6.3.2.10 describes the role of faults. Initial conditions are not included in the model because it is a steady-state model.

Subcriterion (3): The appropriateness of the techniques used to obtain the SZ geologic, hydrologic, and geochemical data used in this model is established in the reliable sources of this data listed in Section 4.1. Adequacy of the data is illustrated by the observation that the model did not change when updated with additional water-level data from new wells (Section 4.1). Section 7.2.3 describes the acquisition of data about permeability from single-hole tests (Section 7.2.3.1) and cross-hole tests (Section 7.2.3.2).

Subcriterion (4): Section 6.5 provides sufficient information to substantiate that the proposed mathematical groundwater modeling approach and proposed model is applicable to site conditions. Section 6.5.1 discusses the equations from the basic laws of flow that were applied and Section 6.5.2 describes the computational model used to solve those equations. Section 6.5.3 describes the inputs from data about the site, including the HFM (Section 6.5.3.1), grid generation (Section 6.5.3.2), hydrogeologic properties (Section 6.5.5.3), discrete features and regions (Section 6.5.3.4), boundary conditions (Section 6.5.3.5), and recharge (Section 6.5.3.6).

Section 6.61 provides sufficient information to substantiate that the proposed mathematical groundwater model is calibrated. Section 6.6.1.1 describes the calibration criteria, Section 6.6.1.2 describes the parameter optimization procedure, Section 6.6.1.3 describes the calibration targets, and Section 6.6.1.4 describes the calibration parameters. Section 6.6.2 describes the calibration results for water levels (Section 6.6.2.1), fluxes (Section 6.6.2.2), flow paths (Section 6.6.2.3), and specific discharge (Section 6.62.4).

\section{Acceptance Criterion 3: Data Uncertainty Is Characterized and Propagated Through the Model Abstraction.}

Subcriterion (1): Section 6.6.1 explains how calibration is used to optimize the values of important model parameters in a way that is technically defensible, reasonably accounts for uncertainties and variabilities, and does not result in an under-representation of the risk estimate.

Subcriterion (2): The effect of climate on flow paths is evaluated adequately in Section 6.4.5.1. 
Subcriterion (3): Section 6.6.1 and 6.8 show how uncertainty has been adequately represented in the development of parameters for the model.

Subcriterion (4): A SZ flow expert elicitation panel was conducted in accordance with Kotra et al. (1996 [DIRS 100909] and addressed the following issues:

- Appropriateness of the horizontal to vertical anisotropy ratio of 10:1 (Section 5)

- Estimates of discharge from the volcanic aquifer (Section 6.3.3)

- Semiperched water as a reason for the observed large hydraulic gradient (Section 6.5.3.4)

- Specific discharge near Yucca Mountain (Sections 6.6.1.2, 6.6.2.4, and 8).

\section{Acceptance Criterion 4: Model Uncertainty Is Characterized and Propagated Through the Model Abstraction.}

Subcriterion (1): Several ACM, which are consistent with available data and current scientific understanding, are identified in Section 6.4. They are: (1) models for the LHG north of Yucca Mountain (Section 6.4.1); (2) a shallow representation of the Solitario Canyon fault (Section 6.4.2); (3) anisotropies in hydraulic properties, with and without vertical anisotropy (Section 6.4.31), and constant and variable horizontal anisotropy ratios (Section 6.4.3.2); (4) four versions of the potentiometric surface of the uppermost part of the SZ (Section 6.4.4); (5) water table rise resulting from climate change (Section 6.4.5); and (6) the alternate model developed to assess the impact of new data and of the analyses which were made available for the SZ site-scale flow model.

Section 6.7 describes two ACMs in detail, the LHG and a Shallow Solitario Canyon fault.

Section 6.7.1 discuss the LHG ACM, which accounts for the observed large hydraulic gradient, which is an observed feature of the flow system near Yucca Mountain. Section 6.7.1.1 provides an overview of this ACM. Three versions of the LHG ACM are discussed in Section 6.7.1.2: (1) ANF, (2) AFW, and (3) AWF plus the AWF/GDF. Water level and flow path results and limitations of the ACMs for the flow fields considered in the TSPA are discussed in Section 6.7.1.3. The assessment in Section 6.7.1.4 shows that this alternative conceptualization of the LHG has little effect on the site-scale flow results, so that the base case provides an adequate model.

Section 6.7.2 discusses the Solitario Canyon fault ACM, which simulates an alternative extension of the fault from the water table to the top of the carbonate aquifer. Section 6.7.2.1 provides an overview of this Shallow fault. A comparison of the heads and flow paths is presented in Section 6.7.2.3, where differences from the base case are identified. The subsystem analysis in Section 6.7.2.4 shows that this ACM representation of the Solitario Canyon fault does not differ substantially from performance of the base case.

The results and limitations of the ACMs were appropriately considered in the abstractions. As discussed in Sections 6.4 and 6.7, the LHG ACM and Solitario fault ACM did not significantly 
affect model results, and, so were not included in the abstractions. Vertical anisotropy was not included (Sections 6.4.3.1 and 6.8.3.2). This is because the vertical anisotropy from an expert elicitation is only a rule of thumb and removal of the vertical anisotropy from model calibration did not significantly affect the difference between the measured and computed heads (Section 6.8.3.1). Horizontal anisotropy was included in the TSPA analysis (Section 6.4.3.2). Of the four versions of the potentiometric surface map discussed in Section 6.4.4.1-6.4.4.4, it was determined that the base-case qualitatively reproduces the important features of the potentiometric surface (Section 6.4.4.4). Sections 6.4.5.1 and 6.4.5.2 explain how the change in SZ flow paths resulting from a rise in the water table need not be included in the TSPA because the use of scaling factors conservatively accounts for the impact of climate changes on SZ flow.

Subcriterion (2): Conceptual model uncertainties are adequately defined and documented in Sections 6.4 and 6.7, as discussed above, and in Section 6.8. These sections also include the proper assessment of the effects on conclusions regarding performance. Section 6.8.1 addresses uncertainty in the flow paths due to alternative conceptualizations of the LHG, and Section 6.8.2 discusses the related issue of perched water.

Section 6.7.1.3 discusses the effects of the three LHG ACMs on flow and demonstrates the adequacy of the base case model for repository performance. The Solitario Canyon fault ACM addresses uncertainty in the depth of the fault. See, Section 6.7.2.1. Section 6.7.2.3 describes the investigations into the importance of the depth of the fault and Section 6.7.2.4 concludes that the alternative depth would not affect repository performance.

Section 6.8.3.1 shows that variations in vertical anisotropy do not substantially affect repository performance. Section 6.8.3.2 explains that variations in horizontal anisotropy are within the uncertainty ranges used in the TSPA-SR. This uncertainty is propagated forward to the TSPA-LA.

Section 6.8.4 explains why the use of volume-averaged representations of faults by zones of enhanced permeability provide adequate representations of fault flow properties.

Uncertainty in the quantification of specific discharge is discussed in Sections 6.8.5 and 6.8.5.2 and is shown that for the volcanic aquifer and the alluvial aquifer along the flow path, there is general consistency between the specific discharge simulated by the model and the median of values of uncertainty ranges estimated by the SZ expert panel from testing data. Accordingly, an uncertainty distribution for specific discharge has been constructed as described in Section 6.8.5. This uncertainty is propagated forward to the TSPA-LA.

Uncertainty in the hydrologic contacts is discussed in Section 6.8.5.1 and shown to have moderate effects in some cases. Accordingly, this uncertainty was determined not to warrant propagation to the TSPA-LA.

Uncertainty due to scaling is discussed in Section 6.8.6, where it is concluded that such uncertainty does not significantly affect flow modeling.

Subcriterion (3): The conceptual model uncertainty considered in this report is consistent with available site characterization data and field measurements. Section 6.8.1 describes the model uncertainty associated with the LHG. Sections 6.7.1.1 and 6.7.1.2 describe how the observed 
LHG is approximated by alternative conceptualizations based on changes in permeability instead of on low permeability east-west feature that has been incorporated in the base-case conceptual model but has not been observed. Section 6.7.1.4 explains why the ACMs are not considered to significantly affect hydrologic conditions. Section 6.7.2.1 discusses the relation between field measurements and the treatment of uncertainty in the depth of the Solitario Canyon fault and shows that flow paths from the water table underneath the repository to the accessible environment are unchanged. Accordingly, the uncertainty does not result in an under-estimate of the risk.

Section 6.8.2 explains why perched water was not included in the SZ site-scale flow model. Section 6.8.3 address vertical and horizontal anisotropy that can affect flow path, flow direction, and specific discharge. Sections 6.8.3.1 and 6.8.3.2 discuss the vertical and horizontal anisotropies, respectively. Section 6.8.4 explains why the uncertainty associated with the representation of faults by grid blocks having enhanced permeability is acceptable. Section 6.8.5 addresses uncertainty in the quantification of groundwater specific discharge. Section 6.8.5.1 addresses the effects of uncertainty in the hydrogeologic contact on specific discharge. Section 6.8.6 addresses uncertainty due to scaling. Section 6.8.5.2 addresses the uncertainty range for specific discharge. Section 6.8.5.3 addresses the uncertainty related to assuming flow in a porous continuum instead of through faults. These sections also explain how these uncertainties have been addressed so as not to result in an under-representation of the risk.

Subcriterion (4): Alternative modeling approaches are appropriate and consistent with available data and current scientific knowledge, and appropriately consider their results and limitations, using analyses that are sensitive to the processes modeled, as discussed above. 


\section{INTENTIONALLY LEFT BLANK}




\section{INPUTS AND REFERENCES}

The following is a list of the references cited in this document. Column 2 represents the unique six-digit numerical identifiers (the Document Input Reference System numbers), which are placed in the text following the reference callout (e.g., BSC 2004 [DIRS 109715]). The purpose of these numbers is to assist in locating a specific reference. Multiple sources by the same author (e.g., BSC 2004) are sorted alphabetically by title.

\subsection{DOCUMENTS CITED}

Ahlers, C.F.; Finsterle, S.; and Bodvarsson, G.S. 1999. "Characterization and 109715 Prediction of Subsurface Pneumatic Response at Yucca Mountain, Nevada." Journal of Contaminant Hydrology, 38, (1-3), 47-68. New York, New York: Elsevier. TIC: 244160.

Arnold, B.W.; Zyvoloski, G.; Economy, K.; and Wallace, M. 2003. "Thermal 164473 Transport in the Saturated Zone Site-Scale Model at Yucca Mountain." Proceedings of the 10th International High-Level Radioactive Waste Management Conference (IHLRWM), March 30-April 2, 2003, Las Vegas, Nevada. Pages 301-306. La Grange Park, Illinois: American Nuclear Society. TIC: 254559.

Benson, L. and Klieforth, H. 1989. "Stable Isotopes in Precipitation and Ground 104370 Water in the Yucca Mountain Region, Southern Nevada: Paleoclimatic Implications." Aspects of Climate Variability in the Pacific and the Western Americas. Peterson, D.H., ed. Geophysical Monograph 55. Pages 41-59. Washington, D.C.: American Geophysical Union. TIC: 224413.

Benson, L.V. and McKinley, P.W. 1985. Chemical Composition of Ground Water

101036 in the Yucca Mountain Area, Nevada, 1971-84. Open-File Report 85-484. Denver, Colorado: U.S. Geological Survey. ACC: NNA.19900207.0281.

Bish, D.L. 1989. Evaluation of Past and Future Alterations in Tuff at Yucca Mountain, Nevada, Based on the Clay Mineralogy of Drill Cores USW G-1, G-2, and G-3. LA-10667-MS. Los Alamos, New Mexico: Los Alamos National Laboratory. ACC: NNA.19890126.0207.

Bish, D.L. and Chipera, S.J. 1989. Revised Mineralogic Summary of Yucca Mountain, Nevada. LA-11497-MS. Los Alamos, New Mexico: Los Alamos National Laboratory. ACC: NNA.19891019.0029.

Blankennagel, R.K. and Weir, J.E., Jr. 1973. Geohydrology of the Eastern Part of 101233 Pahute Mesa, Nevada Test Site, Nye County, Nevada. Professional Paper 712-B. Washington, D.C.: U.S. Geological Survey. TIC: 219642. 
Bower, K.M.; Gable, C.W.; and Zyvoloski, G.A. 2000. Effect of Grid Resolution on Control Volume Finite Element Groundwater Modeling of Realistic Geology. LA-UR-001870. Los Alamos, New Mexico: Los Alamos National Laboratory. TIC: 248256.

Brodsky, N.S.; Riggins, M.; Connolly, J.; and Ricci, P. 1997. Thermal Expansion, 100653 Thermal Conductivity, and Heat Capacity Measurements for Boreholes UE25 NRG-4, UE25 NRG-5, USW NRG-6, and USW NRG-7/7A. SAND95-1955. Albuquerque, New Mexico: Sandia National Laboratories. ACC: MOL.19980311.0316.

Broxton, D.E.; Bish, D.L.; and Warren, R.G. 1987. "Distribution and Chemistry of 102004 Diagenetic Minerals at Yucca Mountain, Nye County, Nevada." Clays and Clay Minerals, 35, (2), 89-110. Long Island City, New York: Pergamon Press.

TIC: 203900.

BSC (Bechtel SAIC Company) 2001. Calibration of the Site-Scale Saturated Zone 155974 Flow Model. MDL-NBS-HS-000011 REV 00 ICN 01. Las Vegas, Nevada: Bechtel SAIC Company. ACC: MOL.20010713.0049.

BSC 2001. Geochemical and Isotopic Constraints on Groundwater Flow Directions, Mixing, and Recharge at Yucca Mountain, Nevada.

158606 ANL-NBS-HS-000021 REV 00 ICN 2. Las Vegas, Nevada: Bechtel SAIC Company. ACC: MOL.20020128.0434.

BSC 2002. Analysis of Geochemical Data for the Unsaturated Zone. ANL-NBS-HS-000017 REV 00 ICN 02. Las Vegas, Nevada: Bechtel SAIC Company. ACC: MOL.20020314.0051.

BSC 2003. Repository Design, Repository/PA IED Subsurface Facilities. 162289 800-IED-EBS0-00401-000-00C. Las Vegas, Nevada: Bechtel SAIC Company. ACC: ENG.20030303.0002.

BSC 2003. Technical Work Plan for: Saturated Zone Flow and Transport Modeling and Testing. TWP-NBS-MD-000002 REV 01 ICN 01. Las Vegas, Nevada: Bechtel SAIC Company. ACC: DOC.20031203.0002.

BSC 2004. Development of Numerical Grids for UZ Flow and Transport Modeling. ANL-NBS-HS-000015 REV 02. Las Vegas, Nevada: Bechtel SAIC Company. ACC: DOC.20040901.0001.

BSC 2004. Engineered Barrier System Features, Events, and Processes. 170900 ANL-WIS-PA-000002 REV 02. Las Vegas, Nevada: Bechtel SAIC Company. ACC: DOC.20040621.0002.

BSC 2004. Features, Events, and Processes in SZ Flow and Transport. 170013 ANL-NBS-MD-000002, Rev. 03. Las Vegas, Nevada: Bechtel SAIC Company. 
BSC 2004. Hydrogeologic Framework Model for the Saturated Zone Site Scale 170008 Flow and Transport Model. MDL-NBS-HS-000024, Rev. 00. Las Vegas, Nevada: Bechtel SAIC Company.

BSC 2004. Particle Tracking Model and Abstraction of Transport Processes. 170041 MDL-NBS-HS-000020 REV 01. Las Vegas, Nevada: Bechtel SAIC Company. ACC: DOC.20041020.0016.

BSC 2004. Probability Distribution for Flowing Interval Spacing. 170014 ANL-NBS-MD-000003 REV 01. Las Vegas, Nevada: Bechtel SAIC Company. ACC: DOC.20040923.0003.

BSC 2004. Q-List. 000-30R-MGR0-00500-000-000 REV 00. Las Vegas, Nevada: 168361 Bechtel SAIC Company. ACC: ENG.20040721.0007.

BSC 2004. Recharge and Lateral Groundwater Flow Boundary Conditions for the 170015 Saturated Zone Site-Scale Flow and Transport Model. ANL-NBS-MD-000010 REV 01. Las Vegas, Nevada: Bechtel SAIC Company.

ACC: DOC.20041008.0004.

BSC 2004. Saturated Zone Flow and Transport Model Abstraction. 170042 MDL-NBS-HS-000021 REV 02. Las Vegas, Nevada: Bechtel SAIC Company. ACC: DOC.20041028.0003.

BSC 2004. Saturated Zone In-Situ Testing. ANL-NBS-HS-000039 REV 01. Las Vegas, Nevada: Bechtel SAIC Company. ACC: DOC.20041115.0008.

BSC 2004. Site-Scale Saturated Zone Transport. MDL-NBS-HS-000010 REV 02. 170036 Las Vegas, Nevada: Bechtel SAIC Company. ACC: DOC.20041103.0004.

BSC 2004. Technical Work Plan For: Natural System - Saturated Zone Analysis 170115 and Model Report Integration. TWP-NBS-MD-000002 REV 02. Las Vegas, Nevada: Bechtel SAIC Company. ACC: DOC.20040706.0007.

BSC 2004. Technical Work Plan for: Natural System - Saturated Zone Analysis 171421 and Model Report Integration. TWP-NBS-MD-000002 REV 02 ICN 01. Las Vegas, Nevada: Bechtel SAIC Company. ACC: DOC.20040818.0004.

BSC 2004. UZ Flow Models and Submodels. MDL-NBS-HS-000006 REV 02. Las Vegas, Nevada: Bechtel SAIC Company. ACC: DOC.20041101.0004.

BSC 2004. Water-Level Data Analysis for the Saturated Zone Site-Scale Flow and 170009 Transport Model. ANL-NBS-HS-000034 REV 02. Las Vegas, Nevada: Bechtel SAIC Company. ACC: DOC.20041012.0002. 
BSC 2004. Yucca Mountain Site Description. TDR-CRW-GS-000001 REV 02

ICN 01. Two volumes. Las Vegas, Nevada: Bechtel SAIC Company.

ACC: DOC.20040504.0008.

Buesch, D.C.; Spengler, R.W.; Moyer, T.C.; and Geslin, J.K. 1996. Proposed

100106

Stratigraphic Nomenclature and Macroscopic Identification of Lithostratigraphic

Units of the Paintbrush Group Exposed at Yucca Mountain, Nevada. Open-File

Report 94-469. Denver, Colorado: U.S. Geological Survey.

ACC: MOL.19970205.0061.

Burke, W.H.; Denison, R.E.; Hetherington, E.A.; Koepnick, R.B.; Nelson, H.F.;

162906 and Otto, J.B. 1982. "Variation of Seawater ${ }^{87} \mathrm{Sr} /{ }^{86} \mathrm{Sr}$ Throughout Phanerozoic Time." Geology, 10, 516-519. Boulder, Colorado: Geological Society of America. TIC: 255085.

Campana, M.E. and Byer, R.M., Jr. 1996. "A Conceptual Evaluation of Regional 126814 Ground-Water Flow, Southern Nevada-California, USA." Environmental and Engineering Geoscience, II, (4), 465-478. Boulder, Colorado: Geological Society of America. TIC: 246651.

Canori, G.F. and Leitner, M.M. 2003. Project Requirements Document.

TER-MGR-MD-000001 REV 02. Las Vegas, Nevada: Bechtel SAIC Company. ACC: DOC.20031222.0006.

Chapman, J.B. and Lyles, B.F. 1993. Groundwater Chemistry at the Nevada Test 162940 Site: Data and Preliminary Interpretations. DOE/NV/10845-16. Las Vegas, Nevada: U.S. Department of Energy, Nevada Operation Office.

ACC: MOL.20031023.0087.

Cheng, H.; Edwards, R.L.; Hoff, J.; Gallup, C.D.; Richards, D.A.; and Asmerom, 153475 Y. 2000. "The Half-Lives of Uranium-234 and Thorium-230." Chemical Geology, 169, 17-33. Amsterdam, The Netherlands: Elsevier. TIC: 249205.

Chipera, S.J. and Bish, D.L. 1997. "Equilibrium Modeling of

Clinoptilolite-Analcime Equilibria at Yucca Mountain, Nevada." Clays and Clay Minerals, 45, (2), 226-239. Long Island City, New York: Pergamon Press.

TIC: 233948.

Chipera, S.J.; Bish, D.L.; and Carlos, B.A. 1995. "Equilibrium Modeling of the 100025 Formation of Zeolites in Fractures at Yucca Mountain, Nevada." Natural Zeolites '93: Occurrence, Properties, Use, Proceedings of the 4th International Conference on the Occurrence, Properties, and Utilization of Natural Zeolites, June 20-28, 1993, Boise, Idaho. Ming, D.W. and Mumpton, F.A., eds. Pages 565-577. Brockport, New York: International Committee on Natural Zeolites. TIC: 243086. 
Claassen, H.C. 1985. Sources and Mechanisms of Recharge for Ground Water in

101125

the West-Central Amargosa Desert, Nevada-A Geochemical Interpretation. U.S. Geological Survey Professional Paper 712-F. Washington, D.C.: United States

Government Printing Office. TIC: 204574.

Clark, I.D. and Fritz, P. 1997. Environmental Isotopes in Hydrogeology.

105738

Boca Raton, Florida: Lewis Publishers. TIC: 233503.

Craig, R.W. and Robison, J.H. 1984. Geohydrology of Rocks Penetrated by Test

101040

Well UE-25p\#1, Yucca Mountain Area, Nye County, Nevada. Water-Resources Investigations Report 84-4248. Denver, Colorado: U.S. Geological Survey.

ACC: NNA.19890905.0209.

CRWMS M\&O (Civilian Radioactive Waste Management System Management \&

100353

Operating Contractor) 1998. Saturated Zone Flow and Transport Expert

Elicitation Project. Deliverable SL5X4AM3. Las Vegas, Nevada: CRWMS

M\&O. ACC: MOL.19980825.0008.

CRWMS M\&O 2000. Calibration of the Site-Scale Saturated Zone Flow Model. MDL-NBS-HS-000011 REV 00. Las Vegas, Nevada: CRWMS M\&O.

ACC: MOL.20000825.0122.

CRWMS M\&O 2000. Input and Results of the Base Case Saturated Zone Flow and Transport Model for TSPA. ANL-NBS-HS-000030 REV 00. Las Vegas, Nevada: CRWMS M\&O. ACC: MOL.20000526.0330.

CRWMS M\&O 2000. Total System Performance Assessment for the Site

Recommendation. TDR-WIS-PA-000001 REV 00 ICN 01. Las Vegas, Nevada:

CRWMS M\&O. ACC: MOL.20001220.0045.

Czarnecki, J.B. 1984. Simulated Effects of Increased Recharge on the

Ground-Water Flow System of Yucca Mountain and Vicinity, Nevada-California.

Water Resources Investigations Report 84-4344. Denver, Colorado: U.S.

Geological Survey. ACC: HQS.19880517.1750.

Czarnecki, J.B. 1985. Simulated Effects of Increased Recharge on the

Ground-Water Flow System of Yucca Mountain and Vicinity, Nevada-California. Water-Resources Investigations Report 84-4344. Denver, Colorado: U.S.

Geological Survey. TIC: 203222.

Czarnecki, J.B.; Faunt, C.C.; Gable, C.W.; and Zyvoloski, G.A. 1997. Hydrogeology and Preliminary Calibration of a Preliminary Three-Dimensional Finite-Element Ground-Water Flow Model of the Site Saturated Zone, Yucca Mountain, Nevada. Administrative Report. Denver, Colorado: U.S. Geological Survey. ACC: MOL.19980204.0519. 
D’Agnese, F.A.; Faunt, C.C.; Turner, A.K.; and Hill, M.C. 1997. Hydrogeologic

100131 Evaluation and Numerical Simulation of the Death Valley Regional Ground-Water Flow System, Nevada and California. Water-Resources Investigations Report 96-4300. Denver, Colorado: U.S. Geological Survey.

ACC: MOL.19980306.0253.

D’Agnese, F.A.; O’Brien, G.M.; Faunt, C.C.; and San Juan, C.A. 1999. Simulated 120425 Effects of Climate Change on the Death Valley Regional Ground-Water Flow System, Nevada and California. Water-Resources Investigations Report 98-4041. Denver, Colorado: U.S. Geological Survey. TIC: 243555.

D’Agnese, F.A.; O’Brien, G.M.; Faunt, C.C.; Belcher, W.R.; and San Juan, C. 158876 2002. A Three-Dimensional Numerical Model of Predevelopment Conditions in the Death Valley Regional Ground-Water Flow System, Nevada and California. Water-Resources Investigations Report 02-4102. Denver, Colorado: U.S. Geological Survey. TIC: 253754.

Davisson, M.L.; Kenneally, J.M.; Smith, D.K.; Hudson, G.B.; Nimz, G.J.; and 162939 Rego, J.H. 1994. Preliminary Report on the Isotope Hydrology Investigations at the Nevada Test Site: Hydrologic Resources Management Program, FY 1992-1993. UCRL-ID-116122. Livermore, California: Lawrence Livermore National Laboratory, Nuclear Chemistry Division. TIC: 210954.

Day, W.C.; Dickerson, R.P.; Potter, C.J.; Sweetkind, D.S.; San Juan, C.A.; Drake, 100027 R.M., II; and Fridrich, C.J. 1998. Bedrock Geologic Map of the Yucca Mountain Area, Nye County, Nevada. Geologic Investigations Series I-2627. Denver, Colorado: U.S. Geological Survey. ACC: MOL.19981014.0301.

Day, W.C.; Potter, C.J.; Sweetkind, D.S.; Dickerson, R.P.; and San Juan, C.A. 1998. Bedrock Geologic Map of the Central Block Area, Yucca Mountain, Nye County, Nevada. Miscellaneous Investigations Series Map I-2601. Washington, D.C.: U.S. Geological Survey. ACC: MOL.19980611.0339.

de Marsily, G. 1986. Quantitative Hydrogeology: Groundwater Hydrology for Engineers. San Diego, California: Academic Press. TIC: 208450.

Dettinger, M.D. 1989. "Reconnaissance Estimates of Natural Recharge to Desert Basins in Nevada, U.S.A., by Using Chloride-Balance Calculations." Journal of Hydrology, 106, 55-78. Amsterdam, The Netherlands: Elsevier. TIC: 236967.

Dettinger, M.D. 1989. Distribution of Carbonate-Rock Aquifers in Southern 154690 Nevada and the Potential for Their Development, Summary of Findings, 1985-88. Summary Report No. 1. Carson City, Nevada: State of Nevada.

ACC: NNA.19940412.0056. 
DOE (U.S. Department of Energy) 2004. Quality Assurance Requirements and

Description. DOE/RW-0333P, Rev. 16. Washington, D.C.: U.S. Department of Energy, Office of Civilian Radioactive Waste Management.

ACC: DOC.20040907.0002.

Drever, J.I. 1988. The Geochemistry of Natural Waters. 2nd Edition. Englewood 118564 Cliffs, New Jersey: Prentice-Hall. TIC: 242836.

Dudley, W.W., Jr. and Larson, J.D. 1976. Effect of Irrigation Pumping on Desert 103415 Pupfish Habitats in Ash Meadows, Nye County, Nevada. Professional Paper 927. Washington, D.C.: U.S. Geological Survey. ACC: MOL.20010724.0312.

Eddebbarh, A.A.; Zyvoloski, G.A.; Robinson, B.A.; Kwicklis, E.M.; Reimus, P.W.; 163577 Arnold, B.W.; Corbet, T.; Kuzio, S.P.; and Faunt, C. 2003. "The Saturated Zone at Yucca Mountain: An Overview of the Characterization and Assessment of the Saturated Zone as a Barrier to Potential Radionuclide Migration." Journal of Contaminant Hydrology, 62-63, 477-493. New York, New York: Elsevier.

TIC: 254205.

Ervin, E.M.; Luckey, R.R.; and Burkhardt, D.J. 1994. Revised Potentiometric100633 Surface Map, Yucca Mountain and Vicinity, Nevada. Water-Resources Investigations Report 93-4000. Denver, Colorado: U.S. Geological Survey. ACC: NNA.19930212.0018.

Faunt, C.C. 1997. Effect of Faulting on Ground-Water Movement in the Death 100146 Valley Region, Nevada and California. Water-Resources Investigations Report 95-4132. Denver, Colorado: U.S. Geological Survey. ACC: MOL.19980429.0119.

Faure, G. 1986. Principles of Isotope Geology. 2nd Edition. New York, 105559 New York: John Wiley \& Sons. TIC: 237212.

Flint, L.E. 1998. Characterization of Hydrogeologic Units Using Matrix 100033 Properties, Yucca Mountain, Nevada. Water-Resources Investigations Report 97-4243. Denver, Colorado: U.S. Geological Survey. ACC: MOL.19980429.0512.

Forester, R.M.; Bradbury, J.P.; Carter, C.; Elvidge-Tuma, A.B.; Hemphill, M.L.; 109425 Lundstrom, S.C.; Mahan, S.A.; Marshall, B.D.; Neymark, L.A.; Paces, J.B.; Sharpe, S.E.; Whelan, J.F.; and Wigand, P.E. 1999. The Climatic and Hydrologic History of Southern Nevada During the Late Quaternary. Open-File Report 98-635. Denver, Colorado: U.S. Geological Survey. TIC: 245717.

Forsyth, P.A. 1989. "A Control Volume Finite Element Method for Local Mesh 144110 Refinement." Proceedings, Tenth] SPE Symposium on Reservoir Simulation, Houston, Texas, February 6-8, 1989. SPE 18415. Pages 85-96. Richardson, Texas: Society of Petroleum Engineers. TIC: 247068. 
Freeze, R.A. and Cherry, J.A. 1979. Groundwater. Englewood Cliffs, New Jersey: 101173 Prentice-Hall. TIC: 217571.

Fridrich, C.J.; Dudley, W.W., Jr.; and Stuckless, J.S. 1994. "Hydrogeologic 100575 Analysis of the Saturated-Zone Ground-Water System, Under Yucca Mountain, Nevada." Journal of Hydrology, 154, 133-168. Amsterdam, The Netherlands: Elsevier. TIC: 224606.

Gascoyne, M. 1992. "Geochemistry of the Actinides and Their Daughters." 127184 Chapter 2 of Uranium-Series Disequilibrium: Applications to Earth, Marine, and Environmental Sciences. Ivanovich, M. and Harmon, R.S., eds. 2nd Edition. New York, New York: Oxford University Press. TIC: 234680.

Geldon, A.L.; Umari, A.M.A.; Earle, J.D.; Fahy, M.F.; Gemmell, J.M.; and Darnell, J. 1998. Analysis of a Multiple-Well Interference Test in Miocene Tuffaceous Rocks at the C-Hole Complex, May-June 1995, Yucca Mountain, Nye County, Nevada. Water-Resources Investigations Report 97-4166. Denver, Colorado: U.S. Geological Survey. TIC: 236724.

Geldon, A.L.; Umari, A.M.A.; Fahy, M.F.; Earle, J.D.; Gemmell, J.M.; and 100397 Darnell, J. 1997. Results of Hydraulic and Conservative Tracer Tests in Miocene Tuffaceous Rocks at the C-Hole Complex, 1995 to 1997, Yucca Mountain, Nye County, Nevada. Milestone SP23PM3. Las Vegas, Nevada: U.S. Geological Survey. ACC: MOL.19980122.0412.

Graves, R.P. 1998. Water Levels in the Yucca Mountain Area, Nevada, 1996. Open-File Report 98-169. Denver, Colorado: U.S. Geological Survey. ACC: MOL.19981117.0340.

Hevesi, J.A.; Flint, A.L.; and Istok, J.D. 1992. "Precipitation Estimation in Mountainous Terrain Using Multivariate Geostatistics. Part II: Isohyetal Maps." Journal of Applied Meteorology, 31, (7), 677-688. Boston, Massachusetts: American Meteorological Society. TIC: 225248.

Ingraham, N.L.; Lyles, B.F.; Jacobson, R.L.; and Hess, J.W. 1991. "Stable Isotopic 145088 Study of Precipitation and Spring Discharge in Southern Nevada." Journal of Hydrology, 125, 243-258. Amsterdam, The Netherlands: Elsevier. TIC: 238581.

Kilroy, K.C. 1991. Ground-Water Conditions in Amargosa Desert, 103010 Nevada-California, 1952-87. Water-Resources Investigations Report 89-4101. Carson City, Nevada: U.S. Geological Survey. TIC 209975.

Kotra, J.P.; Lee, M.P.; Eisenberg, N.A.; and DeWispelare, A.R. 1996. Branch Technical Position on the Use of Expert Elicitation in the High-Level Radioactive Waste Program. NUREG-1563. Washington, D.C.: U.S Nuclear Regulatory Commission. TIC: 226832. 
Kwicklis, E.M. 1999. "Determination of Pneumatic Diffusivity." Hydrogeology of

157414 the Unsaturated Zone, North Ramp Area of the Exploratory Studies Facility, Yucca Mountain, Nevada. Rousseau, J.P.; Kwicklis, E.M.; and Gillies, D.C., eds. Water-Resources Investigations Report 98-4050. Denver, Colorado: U.S. Geological Survey. ACC: MOL.19990419.0335.

La Camera, R.J. and Locke, G.L. 1997. Selected Ground-Water Data for Yucca 103011 Mountain Region, Southern Nevada and Eastern California, Through December 1996. Open-File Report 97-821. Carson City, Nevada: U.S. Geological Survey. ACC: MOL.20010724.0311.

Laczniak, R.J.; Cole, J.C.; Sawyer, D.A.; and Trudeau, D.A. 1996. Summary of 103012 Hydrogeologic Controls on Ground-Water Flow at the Nevada Test Site, Nye County, Nevada. Water-Resources Investigations 96-4109. Carson City, Nevada: U.S. Geological Survey. TIC: 226157.

Lagedrost, J.F. and Capps, W. 1983. Thermal Property and Density Measurements of Samples Taken from Drilling Cores from Potential Geologic Media.

BMI/ONWI-522. Columbus, Ohio: Battelle Memorial Institute, Office of Nuclear Waste Isolation. ACC: MOL.20030609.0316.

Langmuir, D. 1997. Aqueous Environmental Geochemistry. Upper Saddle River, New Jersey: Prentice Hall. TIC: 237107.

LeCain, G.D. 1997. Air-Injection Testing in Vertical Boreholes in Welded and 100153 Nonwelded Tuff, Yucca Mountain, Nevada. Water-Resources Investigations Report 96-4262. Denver, Colorado: U.S. Geological Survey.

ACC: MOL.19980310.0148.

LeCain, G.D.; Anna, L.O.; and Fahy, M.F. 2000. Results from Geothermal 144612 Logging, Air and Core-Water Chemistry Sampling, Air-Injection Testing, and Tracer Testing in the Northern Ghost Dance Fault, Yucca Mountain, Nevada, November 1996 to August 1998. Water-Resources Investigations Report 99-4210. Denver, Colorado: U.S. Geological Survey. TIC: 247708.

Levy, S.S. 1991. "Mineralogic Alteration History and Paleohydrology at Yucca Mountain, Nevada." High Level Radioactive Waste Management, Proceedings of the Second Annual International Conference, Las Vegas, Nevada, April 28-May 3, 1991. 1, 477-485. La Grange Park, Illinois: American Nuclear Society.

TIC: 204272.

Lichty, R.W. and McKinley, P.W. 1995. Estimates of Ground-Water Recharge 100589 Rates for Two Small Basins in Central Nevada. Water-Resources Investigations Report 94-4104. Denver, Colorado: U.S. Geological Survey.

ACC: MOL.19960924.0524. 
Loeven, C. 1993. A Summary and Discussion of Hydrologic Data from the Calico

101258 Hills Nonwelded Hydrogeologic Unit at Yucca Mountain, Nevada. LA-12376-MS. Los Alamos, New Mexico: Los Alamos National Laboratory.

ACC: NNA.19921116.0001.

Luckey, R.R.; Tucci, P.; Faunt, C.C.; Ervin, E.M.; Steinkampf, W.C.; D’Agnese, 100465 F.A.; and Patterson, G.L. 1996. Status of Understanding of the Saturated-Zone Ground-Water Flow System at Yucca Mountain, Nevada, as of 1995. Water-Resources Investigations Report 96-4077. Denver, Colorado: U.S. Geological Survey. ACC: MOL.19970513.0209.

Marshall, B.D.; Peterman, Z.E.; and Stuckless, J.S. 1993. "Strontium Isotopic 101142 Evidence for a Higher Water Table at Yucca Mountain." High Level Radioactive Waste Management, Proceedings of the Fourth Annual International Conference, Las Vegas, Nevada, April 26-30, 1993. 2, 1948-1952. La Grange Park, Illinois: American Nuclear Society. TIC: 208542.

McKinley, P.W.; Long, M.P.; and Benson, L.V. 1991. Chemical Analyses of Water 116222 from Selected Wells and Springs in the Yucca Mountain Area, Nevada and Southeastern California. Open-File Report 90-355. Denver, Colorado: U.S. Geological Survey. ACC: NNA.19901031.0004.

Meijer, A. 2002. "Conceptual Model of the Controls on Natural Water Chemistry 158813 at Yucca Mountain, Nevada." Applied Geochemistry, 17, (6), 793-805. New York, New York: Elsevier. TIC: 252808.

Merlivat, L. and Jouzel, J. 1979. "Global Climatic Interpretation of the Deuterium126847 Oxygen 18 Relationship for Precipitation.” Journal of Geophysical Research, 84, (C8), 5029-5033. Washington, D.C.: American Geophysical Union.

TIC: 247773.

Neuman, S.P. 1975. "Analysis of Pumping Test Data from Anisotropic 150321 Unconfined Aquifers Considering Delayed Gravity Response." Water Resources Research, 11, (2), 329-342. Washington, D.C.: American Geophysical Union. TIC: 222414

Neuman, S.P. 1990. "Universal Scaling of Hydraulic Conductivities and 101464 Dispersivities in Geologic Media." Water Resources Research, 26, (8), 1749-1758. Washington, D.C.: American Geophysical Union. TIC: 237977.

Norton, D. and Knapp, R.B. 1977. "Transport Phenomena in Hydrothermal 147379 Systems: The Nature of Porosity." American Journal of Science, 277, 913-936. New Haven, Connecticut: Yale University, Kline Geology Laboratory. TIC: 247599. 
NRC (U.S. Nuclear Regulatory Commission) 2003. Yucca Mountain Review Plan,

Final Report. NUREG-1804, Rev. 2. Washington, D.C.: U.S. Nuclear Regulatory

Commission, Office of Nuclear Material Safety and Safeguards. TIC: 254568.

NRC 1998. "Proposed Rule: 10 CFR Part 63 'Disposal of High-Level Radioactive

107770 Wastes in a Proposed Geologic Repository at Yucca Mountain, Nevada'."

SECY-98-225. Washington, D.C.: U.S. Nuclear Regulatory Commission.

Accessed October 30, 1999. TIC: 240520.

http://www.nrc.gov/NRC/COMMISSION/SECYS/1998-225scy.html

Nye County Nuclear Waste Repository Project Office 2000. "Early Warning

149364

Drilling Program." Pahrump, Nevada: Nye County. Accessed April 24, 2000.

TIC: 247627. http://www.nyecounty.com/ewdpmain.htm.

O'Brien, G.M. 1998. Analysis of Aquifer Tests Conducted in Borehole USW G-2,

101278 1996, Yucca Mountain, Nevada. Water-Resources Investigations Report 98-4063.

Denver, Colorado: U.S. Geological Survey. ACC: MOL.19980904.0095.

Oatfield, W.J. and Czarnecki, J.B. 1989. Hydrogeologic Inferences from Drillers

Logs and from Gravity and Resistivity Surveys in the Amargosa Desert, Southern Nevada. Open-File Report 89-234. Denver, Colorado: U.S. Geological Survey. TIC: 200468.

Oliver, T. and Root, T. 1997. Hydrochemical Database for the Yucca Mountain Area, Nye County, Nevada. Denver, Colorado: U.S. Geological Survey. ACC: MOL.19980302.0367.

Osmond, J.K. and Cowart, J.B. 1992. "Ground Water." Chapter 9 of Uranium145190 Series Disequilibrium: Applications to Earth, Marine, and Environmental Sciences. Ivanovich, M. and Harmon, R.S., eds. 2nd Edition. New York, New York: Oxford University Press. TIC: 234680.

Paces, J.B. and Whelan, J.F. 2001. "Water-Table Fluctuations in the Amargosa 154724 Desert, Nye County, Nevada." "Back to the Future - Managing the Back End of the Nuclear Fuel Cycle to Create a More Secure Energy Future," Proceedings of the 9th International High-Level Radioactive Waste Management Conference (IHLRWM), Las Vegas, Nevada, April 29-May 3, 2001. La Grange Park, Illinois: American Nuclear Society. TIC: 247873.

Paces, J.B.; Ludwig, K.R.; Peterman, Z.E.; and Neymark, L.A. 2002. “ ${ }^{، 234} U /{ }^{238} U$ 158817 Evidence for Local Recharge and Patterns of Ground-Water Flow in the Vicinity of Yucca Mountain, Nevada, USA.” Applied Geochemistry, 17, (6), 751-779. New York, New York: Elsevier. TIC: 252809. 
Paces, J.B.; Ludwig, K.R.; Peterman, Z.E.; Neymark, L.A.; and Kenneally, J.M. 100072 1998. "Anomalous Ground-Water ${ }^{234} \mathrm{U} /{ }^{238} \mathrm{U}$ Beneath Yucca Mountain: Evidence of Local Recharge?" High-Level Radioactive Waste Management, Proceedings of the Eighth International Conference, Las Vegas, Nevada, May 11-14, 1998. Pages 185-188. La Grange Park, Illinois: American Nuclear Society. TIC: 237082.

Paces, J.B.; Neymark, L.A.; Marshall, B.D.; Whelan, J.F.; and Peterman, Z.E. 107408 1998. "Inferences for Yucca Mountain Unsaturated-Zone Hydrology from Secondary Minerals." High-Level Radioactive Waste Management, Proceedings of the Eighth International Conference, Las Vegas, Nevada, May 11-14, 1998. Pages 36-39. La Grange Park, Illinois: American Nuclear Society. TIC: 237082.

Paces, J.B.; Neymark, L.A.; Marshall, B.D.; Whelan, J.F.; and Peterman, Z.E. 156507 2001. Ages and Origins of Calcite and Opal in the Exploratory Studies Facility Tunnel, Yucca Mountain, Nevada. Water-Resources Investigations Report 01-4049. Denver, Colorado: U.S. Geological Survey. TIC: 251284.

Parkhurst, D.L. and Appelo, C.A.J. 1999. User's Guide to PHREEQC (Version 159511 2)-A Computer Program for Speciation, Batch-Reaction, One-Dimensional Transport, and Inverse Geochemical Calculations. Water-Resources Investigations Report 99-4259. Denver, Colorado: U.S. Geological Survey. TIC: 253046.

Patterson, G.L. 1999. "Occurrences of Perched Water in the Vicinity of the Exploratory Studies Facility North Ramp." Hydrogeology of the Unsaturated Zone, North Ramp Area of the Exploratory Studies Facility, Yucca Mountain, Nevada. Rousseau, J.P.; Kwicklis, E.M.; and Gillies, D.C., eds. Water-Resources Investigations Report 98-4050. Denver, Colorado: U.S. Geological Survey. ACC: MOL.19990419.0335.

Patterson, G.L.; Peterman, Z.E.; and Paces, J.B. 1998. "Hydrochemical Evidence for the Existence of Perched Water at USW WT-24, Yucca Mountain, Nevada." High-Level Radioactive Waste Management, Proceedings of the Eighth International Conference, Las Vegas, Nevada, May 11-14, 1998. Pages 277-278. La Grange Park, Illinois: American Nuclear Society. TIC: 237082.

Peterman, Z.E. and Stuckless, J.S. 1993. "Isotopic Evidence of Complex 101149 Ground-Water Flow at Yucca Mountain, Nevada, USA." High Level Radioactive Waste Management, Proceedings of the Fourth Annual International Conference, Las Vegas, Nevada, April 26-30, 1993. 2, 1559-1566. La Grange Park, Illinois: American Nuclear Society. TIC: 208542.

Plummer, M.A.; Phillips, F.M.; Fabryka-Martin, J.; Turin, H.J.; Wigand, P.E.; and 107034 Sharma, P. 1997. "Chlorine-36 in Fossil Rat Urine: An Archive of Cosmogenic Nuclide Deposition During the Past 40,000 Years." Science, 277, 538-541. Washington, D.C.: American Association for the Advancement of Science. TIC: 237425 . 
Pollock, D.W. 1988. "Semianalytical Computation of Path Lines for 101466 Finite-Difference Models." Ground Water, 26, (6), 743-750. Worthington, Ohio: National Water Well Association. TIC: 226464.

Potter, C.J.; Dickerson, R.P.; Sweetkind, D.S.; Drake, R.M., II; Taylor, E.M.; 160060 Fridrich, C.J.; San Juan, C.A.; and Day, W.C. 2002. Geologic Map of the Yucca Mountain Region, Nye County, Nevada. Geologic Investigations Series I-2755. Denver, Colorado: U.S. Geological Survey. TIC: 253945.

Press, W.H.; Teukolsky, S.A.; Vetterling, W.T.; and Flannery, B.P. 1992. Numerical Recipes in Fortran 77, The Art of Scientific Computing. Volume 1 of Fortran Numerical Recipes. 2nd Edition. Cambridge, United Kingdom: Cambridge University Press. TIC: 243606.

Quade, J. and Cerling, T.E. 1990. "Stable Isotopic Evidence for a Pedogenic Origin of Carbonates in Trench 14 Near Yucca Mountain, Nevada." Science, 250, 1549-1552. Washington, D.C.: American Association for the Advancement of Science. TIC: 222617.

Rasmussen, T.C.; Evans, D.D.; Sheets, P.J.; and Blanford, J.H. 1993. 154688 "Permeability of Apache Leap Tuff: Borehole and Core Measurements Using Water and Air." Water Resources Research, 29, (7), 1997-2006. Washington, D.C.: American Geophysical Union. TIC: 245278.

Robledo, A.R.; Ryder, P.L.; Fenelon, J.M.; and Paillet, F.L. 1998. Geohydrology of Monitoring Wells Drilled in Oasis Valley near Beatty, Nye County, Nevada, 1997. Water-Resources Investigations Report 98-4184. Carson City, Nevada: U.S. Geological Survey. ACC: MOL.20031027.0156.

Rose, T.P.; Benedict Jr., F.C.; Thomas, J.M.; Sicke, W.S.; Hershey, R.L.; Paces, J.B.; Farnham, I.M.; and Peterman, Z.E. 2002. Geochemical Data Analysis and Interpretation of the Pahute Mesa - Oasis Valley Groundwater Flow System, Nye County, Nevada, (Preliminary 08/2002). Livermore, California: Lawrence Livermore National Laboratory. ACC: MOL.20031208.0200. TBV-5667

Rose, T.P.; Kenneally, J.M.; Smith, D.K.; Davisson, M.L.; Hudson, G.B.; and 144725 Rego, J.H. 1997. Chemical and Isotopic Data for Groundwater in Southern Nevada. UCRL-ID-128000. Livermore, California: Lawrence Livermore National Laboratory. TIC: 243649.

Rousseau, J.P.; Kwicklis, E.M.; and Gillies, D.C., eds. 1999. Hydrogeology of the 102097 Unsaturated Zone, North Ramp Area of the Exploratory Studies Facility, Yucca Mountain, Nevada. Water-Resources Investigations Report 98-4050. Denver, Colorado: U.S. Geological Survey. ACC: MOL.19990419.0335. 
Ryder, E.E. 1996. Backfill Generic Concept 1: Effective Thermal Conductivity.

Preliminary Information. Albuquerque, New Mexico: Sandia National

Laboratories. ACC: MOL.19971117.0330.

Sass, J.H.; Kennelly, J.P., Jr.; Smith, E.P.; and Wendt, W.E. 1984. Laboratory

Line-Source Methods for the Measurement of Thermal Conductivity of Rocks Near

Room Temperature. Open-File Report 84-91. Menlo Park, California:

U.S. Geological Survey. ACC: NNA.19920814.0125.

Sass, J.H.; Lachenbruch, A.H.; Dudley, W.W., Jr.; Priest, S.S.; and Munroe, R.J.

100644 1988. Temperature, Thermal Conductivity, and Heat Flow Near Yucca Mountain, Nevada: Some Tectonic and Hydrologic Implications. Open-File Report 87-649.

Denver, Colorado: U.S. Geological Survey. TIC: 203195.

Sawyer, D.A.; Fleck, R.J.; Lanphere, M.A.; Warren, R.G.; Broxton, D.E.; and 100075

Hudson, M.R. 1994. "Episodic Caldera Volcanism in the Miocene Southwestern Nevada Volcanic Field: Revised Stratigraphic Framework, ${ }^{40} \mathrm{Ar} /{ }^{39} \mathrm{Ar}$

Geochronology, and Implications for Magmatism and Extension." Geological Society of America Bulletin, 106, (10), 1304-1318. Boulder, Colorado: Geological Society of America. TIC: 222523.

Sekiguchi, K. 1984. "A Method for Determining Terrestrial Heat Flow in Oil 163363 Basinal Areas." Tectonophysics, 103, (1-4), 67-79. New York, New York: Elsevier. TIC: 254626.

Sharpe, S. 2003. Future Climate Analysis-10,000 Years to 1,000,000 Years After 161591 Present. MOD-01-001 REV 01. [Reno, Nevada: Desert Research Institute]. ACC: MOL.20030407.0055.

Simonds, F.W.; Whitney, J.W.; Fox, K.F.; Ramelli, A.R.; Yount, J.C.; Carr, M.D.; Menges, C.M.; Dickerson, R.P.; and Scott, R.B. 1995. Map Showing Fault Activity in the Yucca Mountain Area, Nye County, Nevada. Miscellaneous Investigations Series Map I-2520. Denver, Colorado: U.S. Geological Survey. TIC: 232483.

Slate, J.L.; Berry, M.E.; Rowley, P.D.; Fridrich, C.J.; Morgan, K.S.; Workman, J.B.; Young, O.D.; Dixon, G.L.; Williams, V.S.; McKee, E.H.; Ponce, D.A.; Hildenbrand, T.G.; Swadley, W C; Lundstrom, S.C.; Ekren, E.B.; Warren, R.G.; Cole, J.C.; Fleck, R.J.; Lanphere, M.A.; Sawyer, D.A.; Minor, S.A.; Grunwald, D.J.; Laczniak, R.J.; Menges, C.M.; Yount, J.C.; Jayko, A.S.; Mankinen, E.A.; Davidson, J.G.; Morin, R.L.; and Blakely, R.J. 2000. Digital Geologic Map of the Nevada Test Site and Vicinity, Nye, Lincoln and Clark Counties, Nevada, and Inyo County, California, Revision 4; Digital Aeromagnetic Map of the Nevada Test Site and Vicinity, Nye, Lincoln, and Clark Counties, Nevada, and Inyo County, California; and Digital Isostatic Gravity Map of the Nevada Test Site and Vicinity, Nye, Lincoln, and Clark Counties, Nevada, and Inyo County, California. Open-File Report 99-554-A, -B, and -C. Denver, Colorado: U.S. Geological Survey. TIC: $248049 ; 251985 ; 251981$. 
Smyth, J.R.; Crowe, B.M.; Halleck, P.M.; and Reed, A.W. 1979. A Preliminary

Evaluation of the Radioactive Waste Isolation Potential of the Alluvium-Filled Valleys of the Great Basin. LA-7962-MS. Los Alamos, New Mexico:

Los Alamos Scientific Laboratory. TIC: 202303.

Steinkampf, W.C. and Werrell, W.L. 2001. Ground-Water Flow to Death Valley, 158818 as Inferred from the Chemistry and Geohydrology of Selected Springs in Death Valley National Park, California and Nevada. Water-Resources Investigations Report 98-4114. Denver, Colorado: U.S. Geological Survey. TIC: 251734.

Streeter, V.L. and Wylie, E.B. 1979. Fluid Mechanics. 7th Edition. New York, 145287 New York: McGraw-Hill. TIC: 4819.

Stuckless, J.S.; Whelan, J.F.; and Steinkampf, W.C. 1991. "Isotopic

Discontinuities in Ground Water Beneath Yucca Mountain, Nevada." High Level Radioactive Waste Management, Proceedings of the Second Annual International Conference, Las Vegas, Nevada, April 28-May 3, 1991. 2, 1410-1415. La Grange

Park, Illinois: American Nuclear Society. TIC: 204272.

Thomas, J.M.; Welch, A.H.; and Dettinger, M.D. 1996. Geochemistry and Isotope 101933 Hydrology of Representative Aquifers in the Great Basin Region of Nevada, Utah, and Adjacent States. Professional Paper 1409-C. Denver, Colorado:

U.S. Geological Survey. ACC: MOL.20010803.0369.

Thordarson, W. 1965. Perched Ground Water in Zeolitized-Bedded Tuff, Rainier Mesa and Vicinity, Nevada Test Site, Nevada. TEI-862. Washington, D.C.:

U.S. Geological Survey. ACC: NN1.19881021.0066.

Thorstenson, D.C.; Weeks, E.P.; Haas, H.; Busenberg, E.; Plummer, L.N.; and 126827 Peters, C.A. 1998. "Chemistry of Unsaturated Zone Gases Sampled in Open Boreholes at the Crest of Yucca Mountain, Nevada: Data and Basic Concepts of Chemical and Physical Processes in the Mountain." Water Resources Research, 34, (6), 1507-1529. Washington, D.C.: American Geophysical Union.

TIC: 246315.

Tompson, A.F.B. and Gelhar, L.W. 1990. "Numerical Simulation of Solute 101490 Transport in Three-Dimensional, Randomly Heterogeneous Porous Media." Water Resources Research, 26, (10), 2541-2562. Washington, D.C.: American Geophysical Union. TIC: 224902.

Tucci, P. and Burkhardt, D.J. 1995. Potentiometric-Surface Map, 1993, Yucca Mountain and Vicinity, Nevada. Water-Resources Investigations Report 95-4149. Denver, Colorado: U.S. Geological Survey. ACC: MOL.19960924.0517. 
USGS (U.S. Geological Survey) 2001. Water-Level Data Analysis for the

USGS 2004. Water-Level Data Analysis for the Saturated Zone Site-Scale Flow and Transport Model. ANL-NBS-HS-000034 REV 01 Errata 002. Denver, Colorado: U.S. Geological Survey. ACC: MOL.20020209.0058;

MOL.20020917.0136; DOC.20040303.0006.

Vaniman, D.T.; Bish, D.L.; Chipera, S.J.; Carlos, B.A.; and Guthrie, G.D., Jr. 1996.105946 Chemistry and Mineralogy of the Transport Environment at Yucca Mountain. Volume I of Summary and Synthesis Report on Mineralogy and Petrology Studies for the Yucca Mountain Site Characterization Project. Milestone 3665.

Los Alamos, New Mexico: Los Alamos National Laboratory.

ACC: MOL.19961230.0037.

Vaniman, D.T.; Chipera, S.J.; Bish, D.L.; Carey, J.W.; and Levy, S.S. 2001.

"Quantification of Unsaturated-Zone Alteration and Cation Exchange in Zeolitized Tuffs at Yucca Mountain, Nevada, USA." Geochimica et Cosmochimica Acta, 65, (20), 3409-3433. New York, New York: Elsevier. TIC: 251574.

Verma, S. and Aziz, K. 1997. "A Control Volume Scheme for Flexible Grids in 143606 Reservoir Simulation.” Proceedings, SPE Reservoir Simulation Symposium, 8-11, June 1997, Dallas, Texas. SPE 37999. Pages 215-227. Richardson, Texas: Society of Petroleum Engineers. TIC: 247097.

Vesselinov, V.V.; Illman, W.A.; Hyun, Y.; Neuman, S.P.; Di Federico, V.; and 154706 Tartakovsky, D.M. 2001. "Observation and Analysis of a Pronounced Permeability and Porosity Scale-Effect in Unsaturated Fractured Tuff." Fractured Rock 2001, An International Conference Addressing Groundwater Flow, Solute Transport, Multiphase Flow, and Remediation in Fractured Rock, March 26-28, 2001, Toronto, Ontario, Canada. Kueper, B.H.; Novakowski, K.S.; and Reynolds, D.A., eds. Smithville, Ontario, Canada: Smithville Phase IV. TIC: 249909.

Waddell, R.K. 1982. Two-Dimensional, Steady-State Model of Ground-Water 101062 Flow, Nevada Test Site and Vicinity, Nevada-California. Water-Resources Investigations Report 82-4085. Denver, Colorado: U.S. Geological Survey. ACC: NNA.19870518.0055. 
Walker, G.E. and Eakin, T.E. 1963. Geology and Ground Water of Amargosa 103022 Desert, Nevada-California. Ground-Water Resources - Reconnaissance Series Report 14. Carson City, Nevada: State of Nevada, Department of Conservation and Natural Resources. TIC: 208665.

Weeks, E.P. 1978. Field Determination of Vertical Permeability to Air in the 108841 Unsaturated Zone. Geological Survey Professional Paper 1051. Washington, D.C.: U.S. Government Printing Office. TIC: 218986.

Wen, X-H. and Gomez-Hernandez, J.J. 1996. "The Constant Displacement 130510 Scheme for Tracking Particles in Heterogeneous Aquifers." Ground Water, 34, (1), 135-142. Worthington, Ohio: Water Well Journal Publishing. TIC: 246656.

Whelan, J.F.; Moscati, R.J.; Allerton, S.B.M.; and Marshall, B.D. 1998. Applications of Isotope Geochemistry to the Reconstruction of Yucca Mountain, Nevada, Paleohydrology-Status of Investigations: June 1996. Open-File Report 98-83. Denver, Colorado: U.S. Geological Survey. ACC: MOL.19981012.0740.

Whelan, J.F.; Moscati, R.J.; Roedder, E.; and Marshall, B.D. 1998. "Secondary 108865 Mineral Evidence of Past Water Table Changes at Yucca Mountain, Nevada." High-Level Radioactive Waste Management, Proceedings of the Eighth International Conference, Las Vegas, Nevada, May 11-14, 1998. Pages 178-181. La Grange Park, Illinois: American Nuclear Society. TIC: 237082.

White, A.F. 1979. Geochemistry of Ground Water Associated with Tuffaceous 101165 Rocks, Oasis Valley, Nevada. Professional Paper 712-E. Washington, D.C.: U.S. Geological Survey. TIC: 219633.

White, A.F. and Chuma, N.J. 1987. "Carbon and Isotopic Mass Balance Models of 108871 Oasis Valley - Fortymile Canyon Groundwater Basin, Southern Nevada." Water Resources Research, 23, (4), 571-582. Washington, D.C.: American Geophysical Union. TIC: 237579.

White, A.F.; Claassen, H.C.; and Benson, L.V. 1980. The Effect of Dissolution of 101166 Volcanic Glass on the Water Chemistry in a Tuffaceous Aquifer, Rainier Mesa, Nevada. Geochemistry of Water. Geological Survey Water-Supply Paper 1535-Q. Washington, D.C.: U.S. Government Printing Office. TIC: 221391.

Winograd, I.J. and Pearson, F.J., Jr. 1976. "Major Carbon 14 Anomaly in a 108882 Regional Carbonate Aquifer: Possible Evidence for Megascale Channeling, South Central Great Basin." Water Resources Research, 12, (6), 1125-1143. Washington, D.C.: American Geophysical Union. TIC: 217731. 
Winograd, I.J. and Thordarson, W. 1975. Hydrogeologic and Hydrochemical

Framework, South-Central Great Basin, Nevada-California, with Special

Reference to the Nevada Test Site. Geological Survey Professional Paper 712-C.

Washington, D.C.: United States Government Printing Office.

ACC: NNA.19870406.0201.

Winograd, I.J.; Coplen, T.B.; Landwehr, J.M.; Riggs, A.C.; Ludwig, K.R.; Szabo,

100094

B.J.; Kolesar, P.T.; and Revesz, K.M. 1992. "Continuous 500,000-Year Climate

Record from Vein Calcite in Devils Hole, Nevada." Science, 258, 255-260.

Washington, D.C.: American Association for the Advancement of Science.

TIC: 237563.

Winterle, J.R. and La Femina, P.C. 1999. Review and Analysis of Hydraulic and

129796

Tracer Testing at the C-Holes Complex Near Yucca Mountain, Nevada. San

Antonio, Texas: Center for Nuclear Waste Regulatory Analyses. TIC: 246623.

Wollenberg, H.A.; Wang, J.S.Y.; and Korbin, G. 1983. An Appraisal of Nuclear

Waste Isolation in the Vadose Zone in Arid and Semiarid Regions (with Emphasis on the Nevada Test Site). LBL-15010. Berkeley, California: University of California, Lawrence Berkeley Laboratory. TIC: 211058.

Yang, I.C. and Peterman, Z.E. 1999. "Chemistry and Isotopic Content of Perched 149596 Water." In Hydrogeology of the Unsaturated Zone, North Ramp Area of the Exploratory Studies Facility, Yucca Mountain, Nevada. Rousseau, J.P.; Kwicklis, E.M.; and Gillies, D.C., eds. Water-Resources Investigations Report 98-4050.

Denver, Colorado: U.S. Geological Survey. ACC: MOL.19990419.0335.

Yang, I.C.; Rattray, G.W.; and Yu, P. 1996. Interpretation of Chemical and Isotopic Data from Boreholes in the Unsaturated Zone at Yucca Mountain, Nevada. Water-Resources Investigations Report 96-4058. Denver, Colorado:

U.S. Geological Survey. ACC: MOL.19980528.0216.

Yang, I.C.; Yu, P.; Rattray, G.W.; Ferarese, J.S.; and Ryan, J.N. 1998.

101441 Hydrochemical Investigations in Characterizing the Unsaturated Zone at Yucca Mountain, Nevada. Water-Resources Investigations Report 98-4132. Denver, Colorado: U.S. Geological Survey. ACC: MOL.19981012.0790.

Zyvoloski, G. 1983. "Finite Element Methods for Geothermal Reservoir 101171 Simulation." International Journal for Numerical and Analytical Methods in Geomechanics, 7, (1), 75-86. New York, New York: John Wiley \& Sons. TIC: 224068.

Zyvoloski, G.; Kwicklis, E.; Eddebbarh, A.A.; Arnold, B.; Faunt, C.; and Robinson, B.A. 2003. "The Site-Scale Saturated Zone Flow Model for Yucca Mountain: Calibration of Different Conceptual Models and their Impact on Flow Paths." Journal of Contaminant Hydrology, 62-63, 731-750. New York, New York: Elsevier. TIC: 254340. 
Zyvoloski, G.A.; Robinson, B.A.; Dash, Z.V.; and Trease, L.L. 1997. User's

100615

Manual for the FEHM Application-A Finite-Element Heat- and Mass-Transfer

Code. LA-13306-M. Los Alamos, New Mexico: Los Alamos National

Laboratory. TIC: 235999.

\subsection{CODES, STANDARDS, REGULATIONS, AND PROCEDURES}

10 CFR 63. Energy: Disposal of High-Level Radioactive Wastes in a Geologic

Repository at Yucca Mountain, Nevada. Readily available.

AP-2.22Q, Rev. 1, ICN 1. Classification Analyses and Maintenance of the Q-List. Washington, D.C.: U.S. Department of Energy, Office of Civilian Radioactive Waste Management. ACC: DOC.20040714.0002.

AP-2.27Q, Rev. 1, ICN 5. Planning for Science Activities. Washington, D.C.: U.S. Department of Energy, Office of Civilian Radioactive Waste Management.

ACC: DOC.20041014.0001.

AP-SI.1Q, Rev. 5, ICN 2. Software Management. Washington, D.C.:

U.S. Department of Energy, Office of Civilian Radioactive Waste Management.

ACC: DOC.20030902.0003.

AP-SIII.10Q, Rev. 2, ICN 7. Models. Washington, D.C.: U.S. Department of Energy, Office of Civilian Radioactive Waste Management.

ACC: DOC.20040920.0002.

LP-SI.11Q-BSC, Rev. 0, ICN 1. Software Management. Washington, D.C.: U.S. Department of Energy, Office of Civilian Radioactive Waste Management.

ACC: DOC.20041005.0008.

\subsection{SOURCE DATA, LISTED BY DATA TRACKING NUMBER}

GS000308312322.003. Preliminary Release of Field, Chemical, and Isotopic Data 149155 from the Nye County Early Warning Drilling Program (EWDP) Wells in Amargosa Valley, Nevada Collected Between 12/11/98 and 11/15/99. Submittal date: $03 / 16 / 2000$.

GS000508312332.001. Water-Level Data Analysis for the Saturated Zone Site-Scale Flow and Transport Model. Submittal date: 06/01/2000.

GS000700012847.001. Chemical and Isotopic Data from Cind-R-Lite Well Samples Collected on 5/17/95 and 9/6/95. Submittal date: 07/10/2000.

GS010208312322.001. Uranium Concentrations and 234U/238U Activity Ratios Analyzed Between August, 1998 and April, 2000 for Saturated-Zone Well Water, Springs, and Runoff Collected between April, 1998 and November 1999. Submittal date: $03 / 30 / 2001$. 
GS010308312322.002. Chemical and Isotopic Data from Wells in Yucca Mountain

162910 Area, Nye County, Nevada, Collected between 12/11/98 and 11/15/99. Submittal date: $03 / 29 / 2001$.

GS010308312322.003. Field, Chemical and Isotopic Data from Wells in Yucca Mountain Area, Nye County, Nevada, Collected Between 12/11/98 and 11/15/99. Submittal date: 03/29/2000.

GS010608312332.001. Potentiometric-Surface Map, Assuming Perched Conditions 155307 North of Yucca Mountain, in the Saturated Site-Scale Model. Submittal date: $06 / 19 / 2001$.

GS010608315215.002. Uranium and Thorium Isotope Data for Waters Analyzed 156187 Between January 18, 1994 and September 14, 1996. Submittal date: 06/26/2001.

GS010808312322.004. Uranium and Uranium Isotopic Data for Water Samples from 156007 Wells and Springs in the Yucca Mountain Vicinity Collected Between December 1996 and December 1997. Submittal date: 08/29/2001.

GS010908312332.002. Borehole Data from Water-Level Data Analysis for the 163555 Saturated Zone Site-Scale Flow and Transport Model. Submittal date: 10/02/2001.

GS010908314221.001. Geologic Map of the Yucca Mountain Region, Nye County, Nevada. Submittal date: 01/23/2002.

GS011108312322.006. Field and Chemical Data Collected between 1/20/00 and 4/24/01 and Isotopic Data Collected between 12/11/98 and 11/6/00 from Wells in the Yucca Mountain Area, Nye County, Nevada. Submittal date: 11/20/2001.

GS021008312322.002. Stable Isotopic Data for Water Samples Collected between 162913 02/20/98 and 08/20/98 in the Yucca Mountain Area, Nye County, Nevada. Submittal date: $11 / 12 / 2002$.

GS021008312332.002. Hydrogeologic Framework Model for the Saturated-Zone 164363 Site-Scale Flow and Transport Model, Version YMP_9_02. Submittal date 12/09/2002.

GS030208312332.001. HFM Final Output - Hydrogeologic Framework Model for the Saturated-Zone Site-Scale Flow and Transport Model. Submittal date: 02/10/2003.

GS031108312322.003. Uranium Concentrations and 234U/238U Ratios for 166467 Ground-Water Samples from Boreholes ER-EC-7, ER-18-2, and UE-18R Collected between December 1999 and June 2000. Submittal date: 11/25/2003.

GS040208312322.003. Uranium Concentrations and 234U/238U Ratios from Spring, Well, Runoff, and Rain Waters Collected from the Nevada Test Site and Death Valley Vicinities and Analyzed between 01/15/98 and 08/15/98. Submittal date: 04/01/2004. 
GS920408312321.003. Chemical Composition of Groundwater in the Yucca

Mountain Area, Nevada 1971 - 1984. Submittal date: 04/24/1987.

GS930108315213.002. Water Chemistry and Sample Documentation for Two

148109

Samples from Lathrop Wells Cone and USW VH-2. Submittal date: 01/15/1993.

GS930108315213.004. Uranium Isotopic Analyses of Groundwaters from SW

145525

Nevada - SE California. Submittal date: 01/21/1993.

GS930208318523.001. Temperature and Thermal Conductivity in Wells Near Yucca

145763

Mountain. Submittal date: 02/16/1993.

GS930308312323.001. Chemical Composition of Groundwater and the Locations of

Permeable Zones in the Yucca Mountain Area. Submittal date: 03/05/1993.

GS930908312323.003. Hydrochemical Data from Field Test and Lab Analyses of

Water Samples Collected at Field Stations: USW VH-1, JF3, UE-29 UZN\#91, Virgin

Spring, Nevares Spring, UE-25 J\#12, UE-25 J\#13, UE-22 ARMY\#1, and USW

UZ-14. Submittal date: 09/30/1993.

GS931100121347.007. Selected Ground-Water Data for Yucca Mountain Region,

149611

Southern Nevada and Eastern California, Through December 1992. Submittal

date: $11 / 30 / 1993$.

GS940908315213.005. U Concentrations and ${ }^{234} \mathrm{U} /{ }^{238} \mathrm{U}$ Ratios for Waters in Yucca Mountain Region. Submittal date: 09/22/1994.

164673

GS950208312232.003. Data, Including Water Potential, Pressure and Temperature, Collected from Boreholes USW NRG-6 and USW NRG-7A from Instrumentation through March 31, 1995. Submittal date: 02/13/1995.

GS950408318523.001. Temperature, Thermal Conductivity, and Heat Flow Near Yucca Mountain, Nevada. Submittal date: 04/21/1995.

107244

GS950708315131.003. Woodrat Midden Age Data in Radiocarbon Years Before

106516 Present. Submittal date: 07/21/1995.

GS950808312322.001. Field, Chemical, and Isotopic Data Describing Water Samples 148114 Collected in Death Valley National Monument and at Various Boreholes in and Around Yucca Mountain, Nevada, Between 1992 and 1995. Submittal date: $08 / 16 / 1995$.

GS951208312272.002. Tritium Analyses of Porewater from USW UZ-14, USW NRG-6, USW NRG-7A and UE-25 UZ\#16 and of Perched Water from USW SD-7, USW SD-9, USW UZ-14 and USW NRG-7A from 12/09/92 to 5/15/95. Submittal date: $12 / 15 / 1995$. 
GS960308315131.001. Woodrat Midden Radiocarbon (C14). Submittal

106517 date: $03 / 07 / 1996$.

GS960408312323.002. Chemical and Isotopic Data Describing Water Samples

162915 Collected from 11 Springs and One Stream Within Death Valley National Park in 1993, 1994, and 1995. Submittal date: 04/02/1996.

GS960808312144.003. Hydrogeologic Evaluation and Numerical Simulation of the 105121 Death Valley Regional Ground-Water Flow System, Nevada and California, Using Geoscientific Information Systems. Submittal date: 08/29/1996.

GS960908312232.012. Comparison of Air-Injection Permeability Values to 114124 Laboratory Permeability Values. Submittal date: 09/26/1996.

GS960908312323.005. Hydrochemical Data Obtained from Water Samples Collected at Water Well ER-30-1 on 1/31/95 and 2/1/95. Submittal date: 09/10/1996.

GS970708312323.001. Delta 18-O and Delta D Stable Isotope Analyses of a 145405 Bore-Hole Waters from GEXA Well 4 and VH-2. Submittal date: 07/22/1997.

GS970708315215.008. Strontium Isotope Ratios and Isotope Dilution Data for 164674 Strontium for Two Samples Collected at UE-25 C\#3, 12/4/96 and 2/19/97. Submittal date: 07/29/1997.

GS970808315215.012. Uranium and Thorium Isotope Data from Secondary Minerals in the ESF Collected Between 02/15/97 and 09/15/97. Submittal date: 09/17/1997.

GS980108312322.005. Water Chemistry Data from Samples Collected at Borehole USW WT-24, Between 10/06/97 and 12/10/97. Submittal date: 01/26/1998.

GS980208312322.006. Uranium Isotopic Data for Saturated- and Unsaturated-Zone 146065 Waters Collected by Non-YMP Personnel Between May 1989 and August 1997. Submittal date: 02/03/1998.

GS980908312322.008. Field, Chemical, and Isotopic Data from Precipitation Sample 145412 Collected Behind Service Station in Area 25 and Ground Water Samples Collected at Boreholes UE-25 C \#2, UE-25 C \#3, USW UZ-14, UE-25 WT \#3, UE-25 WT \#17, and USW WT-24, 10/06/97 to 07/01/98. Submittal date: 09/15/1998.

GS980908312322.009. Uranium Concentrations and ${ }^{234} \mathrm{U} /{ }^{238} \mathrm{U}$ Ratios from Spring, 118977 Well, Runoff, and Rain Waters Collected from the Nevada Test Site and Death Valley Vicinities and Analyzed between 01/15/1998 and 08/15/1998. Submittal date: 09/23/1998. UZ-14 and USW NRG-6. Submittal date: 03/02/1999. 
GS990808312322.001. Field and Isotopic Data From Ground Water Samples From 149393

Wells in the Amargosa Valley and NTS. Submittal date: 08/23/1999.

GS990808312322.002. Chemical and Isotopic Data from Ground Water Samples

162917

Collected from Wells in the Amargosa. Submittal date: 08/23/1999.

GS991208314221.001. Geologic Map of the Yucca Mountain Region. Submittal

145263 date: $12 / 01 / 1999$.

LA0002JF831222.001. Apparent Infiltration Rates in Alluvium from USW UZ-N37, USW UZ-N54, USW UZ-14 and UE-25 UZ\#16, Calculated by Chloride Mass Balance Method. Submittal date: 02/25/2000.

LA0002JF831222.002. Apparent Infiltration Rates in PTN Units from USW UZ-7A, 147079 USW UZ-N55, USW UZ-14, UE-25 UZ\#16, USW NRG-6, USW NRG-7A, and USW SD-6, SD-7, SD-9 and SD-12 Calculated by the Chloride Mass Balance Method. Submittal date: $02 / 25 / 2000$.

LA0202EK831231.002. Calculation of Corrected and Uncorrected Groundwater 165507 Carbon-14 Ages. Submittal date: 02/25/2002.

LA0303PR831231.002. Estimation of Groundwater Drift Velocity from Tracer Responses in Single-Well Tracer Tests at Alluvium Testing Complex. Submittal date: $03 / 18 / 2003$.

LA0304TM831231.002. SZ Site-Scale Flow Model, FEHM Files for Base Case. Submittal date: 04/14/2003.

LA0308RR831233.001. Regional Groundwater Flow Pathways in the Yucca Mountain Area Inferred from Hydrochemical and Isotopic Data. Submittal date: $08 / 25 / 2003$.

LA0309EK831223.001. UTM Coordinates for Selected Amargosa Desert Wells. 165471 Submittal date: 09/05/2003.

LA0309EK831231.001. SZ Flow and Transport Model, FEHM Files for Tracer Transport. Submittal date: 09/02/2003.

LA0309RR831233.001. Regional Groundwater Hydrochemical Data in the Yucca 166546 Mountain Area Used as Direct Inputs for ANL-NBS-HS-000021, REV 01. Submittal date: 09/05/2003.

LA0309RR831233.002. Regional Groundwater Hydrochemical Data in the Yucca Mountain Area Used as Corroborative Data for ANL-NBS-HS-000021, REV 01. Submittal date: 09/05/2003. 
for Selected Wells. Submittal date: 10/16/2003.

LA0310EK831232.001. SZ Geochemical Models, PHREEQC Files for Selected 165995 Groundwater Parameters. Submittal date: 10/02/2003.

LA0311EK831223.001. Well Completion Summary Information for the Nye County 165985

EWDP, Phases I and II. Submittal date: 11/04/2003.

LA0311EK831232.001. Hydrochemical Data Obtained from GEOCHEM.02 166068 Database. Submittal date: 11/06/2003.

LA0311EK831232.002. Groundwater Hydrochemical Data from Nye County Early 166069 Warning Drilling Project Boreholes as Reported by Nye County. Submittal date: $11 / 04 / 2003$.

LA9909JF831222.010. Chloride, Bromide, Sulfate, and Chlorine-36 Analyses of ESF Porewaters. Submittal date: 09/29/1999.

LA9909JF831222.012. Chloride, Bromide, and Sulfate Analyses of Porewater 122736 Extracted from ESF Niche 3566 (Niche \#1) and ESF 3650 (Niche \#2) Drillcore. Submittal date: 09/29/1999.

LAJF831222AQ97.002. Chlorine-36 Analyses of Packrat Urine. Submittal 145401 date: $09 / 26 / 1997$.

LAJF831222AQ98.011. Chloride, Bromide, Sulfate and Chlorine-36 Analyses of 145402 Springs, Groundwater, Porewater, Perched Water and Surface Runoff. Submittal date: $09 / 10 / 1998$.

MO0007GNDWTRIS.002. Isotopic Content of Groundwater from Yucca Mountain 151492 Project Borehole, USW G-2, Extracted from ANL-NBS-HS-000021, Geochemical and Isotopic Constraints on Groundwater Flow Directions, Mixing and Recharge at Yucca Mountain, Nevada. Submittal date: 07/27/2000.

MO0007GNDWTRIS.003. Isotopic Content of Groundwater from Yucca Mountain 151493 Project Boreholes UZ-14, WT-17, and WT \#3, Extracted from ANL-NBS-HS-000021, Geochemical and Isotopic Constraints on Groundwater Flow Directions, Mixing and Recharge at Yucca Mountain, Nevada. Submittal date: 07/27/2000.

MO0007GNDWTRIS.004. Isotopic Content of Groundwater from Borehole TW-5 Extracted from ANL-NBS-HS-000021, Geochemical and Isotopic Constraints on Groundwater Flow Directions, Mixing and Recharge at Yucca Mountain, Nevada. Submittal date: 07/27/2000.

MO0007GNDWTRIS.005. Isotopic Content of Groundwater from Yucca Mountain Project Borehole JF \#3, Extracted from ANL-NBS-HS-000021, Geochemical and 151495 Isotopic Constraints on Groundwater Flow Directions, Mixing and Recharge at Yucca 
Mountain, Nevada. Submittal date: 07/28/2000.

MO0007GNDWTRIS.006. Isotopic Content of Groundwater from Selected Yucca Mountain Project WT Boreholes Extracted from ANL-NBS-HS-000021, Geochemical and Isotopic Constraints on Groundwater Flow Directions, Mixing and Recharge at Yucca Mountain, Nevada. Submittal date: 07/28/2000.

MO0007GNDWTRIS.007. Isotopic Content of Groundwater from Yucca Mountain Project Boreholes WT \#14, WT \#15, and WT \#12, Extracted from ANL-NBS-HS-000021, Geochemical and Isotopic Constraints on Groundwater Flow Directions, Mixing and Recharge at Yucca Mountain, Nevada. Submittal date: $07 / 28 / 2000$.

MO0007GNDWTRIS.008. Isotopic Content of Groundwater from Yucca Mountain Project Borehole UE-25 P \#1 Extracted from ANL-NBS-HS-000021, Geochemical and Isotopic Constraints on Groundwater Flow Directions, Mixing and Recharge at Yucca Mountain, Nevada. Submittal date: 07/28/2000.

MO0007GNDWTRIS.009. Isotopic Content of Groundwater from Selected Yucca Mountain Project Boreholes Extracted from ANL-NBS-HS-000021, Geochemical and Isotopic Constraints on Groundwater Flow Directions, Mixing and Recharge at Yucca Mountain, Nevada. Submittal date: 07/28/2000.

MO0007GNDWTRIS.010. Isotopic Content of Groundwater from Selected Yucca 151500 Mountain Project Boreholes Extracted from ANL-NBS-HS-000021, Geochemical and Isotopic Constraints on Groundwater Flow Directions, Mixing and Recharge at Yucca Mountain, Nevada. Submittal date: 07/28/2000.

MO0007GNDWTRIS.011. Isotopic Content of Groundwater from Selected Boreholes Not Drilled for the Yucca Mountain Project Extracted from ANL-NBS-HS-000021, Geochemical and Isotopic Constraints on Groundwater Flow Directions, Mixing and Recharge at Yucca Mountain, Nevada. Submittal date: 07/28/2000.

MO0007GNDWTRIS.013. Isotopic Content of Perched Groundwater from Yucca Mountain Project Boreholes Extracted from ANL-NBS-HS-000021, Geochemical and Isotopic Constraints on Groundwater Flow Directions, Mixing and Recharge at Yucca Mountain, Nevada. Submittal date: 07/28/2000.

MO0007MAJIONPH.002. Major Ion Content of Groundwater from Borehole TW-5 151507 Extracted from ANL-NBS-HS-000021, Geochemical and Isotopic Constraints on Groundwater Flow Directions, Mixing and Recharge at Yucca Mountain, Nevada. Submittal date: 07/27/2000.

MO0007MAJIONPH.003. Major Ion Content of Groundwater from Yucca Mountain 151513 Project Borehole USW G-2, Extracted from ANL-NBS-HS-000021, Geochemical and Isotopic Constraints on Groundwater Flow Directions, Mixing and Recharge at Yucca Mountain, Nevada. Submittal date: 07/27/2000. 
MO0007MAJIONPH.004. Major Ion Content of Groundwater from Borehole ONC Groundwater Flow Directions, Mixing and Recharge at Yucca Mountain, Nevada.

Submittal date: 07/27/2000.

MO0007MAJIONPH.005. Major Ion Content of Groundwater from Boreholes

UZ-14, WT-17 and WT \#3, Extracted from ANL-NBS-HS-000021, Geochemical and Isotopic Constraints on Groundwater Flow Directions, Mixing and Recharge at Yucca Mountain, Nevada. Submittal date: 07/27/2000.

MO0007MAJIONPH.006. Major Ion Content of Groundwater from Selected Boreholes Not Drilled on the Yucca Mountain Project, Extracted from ANL-NBS-HS-000021, Geochemical and Isotopic Constraints on Groundwater Flow Directions, Mixing and Recharge at Yucca Mountain, Nevada. Submittal date: $07 / 25 / 2000$.

MO0007MAJIONPH.007. Major Ion Content of Groundwater from Yucca Mountain 151519 Project Borehole UE-25 UZ \#16, Extracted from ANL-NBS-HS-000021, Geochemical and Isotopic Constraints on Groundwater Flow Directions, Mixing and Recharge at Yucca Mountain, Nevada. Submittal date: 07/27/2000.

MO0007MAJIONPH.008. Major Ion Content of Groundwater from Selected YMP and Other Boreholes Extracted from ANL-NBS-HS-000021, Geochemical and Isotopic Constraints on Groundwater Flow Directions, Mixing and Recharge at Yucca Mountain, Nevada. Submittal date: 07/27/2000.

MO0007MAJIONPH.009. Major Ion Content of Groundwater from Borehole NDOT Extracted from ANL-NBS-HS-000021, Geochemical and Isotopic Constraints on Groundwater Flow Directions, Mixing and Recharge at Yucca Mountain, Nevada. Submittal date: 07/27/2000.

MO0007MAJIONPH.010. Major Ion Content of Groundwater from Borehole UE-25 P \#1 Extracted from ANL-NBS-HS-000021, Geochemical and Isotopic Constraints on Groundwater Flow Directions, Mixing and Recharge at Yucca Mountain, Nevada. Submittal date: 07/27/2000.

MO0007MAJIONPH.011. Major Ion Content of Groundwater from Selected Yucca 151524 Mountain Project Boreholes Extracted from ANL-NBS-HS-000021, Geochemical and Isotopic Constraints on Groundwater Flow Directions, Mixing and Recharge at Yucca Mountain, Nevada. Submittal date: 07/27/2000.

MO0007MAJIONPH.012. Major Ion Content of Groundwater from Selected YMP and Other Boreholes Extracted from ANL-NBS-HS-000021, Geochemical and Isotopic Constraints on Groundwater Flow Directions, Mixing and Recharge at Yucca Mountain, Nevada. Submittal date: 07/27/2000. 
MO0007MAJIONPH.013. Major Ion Content of Groundwater from Selected YMP and Other Boreholes Extracted from ANL-NBS-HS-000021, Geochemical and Isotopic Constraints on Groundwater Flow Directions, Mixing and Recharge at Yucca Mountain, Nevada. Submittal date: 07/27/2000.

MO0007MAJIONPH.014. Major Ion Content of Groundwater from Selected Boreholes Not Drilled on the Yucca Mountain Project Extracted from ANL-NBS-HS-000021, Geochemical and Isotopic Constraints on Groundwater Flow Directions, Mixing and Recharge at Yucca Mountain, Nevada. Submittal date: $07 / 27 / 2000$.

MO0007MAJIONPH.015. Major Ion Content of Groundwater from NC-EWDP 151532 Boreholes Extracted from ANL-NBS-HS-000021, Geochemical and Isotopic Constraints on Groundwater Flow Directions, Mixing and Recharge at Yucca Mountain, Nevada. Submittal date: 07/27/2000.

MO0007MAJIONPH.016. Major Ion Content of Perched Groundwater from Selected YMP Boreholes with Perched Water Extracted from ANL-NBS-HS-000021, Geochemical and Isotopic Constraints on Groundwater Flow Directions, Mixing and Recharge at Yucca Mountain, Nevada. Submittal date: 07/28/2000.

MO0008MAJIONPH.017. Major Ion Content of Groundwater from Selected WT Boreholes Drilled for the Yucca Mountain Project Extracted from ANL-NBS-HS-000021, Geochemical and Isotopic Constraints on Groundwater Flow Directions, Mixing and Recharge at Yucca Mountain, Nevada. Submittal date: $08 / 02 / 2000$.

MO0008NYE02997.033. EWDP Phase 1 Water and Elevation Data from Westbay 155290 Instrumented Wells, 05/06/99 - 10/18/99. Submittal date: 08/10/2000.

MO0012URANISOT.000. Water - Selected Uranium Abundance and Isotope Ratios. Submittal date: 12/06/2000.

MO0102DQRBTEMP.001. Temperature Data Collected from Boreholes Near Yucca Mountain in Early 1980's. Submittal date: 02/21/2001.

MO0309THDPHRQC.000. Input Data File (PHREEQC.DAT) for Thermodynamic Data Software Code PHREEQC, Version 2.3. Submittal date: 09/22/2003.

MO0405NYE05819.215. Manual Water Level Data for EWDP Phase I Wells from 05/02 - 08/03, Phase II Wells from 05/02 - 08/03, Phase III Wells from 11/02 - 8/03 and Phase IV Wells from 01/03 - 08/03. Submittal date: 05/20/2004.

MO0407SEPFEPLA.000. LA FEP List. Submittal date: 07/20/2004. Drilling Program Data Package. Submittal date: 09/16/1999. 
SN0407T0504404.002. Distributed Recharge and Lateral Boundary Conditions for

170929 the Saturated Zone (SZ) Site-Scale Flow and Transport Model. Submittal date: $07 / 15 / 2004$.

SN9908T0581999.001. Recharge and Lateral Groundwater Flow Boundary 132867 Conditions for the Saturated Zone (SZ) Site-Scale Flow and Transport Model. Submittal date: 08/19/1999.

SNT05082597001.003. TSPA-VA (Total System Performance Assessment-Viability 129714 Assessment) Saturated Zone (SZ) Base Case Modeling Analysis Results. Submittal date: $02 / 03 / 1998$.

\subsection{OUTPUT DATA, LISTED BY DATA TRACKING NUMBER}

LA0304TM831231.001. SZ Flow and Transport Model, Hydrogeologic Surface Files. Submittal date: 04/7/2003.

LA0304TM831231.002. SZ Site-Scale Flow Model, FEHM Files for Base Case. Submittal date: 04/14/2003.

LA0409GZ831231.001. SZ Site-Scale Flow Model, FEHM Files for Alternate Model AM0. Submittal date: 09/09/2004.

LA0409GZ831231.002. SZ Site-Scale Flow Model, FEHM Files for Alternate Model AM1. Submittal date: 09/13/2004.

LA0409GZ831231.003. SZ Site-Scale Flow Model, FEHM Files for Alternate Model AM2. Submittal date: 09/14/2004.

LA0409GZ831231.004. SZ Site-Scale Flow Model, FEHM Files for Alternate Model AM3. Submittal date: 09/14/2004.

LA0409GZ831231.005. SZ Site-Scale Flow Model, FEHM Files for Alternate Model AM4. Submittal date: 09/14/2004.

\subsection{SOFTWARE CODES}

BSC (Bechtel SAIC Company) 2001. Software Code: PHREEQC. V2.3. PC, 155323 LINUX, Windows 95/98/NT, Redhat 6.2. 10068-2.3-00.

BSC 2002. Software Code: PHREEQC. V2.3. PC. 10068-2.3-01.

157837

Landmark Graphics. 1998. Software Code: STRATAMODEL. V4.1.1. SGI. 153238 10121-4.1.1-00.

LANL (Los Alamos National Laboratory) 2000. Software Routine:

150459

READPATHS. V1.0. MDL-NBS-HS-000011. 
LANL 2001. Software Code: LaGriT. V1.0. 10212-1.0-00. 149148

LANL 2001. Software Code: NETPATH. V2.13. Platform: PC, OS: 149910 WINDOWS NT, DOS Emulation. 10303-2.13-00.

LANL 2003. Software Code: FEHM. V2.20. SUN, PC. 10086-2.20-00. 161725

LANL 2003. Software Code: fehm2tec. V 1.0. Sun, Solaris 2.7 and 2.8. 164654 11092-1.0-00.

LANL 2003. Software Code: maketrac. V 1.1. Sun, SunOS 5.7 and 5.8. 164653 11078-1.1-00.

LANL 2003. Software Code: prepare_features_for_surfer. V1.0. SUN OS 5.7, 171911 5.8. 11091-1.0-00.

LANL 2003. Software Code: reformat_sz. V 1.0. Sun, Solaris 2.7 and 2.8 .

164652 11079-1.0-00.

LANL 2003. Software Code: STRAT2AVS. V 1.0. SGI with Irix64 operating 163069 system. 11028-1.0-00.

LANL 2003. Sofware Code: write_temps. V1.0. SUN O.S. 5.7, SUN O.S. 5.8. 171891 11090-1.0-00.

SNL (Sandia National Laboratories) 2002. Software Code: EXT_RECH. V 1.0. 163072 Sun - SunOS 5.7. 10958-1.0-00.

SNL 2002. Software Code: Extract. V 1.0. Sun UltraSPARC - SunOS 5.7. 163070 10955-1.0-00.

SNL 2002. Software Code: Extract. V 1.1. Sun UltraSPARC - SunOS 5.7. 163071 10955-1.1-00.

SNL 2002. Software Code: Mult_Rech. V 1.0. Sun UltraSPARC - SunOS 5.7. 163073 10959-1.0-00.

SNL 2002. Software Code: WTCONVYD. V 1.00. SUN,Solaris 8; PC, 163835 Windows 98. 10815-1.0-00.

SNL 2002. Software Code: Xread_Distr_Rech. V 1.0. Sun

163074

UltraSPARC - SunOS 5.7. 10960-1.0-00.

SNL 2002. Software Code: Xread_Distr_Rech_-UZ. V 1.0. Sun 163075 UltraSPARC - SunOS 5.7. 10961-1.0-00.

SNL 2002. Software Code: Xread_Reaches. V 1.0. Sun UltraSPARC - SunOS 163076 5.7. 10962-1.0-00. 
SNL 2002. Software Code: Xwrite_Flow_New. V 1.0-125. Sun 163077 UltraSPARC - SunOS 5.7. 10963-1.0-125-00.

SNL 2002. Software Code: Zone. V 1.0. Sun UltraSPARC - SunOS 5.7. 163078 10957-1.0-00.

Watermark Computing. 2002. Software Code: PEST. V5.5. SUN, PC, Linux. 161564 10289-5.5-00. 
APPENDIX A

GEOCHEMICAL AND ISOTOPIC CONSTRAINTS ON GROUNDWATER FLOW 


\section{A1. PURPOSE}

The purpose of the work described in this appendix is to provide an analysis of groundwater recharge rates, flow directions and velocities, and mixing proportions of water from different source areas based on groundwater geochemical and isotopic data. The analysis of hydrochemical and isotopic data is intended to provide a basis for evaluating the hydrologic system at Yucca Mountain independently of evaluations that are based purely on hydraulic arguments. In this way, this appendix is intended as an independent corroboration of the saturated zone flow model presented in the main text of this report.

This appendix is a revision of the Geochemical and Isotopic Constraints on Groundwater Flow Directions, Mixing, and Recharge at Yucca Mountain (BSC 2001 [DIRS 158606]). The revisions include the following:

1. Analyze new data to determine chemical reactions in the groundwater system, the evolution of groundwater as it moves from upgradient source areas to downgradient areas of potential groundwater withdrawal, groundwater mixing relationships, and chemical and isotopic distributions of strontium and uranium.

2. Correct groundwater ${ }^{14} \mathrm{C}$ ages for water/rock interactions.

3. Provide an analysis of groundwater recharge rates, flow directions and velocities, and mixing proportions of water from different source areas.

4. Compare patterns of groundwater movement produced by the SZ flow model with flow patterns inferred from hydrochemical and isotopic data.

Information supporting the resolution of several technical issues related to the saturated zone was also developed in this appendix:

1. Groundwater residence times based on ${ }^{14} \mathrm{C}$

2. Flow path lengths in alluvium and tuff.

Addressing these and related issues will help in determining the performance of the saturated zone as a natural barrier to radionuclide migration.

The physical and hydrochemical parameters summarized in this appendix are important controls on the transport of dissolved and colloidal species in the saturated zone. This information can be used in the SZ site-scale flow and SZ transport models to simulate the transport of radionuclides as breakthrough curves. These breakthrough curves are then used as input in the TSPA-LA calculations. 


\section{A2. NOT USED}

\section{A3. SOFTWARE CODES}

The computer code, PHREEQC V2.3, 6.2.10068-2.3-00 (BSC 2001 [DIRS 155323]), used directly in this appendix, is public-domain geochemical software whose description is summarized in Table A3-1. The software was obtained from Software Configuration Management (SCM) and is appropriate for the license application. The code was used only within its range of validation as required by LP-SI.11Q-BSC, Software Management. Input files for this appendix are identified in Section A4; the outputs are listed in Section A7.2.

Table A3-1. Software Used in Support of this Scientific Analysis

\begin{tabular}{|c|c|c|c|c|c|}
\hline $\begin{array}{l}\text { Software } \\
\text { Name and } \\
\text { Version (V) }\end{array}$ & $\begin{array}{c}\text { Software } \\
\text { Tracking } \\
\text { Number (STN) }\end{array}$ & $\begin{array}{l}\text { Description/ } \\
\text { Section Where Used }\end{array}$ & $\begin{array}{l}\text { Computer and } \\
\text { Platform } \\
\text { Identification }\end{array}$ & Reference & $\begin{array}{c}\text { Date } \\
\text { Baselined }\end{array}$ \\
\hline $\begin{array}{l}\text { PHREEQC, } \\
\text { V2.3 }\end{array}$ & $10068-2.3-00$ & $\begin{array}{l}\text { Used to speciate elements in } \\
\text { groundwater, calculate mineral } \\
\text { saturation indices, and calculate } \\
\text { mixing fractions and chemical } \\
\text { reactions required to produce } \\
\text { observed groundwater } \\
\text { compositions. PHREEQC is a } \\
\text { C-language program developed } \\
\text { by the U.S. Geological Survey } \\
\text { (USGS). Used in Sections } \\
\text { 6.7.6.6.2 and 6.7.8. }\end{array}$ & $\begin{array}{l}\text { Windows } \\
95 / 98 / N T \\
\text { Compaq } \\
\text { professional } \\
\text { workstation } \\
\text { AP400 }\end{array}$ & $\begin{array}{l}\text { BSC (2001 } \\
\text { [DIRS 155323]) }\end{array}$ & 03/29/01 \\
\hline $\begin{array}{l}\text { FEHM } \\
\text { V2.20 }\end{array}$ & $10086-2.20-00$ & $\begin{array}{l}\text { Flow modeling/flow and transport } \\
\text { modeling used to illustrate } \\
\text { groundwater flow paths. Used in } \\
\text { Section 6.7.10. }\end{array}$ & $\begin{array}{l}\text { Sun workstation } \\
\text { SunOS v. 5.7-5.8 }\end{array}$ & $\begin{array}{l}\text { LANL }(2003 \\
\text { [DIRS 161725]) }\end{array}$ & 01/28/03 \\
\hline $\begin{array}{l}\text { reformat_sz } \\
\text { V1.0 }\end{array}$ & $11079-1.0-00$ & $\begin{array}{l}\text { Used to reformat hydrochemical } \\
\text { and isotopic data originally in a } \\
\text { text format for input into } \\
\text { PHREEQC. Written in Fortran } \\
\text { 77. Used in Sections 6.7.5, } \\
\text { 6.7.6.6.2, and 6.7.8. }\end{array}$ & Solaris $2.7,2.8$ & $\begin{array}{l}\text { LANL }(2003 \\
\text { [DIRS 164652]) }\end{array}$ & 05/21/03 \\
\hline $\begin{array}{l}\text { maketrac } \\
\text { V1.1 }\end{array}$ & $11078-1.1-00$ & $\begin{array}{l}\text { Used to create trac macro for } \\
\text { FEHM. Used in Section 6.7.10. }\end{array}$ & $\begin{array}{l}\text { Sun workstation } \\
\text { SunOS v. 5.7-5.8 }\end{array}$ & $\begin{array}{l}\text { LANL }(2003 \\
\text { [DIRS 164653]) }\end{array}$ & 07/02/03 \\
\hline $\begin{array}{l}\text { fehm2tec } \\
\text { V1.0 }\end{array}$ & $11092-1.0-00$ & $\begin{array}{l}\text { Used to reformat FEHM output } \\
\text { for plotting with TECPLOT, V 8.0. } \\
\text { Used in Section 6.7.10. }\end{array}$ & $\begin{array}{l}\text { Sun workstation } \\
\text { Solaris } 2.7,2.8\end{array}$ & $\begin{array}{l}\text { LANL }(2003 \\
\text { [DIRS 164654]) }\end{array}$ & 06/26/03 \\
\hline
\end{tabular}

The range of hydrochemical and isotopic data used in PHREEQC V2.3, STN: 10068-2.3-00 (BSC 2001 [DIRS 155323]) is indicated by Tables A6-1 and A6-2. The results of all calculations using PHREEQC were checked with order-of-magnitude estimations. FEHM V2.20, STN: 10086-2.20-00 (LANL 2003 [DIRS 161725]) was used to illustrate groundwater flow paths predicted by the SZ (Table 6-17). The reformat_sz was used to reformat hydrochemical and isotopic data for input into PHREEQC; output from reformat_sz V1.0 STN: 11079-1.0-00 (LANL 2003 [DIRS 164652]) was verified by visual inspection. Maketrac V1.1 STN: 11078-1.1-00 (LANL 2003 [DIRS 164654]) was used to help create the trac macro for FEHM, and fehm2tec V1.0 STN: 11092-1.0-00 (LANL 2003 [DIRS 164654]) was used to 
reformat FEHM output for plotting with TECPLOT. The output from the maketrac and fehm2tec codes was verified by visual inspection of the FEHM results.

\section{A4. INPUTS}

Input data used in this appendix come from several sources, as summarized in Table A4-1 and Table A4-2. Table A4-3 lists the types of chemical and isotopic groundwater data presented by the sources in Table A4-1 and A4-2, including local data for the Yucca Mountain area and regional data for the Death Valley flow system and Nevada Test Site (NTS). The input data referenced in Tables A4-1, A4-2 and Table A4-3 represents geochemical and isotopic characteristics of perched water and groundwater near Yucca Mountain and hence is appropriate for the intended use. Data from the Death Valley flow system immediately surrounding Yucca Mountain are also presented to provide evidence for potential sources of groundwater found near Yucca Mountain and place the Yucca Mountain groundwater system within a regional perspective. The data presented for the area around Yucca Mountain within the SZ site-scale flow model domain (Figure A6-1) include representative historical data sets collected in the 1960s through the 1990s, as well as more recent data from newly drilled wells. In the immediate Yucca Mountain area, nearly all data collected since Yucca Mountain came under consideration as a repository were evaluated. Data from the outlying areas were selected to provide more complete geographic coverage but are not nearly as comprehensive as the data sets in the Yucca Mountain area. When both new data (1990s and later) and historical data sets were available in an area, emphasis was generally given to the newer data sets because they were typically more comprehensive in terms of the suite of chemicals and isotopes that were analyzed. This emphasis was especially true for the areas north of Yucca Mountain in the Timber Mountain, Beatty Wash, Fortymile Canyon and Oasis Valley areas. In the west-central Amargosa Desert, the data represent a blend of historic and recently collected data because of uncertainty in the effects of recent groundwater development on groundwater compositions. Elsewhere (for example, in Amargosa Flats), historical data sets were used where they provided the only representative hydrochemical data for an area.

Data contained in the DTNs and other sources listed in Tables A4-1, A4-2 and A4-3 are summarized for each sample/well location in Section A6.3 (Tables A6-1 and A6-2) where areal distributions and scatterplots of the hydrochemical and isotopic data are discussed and portrayed on figures. Where multiple sets of data were available for a location/sample, these data were averaged to derive the values shown in those tables, and it is these compiled values that are plotted in the figures of Section A6.3. Groundwater samples taken from different depth intervals in the same well were evaluated to examine the trends of groundwater composition with depth in the well (see Section A6.3.3). Groundwater sample depths and information on the geologic units present in the sampled interval are given in Table A4-3 to aid in understanding the causes of similarities or differences in groundwater compositions from particular geographic areas. Tables A4-1 to A4-3 provide the DTN links back to the original data used to generate the compiled and plotted values listed and shown in Section A6. 
Table A4-1. Sources of Data

\section{DTN Description}

Chemical and isotopic data from borehole TW-5

Chemical data from the Nye County EWDP Wells in Amargosa Valley,

Nevada, collected between 12/11/98 and 11/15/99.

Chemical data from borehole NDOT collected 5/17/95

Chemical and isotopic data from boreholes WT-7, WT-10, WT\#12, WT\#14, and WT\#15

Stable isotope ratios and radiocarbon data for WT\#12, WT\#14, and WT\#15

Chemical and isotopic data from test well UE-25 p\#1, Yucca Mountain area, Nye County, Nevada

Chemical and isotopic data for groundwater in the Yucca Mountain area, Nevada 1971 to 1984

Chemical composition of groundwater from ONC\#1

Chemical and isotopic data from perched groundwater at selected YMP boreholes

Chemical analyses of water from selected wells and springs in the Yucca Mountain area, Nevada, and southeastern California

Chemical composition of groundwater in the Yucca Mountain area

Chemical and isotopic data for groundwater in the west-central Amargosa Desert, Nevada

Selected groundwater data for Yucca Mountain region, southern Nevada, through December 1992

Hydrochemical database for the Death Valley Region

Chemical and isotopic data for groundwater samples collected at boreholes USW UZ-14, UE-25 WT\#3, and USW WT-17

Chemical composition of groundwater from UZ\#16

$Z$
0
4
0
0
0
0
0
0
0

Chemical and isotopic data from the CIND-R-LITE well samples collected on $5 / 17 / 95$ and $9 / 6 / 95$

\begin{tabular}{|l|l|}
\multicolumn{1}{|c|}{ DTN } & Tables Used \\
\hline MO0007GNDWTRIS.004 [DIRS 151494] & S00368_001 \\
\hline MO0007MAJIONPH.002 [DIRS 151507] & S00352_001 \\
\hline MO0007MAJIONPH.015 [DIRS 151532] & S00365_001 \\
\hline MO0007MAJIONPH.009 [DIRS 151522] & S00359_001 \\
\hline MO0007GNDWTRIS.006 [DIRS 151496] & S00370_001 \\
\hline MO0008MAJIONPH.017 [DIRS 151534] & S00383_001 \\
\hline MO0007GNDWTRIS.007 [DIRS 151497] & S00371_001 \\
\hline MO0007GNDWTRIS.008 [DIRS 151508] & S00372_001 \\
\hline MO0007MAJIONPH.010 [DIRS 151523] & S00360_001 \\
\hline MO0007GNDWTRIS.009 [DIRS 151509] & S00373_001 \\
\hline MO0007MAJIONPH.011 [DIRS 151524] & S00361_001 \\
\hline MO0007GNDWTRIS.010 [DIRS 151500] & S00374_001 \\
\hline MO0007MAJIONPH.004 [DIRS 151516] & S00354_001 \\
\hline MO0007MAJIONPH.016 [DIRS 151533] & S00378_001 \\
\hline MO0007GNDWTRIS.013 [DIRS 151504] & S00377_001 \\
\hline MO0007MAJIONPH.012 [DIRS 151529] & S00362_001 \\
\hline MO0007MAJIONPH.013 [DIRS 151530] & S00363_001 \\
\hline MO0007GNDWTRIS.011 [DIRS 151501] & S00375_001 \\
\hline MO0007MAJIONPH.014 [DIRS 151531] & S00364_001 \\
\hline MO0007GNDWTRIS.005 [DIRS 151495] & S00369_001 \\
\hline MO0007MAJIONPH.008 [DIRS 151521] & S00358_001 \\
\hline MO0007MAJIONPH.006 [DIRS 151518] & S00356_001 \\
\hline MO0007GNDWTRIS.003 [DIRS 151493] & S00367_001 \\
\hline MO0007MAJIONPH.005 [DIRS 151517] & S00355_001 \\
\hline MO0007MAJIONPH.007 [DIRS 151519] & S00366_001 \\
\hline MO0007GNDWTRIS.002 [DIRS 151492] & \\
\hline MO0007MAJIONPH.003 [DIRS 151513] & S00353001 \\
\hline GS000700012847.001 [DIRS 150842] & \\
\hline
\end{tabular}


Table A4-1. Sources of Data (Continued)

\section{DTN Description}

Field, chemical, and isotopic data describing water samples collected in Death Valley National Monument and at various boreholes in and around Yucca Mountain, Nevada, between 1992 and 1995

$\delta^{18} \mathrm{O}$ and $\delta \mathrm{D}$ stable isotope analyses of borehole waters from GEXA Well 4 and $\mathrm{VH}-2$

Uranium concentrations and ${ }^{234} \mathrm{U} /{ }^{238} \mathrm{U}$ ratios from spring, well, runoff, and rainwater collected from the NTS and Death Valley vicinities and analyzed between 01/15/98 and 08/15/98

Water chemistry and sample documentation for two samples from Amargosa Valley (formerly Lathrop Wells) cone and USW VH-2

Uranium isotopic analyses of groundwater from SW Nevada-SE California

Stable isotopic data for water samples collected between 02/20/98 and $08 / 20 / 98$ in the Yucca Mountain area, Nye County, Nevada

and isotopic data from groundwater samples from wells in the Amargosa Valley and NTS

Chemical and isotopic data from groundwater samples collected from wells in the Amargosa

Field, chemical, and isotopic data from wells in the Yucca Mountain area, Nye County, Nevada, collected between 12/11/98 and 11/15/99

Field and chemical data collected between $1 / 20 / 00$ and $4 / 24 / 01$ and isotopic data collected between 12/11/98 and 11/6/00 from wells in the Yucca

Mountain area, Nye County Nevada

Uranium and thorium isotope data for waters analyzed between January 18 , 1994, and September 14, 1996

Uranium and uranium isotope data for water samples from wells and springs

in the Yucca Mountain vicinity collected between December 1996 and

December 1997

Uranium concentrations and ${ }^{234} \mathrm{U} /{ }^{238} \mathrm{U}$ ratios for waters in Yucca Mountain region
DTN

\begin{tabular}{|c|c|}
\hline DTN & Tables Used $^{1}$ \\
\hline GS950808312322.001 [DIRS 148114] & $\begin{array}{c}\text { S96068_001 to S96068_003, } \\
\text { S96068_010, } \\
\text { S96068_011, } \\
\text { S96068_015 to S96068_018, } \\
\text { S96068_032, } \\
\text { S96068_036 to S96068_040, } \\
\text { S96068_042, } \\
\text { S96068_043 }\end{array}$ \\
\hline GS970708312323.001 [DIRS 145405] & $\begin{array}{l}\text { S97550_001 } \\
\text { S97550_002 }\end{array}$ \\
\hline GS980908312322.009 [DIRS 118977] & S99222_001 \\
\hline GS930108315213.002 [DIRS 148109] & $\begin{array}{c}\text { S98045_002 to S98045_010, } \\
\text { S98045_023, S98045_029 }\end{array}$ \\
\hline GS930108315213.004 [DIRS 145525] & $\begin{array}{l}\text { S96290_001 } \\
\text { S96290_002 }\end{array}$ \\
\hline GS021008312322.002 [DIRS 162913] & $\begin{array}{l}\text { S02343_001 } \\
\text { S02343_002 }\end{array}$ \\
\hline GS990808312322.001 [DIRS 149393] & $\begin{array}{l}\text { S99384_001 } \\
\text { S99384_002 }\end{array}$ \\
\hline GS990808312322.002 [DIRS 162917] & $\begin{array}{l}\text { S99385_001 } \\
\text { S99385_002 }\end{array}$ \\
\hline GS010308312322.003 [DIRS 154734] & $\begin{array}{l}\text { S01053_001 } \\
\text { S01053_002 } \\
\text { S01053_004 }\end{array}$ \\
\hline GS011108312322.006 [DIRS 162911] & $\begin{array}{l}\text { S01174_001 } \\
\text { S01174_002 }\end{array}$ \\
\hline GS010608315215.002 [DIRS 156187] & S01134_001 \\
\hline GS010808312322.004 [DIRS 156007] & S01132_001 \\
\hline GS940908315213.005 [DIRS 164673] & $\begin{array}{l}\text { S96241_002 } \\
\text { S96241_003 }\end{array}$ \\
\hline
\end{tabular}


Table A4-1. Sources of Data (Continued)

\section{DTN Description}

Hydrochemical data obtained from water samples collected at water well ER$30-1$ on $1 / 31 / 95$ and $2 / 1 / 95$

Strontium isotope ratios and isotope dilution data for strontium for two samples collected at UE-25 c\#3, 12/4/96 and 2/19/97

Tritium analyses of pore water from USW UZ-14, USW NRG-6, USW NRG$7 A$, and UE-25 UZ\#16 and of perched water from USW SD-7, USW SD-9,

USW UZ-14, and USW NRG-7A from 12/09/92 to 5/15/95

Chloride, bromide, sulfate and chlorine-36 analyses of springs, groundwater, pore water, perched water, and surface runoff

$\mathrm{SZ}$ site-scale flow model, FEHM files for $\mathrm{SZ}$ site-scale flow model

Thermodynamic characteristics input file required to run PHREEQC

Uranium activity ratios of pore waters from upper lithophysal unit of Topopah Spring tuff

Field, chemical, and isotopic data from a precipitation sample collected

behind the service station in area 25 and groundwater samples collected at

boreholes UE-25 c\#2, UE-25 C\#3, USW UZ-14, UE-25 WT\#3, USW WT-17,

s

and USW WT-24, between 10/06/97 and 07/01/98 (Only the data for WT-24

were used as input from this DTN.)

${ }^{1}$ Names of the tables within each DTN that were sources of data
Tables Used ${ }^{1}$

DTN

GS960908312323.005 [DIRS 162916] $\quad$ S97098_002 to S97098_005,

S97098_013,

S97098_017 to S97098_021

S97098 028 to S97098 031

\begin{tabular}{l|l} 
GS970708315215.008 [DIRS 164674] & S97527_001 \\
& S97527_002
\end{tabular}

GS951208312272.002 [DIRS 151649] $\quad$ S01175_002

\begin{tabular}{|l|c|}
\hline LAJF831222AQ98.011 [DIRS 145402] & S98328_001 \\
\hline LA0304TM831231.002 [DIRS 163788] & - \\
\hline MO0309THDPHRQC.000 [DIRS 165529] & S03316_001 \\
\hline MO0012URANISOT.000 [DIRS 153384] & - \\
\hline GS980908312322.008 [DIRS 145412] & $\begin{array}{c}\text { S98383_001, 003, 005 to 007, 009, } \\
014,016,018,022,024,025,028, \\
031,038,041 \text { to 044, 046 }\end{array}$ \\
& \\
\hline
\end{tabular}

$4,01 \overline{6}, 018,022,024,025,028$, $031,038,041$ to 044,046 
Table A4-2. Sources of Data and Other Information

\section{Information Used}

Reference (DTN)

Chloride, bromide, sulfate, and chlorine-36 analyses of ESF pore waters

Chloride, bromide, and sulfate analyses of pore water extracted from ESF Niche 3566

(Niche \#1) and ESF 3650 (Niche \#2) drill core

Apparent infiltration rates in alluvium from USW UZ-N37, USW UZ-N54, USW UZ-14,

and UE-25 UZ\#16, calculated by chloride mass-balance method

Apparent infiltration rates in PTn units from USW UZ-7A, USA UZ-N55, USW UZ-14,

UE-25 UZ\#16, USW NRG-6, USW NRG-7A, and USW SD-6, SD-7, SD-9, and SD-12 calculated by the chloride mass-balance method

Uranium and thorium isotopic data from secondary minerals in the ESF collected between 02/15/97 and 09/15/97

Chemical and isotopic data from wells in Yucca Mountain area, Nye County, Nevada collected between 12/11/98 and 11/15/99

Uranium concentrations and ${ }^{234} \mathrm{U} /{ }^{238} \mathrm{U}$ activity ratios analyzed between August 1998 and April 2000 for saturated-zone well water, springs, and runoff collected between April 1998 and November 1999

Chemical and isotopic data describing water samples collected from 11 springs and one stream within Death Valley National Park in 1993, 1994, and 1995

Field, chemical, and isotopic data from a precipitation sample collected behind the

service station in area 25 and groundwater samples collected at boreholes UE-25 c\#2,

UE-25 c\#3, USW UZ-14, UE-25 WT\#3, USW WT-17, and USW WT-24, between

$10 / 06 / 97$ and $07 / 01 / 98$
Source of Data Used

S99410 001

\begin{tabular}{l|l} 
LA9909JF831222.010 [DIRS 122733] & S99410_001 \\
\hline LA9909JF831222.012 [DIRS 122736] & S99412_001
\end{tabular}

S00142_001

S00143 001

500143002 S00143_003

S97566 001

S97566_003 S97566 006

S01052_001

GS010308312322.002 [DIRS 162910]

GS010208312322.001 [DIRS 162908]

S01051_001

S00176_001

S98383_001,

S98383_003,

S98383 005,

S98383_006

S98383_007,

S98383 009

S98383 014

S98383_016,

S98383 018,

S98383 022,

S98383_024,

S98383_025,

598383 028,

S98383 031,

S98383_038,

S98383 041 to

S98383 044 S98383_046

GS931100121347.007 [DIRS 149611]

996375006 S96375 007 
Table A4-2. Sources of Data and Other Information (Continued)

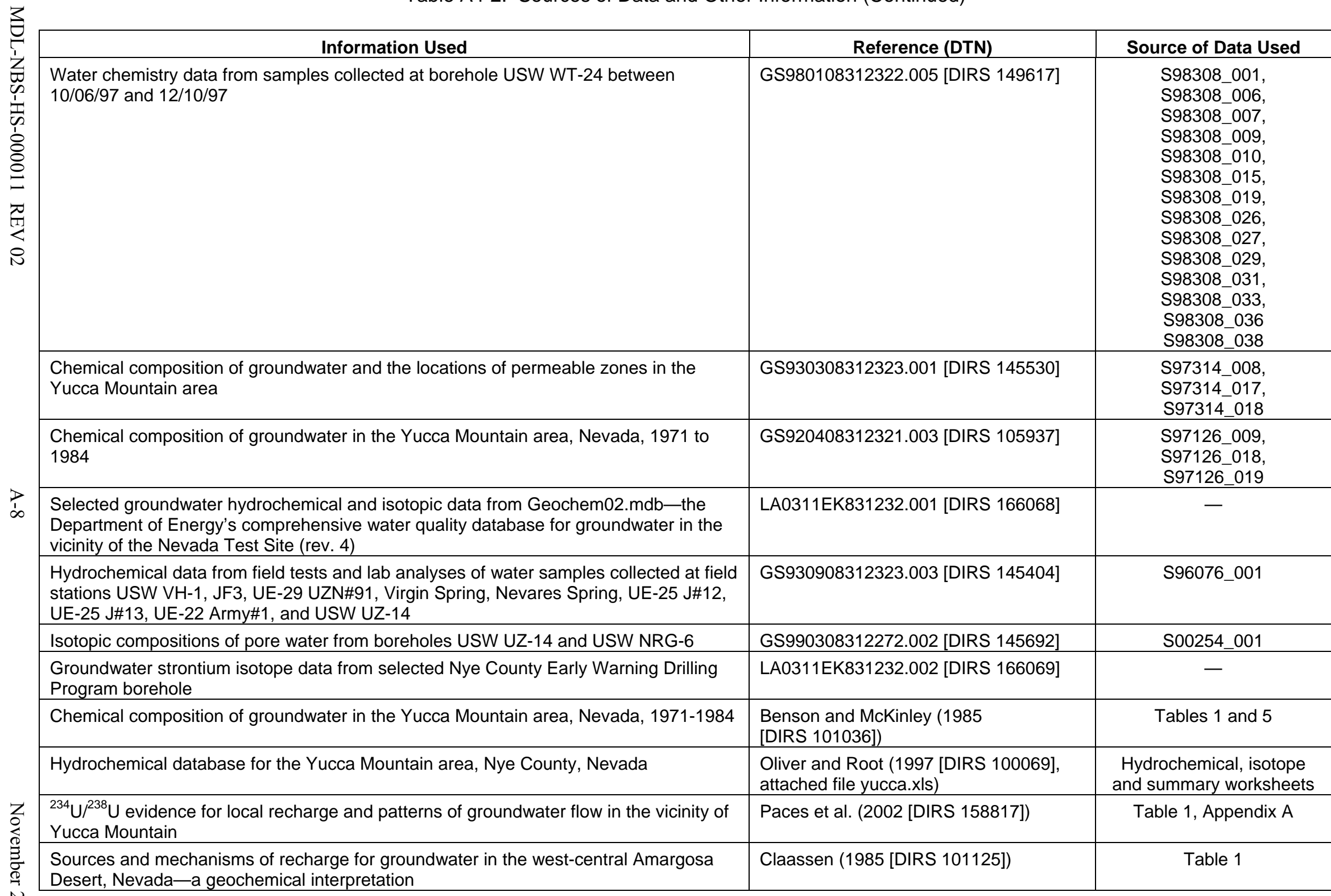


Table A4-2. Sources of Data and Other Information (Continued)

\section{Information Used}

Chemical and isotopic data for groundwater in southern Nevada.

Preliminary report on the isotope hydrology investigations at the Nevada Test Site:

Hydrologic Resources Management Program, FY 1992-1993

Groundwater chemistry at the Nevada Test Site: data and preliminary interpretations

Well completion summary information for the Nye County EWDP, Phases I and II

Well completion data and spring discharge area lithologies for the PM-OV area

UTM coordinates for selected Amargosa Desert wells

Borehole data from water-level analysis for the SZ site-scale flow and transport model

Uranium isotopic data for saturated- and unsaturated-zone waters collected by non-

YMP personnel between May 1989 and August 1997

Uranium concentrations and ${ }^{234} \mathrm{U} /{ }^{238} \mathrm{U}$ ratios for groundwater samples from boreholes

ER-EC-7, ER-18-2, and UE-18r, collected between December 1999 and June 2000
Reference (DTN)

Rose et al. (1997 [DIRS 144725])

Davisson et al. (1994 [DIRS 162939])

Chapman and Lyles (1993

[DIRS 162940])

LA0311EK831223.001 [DIRS 165985]

Rose et al. (2002 [DIRS 162938])

LA0309EK831223.001 [DIRS 165471]

GS010908312332.002 [DIRS 163555]

GS980208312322.006 [DIRS 146065]

GS031108312322.003 [DIRS 166467]
Source of Data Used

Tables 2, 3, and 4

Tables 1 and 2

Appendix B, Figs. 10, 12, and 14

ppendix A

spreadsheet

Claassen_coord.xls

S02298_001

S98201_001 S98201_002 
Table A4-3. Summary of Groundwater Wells and Data Sources

\begin{tabular}{|c|c|c|c|c|c|c|c|c|c|}
\hline Well Identifier & $\begin{array}{c}\text { Abbreviation } \\
\text { Used in } \\
\text { Appendix }\end{array}$ & $\begin{array}{c}\text { Figure } \\
\text { A6-5 }\end{array}$ & $\begin{array}{l}\mathrm{UTM}^{\mathrm{UT}} \mathrm{X}^{\mathrm{a}} \\
(\mathrm{m})\end{array}$ & $\begin{array}{l}\text { UTM-Y } \\
(\mathrm{m})\end{array}$ & & Area $^{\mathrm{b}}$ & $\begin{array}{c}\text { Approximate } \\
\text { Interval } \\
\text { Sampled }(\mathrm{m})^{\mathrm{e}}\end{array}$ & $\begin{array}{c}\text { Geologic } \\
\text { Unit }^{\text {,e }}\end{array}$ & $\begin{array}{c}\text { Reference for Sampled Depth } \\
\text { and Chemical (C) and Isotopic } \\
\text { (I) Data }\end{array}$ \\
\hline \multicolumn{10}{|c|}{ Oasis Valley/Northwest Amargosa } \\
\hline ER-EC-08 & ER-EC-08 & 1 & 532764 & 4106142 & OV/NWA & $\begin{array}{l}\text { Oasis Valley/Northwest } \\
\text { Amargosa }\end{array}$ & $\begin{array}{c}(192.6-320.0) \\
(423.1-474.9) \\
(495.6-606.6)^{4}\end{array}$ & $\begin{array}{l}\text { Tfb } \\
\text { Tmaw } \\
\text { Tmap }\end{array}$ & $\begin{array}{l}\text { DTN: LA0311EK831232.001 } \\
\text { (DIRS 166068), 7/23/99, 6/28/00 } \\
\text { and 7/12/00 samples }\end{array}$ \\
\hline ER-OV-01 & ER-OV-01 & 2 & 528417 & 4104084 & OVINWA & $\begin{array}{l}\text { Oasis Valley/Northwest } \\
\text { Amargosa }\end{array}$ & $(45.7-51.8)^{8}$ & Tuff $^{8}$ & $\begin{array}{l}\text { DTNs: LA0311EK831232.001 } \\
\text { (DIRS 166068), 11/8/97 sample; } \\
\text { GS010808312322.004 } \\
\text { (DIRS 156007), } \\
\text { U concentrations and isotopes }\end{array}$ \\
\hline ER-OV-06a & ER-OV-06a & 3 & 528417 & 4104084 & OV/NWA & $\begin{array}{l}\text { Oasis Valley/Northwest } \\
\text { Amargosa }\end{array}$ & $(154.2-160.3)^{8}$ & Tuff $^{8}$ & $\begin{array}{l}\text { DTNs: LA0311EK831232.001 } \\
\text { (DIRS 166068), 11/7/97 and } \\
\text { 11/8/97 samples; } \\
\text { GS010808312322.004 } \\
\text { (DIRS 156007), U } \\
\text { concentrations and isotopes }\end{array}$ \\
\hline ER-OV-05 & ER-OV-05 & 4 & 520280 & 4099809 & OV/NWA & $\begin{array}{l}\text { Oasis Valley/Northwest } \\
\text { Amargosa }\end{array}$ & $(51.8-57.9)^{8}$ & Alluvium 8 & $\begin{array}{l}\text { DTN: LA0311EK831232.001 } \\
\text { (DIRS 166068), 11/7/97 sample }\end{array}$ \\
\hline ER-OV-02 & ER-OV-02 & 5 & 526310 & 4098716 & OV/NWA & $\begin{array}{l}\text { Oasis Valley/Northwest } \\
\text { Amargosa }\end{array}$ & $(51.8-57.9)^{8}$ & $\begin{array}{l}\text { colluvial and } \\
\text { alluvial } \\
\text { gravel }^{8}\end{array}$ & $\begin{array}{l}\text { DTNs: LA0311EK831232.001 } \\
\text { (DIRS 166068), 11/11/97 } \\
\text { sample); GS010808312322.004 } \\
\text { (DIRS 156007), } \\
\text { U concentrations and isotopes }\end{array}$ \\
\hline $\begin{array}{l}\text { Springdale } \\
\text { Upper Well } \\
\text { (10S/47E- } \\
32 \mathrm{adc})\end{array}$ & $\begin{array}{l}\text { Springdale } \\
\text { Upper Well } \\
\text { (10S/47E- } \\
\text { 32adc) }\end{array}$ & 6 & 523522 & 4097506 & OV/NWA & $\begin{array}{l}\text { Oasis Valley/Northwest } \\
\text { Amargosa }\end{array}$ & $\begin{array}{l}\text { open borehold } \\
\text { (depth not } \\
\text { reported) }\end{array}$ & $\begin{array}{l}\text { tuff breccia } \\
\text { or alluvium }{ }^{4}\end{array}$ & $\begin{array}{l}\text { DTNs: LA0311EK831232.001 } \\
\text { (DIRS 166068), 11/12/97 } \\
\text { sample; GS010808312322.004 } \\
\text { (DIRS 156007), U } \\
\text { concentrations and isotopes }\end{array}$ \\
\hline $\begin{array}{l}\text { Goss Springs } \\
\text { North } \\
(11 \mathrm{~S} / 47 \mathrm{E}- \\
10 \mathrm{bad})\end{array}$ & $\begin{array}{l}\text { Goss Springs } \\
\text { North } \\
(11 \mathrm{~S} / 47 \mathrm{E}- \\
10 \mathrm{bad})\end{array}$ & 7 & 526100 & 4094647 & OV/NWA & $\begin{array}{l}\text { Oasis Valley/Northwest } \\
\text { Amargosa }\end{array}$ & 0.0 (spring) & not reported & $\begin{array}{l}\text { DTNs: LA0311EK831232.001 } \\
\text { (DIRS 166068), 11/13/97 } \\
\text { sample; GS010808312322.004 } \\
\text { (DIRS 156007), } \\
\text { U concentrations and isotopes }\end{array}$ \\
\hline
\end{tabular}




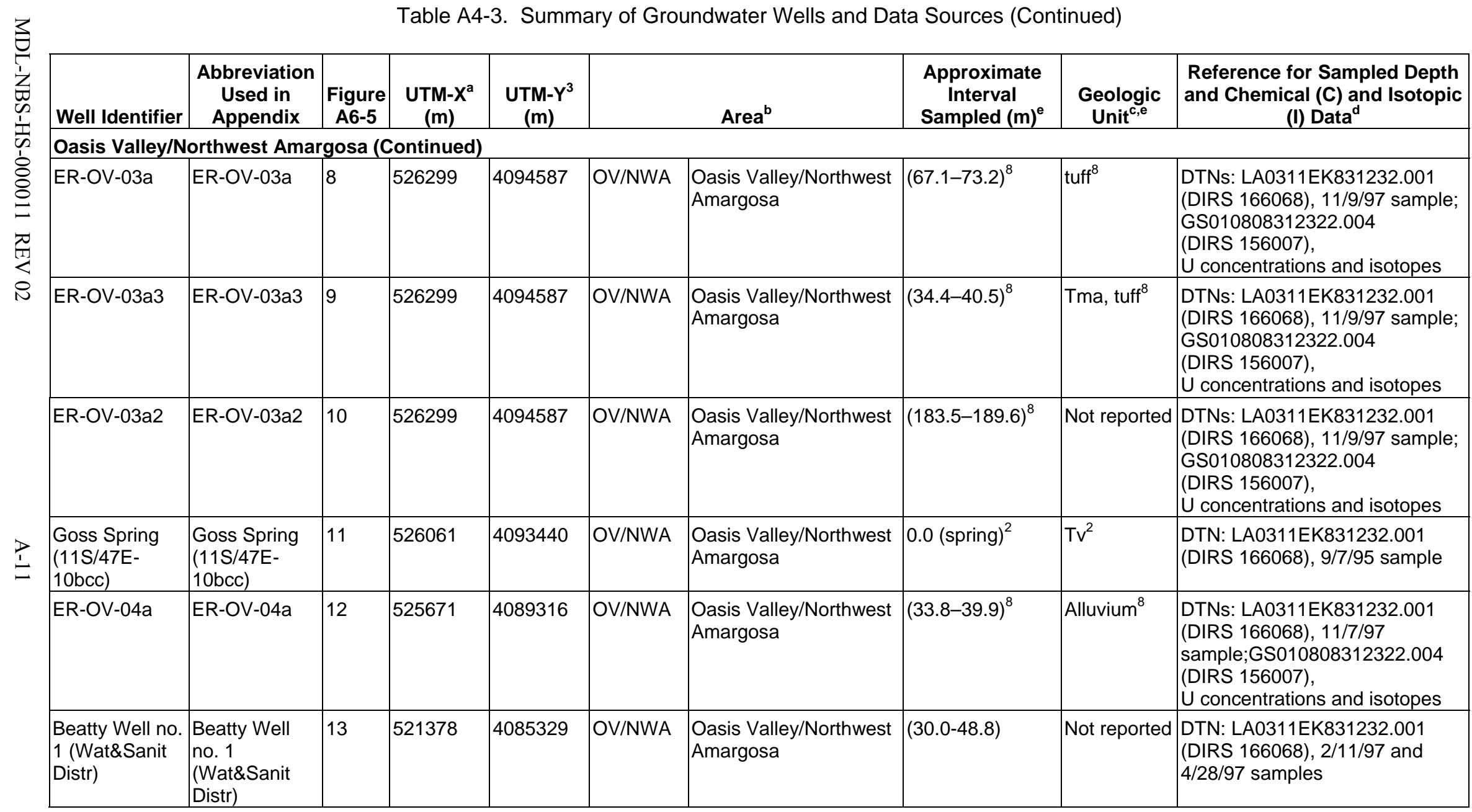


Table A4-3. Summary of Groundwater Wells and Data Sources (Continued)

\begin{tabular}{|c|c|c|c|c|c|c|c|c|c|}
\hline Well Identifier & $\begin{array}{c}\text { Abbreviation } \\
\text { Used in } \\
\text { Appendix }\end{array}$ & $\begin{array}{c}\text { Figure } \\
\text { A6-5 }\end{array}$ & $\begin{array}{l}\text { UTM-X } \\
(\mathrm{m})\end{array}$ & $\begin{array}{l}\text { UTM-Y } \\
(\mathrm{m})\end{array}$ & & Area $^{\text {b }}$ & $\begin{array}{c}\begin{array}{c}\text { Approximate } \\
\text { Interval } \\
\text { Sampled }(m)^{e}\end{array} \\
\end{array}$ & $\begin{array}{c}\text { Geologic } \\
\text { Unit }^{\mathrm{c}, \mathrm{e}}\end{array}$ & $\begin{array}{l}\text { Reference for Sampled Depth } \\
\text { and Chemical (C) and Isotopic } \\
\text { (I) Data }\end{array}$ \\
\hline \multicolumn{10}{|c|}{ Oasis Valley/Northwest Amargosa (Continued) } \\
\hline $\begin{array}{l}\text { Bond Gold } \\
\text { Mining \#1 }\end{array}$ & $\begin{array}{l}\text { Bond Gold } \\
\text { Mining \#1 }\end{array}$ & 14 & 516203 & 4074502 & OV/NWA & $\begin{array}{l}\text { Oasis Valley/Northwest } \\
\text { Amargosa }\end{array}$ & Not reported & $\mathrm{Qal}^{13}$ & $\begin{array}{l}\text { DTNs: GS010308312322.003 } \\
\text { (DIRS 154734), T, pH, Alk, ions, } \\
\left.\delta^{18} \mathrm{O}, \delta \mathrm{D}, \delta^{13} \mathrm{C}\right) ; \\
\mathrm{GSO} \text { ) } \\
1621108312322.006 \text { (DIRS } \\
{ }^{14} \mathrm{C}, \delta^{18} \mathrm{O}, \delta \mathrm{D}, \delta^{13} \mathrm{C}, \\
\delta^{34} \mathrm{~S} ; \mathrm{GS} 010208312322.001 \\
\text { (DIRS 162908), } \\
\text { U-concentrations and isotopes; } \\
\text { GS010308312322.002 } \\
\text { (DIRS 162910),U concentrations }\end{array}$ \\
\hline $\begin{array}{l}\text { US Ecology } \\
\text { MW-313 }\end{array}$ & $\begin{array}{l}\text { US Ecology } \\
\text { MW-313 }\end{array}$ & 15 & 527666 & 4069293 & OV/NWA & $\begin{array}{l}\text { Oasis Valley/Northwest } \\
\text { Amargosa }\end{array}$ & $\begin{array}{l}\text { open borehole } \\
\text { (depth not } \\
\text { reported) }\end{array}$ & $\mathrm{Qa}^{13}$ & $\begin{array}{l}\text { DTNs: GS010308312322.003 } \\
\text { (DIRS 154734), T, pH, Alk, ions, } \\
\delta^{18} \mathrm{O}, \delta \mathrm{D}, \delta^{13} \mathrm{C} ; \\
\text { GSO11108312322.006 } \\
\text { (DIRS 162911), }{ }^{14} \mathrm{C}, \delta^{18} \mathrm{O}, \delta \mathrm{D}, \\
\delta^{13} \mathrm{C}, \delta^{34} \mathrm{~S} ; \\
\text { GS010208312322.001 } \\
\text { (DIRS 162908), } \\
\text { U-concentrations and isotopes; } \\
\text { GS010308312322.002 (DIRS } \\
\text { 162910), U concentrations }\end{array}$ \\
\hline $\begin{array}{l}\text { US Ecology } \\
\text { MW-600 }\end{array}$ & $\begin{array}{l}\text { US Ecology } \\
\text { MW-600 }\end{array}$ & 16 & 527666 & 4069293 & OV/NWA & $\begin{array}{l}\text { Oasis Valley/Northwest } \\
\text { Amargosa }\end{array}$ & $\begin{array}{l}\text { open borehole } \\
\text { (depth not } \\
\text { reported) }\end{array}$ & Qal ${ }^{13}$ & $\begin{array}{l}\text { DTNs: GS010308312322.003 } \\
\text { (DIRS 154734), T, pH, Alk, ions, } \\
\delta^{18} \mathrm{O}, \delta \mathrm{D}, \delta^{13} \mathrm{C} ; \\
\text { GSO11108312322.006 } \\
\text { (DIRS 162911), }{ }^{14} \mathrm{C}, \delta^{18} \mathrm{O}, \delta \mathrm{D}, \\
\delta^{13} \mathrm{C}, \delta^{34} \mathrm{~S} ; \\
\text { GS010208312322.001 } \\
\text { (DIRS 162908), U- } \\
\text { concentrations and isotopes; } \\
\text { GS010308312322.002 (DIRS } \\
\text { 162910), U concentrations }\end{array}$ \\
\hline Nucl. Eng. Co. & NEC Well & 17 & 527519 & 4068738 & OV/NWA & $\begin{array}{l}\text { Oasis Valley/Northwest } \\
\text { Amargosa }\end{array}$ & $\begin{array}{l}\text { open borehole } \\
(86-180)^{3}\end{array}$ & $\mathrm{QTal}^{2}$ & $\begin{array}{l}\text { DTNs: MO0007GNDWTRIS.011 } \\
\text { (DIRS 151501). } \delta^{13} \mathrm{C},{ }^{14} \mathrm{C} \text {; } \\
\text { MO0007MAJIONPH.014 } \\
\text { (DIRS 151531), C }\end{array}$ \\
\hline
\end{tabular}


Table A4-3. Summary of Groundwater Wells and Data Sources (Continued)

\begin{tabular}{|c|c|c|c|c|c|c|c|c|c|}
\hline Well Identifier & $\begin{array}{c}\text { Abbreviation } \\
\text { Used in } \\
\text { Appendix }\end{array}$ & $\begin{array}{c}\text { Figure } \\
\text { A6-5 }\end{array}$ & $\begin{array}{l}\text { UTM-Xa } \\
(\mathrm{m})\end{array}$ & $\begin{array}{l}\text { UTM-Y } \\
(\mathrm{m})\end{array}$ & & Area $^{b}$ & $\begin{array}{c}\text { Approximate } \\
\text { Interval } \\
\text { Sampled }(m)^{\mathrm{e}}\end{array}$ & $\begin{array}{c}\text { Geologic } \\
\text { Unit }^{\mathrm{c}, \mathrm{e}}\end{array}$ & $\begin{array}{l}\text { Reference for Sampled Depth } \\
\text { and Chemical (C) and Isotopic } \\
\text { (I) Data }\end{array}$ \\
\hline \multicolumn{10}{|c|}{ Oasis Valley/Northwest Amargosa (Continued) } \\
\hline $\begin{array}{l}\text { US Ecology } \\
\text { MR-3 }\end{array}$ & $\begin{array}{l}\text { US Ecology } \\
\text { MR-3 }\end{array}$ & 18 & 527395 & 4068707 & OV/NWA & $\begin{array}{l}\text { Oasis Valley/Northwest } \\
\text { Amargosa }\end{array}$ & $\begin{array}{l}\text { open borehole } \\
\text { (depth not } \\
\text { reported) }\end{array}$ & Qal ${ }^{13}$ & 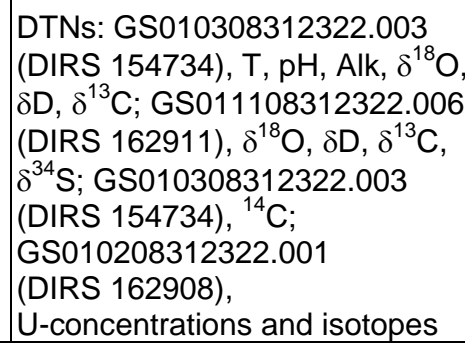 \\
\hline \multicolumn{10}{|c|}{ Timber Mountain } \\
\hline UE-18r & UE-18r & 19 & 549322 & 4109762 & TM & Timber Mountain & $509^{4,6}$ & $\begin{array}{l}\text { Tm, debris } \\
\text { flow }^{4}\end{array}$ & $\begin{array}{l}\text { DTNs: LA0311EK831232.001 } \\
\text { (DIRS 166068), 7/11/91,8/11/92 } \\
\text { and 12/9/99 samples; } \\
\text { GS031108312322.003 } \\
\text { (DIRS 154734), U-isotopes }\end{array}$ \\
\hline ER-18-2 & ER-18-2 & 20 & 555725 & 4106389 & TM & Timber Mountain & $(411.9-758.0)^{4}$ & Tmar $^{4}$ & $\begin{array}{l}\text { DTNs: LA0311EK831232.001 } \\
\text { (DIRS 166068), 3/21/00 sample; } \\
\text { GS031108312322.003 } \\
\text { (DIRS 154734), U-Isotopes }\end{array}$ \\
\hline ER-EC-05 & ER-EC-05 & 21 & 538702 & 4106389 & TM & Timber Mountain & $\begin{array}{l}(356.3-439.8) \\
(559.3-654.1) \\
(688.7-755.9)^{4}\end{array}$ & $\begin{array}{l}\text { Ttc } \\
\text { Tfbr,Tfbw } \\
\text { Tmap }^{4}\end{array}$ & $\begin{array}{l}\text { DTNs: LA0311EK831232.001 } \\
\text { (DIRS 166068), 7/8/99,5/4/00, } \\
\text { and 5/25/00 samples; } \\
\text { GS010808312322.004 } \\
\text { (DIRS 156007), } \\
\text { U concentrations and isotopes }\end{array}$ \\
\hline $\begin{array}{l}\text { Coffer's Ranch } \\
\text { Windmill Well }\end{array}$ & $\begin{array}{l}\text { Coffer's } \\
\text { Ranch } \\
\text { Windmill Well }\end{array}$ & 22 & 539421 & 4095192 & TM & Timber Mountain & $(109.8-146.3)^{4}$ & Not reported & $\begin{array}{l}\text { DTNs: LA0311EK831232.001 } \\
\text { (DIRS 166068), samples from } \\
\text { 1994 through 1997; } \\
\text { GS010808312322.004 } \\
\text { (DIRS 156007), U } \\
\text { concentrations and isotopes }\end{array}$ \\
\hline
\end{tabular}


Table A4-3. Summary of Groundwater Wells and Data Sources (Continued)

\begin{tabular}{|c|c|c|c|c|c|c|c|c|c|}
\hline Well Identifier & $\begin{array}{l}\text { Abbreviation } \\
\text { Used in } \\
\text { Appendix }\end{array}$ & $\begin{array}{c}\text { Figure } \\
\text { A6-5 }\end{array}$ & $\begin{array}{c}\text { UTM-X }^{a} \\
(\mathrm{~m})\end{array}$ & $\begin{array}{l}\text { UTM-Y3 } \\
(\mathrm{m})\end{array}$ & & Area $^{\mathrm{b}}$ & $\begin{array}{c}\text { Approximate } \\
\text { Interval } \\
\text { Sampled }(m)^{\mathrm{e}}\end{array}$ & $\begin{array}{c}\text { Geologic } \\
\text { Unit }^{\mathrm{c}, \mathrm{e}}\end{array}$ & $\begin{array}{l}\text { Reference for Sampled Depth } \\
\text { and Chemical (C) and Isotopic } \\
\text { (I) Data }\end{array}$ \\
\hline \multicolumn{10}{|c|}{ Timber Mountain (Continued) } \\
\hline ER-OV-03c & ER-OV-03c & 23 & 535494 & 4094374 & TM & Timber Mountain & $(156.1-162.2)^{4,8}$ & $\mathrm{Tma}^{4}$ & $\begin{array}{l}\text { DTNs: LA0311EK831232.001 } \\
\text { (DIRS 166068), 11/10/97 } \\
\text { sample; GS010808312322.004 } \\
\text { (DIRS 156007), } \\
\text { U concentrations and isotopes }\end{array}$ \\
\hline ER-EC-07 & ER-EC-07 & 24 & 546484 & 40931217 & TM & Timber Mountain & $\begin{array}{l}(272.8-312.4) \\
(351.4-399.3)^{4}\end{array}$ & $T f b,\left.T f\right|^{4}$ & $\begin{array}{l}\text { DTNs: LA0311EK831232.001 } \\
\text { (DIRS } 166068), 8 / 7 / 99, \\
\text { 4/28/2000 and 6/5/00 samples; } \\
\text { GS031108312322.003 } \\
\text { (DIRS 166467), U-isotopes }\end{array}$ \\
\hline \multicolumn{10}{|c|}{ Fortymile Wash - North } \\
\hline Water Well 8 & Water Well 8 & 25 & 563113 & 4113275 & FMW-N & Fortymile Wash - North & $377^{6}$ & $\mathrm{TV}^{2}$ & $\begin{array}{l}\text { DTNs: LA0311EK831232.001 } \\
\text { (DIRS 166068), 11/4/97 sample; } \\
\text { GS040208312322.003 } \\
\text { (DIRS 172396), } \\
\text { U concentrations and isotopes }\end{array}$ \\
\hline \begin{tabular}{|l} 
Test Well 1 \\
(USGS HTH \\
$\# 1)$ \\
\end{tabular} & \begin{tabular}{|l} 
Test Well 1 \\
(USGS HTH \\
$\# 1)$ \\
\end{tabular} & 26 & 569000 & 4112499 & FMW-N & Fortymile Wash - North & $624^{6}$ & $\mathrm{TV}^{5}$ & $\begin{array}{l}\text { DTN: LA0311EK831232.001 } \\
\text { (DIRS 166068), 8/13/92 sample }\end{array}$ \\
\hline UE-18t & UE-18t & 27 & 559591 & 4109095 & FMW-N & Fortymile Wash - North & $(577.9-792.5)^{4}$ & $\mathrm{Tm}^{4}$ & $\begin{array}{l}\text { DTN: LA0311EK831232.001 } \\
\text { (DIRS 166068), 9/23/88 sample }\end{array}$ \\
\hline $\begin{array}{l}\text { ER-30-1 } \\
\text { (upper) }\end{array}$ & \begin{tabular}{|l} 
ER-30-1 \\
(upper)
\end{tabular} & 28 & 560805 & 4100463 & FMW-N & Fortymile Wash - North & $(179.1-185.2)^{4}$ & $\begin{array}{l}\text { Basaltic } \\
\text { lava }^{4}\end{array}$ & $\begin{array}{l}\text { DTNs: GS960908312323.005 } \\
\text { (DIRS 162916 ), ions and most } \\
\text { isotopes; GS950808312322.001 } \\
\text { (DIRS 148114), T, pH, Alkalinity, } \\
{ }^{87} \mathrm{Sr} /{ }^{86} \mathrm{Sr}\end{array}$ \\
\hline $\begin{array}{l}\text { ER-30-1 } \\
\text { (lower) }\end{array}$ & $\begin{array}{l}\text { ER-30-1 } \\
\text { (lower) }\end{array}$ & 29 & 560805 & 4100463 & FMW-N & Fortymile Wash - North & $(227.2-233.3)^{4}$ & $\begin{array}{l}\text { Gravelly } \\
\text { sand }^{4}\end{array}$ & $\begin{array}{l}\text { DTNs: GS960908312323.005 } \\
\text { (DIRS 162916 ), ions and most } \\
\text { isotopes; GS950808312322.001 } \\
\text { (DIRS 148114), T, pH, Alkalinity, } \\
8^{87} \mathrm{Sr} /{ }^{66} \mathrm{Sr}\end{array}$ \\
\hline
\end{tabular}


Table A4-3. Summary of Groundwater Wells and Data Sources (Continued)

\begin{tabular}{|c|c|c|c|c|c|c|c|c|c|}
\hline Well Identifier & $\begin{array}{c}\text { Abbreviation } \\
\text { Used in } \\
\text { Appendix }\end{array}$ & $\begin{array}{c}\text { Figure } \\
\text { A6-5 }\end{array}$ & $\begin{array}{l}\text { UTM-X }^{\text {a }} \\
(\mathrm{m})\end{array}$ & $\begin{array}{l}\text { UTM-Y } \\
(\mathrm{m})\end{array}$ & & Area $^{\text {b }}$ & $\begin{array}{c}\text { Approximate } \\
\text { Interval } \\
\text { Sampled }(\mathrm{m})^{\mathrm{e}}\end{array}$ & $\begin{array}{c}\text { Geologic } \\
\text { Unit }^{\mathrm{c}, \mathrm{e}}\end{array}$ & $\begin{array}{l}\text { Reference for Sampled Depth } \\
\text { and Chemical (C) and Isotopic } \\
\text { (I) Data }\end{array}$ \\
\hline \multicolumn{10}{|c|}{ Fortymile Wash - North (Continued) } \\
\hline \multirow[t]{2}{*}{ UE-29 a\#2 } & $a \# 2(d p)$ & 30 & \multirow[t]{2}{*}{555753} & \multirow[t]{2}{*}{4088351} & \multirow[t]{2}{*}{ FMW-N } & \multirow[t]{2}{*}{ Fortymile Wash - North } & $247-354^{1}$ & $T h^{2}$ & \multirow[b]{2}{*}{$\begin{array}{l}\text { DTNs: MO0007GNDWTRIS.010 } \\
\text { (DIRS 151500), } \delta^{18} \mathrm{O}, \delta \mathrm{D}, \delta^{13} \mathrm{C}, \\
{ }^{14} \mathrm{C} ; \mathrm{MO0007MAJIONPH} .013 \\
\text { (DIRS 151530), C; } \\
\text { GS010808312322.004 } \\
\text { (DIRS 156007), U } \\
\text { concentrations and isotopes; } \\
\text { GS930308312323.001 } \\
\text { (DIRS 145530), T, } \mathrm{F}^{-}, \mathrm{Sr}^{+}\end{array}$} \\
\hline & a\#2(sh) & 31 & & & & & $87-213^{1}$ & $T h^{2}$ & \\
\hline $\begin{array}{l}\text { UE-29a\#1 } \\
\text { HTH }\end{array}$ & $\begin{array}{l}\text { UE-29a\#1 } \\
\text { HTH }\end{array}$ & 32 & 555758 & 4088341 & FMW-N & Fortymile Wash - North & $(10.7-65.5)^{4}$ & Rhyolite $^{4}$ & $\begin{array}{l}\text { DTNs: LA0311EK831232.001 } \\
\text { (DIRS 166068), 11/6/97 sample; } \\
\text { GS010808312322.004 } \\
\text { (DIRS 156007), } \\
\text { U concentrations and isotopes } \\
\end{array}$ \\
\hline UE-25 WT\#15 & WT\#15 & 33 & 554034 & 4078702 & FMW-N & Fortymile Wash - North & $\begin{array}{l}\text { Open borehole } \\
(354-415)^{9}\end{array}$ & $\mathrm{Tpt}^{9}$ & \multirow{2}{*}{$\begin{array}{l}\text { DTNs: MO0007GNDWTRIS.007 } \\
\text { (DIRS 151497), } \delta^{18} \mathrm{O}, \delta \mathrm{D}, \delta^{13} \mathrm{C} \text {, } \\
{ }^{14} \mathrm{C} ; \text { MO0007GNDWTRIS.006 } \\
\text { (DIRS 151496), } \delta^{18} \mathrm{O}, \delta \mathrm{D}, \delta^{13} \mathrm{C} \text {, } \\
{ }^{14} \mathrm{C} ; \text { MO0008MAJIONPH.017 } \\
\text { (DIRS 151534), C }\end{array}$} \\
\hline UE-25 WT\#14 & WT\#14 & 34 & 552630 & 4077330 & FMW-N & Fortymile Wash - North & $\begin{array}{l}\text { open borehole } \\
(346-399)^{9}\end{array}$ & Tpt, $\operatorname{Tac}^{9}$ & \\
\hline UE-25 J-13 & $\mathrm{J}-13$ & 35 & 554017 & 4073517 & FMW-N & Fortymile Wash - North & $\begin{array}{l}(303-424) \\
(820-1009)^{9}\end{array}$ & $\begin{array}{l}\text { Tpt } \\
\text { Tct, TIr }\end{array}$ & \multirow[b]{2}{*}{$\begin{array}{l}\text { DTNs: MO0007GNDWTRIS.010 } \\
\text { (DIRS 151500). } \delta^{18} \mathrm{O}, \delta \mathrm{D}, \delta^{13} \mathrm{C} \text {, } \\
{ }^{14} \mathrm{C} ; \mathrm{MO0007MAJION} \text { M } 013 \\
\text { (DIRS 151530), C; } \\
\text { GS930108315213.004 } \\
\text { (DIRS 145525), U } \\
\text { concentrations and isotopes; } \\
\text { GS930308312323.001 (DIRS } \\
\text { 145530), T, F- } \mathrm{Fr}^{-} ; \\
\text {LA0311EK831232.001 (DIRS } \\
\text { 166068), 87Sr/86Sr }\end{array}$} \\
\hline UE-25 J-12 & $\mathrm{J}-12$ & 36 & 554444 & 4068774 & FMW-N & Fortymile Wash - North & $\begin{array}{l}\text { open borehole } \\
(227-271)^{9}\end{array}$ & $\mathrm{Tpt}^{9}$ & \\
\hline
\end{tabular}


Table A4-3. Summary of Groundwater Wells and Data Sources (Continued)

\begin{tabular}{|c|c|c|c|c|c|c|c|c|c|}
\hline \multicolumn{10}{|c|}{ Fortymile Wash - North (Continued) } \\
\hline \multicolumn{10}{|c|}{ Solitario Canyon Wash } \\
\hline \multirow[t]{2}{*}{ USW H-6 } & $\mathrm{H}-6(\mathrm{bh})$ & 38 & 546188 & 4077816 & SCW & Solitario Canyon Wash & $\begin{array}{l}\text { open borehole } \\
(526-1220)^{1}\end{array}$ & $\mathrm{Tcb} / \mathrm{Tct}{ }^{2}$ & $\begin{array}{l}\text { DTNs: MO0007GNDWTRIS.010 } \\
\text { (DIRS 151500), } \delta^{18} \mathrm{O}, \delta \mathrm{D}, \delta^{13} \mathrm{C}, \\
{ }^{14} \mathrm{C} ; \mathrm{MO0007MAJIONPH} .013 \\
\text { (DIRS 151530), C; } \\
\text { GS930308312323.001 } \\
\text { (DIRS 145530), }\left(\mathrm{T}, \mathrm{F}^{-}, \mathrm{Sr}^{2+}\right) ;\end{array}$ \\
\hline & $\mathrm{H}-6(\mathrm{Tcb})$ & 40 & & & & & $608-646^{1}$ & $\mathrm{Tcb}^{2}$ & $\begin{array}{l}\text { DTN: MO0007GNDWTRIS.010 } \\
\text { (DIRS 151500), ( }\left(^{18} \mathrm{O}, \delta \mathrm{D}, \delta^{13} \mathrm{C} \text {, }\right. \\
\left.{ }^{14} \mathrm{C}\right) ; \mathrm{MO0007M} \text { JIONPH.012 } \\
\text { (DIRS 151529), (C);Benson and } \\
\text { McKinley 1985 (DIRS 101036), } \\
\mathrm{T}, \mathrm{F}^{-}, \mathrm{Sr}^{2+}\end{array}$ \\
\hline
\end{tabular}


Table A4-3. Summary of Groundwater Wells and Data Sources (Continued)

\begin{tabular}{|c|c|c|c|c|c|c|c|c|c|}
\hline Well Identifier & $\begin{array}{c}\text { Abbreviation } \\
\text { Used in } \\
\text { Appendix }\end{array}$ & \begin{tabular}{|c} 
Figure \\
A6-5
\end{tabular} & $\begin{array}{l}\text { UTM-X }^{\mathrm{a}} \\
(\mathrm{m})\end{array}$ & $\begin{array}{l}\text { UTM-Y }^{3} \\
(\mathrm{~m})\end{array}$ & & Area $^{b}$ & $\begin{array}{c}\begin{array}{c}\text { Approximate } \\
\text { Interval } \\
\text { Sampled }(m)^{e}\end{array} \\
\end{array}$ & $\begin{array}{c}\text { Geologic } \\
\text { Unit }^{\mathrm{c}, \mathrm{e}}\end{array}$ & $\begin{array}{l}\text { Reference for Sampled Depth } \\
\text { and Chemical (C) and Isotopic } \\
\text { (I) Data }\end{array}$ \\
\hline \multicolumn{10}{|c|}{ Solitario Canyon Wash (Continued) } \\
\hline USW WT-7 & WT-7 & 41 & 546151 & 4075474 & SCW & Solitario Canyon Wash & $\begin{array}{l}\text { open borehole } \\
(421-491)^{9}\end{array}$ & Tpt, Tcp ${ }^{9}$ & $\begin{array}{l}\text { DTNs: MO0007GNDWTRIS.006 } \\
\text { (DIRS 151496), } \delta^{18} \mathrm{O}, \delta^{13} \mathrm{C} ; \\
\text { MO0008MAJIONPH.017 } \\
\text { (DIRS 151534), C; } \\
\text { LA0311EK831232.001 } \\
\text { (DIRS 166068), } \mathrm{F}^{-}, \mathrm{Sr}^{2+}, \\
{ }^{87} \mathrm{Sr} /{ }^{86} \mathrm{Sr} ; \text { Paces et al. } 2002 \\
\text { (DIRS 158817), Table 1, } \\
\text { U concentrations and isotopes }\end{array}$ \\
\hline USW WT-10 & WT-10 & 42 & 545964 & 4073378 & SCW & Solitario Canyon Wash & $\begin{array}{l}\text { open borehole } \\
(347-431)^{9}\end{array}$ & $\mathrm{Tpt}^{9}$ & 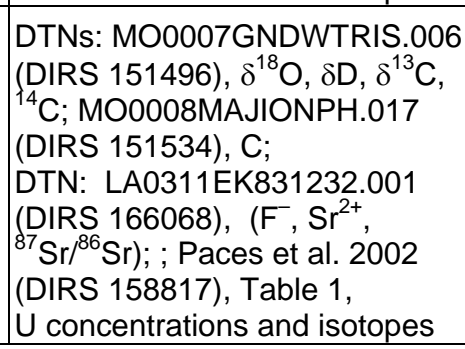 \\
\hline \multicolumn{10}{|c|}{ Yucca Mountain - Crest } \\
\hline USW G-2 & G-2 & 43 & 548143 & 4082542 & YM-CR & Yucca Mountain - Crest & $533-792^{10}$ & Tpt, Tac $^{10}$ & $\begin{array}{l}\text { DTNs: MO0007GNDWTRIS.002 } \\
\text { (DIRS 151492), } \delta^{18} \mathrm{O}, \delta \mathrm{D}, \delta^{13} \mathrm{C}, \\
{ }^{14} \mathrm{C} ; \mathrm{MO0007MAJIONPH} .003 \\
\text { (DIRS 151513), C; } \\
\text { GSO10608315215.002 } \\
\text { (DIRS 156187), U } \\
\text { concentrations and isotopes; } \\
\text { LA0311EK831232.001 } \\
\text { (DIRS 166068), } \mathrm{F}^{-}, \mathrm{Sr}^{2+}, \\
{ }^{87} \mathrm{Sr}{ }^{86} \mathrm{Sr}\end{array}$ \\
\hline USW WT-24 & USW WT-24 & 44 & 548691 & 4081898 & YM-CR & Yucca Mountain - Crest & $688^{11}$ & Not reported & $\begin{array}{l}\text { DTN: GS980908312322.008 } \\
\text { (DIRS 145412), 4/24/98 sample; } \\
\text { Paces et al. 2002 } \\
\text { (DIRS 158817), Table } 1\end{array}$ \\
\hline
\end{tabular}


Table A4-3. Summary of Groundwater Wells and Data Sources (Continued)

\begin{tabular}{|c|c|c|c|c|c|c|c|c|c|}
\hline Well Identifier & $\begin{array}{c}\text { Abbreviation } \\
\text { Used in } \\
\text { Appendix }\end{array}$ & $\begin{array}{c}\text { Figure } \\
\text { A6-5 }\end{array}$ & $\begin{array}{l}\text { UTM-X }^{a} \\
(\mathrm{~m})\end{array}$ & $\begin{array}{c}\text { UTM-Y }{ }^{3} \\
(\mathrm{~m})\end{array}$ & & Area $^{\text {b }}$ & $\begin{array}{c}\text { Approximate } \\
\text { Interval } \\
\text { Sampled }(\mathrm{m})^{\mathrm{e}}\end{array}$ & $\begin{array}{c}\text { Geologic } \\
\text { Unit }^{\mathrm{c}, \mathrm{e}}\end{array}$ & $\begin{array}{l}\text { Reference for Sampled Depth } \\
\text { and Chemical (C) and Isotopic } \\
\text { (I) Data }\end{array}$ \\
\hline \multicolumn{10}{|c|}{ Yucca Mountain - Crest (Continued) } \\
\hline \multirow[t]{2}{*}{ USW UZ-14 } & UZ-14 (sh) & 45 & \multirow[t]{2}{*}{548032} & \multirow[t]{2}{*}{4080260} & \multirow[t]{2}{*}{ YM-CR } & \multirow[t]{2}{*}{ Yucca Mountain - Crest } & bailed $(579)^{11}$ & Tcp & \multirow[b]{2}{*}{$\begin{array}{l}\text { DTNs: MO0007GNDWTRIS.003 } \\
\text { (DIRS 151493), } \delta^{18} \mathrm{O}, \delta \mathrm{D}, \delta^{13} \mathrm{C}, \\
{ }^{14} \mathrm{C} ; \mathrm{MO} 0007 \mathrm{MAJON} \mathrm{O} P \mathrm{O} .005 \\
\text { (DIRS 151517), C; } \\
\text { GS980908312322.008 } \\
\text { (DIRS 145412), T, } \mathrm{F}^{-}, \mathrm{Sr}^{2+}, \mathrm{SiO}_{2} \\
\mathrm{HCO}_{3}^{-} \text {, and } \delta^{34} \mathrm{~S}\end{array}$} \\
\hline & UZ-14 (dp) & 46 & & & & & bailed $(655)^{11}$ & Tcb & \\
\hline \multirow[t]{2}{*}{ USW H-1 } & $\mathrm{H}-1(\mathrm{Tcp})$ & 47 & \multirow[t]{2}{*}{548727} & \multirow[t]{2}{*}{4079926} & \multirow[t]{2}{*}{ YM-CR } & \multirow[t]{2}{*}{ Yucca Mountain - Crest } & $572-687^{1}$ & $\mathrm{Tcp}^{2}$ & \multirow{2}{*}{$\begin{array}{l}\text { DTNs: MO0007GNDWTRIS.010 } \\
\text { (DIRS 151500), } \delta^{18} \mathrm{O}, \delta \mathrm{D}, \delta^{13} \mathrm{C}, \\
{ }^{14} \mathrm{C} ; \mathrm{MO0007MAJIONPH} .013 \\
\text { (DIRS 151530), C; } \\
\text { GS930308312323.001 } \\
\text { (DIRS 145530), T, F } \mathrm{F}^{-} \mathrm{Sr}^{2+}\end{array}$} \\
\hline & $\mathrm{H}-1(\mathrm{Tcb})$ & 48 & & & & & $687-1829^{1}$ & $\mathrm{Tcb}^{2}$ & \\
\hline USW H-5 & $\mathrm{H}-5$ & 49 & 547668 & 4078841 & YM-CR & Yucca Mountain - Crest & $\begin{array}{l}\text { open borehole } \\
(704-1220)^{1}\end{array}$ & $\mathrm{Tcb} / \mathrm{Tct}^{2}$ & $\begin{array}{l}\text { DTNs: MO0007GNDWTRIS.010 } \\
\text { (DIRS 151500), } \delta^{18} \mathrm{O}, \delta \mathrm{D}, \delta^{13} \mathrm{C}, \\
{ }^{14} \mathrm{C} ; \mathrm{MO0007MAJIONPH} .013 \\
\text { (DIRS 151530), C; } \\
\text { GS930308312323.001 } \\
\text { (DIRS 145530), T, } \mathrm{F}^{-}, \mathrm{Sr}^{2+}\end{array}$ \\
\hline USW SD-6 & USW SD-6 & 50 & 547592 & 4077514 & YM-CR & Yucca Mountain - Crest & $\begin{array}{l}\text { open borehole } \\
\text { (depth not } \\
\text { reported) }\end{array}$ & Not reported & $\begin{array}{l}\text { DTNs: GS010308312322.003 } \\
\text { (DIRS } 154734), \mathrm{T}, \mathrm{pH} \text {, alkalinity, } \\
\text { ions, } \delta^{18} \mathrm{O}, \delta \mathrm{D}, \delta^{13} \mathrm{C} ; \\
\text { GSO11108312322.006 } \\
\text { (DIRS 162911), } \delta^{13} \mathrm{C}, \delta^{34} \mathrm{~S} ; \\
\text { GS010208312322.001 } \\
\text { (DIRS 162908), } \\
\text { U-concentrations and isotopes }\end{array}$ \\
\hline USW H-3 & $\mathrm{H}-3$ & 51 & 547562 & 4075759 & YM-CR & Yucca Mountain - Crest & $\begin{array}{l}\text { open borehole } \\
(822-1220)^{1}\end{array}$ & $\mathrm{Tct}^{2}$ & $\begin{array}{l}\text { DTNs: MO0007GNDWTRIS.009 } \\
\text { (DIRS 151509), } \delta^{18} \mathrm{O}, \delta \mathrm{D}, \delta^{13} \mathrm{C} \text {, } \\
{ }^{14} \mathrm{C} ; \mathrm{MO0007MAJIONPH} .011 \\
\text { (DIRS 151524), C; } \\
\text { MOO007MAJIONPH.012 } \\
\text { (DIRS 151529), C; } \\
\text { GS920408312321.003 } \\
\text { (DIRS 105937), T, } \mathrm{F}^{-}, \mathrm{Sr}^{2+}\end{array}$ \\
\hline
\end{tabular}


Table A4-3. Summary of Groundwater Wells and Data Sources (Continued)

\begin{tabular}{|c|c|c|c|c|c|c|c|c|c|}
\hline Well Identifier & $\begin{array}{c}\text { Abbreviation } \\
\text { Used in } \\
\text { Appendix }\end{array}$ & $\begin{array}{c}\text { Figure } \\
\text { A6-5 }\end{array}$ & $\begin{array}{l}\mathrm{UTM}^{\mathrm{UT}-\mathrm{X}^{\mathrm{a}}} \\
(\mathrm{m})\end{array}$ & $\begin{array}{l}\text { UTM-Y } \\
(\mathrm{m})\end{array}$ & & Area $^{b}$ & $\begin{array}{c}\begin{array}{c}\text { Approximate } \\
\text { Interval } \\
\text { Sampled }(m)^{e}\end{array} \\
\end{array}$ & $\begin{array}{c}\text { Geologic } \\
\text { Unit }^{\mathrm{c}, \mathrm{e}}\end{array}$ & $\begin{array}{l}\text { Reference for Sampled Depth } \\
\text { and Chemical (C) and Isotopic } \\
\text { (I) Data }\end{array}$ \\
\hline \multicolumn{10}{|c|}{ Yucca Mountain - Central } \\
\hline USW G-4 & G-4 & 52 & 548933 & 4078602 & YM-C & $\begin{array}{l}\text { Yucca Mountain - } \\
\text { Central }\end{array}$ & $\begin{array}{l}\text { open borehole } \\
(541-915)^{1}\end{array}$ & Tct & $\begin{array}{l}\text { DTNs: MO0007GNDWTRIS.010 } \\
\text { (DIRS 151500), } \delta^{18} \mathrm{O}, \delta \mathrm{D}, \delta^{13} \mathrm{C}, \\
\left.{ }^{14} \mathrm{C}\right) ; \mathrm{MO0007MAJIONPH} .013 \\
\text { (DIRS 151530), (C); } \\
\text { GS930308312323.001 } \\
\text { (DIRS 145530), }\left(\mathrm{T}, \mathrm{F}^{-}, \mathrm{Sr}^{2+}\right)\end{array}$ \\
\hline \multirow[t]{2}{*}{ UE-25 b\#1 } & $\mathrm{b \# 1}(\mathrm{Tcb})$ & 53 & \multirow[t]{2}{*}{549949} & \multirow[t]{2}{*}{4078423} & \multirow[t]{2}{*}{ YM-C } & \multirow{2}{*}{$\begin{array}{l}\text { Yucca Mountain - } \\
\text { Central }\end{array}$} & $863-875^{1}$ & $\mathrm{Tcb}^{2}$ & \multirow{2}{*}{$\begin{array}{l}\text { DTNS: MO0007GNDWTRIS.010 } \\
\text { (DIRS 151500), ( } \delta^{18} \mathrm{O}, \delta \mathrm{D}, \delta^{13} \mathrm{C} \text {, } \\
{ }^{14} \mathrm{C} ; \mathrm{MO0007MAJIONPH} .013 \\
\text { (DIRS 151530), C; } \\
\text { GS930308312323.001 } \\
\text { (DIRS 145530), T, F, } \mathrm{Sr}^{2+}\end{array}$} \\
\hline & $\mathrm{b \# 1(bh)}$ & 54 & & & & & $\begin{array}{l}\text { open borehole } \\
(470-1220)^{1}\end{array}$ & $\mathrm{Th} / \mathrm{Tct}^{2}$ & \\
\hline USW H-4 & $\mathrm{H}-4$ & 55 & 549188 & 4077309 & YM-C & $\begin{array}{l}\text { Yucca Mountain - } \\
\text { Central }\end{array}$ & $\begin{array}{l}\text { open borehole } \\
(519-1220)^{1}\end{array}$ & $\mathrm{Tcb} / \mathrm{Tct}{ }^{2}$ & $\begin{array}{l}\text { DTNs: MO0007GNDWTRIS.010 } \\
\text { (DIRS 151500), } \delta^{18} \mathrm{O}, \delta \mathrm{D}, \delta^{13} \mathrm{C}, \\
{ }^{14} \mathrm{C} \text {; MO0007MAJIONPH.013 } \\
\text { (DIRS 151530), C; } \\
\text { GS930308312323.001 } \\
\text { (DIRS 145530), T, } \mathrm{F}^{-}, \mathrm{Sr}^{2+}\end{array}$ \\
\hline $\begin{array}{l}\text { UE-25 } \\
\text { UZ\#16 }\end{array}$ & UZ\#16 & 56 & 549484.9 & 4076986 & YM-C & $\begin{array}{l}\text { Yucca Mountain - } \\
\text { Central }\end{array}$ & $490-492$ & Tcp & $\begin{array}{l}\text { DTN: MO0007MAJIONPH.007 } \\
\text { (DIRS 151519), C }\end{array}$ \\
\hline \multicolumn{10}{|c|}{ Yucca Mountain - Southeast } \\
\hline $\begin{array}{l}\text { UE-25 } \\
\text { ONC\#1 }\end{array}$ & ONC\#1 & 57 & 550479.9 & 4076608 & YM-SE & $\begin{array}{l}\text { Yucca Mountain - } \\
\text { Southeast }\end{array}$ & $\begin{array}{l}\text { open borehole } \\
(433-469)^{15}\end{array}$ & $\mathrm{Th} / \mathrm{Tcp}^{15}$ & $\begin{array}{l}\text { DTN: MO0007MAJIONPH.004 } \\
\text { (DIRS 151516), C; Oliver and } \\
\text { Root 1997 (DIRS 100069), } \mathrm{Sr}^{2+} \\
\text { and }\left.{ }^{87} \mathrm{Sr}\right|^{86} \mathrm{Sr}\end{array}$ \\
\hline UE-25 c\#1 & c\#1 & 58 & 550955 & 4075933 & YM-SE & $\begin{array}{l}\text { Yucca Mountain - } \\
\text { Southeast }\end{array}$ & $\begin{array}{l}\text { open borehole } \\
(400-914)^{1}\end{array}$ & $\mathrm{Tcb} / \mathrm{Tct}{ }^{2}$ & $\begin{array}{l}\text { DTNs: MO0007GNDWTRIS.009 } \\
\text { (DIRS 151509), } \delta^{18} \mathrm{O}, \delta \mathrm{D}, \delta^{13} \mathrm{C} \text {, } \\
{ }^{14} \mathrm{C} ; \mathrm{MO0007MAJIONPH} .011 \\
\text { (DIRS 151524), C; } \\
\text { MO0007MAJIONPH.012 } \\
\text { (DIRS 151529), C; } \\
\text { GS920408312321.003 } \\
\text { (DIRS 105937), T, F }, \mathrm{Sr}^{2+} ; \\
\text { LA0311EK831232.001 } \\
\text { (DIRS 166068), }{ }^{87} \mathrm{Sr}^{86} \mathrm{Sr} \text { for C\#1 }\end{array}$ \\
\hline
\end{tabular}


Table A4-3. Summary of Groundwater Wells and Data Sources (Continued)

\begin{tabular}{|c|c|c|c|c|c|c|c|c|c|}
\hline Well Identifier & $\begin{array}{c}\text { Abbreviation } \\
\text { Used in } \\
\text { Appendix }\end{array}$ & \begin{tabular}{|c} 
Figure \\
A6-5
\end{tabular} & \begin{tabular}{|c} 
UTM-X $^{\mathrm{a}}$ \\
$(\mathrm{m})$
\end{tabular} & $\begin{array}{c}\text { UTM-Y }{ }^{3} \\
(\mathrm{~m})\end{array}$ & & Area $^{b}$ & $\begin{array}{l}\text { Approximate } \\
\text { Interval } \\
\text { Sampled }(\mathrm{m})^{\mathrm{e}}\end{array}$ & $\begin{array}{c}\text { Geologic } \\
\text { Unit }^{\mathrm{c}, \mathrm{e}}\end{array}$ & $\begin{array}{l}\text { Reference for Sampled Depth } \\
\text { and Chemical (C) and Isotopic } \\
\text { (I) Data }\end{array}$ \\
\hline \multicolumn{10}{|c|}{ Yucca Mountain - Southeast (Continued) } \\
\hline \multirow[t]{2}{*}{ UE-25 c\#3 } & c\#3 & 59 & \multirow[t]{2}{*}{550930} & \multirow[t]{2}{*}{4075902} & \multirow[t]{2}{*}{ YM-SE } & \multirow[t]{2}{*}{$\begin{array}{l}\text { Yucca Mountain - } \\
\text { Southeast }\end{array}$} & \multirow[t]{2}{*}{$\begin{array}{l}\text { open borehole } \\
(402-913)^{1}\end{array}$} & \multirow[t]{2}{*}{$\mathrm{Tcb} / \mathrm{Tct}^{2}$} & $\begin{array}{l}\text { DTNS: MO0007GNDWTRIS.009 } \\
\text { (DIRS 151509), } \delta^{18} \mathrm{O}, \delta \mathrm{D}, \delta^{13} \mathrm{C}, \\
{ }^{14} \mathrm{C} ; \mathrm{MO0007MAJIONPH} .011 \\
\text { (DIRS 151524), C; } \\
\text { MO0007MAJIONPH.012 } \\
\text { (DIRS 151529), C; } \\
\text { GS920408312321.003 } \\
\text { (DIRS 105937), T, } \mathrm{F}^{-}, \mathrm{Sr}^{2+}\end{array}$ \\
\hline & c\#3(95-97) & 60 & & & & & & & $\begin{array}{l}\text { DTNs: GS950808312322.001 } \\
\text { (DIRS 148114), C, } \delta^{18} \mathrm{O}, \delta \mathrm{D} ; \\
\text { GS010808312322.004 (DIRS } \\
\text { 156007);GS010608315215.002 } \\
\text { (DIRS 156187); } \\
\text { GS040208312322.003 } \\
\text { (DIRS 172396); } \\
\text { U concentrations and isotopes; } \\
\text { (DIRS 172396) } \\
\text { GS980908312322.008 } \\
\text { (DIRS 145412), } \delta^{34} \mathrm{~S} ; \\
\text { GS970708315215.008 } \\
\text { (DIRS 164674), }{ }^{87} \mathrm{Sr} /{ }^{86} \mathrm{Sr} \text { for C\#3 }\end{array}$ \\
\hline UE-25 c\#2 & c\#2 & 61 & 550955 & 4075871 & YM-SE & $\begin{array}{l}\text { Yucca Mountain - } \\
\text { Southeast }\end{array}$ & $\begin{array}{l}\text { open borehole } \\
(401-913)^{1}\end{array}$ & $\mathrm{Tcb}^{2}$ & $\begin{array}{l}\text { DTNs: MO0007GNDWTRIS.009 } \\
\text { (DIRS 151509), } \delta^{18} \mathrm{O}, \delta \mathrm{D}, \delta^{13} \mathrm{C}, \\
{ }^{14} \mathrm{C} ; \mathrm{MO0007MAJIONPH.011} \\
\text { (DIRS 151524), C; } \\
\text { MO0007MAJIONPH.012 } \\
\text { (DIRS 151529), C; } \\
\text { GS920408312321.003 } \\
\text { (DIRS 105937), T, F- } \mathrm{Sr}^{2+} ; \\
\text { GS980908312322.008 } \\
\text { (DIRS 145412), } \delta^{34} \mathrm{~S} \text { for } \mathrm{C \# 2} \\
\end{array}$ \\
\hline
\end{tabular}


Table A4-3. Summary of Groundwater Wells and Data Sources (Continued)

\begin{tabular}{|c|c|c|c|c|c|c|c|c|c|}
\hline Well Identifier & $\begin{array}{c}\text { Abbreviation } \\
\text { Used in } \\
\text { Appendix }\end{array}$ & $\begin{array}{c}\text { Figure } \\
\text { A6-5 }\end{array}$ & $\begin{array}{l}\text { UTM-X }^{\text {a }} \\
(\mathrm{m})\end{array}$ & $\begin{array}{l}\text { UTM-Y } \\
(\mathrm{m})\end{array}$ & & Area $^{\text {b }}$ & $\begin{array}{l}\text { Approximate } \\
\text { Interval } \\
\text { Sampled }(\mathbf{m})^{\mathrm{e}}\end{array}$ & $\begin{array}{c}\text { Geologic } \\
\text { Unit }^{\mathrm{c}, \mathrm{e}}\end{array}$ & $\begin{array}{l}\text { Reference for Sampled Depth } \\
\text { and Chemical (C) and Isotopic } \\
\text { (I) Data }\end{array}$ \\
\hline \multicolumn{10}{|c|}{ Yucca Mountain - Southeast (Continued) } \\
\hline \multirow[t]{2}{*}{ UE-25 p\#1 } & $p \# 1(v)$ & 62 & \multirow[t]{2}{*}{551501} & \multirow[t]{2}{*}{4075659} & \multirow[t]{2}{*}{ YM-SE } & \multirow{2}{*}{$\begin{array}{l}\text { Yucca Mountain - } \\
\text { Southeast }\end{array}$} & $381-1197^{1}$ & tuff $^{2}$ & \multirow[b]{2}{*}{$\begin{array}{l}\text { DTNS: MO0007GNDWTRIS.009 } \\
\text { (DIRS 151509), } \delta^{18} \mathrm{O}, \delta \mathrm{D}, \delta^{13} \mathrm{C}, \\
{ }^{14} \mathrm{C} ; \mathrm{MO0007MAJIONNH} .011 \\
\text { (DIRS 151524), C; } \\
\text { MO0007GNDWTRIS.008 } \\
\text { (DIRS 151508), } \delta^{18} \mathrm{O}, \delta \mathrm{D}, \delta^{13} \mathrm{C}, \\
{ }^{14} \mathrm{C} ; \mathrm{MO0007MAJIONPH} .010 \\
\text { (DIRS 151523), C; } \\
\text { GS930108315213.004 } \\
\text { (DIRS 145525), } \\
\text { U concentrations and isotopes; } \\
\text { GS920408312321.003 } \\
\text { (DIRS 105937), T, } \mathrm{F}^{-}, \mathrm{Sr}^{2+} ; \\
\text { LA0311EK831232.001 } \\
\text { (DIRS 166068), }{ }^{87} \mathrm{Sr}^{86} \mathrm{Sr}^{8}\end{array}$} \\
\hline & $p \# 1(c)$ & 63 & & & & & $1297-1805^{1}$ & $\begin{array}{l}\mathrm{Srm} / \\
\mathrm{DSIm}^{2}\end{array}$ & \\
\hline USW WT-17 & WT-17 & 64 & 549905 & 4073307 & YM-SE & $\begin{array}{l}\text { Yucca Mountain - } \\
\text { Southeast }\end{array}$ & $\begin{array}{l}\text { open borehole } \\
(393-443)^{9}\end{array}$ & $\mathrm{Tcp}^{9}$ & $\begin{array}{l}\text { DTNs: MO0007GNDWTRIS.003 } \\
\text { (DIRS 151493), } \delta^{18} \mathrm{O}, \delta \mathrm{D}, \delta^{13} \mathrm{C}, \\
{ }^{14} \mathrm{C} ; \mathrm{MO0007MAJIONPH} .005 \\
\text { (DIRS 151517), C; } \\
\text { GS980908312322.008 } \\
\text { (DIRS 145412), T, } \mathrm{F}^{-}, \mathrm{Sr}^{2+}, \text { and } \\
\delta^{34} \mathrm{~S} ; \mathrm{GS} 980908312322.009 \\
\text { (DIRS 118977), } \\
\text { U concentrations and isotopes }\end{array}$ \\
\hline UE-25 WT\#3 & WT\#3 & 65 & 552090 & 4072550 & YM-SE & $\begin{array}{l}\text { Yucca Mountain - } \\
\text { Southeast }\end{array}$ & $\begin{array}{l}\text { open borehole } \\
(301-348)^{9}\end{array}$ & $\mathrm{Tcb}^{9}$ & $\begin{array}{l}\text { DTNs: MO0007GNDWTRIS.003 } \\
\text { (DIRS 151493), } \delta^{18} \mathrm{O}, \delta \mathrm{D}, \delta^{13} \mathrm{C}, \\
\text { 14 C; MO0007MAJIONPH.005 } \\
\text { (DIRS 151517), C; } \\
\text { GS980908312322.008 } \\
\text { (DIRS 145412), T, } \mathrm{F}^{-}, \mathrm{Sr}^{2+} \text {, and } \\
\left.\delta^{34} \mathrm{~S}\right) ; \mathrm{GS} 980908312322.009 \\
\text { (DIRS 118977), } \\
\text { U concentrations and isotopes }\end{array}$ \\
\hline
\end{tabular}


Table A4-3. Summary of Groundwater Wells and Data Sources (Continued)

\begin{tabular}{|c|c|c|c|c|c|c|c|c|c|}
\hline Well Identifier & $\begin{array}{c}\text { Abbreviation } \\
\text { Used in } \\
\text { Appendix }\end{array}$ & $\begin{array}{c}\text { Figure } \\
\text { A6-5 }\end{array}$ & $\begin{array}{l}\text { UTM-X }{ }^{a} \\
(m)\end{array}$ & $\begin{array}{l}\text { UTM-Y }{ }^{3} \\
(\mathrm{~m})\end{array}$ & & Area $^{b}$ & $\begin{array}{c}\begin{array}{c}\text { Approximate } \\
\text { Interval } \\
\text { Sampled }(m)^{e}\end{array} \\
\end{array}$ & $\begin{array}{c}\text { Geologic } \\
\text { Unit }^{\mathrm{c}, \mathrm{e}}\end{array}$ & $\begin{array}{l}\begin{array}{l}\text { Reference for Sampled Depth } \\
\text { and Chemical (C) and Isotopic } \\
\text { (I) Data }\end{array} \\
\end{array}$ \\
\hline \multicolumn{10}{|c|}{ Yucca Mountain - Southeast (Continued) } \\
\hline $\begin{array}{l}\text { UE-25 } \\
\text { WT\#12 }\end{array}$ & WT\#12 & 66 & 550168 & 4070659 & YM-SE & $\begin{array}{l}\text { Yucca Mountain - } \\
\text { Southeast }\end{array}$ & $\begin{array}{l}\text { open borehole } \\
(345-399)^{9}\end{array}$ & Tpt/Tac ${ }^{9}$ & $\begin{array}{l}\text { DTNs: MO0007GNDWTRIS.007 } \\
\text { (DIRS 151497), } \delta^{18} \mathrm{O}, \delta \mathrm{D}, \delta^{13} \mathrm{C}, \\
\text { 14 }^{14} \mathrm{C} \text { MO0007GNDWTRIS.006 } \\
\text { (DIRS 151496), } \delta^{18} \mathrm{O}, \delta \mathrm{D}, \delta^{13} \mathrm{C}, \\
{ }^{14} \mathrm{C} \text {; MO0008MAJIONPH.017 } \\
\text { (DIRS 151534), C; } \\
\text { GS010608315215.002 } \\
\text { (DIRS 156187), U } \\
\text { concentrations and isotopes; } \\
\text { LA0311EK831232.001 } \\
\text { (DIRS 166068), }{ }^{87} \mathrm{Sr} /{ }^{86} \mathrm{Sr} \text {; Oliver } \\
\text { and Root 1997 (DIRS 100069), } \\
\mathrm{F}^{-}, \mathrm{Sr}^{2+}\end{array}$ \\
\hline \multicolumn{10}{|l|}{ Jackass Flats } \\
\hline UE-25 J-11 & UE-25 J-11 & 67 & 563798 & 4071073 & $\mathrm{JF}$ & Jackass Flats & $\begin{array}{l}\text { open borehole } \\
(317-405)^{9}\end{array}$ & $\mathrm{~Tb}, \mathrm{Tpt}^{9}$ & $\begin{array}{l}\text { DTNs: GS010308312322.003 } \\
\text { (DIRS 154734), pH, alkalinity, } \\
\delta^{18} \mathrm{O}, \delta \mathrm{D}, \delta^{13} \mathrm{C},{ }^{14} \mathrm{C} ; \\
\text { GS011108312322. } \\
\text { (DIRS 162911), } \delta^{34} \mathrm{~S} ; \\
\text { GS010308312322.002 } \\
\text { (DIRS 162910), ions; } \\
\text { GS010208312322.001 } \\
\text { (DIRS 162908), } \\
\text { U concentrations and isotopes }\end{array}$ \\
\hline \multicolumn{10}{|l|}{ Crater Flat } \\
\hline GEXA Well 4 & GEXA Well 4 & 68 & 534069 & 4086110 & $\mathrm{CF}$ & Crater Flat & $(244-488)^{4}$ & $\mathrm{TV}^{4,15}$ & $\begin{array}{l}\text { DTNs: GS970708312323.001 } \\
\text { (DIRS 145405), }{ }^{18} \mathrm{O}, \delta \mathrm{D} ; \\
\text { MO0007MAJIONPH.008 } \\
\text { (DIRS 151521), C; } \\
\text { GS980208312322.006 } \\
\text { (DIRS 146065), } \\
\text { U concentrations and isotopes; } \\
\text { Oliver and Root 1997 } \\
\text { (DIRS 100069), T, F', } \mathrm{Sr}^{2+} \\
{ }^{87} \mathrm{Sr} /^{86} \mathrm{Sr}\end{array}$ \\
\hline
\end{tabular}


Table A4-3. Summary of Groundwater Wells and Data Sources (Continued)

\begin{tabular}{|c|c|c|c|c|c|c|c|c|c|}
\hline Well Identifier & $\begin{array}{l}\text { Abbreviation } \\
\text { Used in } \\
\text { Appendix }\end{array}$ & $\begin{array}{c}\text { Figure } \\
\text { A6-5 }\end{array}$ & $\begin{array}{l}\mathrm{UTM}^{\mathrm{U}}-\mathrm{X}^{\mathrm{a}} \\
(\mathrm{m})\end{array}$ & $\begin{array}{l}\text { UTM-Y }{ }^{3} \\
(\mathrm{~m})\end{array}$ & & Area $^{b}$ & $\begin{array}{l}\text { Approximate } \\
\text { Interval } \\
\text { Sampled }(m)^{\mathrm{e}}\end{array}$ & $\begin{array}{c}\text { Geologic } \\
\text { Unit }^{g, e}\end{array}$ & $\begin{array}{l}\text { Reference for Sampled Depth } \\
\text { and Chemical (C) and Isotopic } \\
\text { (I) Data }{ }^{\mathrm{d}}\end{array}$ \\
\hline \multicolumn{10}{|c|}{ Crater Flat (Continued) } \\
\hline USW VH-1 & $\mathrm{VH}-1$ & 69 & 539976 & 4071714 & CF & Crater Flat & $\begin{array}{l}\text { open borehole } \\
(184-762)^{1}\end{array}$ & $\mathrm{Tcb}^{2}$ & $\begin{array}{l}\text { DTNs: MO0007GNDWTRIS.010 } \\
\text { (DIRS 151500), } \delta^{18} \mathrm{O}, \delta \mathrm{D}, \delta^{13} \mathrm{C} \text {, } \\
{ }^{14} \mathrm{C} ; \mathrm{MO0007MAJIONPH} .013 \\
\text { (DIRS 151530), C; } \\
\text { GS930308312323.001 } \\
\text { (DIRS 145530), T, } \mathrm{F}^{-}, \mathrm{Sr}^{2+} ; \\
\text { LA0311EK831232.0001 } \\
\text { (DIRS 166068), }{ }^{87} \mathrm{Sr}{ }^{86} \mathrm{Sr} ; \text { Paces } \\
\text { et al. } 2002 \text { (DIRS 158817), Table } \\
1, \mathrm{U} \text { concentrations and isotopes }\end{array}$ \\
\hline \multicolumn{10}{|c|}{ Crater Flat - Southwest } \\
\hline USW-VH-2 & $\mathrm{VH}-2$ & 70 & 537738 & 4073214 & CF-SW & Crater Flat - Southwest & $\begin{array}{l}\text { open borehole } \\
\left(^{(164-1219)^{15}}\right.\end{array}$ & $\mathrm{TV}^{15}$ & $\begin{array}{l}\text { DTNs: GS930108315213.002 } \\
\text { (DIRS 148109), C; } \\
\text { GS970708312323.001 } \\
\text { (DIRS 145405), } \delta^{18} \mathrm{O}, \delta \mathrm{D} ; \\
\text { MO0007MAJIONPH.008 } \\
\text { (DIRS 151521), C; } \\
\text { GS930108315213.004 } \\
\text { (DIRS 145525), } \\
\text { U concentrations and isotopes; } \\
\text { LA0311EK831232.001 } \\
\text { (DIRS 166068), } \mathrm{F}^{-}, \mathrm{Sr}^{2+} \\
{ }^{87} \mathrm{Sr} /^{86} \mathrm{Sr}\end{array}$ \\
\hline NC-EWDP-7S & NC-EWDP-7S & 71 & 539558 & 4064318 & CF-SW & Crater Flat - Southwest & $(8.5-12.2)^{7}$ & $\begin{array}{l}\text { Paleospring } \\
\text { deposits }^{7}\end{array}$ & $\begin{array}{l}\text { DTN: GS011108312322.006 } \\
\text { (DIRS 162911), T, pH, ions },{ }^{14} \mathrm{C} \text {, } \\
\delta^{18} \mathrm{O}, \delta \mathrm{D}, \delta^{13} \mathrm{C}, \delta^{34} \mathrm{~S}\end{array}$ \\
\hline $\begin{array}{l}\text { NC-EWDP- } \\
\text { 7SC }\end{array}$ & $\begin{array}{l}\text { NC-EWDP- } \\
\text { 7SC }\end{array}$ & 72 & 539558 & 4064320 & CF-SW & Crater Flat - Southwest & $\begin{array}{l}\text { Open borehole } \\
(7.6-237.3)^{7}\end{array}$ & \begin{tabular}{|l|} 
Paleospring \\
deposits, \\
Tertiary \\
sediments \\
and volcanic \\
rock
\end{tabular} & $\begin{array}{l}\text { DTN: GS011108312322.006 } \\
\text { (DIRS 162911), T, pH, ions },{ }^{14} \mathrm{C} \text {, } \\
\delta^{18} \mathrm{O}, \delta \mathrm{D}, \delta^{13} \mathrm{C}, \delta^{34} \mathrm{~S}\end{array}$ \\
\hline
\end{tabular}


Table A4-3. Summary of Groundwater Wells and Data Sources (Continued)

\begin{tabular}{|c|c|c|c|c|c|c|c|c|c|}
\hline Well Identifier & $\begin{array}{c}\text { Abbreviation } \\
\text { Used in } \\
\text { Appendix }\end{array}$ & $\begin{array}{c}\text { Figure } \\
\text { A6-5 }\end{array}$ & $\begin{array}{l}\text { UTM-X }^{a} \\
(\mathrm{~m})\end{array}$ & $\begin{array}{c}\text { UTM-Y }{ }^{3} \\
(\mathrm{~m})\end{array}$ & & Area $^{\text {b }}$ & $\begin{array}{l}\text { Approximate } \\
\text { Interval } \\
\text { Sampled }(\mathrm{m})^{\mathrm{e}}\end{array}$ & $\begin{array}{c}\text { Geologic } \\
\text { Unit }^{\mathrm{c}, \mathrm{e}}\end{array}$ & $\begin{array}{l}\text { Reference for Sampled Depth } \\
\text { and Chemical (C) and Isotopic } \\
\text { (I) Data }\end{array}$ \\
\hline \multicolumn{10}{|c|}{ Crater Flat - Southwest (Continued) } \\
\hline $\begin{array}{l}\text { NC-EWDP- } \\
1 \mathrm{DX}\end{array}$ & $\begin{array}{l}\text { NC-EWDP- } \\
1 \mathrm{DX}\end{array}$ & 73 & 536768 & 4062503 & CF-SW & Crater Flat - Southwest & $\begin{array}{l}\text { Open borehole } \\
(16.8-762)^{7}\end{array}$ & $\begin{array}{l}\text { Paleospring } \\
\text { deposits, } \\
\text { alluvium, } \\
\text { Tertiary } \\
\text { sediments }^{7}\end{array}$ & $\begin{array}{l}\text { DTNs: GS010308312322.003 } \\
\text { (DIRS 154734), T, pH, alkalinity, } \\
\delta^{18} \mathrm{O}, \delta \mathrm{D}, \delta^{13} \mathrm{C} ; \\
\text { GSO11108312322.006 } \\
\text { (DIRS 162911), } \delta^{34} \mathrm{~S} ; \\
\text { GSO10308312322.002 } \\
\text { (DIRS 162910), } \mathrm{F}^{-}, \mathrm{Sr}^{2+} ; \\
\text { MO0007MAJIONPH.015 } \\
\text { (DIRS 151532), C; } \\
\text { GS010208312322.001 } \\
\text { (DIRS 162908), } \\
\text { U concentrations and isotopes }\end{array}$ \\
\hline $\begin{array}{l}\text { NC-EWDP- } \\
\text { 1DX Zone } 2\end{array}$ & $\begin{array}{l}\text { NC-EWDP- } \\
\text { 1DX Zone } 2\end{array}$ & 74 & 536768 & 4062503 & CF-SW & Crater Flat - Southwest & $(658.4-682.8)^{7}$ & $\begin{array}{l}\text { Tertiary } \\
\text { sediments }\end{array}$ & $\begin{array}{l}\text { DTNs: GS010308312322.003 } \\
\text { (DIRS 154734), T, pH, alkalinity, } \\
\text { ions, } \delta^{18} \mathrm{O}, \delta \mathrm{D}, \delta^{13} \mathrm{C},{ }^{14} \mathrm{C} \text {; } \\
\text { GSO11108312322.006 } \\
\text { (DIRS 162911), } \delta^{34} \mathrm{~S} ; \\
\text { GS010308312322.002 } \\
\text { (DIRS 162910), U concentration } \\
\text { data; GS010208312322.001 } \\
\text { (DIRS 162908), } \\
\text { U concentrations and isotopes; } \\
\text { LA0311EK831232.002 } \\
\text { (DIRS 166069), }{ }^{87} \mathrm{Sr} /{ }^{86} \mathrm{Sr}\end{array}$ \\
\hline $\begin{array}{l}\text { NC-EWDP-1S } \\
\text { Zone } 1\end{array}$ & $\begin{array}{l}\text { NC-EWDP-1S } \\
\text { Zone } 1\end{array}$ & 75 & 536771 & 4062499 & CF-SW & Crater Flat - Southwest & $(48.8-54.9)^{7}$ & \begin{tabular}{|l|} 
Tertiary \\
welded tuff $^{7}$
\end{tabular} & $\begin{array}{l}\text { DTNs: GS010308312322.003 } \\
\text { (DIRS 154734), T, pH, alkalinity, } \\
\text { ions, } \delta^{18} \mathrm{O}, \delta \mathrm{D}, \delta^{13} \mathrm{C},{ }^{14} \mathrm{C} \text {; } \\
\text { GSO11108312322.006 } \\
\text { (DIRS 162911), } \delta^{34} \mathrm{~S} ; \\
\text { GS010308312322.002 } \\
\text { (DIRS 162910), U concentration } \\
\text { data; GS010208312322.001 } \\
\text { (DIRS 162908), } \\
\text { U concentrations and isotopes; } \\
\text { LA0311EK831232.002 } \\
\text { (DIRS 166069), }{ }^{87} \mathrm{Sr} /{ }^{86} \mathrm{Sr}\end{array}$ \\
\hline
\end{tabular}


Table A4-3. Summary of Groundwater Wells and Data Sources (Continued)

\begin{tabular}{|c|c|c|c|c|c|c|c|c|c|}
\hline Well Identifier & $\begin{array}{c}\text { Abbreviation } \\
\text { Used in } \\
\text { Appendix }\end{array}$ & $\begin{array}{c}\text { Figure } \\
\text { A6-5 }\end{array}$ & $\begin{array}{l}\text { UTM-X }^{\mathrm{a}} \\
(\mathrm{m})\end{array}$ & $\begin{array}{l}\text { UTM-Y }^{3} \\
(\mathrm{~m})\end{array}$ & & Area $^{\text {b }}$ & $\begin{array}{l}\text { Approximate } \\
\text { Interval } \\
\text { Sampled }(\mathrm{m})^{\mathrm{e}}\end{array}$ & $\begin{array}{c}\text { Geologic } \\
\text { Unit }^{\mathrm{c}, \mathrm{e}}\end{array}$ & $\begin{array}{l}\text { Reference for Sampled Depth } \\
\text { and Chemical (C) and Isotopic } \\
\text { (I) Data }\end{array}$ \\
\hline \multicolumn{10}{|c|}{ Crater Flat - Southwest (Continued) } \\
\hline $\begin{array}{l}\text { NC-EWDP-1S } \\
\text { Zone } 2\end{array}$ & $\begin{array}{l}\text { NC-EWDP-1S } \\
\text { Zone } 2\end{array}$ & 76 & 536771 & 4062499 & CF-SW & Crater Flat - Southwest & $(64.0-82.3)^{7}$ & $\begin{array}{l}\text { Tertiary } \\
\text { welded tuff }^{7}\end{array}$ & $\begin{array}{l}\text { DTNs: GS010308312322.003 } \\
\text { (DIRS 154734), T, pH, alkalinity, } \\
\text { ions, } \delta^{18} \mathrm{O}, \delta \mathrm{D}, \delta^{13} \mathrm{C},{ }^{14} \mathrm{C} \text {; } \\
\text { GSO11108312322.006 } \\
\text { (DIRS 162911), } \delta^{34} \mathrm{~S} ; \\
\text { GSO10308312322.002 } \\
\text { (DIRS 162910), U concentration } \\
\text { data; GS010208312322.001 } \\
\text { (DIRS 162908), } \\
\text { U concentrations and isotopes; } \\
\text { LA0311EK831232.002 } \\
\text { (DIRS 166069), }{ }^{87} \mathrm{Sr} /{ }^{86} \mathrm{Sr}\end{array}$ \\
\hline NC-EWDP-1S & NC-EWDP-1S & 77 & 536771 & 4062499 & CF-SW & Crater Flat - Southwest & $\begin{array}{l}\text { Open borehole } \\
(15.8-103.6)\end{array}$ & \begin{tabular}{|l} 
Tertiary \\
welded tuff $^{7}$
\end{tabular} & $\begin{array}{l}\text { DTNs: GS010308312322.003 } \\
\text { (DIRS 154734), T, pH, alkalinity, } \\
\delta^{18} \mathrm{O}, \delta \mathrm{D}, \delta^{13} \mathrm{C} ; \\
\text { GSO11108312322.006 } \\
\text { (DIRS 162911), } \delta^{34} \mathrm{~S} ; \\
\text { GS010308312322.002 } \\
\text { (DIRS 162910), ions; } \\
\text { GS010208312322.001 } \\
\text { (DIRS 162908), } \\
\text { U-concentrations and isotopes }\end{array}$ \\
\hline $\begin{array}{l}\text { NC-EWDP- } \\
12 \mathrm{PA}\end{array}$ & $\begin{array}{l}\text { NC-EWDP- } \\
\text { 12PA }\end{array}$ & 78 & 536906 & 4060766 & CF-SW & Crater Flat - Southwest & $(99.0-117.2)^{7}$ & $\begin{array}{l}\text { Tertiary } \\
\text { Reworked } \\
\text { tuff }^{7}\end{array}$ & $\begin{array}{l}\text { DTNs: GS011108312322.006 } \\
\text { (DIRS 162911), } \mathrm{T}, \mathrm{pH} \text {, ions },{ }^{14} \mathrm{C} \text {, } \\
\delta^{18} \mathrm{O}, \delta \mathrm{D}, \delta^{13} \mathrm{C}, \delta^{34} \mathrm{~S} ; \\
\text { LA0311EK831232.002 } \\
\text { (DIRS 166069), }{ }^{87} \mathrm{Sr} /{ }^{86} \mathrm{Sr}\end{array}$ \\
\hline $\begin{array}{l}\text { NC-EWDP- } \\
12 \mathrm{~PB}\end{array}$ & $\begin{array}{l}\text { NC-EWDP- } \\
\text { 12PB }\end{array}$ & 79 & 536863 & 4060794 & CF-SW & Crater Flat - Southwest & $(99.1-117.3)^{7}$ & \begin{tabular}{|l} 
Tertiary \\
Reworked \\
tuff $^{7}$
\end{tabular} & $\begin{array}{l}\text { DTNs: GS011108312322.006 } \\
\text { (DIRS 162911), T, pH, ions, }{ }^{14} \mathrm{C} \text {, } \\
\delta^{18} \mathrm{O}, \delta \mathrm{D}, \delta^{13} \mathrm{C}, \delta^{34} \mathrm{~S} ; \\
\text { LA0311EK831232.002 } \\
\text { (DIRS 166069), }{ }^{87} \mathrm{Sr} /{ }^{86} \mathrm{Sr}\end{array}$ \\
\hline
\end{tabular}


Table A4-3. Summary of Groundwater Wells and Data Sources (Continued)

\begin{tabular}{|c|c|c|c|c|c|c|c|c|c|}
\hline Well Identifier & $\begin{array}{c}\text { Abbreviation } \\
\text { Used in } \\
\text { Appendix }\end{array}$ & \begin{tabular}{|c} 
Figure \\
A6-5
\end{tabular} & $\begin{array}{l}\text { UTM-X }^{\text {a }} \\
(\mathrm{m})\end{array}$ & $\begin{array}{l}\text { UTM-Y }^{3} \\
(\mathrm{~m})\end{array}$ & & Area $^{\text {b }}$ & $\begin{array}{l}\text { Approximate } \\
\text { Interval } \\
\text { Sampled }(\mathrm{m})^{\mathrm{e}}\end{array}$ & $\begin{array}{c}\text { Geologic } \\
\text { Unit }^{\mathrm{c}, \mathrm{e}}\end{array}$ & $\begin{array}{l}\text { Reference for Sampled Depth } \\
\text { and Chemical (C) and Isotopic } \\
\text { (I) Data }\end{array}$ \\
\hline \multicolumn{10}{|c|}{ Crater Flat - Southwest (Continued) } \\
\hline $\begin{array}{l}\text { NC-EWDP- } \\
\text { 12PC }\end{array}$ & $\begin{array}{l}\text { NC-EWDP- } \\
\text { 12PC }\end{array}$ & 80 & 536872 & 4060809 & CF-SW & Crater Flat - Southwest & $(51.8-70.0)^{7}$ & Alluvium ${ }^{7}$ & $\begin{array}{l}\text { DTNs: GS011108312322.006 } \\
\text { (DIRS 162911), T, pH, ions },{ }^{14} \mathrm{C} \text {, } \\
\delta^{18} \mathrm{O}, \delta \mathrm{D}, \delta^{13} \mathrm{C}, \delta^{34} \mathrm{~S} ; \\
\text { LA0311EK831232.002 } \\
\text { (DIRS 166069), }{ }^{87} \mathrm{Sr} /{ }^{86} \mathrm{Sr}\end{array}$ \\
\hline \multicolumn{10}{|c|}{ Yucca Mountain - South } \\
\hline $\begin{array}{l}\text { NC-EWDP- } \\
\text { O9SX }\end{array}$ & $\begin{array}{l}\text { NC-EWDP- } \\
\text { O9SX }\end{array}$ & 81 & 539039 & 4061004 & YM-S & $\begin{array}{l}\text { Yucca Mountain - } \\
\text { South }\end{array}$ & $\begin{array}{l}\text { Open borehole } \\
(30.2-121.0)\end{array}$ & $\begin{array}{l}\text { Valley fill, } \\
\text { Alluvium, } \\
\text { Tertiary } \\
\text { volcanic } \\
\text { rock }^{7}\end{array}$ & $\begin{array}{l}\text { DTNs: GS010308312322.003 } \\
\text { (DIRS 154734), T, pH, alkalinity, } \\
\delta^{18} \mathrm{O}, \delta \mathrm{D}, \delta^{13} \mathrm{C} ; \\
\text { GSO11108312322.006 } \\
\text { (DIRS 162911), } \delta^{13} \mathrm{C}, \delta^{34} \mathrm{~S} ; \\
\text { MO0007MAJIONPH.015 } \\
\text { (DIRS 151532), C; } \\
\text { GS010308312322.002 } \\
\text { (DIRS 162910), } \mathrm{F}^{-}, \mathrm{Sr}^{2+} ; \\
\text { GSO10208312322.001 } \\
\text { (DIRS 162908), } \\
\text { U concentrations and isotopes; } \\
\text { LA0311EK831232.002 } \\
\text { (DIRS 166069), }{ }^{87} \mathrm{Sr} /^{86} \mathrm{Sr}\end{array}$ \\
\hline $\begin{array}{l}\text { NC-EWDP- } \\
\text { O9SX Zone } 1\end{array}$ & $\begin{array}{l}\text { NC-EWDP- } \\
\text { 09SX Zone } 1\end{array}$ & 82 & 539040 & 4061006 & YM-S & $\begin{array}{l}\text { Yucca Mountain - } \\
\text { South }\end{array}$ & $(27.4-36.6)^{7}$ & Alluvium ${ }^{7}$ & $\begin{array}{l}\text { DTNs: GS010308312322.003 } \\
\text { (DIRS 154734), T, pH, alkalinity, } \\
\text { ions, } \delta^{18} \mathrm{O}, \delta \mathrm{D}, \delta^{13} \mathrm{C},{ }^{14} \mathrm{C} \text {; } \\
\text { GSO11108312322.006 } \\
\text { (DIRS 162911), }{ }^{14} \mathrm{C}, \delta^{34} \mathrm{~S} ; \\
\text { GS010308312322.002 } \\
\text { (DIRS 162910), U concentration } \\
\text { data; GS010208312322.001 } \\
\text { (DIRS 162908), } \\
\text { U concentrations and isotopes; } \\
\text { LA0311EK831232.002 } \\
\text { (DIRS 166069), }{ }^{87} \mathrm{Sr} /{ }^{86} \mathrm{Sr}\end{array}$ \\
\hline
\end{tabular}


Table A4-3. Summary of Groundwater Wells and Data Sources (Continued)

\begin{tabular}{|c|c|c|c|c|c|c|c|c|c|}
\hline Well Identifier & $\begin{array}{c}\text { Abbreviation } \\
\text { Used in } \\
\text { Appendix }\end{array}$ & $\begin{array}{c}\text { Figure } \\
\text { A6-5 }\end{array}$ & $\begin{array}{l}\text { UTM-X }^{a} \\
(\mathrm{~m})\end{array}$ & $\begin{array}{c}\text { UTM-Y }{ }^{3} \\
(\mathrm{~m})\end{array}$ & & Area $^{\text {b }}$ & $\begin{array}{l}\text { Approximate } \\
\text { Interval } \\
\text { Sampled }(m)^{e}\end{array}$ & $\begin{array}{c}\text { Geologic } \\
\text { Unit }^{\mathrm{c}, \mathrm{e}}\end{array}$ & $\begin{array}{l}\text { Reference for Sampled Depth } \\
\text { and Chemical (C) and Isotopic } \\
\text { (I) Data }\end{array}$ \\
\hline \multicolumn{10}{|c|}{ Yucca Mountain - South (Continued) } \\
\hline $\begin{array}{l}\text { NC-EWDP- } \\
\text { O9SX Zone } 2\end{array}$ & $\begin{array}{l}\text { NC-EWDP- } \\
\text { 09SX Zone } 2\end{array}$ & 83 & 539040 & 4061006 & YM-S & $\begin{array}{l}\text { Yucca Mountain - } \\
\text { South }\end{array}$ & $(42.7-48.8)^{7}$ & Alluvium ${ }^{7}$ & $\begin{array}{l}\text { DTNs: GS010308312322.003 } \\
\text { (DIRS 154734), T, pH, alkalinity, } \\
\text { ions, } \delta^{18} \mathrm{O}, \delta \mathrm{D}, \delta^{13} \mathrm{C},{ }^{14} \mathrm{C} \text {; } \\
\text { GSO11108312322.006 } \\
\text { (DIRS 162911), } \delta^{34} \mathrm{~S} ; \\
\text { GSO10308312322.002 } \\
\text { (DIRS 162910), U concentration } \\
\text { data; GS010208312322.001 } \\
\text { (DIRS 162908), } \\
\text { U concentrations and isotopes; } \\
\text { LA0311EK831232.002 } \\
\text { (DIRS 166069), }{ }^{87} \mathrm{Sr} /{ }^{86} \mathrm{Sr}\end{array}$ \\
\hline $\begin{array}{l}\text { NC-EWDP- } \\
\text { O9SX Zone } 3\end{array}$ & $\begin{array}{l}\text { NC-EWDP- } \\
\text { O9SX Zone } 3\end{array}$ & 84 & 539040 & 4064006 & YM-S & $\begin{array}{l}\text { Yucca Mountain - } \\
\text { South }\end{array}$ & $(76.2-88.4)^{7}$ & Tertiary tuff $^{7}$ & $\begin{array}{l}\text { DTNs: GS010308312322.003 } \\
\text { (DIRS 154734), T, pH, alkalinity, } \\
\text { ions, } \delta^{18} \mathrm{O}, \delta \mathrm{D}, \delta^{13} \mathrm{C},{ }^{14} \mathrm{C} \text {; } \\
\text { GSO11108312322.006 } \\
\text { (DIRS 162911), } \delta^{34} \mathrm{~S} ; \\
\text { GS010308312322.002 } \\
\text { (DIRS 162910), U concentration } \\
\text { data; GS010208312322.001 } \\
\text { (DIRS 162908), } \\
\text { U concentrations and isotopes; } \\
\text { LA0311EK831232.002 } \\
\text { (DIRS 166069), }{ }^{87} \mathrm{Sr} /{ }^{86} \mathrm{Sr}\end{array}$ \\
\hline $\begin{array}{l}\text { NC-EWDP- } \\
\text { O9SX Zone } 4\end{array}$ & $\begin{array}{l}\text { NC-EWDP- } \\
\text { O9SX Zone } 4\end{array}$ & 85 & 539040 & 4061006 & YM-S & $\begin{array}{l}\text { Yucca Mountain - } \\
\text { South }\end{array}$ & $(100.6-103.7)^{7}$ & Tertiary tuff $^{7}$ & $\begin{array}{l}\text { DTNs: GS010308312322.003 } \\
\text { (DIRS 154734), T, pH, alkalinity, } \\
\text { ions, } \delta^{18} \mathrm{O}, \delta \mathrm{D}, \delta^{13} \mathrm{C},{ }^{14} \mathrm{C} \text {; } \\
\text { GSO11108312322.006 } \\
\text { (DIRS 162911), } \delta^{34} \mathrm{~S} ; \\
\text { GS010308312322.002 } \\
\text { (DIRS 162910), U concentration } \\
\text { data; GS010208312322.001 } \\
\text { (DIRS 162908), } \\
\text { U concentrations and isotopes; } \\
\text { LA0311EK831232.002 } \\
\text { (DIRS 166069), }{ }^{87} \mathrm{Sr} /{ }^{86} \mathrm{Sr}\end{array}$ \\
\hline
\end{tabular}


Table A4-3. Summary of Groundwater Wells and Data Sources (Continued)

\begin{tabular}{|c|c|c|c|c|c|c|c|c|c|}
\hline Well Identifier & $\begin{array}{c}\text { Abbreviation } \\
\text { Used in } \\
\text { Appendix }\end{array}$ & $\begin{array}{c}\text { Figure } \\
\text { A6-5 }\end{array}$ & $\begin{array}{l}\text { UTM-X }^{a} \\
(\mathrm{~m})\end{array}$ & $\begin{array}{c}\text { UTM-Y }{ }^{3} \\
(\mathrm{~m})\end{array}$ & & Area $^{\text {b }}$ & $\begin{array}{l}\text { Approximate } \\
\text { Interval } \\
\text { Sampled }(\mathbf{m})^{\mathrm{e}}\end{array}$ & $\begin{array}{c}\text { Geologic } \\
\text { Unit }^{\mathrm{c}, \mathrm{e}}\end{array}$ & $\begin{array}{l}\text { Reference for Sampled Depth } \\
\text { and Chemical (C) and Isotopic } \\
\text { (I) Data }\end{array}$ \\
\hline \multicolumn{10}{|c|}{ Yucca Mountain - South (Continued) } \\
\hline $\begin{array}{l}\text { NC-EWDP- } \\
\text { O3D }\end{array}$ & $\begin{array}{l}\text { NC-EWDP- } \\
\text { O3D }\end{array}$ & 86 & 541273 & 4059444 & YM-S & $\begin{array}{l}\text { Yucca Mountain - } \\
\text { South }\end{array}$ & $(159-292)^{7}$ & $\begin{array}{l}\text { Alluvium, } \\
\text { Tertiary } \\
\text { sedimentary } \\
\text { and volcanic } \\
\text { rocks }\end{array}$ & $\begin{array}{l}\text { DTNs: GS010308312322.003 } \\
\text { (DIRS 154734), T, pH, alkalinity, } \\
\delta^{18} \mathrm{O}, \delta \mathrm{D}, \delta^{13} \mathrm{C},{ }^{14} \mathrm{C} ; \\
\text { GSO11108312322.006 } \\
\text { (DIRS 162911), } \delta^{34} \mathrm{~S} ; \\
\text { GSO10308312322.002 } \\
\text { (DIRS 162910), } \mathrm{F}^{-}, \mathrm{Sr}^{2+} ; \\
\text { MO0007MAJIONPH.015 } \\
\text { (DIRS 151532), C; } \\
\text { GS010208312322.001 } \\
\text { (DIRS 162908), } \\
\text { U concentrations and isotopes }\end{array}$ \\
\hline $\begin{array}{l}\text { NC-EWDP-3S } \\
\text { Zone } 2\end{array}$ & $\begin{array}{l}\text { NC-EWDP-3S } \\
\text { Zone } 2\end{array}$ & 87 & 541273 & 4059444 & YM-S & $\begin{array}{l}\text { Yucca Mountain - } \\
\text { South }\end{array}$ & $(103.6-128.0)^{14}$ & $\begin{array}{l}\text { Tertiary tuff } \\
\text { and } \\
\text { sediments }\end{array}$ & $\begin{array}{l}\text { DTNs: GS010308312322.003 } \\
\text { (DIRS 154734), T, pH, alkalinity, } \\
\text { ions, } \delta^{18} \mathrm{O}, \delta \mathrm{D}, \delta^{13} \mathrm{C},{ }^{14} \mathrm{C} \text {; } \\
\text { GSO11108312322.006 } \\
\text { (DIRS 162911), } \delta^{34} \mathrm{~S} ; \\
\text { GS010308312322.002 } \\
\text { (DIRS 162910), U concentration } \\
\text { data; GS010208312322.001 } \\
\text { (DIRS 162908), } \\
\text { U concentrations and isotopes; } \\
\text { LA0311EK831232.002 } \\
\text { (DIRS 166069), }{ }^{87} \mathrm{Sr} /{ }^{86} \mathrm{Sr}\end{array}$ \\
\hline $\begin{array}{l}\text { NC-EWDP-3S } \\
\text { Zone } 3\end{array}$ & $\begin{array}{l}\text { NC-EWDP-3S } \\
\text { Zone } 3\end{array}$ & 88 & 541273 & 4059444 & YM-S & $\begin{array}{l}\text { Yucca Mountain - } \\
\text { South }\end{array}$ & $(146.3-160.0)^{14}$ & $\begin{array}{l}\text { Tertiary tuff } \\
\text { and } \\
\text { sediments }\end{array}$ & $\begin{array}{l}\text { DTNs: GS010308312322.003 } \\
\text { (DIRS 154734), T, pH, alkalinity, } \\
\text { ions, } \delta^{18} \mathrm{O}, \delta \mathrm{D}, \delta^{13} \mathrm{C},{ }^{14} \mathrm{C} \text {; } \\
\text { GSO11108312322.006 } \\
\text { (DIRS 162911), } \delta^{18} \mathrm{O}, \delta^{34} \mathrm{~S} \text {; } \\
\text { GS010308312322.002 } \\
\text { (DIRS 162910), U concentration } \\
\text { data; GS010208312322.001 } \\
\text { (DIRS 162908), } \\
\text { U concentrations and isotopes; } \\
\text { LA0311EK831232.002 } \\
\text { (DIRS 166069), }{ }^{87} \mathrm{Sr} /{ }^{86} \mathrm{Sr}\end{array}$ \\
\hline
\end{tabular}


Table A4-3. Summary of Groundwater Wells and Data Sources (Continued)

\begin{tabular}{|c|c|c|c|c|c|c|c|c|c|}
\hline Well Identifier & $\begin{array}{c}\text { Abbreviation } \\
\text { Used in } \\
\text { Appendix }\end{array}$ & $\begin{array}{c}\text { Figure } \\
\text { A6-5 }\end{array}$ & $\begin{array}{l}\text { UTM-X }^{\mathrm{a}} \\
(\mathrm{m})\end{array}$ & $\begin{array}{l}\text { UTM- } Y^{3} \\
(\mathrm{~m})\end{array}$ & & Area $^{\text {b }}$ & $\begin{array}{l}\text { Approximate } \\
\text { Interval } \\
\text { Sampled }(\mathbf{m})^{\mathrm{e}}\end{array}$ & $\begin{array}{c}\text { Geologic } \\
\text { Unit }^{\mathrm{c}, \mathrm{e}}\end{array}$ & $\begin{array}{l}\text { Reference for Sampled Depth } \\
\text { and Chemical (C) and Isotopic } \\
\text { (I) Data }\end{array}$ \\
\hline \multicolumn{10}{|c|}{ Yucca Mountain - South (Continued) } \\
\hline CIND-R-LITE & CIND-R-LITE & 89 & 544027 & 4059809 & YM-S & $\begin{array}{l}\text { Yucca Mountain - } \\
\text { South }\end{array}$ & not reported & $\mathrm{TV}^{15}$ & $\begin{array}{l}\text { DTNs: GS930108315213.002 } \\
\text { (DIRS 148109), C; } \\
\text { MO0007MAJIONPH.006 } \\
\text { (DIRS 151518), C; } \\
\text { GS000700012847.001 } \\
\text { (DIRS 150842), C, l; } \\
\text { GS930108315213.004 } \\
\text { (DIRS 145525), } \\
\text { U concentrations and isotopes; } \\
\text { LA0311EK831232.001 } \\
\text { (DIRS 166068), } \mathrm{F}^{-}, \mathrm{Sr}^{2+} \\
{ }^{87} \mathrm{Sr}^{86} \mathrm{Sr}\end{array}$ \\
\hline $\begin{array}{l}\text { NC-EWDP- } \\
15 P\end{array}$ & $\begin{array}{l}\text { NC-EWDP- } \\
15 P\end{array}$ & 90 & 544848 & 4058158 & YM-S & $\begin{array}{l}\text { Yucca Mountain - } \\
\text { South }\end{array}$ & $(61.0-79.2)^{7}$ & Alluvium ${ }^{7}$ & $\begin{array}{l}\text { DTNs: GS011108312322.006 } \\
\text { (DIRS 162911), T, pH, ions },{ }^{14} \mathrm{C} \text {, } \\
\delta^{18} \mathrm{O}, \delta \mathrm{D}, \delta^{13} \mathrm{C}, \delta^{34} \mathrm{~S} \text {; } \\
\text { LA0311EK831232.002 } \\
\text { (DIRS 166069), }{ }^{87} \mathrm{Sr} r^{86} \mathrm{Sr}\end{array}$ \\
\hline $\begin{array}{l}\text { NC-EWDP- } \\
\text { O2D }\end{array}$ & $\begin{array}{l}\text { NC-EWDP- } \\
\text { O2D }\end{array}$ & 91 & 547744 & 40571647 & YM-S & $\begin{array}{l}\text { Yucca Mountain - } \\
\text { South }\end{array}$ & $\begin{array}{l}\text { Open borehole } \\
(95.1-493.2)^{7}\end{array}$ & Alluvium ${ }^{7}$ & $\begin{array}{l}\text { DTNs: GS010308312322.003 } \\
\text { (DIRS 154734), T, pH, alkalinity, } \\
\delta^{18} \mathrm{O}, \delta \mathrm{D}, \delta^{13} \mathrm{C},{ }^{14} \mathrm{C} ; \\
\text { GSO11108312322.006 } \\
\text { (DIRS 162911), } \delta^{34} \mathrm{~S} ; \\
\text { GS010308312322.002 } \\
\text { (DIRS 162910), } \mathrm{F}^{-}, \mathrm{Sr}^{2+} ; \\
\text { MO0007MAJIONPH.015 } \\
\text { (DIRS 151532), C; } \\
\text { GSO10208312322.001 } \\
\text { (DIRS 162908), } \\
\text { U concentrations and isotopes }\end{array}$ \\
\hline $\begin{array}{l}\text { NC-EWDP- } \\
\text { 19D }\end{array}$ & $\begin{array}{l}\text { NC-EWDP- } \\
\text { 19D }\end{array}$ & 92 & 549238 & 4058265 & YM-S & $\begin{array}{l}\text { Yucca Mountain - } \\
\text { South }\end{array}$ & $\begin{array}{l}\text { Open borehole } \\
(106.1-443.9)^{7}\end{array}$ & $\begin{array}{l}\text { Alluvium, } \\
\text { Tertiary tuff } \\
\text { and } \\
\text { sediments }^{7}\end{array}$ & $\begin{array}{l}\text { DTNs: GS011108312322.006 } \\
\text { (DIRS 162911), T, pH, ions, }{ }^{14} \mathrm{C} \text {, } \\
\delta^{18} \mathrm{O}, \delta \mathrm{D}, \delta^{13} \mathrm{C}, \delta^{34} \mathrm{~S} \text {; } \\
\text { LA0311EK831232.002 } \\
\text { (DIRS 166069), }{ }^{87} \mathrm{Sr} /{ }^{86} \mathrm{Sr}\end{array}$ \\
\hline
\end{tabular}


Table A4-3. Summary of Groundwater Wells and Data Sources (Continued)

\begin{tabular}{|c|c|c|c|c|c|c|c|c|c|}
\hline Well Identifier & $\begin{array}{l}\text { Abbreviation } \\
\text { Used in } \\
\text { Appendix }\end{array}$ & $\begin{array}{c}\text { Figure } \\
\text { A6-5 }\end{array}$ & $\begin{array}{l}\text { UTM-X }^{a} \\
(\mathrm{~m})\end{array}$ & $\begin{array}{c}\text { UTM-Y3 } \\
\text { (m) }\end{array}$ & & Area $^{\mathrm{b}}$ & $\begin{array}{l}\text { Approximate } \\
\text { Interval } \\
\text { Sampled }(\mathrm{m})^{\mathrm{e}}\end{array}$ & $\begin{array}{c}\text { Geologic } \\
\text { Unit }^{\mathrm{c}, \mathrm{e}}\end{array}$ & $\begin{array}{l}\text { Reference for Sampled Depth } \\
\text { and Chemical (C) and Isotopic } \\
\text { (I) Data }{ }^{\mathrm{d}}\end{array}$ \\
\hline \multicolumn{10}{|c|}{ Yucca Mountain - South (Continued) } \\
\hline $\begin{array}{l}\text { NC-EWDP- } \\
19 P\end{array}$ & $\begin{array}{l}\text { NC-EWDP- } \\
19 P\end{array}$ & 93 & 549250 & 4058287 & YM-S & $\begin{array}{l}\text { Yucca Mountain - } \\
\text { South }\end{array}$ & $(109.5-139.8)^{7}$ & Alluvium ${ }^{7}$ & $\begin{array}{l}\text { DTNs: GS011108312322.006 } \\
\text { (DIRS 162911), T, pH, ions, }{ }^{14} \mathrm{C} \text {, } \\
\delta^{18} \mathrm{O}, \delta \mathrm{D}, \delta^{13} \mathrm{C}, \delta^{34} \mathrm{~S} ; \\
\text { LA0311EK831232.002 } \\
\text { (DIRS 166069), }{ }^{87} \mathrm{Sr}{ }^{86} \mathrm{Sr}\end{array}$ \\
\hline $\begin{array}{l}\text { NC-EWDP- } \\
\text { 19D (alluvial) }\end{array}$ & $\begin{array}{l}\text { NC-EWDP- } \\
\text { 19D (alluvial) }\end{array}$ & 94 & 549238 & 4058265 & YM-S & $\begin{array}{l}\text { Yucca Mountain - } \\
\text { South }\end{array}$ & $\begin{array}{l}(125.9-242.4) \\
\text { (assumed to be } \\
\text { combined depth } \\
\text { range of } \\
\text { screened } \\
\text { intervals 1-4) }\end{array}$ & Alluvium ${ }^{7}$ & $\begin{array}{l}\text { DTN: GS011108312322.006 } \\
\text { (DIRS 162911), T, pH, ions, }{ }^{14} \mathrm{C} \text {, } \\
\delta^{18} \mathrm{O}, \delta \mathrm{D}, \delta^{13} \mathrm{C}, \delta^{34} \mathrm{~S}\end{array}$ \\
\hline $\begin{array}{l}\text { NC-EWDP- } \\
\text { 19D (zone \#1) }\end{array}$ & \begin{tabular}{|l|} 
NC-EWDP- \\
19D (zone \#1)
\end{tabular} & 95 & 549238 & 4058265 & YM-S & $\begin{array}{l}\text { Yucca Mountain - } \\
\text { South }\end{array}$ & $(125.9-131.4)^{7}$ & Alluvium $^{7}$ & $\begin{array}{l}\text { DTN: GS011108312322.006 } \\
\text { (DIRS 162911), T, pH, ions, }{ }^{14} \mathrm{C} \text {, } \\
\delta^{18} \mathrm{O}, \delta \mathrm{D}, \delta^{13} \mathrm{C}, \delta^{34} \mathrm{~S}\end{array}$ \\
\hline $\begin{array}{l}\text { NC-EWDP- } \\
19 D \text { (zone \#2) }\end{array}$ & $\begin{array}{l}\text { NC-EWDP- } \\
\text { 19D (zone \#2) }\end{array}$ & 96 & 549238 & 4058265 & YM-S & $\begin{array}{l}\text { Yucca Mountain - } \\
\text { South }\end{array}$ & $(151.8-157.3)^{7}$ & Alluvium $^{7}$ & $\begin{array}{l}\text { DTN: GS011108312322.006 } \\
\text { (DIRS 162911), T, pH, ions, }{ }^{14} \mathrm{C} \text {, } \\
\delta^{18} \mathrm{O}, \delta \mathrm{D}, \delta^{13} \mathrm{C}, \delta^{34} \mathrm{~S}\end{array}$ \\
\hline $\begin{array}{l}\text { NC-EWDP- } \\
\text { 19D (zone \#3) }\end{array}$ & $\begin{array}{l}\text { NC-EWDP- } \\
\text { 19D (zone \#3) }\end{array}$ & 97 & 549238 & 4058265 & YM-S & $\begin{array}{l}\text { Yucca Mountain - } \\
\text { South }\end{array}$ & $(176.1-206.0)^{7}$ & Alluvium $^{7}$ & $\begin{array}{l}\text { DTN: GS011108312322.006 } \\
\text { (DIRS 162911), T, pH, ions, }{ }^{14} \mathrm{C} \text {, } \\
\delta^{18} \mathrm{O}, \delta \mathrm{D}, \delta^{13} \mathrm{C}, \delta^{34} \mathrm{~S}\end{array}$ \\
\hline $\begin{array}{l}\text { NC-EWDP- } \\
\text { 19D (zone \#4) }\end{array}$ & \begin{tabular}{|l|} 
NC-EWDP- \\
19D (zone \#4)
\end{tabular} & 98 & 549238 & 4058265 & YM-S & $\begin{array}{l}\text { Yucca Mountain - } \\
\text { South }\end{array}$ & $(220.2-242.4)^{7}$ & Alluvium $^{7}$ & $\begin{array}{l}\text { DTN: GS011108312322.006 } \\
\text { (DIRS 162911), T, pH, ions, }{ }^{14} \mathrm{C} \text {, } \\
\delta^{18} \mathrm{O}, \delta \mathrm{D}, \delta^{13} \mathrm{C}, \delta^{34} \mathrm{~S}\end{array}$ \\
\hline \multicolumn{10}{|c|}{ Amargosa Valley } \\
\hline $\begin{array}{l}\text { NC-EWDP- } \\
4 \mathrm{~PB}\end{array}$ & $\begin{array}{l}\text { NC-EWDP- } \\
4 \mathrm{~PB}\end{array}$ & 99 & 553202 & 4056768 & LW & Amargosa Valley & $(225.4-255.8)^{7}$ & Alluvium $^{7}$ & $\begin{array}{l}\text { DTNs: GS011108312322.006 } \\
\text { (DIRS 162911), T, pH, ions, }{ }^{14} \mathrm{C} \text {, } \\
\delta^{18} \mathrm{O}, \delta \mathrm{D}, \delta^{13} \mathrm{C}, \delta^{34} \mathrm{~S} ; \\
\text { LA0311EK831232.002 } \\
\text { (DIRS 166069), }{ }^{87} \mathrm{Sr} /{ }^{86} \mathrm{Sr}\end{array}$ \\
\hline $\begin{array}{l}\text { NC-EWDP- } \\
\text { 4PA }\end{array}$ & $\begin{array}{l}\text { NC-EWDP- } \\
\text { 4PA }\end{array}$ & 100 & 553167 & 4056766 & LW & Amargosa Valley & $(123.5-147.9)^{7}$ & Alluvium $^{7}$ & $\begin{array}{l}\text { DTNs: GS011108312322.006 } \\
\text { (DIRS 162911), T, pH, ions, }{ }^{14} \mathrm{C} \text {, } \\
\delta^{18} \mathrm{O}, \delta \mathrm{D}, \delta^{13} \mathrm{C}, \delta^{34} \mathrm{~S} ; \\
\text { LA0311EK831232.002 } \\
\text { (DIRS 166069), }{ }^{87} \mathrm{Sr} /{ }^{86} \mathrm{Sr}\end{array}$ \\
\hline
\end{tabular}


Table A4-3. Summary of Groundwater Wells and Data Sources (Continued)

\begin{tabular}{|c|c|c|c|c|c|c|c|c|c|}
\hline Well Identifier & $\begin{array}{c}\text { Abbreviation } \\
\text { Used in } \\
\text { Appendix }\end{array}$ & $\begin{array}{c}\text { Figure } \\
\text { A6-5 }\end{array}$ & \begin{tabular}{|}
$\mathrm{UTM}^{\mathrm{UT}-\mathrm{X}^{\mathrm{a}}}$ \\
$(\mathrm{m})$
\end{tabular} & $\begin{array}{l}\text { UTM-Y }{ }^{3} \\
(\mathrm{~m})\end{array}$ & & Area $^{b}$ & $\begin{array}{c}\text { Approximate } \\
\text { Interval } \\
\text { Sampled }(m)^{\mathrm{e}}\end{array}$ & $\begin{array}{c}\text { Geologic } \\
\text { Unit }^{\mathrm{c}, \mathrm{e}}\end{array}$ & $\begin{array}{l}\text { Reference for Sampled Depth } \\
\text { and Chemical (C) and Isotopic } \\
\text { (I) Data }\end{array}$ \\
\hline \multicolumn{10}{|c|}{ Amargosa Valley (Continued) } \\
\hline $\begin{array}{l}\text { Desert Farms } \\
\text { Garlic Plot }\end{array}$ & $\begin{array}{l}\text { Desert Farms } \\
\text { Garlic Plot }\end{array}$ & 101 & 553295 & 4055305 & LW & Amargosa Valley & $\begin{array}{l}\text { open borehole } \\
\text { (depth not } \\
\text { reported) }\end{array}$ & Qal ${ }^{13}$ & $\begin{array}{l}\text { DTNs: GS990808312322.001 } \\
\text { (DIRS 149393), T, pH, } \delta^{18} \mathrm{O}, \delta \mathrm{D}, \\
\delta^{13} \mathrm{C} ; \mathrm{GS} 990808312322.002 \\
\text { (DIRS 162917), ions and }{ }^{14} \mathrm{C} ; \\
\text { GSO21008312322.002 } \\
\text { (DIRS 162913), } \delta^{34} \mathrm{~S} ; \\
\text { GSO10208312322.001 } \\
\text { (DIRS 162908), } \\
\text { U concentrations and isotopes } \\
\end{array}$ \\
\hline 15S/50E-18ccc & $\begin{array}{l}15 \mathrm{~S} / 50 \mathrm{E}- \\
18 \mathrm{ccc}\end{array}$ & 103 & 553710 & 4055273 & LW & Amargosa Valley & $\begin{array}{l}\text { open borehole } \\
(105-102)^{2}\end{array}$ & $\mathrm{Qal}^{2}$ & $\begin{array}{l}\text { DTN: MO0007MAJIONPH.006 } \\
\text { (DIRS 151518), C; Oliver and } \\
\text { Root } 1997 \text { (DIRS 100069), F', } \\
\mathrm{Sr}^{2+}\end{array}$ \\
\hline NDOT & NDOT & 104 & 553685 & 4055242 & LW & Amargosa Valley & $\begin{array}{l}\text { open borehole } \\
(105-151)\end{array}$ & $|\mathrm{Qa}|^{13}$ & $\begin{array}{l}\text { DTN: MO0007MAJIONPH.008 } \\
\text { (DIRS 151521), C; } \\
\text { MO0007MAJIONPH.009 } \\
\text { (DIRS 151522), C; } \\
\text { GS940908315213.005 } \\
\text { (DIRS 164673), } \\
\text { U concentrations and isotopes; } \\
\text { Oliver and Root 1997 } \\
\text { (DIRS 100069), } \mathrm{F}^{-} \text {and }{ }^{87} \mathrm{Sr} /{ }^{86} \mathrm{Sr}\end{array}$ \\
\hline $15 \mathrm{~S} / 50 \mathrm{E}-18 \mathrm{cdc}$ & $\begin{array}{l}15 S / 50 E- \\
18 c d c\end{array}$ & 105 & 553934.3 & 4055151 & LW & Amargosa Valley & $\begin{array}{l}\text { open borehole } \\
(105-120)^{2}\end{array}$ & $\mid \mathrm{Qal}^{2}$ & $\begin{array}{l}\text { DTN: MO0007MAJIONPH.006 } \\
\text { (DIRS 151518), C;Claassen } \\
1985 \text { (DIRS 101125), Table 1, } \\
\text { sample 34, T }\end{array}$ \\
\hline
\end{tabular}


Table A4-3. Summary of Groundwater Wells and Data Sources (Continued)

\begin{tabular}{|c|c|c|c|c|c|c|c|c|c|}
\hline Well Identifier & $\begin{array}{c}\text { Abbreviation } \\
\text { Used in } \\
\text { Appendix }\end{array}$ & $\begin{array}{c}\text { Figure } \\
\text { A6-5 }\end{array}$ & $\begin{array}{l}\text { UTM-X }^{\text {a }} \\
(\mathrm{m})\end{array}$ & $\begin{array}{l}\text { UTM-Y } \\
(\mathrm{m})\end{array}$ & & Area $^{\text {b }}$ & $\begin{array}{c}\text { Approximate } \\
\text { Interval } \\
\text { Sampled }(\mathbf{m})^{\mathrm{e}}\end{array}$ & $\begin{array}{c}\text { Geologic } \\
\text { Unit }^{\mathrm{c}, \mathrm{e}}\end{array}$ & $\begin{array}{l}\text { Reference for Sampled Depth } \\
\text { and Chemical (C) and Isotopic } \\
\text { (I) Data }\end{array}$ \\
\hline \multicolumn{10}{|c|}{ Amargosa Valley (Continued) } \\
\hline Airport Well & Airport Well & 106 & 552846 & 4054904 & LW & Amargosa Valley & $\begin{array}{l}\text { open borehole } \\
(76-229)^{15}\end{array}$ & $\mathrm{Qal}^{15}$ & $\begin{array}{l}\text { DTNs: GS990808312322.001 } \\
\text { (DIRS 149393), T, pH, alkalinity); } \\
\text { GS010308312322.003 } \\
\text { (DIRS 154734), ions, } \delta \mathrm{D}, \delta^{13} \mathrm{C} ; \\
\text { GS990808312322.002 } \\
\text { (DIRS 162917), ions and }{ }^{14} \mathrm{C} ; \\
\text { GS011108312322.006 } \\
\text { (DIRS 162911), } \delta^{34} \mathrm{~S} ; \\
\text { GS021008312322.002 } \\
\text { (DIRS } 162913), \delta^{34} \mathrm{~S} ; \text { Paces et } \\
\text { al. } 2002 \text { (DIRS 158817), Table 1, } \\
\text { U concentrations and isotopes }\end{array}$ \\
\hline 15S/50E-19b1 & 15S/50E-19b1 & 107 & 553862.5 & 4054720 & LW & Amargosa Valley & $\begin{array}{l}\text { open borehole } \\
(103-110)^{15}\end{array}$ & $\mathrm{Qa}^{13}$ & $\begin{array}{l}\text { DTN: MO0007MAJIONPH.006 } \\
\text { (DIRS 151518), C }\end{array}$ \\
\hline \multicolumn{10}{|c|}{ Amargosa River } \\
\hline $16 \mathrm{~S} / 48 \mathrm{E}-8 \mathrm{ba}$ & 16S/48E-8ba & 108 & 536979 & 4048129 & AR & Amargosa River & $\begin{array}{l}\text { open borehole } \\
(34-80)^{2}\end{array}$ & Qal $\left.\right|^{2}$ & $\begin{array}{l}\text { DTN: MO0007MAJIONPH.012 } \\
\text { (DIRS 151529), C; Claassen } \\
1985 \text { (DIRS 101125), Table 1, } \\
\text { sample } 45\end{array}$ \\
\hline $16 \mathrm{~S} / 48 \mathrm{E}-7 \mathrm{bba}$ & 16S/48E-7bba & 109 & 534791 & 4048366 & AR & Amargosa River & $\begin{array}{l}\text { open borehole } \\
(0-38)^{2}\end{array}$ & Qal $\left.\right|^{2}$ & $\begin{array}{l}\text { DTN: MO0007MAJIONPH.012 } \\
\text { (DIRS 151529), C; Claassen } \\
1985 \text { (DIRS 101125), Table 1, } \\
\text { sample 46, T }\end{array}$ \\
\hline $16 S / 48 E-7 c b c$ & $16 \mathrm{~S} / 48 \mathrm{E}-7 \mathrm{cbc}$ & 110 & 534546 & 4047441 & AR & Amargosa River & $\begin{array}{l}\text { open borehole } \\
(23-46)^{2}\end{array}$ & Qal $\left.\right|^{2}$ & $\begin{array}{l}\text { DTN: MO0007MAJIONPH.012 } \\
\text { (DIRS 151529), C; } \\
\text { MO0007GNDWTRIS.011 } \\
\text { (DIRS 151501), } \delta^{18} \mathrm{O}, \delta \mathrm{D}, \delta^{13} \mathrm{C} \text {, } \\
{ }^{14} \mathrm{C} ; \text { MO0007MAJIONPH.014 } \\
\text { (DIRS 151531), C; Claassen } \\
\text { 1985 (DIRS 101125), Table 1, } \\
\text { sample 47, T }\end{array}$ \\
\hline $16 \mathrm{~S} / 48 \mathrm{E}-18 \mathrm{bcc}$ & $\begin{array}{l}\text { 16S/48E- } \\
18 \mathrm{bcc}\end{array}$ & 111 & 534827 & 4045747 & AR & Amargosa River & $\begin{array}{l}\text { open borehole } \\
(27-110)^{2}\end{array}$ & $\mathrm{Qal}^{2}$ & $\begin{array}{l}\text { DTN: MO0007MAJIONPH.012 } \\
\text { (DIRS 151529), C }\end{array}$ \\
\hline
\end{tabular}


Table A4-3. Summary of Groundwater Wells and Data Sources (Continued)

\begin{tabular}{|c|c|c|c|c|c|c|c|c|c|}
\hline Well Identifier & $\begin{array}{c}\text { Abbreviation } \\
\text { Used in } \\
\text { Appendix }\end{array}$ & $\begin{array}{c}\text { Figure } \\
\text { A6-5 }\end{array}$ & $\begin{array}{c}\mathrm{UTM}^{\mathrm{T}-\mathrm{X}^{\mathrm{a}}} \\
(\mathrm{m})\end{array}$ & $\begin{array}{l}\text { UTM-Y } \\
(\mathrm{m})\end{array}$ & & Area $^{\mathbf{b}}$ & $\begin{array}{c}\text { Approximate } \\
\text { Interval } \\
\text { Sampled }(m)^{\mathrm{e}}\end{array}$ & $\begin{array}{c}\text { Geologic } \\
\text { Unit }^{\mathrm{c}, \mathrm{e}}\end{array}$ & $\begin{array}{l}\text { Reference for Sampled Depth } \\
\text { and Chemical (C) and Isotopic } \\
\text { (I) Data }\end{array}$ \\
\hline \multicolumn{10}{|c|}{ Amargosa River (Continued) } \\
\hline 16S/48E-17ccc & $\begin{array}{l}16 \mathrm{~S} / 48 \mathrm{E}- \\
17 \mathrm{ccc}\end{array}$ & 112 & 536122 & 4045106 & AR & Amargosa River & $\begin{array}{l}\text { open borehole } \\
\text { (depth not } \\
\text { reported) }\end{array}$ & $\mathrm{Qal}^{2}$ & $\begin{array}{l}\text { DTN: MO0007MAJIONPH.012 } \\
\text { (DIRS 151529), C }\end{array}$ \\
\hline $\begin{array}{l}\text { 16S/48E- } \\
18 d a d\end{array}$ & $\begin{array}{l}\text { 16S/48E- } \\
18 \mathrm{dad}\end{array}$ & 113 & 536069 & 4045814 & AR & Amargosa River & $\begin{array}{l}\text { open borehole } \\
\text { (depth not } \\
\text { reported) }\end{array}$ & Qal ${ }^{13}$ & $\begin{array}{l}\text { DTN: MO0007MAJIONPH.012 } \\
\text { (DIRS 151529), C; } \\
\text { MO0007GNDWTRIS.011 } \\
\text { (DIRS 151501), } \delta^{18} \mathrm{O}, \delta \mathrm{D}, \delta^{13} \mathrm{C} ; \\
\text { MO0007MAJIONPH.014 } \\
\text { (DIRS 151531), C }\end{array}$ \\
\hline 16S/48E-8cda & $16 S / 48 E-8 c d a$ & 114 & 537063 & 4045941 & AR & Amargosa River & $\begin{array}{l}\text { open borehole } \\
\text { (40-unknown) }\end{array}$ & $\mathrm{Qal}^{2}$ & $\begin{array}{l}\text { DTN: MO0007MAJIONPH.012 } \\
\text { (DIRS 151529), C; Claassen } \\
1985 \text { (DIRS 101125), Table 1, } \\
\text { sample 51, T }\end{array}$ \\
\hline $\begin{array}{l}16 \mathrm{~S} / 48 \mathrm{E}- \\
17 \mathrm{abb}\end{array}$ & $\begin{array}{l}16 \mathrm{~S} / 48 \mathrm{E}- \\
17 \mathrm{abb}\end{array}$ & 115 & 537035 & 4046681 & AR & Amargosa River & $\begin{array}{l}\text { open borehole } \\
(31-90)^{3}\end{array}$ & $\mathrm{Qal}^{2}$ & $\begin{array}{l}\text { DTN: MO0007MAJIONPH.012 } \\
\text { (DIRS 151529), C; Claassen } \\
1985 \text { (DIRS 101125), Table 1, } \\
\text { sample 52, T }\end{array}$ \\
\hline $\begin{array}{l}\text { Barrachman } \\
\text { Dom/lrr. }\end{array}$ & $\begin{array}{l}\text { Barrachman } \\
\text { Dom/Irr. }\end{array}$ & 116 & 534951 & 4048117 & AR & Amargosa River & $\begin{array}{l}\text { open borehole } \\
\text { (depth not } \\
\text { reported) }\end{array}$ & $\left.\mathrm{Qa}\right|^{13}$ & $\begin{array}{l}\text { DTN: GS990808312322.001 } \\
\text { (DIRS 149393), } \delta^{18} \mathrm{O}, \delta \mathrm{D}, \delta^{13} \mathrm{C} ; \\
\text { GS990808312322.002 } \\
\text { (DIRS 162917), ions and }{ }^{14} \mathrm{C} ; \\
\text { GS021008312322.002 } \\
\text { (DIRS 162913), } \delta^{34} \mathrm{~S} ; \\
\text { GS010208312322.001 } \\
\text { (DIRS 162908), } \\
\text { U concentrations and isotopes } \\
\end{array}$ \\
\hline
\end{tabular}


Table A4-3. Summary of Groundwater Wells and Data Sources (Continued)

\begin{tabular}{|c|c|c|c|c|c|c|c|c|c|}
\hline Well Identifier & $\begin{array}{c}\text { Abbreviation } \\
\text { Used in } \\
\text { Appendix }\end{array}$ & $\begin{array}{c}\text { Figure } \\
\text { A6-5 }\end{array}$ & $\begin{array}{l}\text { UTM-X }^{\text {a }} \\
(\mathrm{m})\end{array}$ & $\begin{array}{l}\text { UTM-Y } \\
(\mathrm{m})\end{array}$ & & Area $^{\text {b }}$ & $\begin{array}{c}\begin{array}{c}\text { Approximate } \\
\text { Interval } \\
\text { Sampled }(m)^{e}\end{array} \\
\end{array}$ & $\begin{array}{c}\text { Geologic } \\
\text { Unit }^{\mathrm{c}, \mathrm{e}}\end{array}$ & $\begin{array}{l}\text { Reference for Sampled Depth } \\
\text { and Chemical (C) and Isotopic } \\
\text { (I) Data }\end{array}$ \\
\hline \multicolumn{10}{|c|}{ Amargosa River (Continued) } \\
\hline $\begin{array}{l}\text { McCracken } \\
\text { Domestic }\end{array}$ & $\begin{array}{l}\text { McCracken } \\
\text { Domestic }\end{array}$ & 117 & 537372 & 4047061 & AR & Amargosa River & $\begin{array}{l}\text { open borehole } \\
\text { (depth not } \\
\text { reported) }\end{array}$ & $\mathrm{Qal}^{13}$ & $\begin{array}{l}\text { DTN: GS990808312322.001 } \\
\text { (DIRS 149393), T, pH, alkalinity, } \\
\delta^{18} \mathrm{O}, \delta \mathrm{D}, \delta^{13} \mathrm{C} ; \\
\text { GS990808312322.002 } \\
\text { (DIRS 162917), ions and }{ }^{14} \mathrm{C} ; \\
\text { GS021008312322.002 } \\
\text { (DIRS 162913), } \delta^{34} \mathrm{~S} ; \\
\text { GSO10208312322.001 } \\
\text { (DIRS 162908), } \\
\text { U concentrations and isotopes; } \\
\text { LA0311EK831232.002 } \\
\text { (DIRS 166069), }{ }^{87} \mathrm{Sr} /{ }^{86} \mathrm{Sr}\end{array}$ \\
\hline \multicolumn{10}{|c|}{ Fortymile Wash - West } \\
\hline $16 \mathrm{~S} / 48 \mathrm{E}-15 \mathrm{ba}$ & $16 S / 48 E-15 b a$ & 118 & 539670 & 4046693 & FMW-W & Fortymile Wash - West & $\begin{array}{l}\text { open borehole } \\
(30-50)^{3}\end{array}$ & $\mathrm{Qal}^{13}$ & $\begin{array}{l}\text { DTN: MO0007MAJIONPH.012 } \\
\text { (DIRS 151529), C; Claassen } \\
1985 \text { (DIRS 101125), Table 1, } \\
\text { sample 37, T }\end{array}$ \\
\hline $\begin{array}{l}16 \mathrm{~S} / 48 \mathrm{E}- \\
10 \mathrm{cba}\end{array}$ & $\begin{array}{l}16 \mathrm{~S} / 48 \mathrm{E}- \\
10 \mathrm{cba}\end{array}$ & 119 & 539766 & 4047463 & FMW-W & Fortymile Wash - West & $\begin{array}{l}\text { open borehole } \\
\text { (depth not } \\
\text { reported) }\end{array}$ & $\mathrm{Qal}^{13}$ & $\begin{array}{l}\text { DTN: MO0007MAJIONPH.012 } \\
\text { (DIRS 151529), C; } \\
\text { MO0007GNDWTRIS.011 } \\
\text { (DIRS 151501), } \delta^{18} \mathrm{O}, \delta \mathrm{D}, \delta^{13} \mathrm{C} \text {, } \\
{ }^{14} \mathrm{C} ; \text { MO0007MAJIONPH.014 } \\
\text { (DIRS 151531), C; Claassen } \\
\text { 1985 (DIRS 101125), Table 1, } \\
\text { sample 25, T }\end{array}$ \\
\hline $\begin{array}{l}\text { 16S/48E- } \\
15 a a a\end{array}$ & $\begin{array}{l}\text { 16S/48E- } \\
15 a a a\end{array}$ & 120 & 540763 & 4046852 & FMW-W & Fortymile Wash - West & $\begin{array}{l}\text { open borehole } \\
(29-50)^{3}\end{array}$ & $\mathrm{Qal}^{13}$ & $\begin{array}{l}\text { DTN: MO0007MAJIONPH.012 } \\
\text { (DIRS 151529), C; } \\
\text { MO0007GNDWTRIS.011 } \\
\text { (DIRS 151501), } \delta^{18} \mathrm{O}, \delta \mathrm{D}, \delta^{13} \mathrm{C}, \\
{ }^{14} \mathrm{C} ; \text { MO0007MAJIONPH.014 } \\
\text { (DIRS 151531), C; Claassen } \\
\text { 1985 (DIRS 101125), Table 1, } \\
\text { sample 23, T }\end{array}$ \\
\hline
\end{tabular}


Table A4-3. Summary of Groundwater Wells and Data Sources (Continued)

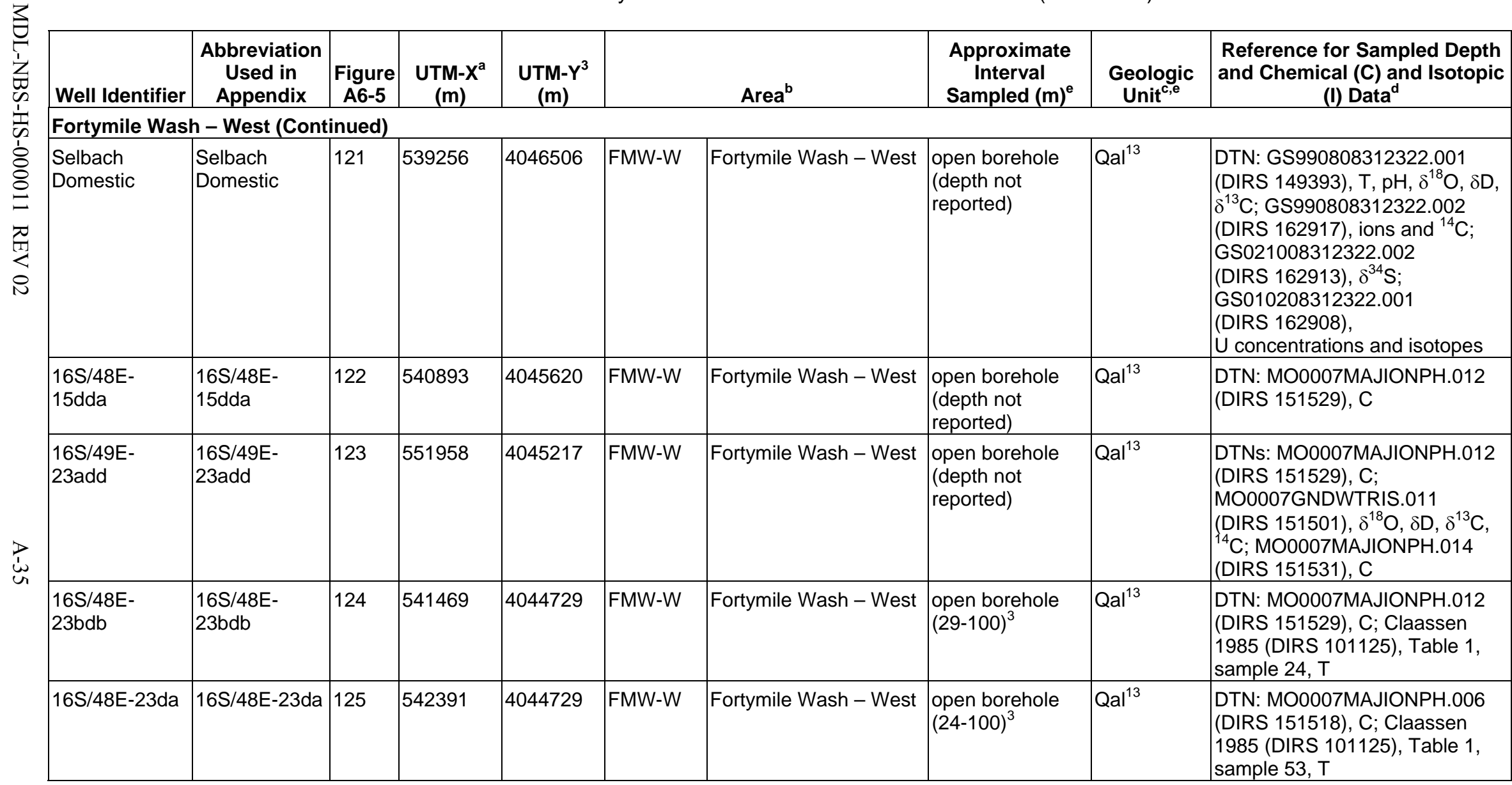


Table A4-3. Summary of Groundwater Wells and Data Sources (Continued)

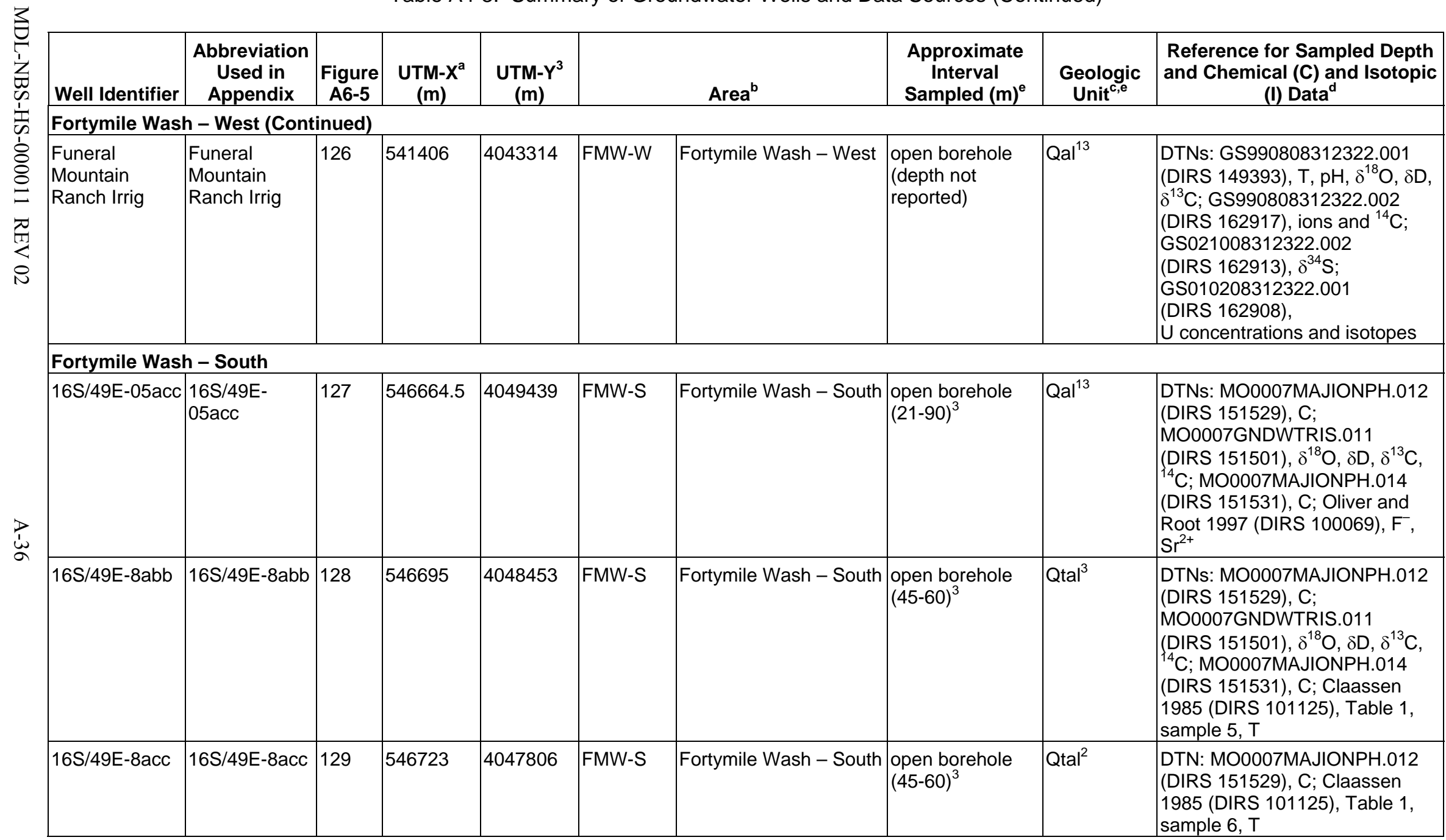


Table A4-3. Summary of Groundwater Wells and Data Sources (Continued)

\begin{tabular}{|c|c|c|c|c|c|c|c|c|c|}
\hline Well Identifier & $\begin{array}{c}\text { Abbreviation } \\
\text { Used in } \\
\text { Appendix }\end{array}$ & $\begin{array}{c}\text { Figure } \\
\text { A6-5 }\end{array}$ & $\begin{array}{l}\text { UTM-X }^{\text {a }} \\
(\mathrm{m})\end{array}$ & $\begin{array}{l}\text { UTM-Y }^{3} \\
(\mathrm{~m})\end{array}$ & & Area $^{\text {b }}$ & $\begin{array}{l}\text { Approximate } \\
\text { Interval } \\
\text { Sampled }(m)^{e}\end{array}$ & $\begin{array}{c}\text { Geologic } \\
\text { Unit }^{\mathrm{c}, \mathrm{e}}\end{array}$ & $\begin{array}{l}\text { Reference for Sampled Depth } \\
\text { and Chemical (C) and Isotopic } \\
\text { (I) Data }\end{array}$ \\
\hline \multicolumn{10}{|c|}{ Fortymile Wash - South (Continued) } \\
\hline 16S/49E-18dc & $16 S / 49 E-18 d c$ & 130 & 545144 & 4045579 & FMW-S & Fortymile Wash - South & $\begin{array}{l}\text { open borehole } \\
(33-110)^{3}\end{array}$ & $\mathrm{Qtal}^{2}$ & $\begin{array}{l}\text { DTNs: MO0007MAJIONPH.012 } \\
\text { (DIRS 151529), C; } \\
\text { MO0007GNDWTRIS.011 } \\
\text { (DIRS 151501), } \delta^{18} \mathrm{O}, \delta \mathrm{D},{ }^{14} \mathrm{C} \text {; } \\
\text { MO0007MAJIONPH.014 } \\
\text { (DIRS 151531), C }\end{array}$ \\
\hline $\begin{array}{l}\text { 16S/48E- } \\
24 \text { aaa }\end{array}$ & $\begin{array}{l}\text { 16S/48E- } \\
24 a a a\end{array}$ & 131 & 544077 & 4045235 & FMW-S & Fortymile Wash - South & $\begin{array}{l}\text { open borehole } \\
(29-150)^{3}\end{array}$ & $\mathrm{Qtal}^{2}$ & $\begin{array}{l}\text { DTN: MO0007MAJIONPH.012 } \\
\text { (DIRS 151529), C; Claassen } \\
1985 \text { (DIRS 101125), Table 1, } \\
\text { sample 12, T }\end{array}$ \\
\hline $\begin{array}{l}\text { 16S/49E- } \\
19 \text { daa }\end{array}$ & $\begin{array}{l}\text { 16S/49E- } \\
19 d a a\end{array}$ & 132 & 545777 & 4044535 & FMW-S & Fortymile Wash - South & $\begin{array}{l}\text { open borehole } \\
(30-90)^{3}\end{array}$ & $\mathrm{Qtal}^{2}$ & $\begin{array}{l}\text { DTNs: MO0007MAJIONPH.012 } \\
\text { (DIRS 151529), C; } \\
\text { MO0007GNDWTRIS.011 } \\
\text { (DIRS 151501), } \delta^{18} \mathrm{O}, \delta \mathrm{D},{ }^{14} \mathrm{C} \text {; } \\
\text { MO0007MAJIONPH.014 } \\
\text { (DIRS 151531), C; Claassen } \\
\text { 1985 (DIRS 101125), Table 1, } \\
\text { sample 11, T }\end{array}$ \\
\hline \begin{tabular}{|l} 
DeLee Large \\
Irrigation
\end{tabular} & $\begin{array}{l}\text { DeLee Large } \\
\text { Irrigation }\end{array}$ & 133 & 544975 & 4043727 & FMW-S & Fortymile Wash - South & $\begin{array}{l}\text { open borehole } \\
\text { (depth not } \\
\text { reported) }\end{array}$ & $\mathrm{Qal}^{13}$ & $\begin{array}{l}\text { DTNs: GS990808312322.001 } \\
\text { (DIRS 149393), T, pH, } \delta^{18} \mathrm{O}, \delta \mathrm{D} \text {, } \\
\delta^{13} \mathrm{C} ; \mathrm{GS} 990808312322.002 \\
\text { (DIRS 162917), ions and }{ }^{14} \mathrm{C} ; \\
\text { GS021008312322.002 } \\
\text { (DIRS 162913), } \delta^{34} \mathrm{~S} ; \\
\text { GS010208312322.001 } \\
\text { (DIRS 162908), } \\
\text { U concentrations and isotopes } \\
\end{array}$ \\
\hline 16S/48E-25aa & 16S/48E-25aa & 134 & 544160 & 4043602 & FMW-S & Fortymile Wash - South & $\begin{array}{l}\text { open borehole } \\
(26-50)^{3}\end{array}$ & $\mathrm{QTal}^{2}$ & $\begin{array}{l}\text { DTNs: MO0007MAJIONPH.012 } \\
\text { (DIRS 151529), C; } \\
\text { MO0007GNDWTRIS.011 } \\
\text { (DIRS 151501), } \delta^{18} \mathrm{O}, \delta \mathrm{D},{ }^{14} \mathrm{C} ; \\
\text { MO0007MAJIONPH.014 } \\
\text { (DIRS 151531), C; Claassen } \\
\text { 1985 (DIRS 101125), Table 1, } \\
\text { sample 13, T }\end{array}$ \\
\hline
\end{tabular}


Table A4-3. Summary of Groundwater Wells and Data Sources (Continued)

\begin{tabular}{|c|c|c|c|c|c|c|c|c|c|}
\hline Well Identifier & $\begin{array}{c}\text { Abbreviation } \\
\text { Used in } \\
\text { Appendix }\end{array}$ & $\begin{array}{c}\text { Figure } \\
\text { A6-5 }\end{array}$ & $\begin{array}{l}\text { UTM-X }{ }^{a} \\
(m)\end{array}$ & $\begin{array}{l}\text { UTM-Y }{ }^{3} \\
(\mathrm{~m})\end{array}$ & & Area $^{b}$ & $\begin{array}{c}\text { Approximate } \\
\text { Interval } \\
\text { Sampled }(m)^{\mathrm{e}}\end{array}$ & $\begin{array}{c}\text { Geologic } \\
\text { Unit }^{\mathrm{c}, \mathrm{e}}\end{array}$ & $\begin{array}{l}\text { Reference for Sampled Depth } \\
\text { and Chemical (C) and Isotopic } \\
\text { (I) Data }\end{array}$ \\
\hline \multicolumn{10}{|c|}{ Fortymile Wash - South (Continued) } \\
\hline $\begin{array}{l}\text { 16S/48E- } \\
\text { 36aaa }\end{array}$ & $\begin{array}{l}\text { 16S/48E- } \\
\text { 36aaa }\end{array}$ & 135 & 544168 & 4042031 & FMW-S & Fortymile Wash - South & $\begin{array}{l}\text { open borehole } \\
(21-50)^{3}\end{array}$ & $\mathrm{Qal}^{2}$ & $\begin{array}{l}\text { DTNs: MO0007MAJIONPH.012 } \\
\text { (DIRS 151529), C, } \\
\text { MO0007GNDWTRIS.011 } \\
\text { (DIRS 151501), } \delta^{18} \mathrm{O}, \delta \mathrm{D}, \\
\text { MO0007MAJIONPH.014 } \\
\text { (DIRS 151531), C }\end{array}$ \\
\hline Bray Domestic & Bray Domestic & 136 & 546665 & 4040701 & FMW-S & Fortymile Wash - South & $\begin{array}{l}\text { open borehole } \\
\text { (depth not } \\
\text { reported) }\end{array}$ & $\mathrm{Qa}^{13}$ & $\begin{array}{l}\text { DTNs: GS990808312322.001 } \\
\text { (DIRS 149393), T, } \mathrm{pH}, \delta^{18} \mathrm{O}, \delta \mathrm{D}, \\
\delta^{13} \mathrm{C} ; \mathrm{GS} 990808312322.002 \\
\text { (DIRS 162917), ions and }{ }^{14} \mathrm{C} ; \\
\text { GS021008312322.002 } \\
\text { (DIRS 162913), } \delta^{34} \mathrm{~S} ; \\
\text { GS010208312322.001 } \\
\text { (DIRS 162908), } \\
\text { U concentrations and isotopes } \\
\end{array}$ \\
\hline $\begin{array}{l}\text { Amargosa } \\
\text { Estates \#2 }\end{array}$ & $\begin{array}{l}\text { Amargosa } \\
\text { Estates \#2 }\end{array}$ & 137 & 544634 & 4040394 & FMW-S & Fortymile Wash - South & $\begin{array}{l}\text { open borehole } \\
\text { (depth not } \\
\text { reported) }\end{array}$ & Qal ${ }^{13}$ & $\begin{array}{l}\text { DTNs: GS990808312322.001 } \\
\text { (DIRS 149393), T, } \delta^{18} \mathrm{O}, \delta \mathrm{D}, \\
\delta^{13} \mathrm{C} ; \mathrm{GS} 990808312322.002 \\
\text { (DIRS 162917), pH, ions and } \\
{ }^{14} \mathrm{C} ; \mathrm{GS} 021008312322.002 \\
\text { (DIRS 162913), } \delta^{34} \mathrm{~S} ; \\
\text { GSO10208312322.001 } \\
\text { (DIRS 162908), } \\
\text { U concentrations and isotopes }\end{array}$ \\
\hline $17 S / 48 E-1 a b$ & 17S/48E-1ab & 138 & 544152 & 4040182 & FMW-S & Fortymile Wash - South & $\begin{array}{l}\text { open borehole } \\
(16-60)^{3}\end{array}$ & $\left.\mathrm{Qa}\right|^{13}$ & $\begin{array}{l}\text { DTNs: MO0007MAJIONPH.012 } \\
\text { (DIRS 151529), C; } \\
\text { MO0007GNDWTRIS.011 } \\
\text { (DIRS 151501), } \delta^{18} \mathrm{O}, \delta \mathrm{D},{ }^{14} \mathrm{C} ; \\
\text { MO0007MAJIONPH.014 } \\
\text { (DIRS 151531), C }\end{array}$ \\
\hline
\end{tabular}


Table A4-3. Summary of Groundwater Wells and Data Sources (Continued)

\begin{tabular}{|c|c|c|c|c|c|c|c|c|c|}
\hline Well Identifier & $\begin{array}{c}\text { Abbreviation } \\
\text { Used in } \\
\text { Appendix }\end{array}$ & $\begin{array}{c}\text { Figure } \\
\text { A6-5 }\end{array}$ & $\begin{array}{l}\text { UTM-X }^{\text {a }} \\
(\mathrm{m})\end{array}$ & $\begin{array}{l}\text { UTM-Y }^{3} \\
(\mathrm{~m})\end{array}$ & & Area $^{\text {b }}$ & $\begin{array}{l}\text { Approximate } \\
\text { Interval } \\
\text { Sampled }(m)^{e}\end{array}$ & $\begin{array}{c}\text { Geologic } \\
\text { Unit }^{\mathrm{c}, \mathrm{e}}\end{array}$ & $\begin{array}{l}\text { Reference for Sampled Depth } \\
\text { and Chemical (C) and Isotopic } \\
\text { (I) Data }\end{array}$ \\
\hline \multicolumn{10}{|c|}{ Fortymile Wash - South (Continued) } \\
\hline 17S/49E-7bb & $17 S / 49 E-7 b b$ & 139 & 544758 & 4038645 & FMW-S & Fortymile Wash - South & $\begin{array}{l}\text { open borehole } \\
(12-150)^{3}\end{array}$ & $\mathrm{Qal}^{13}$ & $\begin{array}{l}\text { DTNs: MO0007MAJIONPH.012 } \\
\text { (DIRS 151529), C; } \\
\text { MO0007GNDWTRIS.011 } \\
\text { (DIRS 151501), } \delta^{18} \mathrm{O}, \delta \mathrm{D},{ }^{14} \mathrm{C} ; \\
\text { MO0007MAJIONPH.014 } \\
\text { (DIRS 151531), C; Claassen } \\
\text { 1985 (DIRS 101125), Table 1, } \\
\text { sample 16, T }\end{array}$ \\
\hline 17S/49E-8ddb & 17S/49E-8ddb & 140 & 547575 & 4037612 & FMW-S & Fortymile Wash - South & $\begin{array}{l}\text { open borehole } \\
(15-100)^{3}\end{array}$ & $\mathrm{Qal}^{13}$ & $\begin{array}{l}\text { DTNs: MO0007MAJIONPH.012 } \\
\text { (DIRS 151529), C; } \\
\text { MO0007GNDWTRIS.011 } \\
\text { (DIRS 151501), } \delta^{18} \mathrm{O}, \delta \mathrm{DD},{ }^{14} \mathrm{C} ; \\
\text { MO0007MAJIONPH.014 } \\
\text { (DIRS 151531), C; Claassen } \\
\text { 1985 (DIRS 101125), Table 1, T }\end{array}$ \\
\hline $\begin{array}{l}\text { 17S/49E- } \\
35 d d d\end{array}$ & $\begin{array}{l}\text { 17S/49E- } \\
35 d d d\end{array}$ & 141 & 552739 & 4031202 & FMW-S & Fortymile Wash - South & $\begin{array}{l}0.0 \text { (Ash Tree }_{\text {Spring) }}^{3}\end{array}$ & $\mathrm{Qal}^{13}$ & $\begin{array}{l}\text { DTNs: MO0007MAJIONPH.012 } \\
\text { (DIRS 151529), C; } \\
\text { MO0007GNDWTRIS.011 } \\
\text { (DIRS 151501), } \delta^{18} \mathrm{O}, \delta \mathrm{D},{ }^{14} \mathrm{C} ; \\
\text { MO0007MAJIONPH.014 } \\
\text { (DIRS 151531), C; Claassen } \\
\text { 1985 (DIRS 101125), Table 1, } \\
\text { sample 20, T }\end{array}$ \\
\hline \multicolumn{10}{|c|}{ Fortymile Wash - East } \\
\hline 15S/49E-22a1 & 15S/49E-22a1 & 142 & 550086.3 & 4054974 & FMW-E & Fortymile Wash - East & $\begin{array}{l}\text { open borehole } \\
(90-174)^{15}\end{array}$ & Qal ${ }^{15}$ & $\begin{array}{l}\text { DTN: MO0007MAJIONPH.006 } \\
\text { (DIRS 151518), C; Oliver and } \\
\text { Root } 1997 \text { (DIRS 100069), F }\end{array}$ \\
\hline $15 S / 49 E-22 d c c$ & $\begin{array}{l}\text { 15S/49E- } \\
22 \mathrm{dcc}\end{array}$ & 143 & 549672.5 & 4053523 & FMW-E & Fortymile Wash - East & $\begin{array}{l}\text { open borehole } \\
(78-148)^{3}\end{array}$ & $\mathrm{Qal}^{13}$ & $\begin{array}{l}\text { DTNs: MO0007MAJIONPH.006 } \\
\text { (DIRS 151518), C; } \\
\text { MO0007GNDWTRIS.011 } \\
\text { (DIRS 151501), I, "Amargosa } \\
\text { well 3"; Oliver and Root } 1997 \\
\text { (DIRS 100069), F', } \text { Sr }^{2+}\end{array}$ \\
\hline
\end{tabular}


Table A4-3. Summary of Groundwater Wells and Data Sources (Continued)

\begin{tabular}{|c|c|c|c|c|c|c|c|c|c|}
\hline Well Identifier & $\begin{array}{c}\text { Abbreviation } \\
\text { Used in } \\
\text { Appendix }\end{array}$ & $\begin{array}{c}\text { Figure } \\
\text { A6-5 }\end{array}$ & \begin{tabular}{|c} 
UTM-X $^{\mathrm{a}}$ \\
$(\mathrm{m})$
\end{tabular} & $\begin{array}{l}\text { UTM-Y }^{3} \\
(\mathrm{~m})\end{array}$ & & Area $^{\text {b }}$ & $\begin{array}{c}\text { Approximate } \\
\text { Interval } \\
\text { Sampled }(\mathbf{m})^{\mathrm{e}}\end{array}$ & $\begin{array}{c}\text { Geologic } \\
\text { Unit }^{\mathrm{c}, \mathrm{e}}\end{array}$ & $\begin{array}{l}\text { Reference for Sampled Depth } \\
\text { and Chemical (C) and Isotopic } \\
\text { (I) Data }\end{array}$ \\
\hline \multicolumn{10}{|c|}{ Fortymile Wash - East (Continued) } \\
\hline 15S/49E-27acc & $\begin{array}{l}\text { 15S/49E- } \\
27 \mathrm{acc}\end{array}$ & 144 & 549552.9 & 4052722 & FMW-E & Fortymile Wash - East & $\begin{array}{l}\text { open borehole } \\
(73-467)^{2}\end{array}$ & $\mathrm{Qal}^{13}$ & $\begin{array}{l}\text { DTN: MO0007MAJIONPH.012 } \\
\text { (DIRS 151529), C; Oliver and } \\
\text { Root } 1997 \text { (DIRS 100069), F', } \\
\text { Sr }^{2+}\end{array}$ \\
\hline $\begin{array}{l}\text { O'Neill } \\
\text { Domestic }\end{array}$ & $\begin{array}{l}\text { O'Neill } \\
\text { Domestic }\end{array}$ & 145 & 547304 & 4047893 & FMW-E & Fortymile Wash - East & $\begin{array}{l}\text { open borehole } \\
\text { (depth not } \\
\text { reported) }\end{array}$ & $\mathrm{Qal}^{13}$ & $\begin{array}{l}\text { DTNs: GS990808312322.001 } \\
\text { (DIRS 149393), T, pH, } \delta^{18} \mathrm{O}, \delta \mathrm{D}, \\
\delta^{13} \mathrm{C} ; \mathrm{GS} 990808312322.002 \\
\text { (DIRS 162917), ions and }{ }^{14} \mathrm{C} ; \\
\text { GSO21008312322.002 } \\
\text { (DIRS 162913), } \delta^{34} \mathrm{~S} ; \\
\text { GSO10208312322.001 } \\
\text { (DIRS 162908), } \\
\text { U concentrations and isotopes } \\
\end{array}$ \\
\hline 16S/49E-9cda & $16 S / 49 E-9 c d a$ & 146 & 548168 & 4047291 & FMW-E & Fortymile Wash - East & $\begin{array}{l}\text { open borehole } \\
(46-90)^{3}\end{array}$ & Qal $\left.\right|^{2}$ & $\begin{array}{l}\text { DTN: MO0007MAJIONPH.012 } \\
\text { (DIRS 151529), C; Claassen } \\
1985 \text { (DIRS 101125), Table 1, } \\
\text { sample 7, T }\end{array}$ \\
\hline 16S/49E-9dcc & 16S/49E-9dcc & 147 & 548343 & 4047045 & FMW-E & Fortymile Wash - East & $\begin{array}{l}\text { open borehole } \\
(49-60)^{3}\end{array}$ & $\mathrm{Qal}^{2}$ & $\begin{array}{l}\text { DTNs: MO0007MAJIONPH.012 } \\
\text { (DIRS 151529), C; } \\
\text { MO0007GNDWTRIS.011 } \\
\text { (DIRS 151501), } \delta^{18} \mathrm{O}, \delta \mathrm{D}, \delta^{13} \mathrm{C}, \\
{ }^{14} \mathrm{C} ; \text { MO0007MAJIONPH.014 } \\
\text { (DIRS 151531), C; Claassen } \\
\text { 1985 (DIRS 101125), Table 1, } \\
\text { sample 8, T }\end{array}$ \\
\hline $16 \mathrm{~S} / 49 \mathrm{E}-16 \mathrm{ccc}$ & $\begin{array}{l}16 S / 49 E- \\
16 \mathrm{ccc}\end{array}$ & 148 & 547508 & 4045222 & FMW-E & Fortymile Wash - East & $\begin{array}{l}\text { open borehole } \\
\text { (depth not } \\
\text { reported) }\end{array}$ & $\mathrm{Qaa}^{13}$ & $\begin{array}{l}\text { DTNs: MO0007MAJIONPH.012 } \\
\text { (DIRS 151529), C; } \\
\text { MO0007GNDWTRIS.011 } \\
\text { (DIRS 151501), } \delta^{18} \mathrm{O}, \delta \mathrm{D}, \delta^{13} \mathrm{C} \text {, } \\
{ }^{14} \mathrm{C} ; \text { MO0007MAJIONPH.014 } \\
\text { (DIRS 151531), C }\end{array}$ \\
\hline
\end{tabular}


Table A4-3. Summary of Groundwater Wells and Data Sources (Continued)

\begin{tabular}{|c|c|c|c|c|c|c|c|c|c|}
\hline Well Identifier & $\begin{array}{c}\text { Abbreviation } \\
\text { Used in } \\
\text { Appendix }\end{array}$ & \begin{tabular}{|c} 
Figure \\
A6-5
\end{tabular} & $\begin{array}{l}\text { UTM-X }^{\mathrm{a}} \\
(\mathrm{m})\end{array}$ & $\begin{array}{l}\text { UTM-Y }{ }^{3} \\
(\mathrm{~m})\end{array}$ & & Area $^{b}$ & $\begin{array}{c}\text { Approximate } \\
\text { Interval } \\
\text { Sampled }(\mathbf{m})^{\mathrm{e}}\end{array}$ & $\begin{array}{c}\text { Geologic } \\
\text { Unit }^{\mathrm{c}, \mathrm{e}}\end{array}$ & $\begin{array}{l}\text { Reference for Sampled Depth } \\
\text { and Chemical (C) and Isotopic } \\
\text { (I) Data }\end{array}$ \\
\hline \multicolumn{10}{|c|}{ Fortymile Wash - East (Continued) } \\
\hline $\begin{array}{l}\text { Ponderosa } \\
\text { Dairy \#1 }\end{array}$ & $\begin{array}{l}\text { Ponderosa } \\
\text { Dairy \#1 }\end{array}$ & 149 & 549382 & 4038747 & FMW-E & Fortymile Wash - East & $\begin{array}{l}\text { open borehole } \\
\text { (depth not } \\
\text { reported) }\end{array}$ & Qal| $\left.\right|^{13}$ & $\begin{array}{l}\text { DTNs: GS990808312322.001 } \\
\text { (DIRS 149393), T, } \delta^{18} \mathrm{O}, \delta \mathrm{D}, \\
\delta^{13} \mathrm{C} ; \mathrm{GS} 990808312322.002 \\
\text { (DIRS 162917), ions and }{ }^{14} \mathrm{C} ; \\
\text { GSO21008312322.002 } \\
\text { (DIRS 162913), } \delta^{34} \mathrm{~S} ; \\
\text { GS010208312322.001 } \\
\text { (DIRS 162908), } \\
\text { (U concentrations and isotopes }\end{array}$ \\
\hline 17S/49E-9aa & 17S/49E-9aa & 150 & 549382 & 4038262 & FMW-E & Fortymile Wash - East & $\begin{array}{l}\text { open borehole } \\
(5-6)^{2}\end{array}$ & $\mathrm{Qal}^{2}$ & $\begin{array}{l}\text { DTNs: MO0007MAJIONPH.012 } \\
\text { (DIRS 151529), C; } \\
\text { MO0007GNDWTRIS.011 } \\
\text { (DIRS 151501), } \delta^{18} \mathrm{O}, \delta \mathrm{D},{ }^{14} \mathrm{C} ; \\
\text { MO0007MAJIONPH.014 } \\
\text { (DIRS 151531), C } \\
\end{array}$ \\
\hline $\begin{array}{l}\text { 17S/49E- } \\
15 \mathrm{bbd}\end{array}$ & $\begin{array}{l}\text { 17S/49E- } \\
15 \mathrm{bbd}\end{array}$ & 151 & 549843 & 4036855 & FMW-E & Fortymile Wash - East & $\begin{array}{l}\text { open borehole } \\
(17-110)^{3}\end{array}$ & $\mathrm{Qa}^{13}$ & $\begin{array}{l}\text { DTNs: MO0007MAJIONPH.012 } \\
\text { (DIRS 151529), C; } \\
\text { MO0007GNDWTRIS.011 } \\
\text { (DIRS 151501), }{ }^{14} \text { C; } \\
\text { MO0007MAJIONPH.014 } \\
\text { (DIRS 151531), C; Claassen } \\
\text { 1985 (DIRS 101125), Table 1, } \\
\text { sample 19, T }\end{array}$ \\
\hline M. Gilgan Well & M. Gilgan Well & 152 & 549550 & 4036791 & FMW-E & Fortymile Wash - East & $\begin{array}{l}\text { open borehole } \\
\text { (depth not } \\
\text { reported) }\end{array}$ & Qal| $\left.\right|^{13}$ & $\begin{array}{l}\text { DTNs: GS990808312322.001 } \\
\text { (DIRS 149393), T, pH, } \delta^{18} \mathrm{O}, \delta \mathrm{D}, \\
\delta^{13} \mathrm{C} ; \mathrm{GS} 990808312322.002 \\
\text { (DIRS 162917), ions and }{ }^{14} \mathrm{C} ; \\
\text { GSO21008312322.002 } \\
\text { (DIRS 162913), } \delta^{34} \mathrm{~S} ; \\
\text { GSO10208312322.001 } \\
\text { (DIRS 162908), } \\
\text { U concentrations and isotopes }\end{array}$ \\
\hline 17S/49E-15bc & $17 S / 49 E-15 b c$ & 153 & 549870 & 4036577 & FMW-E & Fortymile Wash - East & $\begin{array}{l}\text { open borehole } \\
(15-157)^{2}\end{array}$ & $\mathrm{Qal}^{2}$ & $\begin{array}{l}\text { DTN: MO0007MAJIONPH.012 } \\
\text { (DIRS 151529), C; Claassen } \\
1985 \text { (DIRS 101125), Table 1, } \\
\text { sample 38, T }\end{array}$ \\
\hline
\end{tabular}


Table A4-3. Summary of Groundwater Wells and Data Sources (Continued)

\begin{tabular}{|c|c|c|c|c|c|c|c|c|c|}
\hline Well Identifier & $\begin{array}{c}\text { Abbreviation } \\
\text { Used in } \\
\text { Appendix }\end{array}$ & $\begin{array}{c}\text { Figure } \\
\text { A6-5 }\end{array}$ & $\begin{array}{l}\text { UTM-X }^{\text {a }} \\
(\mathrm{m})\end{array}$ & $\begin{array}{l}\text { UTM-Y } \\
(\mathrm{m})\end{array}$ & & Area $^{\text {b }}$ & $\begin{array}{l}\text { Approximate } \\
\text { Interval } \\
\text { Sampled }(m)^{e}\end{array}$ & $\begin{array}{c}\text { Geologic } \\
\text { Unit }^{\mathrm{c}, \mathrm{e}}\end{array}$ & $\begin{array}{l}\text { Reference for Sampled Depth } \\
\text { and Chemical (C) and Isotopic } \\
\text { (I) Data }\end{array}$ \\
\hline \multicolumn{10}{|l|}{ Gravity Fault } \\
\hline NC-EWDP-5S & NC-EWDP-5S & 154 & 555676 & 4058229 & GF & Gravity fault & $(183.3-237.7)^{7}$ & Alluvium ${ }^{7}$ & $\begin{array}{l}\text { DTNs: GS010308312322.003 } \\
\text { (DIRS 154734), T, } \delta^{18} \mathrm{O}, \delta \mathrm{D} ; \\
\text { GS010308312322.002 } \\
\text { (DIRS 162910), } \mathrm{F}^{-}, \mathrm{Sr}^{2+}, \mathrm{SiO}_{2} ; \\
\text { MO0007MAJIONPH.015 } \\
\text { (DIRS 151532), pH, C; } \\
\text { GS010208312322.001 } \\
\text { (DIRS 162908), } \\
\text { U concentrations and isotopes; } \\
\text { LA0311EK831232.002 } \\
\text { (DIRS 166069), }{ }^{87} \mathrm{Sr}^{86} \mathrm{Sr}^{8}\end{array}$ \\
\hline $\begin{array}{l}\text { NC-EWDP- } \\
5 S B\end{array}$ & $\begin{array}{l}\text { NC-EWDP- } \\
5 \mathrm{SB}\end{array}$ & 155 & 555678 & 4058216 & GF & Gravity fault & $(115.6-149.0)^{7}$ & Alluvium $^{7}$ & $\begin{array}{l}\text { DTNs: GS011108312322.006 } \\
\text { (DIRS 162911), T, pH, ions, }{ }^{14} \mathrm{C} \text {, } \\
\delta^{18} \mathrm{O}, \delta \mathrm{D}, \delta^{13} \mathrm{C}, \delta^{34} \mathrm{~S} ; \\
\text { LA0311EK831232.002 (DIRS } \\
\text { 166069), }{ }^{87} \mathrm{Sr} /{ }^{86} \mathrm{Sr}\end{array}$ \\
\hline $16 \mathrm{~S} / 50 \mathrm{E}-7 \mathrm{bcd}$ & $16 \mathrm{~S} / 50 \mathrm{E}-7 \mathrm{bcd}$ & 156 & 553932 & 4047540 & GF & Gravity fault & $\begin{array}{l}\text { open borehole } \\
(43-60)^{3}\end{array}$ & $\mathrm{Qal}^{2}$ & $\begin{array}{l}\text { DTNs: MO0007MAJIONPH.012 } \\
\text { (DIRS 151529), C; } \\
\text { MO0007GNDWTRIS.011 } \\
\text { (DIRS 151501), } \delta^{18} \mathrm{O}, \delta \mathrm{D}, \delta^{13} \mathrm{C} \text {, } \\
{ }^{14} \mathrm{C} ; \text { MO0007MAJIONPH.014 } \\
\text { (DIRS 151531), C }\end{array}$ \\
\hline $\begin{array}{l}\text { Nelson } \\
\text { Domestic }\end{array}$ & $\begin{array}{l}\text { Nelson } \\
\text { Domestic }\end{array}$ & 157 & 553683 & 4047702 & GF & Gravity fault & $\begin{array}{l}\text { open borehole } \\
\text { (depth not } \\
\text { reported) }\end{array}$ & Qa $\left.\right|^{13}$ & $\begin{array}{l}\text { DTNs: GS990808312322.001 } \\
\text { (DIRS 149393), T, pH, } \delta^{18} \mathrm{O}, \delta \mathrm{D}, \\
\delta^{13} \mathrm{C} ; \mathrm{GS} 990808312322.002 \\
\text { (DIRS 162917), ions and }{ }^{14} \mathrm{C} ; \\
\text { GSO21008312322.002 } \\
\text { (DIRS 162913), } \delta^{34} \mathrm{~S} ; \\
\text { GS010208312322.001 } \\
\text { (DIRS 162908), } \\
\text { U concentrations and isotopes } \\
\end{array}$ \\
\hline $\begin{array}{l}16 \mathrm{~S} / 49 \mathrm{E}- \\
12 \mathrm{ddd}\end{array}$ & $\begin{array}{l}\text { 16S/49E- } \\
\text { 12ddd }\end{array}$ & 158 & 553834 & 4047386 & GF & Gravity fault & $\begin{array}{l}\text { open borehole } \\
\text { (depth not } \\
\text { reported) }\end{array}$ & Qa $\left.\right|^{13}$ & $\begin{array}{l}\text { DTN: MO0007MAJIONPH.012 } \\
\text { (DIRS 151529), C }\end{array}$ \\
\hline
\end{tabular}


Table A4-3. Summary of Groundwater Wells and Data Sources (Continued)

\begin{tabular}{|c|c|c|c|c|c|c|c|c|c|}
\hline Well Identifier & $\begin{array}{c}\text { Abbreviation } \\
\text { Used in } \\
\text { Appendix }\end{array}$ & $\begin{array}{c}\text { Figure } \\
\text { A6-5 }\end{array}$ & $\begin{array}{l}\text { UTM-X }^{\text {a }} \\
(\mathrm{m})\end{array}$ & $\begin{array}{l}\text { UTM-Y } \\
(\mathrm{m})\end{array}$ & & Area $^{\text {b }}$ & $\begin{array}{l}\text { Approximate } \\
\text { Interval } \\
\text { Sampled }(m)^{e}\end{array}$ & $\begin{array}{c}\text { Geologic } \\
\text { Unit }^{\mathrm{c}, \mathrm{e}}\end{array}$ & $\begin{array}{l}\text { Reference for Sampled Depth } \\
\text { and Chemical (C) and Isotopic } \\
\text { (I) Data }\end{array}$ \\
\hline \multicolumn{10}{|c|}{ Gravity Fault (Continued) } \\
\hline Lowe Domestic & $\begin{array}{l}\text { Lowe } \\
\text { Domestic }\end{array}$ & 159 & 552116 & 4047002 & GF & Gravity fault & $\begin{array}{l}\text { open borehole } \\
\text { (depth not } \\
\text { reported) }\end{array}$ & $\mathrm{Qal}^{13}$ & $\begin{array}{l}\text { DTNs: GS990808312322.001 } \\
\text { (DIRS 149393), T, } \delta^{18} \mathrm{O}, \delta \mathrm{D}, \\
\delta^{13} \mathrm{C} ; \mathrm{GS} 990808312322.002 \\
\text { (DIRS 162917), ions and }{ }^{11} \mathrm{C} ; \\
\text { GS021008312322.002 } \\
\text { (DIRS 162913), } \delta^{34} \mathrm{~S} ; \\
\text { GS010208312322.001 } \\
\text { (DIRS 162908), } \\
\text { U concentrations and isotopes }\end{array}$ \\
\hline $\begin{array}{l}16 \mathrm{~S} / 49 \mathrm{E}- \\
15 a a a\end{array}$ & $\begin{array}{l}\text { 16S/49E- } \\
15 a a a\end{array}$ & 160 & 550556 & 4046842 & GF & Gravity fault & $\begin{array}{l}\text { open borehole } \\
(51-120)^{3}\end{array}$ & $\mathrm{Qal}^{2}$ & $\begin{array}{l}\text { DTNS: MO0007MAJIONPH.012 } \\
\text { (DIRS 151529), C; } \\
\text { MO0007GNDWTRIS.011 } \\
\text { (DIRS 151501), } \delta^{18} \mathrm{O}, \delta \mathrm{D}, \delta^{13} \mathrm{C} ; \\
\text { MO0007MAJIONPH.014 } \\
\text { (DIRS 151531), C; Claassen } \\
\text { 1985 (DIRS 101125), Table 1, } \\
\text { sample 29, T }\end{array}$ \\
\hline $\begin{array}{l}\text { Anvil Ranch } \\
\text { Irrigation }\end{array}$ & $\begin{array}{l}\text { Anvil Ranch } \\
\text { Irrigation }\end{array}$ & 161 & 548906 & 4043723 & GF & Gravity fault & $\begin{array}{l}\text { open borehole } \\
\text { (depth not } \\
\text { reported) }\end{array}$ & Qal| $\left.\right|^{13}$ & $\begin{array}{l}\text { DTNs: GS990808312322.001 } \\
\text { (DIRS 149393), pH, } \delta^{18} \mathrm{O}, \delta \mathrm{D}, \\
\delta^{13} \mathrm{C} ; \mathrm{GS} 990808312322.002 \\
\text { (DIRS 162917), ions and }{ }^{14} \mathrm{C} ; \\
\text { GS021008312322.002 } \\
\text { (DIRS 162913), } \delta^{34} \mathrm{~S} ; \\
\text { GSO10208312322.001 } \\
\text { (DIRS 162908), } \\
\text { U concentrations and isotopes }\end{array}$ \\
\hline $\begin{array}{l}\text { 16S/49E- } \\
\text { 36aaa }\end{array}$ & $\begin{array}{l}\text { 16S/49E- } \\
\text { 36aaa }\end{array}$ & 162 & 553569 & 4042053 & GF & Gravity fault & $\begin{array}{l}\text { open borehole } \\
\text { (depth not } \\
\text { reported) }\end{array}$ & $\mathrm{Qal}^{13}$ & $\begin{array}{l}\text { DTNs: MO0007GNDWTRIS.011 } \\
\text { (DIRS 151501), } \delta^{18} \mathrm{O}, \delta \mathrm{D}, \delta^{13} \mathrm{C}, \\
{ }^{14} \mathrm{C} ; \text { MO0007MAJIONPH.014 } \\
\text { (DIRS 151531), C }\end{array}$ \\
\hline $\begin{array}{l}16 \mathrm{~S} / 49 \mathrm{E}- \\
35 \mathrm{baa}\end{array}$ & $\begin{array}{l}\text { 16S/49E- } \\
\text { 35baa }\end{array}$ & 163 & 551307 & 4042040 & GF & Gravity fault & $\begin{array}{l}\text { open borehole } \\
(26-100)^{3}\end{array}$ & Qal $\left.\right|^{2}$ & $\begin{array}{l}\text { DTN: MO0007MAJIONPH.012 } \\
\text { (DIRS 151529), C; Claassen } \\
1985 \text { (DIRS 101125), Table 1, } \\
\text { sample 33, T }\end{array}$ \\
\hline
\end{tabular}


Table A4-3. Summary of Groundwater Wells and Data Sources (Continued)

\begin{tabular}{|c|c|c|c|c|c|c|c|c|c|}
\hline Well Identifier & $\begin{array}{c}\text { Abbreviation } \\
\text { Used in } \\
\text { Appendix }\end{array}$ & $\begin{array}{c}\text { Figure } \\
\text { A6-5 }\end{array}$ & \begin{tabular}{|l}
$\mathrm{UTM}^{\mathrm{UT}}-\mathrm{X}^{\mathrm{a}}$ \\
$(\mathrm{m})$
\end{tabular} & $\begin{array}{l}\text { UTM-Y } \\
(\mathrm{m})\end{array}$ & & Area $^{\text {b }}$ & $\begin{array}{l}\text { Approximate } \\
\text { Interval } \\
\text { Sampled }(m)^{e}\end{array}$ & $\begin{array}{c}\text { Geologic } \\
\text { Unit }^{\mathrm{c}, \mathrm{e}}\end{array}$ & $\begin{array}{l}\text { Reference for Sampled Depth } \\
\text { and Chemical (C) and Isotopic } \\
\text { (I) Data }\end{array}$ \\
\hline \multicolumn{10}{|c|}{ Gravity Fault (Continued) } \\
\hline $\begin{array}{l}\text { Payton } \\
\text { Domestic }\end{array}$ & $\begin{array}{l}\text { Payton } \\
\text { Domestic }\end{array}$ & 164 & 553134 & 4041977 & GF & Gravity fault & $\begin{array}{l}\text { open borehole } \\
\text { (depth not } \\
\text { reported) }\end{array}$ & $\mathrm{Qal}^{13}$ & $\begin{array}{l}\text { DTNs: GS990808312322.001 } \\
\text { (DIRS 149393), T, pH, } \delta^{18} \mathrm{O}, \delta \mathrm{D}, \\
\delta^{13} \mathrm{C} ; \mathrm{GS} 990808312322.002 \\
\text { (DIRS 162917), ions and }{ }^{14} \mathrm{C} ; \\
\text { GSO21008312322.002 } \\
\text { (DIRS 162913), } \delta^{34} \mathrm{~S} ; \\
\text { GSO10208312322.001 } \\
\text { (DIRS 162908), } \\
\text { U concentrations and isotopes } \\
\end{array}$ \\
\hline $\begin{array}{l}\text { 16S/49E- } \\
36 \mathrm{aba}\end{array}$ & $\begin{array}{l}\text { 16S/49E- } \\
36 \mathrm{aba}\end{array}$ & 165 & 553222 & 4041836 & GF & Gravity fault & $\begin{array}{l}\text { open borehole } \\
\text { (depth not } \\
\text { reported) }\end{array}$ & $\mathrm{Qal}^{2}$ & $\begin{array}{l}\text { DTN: MO0007MAJIONPH.012 } \\
\text { (DIRS 151529), C }\end{array}$ \\
\hline \begin{tabular}{|l} 
16S/49E- \\
35aaa
\end{tabular} & $\begin{array}{l}\text { 16S/49E- } \\
\text { 35aaa }\end{array}$ & 166 & 551980 & 4041520 & GF & Gravity fault & $\begin{array}{l}\text { open borehole } \\
(35-52)^{2}\end{array}$ & Qal $\left.\right|^{2}$ & $\begin{array}{l}\text { DTN: MO0007MAJIONPH.012 } \\
\text { (DIRS 151529), C }\end{array}$ \\
\hline Oettinger Well & Oettinger Well & 167 & 551698 & 4040954 & GF & Gravity fault & $\begin{array}{l}\text { open borehole } \\
\text { (depth not } \\
\text { reported) }\end{array}$ & $\mathrm{Qa}^{13}$ & $\begin{array}{l}\text { DTNs: GS990808312322.001 } \\
\text { (DIRS 149393), T, pH, } \delta^{18} \mathrm{O}, \delta \mathrm{D}, \\
\delta^{13} \mathrm{C} ; \mathrm{GS} 990808312322.002 \\
\text { (DIRS 162917), ions and }{ }^{14} \mathrm{C} ; \\
\text { GSO21008312322.002 } \\
\text { (DIRS 162913), } \delta^{34} \mathrm{~S} ; \\
\text { GSO10208312322.001 } \\
\text { (DIRS 162908), } \\
\text { U concentrations and isotopes }\end{array}$ \\
\hline $\begin{array}{l}\text { Amargosa } \\
\text { Motel (b) }\end{array}$ & $\begin{array}{l}\text { Amargosa } \\
\text { Motel (b) }\end{array}$ & 168 & 551720 & 4038945 & GF & Gravity fault & $\begin{array}{l}\text { open borehole } \\
\text { (depth not } \\
\text { reported) }\end{array}$ & $\mathrm{Qal}^{13}$ & $\begin{array}{l}\text { DTNs: GS990808312322.001 } \\
\text { (DIRS 149393), T, pH, } \delta^{18} \mathrm{O}, \delta \mathrm{D}, \\
\delta^{13} \mathrm{C} ; \mathrm{GS} 990808312322.002 \\
\text { (DIRS 162917), ions and }{ }^{14} \mathrm{C} ; \\
\text { GSO21008312322.002 } \\
\text { (DIRS 162913), } \delta^{34} \mathrm{~S} ; \\
\text { GSO10208312322.001 } \\
\text { (DIRS 162908), } \\
\text { U concentrations and isotopes } \\
\end{array}$ \\
\hline
\end{tabular}


Table A4-3. Summary of Groundwater Wells and Data Sources (Continued)

\begin{tabular}{|c|c|c|c|c|c|c|c|c|c|}
\hline Well Identifier & $\begin{array}{c}\text { Abbreviation } \\
\text { Used in } \\
\text { Appendix }\end{array}$ & $\begin{array}{c}\text { Figure } \\
\text { A6-5 }\end{array}$ & \begin{tabular}{|l}
$\mathrm{UTM}^{\mathrm{UT}}-\mathrm{X}^{\mathrm{a}}$ \\
$(\mathrm{m})$
\end{tabular} & $\begin{array}{l}\text { UTM-Y } \\
(\mathrm{m})\end{array}$ & & Area $^{\text {b }}$ & $\begin{array}{c}\text { Approximate } \\
\text { Interval } \\
\text { Sampled }(\mathbf{m})^{\mathrm{e}}\end{array}$ & $\begin{array}{c}\text { Geologic } \\
\text { Unit }^{\mathrm{c}, \mathrm{e}}\end{array}$ & $\begin{array}{l}\text { Reference for Sampled Depth } \\
\text { and Chemical (C) and Isotopic } \\
\text { (I) Data }\end{array}$ \\
\hline \multicolumn{10}{|c|}{ Gravity Fault (Continued) } \\
\hline $17 S / 49 E-11 b a$ & $17 S / 49 E-11 b a$ & 169 & 551873 & 4038623 & GF & Gravity fault & $\begin{array}{l}\text { open borehole } \\
(20-56)^{2}\end{array}$ & $\mathrm{Qal}^{2}$ & $\begin{array}{l}\text { DTN: MO0007MAJIONPH.012 } \\
\text { (DIRS 151529), C; Claassen } \\
1985 \text { (DIRS 101125), Table 1, } \\
\text { sample 36, T }\end{array}$ \\
\hline $\begin{array}{l}\text { Spring } \\
\text { Meadows Well } \\
\# 8\end{array}$ & $\begin{array}{l}\text { Spring } \\
\text { Meadows Well } \\
\# 8\end{array}$ & 170 & 560913 & 4038129 & GF & Gravity fault & $\begin{array}{l}\text { open borehole } \\
\text { (depth not } \\
\text { reported) }\end{array}$ & Not reported & $\begin{array}{l}\text { DTN: LA0311EK831232.001 } \\
\text { (DIRS 166068), 10/15/70 sample }\end{array}$ \\
\hline $\begin{array}{l}\text { 17S/50E- } \\
\text { 19aab }\end{array}$ & $\begin{array}{l}\text { 17S/50E- } \\
19 a a b\end{array}$ & 171 & 555998 & 4035691 & GF & Gravity fault & $\begin{array}{l}\text { open borehole } \\
\text { (depth not } \\
\text { reported) }\end{array}$ & $\mathrm{Qa}^{13}$ & $\begin{array}{l}\text { DTN: MO0007MAJIONPH.012 } \\
\text { (DIRS 151529), C; Claassen } \\
1985 \text { (DIRS 101125), Table 1, } \\
\text { sample 58, T }\end{array}$ \\
\hline $\begin{array}{l}\text { USFWS - Five } \\
\text { Springs Well }\end{array}$ & $\begin{array}{l}\text { USFWS - Five } \\
\text { Springs Well }\end{array}$ & 172 & 561126 & 4035571 & GF & Gravity fault & $\begin{array}{l}\text { open borehole } \\
\text { (depth not } \\
\text { reported) }\end{array}$ & Not reported & $\begin{array}{l}\text { DTN: LA0311EK831232.001 } \\
\text { (DIRS 166068), 8/24/90, } \\
\text { 4/28/92, 8/18/92, and 9/22/96 } \\
\text { samples; the 1990 and 1992 } \\
\text { samples are also in DTN: } \\
\text { GS931100121347.007 } \\
\text { (DIRS 149611) }\end{array}$ \\
\hline $\begin{array}{l}\text { Spring } \\
\text { Meadows Well } \\
\# 10\end{array}$ & $\begin{array}{l}\text { Spring } \\
\text { Meadows Well } \\
\# 10\end{array}$ & 173 & 556916 & 4034042 & GF & Gravity fault & $\begin{array}{l}\text { open borehole } \\
\text { (depth not } \\
\text { reported) }\end{array}$ & Not reported & $\begin{array}{l}\text { DTN: LA0311EK831232.001 } \\
\text { (DIRS 166068), 8/15/62 sample }\end{array}$ \\
\hline 18S/49E-1aba & 18S/49E-1aba & 174 & 554035 & 4031056 & GF & Gravity fault & 0 (Spring) $^{3}$ & $\mathrm{Qa}^{13}$ & $\begin{array}{l}\text { DTN: MO0007MAJIONPH.014 } \\
\text { (DIRS 151531), C; Claassen } \\
1985 \text { (DIRS 101125), Table 1, } \\
\text { sample 40, T }\end{array}$ \\
\hline 18S/50E-6dac & 18S/50E-6dac & 175 & 556035 & 4029960 & GF & Gravity fault & $\begin{array}{l}\text { open borehole } \\
\text { (depth not } \\
\text { reported) }\end{array}$ & $|\mathrm{Qa}|^{13}$ & $\begin{array}{l}\text { DTN: MO0007MAJIONPH.012 } \\
\text { (DIRS 151529), C }\end{array}$ \\
\hline 18S/50E-7aa & 18S/50E-7aa & 176 & 556040 & 4029158 & GF & Gravity fault & $\begin{array}{l}\text { open borehole } \\
\text { (depth not } \\
\text { reported) }\end{array}$ & $\mathrm{Qa}^{13}$ & $\begin{array}{l}\text { DTN: MO0007MAJIONPH.014 } \\
\text { (DIRS 151531), C; Claassen } \\
1985 \text { (DIRS 101125), Table 1, } \\
\text { sample 59, T }\end{array}$ \\
\hline
\end{tabular}


Table A4-3. Summary of Groundwater Wells and Data Sources (Continued)

\begin{tabular}{|c|c|c|c|c|c|c|c|c|c|}
\hline Well Identifier & $\begin{array}{c}\text { Abbreviation } \\
\text { Used in } \\
\text { Appendix }\end{array}$ & $\begin{array}{c}\text { Figure } \\
\text { A6-5 }\end{array}$ & $\begin{array}{l}\text { UTM-X }^{\text {a }} \\
(\mathrm{m})\end{array}$ & $\begin{array}{l}\text { UTM-Y } \\
(\mathrm{m})\end{array}$ & & Area $^{\text {b }}$ & $\begin{array}{c}\begin{array}{c}\text { Approximate } \\
\text { Interval } \\
\text { Sampled }(m)^{e}\end{array} \\
\end{array}$ & $\begin{array}{c}\text { Geologic } \\
\text { Unit }^{\mathrm{c}, \mathrm{e}}\end{array}$ & $\begin{array}{l}\text { Reference for Sampled Depth } \\
\text { and Chemical (C) and Isotopic } \\
\text { (I) Data }\end{array}$ \\
\hline \multicolumn{10}{|c|}{ Amargosa Riverl Fortymile Wash } \\
\hline $16 S / 48 E-36 d c c$ & $\begin{array}{l}16 \mathrm{~S} / 48 \mathrm{E}- \\
36 \mathrm{dcc}\end{array}$ & 177 & 543530 & 4040395 & AR/FMW & $\begin{array}{l}\text { Amargosa River/ } \\
\text { Fortymile Wash }\end{array}$ & $\begin{array}{l}\text { open borehole } \\
(13-120)^{3}\end{array}$ & Qal $\left.\right|^{2}$ & $\begin{array}{l}\text { DTN: MO0007MAJIONPH.012 } \\
\text { (DIRS 151529), C; Claassen } \\
1985 \text { (DIRS 101125), Table 1, } \\
\text { sample 26, T }\end{array}$ \\
\hline $\begin{array}{l}\text { Crane } \\
\text { Domestic }\end{array}$ & $\begin{array}{l}\text { Crane } \\
\text { Domestic }\end{array}$ & 178 & 543587 & 4037930 & AR/FMW & $\begin{array}{l}\text { Amargosa River/ } \\
\text { Fortymile Wash }\end{array}$ & $\begin{array}{l}\text { open borehole } \\
\text { (depth not } \\
\text { reported) }\end{array}$ & $\mathrm{Qal}^{13}$ & $\begin{array}{l}\text { DTNS: GS990808312322.001 } \\
\text { (DIRS 149393), T, pH, } \delta^{18} \mathrm{O}, \delta \mathrm{D}, \\
\delta^{13} \mathrm{C} ; \mathrm{GS} 990808312322.002 \\
\text { (DIRS 162917), ions and }{ }^{14} \mathrm{C} ; \\
\text { GSO21008312322.002 } \\
\text { (DIRS 162913), } \delta^{34} \mathrm{~S} ; \\
\text { GSO10208312322.001 } \\
\text { (DIRS 162908), } \\
\text { U concentrations and isotopes } \\
\end{array}$ \\
\hline $27 \mathrm{~N} / 4 \mathrm{E}-27 \mathrm{bbb}$ & $27 \mathrm{~N} / 4 \mathrm{E}-27 \mathrm{bbb}$ & 179 & 541520 & 4034130 & AR/FMW & $\begin{array}{l}\text { Amargosa River/ } \\
\text { Fortymile Wash }\end{array}$ & $\begin{array}{l}\text { open borehole } \\
(14-90)^{3}\end{array}$ & $\mathrm{Qal}^{2}$ & $\begin{array}{l}\text { DTN: MO0007MAJIONPH.012 } \\
\text { (DIRS 151529), C; Claassen } \\
1985 \text { (DIRS 101125), Table 1, } \\
\text { sample 54, T }\end{array}$ \\
\hline $\begin{array}{l}\text { IMV on } \\
\text { Windjammer }\end{array}$ & $\begin{array}{l}\text { IMV on } \\
\text { Windjammer }\end{array}$ & 180 & 548115 & 4033603 & AR/FMW & $\begin{array}{l}\text { Amargosa River/ } \\
\text { Fortymile Wash }\end{array}$ & $\begin{array}{l}\text { open borehole } \\
\text { (depth not } \\
\text { reported) }\end{array}$ & $\mathrm{Qal}^{13}$ & $\begin{array}{l}\text { DTNs: GS990808312322.001 } \\
\text { (DIRS 149393), T, pH, } \delta^{18} \mathrm{O}, \delta \mathrm{D}, \\
\delta^{13} \mathrm{C} ; \mathrm{GS} 990808312322.002 \\
\text { (DIRS 162917), ions and }{ }^{14} \mathrm{C} ; \\
\text { GS021008312322.002 } \\
\text { (DIRS 162913), } \delta^{34} \mathrm{~S} ; \\
\text { GSO10208312322.001 } \\
\text { (DIRS 162908), } \\
\text { U concentrations and isotopes }\end{array}$ \\
\hline 17S/49E-29acc & $\begin{array}{l}\text { 17S/49E- } \\
29 \text { acc }\end{array}$ & 181 & 547349 & 4033420 & AR/FMW & $\begin{array}{l}\text { Amargosa River/ } \\
\text { Fortymile Wash }\end{array}$ & $\begin{array}{l}\text { open borehole } \\
\text { (depth not } \\
\text { reported) }\end{array}$ & $\mathrm{Qal}^{13}$ & $\begin{array}{l}\text { DTN: MO0007MAJIONPH.012 } \\
\text { (DIRS 151529), C; Claassen } \\
1985 \text { (DIRS 101125), Table 1, } \\
\text { sample 44, T }\end{array}$ \\
\hline $\begin{array}{l}17 \mathrm{~S} / 49 \mathrm{E}- \\
28 \mathrm{bcd}\end{array}$ & $\begin{array}{l}17 \mathrm{~S} / 49 \mathrm{E}- \\
28 \mathrm{bcd}\end{array}$ & 182 & 548370 & 4033395 & AR/FMW & $\begin{array}{l}\text { Amargosa River/ } \\
\text { Fortymile Wash }\end{array}$ & $\begin{array}{l}\text { open borehole } \\
\text { (depth not } \\
\text { reported) }\end{array}$ & $\mathrm{Qal}^{13}$ & $\begin{array}{l}\text { DTN: MO0007MAJIONPH.012 } \\
\text { (DIRS 151529), C }\end{array}$ \\
\hline
\end{tabular}


Table A4-3. Summary of Groundwater Wells and Data Sources (Continued)

\begin{tabular}{|c|c|c|c|c|c|c|c|c|c|}
\hline Well Identifier & $\begin{array}{c}\text { Abbreviation } \\
\text { Used in } \\
\text { Appendix }\end{array}$ & \begin{tabular}{|c|} 
Figure \\
A6-5
\end{tabular} & $\begin{array}{c}\mathrm{UTM}^{\mathrm{U}}-\mathrm{X}^{\mathrm{a}} \\
(\mathrm{m})\end{array}$ & $\begin{array}{l}\text { UTM-Y }^{3} \\
(\mathrm{~m})\end{array}$ & & Area $^{b}$ & $\begin{array}{c}\text { Approximate } \\
\text { Interval } \\
\text { Sampled }(\mathrm{m})^{\mathrm{e}}\end{array}$ & $\begin{array}{c}\text { Geologic } \\
\text { Unit }^{\mathrm{c}, \mathrm{e}}\end{array}$ & $\begin{array}{l}\text { Reference for Sampled Depth } \\
\text { and Chemical (C) and Isotopic } \\
\text { (I) Data }\end{array}$ \\
\hline \multicolumn{10}{|c|}{ Amargosa Riverl Fortymile Wash (Continued) } \\
\hline $18 \mathrm{~S} / 49 \mathrm{E}-2 \mathrm{cbc}$ & 18S/49E-2cbc & 183 & 551377 & 4030023 & AR/FMW & $\begin{array}{l}\text { Amargosa River/ } \\
\text { Fortymile Wash }\end{array}$ & $\begin{array}{l}\text { open borehole } \\
(22-160)^{3}\end{array}$ & $\mathrm{Qal}^{2}$ & $\begin{array}{l}\text { DTN: MO0007MAJIONPH.012 } \\
\text { (DIRS 151529), C; Claassen } \\
1985 \text { (DIRS 101125), Table 1, } \\
\text { sample 41, T }\end{array}$ \\
\hline Mom's Place & Mom's Place & 184 & 551996 & 4029417 & AR/FMW & $\begin{array}{l}\text { Amargosa River/ } \\
\text { Fortymile Wash }\end{array}$ & $\begin{array}{l}\text { open borehole } \\
\text { (depth not } \\
\text { reported) }\end{array}$ & Qa $\left.\right|^{13}$ & $\begin{array}{l}\text { DTNs: GS990808312322.001 } \\
\text { (DIRS 149393), T, pH, } \delta^{18} \mathrm{O}, \delta \mathrm{D}, \\
\delta^{13} \mathrm{C} ; \mathrm{GS} 990808312322.002 \\
\text { (DIRS 162917), ions and }{ }^{14} \mathrm{C} ; \\
\text { GS021008312322.002 } \\
\text { (DIRS 162913), } \delta^{34} \mathrm{~S} ; \\
\text { GS010208312322.001 } \\
\text { (DIRS 162908), } \\
\text { U concentrations and isotopes } \\
\end{array}$ \\
\hline $\begin{array}{l}18 \mathrm{~S} / 49 \mathrm{E}- \\
11 \mathrm{bbb}\end{array}$ & $\begin{array}{l}18 \mathrm{~S} / 49 \mathrm{E}- \\
11 \mathrm{bbb}\end{array}$ & 185 & 551307 & 4029283 & AR/FMW & $\begin{array}{l}\text { Amargosa River/ } \\
\text { Fortymile Wash }\end{array}$ & $\begin{array}{l}\text { open borehole } \\
\text { (depth not } \\
\text { reported) }\end{array}$ & Qa $\left.\right|^{13}$ & $\begin{array}{l}\text { DTN: MO0007MAJIONPH.012 } \\
\text { (DIRS 151529), C; Claassen } \\
1985 \text { (DIRS 101125), Table 1, } \\
\text { sample 42, T } \\
\end{array}$ \\
\hline \multicolumn{10}{|l|}{ Skeleton Hills } \\
\hline TW-5 & TW-5 & 186 & 562604 & 4054686 & $\mathrm{SH}$ & Skeleton Hills & $\begin{array}{l}\text { open borehole } \\
(207-244)^{15}\end{array}$ & $\begin{array}{l}\text { Protozoic } \\
\text { clastic } \\
\text { rocks }^{16}\end{array}$ & $\begin{array}{l}\text { DTNs: MO0007MAJIONPH.006 } \\
\text { (DIRS 151518), C; } \\
\text { MO0007GNDWTRIS.004 } \\
\text { (DIRS 151494), } \delta^{18} \mathrm{O}, \delta \mathrm{\delta} ; \\
\text { MO0007MAJIONPH.002 } \\
\text { (DIRS 151507), C; Oliver and } \\
\text { Root } 1997 \text { (DIRS 100069), } \mathrm{F}^{-} \text {, } \\
\mathrm{Sr}^{2+},{ }^{87} \mathrm{Sr}^{86} \mathrm{Sr} \\
\end{array}$ \\
\hline $\begin{array}{l}\text { Unnamed Well } \\
\text { 15S/50E-22-7 }\end{array}$ & $\begin{array}{l}\text { Unnamed Well } \\
\text { 15S/50E-22-7 }\end{array}$ & 187 & 559605 & 4053895 & $\mathrm{SH}$ & Skeleton Hills & $\begin{array}{l}\text { open borehole } \\
\text { (depth not } \\
\text { reported) }\end{array}$ & Not reported & $\begin{array}{l}\text { DTN: LA0311EK831232.001 } \\
\text { (DIRS 166068), 11/20/72 sample }\end{array}$ \\
\hline
\end{tabular}


Table A4-3. Summary of Groundwater Wells and Data Sources (Continued)

\begin{tabular}{|c|c|c|c|c|c|c|c|c|c|}
\hline Well Identifier & $\begin{array}{l}\text { Abbreviation } \\
\text { Used in } \\
\text { Appendix }\end{array}$ & $\begin{array}{c}\text { Figure } \\
\text { A6-5 }\end{array}$ & $\begin{array}{c}\mathrm{UTM}^{\mathrm{U}}-\mathrm{X}^{\mathrm{a}} \\
(\mathrm{m})\end{array}$ & $\begin{array}{l}\text { UTM-Y } \\
(\mathrm{m})\end{array}$ & & Area $^{\mathrm{b}}$ & $\begin{array}{l}\text { Approximate } \\
\text { Interval } \\
\text { Sampled }(m)^{\mathrm{e}}\end{array}$ & $\begin{array}{c}\text { Geologic } \\
\text { Unit }^{\mathrm{c}, \mathrm{e}}\end{array}$ & $\begin{array}{l}\text { Reference for Sampled Depth } \\
\text { and Chemical (C) and Isotopic } \\
\text { (I) Data }\end{array}$ \\
\hline \multicolumn{10}{|l|}{ Amargosa Flat } \\
\hline $\begin{array}{l}\text { Amargosa } \\
\text { Tracer Hole \#2 }\end{array}$ & $\begin{array}{l}\text { Amargosa } \\
\text { Tracer Hole } \\
\# 2\end{array}$ & 188 & 569158 & 4043531 & AF & Amargosa Flat & $\begin{array}{l}\text { open borehole } \\
(12-252)^{2}\end{array}$ & $\begin{array}{l}\text { Paleozoic } \\
\text { carbonate } \\
\text { rocks }^{2}\end{array}$ & $\begin{array}{l}\text { DTN: LA0311EK831232.001 } \\
\text { (DIRS 166068), 9/17/66, } \\
\text { 10/7/67, 2/15/88 and 2/16/68 } \\
\text { samples }\end{array}$ \\
\hline $\begin{array}{l}\text { Cherry Patch } \\
\text { Well, } 17 \mathrm{~S} / 52 \mathrm{E}- \\
08 \mathrm{cdb}\end{array}$ & $\begin{array}{l}\text { Cherry Patch } \\
\text { Well, } \\
\text { 17S/52E- } \\
\text { 08cdb }\end{array}$ & 189 & 576207 & 4038588 & AF & Amargosa Flat & $\begin{array}{l}\text { open borehole } \\
(10-122)^{2}\end{array}$ & $\begin{array}{l}\text { Qal } \\
\text { (limestone) }^{2}\end{array}$ & $\begin{array}{l}\text { DTN: LA0311EK831232.001 } \\
\text { (DIRS 166068), 8/24/90, } \\
\text { 3/24/92, 9/5/91,and 5/15/97 } \\
\text { samples; the 1990 through } 1992 \\
\text { data are also in } \\
\text { DTN: GS931100121347.007 } \\
\text { (DIRS 149611) }\end{array}$ \\
\hline $\begin{array}{l}\text { USDOE-MSH- } \\
\text { C shallow Well }\end{array}$ & $\begin{array}{l}\text { USDOE-MSH- } \\
\text { C shallow Well }\end{array}$ & 190 & 565396 & 4039700 & AF & Amargosa Flat & $\begin{array}{l}\text { open borehole } \\
\text { (depth not } \\
\text { reported) }\end{array}$ & Not reported & $\begin{array}{l}\text { DTN: LA0311EK831232.001 } \\
\text { (DIRS 166068), 9/27/96 sample }\end{array}$ \\
\hline \multicolumn{10}{|l|}{ Mine Mountain } \\
\hline UE-17a & UE-17a & 191 & 574116 & 4103157 & MM & Mine Mountain & $\begin{array}{l}\text { Bailed from } 254 \\
\text { Open borehole } \\
(194-354)^{6}\end{array}$ & Not reported & $\begin{array}{l}\text { DTN: LA0311EK831232.001 } \\
\text { (DIRS 166068), 6/9/93 sample; } \\
\text { also in Rose et al. } 1997 \\
\text { (DIRS 144725), samples 56-58 }\end{array}$ \\
\hline UE-1a & UE-1a & 192 & 578395 & 4100387 & MM & Mine Mountain & $\begin{array}{l}\text { Bailed from } 168 \\
\text { Open borehole } \\
(167-171)^{6}\end{array}$ & $\mathrm{TV}^{5}$ & $\begin{array}{l}\text { DTN: LA0311EK831232.001 } \\
\text { (DIRS 166068), 9/1/92 sample; } \\
\text { also in Davisson et al. } 1994 \\
\text { (DIRS 162939); Rose et al. } 1997 \\
\text { (DIRS 144725), sample 46 }\end{array}$ \\
\hline UE-1b & UE-1b & 193 & 579004 & 4100389 & MM & Mine Mountain & $\begin{array}{l}\text { Bailed from } 207 \\
\text { Open borehole } \\
(198-382)^{6}\end{array}$ & $\begin{array}{l}\text { Paleozoic } \\
\text { carbonate } \\
\text { rocks }^{5}\end{array}$ & $\begin{array}{l}\text { DTN: LA0311EK831232.001 } \\
\text { (DIRS 166068), 9/1/92 sample; } \\
\text { also in Davisson et al. } 1994 \\
\text { (DIRS 162939); Rose et al. } 1997 \\
\text { (DIRS 144725), sample 45 }\end{array}$ \\
\hline UE-16f & UE-16f & 194 & 574100 & 4098960 & MM & Mine Mountain & $\begin{array}{l}\text { Bailed from } 395 \\
\text { Open borehole } \\
(112-422)^{6}\end{array}$ & Eleana Fm. ${ }^{5}$ & $\begin{array}{l}\text { DTN: LA0311EK831232.001 } \\
\text { (DIRS 166068), 7/12/93; Rose et } \\
\text { al. } 1997 \text { (DIRS 144725), } \\
\text { sample 42, sulfate, } \mathrm{SO}_{4}{ }^{2-} \text { and } \\
\mathrm{Na}^{+}\end{array}$ \\
\hline
\end{tabular}


Table A4-3. Summary of Groundwater Wells and Data Sources (Continued)

\begin{tabular}{|c|c|c|c|c|c|c|c|c|c|}
\hline Well Identifier & $\begin{array}{c}\text { Abbreviation } \\
\text { Used in } \\
\text { Appendix }\end{array}$ & $\begin{array}{c}\text { Figure } \\
\text { A6-5 }\end{array}$ & \begin{tabular}{|c} 
UTM-X $^{\mathrm{a}}$ \\
$(\mathrm{m})$
\end{tabular} & $\begin{array}{l}\text { UTM-Y }^{3} \\
(\mathrm{~m})\end{array}$ & & Area $^{\text {b }}$ & $\begin{array}{l}\text { Approximate } \\
\text { Interval } \\
\text { Sampled }(m)^{e}\end{array}$ & $\begin{array}{c}\text { Geologic } \\
\text { Unit }^{\mathrm{c}, \mathrm{e}}\end{array}$ & $\begin{array}{l}\text { Reference for Sampled Depth } \\
\text { and Chemical (C) and Isotopic } \\
\text { (I) Data }\end{array}$ \\
\hline \multicolumn{10}{|c|}{ Mine Mountain (Continued) } \\
\hline UE-14b & UE-14b & 195 & 575427 & 4087304 & MM & Mine Mountain & Not reported & $\mathrm{TV}^{5}$ & $\begin{array}{l}\text { DTN: LA0311EK831232.001 } \\
\text { (DIRS 166068), 9/1/88 and } \\
\text { 7/24/91 samples; the 9/1/88 } \\
\text { sample is in Chapman and Lyles } \\
1993 \text { (DIRS 162940), p } 39\end{array}$ \\
\hline Pluto 1 & Pluto 1 & 196 & 579238 & 4075338 & MM & Mine Mountain & $\begin{array}{l}\text { Possibly } \\
\text { perched }^{5}\end{array}$ & $\mathrm{TV}^{5}$ & $\begin{array}{l}\text { DTN: LA0311EK831232.001 } \\
\text { (DIRS 166068), 11/2/84 sample; } \\
\text { also in Chapman and Lyles } 1993 \\
\text { (DIRS 162940), p. } 38\end{array}$ \\
\hline Pluto 5 & Pluto 5 & 197 & 579263 & 4074977 & MM & Mine Mountain & $\begin{array}{l}\text { Possibly } \\
\text { perched }^{5}\end{array}$ & $\mathrm{TV}^{5}$ & $\begin{array}{l}\text { DTN: LA0311EK831232.001 } \\
\text { (DIRS 166068), 9/26/88 sample; } \\
\text { also in Chapman and Lyles } 1993 \\
\text { (DIRS 162940), p. } 38 .\end{array}$ \\
\hline $\begin{array}{l}\text { USGS Test } \\
\text { Well F (HTH) }\end{array}$ & $\begin{array}{l}\text { USGS Test } \\
\text { Well F (HTH) }\end{array}$ & 198 & 578858 & 4068348 & MM & Mine Mountain & Not reported & $\mathrm{TV}^{5}$ & $\begin{array}{l}\text { DTN: LA0311EK831232.001 } \\
\text { (DIRS 166068), 5/21/75,2/2/76, } \\
\text { and 3/12/80 samples }\end{array}$ \\
\hline \multicolumn{10}{|c|}{ Funeral Mountains } \\
\hline $\begin{array}{l}\text { Woodcamp } \\
\text { Spring }\end{array}$ & $\begin{array}{l}\text { Woodcamp } \\
\text { Spring }\end{array}$ & 199 & 502027 & 4091249 & FMt & Funeral Mountains & $\begin{array}{l}0.0 \text { (spring }^{12} \\
\text { discharge) }\end{array}$ & $\begin{array}{l}\text { Tertiary } \\
\text { volcanic } \\
\text { rock }^{12}\end{array}$ & $\begin{array}{l}\text { DTN: GS960408312323.002 } \\
\text { (DIRS 162915), C, I }\end{array}$ \\
\hline $\begin{array}{l}\text { Bond Gold } \\
\text { Mining \#13 }\end{array}$ & $\begin{array}{l}\text { Bond Gold } \\
\text { Mining \#13 }\end{array}$ & 200 & 519383 & 4059841 & FMt & Funeral Mountains & $\begin{array}{l}\text { open borehole } \\
\text { (depth not } \\
\text { reported) }\end{array}$ & $|\mathrm{Qa}|^{13}$ & $\begin{array}{l}\text { DTN: GS010308312322.003 } \\
\text { (DIRS 154734), T, pH, alkalinity, } \\
\text { ions, }{ }^{18} \mathrm{O}, \delta \mathrm{D}, \delta^{13} \mathrm{C},{ }^{14} \mathrm{C} \text {; } \\
\text { GS011108312322.006 } \\
\text { (DIRS 162911), } \delta^{34} \mathrm{~S} ; \\
\text { GS010208312322.001 } \\
\text { (DIRS 162908), } \\
\text { U concentrations and isotopes; } \\
\text { GS010308312322.002 } \\
\text { (DIRS 162910), } \\
\text { U concentrations); } \\
\text { LA0311EK831232.002 } \\
\text { (DIRS 166069), }{ }^{87} \mathrm{Sr} /{ }^{86} \mathrm{Sr}\end{array}$ \\
\hline
\end{tabular}


Table A4-3. Summary of Groundwater Wells and Data Sources (Continued)

\begin{tabular}{|c|c|c|c|c|c|c|c|c|c|}
\hline Well Identifier & $\begin{array}{c}\text { Abbreviation } \\
\text { Used in } \\
\text { Appendix }\end{array}$ & \begin{tabular}{|c|} 
Figure \\
A6-5
\end{tabular} & $\begin{array}{l}\text { UTM-Xa } \\
(\mathrm{m})\end{array}$ & $\begin{array}{l}\text { UTM-Y3 } \\
(\mathrm{m})\end{array}$ & & Area $^{\mathrm{b}}$ & $\begin{array}{l}\text { Approximate } \\
\text { Interval } \\
\text { Sampled }(m)^{e}\end{array}$ & $\begin{array}{c}\text { Geologic } \\
\text { Unit }^{, e}\end{array}$ & $\begin{array}{l}\text { Reference for Sampled Depth } \\
\text { and Chemical (C) and Isotopic } \\
\text { (I) Data }\end{array}$ \\
\hline \multicolumn{10}{|c|}{ Funeral Mountains (Continued) } \\
\hline $\begin{array}{l}\text { Nevares } \\
\text { Spring }\end{array}$ & $\begin{array}{l}\text { Nevares } \\
\text { Spring }\end{array}$ & 201 & 516068 & 516068 & FMt & Funeral Mountains & $\begin{array}{l}0.0 \text { (spring }^{12} \\
\text { discharge) }\end{array}$ & Travertine $^{12}$ & $\begin{array}{l}\text { DTN: GS960408312323.002 } \\
\text { (DIRS 162915), C, I }\end{array}$ \\
\hline $\begin{array}{l}\text { Travertine } \\
\text { Spring }\end{array}$ & $\begin{array}{l}\text { Travertine } \\
\text { Spring }\end{array}$ & 202 & 515211 & 4032657 & FMt & Funeral Mountains & $\begin{array}{l}0.0 \text { (spring }^{12} \\
\text { discharge) }\end{array}$ & $\mathrm{Qal}^{12}$ & $\begin{array}{l}\text { DTN: GS960408312323.002 } \\
\text { (DIRS 162915), C, I }\end{array}$ \\
\hline
\end{tabular}

${ }^{a}$ Coordinate data are from (1) LA0311EK831232.001 (DIRS 166068), , (2) GS010908312332.002 (DIRS 163555), (3) GS010208312322.001 (DIRS 162908), , (4)

Paces et al. (2002 [DIRS 158817]), (5) GS010808312322.004 (DIRS 156007), , and (6) LA0309EK831223.001 (DIRS 165471). These sources do not always identify whether coordinates are reported relative to North American Datum (NAD) 1927 or 1983, and the coordinates listed may represent a mixture of both coordinate systems. Because of uncertainty in the reference system used in any source, an uncertainty of approximately $100 \mathrm{~m}$ results in the coordinates of boreholes listed. Because of the scale at which data are presented, this uncertainty has a negligible effect on the interpretation of groundwater geochemical patterns and flow paths given in this appendix.

b See Figure A6-5 and Section A6.7.2 for a definition of subareas near Yucca Mountain. The subareas used in this appendix may differ from subareas used in DTNs that begin MO000..., which are associated with the earlier analysis model report version of this appendix.

c Geologic units: Qal Quaternary alluvium; QTal Quaternary-Tertiary alluvium; Tv Tertiary volcanic rocks; Tb Tertiary basalts; Tpt Tertiary Topopah Spring Member of Paintbrush tuff; Tct Tertiary Crater Flat tuff; Th Tertiary tuffaceous beds of Calico Hills; Tac Tertiary Calico Hills Formation; Tcb Tertiary Bullfrog Member of Crater Flat tuff; Tcp Tertiary Prow Pass Member of Crater Flat tuff; TIr Tertiary Lithic Ridge tuff; DSIm Devonian and Silurian Lone Mountain Dolomite; Srm Silurian Roberts Mountain Dolomite; Tfb (and its subunits Tfbr and Tfbw) are volcanic rocks of the Tertiary Beatty Wash Formation; Tm is the Tertiary Timber Mountain tuff; Tma (and its subunits Tmaw, Tmap and Tmar) are the Tertiary Ammonia Tanks tuff; Tft is a basalt; and Ttc is the Tertiary commendite of Ribbon Cliff). Geologic

is units are defined in (Oliver and Root 1997 [DIRS 100069], p. 5; Buesch et al. 1996 [DIRS 100106], Table 4; McKinley et al. 1991 [DIRS 116222], p. 5-6; Day et al. 1998 [DIRS 101557], map sheet 2; Slate et al. (1999 [DIRS 150228]). Also, see stratigraphic column in Figure A6-2.

${ }^{d} \mathrm{C}$ : the DTN or reference was the source for chemical data for this well; I: the DTN or reference was the source for isotopic data for this well. References to sample identifiers in Claassen (1985 [DIRS 101125], Table 1) provide traceability between identifiers used in the listed DTNs and those listed in column 1 of this table.

e Sources of data on interval depths and geologic units sampled are (1) Benson and McKinley (1985, [DIRS 101036], Table 1), (2) McKinley et al. (1991 [DIRS 116222], Tables 1 and 5), (3) Claassen (1985 [DIRS 101125], Table 1), (4) Rose et al. (2002 [DIRS 162938], Table A-1), (5) Chapman and Lyles (1993 [DIRS 162940], Figures. 11, 13, 16), (6) Davisson et al. (1994 [DIRS 162939], Table 1), (7) LA0311EK831223.001 (8) Robledo et al. (1998 [DIRS 165986], Tables 1 and 4), (9) Graves et al. (1998 [DIRS 155411], throughout report), (10) O'Brien (1998 [DIRS 101278], Table 2), (11) DTN GS980908312322.008 (DIRS 145412), , (12) Steinkampf and Werrell (2001 [DIRS 158818], pp. 11 to 14), (13) lithology estimated from Figure 1 of Claassen (1985 [DIRS 101125]), (14) GS010308312322.003 (DIRS 154734), , (15) Oliver and Root (1997 [DIRS 100069], yucca.xIs), (16) Winograd and Thordarson (1975, [DIRS 101167], Plate 1) 


\section{A5. ASSUMPTIONS}

The scientific analyses presented in this appendix sometimes required that assumptions be made about certain aspects of the hydrochemical or hydrologic system. Typically, these assumptions were made (1) to simplify a problem so that a solution could be approximated, (2) to obtain bounding estimates, or (3) because no relevant data were available at the time the analysis was made.

Table A5-1. Assumptions

\begin{tabular}{|c|c|c|}
\hline & Assumption & Rationale for Assumption \\
\hline 1 & $\begin{array}{l}\text { To provide an initial assessment } \\
\text { of flow directions indicated by } \\
\text { the hydraulic gradient in Figure } \\
\text { A6-3, flow vectors are drawn } \\
\text { parallel to this gradient, implicitly } \\
\text { assuming the hydraulic } \\
\text { conductivity of the rocks is } \\
\text { isotropic. }\end{array}$ & $\begin{array}{l}\text { In spite of the likely anisotropy introduced by the presence of north and } \\
\text { northwest trending faults in the Yucca Mountain area, this assumption } \\
\text { was made to get an initial sense of the flow directions indicated by the } \\
\text { hydraulic gradients. The likelihood that actual flow directions may be } \\
\text { more aligned with fault orientations than indicated by these flow lines is } \\
\text { acknowledged in the text. This assumption does not influence the } \\
\text { conclusions herein that are based solely on groundwater geochemical } \\
\text { and isotopic data. }\end{array}$ \\
\hline 2 & $\begin{array}{l}\text { The dissolved aluminum } \\
\text { concentration of groundwater in } \\
\text { the Yucca Mountain area is in } \\
\text { equilibrium with kaolinite. }\end{array}$ & $\begin{array}{l}\text { The assumption that groundwater aluminum concentrations are } \\
\text { controlled by equilibrium with kaolinite was supported by calculating } \\
\text { dissolved aluminum concentrations in equilibrium with a variety of } \\
\text { secondary minerals with PHREEQC (Parkhurst and Appelo } 1999 \\
\text { [DIRS 159511]) and comparing these calculated concentrations with } \\
\text { concentrations measured at a subset of wells in the Yucca Mountain } \\
\text { area (Figure A6-30). This assumption affects calculation of mineral } \\
\text { saturation indices in Table A6.3-5. }\end{array}$ \\
\hline 3 & $\begin{array}{l}\text { For the purpose of calculating } \\
\text { mineral saturation indices, the } \\
\text { temperature of groundwater } \\
\text { samples can be approximated } \\
\text { either from published maps of } \\
\text { water table temperatures at } \\
\text { Yucca Mountain, or, in the } \\
\text { Amargosa Desert, can be } \\
\text { assumed to be } 25^{\circ} \mathrm{C} \text {. }\end{array}$ & $\begin{array}{l}\text { The use of a contour map of water table temperatures (Fridrich et al. } \\
1994 \text { [DIRS 100575], Figure 8) to estimate groundwater sample } \\
\text { temperatures at Yucca Mountain is an acceptable approximation } \\
\text { because most of the samples for which this approximation was made } \\
\text { are from the upper part of the saturated zone (Figure A6-2 samples } 33 \text {, } \\
34,41,56,57 \text {, and 66). Likewise, the assumption that groundwater } \\
\text { samples in the Amargosa Desert with no measured temperatures are at } \\
25^{\circ} \mathrm{C} \text { is an acceptable approximation because most of the measured } \\
\text { groundwater sample temperatures are in the range of } 20^{\circ} \mathrm{C} \text { to } 30^{\circ} \mathrm{C} \text { (see } \\
\text { data for the LW, FMW-S, FMW-E, FMW-W, GF, AR, and AR/FMW } \\
\text { sample groups in Table A6-1. }\end{array}$ \\
\hline 4 & $\begin{array}{l}\text { The chemical and isotopic } \\
\text { composition of the groundwater } \\
\text { sample from the carbonate } \\
\text { aquifer at borehole p\#1 (sample } \\
\mathrm{p \# 1(c)} \mathrm{in} \mathrm{Tables} \mathrm{A} 6-1 \text { and } \mathrm{A6}-2 \text { ) } \\
\text { and, in particular, its } \mathrm{Cl}^{-} \text {and } \\
\mathrm{SO}_{4}^{2-} \text { concentrations, are } \\
\text { representative of the } \\
\text { composition of groundwater in } \\
\text { carbonate aquifer at Yucca } \\
\text { Mountain. }\end{array}$ & $\begin{array}{l}\text { Borehole } \mathrm{p} \# 1 \text { is the only borehole near Yucca Mountain where } \\
\text { groundwater was directly sampled from the carbonate aquifer, so this } \\
\text { assumption is made out of necessity. The } \mathrm{Cl}^{-} \text {and } \mathrm{SO}_{4}{ }^{2-} \text { concentrations } \\
\text { of groundwater at p\#1 ( } 28 \text { and } 160 \mathrm{mg} / \mathrm{L} \text {, respectively) are similar to the } \\
\text { concentrations of these ions in groundwater from the carbonate aquifer } \\
\text { at Ash Meadows where } \mathrm{Cl}^{-} \text {ranges from } 21 \text { to } 27 \mathrm{mg} / \mathrm{L}^{2} \text { and } \mathrm{SO}_{4}{ }^{2-} \text { ranges } \\
\text { from } 80 \text { to } 111 \mathrm{mg} / \mathrm{L} \text { (Winograd and Pearson } 1976 \text { [DIRS } 108882] \text {, } \\
\text { Table 1). The variability in the concentrations of } \mathrm{Cl}^{-} \text {and SO }{ }_{4}{ }^{2-} \text { in the } \\
\text { carbonate aquifer at Ash Meadows may indicate the extent of the } \\
\text { variability that could be expected at Yucca Mountain. }\end{array}$ \\
\hline
\end{tabular}


Table A5-1. Assumptions (Continued)

\begin{tabular}{|c|c|c|}
\hline & Assumption & Rationale for Assumption \\
\hline 5 & $\begin{array}{l}\text { The chloride mass-balance } \\
\text { (CMB) method is assumed to be } \\
\text { applicable to the estimation of } \\
\text { recharge rates at Yucca } \\
\text { Mountain. The CMB method } \\
\text { assumes one-dimensional, } \\
\text { downward piston flow in the soil } \\
\text { zone, no run-on or runoff, no } \mathrm{Cl}^{-} \\
\text {source other than precipitation, } \\
\text { and no } \mathrm{Cl}^{-} \text {sink (e.g. the } \\
\text { formation of halite is negligible). }\end{array}$ & $\begin{array}{l}\text { The absence of chloride sources and sinks is indicated by the absence } \\
\text { of halite or other chloride-bearing minerals in the soils and rocks at } \\
\text { Yucca Mountain. The departures of actual flow conditions from the } \\
\text { assumption of one-dimensional piston flow are mitigated somewhat for } \\
\text { the calculations done on the basis of the saturated-zone chloride data. } \\
\text { This result is because, for Yucca Mountain as a whole, flow can be } \\
\text { assumed to be vertical between the ground surface and the water table, } \\
\text { even though lateral flow in the unsaturated zone could redistribute water } \\
\text { on a more local scale. Similarly, when using the saturated-zone data } \\
\text { with the CMB method, the effects of nonpiston flow are mitigated } \\
\text { because hydrodynamic mixing and mixing in the well bore when } \\
\text { groundwater is pumped tend to average the Cl- concentrations of fast- } \\
\text { and slow-moving water percolating through fractures and matrix in the } \\
\text { unsaturated zone. Run-on and runoff both can redistribute Cl locally at } \\
\text { Yucca Mountain. However, although run-on is a factor to consider for } \\
\text { wells near Fortymile Wash, run-on from other areas to Yucca Mountain } \\
\text { does not occur, and so the total } \mathrm{Cl}^{-} \text {balance for Yucca Mountain itself is } \\
\text { not affected by this process. Runoff from Yucca Mountain to Fortymile } \\
\text { Wash would tend to cause the actual } \mathrm{Cl}^{-} \text {-deposition rates at Yucca } \\
\text { Mountain to be less than those assumed in the calculations and, thus, } \\
\text { cause the estimated Yucca Mountain recharge to overestimate the } \\
\text { actual recharge. }\end{array}$ \\
\hline 6 & $\begin{array}{l}\text { The estimated range of annual } \\
\text { deposition rates for chloride at } \\
\text { Yucca Mountain encompasses } \\
\text { the present-day rate as well as } \\
\text { the rates that prevailed when the } \\
\text { sampled pore waters infiltrated } \\
\text { below the soil zone. }\end{array}$ & $\begin{array}{l}\text { Several independent lines of evidence support this assumption. First, } \\
\text { the range of deposition rates assumed for Yucca Mountain reflect the } \\
\text { present-day wet and dry chloride deposition rates estimated for sites at } \\
\text { Red Rock Canyon and Kawich Range, Nevada (BSC } 2002 \\
\text { [DIRS 160247]), which represent climates that are drier and wetter, } \\
\text { respectively, than that prevailing at Yucca Mountain today. The second } \\
\text { line of evidence is the constancy of the }{ }^{36} \mathrm{Cl} / \mathrm{Cl} \text { ratio throughout the } \\
\text { Holocene, based on packrat midden data (Plummer et al. } 1997 \\
\text { [DIRS 107034]). Finally, the nearly uniform } \mathrm{Cl} \text { concentrations in the } \\
\text { perched water and SZ groundwater beneath Yucca Mountain also } \\
\text { support the assumption. Section A6.3.6.5 addresses the uncertainty in } \\
\text { the deposition rate and propagation of that uncertainty through the } \\
\text { resulting estimates of recharge obtained by the chloride mass-balance } \\
\text { method. }\end{array}$ \\
\hline 7 & $\begin{array}{l}\text { The chemical and isotopic } \\
\text { composition of deep-perched } \\
\text { water from boreholes UZ-14 and } \\
\text { SD-7 is representative of local } \\
\text { recharge at Yucca Mountain. }\end{array}$ & $\begin{array}{l}\text { A possible conceptual model for the formation of perched water at Yucca } \\
\text { Mountain is that perched water originates when local infiltration rates } \\
\text { exceed the hydraulic conductivity of the perching layer, so that deep } \\
\text { infiltration begins to pond at the top of the layer. The perched water then } \\
\text { moves toward the water table to become recharge either by (1) seeping } \\
\text { slowly through the matrix of the perching layer, (2) moving laterally } \\
\text { down-dip along the top of the perching layer, or (3) by draining down } \\
\text { faults where these intersect the perching layer, depending on local } \\
\text { structural conditions. Although some additional water/rock interactions } \\
\text { such as cation exchange may occur in the deep UZ between the surface } \\
\text { and perched-water horizons, the deep perched water already } \\
\text { incorporates the effects of evaporative processes and water/rock/gas } \\
\text { interactions in the soil zone that dominate the chemical and isotopic } \\
\text { compositions of unsaturated-zone waters (Meijer } 2002 \text { [DIRS 158813]). } \\
\text { The compositions of the deep-perched waters are therefore a good } \\
\text { approximation of the water compositions of local recharge. }\end{array}$ \\
\hline
\end{tabular}


Table A5-1. Assumptions (Continued)

\begin{tabular}{|c|c|c|}
\hline & Assumption & Rationale for Assumption \\
\hline 8 & $\begin{array}{l}\text { Carbon isotope exchange is not } \\
\text { a significant process affecting } \\
{ }^{14} \mathrm{C} \text { activities of groundwater } \\
\text { near Yucca Mountain. }\end{array}$ & $\begin{array}{l}\text { The age-correction models (Section A6.3.6.6.2) did not consider the } \\
\text { process of carbon-isotope exchange, a process that alters the carbon- } \\
\text { isotope composition of groundwater without increasing the net } \\
\text { concentrations of elements contained in the carbon-bearing solid } \\
\text { phases. Isotope exchange is important to consider where the } \\
\text { groundwater is already saturated with calcite and additional interaction } \\
\text { between groundwater and calcite that might alter the isotopic } \\
\text { composition }\left({ }^{14} \mathrm{C} \text { and } \delta^{13} \mathrm{C}\right) \text { of the dissolved carbon would not be } \\
\text { reflected by a change in the concentration of the total dissolved carbon. } \\
\text { The groundwater in the carbonate aquifer is already saturated with } \\
\text { calcite, and thus, exchange reactions are important to consider in this } \\
\text { environment. In the volcanic aquifer, almost all groundwater samples for } \\
\text { which age corrections were made were under saturated with calcite. } \\
\text { Any interaction between groundwater and calcite in the volcanic aquifer } \\
\text { should, therefore, be reflected by an increase in the dissolved carbon } \\
\text { concentrations in the groundwater, a process already considered by the } \\
\text { mass-balance approach embedded in the modeling. }\end{array}$ \\
\hline 9 & $\begin{array}{l}\text { The } \delta^{13} \mathrm{C} \text { of calcite in alluvium is } \\
\text { similar to the } \delta^{13} \mathrm{C} \text { of pedogenic } \\
\text { calcite in the unsaturated zone of } \\
\text { Yucca Mountain (about }-4 \text { per } \\
\text { mil). }\end{array}$ & $\begin{array}{l}\text { No data presently exists on the isotopic composition of calcite contained } \\
\text { in alluvium south and southeast of the repository area at Yucca } \\
\text { Mountain. Late-stage fracture-lining calcite from the unsaturated zone } \\
\text { has a distribution with a mode of about }-6 \text { per mil, whereas } \\
\text { intermediate-stage calcite is more uniformly distributed and has a mode } \\
\text { of about }-2 \text { per mil (Whelan et al. } 1998 \text { [DIRS } 108865, p \text {. 179). An } \\
\text { average value of }-4 \text { per mil approximates an average value for the } \\
\text { intermediate and late-stage fracture-lining calcite in the unsaturated } \\
\text { zone at Yucca Mountain. }\end{array}$ \\
\hline 10 & $\begin{array}{l}\text { It is assumed for the purpose of } \\
\text { tracing flow lines from chemical } \\
\text { and isotopic data that, once in } \\
\text { the saturated-zone groundwater } \\
\text { system, } \delta \mathrm{D}, \delta^{18} \mathrm{O}, \mathrm{Cl}^{-}, \mathrm{SO}_{4}^{2-}, \text { and } \\
\delta^{34} \mathrm{~S} \text { are sufficiently conservative } \\
\text { (i.e., nonreactive) to identify } \\
\text { likely flow paths and } \\
\text { groundwater mixing } \\
\text { relationships. }\end{array}$ & $\begin{array}{l}\text { This assumption is sound for } \delta \mathrm{D} \text { and } \delta^{18} \mathrm{O} \text { because these constitute the } \\
\text { water molecule; thus, large amounts of water/rock interaction are } \\
\text { required to alter their composition. This assumption is acknowledged in } \\
\text { the text as an approximation for } \mathrm{Cl}^{-} \text {and } \mathrm{SO}_{4}{ }^{2-} \text {. Changes in the input } \\
\text { concentrations of these constituents as a result of climate change or } \\
\text { modifications due to water/rock interaction will result in variability along a } \\
\text { flow path. However, in most cases, this effect is expected to be small. } \\
\text { Regardless, the areal contrast in concentrations between these } \\
\text { constituents is large enough that meaningful inferences about flow } \\
\text { directions can be made. }\end{array}$ \\
\hline 11 & $\begin{array}{l}\text { The chemical composition of } \\
\text { groundwater at borehole } \mathrm{J}-11 \text { is } \\
\text { representative of groundwater in }\end{array}$ & $\begin{array}{l}\text { ecause borehole J-11 is the only borehole that has been drilled and } \\
\text { ampled in central Jackass Flats, this is a necessary assumption. }\end{array}$ \\
\hline 12 & $\begin{array}{l}\text { A straight-line } d \\
\text { assumed in eva } \\
\text { times between } \\
{ }^{14} \mathrm{C} \text {. }\end{array}$ & $\begin{array}{l}\text { The straight-line distance assumption allows for straightforward } \\
\text { calculation of transport times and results in the fastest transport time. It } \\
\text { is therefore a conservative assumption. }\end{array}$ \\
\hline 13 & $\begin{array}{l}\text { No correction was made to } \\
\text { estimated }{ }^{14} \mathrm{C} \text { transport times in } \\
\text { fractured volcanics for matrix } \\
\text { diffusion. }\end{array}$ & $\begin{array}{l}\text { Corrections for diffusion of }{ }^{14} \mathrm{C} \text { into the matrix of fractured volcanics } \\
\text { would tend to increase the calculated groundwater transport times } \\
\text { because the matrix pore waters tend to have lower pmc values. } \\
\text { However, detailed data on the }{ }^{14} \mathrm{C} \text { content of pore waters along potential } \\
\text { pathways are lacking. }\end{array}$ \\
\hline 14 & $\begin{array}{l}\text { No additional }{ }^{14} \mathrm{C} \text { is added to } \\
\text { groundwater from downgradient } \\
\text { recharge as a groundwater } \\
\text { moves from an upgradient to a } \\
\text { downgradient well defining a } \\
\text { flow-path segment. }\end{array}$ & $\begin{array}{l}\text { The data on oxygen and hydrogen isotopes for groundwater sampled in } \\
\text { downgradient wells generally indicate lighter isotope ratios as water is } \\
\text { sampled from wells progressively further downgradient. The lighter } \\
\text { isotope ratios represent older waters (Pleistocene). The lack of modern } \\
\text { hydrogen and oxygen isotope ratios in downgradient locations is } \\
\text { evidence of minimal modern recharge at these locations. }\end{array}$ \\
\hline
\end{tabular}




\section{A.6. SCIENTIFIC ANALYSIS}

\section{A6.1 OBJECTIVES}

The objective is to provide an analysis of groundwater recharge rates, flow directions and velocities, and mixing proportions of water from different source areas based on groundwater geochemical and isotopic data. An analysis of these processes based on geochemical data can provide an independent basis for evaluating the interpretation of the flow system provided by the SZ site-scale flow model.

The analysis is structured as follows: Section A6.2 provides background information regarding geographic, geologic and hydrologic setting as well as a summary of over twenty five years of geologic and hydrologic research that has taken place in the region. Information within these sections is continually used and evaluated throughout this appendix. Sections A6.3.1 through A6.3.5 provide an overview of the hydrochemical setting in the study area. A discussion of hydrochemical trends with depth for some boreholes provided in Section A6.3.3, areal distribution plots of hydrochemical and isotopic data discussed in Section A6.3.4, and calculated geochemical parameters presented in Section A6.3.5 provide the initial hydrochemical framework for evaluating the hydraulic system. Particular attention is provided in Section A6.3.6 to evaluate the sources and evolution of water beneath Yucca Mountain. Sections A6.3.7 through A6.3.10 then evaluate flow away from Yucca Mountain. Section A6.3.7 evaluates mixing patterns evident in some areas, and Section A6.3.8 describes PHREEQC models of groundwater mixing and evolution. Section A6.3.9 uses ${ }^{14} \mathrm{C}$ groundwater ages to evaluate flow velocities, and Section A6.3.10 confirms the consistency of flow models using FEHM and flow models derived from hydrochemical arguments. Finally, Section A6.3.11 integrates all the above sections to produce a map describing regional flow pathways.

\section{A6.2 INTRODUCTION AND PREVIOUS WORK}

\section{A6.2.1 Geography, Geology, and Physical Hydrology}

Yucca Mountain is located in the Great Basin about $150 \mathrm{~km}$ northwest of Las Vegas, Nevada. The mountain consists of a series of fault-bounded blocks of ash-flow and ash-fall tuffs and a smaller volume of lava deposited between 14 and $11 \mathrm{Ma}$ (million years before present) from a series of calderas located a few to several tens of kilometers to the north in the vicinity of Timber Mountain (Sawyer et al. 1994 [DIRS 100075], Figure 1). Volcanic rocks erupted from these calderas typically thin to the south and eventually pinch out beneath alluvium in the Amargosa Desert (Figure A6-1). Yucca Mountain itself extends southward from Pinnacles Ridge toward the Amargosa Desert (Figure A6-1). Volcanic units on Yucca Mountain typically dip 5 to 10 degrees to the east. Crater Flat is west of Yucca Mountain and separated from it by Solitario Canyon, which is the surface expression of the Solitario Canyon fault - a steeply dipping scissors fault with down-to-the-west displacement of as much as $500 \mathrm{~m}$ in southern Yucca Mountain (Day et al. 1998 [DIRS 101557], pp. 6 and 7). Underlying Crater Flat is a thick sequence of alluvium, lava, and tuff that has been locally cut by faults and volcanic dikes. East of Yucca Mountain, and separated from it by Fortymile Wash, is Jackass Flats, which is also underlain by a thick sequence of alluvium and volcanic rocks. Timber Mountain, approximately $25 \mathrm{~km}$ to the 
north of the repository area, is a resurgent dome within the larger caldera complex that erupted the tuffs at Yucca Mountain.

The central block of Yucca Mountain is bounded by Drill Hole Wash on the north, the Solitario Canyon fault on the west, the Bow Ridge fault on the east, and is dissected by the Ghost Dance and Dune Wash faults (Figure A6-1). Topography north of the central block at Yucca Mountain is controlled by long, northwest-trending, fault-controlled washes. Within and south of the central block, washes are shorter and trend eastward. Topography in the southern part of Yucca Mountain is controlled by south-trending faults.

Based on similarities in their core-scale hydrologic and mechanical properties, saturated volcanic units at Yucca Mountain were grouped into two confining layers and two aquifers by Luckey et al. (1996 [DIRS 100465], pp. 17 to 19) (Figure A6-2). Figure A6-2 represents a simplification of the more detailed hydrostratigraphic framework presented in Hydrogeologic Framework Model for the Saturated-Zone Site-Scale Flow and Transport Model ANL-NBS-HS-000033 (BSC 2004 [DIRS 170008]) that is used in the SZ site-scale flow model, (Table 6-17) and is used here only to provide a broad overview of the site hydrostratigraphy. In general, the confining units are zeolitic, nonwelded tuffs and the uppermost aquifers are fractured, welded, and devitrified tuffs (the Upper Volcanic Aquifer) or include intervals of fractured, welded, and devitrified tuffs (the Lower Volcanic Aquifer). Most zeolite formation took place before approximately $11 \mathrm{Ma}$ (Broxton et al. 1987 [DIRS 102004], p. 101; Bish 1989 [DIRS 101194], pp. 31, 33) and was concentrated in the originally permeable, nonwelded vitric tuffs; zeolitization was less intense in the partly to densely welded, devitrified tuffs that are present in the interiors of the Prow Pass and Bullfrog tuffs of the Crater Flat group. Zeolitization and clay alteration is more intense and zeolite facies alteration occurs higher in the section in northern Yucca Mountain because of the high paleotemperature gradients that existed near the calderas (Broxton et al. 1987 [DIRS 102004], pp 107 to 108; Bish 1989 [DIRS 101194], p. 35). Regionally, argillite of the Eleana Formation is a confining layer, and the Paleozoic carbonate rocks are an important aquifer (Winograd and Thordarson 1975 [DIRS 101167], Table 1, columns 6, 7; Laczniak et al. 1996 [DIRS 103012], Table 1). The Eleana Formation is inferred to be present in northern Yucca Mountain based on areal magnetic data (Luckey et al. 1996 [DIRS 100465], p. 20), though it has not been penetrated by drill core. The carbonate aquifer was penetrated at borehole p\#1 (the correspondence between well identifiers and borehole abbreviations is given in Table A4-3), but its continuity and thickness in this part of southern Nevada, and consequently its importance as a regional aquifer, is thought to be less near Yucca Mountain than in areas farther to the east (Thomas et al. 1996 [DIRS 101933], Figure 17). 


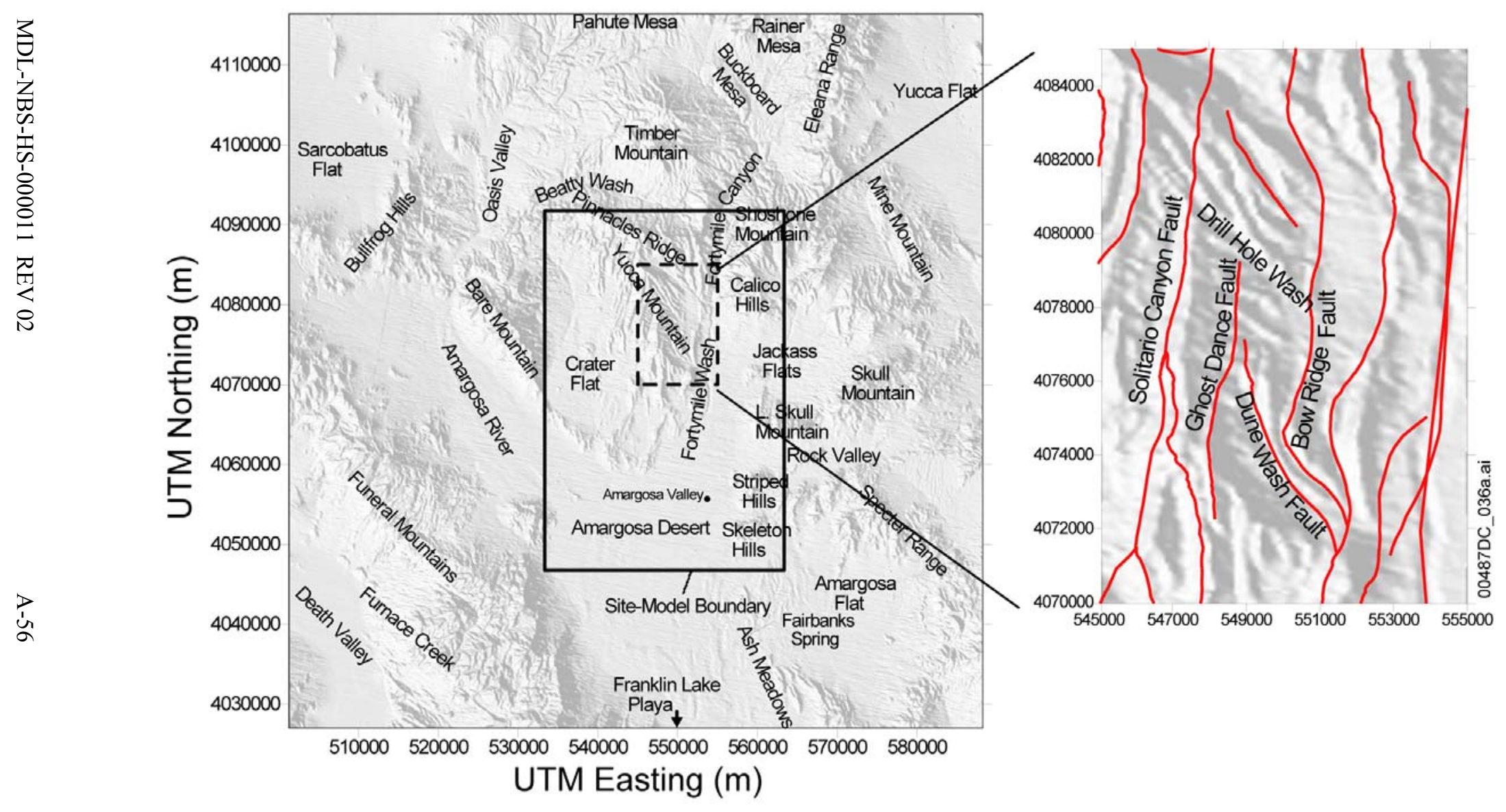

DTN: GS991208314221.001 [DIRS 145263] (Tertiary faults).

NOTE: The solid rectangle is the boundary of the SZ site-scale flow and transport model. UTM=Universal Transverse Mercator.

Figure A6-1. Important Physiographic Features near Yucca Mountain 


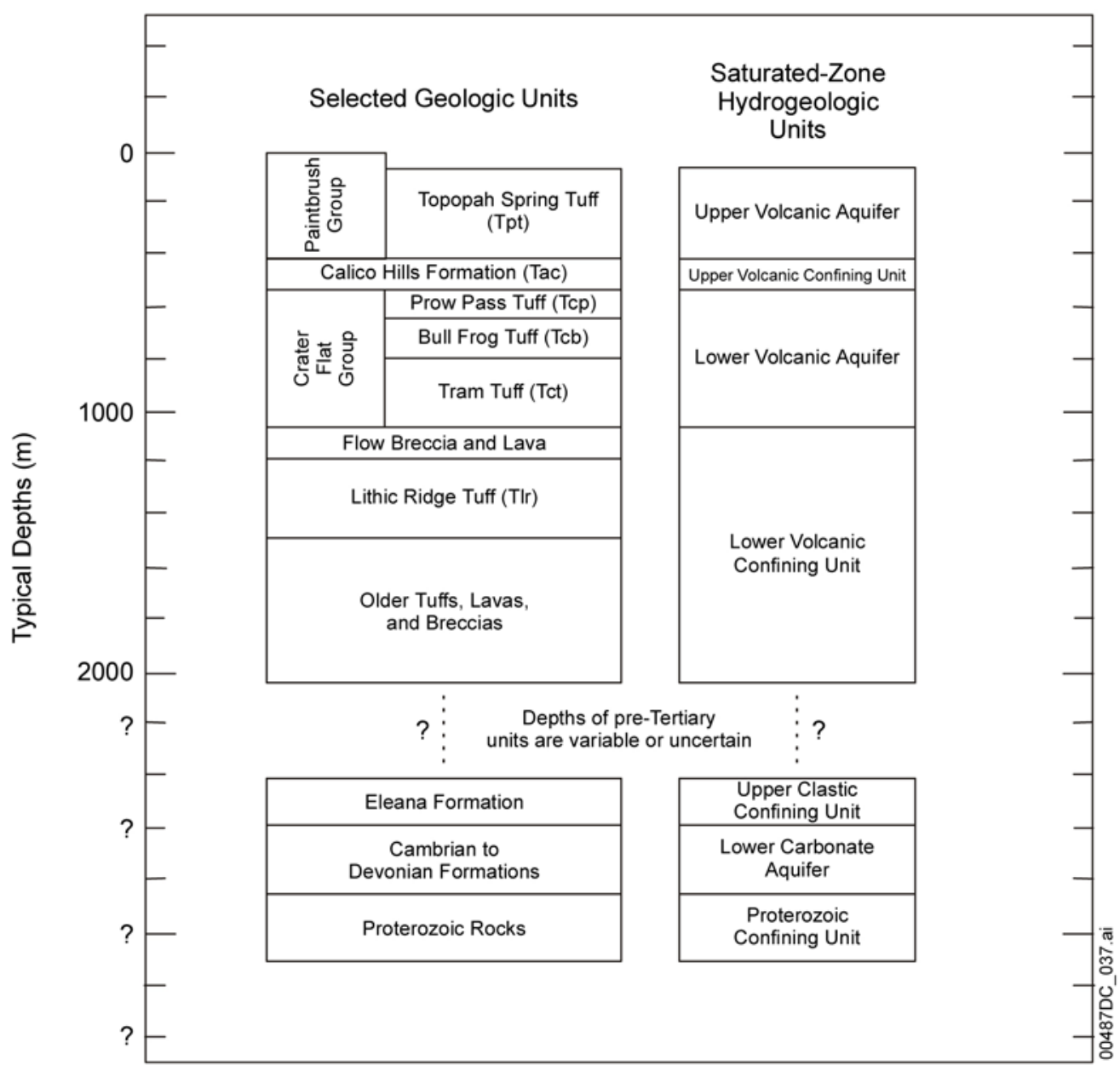

Source: Luckey et al. (1996 [DIRS 100465]), Figure 7.

NOTE: Valley Fill of variable age, consisting of sands, gravels, clays, freshwater limestones, and basaltic lavas, overlies various units of the Tertiary volcanic rocks and pre-Tertiary rocks in basins to the west, east, and south of Yucca Mountain. For example, see Kilroy (1991 [DIRS 103010], Figure 3).

Figure A6-2. Selected Geologic and Hydrogeologic Units for the Saturated Zone at Yucca Mountain

A map of the potentiometric surface in the Yucca Mountain area was developed as part of an associated analysis report (USGS 2001[DIRS 154625], Figure 1-2) based on average water-level data collected from 1985 to 1995 (Figure A6-3). The potentiometric-surface elevations at individual boreholes are based on composite water levels in the volcanic units or, at boreholes where heads were measured at multiple depths in the units, on the shallowest head measurement. (USGS 2001 [DIRS 154625], p. 18). The water levels have been influenced by local pumping in the southern part of the model area (USGS 2001 [DIRS 154625], p. 23). 


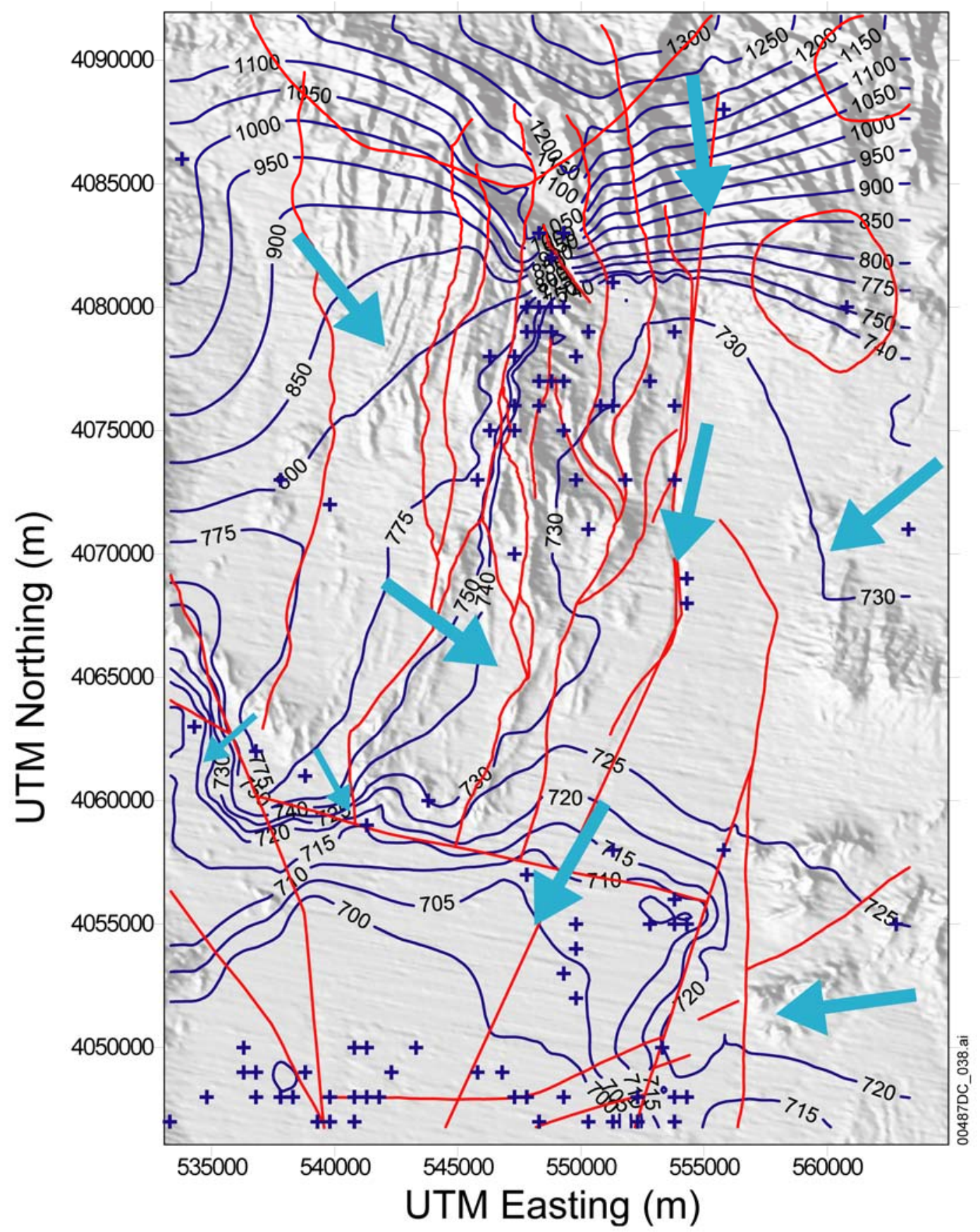

DTN: GS991208314221.001 [DIRS 145263] (Tertiary faults); GS00050812332.0001 [DIRS 149947] (Water-level contours)

Source: USGS (2001 [DIRS 154625], Figure 1-2)

NOTE: The inferred groundwater flow directions are based on Assumption 1 in Table A5-1. The circular areas outlined in red near the Calico Hills in the northeast corner of the map are zones of hydrothermal alteration associated with granitic intrusions (Table 6-17). The semicircular area along the central northern portion of the map is the southern boundary of the Claim Canyon caldera (Table 6-17). The other red lines are selected faults; blue crosses indicated the location of hydraulic head measurements. Blue lines are contours showing elevation (in meters above sea level) of the potentiometric surface; contour intervals vary. UTM=Universal Transverse Mercator.

Figure A6-3. Potentiometric Surface and Inferred Flow Directions (light blue arrows) for Yucca Mountain and Vicinity 
Several possible flow directions were defined by drawing arrows parallel to the gradient in the potentiometric surface (Figure A6-3). The flow directions were drawn under the assumption that hydraulic conductivity and transmissivity are isotropic (Assumption 1 in Table A5-1). In fractured-rock aquifers, such as those at Yucca Mountain, hydraulic conductivity probably is anisotropic (Luckey et al. 1996 [DIRS 100465], p. 36). Nonetheless, this assumption provides a starting point for evaluating the possible flow pathways of groundwater in the Yucca Mountain area. Groundwater models of the site that account for the effects of faults and anisotropy on the flow paths may indicate paths substantially different than those drawn from Figure A6-3.

The flow paths shown in Figure A6-3 indicate that water may flow from the north and northwest under Yucca Mountain. In Figure A6-3, some of the flow from the north is predicted to flow southeastward toward Fortymile Wash in northern Yucca Mountain, an area dominated by northwest-trending, fault-controlled washes. The inferred flow directions indicate that groundwater flows southeast from Yucca Mountain and southwest from Jackass Flats toward the Fortymile Wash area. Groundwater from the Fortymile Canyon area flows south and then southwest in the southern part of the site model area. Flow in the southern part of Yucca Mountain is predominantly southeastward toward Fortymile Wash rather than south toward the Amargosa Desert (Figure A6-3). The faults in the southern part of Yucca Mountain do not seem to exert an observable effect on the potentiometric surface, but this may reflect the sparseness of boreholes and small hydraulic gradient in this area.

\section{A6.2.2 Previous Hydrochemical Investigations}

Yucca Mountain has been under investigation as a repository site since the early 1980s, and an extensive body of literature exists concerning its groundwater hydrochemical and isotopic characteristics. The following summary of that literature is not exhaustive but represents the range of interpretations that have been made concerning groundwater flow at and near Yucca Mountain. Literature data were used to create and evaluate conceptual models, corroborate existing models, and to enhance the database of hydrochemistry data obtained by the Project.

Several published studies (White and Chuma 1987 [DIRS 108871]; Benson and Klieforth 1989 [DIRS 104370]; Stuckless et al. 1991 [DIRS 101159]; Fridrich et al. 1994 [DIRS 100575]; Luckey et al. 1996 [DIRS 100465]; Campana and Byer 1996 [DIRS 126814]; Paces et al. 2002 [DIRS 158817]) have focused on the origin and flow paths of groundwater in the vicinity of Yucca Mountain. These authors primarily differed with respect to the extent of recharge occurring through Yucca Mountain or along Fortymile Wash, the residence time of groundwater beneath Yucca Mountain, and the extent of mixing between the volcanic and carbonate aquifers.

Based on $\delta \mathrm{D}$ and $\delta^{18} \mathrm{O}$ data for the Yucca Mountain region, Benson and Klieforth (1989 [DIRS 104370], p. 48) proposed that groundwater beneath Yucca Mountain could be a mixture of overland flow along Fortymile Wash and groundwater flow from upland areas to the north (Pahute Mesa). Benson and Klieforth (1989 [DIRS 104370], pp. 48 and 49, Figure 11) reported that the $\delta^{18} \mathrm{O}$ values of groundwater in the vicinity of Yucca Mountain were lower for water with apparent ${ }^{14} \mathrm{C}$ ages between 18.5 - and 9-ka (thousand years before present) and were higher and constant since then, a relation that was attributed to global climate change and accompanying changes in the paths of storms bringing moisture to southern Nevada prior to 9-ka. Benson and Klieforth (1989 [DIRS 104370], p. 42) also argued that groundwater ${ }^{14} \mathrm{C}$ ages 
in the Yucca Mountain area do not require substantial correction to account for the dissolution of calcite, based on geochemical modeling of three wells in Fortymile Wash by White and Chuma (1987 [DIRS 108871], Table 2, Figure 23) and the observation that surface runoff in Fortymile Wash was saturated with calcite and yet still had a ${ }^{14} \mathrm{C}$ activity of 100 percent modern carbon (pmc).

Groundwater in the volcanic aquifers in the Yucca Mountain area was interpreted by Stuckless et al. (1991 [DIRS 101159], p. 1414) to be a mixture of at least three end members. One source of groundwater in the volcanic aquifer, represented by groundwater from borehole UE-29 a\#2 in Fortymile Canyon, is characterized by isotopically light ${ }^{13} \mathrm{C}\left(\delta^{13} \mathrm{C}\right)$, a high ${ }^{14} \mathrm{C}$ activity, and isotopically heavy $\delta \mathrm{D}$. This groundwater is either mixed with a second source of groundwater from the Paleozoic carbonate aquifer having an isotopically heavy $\delta^{13} \mathrm{C}$ and a low ${ }^{14} \mathrm{C}$ activity or, alternatively, is modified by calcite derived from the carbonate aquifer with these isotopic characteristics. A third, poorly constrained end member with a $\delta^{13} \mathrm{C}$ value and ${ }^{14} \mathrm{C}$ activity intermediate between that of the first and second sources and having a lighter $\delta \mathrm{D}$ value than the first source was hypothesized to explain the scatter in the $\delta^{13} \mathrm{C}$ and ${ }^{14} \mathrm{C}$ about a possible mixing trend line (Stuckless et al. 1991 [DIRS 101159], Figure 4). Groundwater at Pahute Mesa from borehole UE-20 a\#2 has these characteristics and it was suggested by Stuckless et al. (1991 [DIRS 101159], p. 1414) as a possible third source for the groundwater at Yucca Mountain.

Fridrich et al. (1994 [DIRS 100575], pp. 153 to 159) used the spatial variability in $\delta^{13} \mathrm{C}$, water table temperature, magnetic data, and unsaturated zone heat flux to infer that groundwater in the northern part of Yucca Mountain entered the deep carbonate aquifer and reemerged into the shallow volcanic aquifer along faults in the central and southern parts of the mountain. Luckey et al. (1996 [DIRS 100465], p. 44) noted the downgradient increase in the calcium-to-sodium ratio from west to east across Yucca Mountain and speculated that it might reflect either upwelling from the underlying carbonate aquifer through faults on the east side of Yucca Mountain or mixing of water flowing from the west with calcium-rich water recharged from Fortymile Wash.

Campana and Byer (1996 [DIRS 126814], p. 465) presented a steady-state mixing-cell model of the NTS regional groundwater flow system that used corrected ${ }^{14} \mathrm{C}$ ages to determine flow volumes and directions and recharge rates in the regional flow system. Their results indicated that between 28 and 88 percent of the groundwater beneath Yucca Mountain originated as local recharge, which was estimated to be between 1.9 to $4.2 \mathrm{~mm} / \mathrm{yr}^{-1}$ as an annual average distributed evenly across the cell's surface area (Campana and Byer 1996 [DIRS 126814], p. 473). In their model, the remainder of the flow beneath Yucca Mountain originated from the west in Crater Flat. Flow from upland areas north of Yucca Mountain was diverted eastward toward Fortymile Canyon and Fortymile Wash before reaching Yucca Mountain. Groundwater beneath Yucca Mountain was interpreted by Campana and Byer (1996 [DIRS 126814], Figure 5) to be a mixture of groundwaters having different ${ }^{14} \mathrm{C}$ activities, with a mean age of 10.9- to 16.0-ka and a median age of 6.3- to 6.5-ka (Campana and Byer 1996 [DIRS 126814], Table 7). Approximately 20 to 25 percent of the total recharge in their regional model domain originated from the Fortymile Canyon and Wash area, where areally distributed recharge rates were estimated to be 26 to $32 \mathrm{~mm} / \mathrm{yr}^{-1}\left(5.3 \times 10^{6}\right.$ to $\left.6.6 \times 10^{6} \mathrm{~m}^{3} / \mathrm{yr}^{-1}\right)$ (Campana and Byer 1996 [DIRS 126814], p. 476). 
Water in the Amargosa Desert originated from groundwater flow from Fortymile Canyon and Wash area and Crater Flat.

Based on ${ }^{234} \mathrm{U} /{ }^{238} \mathrm{U}$ activity ratios in perched water and the underlying groundwater, Paces et al. (2002 [DIRS 158817]) concluded that at least some of the shallow groundwater presently beneath Yucca Mountain appears to have been recharged locally. Paces et al. (2002 [DIRS 158817], p. 770) suggested a conceptual model that explains the presence of high ${ }^{234} \mathrm{U} /{ }^{238} \mathrm{U}$ data in the saturated zone beneath Yucca Mountain. The hydraulic barriers that cause the comparatively large hydraulic gradients in the northern and western parts of Yucca Mountain inhibit underflow from upgradient areas, thereby allowing the chemical and isotopic composition of a small amount of local recharge to exert a prominent influence on the isotopic and chemical composition of the groundwater. Likewise, because both the present-day recharge rates and rates of groundwater flow from upgradient areas are small, hydraulic gradients beneath Yucca Mountain are relatively flat and groundwater that was recharged at Yucca Mountain in the late Pleistocene continues to persist in the groundwater beneath the Yucca Mountain (Paces et al. 2002 [DIRS 158817], p. 770). The absence of high ${ }^{234} \mathrm{U} /{ }^{238} \mathrm{U}$ activity ratios in groundwater downgradient from Yucca Mountain could reflect the hydraulic isolation of Yucca Mountain, dilution by Fortymile Wash groundwater or other Yucca Mountain recharge with lower ${ }^{234} \mathrm{U} /{ }^{238} \mathrm{U}$ activity ratios (bulk-rock dissolution seems to have lowered ${ }^{234} \mathrm{U} /{ }^{238} \mathrm{U}$ activity ratios in perched water at borehole USW SD-7 (Paces et al. 2002 [DIRS 158817], p. 768)), water/rock interactions that incorporate other sources of uranium, or the upwelling of small amounts of groundwater from the carbonate aquifer.

Winograd and Thordarson (1975 [DIRS 101167], p. C111) concluded from chemical data that groundwater in the central Amargosa Desert (Figure A6-1) originates from at least three sources: (1) water dominated by calcium, magnesium, sodium, and bicarbonate that flows across the hydraulic barrier responsible for springs at Ash Meadows; (2) water southwest of Amargosa Valley (formerly, Lathrop Wells) dominated by sodium, potassium, and bicarbonate that probably flows from western Jackass Flats; and (3) water in the west-central and northwestern Amargosa Desert that flows from Oasis Valley. In addition, Winograd and Thordarson (1975 [DIRS 101167], p. C112) noted the dilute nature of the groundwater near Fortymile Wash and interpreted the low dissolved solids content of this water to indicate an origin from paleorecharge along the channel rather than underflow from areas north of Jackass Flats. Winograd and Thordarson (1975 [DIRS 101167], p. C112) also noted the higher dissolved solids content in wells at and south of Amargosa Valley, which they attributed to small amounts of groundwater leaking upward from the carbonate aquifer into the valley fill near the Gravity fault.

Claassen (1985 [DIRS 101125]) and White and Chuma (1987 [DIRS 108871]) presented different hypotheses regarding the origin of water in the northern Amargosa Desert near the present-day Fortymile Wash drainage. Claassen (1985 [DIRS 101125], p. F30) argued that groundwater near surface drainages was predominantly derived from surface runoff during the Pleistocene and the very early Holocene based on its apparent ${ }^{14} \mathrm{C}$ age (Claassen 1985 [DIRS 101125], Figure 15), and on the high ratio of calcium plus magnesium to sodium plus potassium $[(\mathrm{Ca}+\mathrm{Mg}) /(\mathrm{Na}+\mathrm{K})]$ of groundwater from the northern Amargosa Desert compared to groundwater from upgradient locations (Claassen 1985 [DIRS 101125], p. F13, Figure 9). The ${ }^{234} \mathrm{U} /{ }^{238} \mathrm{U}$ activity ratios and $\delta \mathrm{D}$ values of groundwater near Fortymile Wash in the northern Amargosa Desert were also later interpreted as supportive of this hypothesis (Paces et al. 2002 
[DIRS 158817], p. 767). In contrast, White and Chuma (1987 [DIRS 108871], p. 578) argued that groundwater in the northern Amargosa Desert evolved chemically from groundwater that had recharged upgradient in Fortymile Canyon. The ${ }^{14} \mathrm{C}$ age of groundwater in the northern Amargosa was used to calculate groundwater velocities beneath Fortymile Wash of between 3 and $30 \mathrm{~m} \mathrm{yr}^{-1}$ over an average distance of about $15 \mathrm{~km}$ extending southward from borehole J-13 to the north-central Amargosa Desert (White and Chuma 1987 [DIRS 108871], p. 578).

\section{A6.3 ANALYSIS OF HYDROCHEMICAL AND ISOTOPIC DATA}

This section presents the results of the analysis of the hydrochemical and isotopic data in the vicinity of Yucca Mountain in eleven major subsections. Section A6.3.1 discusses factors affecting the chemical and isotopic composition of groundwater. In section A6.3.2 all groundwater samples evaluated in this appendix are assigned to a specific grouping to facilitate interpretation and discussion. Section A6.3.3 discusses depth-dependent trends in the chemical and isotopic composition of groundwater. Section A6.3.4 presents areal distribution maps of hydrochemical data and discusses geographic trends shown by these data. Section A6.3.5 presents areal distribution maps showing calculated geochemical parameters such as mineral saturation indices. Section A6.3.6 presents an evaluation of the evidence regarding local recharge at Yucca Mountain. Also discussed in this subsection are evaluations of the evidence for the timing and magnitude of recharge. Section A6.3.7 presents an evaluation of mixing relations among groundwaters. Section A6.3.8 presents an analysis of mixing and water rock interactions using PHREEQC V2.3 (BSC 2001 [DIRS 155323]). Section A6.3.9 addresses groundwater flow velocities. Section A6.3.10 presents results of the site-scale saturated zone groundwater flow model for a portion of the study area. Section A6.3.11 presents an analysis of groundwater flow paths in the Yucca Mountain region based on cumulative evidence presented in the previous sections.

The data derived from the DTNs and other sources are summarized here for each sample/well location for the major ions (Table A6-1) and for the isotopes and trace elements (Table A6-2). Where multiple sets of data were available for a location/sample, these data were averaged to derive the values shown in these two tables, and the areal distribution of the hydrochemical and isotopic data discussed in this section and portrayed on figures of the area of study uses the compiled values of Tables A6-1 and A6-2. All analytical data have uncertainty associated with the individual values, as fully described in Sections A7.3.1 and A7.3.2. Because these samples were collected over a time-span of several decades by different organizations using different methods, analytical precision and accuracy may be variable for particular analytes. In many cases, the original data sources do not provide an indication of the precision or accuracy. However, a sense of the uncertainties associated with historic measurements can be obtained from data that are more recently collected; uncertainties in historic data are probably higher than the values listed below because of recent developments in measurement technology. 
Analytical accuracy for recent measurements are (Section A7.3.1):

- Ten percent for major anions, cations and strontium concentration, except for fluoride, for which accuracy is estimated as better than \pm 15 percent. In some cases, strontium was determined by isotope dilution, mass spectrometry methods, for which data are more precise (e.g., \pm 0.5 percent)

- \pm 3.0 per mil for $\delta \mathrm{D}, \pm 0.2$ per mil for $\delta^{18} \mathrm{O}, \delta^{13} \mathrm{C}$, and $\delta^{34} \mathrm{~S}$, and \pm 0.1 pmc for ${ }^{14} \mathrm{C}$

- Better than 1 percent for uranium concentrations and from 0.09 percent to 4.5 percent (with a mean of 0.73 percent) for ${ }^{234} U^{238} U$

- \pm 0.00001 for ${ }^{87} \mathrm{Sr} /{ }^{86} \mathrm{Sr}$, which translates to an uncertainty of approximately 0.01 per mil in $\delta^{87} \mathrm{Sr}$ units.

An additional guide to the reliability of individual water analyses is also provided by the calculated charge-balance errors listed in Table A6-3. Groundwaters from most sites used in this analysis, especially those near Yucca Mountain itself, have charge-balance errors less than \pm 5 percent. However, groundwaters from some outlying areas that were used as data in this analysis have charge-balance errors as high as 10-20 percent. These sample sites are located primarily in the Mine Mountain (MM) group of samples and did not have a significant influence on the conclusions derived in this analysis. 
Table A6-1. Field Parameters and Major Ion Composition

\begin{tabular}{|c|c|c|c|c|c|c|c|c|c|c|c|c|c|}
\hline Well Name $^{a}$ & $\begin{array}{c}\text { Figure } \\
\text { A6-5 } \\
\text { Sample }\end{array}$ & $\begin{array}{c}\text { Temperature } \\
\left({ }^{\circ} \mathrm{C}\right)\end{array}$ & $\mathrm{pH}$ & $\begin{array}{l}\mathrm{Ca}^{2+} \\
(\mathrm{mg} / \mathrm{L})\end{array}$ & $\begin{array}{l}\mathrm{Mg}^{2+} \\
(\mathrm{mg} / \mathrm{L})\end{array}$ & $\begin{array}{c}\mathrm{Na}^{+} \\
(\mathrm{mg} / \mathrm{L})\end{array}$ & $\begin{array}{c}\mathrm{K}^{+} \\
(\mathrm{mg} / \mathrm{L})\end{array}$ & $\begin{array}{c}\mathrm{Cl}^{-} \\
(\mathrm{mg} / \mathrm{L})\end{array}$ & $\begin{array}{l}\mathrm{SO}_{4}{ }^{2-} \\
(\mathrm{mg} / \mathrm{L})\end{array}$ & $\begin{array}{l}\mathrm{HCO}_{3}^{-} \\
\text {(mg/L) }\end{array}$ & $\begin{array}{l}\mathrm{CO}_{3}{ }^{2-} \\
(\mathrm{mg} / \mathrm{L})\end{array}$ & $\begin{array}{c}\mathrm{F}^{-} \\
(\mathrm{mg} / \mathrm{L})\end{array}$ & $\begin{array}{c}\mathrm{SiO}_{2} \\
(\mathrm{mg} / \mathrm{L})\end{array}$ \\
\hline \multicolumn{14}{|l|}{ Oasis Valley/NW Amargosa } \\
\hline ER-EC-08 & 1 & 38.2 & 8.0 & 10.3 & 0.9 & 120.0 & 5.6 & 50.7 & 84.8 & 176.8 & $-^{d}$ & 5.3 & 49.1 \\
\hline ER-OV-01 & 2 & 25.7 & 8.3 & 6.2 & 0.1 & 139.7 & 6.8 & 45.6 & 82.7 & 196.9 & 1.7 & 2.1 & 70.0 \\
\hline ER-OV-06a & 3 & 28.6 & 8.3 & 2.1 & 0.7 & 144.5 & 7.5 & 48.5 & 80.0 & 197.9 & 3.0 & 3.1 & 52.9 \\
\hline ER-OV-05 & 4 & 21.9 & 7.8 & 21.5 & 4.4 & 103.5 & 10.0 & 37.7 & 55.6 & 235.6 & - & 1.7 & 82.4 \\
\hline ER-OV-02 & 5 & 18.9 & 8.2 & 14.3 & 0.6 & 143.0 & 4.1 & 51.2 & 88.1 & 227.1 & - & 2.3 & 57.4 \\
\hline $\begin{array}{l}\text { Springdale Upper Well (10S/47E- } \\
\text { 32adc) (11/12/97) }\end{array}$ & 6 & 23.6 & 7.7 & 22.0 & 4.1 & 130.0 & 8.7 & 37.2 & 67.7 & 292.8 & - & 2.1 & 69.9 \\
\hline $\begin{array}{l}\text { Goss Springs North (11S/47E-10bad) } \\
(11 / 13 / 97)\end{array}$ & 7 & 17.7 & 8.2 & 16.4 & 1.2 & 107.0 & 5.0 & 43.0 & 76.4 & 180.1 & - & 2.4 & 53.2 \\
\hline Er-OV-03a & 8 & 17.5 & 8.1 & 14.0 & 1.0 & 118.0 & 5.2 & 42.6 & 76.0 & 183.6 & - & 2.3 & 54.7 \\
\hline ER-OV-03a3 & 9 & 21.2 & 8.3 & 13.3 & 1.1 & 120.5 & 5.7 & 44.9 & 81.2 & 184.2 & - & 2.1 & 55.1 \\
\hline ER-OV-03a2 & 10 & 20.0 & 9.2 & 5.7 & 1.0 & 331.0 & 84.7 & 262.0 & 295.0 & 186.2 & 41.6 & - & 20.0 \\
\hline Goss Spring (11S/47E-10bcc) & 11 & 22.0 & 7.7 & 17.5 & 1.3 & 116.5 & 5.1 & 45.0 & 78.1 & 181.0 & - & 2.8 & 50.4 \\
\hline ER-OV-04a (11/07/97) & 12 & 23.7 & 8.4 & 8.7 & 0.1 & 98.8 & 7.8 & 28.2 & 59.9 & 162.4 & 2.2 & 2.8 & 68.9 \\
\hline Beatty Well no. 1 (Wat\&Sanit Distr) & 13 & 22.2 & 8.0 & 39.2 & 5.5 & 126.3 & 8.5 & 48.4 & 113.0 & 203.0 & - & 1.4 & - \\
\hline Bond Gold Mining \#1 & 14 & - & 8.3 & 23.0 & 6.0 & 65.0 & 7.3 & 40.0 & 52.0 & 161.0 & 0.0 & 0.6 & 29.0 \\
\hline US Ecology MW-313 & 15 & - & 7.5 & 54.0 & 16.0 & 146.0 & 13.0 & 69.0 & 205.0 & 336.0 & 0.0 & 5.0 & 68.0 \\
\hline US Ecology MW-600 & 16 & - & 7.9 & 20.0 & 11.5 & 167.5 & 8.8 & 67.5 & 153.0 & 296.0 & 0.0 & 5.2 & 62.5 \\
\hline NECWell & 17 & - & 7.6 & 54.9 & 14.1 & 170.1 & 10.2 & 79.1 & 190.2 & 328.3 & 0.0 & - & 70.3 \\
\hline US Ecology MR-3 & 18 & - & 7.7 & - & - & - & - & - & - & 325.0 & 0.0 & - & - \\
\hline \multicolumn{14}{|l|}{ Timber Mountain } \\
\hline UE-18r & 19 & 30.6 & 8.2 & 18.5 & 0.7 & 73.3 & 2.7 & 6.8 & 19.7 & 202.8 & 5.2 & 2.7 & 48.6 \\
\hline ER-18-2 & 20 & 55.2 & 7.6 & 5.8 & 0.2 & 351.7 & 3.1 & 13.2 & 54.0 & 730.0 & - & 12.8 & 42.8 \\
\hline ER-EC-05 & 21 & 29.9 & 8.0 & 20.3 & 0.6 & 73.9 & 1.7 & 16.2 & 35.5 & 176.8 & - & 4.7 & 40.9 \\
\hline Coffer's Ranch Windmill Well & 22 & 20.1 & 8.3 & 16.2 & 0.2 & 70.6 & 0.9 & 7.5 & 30.2 & 184.0 & - & 3.4 & 40.2 \\
\hline ER-OV-03c & 23 & 22.2 & 8.2 & 15.1 & 0.4 & 79.7 & 1.3 & 17.4 & 43.6 & 161.5 & - & 4.5 & 42.9 \\
\hline ER-EC-07 & 24 & 30.0 & 7.9 & 21.6 & 1.7 & 36.8 & 3.1 & 6.0 & 18.3 & 148.8 & - & 1.5 & 44.0 \\
\hline
\end{tabular}


Table A6-1. Field Parameters and Major Ion Composition (Continued)

\begin{tabular}{|c|c|c|c|c|c|c|c|c|c|c|c|c|c|}
\hline Well Name $^{\mathrm{a}}$ & $\begin{array}{c}\text { Figure } \\
\text { A6-5 } \\
\text { Sample } \\
\end{array}$ & $\begin{array}{c}\text { Temperature } \\
\left({ }^{\circ} \mathrm{C}\right)\end{array}$ & pH & $\begin{array}{c}\mathrm{Ca}^{2+} \\
(\mathrm{mg} / \mathrm{L})\end{array}$ & $\begin{array}{c}\mathrm{Mg}^{2+} \\
(\mathrm{mg} / \mathrm{L})\end{array}$ & $\begin{array}{c}\mathrm{Na}^{+} \\
(\mathrm{mg} / \mathrm{L})\end{array}$ & $\begin{array}{c}\mathrm{K}^{+} \\
(\mathrm{mg} / \mathrm{L})\end{array}$ & $\left|\begin{array}{c}\mathrm{Cl}^{-} \\
(\mathrm{mg} / \mathrm{L})\end{array}\right|$ & $\begin{array}{c}\mathrm{SO}_{4}{ }^{2-} \\
(\mathrm{mg} / \mathrm{L})\end{array}$ & $\begin{array}{l}\mathrm{HCO}_{3}^{-} \\
(\mathrm{mg} / \mathrm{L})\end{array}$ & $\begin{array}{l}\mathrm{CO}_{3}{ }^{2-} \\
(\mathrm{mg} / \mathrm{L})\end{array}$ & $\begin{array}{c}F^{-} \\
(\mathrm{mg} / \mathrm{L})\end{array}$ & $\begin{array}{c}\mathrm{SiO}_{2} \\
\text { (mg/L) }\end{array}$ \\
\hline \multicolumn{14}{|l|}{ Fortymile Wash-North } \\
\hline Water Well 8 & 25 & 24.2 & 7.3 & 7.9 & 1.2 & 31.1 & 3.3 & 7.3 & 15.0 & 78.0 & - & 0.7 & 50.0 \\
\hline Test Well 1 (USGS HTH \#1) & 26 & 26.6 & 8.7 & 1.2 & 0.0 & 51.3 & 0.5 & 3.2 & 8.7 & 104.0 & - & - & 19.5 \\
\hline UE-18t & 27 & - & 8.6 & 22.2 & 1.0 & 141.0 & 8.2 & 64.4 & 10.8 & 331.0 & & - & 7.0 \\
\hline ER-30-1 (upper) & 28 & 22.9 & 9.4 & 3.5 & 0.1 & 62.0 & 1.8 & 6.2 & 12.0 & 87.5 & 22.1 & 1.7 & 29.0 \\
\hline ER-30-1 (lower) & 29 & 24.3 & 9.2 & 2.1 & 0.1 & 65.0 & 1.0 & 6.5 & 9.9 & 106.3 & 11.1 & 1.4 & 25.0 \\
\hline $\mathrm{a} 2(\mathrm{dp})$ & 30 & 25.1 & 7.2 & 10.0 & 0.2 & 44.0 & 1.1 & 11.0 & 22.0 & 107.0 & 0.0 & 1.0 & 44.0 \\
\hline
\end{tabular}

a\#2(sh)

UE-29a\#1 HTH

WT\#15

WT\#14

$\mathrm{J}-1$

$\mathrm{J}-12$

$\mathrm{JF} \# 3$

Solitario Canyon Wash

$\mathrm{H}-6$ (bh)

$\mathrm{H}-6(\mathrm{Tct})$

$\mathrm{H}-6(\mathrm{Tcb})$

WT-7

22.7

\begin{tabular}{l|l}
31 & 22.7 \\
32 & 22 \\
\hline
\end{tabular}

WT-10

$33.0^{\mathrm{b}}$

\begin{tabular}{|l|l|l|l|l|l|l|l|l|l|l|l|}
7.0 & 10.0 & 0.3 & 44.0 & 1.3 & 8.8 & 21.0 & 107.0 & 0.0 & 0.9 & 44.0 \\
\hline
\end{tabular}

\begin{tabular}{|l|l|l|l|l|l|l|l|l|l|l|l|l}
7.6 & 15.0 & 2.3 & 36.5 & 4.1 & 7.9 & 16.2 & 108.9 & 0.0 & 0.6 & 57.2 \\
\hline 7.5 & 12.0 & 1.7 & 62.0 & 4.6 & 12.0 & 16.0 & 166.0 & 0.0 & & 52.0 \\
\hline
\end{tabular}

\begin{tabular}{l|l|l|l|l|l|l|l|l|l|l|l|l|l|}
33 & $33.0^{\mathrm{b}}$ & 7.5 & 12.0 & 1.7 & 62.0 & 4.6 & 12.0 & 16.0 & 166.0 & 0.0 & - & 52.0 \\
34 & $30.0^{\mathrm{b}}$ & 7.3 & 10.0 & 0.8 & 45.0 & 5.0 & 8.2 & 22.0 & 119.0 & 0.0 & - & 57.0 \\
\hline
\end{tabular}

Yucca Mountain-Crest

G-2

USW WT-24

$\mathrm{UZ-14}(\mathrm{sh})$

$\mathrm{UZ}-14(\mathrm{dp})$

$\mathrm{H}-1$ (Tcp)

\begin{tabular}{l|l}
35 & 31.0 \\
\hline
\end{tabular}

\begin{tabular}{l|l|l|l|l|}
\hline 1.0 & 7.2 & 12.0 & 2.1 & 42.0 \\
\hline 2.0 & 7.1 & 14.0 & 2.1 & 38.0 \\
\hline
\end{tabular}

\begin{tabular}{|l|l|l|l|l|l|l|l|}
\hline 2.0 & 5.0 & 7.1 & 17.0 & 124.0 & 0.0 & 2.4 & 57.0 \\
\hline 8.0 & 5.1 & 7.3 & 22.0 & 119.0 & 0.0 & 2.1 & 54.0 \\
\hline
\end{tabular}

$\mathrm{H}-1(\mathrm{Tcb})$

$\mathrm{H}-5$

\begin{tabular}{l|l}
37 & 26.6 \\
\hline
\end{tabular}

6.6

\begin{tabular}{|l|l|l|l|l|l|l|l|l|l|l|}
7.1 & 14.0 & 2.1 & 38.0 & 5.1 & 7.3 & 22.0 & 119.0 & 0.0 & 2.1 & 54.0 \\
\hline
\end{tabular}

\begin{tabular}{|l|l|l|l|l|l|l|l|l|l|l|l|l|}
38 & 37.8 & 8.1 & 4.1 & 0.1 & 86.0 & 1.3 & 7.6 & 29.0 & 182.0 & 0.0 & 4.7 & 48.0 \\
\hline
\end{tabular}

\begin{tabular}{|l|l|l|l|l|l|l|l|l|l|l|l|l|l|l|}
39 & 41.6 & 8.3 & 1.4 & 0.0 & 88.0 & 1.3 & 7.2 & 25.0 & 217.0 & 0.0 & 3.9 & 47.0 \\
\hline
\end{tabular}

\begin{tabular}{|l|l|l|l|l|l|l|l|l|l|l|l|}
37.2 & 8.3 & 4.7 & 0.1 & 88.0 & 1.4 & 7.4 & 32.0 & 234.0 & 0.0 & 4.7 & 49.0 \\
\hline
\end{tabular}

\begin{tabular}{l|l|l|l|l|l|l|l|l|l|l|l|l|l}
41 & $34.0^{\mathrm{b}}$ & 8.7 & 2.6 & 0.2 & 97.0 & 2.1 & 13.0 & 7.2 & 252.0 & 0.0 & - & 20.0 \\
\hline
\end{tabular}


Table A6-1. Field Parameters and Major Ion Composition (Continued)

\begin{tabular}{|c|c|c|c|c|c|c|c|c|c|c|c|c|c|}
\hline Well Name $^{\mathrm{a}}$ & $\begin{array}{c}\text { Figure } \\
\text { A6-5 } \\
\text { Sample }\end{array}$ & $\begin{array}{c}\text { Temperature } \\
\left({ }^{\circ} \mathrm{C}\right)\end{array}$ & $\mathrm{pH}$ & $\begin{array}{c}\mathrm{Ca}^{2+} \\
(\mathrm{mg} / \mathrm{L})\end{array}$ & $\begin{array}{c}\mathrm{Mg}^{2+} \\
(\mathrm{mg} / \mathrm{L})\end{array}$ & $\begin{array}{c}\mathrm{Na}^{+} \\
(\mathrm{mg} / \mathrm{L})\end{array}$ & $\begin{array}{c}\mathrm{K}^{+} \\
(\mathrm{mg} / \mathrm{L})\end{array}$ & $\begin{array}{c}\mathrm{Cl}^{-} \\
(\mathrm{mg} / \mathrm{L})\end{array}$ & $\begin{array}{c}\mathrm{SO}_{4}{ }^{2-} \\
(\mathrm{mg} / \mathrm{L})\end{array}$ & $\begin{array}{l}\mathrm{HCO}_{3}^{-} \\
(\mathrm{mg} / \mathrm{L})\end{array}$ & $\begin{array}{l}\mathrm{CO}_{3}{ }^{2-} \\
(\mathrm{mg} / \mathrm{L})\end{array}$ & $\begin{array}{c}\mathrm{F}^{-} \\
(\mathrm{mg} / \mathrm{L})\end{array}$ & $\begin{array}{c}\mathrm{SiO}_{2} \\
(\mathrm{mg} / \mathrm{L})\end{array}$ \\
\hline \multicolumn{14}{|c|}{ Yucca Mountain-Crest Continued } \\
\hline USW SD-6 & 50 & 35.0 & 8.4 & 0.4 & 0.0 & 90.6 & 1.5 & 6.8 & 26.7 & 181.8 & 2.5 & 4.7 & 45.6 \\
\hline $\mathrm{H}-3$ & 51 & 26.5 & 9.2 & 0.8 & 0.0 & 120.0 & 1.1 & 9.5 & 31.0 & 274.0 & 0.0 & 5.5 & 43.0 \\
\hline \multicolumn{14}{|l|}{ Yucca Mountain-Central } \\
\hline G-4 & 52 & 35.6 & 7.7 & 13.0 & 0.2 & 57.0 & 2.1 & 5.9 & 19.0 & 139.0 & 0.0 & 2.5 & 45.0 \\
\hline $\mathrm{b \# 1(Tcb)}$ & 53 & 37.2 & 7.1 & 18.0 & 0.7 & 46.0 & 2.8 & 7.5 & 21.0 & 133.0 & 0.0 & 1.6 & 51.0 \\
\hline $\mathrm{b \# 1(bh)}$ & 54 & 36.0 & 7.3 & 18.0 & 0.7 & 49.5 & 3.6 & 10.8 & 23.0 & 156.0 & 0.0 & 1.6 & 52.5 \\
\hline
\end{tabular}

34.8

UZ\#16

$56-30.0^{b}$

Yucca Mountain-Southeas

\begin{tabular}{|c|c|c|c|c|c|c|c|c|c|c|c|c|c|}
\hline ONC\#1 & 57 & $31.0^{b}$ & 8.7 & 13.0 & 1.1 & 51.0 & 3.6 & 7.1 & 24.0 & 115.0 & 8.8 & - & 27.0 \\
\hline c\#1 & 58 & 41.5 & 7.6 & 11.0 & 0.3 & 56.0 & 2.0 & 7.4 & 23.0 & 151.0 & 0.0 & 2.1 & 56.0 \\
\hline $\mathrm{c \# 3}$ & 59 & 40.8 & 7.7 & 11.0 & 0.4 & 55.0 & 1.9 & 7.2 & 22.0 & 137.0 & 0.0 & 2.0 & 53.0 \\
\hline c\#3(95-97) & 60 & $40.8^{c}$ & 7.7 & 11.0 & 0.3 & 57.0 & 1.9 & 6.5 & 19.0 & 141.0 & 0.0 & - & 58.0 \\
\hline c\#2 & 61 & 40.5 & 7.7 & 12.0 & 0.4 & 54.0 & 2.1 & 7.1 & 22.0 & 139.0 & 0.0 & 2.1 & 54.0 \\
\hline$p \# 1(v)$ & 62 & 44.3 & 6.8 & 37.0 & 10.0 & 92.0 & 5.6 & 13.0 & 38.0 & 344.0 & 0.0 & 3.4 & 49.0 \\
\hline$p \# 1$ (c) & 63 & 56.0 & 6.6 & 100.0 & 39.0 & 150.0 & 12.0 & 28.0 & 160.0 & 694.0 & 0.0 & 4.7 & 41.0 \\
\hline WT-17 & 64 & 28.7 & 7.1 & 8.9 & 0.9 & 49.0 & 2.6 & 6.4 & 17.5 & 129.5 & 0.0 & 2.0 & 39.0 \\
\hline WT\#3 & 65 & 31.8 & 7.6 & 11.2 & 1.0 & 49.0 & 3.9 & 6.0 & 18.3 & 138.5 & 0.0 & 2.3 & 56.2 \\
\hline WT\#12 & 66 & $33.0^{b}$ & 7.6 & 15.0 & 0.3 & 66.0 & 2.6 & 7.8 & 28.0 & 167.0 & 0.0 & 3.1 & 47.0 \\
\hline \multicolumn{14}{|l|}{ Jackass Flats } \\
\hline UE-25 J-11 & 67 & - & 8.1 & 76.5 & 15.0 & 154.0 & 17.0 & 17.5 & 479.5 & 82.0 & 0.0 & 1.2 & 57.5 \\
\hline \multicolumn{14}{|l|}{ Crater Flat } \\
\hline GEXA Well4 & 68 & 31.8 & 7.9 & 11.5 & 0.4 & 71.0 & 3.3 & 13.5 & 45.5 & 150.0 & 0.0 & 3.2 & 48.0 \\
\hline $\mathrm{VH}-1$ & 69 & 35.4 & 7.6 & 10.3 & 1.5 & 79.0 & 1.9 & 10.3 & 44.3 & 164.7 & 0.0 & 2.7 & 49.7 \\
\hline \multicolumn{14}{|c|}{ Southwest Crater Flat } \\
\hline $\mathrm{VH}-2$ & 70 & 32.8 & 7.1 & 78.5 & 29.8 & 70.8 & 8.1 & 16.0 & 142.5 & 391.8 & 0.0 & 1.1 & 26.3 \\
\hline NC-EWDP-7S & 71 & 21.5 & 7.3 & 77.0 & 37.0 & 86.0 & 8.2 & 19.5 & 167.0 & 420.0 & 0.0 & 1.0 & 23.0 \\
\hline
\end{tabular}


Table A6-1. Field Parameters and Major Ion Composition (Continued)

\begin{tabular}{|c|c|c|c|c|c|c|c|c|c|c|c|c|c|}
\hline Well Name $^{a}$ & $\begin{array}{c}\text { Figure } \\
\text { A6-5 } \\
\text { Sample }\end{array}$ & $\begin{array}{c}\text { Temperature } \\
\left({ }^{\circ} \mathrm{C}\right)\end{array}$ & pH & $\begin{array}{c}\mathrm{Ca}^{2+} \\
(\mathrm{mg} / \mathrm{L})\end{array}$ & $\begin{array}{c}\mathrm{Mg}^{2+} \\
(\mathrm{mg} / \mathrm{L})\end{array}$ & $\begin{array}{c}\mathrm{Na}^{+} \\
(\mathrm{mg} / \mathrm{L})\end{array}$ & $\begin{array}{c}\mathrm{K}^{+} \\
(\mathrm{mg} / \mathrm{L})\end{array}$ & $\begin{array}{c}\mathrm{Cl}^{-} \\
(\mathrm{mg} / \mathrm{L})\end{array}$ & $\begin{array}{c}\mathrm{SO}_{4}{ }^{2-} \\
(\mathrm{mg} / \mathrm{L})\end{array}$ & $\begin{array}{l}\mathrm{HCO}_{3}{ }^{-} \\
\text {(mg/L) }\end{array}$ & $\begin{array}{c}\mathrm{CO}_{3}{ }^{2-} \\
(\mathrm{mg} / \mathrm{L})\end{array}$ & $\begin{array}{c}F^{-} \\
(\mathrm{mg} / \mathrm{L})\end{array}$ & $\begin{array}{c}\mathrm{SiO}_{2} \\
\text { (mg/L) }\end{array}$ \\
\hline \multicolumn{14}{|c|}{ Southwest Crater Flat Continued } \\
\hline NC-EWDP-7SC & 72 & - & 7.2 & 83.0 & 38.0 & 90.7 & 4.3 & 22.0 & 179.0 & 429.0 & 0.0 & 0.9 & 23.7 \\
\hline NC-EWDP-1DX & 73 & - & 7.2 & 55.5 & 31.0 & 73.5 & 10.0 & 16.0 & 136.0 & 369.0 & 0.0 & 0.7 & 46.5 \\
\hline NC-EWDP-1DX Zone 2 & 74 & 28.6 & 6.7 & 40.0 & 11.0 & 329.7 & 6.2 & 49.7 & 112.3 & 1011.5 & 0.0 & 11.0 & 51.3 \\
\hline NC-EWDP-1S Zone 1 & 75 & 26.7 & 7.4 & 57.5 & 30.5 & 65.0 & 9.0 & 15.5 & 128.5 & 360.0 & 0.0 & 0.6 & 50.5 \\
\hline NC-EWDP-1S Zone 2 & 76 & 27.6 & 7.3 & 55.5 & 30.5 & 64.5 & 8.9 & 15.5 & 126.0 & 356.0 & 0.0 & 0.6 & 48.5 \\
\hline NC-EWDP-1S & 77 & 27.8 & 7.3 & 59.0 & 31.0 & 67.5 & 8.6 & 15.0 & 127.0 & 358.0 & 0.0 & 0.6 & 55.0 \\
\hline NC-EWDP-12PA & 78 & 28.5 & 6.8 & 30.3 & 8.2 & 146.0 & 27.0 & 14.0 & 102.3 & 414.5 & 0.0 & 4.1 & 69.3 \\
\hline NC-EWDP-12PB & 79 & 29.3 & 6.9 & 30.5 & 8.2 & 140.5 & 27.0 & 14.0 & 105.0 & 396.5 & 0.0 & 4.2 & 68.0 \\
\hline NC-EWDP-12PC & 80 & 28.6 & 7.5 & 53.0 & 27.5 & 72.0 & 10.0 & 14.0 & 123.5 & 323.0 & 0.0 & 1.0 & 55.5 \\
\hline \multicolumn{14}{|l|}{ Southern Yucca Mountain } \\
\hline NC-EWDP-09SX & 81 & 28.4 & 8.0 & 20.3 & 7.7 & 76 & 4.3 & 11.0 & 61.7 & 212.3 & 0.0 & 2.2 & 52.7 \\
\hline NC-EWDP-9SX Zone 1 & 82 & 26.0 & 8.3 & 17.5 & 5.8 & 76.5 & 5.5 & 15.0 & 57.5 & 193.5 & 1.9 & 2.2 & 40.5 \\
\hline NC-EWDP-9SX Zone 2 & 83 & 27.6 & 7.9 & 18.0 & 7.2 & 73.0 & 4.5 & 11.3 & 59.3 & 203.5 & 0.0 & 2.1 & 44.7 \\
\hline NC-EWDP-9SX Zone 3 & 84 & 27.5 & 8.1 & 17.5 & 7.1 & 71.5 & 4.2 & 10.0 & 58.0 & 207.0 & 0.0 & 2.2 & 42.5 \\
\hline NC-EWDP-9SX Zone 4 & 85 & 27.9 & 8.0 & 18.3 & 7.2 & 70.3 & 3.8 & 9.9 & 58.3 & 208.7 & 0.0 & 2.1 & 46.3 \\
\hline NC-EWDP-03D & 86 & 34.3 & 8.4 & 0.5 & 0.1 & 113.0 & 3.0 & 9.0 & 45.0 & 223.3 & 6.2 & 2.9 & 54.0 \\
\hline NC-EWDP-3S Zone 2 & 87 & 32.2 & 8.7 & 0.8 & 0.1 & 127.5 & 1.8 & 18.0 & 47.5 & 224.5 & 11.7 & 3.0 & 59.0 \\
\hline NC-EWDP-3S Zone 3 & 88 & 32.4 & 8.9 & 0.8 & 0.1 & 134.7 & 3.0 & 10.2 & 47.3 & 255.5 & 23.5 & 4.2 & 47.7 \\
\hline CIND-R-LITE & 89 & $50.0^{b}$ & 7.8 & 12.3 & 6.2 & 71.7 & 4.0 & 9.2 & 46.0 & 193.7 & 0.0 & 2.5 & 54.3 \\
\hline NC-EWDP-15P & 90 & 29.9 & 7.8 & 10.0 & 2.5 & 80.0 & 3.3 & 8.7 & 44.0 & 188.0 & 0.0 & 2.2 & 49.3 \\
\hline NC-EWDP-02D & 91 & - & 7.5 & 19.0 & 1.2 & 42.0 & 4.1 & 6.1 & 22.0 & 149.0 & 0.0 & 1.6 & 49.0 \\
\hline NC-EWDP-19D & 92 & 30.2 & 8.7 & 1.8 & 0.1 & 107.8 & 3.6 & 6.2 & 27.8 & 219.3 & 13.5 & 2.2 & 61.0 \\
\hline NC-EWDP-19P & 93 & 29.2 & 8.7 & 14.0 & 0.9 & 44.0 & 3.7 & 8.9 & 24.0 & 110.0 & 7.4 & 1.7 & 57.0 \\
\hline NC-EWDP-19D (alluvial) & 94 & 30.9 & 8.6 & 2.3 & 0.2 & 96.5 & 3.4 & 6.3 & 22.0 & 202.5 & 17.5 & 2.2 & 57.0 \\
\hline NC-EWDP-19D (zone \#1) & 95 & 32.0 & 8.6 & 3.7 & 0.3 & 91.5 & 3.7 & 6.1 & 22.0 & 189.0 & 12.5 & 2.0 & 58.0 \\
\hline NC-EWDP-19D (zone \#2) & 96 & 28.9 & 8.3 & 10.7 & 1.0 & 60.5 & 3.8 & 6.3 & 21.5 & 153.0 & 0.0 & 1.7 & 60.5 \\
\hline NC-EWDP-19D (zone \#3) & 97 & 30.8 & 8.5 & 1.3 & 0.1 & 99.0 & 3.2 & 6.3 & 26.0 & 204.0 & 7.4 & 2.0 & 55.0 \\
\hline
\end{tabular}


Table A6-1. Field Parameters and Major Ion Composition (Continued)

\begin{tabular}{|c|c|c|c|c|c|c|c|c|c|c|c|c|c|}
\hline Well Name ${ }^{\mathrm{a}}$ & $\begin{array}{c}\text { Figure } \\
\text { A6-5 } \\
\text { Sample }\end{array}$ & $\begin{array}{c}\text { Temperature } \\
\left({ }^{\circ} \mathrm{C}\right)\end{array}$ & pH & $\begin{array}{c}\mathrm{Ca}^{2+} \\
(\mathrm{mg} / \mathrm{L})\end{array}$ & $\begin{array}{c}\mathrm{Mg}^{2+} \\
(\mathrm{mg} / \mathrm{L})\end{array}$ & $\underset{(\mathrm{mg} / \mathrm{L})}{\mathrm{Na}^{+}}$ & $\underset{(\mathrm{mg} / \mathrm{L})}{\mathrm{K}^{+}}$ & $\begin{array}{c}\mathrm{Cl}^{-} \\
(\mathrm{mg} / \mathrm{L})\end{array}$ & $\begin{array}{l}\mathrm{SO}_{4}{ }^{2-} \\
(\mathrm{mg} / \mathrm{L})\end{array}$ & $\begin{array}{l}\mathrm{HCO}_{3}^{-} \\
\text {(mg/L) }\end{array}$ & $\begin{array}{l}\mathrm{CO}_{3}{ }^{2-} \\
(\mathrm{mg} / \mathrm{L})\end{array}$ & $\begin{array}{c}\mathrm{F}^{-} \\
(\mathrm{mg} / \mathrm{L})\end{array}$ & $\begin{array}{c}\mathrm{SiO}_{2} \\
\text { (mg/L) }\end{array}$ \\
\hline \multicolumn{14}{|c|}{ Southern Yucca Mountain Continued } \\
\hline NC-EWDP-19D (zone \#4) & 98 & 31.3 & 8.9 & 0.9 & 0.0 & 107.3 & 3.4 & 5.6 & 18.7 & 212.0 & 21.5 & 2.7 & 59.7 \\
\hline \multicolumn{14}{|l|}{ Amargosa Valley } \\
\hline NC-EWDP-4PB & 99 & 24.2 & 9.5 & 6.7 & 0.0 & 67.0 & 1.9 & 5.5 & 34.7 & 63.0 & 40.7 & 1.7 & 32.0 \\
\hline NC-EWDP-4PA & 100 & 24.3 & 8.2 & 12.5 & 0.3 & 55.0 & 2.9 & 7.4 & 52.5 & 108.5 & 0.0 & 1.2 & 32.5 \\
\hline Desert Farms Garlic Plot & 101 & 26.2 & 7.8 & 30.0 & 2.1 & 71.0 & 5.1 & 13.0 & 117.0 & 125.0 & 0.0 & 0.8 & 40.0 \\
\hline 15S/49E-13dda & 102 & - & - & - & - & - & - & - & - & - & - & - & - \\
\hline $15 \mathrm{~S} / 50 \mathrm{E}-18 \mathrm{ccc}$ & 103 & - & 8.4 & 16.8 & 0.5 & 93.1 & 3.9 & 13.1 & 100 & 157 & 0.0 & 2.1 & 34.3 \\
\hline NDOT & 104 & 27.3 & 8.0 & 16.3 & 0.8 & 101.3 & 3.8 & 14.7 & 110.0 & 160.0 & 0.0 & 1.9 & 43.7 \\
\hline 15S/50E-18cdc & 105 & 25.1 & 8.0 & 12.0 & 0.5 & 93.0 & 3.9 & 13.1 & 100.0 & 157.0 & 0.0 & 1.9 & 34.0 \\
\hline Airport Well & 106 & 27.6 & 8.7 & 5.6 & 0.1 & 69.0 & 1.5 & 6.6 & 45.0 & 116.0 & 6.2 & 1.8 & 38.0 \\
\hline 15S/50E-19b1 & 107 & 23.9 & 8.1 & 20.0 & 3.9 & 107.5 & 6.0 & 17.5 & 127.5 & 167.5 & 0.0 & 1.4 & 43.0 \\
\hline \multicolumn{14}{|l|}{ Amargosa River } \\
\hline $16 \mathrm{~S} / 48 \mathrm{E}-8 \mathrm{ba}$ & 108 & 25.0 & 7.9 & 58.5 & 6.3 & 180.5 & 12.9 & 79.8 & 202.7 & 295.9 & 0.0 & - & 37.9 \\
\hline $16 \mathrm{~S} / 48 \mathrm{E}-7 \mathrm{bba}$ & 109 & 24.7 & 7.4 & 52.9 & 9.5 & 140.0 & 10.2 & 63.1 & 179.6 & 250.8 & 0.0 & - & 69.1 \\
\hline $16 \mathrm{~S} / 48 \mathrm{E}-7 \mathrm{cbc}$ & 110 & 24.2 & 7.7 & 46.9 & 16.0 & 130.1 & 9.4 & 62.0 & 179.6 & 239.2 & 0.0 & - & 64.3 \\
\hline $16 \mathrm{~S} / 48 \mathrm{E}-18 \mathrm{bcc}$ & 111 & - & 8.0 & 54.9 & 10.9 & 150.1 & 11.7 & 61.0 & 190.2 & 271.5 & 0.0 & - & 79.9 \\
\hline $16 \mathrm{~S} / 48 \mathrm{E}-17 \mathrm{ccc}$ & 112 & - & 7.7 & 66.1 & 10.9 & 169.9 & 12.1 & 83.0 & 235.3 & 239.2 & 0.0 & - & 77.5 \\
\hline 16S/48E-18dad & 113 & - & 7.7 & 52.9 & 8.5 & 149.9 & 10.6 & 63.1 & 187.3 & 236.1 & 0.0 & - & 76.9 \\
\hline $16 \mathrm{~S} / 48 \mathrm{E}-8 \mathrm{cda}$ & 114 & 23.3 & 7.6 & 48.1 & 6.8 & 160.0 & 10.2 & 67.0 & 179.6 & 264.2 & 0.0 & - & 67.9 \\
\hline $16 \mathrm{~S} / 48 \mathrm{E}-17 \mathrm{abb}$ & 115 & 24.0 & 7.4 & 60.1 & 7.8 & 157.0 & 12.1 & 69.1 & 178.7 & 302.0 & 0.0 & - & 75.1 \\
\hline Barrachman Dom/Irr. & 116 & 19.0 & 7.5 & 53.0 & 12.0 & 128.0 & 10.0 & 62.0 & 179.0 & 286.0 & 0.0 & 1.8 & 66.0 \\
\hline McCracken Domestic & 117 & 21.7 & 7.5 & 83.0 & 12.0 & 194.0 & 12.0 & 123.0 & 266.0 & 243.0 & 0.0 & 1.7 & 73.0 \\
\hline \multicolumn{14}{|l|}{ Fortymile Wash-West } \\
\hline $16 \mathrm{~S} / 48 \mathrm{E}-15 \mathrm{ba}$ & 118 & 25.0 & 8.0 & 60.1 & 7.8 & 147.1 & 9.8 & 65.6 & 198.8 & 264.2 & 0.0 & - & 37.3 \\
\hline $16 \mathrm{~S} / 48 \mathrm{E}-10 \mathrm{cba}$ & 119 & 24.5 & 8.3 & 9.2 & 3.9 & 60.9 & 5.5 & 8.2 & 32.7 & 166.0 & 0.0 & - & 64.3 \\
\hline 16S/48E-15aaa & 120 & 25.5 & 8.1 & 9.6 & 3.2 & 57.9 & 5.9 & 7.4 & 27.9 & 153.2 & 0.0 & - & 67.9 \\
\hline Selbach Domestic & 121 & 23.9 & 8.0 & 23.0 & 8.1 & 90.0 & 6.6 & 36.0 & 96.0 & 178.0 & 0.0 & 1.4 & 68.0 \\
\hline
\end{tabular}


Table A6-1. Field Parameters and Major Ion Composition (Continued)

\begin{tabular}{|c|c|c|c|c|c|c|c|c|c|c|c|c|c|}
\hline Well Name ${ }^{a}$ & $\begin{array}{c}\text { Figure } \\
\text { A6-5 } \\
\text { Sample }\end{array}$ & $\begin{array}{c}\text { Temperature } \\
\left({ }^{\circ} \mathrm{C}\right)\end{array}$ & $\mathrm{pH}$ & $\begin{array}{c}\mathrm{Ca}^{2+} \\
(\mathrm{mg} / \mathrm{L})\end{array}$ & $\begin{array}{c}\mathrm{Mg}^{2+} \\
(\mathrm{mg} / \mathrm{L})\end{array}$ & $\begin{array}{c}\mathrm{Na}^{+} \\
(\mathrm{mg} / \mathrm{L})\end{array}$ & $\begin{array}{c}\mathrm{K}^{+} \\
(\mathrm{mg} / \mathrm{L})\end{array}$ & $\begin{array}{c}\mathrm{Cl}^{-} \\
(\mathrm{mg} / \mathrm{L})\end{array}$ & $\begin{array}{c}\mathrm{SO}_{4}{ }^{2-} \\
(\mathrm{mg} / \mathrm{L})\end{array}$ & $\begin{array}{l}\mathrm{HCO}_{3}{ }^{-} \\
\text {(mg/L) }\end{array}$ & $\begin{array}{c}\mathrm{CO}_{3}{ }^{2-} \\
(\mathrm{mg} / \mathrm{L})\end{array}$ & $\begin{array}{c}F^{-} \\
(\mathrm{mg} / \mathrm{L})\end{array}$ & $\begin{array}{c}\mathrm{SiO}_{2} \\
\text { (mg/L) }\end{array}$ \\
\hline \multicolumn{14}{|c|}{ Fortymile Wash-West Continued } \\
\hline 16S/48E-15dda & 122 & - & 8.0 & 20.0 & 5.8 & 70.8 & 7.4 & 17.4 & 37.5 & 175.7 & 0.0 & - & 71.5 \\
\hline 16S/49E-23add & 123 & - & 8.2 & 16.0 & 1.7 & 55.9 & 6.6 & 8.9 & 34.6 & 126.9 & 0.0 & - & 76.3 \\
\hline 16S/48E-23bdb & 124 & 24.0 & 7.3 & 9.2 & 1.0 & 66.0 & 6.6 & 8.9 & 26.9 & 156.2 & 0.0 & - & 73.9 \\
\hline 16S/48E-23da & 125 & 27.8 & 8.2 & 22.0 & 2.2 & 69.0 & 6.6 & 26.6 & 67.2 & 134.2 & 0.0 & - & - \\
\hline Funeral Mountain Ranch Irrig. & 126 & 22.2 & 8.2 & 12.0 & 2.4 & 80.0 & 7.0 & 12.0 & 43.0 & 200.0 & 0.0 & 2.3 & 87.0 \\
\hline \multicolumn{14}{|l|}{ Fortymile Wash-South } \\
\hline 16S/49E-05acc & 127 & - & 8.1 & 29.0 & 2.2 & 35.0 & 5.1 & 6.0 & 26.0 & 135.0 & 0.0 & 1.0 & 62.0 \\
\hline 16S/49E-8abb & 128 & 23.0 & 7.5 & 30.1 & 2.7 & 37.0 & 5.5 & 7.8 & 29.8 & 151.9 & 0.0 & - & 54.1 \\
\hline 16S/49E-8acc & 129 & 25.8 & 7.9 & 22.8 & 2.4 & 37.0 & 6.6 & 6.0 & 28.8 & 137.9 & 0.0 & - & 58.3 \\
\hline 16S/49E-18dc & 130 & - & 8.1 & 20.0 & 2.7 & 42.1 & 9.0 & 7.4 & 27.9 & 150.1 & 0.0 & - & 58.9 \\
\hline 16s/48E-24aaa & 131 & 27.0 & 8.1 & 18.0 & 0.7 & 54.0 & 7.0 & 7.8 & 29.8 & 147.1 & 0.0 & - & 78.7 \\
\hline 16S/49E-19daa & 132 & 26.4 & 8.2 & 24.0 & 1.2 & 36.1 & 8.2 & 6.7 & 32.7 & 134.2 & 0.0 & - & 75.1 \\
\hline DeLee Large Irrigation & 133 & 14.6 & 8.0 & 24.0 & 1.1 & 37.0 & 8.4 & 6.2 & 25.0 & 135.0 & 0.0 & 1.1 & 76.5 \\
\hline 16S/48E-25aa & 134 & 26.5 & 8.1 & 18.8 & 0.7 & 43.0 & 7.4 & 9.2 & 27.9 & 133.0 & 0.0 & - & 72.1 \\
\hline 16S/48E-36aaa & 135 & - & 8.4 & 16.8 & 1.9 & 40.0 & 6.3 & 6.7 & 25.0 & 133.0 & 0.0 & - & 78.7 \\
\hline Bray Domestic & 136 & 20.9 & 8.0 & 22.0 & 1.8 & 35.0 & 8.8 & 7.9 & 25.0 & 131.0 & 0.0 & 1.0 & 74.0 \\
\hline Amargosa Estates \#2 & 137 & 24.0 & 8.1 & 20.0 & 2.1 & 38.0 & 6.8 & 6.5 & 22.0 & 134.0 & 0.0 & 1.6 & 79.0 \\
\hline 17S/48E-1ab & 138 & - & 8.2 & 18.8 & 1.5 & 40.0 & 7.0 & 6.4 & 25.0 & 134.9 & 0.0 & - & 78.7 \\
\hline 17S/49E-7bb & 139 & - & 8.3 & 24.0 & 1.7 & 48.0 & 7.4 & 9.6 & 30.7 & 153.2 & 0.0 & - & 79.9 \\
\hline 17S/49E-8ddb & 140 & 24.0 & 8.4 & 20.8 & 2.7 & 36.1 & 7.4 & 6.4 & 26.9 & 123.3 & 0.0 & - & 80.8 \\
\hline 17S/49E-35ddd & 141 & 23.0 & 8.0 & 15.2 & 4.6 & 50.6 & 8.2 & 6.7 & 40.3 & 157.4 & 0.0 & - & 81.1 \\
\hline \multicolumn{14}{|l|}{ Fortymile Wash-East } \\
\hline 15S/49E-22a1 & 142 & 27.8 & 8.0 & 25.0 & 2.4 & 41.0 & 5.2 & 8.0 & 33.0 & 145.0 & 0.0 & 1.4 & 52.0 \\
\hline 15S/49E-22dcc & 143 & 29.5 & 6.7 & 27.0 & 2.0 & 43.0 & 4.6 & 8.5 & 33.0 & 149.0 & 0.0 & 1.0 & 49.0 \\
\hline 15S/49E-27acc & 144 & 44.1 & 7.8 & 22.0 & 1.6 & 48.0 & 2.9 & 7.3 & 36.0 & 151.0 & 0.0 & 0.9 & 19.0 \\
\hline O'Neill Domestic & 145 & 19.5 & 7.9 & 26.0 & 2.4 & 44.0 & 7.6 & 7.4 & 43.0 & 141.0 & 0.0 & 0.8 & 65.0 \\
\hline 16S/49E-9cda & 146 & 24.0 & 7.6 & 30.5 & 3.4 & 51.0 & 8.6 & 12.1 & 64.4 & 143.4 & 0.0 & - & 65.5 \\
\hline
\end{tabular}


Table A6-1. Field Parameters and Major Ion Composition (Continued)

\begin{tabular}{|c|c|c|c|c|c|c|c|c|c|c|c|c|c|}
\hline Well Name ${ }^{a}$ & $\begin{array}{c}\text { Figure } \\
\text { A6-5 } \\
\text { Sample }\end{array}$ & $\begin{array}{c}\text { Temperature } \\
\left({ }^{\circ} \mathrm{C}\right)\end{array}$ & $\mathrm{pH}$ & $\begin{array}{c}\mathrm{Ca}^{2+} \\
(\mathrm{mg} / \mathrm{L})\end{array}$ & $\begin{array}{c}\mathrm{Mg}^{2+} \\
(\mathrm{mg} / \mathrm{L})\end{array}$ & $\begin{array}{c}\mathrm{Na}^{+} \\
(\mathrm{mg} / \mathrm{L})\end{array}$ & $\begin{array}{c}\mathrm{K}^{+} \\
(\mathrm{mg} / \mathrm{L})\end{array}$ & $\begin{array}{c}\mathrm{Cl}^{-} \\
(\mathrm{mg} / \mathrm{L})\end{array}$ & $\begin{array}{c}\mathrm{SO}_{4}{ }^{2-} \\
(\mathrm{mg} / \mathrm{L})\end{array}$ & $\begin{array}{l}\mathrm{HCO}_{3}{ }^{-} \\
\text {(mg/L) }\end{array}$ & $\begin{array}{c}\mathrm{CO}_{3}{ }^{2-} \\
(\mathrm{mg} / \mathrm{L})\end{array}$ & $\begin{array}{c}F^{-} \\
(\mathrm{mg} / \mathrm{L})\end{array}$ & $\begin{array}{c}\mathrm{SiO}_{2} \\
\text { (mg/L) }\end{array}$ \\
\hline \multicolumn{14}{|c|}{ Fortymile Wash-East Continued } \\
\hline 16S/49E-9dcc & 147 & 23.3 & 8.2 & 22.8 & 2.7 & 56.1 & 9.0 & 9.9 & 67.2 & 140.9 & 0.0 & - & 72.1 \\
\hline 16S/49E-16ccc & 148 & - & 7.9 & 30.1 & 1.9 & 39.8 & 4.3 & 8.2 & 50.9 & 132.4 & 0.0 & - & 76.9 \\
\hline Ponderosa Dairy \#1 & 149 & 28.3 & 8.0 & 30.0 & 4.5 & 59.0 & 11.0 & 16.0 & 93.0 & 145.0 & 0.0 & 1.2 & 74.0 \\
\hline 17S/49E-9aa & 150 & - & 8.0 & 24.8 & 3.6 & 48.0 & 9.8 & 9.9 & 69.2 & 131.2 & 0.0 & - & 70.3 \\
\hline 17S/49E-15bbd & 151 & 22.5 & 8.1 & 20.8 & 3.9 & 31.3 & 8.2 & 9.9 & 34.6 & 120.2 & 0.0 & - & 72.7 \\
\hline M. Gilgan Well & 152 & 24.5 & 8.2 & 19.0 & 2.3 & 41.0 & 7.5 & 8.0 & 28.0 & 129.0 & 0.0 & 1.6 & 77.0 \\
\hline 17S/49E-15bc & 153 & 24.0 & 8.2 & 21.6 & 1.0 & 39.1 & 6.6 & 10.6 & 27.9 & 122.0 & 0.0 & - & - \\
\hline \multicolumn{14}{|l|}{ Gravity fault } \\
\hline NC-EWDP-5S & 154 & - & 8.3 & 17.0 & 3.5 & 149.0 & 11.0 & 39.0 & 146.0 & - & - & 1.0 & 3.7 \\
\hline NC-EWDP-5SB & 155 & 23.4 & 7.6 & 14.0 & 1.7 & 107.0 & 6.9 & 32.0 & 61.0 & 211.0 & 0.0 & 1.2 & 21.0 \\
\hline 16S/50E-7bcd & 156 & 30.6 & 7.6 & 47.7 & 17.5 & 111.5 & 12.9 & 29.1 & 151.8 & 291.7 & 0.0 & - & 28.8 \\
\hline Nelson Domestic & 157 & 29.4 & 7.5 & 43.0 & 16.0 & 110.0 & 11.5 & 26.5 & 154.0 & 308.0 & 0.0 & 3.8 & 25.5 \\
\hline 16S/49E-12ddd & 158 & - & 7.6 & 45.7 & 17.0 & 120.0 & 4.3 & 24.1 & 160.4 & 288.6 & 0.0 & - & 20.4 \\
\hline Lowe Domestic & 159 & 18.5 & 7.7 & 44.0 & 11.0 & 111.0 & 11.0 & 30.0 & 147.0 & 274.0 & 0.0 & 1.4 & 43.0 \\
\hline 16S/49E-15aaa & 160 & 23.8 & 7.7 & 40.9 & 7.5 & 80.0 & 9.8 & 23.0 & 129.7 & 195.3 & 0.0 & - & 46.3 \\
\hline Anvil Ranch Irrigation & 161 & 20.5 & 7.9 & 47.0 & 5.8 & 68.0 & 13.0 & 40.0 & 120.0 & 138.0 & 0.0 & 1.1 & 71.0 \\
\hline 16S/49E-36aaa & 162 & - & 7.8 & 52.1 & 22.1 & 120.0 & 18.0 & 26.9 & 168.1 & 314.3 & 0.0 & - & 37.9 \\
\hline 16S/49E-35baa & 163 & 24.0 & 7.4 & 53.3 & 18.0 & 113.1 & 13.3 & 31.2 & 170.0 & 302.7 & 0.0 & - & 37.9 \\
\hline Payton Domestic & 164 & 20.2 & 7.6 & 51.0 & 19.0 & 107.0 & 16.0 & 41.0 & 155.0 & 290.0 & 0.0 & 3.9 & 36.0 \\
\hline 16S/49E-36aba & 165 & - & 7.7 & 44.9 & 19.9 & 110.1 & 16.8 & 24.1 & 155.6 & 292.9 & 0.0 & - & 42.7 \\
\hline 16S/49E-35aaa & 166 & - & 7.7 & 44.1 & 16.0 & 120.0 & 16.0 & 29.1 & 147.9 & 271.5 & 0.0 & - & 36.7 \\
\hline Oettinger Well & 167 & 25.2 & 7.5 & 50.0 & 16.0 & 103.0 & 15.0 & 29.0 & 157.0 & 291.0 & 0.0 & 3.3 & 39.0 \\
\hline Amargosa Motel (b) & 168 & 24.0 & 7.6 & 49.5 & 18.0 & 97.5 & 14.0 & 27.0 & 151.0 & 286.0 & 0.0 & 3.0 & 43.5 \\
\hline 17S/49E-11ba & 169 & 22.0 & 8.1 & 40.1 & 14.1 & 97.0 & 14.1 & 28.0 & 160.4 & 209.9 & 0.0 & - & 52.9 \\
\hline Spring Meadows Well \#8 & 170 & 21.0 & - & 22.0 & 10.9 & 110.0 & 14.9 & 21.9 & 73.9 & 295.8 & - & 2.1 & 31.0 \\
\hline 17S/50E-19aab & 171 & 16.0 & 8.6 & 7.6 & 8.5 & 252.0 & 27.4 & 69.8 & 175.8 & 415.5 & 0.0 & - & 42.7 \\
\hline USFWS - Five Springs Well & 172 & 33.5 & 7.5 & 47.0 & 20.0 & 67.5 & 7.9 & 23.3 & 82.0 & 304.0 & - & 1.6 & 21.8 \\
\hline
\end{tabular}


Table A6-1. Field Parameters and Major Ion Composition (Continued)

\begin{tabular}{|c|c|c|c|c|c|c|c|c|c|c|c|c|c|}
\hline Well Name ${ }^{a}$ & $\begin{array}{c}\text { Figure } \\
\text { A6-5 } \\
\text { Sample }\end{array}$ & $\begin{array}{c}\text { Temperature } \\
\left({ }^{\circ} \mathrm{C}\right)\end{array}$ & $\mathrm{pH}$ & $\begin{array}{c}\mathrm{Ca}^{2+} \\
(\mathrm{mg} / \mathrm{L})\end{array}$ & $\begin{array}{c}\mathrm{Mg}^{2+} \\
(\mathrm{mg} / \mathrm{L})\end{array}$ & $\begin{array}{c}\mathrm{Na}^{+} \\
(\mathrm{mg} / \mathrm{L})\end{array}$ & $\begin{array}{c}\mathrm{K}^{+} \\
(\mathrm{mg} / \mathrm{L})\end{array}$ & $\begin{array}{c}\mathrm{Cl}^{-} \\
(\mathrm{mg} / \mathrm{L})\end{array}$ & $\begin{array}{l}\mathrm{SO}_{4}{ }^{2-} \\
(\mathrm{mg} / \mathrm{L})\end{array}$ & $\begin{array}{l}\mathrm{HCO}_{3}^{-} \\
\text {(mg/L) }\end{array}$ & $\begin{array}{l}\mathrm{CO}_{3}{ }^{2-} \\
(\mathrm{mg} / \mathrm{L})\end{array}$ & $\begin{array}{c}\mathrm{F}^{-} \\
(\mathrm{mg} / \mathrm{L})\end{array}$ & $\begin{array}{c}\mathrm{SiO}_{2} \\
(\mathrm{mg} / \mathrm{L})\end{array}$ \\
\hline \multicolumn{14}{|l|}{ Gravity fault Continued } \\
\hline Spring Meadows Well \#10 & 173 & 19.5 & - & 2.8 & 2.9 & 250.0 & 14.9 & 25.8 & 105.1 & 494.0 & - & 3.2 & 67.0 \\
\hline 18S/49E-1aba & 174 & 17.5 & 8.6 & 24.0 & 11.9 & 94.9 & 19.2 & 18.1 & 99.9 & 263.0 & 0.0 & - & 72.7 \\
\hline 18S/50E-6dac & 175 & - & 8.2 & 23.6 & 11.9 & 102.5 & 13.7 & 20.6 & 106.6 & 230.0 & 0.0 & - & 80.5 \\
\hline 18S/50E-7aa & 176 & 13.0 & 8.4 & 25.7 & 9.5 & 140.9 & 19.2 & 37.6 & 147.0 & 261.2 & 0.0 & - & 47.5 \\
\hline \multicolumn{14}{|c|}{ Amargosa River/Fortymile Wash } \\
\hline $16 \mathrm{~S} / 48 \mathrm{E}-36 \mathrm{dcc}$ & 177 & 26.0 & 7.2 & 54.9 & 9.7 & 100.0 & 12.9 & 33.0 & 110.5 & 300.2 & 0.0 & - & 70.3 \\
\hline
\end{tabular}

Crane Domestic

27N/4E-27bbb

IMV on Windjammer

17S/49E-29acc

$17 \mathrm{~S} / 49 \mathrm{E}-28 \mathrm{bcd}$

18S/49E-2cbc

Mom's Place

18S/49E-11bbb

Skeleton Hills

TW-5

Unnamed Well 15S/50E-22-7

\begin{tabular}{|c|c|c|}
\hline 178 & 26.3 & \\
\hline 179 & 22.0 & \\
\hline 180 & 23.5 & \\
\hline 181 & 21.0 & \\
\hline 182 & - & \\
\hline 183 & 23.8 & \\
\hline 184 & 22.8 & \\
\hline 185 & 25.0 & \\
\hline
\end{tabular}

\begin{tabular}{l|l}
7.2 & 64.0 \\
\hline 7.8 & 58.1 \\
\hline
\end{tabular}

Amargosa Fla

Amargosa Tracer Hole \#2

Cherry Patch Well, 17S/52E-08cdb

USDOE-MSH-C shallow Well

\begin{tabular}{l|l}
\hline .5 & 45.0 \\
\hline
\end{tabular}

$19.0 \quad 134.0$

\begin{tabular}{|l|l|l|}
19.0 & 134.0 & 19.2 \\
\hline
\end{tabular}

\section{Mine Mountain}

UE-17a

UE-1a

UE-1b

UE-16f

UE-14b

\begin{tabular}{l|r}
\hline 186 & 30.0 \\
\hline 187 & \\
\hline
\end{tabular}

\begin{tabular}{l|l}
30.0 & 7. \\
- & 6.
\end{tabular}

\begin{tabular}{l|l|l|l|l|l|l|}
7.6 & 54.1 & 15.1 & 160.0 & 19.9 & 69.8 & 186.4 \\
\hline
\end{tabular}

\begin{tabular}{l|l}
7.6 & 42.9 \\
\hline
\end{tabular}

\begin{tabular}{l|l|}
\hline 0 & 100.0 \\
\hline
\end{tabular}

\begin{tabular}{|c|c|c|c|c|c|c}
7.8 & 28.9 & 11.9 & 120.0 & 9.8 & 19.9 & 74.0 \\
\hline 7.8 & 27.0 & 6.7 & 77.0 & 9.4 & 14.0 & 55.0
\end{tabular}

\begin{tabular}{c|c|c|c|c|c|c|}
7.8 & 28.9 & 11.9 & 120.0 & 9.8 & 19.9 & 74.0 \\
\hline 7.8 & 27.0 & 6.7 & 77.0 & 9.4 & 14.0 & 55.0 \\
\hline
\end{tabular}

\begin{tabular}{l|l}
6.7 & 1 \\
8.5 & 9
\end{tabular}

\begin{tabular}{c|c|c|}
77.0 & 9.4 & 14.0 \\
\hline 9.1 & 11.7 & 30.8
\end{tabular}

55.0
90.3

\begin{tabular}{|l|l|l|l|l|}
\hline 0 & 451.0 & 0.0 & 3.3 & 45.0 \\
\hline 6 & 438.1 & 0.0 & - & 72.1 \\
\hline .0 & 303.0 & 0.0 & 2.8 & 67.5 \\
\hline 3 & 275.8 & 0.0 & - & 72.1 \\
\hline 0 & 294.7 & 0.0 & - & 70.3 \\
\hline 0 & 352.1 & 0.0 & - & 58.9 \\
\hline 3 & 236.0 & 0.0 & 2.6 & 75.0 \\
\hline
\end{tabular}

7.9

\begin{tabular}{|l|l|}
\hline 33.0 & 17.0 \\
\hline 27.0 & 2.0 \\
\hline
\end{tabular}

\begin{tabular}{|c|c|c|}
\hline 17.0 & 130.0 & 12.0 \\
\hline 2.0 & 43.0 & 4.6
\end{tabular}

\begin{tabular}{|c|c|c|c|c|c|c|}
\hline .0 & 21.0 & 99.0 & 395.0 & 0.0 & 3.4 & 19.0 \\
\hline .6 & 8.5 & 33.0 & 148.8 & - & 0.9 & 49.0 \\
\hline
\end{tabular}

\begin{tabular}{|l|l|l|l|l|c|c|c|c|c|c|c|c|}
\hline 188 & 30.5 & 8.0 & 42.8 & 18.5 & 63.8 & 7.5 & 21.0 & 68.7 & 279.2 & - & 1.9 & 22.0 \\
\hline 189 & 26.2 & 7.3 & 76.0 & 38.8 & 272.5 & 9.6 & 122.5 & 485.0 & 344.7 & - & 1.7 & 25.5 \\
\hline 190 & 20.5 & 8.0 & 16.0 & 17.0 & 81.0 & 9.4 & 17.0 & 58.0 & 261.0 & - & 1.7 & 34.0 \\
\hline
\end{tabular}

\begin{tabular}{|c|c|c|c|c|c|c|c|c|c|c|c|c|}
191 & 27.0 & 7.6 & 41.0 & 29.9 & 80.0 & 3.0 & 27.7 & 95.5 & 200.0 & - & 0.9 & 11.8 \\
\hline 192 & 25.4 & 7.4 & 48.5 & 23.9 & 50.5 & 8.7 & 26.3 & - & 402.5 & & - & 19.3 \\
\hline 193 & 27.4 & 7.4 & 37.4 & 13.7 & 31.3 & 10.7 & 5.9 & - & 184.0 & & - & 80.9 \\
\hline 194 & 29.4 & 8.9 & 1.8 & 1.9 & 421.2 & 5.0 & 18.8 & 423.0 & 900.0 & 33.0 & 5.2 & 4.5 \\
\hline 195 & - & 8.4 & 10.5 & 0.2 & 77.5 & 1.5 & 7.1 & 80.8 & 116.0 & & - & 43.8 \\
\hline
\end{tabular}


Table A6-1. Field Parameters and Major Ion Composition (Continued)

\begin{tabular}{|c|c|c|c|c|c|c|c|c|c|c|c|c|c|}
\hline Well Name ${ }^{a}$ & $\begin{array}{c}\text { Figure } \\
\text { A6-5 } \\
\text { Sample }\end{array}$ & $\begin{array}{c}\text { Temperature } \\
\left({ }^{\circ} \mathrm{C}\right)\end{array}$ & $\mathrm{pH}$ & $\begin{array}{c}\mathrm{Ca}^{2+} \\
(\mathrm{mg} / \mathrm{L})\end{array}$ & $\begin{array}{c}\mathrm{Mg}^{2+} \\
(\mathrm{mg} / \mathrm{L})\end{array}$ & $\begin{array}{c}\mathrm{Na}^{+} \\
(\mathrm{mg} / \mathrm{L})\end{array}$ & $\begin{array}{c}\mathrm{K}^{+} \\
(\mathrm{mg} / \mathrm{L})\end{array}$ & $\begin{array}{c}\mathrm{Cl}^{-} \\
(\mathrm{mg} / \mathrm{L})\end{array}$ & $\begin{array}{c}\mathrm{SO}_{4}{ }^{2-} \\
(\mathrm{mg} / \mathrm{L})\end{array}$ & $\begin{array}{l}\mathrm{HCO}_{3}{ }^{-} \\
(\mathrm{mg} / \mathrm{L})\end{array}$ & $\begin{array}{l}\mathrm{CO}_{3}{ }^{2-} \\
(\mathrm{mg} / \mathrm{L})\end{array}$ & $\begin{array}{c}F^{-} \\
(\mathrm{mg} / \mathrm{L})\end{array}$ & $\begin{array}{c}\mathrm{SiO}_{2} \\
\text { (mg/L) }\end{array}$ \\
\hline \multicolumn{14}{|l|}{ Mine Mountain Continued } \\
\hline Pluto 1 & 196 & - & 8.0 & 40.5 & 9.8 & 36.2 & 7.7 & 23.7 & 46.9 & 150.0 & - & - & 54.0 \\
\hline Pluto 5 & 197 & - & 7.9 & 55.0 & 21.6 & 26.4 & 4.3 & 11.5 & 54.2 & 218.0 & - & - & 58.0 \\
\hline USGS Test Well F (HTH) & 198 & 64.5 & 6.9 & 46.0 & 16.7 & 63.0 & 9.1 & 12.9 & 79.3 & 254.2 & - & 3.2 & 36.4 \\
\hline \multicolumn{14}{|l|}{ Funeral Mountains } \\
\hline Woodcamp Spring & 199 & 19.2 & 7.2 & 23.0 & 3.3 & 38.0 & 14.0 & 24.0 & 24.0 & 122.0 & - & 0.2 & 57.0 \\
\hline Bond Gold Mining \#13 & 200 & 32.4 & 7.3 & 144.5 & 79.5 & 85.5 & 7.0 & 63.5 & 621.5 & 274.5 & 0.0 & 0.6 & 16.5 \\
\hline Nevares Spring & 201 & 39.4 & 7.4 & 42.0 & 20.0 & 140.0 & 11.0 & 37.0 & 170.0 & 353.0 & - & 3.2 & 26.0 \\
\hline Travertine Spring & 202 & 35.3 & 7.4 & 33.0 & 18.0 & 140.0 & 12.0 & 37.0 & 150.0 & 343.0 & - & 3.7 & 30.0 \\
\hline
\end{tabular}

DTNs: LA0309RR831233.001 [DIRS 166546]; LA0309RR831233.002 [DIRS 166548].

${ }^{a} \mathrm{dp}=$ deep sample, $\mathrm{sh}=$ shallow sample, $\mathrm{Tcp}=$ sample from Prow Pass tuff, $\mathrm{Tcb}=$ sample from Bullfrog tuff, bh = sample from entire borehole, '95 = sample from 1995, v = sample from volcanic aquifer, c = sample from carbonate aquifer, Tct = sample from Tram Member or Crater Flat tuff. Where not otherwise

indicated, sample is from entire open interval of borehole.
1 The groundwater temperature was estimated from the map of water table temperature shown in Fridrich et al. (1994 [DIRS 100575], Figure 8)

$\mathrm{N}$ c The groundwater temperature for this sample was assumed to be the same as for the c\#3 sample.

d The symbol "- -" indicates the data are not available. 
Table A6-2. Isotope and Trace Element Composition

\begin{tabular}{|c|c|c|c|c|c|c|c|c|c|c|c|}
\hline Well Name & $\begin{array}{c}\text { Figure } \\
\text { A6-5 } \\
\text { Sample }\end{array}$ & $\begin{array}{c}\delta^{13} \mathrm{C} \\
\text { (per mil) }\end{array}$ & $\begin{array}{c}{ }^{14} \mathrm{C} \\
\text { (pmc) }\end{array}$ & $\begin{array}{c}\delta D \\
\text { (per mil) }\end{array}$ & $\begin{array}{c}\delta^{18} \mathrm{O} \\
\text { (per mil) }\end{array}$ & $\begin{array}{c}\delta^{34} S \\
\text { (per mil) }\end{array}$ & $\underset{(\mu \mathrm{g})}{\mathrm{U}}$ & $\begin{array}{c}{ }^{234} \mathrm{U}^{238} \mathrm{U} \\
\text { (AR) }\end{array}$ & $\begin{array}{l}\mathrm{Sr}^{2+} \\
(\mu \mathrm{g})\end{array}$ & $\begin{array}{c}{ }^{87} \mathrm{Sr}^{86}{ }^{86} \mathrm{Sr} \\
\text { (ratio) }\end{array}$ & $\begin{array}{c}\delta^{87} \mathrm{Sr} \\
\text { (per mil) }\end{array}$ \\
\hline \multicolumn{12}{|l|}{ Oasis Valley/NW Amargosa } \\
\hline ER-EC-08 & 1 & -1.0 & 8.7 & -116.0 & -14.8 & - & 4.4 & - & - & 0.70864 & -0.8 \\
\hline ER-OV-01 & 2 & -2.0 & 5.0 & -112.5 & -14.7 & - & 9.4 & 3.7 & 4.9 & 0.71058 & 1.9 \\
\hline ER-OV-06a & 3 & -2.2 & 6.0 & -113.0 & -14.7 & - & 5.2 & 3.3 & 10.6 & 0.70932 & 0.2 \\
\hline ER-OV-05 & 4 & -3.1 & 17.3 & -106.0 & -13.7 & - & 2.2 & 2.8 & 192.0 & 0.70976 & 0.8 \\
\hline ER-OV-02 & 5 & -2.6 & 16.2 & -112.0 & -14.7 & - & 18.3 & 2.5 & 46.0 & 0.71006 & 1.2 \\
\hline Springdale Upper Well (10S/47E-32adc) & 6 & -1.7 & 10.8 & -104.0 & -13.9 & - & 2.6 & 5.4 & 291.0 & 0.71026 & 1.5 \\
\hline Goss Springs North (11S/47E-10bad) & 7 & -2.9 & 21.8 & -110.0 & -14.7 & - & 9.23 & 2.9 & 88.0 & 0.71039 & 1.7 \\
\hline Er-OV-03a & 8 & -3.0 & 16.3 & -111.0 & -14.7 & - & 9.1 & 2.9 & 75.2 & 0.71029 & 1.5 \\
\hline ER-OV-03a3 & 9 & -2.8 & 16.5 & -110.0 & -14.6 & - & 9.1 & 2.9 & 76.8 & 0.71003 & 1.2 \\
\hline ER-OV-03a2 & 10 & -5.0 & 21.0 & -109.0 & -14.5 & - & 9.8 & 5.4 & 167.0 & 0.70809 & -1.6 \\
\hline Goss Spring (11S/47E-10bcc) & 11 & - & 20.8 & -111.7 & -14.7 & - & 9.2 & 2.9 & 90.0 & 0.71050 & 1.8 \\
\hline ER-OV-04a & 12 & -3.4 & 8.0 & -109.5 & -14.8 & - & 3.0 & 3.0 & 22.0 & 0.71006 & 1.2 \\
\hline Beatty Well no. 1 (Wat \& Sanit Distr) & 13 & - & - & - & - & - & 8.8 & - & 155.3 & - & \\
\hline Bond Gold Mining \#1 & 14 & -8.8 & 12.8 & -100.0 & -13.8 & 15.7 & 0.1 & 3.5 & 150.0 & - & - \\
\hline US Ecology MW-313 & 15 & -6.1 & 17.0 & -109.0 & -14.1 & 21.8 & 7.8 & 3.2 & 361.0 & - & - \\
\hline US Ecology MW-600 & 16 & -8.4 & 19.3 & -108.3 & -14.4 & 19.5 & 4.9 & 2.5 & 340.0 & - & - \\
\hline NECWell & 17 & -5.9 & 28.8 & - & - & - & - & - & - & - & - \\
\hline US Ecology MR-3 & 18 & -6.5 & 323.0 & -109.0 & -14.5 & 20.1 & 6.5 & 3.2 & - & - & - \\
\hline \multicolumn{12}{|l|}{ Timber Mountain } \\
\hline UE-18r & 19 & -1.7 & 7.7 & -110.0 & -14.7 & - & 5.1 & 6.1 & 116.5 & 0.70903 & -0.2 \\
\hline ER-18-2 & 20 & -0.7 & 1.6 & -112.0 & -14.7 & - & 8.0 & 12.7 & 224.3 & 0.70872 & -0.7 \\
\hline ER-EC-05 & 21 & -2.5 & 6.3 & -113.0 & -14.9 & - & 3.2 & 6.4 & 140.1 & 0.70916 & -0.1 \\
\hline Coffer's Ranch Windmill Well & 22 & -3.9 & 9.6 & -103.9 & -13.5 & - & 5.5 & 4.9 & 162.1 & 0.70922 & 0.0 \\
\hline ER-OV-03c & 23 & -3.2 & 6.8 & -109.0 & -14.7 & - & 4.2 & 5.4 & 99.0 & 0.70924 & 0.1 \\
\hline ER-EC-07 & 24 & -6.3 & 36.5 & -98.0 & -13.2 & - & 1.8 & 7.2 & 123.1 & 0.70938 & 0.2 \\
\hline \multicolumn{12}{|l|}{ Fortymile Wash-North } \\
\hline Water Well 8 & 25 & -11.6 & 25.0 & -103.0 & -13.5 & - & 0.4 & 3.9 & 5.2 & 0.71025 & 1.5 \\
\hline
\end{tabular}


Table A6-2. Isotope and Trace Element Composition (Continued)

\begin{tabular}{c|c|c|c|c|c|c|c|c|c|c}
\hline $\begin{array}{c}\text { Figure } \\
\text { A6-5 }\end{array}$ & $\delta^{13} \mathrm{C}$ & ${ }^{14} \mathrm{C}$ & $\delta \mathrm{D}$ & $\delta^{18} \mathrm{O}$ & $\delta^{34} \mathrm{~S}$ & $\mathrm{U}$ & ${ }^{234} \mathrm{U}^{238} \mathrm{U}$ & $\mathrm{Sr}^{2+}$ & ${ }^{87} \mathrm{Sr} /^{86} \mathrm{Sr}$ & $\delta^{87} \mathrm{Sr}$
\end{tabular}

\begin{tabular}{|c|c|c|c|c|c|c|c|c|c|c|c|}
\hline Test Well 1 (USGS HTH \#1) & 26 & -10.2 & 30.1 & - & -14.7 & - & 0.6 & - & 15.0 & 0.70892 & -0.4 \\
\hline UE-18t & 27 & - & - & - & - & - & - & - & - & - & \\
\hline ER-30-1 (upper) & 28 & -6.3 & - & -93.2 & -12.4 & - & - & - & 13.0 & 0.70778 & -2.0 \\
\hline ER-30-1 (lower) & 29 & -6.0 & - & -86.7 & -11.8 & - & - & - & 7.0 & 0.70807 & -1.59 \\
\hline $\mathrm{a} \# 2(\mathrm{dp})$ & 30 & -12.6 & 62.3 & -93.5 & -12.8 & - & - & - & 39.0 & - & - \\
\hline a\#2(sh) & 31 & -13.1 & 60.0 & -93.0 & -12.8 & - & 0.7 & 4.0 & 33.0 & - & - \\
\hline UE-29a\#1 HTH & 32 & -10.5 & 75.7 & -91.0 & -12.6 & - & 1.5 & 3.6 & 54.7 & 0.71105 & 2.6 \\
\hline WT\#15 & 33 & -11.8 & 21.6 & -97.5 & -13.2 & - & - & - & - & - & - \\
\hline WT\#14 & 34 & -12.8 & 24.1 & -97.5 & -12.8 & - & - & - & - & - & - \\
\hline $\mathrm{J}-13$ & 35 & -7.3 & 29.2 & -97.5 & -13.0 & - & 0.6 & 7.2 & 20.0 & 0.71146 & 3.2 \\
\hline $\mathrm{J}-12$ & 36 & -7.9 & 32.2 & -97.5 & -12.8 & - & 0.3 & 5.5 & 10.0 & 0.71164 & 3.4 \\
\hline $\mathrm{JF} \# 3$ & 37 & -8.6 & 30.7 & -97.0 & -13.2 & - & 0.8 & 4.1 & - & 0.71133 & 3.0 \\
\hline
\end{tabular}

Solitario Canyon Wash

$\mathrm{H}-6(\mathrm{bh})$

$\mathrm{H}-6$ (Tct)

$\mathrm{H}-6(\mathrm{Tcb})$

WT-7

WT-10

Yucca Mountain-Crest

\begin{tabular}{|l|c|c|c|c|c|c|c|c|c|c|c|}
\hline G-2 & 43 & -11.8 & 20.5 & -98.8 & -13.3 & - & 1.2 & 7.6 & 10.0 & 0.71070 & 2.1 \\
\hline USW WT-24 & 44 & -10.6 & 27.3 & -101.1 & -13.2 & - & 1.1 & 6.4 & 1.5 & - & - \\
\hline UZ-14(sh) & 45 & -14.1 & 24.6 & -100.4 & -14.0 & 11.4 & - & - & 57.0 & - & - \\
\hline UZ-14(dp) & 46 & -14.4 & 21.1 & -100.6 & -14.0 & - & - & - & 32.0 & - & - \\
\hline H-1(Tcp) & 47 & - & 19.9 & -103.0 & -13.4 & - & - & - & 5.0 & - & - \\
\hline H-1(Tcb) & 48 & -11.4 & 23.9 & -101.0 & -13.5 & - & - & - & 20.0 & - & - \\
\hline H-5 & 49 & -10.3 & 19.8 & -102.0 & -13.6 & - & - & - & 6.5 & - & - \\
\hline
\end{tabular}

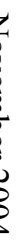


Table A6-2. Isotope and Trace Element Composition (Continued)

\begin{tabular}{|c|c|c|c|c|c|c|c|c|c|c|c|}
\hline Well Name & $\begin{array}{c}\text { Figure } \\
\text { A6-5 } \\
\text { Sample }\end{array}$ & $\begin{array}{c}\delta^{13} \mathrm{C} \\
\text { (per mil) }\end{array}$ & $\begin{array}{c}{ }^{14} \mathrm{C} \\
\text { (pmc) }\end{array}$ & $\begin{array}{c}\delta D \\
\text { (per mil) }\end{array}$ & $\begin{array}{c}\delta^{18} \mathrm{O} \\
\text { (per mil) }\end{array}$ & $\begin{array}{c}\delta^{34} \mathbf{S} \\
\text { (per mil) }\end{array}$ & $\underset{(\mu g / L)}{U}$ & $\begin{array}{c}{ }^{234} \mathrm{U}^{238} \mathrm{U} \\
\text { (AR) }\end{array}$ & $\begin{array}{c}\mathrm{Sr}^{2+} \\
(\mu \mathrm{g} / \mathrm{L})\end{array}$ & $\begin{array}{c}{ }^{87} \mathrm{Sr} l^{86} \mathrm{Sr} \\
\text { (ratio) }\end{array}$ & $\begin{array}{c}\delta^{87} \mathrm{Sr} \\
\text { (per mil) }\end{array}$ \\
\hline \multicolumn{12}{|c|}{ Yucca Mountain-Crest Continued } \\
\hline USW SD-6 & 50 & -9.4 & - & -105.3 & -14.4 & 12.5 & 5.0 & 3.9 & $>1.0$ & - & - \\
\hline $\mathrm{H}-3$ & 51 & -4.9 & 10.5 & -101.0 & -13.9 & - & - & - & 1.0 & - & - \\
\hline \multicolumn{12}{|l|}{ Yucca Mountain-Central } \\
\hline G-4 & 52 & -9.1 & 22.0 & -103.0 & -13.8 & - & - & - & 17.0 & - & - \\
\hline $\mathrm{b} \# 1(\mathrm{Tcb})$ & 53 & -8.6 & 18.9 & -99.5 & -13.5 & - & - & - & 47.0 & - & - \\
\hline $\mathrm{b} \# 1(\mathrm{bh})$ & 54 & -10.6 & 16.7 & -100.3 & -13.4 & - & - & - & 41.0 & - & - \\
\hline $\mathrm{H}-4$ & 55 & -7.4 & 11.8 & -104.0 & -14.0 & - & - & - & 27.0 & - & - \\
\hline $\mathrm{UZ \# 16}$ & 56 & - & - & - & - & - & - & - & - & - & - \\
\hline \multicolumn{12}{|l|}{ Yucca Mountain-Southeast } \\
\hline ONC\#1 & 57 & - & - & - & - & - & - & - & 1720.0 & 0.71040 & 1.7 \\
\hline $\mathrm{c} \# 1$ & 58 & -7.1 & 15.0 & -102.0 & -13.5 & - & - & - & 30.0 & 0.71040 & 1.7 \\
\hline c\#3 & 59 & -7.5 & 15.7 & -103.0 & -13.5 & - & - & - & 44.0 & - & - \\
\hline c\#3(95-97) & 60 & - & - & -99.7 & -13.4 & 10.8 & 1.2 & 8.1 & 60.0 & 0.70981 & 0.9 \\
\hline c\#2 & 61 & -7.0 & 16.6 & -100.0 & -13.4 & 10.9 & - & - & 45.0 & - & - \\
\hline$p \# 1(v)$ & 62 & -4.2 & 3.5 & -106.0 & -13.5 & - & - & - & 180.0 & - & - \\
\hline$p \# 1(c)$ & 63 & -2.3 & 2.3 & -106.0 & -13.8 & - & 13.3 & 2.3 & 450.0 & 0.71177 & 3.6 \\
\hline WT-17 & 64 & -8.3 & 16.2 & -101.9 & -13.7 & 10.5 & 1.1 & 7.6 & - & - & - \\
\hline WT\#3 & 65 & -8.2 & 22.3 & -102.1 & -13.6 & 10.8 & 0.8 & 7.2 & 32.0 & - & - \\
\hline WT\#12 & 66 & -8.1 & 11.4 & -102.5 & $\begin{array}{ll}-13.8 \\
\end{array}$ & - & 2.5 & 7.2 & 23.0 & 0.70991 & 1.0 \\
\hline \multicolumn{12}{|l|}{ Jackass Flats } \\
\hline UE-25 J-11 & 67 & -11.0 & 12.3 & -105.3 & -13.5 & 8.8 & 2.0 & 1.5 & 264.0 & - & - \\
\hline \multicolumn{12}{|l|}{ Crater Flat } \\
\hline GEXA Well4 & 68 & - & - & -105.6 & -14.1 & - & 3.0 & 5.1 & 34.0 & 0.70974 & 0.8 \\
\hline $\mathrm{VH}-1$ & 69 & -8.5 & 12.2 & -108.0 & -14.2 & - & 3.6 & 5.5 & 66.7 & 0.71096 & 2.5 \\
\hline \multicolumn{12}{|l|}{ Southwest Crater Flat } \\
\hline $\mathrm{VH}-2$ & 70 & - & - & -99.5 & -13.5 & - & 3.0 & 3.1 & 570.0 & 0.71300 & 5.4 \\
\hline NC-EWDP-7S & 71 & -4.9 & 8.4 & -98.0 & -13.0 & 14.3 & - & - & 630.0 & - & - \\
\hline
\end{tabular}


Table A6-2. Isotope and Trace Element Composition (Continued)

\begin{tabular}{|c|c|c|c|c|c|c|c|c|c|c|c|}
\hline Well Name & $\begin{array}{c}\text { Figure } \\
\text { A6-5 } \\
\text { Sample }\end{array}$ & $\begin{array}{c}\delta^{13} \mathrm{C} \\
\text { (per mil) }\end{array}$ & $\begin{array}{c}{ }^{14} \mathrm{C} \\
(\mathrm{pmc})\end{array}$ & $\begin{array}{c}\delta D \\
\text { (per mil) }\end{array}$ & $\begin{array}{c}\delta^{18} \mathrm{O} \\
\text { (per mil) }\end{array}$ & $\begin{array}{c}\delta^{34} S \\
\text { (per mil) }\end{array}$ & $\begin{array}{c}\mathbf{U} \\
(\mu \mathrm{g} / \mathrm{L})\end{array}$ & $\begin{array}{c}{ }^{234} \mathrm{U}^{238} \mathrm{U} \\
(\mathrm{AR})\end{array}$ & $\begin{array}{c}\mathrm{Sr}^{2+} \\
(\mu \mathrm{g} / \mathrm{L})\end{array}$ & $\begin{array}{c}{ }^{87} \mathrm{Sr} l^{86} \mathrm{Sr} \\
\text { (ratio) }\end{array}$ & $\begin{array}{c}\delta^{87} \mathrm{Sr} \\
\text { (per mil) }\end{array}$ \\
\hline \multicolumn{12}{|c|}{ Southwest Crater Flat Continued } \\
\hline NC-EWDP-7SC & 72 & - & - & - & - & - & - & - & 558.0 & - & - \\
\hline NC-EWDP-1DX & 73 & -4.5 & - & -101.3 & -13.5 & 14.6 & 5.1 & 3.9 & 510.0 & - & - \\
\hline NC-EWDP-1DX Zone 2 & 74 & -2.1 & 2.5 & -105.7 & -14.7 & 28.3 & 0.0 & 3.0 & 981.0 & 0.71293 & 5.3 \\
\hline NC-EWDP-1S Zone 1 & 75 & -5.8 & 7.7 & -101.3 & -13.6 & 14.8 & 8.6 & 4.5 & 568.0 & 0.71279 & 5.1 \\
\hline NC-EWDP-1S Zone 2 & 76 & -5.6 & 7.2 & -100.8 & -13.7 & 15.2 & 7.6 & 4.5 & 533.0 & 0.71288 & 5.2 \\
\hline NC-EWDP-1S & 77 & -5.6 & - & -99.6 & -13.8 & 14.5 & 8.6 & 4.5 & 557.0 & - & - \\
\hline NC-EWDP-12PA & 78 & -3.4 & 4.7 & -103.8 & -13.6 & 16.9 & - & - & 302.0 & 0.71561 & 9.0 \\
\hline NC-EWDP-12PB & 79 & -3.6 & 4.5 & -100.5 & -13.6 & 16.7 & - & - & 296.0 & 0.71460 & 7.6 \\
\hline NC-EWDP-12PC & 80 & -5.3 & 9.0 & -101.8 & -13.4 & 14.7 & - & - & 462.0 & 0.71269 & 4.9 \\
\hline \multicolumn{12}{|l|}{ Southern Yucca Mountain } \\
\hline NC-EWDP-09SX & 81 & -6.5 & - & -104.2 & -14.0 & 13.3 & 5.1 & 5.0 & 151.3 & 0.71250 & 4.7 \\
\hline NC-EWDP-9SX Zone 1 & 82 & -7.1 & 12.2 & -102.0 & -14.3 & 14.2 & 4.6 & 4.9 & 129.0 & 0.71247 & 4.6 \\
\hline NC-EWDP-9SX Zone 2 & 83 & -7.0 & 11.4 & -104.7 & -14.3 & 13.9 & 4.6 & 5.0 & 149.0 & 0.71239 & 4.5 \\
\hline NC-EWDP-9SX Zone 3 & 84 & -6.8 & 10.9 & -104.5 & -14.1 & 14.4 & 4.4 & 5.0 & 144.5 & 0.71246 & 4.6 \\
\hline NC-EWDP-9SX Zone 4 & 85 & -6.2 & 11.0 & -105.0 & -14.2 & 13.8 & 4.6 & 5.0 & 146.7 & 0.71254 & 4.7 \\
\hline NC-EWDP-03D & 86 & -6.8 & 10.0 & -105.6 & -14.4 & 11.2 & 2.0 & 3.4 & 1.3 & - & - \\
\hline NC-EWDP-3S Zone 2 & 87 & -8.4 & 21.5 & -104.8 & -14.3 & 10.9 & 2.6 & 3.2 & 2.5 & 0.71032 & 1.6 \\
\hline NC-EWDP-3S Zone 3 & 88 & -5.0 & 8.4 & -106.2 & -14.2 & 9.8 & 7.4 & 2.9 & 3.7 & 0.71100 & 2.5 \\
\hline CIND-R-LITE & 89 & - & - & -102.0 & -13.6 & - & 2.8 & 4.7 & 108.0 & 0.71221 & 4.2 \\
\hline NC-EWDP-15P & 90 & -6.3 & 12.0 & -106.3 & -13.8 & 13.2 & - & - & 50.0 & 0.71222 & 4.3 \\
\hline NC-EWDP-02D & 91 & -8.3 & 23.5 & -104.0 & -14.1 & 11.9 & 1.2 & 4.8 & 53.0 & - & - \\
\hline NC-EWDP-19D & 92 & -7.6 & 12.4 & -106.1 & -13.8 & 9.0 & - & - & 3.5 & 0.71056 & 1.9 \\
\hline NC-EWDP-19P & 93 & -9.5 & 23.5 & -103.5 & -13.6 & 11.7 & - & - & 57.0 & 0.71133 & 3.0 \\
\hline NC-EWDP-19D (alluvial) & 94 & -7.1 & 12.4 & -108.8 & -13.8 & 10.7 & - & - & 7.5 & - & - \\
\hline NC-EWDP-19D(zone \#1) & 95 & -7.0 & 17.6 & -109.0 & -13.9 & 10.1 & - & - & 15.0 & - & - \\
\hline NC-EWDP-19D(zone \#2) & 96 & -7.6 & 21.0 & -104.0 & -13.6 & 10.6 & - & - & 36.0 & - & - \\
\hline
\end{tabular}

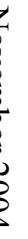


Table A6-2. Isotope and Trace Element Composition (Continued)

\begin{tabular}{c|c|c|c|c|c|c|c|c|c|c}
\hline $\begin{array}{c}\text { Figure } \\
\text { A6-5 }\end{array}$ & $\delta^{13} \mathrm{C}$ & ${ }^{14} \mathrm{C}$ & $\delta \mathrm{D}$ & $\delta^{18} \mathrm{O}$ & $\delta^{34} \mathrm{~S}$ & $\mathrm{U}$ & ${ }^{234} \mathrm{U}^{238} \mathrm{U}$ & $\mathrm{Sr}^{2+}$ & ${ }^{87} \mathrm{Sr} /^{86} \mathrm{Sr}$ & $\delta^{87} \mathrm{Sr}$ \\
\hline
\end{tabular}

\section{Southern Yucca Mountain Continued}

\begin{tabular}{|c|c|c|c|c|c|c|c|c|c|c|c|}
\hline NC-EWDP-19D(zone \#3) & 97 & -9.4 & 12.5 & -106.3 & -13.5 & 10.9 & - & - & 3.0 & - & - \\
\hline NC-EWDP-19D(zone \#4) & 98 & -6.4 & 11.2 & -110.2 & -13.9 & 11.7 & - & - & 2.0 & - & - \\
\hline
\end{tabular}

NC-EWDP-19D(zone \#4)

Amargosa Valley

NC-EWDP-4PB

NC-EWDP-4PA

Desert Farms Garlic Plot

15S/49E-13dda

$15 \mathrm{~S} / 50 \mathrm{E}-18 \mathrm{ccc}$

NDOT

$15 \mathrm{~S} / 50 \mathrm{E}-18 \mathrm{cdc}$

Airport Well

15S/50E-19b1

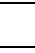

\begin{tabular}{l|l|l|l}
-6.4 & 11.2 & -110.2 \\
\hline
\end{tabular}

\begin{tabular}{l}
- \\
- \\
\hline 1.3 \\
- \\
- \\
\hline 2.5 \\
- \\
0.6 \\
-
\end{tabular}

\begin{tabular}{|c|}
\hline- \\
\hline- \\
\hline 3.4 \\
- \\
\hline- \\
\hline 2.5 \\
\hline- \\
\hline 3.1 \\
-
\end{tabular}

\begin{tabular}{|c|c|c|}
\hline 36.0 & 0.71021 & 1.4 \\
\hline 62.5 & 0.70949 & 0.4 \\
\hline 144.0 & - & - \\
\hline- & - & - \\
\hline 80.0 & - & - \\
\hline- & 0.71081 & 2.3 \\
\hline- & - & - \\
\hline 24.0 & - & - \\
- & - & - \\
\hline
\end{tabular}

Amargosa River

16S/48E-8ba

$16 \mathrm{~S} / 48 \mathrm{E}-7 \mathrm{bba}$

$16 \mathrm{~S} / 48 \mathrm{E}-7 \mathrm{cbc}$

16S/48E-18bcc

$16 \mathrm{~S} / 48 \mathrm{E}-17 \mathrm{ccc}$

16S/48E-18dad

$16 \mathrm{~S} / 48 \mathrm{E}-8 \mathrm{cda}$

16S/48E-17abb

Barrachman Dom/Irr.

McCracken Domestic

\begin{tabular}{c|c|c|c|c|c}
99 & -10.0 & 15.9 & -108.5 & -13.9 & 9.6 \\
\hline 100 & -10.5 & 23.1 & -101.3 & -13.3 & 8.9 \\
\hline 101 & -9.1 & 8.8 & -106.4 & -13.1 & 8.8 \\
102 & - & - & - & - & - \\
103 & - & - & - & - & - \\
104 & - & - & - & - & - \\
105 & - & - & - & - & - \\
106 & -10.3 & 10.5 & -106.2 & -13.2 & 8.7 \\
107 & - & - & - & - & - \\
\hline
\end{tabular}

$-$

$-$

$-$

$-$

Fortymile Wash-West

16S/48E-15ba

16S/48E-10cba

16S/48E-15aaa

\begin{tabular}{|c|c|c|c|c|c|}
\hline 108 & - & - & - & - & - \\
\hline 109 & - & - & - & - & - \\
\hline 110 & -6.2 & 31.4 & -102.0 & -13.1 & - \\
\hline 111 & - & - & - & - & - \\
\hline 112 & - & - & - & - & - \\
\hline 113 & -5.7 & - & -104.0 & -13.6 & - \\
\hline 114 & - & - & - & - & - \\
\hline 115 & - & - & - & - & - \\
\hline 116 & -5.8 & 17.9 & -107.4 & -13.5 & 20.9 \\
\hline 117 & -12.1 & 32.9 & -102.7 & -12.9 & 18.5 \\
\hline
\end{tabular}

\begin{tabular}{|c|c|c|c|c|}
\hline- & - & - & - & - \\
\hline- & - & - & - & - \\
\hline- & - & - & - & - \\
\hline- & - & - & - & - \\
\hline- & - & - & - & - \\
\hline- & - & - & - & - \\
\hline- & - & - & - & - \\
\hline- & - & - & - & - \\
\hline 5.2 & 3.4 & 473.0 & - & - \\
\hline 5.2 & 3.3 & 600.0 & 0.71456 & 7.6 \\
\hline
\end{tabular}

象

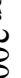


Table A6-2. Isotope and Trace Element Composition (Continued)

\section{Fortymile Wash-West Continued}

Well Name

\begin{tabular}{|c|c|c|c|c|c|c|c|c|c|c|}
\hline $\begin{array}{c}\text { Figure } \\
\text { A6-5 } \\
\text { Sample }\end{array}$ & $\begin{array}{c}\delta^{13} \mathrm{C} \\
\text { (per mil) }\end{array}$ & $\begin{array}{c}{ }^{14} \mathrm{C} \\
\text { (pmc) }\end{array}$ & $\begin{array}{c}\delta D \\
\text { (per mil) }\end{array}$ & $\begin{array}{c}\delta^{18} \mathrm{O} \\
\text { (per mil) }\end{array}$ & $\begin{array}{c}\delta^{34} \mathbf{S} \\
\text { (per mil) }\end{array}$ & $\underset{(\mu \mathrm{g} / L)}{\mathbf{U}}$ & $\begin{array}{c}{ }^{234} \mathrm{U} /^{238} \mathrm{U} \\
\text { (AR) }\end{array}$ & $\begin{array}{c}\mathrm{Sr}^{2+} \\
(\mu \mathrm{g} / \mathrm{L})\end{array}$ & $\begin{array}{c}{ }^{87} \mathrm{Srl}{ }^{86} \mathrm{Sr} \\
\text { (ratio) }\end{array}$ & $\begin{array}{c}\delta^{87} \mathrm{Sr} \\
\text { (per mil) }\end{array}$ \\
\hline
\end{tabular}

\begin{tabular}{|l|c|c|c|c|c|c|c|c|c|c|}
\hline Selbach Domestic & 121 & -8.1 & 30.7 & -103.2 & -12.9 & 10.9 & 2.7 & 4.2 & 217.0 & - \\
\hline
\end{tabular}

$16 \mathrm{~S} / 48 \mathrm{E}-15 \mathrm{dda}$

16S/49E-23add

$16 \mathrm{~S} / 48 \mathrm{E}-23 \mathrm{bdb}$

$16 \mathrm{~S} / 48 \mathrm{E}-23 \mathrm{da}$

Funeral Mountain Ranch Irrig.

\begin{tabular}{c|c|c|c|c|c|c}
121 & -8.1 & 30.7 & -103.2 & -12.9 & 10.9 & \\
122 & - & - & - & - & - & \\
123 & -8.4 & 27.4 & -99.0 & -13.2 & - & \\
124 & - & - & - & - & - & \\
125 & - & - & - & - & - & \\
126 & -5.5 & 6.5 & -106.6 & -13.7 & 13.2 &
\end{tabular}

\section{Fortymile Wash-South}

16S/49E-05acc

16S/49E-8abb

16S/49E-8acc

16S/49E-18dc

16s/48E-24aaa

16S/49E-19daa

DeLee Large Irrigation

16S/48E-25aa

16S/48E-36aaa

Bray Domestic

Amargosa Estates \#2

17S/48E-1ab

$17 \mathrm{~S} / 49 \mathrm{E}-7 \mathrm{bb}$

17S/49E-8ddb

17S/49E-35ddd

\begin{tabular}{l|l}
\hline 27 & -7.1 \\
\hline
\end{tabular}

$.5-106.6$

\begin{tabular}{l|l}
\hline- & \\
\hline- & \\
\hline- & \\
\hline- & \\
\hline
\end{tabular}

\begin{tabular}{l|l}
- & \\
\hline- & \\
\hline- & \\
\hline- & \\
\hline
\end{tabular}

$-$

\begin{tabular}{l|l}
- & - \\
\hline- & - \\
\hline- & - \\
\hline- & -
\end{tabular}

Fortymile Wash-East

15S/49E-22a1

15S/49E-22dcc

15S/49E-27acc

O'Neill Domestic

\begin{tabular}{|c|c|c|}
\hline 127 & -7.1 & \\
\hline 128 & -6.8 & - \\
129 & - & \\
130 & - & - \\
131 & - & \\
\hline 132 & -8.4 & \\
\hline 133 & - & \\
\hline 134 & - & \\
\hline 135 & -10.0 & \\
\hline 136 & -10.6 & \\
\hline 137 & - & \\
\hline 138 & - & \\
139 & - & \\
140 & - & \\
\hline 141 & 1
\end{tabular}

\begin{tabular}{l|l|l|}
\hline 19.3 & -103.0 & -13.2 \\
\hline
\end{tabular}

\begin{tabular}{l|l}
- & \\
- &
\end{tabular}

\begin{tabular}{l|l|l}
- & - & 50.0
\end{tabular}

\begin{tabular}{l|l|l|}
\hline & \\
\hline
\end{tabular}

\begin{tabular}{l|l}
21.4 & -99.5 \\
\hline
\end{tabular}

\begin{tabular}{l|c|c}
\hline 28.4 & - & - \\
\hline
\end{tabular}

\begin{tabular}{l|l}
\hline 0.8 & -101 \\
\hline
\end{tabular}

-

\begin{tabular}{l|l|l}
20.5 & -104.1 & -13.3 \\
\hline
\end{tabular}

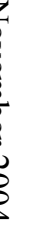


Table A6-2. Isotope and Trace Element Composition (Continued)

\begin{tabular}{c|c|c|c|c|c|c|c|c|c|c}
\hline $\begin{array}{c}\text { Figure } \\
\text { A6-5 }\end{array}$ & $\delta^{13} \mathrm{C}$ & ${ }^{14} \mathrm{C}$ & $\delta \mathrm{D}$ & $\delta^{18} \mathrm{O}$ & $\delta^{34} \mathrm{~S}$ & $\mathrm{U}$ & ${ }^{234} \mathrm{U}^{238} \mathrm{U}$ & $\mathrm{Sr}^{2+}$ & $\left.{ }^{87} \mathrm{Sr}\right|^{86} \mathrm{Sr}$ & $\delta^{87} \mathrm{Sr}$
\end{tabular}

\section{Fortymile Wash-East Continued}

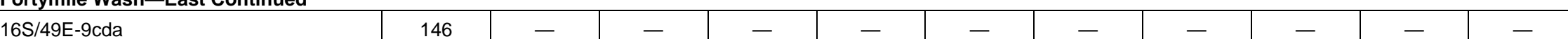

\begin{tabular}{|l|c|c|c|c|c|c|c|c|c|c|c|}
\hline $16 \mathrm{~S} / 49 \mathrm{E}-9 \mathrm{cda}$ & 146 & - & - & - & - & - & - & - & - & - & - \\
\hline $16 \mathrm{~S} / 49 \mathrm{E}-9 \mathrm{dcc}$ & 147 & -7.3 & 21.9 & -103.0 & -13.4 & - & - & - & - & - \\
\hline
\end{tabular}

$16 \mathrm{~S} / 49 \mathrm{E}-16 \mathrm{ccc}$

Ponderosa Dairy \#1

17S/49E-9aa

$17 \mathrm{~S} / 49 \mathrm{E}-15 \mathrm{bbd}$

M. Gilgan Well

17S/49E-15bc

Gravity fault

NC-EWDP-5S

NC-EWDP-5SB

$16 \mathrm{~S} / 50 \mathrm{E}-7 \mathrm{bcd}$

Nelson Domestic

16S/49E-12ddd

Lowe Domestic

16S/49E-15aaa

Anvil Ranch Irrigation

16S/49E-36aaa

16S/49E-35baa

Payton Domestic

16S/49E-36aba

16S/49E-35aaa

Oettinger Well

Amargosa Motel (b)

17S/49E-11ba

Spring Meadows Well \#8

17S/50E-19aab

\begin{tabular}{|l|l} 
& 154 \\
\hline & 155 \\
\hline ic & 156 \\
\hline & 157 \\
\hline & 158 \\
\hline
\end{tabular}

149

\begin{tabular}{l|l|l}
148 & -5.2 & 24.8 \\
\hline 149 & -7.2 & 14.2
\end{tabular}

\begin{tabular}{|c|c|c|c|}
\hline & 150 & - & \\
& 151 & - & \\
& 152 & -9.0 & \\
& 153 & - & \\
\hline
\end{tabular}

\begin{tabular}{l|l|l|l}
14.2 & -105.5 & -13.3 & 16.6 \\
\hline 18.9 & -105.0 & -12.8 &
\end{tabular}

\begin{tabular}{c|c|c|c|c}
18.9 & -105.0 & -12.8 & - & - \\
\hline 40.3 & - & - & - & - \\
\hline 27.9 & -100.1 & -13.0 & 9.4 & 0.8 \\
\hline- & - & - & - & -
\end{tabular}

\begin{tabular}{l|l}
\hline .3 & 2.9 \\
\hline- & \\
\hline- & \\
\hline 0.8 & 3.0 \\
\hline
\end{tabular}

8

\begin{tabular}{|c|c|c|c|c|c|c|c|c|c|c|}
\hline 54 & - & - & -107.0 & -14.0 & - & 0.04 & 6.7 & 361.0 & 0.71206 & 4.0 \\
\hline 55 & -1.5 & 4.0 & -107.0 & -13.3 & 17.8 & - & - & 204.0 & 0.71232 & 4.4 \\
\hline 56 & -3.6 & 7.0 & -105.0 & -13.8 & - & - & - & - & - & - \\
\hline 57 & -2.0 & 0.9 & -110.2 & -13.8 & 22.6 & 1.7 & 3.2 & 829.5 & - & - \\
\hline 58 & - & - & - & - & - & - & - & - & - & - \\
\hline 59 & -3.0 & 1.2 & -103.7 & -13.8 & 21.5 & 2.8 & 3.3 & 724.0 & - & - \\
\hline 60 & -3.4 & - & -105.0 & -13.8 & - & - & - & - & - & - \\
\hline 61 & -10.4 & 11.8 & -103.3 & -13.1 & 13.2 & 2.1 & 2.8 & 319.0 & - & - \\
\hline 62 & -4.4 & 10.3 & -104.0 & -13.7 & - & - & - & - & - & - \\
\hline 63 & - & - & - & - & - & - & - & - & - & - \\
\hline 64 & -2.7 & 3.3 & -109.7 & -13.8 & 21.7 & 1.0 & 3.6 & 1069.0 & - & - \\
\hline 65 & - & - & - & - & - & - & - & - & - & - \\
\hline 66 & - & - & - & - & - & - & - & - & - & - \\
\hline 67 & -2.6 & 1.4 & -108.5 & -13.8 & 21.8 & 1.5 & 3.3 & 915.0 & - & - \\
\hline 68 & -3.0 & 1.9 & -109.0 & -13.7 & 22.0 & 1.6 & 3.2 & 954.0 & - & - \\
\hline 69 & - & - & - & - & - & - & - & - & - & - \\
\hline 70 & - & - & - & - & - & - & - & - & - & - \\
\hline 71 & - & - & - & - & - & - & - & - & - & - \\
\hline
\end{tabular}


Table A6-2. Isotope and Trace Element Composition (Continued)

\section{Gravity fault Continued}

\begin{tabular}{|l|c|c|c|c|c|c|c|c|c|c|c|}
\hline USFWS - Five Springs Well & 172 & - & - & -104.0 & -13.6 & - & - & - & 860.0 & - & - \\
\hline
\end{tabular}

Spring Meadows Well \#10

18S/49E-1aba

$18 \mathrm{~S} / 50 \mathrm{E}-6 \mathrm{dac}$

18S/50E-7aa

Amargosa River/Fortymile Wash

16S/48E-36dcc

Crane Domestic

27N/4E-27bbb

IMV on Windjammer

17S/49E-29acc

$17 \mathrm{~S} / 49 \mathrm{E}-28 \mathrm{bcd}$

$18 \mathrm{~S} / 49 \mathrm{E}-2 \mathrm{cbc}$

Mom's Place

18S/49E-11bbb

Skeleton Hills

TW-5

Unnamed Well 15S/50E-22-7

\begin{tabular}{c|c|c|c|c|c|c|c|}
172 & - & - & -104.0 & -13.6 & - & - & \\
\hline 173 & - & - & - & - & - & - & \\
174 & - & - & - & - & - & - & \\
175 & - & - & - & - & - & - & \\
176 & - & - & - & - & - & - &
\end{tabular}

\section{Amargosa Flat}

Amargosa Tracer Hole \#2

Cherry Patch Well, 17S/52E-08cdb

USDOE-MSH-C shallow Well

\begin{tabular}{c|c|c}
\hline 177 & - & \\
\hline 178 & -4.3 & 7.9 \\
\hline 179 & - & \\
\hline 180 & -5.0 & 6.6 \\
\hline 181 & - & \\
\hline 182 & - & \\
\hline 183 & - & \\
\hline 184 & -4.9 & 1 \\
\hline 185 & - & \\
\hline
\end{tabular}

\begin{tabular}{ll}
- & - \\
\hline
\end{tabular}

-

\begin{tabular}{|c|c|c|c}
\hline- & - & - & - \\
\hline-108.8 & -13.4 & 22.3 & 4 \\
\hline- & - & - & - \\
-104.0 & -13.4 & 19.3 & 3 \\
- & - & - & - \\
- & - & - & - \\
- & - & - & - \\
-105.5 & -13.2 & 17.1 & 1 \\
\hline- & - & - & -
\end{tabular}

\begin{tabular}{l|r}
- & - \\
\hline 4.0 & 3.3 \\
\hline- & - \\
\hline 3.6 & 3.0 \\
- & - \\
- & - \\
\hline- & - \\
\hline 1.9 & 3.0 \\
\hline- & \\
\hline
\end{tabular}

\begin{tabular}{c|c|c|}
- & 860.0 & \\
- & - & \\
- & - & \\
\hline- & - & \\
\hline- & - &
\end{tabular}

\begin{tabular}{l|l|}
- & - \\
\hline- & - \\
\hline- & - \\
\hline- & - \\
\hline- & -
\end{tabular}

-

$-$

-

\section{Mine Mountain}

\begin{tabular}{|c|c|c|c|c|c|c|c|c|c|c|c|}
\hline UE-17a & 191 & -9.9 & 4.9 & -100.0 & -13.3 & - & 0.4 & - & 829.0 & 0.71020 & 1.5 \\
\hline UE-1a & 192 & -8.6 & 60.5 & -103.0 & -13.5 & - & 4.3 & - & 630.0 & 0.70957 & 0.5 \\
\hline UE-1b & 193 & -4.5 & 16.0 & -105.0 & - & - & 4.3 & - & 470.0 & 0.70950 & 0.4 \\
\hline UE-16f & 194 & -11.7 & 3.4 & -104.0 & -13.5 & - & - & - & 550.0 & 0.71138 & 3.1 \\
\hline
\end{tabular}

\begin{tabular}{c|c|c|c|c|c|c|c|c|c|c|}
186 & - & - & -113.2 & -15.4 & - & - & - & 1509.0 & 0.71505 & 8.2 \\
\hline 187 & - & - & - & - & - & - & - & 80.0 & - & - \\
\hline
\end{tabular}

\begin{tabular}{|c|c|c|c|c|c|c|c|c|c|c|}
188 & -6.0 & 4.6 & - & -13.6 & - & - & - & 790.0 & - & - \\
\hline 189 & - & - & - & - & - & 1.8 & 2.9 & 1500.0 & - & - \\
\hline 190 & - & - & -108.0 & -14.1 & - & - & - & 540.0 & - & - \\
\hline
\end{tabular}

194

$-11.7$

\begin{tabular}{l|l}
3.4 & -104.0 \\
\hline
\end{tabular}

$-13.5$

$x^{2}$


Table A6-2. Isotope and Trace Element Composition (Continued)

\begin{tabular}{|c|c|c|c|c|c|c|c|c|c|c|c|}
\hline Well Name & $\begin{array}{c}\text { Figure } \\
\text { A6-5 } \\
\text { Sample }\end{array}$ & $\begin{array}{c}\delta^{13} \mathrm{C} \\
(\text { per mil) }\end{array}$ & $\begin{array}{l}{ }^{14} \mathrm{C} \\
(\mathrm{pmc})\end{array}$ & $\begin{array}{c}\delta \mathrm{D} \\
\text { (per mil) }\end{array}$ & $\begin{array}{c}\delta^{18} \mathrm{O} \\
\text { (per mil) }\end{array}$ & $\begin{array}{c}\delta^{34} S \\
\text { (per mil) }\end{array}$ & $\underset{(\mu \mathrm{g} / \mathrm{L})}{\mathbf{U}}$ & $\begin{array}{c}{ }^{234} U /^{238} \mathrm{U} \\
\text { (AR) }\end{array}$ & $\begin{array}{c}\mathrm{Sr}^{2+} \\
(\mu \mathrm{g} / \mathrm{L})\end{array}$ & $\begin{array}{c}{ }^{87} \mathrm{Srl}{ }^{86} \mathrm{Sr} \\
\text { (ratio) }\end{array}$ & $\begin{array}{c}\delta^{87} \mathrm{Sr} \\
\text { (per mil) }\end{array}$ \\
\hline \multicolumn{12}{|l|}{ Mine Mountain Continued } \\
\hline UE-14b & 195 & - & - & - & - & - & - & - & - & - & - \\
\hline Pluto 1 & 196 & - & - & - & - & - & - & - & - & - & - \\
\hline Pluto 5 & 197 & - & - & - & - & - & - & - & - & - & - \\
\hline USGS Test Well F (HTH) & 198 & - & - & - & - & - & - & - & 570.0 & - & - \\
\hline \multicolumn{12}{|l|}{ Funeral Mountains } \\
\hline Woodcamp Spring & 199 & -12.2 & 78.0 & -91.6 & -12.4 & - & - & - & 20.0 & 0.70871 & -0.7 \\
\hline Bond Gold Mining \#13 & 200 & -7.5 & 8.1 & -100.6 & -13.3 & 29.3 & 8.1 & 1.9 & 2140.0 & 0.72732 & 25.5 \\
\hline Nevares Spring & 201 & -5.5 & 3.0 & -101.0 & -13.5 & - & 1.3 & 2.1 & 1100.0 & 0.71679 & 10.7 \\
\hline Travertine Spring & 202 & -3.8 & 3.3 & -102.0 & -13.5 & - & 3.3 & 2.4 & 1100.0 & 0.71734 & 11.5 \\
\hline \multicolumn{12}{|c|}{ DTNs: LA0309RR831233.001[DIRS 166546]; LA0309RR831233.002 [DIRS 166548] } \\
\hline \multicolumn{12}{|l|}{$A R=$ activity ratio } \\
\hline & & & & & & & & & & & \\
\hline
\end{tabular}




\section{A6.3.1 Factors Affecting the Chemical and Isotopic Composition of Groundwater}

This section will summarize the study of Meijer (2002 [DIRS 158813]) that describes the effects of: (1) precipitation composition, (2) evaporation, (3) precipitation/dissolution reactions, (4) adsorption and ion-exchange reactions, and (5) climate change on the chemical composition of groundwater. Additional details are presented in Meijer (2002 [DIRS 158813]) and in the Yucca Mountain Site Description (BSC 2004 [DIRS 169734], Sections 5.2.2, 8.2.7 and 8.3.6).

\section{A6.3.1.1 Factors Affecting the Chemical Composition of Groundwater}

The main processes that control groundwater chemistry are:

- Precipitation (atmospheric) quantities and compositions

- Surface water quantities and compositions in recharge areas and along stream courses

- Soil-zone processes in recharge areas and along flow paths between the soil and saturated zone

- Rock-water interactions in the unsaturated zone

- Rock-water interactions in the saturated zone

- Temperature and pressure effects in the unsaturated and saturated zones

- Mixing of groundwater from different flow systems.

Although all the processes listed above may affect the groundwater chemistry, mixing and rock-water interactions generally are the most dominant in determining changes to the major-ion composition of recharge after it has reached the saturated zone.

Processes that affect infiltrating waters in the soil zone or the unsaturated zone include evapotranspiration, mineral and gas dissolution reactions, gas ex-solution and mineral-precipitation reactions, and ion-exchange reactions. The dominant changes to the water compositions that result from these processes in the volcanic rock in the Yucca Mountain area are increases in the concentration of all chemical species and major relative increases in $\mathrm{SiO}_{2}$, $\mathrm{Na}^{+}$, and $\mathrm{HCO}_{3}{ }^{-}$compared to the composition of precipitation.

The dominant water-rock reactions that impact the water chemistry after the shallow unsaturated-zone or soil-zone reactions are $\mathrm{SiO}_{2}$-precipitation reactions and ion-exchange reactions involving minerals such as zeolites and clays. The cation-hydrogen ion-exchange reaction will also continue to be of significance. The ion-exchange reactions lead to increased $\mathrm{Na}^{+}$concentrations and decreased $\mathrm{Ca}^{2+}, \mathrm{Mg}^{2+}$, and $\mathrm{K}^{+}$concentrations in the waters. However, changes in the concentrations of these ions will only occur if zeolites and/or clays are present in adequate quantities in rock units through which the waters migrate. The $\mathrm{Na}^{+}-\mathrm{H}^{+}$ion-exchange reaction will continue to increase the $\mathrm{Na}^{+}$content of the waters until thermodynamic equilibrium is achieved with the host rock. 
The primary controls on the $\mathrm{pH}$ of groundwater in the saturated zone are the partial pressure of $\mathrm{CO}_{2}$ and the rate at which hydrogen ions are consumed by the rock-mineral matrix. In the saturated zone, access to the $\mathrm{CO}_{2}$ reservoir in the gas phase of the unsaturated zone becomes progressively more difficult with depth. Therefore, unless a secondary source of $\mathrm{H}_{2} \mathrm{CO}_{3}$ or another source of acidity (e.g., sulfide minerals) exists in the saturated zone, the reaction of hydrogen ions with the rock mineral matrix will eventually consume the available acidity, leading to increased $\mathrm{pH}$.

Winograd and Thordarson (1975 [DIRS 101167], pp. C97 to C102, Plate C) identified six hydrochemical facies in the vicinity of the Nevada Test Site. Where the host rocks are limestone and dolomite, as in the case of the carbonate aquifer, the dominant ions are $\mathrm{Ca}^{2+}$, $\mathrm{Mg}^{2+}$, and $\mathrm{HCO}_{3}^{-}$. Tuffaceous aquifers are characterized by groundwater having $\mathrm{Na}^{+}, \mathrm{K}^{+}$and $\mathrm{HCO}_{3}{ }^{-}$as the dominant ions. Groundwater of mixed compositions occurs where groundwater flows from one aquifer type into another, or from alluvium derived from one rock type into alluvium derived from another rock type. Groundwater mixing can also produce groundwaters that are intermediate in compositions between the carbonate and tuffaceous aquifers. In the alluvial valley fill deposits, the host rocks consist of fragments that reflect the rock composition in the upland sediment source areas. For example, in the west central Amargosa Desert, a central region of predominantly tuffaceous valley fill is flanked to the east and west by zones containing significant proportions of carbonate-rock detritus (Claassen 1985 [DIRS 101125], p. F5, Figure 1), which greatly affect the major-ion composition of the groundwater. This lateral sedimentary facies relationship is further complicated in the Amargosa Desert by the local presence of playa deposits (Claassen 1985 [DIRS 101125], pp. F5, F30). Groundwater in the vicinity of playa deposits typically contains greater concentrations of $\mathrm{SO}_{4}{ }^{2-}$ and $\mathrm{Cl}^{-}$, which were concentrated in the playa deposits through earlier cycles of evaporation (Claassen 1985 [DIRS 101125], p. F18).

\section{A6.3.1.2 Factors Affecting the Isotopic Composition of Groundwater}

The main processes that control the isotopic chemistry of SZ groundwaters have some common ground with those that control major-ion chemistry; however, major differences exist between these chemical regimes. As with major-ion content, precipitation quantity and composition are the starting point for the isotopic evolution of groundwater.

\section{A6.3.1.2.1 Hydrogen and Oxygen}

Hydrogen and oxygen isotope ratios are useful for tracing groundwater movement where spatial differences in their concentrations exist. Both hydrogen and oxygen are composed of more than one stable isotope. The stable hydrogen isotopes of interest here are ${ }^{1} \mathrm{H}$ and ${ }^{2} \mathrm{H}$. The latter isotope is commonly referred to as deuterium with the chemical symbol $\mathrm{D}$. The ratio of these two isotopes is measured and is generally reported in $\delta$ notation as follows, with units of per mil:

$$
\delta \mathrm{D}=\left[\left(\mathrm{D} /{ }^{1} \mathrm{H}\right)_{\text {sample }} /\left(\mathrm{D} /{ }^{1} \mathrm{H}\right)_{\text {standard }}-1\right] \times 1000
$$

The standard used for these measurements is known as Vienna Standard Mean Ocean Water (Clark and Fritz 1997 [DIRS 105738], p. 8). 
The stable oxygen isotopes of interest here are ${ }^{16} \mathrm{O}$ and ${ }^{18} \mathrm{O}$. The ratio of these isotopes is measured and also reported in $\delta$ notation as follows, with units of per mil:

$$
\delta^{18} \mathrm{O}=\left[\left({ }^{18} \mathrm{O} /{ }^{16} \mathrm{O}\right)_{\text {sample }}\left({ }^{18} \mathrm{O} /{ }^{16} \mathrm{O}\right)_{\text {standard }}-1\right] \times 1000
$$

Vienna Standard Mean Ocean Water is also used as the standard for oxygen isotope measurements (Clark and Fritz 1997 [DIRS 105738], p. 8).

The ${ }^{2} \mathrm{H}$ and ${ }^{18} \mathrm{O}$ atoms are part of the water molecule and, at low temperatures, are generally unaffected by water-rock interactions. The values of $\delta \mathrm{D}$ and $\delta^{18} \mathrm{O}$ in precipitation, fresh surface water, and groundwater are typically negative because of fractionation between the heavy and light isotopes of hydrogen and oxygen during evaporation over the initial moisture source area and because the residual water vapor becomes progressively more depleted in the heavier isotopes $\left({ }^{2} \mathrm{H}\right.$ and $\left.{ }^{18} \mathrm{O}\right)$ during successive precipitation events. A detailed discussion of all the processes affecting the isotopic composition of precipitation and recharge, and possible effects of water-rock interactions, is beyond the scope of this report. A summary of these processes is available in textbooks, such as Clark and Fritz (1997 [DIRS 105738], Sections 2 to 4, 9). Some of the net effects of these processes are depicted in Figure A6-4.

The values of $\delta \mathrm{D}$ and $\delta^{18} \mathrm{O}$ in precipitation are strongly correlated on a global basis. This correlation has been termed the "global meteoric water line." The equation for this line is $\delta \mathrm{D}=8$ $\delta^{18} \mathrm{O}+10$ (Clark and Fritz 1997 [DIRS 105738], p. 36). The slope of the line is related to the ratio of the equilibrium fractionation factors for ${ }^{2} \mathrm{H}$ and ${ }^{18} \mathrm{O}$, which are approximately 8.2 at $25^{\circ} \mathrm{C}$ (Clark and Fritz 1997 [DIRS 105738], p. 50). Locally, the isotopic composition of precipitation may follow a line with a somewhat different slope and intercept. Such lines have been referred to as the "local meteoric water line." The deuterium "excess" is the intercept in the meteoric water line when the slope is eight. This "excess" is inversely related to the relative humidity of the air in the moisture source area (Clark and Fritz 1997 [DIRS 105738], p. 45; Merlivat and Jouzel 1979 [DIRS 126847], p. 5029).

One of the primary factors affecting the isotopic composition of precipitation is condensation temperature, which is a function of season, elevation, and climate. Precipitation falling during periods when temperatures are low has more negative ("depleted") $\delta \mathrm{D}$ and $\delta{ }^{18} \mathrm{O}$ values than precipitation falling during warm periods. Because average surface temperatures are correlated with elevation, precipitation falling at higher elevations tends to have more negative isotope ratios than precipitation falling at lower elevations. Late Pleistocene groundwater, identified by ${ }^{14} \mathrm{C}$ age dating or other techniques, is often more isotopically depleted compared to modern waters because it was recharged under conditions that were cooler than at present. Also, because of the inverse relation between the value for the deuterium excess and relative humidity of the moisture source areas, data for old groundwaters recharged during pluvial periods in the Pleistocene sometimes plot below the present-day global or local meteoric water line (Clark and Fritz 1997 [DIRS 105738], pp. 198 to 199, Figure 8-2). 


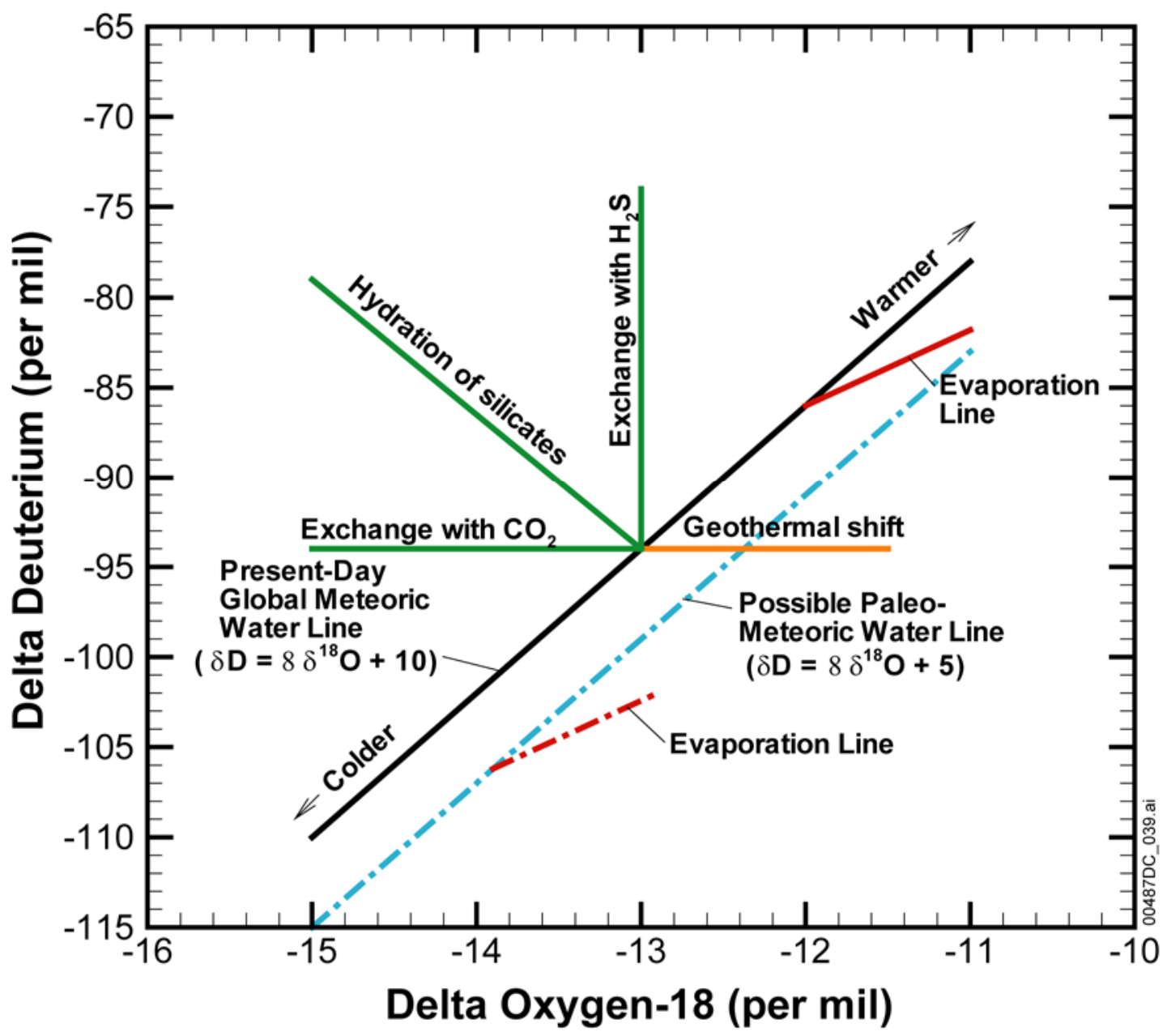

Source: $\quad$ Based on Clark and Fritz (1997 [DIRS 105738], Figures 2-1, 2-9, 2-11, and 9-1). The possible paleometeoric water line for the Amargosa Desert area is based on arguments in White and Chuma, 1987 [DIRS 108871], p. 573).

Figure A6-4. Effects of Different Processes on Delta Deuterium and Delta Oxygen-18 Composition of Subsurface Water

Despite seasonal variations in the $\delta \mathrm{D}$ and $\delta^{18} \mathrm{O}$ composition of precipitation, the isotopic composition of the recharge water in humid regions is generally close to the average volume-weighted isotopic composition of precipitation. In arid climates, the isotopic composition of the recharge can be substantially different from the average volume-weighted isotopic composition of precipitation because of the preferential recharge of winter precipitation (see, for example, Ingraham et al. 1991 [DIRS 145088], p. 256) and because of evaporation prior to recharge. Generally, evaporation shifts the $\delta \mathrm{D}$ and $\delta^{18} \mathrm{O}$ composition of the infiltrating water to the right of the meteoric water line. The slope of the evaporation line increases with increasing relative humidity of the air (Clark and Fritz 1997 [DIRS 105738], Figure 2-8). The slope of the evaporation line ranges between 3.9 and 4.5 for relative humidities between 0 and 50 percent, which encompasses the range of relative humidities typical of Yucca Mountain during the summer months. Like evaporation, transpiration by plants increases the salinity of soil moisture; however, transpiration is a nonfractionating process and does not result in isotopic 
enrichment of the residual soil moisture (Clark and Fritz [DIRS 105738], pp. 80, 94). The relative importance of evaporation and transpiration on soil water loss can be evaluated by examining if increases in soil-water salinity are accompanied by corresponding increases in $\delta \mathrm{D}$ and $\delta^{18} \mathrm{O}$ compositions along an evaporation trend.

Once in the ground, interaction between groundwater and the solid surfaces in soil or rock can cause the $\delta^{18} \mathrm{O}$ composition of groundwater to be shifted horizontally to the right of the meteoric water line. This interaction is facilitated by high temperatures such as those associated with known geothermal fields (Clark and Fritz 1997 [DIRS 105738], pp. 250 to 255). At low temperatures, these interactions are kinetically inhibited. However, under special circumstances, interactions between groundwater and silicate minerals, or between groundwater and subsurface gases, may cause the isotopic compositions of groundwater to be shifted to the left of the meteoric water line (Clark and Fritz 1997 [DIRS 105738], Figure 9-1). The special circumstances typically involve alteration of rock to clays at high rock/water ratios or, in the case of gases, proximity to gas vents associated with volcanoes. Note that hydrogen isotope ratios are not generally affected as much by water/rock interactions as oxygen isotope ratios because rocks generally contain much less hydrogen than water on a volume-to-volume basis.

\section{A6.3.1.2.2 Carbon}

Carbon has two stable isotopes ${ }^{12} \mathrm{C}$ and ${ }^{13} \mathrm{C}$ and a third isotope, ${ }^{14} \mathrm{C}$, which is radioactive. Carbon-14 is produced in the atmosphere by interactions of nitrogen and cosmic rays that bombard the earth constantly. The reaction can be described as ${ }^{14} \mathrm{~N}(\mathrm{n}, \mathrm{p}) \Rightarrow{ }^{14} \mathrm{C} .{ }^{14} \mathrm{C}$ is rapidly mixed in the atmosphere and incorporated into the $\mathrm{CO}_{2}$ molecule where it is then available for incorporation into terrestrial carbonaceous material. The radioactive decay of ${ }^{14} \mathrm{C}$, with a halflife $\left(t_{1 / 2}\right)$ of 5,730 years (Clark and Fritz 1997 [DIRS 105738], Table 1-3), forms the basis for radiocarbon dating. The ${ }^{14} \mathrm{C}$ age of a sample is calculated by the following equation:

$$
t=(-1 / \lambda) \ln \left({ }^{14} A /{ }^{14} A_{0}\right)
$$

where

$t$ is the mean groundwater age (yr)

$\lambda$ is the radioactive decay constant, equal to $\ln (2) / \mathrm{t}_{1 / 2}: 1.21 \mathrm{x} \quad 10^{-4} \mathrm{yr}^{-1}$ (Clark and Fritz 1997 [DIRS 105738], p. 201)

${ }^{14} \mathrm{~A}$ is the measured ${ }^{14} \mathrm{C}$ activity

${ }^{14} A_{0}$ is the assumed initial activity.

${ }^{14} \mathrm{C}$ ages are typically expressed in percent modern carbon $(\mathrm{pmc}) . \mathrm{A}^{14} \mathrm{C}$ activity of $100 \mathrm{pmc}$ is taken as the ${ }^{14} \mathrm{C}$ activity of the atmosphere in the year 1890 , before the natural ${ }^{14} \mathrm{~A}$ of the atmosphere was diluted by large amounts of ${ }^{14} \mathrm{C}$-free carbon-dioxide gas from the burning of fossil fuel (Clark and Fritz 1997 [DIRS 105738], p. 18).

Theoretically, the activity of ${ }^{14} \mathrm{C}$ in a groundwater sample reflects the time at which the water was recharged. Unfortunately, precipitation is generally very dilute and has a high affinity for 
dissolution of solid phases in the soil zone, unsaturated zone, and/or saturated zone. In particular, in the transition from precipitation compositions to groundwater compositions, the bicarbonate + carbonate concentration in the water commonly increases by orders of magnitude (Langmuir 1997 [DIRS 100051], p. 292, Table 8.7; Meijer 2002 [DIRS 158813]). Because bicarbonate is the principal ${ }^{14} \mathrm{C}$-containing species in most groundwaters, the source of this additional bicarbonate can have a major impact on the "age" calculated from the ${ }^{14} \mathrm{C}$ activity of a given water sample. If the source is primarily decaying plant material in an active soil zone, the calculated "age" for the water sample should be close to the real age. On the other hand, if the source of the bicarbonate is dissolution of old $\left(\geq 10^{4} \mathrm{yr}\right)$ calcite with low ${ }^{14} \mathrm{C}$ activity, the calculated age for the sample will be too old.

A useful measure of the source of the carbon in a water sample is the $\delta^{13} \mathrm{C}$ value of the sample because this value is different for organic materials compared to calcites. The $\delta^{13} \mathrm{C}$ value is defined as follows, and expressed in units of per mil:

$$
\delta^{13} \mathrm{C}=\left[\left({ }^{13} \mathrm{C} /{ }^{12} \mathrm{C}\right)_{\text {sample }} /\left({ }^{13} \mathrm{C} /{ }^{12} \mathrm{C}\right)_{\text {standard }}-1\right] \times 1000
$$

The standard used for reporting stable carbon isotope measurements is carbon from a belemnite fossil from the Cretaceous Pee Dee Formation belemnite in South Carolina (Clark and Fritz 1997 [DIRS 105738], p. 9).

The $\delta^{13} \mathrm{C}$ values of carbon species typical of the soil waters in arid environments range from -25 to -13 per mil (Forester et al. 1999 [DIRS 109425], p. 36). At Yucca Mountain, pedogenic carbonate minerals have $\delta^{13} \mathrm{C}$ values that generally are between -8 and -4 per mil, although early formed calcites are also present that have $\delta^{13} \mathrm{C}$ values greater than 0 per mil (Forester et al. 1999 [DIRS 109425], Figure 16; Whelan et al. 1998 [DIRS 137305], Figure 5). Paleozoic carbonate rocks typically have $\delta^{13} \mathrm{C}$ values close to 0 per mil (Forester et al. 1999 [DIRS 109425], Figure 16; Whelan et al. 1998 [DIRS 137305], Figure 5).

\section{A6.3.1.2.3 Sulfur}

Four stable isotopes of sulfur occur in nature; of these ${ }^{32} \mathrm{~S}$ and ${ }^{34} \mathrm{~S}$ are the most abundant. The sulfur isotopes are fractionated as a result of reduction of sulfate and by isotope exchange reactions. The isotopic composition of sulfur is expressed in terms of delta- ${ }^{34} \mathrm{~S}\left(\delta^{34} \mathrm{~S}\right)$ as defined by:

$$
\delta^{34} \mathrm{~S}=\left[\left({ }^{34} \mathrm{~S} /{ }^{32} \mathrm{~S}\right)_{\text {sample }}\left({ }^{34} \mathrm{~S} /{ }^{32} \mathrm{~S}\right)_{\text {standard }}-1\right] \times 1000
$$

The standard used for reporting $\delta^{34} \mathrm{~S}$ is the troilite $(\mathrm{FeS})$ phase of the Canon Diablo meteorite (CDT), which has a ${ }^{34} \mathrm{~S} /{ }^{32} \mathrm{~S}$ ratio of 0.0450 . Analytical precision is generally greater than \pm 0.3 per mil (Clark and Fritz 1997 [DIRS 105738], p. 11).

In groundwater, sulfur is transported principally as the conservative ion $\mathrm{SO}_{4}{ }^{2-}$ and thus is a potentially useful indicator of groundwater mixing. Dissolution of solids containing sulfur can also readily change the $\delta^{34} \mathrm{~S}$ of groundwater. Of particular importance for this study is the fact the early Paleozoic marine carbonate that forms the carbonate aquifer near Yucca Mountain and, presumably, the groundwater from this aquifer, should both have distinctly high $\delta^{34} \mathrm{~S}$ values 
(25 to 30 per mil) compared to volcanic aquifer groundwater (Clark and Fritz 1997 [DIRS 105738], pp. 138 to 148 , Figures. 6-1 and 6-2). The $\delta^{34} \mathrm{~S}$ in volcanic environments is about $0 \pm 2$ per mil where the sulfur is in a reduced oxidation state and ranges from about 3 to 15 per mil in more oxidizing environments (Clark and Fritz 1997 [DIRS 105738], Figure 6-1).

\section{A6.3.1.2.4 Uranium}

Uranium-234 $\left(t_{1 / 2}=2.45 \times 10^{5} \mathrm{yr}\right)$ (Cheng et al. 2000 [DIRS 153475], p. 17) is part of the ${ }^{238} \mathrm{U}$ $\left(t_{1 / 2}=4.47 \times 10^{9} \mathrm{yr}\right)$ radioactive decay series (Clark and Fritz 1997 [DIRS 105738], Table 1-3). The ${ }^{234} \mathrm{U} /{ }^{238} \mathrm{U}$ activity ratio in rocks is generally close to the secular equilibrium value 1 . However, ${ }^{234} \mathrm{U}$ is typically enriched relative to ${ }^{238} \mathrm{U}$ in groundwater (Activity ratios $>1$; Osmond and Cowart 1992 [DIRS 145190], Figure 9.1). The primary causes for this enrichment are: preferential dissolution of ${ }^{234} \mathrm{U}$ from crystallographic defects caused by alpha decay; the tendency for ${ }^{234} \mathrm{U}$ atoms to be converted to the more soluble uranyl ion due to the effects of radiation-induced ionization (Gascoyne 1992 [DIRS 127184], Section 2.5.1), and direct ejection of ${ }^{234} \mathrm{Th}$ (which decays in about 24 days to ${ }^{234} \mathrm{U}$ ) into groundwater by alpha recoil. Uranium activity ratios may be lowered by release of uranium from rock and minerals with ${ }^{234} \mathrm{U} /{ }^{238} \mathrm{U}$ ratios near secular equilibrium through dissolution. Consequently, the ${ }^{234} \mathrm{U} /{ }^{238} \mathrm{U}$ activity ratios are the result of the competing effects of enrichment processes and dissolution of uranium-bearing material. Given the long half-life of ${ }^{234} \mathrm{U}$ relative to groundwater ages in this region, changes in the ${ }^{234} \mathrm{U} /{ }^{238} \mathrm{U}$ activity ratio due to ${ }^{234} \mathrm{U}$ decay are insignificant. Removal of uranium from solution by precipitation or sorption decrease $U$ concentrations, but these processes do not affect the isotopic ratio. Therefore, the isotopic ratio should be relatively constant along a groundwater pathway unless additional $U$ is added to the groundwater through mixing or by mineral or glass dissolution, or recoil-related processes.

\section{A6.3.1.2.5 Strontium}

Strontium is a trace constituent in groundwaters, with concentrations typically ranging from $10 \mu \mathrm{g} / \mathrm{L}$ to $1,000 \mu \mathrm{g} / \mathrm{L}$. Strontium has four naturally occurring isotopes, ${ }^{84} \mathrm{Sr},{ }^{86} \mathrm{Sr},{ }^{87} \mathrm{Sr}$ and ${ }^{88} \mathrm{Sr}$, all of which are stable. The absolute abundances of ${ }^{84} \mathrm{Sr},{ }^{86} \mathrm{Sr}$ and ${ }^{88} \mathrm{Sr}$ do not change. In contrast, the absolute abundance of ${ }^{87} \mathrm{Sr}$ is continually increasing because this nuclide is produced from decay of ${ }^{87} \mathrm{Rb}$. Therefore, the ${ }^{87} \mathrm{Sr} /{ }^{86} \mathrm{Sr}$ ratios of rocks and minerals continually increase; the present day ${ }^{87} \mathrm{Sr} /{ }^{86} \mathrm{Sr}$ ratio depends on the relative abundances of $\mathrm{Rb}$ to $\mathrm{Sr}$ and on their age (Faure 1986 [DIRS 105559], Section 8). Strontium in groundwater is acquired from the materials through which the water passes. The ${ }^{87} \mathrm{Sr} /{ }^{86} \mathrm{Sr}$ ratios in groundwater will evolve toward the isotopic composition of the host material along its flow path as water-rock reaction progresses. Strontium isotope ratios can therefore provide a record of groundwater sources, flow pathways, and water-rock interaction.

Strontium isotope ratios are commonly expressed using the delta notation relative to a standard value according to the equation:

$$
\delta^{87} \mathrm{Sr}=\left[\left({ }^{87} \mathrm{Sr} /{ }^{86} \mathrm{Sr}\right)_{\text {sample }} /\left({ }^{87} \mathrm{Sr} /{ }^{86} \mathrm{Sr}\right)_{\text {standard }}-1\right] \times 1000
$$

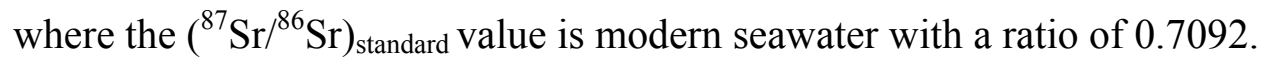


Strontium in the oceans has a residence time of about 5,000,000 years, considerably longer than oceanic mixing times, which are on the order of 1,000/yr (Faure 1986 [DIRS 105559], Section 11). As a result, the ${ }^{87} \mathrm{Sr} /{ }^{86} \mathrm{Sr}$ ratio of strontium in the open oceans is consistent globally. This ratio, however, has changed throughout the Phanerozoic in response to the relative contributions of the different rock types that are exposed to chemical weathering. The variations of the ${ }^{87} \mathrm{Sr} /{ }^{86} \mathrm{Sr}$ ratios throughout the Phanerozoic have been determined by analyzing unaltered samples of marine carbonate (e.g., Burke et al. 1982 [DIRS 162906]). This work and subsequent refinements by a number of other studies have produced a detailed history of the variations in oceanic ${ }^{87} \mathrm{Sr} /{ }^{86} \mathrm{Sr}$ ratios throughout the Phanerozoic. Such information can be quite useful when interpreting ${ }^{87} \mathrm{Sr} /{ }^{86} \mathrm{Sr}$ ratios of groundwater that has interacted with marine carbonate rock.

\section{A6.3.2 Assignment and Description of Hydrochemical Groupings in the Vicinity of Yucca Mountain}

Hydrochemical and isotopic data from over 200 groundwater samples are presented in this appendix. The locations of wells cited in this section are shown in Figure A6-5, with insets to show greater detail. As these maps show, the data are unevenly distributed throughout the Yucca Mountain region, with clusters of wells in central and northern Yucca Mountain, farming areas of the Amargosa Desert, and along U.S. Highway 95. Elsewhere, data are relatively sparse, particularly to the west and east of Yucca Mountain in Crater Flat and Jackass Flats, respectively. An important data gap also exists at Yucca Mountain itself, between the cluster of wells in central and northern Yucca Mountain, and the line of wells along U.S. Highway 95. The potential impact of these gaps in data coverage is to make mixing trends among groundwaters separated by the gaps less obvious.

To facilitate interpretation and discussion, these samples are assigned to 22 different groups. Each group is identified by a unique symbol and color, which are used in plots throughout. Samples are numbered sequentially within groups. Numbering within and between groups generally increases from north to south, with the exception of the last three groups, Mine Mountain, Amargosa Flat, and Funeral Mountains. All groupings are based largely on geographic distribution, or geographic affiliation. Hydrochemical similarities and/or trends were also considered in the group assignments. Accordingly, some groups show a relatively uniform hydrochemical composition, whereas others show a spread in hydrochemistry and were grouped to emphasize this transition. A brief geographic and hydrochemical description of each group follows. Hydrochemistry of all samples is shown on trilinear (Piper) and scatter plots (Figures A6-6 through A6-8), with the groups divided into three separate figures for clarity. 

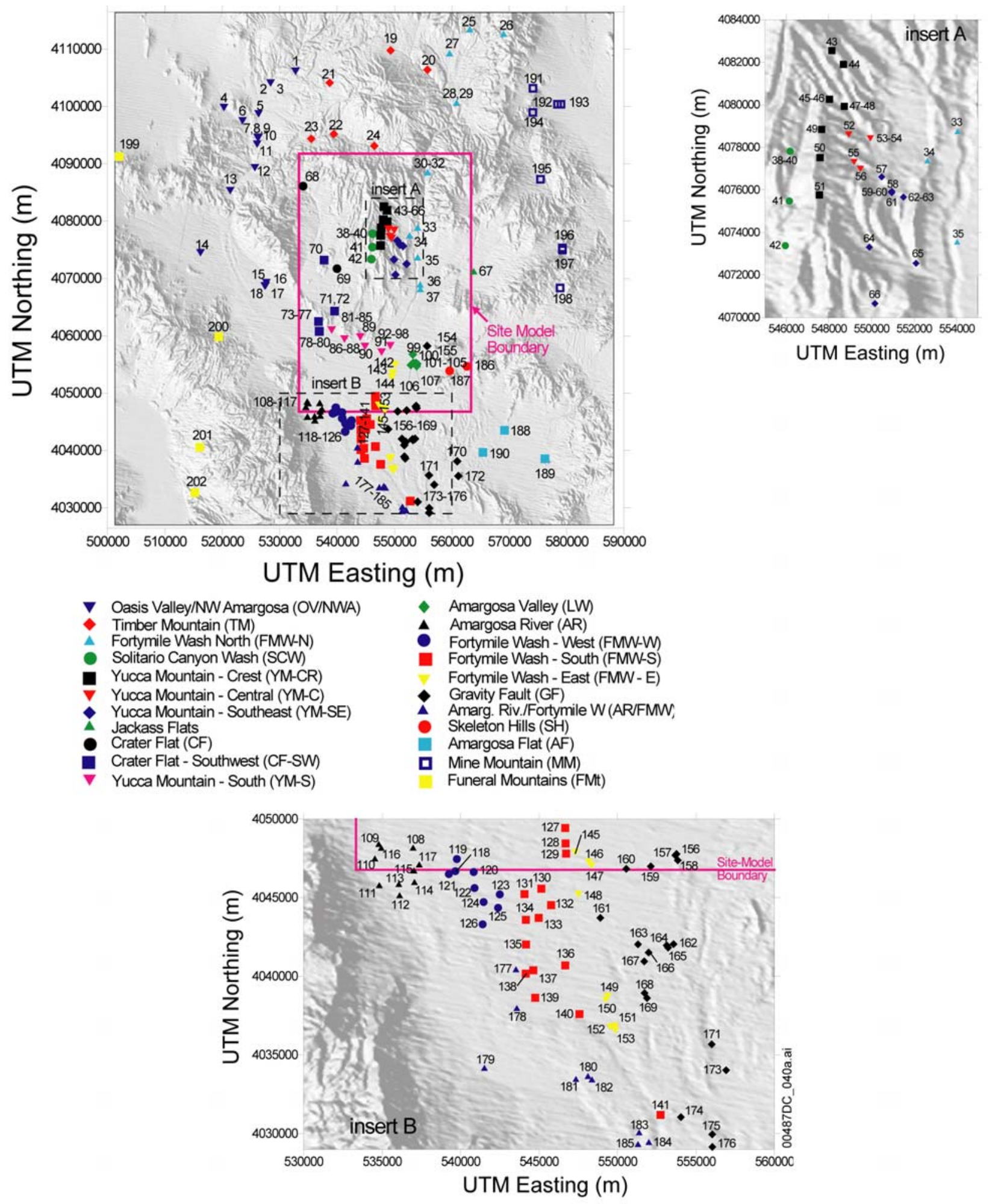

NOTES: The figure has color-coded data points and should not be read in a black and white version. The upper right panel corresponds to the area marked "insert A"; the lower panel corresponds to the area marked "insert B." UTM=Universal Transverse Mercator.

Figure A6-5. Locations of Boreholes in the Vicinity of Yucca Mountain and the Northern Amargosa Desert 
The Oasis Valley/northwest Amargosa Desert group (OV/NWA) comprises boreholes located from the northern part of Oasis Valley extending southward along the course of the Amargosa River to the west and south of Bare Mountain. Boreholes drilled as part of the Nye County Early Warning Drilling Program (NC-EWDP) are located along the southern edge of Crater Flat and extend southeasterly into Fortymile Wash. Most of these wells have been assigned into two groupings, Crater Flat-southwest (CF-SW) and Yucca Mountain-south (YM-S), on the basis of geographic position and hydrochemistry. Two boreholes with similar chemistry comprise the Crater Flat group (CF). Boreholes to the north of Yucca Mountain are assigned to the Timber Mountain group (TM). A single borehole, though one with unique hydrochemical characteristics comprises the Jackass Flats group. Several tightly grouped boreholes along U.S. Highway 95 are assigned to the Amargosa Valley (formerly Lathrop Wells) group (LW). Finally, the boreholes in the northeast part of the study area are assigned to the Mine Mountain group.

Most groundwaters from these regions are a sodium-bicarbonate type (Figure A6-6). Notable exceptions are those samples from the SW Crater Flat Group and the Mine Mountain Group, which contain greater $\mathrm{Ca}^{2+}+\mathrm{Mg}^{2+}$ relative to $\mathrm{Na}^{+}+\mathrm{K}^{+}$. These groundwaters either originate from the regional carbonate aquifer or have contacted alluvium derived from carbonate rocks and their greater $\mathrm{Ca}^{2+}+\mathrm{Mg}^{2+}$ contents reflect the composition of these rock. The hydrochemical characteristics of groundwater beneath the broad area of Jackass Flats are represented by data from a single borehole (J-11), which has a unique chemical signature that may or may not be representative of regional groundwater flow in this area.

Boreholes at Yucca Mountain were divided into (1) a western group designated Solitario Canyon Wash (SCW), which includes samples from west of the Solitario Canyon fault, (2) a group of samples that encompasses the crest of Yucca Mountain (Yucca Mountain-Crest YM-CR), (3) a central group (Yucca Mountain Central, YM-C), which includes boreholes located within the central block of Yucca Mountain, and (4) a southeastern group (Yucca Mountain-Southeast, YM-SE), which includes boreholes along and south of Dune Wash. Boreholes near Fortymile Wash east and northeast of Yucca Mountain are assigned to a northern Fortymile Wash North group (FMW-N), distinguishing them from samples along the course of the Fortymile Wash in the Amargosa Desert (discussed below).

These groundwater are mostly sodium-bicarbonate water, typically with low total dissolved solids (TDS) (Figure A6-7). An important exception to this is the borehole p\#1(c) sample from the YM-SE group (site 63), which penetrates to the carbonate aquifer. This sample is distinct from those from the volcanic aquifer in that it has higher calcium, magnesium, and TDS. The

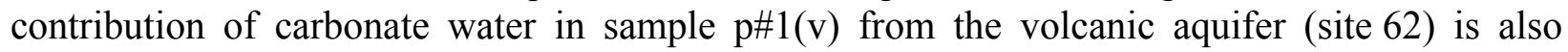
evident in Figure A6-7. It was estimated that about 28.6 percent of the groundwater in this sample originated from upward flow in the borehole from the carbonate aquifer (Craig and Robison 1984 [DIRS 101040], p. 49). 

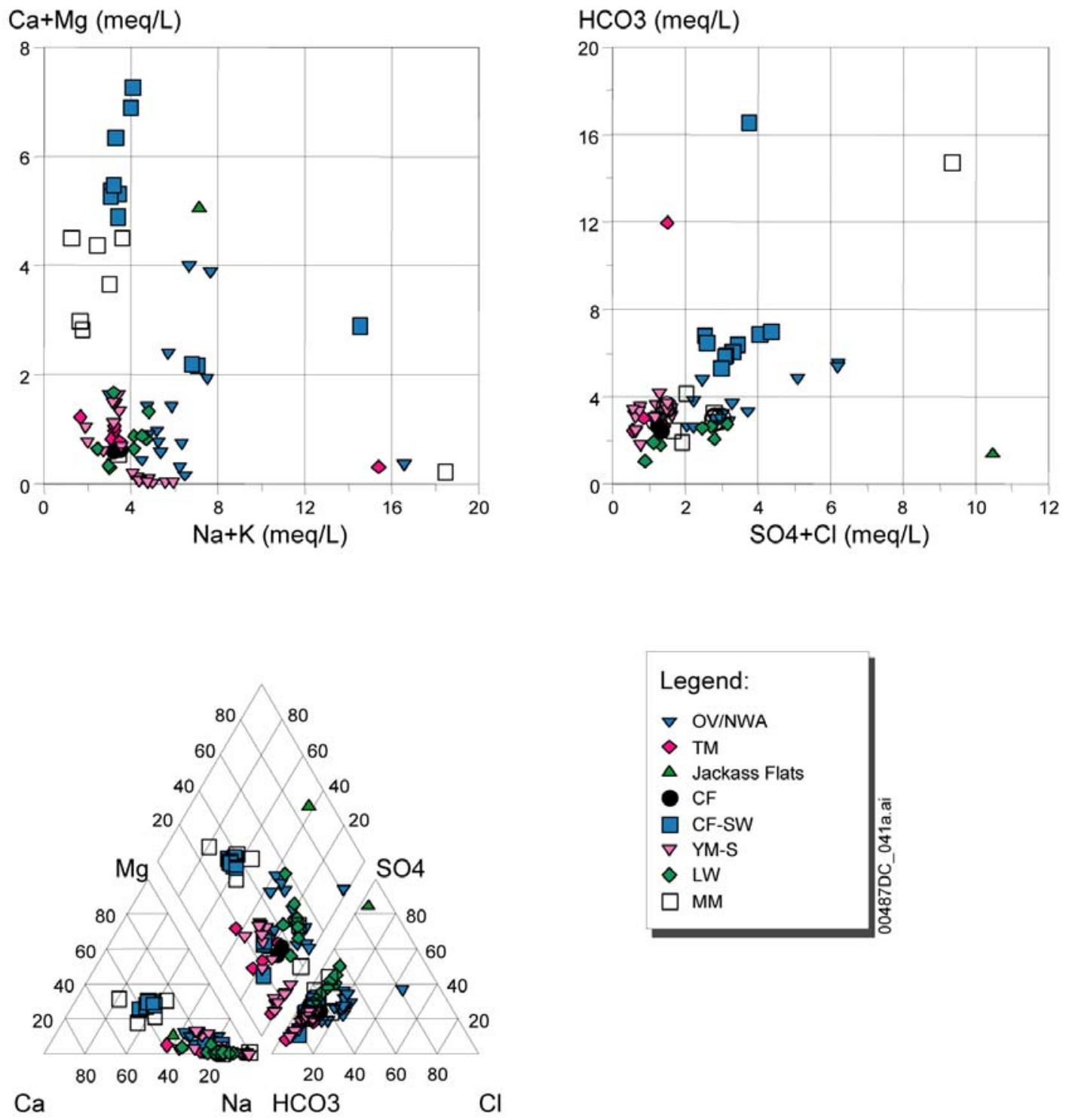

Source: Table A6-1.

NOTE: Units for the trilinear plots are percent milliequivalents per liter. Legend explained in text.

Figure A6-6. Trilinear and Scatter Plots for Samples that Surround Yucca Mountain But Are Generally North of the Amargosa Valley

Figure A6-8 shows hydrochemical characteristics from boreholes located south of U.S. Highway 95. The Amargosa River (AR) and Gravity fault (GF) groupings constitute boreholes located on the west and east sides of the Amargosa Desert, respectively. Groundwater from these groupings is typically sodium-calcium-bicarbonate-sulfate water type with higher TDS than samples in the central Amargosa Desert. Boreholes located along and near the main channel of Fortymile Wash in the Amargosa Desert are assigned to the Fortymile Wash-south (FMW-S) grouping. These are relatively dilute sodium-bicarbonate waters. The Amargosa River, Gravity fault and FMW-S groups, in general, represent three end-members of the hydrochemistry displayed in the Amargosa Desert region. Boreholes of the 
Fortymile Wash-East (FMW-E), Fortymile Wash-West (FMW-W) and Amargosa River/Fortymile Wash (AR/FMW) groupings are transitional between these end members. Boreholes near the Skeleton Hills and Specter Range Thrust fault are grouped together as Skeleton Hills (SH). Boreholes in the far east of the study area are assigned to the Amargosa Flat group (AF), and finally, the widely spaced samples along the western part of the study area are grouped as the Funeral Mountains (FMt) group.
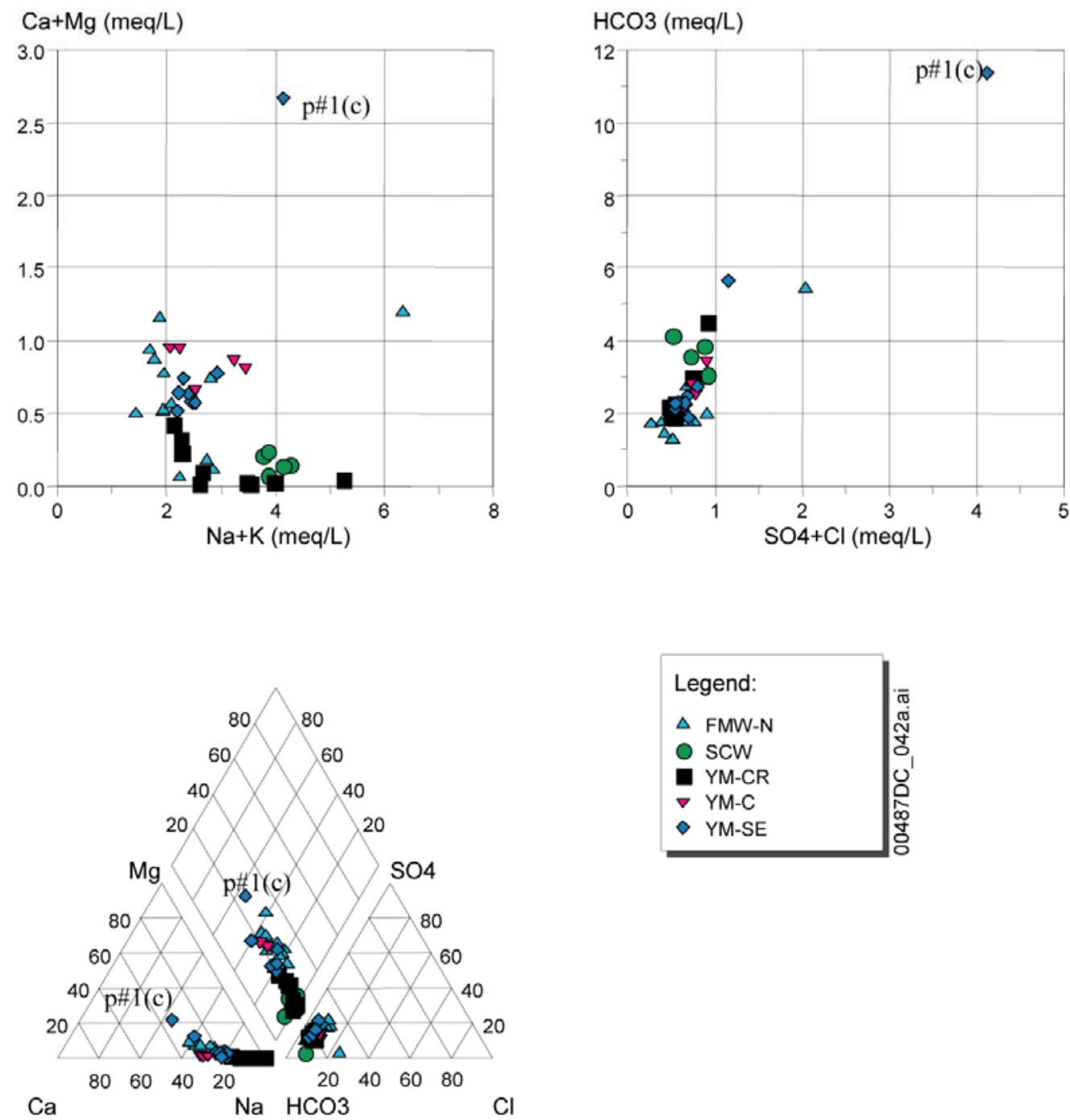

Source: Table A6-1.

NOTE: Units for the trilinear plots are percent milliequivalents per liter. Legend explained in text.

Figure A6-7. Trilinear and Scatter Plots for Samples from the Yucca Mountain Area 

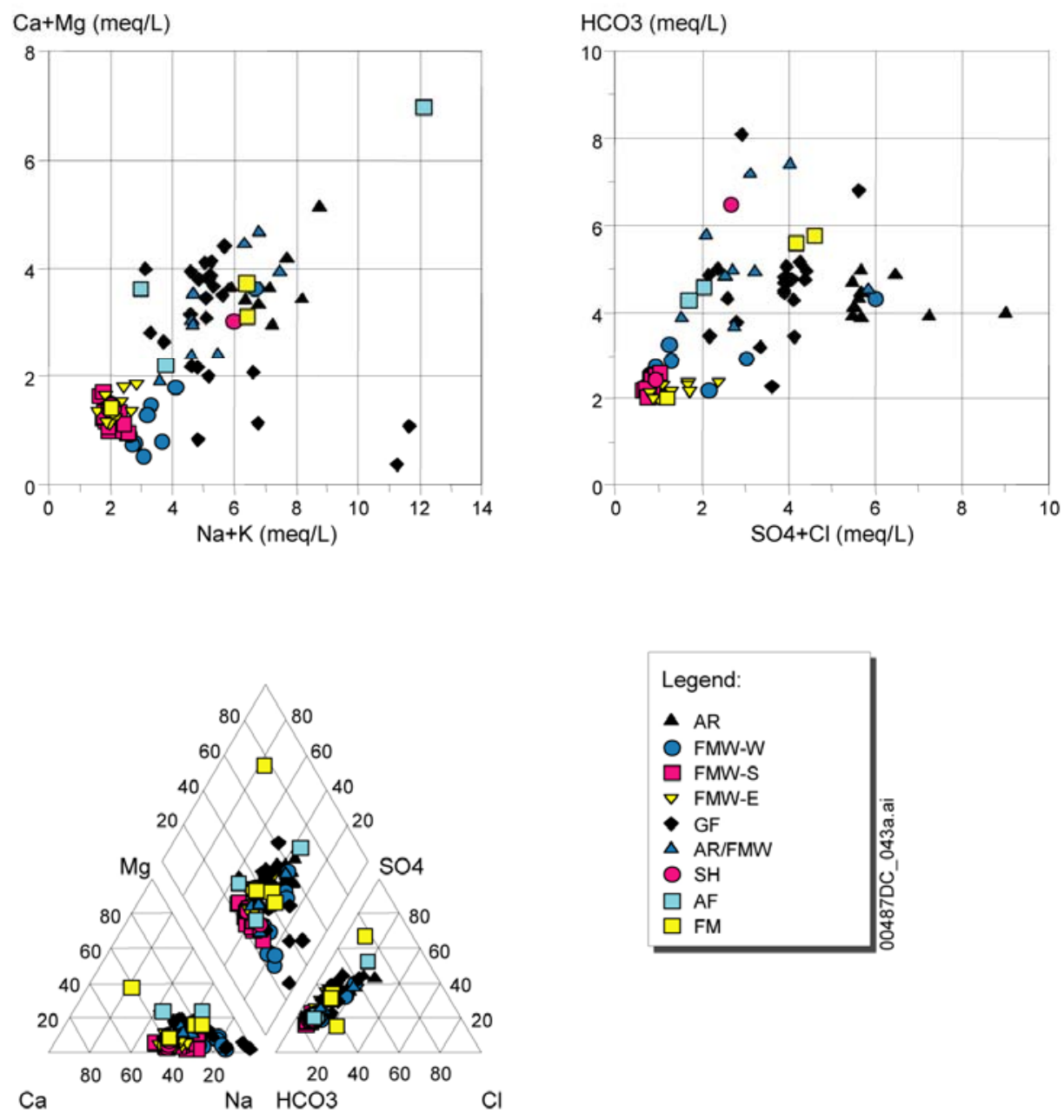

Source: Table A6-1.

NOTE: Units for the trilinear plots are percent milliequivalents per liter. Legend explained in text.

Figure A6-8. Trilinear and Scatter Plots for Samples from Groupings in the Amargosa Desert Region

\section{A6.3.3 Depth-Dependent Trends in the Chemical and Isotopic Composition of Groundwater}

This section describes groundwater samples from different depth intervals in single well or closely spaced wells to evaluate the relationship between hydrochemistry and depth and/or aquifer rock type. For most wells in the Yucca Mountain area, groundwater samples were obtained by pumping from an open borehole. In some boreholes, flow logs made during pumping indicate that much of the groundwater came from a relatively narrow depth interval, whereas in other boreholes, flow logs indicate the mixing of groundwater from different depth intervals. Sampling groundwater from an open borehole produces a groundwater composition that is naturally weighted by the permeability of the producing zones and which may be 
representative of the average composition of groundwater flowing past the open interval of the borehole (see Section A6.3.4). However, it may also result in artificial mixing of groundwaters that would not otherwise mix and thereby obscure compositional differences that reflect different groundwater sources and rates of groundwater movement. This section examines data from the NC-EWDP wells obtained from discrete-interval sampling or from closely spaced wells and piezometers completed at different depths to assess the magnitude and importance of these differences.

\section{A6.3.3.1 Boreholes NC-EWDP-19D and -19P}

Groundwater samples were collected at borehole NC-EWDP-19D (Site 92) from the open borehole ("composite" sample), from the saturated alluvial section (Site 94), from zones 1 to 4 at different depth intervals within the alluvium (Sites 95-98), and from the alluvium at nearby piezometer NC-EWDP-19P (Site 93). The screened interval in NC-EWDP-19P (109.5- to 139.8-m depth) is slightly higher but overlaps with Zone 1 of NC-EWDP-19D (125.9-131.4 m). The open borehole sample from NC-EWDP-19D included contributions from a lithic ash flow tuff between depths of 251 and $379 \mathrm{~m}$, whereas the remainder of the groundwater samples originated from the alluvium overlying the tuffs (DTN: LA0311EK831223.001 [DIRS 165985]). The composition of groundwater from the open-hole and the composite alluvial interval likely reflect the relative amounts of inflow from different zones into the borehole during pumping.

All of the groundwater samples from NC-EWDP-19D and -19P are characterized by low $\mathrm{Cl}$-concentrations compared to Crater Flat area groundwater and very light $\delta^{18} \mathrm{O}$ compared to northern Fortymile Wash area (FMW-N) groundwater found at boreholes J-13, J-12, and JF-3 (Tables A6-1 and A6-2). Samples from wells NC-EWDP-19P and -19D (Zone 2) have higher concentrations of $\mathrm{Ca}^{2+}$ and $\mathrm{Sr}^{2+}$ (not shown, see Table A6-2), lower concentrations of $\mathrm{Na}^{+}$and $\mathrm{HCO}_{3}{ }^{-}$, heavier $\delta \mathrm{D}$, and higher ${ }^{14} \mathrm{C}$ activity compared to other alluvial groundwater from well NC-EWDP-19D (Figure A6-9). These compositional characteristics are compatible with less water-rock interaction and short residence times of groundwater in this interval compared with other intervals in the alluvium. However, hydraulic testing (BSC 2004 [DIRS 170010]) at NC-EWDP-19D indicated that Zone 4 was the most permeable zone in the immediate vicinity of the borehole. 

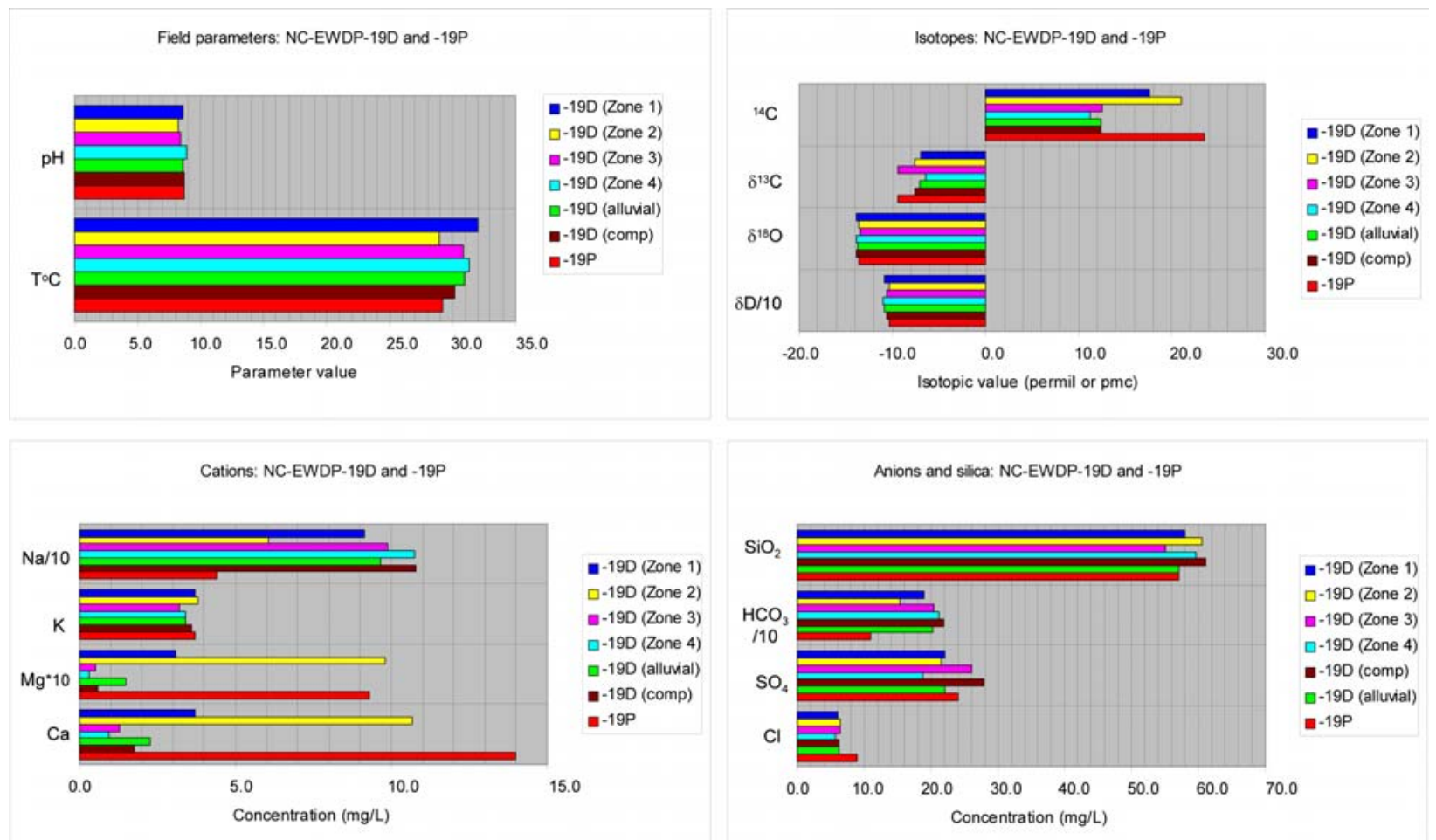

00487DC_074.ai

Source: Tables A6-1 and A6-2.

NOTE: For plotting purposes only, Mg2+ concentration has been multiplied by 10 , and the values for $\mathrm{Na}+, \mathrm{D}$, and HCO3- have been divided by 10.

Figure A6-9. Plots of Selected Hydrochemical Constituents for the Different Depth Intervals of Boreholes NC-EWDP-19D and -19P

\section{A6.3.3.2 Borehole NC-EWDP-9SX}

Groundwater from four depth intervals in borehole NC-EWDP-9SX (Sites 82 to 85) originates from the upper $91 \mathrm{~m}$ of the SZ just south of Crater Flat. The groundwater over this relatively narrow depth range is similar in all four-depth intervals (Figure A6-10). In general, ${ }^{14} \mathrm{C}, \delta^{13} \mathrm{C}$, $\delta \mathrm{D}, \mathrm{Na}^{+}, \mathrm{K}^{+}$, and $\mathrm{Cl}^{-}$decrease slightly and $\mathrm{HCO}_{3}{ }^{-}$increases with depth in the borehole, but overall, there is relatively little chemical or isotopic variability within the depth range spanned by sampling Zones 1 to 4 . In addition to the data shown in Figure A6-10, the $\mathrm{Sr}^{2+}$ concentration in Zone 1 is slightly less than in the other zones, but the $\delta^{87} \mathrm{Sr}, \delta^{34} \mathrm{~S}$, and ${ }^{234} \mathrm{U} /{ }^{238} \mathrm{U}$ activity ratio data are very similar in all four zones (Table A6-2). The composite sample from borehole NC-EWDP-9SX (Site 81) has a composition that is similar to that of the individual zones but with slightly higher concentrations of $\mathrm{Ca}^{2+}, \mathrm{Mg}^{2+}, \mathrm{Na}^{+}, \mathrm{SO}_{4}{ }^{2-}, \mathrm{SiO}_{2}$, and $\mathrm{Sr}^{2+}$. The remainder of the chemical and isotopic species of the composite sample is similar or intermediate to those of the four individual zones. 

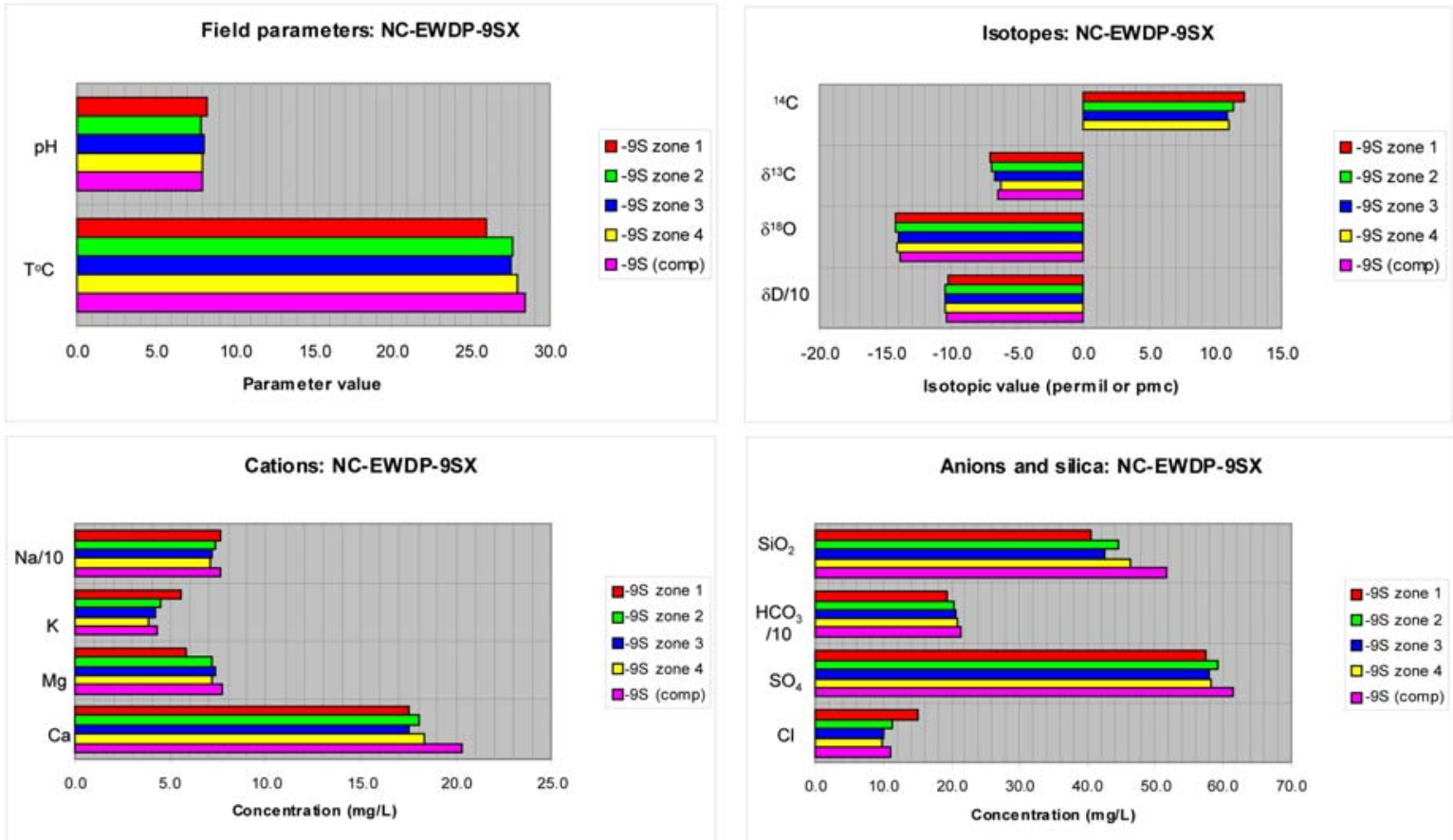

Source: Tables A6-1 and A6-2.

NOTE: For plotting purposes only, the values for $\mathrm{Na}+, \mathrm{D}$, and $\mathrm{HCO}-$ have been divided by 10.

Figure A6-10. Plots of Selected Hydrochemical Constituents for the Different Depth Intervals of Borehole NC-EWDP-9SX

\section{A6.3.3.3 Boreholes NC-EWDP-1DX and -1S}

Groundwater from shallow intervals (48.8-54.9 and 64.0-82.3 m) in borehole NC-EWDP-1S (Sites 75 to 76) shows large differences in both chemical and isotopic composition compared to deep groundwater $(658.4$ to $682.8 \mathrm{~m}$ ) from Zone 2 (Site 74 ) in borehole NC-EWDP-1DX (Figure A6-11). Chemically, groundwater from Zone 2 in NC-EWDP-1DX has much higher $\mathrm{Na}^{+}, \mathrm{Sr}^{2+}$ (not shown, see Table A6-2), $\mathrm{Cl}^{-}, \mathrm{F}^{-}$(not shown, see Table A6-2), and $\mathrm{HCO}_{3}^{-}$ concentrations and has lower $\mathrm{pH}$ and lower $\mathrm{Ca}^{2+}$ and $\mathrm{SO}_{4}{ }^{2-}$ concentrations than the shallower groundwater from NC-EWDP-1S. The deep groundwater from Zone 2 of borehole NC-EWDP1DX is heavier in $\delta^{13} \mathrm{C}$ and $\delta^{34} \mathrm{~S}$ (not shown, see Table A6-2), lighter in $\delta^{18} \mathrm{O}$ and $\delta \mathrm{D}$, and has a lower ${ }^{234} \mathrm{U} /{ }^{238} \mathrm{U}$ activity ratio (not shown, see Table A6-2) than the shallow zones in NC-EWDP1S (Figure A6-11 and Table A6-2). The composite groundwater samples from boreholes NCEWDP-1S (Site 77) and NC-EWDP-1DX (Site 73) have similar isotopic and chemical compositions to the shallow groundwater samples from NC-EWDP-1S. 

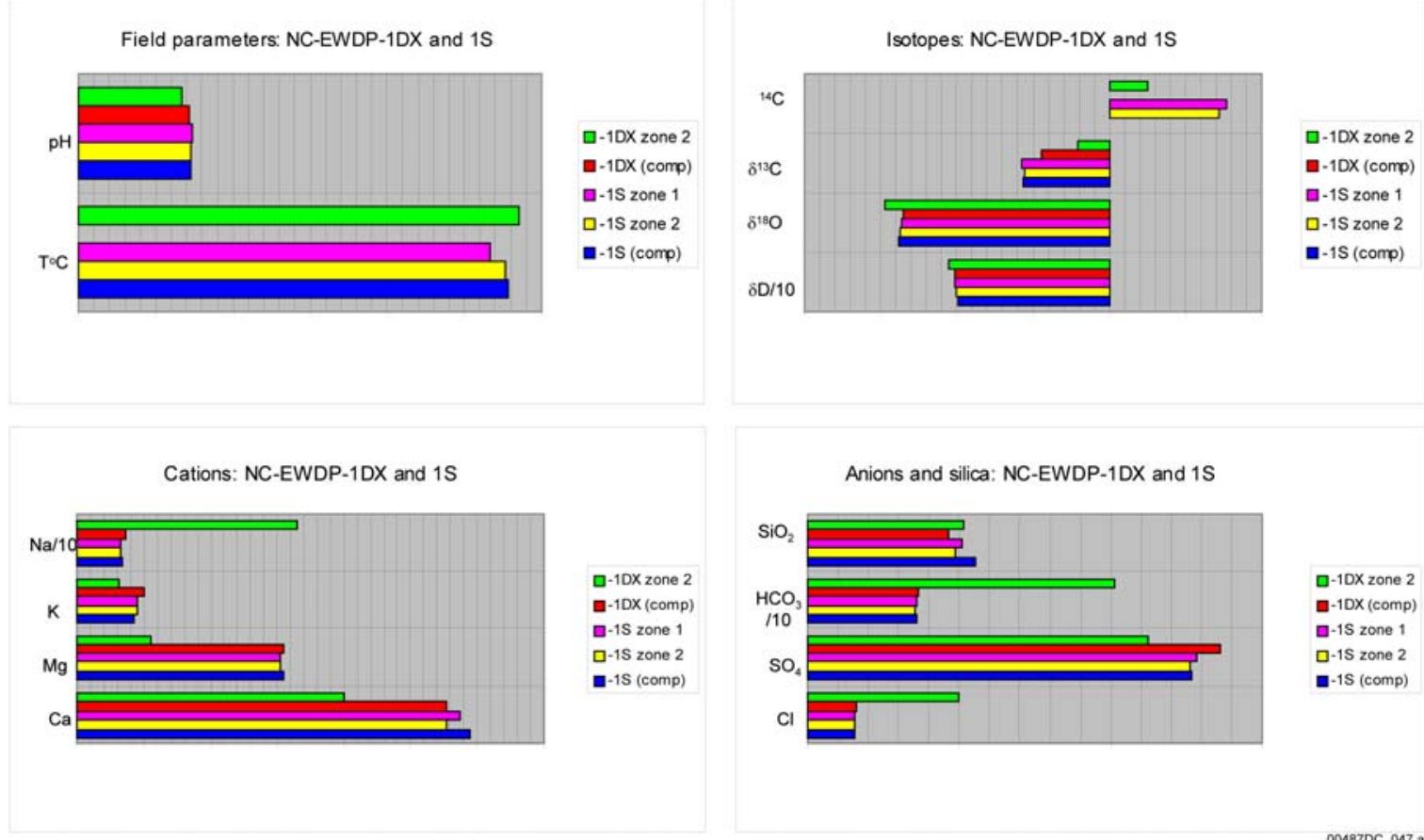

Source: Tables A6-1 and A6-2.

NOTE: For plotting purposes only, the values for $\mathrm{Na}+, \mathrm{D}$, and $\mathrm{HCO}-$ have been divided by 10 .

Figure A6-11. Plots of Selected Hydrochemical Constituents for the Different Depth Intervals of Boreholes NC-EWDP-1S and -1DX

\section{A6.3.3.4 Boreholes NC-EWDP-3D and -3S}

Groundwater at NC-EWDP-3S was sampled from Zone 2 between depths of 103.6 and $128.0 \mathrm{~m}$ (site 87) and from Zone 3 between depths of 146.3 and $160.0 \mathrm{~m}$ (Site 88) (DTN: GS010308312322.003 [DIRS 154734]). Well NC-EWDP-3D (Site 86) was drilled to $762 \mathrm{~m}$ but was open between 159 to $292 \mathrm{~m}$ (DTN: LA0311EK831223.001 [DIRS 165985]). The groundwaters from these three sample locations have similar concentrations in most major ions with the exception that the sample from Zone 2 of $\mathrm{NC}-E W D P-3 \mathrm{~S}$ is higher in $\mathrm{Cl}^{-}$ concentration, has higher ${ }^{14} \mathrm{C}$, and is lighter in $\delta^{13} \mathrm{C}$ compared to the other two samples (Figure A6-12). Compared to other wells in the YM-S group, groundwater samples from $\mathrm{NC}-E W D P-3 \mathrm{D}$ and $-3 \mathrm{~S}$ are very low in divalent cations, including $\mathrm{Ca}^{2+}, \mathrm{Mg}^{2+}$, and $\mathrm{Sr}^{2+}$ (not shown, see Table A6-2). 
Field parameters: NC-EWDP-3S and 3D

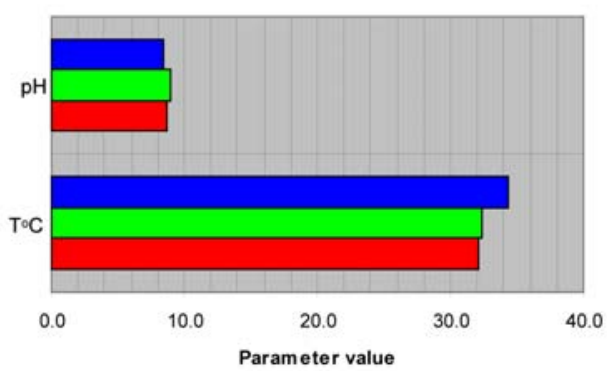

Cations: NC-EWDP-3S and 3D

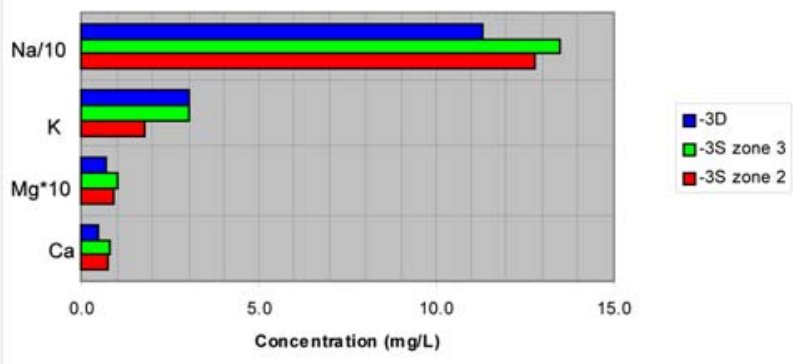

Isotopes: NC-EWDP-3S and 3D

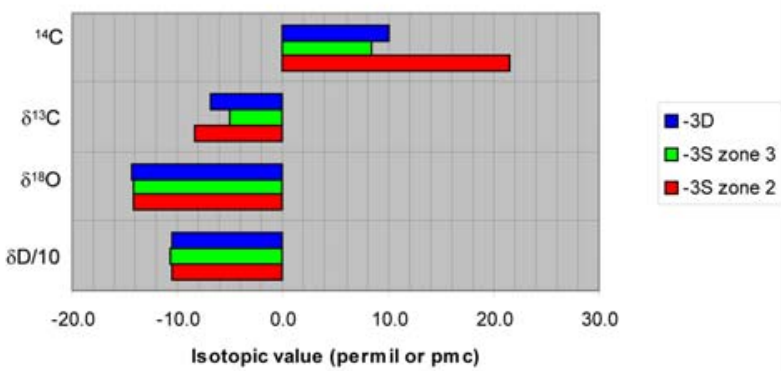

Anions ans silica: NC-EWDP-3S and 3D

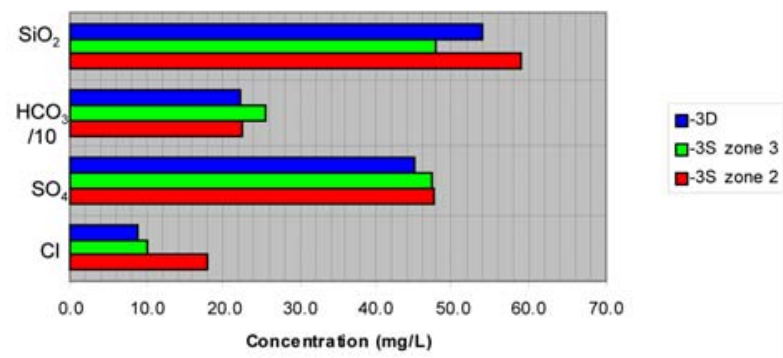

00487DC_045.ai

Source: Tables A6-1 and A6-2.

NOTE: For plotting purposes only, Mg2+ concentration has been multiplied by 10 , and the values for $\mathrm{Na}+, \mathrm{D}$, and HCO3- have been divided by 10.

Figure A6-12. Plots of Selected Hydrochemical Constituents for the Different Depth Intervals of Boreholes NC-EWDP-3S and NC-EWDP-3D

\section{A6.3.3.5 Boreholes NC-EWDP-12PA, -12PB, and -12PC}

Boreholes NC-EWDP-12PA (Site 78), -12PB (Site 79), and -12PC (Site 80) form a piezometer nest in the northern Amargosa Desert just south of western Crater Flat. As shown in Table A4-3, the open intervals of the piezometers in boreholes NC-EWDP-12PA and NC-EWDP-12PB are located about $46 \mathrm{~m}$ below the open interval in NC-EWDP-12PC. Groundwater from boreholes NC-EWDP-12PA and NC-EWDP-12PB is very similar with respect to almost all chemical species and isotopes (Figure A6-13). The shallower groundwater from NC-EWDP-12PC is higher in ${ }^{14} \mathrm{C}_{,} \mathrm{Ca}^{2+}, \mathrm{Mg}^{2+}$, and $\mathrm{SO}_{4}{ }^{2-}$, lower in $\mathrm{K}^{+}, \mathrm{Na}^{+}, \mathrm{HCO}_{3}{ }^{-}, \mathrm{F}^{-}$(not shown, see Table A6-2), and $\mathrm{SiO}_{2}$, and lighter in $\delta^{13} \mathrm{C}$ than groundwater from the other boreholes. The lower ${ }^{14} \mathrm{C}$ and heavier $\delta^{13} \mathrm{C}$ of the groundwater in boreholes NC-EWDP-12PA and -12PB indicates the deep groundwater has interacted with more carbonate rocks. The geologic map of the NTS and vicinity shows that a slide block of carbonate sedimentary rock from Bare Mountain outcrops along the low ridge bordering southern Crater Flat just north of these boreholes (Slate et al. 2000 [DIRS 150228], Plate 1, p. 13). The groundwater at all three boreholes has similar $\delta^{18} \mathrm{O}$ and $\delta \mathrm{D}$ to groundwater at borehole VH-2 in western Crater Flat (Table A6-2). 

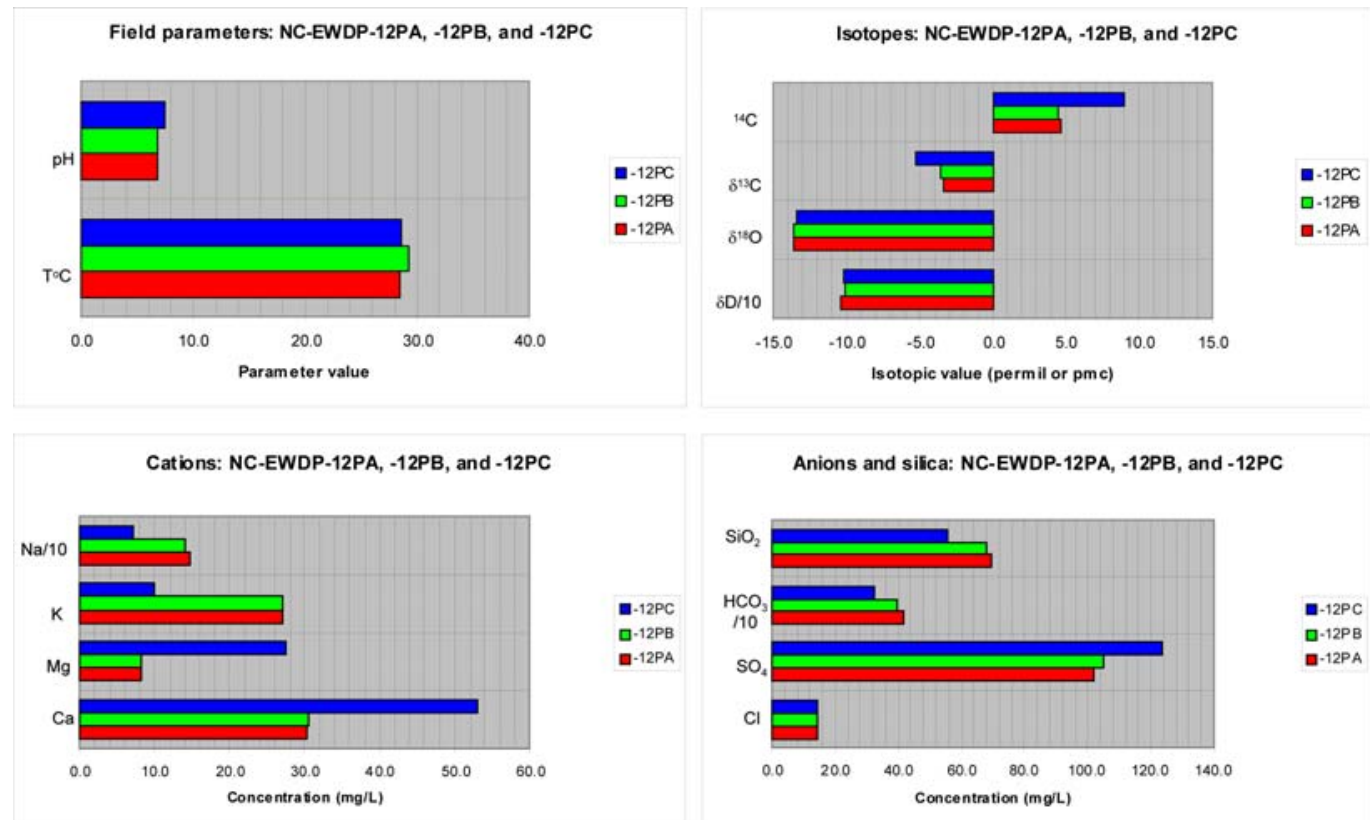

Source: Tables A6-1 and A6-2.

NOTE: For plotting purposes only, the values for $\mathrm{Na}+, \mathrm{D}$, and $\mathrm{HCO}-$ have been divided by 10 .

Figure A6-13. Plots of Selected Hydrochemical Constituents for the Different Depth Intervals of Boreholes NC-EWDP-12PA, -12PB and NC-EWDP-12PC

\section{A6.3.3.6 Summary of Depth-Dependent Trends in Groundwater Compositions}

Groundwater geochemical and isotopic data from five groups of NC-EWDP wells and piezometers along U.S. Highway 95 were examined to determine the extent of compositional changes with sampling depth. The changes with depth for most constituents were small at wells NC-EWDP-9SX, piezometers NC-EWDP-12PA, NC-EWDP-12PB and NC-EWDP-12PC, and wells NC-EWDP-3D and NC-EWDP-3S. This may be due, in part, to the relatively small range of depths sampled within each of these groups. For these groups, the composition of the groundwater sampled from the open borehole within the group does not substantially differ from any of the samples taken from a narrower depth interval. For wells NC-EWD-1DX and NC-EWD-1S, the deep (658.4-682.8 m) sample from Zone 2 of NC-EWDP-1DX (Site 74) is very different from the other samples in this group. However, groundwater from Zone 2 does not appear to contribute significantly to the composition of groundwater pumped from the open interval of NC-EWDP-1DX (Site 73), which more closely resembles shallow groundwater from nearby well NC-EWDP-1S. This observation indicates that the deep groundwater from Zone 2 at NC-EWDP-1DX may be relatively stagnant and not representative of the flowing groundwater composition at this location. Groundwaters from wells NC-EWDP-19D and NC-EWDP-19P have significant compositional variations with depth that indicate possible differences in groundwater sources, flow rates, or extent of water/rock interactions. The shallow groundwater from piezometer NC-EWDP-19P (Site 93) represents the composition of the shallowest and, perhaps, youngest groundwater in this area. The composite alluvial sample from well NC-EWDP-19D (Site 94) approximates the average composition of alluvial groundwater in this area. 


\section{A6.3.4 Areal Distributions of Chemical and Isotopic Species}

In this section, areal distributions of values measured for the concentrations of major cations and anions and for isotopic ratios are presented, along with some preliminary analysis. The discussions of areal trends in individual chemical and isotopic constituents presented in this section are intended to be somewhat general in character. More detailed discussions are presented below. Many boreholes, particularly the Nye County-EWDP boreholes along U.S. Highway 95 (Yucca Mountain-South grouping) have numerous sampled intervals as discussed previously. In these cases, one value, which is considered to best represent the average value for that borehole and to best represent regional hydrochemical trends is plotted. Typically, data for groundwater samples pumped from the entire open interval of borehole are plotted in figures in Sections A6.3.4 and A6.3.5. Thus, the sampled groundwater compositions are naturally weighted toward the compositions in the most permeable intervals of the well, and the compositions of groundwater from less permeable zones attain less emphasis. These composite samples thus provide a good indication of the flux-weighted composition of groundwater actually moving past the well in the aquifer. (Note: One exception to this generalization exists in the case of NC-EWDP-19D, where the composite alluvial sample, rather than the composite borehole sample, was used.) Nonetheless, vertical heterogeneity displayed among the samples is recognized as an important element in evaluating the flow system. Although groundwater pumped from the open interval of a borehole may be representative of the average flowing composition, more detailed depth sampling, like that available for well NC-EWDP-19D (Section A6.3.3.1), does suggest that in some locations groundwaters may originate from different sources, travel at different velocities, or undergo different degrees of water/rock interaction. These groundwaters can become artificially mixed in samples pumped from large open intervals, partially obscuring details of the flow system.

\section{A6.3.4.1 pH}

Groundwater $\mathrm{pH}$ at Yucca Mountain varies between about 7 and 9 (Figure A6-14). Some of the higher $\mathrm{pH}$ values are found in the vicinity of Yucca Crest, with similarly high $\mathrm{pH}$ values found in groundwater associated with Solitario Canyon Wash. Groundwater in the carbonate aquifer at borehole $\mathrm{p \# 1} \mathrm{(Site} \mathrm{63)} \mathrm{has} \mathrm{a} \mathrm{distinctly} \mathrm{lower} \mathrm{pH}$ value (6.6) compared to groundwater in the volcanic aquifer at Yucca Mountain. Groundwater to the north and northeast of Yucca Mountain also has a $\mathrm{pH}$ range of 7 to 9 , with the highest values present in the northernmost part of Fortymile Wash. South of the northern boundary of the site model, groundwater $\mathrm{pH}$ along Fortymile Wash shows an overall increase from values of about 7.2 to 7.6 directly east of Yucca Mountain to values greater than 8 near Fortymile Wash in the Amargosa Desert. Groundwater $\mathrm{pH}$ values less than 8 generally are typical of the groundwater associated with the Amargosa River and Gravity fault areas (Figure A6-14). 


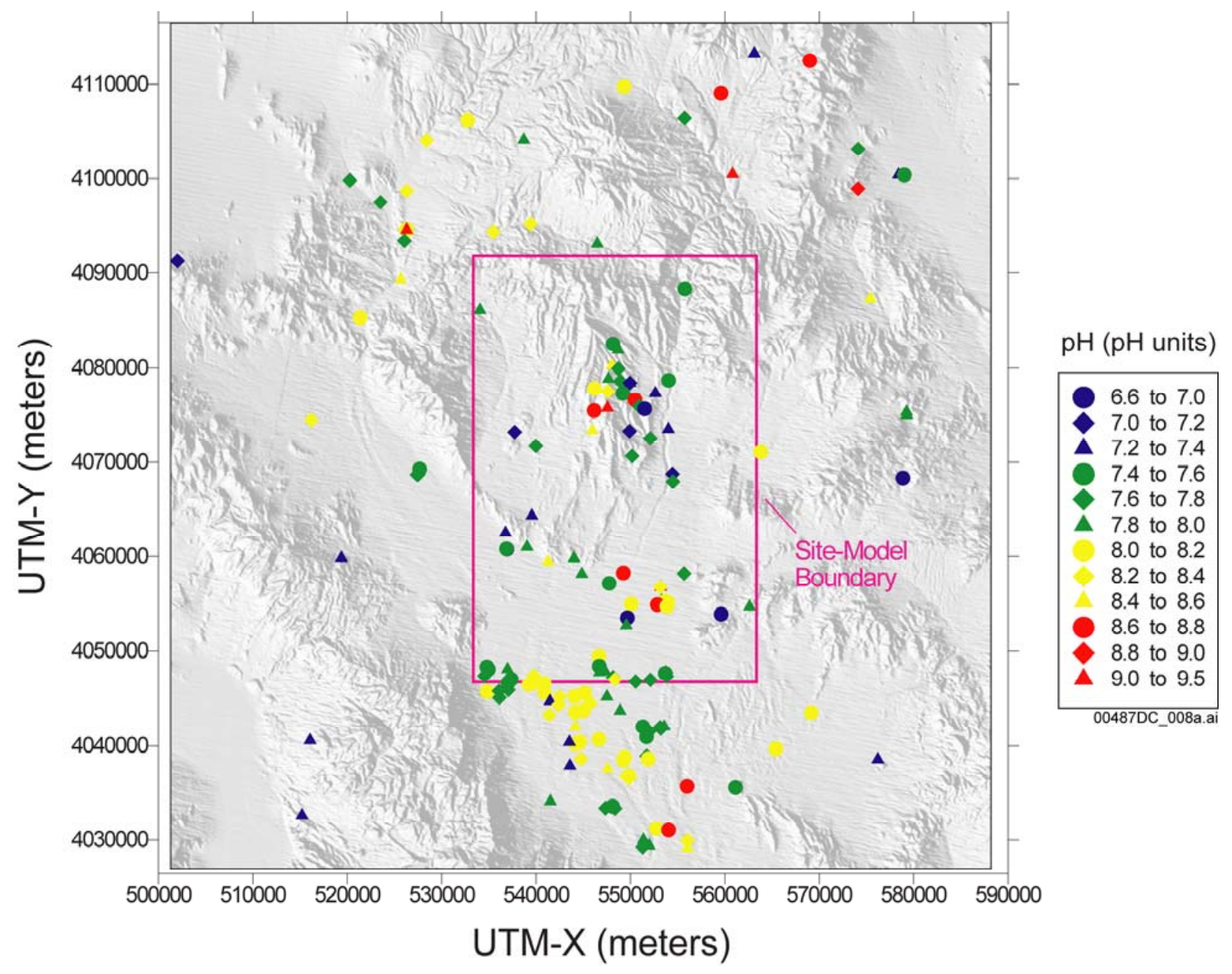

Source: Table A6-1.

NOTES: This figure has color-coded data points and should not be read in a black and white version. The $\mathrm{pH}$ is $-\log \left[\mathrm{H}^{+}\right]$where $\left[\mathrm{H}^{+}\right]$is the activity of hydrogen ion in moles/L. UTM-X $=U$ UTM-Easting and UTM- $Y=U T M-N o r t h i n g$. UTM=Universal Transverse Mercator.

Figure A6-14. Areal Distribution of $\mathrm{pH}$ in Groundwater

\section{A6.3.4.2 Chloride}

The chloride $\left(\mathrm{Cl}^{-}\right)$concentrations of groundwater samples in the Yucca Mountain vicinity are shown in Figure A6-15. The areal distribution clearly shows coherent spatial patterns in $\mathrm{Cl}^{-}$concentrations. Except for borehole p\#1, where groundwater was sampled from the carbonate aquifer (Site 62) and from deep in the volcanic section (Site 62) where groundwater seems to be mixed with groundwater from the carbonate aquifer, the $\mathrm{Cl}^{-}$concentrations of groundwater in the Yucca Mountain area generally are low (less than $9 \mathrm{mg} / \mathrm{L}$ ) compared to areas to the west and east. Several wells to the north of Yucca Mountain in the Timber Mountain area have similarly low $\mathrm{Cl}^{-}$concentrations. Groundwater from the Oasis Valley to the northwest of the site model area generally has $\mathrm{Cl}^{-}$concentrations of 20 to $50 \mathrm{mg} / \mathrm{L}$. These concentrations are slightly lower than the $\mathrm{Cl}^{-}$concentrations of $50 \mathrm{mg} / \mathrm{L}$ or more measured in groundwater near the Nuclear Engineering Company (NEC) wells west of Bare Mountain or in groundwater in the southwest 
corner of the site model boundary. Groundwater to the northeast and east of the site model boundary shows considerable variability between closely spaced wells, so that it is difficult to make generalizations about $\mathrm{Cl}^{-}$concentrations in these areas.

Groundwater in eastern Crater Flat has low $\mathrm{Cl}^{-}$concentrations compared to groundwater in western Crater Flat, a distinction that is preserved at the south end of Crater Flat at the NC-EWDP boreholes. One borehole at the southern end of Crater Flat (Site 71 - NC-EWDP-7S) has a relatively high $\mathrm{Cl}^{-}$concentration of 18 to $20 \mathrm{mg} / \mathrm{L}$. The depth to groundwater at this borehole is only about $7 \mathrm{~m}$ and groundwater in this area, like the shallow groundwater in Oasis Valley, may have been affected by evapotranspiration. Low $\mathrm{Cl}^{-}$concentrations associated with the Fortymile Wash area east of Yucca Mountain extend southward into the Amargosa Desert, where the low-concentration zone is bounded by areas having substantially higher $\mathrm{Cl}^{-}$concentrations.

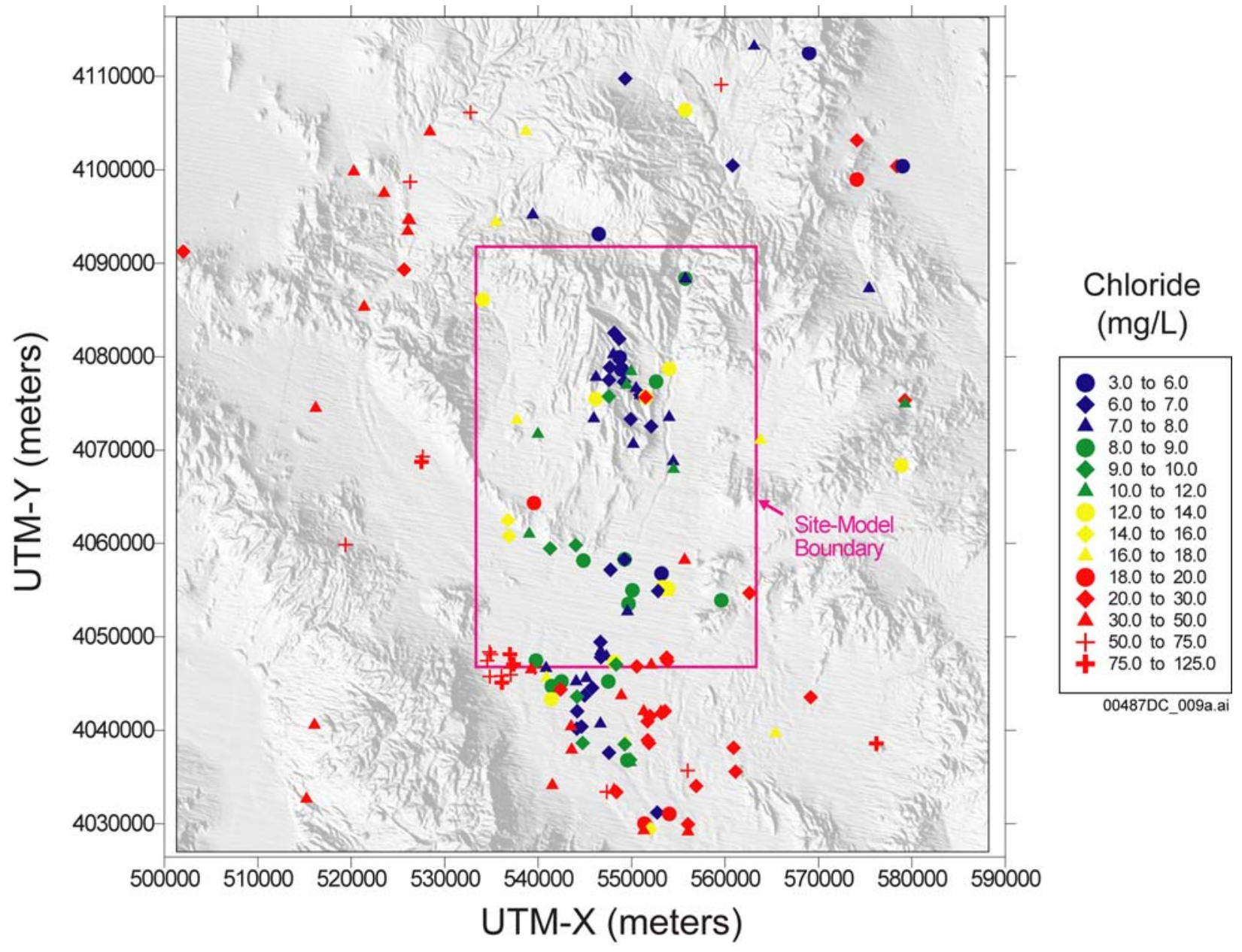

Source: Table A6-1.

NOTE: This figure has color-coded data points and should not be read in a black and white version. UTM-X =UTM-Easting and UTM-Y =UTM-Northing. UTM=Universal Transverse Mercator.

Figure A6-15. Areal Distribution of Chloride in Groundwater 


\section{A6.3.4.3 Sulfate}

The areal distribution of sulfate $\left(\mathrm{SO}_{4}{ }^{2-}\right)$ (Figure A6-16) has patterns similar to those described for $\mathrm{Cl}^{-}$(Figure A6-15). Except at borehole p\#1 where the $\mathrm{SO}_{4}{ }^{2-}$ concentrations are much higher, groundwater at Yucca Mountain generally has $\mathrm{SO}_{4}{ }^{2-}$ concentrations less than $35 \mathrm{mg} / \mathrm{L}$, whereas $\mathrm{SO}_{4}{ }^{2-}$ concentrations west and east of Yucca Mountain are moderately to substantially higher. Borehole J-11 (Site 67) in central Jackass Flat has a $\mathrm{SO}_{4}{ }^{2-}$ concentration of $479 \mathrm{mg} / \mathrm{L}$. Groundwater north of Yucca Mountain at Timber Mountain and in the upper part of Fortymile Wash near Rainer Mesa has $\mathrm{SO}_{4}{ }^{2-}$ concentrations in the same range as those found at Yucca Mountain. Groundwater $\mathrm{SO}_{4}{ }^{2-}$ concentrations north of the site model area increase toward Oasis Valley. The compositional differences between groundwater in western and eastern Crater Flat observed in $\mathrm{Cl}^{-}$concentrations are also evident in $\mathrm{SO}_{4}{ }^{2-}$ concentrations, with the difference that the $\mathrm{SO}_{4}{ }^{2-}$ concentration at Gexa Well 4 (Site 68) in the northwest corner of the site model area more closely resembles groundwater in eastern Crater Flat at borehole VH-1 (Site 69) rather than western Crater Flat at borehole VH-2 (Site 70). As is the case for $\mathrm{Cl}^{-}$, the low $\mathrm{SO}_{4}{ }^{2-}$ groundwater associated with Fortymile Wash east of Yucca Mountain also extends southward into the Amargosa Desert, where it is surrounded by groundwater having distinctly higher $\mathrm{SO}_{4}{ }^{2-}$ concentrations. Unlike $\mathrm{Cl}^{-}$, however, groundwater $\mathrm{SO}_{4}{ }^{2-}$ concentrations increase toward the south along Fortymile Wash.

The groundwater with high $\mathrm{Cl}^{-}$concentrations near the southwest corner of the site model area also has relatively high (100 to $200 \mathrm{mg} / \mathrm{L}) \mathrm{SO}_{4}{ }^{2-}$ concentrations. Groundwater to the north of this area in western Crater Flat and to the northwest in southern Oasis Valley has similarly high $\mathrm{SO}_{4}{ }^{2-}$ concentrations.

\section{A6.3.4.4 Bicarbonate}

The areal distribution of bicarbonate $\left(\mathrm{HCO}_{3}^{-}\right)$is shown in Figure A6-17. The areal patterns for $\mathrm{HCO}_{3}{ }^{-}$are similar to those described for $\mathrm{SO}_{4}{ }^{2-}$ and $\mathrm{Cl}^{-}$with some differences. Groundwater with high (greater than $200 \mathrm{mg} / \mathrm{L}$ ) $\mathrm{HCO}_{3}{ }^{-}$concentrations is present in easternmost Crater Flat and western Yucca Mountain near Solitario Canyon. Elsewhere at Yucca Mountain, groundwater generally has $\mathrm{HCO}_{3}{ }^{-}$concentrations less than $175 \mathrm{mg} / \mathrm{L}$. Groundwater near the Fortymile Wash drainage in the Amargosa Desert (FMW-S group) has much lower (less than $160 \mathrm{mg} / \mathrm{L}$ ) $\mathrm{HCO}_{3}{ }^{-}$concentrations than groundwater in the surrounding areas in the $\mathrm{GF}$, AR, and AR/FMW groups but has slightly higher $\mathrm{HCO}_{3}{ }^{-}$concentrations than groundwater upgradient along Fortymile Wash (FMW-N group).

Most groundwater in the TM group has $\mathrm{HCO}_{3}{ }^{-}$concentrations of $170 \mathrm{mg} / \mathrm{L}$ or greater with the exception of Site 24 (well ER-EC-07) in Beatty Wash, which has a concentration (148.8 mg/L) similar to that typically found in northern Yucca Mountain (120 to $140 \mathrm{mg} / \mathrm{L})$. The moderately high $\mathrm{HCO}_{3}{ }^{-}$concentrations found in the Oasis Valley area increase southeastward along the Amargosa River toward the AR and AR/FMW group wells. 


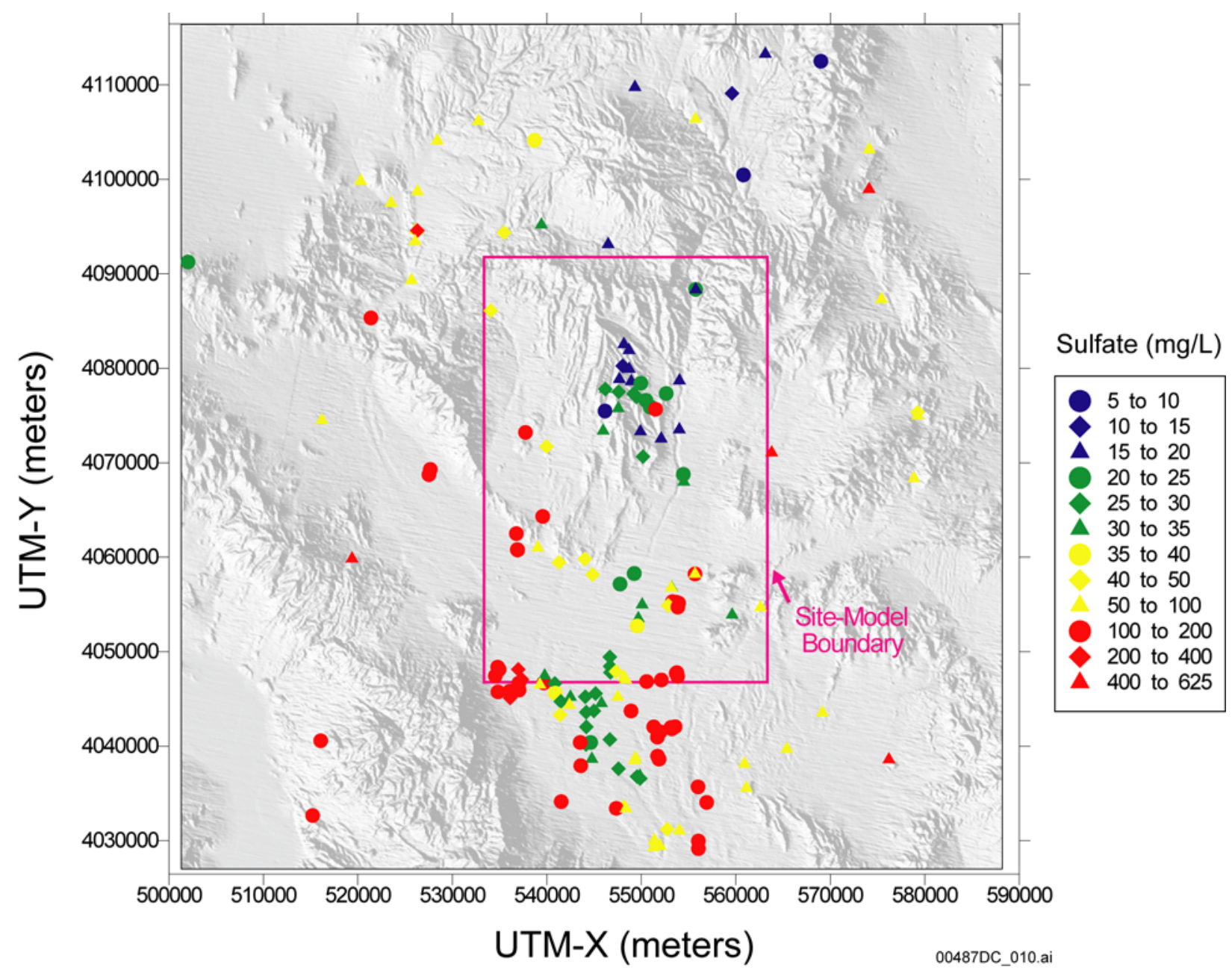

Source: Table A6-1.

NOTE: This figure has color-coded data points and should not be read in a black and white version. UTM-X =UTM-Easting and UTM-Y =UTM-Northing. UTM=Universal Transverse Mercator.

Figure A6-16. Areal Distribution of Sulfate in Groundwater

Groundwater in southwestern Crater Flat (CF-SW group) has higher $\mathrm{HCO}_{3}{ }^{-}$than groundwater in the CF grouping. Bicarbonate concentrations at site NC-EWDP-7S (Site 71) are particularly high, possibly reflecting the location of this well in a paleospring deposit or evaporative effects associated with a shallow water table (Table A6-1). Groundwater in central Jackass Flats at borehole J-11 (Site 67), where the high $\mathrm{SO}_{4}{ }^{2-}$ was noted previously, has one of the lowest $\mathrm{HCO}_{3}{ }^{-}$concentrations $(82 \mathrm{mg} / \mathrm{L})$ in the map area. Similarly low $\mathrm{HCO}_{3}{ }^{-}$concentrations are found in some of the LW group wells to the southwest of borehole J-11. 


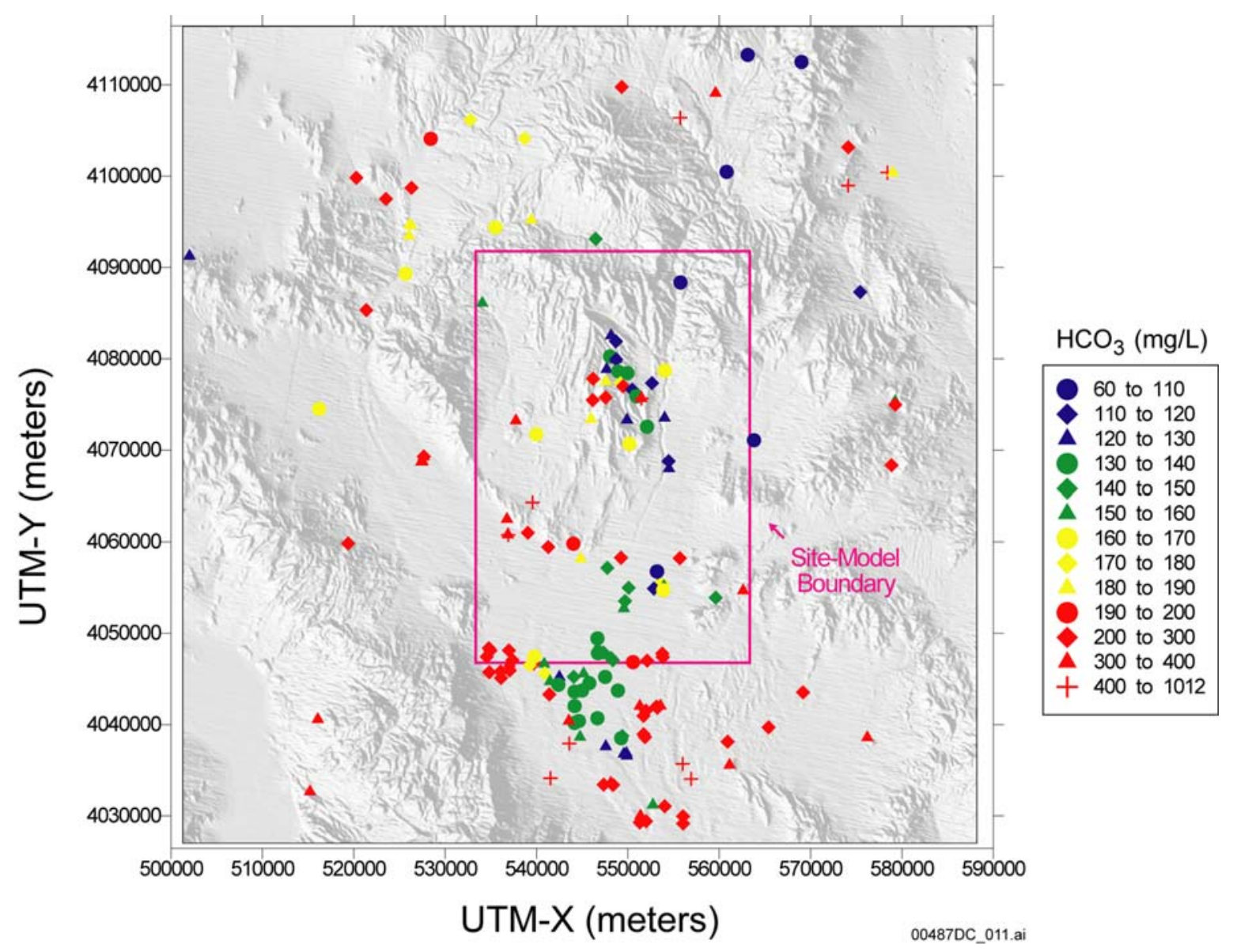

Source: Table A6-1.

NOTE: This figure has color-coded data points and should not be read in a black and white version. UTM-X $=\mathrm{UTM}$-Easting and UTM-Y =UTM-Northing. UTM=Universal Transverse Mercator.

Figure A6-17. Areal Distribution of Bicarbonate in Groundwater

\section{A6.3.4.5 Fluoride}

Few data for $\mathrm{F}^{-}$concentrations are available for the Yucca Mountain. (Figure A6-18). These data are consistent with the concentration distributions for other anions like $\mathrm{Cl}^{-}$(Figure A6-15) in this area, with dilute concentrations found near Fortymile Wash and concentrations that increase to the west and east of the wash. Groundwater fluoride concentrations at Yucca Mountain have a variability that is comparable to the variability found in the Yucca Mountain region as a whole (Figure A6-18). The F concentrations in northern Yucca Mountain are low compared to other areas of Yucca Mountain. Relatively high $\mathrm{F}^{-}$concentrations of 4.5 to $13.0 \mathrm{mg} / \mathrm{L}$ are found in groundwater at several wells along Yucca Crest (YM-CR group), in the Solitario Canyon Wash (SWC) group, and in the carbonate aquifer at well p\#1 (Sites 62 and 63). Groundwater along Fortymile Wash has $\mathrm{F}^{-}$concentrations that generally vary between 1 and $2 \mathrm{mg} / \mathrm{L}$, with no systematic north-south variations evident. Groundwater in southwest Crater Flat has lower $\mathrm{F}^{-}$concentrations than groundwater in eastern Crater Flat or in the NC-EWDP wells farther to the east. 


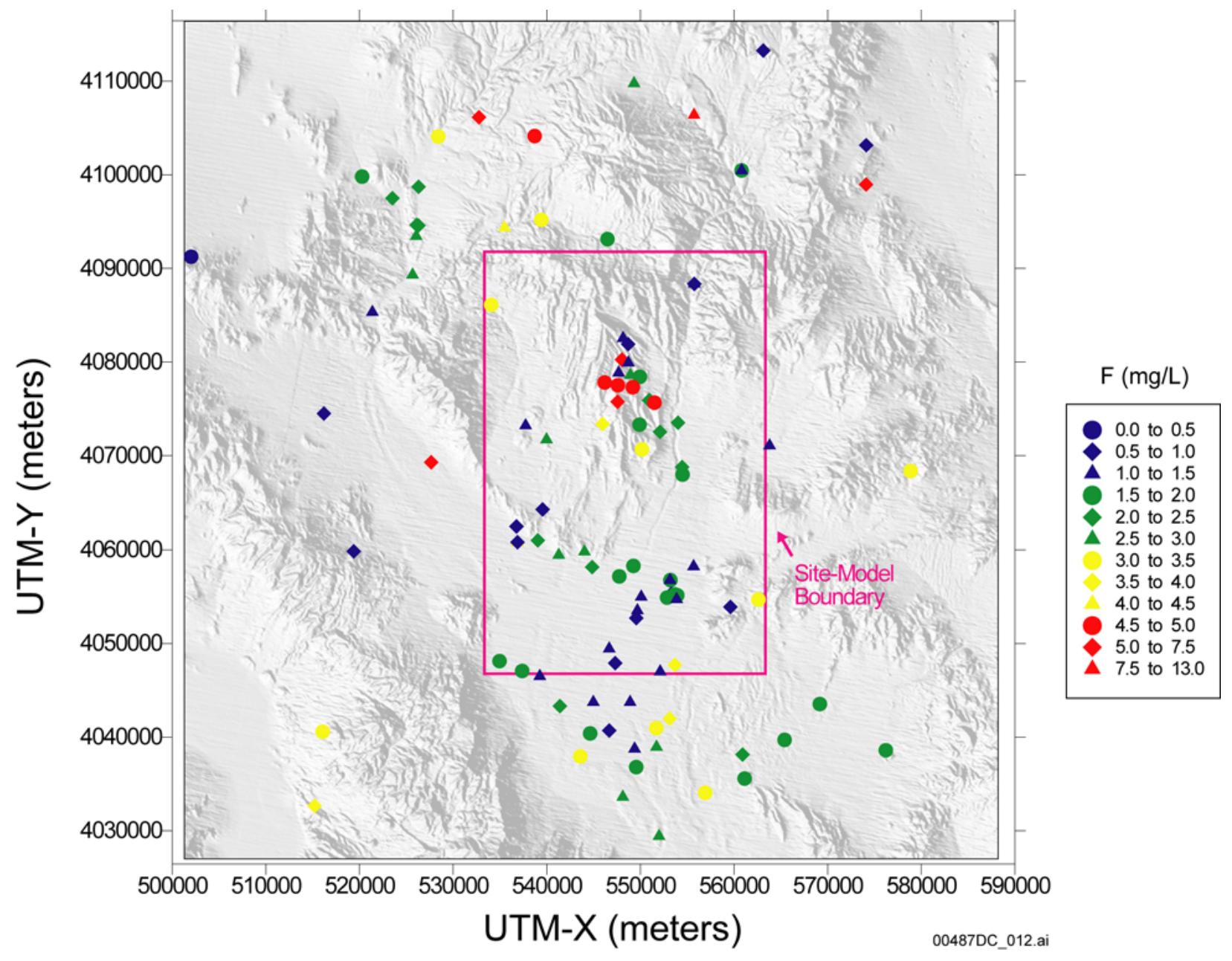

Source: Table A6-1.

NOTE: This figure has color-coded data points and should not be read in a black and white version. UTM-X $=$ UTM-Easting and UTM-Y =UTM-Northing. UTM=Universal Transverse Mercator.

Figure A6-18. Areal Distribution of Fluoride in Groundwater

\section{A6.3.4.6 Silica}

Groundwater in northern and central Yucca Mountain has $\mathrm{SiO}_{2}$ concentrations that range from 30 to $60 \mathrm{mg} / \mathrm{L}$ (Figure A6-19). Groundwater beneath Fortymile Wash east of Yucca Mountain has $\mathrm{SiO}_{2}$ concentrations that are approximately 50 to $60 \mathrm{mg} / \mathrm{L}$. Southward from Yucca Mountain and along Fortymile Wash, $\mathrm{SiO}_{2}$ concentrations in groundwater near the southern site model boundary increase abruptly. Relatively high $\mathrm{SiO}_{2}$ concentrations (65 to $90 \mathrm{mg} / \mathrm{L}$ ) characterize groundwater throughout most of Amargosa Desert, except near the Gravity fault where $\mathrm{SiO}_{2}$ concentrations are considerably lower. Groundwater associated with carbonate rocks is typically more concentrated in most chemical species than groundwater in the volcanic rocks, except for $\mathrm{SiO}_{2}$ (Winograd and Thordarson 1975 [DIRS 101167], Table 8). High $\mathrm{SiO}_{2}$ concentrations can also be traced southeastward from the Oasis Valley area through the northwest Amargosa Desert. 


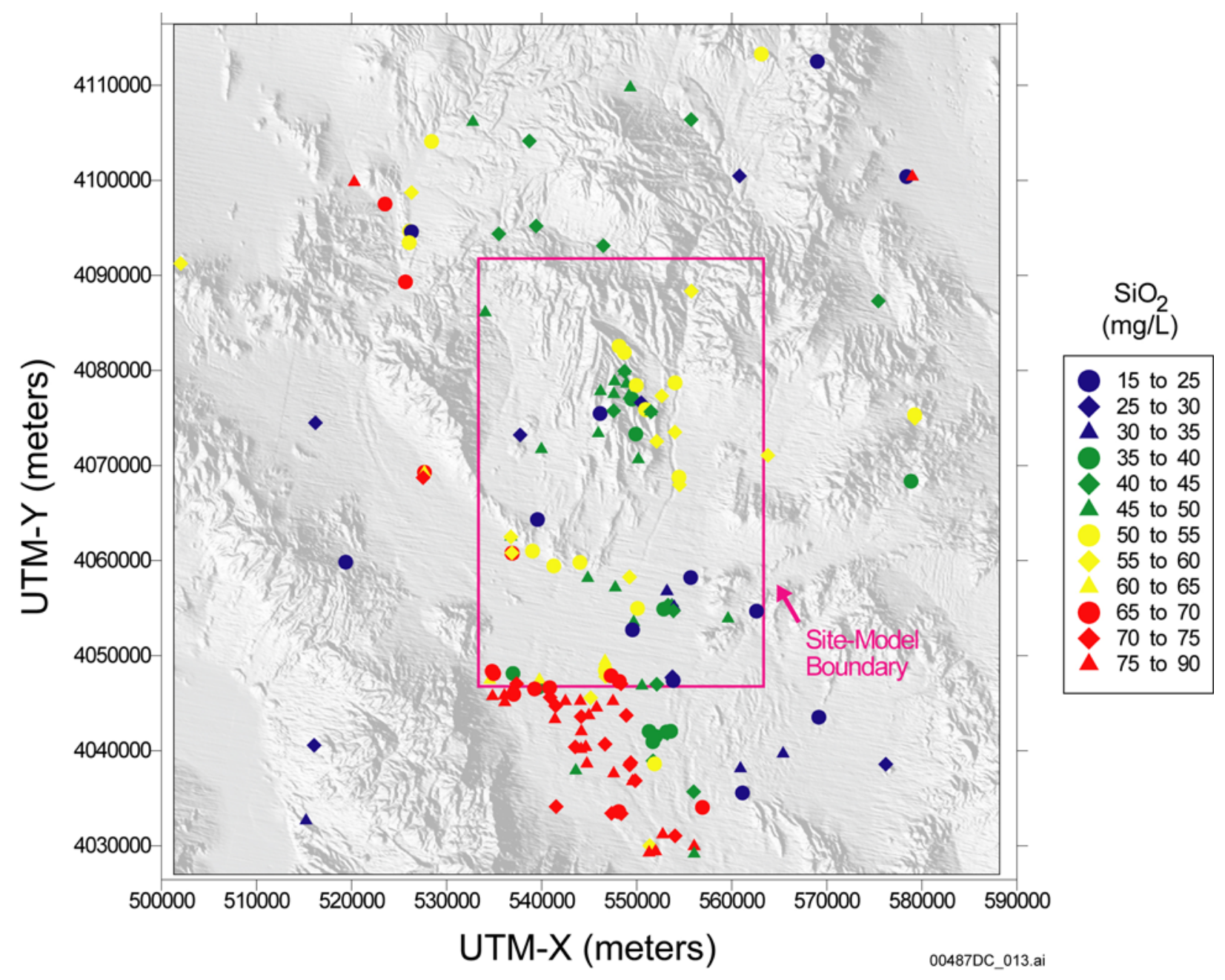

Source: Table A6-1.

NOTE: This figure has color-coded data points and should not be read in a black and white version. UTM-X =UTM-Easting and UTM-Y =UTM-Northing. UTM=Universal Transverse Mercator.

Figure A6-19. Areal Distribution of Silica in Groundwater

\section{A6.3.4.7 Calcium}

The calcium $\left(\mathrm{Ca}^{2+}\right)$ concentrations of groundwater at Yucca Mountain are generally less than $20 \mathrm{mg} / \mathrm{L}$ (Figure A6-20), except at borehole p\#1 (Site 63), where groundwater from the carbonate aquifer has a concentration of $100 \mathrm{mg} / \mathrm{L}$. Along the eastern edge of Crater Flat and in western Yucca Mountain, $\mathrm{Ca}^{2+}$ concentrations are less than $5 \mathrm{mg} / \mathrm{L}$. The $\mathrm{Ca}^{2+}$ concentration is higher in western Crater Flat at borehole VH-2 (Site 70) than in eastern Crater Flat at borehole VH-1 (Site 69). The $\mathrm{Ca}^{2+}$ concentration at Gexa Well 4 in the northwest corner of the site model area is similar to the value at VH-1 and at NC-EWDP wells southeast of Crater Flat (Yucca Mountain-South group). The $\mathrm{Ca}^{2+}$ concentration is relatively high $(82 \mathrm{mg} / \mathrm{L})$ at borehole $\mathrm{J}-11$ (Site 67) in central Jackass Flats, where $\mathrm{SO}_{4}{ }^{2-}$ is also relatively high (Figure A6-16). The $\mathrm{Ca}^{2+}$ concentration along Fortymile Wash is between 10 to $20 \mathrm{mg} / \mathrm{L}$ east and northeast of Yucca Mountain and increases to values generally between 20 to $30 \mathrm{mg} / \mathrm{L}$ in the Amargosa Desert. 


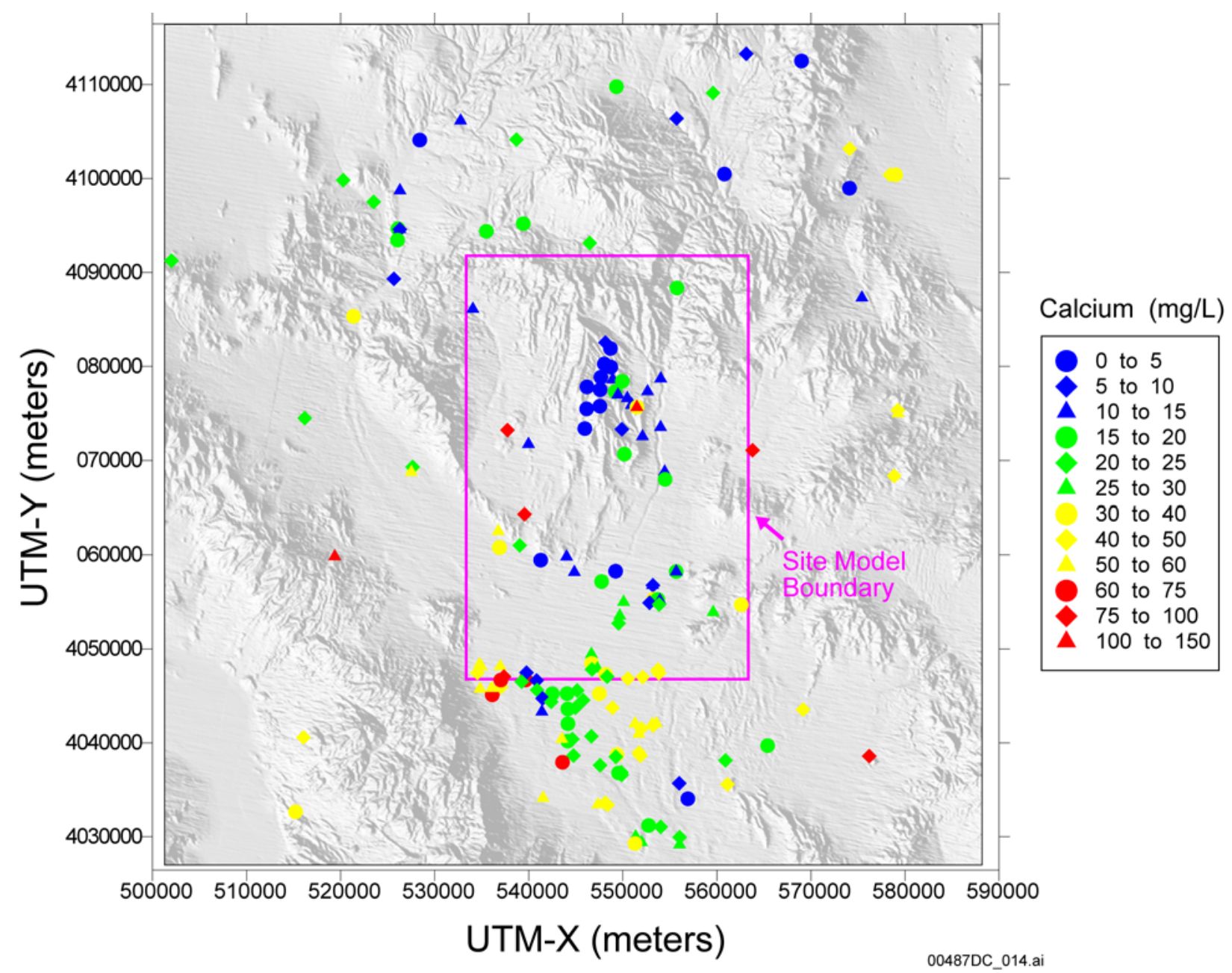

Source: Table A6-1.

NOTE: This figure has color-coded data points and should not be read in a black and white version. UTM-X =UTM-Easting and UTM-Y =UTM-Northing. UTM=Universal Transverse Mercator.

Figure A6-20. Areal Distribution of Calcium in Groundwater

The $\mathrm{Ca}^{2+}$ concentration increases to the west and the east of Fortymile Wash in the Amargosa Desert. Groundwater $\mathrm{Ca}^{2+}$ concentrations in the southwest corner of the site model area (Amargosa River group) are generally higher than $\mathrm{Ca}^{2+}$ concentrations in upgradient areas in western Crater Flat, west of Bare Mountain, and in the Oasis Valley.

\section{A6.3.4.8 Magnesium}

The areal distribution of magnesium $\left(\mathrm{Mg}^{2+}\right)$ concentrations (Figure A6-21) display a pattern that is similar, in terms of relative concentrations, to that of $\mathrm{Ca}^{2+}$. Magnesium concentrations in groundwater at Yucca Mountain range from 0.1 to $1.6 \mathrm{mg} / \mathrm{L}$, except at borehole $\mathrm{p \# 1}$ where the $\mathrm{Mg}^{2+}$ concentration is $10 \mathrm{mg} / \mathrm{L}$ in the volcanic aquifer and $39 \mathrm{mg} / \mathrm{L}$ in the carbonate aquifer. The $\mathrm{Mg}^{2+}$ concentration in groundwater in western Crater Flat at borehole VH-2 (Site 70) is high $(30 \mathrm{mg} / \mathrm{L})$ compared to the concentration of $1.5 \mathrm{mg} / \mathrm{L}$ measured in groundwater at borehole VH-1 (Site 69). In Nye County-EWDP wells south and southeast of Crater Flat (SW Crater Flat 
and Yucca Mountain-South groups), $\mathrm{Mg}^{2+}$ concentrations are quite variable with concentrations generally increasing to the northwest. Concentrations of $\mathrm{Mg}^{2+}$ are generally low (less than $1.5 \mathrm{mg} / \mathrm{L}$ ) at Timber Mountain and in upper Fortymile Canyon, but are generally between 2 and $3 \mathrm{mg} / \mathrm{L}$ along the length of Fortymile Wash east of Yucca Mountain and in the Amargosa Desert. Magnesium concentrations on the east and west side of the Amargosa Desert are considerably higher with values typically between 5 and $20 \mathrm{mg} / \mathrm{L}$. In the southwest corner of the model area (Amargosa River group), $\mathrm{Mg}^{2+}$ concentrations generally are between 5 to $10 \mathrm{mg} / \mathrm{L}$, but a few samples have concentrations between 10 and $20 \mathrm{mg} / \mathrm{L}$, similar to the concentration of groundwater at the sites 15 to 17 west of Bare Mountain $(11.5$ to $16 \mathrm{mg} / \mathrm{L})$, but higher than those in Oasis Valley. The concentration of $\mathrm{Mg}^{2+}$ is $13 \mathrm{mg} / \mathrm{L}$ at borehole $\mathrm{J}-11$ (Site 67) in central Jackass Flats.

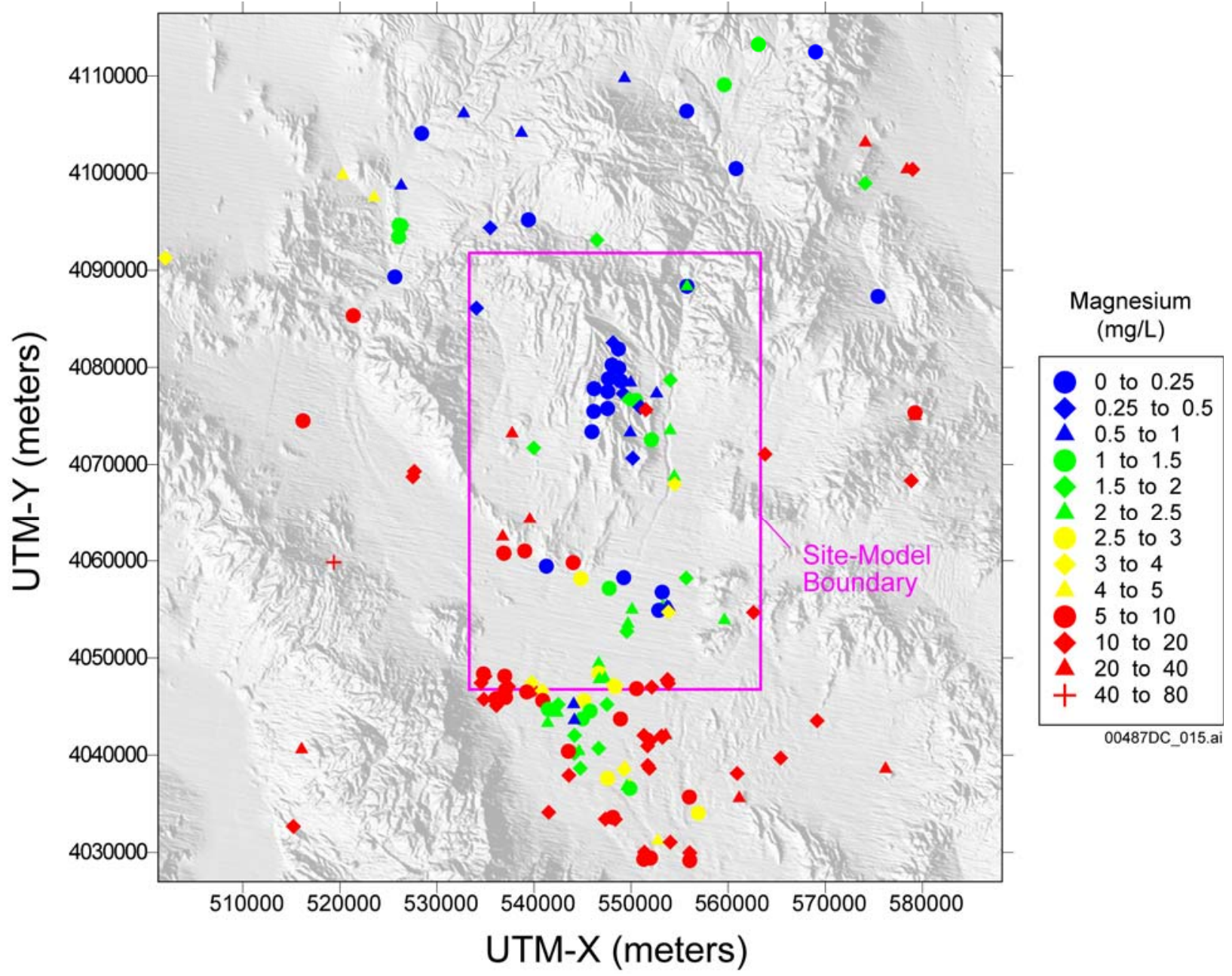

Source: Table A6-1.

NOTE: This figure has color-coded data points and should not be read in a black and white version.

UTM-X =UTM-Easting and UTM-Y =UTM-Northing. UTM=Universal Transverse Mercator.

Figure A6-21. Areal Distribution of Magnesium in Groundwater 


\section{A6.3.4.9 Sodium}

The areal distribution of sodium $\left(\mathrm{Na}^{+}\right)$is shown in Figure A6-22. Excluding data from the

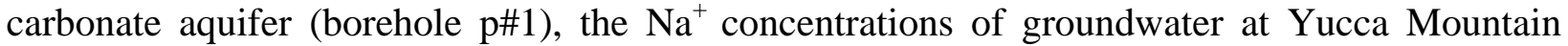
range between 46 and $130 \mathrm{mg} / \mathrm{L}$ with the higher values from samples in the western part of Yucca Mountain (Solitario Canyon Wash and Yucca Crest groups). A zone of relatively low $\mathrm{Na}^{+}$concentrations (less than $60 \mathrm{mg} / \mathrm{L}$ ) extends southeastward from northern Yucca Mountain toward lower Dune Wash and Fortymile Wash. The $\mathrm{Na}^{+}$concentrations of groundwater in the NC-EWDP boreholes west of Fortymile Wash are generally between 40 and $100 \mathrm{mg} / \mathrm{L}$, except at boreholes NC-EWDP-3D and NC-EWDP-3S (Sites 86 to 88) where the $\mathrm{Na}^{+}$concentration was anomalously high (113 to $135 \mathrm{mg} / \mathrm{L})$. The $\mathrm{Na}^{+}$concentrations of groundwater at borehole NC-EWDP-5S (Site 154) west of the Striped Hills and at well J-11 (Site 67) in central Jackass Flats are also high (149 and $154 \mathrm{mg} / \mathrm{L}$, respectively [Table A6-1]). Note that the value of $149 \mathrm{mg} / \mathrm{L}$ at NC-EWDP-5S listed in Table A6-1 is obscured in Figure A6-22 by the somewhat lower value of $107 \mathrm{mg} / \mathrm{L}$ at nearby Site 155. Most of the groundwater samples along Fortymile Wash have $\mathrm{Na}^{+}$concentrations between 35 and $50 \mathrm{mg} / \mathrm{L}$; there are not any obvious trends in the $\mathrm{Na}^{+}$concentrations of groundwater beneath Fortymile Wash east of Yucca Mountain and beneath the wash in the Amargosa Desert. In the Amargosa Desert, $\mathrm{Na}^{+}$concentrations in groundwater increase away from Fortymile Wash in both eastward and westward directions. Groundwater in the southwest corner of the site model area (Amargosa River group) has high $\mathrm{Na}^{+}$concentrations (130 to $180 \mathrm{mg} / \mathrm{L})$, similar to those of sites 15 to 17 west of Bare Mountain and groundwater in Oasis Valley.

\section{A6.3.4.10 Potassium}

Potassium (Figure A6-23) concentrations in groundwater at Yucca Mountain range between 1 and $6 \mathrm{mg} / \mathrm{L}$, except in the carbonate aquifer at borehole p\#1 (Site 63) where the $\mathrm{K}^{+}$concentration is $12 \mathrm{mg} / \mathrm{L}$. Groundwater from the Solitario Canyon and Yucca Crest groups typically has smaller $\mathrm{K}^{+}$concentration when compared to groundwater farther east at Yucca Mountain in the FMW-N group. The $\mathrm{K}^{+}$concentrations in groundwater in western Crater Flat at borehole VH-2 (Site 70) is high $(8 \mathrm{mg} / \mathrm{L})$. Similarly high $\mathrm{K}^{+}$concentrations are found south of VH-2 in Nye County-EWDP wells 1S (Site 77) and 1DX (Site 73) and even higher concentrations exist at NC-EWDP-12PA (Site 78) and -12PB (Site 79). Concentrations of $\mathrm{K}^{+}$are generally low (less than $5 \mathrm{mg} / \mathrm{L}$ ) in northern Fortymile Canyon but are generally between 5 and $8 \mathrm{mg} / \mathrm{L}$ along the length of Fortymile Wash east of Yucca Mountain and in the Amargosa Desert. In the eastern and western parts of the Amargosa Desert, $\mathrm{K}^{+}$concentrations are typically higher than those in groundwater near the adjacent reach of Fortymile Wash. However, even among the FMW-S samples along Fortymile Wash, $\mathrm{K}^{+}$concentrations are two to three times higher than $\mathrm{K}^{+}$concentrations in upgradient areas in the southern Yucca Mountain (YM-S) group. Potassium concentrations in the Amargosa River (AR) group are similar to those of groundwater at Sites 15 through 17 west of Bare Mountain and somewhat higher than those found in Oasis Valley. 


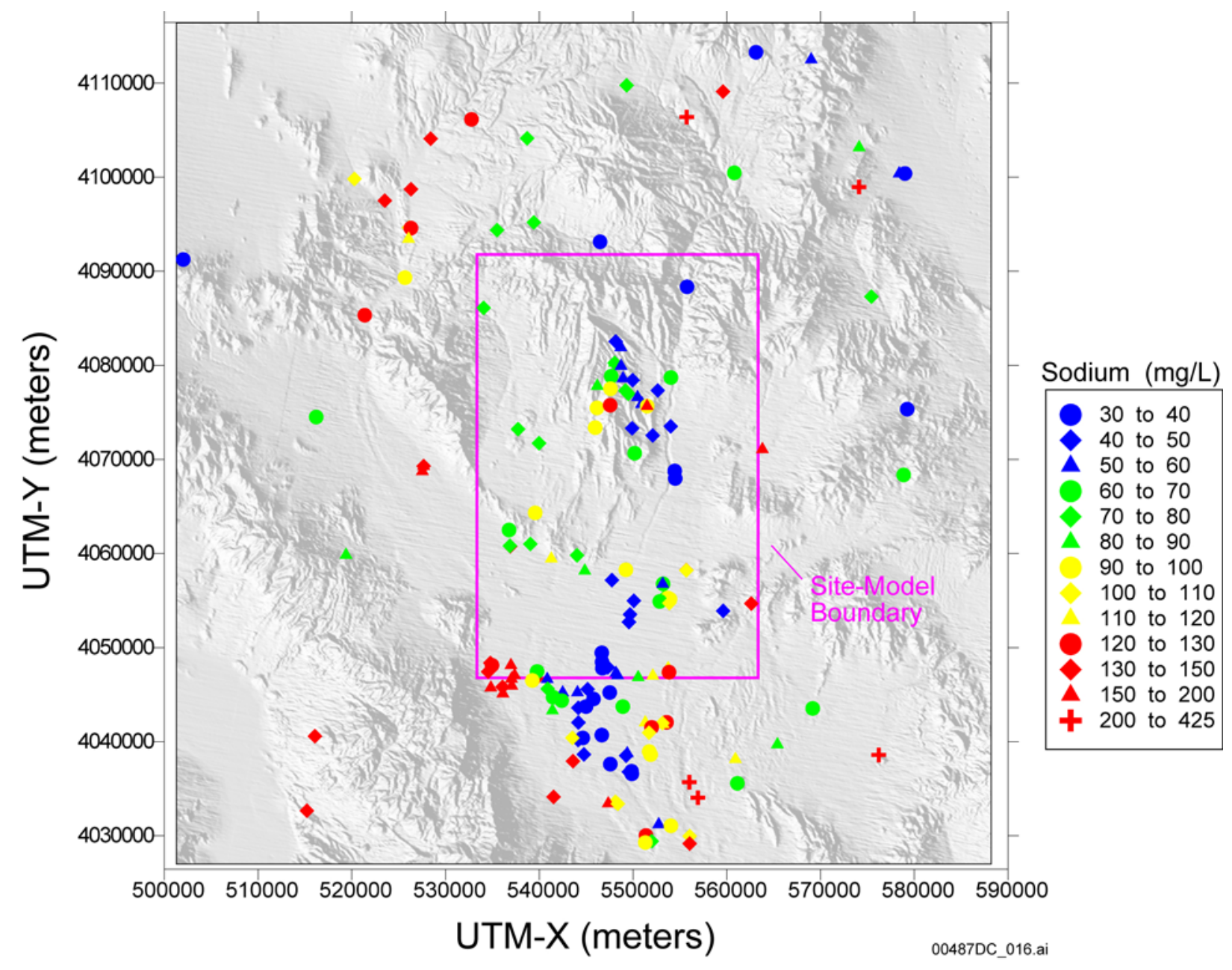

Source: Table A6-1.

NOTE: This figure has color-coded data points and should not be read in a black and white version. UTM-X =UTM-Easting and UTM-Y =UTM-Northing. UTM=Universal Transverse Mercator.

Figure A6-22. Areal Distribution of Sodium in Groundwater

\section{A6.3.4.11 Delta Deuterium}

The areal distribution of delta deuterium $(\delta \mathrm{D})$ values is shown in Figure A6-24 (this isotopic parameter is defined and discussed in Section A6.3.1.2). The $\delta \mathrm{D}$ values in groundwaters from the Yucca Mountain area range from about -105 per mil at borehole USW SD-6 (Site 50) to about -99 per mil at borehole G-2 (Site 43). In Crater Flat, the $\delta D$ values of -108 and -106 per mil measured in water from borehole VH-1 (Site 69) and from Gexa Well 4 (Site 68) are substantially lighter (i.e., more negative) than the $\delta \mathrm{D}$ value of -99 per mil measured in groundwater from borehole VH-2 (Site 70), but similar to the extremely light values found in Oasis Valley and lower Beatty Wash. The $\delta \mathrm{D}$ values at borehole NC-EWDP-1DX (Site 73) of -101.3 per mil and at borehole NC-EWDP-3D (Site 86) of -105.6 per mil are generally similar to the values at upgradient boreholes $\mathrm{VH}-2$ and $\mathrm{VH}-1$ ( -99.5 and -108.0 , respectively). The groundwater $\delta \mathrm{D}$ value of -98.0 per mil at Site 71 (NC-EWDP-7S) is also relatively heavy and comparable to the value at borehole $\mathrm{VH}-2$. 


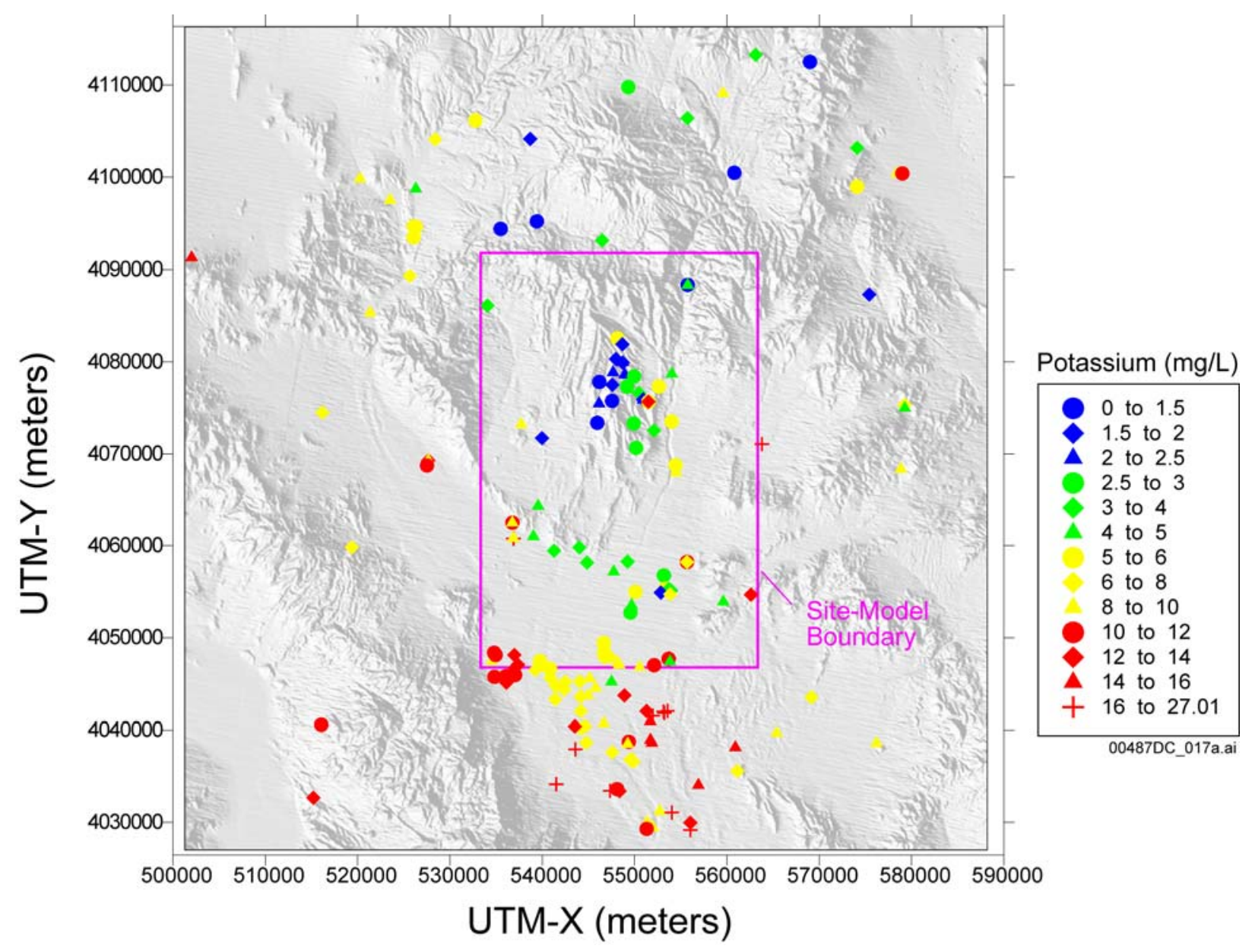

Source: Table A6-1.

NOTE: This figure has color-coded data points and should not be read in a black and white version. UTM-X $=$ UTM-Easting and UTM-Y =UTM-Northing. UTM=Universal Transverse Mercator.

Figure A6-23. Areal Distribution of Potassium in Groundwater

The $\delta \mathrm{D}$ values of groundwater near Fortymile Wash show a general trend toward more depleted values from north to south, ranging from about -93 to -91 per mil at boreholes UE-29 a\#1 and a\#2 (Sites 30-32) near the northern boundary of the site model area to values that are generally -100 per mil or less near the southern boundary of the model area. East of Yucca Mountain, groundwater beneath Fortymile Wash has $\delta \mathrm{D}$ values of about -97 per mil. The $\delta \mathrm{D}$ values of -104 per mil of groundwater at boreholes NC-EWDP-2D (Site 91)) and $\delta$ D values of -110 to -104 per mil at well NC-EWDP-19D (Sites 92 and 94-98) are substantially lighter than in groundwater associated with Fortymile Wash in the FMW-N group. Groundwater in the Amargosa Desert has variable values, and spatial patterns are not as regular as for other chemical species, but groundwater in the eastern part of the Amargosa Desert is generally lighter in $\delta \mathrm{D}$ than groundwater farther to the west near Fortymile Wash. 


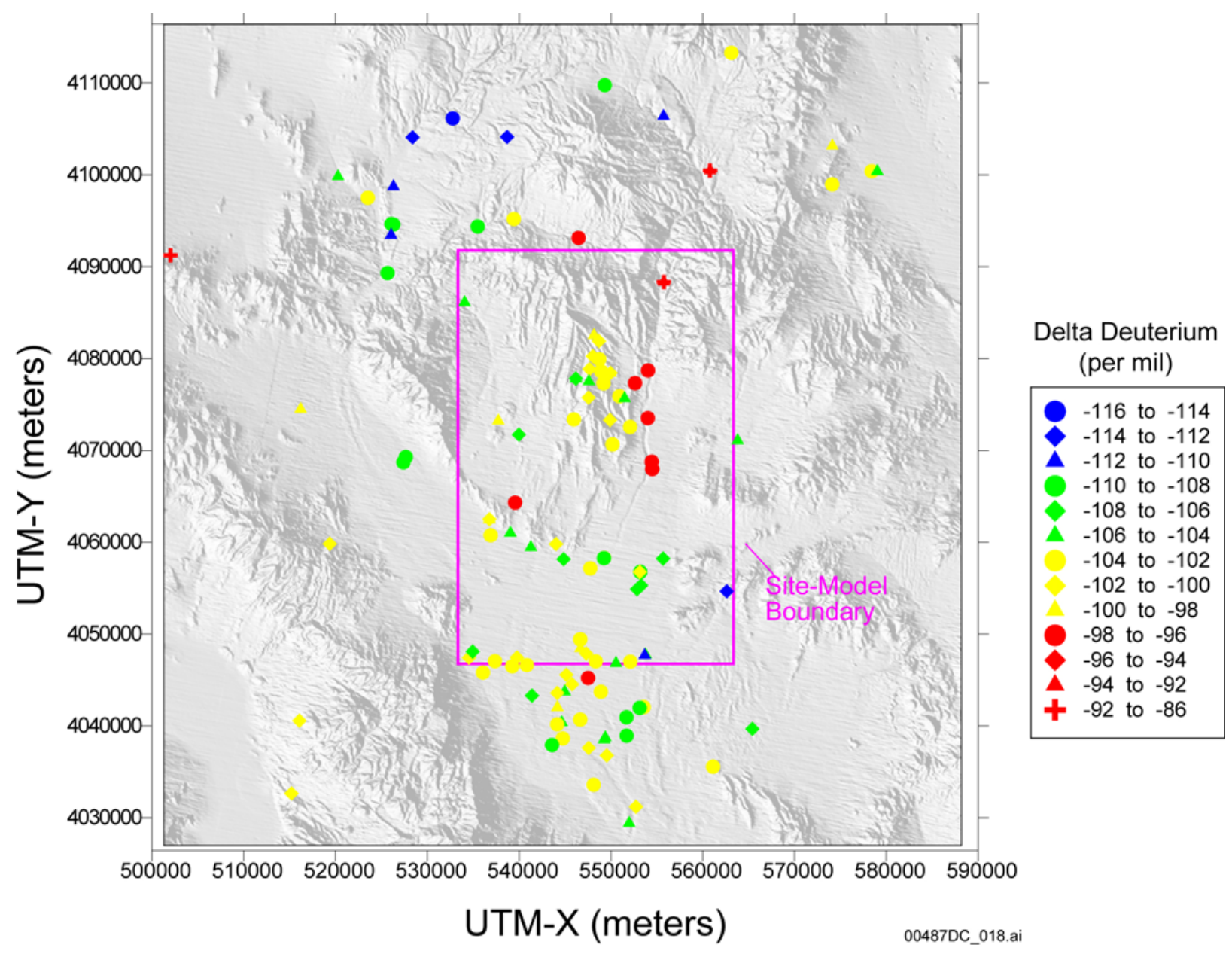

Source: Table A6-2

NOTE: This figure has color-coded data points and should not be read in a black and white version. UTM-X =UTM-Easting and UTM-Y =UTM-Northing. UTM=Universal Transverse Mercator.

Figure A6-24. Areal Distribution of Delta Deuterium in Groundwater

Groundwater $\delta \mathrm{D}$ values at Timber Mountain are quite variable, ranging from about -114 to -96 per mil, with the heaviest value found in upper Beatty Wash at Site 24 (well ER-EC-07). The groundwater $\delta \mathrm{D}$ values near Oasis Valley are among the lightest in the vicinity of Yucca Mountain ( -116 to -108 per mil). Groundwater $\delta \mathrm{D}$ values lighter than -108 per mil are also found at sites 15 to 18 (Figure A6-5) west of Bare Mountain in the northwest Amargosa Desert. Southeast of these sites along the Amargosa River, groundwater from the AR and AR/FMW well groups has $\delta \mathrm{D}$ values that are typically heavier than values from wells to the northwest.

\section{A6.3.4.12 Delta Oxygen-18}

Figure A6-25 shows the areal distribution of delta oxygen-18 $\left(\delta^{18} \mathrm{O}\right)$ values for the Yucca Mountain area (this isotopic parameter is defined and discussed in Section A6.3.1.2). Groundwater at Yucca Mountain has $\delta^{18} \mathrm{O}$ values between -13.3 and -14.4 per mil, with 
groundwater in western Yucca Mountain near Solitario Canyon having values that fall toward the lighter end of this range. Groundwater at borehole VH-1 (Site 69) in Crater Flat has a $\delta^{18} \mathrm{O}$ value of -14.2 per mil, similar to the $\delta^{18} \mathrm{O}$ value of -14.1 per mil of groundwater at Gexa Well 4 (Site 68) and at Site 23 (well ER-OV-03c) in lower Beatty Wash. Groundwater in southwestern Crater Flat has substantially heavier $\delta^{18} \mathrm{O}$ values, with groundwater at $\mathrm{VH}-2$ (Site 70 ) having a $\delta^{18} \mathrm{O}$ value of -13.4 per mil. Groundwaters sampled from the NC-EWDP wells along the southern edge of Crater Flat generally have $\delta^{18} \mathrm{O}$ values that are similar to those in wells directly to the north at boreholes $\mathrm{VH}-1$ and $\mathrm{VH}-2$. However, the groundwater $\delta^{18} \mathrm{O}$ value at site 71 (NC-EWDP-7S) has a somewhat heavier $\delta^{18} \mathrm{O}$ value than upgradient groundwater, perhaps reflecting the effects of evapotranspiration due to the shallow water table $(7 \mathrm{~m})$ at this well.

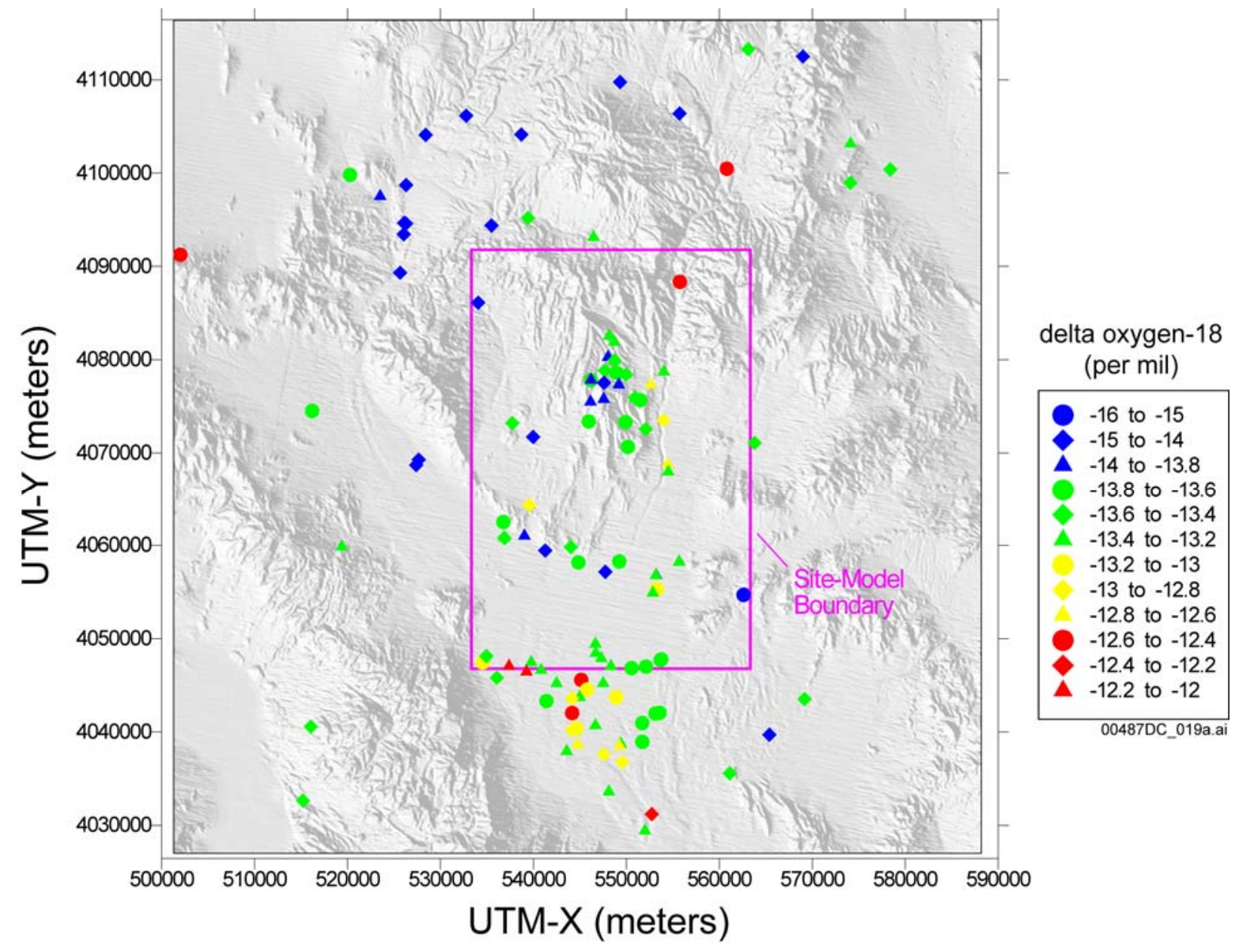

Source: Table A6-2.

NOTE: This figure has color-coded data points and should not be read in a black and white version. UTM-X =UTM-Easting and UTM-Y =UTM-Northing. UTM=Universal Transverse Mercator.

Figure A6-25. Areal Distribution of Delta Oxygen-18 in Groundwater 
The groundwater $\delta^{18} \mathrm{O}$ values at Sites 28 to 32 (Figure A6-5) in the FMW-N group are relatively heavy ( -12.8 to -11.8 per mil) compared to wells to the south within this group and to most groundwater in the FMW-S group (Table A6-2). (Note that the apparent range of values on Figure A6-25 is somewhat less because not all data are evident in the figure). Groundwater within the FMW-N group is distinctly heavier in $\delta^{18} \mathrm{O}$ than groundwater to the west at Yucca Mountain. In the Amargosa Desert, the $\delta^{18} \mathrm{O}$ of groundwaters near Fortymile Wash generally are distinct from those of groundwater farther east or west from the Wash, although near the southern boundary of the site model area, this distinction becomes less well defined.

The groundwater $\delta^{18} \mathrm{O}$ at Timber Mountain are generally lighter than most groundwater found at Yucca Mountain, except for groundwater found directly north of Yucca Mountain in upper Beatty Wash. Groundwater $\delta^{18} \mathrm{O}$ values become lighter toward the west in Beatty Wash. Relatively light groundwater $\delta^{18} \mathrm{O}$ values are found in Oasis Valley and in the northwest Amargosa Desert west of Bare Mountain at Sites 15 to 18 . As with $\delta \mathrm{D}$ values, groundwater $\delta^{18} \mathrm{O}$ increase downstream along the Amargosa River toward the AR and AR/FMW sites.

\section{A6.3.4.13 Delta Sulfur-34}

Groundwater data for delta ${ }^{34} \mathrm{~S}\left(\delta^{34} \mathrm{~S}\right)$ were not collected from the Yucca Mountain area and Amargosa Desert before the late 1990s, nor have they been collected in areas north of Yucca Mountain. Consequently, areal coverage is not as complete as for most other ions and isotopes. The limited data from Yucca Mountain shows that groundwater from two wells along Yucca Crest have higher $\delta^{34} \mathrm{~S}$ values than groundwater in the YM-SE grouping near Dune Wash (Figure A6-26). Groundwater from wells in the CF-SW and YM-S groupings near U.S. Highway 95 generally show an overall increase toward the west. Groundwaters in the easternmost wells of the YM-S grouping (wells NC-EWDP-2D, NC-EWDP-19D, and NC-EWDP-19P) have $\delta^{34} S$ values that span a range similar to that defined by the groundwater samples from Yucca Crest and Dune Wash. In the Amargosa Desert, groundwater associated with the Amargosa River and the Gravity fault has substantially higher $\delta^{34} \mathrm{~S}$ values than groundwater associated with Fortymile Wash, perhaps reflecting the presence of alluvium derived from carbonate rocks in these areas. As discussed in Section A6.3.1.2.3, marine sulfates from the early Paleozoic have $\delta^{34} \mathrm{~S}$ values near 30 per mil, values that are considerably higher than the values of 0 to 15 typical of sulfur of a volcanic origin. Some of the lowest groundwater $\delta^{34} \mathrm{~S}$ values are found in Jackass Flat at well J-11 (Site 67) and in several of the LW-group wells in the Amargosa Valley area. 


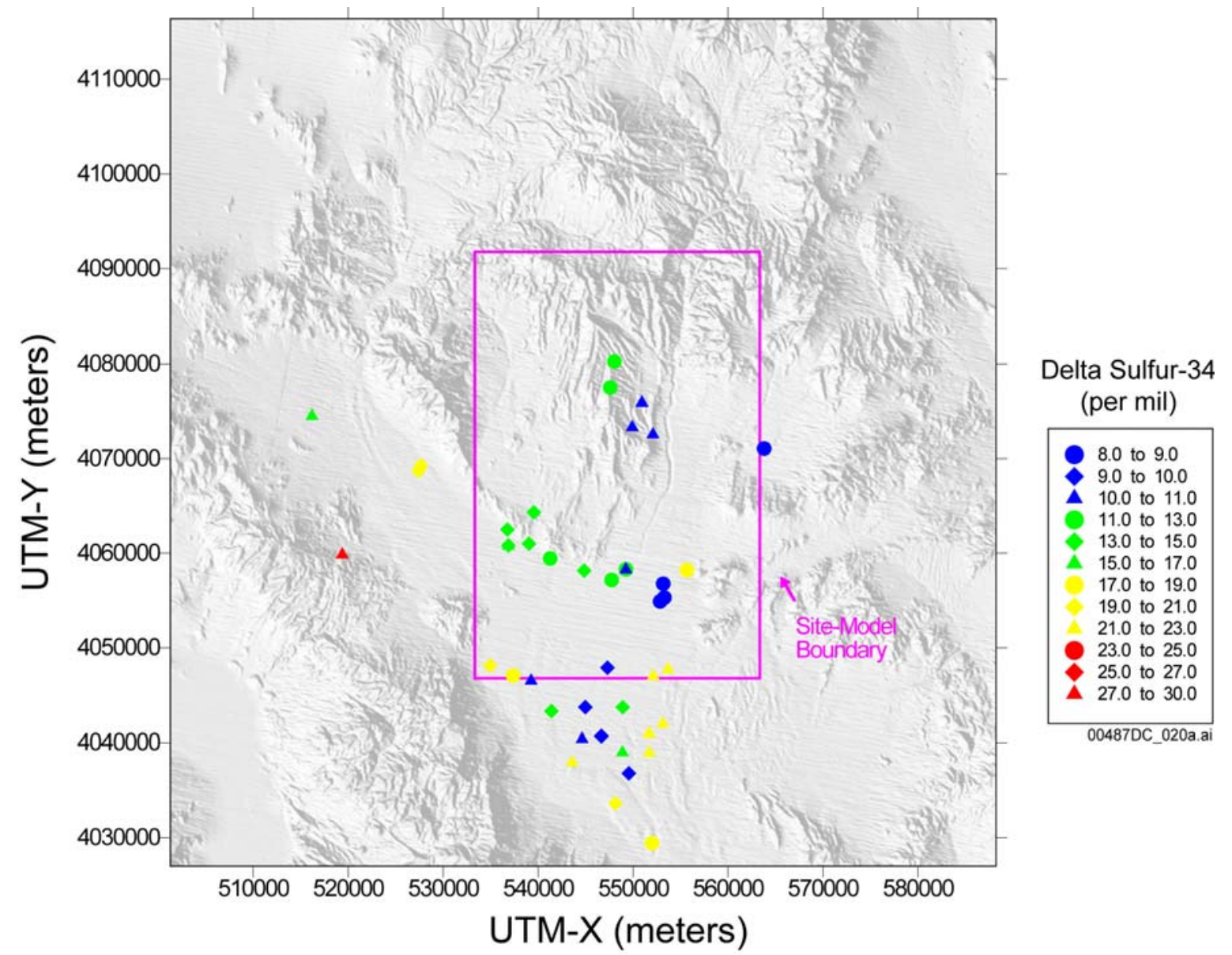

Source: Table A6-2.

NOTE: This figure has color-coded data points and should not be read in a black and white version. UTM-X =UTM-Easting and UTM-Y =UTM-Northing. UTM=Universal Transverse Mercator.

Figure A6-26. Areal Distribution of Delta Sulfur-34 in Groundwater

\section{A6.3.4.14 Delta Carbon-13}

The areal distribution of delta $\delta^{13} \mathrm{C}$ values is shown in Figure A6-27 (this isotopic parameter is defined and discussed in Section A6.3.1.2). Excluding the data from borehole p\#1 (Sites 62 and 63), where groundwater has $\delta^{13} \mathrm{C}$ values of -2.3 per mil in the carbonate aquifer and -4.2 per mil in the volcanic aquifer, the $\delta^{13} \mathrm{C}$ values of groundwater at Yucca Mountain vary between -14.4 per mil at borehole UZ-14 (Sites 45 and 46) to -4.9 per mil at borehole H-3 (Site 51). Although patterns are complex on a borehole-by-borehole basis, groundwater in the northern most part of Yucca Mountain is generally lighter in $\delta^{13} \mathrm{C}$ than groundwaters found toward the central and southern parts of the mountain. North of Yucca Mountain, groundwater $\delta^{13} \mathrm{C}$ values are generally considerably heavier than the groundwater $\delta^{13} \mathrm{C}$ values found at Yucca Mountain. Only groundwater from well ER-EC-07 (Site 24) in Beatty Wash has a $\delta^{13} \mathrm{C}$ within the range of values found at Yucca Mountain, in the Solitario Canyon Wash area, or in Crater Flat at borehole VH-1 (Site 69). Overall, the $\delta^{13} \mathrm{C}$ values of groundwater in the Nye County-EWDP boreholes at the southern edge of Crater Flat increase toward the west, reflecting the increasing proximity of groundwater to carbonate rocks with relatively heavy $\delta^{13} \mathrm{C}$ values. 


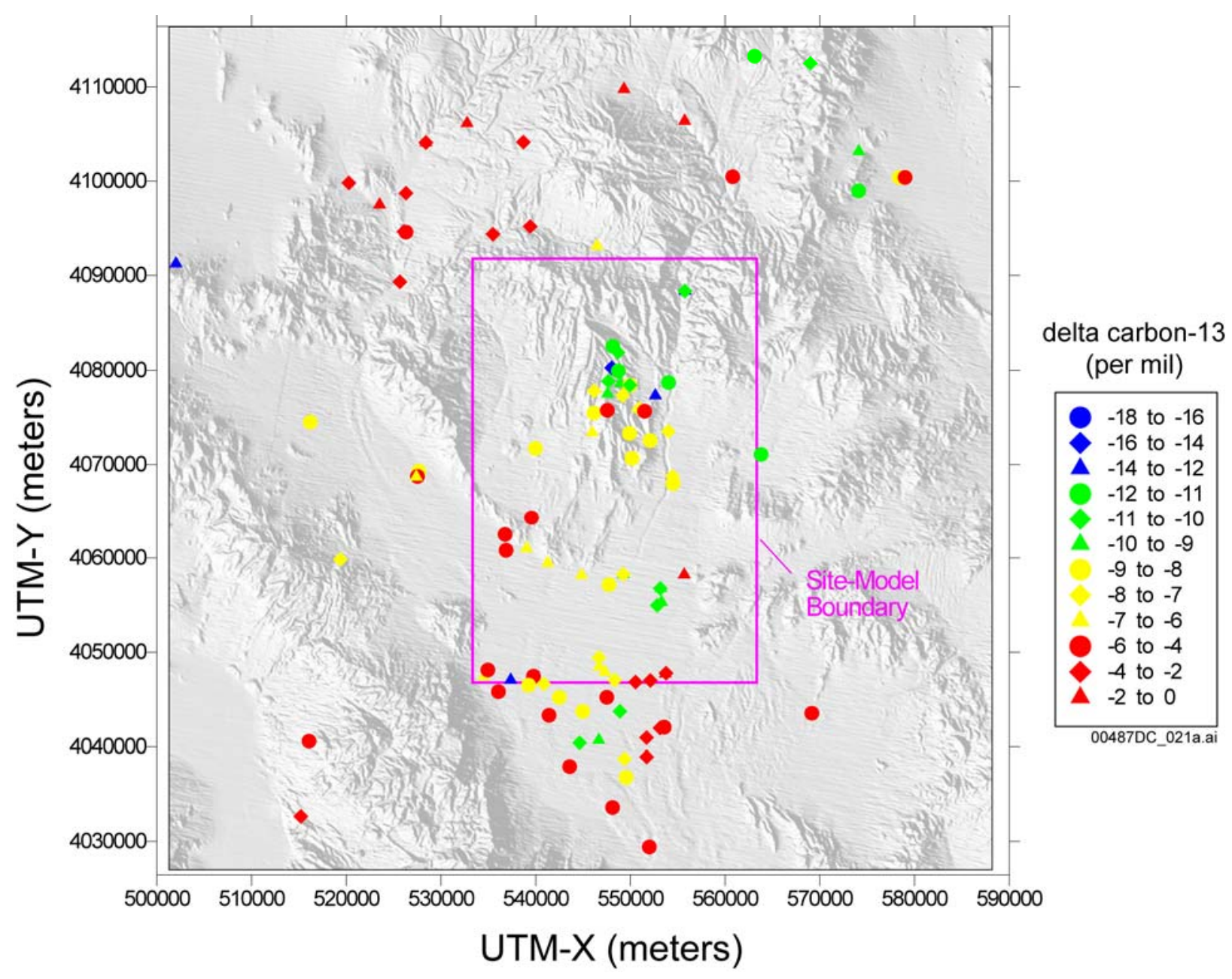

Source: Table A6-2.

NOTE: This figure has color-coded data points and should not be read in a black and white version. UTM-X $=$ UTM-Easting and UTM-Y =UTM-Northing. UTM=Universal Transverse Mercator.

Figure A6-27. Areal Distribution of Delta Carbon-13 in Groundwater

The $\delta^{13} \mathrm{C}$ values of groundwater near Fortymile Wash generally increase between the north and south boundaries of the site model area, although local reversals in this trend are evident. The groundwater $\delta^{13} \mathrm{C}$ values near Fortymile Wash are generally lower than the $\delta^{13} \mathrm{C}$ values toward the western and eastern parts of the Amargosa Desert, where groundwater $\delta^{13} \mathrm{C}$ values reflect the proximity to carbonate rocks of the southern Funeral Mountains and discharge from the carbonate aquifer across the Gravity fault, respectively. Several of the $\delta^{13} \mathrm{C}$ values of groundwater near the southwest corner of the site model area are similar to the values measured in groundwater at sites 15 to 18 west of Bare Mountain and in wells and springs in Oasis Valley. Groundwater in Jackass Flats and some groundwater at Amargosa Valley have relatively light $\delta^{13} \mathrm{C}$ values, despite the proximity of the Amargosa Valley (LW) group to groundwater near the Gravity fault with considerably heavier $\delta^{13} \mathrm{C}$ values. 


\section{A6.3.4.15 Carbon-14 Activity}

The areal distribution of ${ }^{14} \mathrm{C}$ activity in pmc is shown in Figure A6-28. This hydrochemical parameter is discussed in Section A6.3.1.2. Excluding groundwater from borehole p\#1 (Sites 62 and 63), which has a ${ }^{14} \mathrm{C}$ activity of $2.3 \mathrm{pmc}$ in the carbonate aquifer and $3.5 \mathrm{pmc}$ in the volcanic aquifer, the ${ }^{14} \mathrm{C}$ activity of groundwater at Yucca Mountain ranges from $10.5 \mathrm{pmc}$ at borehole H-3 (Site 51) to 27 pmc at borehole WT-24 (Site 44) in northern Yucca Mountain. Groundwater at the eastern edge of Crater Flat near Solitario Canyon has some of the lowest ${ }^{14} \mathrm{C}$ activities of groundwater in the map area, with values as low as $7.3 \mathrm{pmc}$ at borehole WT-10 (Site 42) and $10 \mathrm{pmc}$ in a sample from borehole H-6 (Site 34). Groundwater ${ }^{14} \mathrm{C}$ activities are slightly higher $(12 \mathrm{pmc})$ farther to the west in Crater Flat at borehole VH-1 (Site 69). Groundwater at several Nye County-EWDP wells in the YM-S grouping to the south of borehole VH-1 has similar ${ }^{14} \mathrm{C}$ activities. The groundwater at boreholes NC-EWDP-2D (Site 91), NC-EWDP-19P (Site 93), and some zones in NC-EWDP-19D (i.e. Site 96) have ${ }^{14} \mathrm{C}$ activities of 20 pmc or more, similar to the ${ }^{14} \mathrm{C}$ activities of groundwater in Dune Wash and Fortymile Wash.

Groundwater near Fortymile Wash has ${ }^{14} \mathrm{C}$ activities that range from about $76 \mathrm{pmc}$ at borehole a\#1 (Site 32) near the northern boundary of the model area to values less than 20 pmc near the southern boundary of the model area, with local reversals in this overall trend among the FMW-N group of samples. Southward from this area along Fortymile Wash, groundwater ${ }^{14} \mathrm{C}$ activities are lower but also do not show an obvious north-to-south trend. South of the southern boundary of the site model area, groundwater ${ }^{14} \mathrm{C}$ activities near Fortymile Wash range from 10 to 40 pmc. Elsewhere in the Amargosa Desert, several groundwater ${ }^{14} \mathrm{C}$ activities measured in the southwest corner of the site model area are approximately $30 \mathrm{pmc}$, which is considerably higher than the values of groundwater to the north and moderately higher than the values measured to the northwest at sites 15 to 18 west of Bare Mountain and in Oasis Valley.

In general, it can be noted that where relatively high groundwater $\delta^{13} \mathrm{C}$ values indicate water/rock interactions with isotopically heavy carbonate rock (Figure A6-27), the groundwater ${ }^{14} \mathrm{C}$ activities are generally low compared to other areas. These carbonate-rock-affected groundwaters are present at Timber Mountain, near Bare Mountain in the CF-SW area, near the southern Funeral Mountains in some AR and AR/FMW groundwaters, and near the GF samples. The highest ${ }^{14} \mathrm{C}$ activities are associated with major drainages, including the Amargosa River in the southwest corner of the site model area, upper Beatty Wash, and along Fortymile Wash, suggesting that these major washes are important areas of Holocene recharge. 


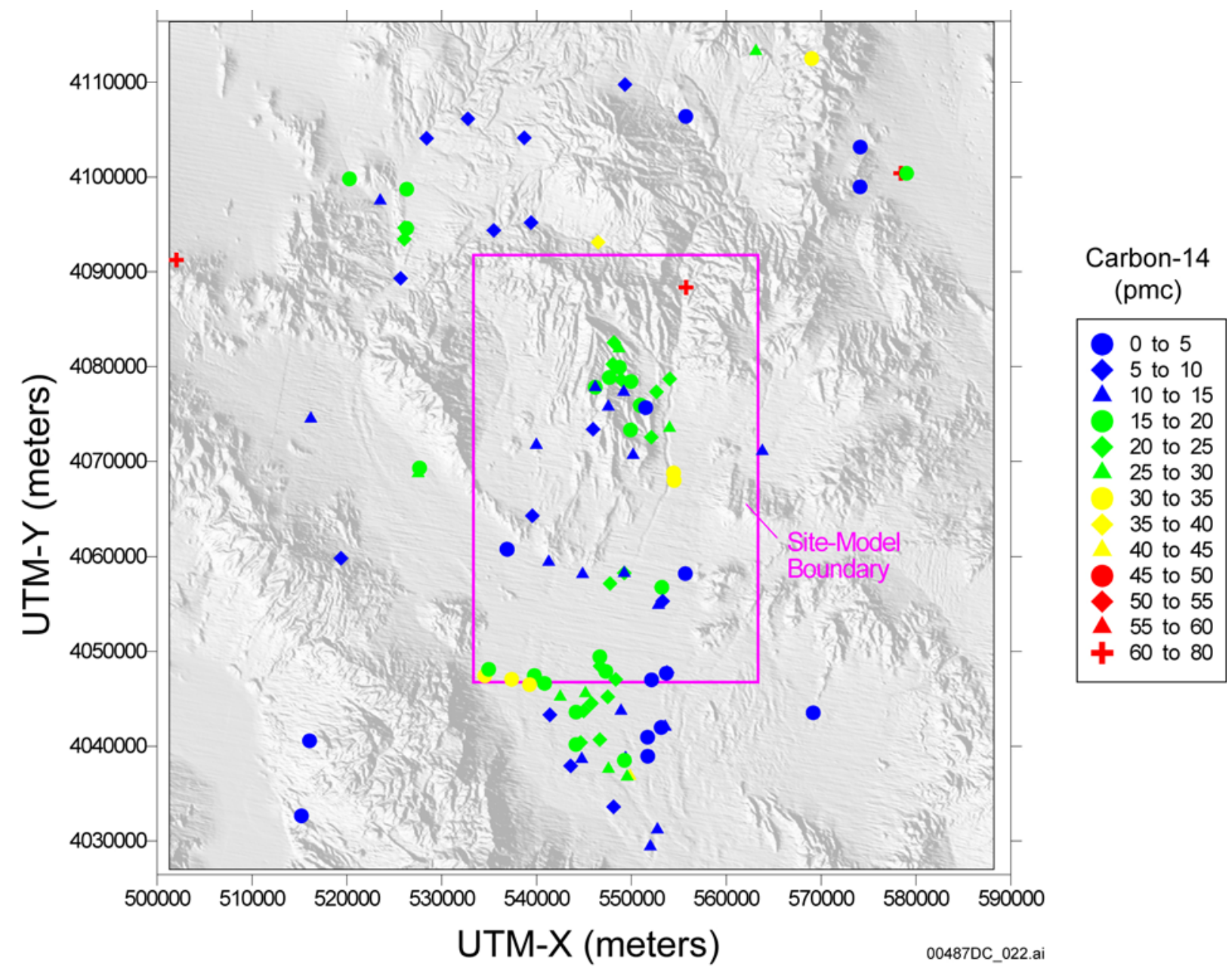

Source: Table A6-2.

NOTE: This figure has color-coded data points and should not be read in a black and white version. UTM-X $=$ UTM-Easting and UTM-Y =UTM-Northing. UTM=Universal Transverse Mercator.

Figure A6-28. Areal Distribution of Carbon-14 in Groundwater

\section{A6.3.4.16 Uranium Concentration and ${ }^{234} \mathbf{U} /{ }^{238} \mathbf{U}$ Activity Ratios}

Uranium concentration and ${ }^{234} \mathrm{U} /{ }^{238} \mathrm{U}$ activity ratio data are shown in Figures A6-29 and A6-30 respectively. Processes affecting uranium concentrations and ${ }^{234} \mathrm{U} /{ }^{238} \mathrm{U}$ activity ratios are discussed in Section A6.3.1.2 and in Paces et al (2002 [DIRS 158817]). Some of the highest activity ratios in the region are found at Timber Mountain (TM group) and in northern and southeastern Yucca Mountain (YM-CR and YM-SE groups). Samples in the YM-CR and YM-SE with these elevated ${ }^{234} \mathrm{U} /{ }^{238} \mathrm{U}$ activity ratios also have relatively small uranium concentrations (less than $2.5 \mu \mathrm{g} / \mathrm{L}$, but most approximately $1 \mu \mathrm{g} / \mathrm{L}$ ), whereas groundwaters from the TM group (except for Site 24 in upper Beatty Wash) have somewhat higher uranium concentrations (Figure A6-29). In addition to different uranium concentrations, other hydrochemical attributes of the Timber Mountain and Yucca Mountain groundwaters, such as $\mathrm{Na}^{+}$(Figure A6-22), $\mathrm{HCO}_{3}{ }^{-}$(Figure A6-17), and $\delta^{13} \mathrm{C}$ (Figure A6-27), are also generally different, suggesting the groundwaters from these areas are not necessarily related, despite their 
similar ${ }^{234} U /{ }^{238} U$ activity ratios. Data from borehole $p \# 1$ (Site 63) at Yucca Mountain indicate the carbonate aquifer has comparatively high uranium concentrations $(13.3 \mu \mathrm{g} / \mathrm{L})$ and low ${ }^{234} \mathrm{U} /{ }^{238} \mathrm{U}$ activity ratios (2.3) compared to some shallow groundwater at Yucca Mountain.

Uranium activity ratios decrease southward along Fortymile Wash from a value as high as 7 at well J-13 (Site 35) to values below 3.0 in the northern Amargosa Desert. Paces et al (2002 [DIRS 158817], p. 769) suggested that significant groundwater pumping from well J-13 and nearby well J-12 (Site 36) may have disrupted natural flow patterns and induced Yucca Mountain groundwater with high ${ }^{234} \mathrm{U} /{ }^{238} \mathrm{U}$ activity ratios to flow eastward toward Fortymile Wash. Measurements of archived water samples from well $\mathrm{J}-12$ indicated its ${ }^{234} \mathrm{U} /{ }^{238} \mathrm{U}$ activity ratio in 1971 was 5.5 , supporting the authors' contention that the ${ }^{234} \mathrm{U} /{ }^{238} \mathrm{U}$ activity ratios at well $\mathrm{J}-13$ may have initially been lower than recent measurement at that well have indicated.

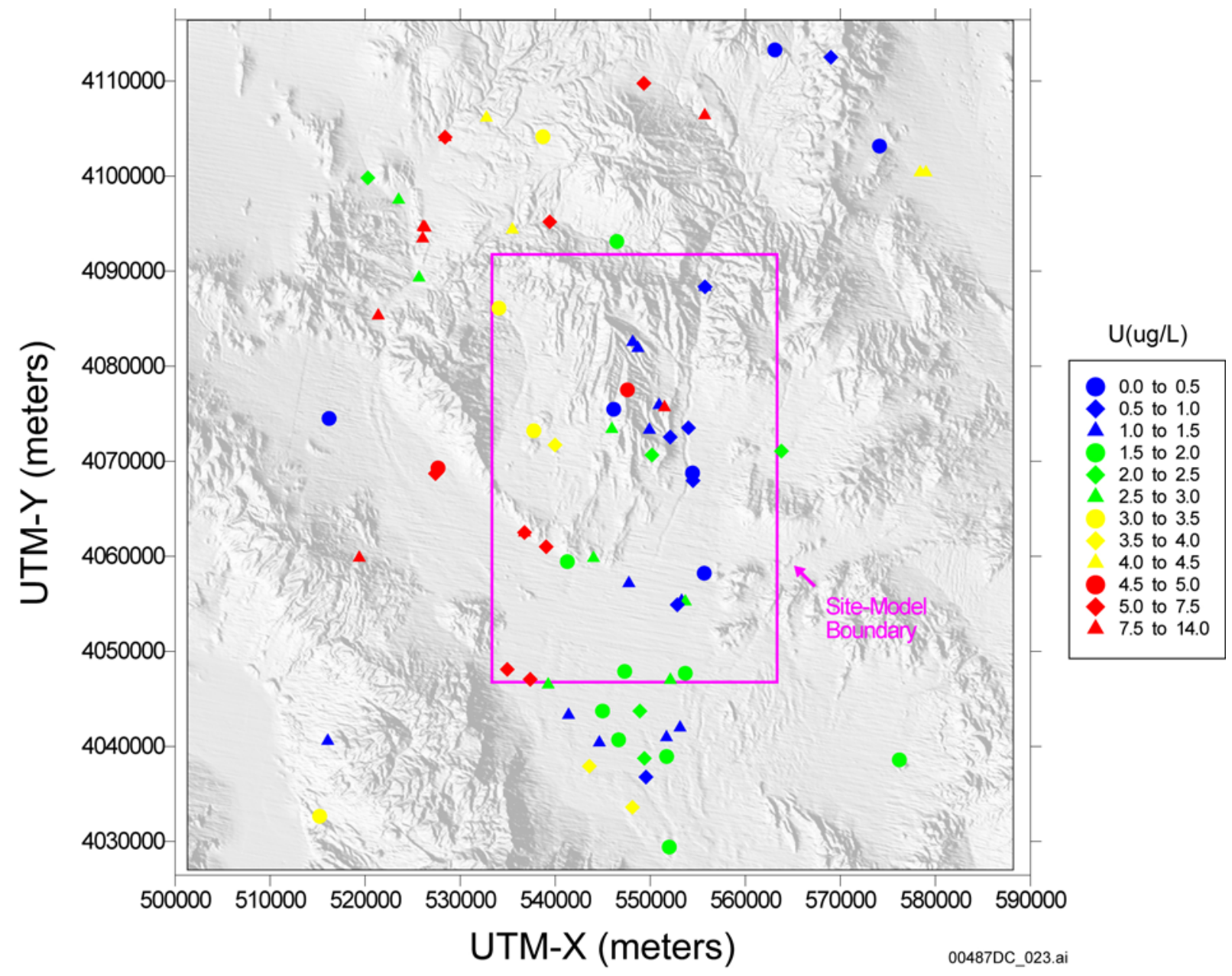

Source: Table A6-2.

NOTE: This figure has color-coded data points and should not be read in a black and white version. UTM-X =UTM-Easting and UTM-Y =UTM-Northing. UTM=Universal Transverse Mercator.

Figure A6-29. Areal Distribution of Uranium in Groundwater 
Uranium concentrations and ${ }^{234} U /{ }^{238} U$ activity ratios in the Amargosa Desert region have a relatively narrow range with concentrations typically between 1 and $4 \mu \mathrm{g} / \mathrm{L}$ and activity ratios mostly between 2.5 and 3.5. Borehole NC-EWDP-5S (Site 154) has an anomalously high ${ }^{234} \mathrm{U} /{ }^{238} \mathrm{U}$ activity ratio for this location of 6.6 and a very low uranium concentration of $0.04 \mu \mathrm{g} / \mathrm{L}$. From east to west of Yucca Mountain through the Crater Flat area into the Oasis Valley, ${ }^{234} \mathrm{U} /{ }^{238} \mathrm{U}$ activity ratios generally decrease whereas uranium concentrations increase.

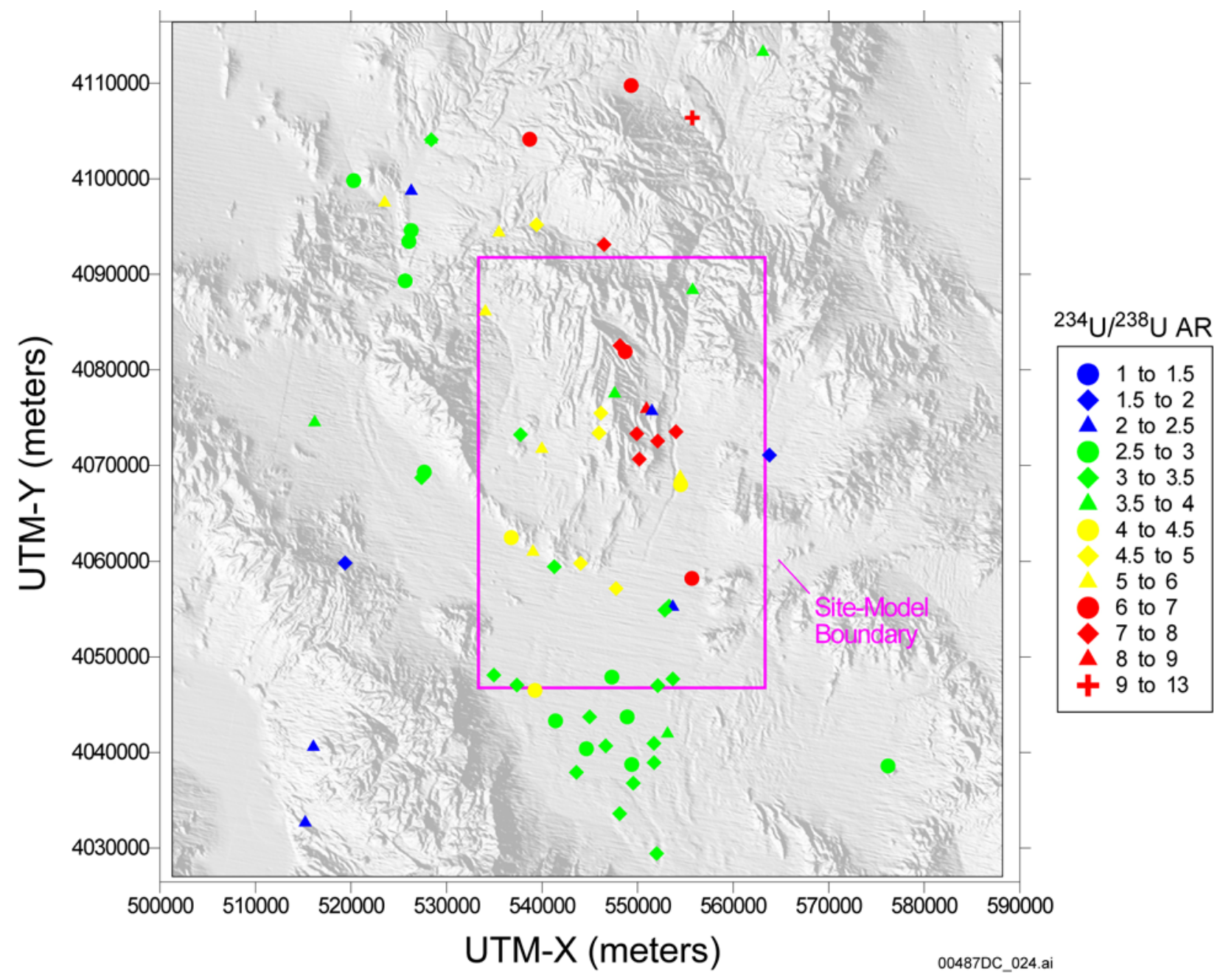

Source: Table A6-2.

NOTE: This figure has color-coded data points and should not be read in a black and white version. UTM-X =UTM-Easting and UTM-Y =UTM-Northing. UTM=Universal Transverse Mercator.

Figure A6-30. Areal Distribution of ${ }^{234} \mathrm{U} /{ }^{238} \mathrm{U}$ Activity Ratios (AR) in Groundwater

\section{A6.3.4.17 Strontium Concentrations and Delta Strontium-87}

Strontium concentrations from groundwater at Yucca Mountain vary considerably with values between 1.0 and $1720 \mu \mathrm{g} / \mathrm{L}$; most values, however, are between 10 and $50 \mu \mathrm{g} / \mathrm{L}$. In general, groundwater near Fortymile Wash has lower $\mathrm{Sr}^{2+}$ concentrations than groundwater to the east or west of the wash. Strontium concentrations in the FMW-N group are low (values mostly less 
than $50 \mu \mathrm{g} / \mathrm{L}$ ) relative to those in the FMW-S group (most values greater than $100 \mu \mathrm{g} / \mathrm{L}$ ). $\mathrm{Sr}^{2+}$ concentrations in Beatty Wash are one-to-two orders of magnitude higher that $\mathrm{Sr}^{2+}$ concentrations in northern Yucca Mountain in the YM-CR group, which are among the lowest in the region. Groundwater from $\mathrm{p \# 1(c)} \mathrm{has} \mathrm{a} \mathrm{relatively} \mathrm{high} \mathrm{Sr}^{2+}$ concentration of $450 \mu \mathrm{g} / \mathrm{L}$. Similarly high values also characterize groundwater that is likely to have contacted Paleozoic carbonate rocks elsewhere in the area (e.g., samples from SW Crater Flat, Gravity fault, Funeral Mountains, and Amargosa Flat groupings). Groundwater in the Timber Mountain area has $\mathrm{Sr}^{2+}$ concentrations between about 99 and $224 \mu \mathrm{g} / \mathrm{L}$.

Strontium isotope-ratio data (expressed as $\delta^{87} \mathrm{Sr}$ ) are unevenly distributed throughout the area with numerous values to the north of Yucca Mountain, some in the Yucca Mountain area and along U.S. Highway 95, and none in the Amargosa Desert region. Very low $\delta^{87} \mathrm{Sr}$ values are found in groundwater in Beatty Wash, in the Timber Mountain area, and in Oasis Valley (less than 1.8 per mil, with some negative values). Generally higher values exist to the south of the TM and upper FMW-N groups, although some Yucca Mountain groundwaters also have comparably low $\delta^{87} \mathrm{Sr}$ values. Interestingly, $\delta^{87} \mathrm{Sr}$ values of groundwater from the carbonate aquifer or from boreholes that have a component of water from the carbonate aquifer (e.g. p\#1(c), SW Crater Flat, Funeral Mountains) have high $\delta^{87} \mathrm{Sr}$. These waters also typically have high strontium concentrations. Reaction with the Paleozoic carbonate aquifer rock cannot explain this trend as these rocks are expected to have $\delta^{87} \mathrm{Sr}$ values of less than zero. A possible explanation is that these waters have reacted with Paleozoic or Precambrian clastic rocks, which are expected to have high $\delta^{87} \mathrm{Sr}$ due to their composition and age of the original detrital material (Peterman and Stuckless 1993 [DIRS 101149], p. 1561). 


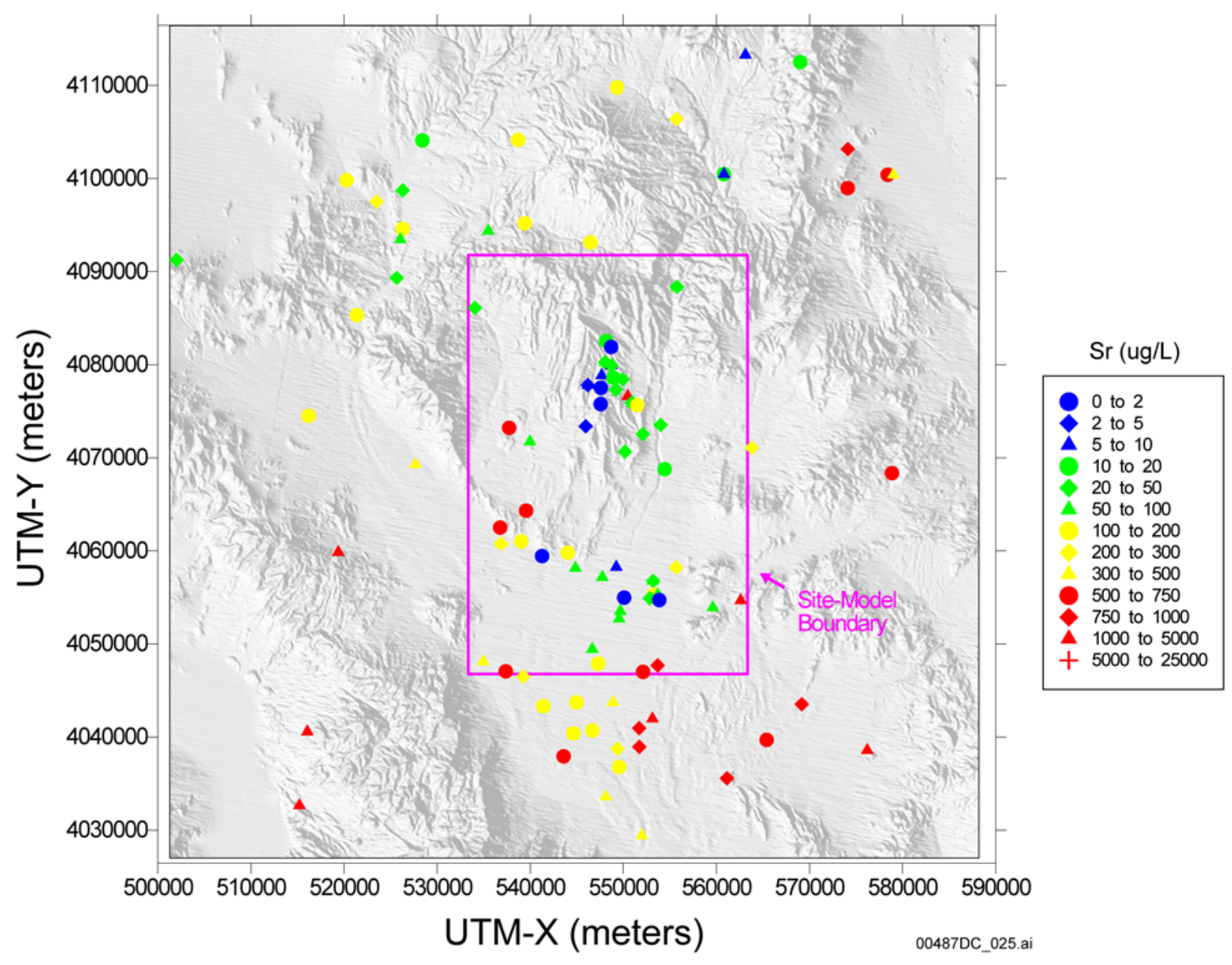

Source: Table A6-2.

NOTE: This figure has color-coded data points and should not be read in a black and white version. UTM-X =UTM-Easting and UTM-Y =UTM-Northing. UTM=Universal Transverse Mercator.

Figure A6-31. Areal Distribution of Strontium in Groundwater 


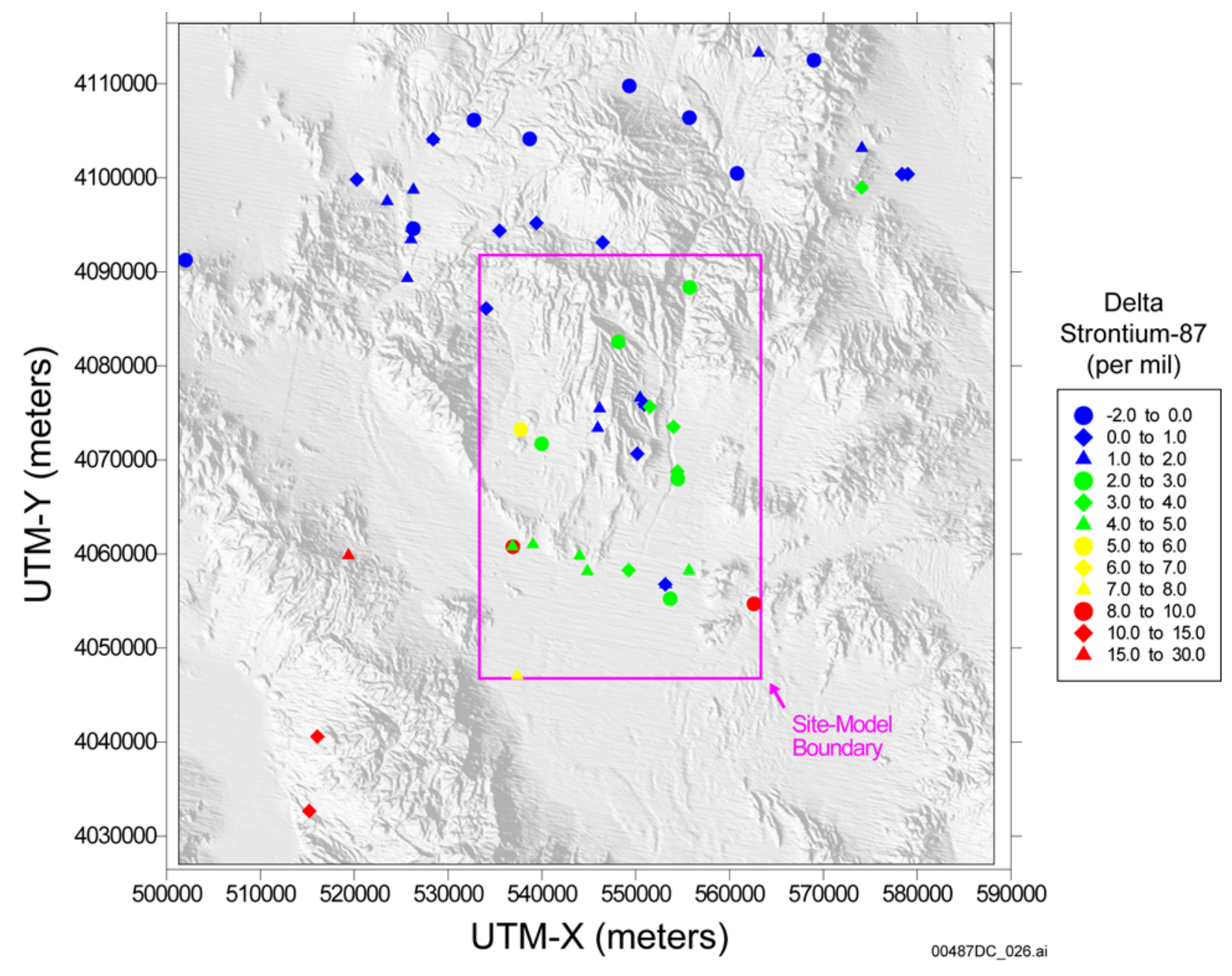

Source: Table A6-2.

NOTE: This figure has color-coded data points and should not be read in a black and white version. UTM-X $=$ UTM-Easting and UTM-Y =UTM-Northing. UTM=Universal Transverse Mercator.

Figure A6-32. Areal Distribution of Delta Strontium-87 in Groundwater

\section{A6.3.5 Areal Distribution of Calculated Geochemical Parameters}

The following subsections describe the areal distribution of the calculated geochemical parameters, including a brief summary of how the calculated parameters would be expected to reflect the relative state of evolution of the groundwater. A number of geochemical parameters were calculated with PHREEQC V2.3, STN: 10068-2.3-00 (BSC 2001 [DIRS 155323]: Parkhurst and Appelo 1999 [DIRS 159511]) to further characterize groundwater in the Yucca Mountain area. These parameters include charge balance error, ionic strength, dissolved inorganic carbon (DIC), the logarithm of dissolved carbon-dioxide partial pressure $\left(\log P_{\mathrm{CO}_{2}}\right)$, and the saturation indices of many minerals identified at Yucca Mountain (Table A6-3 below). The charge-balance errors are helpful in evaluating the reliability of hydrochemical analyses given in Table A6-1 of this report. The calculated DIC concentrations are used for evaluating 
the extent of calcite dissolution Yucca Mountain recharge undergoes as it moves through the saturated zone (Section A6.3.6.6) and in mixing models involving ${ }^{14} \mathrm{C}$ (Sections A6.3.6.7 and A7.3.6). The saturation indices are used to help constrain the possible reactions in inverse mixing and water/rock interaction models presented in Section A6.3.8.

The saturation indices of many common minerals such as K-feldspar, amorphous silica $\left[\mathrm{SiO}_{2}(\mathrm{a})\right]$, and calcite were based on thermodynamic data contained in the phreeqc.dat database provided with PHREEQC (Parkhurst and Appelo 1999 [DIRS 159511] Table 55). In addition, the specific chemical formulas and thermodynamic data for $\mathrm{Ca}$ - and $\mathrm{Na}$-clinoptilolite and smectite that have been identified at Yucca Mountain were used in PHREEQC to compute saturation indices. The chemical formulas of these minerals and the Gibbs free-energies $\left(\Delta \mathbf{G}_{f}^{\mathbf{O}}\right)$ and enthalpies $\left(\Delta \mathbf{H}_{\mathbf{f}} \mathbf{O}\right)$ of formation estimated for these minerals are listed in Table A6-4.

For the purpose of calculating mineral saturation indices, when field temperature measurements are unavailable, the temperature of groundwater samples was approximated either from published maps of water table temperatures at Yucca Mountain or, in the Amargosa Desert, was assumed to be $25^{\circ} \mathrm{C}$. The use of a contour map of water table temperatures (Fridrich et al. 1994 [DIRS 100575], Figure 8) to estimate groundwater sample temperatures at Yucca Mountain is an acceptable approximation because most of the samples for which this approximation was made are from the upper part of the saturated zone (Figure 6.7-2 samples 33, 34, 41, 57, and 66). Likewise, the assumption that groundwater samples in the Amargosa Desert with no measured temperatures are at $25^{\circ} \mathrm{C}$ is an acceptable approximation because most of the measured groundwater sample temperatures are in the range of 25 to $30^{\circ} \mathrm{C}$ (see data for $\mathrm{LW}, \mathrm{FMW}-\mathrm{S}$, FMW-E, FMW-W, GF, AR, and AR/FMW sample groups in Table A6-1.

The calculation of saturation indices for alumino-silicate minerals such as those listed in Table A6-4 requires measurements of dissolved $\mathrm{Al}^{3+}$ concentrations in the groundwater. Although recent groundwater samples from the Yucca Mountain area have reported dissolved $\mathrm{Al}^{3+}$ concentrations, historic data from the Yucca Mountain area are generally lacking this information. To get an estimate of the saturation indices of alumino-silicate minerals throughout the Yucca Mountain area, dissolved $\mathrm{Al}^{3+}$ concentrations for each sample were assumed to be in equilibrium with kaolinite (see Table A5-1, Assumption 2). This assumption provides estimates of dissolved $\mathrm{Al}^{3+}$ concentrations that are in good agreement with measured $\mathrm{Al}^{3+}$ concentrations at sites where these data are available (Figure A6-33). Estimates of Al concentrations made by assuming groundwater equilibrium with other $\mathrm{Al}^{3+}$-bearing minerals such as gibbsite, smectite, clinoptilolite, and $\mathrm{K}$-feldspar did not produce nearly as good a match to the available $\mathrm{Al}^{3+}$ data. Other factors affecting the calculated saturation indices are discussed in Section A7.3.2. These factors include uncertainty in thermodynamic data use to calculate the mineral solubility constants, variability in mineral compositions and particle sizes, and slow reaction rates relative to the groundwater residence times. 
Table A6-3. Calculated Geochemical Parameters of Groundwater Samples Used in this Report

\begin{tabular}{|c|c|c|c|c|c|c|c|c|c|c|c|c|c|}
\hline \multirow[b]{2}{*}{ Well } & \multirow[b]{2}{*}{$\begin{array}{c}\text { Figure. } \\
\text { A6-5 } \\
\text { Sample }\end{array}$} & \multirow[b]{2}{*}{$\begin{array}{c}\text { Ionic } \\
\text { Strength }\end{array}$} & \multirow{2}{*}{\begin{tabular}{|c|} 
Charge \\
Balance \\
Error \\
$(\%)^{1}$ \\
\end{tabular}} & \multirow[b]{2}{*}{$\begin{array}{l}\mathrm{DIC} \text { as } \\
(\mathrm{mg} / \mathrm{L} \\
\left.\mathrm{HCO}_{3}^{-}\right)\end{array}$} & \multirow[b]{2}{*}{$\begin{array}{c}\text { log } \\
\text { P co2 } \\
\text { (atm) }\end{array}$} & \multicolumn{8}{|c|}{ Mineral Saturation Indices ${ }^{2,3}$} \\
\hline & & & & & & Calcite & Smectite & Ca-Clino. & $\mathrm{SiO}_{2}(\mathrm{a})$ & Fluorite & Albite & $\begin{array}{c}\text { K- } \\
\text { Feldspar }\end{array}$ & Dolomite \\
\hline \multicolumn{14}{|c|}{ Oasis Valley/NW Amargosa } \\
\hline ER-EC-08 & 1 & $7.18 \times 10^{-3}$ & -3.5 & 176.8 & -2.68 & -0.06 & 4.00 & 16.11 & -0.49 & -0.53 & -1.51 & -0.65 & -0.73 \\
\hline ER-OV-01 & 2 & $7.43 \times 10^{-3}$ & 1.3 & 197.2 & -3.02 & -0.10 & 6.16 & 29.11 & -0.24 & -1.43 & -0.80 & 0.22 & -1.64 \\
\hline ER-OV-06a & 3 & $7.46 \times 10^{-3}$ & 0.8 & 201.0 & -2.99 & -0.53 & 5.32 & 23.90 & -0.39 & -1.59 & -1.04 & -0.03 & -1.14 \\
\hline ER-OV-05 & 4 & $7.27 \times 10^{-3}$ & 0.2 & 241.5 & -2.46 & -0.01 & 6.81 & 31.43 & -0.13 & -1.01 & -1.25 & 0.11 & -0.41 \\
\hline ER-OV-02 & 5 & $8.24 \times 10^{-3}$ & -0.2 & 226.6 & -2.90 & 0.12 & 6.80 & 30.85 & -0.26 & -0.91 & -1.03 & -0.16 & -0.87 \\
\hline $\begin{array}{l}\text { Springdale Upper Well } \\
\text { (10S/47E-32adc) }\end{array}$ & 6 & $8.51 \times 10^{-3}$ & -0.3 & 303.0 & -2.26 & 0.00 & 6.31 & 27.98 & -0.21 & -0.86 & -1.40 & -0.22 & -0.41 \\
\hline $\begin{array}{l}\text { Goss Springs North } \\
\text { (11S/47E-10bad) }\end{array}$ & 7 & $6.88 \times 10^{-3}$ & -1.6 & 179.7 & -3.01 & 0.08 & 6.88 & 31.04 & -0.29 & -0.77 & -1.22 & -0.12 & -0.72 \\
\hline Er-OV-03a & 8 & $7.02 \times 10^{-3}$ & 1.1 & 184.6 & -2.90 & -0.08 & 6.90 & 30.91 & -0.27 & -0.87 & -1.25 & -0.17 & -1.06 \\
\hline ER-OV-03a3 & 9 & $7.19 \times 10^{-3}$ & 0.5 & 182.0 & -3.08 & 0.14 & 6.47 & 29.69 & -0.31 & -1.03 & -1.05 & 0.01 & -0.50 \\
\hline ER-OV-03a2 & 10 & $2.06 \times 10^{-2}$ & -3.0 & 241.6 & -3.92 & 0.54 & 5.39 & 26.20 & -0.81 & - & -0.76 & 1.05 & 0.64 \\
\hline $\begin{array}{l}\text { Goss Spring (11S/47E- } \\
\text { 10bcc) }\end{array}$ & 11 & $7.21 \times 10^{-3}$ & 1.4 & 187.6 & -2.47 & -0.32 & 6.04 & 24.88 & -0.34 & -0.67 & -1.73 & -0.71 & -1.46 \\
\hline ER-OV-04a & 12 & $5.71 \times 10^{-3}$ & 0.2 & 162.7 & -3.21 & 0.06 & 6.46 & 30.96 & -0.23 & -0.97 & -0.86 & 0.40 & -1.48 \\
\hline $\begin{array}{l}\text { Beatty Well no. } 1 \\
\text { (Wat\&Sanit Distr) }\end{array}$ & 13 & - & - & - & - & - & - & - & - & - & - & - & - \\
\hline Bond Gold Mining \#1 & 14 & $5.90 \times 10^{-3}$ & -2.4 & 158.7 & -3.12 & 0.39 & 5.10 & 20.82 & -0.62 & -1.91 & -1.89 & -0.50 & 0.55 \\
\hline US Ecology MW-313 & 15 & $1.42 \times 10^{-2}$ & -6.0 & 355.2 & -2.00 & 0.18 & 6.08 & 26.48 & -0.23 & 0.16 & -1.59 & -0.30 & 0.18 \\
\hline US Ecology MW-600 & 16 & $1.18 \times 10^{-2}$ & -4.0 & 300.4 & -2.45 & 0.12 & 6.04 & 27.07 & -0.28 & -0.20 & -1.21 & -0.15 & 0.34 \\
\hline Nucl. Eng. Co. Well & 17 & $1.43 \times 10^{-2}$ & -0.1 & 342.4 & -2.11 & 0.28 & 6.15 & 27.23 & -0.22 & - & -1.40 & -0.28 & 0.32 \\
\hline US Ecology MR-3 & 18 & - & - & - & - & - & - & - & - & - & - & - & - \\
\hline
\end{tabular}


Table A6-3. Calculated Geochemical Parameters of Groundwater Samples Used in this Report (Continued)

\begin{tabular}{|c|c|c|c|c|c|c|c|c|c|c|c|c|c|}
\hline \multirow[b]{2}{*}{ Well } & \multirow[b]{2}{*}{$\begin{array}{c}\text { Figure. } \\
\text { A6-5 } \\
\text { Sample }\end{array}$} & \multirow[b]{2}{*}{$\begin{array}{c}\text { Ionic } \\
\text { Strength }\end{array}$} & \multirow{2}{*}{$\begin{array}{c}\text { Charge } \\
\text { Balance } \\
\text { Error } \\
(\%)^{1}\end{array}$} & \multirow[b]{2}{*}{$\begin{array}{c}\text { DIC as } \\
(\mathrm{mg} / \mathrm{L} \\
\left.\mathrm{HCO}_{3}{ }^{-}\right)\end{array}$} & \multirow[b]{2}{*}{$\begin{array}{c}\text { log } \\
P_{\text {co2 }} \\
\text { (atm) } \\
\end{array}$} & \multicolumn{8}{|c|}{ Mineral Saturation Indices ${ }^{2,3}$} \\
\hline & & & & & & Calcite & Smectite & Ca-Clino. & $\mathrm{SiO}_{2}(\mathrm{a})$ & Fluorite & Albite & $\mid \begin{array}{c}\mathrm{K}- \\
\text { Feldspar }\end{array}$ & Dolomite \\
\hline \multicolumn{14}{|l|}{ Timber Mountain } \\
\hline UE-18r & 19 & $4.84 \times 10^{-3}$ & 0.0 & 211.2 & -2.85 & 0.42 & 5.01 & 21.03 & -0.44 & -0.73 & -1.50 & -0.66 & -0.17 \\
\hline ER-18-2 & 20 & $1.54 \times 10^{-2}$ & 5.3 & 755.1 & -1.55 & 0.02 & 1.65 & 2.43 & -0.67 & -0.29 & -1.64 & -1.68 & -0.91 \\
\hline ER-EC-05 & 21 & $4.84 \times 10^{-3}$ & 6.5 & 144.8 & -2.82 & 0.09 & 4.78 & 18.13 & -0.50 & -0.20 & -1.84 & -1.19 & -0.95 \\
\hline $\begin{array}{l}\text { Coffer's Ranch Windmill } \\
\text { Well }\end{array}$ & 22 & $4.63 \times 10^{-3}$ & -1.4 & 182.4 & -3.08 & 0.26 & 6.11 & 25.06 & -0.43 & -0.45 & -1.55 & -1.04 & -1.10 \\
\hline ER-OV-03c & 23 & $5.03 \times 10^{-3}$ & 0.1 & 160.8 & -3.02 & 0.10 & 5.90 & 24.21 & -0.42 & -0.28 & -1.54 & -0.95 & -1.07 \\
\hline ER-EC-07 & 24 & $3.69 \times 10^{-3}$ & -2.9 & 150.6 & -2.70 & 0.06 & 4.86 & 18.66 & -0.47 & -1.13 & -2.17 & -0.96 & -0.58 \\
\hline \multicolumn{14}{|l|}{ Fortymile Wash-North } \\
\hline Water Well 8 & 25 & $2.26 \times 10^{-3}$ & 2.6 & 86.1 & -2.40 & -1.29 & 5.51 & 19.66 & -0.36 & -2.12 & -2.70 & -1.32 & -3.06 \\
\hline $\begin{array}{l}\text { Test Well } 1 \text { (USGS HTH } \\
\# 1)\end{array}$ & 26 & $2.29 \times 10^{-3}$ & 7.7 & 99.6 & -3.70 & -0.60 & 4.15 & 13.12 & -0.82 & - & -1.97 & -1.66 & - \\
\hline UE-18t & 27 & $8.09 \times 10^{-3}$ & 0.5 & 320.8 & -3.12 & 0.93 & 3.21 & 7.90 & -1.25 & - & -2.52 & -1.41 & 0.89 \\
\hline ER-30-1 (upper) & 28 & $3.17 \times 10^{-3}$ & 4.4 & 108.9 & -4.43 & 0.43 & 5.26 & 23.32 & -0.72 & -1.78 & -1.04 & -0.21 & -0.34 \\
\hline ER-30-1 (lower) & 29 & $3.04 \times 10^{-3}$ & 7.1 & 113.2 & -4.18 & 0.09 & 4.86 & 19.81 & -0.76 & -2.17 & -1.27 & -0.73 & -0.79 \\
\hline$a \# 2$ (dp) & 30 & $2.96 \times 10^{-3}$ & -2.3 & 121.0 & -2.16 & -1.16 & 5.14 & 16.23 & -0.42 & -1.74 & -2.76 & -2.03 & -3.66 \\
\hline a\#2 (sh) & 31 & $2.92 \times 10^{-3}$ & -0.3 & 130.2 & -1.98 & -1.39 & 5.39 & 16.75 & -0.40 & -1.80 & -2.95 & -2.12 & -3.98 \\
\hline UE-29a\#1 HTH & 32 & $3.09 \times 10^{-3}$ & 5.2 & 114.1 & -2.57 & -0.61 & 6.04 & 24.28 & -0.29 & -1.98 & -2.21 & -0.80 & -1.71 \\
\hline WT\#15 & 33 & $3.95 \times 10^{-3}$ & 2.3 & 175.2 & -2.23 & -0.50 & 4.55 & 16.64 & -0.42 & 一 & -2.20 & -1.08 & -1.42 \\
\hline WT\#14 & 34 & $3.11 \times 10^{-3}$ & 0.2 & 130.5 & -2.19 & -0.95 & 4.97 & 18.11 & -0.35 & - & -2.45 & -1.12 & -2.59 \\
\hline $\mathrm{J}-13$ & 35 & $3.23 \times 10^{-3}$ & 0.3 & 139.0 & -2.06 & -0.94 & 4.82 & 16.97 & -0.36 & -0.97 & -2.58 & -1.23 & -2.22 \\
\hline $\mathrm{J}-12$ & 36 & $3.29 \times 10^{-3}$ & -1.3 & 138.1 & -2.01 & -1.04 & 5.22 & 18.33 & -0.35 & -0.98 & -2.75 & -1.31 & -2.54 \\
\hline $\mathrm{JF} \# 3$ & 37 & $3.78 \times 10^{-3}$ & 1.3 & 123.8 & -2.61 & -0.36 & 5.60 & 23.21 & -0.33 & -1.12 & -2.13 & -0.44 & -1.11 \\
\hline
\end{tabular}


Table A6-3. Calculated Geochemical Parameters of Groundwater Samples Used in this Report (Continued)

\begin{tabular}{|c|c|c|c|c|c|c|c|c|c|c|c|c|c|}
\hline \multirow[b]{2}{*}{ Well } & \multirow{2}{*}{$\begin{array}{c}\text { Figure. } \\
\text { A6-5 } \\
\text { Sample }\end{array}$} & \multirow[b]{2}{*}{$\begin{array}{c}\text { Ionic } \\
\text { Strength }\end{array}$} & \multirow{2}{*}{$\begin{array}{c}\text { Charge } \\
\text { Balance } \\
\text { Error } \\
(\%)^{1}\end{array}$} & \multirow{2}{*}{$\begin{array}{c}\mathrm{DIC} \text { as } \\
(\mathrm{mg} / \mathrm{L} \\
\left.\mathrm{HCO}_{3}{ }^{-}\right)\end{array}$} & \multirow{2}{*}{$\begin{array}{c}\text { log } \\
P_{\mathrm{cO} 2} \\
\text { (atm) }\end{array}$} & \multicolumn{8}{|c|}{ Mineral Saturation Indices ${ }^{2,3}$} \\
\hline & & & & & & Calcite & Smectite & Ca-Clino. & $\mathrm{SiO}_{2}(\mathrm{a})$ & Fluorite & Albite & $\begin{array}{c}\text { K- } \\
\text { Feldspar }\end{array}$ & Dolomite \\
\hline \multicolumn{14}{|c|}{ Solitario Canyon Wash } \\
\hline $\mathrm{H}-6$ (bh) & 38 & $4.41 \times 10^{-3}$ & -0.8 & 181.1 & -2.76 & -0.30 & 3.93 & 14.51 & -0.50 & -0.97 & -1.57 & -1.20 & -1.75 \\
\hline H-6(Tct) & 39 & $4.52 \times 10^{-3}$ & -6.6 & 212.4 & -2.87 & -0.47 & 3.43 & 12.50 & -0.55 & -1.65 & -1.41 & -1.09 & - \\
\hline $\mathrm{H}-6$ (Tcb) & 40 & $4.97 \times 10^{-3}$ & -9.5 & 229.7 & -2.87 & 0.03 & 4.10 & 16.23 & -0.49 & -0.93 & -1.35 & -0.95 & -1.15 \\
\hline WT-7 & 41 & $4.76 \times 10^{-3}$ & -2.5 & 241.0 & -3.27 & 0.13 & 3.31 & 10.76 & -0.88 & - & -1.73 & -1.16 & -0.39 \\
\hline WT-10 & 42 & $4.64 \times 10^{-3}$ & 1.4 & 180.3 & -3.06 & -0.21 & 3.84 & 14.76 & -0.53 & -1.40 & -1.28 & -1.08 & -1.36 \\
\hline \multicolumn{14}{|c|}{ Yucca Mountain-Crest } \\
\hline G-2 & 43 & $2.89 \times 10^{-3}$ & 0.6 & 127.6 & -2.35 & -0.79 & 4.35 & 15.53 & -0.44 & -1.95 & -2.35 & -1.05 & -2.33 \\
\hline USW WT-24 & 44 & $2.73 \times 10^{-3}$ & 2.4 & 120.9 & -2.82 & -1.93 & 5.49 & 21.06 & -0.35 & -3.34 & -1.78 & -1.01 & - \\
\hline UZ-14(sh) & 45 & $3.41 \times 10^{-3}$ & 8.1 & 129.2 & -3.29 & -1.41 & 5.31 & 21.74 & -0.45 & -1.69 & -1.35 & -0.61 & -2.95 \\
\hline UZ-14(dp) & 46 & $3.53 \times 10^{-3}$ & 6.3 & 133.8 & -3.26 & -1.55 & 5.14 & 21.26 & -0.43 & -1.84 & -1.29 & -0.50 & -3.04 \\
\hline $\mathrm{H}-1$ (Tcp) & 47 & $2.78 \times 10^{-3}$ & 0.6 & 118.5 & -2.58 & -0.86 & 4.40 & 15.47 & -0.46 & -2.01 & -2.17 & -1.25 & -2.95 \\
\hline $\mathrm{H}-1$ (Tcb) & 48 & $2.93 \times 10^{-3}$ & -0.7 & 125.7 & -2.55 & -0.68 & 3.96 & 12.49 & -0.55 & -2.05 & -2.32 & -1.60 & -2.71 \\
\hline $\mathrm{H}-5$ & 49 & $2.92 \times 10^{-3}$ & 2.1 & 127.8 & -2.73 & -0.95 & 4.08 & 14.59 & -0.48 & -2.26 & -1.90 & -1.14 & - \\
\hline USW SD-6 & 50 & $4.35 \times 10^{-3}$ & -0.7 & 182.1 & -3.08 & -1.05 & 4.16 & 16.13 & -0.51 & -1.96 & -1.30 & -0.86 & - \\
\hline $\mathrm{H}-3$ & 51 & $6.12 \times 10^{-3}$ & -3.7 & 240.9 & -3.85 & -0.09 & 5.23 & 23.60 & -0.55 & -1.55 & -0.57 & -0.28 & - \\
\hline \multicolumn{14}{|c|}{ Yucca Mountain-Central } \\
\hline G-4 & 52 & $3.56 \times 10^{-3}$ & 3.7 & 143.0 & -2.49 & -0.31 & 4.07 & 13.89 & -0.50 & -0.96 & -2.18 & -1.39 & -1.98 \\
\hline $\mathrm{b \# 1(Tcb)}$ & 53 & $3.59 \times 10^{-3}$ & 2.0 & 152.4 & -1.89 & -0.76 & 3.85 & 11.12 & -0.46 & -1.22 & -2.76 & -1.78 & -2.47 \\
\hline $\mathrm{b \# 1(bh)}$ & 54 & $3.94 \times 10^{-3}$ & -3.4 & 170.1 & -2.03 & -0.51 & 4.13 & 13.61 & -0.44 & -1.22 & -2.50 & -1.43 & -1.99 \\
\hline $\mathrm{H}-4$ & 55 & $4.58 \times 10^{-3}$ & 3.9 & 185.2 & -2.10 & -0.42 & 4.11 & 13.31 & -0.48 & -0.33 & -2.34 & -1.57 & -2.16 \\
\hline UZ\#16 & 56 & $5.79 \times 10^{-3}$ & 10.8 & 185.9 & -3.75 & 0.85 & - & - & -0.62 & - & -1.05 & - & 2.27 \\
\hline
\end{tabular}


Table A6-3. Calculated Geochemical Parameters of Groundwater Samples Used in this Report (Continued)

\begin{tabular}{|c|c|c|c|c|c|c|c|c|c|c|c|c|c|}
\hline \multirow[b]{2}{*}{ Well } & \multirow[b]{2}{*}{$\begin{array}{c}\text { Figure. } \\
\text { A6-5 } \\
\text { Sample }\end{array}$} & \multirow[b]{2}{*}{$\begin{array}{c}\text { lonic } \\
\text { Strength }\end{array}$} & \multirow{2}{*}{$\begin{array}{c}\text { Charge } \\
\text { Balance } \\
\text { Error } \\
(\%)^{1}\end{array}$} & \multirow[b]{2}{*}{$\begin{array}{l}\mathrm{DIC} \text { as } \\
(\mathrm{mg} / \mathrm{L} \\
\left.\mathrm{HCO}_{3}^{-}\right)\end{array}$} & \multirow[b]{2}{*}{$\begin{array}{c}\text { log } \\
P_{\mathrm{co} 2} \\
(\mathrm{~atm})\end{array}$} & \multicolumn{8}{|c|}{ Mineral Saturation Indices ${ }^{2,3}$} \\
\hline & & & & & & Calcite & Smectite & Ca-Clino. & $\mathrm{SiO}_{2}(\mathrm{a})$ & Fluorite & Albite & $\mid \begin{array}{c}\text { K- } \\
\text { Feldspar }\end{array}$ & Dolomite \\
\hline \multicolumn{14}{|c|}{ Yucca Mountain-Southeast } \\
\hline ONC\#1 & 57 & $3.40 \times 10^{-3}$ & 9.1 & 107.8 & -3.64 & 0.49 & 4.24 & 16.99 & -0.72 & - & -1.72 & -0.60 & 0.33 \\
\hline c\#1 & 58 & $3.63 \times 10^{-3}$ & -3.4 & 156.6 & -2.31 & -0.37 & 3.61 & 12.00 & -0.45 & -1.25 & -2.12 & -1.41 & -1.82 \\
\hline c\#3 & 59 & $3.48 \times 10^{-3}$ & 0.2 & 140.5 & -2.46 & -0.32 & 3.65 & 12.34 & -0.47 & -1.28 & -2.07 & -1.37 & -1.60 \\
\hline C\#3(95-97) & 60 & $3.43 \times 10^{-3}$ & 3.6 & 144.5 & -2.45 & -0.30 & 3.78 & 13.30 & -0.43 & - & -1.98 & -1.29 & -1.69 \\
\hline c\#2 & 61 & $3.53 \times 10^{-3}$ & -0.2 & 142.5 & -2.45 & -0.28 & 3.72 & 12.85 & -0.46 & -1.20 & -2.06 & -1.31 & -1.56 \\
\hline$p \# 1(v)$ & 62 & $8.25 \times 10^{-3}$ & -1.2 & 438.7 & -1.14 & -0.32 & 2.90 & 6.20 & -0.53 & -0.44 & -2.83 & -1.93 & -0.72 \\
\hline$p \# 1(c)$ & 63 & $1.85 \times 10^{-2}$ & -2.5 & 976.6 & -0.58 & 0.22 & 1.35 & -1.76 & -0.68 & -0.02 & -3.04 & -2.14 & 0.53 \\
\hline WT-17 & 64 & $3.15 \times 10^{-3}$ & -1.0 & 150.1 & -1.96 & -1.18 & 4.50 & 13.04 & -0.51 & -1.23 & -2.93 & -1.91 & -2.96 \\
\hline WT\#3 & 65 & $3.37 \times 10^{-3}$ & -1.2 & 144.3 & -2.41 & -0.52 & 4.83 & 18.44 & -0.37 & -1.05 & -2.13 & -0.97 & -1.66 \\
\hline WT\#12 & 66 & $4.30 \times 10^{-3}$ & 0.1 & 174.0 & -2.33 & -0.31 & 4.43 & 15.67 & -0.46 & -0.71 & -2.16 & -1.32 & -1.90 \\
\hline \multicolumn{14}{|l|}{ Jackass Flats } \\
\hline $\mathrm{J}-11$ & 67 & $1.69 \times 10^{-2}$ & 1.4 & 80.6 & -3.23 & 0.24 & 6.09 & 28.57 & -0.31 & -1.00 & -1.13 & 0.25 & 0.10 \\
\hline \multicolumn{14}{|l|}{ Crater Flat } \\
\hline GEXA Well 4 & 68 & $4.56 \times 10^{-3}$ & -2.3 & 151.8 & -2.69 & -0.21 & 4.72 & 18.48 & -0.45 & -0.80 & -1.82 & -0.89 & -1.46 \\
\hline $\mathrm{VH}-1$ & 69 & $4.77 \times 10^{-3}$ & 0.9 & 171.3 & -2.32 & -0.47 & 4.18 & 14.35 & -0.46 & -1.03 & -2.05 & -1.45 & -1.33 \\
\hline \multicolumn{14}{|l|}{ Crater Flat-Southwest } \\
\hline $\mathrm{VH}-2$ & 70 & $1.29 \times 10^{-2}$ & -1.3 & 446.9 & -1.48 & 0.14 & 3.60 & 8.75 & -0.71 & -1.08 & -3.15 & -1.85 & 0.28 \\
\hline NC-EWDP-7S & 71 & $1.44 \times 10^{-2}$ & -0.6 & 461.8 & -1.73 & 0.19 & 4.96 & 15.69 & -0.68 & -1.06 & -2.95 & -1.59 & 0.37 \\
\hline NC-EWDP-7SC & 72 & $1.50 \times 10^{-2}$ & -0.4 & 480.4 & -1.60 & 0.18 & 4.47 & 12.52 & -0.69 & -1.17 & -3.01 & -2.00 & 0.36 \\
\hline NC-EWDP-1DX & 73 & $1.19 \times 10^{-2}$ & -3.5 & 414.1 & -1.66 & -0.03 & 5.42 & 20.19 & -0.40 & -1.52 & -2.51 & -1.04 & 0.03 \\
\hline NC-EWDP-1DX Zone 2 & 74 & $2.09 \times 10^{-2}$ & -9.3 & 1385.6 & -0.70 & -0.26 & 4.86 & 15.91 & -0.38 & 0.62 & -2.30 & -1.72 & -0.70 \\
\hline NC-EWDP-01S Zone 1 & 75 & $1.15 \times 10^{-2}$ & -3.7 & 386.1 & -1.86 & 0.20 & 5.39 & 21.01 & -0.38 & -1.65 & -2.30 & -0.84 & 0.49 \\
\hline NC-EWDP-01S Zone 2 & 76 & $1.14 \times 10^{-2}$ & -3.8 & 389.0 & -1.75 & 0.09 & 5.17 & 19.40 & -0.40 & -1.68 & -2.44 & -0.99 & 0.30 \\
\hline
\end{tabular}


Table A6-3. Calculated Geochemical Parameters of Groundwater Samples Used in this Report (Continued)

\begin{tabular}{|c|c|c|c|c|c|c|c|c|c|c|c|c|c|}
\hline \multirow[b]{2}{*}{ Well } & \multirow{2}{*}{$\begin{array}{c}\text { Figure. } \\
\text { A6-5 } \\
\text { Sample }\end{array}$} & \multirow[b]{2}{*}{$\begin{array}{c}\text { Ionic } \\
\text { Strength }\end{array}$} & \multirow{2}{*}{$\begin{array}{c}\text { Charge } \\
\text { Balance } \\
\text { Error } \\
(\%)^{1} \\
\end{array}$} & \multirow{2}{*}{$\begin{array}{c}\text { DIC as } \\
\left(\mathrm{mg}^{\prime} \mathrm{L}\right. \\
\left.\mathrm{HCO}_{3}{ }^{-}\right)\end{array}$} & \multirow{2}{*}{$\begin{array}{c}\log \\
P_{\mathrm{cO} 2} \\
\text { (atm) }\end{array}$} & \multicolumn{8}{|c|}{ MINERAL SATURATION INDICES ${ }^{2,3}$} \\
\hline & & & & & & Calcite & Smectite & Ca-Clino. & $\mathrm{SiO}_{2}(\mathrm{a})$ & Fluorite & Albite & $\begin{array}{c}\text { K- } \\
\text { Feldspar }\end{array}$ & Dolomite \\
\hline \multicolumn{14}{|c|}{ Crater Flat-Southwest (Continued) } \\
\hline NC-EWDP-01S & 77 & $1.16 \times 10^{-2}$ & -1.9 & 390.9 & -1.75 & 0.12 & 5.32 & 20.60 & -0.35 & -1.66 & -2.31 & -0.90 & 0.34 \\
\hline NC-EWDP-12PA & 78 & $1.10 \times 10^{-2}$ & -1.6 & 540.6 & -1.18 & -0.58 & 5.37 & 20.88 & -0.25 & -0.25 & -2.28 & -0.71 & -1.35 \\
\hline NC-EWDP-12PB & 79 & $1.08 \times 10^{-2}$ & -1.7 & 491.4 & -1.29 & -0.48 & 5.28 & 20.77 & -0.27 & -0.23 & -2.21 & -0.64 & -1.15 \\
\hline NC-EWDP-12PC & 80 & $1.09 \times 10^{-2}$ & 0.0 & 340.5 & -1.99 & 0.25 & 5.31 & 21.52 & -0.35 & -1.26 & -2.08 & -0.64 & 0.60 \\
\hline \multicolumn{14}{|l|}{ Yucca Mountain-South } \\
\hline NC-EWDP-09SX & 81 & $6.32 \times 10^{-3}$ & -1.1 & 213.3 & -2.67 & 0.21 & 5.33 & 22.48 & -0.39 & -0.89 & -1.62 & -0.57 & 0.37 \\
\hline NC-EWDP-9SX Zone 1 & 82 & $5.95 \times 10^{-3}$ & -1.6 & 194.5 & -3.02 & 0.37 & 5.41 & 23.28 & -0.48 & -0.92 & -1.53 & -0.35 & 0.62 \\
\hline NC-EWDP-9SX Zone 2 & 83 & $6.01 \times 10^{-3}$ & -2.3 & 206.4 & -2.59 & 0.03 & 5.20 & 20.88 & -0.44 & -0.96 & -1.86 & -0.76 & 0.04 \\
\hline NC-EWDP-9SX Zone 3 & 84 & $5.94 \times 10^{-3}$ & -3.2 & 206.8 & -2.78 & 0.22 & 5.20 & 21.43 & -0.47 & -0.93 & -1.72 & -0.64 & 0.44 \\
\hline NC-EWDP-9SX Zone 4 & 85 & $5.95 \times 10^{-3}$ & -3.8 & 209.9 & -2.68 & 0.15 & 5.23 & 21.43 & -0.43 & -0.96 & -1.75 & -0.71 & 0.28 \\
\hline NC-EWDP-03D & 86 & $5.63 \times 10^{-3}$ & -1.8 & 230.1 & -2.99 & -0.90 & 4.52 & 19.24 & -0.43 & -2.31 & -1.06 & -0.40 & -2.05 \\
\hline NC-EWDP-3S Zone 2 & 87 & $6.27 \times 10^{-3}$ & -0.7 & 234.5 & -3.30 & -0.45 & 4.97 & 22.47 & -0.40 & -2.09 & -0.66 & -0.26 & -1.36 \\
\hline NC-EWDP-3S Zone 3 & 88 & $6.90 \times 10^{-3}$ & -3.9 & 279.9 & -3.44 & -0.22 & 4.67 & 21.29 & -0.51 & -1.85 & -0.67 & -0.07 & -0.89 \\
\hline CIND-R-LITE & 89 & $5.26 \times 10^{-3}$ & -2.0 & 195.9 & -2.35 & 0.04 & 2.69 & 8.92 & -0.53 & -1.18 & -1.88 & -1.08 & 0.29 \\
\hline NC-EWDP-15P & 90 & $5.02 \times 10^{-3}$ & -1.0 & 192.2 & -2.50 & -0.30 & 4.95 & 19.33 & -0.42 & -1.17 & -1.83 & -0.94 & -0.81 \\
\hline NC-EWDP-02D & 91 & $3.74 \times 10^{-3}$ & -2.9 & 158.2 & -2.33 & -0.45 & 5.52 & 20.90 & -0.38 & -1.07 & -2.39 & -1.06 & -1.76 \\
\hline NC-EWDP-19D & 92 & $5.31 \times 10^{-3}$ & -0.4 & 233.7 & -3.31 & -0.10 & 5.36 & 25.23 & -0.36 & -1.96 & -0.69 & 0.11 & -1.03 \\
\hline NC-EWDP-19P & 93 & $3.40 \times 10^{-3}$ & -1.9 & 115.4 & -3.62 & 0.53 & 5.52 & 25.93 & -0.38 & -1.22 & -1.13 & 0.09 & 0.26 \\
\hline NC-EWDP-19D (alluvial) & 94 & $4.88 \times 10^{-3}$ & -2.6 & 228.2 & -3.22 & -0.08 & 5.17 & 23.71 & -0.39 & -1.84 & -0.88 & -0.07 & -0.79 \\
\hline NC-EWDP-19D (zone \#1) & 95 & $4.63 \times 10^{-3}$ & 0.4 & 204.5 & -3.26 & 0.10 & 5.08 & 23.52 & -0.39 & -1.72 & -0.90 & -0.03 & -0.45 \\
\hline NC-EWDP-19D (zone \#2) & 96 & $3.77 \times 10^{-3}$ & 1.9 & 149.8 & -3.11 & 0.13 & 5.54 & 24.92 & -0.33 & -1.33 & -1.29 & -0.20 & -0.37 \\
\hline NC-EWDP-19D (zone \#3) & 97 & $4.78 \times 10^{-3}$ & 0.5 & 212.1 & -3.15 & -0.44 & 5.08 & 22.61 & -0.40 & -2.16 & -0.99 & -0.21 & -1.58 \\
\hline NC-EWDP-19D (zone \#4) & 98 & $5.20 \times 10^{-3}$ & -0.8 & 234.4 & -3.51 & -0.22 & 5.14 & 24.52 & -0.40 & -2.11 & -0.56 & 0.21 & - \\
\hline
\end{tabular}


Table A6-3. Calculated Geochemical Parameters of Groundwater Samples Used in this Report (Continued)

\begin{tabular}{|c|c|c|c|c|c|c|c|c|c|c|c|c|c|}
\hline \multirow[b]{2}{*}{ Well } & \multirow[b]{2}{*}{$\begin{array}{c}\text { Figure. } \\
\text { A6-5 } \\
\text { Sample }\end{array}$} & \multirow[b]{2}{*}{$\begin{array}{c}\text { lonic } \\
\text { Strength }\end{array}$} & \multirow{2}{*}{$\begin{array}{c}\text { Charge } \\
\text { Balance } \\
\text { Error } \\
(\%)^{1}\end{array}$} & \multirow[b]{2}{*}{ 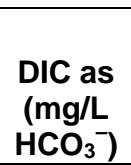 } & \multirow[b]{2}{*}{$\begin{array}{c}\text { log } \\
P_{\text {cor }} \\
\text { (atm) }\end{array}$} & \multicolumn{8}{|c|}{ MINERAL SATURATION INDICES ${ }^{2,3}$} \\
\hline & & & & & & Calcite & Smectite & Ca-Clino. & $\mathrm{SiO}_{2}(\mathrm{a})$ & Fluorite & Albite & $\mid \begin{array}{c}\mathrm{K}- \\
\text { Feldspar }\end{array}$ & Dolomite \\
\hline \multicolumn{14}{|l|}{ Amargosa Valley } \\
\hline NC-EWDP-4PB & 99 & $3.98 \times 10^{-3}$ & -0.9 & 113.6 & -4.53 & 0.78 & 5.18 & 23.61 & -0.73 & -1.56 & -0.90 & -0.10 & - \\
\hline NC-EWDP-4PA & 100 & $3.91 \times 10^{-3}$ & -0.4 & 107.8 & -3.18 & -0.11 & 5.25 & 20.58 & -0.56 & -1.51 & -1.95 & -0.88 & -1.51 \\
\hline Desert Farms Garlic Plot & 101 & $6.54 \times 10^{-3}$ & 0.0 & 127.7 & -2.71 & -0.09 & 5.22 & 20.39 & -0.48 & -1.58 & -2.06 & -0.88 & -0.99 \\
\hline 15S/49E-13dda & 102 & - & - & - & - & - & - & - & - & - & - & - & - \\
\hline 15S/50E-18ccc & 103 & $6.35 \times 10^{-3}$ & -1.0 & 153.5 & -3.23 & 0.32 & 5.32 & 22.38 & -0.55 & -0.97 & -1.50 & -0.53 & -0.54 \\
\hline NDOT & 104 & $6.76 \times 10^{-3}$ & -0.4 & 161.0 & -2.80 & -0.04 & 5.22 & 21.28 & -0.45 & -1.11 & -1.64 & -0.75 & -1.03 \\
\hline $15 \mathrm{~S} / 50 \mathrm{E}-18 \mathrm{cdc}$ & 105 & $6.16 \times 10^{-3}$ & -3.5 & 158.4 & -2.81 & -0.20 & 5.15 & 19.90 & -0.54 & -1.20 & -1.88 & -0.92 & -1.44 \\
\hline Airport Well & 106 & $3.93 \times 10^{-3}$ & 0.0 & 121.5 & -3.61 & 0.12 & 5.08 & 21.47 & -0.54 & -1.56 & -1.28 & -0.63 & -1.14 \\
\hline 15S/50E-19b1 & 107 & $7.69 \times 10^{-3}$ & 1.5 & 167.5 & -2.90 & 0.10 & 5.72 & 24.44 & -0.43 & -1.26 & -1.52 & -0.42 & -0.18 \\
\hline \multicolumn{14}{|l|}{ Amargosa River } \\
\hline $16 \mathrm{~S} / 48 \mathrm{E}-8 \mathrm{ba}$ & 108 & $1.42 \times 10^{-2}$ & 1.4 & 299.8 & -2.46 & 0.56 & 5.42 & 22.83 & -0.49 & - & -1.61 & -0.42 & 0.49 \\
\hline $16 \mathrm{~S} / 48 \mathrm{E}-7 \mathrm{bba}$ & 109 & $1.23 \times 10^{-2}$ & 0.8 & 269.6 & -2.02 & -0.03 & 6.09 & 25.98 & -0.23 & - & -1.69 & -0.48 & -0.47 \\
\hline $16 \mathrm{~S} / 48 \mathrm{E}-7 \mathrm{cbc}$ & 110 & $1.21 \times 10^{-2}$ & 0.8 & 246.8 & -2.35 & 0.18 & 6.16 & 27.12 & -0.25 & - & -1.49 & -0.28 & 0.24 \\
\hline 16S/48E-18bcc & 111 & $1.30 \times 10^{-2}$ & 1.7 & 272.1 & -2.60 & 0.60 & 6.48 & 30.96 & -0.17 & - & -0.95 & 0.28 & 0.84 \\
\hline $16 \mathrm{~S} / 48 \mathrm{E}-17 \mathrm{ccc}$ & 112 & $1.47 \times 10^{-2}$ & 3.4 & 246.3 & -2.35 & 0.31 & 6.34 & 29.10 & -0.18 & - & -1.21 & -0.02 & 0.19 \\
\hline 16S/48E-18dad & 113 & $1.25 \times 10^{-2}$ & 3.1 & 243.3 & -2.35 & 0.24 & 6.32 & 28.73 & -0.18 & - & -1.27 & -0.08 & 0.02 \\
\hline $16 \mathrm{~S} / 48 \mathrm{E}-8 \mathrm{cda}$ & 114 & $1.25 \times 10^{-2}$ & 1.2 & 276.1 & -2.21 & 0.12 & 6.32 & 27.88 & -0.22 & - & -1.44 & -0.28 & -0.28 \\
\hline 16S/48E-17abb & 115 & $1.33 \times 10^{-2}$ & 0.8 & 324.8 & -1.95 & 0.08 & 6.31 & 27.59 & -0.18 & - & -1.57 & -0.33 & -0.39 \\
\hline Barrachman Dom/Irr. & 116 & $1.26 \times 10^{-2}$ & -4.2 & 304.4 & -2.10 & 0.04 & 6.83 & 29.73 & -0.20 & -0.63 & -1.65 & -0.35 & -0.29 \\
\hline McCracken Domestic & 117 & $1.71 \times 10^{-2}$ & 3.2 & 257.3 & -2.17 & 0.16 & 6.64 & 29.58 & -0.18 & -0.57 & -1.40 & -0.23 & -0.22 \\
\hline
\end{tabular}


Table A6-3. Calculated Geochemical Parameters of Groundwater Samples Used in this Report (Continued)

\begin{tabular}{|c|c|c|c|c|c|c|c|c|c|c|c|c|c|}
\hline \multirow[b]{2}{*}{ Well } & \multirow[b]{2}{*}{$\begin{array}{c}\text { Figure. } \\
\text { A6-5 } \\
\text { Sample }\end{array}$} & \multirow[b]{2}{*}{$\begin{array}{c}\text { lonic } \\
\text { Strength }\end{array}$} & \multirow{2}{*}{$\begin{array}{c}\text { Charge } \\
\text { Balance } \\
\text { Error } \\
(\%)^{1}\end{array}$} & \multirow[b]{2}{*}{$\begin{array}{l}\mathrm{DIC} \text { as } \\
(\mathrm{mg} / \mathrm{L} \\
\left.\mathrm{HCO}_{3}^{-}\right)\end{array}$} & \multirow[b]{2}{*}{$\begin{array}{c}\text { log } \\
P_{\mathrm{cO} 2} \\
(\mathrm{~atm})\end{array}$} & \multicolumn{8}{|c|}{ MINERAL SATURATION INDICES ${ }^{2,3}$} \\
\hline & & & & & & Calcite & Smectite & Ca-Clino. & $\mathrm{SiO}_{2}(\mathrm{a})$ & Fluorite & Albite & $\mid \begin{array}{c}\text { K- } \\
\text { Feldspar }\end{array}$ & Dolomite \\
\hline \multicolumn{14}{|l|}{ Fortymile Wash-West } \\
\hline 16S/48E-15ba & 118 & $1.30 \times 10^{-2}$ & -0.2 & 265.4 & -2.61 & 0.62 & 5.42 & 22.86 & -0.50 & - & -1.62 & -0.45 & 0.71 \\
\hline 16S/48E-10cba & 119 & $4.25 \times 10^{-3}$ & -0.9 & 163.3 & -3.10 & 0.03 & 6.21 & 28.67 & -0.27 & - & -1.22 & 0.08 & 0.04 \\
\hline 16S/48E-15aaa & 120 & $3.95 \times 10^{-3}$ & 1.7 & 152.8 & -2.92 & -0.15 & 6.10 & 27.61 & -0.25 & - & -1.39 & -0.04 & -0.43 \\
\hline Selbach Domestic & 121 & $7.48 \times 10^{-3}$ & -0.9 & 178.9 & -2.77 & 0.10 & 6.33 & 28.77 & -0.23 & -1.19 & -1.29 & -0.08 & 0.08 \\
\hline 16S/48E-15dda & 122 & $5.41 \times 10^{-3}$ & 6.8 & 176.5 & -2.77 & 0.10 & 6.26 & 28.59 & -0.22 & - & -1.35 & 0.01 & 0.00 \\
\hline 16S/49E-23add & 123 & $4.02 \times 10^{-3}$ & 7.5 & 125.0 & -3.11 & 0.07 & 6.39 & 30.06 & -0.19 & - & -1.20 & 0.21 & -0.48 \\
\hline 16S/48E-23bdb & 124 & $3.97 \times 10^{-3}$ & 3.0 & 172.3 & -2.11 & -0.97 & 6.12 & 24.99 & -0.19 & - & -2.04 & -0.68 & -2.56 \\
\hline 16S/48E-23da & 125 & - & - & - & - & - & - & - & - & - & - & - & - \\
\hline $\begin{array}{l}\text { Funeral Mountain Ranch } \\
\text { Irrig. }\end{array}$ & 126 & $5.29 \times 10^{-3}$ & -2.0 & 198.4 & -2.93 & 0.08 & 6.94 & 33.28 & -0.11 & -0.97 & -0.93 & 0.39 & -0.22 \\
\hline \multicolumn{14}{|l|}{ Fortymile Wash-South } \\
\hline 16S/49E-05acc & 127 & $4.07 \times 10^{-3}$ & 5.0 & 134.3 & -2.98 & 0.26 & 6.09 & 27.16 & -0.28 & -1.31 & -1.68 & -0.18 & -0.24 \\
\hline 16S/49E-8abb & 128 & $4.42 \times 10^{-3}$ & 2.2 & 161.4 & -2.33 & -0.29 & 5.96 & 23.69 & -0.32 & - & -2.36 & -0.82 & -1.30 \\
\hline 16S/49E-8acc & 129 & $3.91 \times 10^{-3}$ & 1.4 & 139.7 & -2.76 & -0.01 & 5.83 & 25.07 & -0.31 & - & -1.91 & -0.33 & -0.64 \\
\hline 16S/49E-18dc & 130 & $4.05 \times 10^{-3}$ & 0.5 & 149.7 & -2.93 & 0.15 & 6.03 & 27.13 & -0.30 & - & -1.65 & 0.02 & -0.22 \\
\hline 16s/48E-24aaa & 131 & $4.06 \times 10^{-3}$ & 3.5 & 146.1 & -2.93 & 0.12 & 6.15 & 28.67 & -0.20 & - & -1.29 & 0.13 & -0.80 \\
\hline 16S/49E-19daa & 132 & $3.92 \times 10^{-3}$ & 0.1 & 131.9 & -3.08 & 0.29 & 6.22 & 29.24 & -0.21 & - & -1.41 & 0.27 & -0.35 \\
\hline DeLee Large Irrigation & 133 & $3.85 \times 10^{-3}$ & 2.5 & 136.6 & -2.94 & -0.06 & 7.79 & 36.15 & -0.10 & -1.16 & -1.54 & 0.29 & -1.25 \\
\hline 16S/48E-25aa & 134 & $3.73 \times 10^{-3}$ & 0.6 & 132.1 & -2.98 & 0.10 & 6.10 & 28.06 & -0.23 & - & -1.47 & 0.09 & -0.87 \\
\hline 16S/48E-36aaa & 135 & $3.56 \times 10^{-3}$ & 0.1 & 128.3 & -3.30 & 0.31 & 6.50 & 31.26 & -0.19 & - & -1.13 & 0.41 & 0.03 \\
\hline Bray Domestic & 136 & $3.75 \times 10^{-3}$ & 0.9 & 131.8 & -2.91 & -0.01 & 6.87 & 31.56 & -0.17 & -1.37 & -1.61 & 0.18 & -0.82 \\
\hline Amargosa Estates \#2 & 137 & $3.68 \times 10^{-3}$ & 1.4 & 133.3 & -2.99 & 0.09 & 6.56 & 30.50 & -0.17 & -1.04 & -1.43 & 0.17 & -0.45 \\
\hline 17S/48E-1ab & 138 & $3.65 \times 10^{-3}$ & 1.2 & 134.1 & -2.98 & 0.08 & 6.42 & 29.84 & -0.18 & - & -1.42 & 0.17 & -0.58 \\
\hline 17S/49E-7bb & 139 & $4.37 \times 10^{-3}$ & 2.8 & 149.5 & -3.14 & 0.42 & 6.52 & 31.32 & -0.18 & - & -1.14 & 0.39 & 0.04 \\
\hline
\end{tabular}


Table A6-3. Calculated Geochemical Parameters of Groundwater Samples Used in this Report (Continued)

\begin{tabular}{|c|c|c|c|c|c|c|c|c|c|c|c|c|c|}
\hline \multirow[b]{2}{*}{ Well } & \multirow{2}{*}{$\begin{array}{c}\text { Figure. } \\
\text { A6-5 } \\
\text { Sample }\end{array}$} & \multirow[b]{2}{*}{$\begin{array}{c}\text { lonic } \\
\text { Strength }\end{array}$} & \multirow{2}{*}{\begin{tabular}{|c|} 
Charge \\
Balance \\
Error \\
$(\%)^{1}$
\end{tabular}} & \multirow{2}{*}{$\begin{array}{c}\mathrm{DIC} \text { as } \\
(\mathrm{mg} / \mathrm{L} \\
\left.\mathrm{HCO}_{3}^{-}\right)\end{array}$} & \multirow{2}{*}{$\begin{array}{c}\log \\
P_{\mathrm{co} 2} \\
(\mathrm{~atm})\end{array}$} & \multicolumn{8}{|c|}{ MINERAL SATURATION INDICES ${ }^{2,3}$} \\
\hline & & & & & & Calcite & Smectite & Ca-Clino. & $\mathrm{SiO}_{2}(\mathrm{a})$ & Fluorite & Albite & $\mid \begin{array}{c}\text { K- } \\
\text { Feldspar }\end{array}$ & Dolomite \\
\hline \multicolumn{14}{|c|}{ Fortymile Wash-South (Continued) } \\
\hline 17S/49E-8ddb & 140 & $3.68 \times 10^{-3}$ & 4.6 & 118.6 & -3.34 & 0.35 & 6.69 & 32.46 & -0.17 & - & -1.15 & 0.52 & 0.16 \\
\hline 17S/49E-35ddd & 141 & $4.43 \times 10^{-3}$ & -0.9 & 158.3 & -2.82 & -0.09 & 6.68 & 31.02 & -0.15 & - & -1.38 & 0.19 & -0.36 \\
\hline \multicolumn{14}{|c|}{ Fortymile Wash-East } \\
\hline 15S/49E-22a1 & 142 & $4.27 \times 10^{-3}$ & 0.0 & 145.5 & -2.83 & 0.17 & 5.44 & 23.00 & -0.38 & -1.12 & -1.87 & -0.46 & -0.31 \\
\hline 15S/49E-22dcc & 143 & $4.41 \times 10^{-3}$ & 1.2 & 207.6 & -1.50 & -1.05 & 4.64 & 13.63 & -0.41 & -1.40 & -3.20 & -1.88 & -2.84 \\
\hline 15S/49E-27acc & 144 & $4.26 \times 10^{-3}$ & -1.3 & 153.3 & -2.50 & 0.14 & 1.93 & 1.05 & -0.94 & -1.73 & -2.94 & -2.04 & -0.37 \\
\hline O'Neill Domestic & 145 & $4.56 \times 10^{-3}$ & 2.2 & 143.4 & -2.79 & -0.05 & 6.84 & 30.57 & -0.21 & -1.50 & -1.72 & -0.07 & -0.85 \\
\hline 16S/49E-9cda & 146 & $5.43 \times 10^{-3}$ & 2.6 & 149.9 & -2.46 & -0.22 & 6.15 & 26.24 & -0.24 & - & -1.96 & -0.38 & -1.06 \\
\hline 16S/49E-9dcc & 147 & $5.16 \times 10^{-3}$ & 0.5 & 139.2 & -3.08 & 0.22 & 6.57 & 31.04 & -0.20 & - & -1.25 & 0.32 & -0.16 \\
\hline 16S/49E-16ccc & 148 & $4.62 \times 10^{-3}$ & 0.6 & 133.8 & -2.79 & 0.06 & 6.32 & 28.15 & -0.19 & - & -1.64 & -0.26 & -0.73 \\
\hline Ponderosa Dairy \#1 & 149 & $6.29 \times 10^{-3}$ & -1.2 & 153.1 & -2.33 & -0.29 & 5.72 & 24.50 & -0.23 & -1.24 & -1.91 & -0.34 & -1.02 \\
\hline 17S/49E-9aa & 150 & $5.10 \times 10^{-3}$ & 0.0 & 131.5 & -2.90 & 0.06 & 6.25 & 28.64 & -0.23 & - & -1.54 & 0.11 & -0.38 \\
\hline 17S/49E-15bbd & 151 & $3.85 \times 10^{-3}$ & -0.7 & 119.6 & -3.05 & 0.04 & 6.65 & 30.72 & -0.19 & - & -1.58 & 0.21 & -0.34 \\
\hline M. Gilgan Well & 152 & $3.82 \times 10^{-3}$ & 1.8 & 127.0 & -3.11 & 0.15 & 6.49 & 30.56 & -0.19 & -1.08 & -1.33 & 0.28 & -0.27 \\
\hline 17S/49E-15bc & 153 & - & - & - & - & - & - & - & - & - & - & - & - \\
\hline \multicolumn{14}{|l|}{ Gravity Fault } \\
\hline NC-EWDP-5S & 154 & - & - & - & - & - & - & - & - & - & - & - & - \\
\hline NC-EWDP-5SB & 155 & $6.60 \times 10^{-3}$ & -0.2 & 221.3 & -2.29 & -0.42 & 4.59 & 14.45 & -0.73 & -1.50 & -2.63 & -1.46 & -1.42 \\
\hline 16S/50E-7bcd & 156 & $1.13 \times 10^{-2}$ & 1.4 & 303.4 & -2.12 & 0.27 & 4.19 & 14.45 & -0.65 & - & -2.37 & -1.03 & 0.51 \\
\hline Nelson Domestic & 157 & $1.12 \times 10^{-2}$ & -3.8 & 325.0 & -2.00 & 0.14 & 4.12 & 13.15 & -0.70 & -0.20 & -2.58 & -1.27 & 0.23 \\
\hline 16S/49E-12ddd & 158 & $1.14 \times 10^{-2}$ & 1.6 & 301.5 & -2.16 & 0.18 & 4.39 & 13.17 & -0.76 & - & -2.62 & -1.72 & 0.27 \\
\hline Lowe Domestic & 159 & $1.07 \times 10^{-2}$ & -1.5 & 284.4 & -2.32 & 0.16 & 6.38 & 26.74 & -0.38 & -0.90 & -1.88 & -0.47 & -0.03 \\
\hline 16S/49E-15aaa & 160 & $8.50 \times 10^{-3}$ & -1.3 & 201.8 & -2.43 & 0.08 & 5.75 & 23.76 & -0.39 & - & -1.97 & -0.53 & -0.25 \\
\hline
\end{tabular}


Table A6-3. Calculated Geochemical Parameters of Groundwater Samples Used in this Report (Continued)

\begin{tabular}{|c|c|c|c|c|c|c|c|c|c|c|c|c|c|}
\hline \multirow[b]{2}{*}{ Well } & \multirow[b]{2}{*}{$\begin{array}{c}\text { Figure. } \\
\text { A6-5 } \\
\text { Sample }\end{array}$} & \multirow[b]{2}{*}{$\begin{array}{c}\text { lonic } \\
\text { Strength }\end{array}$} & \multirow{2}{*}{$\begin{array}{c}\text { Charge } \\
\text { Balance } \\
\text { Error } \\
(\%)^{1}\end{array}$} & \multirow[b]{2}{*}{$\begin{array}{c}\mathrm{DIC} \text { as } \\
(\mathrm{mg} / \mathrm{L} \\
\left.\mathrm{HCO}_{3}^{-}\right)\end{array}$} & \multirow[b]{2}{*}{$\begin{array}{c}\text { log } \\
P_{\mathrm{co} 2} \\
\text { (atm) }\end{array}$} & \multicolumn{8}{|c|}{ MINERAL SATURATION INDICES ${ }^{2,3}$} \\
\hline & & & & & & Calcite & Smectite & Ca-Clino. & $\mathrm{SiO}_{2}(\mathrm{a})$ & Fluorite & Albite & $\mid \begin{array}{c}\text { K- } \\
\text { Feldspar }\end{array}$ & Dolomite \\
\hline \multicolumn{14}{|l|}{ Gravity Fault (Continued) } \\
\hline Anvil Ranch Irrigation & 161 & $8.09 \times 10^{-3}$ & 1.5 & 139.8 & -2.81 & 0.15 & 6.88 & 31.83 & -0.18 & -1.06 & -1.47 & 0.21 & -0.33 \\
\hline 16S/49E-36aaa & 162 & $1.25 \times 10^{-2}$ & 3.8 & 321.1 & -2.33 & 0.45 & 5.39 & 22.40 & -0.49 & - & -1.89 & -0.37 & 0.88 \\
\hline 16S/49E-35baa & 163 & $1.21 \times 10^{-2}$ & 0.1 & 325.8 & -1.95 & 0.04 & 5.36 & 20.36 & -0.48 & - & -2.30 & -0.88 & -0.05 \\
\hline Payton Domestic & 164 & $1.19 \times 10^{-2}$ & -0.8 & 304.0 & -2.19 & 0.16 & 5.88 & 23.63 & -0.47 & 0.01 & -2.16 & -0.59 & 0.17 \\
\hline 16S/49E-36aba & 165 & $1.14 \times 10^{-2}$ & 2.3 & 302.3 & -2.26 & 0.27 & 5.51 & 22.89 & -0.44 & - & -1.92 & -0.39 & 0.54 \\
\hline 16S/49E-35aaa & 166 & $1.11 \times 10^{-2}$ & 4.8 & 280.3 & -2.29 & 0.24 & 5.29 & 21.29 & -0.50 & - & -2.01 & -0.54 & 0.38 \\
\hline Oettinger Well & 167 & $1.14 \times 10^{-2}$ & -2.0 & 307.9 & -2.06 & 0.12 & 5.28 & 20.55 & -0.48 & -0.20 & -2.22 & -0.72 & 0.09 \\
\hline Amargosa Motel (b) & 168 & $1.12 \times 10^{-2}$ & -1.1 & 298.8 & -2.17 & 0.20 & 5.63 & 22.94 & -0.42 & -0.27 & -2.05 & -0.54 & 0.28 \\
\hline 17S/49E-11ba & 169 & $1.00 \times 10^{-2}$ & 1.2 & 209.6 & -2.82 & 0.44 & 6.34 & 29.04 & -0.33 & - & -1.38 & 0.16 & 0.74 \\
\hline Spring Meadows Well \#8 & 170 & - & - & - & - & - & - & - & - & - & - & - & - \\
\hline 17S/50E-19aab & 171 & $1.46 \times 10^{-2}$ & 1.2 & 405.5 & -3.08 & 0.35 & 6.95 & 33.70 & -0.38 & - & -0.67 & 0.82 & 0.99 \\
\hline $\begin{array}{l}\text { USFWS - Five Springs } \\
\text { Well }\end{array}$ & 172 & $8.94 \times 10^{-3}$ & 4.9 & 261.4 & -2.07 & 0.18 & 3.38 & 8.48 & -0.80 & -0.91 & -2.93 & -1.63 & 0.42 \\
\hline Spring Meadows Well \#10 & 173 & - & - & - & - & - & - & - & - & - & - & - & - \\
\hline 18S/49E-1aba & 174 & $8.51 \times 10^{-3}$ & -0.8 & 253.0 & -3.27 & 0.75 & 7.53 & 38.08 & -0.16 & - & -0.62 & 1.11 & 1.44 \\
\hline 18S/50E-6dac & 175 & $8.45 \times 10^{-3}$ & 3.1 & 227.2 & -2.87 & 0.41 & 6.52 & 31.77 & -0.17 & - & -0.91 & 0.56 & 0.87 \\
\hline 18S/50E-7aa & 176 & $1.06 \times 10^{-2}$ & 1.7 & 258.0 & -3.08 & 0.50 & 7.53 & 35.92 & -0.30 & - & -1.00 & 0.63 & 0.75 \\
\hline \multicolumn{14}{|c|}{ Amargosa River/Fortymile Wash } \\
\hline 16S/48E-36dcc & 177 & $1.04 \times 10^{-2}$ & 0.4 & 336.8 & -1.73 & -0.09 & 5.88 & 24.31 & -0.23 & - & -2.02 & -0.58 & -0.57 \\
\hline Crane Domestic & 178 & $1.42 \times 10^{-2}$ & -0.5 & 504.9 & -1.56 & 0.12 & 5.24 & 19.91 & -0.42 & -0.14 & -2.25 & -0.89 & 0.04 \\
\hline $27 \mathrm{~N} / 4 \mathrm{E}-27 \mathrm{bbb}$ & 179 & $1.30 \times 10^{-2}$ & 2.4 & 448.3 & -2.21 & 0.61 & 6.70 & 31.22 & -0.19 & - & -1.27 & 0.26 & 1.05 \\
\hline IMV on Windjammer & 180 & $9.65 \times 10^{-3}$ & -0.8 & 321.2 & -2.05 & 0.10 & 6.25 & 26.99 & -0.23 & -0.32 & -1.75 & -0.35 & -0.12 \\
\hline 17S/49E-29acc & 181 & $1.37 \times 10^{-2}$ & 5.0 & 288.6 & -2.21 & 0.15 & 6.75 & 30.78 & -0.18 & - & -1.39 & 0.10 & 0.05 \\
\hline 17S/49E-28bcd & 182 & $9.34 \times 10^{-3}$ & 1.8 & 307.7 & -2.15 & 0.19 & 6.15 & 27.12 & -0.22 & - & -1.62 & -0.20 & 0.10 \\
\hline
\end{tabular}


Table A6-3. Calculated Geochemical Parameters of Groundwater Samples Used in this Report (Continued)

\begin{tabular}{|c|c|c|c|c|c|c|c|c|c|c|c|c|c|}
\hline \multirow[b]{2}{*}{ Well } & \multirow[b]{2}{*}{$\begin{array}{c}\text { Figure. } \\
\text { A6-5 } \\
\text { Sample }\end{array}$} & \multirow[b]{2}{*}{\begin{tabular}{|c|} 
Ionic \\
Strength
\end{tabular}} & \multirow{2}{*}{\begin{tabular}{|c|} 
Charge \\
Balance \\
Error \\
$(\%)^{1}$ \\
\end{tabular}} & \multirow[b]{2}{*}{$\begin{array}{c}\mathrm{DIC} \text { as } \\
(\mathrm{mg} / \mathrm{L} \\
\left.\mathrm{HCO}_{3}{ }^{-}\right)\end{array}$} & \multirow[b]{2}{*}{$\begin{array}{l}\text { log } \\
P_{\text {co2 }} \\
\text { (atm) }\end{array}$} & \multicolumn{8}{|c|}{ MINERAL SATURATION INDICES ${ }^{2,3}$} \\
\hline & & & & & & Calcite & Smectite & Ca-Clino. & $\mathrm{SiO}_{2}(\mathrm{a})$ & Fluorite & Albite & $\begin{array}{c}\text { K- } \\
\text { Feldspar }\end{array}$ & Dolomite \\
\hline \multicolumn{14}{|c|}{ Amargosa River/Fortymile Wash (Continued) } \\
\hline 18S/49E-2cbc & 183 & $9.42 \times 10^{-3}$ & 0.1 & 360.7 & -2.28 & 0.28 & 6.11 & 26.86 & -0.29 & - & -1.49 & -0.23 & 0.51 \\
\hline Mom's Place & 184 & $6.77 \times 10^{-3}$ & -0.5 & 241.7 & -2.45 & 0.10 & 6.57 & 29.79 & -0.18 & -0.55 & -1.47 & -0.01 & -0.08 \\
\hline 18S/49E-11bbb & 185 & $8.40 \times 10^{-3}$ & 4.5 & 234.5 & -2.26 & -0.01 & 6.28 & 28.08 & -0.18 & - & -1.53 & -0.12 & -0.28 \\
\hline \multicolumn{14}{|l|}{ Skeleton Hills } \\
\hline TW-5 & 186 & $1.10 \times 10^{-2}$ & -1.5 & 400.0 & -2.30 & 0.54 & 3.77 & 12.02 & -0.83 & -0.41 & -2.37 & -1.12 & 1.19 \\
\hline $\begin{array}{l}\text { Unnamed Well 15S/50E- } \\
22-7\end{array}$ & 187 & $4.19 \times 10^{-3}$ & 8.6 & 171.5 & -1.62 & -1.20 & 5.23 & 16.45 & -0.38 & -1.43 & -3.18 & -1.81 & -3.18 \\
\hline \multicolumn{14}{|l|}{ Amargosa Flat } \\
\hline Amargosa Tracer Hole \#2 & 188 & $8.57 \times 10^{-3}$ & -0.4 & 279.8 & -2.54 & 0.64 & 3.94 & 13.13 & -0.78 & -0.77 & -2.45 & -1.11 & 1.32 \\
\hline $\begin{array}{l}\text { Cherry Patch Well, } \\
\text { 17S/52E-08cdb }\end{array}$ & 189 & $2.37 \times 10^{-2}$ & 2.5 & 307.4 & -1.88 & -0.02 & 4.48 & 14.33 & -0.67 & -0.77 & -2.39 & -1.52 & 0.01 \\
\hline $\begin{array}{l}\text { USDOE-MSH-C shallow } \\
\text { Well }\end{array}$ & 190 & $7.40 \times 10^{-3}$ & -0.7 & 263.9 & -2.63 & 0.07 & 5.82 & 23.92 & -0.50 & -1.14 & -1.93 & -0.47 & 0.46 \\
\hline \multicolumn{14}{|l|}{ Mine Mountain } \\
\hline UE-17a & 191 & $9.51 \times 10^{-3}$ & 14.9 & 208.5 & -2.31 & 0.03 & 3.34 & 5.62 & -1.01 & -1.42 & -3.27 & -2.38 & 0.30 \\
\hline UE-1a & 192 & $9.02 \times 10^{-3}$ & -3.7 & 432.9 & -1.81 & 0.21 & 4.21 & 11.64 & -0.79 & - & -3.24 & -1.66 & 0.48 \\
\hline UE-1b & 193 & $5.32 \times 10^{-3}$ & 18.9 & 197.6 & -2.13 & -0.15 & 5.94 & 25.26 & -0.18 & - & -2.20 & -0.35 & -0.37 \\
\hline UE-16f & 194 & $2.66 \times 10^{-2}$ & -15.7 & 902.7 & -2.98 & 0.31 & 1.82 & -0.30 & -1.51 & -1.59 & -2.25 & -1.88 & 1.08 \\
\hline UE-14b & 195 & $4.87 \times 10^{-3}$ & 2.2 & 113.0 & -3.36 & 0.01 & 5.59 & 23.60 & -0.44 & - & -1.36 & -0.73 & -1.35 \\
\hline \begin{tabular}{|l|} 
Pluto 1 \\
\end{tabular} & 196 & $5.92 \times 10^{-3}$ & 5.9 & 150.4 & -2.84 & 0.32 & 5.90 & 25.75 & -0.34 & - & -1.89 & -0.22 & 0.38 \\
\hline \begin{tabular}{|l|} 
Pluto 5 \\
\end{tabular} & 197 & $7.65 \times 10^{-3}$ & 7.4 & 220.2 & -2.59 & 0.49 & 5.95 & 25.27 & -0.31 & - & -2.07 & -0.51 & 0.93 \\
\hline USGS Test Well F (HTH) & 198 & $7.90 \times 10^{-3}$ & 9.4 & 252.6 & -1.31 & -0.11 & 0.35 & -6.49 & -0.79 & -0.57 & -3.24 & -2.17 & -0.19 \\
\hline
\end{tabular}




\begin{tabular}{|c|c|c|c|c|c|c|c|c|c|c|c|c|c|}
\hline \multirow[b]{2}{*}{ Well } & \multirow[b]{2}{*}{$\begin{array}{c}\text { Figure. } \\
\text { A6-5 } \\
\text { Sample }\end{array}$} & \multirow[b]{2}{*}{$\begin{array}{c}\text { Ionic } \\
\text { Strength }\end{array}$} & \multirow{2}{*}{$\begin{array}{c}\text { Charge } \\
\text { Balance } \\
\text { Error } \\
(\%)^{1} \\
\end{array}$} & \multirow[b]{2}{*}{$\begin{array}{c}\mathrm{DIC} \text { as } \\
(\mathrm{mg} / \mathrm{L} \\
\left.\mathrm{HCO}_{3}{ }^{-}\right)\end{array}$} & \multirow[b]{2}{*}{$\begin{array}{l}\log \\
P_{\mathrm{co} 2} \\
\text { (atm) } \\
\end{array}$} & \multicolumn{8}{|c|}{ Mineral Saturation Indices ${ }^{2,3}$} \\
\hline & & & & & & Calcite & Smectite & Ca-Clino. & $\mathrm{SiO}_{2}(\mathrm{a})$ & Fluorite & Albite & $\begin{array}{c}\text { K- } \\
\text { Feldspar }\end{array}$ & Dolomite \\
\hline \multicolumn{14}{|l|}{ Funeral Mountains } \\
\hline Woodcamp Spring & 199 & $4.17 \times 10^{-3}$ & 3.7 & 139.1 & -2.15 & -0.84 & 6.45 & 25.84 & -0.26 & -2.73 & -2.59 & -0.61 & -2.26 \\
\hline Bond Gold Mining \#13 & 200 & $2.44 \times 10^{-2}$ & -5.3 & 296.7 & -1.86 & 0.30 & 3.09 & 5.38 & -0.91 & -1.53 & -3.29 & -2.13 & 0.74 \\
\hline Nevares Spring & 201 & $1.27 \times 10^{-2}$ & -2.1 & 375.7 & -1.78 & 0.20 & 2.87 & 6.81 & -0.77 & -0.49 & -2.59 & -1.53 & 0.53 \\
\hline Travertine Spring & 202 & $1.19 \times 10^{-2}$ & -2.3 & 366.1 & -1.82 & 0.04 & 3.55 & 10.70 & -0.67 & -0.41 & -2.45 & -1.30 & 0.25 \\
\hline
\end{tabular}

\section{DTN: LA0310EK831232.001 [DIRS 165995].}

${ }^{1}$ PHREEQC calculates percent error in the selected output file as $100 \times($ cations $-\mid$ anions $\mid) /($ cations $+\mid$ anions $\mid$ ), where cations is the electrical charge of the cations in equivalents per liter and anions is the electrical charge of the anions in equivalents per liter (Parkhurst and Appelo 1999 [DIRS 159511], p. 140).

2 The saturation index of a mineral phase is calculated as the base-ten logarithm of the ratio of the ion activity product (IAP) to the solubility constant $\left(K_{\mathrm{sp}}\right)$ of the mineral at the prevailing temperature: $\log \left(I A P / K_{s p}\right)$. Values of $\log \left(I A P / K_{s p}\right)$ less than zero indicate the groundwater is undersaturated with that mineral.

Conversely, values of $\log \left(I A P / K_{s p}\right)$ greater than zero indicate the groundwater is oversaturated with that mineral. Values of log (IAP/K $\left.K_{s p}\right)$ equal to zero indicate the groundwater is at equilibrium with the mineral (Langmuir 1997 [DIRS 100051], p. 8).

3 The log $P_{\mathrm{CO} 2}$ and saturation indices for calcite, $\mathrm{SiO}_{2}(\mathrm{a})$, fluorite, albite and K-feldspar were calculated using the database phreeqc.dat (Parkhurst and Appelo 1999 [DIRS 159511], Table 55). The saturation indices for smectite and Ca-clinoptilolite were calculated based on the Gibbs free-energy data listed in Table A6-4 of this report.

Table A6-4. Yucca Mountain Mineral Phase Compositions and Thermodynamic Data Used in PHREEQC Analyses

\begin{tabular}{|l|r|l|l|l|}
\hline \multicolumn{1}{|c|}{ Phase } & \multicolumn{1}{|c|}{ Formula } & \multicolumn{1}{c|}{$\begin{array}{c}\Delta \mathbf{G}^{\circ}{ }_{\mathbf{f}} \\
\left(\mathbf{k J / m o l}-{ }^{\circ} \mathrm{K}\right)\end{array}$} & $\begin{array}{c}\Delta \mathbf{H}^{\circ}{ }_{\mathbf{f}} \\
(\mathbf{k J / m o l})\end{array}$ & \multicolumn{1}{c|}{ Reference } \\
\hline Smectite & $\mathrm{K}_{0.1} \mathrm{Na}_{0.02} \mathrm{Ca}_{0.14} \mathrm{Al}_{4.4} \mathrm{Si}_{7.6} \mathrm{O}_{20}(\mathrm{OH})_{4} \bullet 4 \mathrm{H}_{2} \mathrm{O}$ & $-11,619.6$ & $-12,595.6$ & $\begin{array}{l}\text { Chipera et al. (1995 } \\
\text { [DIRS 100025], Table 1) }\end{array}$ \\
\hline $\begin{array}{l}\text { Ca- } \\
\text { Clinoptilolite }\end{array}$ & $\mathrm{K}_{2.5} \mathrm{Na}_{1.1} \mathrm{Ca}_{1.2} \mathrm{Al}_{6.0} \mathrm{Si}_{30.0} \mathrm{O}_{72.0} \cdot 26.8 \mathrm{H}_{2} \mathrm{O}$ & $-39,067.7$ & $-42,491.3$ & $\begin{array}{l}\text { Chipera and Bish (1997 } \\
\text { [DIRS 105079], Tables 1-2) }\end{array}$ \\
\hline $\begin{array}{l}\text { Na- } \\
\text { Clinoptilolite }\end{array}$ & $\mathrm{K}_{2.8} \mathrm{Na}_{1.5} \mathrm{Ca}_{0.9} \mathrm{Al}_{6.1} \mathrm{Si}_{29.9} \mathrm{O}_{72.0} \bullet 26.8 \mathrm{H}_{2} \mathrm{O}$ & $-39,093.8$ & $-42,512.1$ & $\begin{array}{l}\text { Chipera and Bish (1997 } \\
\text { [DIRS 105079], Tables 1-2) }\end{array}$ \\
\hline
\end{tabular}


The geochemical parameters calculated in this section provide an indication of which minerals are potentially dissolving or precipitating in Yucca Mountain groundwater and, thus, provide important constraints on groundwater mixing and reaction models. Table A6-3 indicates that groundwater in the Yucca Mountain area is generally slightly undersaturated with amorphous silica $\left[\mathrm{SiO}_{2}(\mathrm{a})\right]$, fluorite, and albite and greatly supersaturated with Ca-clinoptilolite and smectite typical of Yucca Mountain. The spatial distribution of saturation indices of minerals whose saturation state in groundwater are more variable are discussed in more detail in the following subsections.

In addition to the saturation indices shown in Table A6-3, saturation indices were also calculated for other common minerals (DTN: LA0310EK831232.001 [DIRS 165995). The calculated Na-clinoptilolite saturation indices generally are similar to those shown in Table A6-3 for Ca-clinoptilolite. All groundwaters in the Yucca Mountain area are significantly undersaturated with gypsum and halite and slightly oversaturated with quartz (chalcedony). Yucca Mountain area groundwaters are generally undersaturated with respect to sepiolite $\left(\mathrm{Mg}_{2} \mathrm{Si}_{3} \mathrm{O}_{7.5}(\mathrm{OH}) \cdot 3 \mathrm{H}_{2} \mathrm{O}\right)$, except in areas of the Amargosa Desert such as the Gravity fault area where Si-rich groundwater from the volcanic alluvium mixes with $\mathrm{Mg}$-rich discharge from the carbonate aquifer. Kaolinite saturation indices are zero in all cases because of the assumption (Table A5-1, Assumption 2) that all groundwaters are in equilibrium with kaolinite.

\section{A6.3.5.1 Ionic Strength}

Ionic strength $(I)$ is a measure of the interionic effects resulting from the electrical attraction and repulsion between various ions in solution. It is defined by $I=1 / 2 \sum_{i} C_{i} Z_{i}^{2}$ (Langmuir 1997 [DIRS 100051], p. 123), where $C_{\mathrm{i}}$ is the concentration (mol $/ \mathrm{kg}$ solution) and $Z_{\mathrm{i}}$ is the charge of ion $i$. Ionic strength is expressed in this report as moles per kilogram of groundwater.

Al estimated from equilibrium with Kaolinite

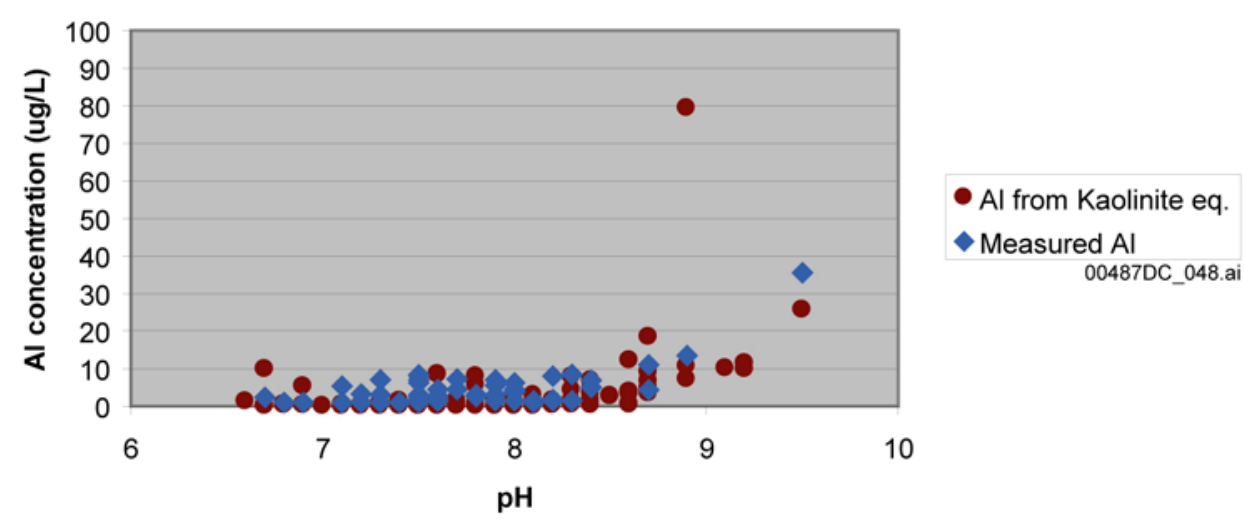

DTNs: GS980908312322.008 [DIRS 145412, GS990808312322.002 [DIRS 162917], GS010308312322.002, [DIRS 162910] GS011108312322.006 [DIRS 162911].

NOTE: The single large calculated Al value is from a sample with very small SiO2 value (UE-16f, sample 194).

Figure A6-33. Comparison between Measured Dissolved Aluminum Concentrations and Dissolved Aluminum Concentrations Calculated by PHREEQC Assuming Equilibrium with Kaolinite 


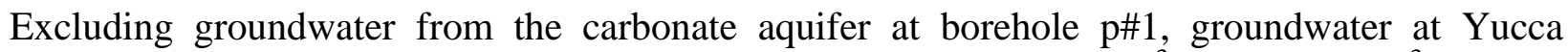
Mountain has an ionic strength that ranges from about $2.2 \times 10^{-3}$ to $4.8 \times 10^{-3} \mathrm{~mole} / \mathrm{kg}$ (Figure A6-34). A single groundwater from the Yucca Crest area from borehole H-3 (Site 51) has a somewhat higher value $\left(6.12 \times 10^{-3} \mathrm{~mole} / \mathrm{kg}\right)$. The ionic strength of groundwater at the NC-EWDP wells in southern Yucca Mountain and south of Crater Flat increases toward the west, reflecting the differences in the ionic strength of the groundwater to the north and west of these wells. North of Yucca Mountain, groundwater shows a westward increase in ionic strength from the northern Fortymile Wash area through Timber Mountain and toward Oasis Valley. The highest ionic strength groundwaters are associated with the southwestern Crater Flat, the Amargosa River, the Gravity fault area, and central Jackass Flats.

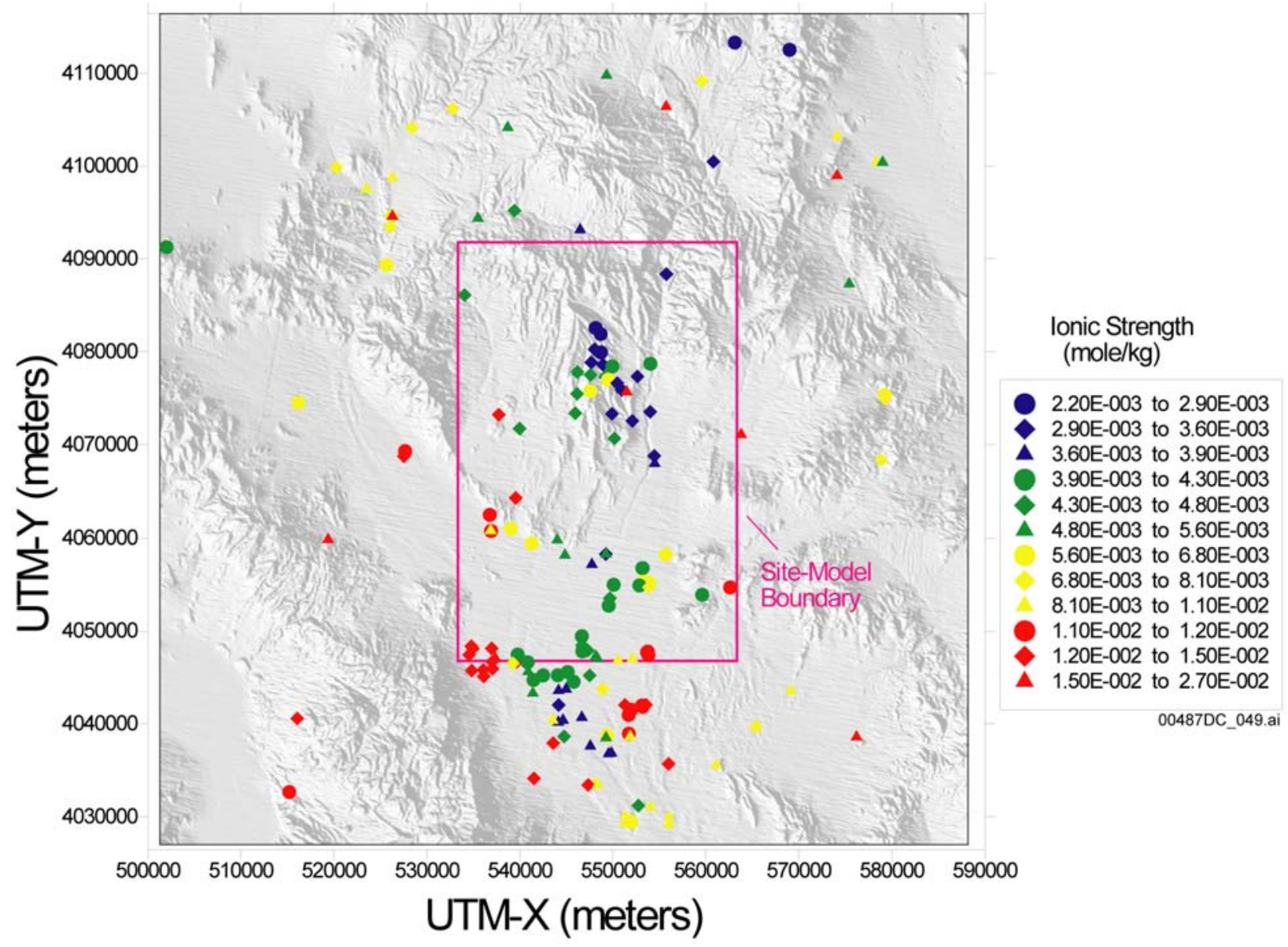

DTN: LA0310EK831232.001 [DIRS 165995].

Source: Table A6-1.

NOTE: This figure has color-coded data points and should not be read in a black and white version. UTM-X =UTM-Easting and UTM-Y =UTM-Northing. UTM=Universal Transverse Mercator.

Figure A6-34. Areal Distribution of Ionic Strength in Groundwater 


\section{A6.3.5.2 Dissolved Inorganic Carbon}

Dissolved inorganic carbon (DIC) represents the total amount of carbon present in all dissolved carbon species, including $\mathrm{H}_{2} \mathrm{CO}_{3}, \mathrm{HCO}_{3}{ }^{-}$, and $\mathrm{CO}_{3}{ }^{2-}$. It is expressed in Table A6-6 and Figure A6-35 as the $\mathrm{mg} / \mathrm{L}_{\mathrm{HCO}_{3}}{ }^{-}$having the same number of moles of carbon per liter. Although alkalinity changes can result from groundwater interactions with noncarbonate rocks, the DIC of groundwater can change only if (1) the groundwater mixes with groundwater having different DIC concentrations, (2) the groundwater dissolves carbon-bearing minerals such as calcite or dolomite, (3) calcite is precipitated from the groundwater, or (4) the groundwater interacts with $\mathrm{CO}_{2}(\mathrm{~g})$ in the overlying unsaturated zone. The last process tends to be of limited importance due to the very low diffusion of $\mathrm{CO}_{2}(\mathrm{~g})$ in water. Hence, in the absence of mixing, downgradient increases in DIC are a good indicator of contact between groundwater and either calcite or dolomite.

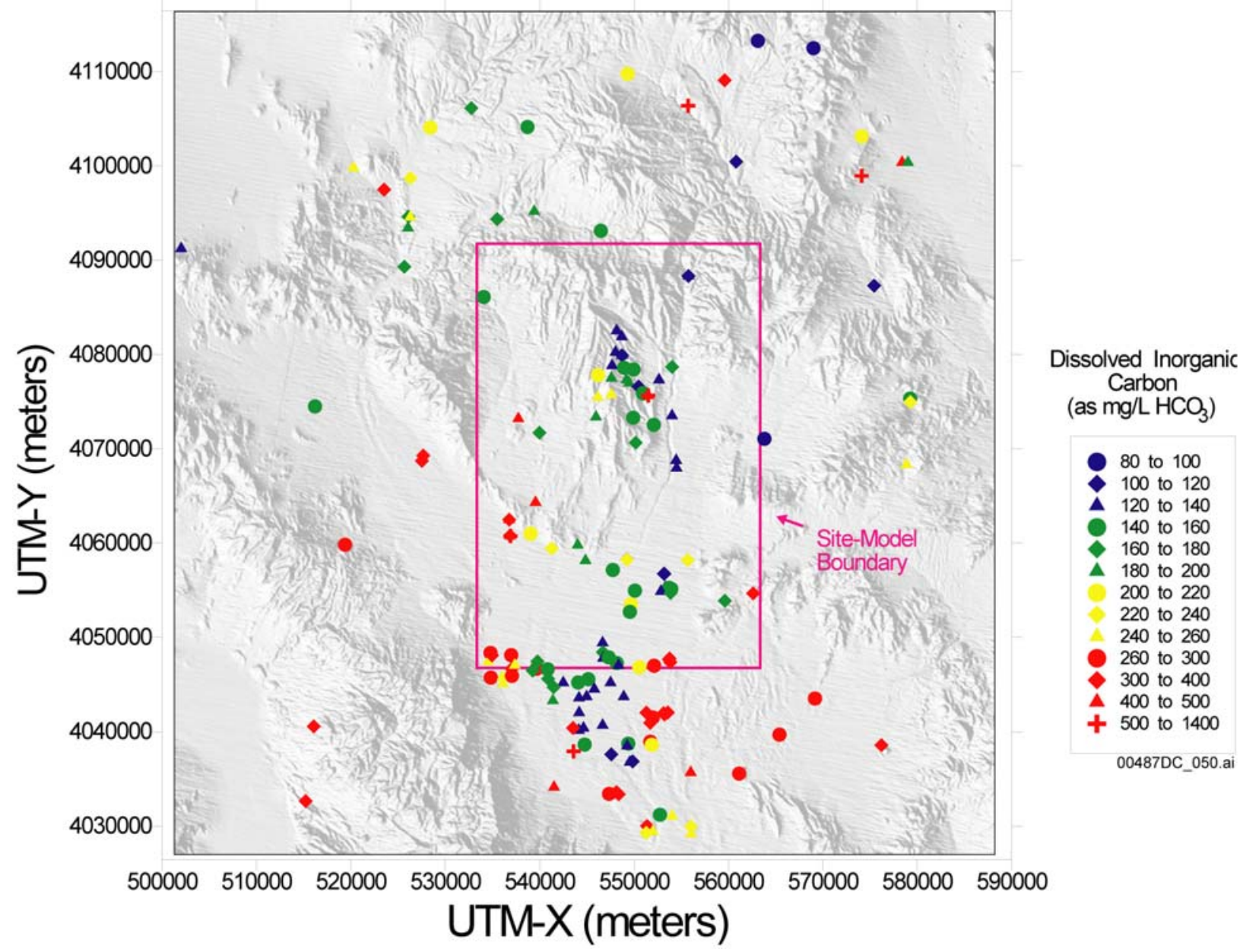

DTN: LA0310EK831232.001 [DIRS 165995].

Source: Table A6-1.

NOTE: This figure has color-coded data points and should not be read in a black and white version. UTM-X =UTM-Easting and UTM-Y =UTM-Northing. UTM=Universal Transverse Mercator.

Figure A6-35. Areal Distribution of Dissolved Inorganic Carbon in Groundwater 
Groundwater in the northern part of Yucca Mountain has relatively low concentrations of DIC (Figure A6-35). Somewhat higher DIC concentrations are found near Solitario Canyon in some of the SCW and YM-CR wells. Groundwater DIC concentrations increase toward the south at Yucca Mountain. The groundwater in Beatty Wash directly north of Yucca Mountain at well ER-EC-07 (Site 24) has similarly low DIC concentrations as northern Yucca Mountain, as does groundwater at most of the FMW-N wells northeast and east of Yucca Mountain. Southward along Fortymile Wash, the DIC concentrations of groundwater in the FMW-S wells increases and then decreases slightly but are generally low compared to the higher values found in groundwater in the surrounding AR, AR/FMW, and GF area wells. Groundwater in several of the wells in the Amargosa Valley area (LW group) has DIC concentrations that are nearly as low as that found at well J-11 (Site 67) in Jackass Flats. Groundwater in western and southwestern Crater Flat has much higher DIC concentrations than groundwater in the eastern part of the Crater Flat area, reflecting the presence of carbonate rocks at Bare Mountain.

\section{A6.3.5.3 Dissolved Carbon-Dioxide Partial Pressure}

The logarithm of dissolved carbon-dioxide partial pressure $\left[\log P_{\mathrm{CO}_{2}}(\mathrm{~atm})\right]$ is generally higher than expected due to equilibrium with the atmosphere $\left(\log P_{\mathrm{CO}_{2}}=-3.5 \mathrm{~atm}\right)$ because of the much higher carbon-dioxide partial pressures found in the soil zone through which the water recharging the groundwater has passed. Soil-zone $\log P_{\mathrm{CO}_{2}}$ values can be -2.0 atm or greater depending on climate and vegetation cover. Unsaturated-zone $\log P_{\mathrm{CO}_{2}}$ at Yucca Mountain under the present climate is about -3.0 atm (Yang et al. 1996 [DIRS 100194]; Thorstenson et al. 1998 [DIRS 126827]). However, $\mathrm{CO}_{2}(\mathrm{~g})$ production rates in the soil zones depend on climate, which has changed over time and presently changes with elevation and latitude (Quade and Cerling 1990 [DIRS 100073]), so unsaturated zone log $P_{\mathrm{CO}_{2}}$ values could have been higher under past wetter climates. Most Yucca Mountain area groundwaters have $\log P_{\mathrm{CO}_{2}}$ values that are higher than are found in the unsaturated zone at Yucca Mountain.

In the absence of climate change, the tendency in groundwater is for $\log P_{\mathrm{CO}_{2}}$ values to decrease downgradient from the recharge area as hydrogen ions and dissolved $\mathrm{CO}_{2}$ react with the rock to form secondary minerals and $\mathrm{HCO}_{3}^{-}$(Drever 1988 [DIRS 118564]). However, as stated above, climate change and other conditions particular to the recharge area can complicate this simple model.

At Yucca Mountain, groundwater in the Solitario Canyon and Yucca Crest area generally has lower $\log P_{\mathrm{CO}_{2}}$ values than groundwater further to the east at Yucca Mountain (Figure A6-36). Along Fortymile Wash, groundwater $\log P_{\mathrm{CO}_{2}}$ values show an overall southward decrease between the FMW-N and FMW-S area wells. Groundwater $\log P_{\mathrm{CO}_{2}}$ values for well J-11 (Site 67) in Jackass Flats and at some LW area wells are also relatively low, whereas $\log P_{\mathrm{CO}_{2}}$ values are relatively high at wells in southwest Crater Flat and AR and AR/FMW area wells.

\section{A6.3.5.4 Calcite Saturation Index}

In general, calcite saturation indices $\left(\mathrm{SI}_{\text {calcite }}\right)$ are expected to increase along a flow path as $\mathrm{H}^{+}$ ions and dissolved $\mathrm{CO}_{2}$ are converted to $\mathrm{HCO}_{3}{ }^{-}$and $\mathrm{CO}_{3}{ }^{2-}$ during silicate weathering reactions or $\mathrm{Ca}^{2+}$ and $\mathrm{HCO}_{3}{ }^{-}$are added to the groundwater from calcite dissolution. Downgradient decreases in $S I_{\text {calcite }}$ could result from loss of $\mathrm{Ca}^{2+}$ through mineral precipitation or ion exchange. 


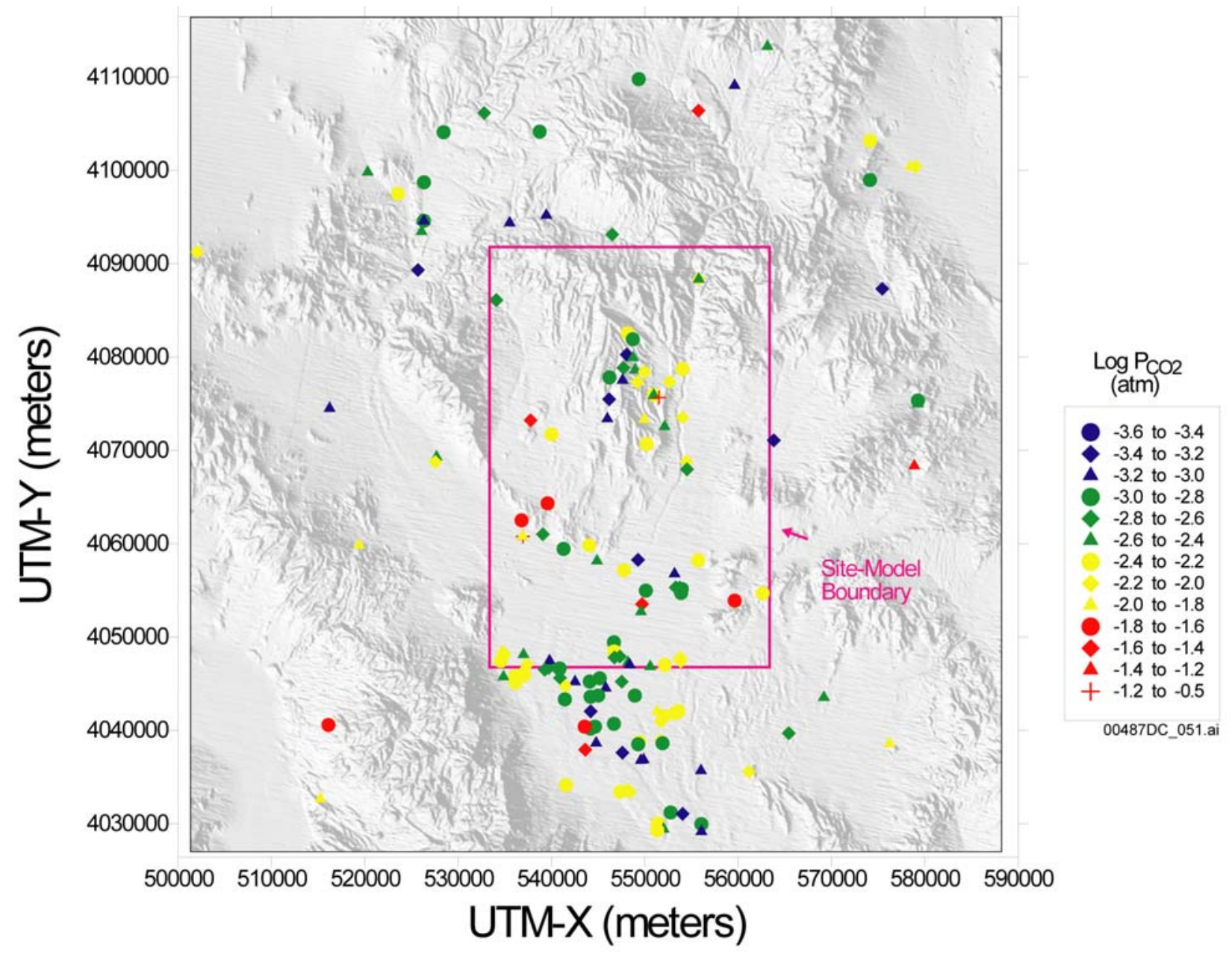

DTN: LA0310EK831232.001 [DIRS 165995].

Source: Table A6-1.

NOTE: This figure has color-coded data points and should not be read in a black and white version. UTM-X =UTM-Easting and UTM-Y =UTM-Northing. UTM=Universal Transverse Mercator.

Figure A6-36. Areal Distribution of Dissolved Carbon-Dioxide Partial Pressure in Groundwater

Groundwater north and northwest of Yucca Mountain in the Timber Mountain and Oasis Valley/Northwest Amargosa areas is generally saturated or supersaturated with calcite (Figure A6-37). Groundwater throughout most of Yucca Mountain is undersaturated with calcite, with the most undersaturated groundwater present in northern Yucca Mountain. Along Fortymile Wash, groundwater shows a southward increase in $S I_{\text {Calcite. Almost all groundwater in }}$ the Amargosa Desert south of U.S. Highway 95 is saturated or supersaturated with calcite. Groundwater in most of the Crater Flat area is saturated or supersaturated with calcite. 


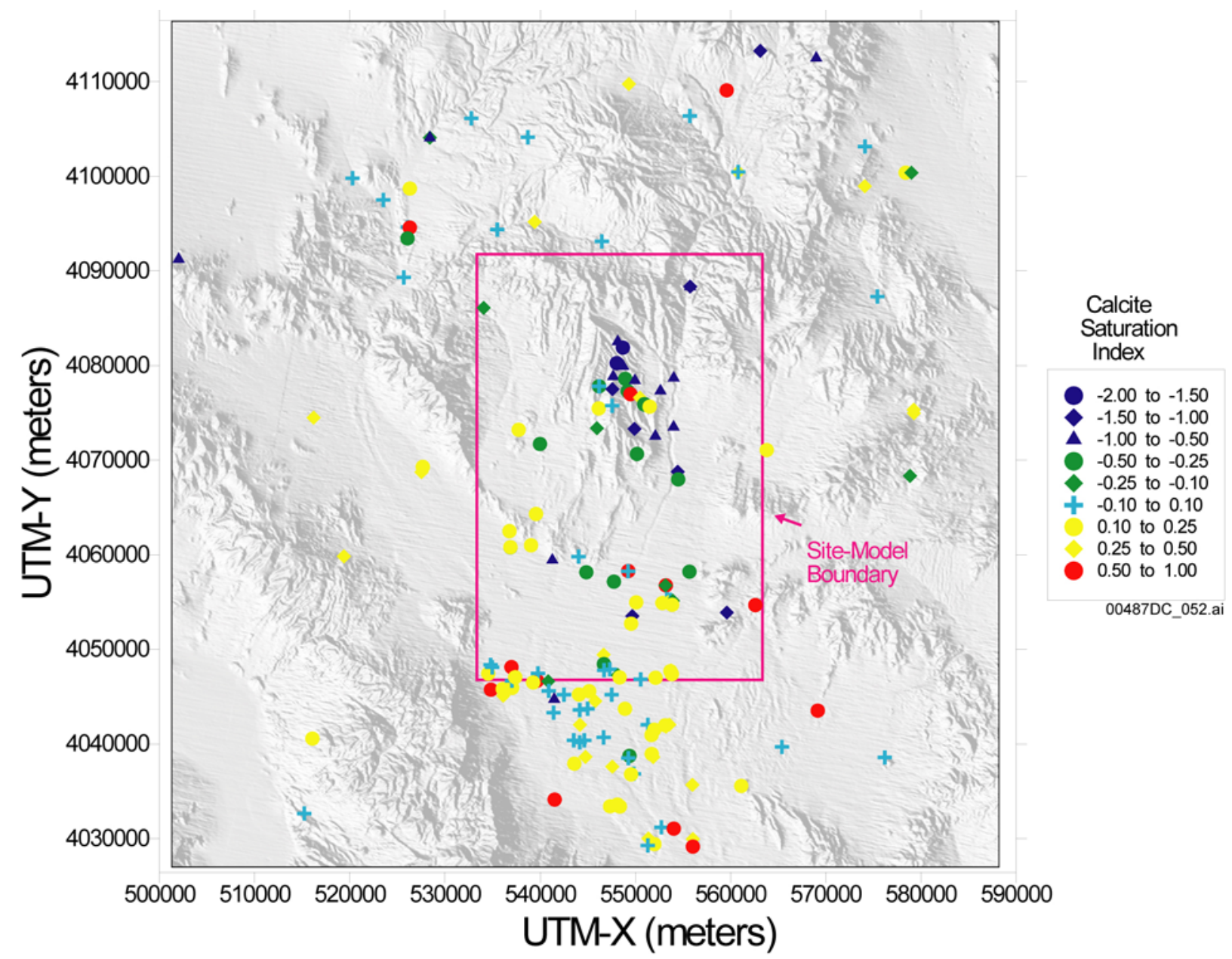

DTN: LA0310EK831232.001 [DIRS: 165995].

Source: Table A6-1.

NOTE: This figure has color-coded data points and should not be read in a black and white version. UTM-X =UTM-Easting and UTM-Y =UTM-Northing. UTM=Universal Transverse Mercator.

Figure A6-37. Areal Distribution of Calcite Saturation Index in Groundwater

\section{A6.3.5.5 Smectite Saturation Index}

Except for a few samples in the Mine Mountain area, groundwater throughout the Yucca Mountain region is supersaturated with smectite (Figure A6-38). The degree of supersaturation increases southward from Yucca Mountain toward the Amargosa Desert. If groundwater from Yucca Mountain and Fortymile Wash flows southward toward the Amargosa Desert, the southward increase in smectite saturation indices suggests that silicate-weathering reactions are providing ions to the groundwater faster than they can be removed by smectite precipitation. 


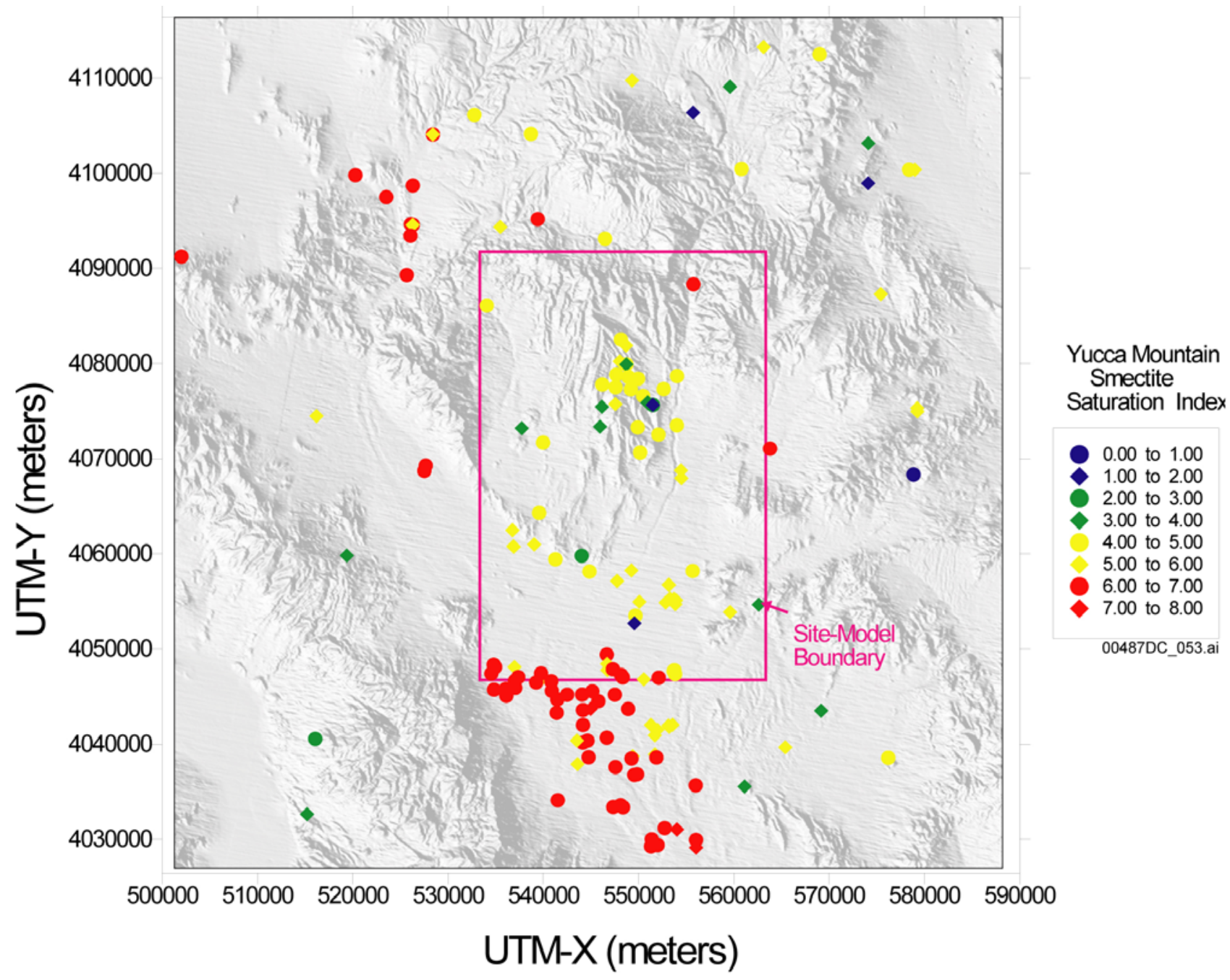

DTN: A0310EK831232.001 [DIRS: 165995].

Source: Table A6-1.

NOTE: This figure has color-coded data points and should not be read in a black and white version. UTM-X $=$ UTM-Easting and UTM-Y =UTM-Northing. UTM=Universal Transverse Mercator.

Figure A6-38. Areal Distribution of Smectite Saturation Index in Groundwater

\section{A6.3.5.6 Calcium Clinoptilolite Saturation Index}

Throughout most of the Yucca Mountain region, groundwater is also supersaturated with Ca-clinoptilolite (Figure A6-39). As is the case for smectite, the degree of supersaturation increases southward from the Yucca Mountain area toward the Amargosa Desert. 


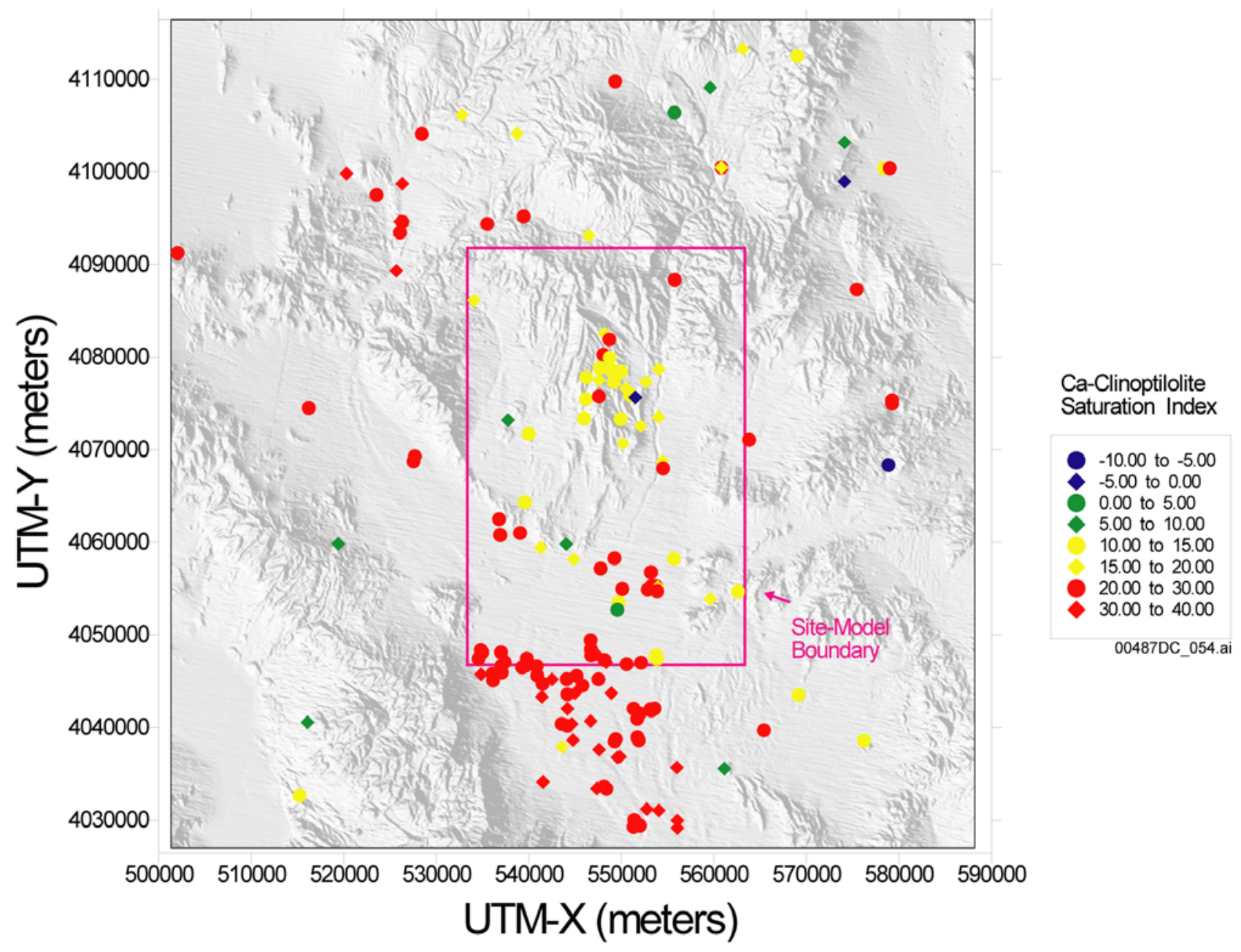

DTN: LA0310EK831232.001 [DIRS 165995].

Source: Table A6-1.

NOTE: This figure has color-coded data points and should not be read in a black and white version. UTM-X =UTM-Easting and UTM-Y =UTM-Northing. UTM=Universal Transverse Mercator.

Figure A6-39. Areal Distribution of Calcium Clinoptilolite Saturation Index in Groundwater

\section{A6.3.5.7 Potassium Feldspar Saturation Index}

Except for some wells in the Oasis Valley area, the groundwater at most wells along or north of U.S. Highway 95 are undersaturated with K-feldspar (Figure A6-40). Conversely, south of the site model area, most groundwater along or adjacent to Fortymile Wash is saturated or slightly supersaturated with $\mathrm{K}$-feldspar, reflecting the much higher $\mathrm{K}$ and dissolved $\mathrm{SiO}_{2}$ concentrations of groundwater in these areas. 


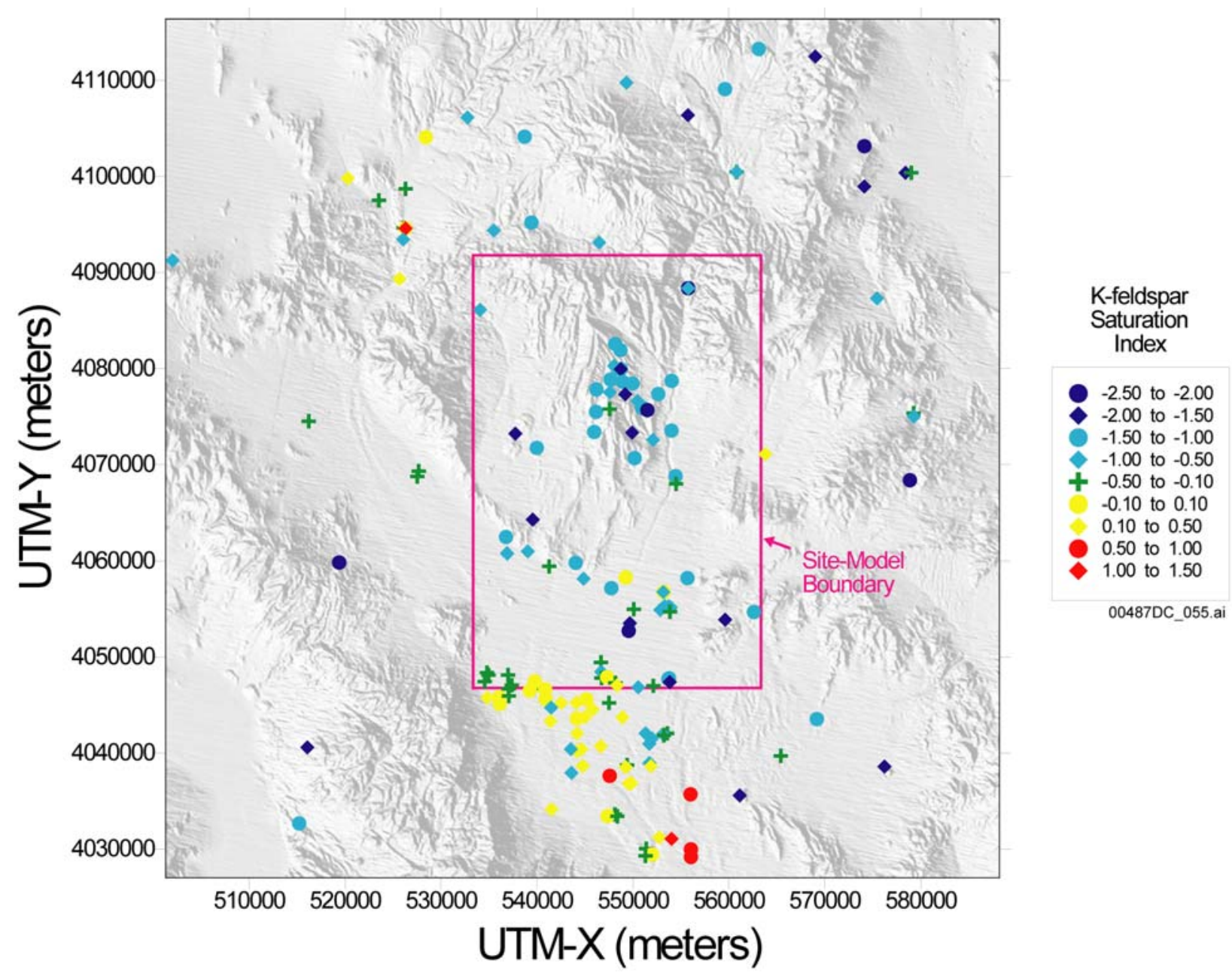

DTN: LA0310EK831232.001 [DIRS: 165995].

Source: Table A6-1.

NOTE: This figure has color-coded data points and should not be read in a black and white version. UTM-X $=$ UTM-Easting and UTM-Y =UTM-Northing. UTM=Universal Transverse Mercator.

Figure A6-40. Areal Distribution of K-Feldspar Saturation Index in Groundwater

\section{A6.3.5.8 Summary of Areal Distribution of Calculated Geochemical Parameters}

If groundwater is moving southward from Yucca Mountain and Fortymile Wash into the northern Amargosa Desert, the areal distributions of calculated geochemical parameters presented in Table A6-3 and shown in Figures A6-34 to A6-40, combined with the areal distribution plots shown in Section A6.3.4, provide some insight into the potential reactions affecting groundwater compositions. Groundwater in these areas has low and relatively constant $\mathrm{Cl}^{-}$concentrations (6-8 mg/L) compared to surrounding areas, and so downgradient changes in composition and in saturation indices can be attributed to water/rock interaction rather then evaporation. 
Silicate weathering reactions are indicated by the overall increase in dissolved $\mathrm{SiO}_{2}$ near the southern boundary of the SZ site model (Figure A6-3.6) and increases in pH (Figure A6-3.1), $\mathrm{HCO}_{3}{ }^{-}$(Figure A6-3.4), and $\mathrm{SI}_{\text {calcite }}$ (Figure A6-37). Weathering of primary silicate minerals like plagioclase or K-feldspar typically involves the consumption of $\mathrm{H}^{+}$ions and dissolved $\mathrm{CO}_{2}$ and the production of cations, $\mathrm{HCO}_{3}{ }^{-}$, dissolved $\mathrm{SiO}_{2}$, and secondary minerals like kaolinite or smectite, consistent with these trends (Drever 1988 [DIRS 118564], p. 151; Langmuir 1997 [DIRS 100051], p. 325). The overall southward increase in $S I_{\mathrm{K} \text {-feldspar }}$ (Figure A6-40) and accompanying increase in $S I_{\text {Smectite }}$ (Figure A6-38) and $S I_{\text {Ca-clinoptilolite }}$ (Figure A6-39) indicate that, if secondary minerals are precipitated, the primary silicate dissolution reactions may be faster than the precipitation rates for the secondary minerals. The extreme supersaturation of smectite and Ca-clinoptilolite may be indicating that these precipitation reactions are kinetically inhibited.

The saturation indices of alumino-silicate minerals are based the apparent control of $\mathrm{Al}^{3+}$ concentrations by kaolinite (Figure A6-33). Kaolinite has been documented only in trace amounts in the Yucca Mountain area, unlike zeolites, which are prevalent throughout the saturated zone near Yucca Mountain (Vaniman et al. 1996 [DIRS 105946]). Although this assumption is somewhat empirical (see Table A5-1, Assumption 2), it is reasonable because reaction pathways represented on phase-stability diagrams typically represent kaolinite as an intermediate weathering product that is eventually replaced by more stable secondary phases (Drever 1988 [DIRS 118564], Figure 8-8, pp. 156 to 158; Langmuir 1997 [DIRS 100051], Figure 9.14).

\section{A6.3.6 Sources and Evolution of Groundwater beneath Yucca Mountain}

The following sections provide an analysis of the origin and evolution of groundwater at Yucca Mountain. Data on perched water from the unsaturated zone at Yucca Mountain are presented in Section A6.3.6.1. Perched water compositions are taken to approximate the composition of local recharge from Yucca Mountain itself. Perched water compositions and other groundwaters upgradient from Yucca Mountain are compared to groundwater presently beneath Yucca Mountain evaluate the possible sources of Yucca Mountain groundwaters.

\section{A6.3.6.1 Description of Perched-Water Data}

Perched water was encountered in at least five boreholes at Yucca Mountain: USW UZ-14, USW NRG-7a, USW SD-9, USW SD-7, and USW WT-24. The perched-water samples were obtained by bailing or by pumping, depending on factors related to the drilling of the borehole. In general, it is believed that pumping produces a water sample that is more likely to represent in situ chemical and isotopic conditions for the following reasons. Drilling may affect the chemical and isotopic composition of water in the borehole by introducing foreign drilling fluids (generally air) into the water and by grinding the rock, thereby exposing fresh, unaltered rock surfaces that may react with the water. To minimize these drilling effects, a borehole is typically purged of water present in the borehole, and many additional borehole water volumes are pumped from the formation before sampling. This process increases confidence that the water sample represents actual hydrochemical conditions in the formation. In cases for which a water sample is bailed without first pumping the borehole, the water sample may not be representative of in situ hydrochemical conditions. 
Of the perched-water samples considered in this analysis, samples from boreholes SD-9 and NRG-7a (Table A6-5) were obtained exclusively by bailing (Yang and Peterman 1999 [DIRS 149596], Table 19) during a hiatus in drilling following the encounter with the perched water. No pumping was done prior to sample collection at these boreholes.

Perched-water samples from UZ-14 (Table A6-5) obtained prior to August 17, 1993, were obtained without first pumping the borehole. Pumped samples were obtained between August 17 and August 27, and an additional bailed sample was taken after pumping on August 31, 1993. A time series of delta strontium- $87\left(\delta^{87} \mathrm{Sr}\right)$ versus water production showed that $\delta^{87} \mathrm{Sr}$ values continued to change until about 12,000 liters had been pumped from the borehole, or sometime after August 25, 1993 (Yang and Peterman 1999 [DIRS 149596], Table 19, Figure 113). Therefore, the $\delta^{87} \mathrm{Sr}$ data, and likely other data, obtained from samples collected from UZ-14 after this date probably best represent in situ conditions. These samples include UZ-14 PT-4 and UZ-14 D (Table A6-5).

Perched water from borehole SD-7 sampled on March 8, 1995, was obtained by bailing prior to pumping. Perched-water samples obtained from borehole SD-7 between March 16 and March 21, 1995, were obtained by pumping (Yang et al. 1996 [DIRS 100194], p. 37).

Perched water was sampled by pumping from borehole WT-24. However, according to Patterson et al. (1998 [DIRS 107402], p. 277), the isotopic data obtained prior to the end of the 24-hour pumping test conducted on October 21 to 22, 1997, were collected during what the authors considered a clean-out period. Only data collected from borehole WT-24 following this clean-out period are presented in this report.

In summary, the perched-water data are thought to represent in situ conditions to varying degrees, depending on whether the samples were bailed or pumped and the extent to which the borehole was cleaned out prior to sampling. The data collected from borehole SD-7 on or after March 16, 1995, from borehole UZ-14 after August 25, 1993, and from borehole WT-24 on or after October 22, 1997, are thought to best represent the actual chemical and isotopic conditions of the perched water at Yucca Mountain. These samples are weighted more heavily than the remaining samples in developing the conclusions of this report. 


\begin{tabular}{|c|c|c|c|c|c|c|c|c|c|c|c|c|c|c|c|c|c|c|c|}
\hline \multirow{2}{*}{$\begin{array}{l}\text { Water } \\
\text { Sample }\end{array}$} & \multirow{2}{*}{$\begin{array}{l}\text { Depth } \\
\text { (m) }\end{array}$} & \multirow{2}{*}{$\begin{array}{l}\text { Sampling } \\
\text { Method }\end{array}$} & \multirow[b]{2}{*}{ Date } & \multirow[b]{2}{*}{$\mathrm{pH}$} & \multicolumn{8}{|c|}{ Chemical Concentrations (mg/L) } & \multirow[b]{2}{*}{${ }^{13} \mathrm{C}(\%)$} & \multirow[b]{2}{*}{${ }^{14} \mathrm{C}(\mathrm{pmc})$} & \multirow{2}{*}{$\begin{array}{c}{ }^{3} \mathrm{H}^{\mathrm{a}} \\
(\mathrm{TU})\end{array}$} & \multirow{2}{*}{$\begin{array}{c}\delta \mathrm{D} \\
(\%)\end{array}$} & \multirow{2}{*}{$\begin{array}{l}\delta^{18} 0 \\
(\%)\end{array}$} & \multirow{2}{*}{\begin{tabular}{|c|}
${ }^{234} U I^{238} U$ \\
Activity \\
Ratio
\end{tabular}} & \multirow{2}{*}{$\begin{array}{r}{ }^{36} \mathrm{Cl} / \mathrm{Cl} \\
\left(\times 10^{-15}\right)\end{array}$} \\
\hline & & & & & $\mathrm{Ca}^{2+}$ & $\mathbf{M g}^{2+}$ & $\mathrm{Na}^{+}$ & $\mathrm{K}^{+}$ & $\mathrm{Cl}^{-}$ & $\mathrm{SO}_{4}{ }^{2-}$ & $\mathrm{HCO}_{3}^{-}$ & $\mathrm{SiO}_{2}$ & & & & & & & \\
\hline \multirow[t]{5}{*}{ SD-7 } & 479.76 & Bailed & 03-08-95 & - & 14.2 & 0.13 & 45.5 & 5.3 & 4.4 & 9.1 & 112 & 62.3 & -10.4 & 34.4 & 6.2 & -99.8 & -13.4 & - & 511 \\
\hline & 488.29 & Pumped & 03-16-95 & 8.1 & 13.3 & 0.13 & 45.5 & 5.3 & 4.1 & 9.1 & 128 & 57.4 & -9.4 & 28.6 & - & -99.7 & -13.3 & - & - \\
\hline & 488.29 & Pumped & 03-17-95 & 8.2 & 12.8 & 0.08 & 45.8 & 5.5 & 4.1 & 8.6 & 130 & 50.9 & -9.5 & 28.4 & - & -99.6 & -13.4 & 3.504 & 657 \\
\hline & 488.29 & Pumped & 03-20-95 & 8.0 & 12.9 & 0.07 & 45.5 & 5.4 & 4.1 & 8.5 & 127 & 55 & -9.5 & 27.9 & - & -99.6 & -13.4 & 3.58 & - \\
\hline & 488.29 & Pumped & 03-21-95 & 8.2 & 13.5 & 0.08 & 44.6 & 5.5 & 4.1 & 10.3 & 128 & 55.9 & -9.5 & 28.4 & $<0.3$ & -99.6 & -13.3 & 3.69 & 609,635 \\
\hline \multirow[t]{4}{*}{ SD-9 } & - & Bailed & 03-07-94 & - & - & - & - & - & - & - & - & - & -14.4 & 41.8 & 0 & -97.8 & -13.3 & - & - \\
\hline & - & Bailed & 07-07-94 & - & - & - & - & - & - & - & - & - & - & - & - & - & - & $2.42^{b}$ & - \\
\hline & 453.85 & Bailed & $07-17-94$ & 8.6 & 2.9 & 0.2 & 98 & 9.8 & 5.6 & 27.6 & $197^{\mathrm{C}}$ & 64.2 & -14.4 & 41.8 & 0 & -97.8 & -13.3 & - & 449 \\
\hline & - & Bailed & 09-12-94 & - & - & - & - & - & - & - & - & - & - & - & - & - & - & $2.42^{b}$ & 497 \\
\hline UZ-14 A & 384.60 & Bailed & 08-02-93 & 7.6 & 23 & 1.8 & 39 & 5.6 & 7.9 & 14.3 & 150 & 34.2 & -10.2 & 41.7 & 0.3 & -98.6 & -13.8 & - & 559 \\
\hline UZ-14 A2 & 384.60 & Bailed & 08-02-93 & 7.8 & 24 & 1.8 & 38 & 3.9 & 9.1 & 13.8 & 148.8 & 36.4 & -10.1 & 40.6 & 3.1 & -97.5 & -13.5 & - & 538 \\
\hline UZ-14 B & 387.68 & Bailed & 08-03-93 & 8.1 & 31 & 2.7 & 40 & 4.4 & 8.3 & 16.3 & 147.6 & 51.4 & -9.5 & 36.6 & 0 & -97.1 & -13.4 & - & 566 \\
\hline UZ-14 C & 390.75 & Bailed & 08-05-93 & 8.3 & 45 & 4.1 & 88 & 5.8 & 15.5 & 223 & 106.1 & 7.7 & -9.2 & 66.8 & 0.4 & -87.4 & -12.1 & - & 389 \\
\hline UZ-14 PT-1 & 390.75 & Pumped & $08-17-93$ & - & 37 & 3.1 & 40 & 6.3 & 7.2 & 57.3 & 144 & 21.4 & -9.8 & 32.3 & 1.8 & -97.8 & -13.3 & - & 644 \\
\hline UZ-14 PT-2 & 390.75 & Pumped & 08-19-93 & - & 30 & 2.4 & 35 & 3.3 & 7.0 & 22.9 & 144 & 25.7 & - & 28.9 & 3.1 & -97.9 & -13.4 & - & 656 \\
\hline UZ-14 PT-4 & 390.75 & Pumped & 08-27-93 & - & 27 & 2.1 & 34 & 1.8 & 6.7 & 14.1 & 141.5 & 32.1 & -9.6 & 27.2 & 0 & -97.3 & -13.4 & 7.56 & 675 \\
\hline UZ-14 D & 390.75 & Bailed & 08-31-93 & 7.8 & 31 & 2.5 & 35 & 4.1 & 7.0 & 24.2 & 146.4 & 40.7 & -11.3 & 29.2 & 0 & -97.6 & -13.1 & - & 690 \\
\hline
\end{tabular}




\begin{tabular}{|c|c|c|c|c|c|c|c|c|c|c|c|c|c|c|c|c|c|c|c|}
\hline \multirow{2}{*}{$\begin{array}{c}\text { Water } \\
\text { Sample }\end{array}$} & \multirow{2}{*}{$\begin{array}{c}\text { Depth } \\
(\mathrm{m})\end{array}$} & \multirow{2}{*}{$\begin{array}{l}\text { Sampling } \\
\text { Method }\end{array}$} & \multirow[b]{2}{*}{ Date } & \multirow[b]{2}{*}{ pH } & \multicolumn{8}{|c|}{ Chemical Concentrations (mg/L) } & \multirow[b]{2}{*}{${ }^{13} \mathrm{C}(\%)$} & \multirow[b]{2}{*}{${ }^{14} \mathrm{C}(\mathrm{pmc})$} & \multirow{2}{*}{$\begin{array}{c}{ }^{3} \mathrm{H}^{\mathrm{a}} \\
(\mathrm{TU})\end{array}$} & \multirow{2}{*}{$\begin{array}{l}\delta D \\
(\%)\end{array}$} & \multirow{2}{*}{$\begin{array}{c}\delta^{18} O \\
(\% \circ)\end{array}$} & \multirow{2}{*}{$\begin{array}{c}{ }^{234} U I^{238} U \\
\text { Activity } \\
\text { Ratio }\end{array}$} & \multirow{2}{*}{$\begin{array}{l}{ }^{36} \mathrm{Cl} / \mathrm{Cl} \\
\left(\times 10^{-15}\right)\end{array}$} \\
\hline & & & & & $\mathrm{Ca}^{2+}$ & $\mathrm{Mg}^{2+}$ & $\mathrm{Na}^{+}$ & $\mathrm{K}^{+}$ & $\mathrm{Cl}^{-}$ & $\mathrm{SO}_{4}{ }^{2-}$ & $\mathrm{HCO}_{3}{ }^{-}$ & $\mathrm{SiO}_{2}$ & & & & & & & \\
\hline \multirow[t]{2}{*}{ WT-24 ${ }^{d}$} & \multirow[t]{2}{*}{-} & Pumped & $10-22-97$ & 8.1 & 23 & 1.4 & 37 & 2.4 & 9.0 & 16 & 135 & 46 & -11.8 & 29.6 & $<0.3$ & -99.4 & -13.5 & 8.34 & 596 \\
\hline & & Pumped & $12-10-97$ & 8.6 & 18.0 & 1.3 & 37.5 & 2.9 & 8.9 & 16.0 & 121.0 & 36.5 & -10.8 & --- & --- & $\begin{array}{c}- \\
100.6\end{array}$ & -13.5 & 8.12 & --- \\
\hline \multirow[t]{3}{*}{ NRG-7a } & - & Bailed & 03-04-94 & - & - & - & - & - & - & - & - & - & - & - & - & - & - & $5.17^{b}$ & 518 \\
\hline & 460.25 & Bailed & 03-07-94 & 8.7 & 3 & 0 & 42 & 6.8 & 7 & 4 & 114 & 9 & -16.6 & 66.9 & 10 & -93.9 & -12.8 & - & 491 \\
\hline & - & Bailed & 03-08-94 & - & - & - & - & - & - & - & - & - & - & - & - & - & - & - & 474 \\
\hline
\end{tabular}

DTNs: GS980108312322.005 [DIRS 149617] (ions, pH, $\left.\delta^{13} \mathrm{C}, \delta \mathrm{D}, \delta^{18} \mathrm{O},{ }^{3} \mathrm{H}\right){ }^{\mathrm{d}}, \mathrm{GS} 950808312322.001$ [DIRS 148114] $\left({ }^{3} \mathrm{H}\right), \mathrm{GS} 010808312322.004$ [DIRS 156007] $\left({ }^{234} \mathrm{U} /{ }^{238} \mathrm{U}\right.$ activity ratios), GS951208312272.002 [DIRS 151649] $\left({ }^{3} \mathrm{H}\right)$, LAJF831222AQ98.011[DIRS 145402] $\left({ }^{36} \mathrm{Cl} / \mathrm{Cl}\right), \mathrm{MO0007GNDWTRIS} .013$ [DIRS 151504] $\left(\delta^{13} \mathrm{C}, \delta \mathrm{D}, \delta^{18} \mathrm{O},{ }^{14} \mathrm{C}\right), \mathrm{MO0007MAJIONPH.016}$ [DIRS 151533] (ions and pH), GS980908312322.008 [DIRS 145412] $\left({ }^{14} \mathrm{C}\right){ }^{\mathrm{d}}$

NOTES: "- " not available

${ }^{a}$ Tritium analyses have an accuracy of plus or minus $12 \mathrm{TU}$.

b These results are not representative of in situ conditions due to sample contamination.

c This sample also contains $10 \mathrm{mg} / \mathrm{L} \mathrm{CO}_{3}{ }^{2-}$

${ }^{d}$ Average values of samples collected on the indicated date. 


\section{A6.3.6.2 Evidence from ${ }^{234} \mathrm{U} /{ }^{238} \mathrm{U}$ Activity Ratios for Local Recharge}

Precipitation typically contains low concentrations of solutes, including uranium. As the precipitation infiltrates through the soil, uranium is dissolved from the readily soluble soil components. Measured ${ }^{234} \mathrm{U} /{ }^{238} \mathrm{U}$ activity ratios in secondary minerals formed in soil zones on Yucca Mountain range from 1.4 to 1.8 reflecting both enrichment and dissolution processes (DTNs: GS010608315215.002 [DIRS 156187], GS970808315215.012 [DIRS 145921], and GS980908312322.009 [DIRS 118977]). Pore waters extracted from a small number of core samples from the unsaturated zone at Yucca Mountain have ${ }^{234} U /{ }^{238} U$ activity ratios that range from 1.5 to 3.8. Pore waters extracted from the top of the Paintbrush tuff nonwelded hydrogeologic unit $(\mathrm{PTn})$ have ${ }^{234} \mathrm{U} /{ }^{238} \mathrm{U}$ activity ratios of 1.5 to 2.5 , whereas pore waters from the stratigraphically lower upper lithophysal unit of the welded Topopah Spring tuff (Tpt) have ${ }^{234} \mathrm{U} /{ }^{238} \mathrm{U}$ activity ratios of 2.5 to 3.8 (DTN: MO0012URANISOT.000 [DIRS 153384], pp. 1 to 4). These data, as well as data from fracture-lining minerals (Paces et al. 1998 [DIRS 107408], Figure 3), suggest a general increase in ${ }^{234} \mathrm{U} /{ }^{238} \mathrm{U}$ activity ratios in pore waters from the soil zone down through the upper unsaturated zone.

Activity ratios of ${ }^{234} \mathrm{U}{ }^{238} \mathrm{U}$ in perched-water samples range from 3.5 at borehole SD-7 to 8.4 at borehole WT-24 (DTNs: GS010608315215.002 [DIRS 156187] and GS010808312322.004 [DIRS 156007]). The values at the high end of this range are unusual and suggest the existence of certain flow conditions. In particular, the high ratios require that the ${ }^{234} \mathrm{U}$ enrichment processes discussed in Section A6.3.1.2.4 dominate over dissolution of uranium-bearing minerals. This situation suggests small water-to-rock ratios. For the unsaturated zone at Yucca Mountain, the high ${ }^{234} \mathrm{U} /{ }^{238} \mathrm{U}$ ratios are consistent with small water fluxes passing through a fracture network. In fractures with small, and probably intermittent water fluxes, ${ }^{234} \mathrm{U}$ will accumulate over time whereas the relative amount of ${ }^{238} \mathrm{U}$ that may be incorporated into the water via dissolution will likely be small. In this way, a small flux of water flowing through a fracture may preferentially incorporate ${ }^{234} \mathrm{U}$ relative to ${ }^{238} \mathrm{U}$, resulting in water with an elevated ${ }^{234} \mathrm{U} /{ }^{238} \mathrm{U}$ ratio, as suggested by Paces et al (2001 [DIRS 156507] and 2002 [DIRS 158817]). The progressive accumulation of such small water fluxes could result in perched water with the observed high ${ }^{234} \mathrm{U} /{ }^{238} \mathrm{U}$ ratios. The changes to the ${ }^{234} \mathrm{U}{ }^{238} \mathrm{U}$ activity ratios that would occur over time within the perched water depend on the ${ }^{238} \mathrm{U}$ content of the host rock, the weathering characteristics of the rock, the water volume to rock surface area, redox conditions, and other factors (Clark and Fritz 1997 [DIRS 105738], pp. 238 to 240). The ${ }^{234} \mathrm{U}^{238} \mathrm{U}$ activity ratio of the perched water may either increase or decrease with time, depending on the relative importance of these factors.

The elevated ${ }^{234} \mathrm{U} /{ }^{238} \mathrm{U}$ activity ratios found in Yucca Mountain perched water and shallow groundwater are attributable to unsaturated zone flow through the thick sequence of fractured, welded tuffs that constitute the Topopah Spring tuff. Figure A6-41 summarizes the change in ${ }^{234} \mathrm{U} /{ }^{238} \mathrm{U}$ ratios with depth in the vicinity of Yucca Mountain. In surface water and pore water from the nonwelded PTn, ${ }^{234} \mathrm{U} /{ }^{238} \mathrm{U}$ activity ratios are small, reflecting the relatively important contribution of ${ }^{238} \mathrm{U}$ from dissolution. Deeper in the subsurface, calcite and opal from the ESF have higher, though variable ${ }^{234} \mathrm{U} /{ }^{238} \mathrm{U}$ activity ratios. The variability of these ratios is attributed to precipitation of these materials from waters that have experienced variable transport times and paths through the unsaturated zone (Paces et al. 2001 [DIRS 156507], p. 63). Permeable vitric tuffs are absent beneath the Topopah Spring tuff in the northern part of Yucca Mountain 
(Rousseau et al. 1999 [DIRS 102097], Figure 16) where perched water has high ${ }^{234} \mathrm{U} /{ }^{238} \mathrm{U}$. In this part of the mountain, recharge to the saturated zone is estimated to occur mainly along faults and other preferential pathways due to the low permeability of the underlying zeolitic tuffs (BSC 2004 [DIRS 169861], Appendix A and Figure 6.6-3 ). Toward the southern part of the central block, however, thick permeable vitric intervals activity ratios and uranium in perched water at boreholes UZ-14 and WT-24 in northern Yucca Mountain, where vitric tuffs are thin or absent. The relatively low ${ }^{234} \mathrm{U} /{ }^{238} \mathrm{U}$ activity ratio (3.5) and higher uranium concentrations for perched water at borehole SD-7 compared to perched water in boreholes WT-24 and UZ-14 (Paces et al 2002 [DIRS 158817], Table 2) are consistent with this conceptual model.

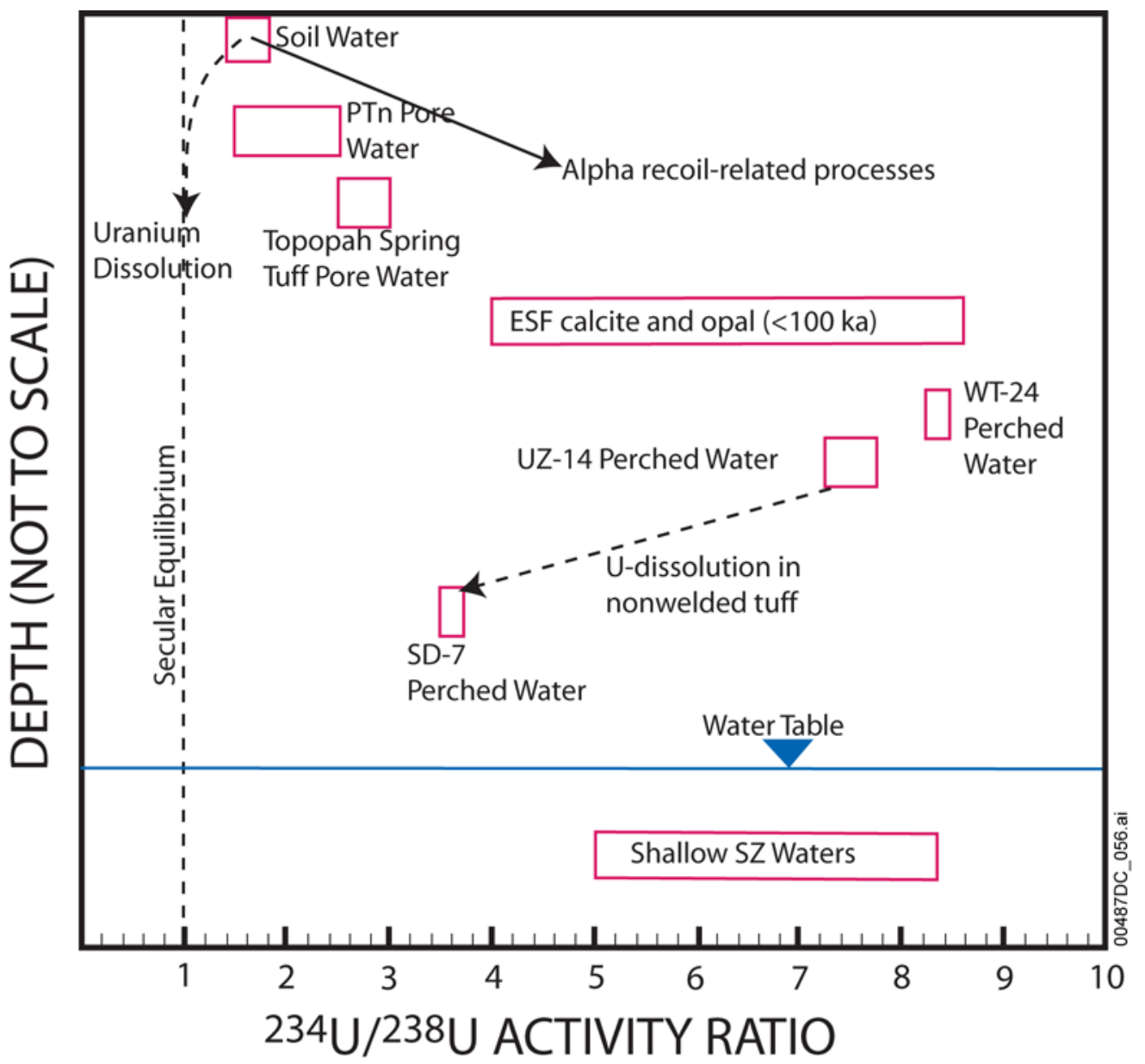

Source: Modified from Paces et al 2001 [DIRS 156507], Figure 37.

Figure A6-41. Uranium Isotopic Compositions and Schematic Evolutionary Trends at Yucca Mountain

In summary, the high ${ }^{234} \mathrm{U} /{ }^{238} \mathrm{U}$ activity ratios found in some Yucca Mountain perched water are interpreted to be due to percolation of groundwater through a very thick unsaturated interval of fractured, welded tuff. In the northern part of Yucca Mountain where deep, permeable vitric tuffs are absent and recharge occurs by preferential flow along faults, the relatively high ${ }^{234} \mathrm{U} /{ }^{238} \mathrm{U}$ activities are unmodified by further bulk-rock dissolution. In the southern part of Yucca Mountain where deep unsaturated flow takes place through the matrix of vitric, nonwelded tuffs, bulk-rock dissolution may reduce the high ${ }^{234} \mathrm{U} /{ }^{238} \mathrm{U}$ activity ratios acquired by 
fracture flow through the welded tuffs. One inference of this conceptual model is that the high ${ }^{234} \mathrm{U} /{ }^{238} \mathrm{U}$ activity ratios found in groundwater near Dune Wash at boreholes WT-3, WT-12, and WT-17 may reflect recharge through areas where deep vitric tuffs are absent, such as north of the Drill Hole Wash area (the reader should note that in this appendix the location WT-3 refers to UE-25 WT \#3 and WT-12 refers to UE-25 WT \#12). However, the necessary data from the deep unsaturated zone are too few to fully substantiate this hypothesis at this time.

\section{A6.3.6.3 Evidence for Local Recharge from Other Chemical Constituents}

This section compares other chemical and isotopic characteristics of perched water and groundwater to further evaluate that Yucca Mountain recharge, as represented by perched water, is the principal source of groundwater beneath Yucca Mountain. A comparison of perched water analyses from Table A6-5 with SZ groundwater from Yucca Mountain (YM-CR, YM-C, YM-SE and YM-S groups) and groundwater upgradient from Yucca Mountain in the TM, FMW-N, SCW, and CF groups are shown in Figures A6-42 to A6-46.

The scatter plot of $\mathrm{SO}_{4}{ }^{2-}$ versus $\mathrm{Cl}^{-}$(Figure A6-42) shows that perched waters pumped from boreholes UZ-14, WT-24, and SD-7 have $\mathrm{SO}_{4}{ }^{2-}$ and $\mathrm{Cl}^{-}$concentrations that are similar to those of groundwaters at many YM-CR area wells. These concentrations plot near a line, termed the Southern Nevada Precipitation line that was derived by considering how the $\mathrm{SO}_{4}{ }^{2-}$ and $\mathrm{Cl}^{-}$concentrations measured in precipitation from the Kawich Range, just north of the Nevada Test Site, would change with progressive evaporation. With progressive evaporation, the dissolved $\mathrm{SO}_{4}{ }^{2-}$ and $\mathrm{Cl}^{-}$concentrations in the remaining water would increase and plot along a line with a slope (2.7) equal to the ratio of their concentrations in precipitation $(96$ and $35 \mathrm{mg} / \mathrm{L}$, respectively) (Meijer 2002 [DIRS 158813], Table 1). Groundwaters that plot on or near the Southern Nevada Precipitation line are likely to have had most of their $\mathrm{SO}_{4}{ }^{2-}$ and $\mathrm{Cl}^{-}$derived from atmospheric deposition of salts composed of these ions.

In contrast, other Yucca Mountain groundwaters, particularly groundwaters at some YM-S sites, show elevated $\mathrm{SO}_{4}{ }^{2-}$ concentrations relative to perched water and appear to trend from the perched-water data toward the p\#1 mixing line. This line (slope $=5.7$ ) is defined by the origin and groundwater $\mathrm{SO}_{4}{ }^{2-}$ and $\mathrm{Cl}^{-}$concentrations from the carbonate aquifer at borehole $\mathrm{p \# 1}$ (160 and $28 \mathrm{mg} / \mathrm{L}$, respectively). Groundwaters that included a component of groundwater from the carbonate aquifer would be expected to trend toward this line, depending on the concentrations of $\mathrm{SO}_{4}{ }^{2-}$ and $\mathrm{Cl}^{-}$dissolved in the groundwater before mixing occurred. Elevated groundwater $\mathrm{SO}_{4}{ }^{2-}$ concentrations relative to the Southern Nevada Precipitation line could also indicate the addition of $\mathrm{SO}_{4}{ }^{2-}$ through the dissolution of S-bearing minerals like gypsum, pyrite or alunite. 


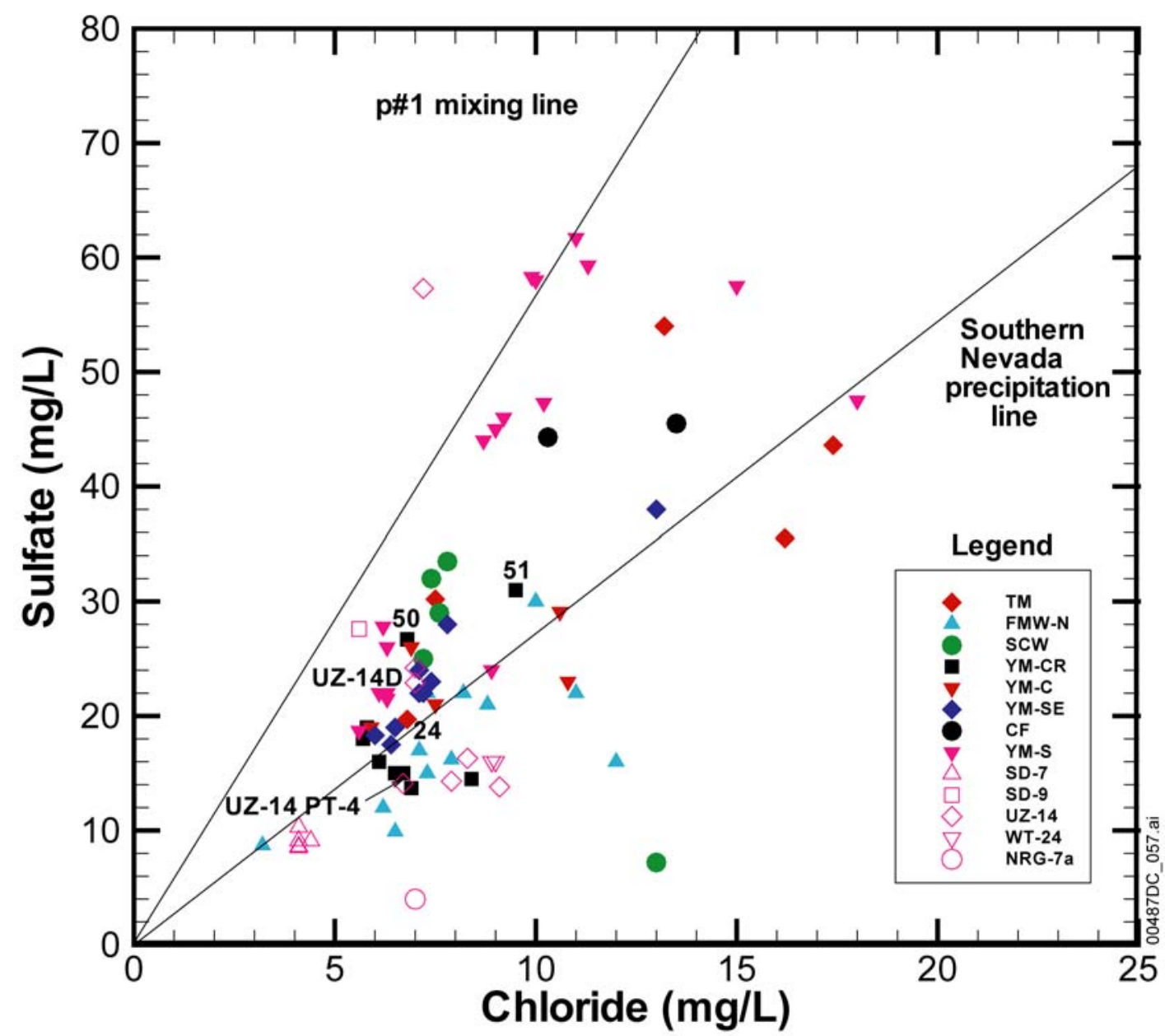

Source: Tables A6-1 and A6-5.

NOTES: Sample p\#1 plots well above limits of the figure. This figure has color-coded data points and should not be read in a black and white version. Perched water data are represented by open symbols. The more representative samples of perched water from borehole UZ-14 are labeled in the figure.

Figure A6-42. Scatter Plot Comparing Sulfate and Chloride Compositions of Perched Waters and Saturated Zone Groundwaters

The scatter plot of $\delta^{13} \mathrm{C}$ versus 1/DIC (Figure A6-43) shows that perched water at Yucca Mountain is generally more dilute in DIC and has lighter $\delta^{13} \mathrm{C}$ than most Yucca Mountain groundwater, although some groundwater from the YM-CR group in northern Yucca Mountain has comparable DIC and $\delta^{13} \mathrm{C}$ values. No systematic differences between the northern (boreholes UZ-14 and WT-24) and central Yucca Mountain perched water (borehole SD-7) compositions are evident in $\delta^{13} \mathrm{C}$ and DIC compositions, suggesting the relative uniformity of recharge compositions throughout Yucca Mountain. The Yucca Mountain groundwater shows an overall southward trend toward heavier $\delta^{13} \mathrm{C}$ and higher DIC concentrations (lower 1/DIC). 


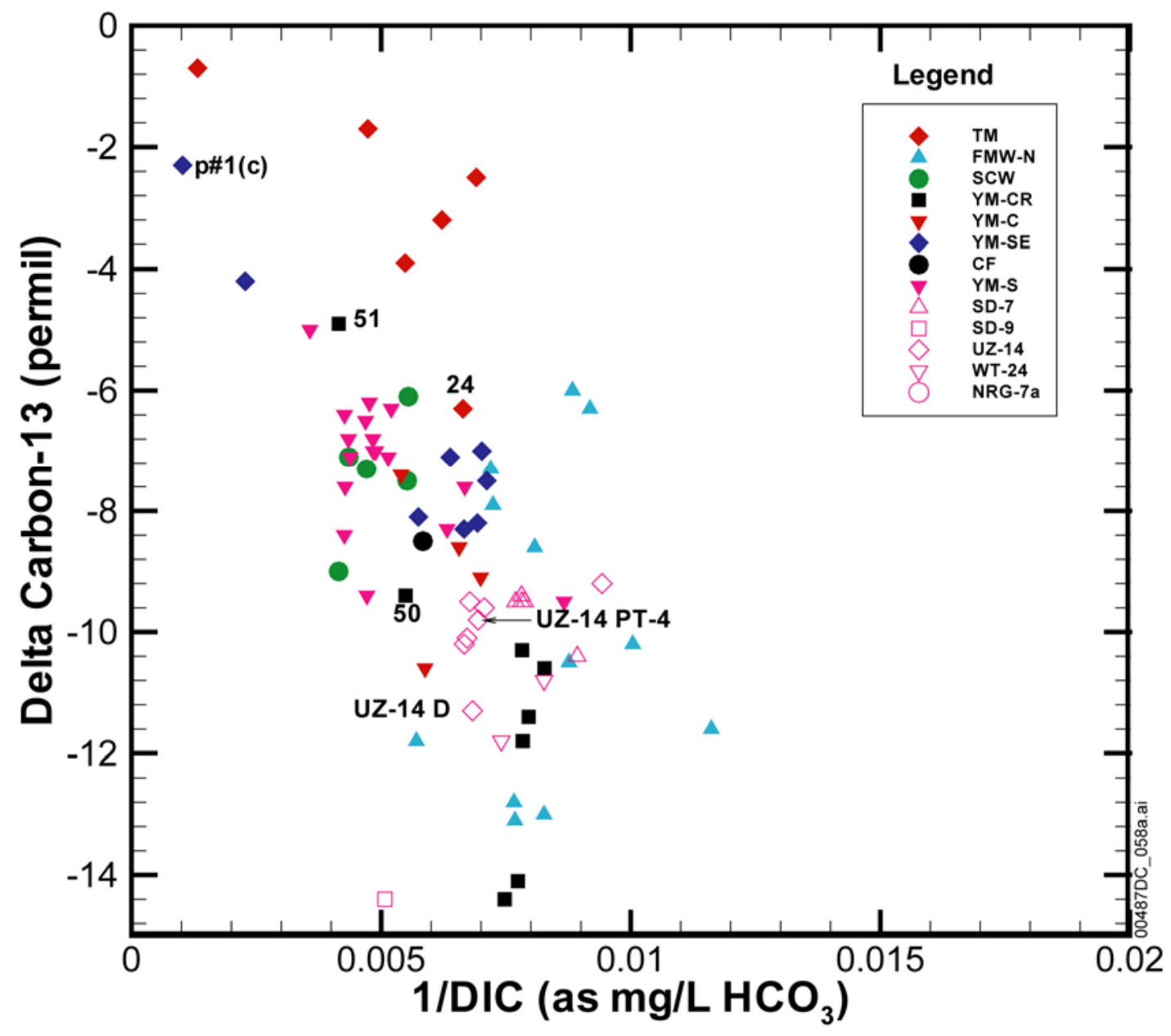

Source: Tables A6-2, A6-3, and A6-5.

NOTES: This figure has color-coded data points and should not be read in a black and white version. Perched water data are represented by open symbols. The more representative samples of perched water from borehole UZ-14 are labeled in the figure.

Figure A6-43. Scatter Plot Comparing Delta Carbon-13 and Dissolved Inorganic Carbon Compositions of Perched Waters and Saturated Zone Groundwaters

Perched groundwater at Yucca Mountain has $\delta^{18} \mathrm{O}$ and $\delta \mathrm{D}$ compositions that are slightly heavier in $\delta \mathrm{D}$ but generally similar to many YM-CR groundwaters (Figure A6-44). Elsewhere at Yucca Mountain, groundwaters tend to be lighter in $\delta \mathrm{D}$ than the perched water. There is an overall southward trend toward lighter $\delta \mathrm{D}$ among the YM-CR, YM-C, YM-SE and YM-S groups. 


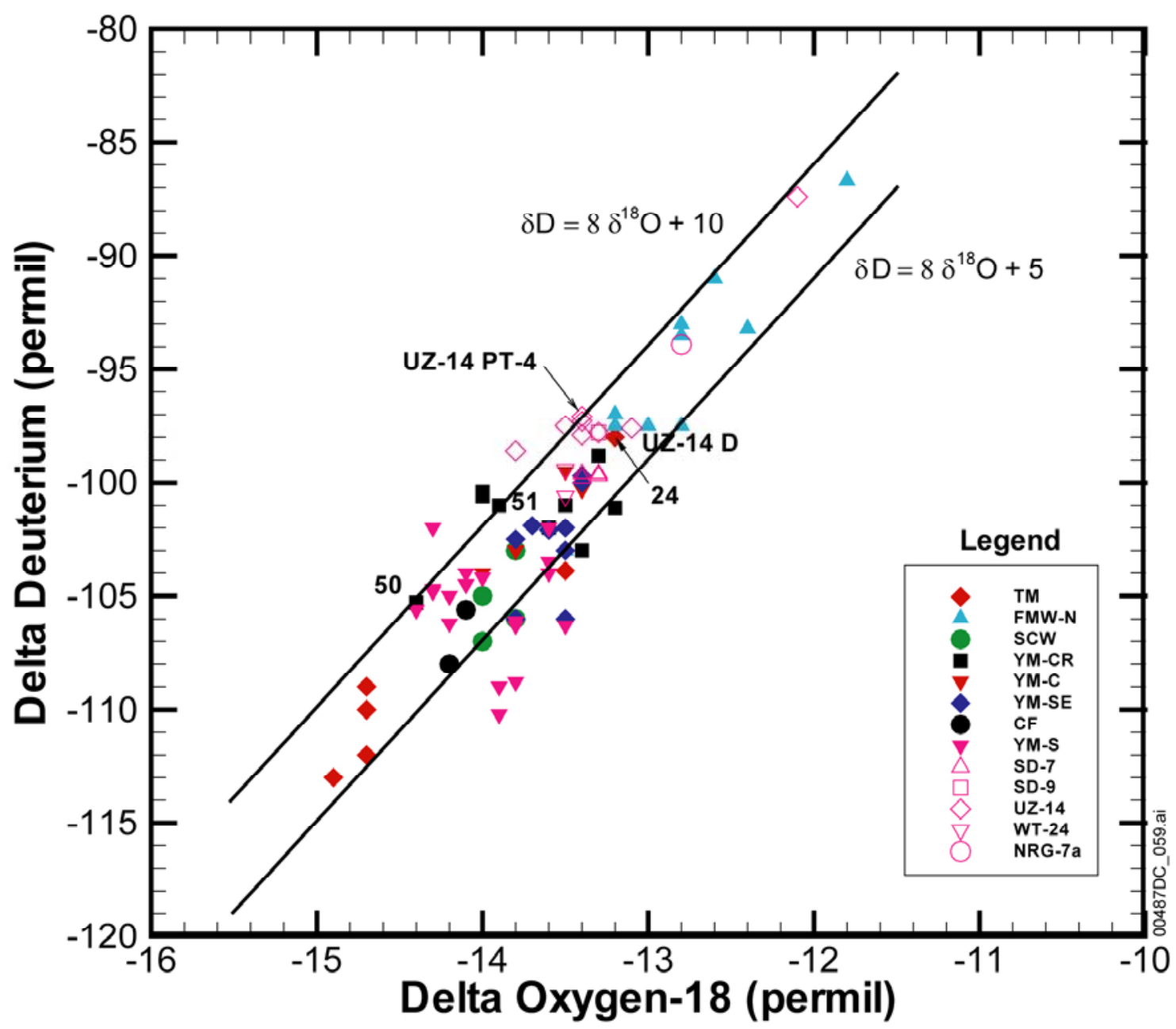

Source: Tables A6-2 and A6-5.

NOTE: This figure has color-coded data points and should not be read in a black and white version. The solid lines are the global meteoric water line $\left(\delta \mathrm{D}=8 \delta^{18} \mathrm{O}+10\right)$ (Clark and Fritz 1997 [DIRS 105738], p. 36) and a possible paleometeoric water line for southern Nevada $\left(\delta \mathrm{D}=8 \delta^{18} \mathrm{O}+5\right)$ (White and Chuma 1987 [DIRS 108871], pp. 573 to 574). Perched water data are represented by open symbols. The more representative samples of perched water from borehole UZ-14 are labeled in the figure.

Figure A6-44. Scatter Plot Comparing Delta Deuterium and Delta Oxygen-18 Data for Perched Water and Groundwater near Yucca Mountain

Perched waters at Yucca Mountain have ${ }^{14} \mathrm{C}$ activities that are higher than most Yucca Mountain area groundwaters (Figure A6-45). As discussed in connection with Figure A6-43, the $\delta^{13} \mathrm{C}$ values of perched water are comparable to or lighter than all but a few of the Yucca Mountain area groundwaters. These groundwaters show a southward trend toward heavier $\delta^{13} \mathrm{C}$ and lower ${ }^{14} \mathrm{C}$ activities. 


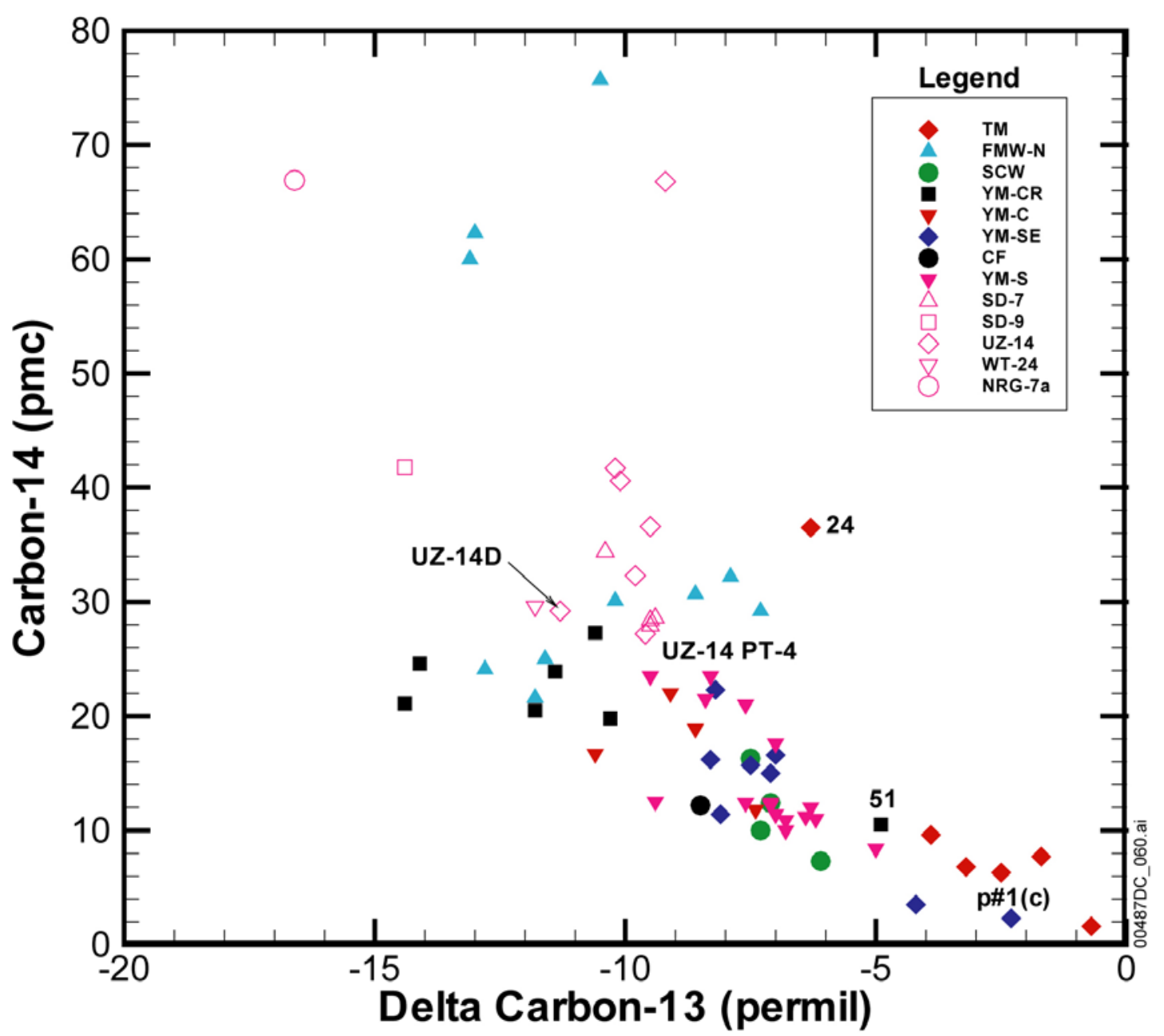

Source: Tables A6-2 and A6-5.

NOTE: This figure has color-coded data points and should not be read in a black and white version. Perched water data are represented by open symbols. The more representative samples of perched water from borehole UZ-14 are labeled in the figure.

Figure A6-45. ${ }^{14} \mathrm{C}$ Activity versus Delta ${ }^{13} \mathrm{C}$ of Perched Water and Groundwater near Yucca Mountain

Perched waters at Yucca Mountain have higher $\mathrm{Ca}^{2+}$ and lower $\mathrm{Na}^{+}$concentrations than most Yucca Mountain groundwaters (Figure A6-46). The YM-C and YM-SE area groundwaters are most similar to the perched water with regard to $\mathrm{Ca}^{2+}$ and $\mathrm{Na}^{+}$concentrations, whereas most YM-CR and YM-S groundwater have substantially less $\mathrm{Ca}^{2+}$ and more $\mathrm{Na}^{+}$than the perched water. Some YM-S groundwaters and one YM-C groundwater (from well H-4) also appear to be

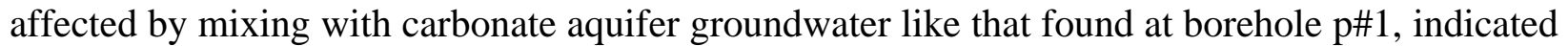
by increased $\mathrm{Ca}^{2+}$ and $\mathrm{Na}^{+}$concentrations in these groundwaters along a mixing trend defined by the groundwaters from well $\mathrm{p \# 1.}$ 


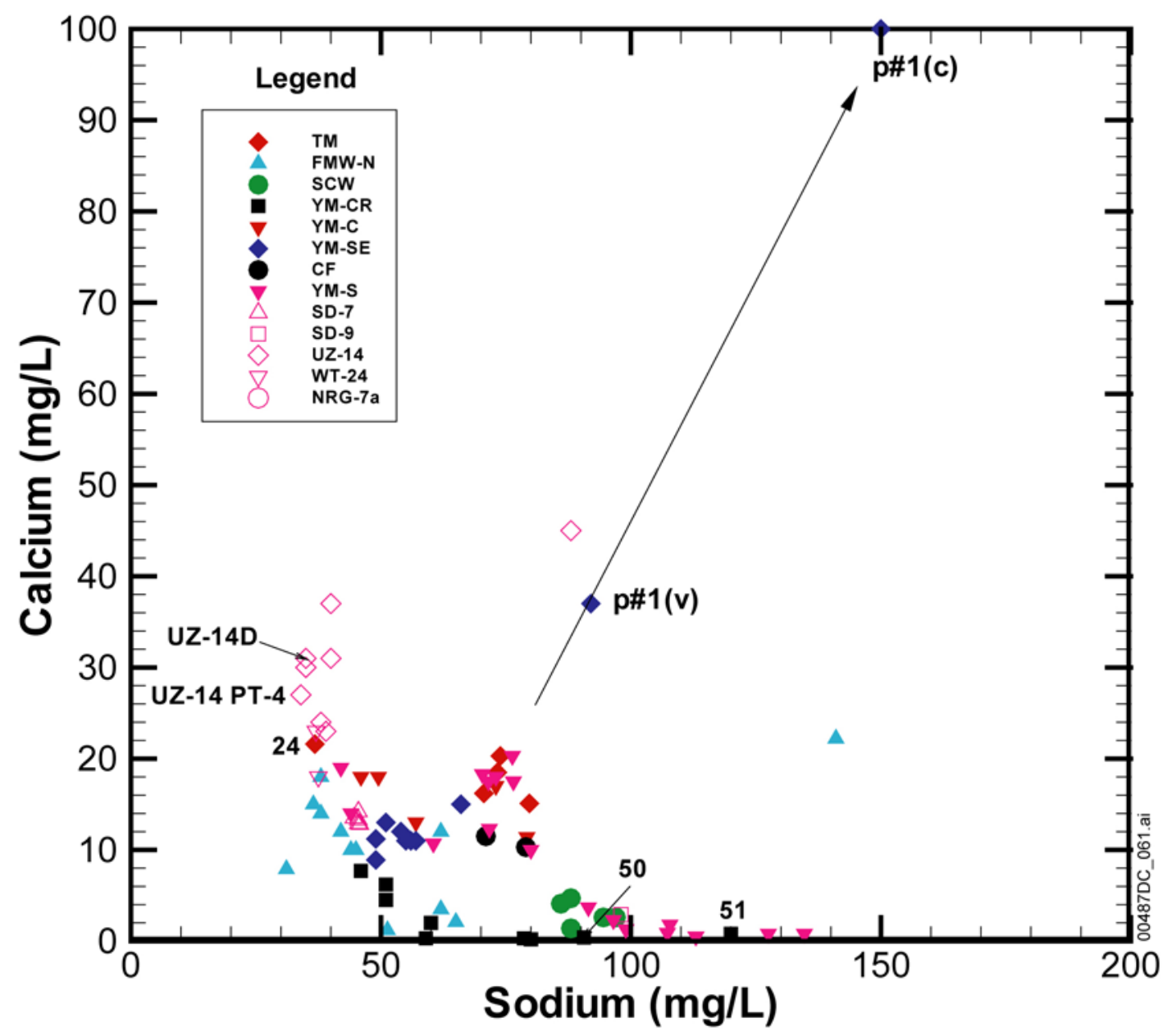

Source: Tables A6-1 and A6-5.

NOTE: This figure has color-coded data points and should not be read in a black and white version. Perched water data are represented by open symbols. The more representative samples of perched water from borehole UZ-14 are labeled in the figure.

Figure A6-46. Scatter Plot Comparing Calcium and Sodium Compositions of Perched Waters and Saturated Zone Groundwaters

In summary, groundwater chemical and isotopic compositions at Yucca Mountain are compatible with the hypothesis that much or most of the groundwater is derived from local recharge. The perched-water and groundwater $\mathrm{Cl}^{-}$and $\mathrm{SO}_{4}{ }^{2-}$ concentrations are similar, although southward increases in groundwater $\mathrm{SO}_{4}{ }^{2-}$ concentrations require some additional sources of $\mathrm{SO}_{4}{ }^{2-}$ through water-rock interaction or mixing with groundwater having higher $\mathrm{SO}_{4}{ }^{2-}$ concentrations. Similarly, the $\delta^{13} \mathrm{C}$ and DIC concentrations of perched water are similar to those of groundwater in northern Yucca Mountain, but water-rock interactions involving isotopically heavy calcite or mixing with small amounts of a groundwater having high DIC concentrations and heavy $\delta^{13} \mathrm{C}$ is required to explain the southward increases in $\delta^{13} \mathrm{C}$ and DIC. Perched water $\delta^{18} \mathrm{O}$ and $\delta \mathrm{D}$ compositions are similar to those found in groundwater in northern Yucca Mountain but are slightly heavier than those found toward the southern end of the mountain. Because climate change has probably affected the $\delta^{18} \mathrm{O}$ and $\delta \mathrm{D}$ composition of recharge over time (see 
Section A6.3.1.2), the differences between the perched water $\delta^{18} \mathrm{O}$ and $\delta \mathrm{D}$ compositions and groundwater $\delta^{18} \mathrm{O}$ and $\delta \mathrm{D}$ compositions elsewhere at Yucca Mountain do not rule out local recharge as a source for these groundwaters. The higher ${ }^{14} \mathrm{C}$ activities of the perched water compared to Yucca Mountain groundwater are compatible with the hypotheses that Yucca Mountain groundwater is derived from local recharge. Groundwater is expected to be older than the recharge from which it is derived. Similarly, the fact that perched water has high $\mathrm{Ca}^{2+}$ and lower $\mathrm{Na}^{+}$than the underlying groundwater is compatible with local recharge being the source of the groundwater. Pore-water analyses from the deep unsaturated zone indicate that $\mathrm{Ca}^{2+}$ is exchanged for $\mathrm{Na}^{+}$on minerals in the deep unsaturated zone (Meijer 2002 [DIRS 158813], p. 799), consistent with the observed relation between $\mathrm{Ca}^{2+}$ and $\mathrm{Na}^{+}$in the perched and SZ waters. Likewise, it appears that other divalent cations like $\mathrm{Mg}^{2+}$ and $\mathrm{Sr}^{2+}$, as well as $\mathrm{Ca}^{2+}$, are selectively removed by zeolites in exchange for $\mathrm{Na}^{+}$(and perhaps for $\mathrm{K}^{+}$) in the deep unsaturated zone (Vaniman et al. 2001 [DIRS 157427], Table 2).

\section{A6.3.6.4 Evaluation of Saturated Zone Flow beneath Yucca Mountain}

The steep gradient in the potentiometric surface to the north and along the west side of Yucca Mountain requires flow in southerly or easterly directions beneath Yucca Mountain. The N-S and NW-SE fault orientations in the area may also focus flow in these directions. Therefore, if SZ groundwater does contribute to flow beneath Yucca Mountain, then this groundwater would most likely originate from the north, northwest or west. These possibilities are evaluated below.

For the most part, the hydrochemistry of groundwater north of Yucca Mountain that was sampled as part of the NTS Underground Test Area Restoration Project (DTN: LA0311EK831232.001 [DIRS 166068]) differs from that of SZ groundwater beneath Yucca Mountain. As shown in Figures A6-32, A6-33, and A6-42, the $\mathrm{Cl}^{-}$and $\mathrm{SO}_{4}{ }^{2-}$ concentrations of most samples in the Timber Mountain group are substantially higher than those for Yucca Mountain groundwater. Similarly, $\delta^{13} \mathrm{C}$ are generally too heavy and the ${ }^{14} \mathrm{C}$ too low for groundwater near Timber Mountain to be the primary source of Yucca Mountain groundwater (Figure A6-45). Only one well (ER-EC-07, Sample 24) in Beatty Wash has $\mathrm{Cl}^{-}$, $\mathrm{SO}_{4}{ }^{2-}, \delta{ }^{13} \mathrm{C}$, and ${ }^{14} \mathrm{C}$ values that suggest it could be a major component of the groundwater beneath Yucca Mountain (Figures A6-42 and A6-45). Although limited data for $\delta^{87} \mathrm{Sr}$ are available from Yucca Mountain, the $\delta^{87} \mathrm{Sr}$ in groundwater from the northernmost well at Yucca Mountain (G-2) is too high for this groundwater to have originated from groundwater at well ER-EC-07 (Figure A6-49). The much higher $\mathrm{Sr}^{2+}$ concentrations in groundwater at well ER-EC-07 compared to all northern Yucca Mountain groundwater (Figure A6-48) indicates that acquisition of more radiogenic strontium through water-rock interaction during flow between wells ER-EC-07 and G-2 is not a likely explanation for the difference in $\delta^{87} \mathrm{Sr}$ values at these wells.

It has been suggested that water may upwell from the carbonate aquifer into the tuff aquifer of Yucca Mountain (Stuckless et al. 1991 [DIRS 101159]). The $\mathrm{Cl}^{-}$and $\mathrm{SO}_{4}{ }^{2-}$ concentrations in

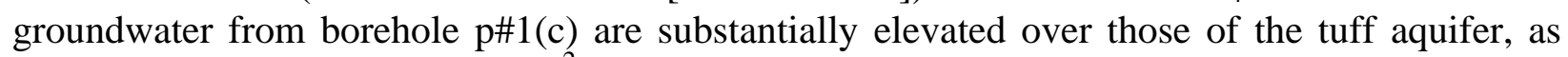
discussed above. The $\mathrm{Cl}^{-}$and $\mathrm{SO}_{4}{ }^{2-}$ concentrations of groundwater at borehole $\mathrm{p} \# 1$ are similar to those of groundwater from other areas where carbonate rocks are present (e.g., Crater Flat-SW), suggesting that groundwater from borehole p\#1 may be representative of compositions in the carbonate aquifer beneath Yucca Mountain. Groundwater from sample p\#1(c) also has much 
higher $\delta^{13} \mathrm{C}$, lower ${ }^{14} \mathrm{C}$, and much higher concentrations of $\mathrm{DIC}, \mathrm{Ca}^{2+}$, and $\mathrm{Na}^{+}$ (Figures A6-43 A6-46) when compared to the tuff aquifer. As is evident from Figures A6-42 to A6-46, most of the groundwater samples from the volcanic aquifer do not resemble the

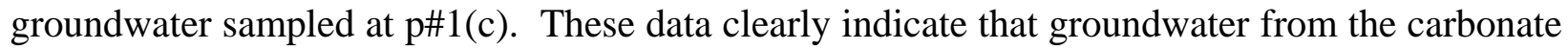
aquifer does not constitute a major part of the groundwater beneath Yucca Mountain. However, the higher $\mathrm{Cl}^{-}$and $\mathrm{SO}_{4}{ }^{2-}$ concentration as well as other constituents (Figure A6-46) of sample p\#1(v) are readily explained by mixing between groundwater from the carbonate and volcanic aquifers within the borehole. It is estimated from flow logs that the p\#1(v) sample received about 28.6 percent of its water from the carbonate aquifer as a result of upward flow in the borehole, despite an attempt to isolate the volcanic and carbonate aquifers from each other with a temporary plug (Craig and Robison 1984 [DIRS 101040], p. 49).

Carbon isotope data can be used to limit the amount of mixing of waters in the volcanic and Paleozoic aquifers, as follows. The $\delta^{13} \mathrm{C}$ and DIC of the carbonate aquifer at p\#1(c) are -2.3 per mil (Table A6-2) and $976.6 \mathrm{mg} / \mathrm{L}$ as $\mathrm{HCO}_{3}{ }^{-}$(Table A6-3), respectively. In contrast, for groundwater samples where uranium isotopes indicate only Yucca Mountain recharge exists (i.e., samples 43, 44, 60, 64, 65, and 66) the average DIC concentration is about $143.6 \pm 18.6 \mathrm{mg} / \mathrm{L}$ as $\mathrm{HCO}_{3}{ }^{-}$and the average $\delta^{13} \mathrm{C}$ is $-9.1 \pm 1.4$ per mil (Note: uncertainty is given as 1 standard deviation and the $\delta^{13} \mathrm{C}$ of sample 59 was used for sample 60). Mixing calculations were done using the composition for sample p\#1(c) and the average composition of Yucca Mountain recharge from samples 43, 44, 60, 64, 65, and 66 as end members. The calculations employed the relations $D I C_{\text {mix }}=X_{\mathrm{c}} \bullet D I C_{\mathrm{c}}+\left(1-X_{\mathrm{c}}\right) \bullet D I C_{\mathrm{v}}$ and $\delta^{13} \mathrm{C}_{\text {mix }} \bullet D I C_{\text {mix }}=$ $X_{\mathrm{c}} \bullet \delta^{13} \mathrm{C}_{\mathrm{c}} \bullet D I C_{\mathrm{c}}+\left(1-X_{\mathrm{c}}\right) \bullet \delta^{13} \mathrm{C}_{\mathrm{v}} \bullet D I C_{\mathrm{v}}$, where $X_{\mathrm{c}}$ is the fraction of groundwater from the carbonate aquifer in the mixture and the subscripts $\operatorname{mix}, c$, and $v$ indicate that the variables pertain to the mixture, carbonate aquifer, and volcanic aquifer, respectively. These calculations indicate that the presence of 10 percent carbonate aquifer water would increase the DIC and $\delta^{13} \mathrm{C}$ of Yucca Mountain recharge water to 227 and -6.2 per mil, respectively; similarly, the presence of 20 percent carbonate aquifer water in the mixture would increase DIC and $\delta^{13} \mathrm{C}$ to 310 and -4.8 per mil, respectively. On the basis of these calculations, groundwater from borehole USW $\mathrm{H}-3$ (Site 51) with a DIC concentration of $240.9 \mathrm{mg} / \mathrm{L} \mathrm{HCO}_{3}$ and a $\delta^{13} \mathrm{C}$ of -4.9 per mil may have approximately 10 to 20 percent carbonate aquifer water. However, all other samples from the Yucca Mountain block have less than 5 percent carbonate aquifer water. These relatively small amounts of carbonate aquifer water in the volcanic aquifer probably form upper limits because isotopically heavy calcite is present in the volcanic aquifer that, if dissolved, would result in effects on DIC and $\delta^{13} \mathrm{C}$ compositions similar to those produced by mixing.

Groundwater from the Solitario Canyon Wash (SCW) area wells is similar with respect to most chemical and isotopic constituents to groundwater in the southern Yucca Mountain (YM-S) well grouping and to groundwater from wells H-3 (Site 51) and SD-6 (Site 50) in the Yucca Crest (YM-CR) grouping (Figures A6-42 to A6-46). The chemical and isotopic similarities between the SCW and YM-S groupings indicates the generally southward flow of groundwater from the SCW area wells, whereas the chemical and isotopic similarities between groundwaters at wells H-3 and SD-6 and SCW area groundwater is compatible with at least a small amount of groundwater leakage eastward across the Solitario Canyon fault. However, because the vast majority of YM-C and YM-SE area groundwaters appear to be unrelated to groundwater from 
the Solitario Canyon area, groundwater leakage from Solitario Canyon to these areas must be relatively small compared to other groundwater sources, such as local recharge.

In summary, considerable hydrochemical evidence exists to support the hypothesis that the bulk of the SZ water beneath Yucca Mountain was derived from local recharge. Similarly, evidence in support of groundwater flow to Yucca Mountain from upgradient areas is weak. Exceptions to this are leakage of groundwater from the Solitario Canyon area into groundwater at wells SD-6 and $\mathrm{H}-3$, and potentially wells in southern Yucca Mountain, including those near Fortymile Wash. Local upwelling of relatively small amounts (generally less than 5 percent) of carbonate aquifer water into the volcanic aquifer is permitted by the groundwater data from most YM-CR, YM-C and YM-SE area wells.

On the basis of the above discussions, groundwater beneath Yucca Mountain is best characterized by generally low concentrations of dissolved solids and by high ${ }^{234} \mathrm{U} /{ }^{238} \mathrm{U}$ activity ratios. Lower ${ }^{234} \mathrm{U} /{ }^{238} \mathrm{U}$ ratios do not, however, exclude the presence of Yucca Mountain recharge in the groundwater. Low ${ }^{234} U /{ }^{238} U$ activity ratios (less than 6) in downgradient groundwater can result from recharge in southern Yucca Mountain with a lower ${ }^{234} \mathrm{U} /{ }^{238} \mathrm{U}$ activity ratio, mixing of Yucca Mountain recharge with groundwater from other sources, and water-rock interactions that add dissolved uranium to the groundwater.

\section{A6.3.6.5 Evaluation of Evidence for the Magnitude of Recharge at Yucca Mountain}

The magnitude of recharge at Yucca Mountain is estimated in this section on the basis of the concentrations of constituents such as chloride that are considered conservative in groundwater systems of the type present at Yucca Mountain. In particular, the chloride mass balance (CMB) method will be used for this purpose. This method is based on the premise that the flux of $\mathrm{Cl}^{-}$deposited at the surface equals the flux of $\mathrm{Cl}^{-}$carried beneath the root zone by infiltrating water. With increasing depth in the root zone, $\mathrm{Cl}^{-}$concentrations in soil waters increase and apparent infiltration rates decrease as water is extracted by the processes of evapotranspiration (Figure A6-47). However, once soil waters move below the zone of evapotranspiration, they become net infiltration, and their $\mathrm{Cl}^{-}$concentrations are assumed to remain constant. It is these $\mathrm{Cl}^{-}$concentrations that are used to calculate net infiltration rates and, ultimately, recharge rates.

The CMB method (e.g., Dettinger 1989 [DIRS 105384], p. 59) uses the following equation to calculate the infiltration rate $(I$, in $\mathrm{mm})$ when runoff or run-on is negligible:

$$
I=\left(P C_{0}\right) / C_{\mathrm{p}}
$$

where

$P$ is average annual precipitation $(\mathrm{mm})$

$C_{0}$ is average $\mathrm{Cl}^{-}$concentration in precipitation, including the contribution from dry fallout $(\mathrm{mg} / \mathrm{L})$

$C_{\mathrm{p}}$ is the measured $\mathrm{Cl}^{-}$concentration in groundwaters $(\mathrm{mg} / \mathrm{L})$. 
The CMB method (Figure A6-47) assumes steady one-dimensional, downward piston flow, constant average annual precipitation rate, constant average annual $\mathrm{Cl}^{-}$deposition rate $\left(P C_{0}\right)$, no run-on or run-off, no $\mathrm{Cl}^{-}$source other than precipitation (e.g., it is assumed that the concentrations of $\mathrm{Cl}^{-}$brought in by surface runoff and $\mathrm{Cl}^{-}$released from weathering of surface rocks are negligible), and no $\mathrm{Cl}^{-}$sink (Table A5-1, Assumption 5). When these conditions are met, the estimates of infiltration rate are equal to the recharge rate at the water table; the terms infiltration rate and recharge rate are used interchangeably in the remainder of this section.

Estimates of recharge using the CMB technique for 15 groundwater basins in Nevada were found to be in fairly good agreement with estimates obtained by the Maxey-Eakin linear step function (Dettinger 1989 [DIRS 105384], p. 75). Using a 6-year study of two upland basins selected as analogue wetter climate sites for Yucca Mountain, Lichty and McKinley (1995 [DIRS 100589], p. 1) showed the CMB method to be more robust than a water-balance modeling approach using a deterministic watershed model for estimating basin-wide recharge for two comparatively wet sites in the Kawich Range north of Yucca Mountain. They attributed the robustness of the CMB method to the small number of measured parameters required as compared to the number of parameters needed for defining a deterministic watershed model.

Point estimates of net infiltration or recharge using the CMB method tend to be less robust than basin-wide estimates because of additional assumptions concerning vertical groundwater flow and surface water flow. Conditions under which these assumptions may not be valid at Yucca Mountain are discussed in another scientific analysis report (BSC 2001 [DIRS 160247], Section A6.9.2.2). Values of net infiltration estimated at Yucca Mountain using the CMB method range from less than $0.5 \mathrm{~mm} / \mathrm{year}$ in washes to a maximum of nearly $20 \mathrm{~mm} / \mathrm{year}$ beneath ridgetops and side slopes (based on data and calculations in DTNs: (LA0002JF831222.001, [DIRS 147077] LA0002JF831222.002 [DIRS 147079], LA9909JF831222.010 [DIRS 122733], LA9909JF831222.012 [DIRS 122736]; and BSC 2001 [DIRS 160247], Section A6.9.2.4), depending on the $\mathrm{Cl}^{-}$deposition rate assumed in the calculation.

Table A6-6 lists recharge rates calculated from measured groundwater $\mathrm{Cl}^{-}$concentrations using the CMB method. This method requires that the $\mathrm{Cl}^{-}$deposition rate, which is the product of precipitation and effective $\mathrm{Cl}^{-}$concentration in precipitation (including both wet and dry fallout), be known. The average annual precipitation rate for Yucca Mountain is $170 \mathrm{~mm}$ (Hevesi et al. 1992 [DIRS 116809], p. 677), and estimates of average $\mathrm{Cl}^{-}$concentrations in precipitation at Yucca Mountain range from 0.3 to $0.6 \mathrm{mg} / \mathrm{L}$ (BSC 2001 [DIRS 160247], Section A6.9.2.3). To bound the recharge rate estimates, Rate 1 in Table A6-6 is calculated using the lower estimate for $\mathrm{Cl}^{-}$concentration whereas Rate 2 is calculated using the higher estimate. The CMB recharge estimates average $7 \pm 1 \mathrm{~mm} /$ year for Rate 1 and $14 \pm 2 \mathrm{~mm} /$ year for Rate 2 (Table A6-6). The much narrower range of fluxes estimated for the saturated-zone samples compared to the unsaturated zone samples can probably be attributed to the greater volume averaging of the SZ samples, as well as to mixing in the aquifer and in the borehole when the SZ samples were pumped. 

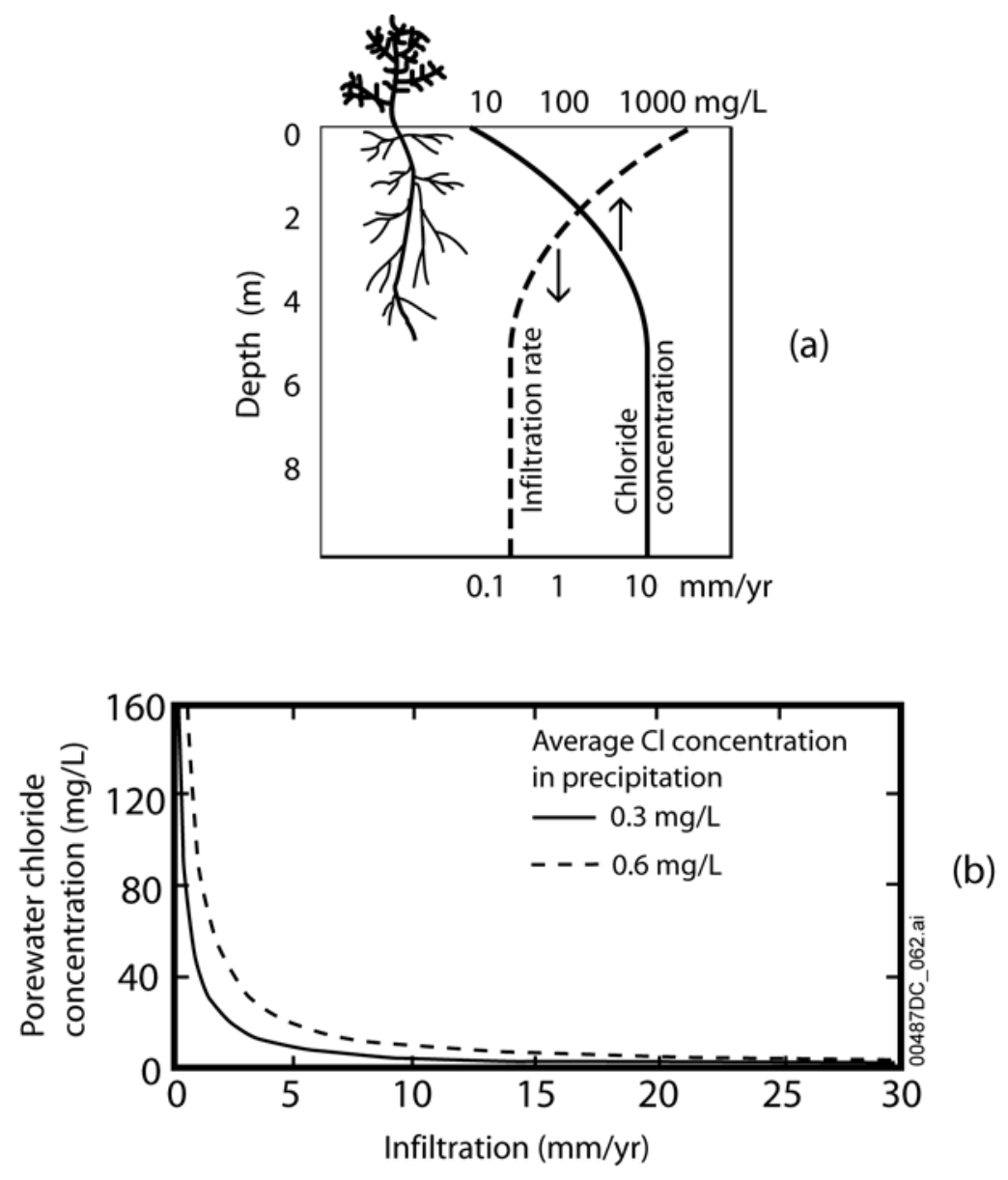

For illustration only.

NOTES: Part (a) illustrates the underlying basis of the CMB method. Part (b) shows pore-water $\mathrm{Cl}^{-}$concentrations as a function of infiltration, assuming a range of chloride deposition rates (106 to $183 \mathrm{mg}$ pore-water $\mathrm{Cl}^{-} /\left(\mathrm{m}^{-2}\right.$ year). Using an average annual precipitation rate of $170 \mathrm{~mm}$ (Hevesi et al. 1992 [DIRS 116809], p. 677), these deposition rates correspond to effective $\mathrm{Cl}^{-}$concentrations of $0.62 \mathrm{mg} / \mathrm{L}$ to $1.07 \mathrm{mg} / \mathrm{L}$ in local precipitation.

Figure A6-47. Chloride Mass-Balance Method for Estimating Infiltration

As indicated in the following section, it appears from interpretations of both stable isotope $\left(\delta \mathrm{D}\right.$ and $\delta^{18} \mathrm{O}$ ) and ${ }^{14} \mathrm{C}$ data that most of the groundwater presently beneath Yucca Mountain infiltrated in the late Pleistocene, when precipitation and $\mathrm{Cl}^{-}$deposition rates were potentially different from present conditions. It is estimated from wood rat midden data that mean annual precipitation during the Pleistocene was 1.9 times present precipitation at a 1,500-m elevation and 1.3 times present precipitation at a 750-m elevation (Forester et al. 1999 [DIRS 109425], p. 32). For the elevation range of 1,000 to 1,500-m that encompasses the surface elevations of most wells listed in Table A6-6 (DTN: GS010908312332.002 [DIRS 163555]), an average increase in Pleistocene precipitation of 1.7 times present precipitation can be estimated for Yucca Mountain. However, it is not clear if $\mathrm{Cl}^{-}$concentrations in precipitation were the same during the Pleistocene or if $\mathrm{Cl}^{-}$concentrations decreased so that $\mathrm{Cl}^{-}$deposition rates (the product of $P$ and $C_{0}$ ) were constant or even lower than today. If $\mathrm{Cl}^{-}$concentrations in precipitation were similar in the late Pleistocene to those of the present day, Pleistocene infiltration rates may have 
been approximately 70 percent higher, on average, than the rates listed in Table A6-6 using present-day precipitation rates and $\mathrm{Cl}^{-}$concentrations. On the other hand, if $\mathrm{Cl}^{-}$deposition rates in the Pleistocene were approximately the same as today, as inferred by (Plummer et al. 1997 [DIRS 107034], p. 540) from ${ }^{36} \mathrm{Cl} / \mathrm{Cl}$ ratios in packrat middens, the infiltration rates listed in Table A6-8 using present-day $\mathrm{Cl}^{-}$deposition rates are valid.

\section{A6.3.6.6 Evaluation of Evidence for Timing of Recharge}

Hydrochemical data that bear on the question of the age or timing of local recharge include hydrogen and oxygen isotope ratios and ${ }^{14} \mathrm{C}$ activities. Hydrogen and oxygen isotope ratios may contain age information because the numerical values of these ratios in groundwaters reflect the climate under which the waters were infiltrated. Therefore, if waters were recharged in a climatic regime different from the current regime, this fact should be reflected in the isotope ratios of the groundwaters.

The activity of ${ }^{14} \mathrm{C}$ in a particular groundwater sample potentially offers a more direct indication of the time at which that groundwater was recharged. In general, the older the sample, the lower the ${ }^{14} \mathrm{C}$ activity. However, the interpretation of the age of a groundwater sample from ${ }^{14} \mathrm{C}$ activity data is complicated by the fact that groundwaters can undergo soil-water-rock-gas interactions that can alter the proportions of carbon isotopes in a groundwater sample. This process, in turn, can lead to modification of the age calculated for the sample based on ${ }^{14} \mathrm{C}$ activity as discussed further below.

Table A6-6. Recharge Rates Based on the Chloride Mass Balance Method

\begin{tabular}{|c|c|c|c|}
\hline \multirow[b]{2}{*}{ Well Identifier } & \multirow{2}{*}{$\begin{array}{c}\text { Chloride } \\
\text { concentration } \\
\text { (mg/L) }\end{array}$} & \multicolumn{2}{|c|}{ Apparent Recharge Rate ${ }^{a}$ (mm/year) } \\
\hline & & Rate 1 & Rate 2 \\
\hline G-2 & 6.5 & 7.8 & 15.7 \\
\hline UZ-14 (sh) & 6.9 & 7.4 & 14.8 \\
\hline $\mathrm{H}-1$ (Tcp) & 5.7 & 8.9 & 17.9 \\
\hline $\mathrm{b \# 1(bh)}$ & 10.8 & 4.7 & 9.4 \\
\hline $\mathrm{c} \# 1$ & 7.4 & 6.9 & 13.8 \\
\hline $\mathrm{C \# 2}$ & 7.1 & 7.2 & 14.4 \\
\hline $\mathrm{c} \# 3$ & 7.2 & 7.1 & 14.2 \\
\hline C\#3('95-97) & 6.5 & 7.8 & 15.7 \\
\hline ONC\#1 & 7.1 & 7.2 & 14.4 \\
\hline $\mathrm{p} \# 1(\mathrm{v})^{\mathrm{b}}$ & 13.0 & 3.9 & 7.8 \\
\hline G-4 & 5.9 & 8.6 & 17.3 \\
\hline $\mathrm{H}-3$ & 9.5 & 5.4 & 10.7 \\
\hline $\mathrm{H}-4$ & 6.9 & 7.4 & 14.8 \\
\hline $\mathrm{H}-5$ & 6.1 & 8.4 & 16.7 \\
\hline UZ\#16 & 10.6 & 4.8 & 9.6 \\
\hline WT\#12 & 7.8 & 6.5 & 13.1 \\
\hline
\end{tabular}


Table A6-6. Recharge Rates Based on the Chloride Mass Balance Method (Continued)

\begin{tabular}{|c|c|c|c|}
\hline & \multirow{2}{*}{$\begin{array}{c}\text { Chloride } \\
\text { Concentration } \\
\text { Well Identifier }\end{array}$} & \multicolumn{2}{|c|}{ Apparent Recharge Rate $^{\mathbf{a}}$ (mm/year) } \\
\cline { 3 - 4 } & (mg/L) & Rate 1 & Rate 2 \\
\hline WT-17 & 6.4 & 7.7 & 15.5 \\
\hline WT\#3 & 6.0 & 8.2 & 16.5 \\
\hline
\end{tabular}

Source: Table A6-1.

${ }^{a}$ Infiltration rates were calculated based on equation (7). Rate 1 is calculated using the lower estimate for $\mathrm{Cl}^{-}$concentration in precipitation $(0.3 \mathrm{~g} / \mathrm{L})$; Rate 2 is calculated using the higher estimate $(0.6 \mathrm{mg} / \mathrm{L})$. Recharge estimates obtained by the CMB method are based on Table A5-1, Assumption 5.

b Approximately 28.6 percent of the water in this sample is from upward flow in the borehole from the carbonate aquifer (Craig and Robison 1984 [DIRS 101040], p. 49).

\section{A6.3.6.6.1 Evidence for the Timing of Recharge from Hydrogen and Oxygen Isotope Ratios}

Many of the effects of seasonal and long-term temperature changes on hydrogen and oxygen values in groundwater described in Section A6.3.1.2.1 have been reported for the Yucca Mountain area. Benson and Klieforth (1989 [DIRS 104370], Figure 11) noted a correlation between $\delta^{18} \mathrm{O}$ values and the ${ }^{14} \mathrm{C}$ age of groundwaters near Yucca Mountain. Waters are lighter in $\delta^{18} \mathrm{O}$ with increasing age between 9,000 and 18,500 years ago, a trend they attributed to the colder temperatures existing at the time the older water was recharged. Variations in the $\delta^{18} \mathrm{O}$ compositions of groundwater discharging in the Ash Meadows area at Devils Hole 55-km southeast of Yucca Mountain were preserved in calcites deposited between 570,000 and 60,000 years before the present (Winograd et al. 1992 [DIRS 100094], Figures 2 and 3). These variations were shown to correlate well with known glacial and interglacial episodes during the period of record, with $\delta^{18} \mathrm{O}$ decreasing, on average, by 1.9 per mil during glacial periods.

The $\delta \mathrm{D}$ and $\delta^{18} \mathrm{O}$ values of regional groundwater samples and perched-water samples at Yucca Mountain are plotted in Figure A6-48. The modern global meteoric water line $\left(\delta \mathrm{D}=8 \delta^{18} \mathrm{O}+10.0\right)$ shown on Figure A6-48 is approximately equal to the local Yucca Mountain meteoric water line $\left(\delta \mathrm{D}=8 \delta^{18} \mathrm{O}+8.9\right)$ as defined by Benson and Klieforth (1989 [DIRS 104370], Figure 14) from snow samples obtained from Yucca Mountain. Snow samples were used to define the local meteoric water line because these samples were less likely to be affected by evaporation than rain samples, especially samples of light summer rains that can have a substantial fraction of their volume evaporated before reaching the ground. A paleometeoric water line of $\delta \mathrm{D}=8 \delta^{18} \mathrm{O}+5.0$ was suggested by White and Chuma (1987 [DIRS 108871], pp. 573 to 574) to fit data from the Amargosa Desert and Oasis Valley.

Although considerable variability in $\delta \mathrm{D}$ and $\delta^{18} \mathrm{O}$ values is evident in Figure A6-48, much of this variability is attributable to the heavy $\delta \mathrm{D}$ and $\delta^{18} \mathrm{O}$ values of the FMW-N samples and the light $\delta \mathrm{D}$ and $\delta^{18} \mathrm{O}$ values of the TM samples. The Yucca Mountain groundwaters (YM groupings only) and most perched waters (excluding NRG-7a and one UZ-14 sample) vary in $\delta \mathrm{D}$ by about 13 per mil and in $\delta^{18} \mathrm{O}$ by about 1 per mil. The high ${ }^{14} \mathrm{C}$ activities associated with the 
FMW-N groundwater and the low ${ }^{14} \mathrm{C}$ activities associated with the TM groundwater suggest that some of the differences between the $\delta \mathrm{D}$ and $\delta^{18} \mathrm{O}$ values in these groups is attributable to changes in the $\delta \mathrm{D}$ and $\delta^{18} \mathrm{O}$ composition in response to climate change, with the heavy values representing the composition of groundwater recharged under the modern climate.

Because the groundwaters shown in Figure A6-48 probably originated from different recharge areas and recharge elevations, the effects of climate-induced changes and these other factors are mixed. The effects of time- and climate-induced changes on $\delta \mathrm{D}$ and $\delta^{18} \mathrm{O}$ composition can be isolated from these other effects by examining the changes in the composition of pore and perched water with depth in the unsaturated zone at Yucca Mountain (Figure A6-48). In this case, because all of the perched and pore-water data from borehole UZ-14 probably originated close to the borehole, the effects of spatial and elevation distributions of recharge are minimal. At borehole UZ-14, the pore-water data from borehole UZ-14 show a general trend of lighter $\delta \mathrm{D}$ and $\delta^{18} \mathrm{O}$ in the deeper (Tac and Tcp) pore waters and heavier $\delta \mathrm{D}$ and $\delta^{18} \mathrm{O}$ in shallow pore waters (PTn). The shallow pore water that results from infiltration at Yucca Mountain is similar in $\delta \mathrm{D}$ and $\delta^{18} \mathrm{O}$ composition to the modern groundwater from upper Fortymile Canyon, suggesting that the $\delta \mathrm{D}$ and $\delta^{18} \mathrm{O}$ composition of modern precipitation is similar in both locations. Note that none of the pore-water data in Figure A6-48 show systematic trends that indicate evaporative effects (Section A6.3.1.2.1, Figure A6-4). This observation suggests that the relatively high pore-water salinities observed in the shallow part of this borehole (Yang et al. 1996 [DIRS 100194], Table 3), and perhaps other parts of Yucca Mountain, are due to plant transpiration rather than evaporation (Section A6.3.1.2.1). Other groundwaters from the Yucca Mountain area, like those in the FMW-S group, may indicate more significant evaporative effects (Figure A6-48).

Perched waters from UZ-14 have $\delta \mathrm{D}$ and $\delta^{18} \mathrm{O}$ compositions that are intermediate between the shallow and deep pore waters. The deep pore water from the relatively impermeable Tac unit is lighter than the pore water from the underlying, but more permeable Tcp unit, suggesting that it has been more difficult to flush the older, lighter pore water in the Tac with younger water (Yang et al. 1998 [DIRS 101441]). The pore-water data indicate that groundwater from the YM-C and YM-SE is similar in composition to the deep pore water from the Tac unit at borehole UZ-14, supportive of their possible origin from local recharge. The decrease in $\delta^{18} \mathrm{O}$ composition of about 2 per mil between the shallow pore water and the deep pore-water and Yucca Mountain groundwater compositions from the YM-CR, YM-C and YM-SE groupings is comparable to the approximately 1.9 per mil differences in calcite $\delta^{18} \mathrm{O}$ composition at Devils Hole (Winograd et al. 1992 [DIRS 100094], Figure 2) for glacial and subsequent interglacial periods, suggesting the deep pore water and Yucca Mountain groundwater were recharged under a paleoclimatic conditions that existed until the late Pleistocene. 


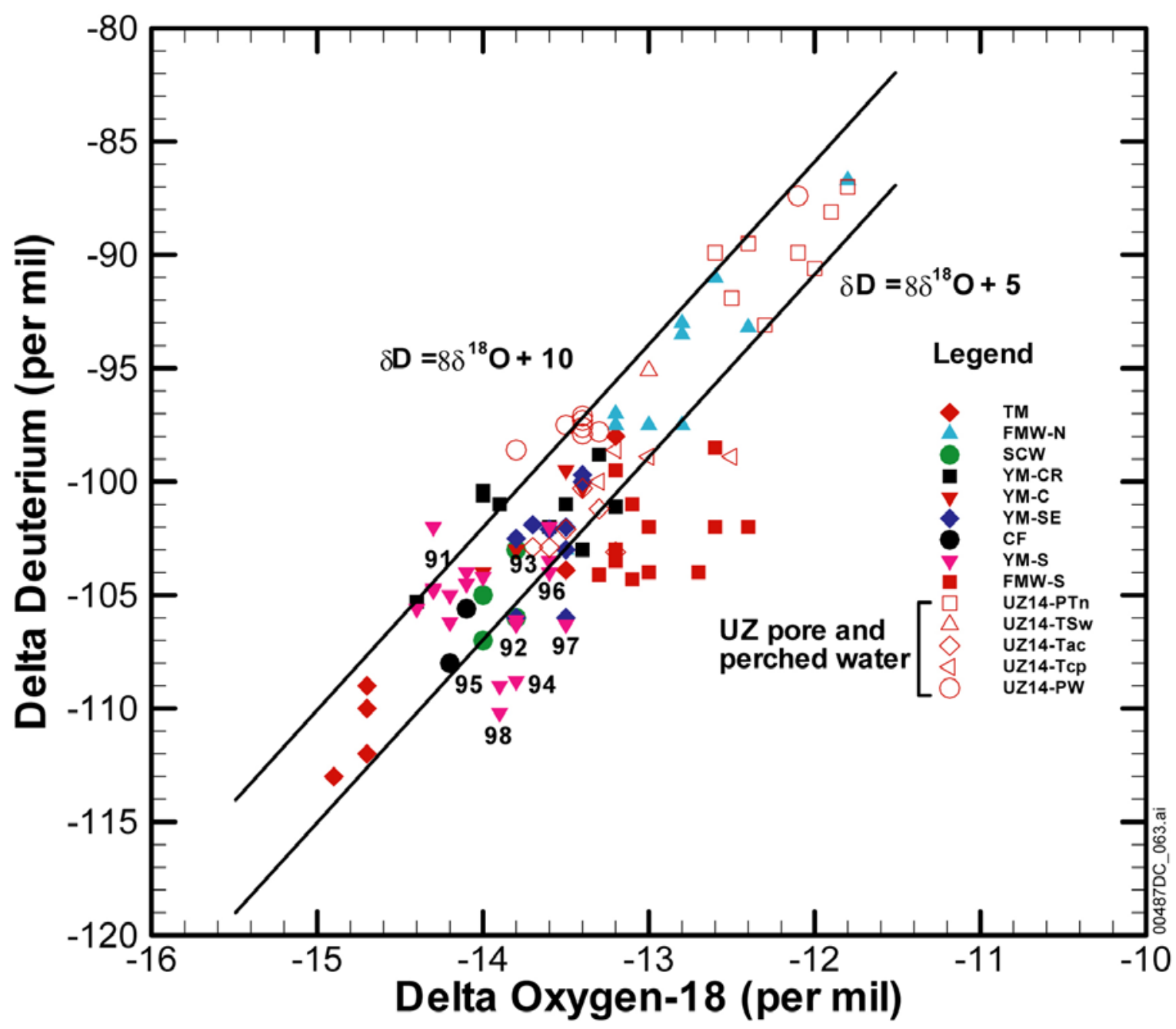

DTN: GS990308312272.002 [DIRS 145692.

Source: Tables A6-2 and A6-5; pore-water data for borehole UZ-14 are from Yang et al. (1998 [DIRS 101441] Tables 9-12).

NOTE: This figure has color-coded data points and should not be read in a black and white version. The solid lines are the global meteoric water line $\left(\delta \mathrm{D}=8 \delta^{18} \mathrm{O}+10\right)$ (Clark and Fritz 1997 [DIRS 105738], p. 36) and a possible paleometeoric water line for southern Nevada $\left(\delta \mathrm{D}=8 \delta^{18} \mathrm{O}+5\right)$ (White and Chuma 1987 [DIRS 108871], pp. 573 to 574).

Figure A6-48. Delta Deuterium and Delta ${ }^{18} \mathrm{O}$ Data for Borehole UZ-14 Unsaturated Zone Pore Water, Perched Water, and Groundwater near Yucca Mountain

In contrast, some of the YM-S area groundwater does not overlap with the deep pore-water data from the borehole, raising doubts as to whether it originated predominantly from Yucca Mountain recharge. Many groundwaters from the YM-S group, including Sites 91 (NC-EWDP-2D) and 92 (NC-EWDP-19D composite) near Fortymile Wash are isotopically similar to groundwaters in the Crater Flat (CF) and Solitario Canyon Wash (SCW) groups. Groundwaters from Sites 93 (NC-EWDP-19P) and 96 (NC-EWDP-19D Zone 2) plot nearer to the deep pore water from borehole UZ-14. The remaining groundwater samples from NC-EWDP-19D (Sites 94, 95, 97, and 98) have no clear affinity with groundwater from other 
areas. In general, it does not appear likely from the $\delta \mathrm{D}$ and $\delta^{18} \mathrm{O}$ compositions that groundwater from wells NC-EWDP-2D or NC-EWDP-19D originated from present or paleorecharge along Fortymile Wash, based on the lack of overlap between data from these sites and data from the FMW-N and FMW-S groups. However, for groundwaters from Sites 93 (NC-EWDP-19P) and 96 (NC-EWDP-19D Zone 2), the $\delta \mathrm{D}$ and $\delta^{18} \mathrm{O}$ data do not obviously rule out an origin from paleorecharge along Fortymile Wash.

\section{A6.3.6.6.2 Evidence for the Timing of Recharge from Carbon Isotope Data}

As is discussed in Section A6.3.1, the ${ }^{14} \mathrm{C}$ ages of groundwater are susceptible to modification through water-rock reactions. Nonetheless, various observations indicate that the ${ }^{14} \mathrm{C}$ ages of the perched-water samples do not require substantial correction for the dissolution of carbonate. First, the ratios of ${ }^{36} \mathrm{Cl}$ to stable chlorine $\left({ }^{36} \mathrm{Cl} / \mathrm{Cl}\right)$ of the perched-water samples are similar to those expected for their uncorrected ${ }^{14} \mathrm{C}$ age, based on reconstructions of ${ }^{36} \mathrm{Cl} / \mathrm{Cl}$ ratios in precipitation throughout the late Pleistocene and Holocene from packrat midden data (Plummer et al. 1997 [DIRS 107034], Figure 3; DTNs: LAJF831222AQ97.002 [DIRS 145401], GS950708315131.003 [DIRS 106516], and GS960308315131.001 [DIRS 106517]). Second, Winograd et al. (1992 [DIRS 100094], Figure 2) presented data from calcite deposits that indicated the $\delta^{18} \mathrm{O}$ values in precipitation during the Pleistocene were, on average, 1.9 per mil more depleted during pluvial periods compared to interpluvial periods. The $\delta^{18} \mathrm{O}$ values of the perched-water samples generally are more depleted than pore-water samples from the shallow unsaturated zone at Yucca Mountain by more than 1.0 per mil (Figure A6-48). This consistent difference suggests that, at some boreholes, the perched water may contain a substantial component of water from the Pleistocene.

Values for $\delta^{13} \mathrm{C}$ and ${ }^{14} \mathrm{C}$ in perched waters and groundwaters from the Yucca Mountain area are plotted in Figure A6-45. Excluding the perched-water and the Fortymile Wash area (FMW-N) samples, the $\delta^{13} \mathrm{C}$ and ${ }^{14} \mathrm{C}$ values reported for the groundwater samples are negatively correlated. In the absence of chemical reactions and/or mixing, waters moving from source areas to Yucca Mountain should experience no change in $\delta^{13} \mathrm{C}$, but their ${ }^{14} \mathrm{C}$ activity should decrease with time. If waters infiltrating into the source area had more or less constant $\delta^{13} \mathrm{C}$ values, data points for waters infiltrated at different times would form a vertical trend in Figure A6-45. The fact that the data points in the figure do not form a vertical trend suggests either that the $\delta^{13} \mathrm{C}$ of waters infiltrated at the source areas are not constant or that chemical reactions or mixing have affected the carbon isotope values. If waters that infiltrate into the source areas have randomly variable $\delta^{13} \mathrm{C}$ ratios, then a random relation between $\delta^{13} \mathrm{C}$ and ${ }^{14} \mathrm{C}$ values would be expected. Rather the $\delta^{13} \mathrm{C}$ and ${ }^{14} \mathrm{C}$ values for Yucca Mountain and Crater Flat groundwaters are well correlated as shown in Figure A6-45.

It has been noted that $\delta^{13} \mathrm{C}$ values in infiltrating waters reflect the types of vegetation present at the infiltration point. According to the data of Quade and Cerling (1990 [DIRS 100073], p. 1550), the $\delta^{13} \mathrm{C}$ of modern water infiltrated in cooler climates (for example, at higher elevations) is more negative than for modern water infiltrated in warmer climates (for example, at lower elevations). The change from a relatively wet, cool climate to a relatively warm, dry climate at the end of the Pleistocene would be expected to exert a similar effect on the $\delta^{13} \mathrm{C}$ of infiltration as elevation does on modern infiltration. In other words, Pleistocene infiltration 
would be expected to have lighter $\delta^{13} \mathrm{C}$ than modern infiltration at the same elevation. However, both a climate induced change in $\delta^{13} \mathrm{C}$ values, or recharge from a distant, high-elevation source would result in a positive correlation in Figure A6-45 because the older samples (that is, lowest pmc) plotted would tend to have the most negative $\delta^{13} \mathrm{C}$ (that is, they infiltrated when the climate was cooler than it is now or in distant, high-elevation areas). Because the observed correlation in the groundwater values is negative instead of positive, the primary cause of the correlation must involve some other process(es). Both calcite dissolution and mixing with groundwater from the carbonate aquifer are possible explanations for this observed trend. Both of these processes would tend to introduce DIC with heavy $\delta^{13} \mathrm{C}$ and little ${ }^{14} \mathrm{C}$. The importance of each process probably varies spatially and can be assessed by determining if increases in other ions and isotopes present at high concentrations in the carbonate aquifer are evident in the groundwater.

A likely cause of the negative correlation evident in Figure A6-45 is the dissolution of carbonate minerals such as calcite. For example, calcite with a $\delta^{13} \mathrm{C}$ value of -4 per mil and a ${ }^{14} \mathrm{C}$ activity of zero could readily explain the correlation if it were being dissolved by infiltrating soil waters. This explanation assumes that points on the regression line are of the same age but that the water dissolved different amounts of calcite. In this explanation, the scatter of points about the regression line could represent samples of slightly different ages. For example, $\delta \mathrm{D}$ and $\delta^{18} \mathrm{O}$ data suggest that groundwaters from the northern part of Fortymile Wash (FMW-N) and the perched waters have younger ages than most Yucca Mountain groundwaters. This observation is consistent with the data plotted in Figure A6-45.

The data points for groundwater from the FMW-N grouping with high ${ }^{14} \mathrm{C}$ activities (Sites 30 to 32) are of particular interest because they represent recent infiltration based on their high tritium and ${ }^{36} \mathrm{Cl}$-to-chloride ratios (DTN: LAJF831222AQ98.011 [DIRS 145402]). As shown in Figure A6-45, the ${ }^{14} \mathrm{C}$ activities in these samples vary between 60 and 75 pmc. This result suggests these samples obtained a significant fraction of their bicarbonate concentrations from a source with little or no ${ }^{14} \mathrm{C}$ activity. Interestingly, these samples have lower $\delta^{13} \mathrm{C}$ values than most groundwaters from the Yucca Mountain area. This result suggests the bicarbonate source was not calcite typical of the soil zone on Yucca Mountain, as these have $\delta^{13} \mathrm{C}$ values between -2 and -8 per mil (Whelan et al. 1998 [DIRS 137305], Figure 5).

In instances where the recharge source for a groundwater can be identified, it is possible to estimate the extent to which the ${ }^{14} \mathrm{C}$ activity of the groundwater has been lowered through water/rock interactions in the saturated zone by comparing the DIC concentrations of the recharge $\left(D I C_{\text {rech }}\right)$ and the downgradient groundwater $\left(D I C_{\mathrm{gw}}\right)$ (Clark and Fritz 1997 [DIRS 105738], Chapter. 8). The downgradient increase in $D I C_{\mathrm{gw}}$ relative to $D I C_{\text {rech }}$ represents the extent to which mineral sources of carbon have been added to the groundwater. These mineral sources of carbon may have diluted the initial ${ }^{14} \mathrm{C}$ activity of the recharge by the addition of ${ }^{14} \mathrm{C}$-free carbon. The extent of this dilution and its effect on the calculated groundwater ${ }^{14} \mathrm{C}$ age can be represented by a correction factor $\left(q_{\mathrm{DIC}}=D I C_{\mathrm{rech}} / D I C_{\mathrm{gw}}\right)$ which is then applied to the radioactive decay equation to calculate the corrected ${ }^{14} \mathrm{C}$ age, as indicated in footnote (b) to Table A6-9. The basis for the equations given in footnote (b) and their limitations are described in more detail in Section A6.3.9. 
As described in Sections A6.3.6.2 to A6.3.6.4, evidence exists that some groundwater samples from Yucca Mountain originated almost exclusively from recharge through Yucca Mountain itself. Corrections were made to groundwater ${ }^{14} \mathrm{C}$ ages at locations within $18-\mathrm{km}$ of the repository where groundwater had been identified from anomalously high ${ }^{234} U /{ }^{238} \mathrm{U}$ ratios as having originated mostly from local recharge (Paces et al. 1998 [DIRS 100072]; see also Table A6-5). Corrections were also made to the ${ }^{14} \mathrm{C}$ ages of groundwater from several locations for which ${ }^{234} \mathrm{U} /{ }^{238} \mathrm{U}$ activity ratios were not measured, but which may contain substantial fractions of local Yucca Mountain recharge based on proximity to groundwater with high ${ }^{234} \mathrm{U} /{ }^{238} \mathrm{U}$ activity ratios. For these samples, total DIC concentrations, calcite saturation indices, and logarithms of the partial pressure of carbon dioxide $\left(\log P_{\mathrm{CO}_{2}}\right)$ were computed with PHREEQC (DTN: MO0309THDPHRQC.000 [DIRS 165529]). In these corrections, the values of $D I C_{\text {rech }}$ are allowed to vary between 128.3 and $144 \mathrm{mg} / \mathrm{L}$ bicarbonate $\left(\mathrm{HCO}_{3}{ }^{-}\right)$, based on values measured in perched water at Yucca Mountain (Yang et al. 1996 [DIRS 100194]; Table A6-5). The correction factor $q_{D I C}$ ranges from 0.74 at borehole WT\#12 to 1.0 at several boreholes (Table A6-5). Corrected groundwater ${ }^{14} \mathrm{C}$ ages range from 11,430 years at borehole WT\#3 to 16,390 years at borehole WT\#12 (Table A6-7). These calculations show that only minor corrections to the groundwater ${ }^{14} \mathrm{C}$ ages are necessary for samples located along the estimated flow path from the repository (see below).

Table A6-7. Chemistry and Ages of Groundwaters from Seven Boreholes at Yucca Mountain

\begin{tabular}{|c|c|c|c|c|c|c|c|c|}
\hline Borehole & $\begin{array}{c}{ }^{234} \mathrm{U} /^{238} \mathrm{U} \\
\text { Activity } \\
\text { Ratio }\end{array}$ & $\begin{array}{c}{ }^{14} \text { C Activity } \\
\text { (pmc) }\end{array}$ & $\begin{array}{l}\mathrm{DIC}, \text { as } \\
\mathrm{HCO}_{3}^{-} \\
\text {( } \mathrm{mg} / \mathrm{L})\end{array}$ & $\begin{array}{c}\log P_{\mathrm{cO} 2} \\
(\text { atm) }\end{array}$ & $\begin{array}{c}\log \\
\left(I A P I K_{\text {cal }}\right)^{a}\end{array}$ & $\begin{array}{c}\text { Factor } \\
q_{D I C}\end{array}$ & $\begin{array}{c}\text { Corrected } \\
\text { Age }(y r){ }^{14} \mathrm{C}\end{array}$ & $\begin{array}{l}\text { Uncorrected } \\
{ }^{14} \mathrm{C} \text { Age (yr) }\end{array}$ \\
\hline G-2 & 7.6 & 20.5 & 127.6 & -2.352 & -0.791 & 1 & 13,100 & 13,100 \\
\hline WT-17 & 7.6 & 16.2 & 150.0 & -1.958 & -1.175 & $0.86-0.96$ & $\begin{array}{l}13,750- \\
14,710\end{array}$ & 15,040 \\
\hline WT\#3 & 7.2 & 22.3 & 144.3 & -2.413 & -0.515 & $0.89-1.0$ & $\begin{array}{l}11,430- \\
12,380\end{array}$ & 12,400 \\
\hline WT\#12 & 7.2 & 11.4 & 173.9 & -2.327 & -0.313 & $0.74-0.83$ & $\begin{array}{l}15,430- \\
16,390\end{array}$ & 17,950 \\
\hline c\#3 & 8.1 & 15.7 & 140.2 & -2.458 & -0.319 & $0.92-1.0$ & $\begin{array}{l}14,570- \\
15,300\end{array}$ & 15,300 \\
\hline$b \# 1(T c b)^{d}$ & - & 18.9 & 152.3 & -1.892 & -0.757 & $0.84-0.95$ & $\begin{array}{l}12,350- \\
13,300\end{array}$ & 13,770 \\
\hline G-4 & - & 22.0 & 142.8 & -2.490 & -0.305 & $0.90-1.0$ & $\begin{array}{l}11,630- \\
12,510\end{array}$ & 12,500 \\
\hline
\end{tabular}

DTN: LA0202EK831231.002 [DIRS 165507].

Source: Tables A6-1 and A6-2;

${ }^{a} \log \left(I A P / K_{\text {cal }}\right)$ is the calcite saturation index. Negative values indicate undersaturation with calcite.

${ }^{b}$ The corrected age is calculated by multiplying the initial ${ }^{14} \mathrm{C}$ activity $\left({ }^{14} A_{0}\right)$ in Equation $A 6-3$ by $q_{\text {DIC }}: t=(-1 / \lambda)$ In

$\left({ }^{14} A /\left({ }^{14} A_{0} q_{D I C}\right)\right)$. The factor $q_{D I C}$ is calculated as $q_{D I C}=D / C_{\text {rech }} / D / C_{\text {gw }}$, where the subscripts rech and $g w$ indicate the DIC of recharge and downgradient groundwater.

${ }^{c}$ Calculated from Equation A6-3.

${ }^{d}$ The sample from borehole $b \# 1$ came from the Bullfrog tuff $(T c b)$. 


\section{A6.3.6.7 Calculations to Determine the Fraction of Young Water in Yucca Mountain Recharge}

Given that groundwater samples at Yucca Mountain were often pumped over large depth intervals that mixed shallow and deep water (Table A4-3), it may be difficult to demonstrate conclusively that groundwater does not contain a small fraction of young water. In this section, however, calculations are performed to bound the maximum percentage of young water that could be present in the sampled groundwater.

Recharge at Yucca Mountain has probably been continuous in time, so that the measured groundwater ${ }^{14} \mathrm{C}$ activities result from the mixing of recharge (and possibly groundwater from other areas) having a broad range of ages (Campana and Byer 1996 [DIRS 126814], Figure 5). However, because data on the temporal distribution of recharge, mixing depth, and storage volume required for more detailed analyses are lacking, the fraction of young water in a groundwater sample is calculated in this section by idealizing individual groundwater samples as a binary mixture of younger and older groundwaters. Young water is arbitrarily defined as having a ${ }^{14} \mathrm{C}$ age, or residence time, of less than 1,000 years. In a binary mixture, the total number of ${ }^{14} \mathrm{C}$ atoms in the mixture depends on the ${ }^{14} \mathrm{C}$ activities, volume fractions, and total DIC concentrations of the two components, which in this case, are taken to be young and old waters:

$$
\left({ }^{14} C_{\text {mix }}\right)\left(D I C_{\text {mix }}\right)=\left(X_{\text {young }}\right)\left({ }^{14} C_{\text {young }}\right)\left(D I C_{\text {young }}\right)+\left(X_{\text {old }}\right)\left({ }^{14} C_{\text {old }}\right)\left(D I C_{\text {old }}\right)
$$

where

${ }^{14} \mathrm{C}=$ the ${ }^{14} \mathrm{C}$ activity (in pmc)

$D I C_{i}=$ dissolved inorganic carbon concentration $(\mathrm{mg} / \mathrm{L})$ of component $i$

$X_{i}=$ the volume fraction of component $i$

mix, young, and old = mixed, young, and old components of the groundwater.

The volume fractions sum to one, so that $X_{\text {old }}=1-X_{\text {young. }}$ Equation A6-8 can be solved for $X_{\text {young: }}$

$$
X_{\text {young }}=\frac{\left({ }^{14} C_{\text {mix }}\right)\left(D I C_{\text {mix }}\right)-\left({ }^{14} C_{\text {old }}\right)\left(D I C_{\text {old }}\right)}{\left({ }^{14} C_{\text {young }}\right)\left(D I C_{\text {young }}\right)-\left({ }^{14} C_{\text {old }}\right)\left(D I C_{\text {old }}\right)}
$$

The ${ }^{14} \mathrm{C}$ activity of 1,000 -year-old water with an initial ${ }^{14} \mathrm{C}$ activity of $100 \mathrm{pmc}$ is equal to 88.6 pmc. $D I C_{\text {young }}$ is expressed in these calculations as equivalent to $\mathrm{mg} / \mathrm{L} \mathrm{HCO}_{3}^{-}$and is assigned a value of $130 \mathrm{mg} / \mathrm{L}$ based on the typical alkalinity of many perched-water samples (Table A6-5). For samples with $\mathrm{pH}$ values above 7, which include perched water from the unsaturated zone at Yucca Mountain, alkalinity is approximately equal to the total DIC (Drever 1988 [DIRS 118564], p. 51). The value for ${ }^{14} C_{\text {old }}$ was assigned a value of $10 \mathrm{pmc}$, which is approximately the lowest value measured in groundwater from the volcanic aquifer at Yucca Mountain (boreholes H-3 (10.5 pmc) and H-4 (11.8 pmc)). 
Calculations of the possible fraction of young water in a sample (age less than 1,000 years) considered various DIC concentrations for the old component in the mixed water (Table A6-8). In Case 1, the DIC concentrations of the water components (mixed, old, and young) are assigned to be essentially equal, so that $X_{\text {young }}$ depends only on values of ${ }^{14} C$. In Case 2 , a moderately high value of $175 \mathrm{mg} / \mathrm{L} \mathrm{HCO}_{3}^{-}$was assigned for $D I C_{\text {old. }}$ In Case 3, a value of $225 \mathrm{mg} / \mathrm{L} \mathrm{HCO}_{3}{ }^{-}$was assigned for $D I C_{\text {old }}$. For Case 1, the calculated values of $X_{\text {young }}$ range from about 0.02 (borehole WT\#12) to 0.16 (boreholes WT\#3 and G-4). For Case 2, the range of values for $X_{\text {young }}$ is similar to, but slightly lower than, those from Case 1. In Case 3, the calculated values for $X_{\text {young }}$ were lower than those from Cases 1 and 2, and three values were negative, which indicates that the value of $225 \mathrm{mg} / \mathrm{L} \mathrm{HCO}_{3}{ }^{-}$for $D I C_{\text {old }}$ was too high to be generally applicable.

Table A6-8. Sensitivity of the Permissible Fraction of Young Water Present in Groundwater to Dissolved Inorganic Carbon Concentration Assumed for the Old Component of the Mixed Groundwater

\begin{tabular}{|c|c|c|c|c|c|}
\hline Borehole & $\begin{array}{c}\text { Sample }{ }^{14} C \\
(\text { pmc })\end{array}$ & $\begin{array}{c}\text { Sample } D I C \\
\left(\mathrm{mg} / \mathrm{L} \mathrm{HCO}_{3}^{-}\right)\end{array}$ & $\begin{array}{c}X_{\text {young }} \\
(\text { Case 1)* }\end{array}$ & $\begin{array}{c}X_{\text {young }} \\
(\text { Case 2)* }\end{array}$ & $\begin{array}{c}X_{\text {young }} \\
\text { (Case 3)* }\end{array}$ \\
\hline G-2 & 20.5 & 127.6 & 0.134 & 0.089 & 0.039 \\
\hline WT\#12 & 11.4 & 173.9 & 0.018 & 0.024 & -0.029 \\
\hline WT-17 & 16.2 & 150.0 & 0.079 & 0.070 & -0.019 \\
\hline WT\#3 & 22.3 & 144.3 & 0.156 & 0.150 & 0.104 \\
\hline C\#3 & 15.7 & 140.2 & 0.073 & 0.046 & -0.005 \\
\hline $\mathrm{b \# 1}$ (Tcb) & 18.9 & 152.3 & 0.113 & 0.116 & 0.068 \\
\hline G-4 & 22.0 & 142.8 & 0.153 & 0.142 & 0.096 \\
\hline
\end{tabular}

Output DTN: LA0202EK831231.004.

Source: Tables A6-1 and A6-2

NOTES: Table values were calculated based on data in Tables A6-1 and A6-2, Equation A6-9, and parameter values given in the text. Young groundwater is defined as less than 1,000 year old.

${ }^{*}$ Case 1: $D I C_{\text {old }}=D I C_{\text {young }}=D I C_{\text {mix }} ;$ Case 2: $D I C_{\text {old }}=175 \mathrm{mg} / \mathrm{L} \mathrm{HCO}_{3}{ }^{-} ;$Case 3: $D I C_{\text {old }}=225 \mathrm{mg} / \mathrm{L} \mathrm{HCO}_{3}$.

Sensitivity studies were conducted to examine the effects of assigning variable values of ${ }^{14} C_{\text {old }}$ with $D I C_{\text {old }}=175 \mathrm{mg} / \mathrm{L} \mathrm{HCO}_{3}{ }^{-}$. Results of these studies show that the calculated values of $X_{\text {young }}$ are somewhat sensitive to the value of ${ }^{14} C_{\text {old }}$ (Table A6-9). Using ${ }^{14} C_{\text {old }}=5$ pmc (Case 4) more than doubles the calculated value of $X_{\text {young }}$ at many boreholes; however, values less than 10 pmc have not been observed at Yucca Mountain, so a value for ${ }^{14} C_{\text {old }}$ of 5 pmc is considered unrealistic. A value for ${ }^{14} C_{\text {old }}$ of 15 pmc (Case 5) is also generally unrealistic, given the many negative values calculated for $X_{\text {young. }}$.

In summary, it is possible that a small fraction of young water (less than 1,000-year-old) is present in the saturated zone downgradient from the repository area. Estimates range from a low of about 0.02 at borehole WT\#12 to more than 0.15 at boreholes WT\#3 and G-4. Smaller fractions of young water would be estimated to be present if water younger than 1,000-year-old were assumed in the calculations. 
Table A6-9. Sensitivity of the Permissible Fraction of Young Water Present in Groundwater to the Assumed ${ }^{14} \mathrm{C}$ Activity of the Old Component of the Mixed Groundwater

\begin{tabular}{|l|c|c|c|c|c|}
\hline \multicolumn{1}{|c|}{ Borehole } & $\begin{array}{c}\text { Sample }{ }^{\mathbf{1 4}} \mathbf{C} \\
(\mathbf{p m c})\end{array}$ & $\begin{array}{c}\text { Sample DIC } \\
\left(\mathbf{m g / L ~ H C O}^{-} \text {) }\right.\end{array}$ & $\begin{array}{c}\boldsymbol{X}_{\text {young }} \\
(\text { Case 4) }\end{array}$ & $\begin{array}{c}\boldsymbol{X}_{\text {young }} \\
(\text { Case 2) }\end{array}$ & $\begin{array}{c}\boldsymbol{X}_{\text {young }} \\
(\text { Case 5) }\end{array}$ \\
\hline G-2 & 20.5 & 127.6 & 0.164 & 0.089 & -0.001 \\
\hline WT\#12 & 11.4 & 173.9 & 0.104 & 0.024 & -0.072 \\
\hline WT-17 & 16.2 & 150.0 & 0.146 & 0.070 & -0.022 \\
\hline WT\#3 & 22.3 & 144.3 & 0.220 & 0.150 & 0.067 \\
\hline C\#3 & 15.7 & 140.2 & 0.125 & 0.046 & -0.048 \\
\hline B\#1 (Tcb) & 18.9 & 152.3 & 0.188 & 0.116 & 0.029 \\
\hline G-4 & 22.0 & 142.8 & 0.213 & 0.142 & 0.058 \\
\hline
\end{tabular}

Output DTN: LA0202EK831231.004.

Source: Tables A6-1 and A6-2.

NOTES: Table values were calculated based on data in Tables A6-3 and A6-4, Equation A6-9, and assumptions given in the text. Young groundwater is defined as less than 1,000-year-old.

${ }^{*}$ Case 4: ${ }^{14} \mathrm{C}_{\text {old }}=5$ pmc; Case 2: ${ }^{14} \mathrm{C}_{\text {old }}=10 \mathrm{pmc}$; Case $5:{ }^{14} \mathrm{C}_{\text {old }}=15 \mathrm{pmc}$.

\section{A6.3.7 Hydrochemical Evidence for Mixing of Groundwater}

Groundwater chemical and isotopic compositions in the Yucca Mountain area exhibit both gradual and relatively abrupt spatial variability (Section A6.3.4) that may be related to mixing. Mixing may occur when (1) groundwater from adjacent flow paths is spread by dispersion and diffusion, (2) the groundwater passes beneath a recharge area, (3) deep groundwater moves upward because of head gradients, faults, or hydraulic barriers, or (4) groundwater from different areas converges toward either natural discharge areas or toward wells. Preliminary mixing relations are investigated in this section through scatterplots involving relatively nonreactive chemical and isotopic species like $\mathrm{Cl}^{-}, \mathrm{SO}_{4}{ }^{2-}, \delta \mathrm{D}$, and $\delta^{34} \mathrm{~S}$. Potential mixing relations identified through these scatterplots are further explored through the use of inverse geochemical models in Section A6.3.8 that seek to quantitatively explain groundwater chemical and isotopic evolution in terms of mixing and water-rock interactions.

\section{A6.3.7.1 Mixing Relations South of Yucca Mountain}

Groundwater samples from boreholes located south of Yucca Mountain that constitute the YM-S, CF, and CF-SW groupings show a wide range of solute concentrations that generally increase to the northwest. Scatter plots (Figure A6-49) illustrate the distinct hydrochemistry of

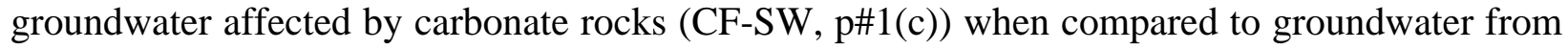
the volcanic or tuff-derived alluvial aquifers. In fact, samples from the CF-SW group define a trend with a dilute end member intersecting typical groundwater compositions of the volcanic aquifer at Yucca Mountain. Importantly, some samples from the YM-S group fall along this line. In the YM-S group, groundwaters from borehole NC-EWDP-9SX (Samples 81 to 85) are most similar to samples from the CF-SW group chemically and are also geographically proximal to the CF-SW wells to the north and west. It is interpreted that the hydrochemistry of samples from borehole NC-EWDP-9SX represents a mix of carbonate aquifer-like water from southwest Crater Flat and dilute groundwater from the volcanic aquifer. Samples 89 and 90 also plot along mixing lines between the volcanic aquifer and the carbonate aquifer-like groundwaters. Given 
the geographic position of these wells, it is unclear as to whether this carbonate aquifer-like water enters the system via upward gradient flow from depth or if it could be due to dispersive mixing of groundwater from the CF-SW Group. On the $\mathrm{Cl}^{-}$versus $\delta \mathrm{D}$ plot (Figure A6-49) groundwater from the YM-S group define a trend toward the CF-SW group, not toward the composition of $\mathrm{p \# 1}$ or deep groundwater from NC-EWDP-1DX Zone 2 (Site 74), indicating dispersive mixing rather than groundwater upwelling as the more likely hypothesis. The $\mathrm{Cl}^{-}$versus $\delta \mathrm{D}$ plot (Figure A6-49) also helps to eliminate the possibility that the compositional trends defined by these samples are due to water/rock interaction with alluvium that is increasingly dominated by carbonate detritus derived from Bare Mountain because $\delta \mathrm{D}$ is not affected by this process.

\section{A6.3.7.2 Evaluation of Mixing Relationships in the Amargosa Desert Region}

The different groundwater groupings in the Amargosa Desert display a great contrast in solute concentration and isotopic data (Section A6.3.4). Indeed, much of the hydrochemical variation displayed in areal plots of chemical and isotopic species is contained in the relatively small area of the Amargosa Desert. This pronounced contrast in hydrochemistry, along with the relatively dense sample distribution allows for detailed evaluation of possible mixing patterns.

Groundwater in the AR grouping is chemically quite distinct with relatively large concentrations of solutes compared to groundwater to the east in Amargosa Desert, and thus, it is readily distinguishable and traceable. East and southeast of the AR grouping the consistent and distinct character of this groundwater is absent. Mixing with the dilute groundwater that constitutes the FMW-W and FMW-S groupings readily explains this observation. On a plot of the conservative solutes $\mathrm{Cl}^{-}$and $\mathrm{SO}_{4}{ }^{2-}$ (Figure A6-50) the hydrochemically distinct groupings of the AR and FMW-S groupings is evident along with the trend displayed by some samples of the FMW-W group and all of the samples from the AR/FMW grouping. This relationship is taken as sound evidence that intermediate $\mathrm{Cl}^{-}$and $\mathrm{SO}_{4}{ }^{2-}$ compositions of $\mathrm{FMW}-\mathrm{W}$ and AR/FMW are a result of mixing of Amargosa Desert groundwater with dilute groundwater of the FMW-W grouping and/or FMW-S grouping (shown as mixing line 1, Mix 1, in Figure A6-50). This hypothesis is also supported by cross plots of other constituents. For example, although the number of samples is limited, Figure A6-51 shows the mixing relationships on a plot of $\delta^{34} \mathrm{~S}$ versus $1 / \mathrm{SO}_{4}{ }^{2-}$. On this plot, the few samples from FMW-W and AR/FMW are near the mixing line drawn between the FMW-S and AR samples (Mix 1). Scatter plots of other constituents show similar relations, although some deviations from the consistent trend displayed in Figure A6-50 suggest that water-rock interaction has modified the hydrochemistry in some samples. Hydrochemical data are interpreted to indicate that samples 121, 122, 125, and $126(\mathrm{FMW}-\mathrm{W})$ and most samples from the AR/FMW group represent mixtures of AR groundwater with FMW-S and/or dilute groundwater from FMW-W. Samples 139 and 134 from FMW-S also plot along mixing line 1 (Figure A6-50) suggesting that these samples also contain a small fraction of AR groundwater. These samples are among the more westerly in this grouping; thus, the geographic position is consistent with this mixing hypothesis. 

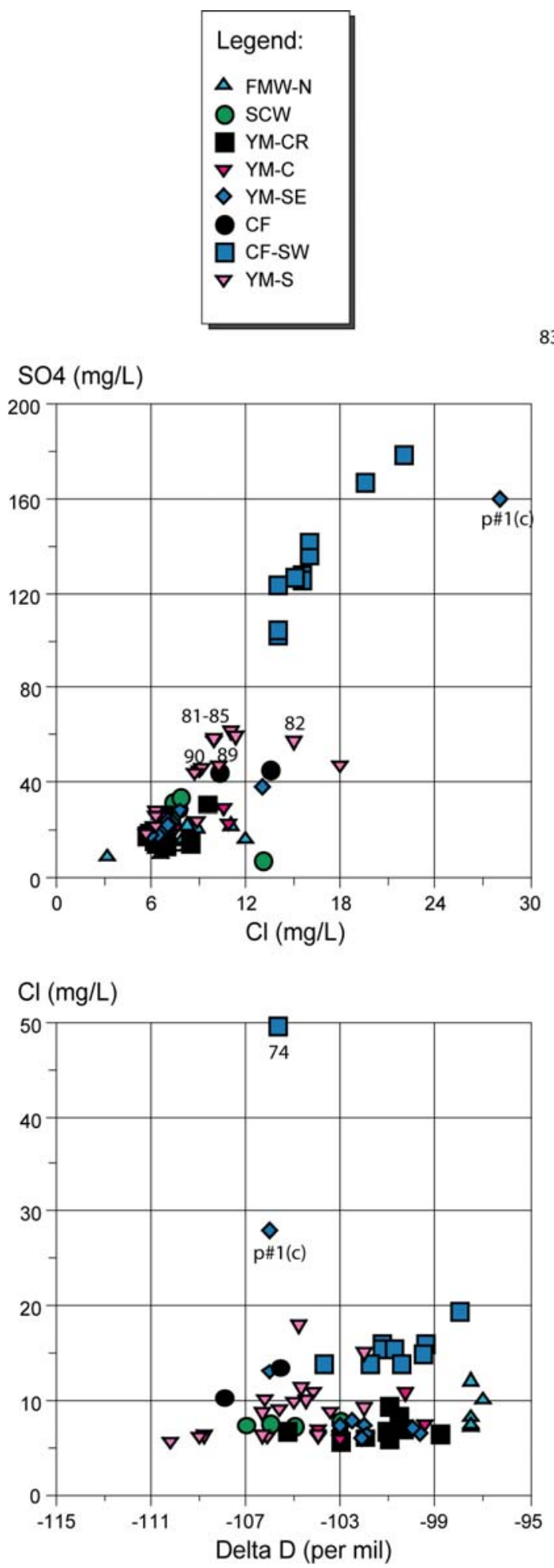

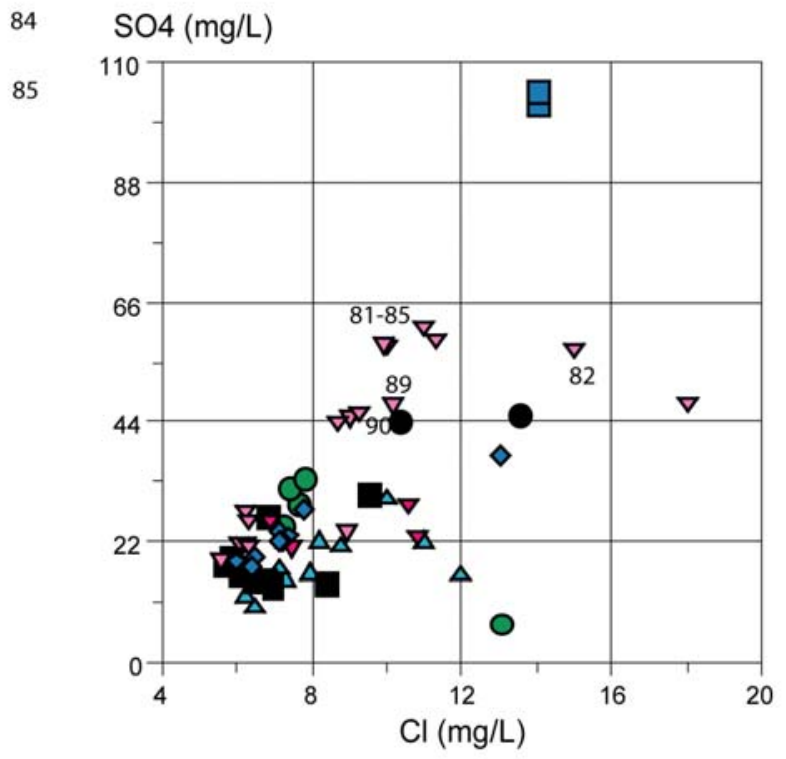

$\mathrm{Cl}(\mathrm{mg} / \mathrm{L})$

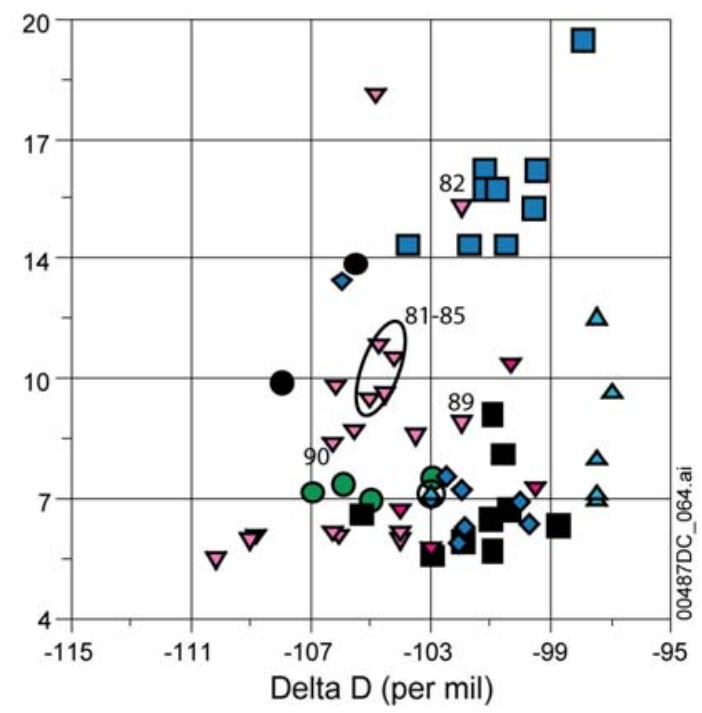

Source: Tables A6-1 and A6-2.

NOTE: The plots on the right side of this figure have expanded scales compared to similar plots directly to their left to better display details in the tightly clustered data.

Figure A6-49. Scatter Plots Showing Mixing in Southern Yucca Mountain 


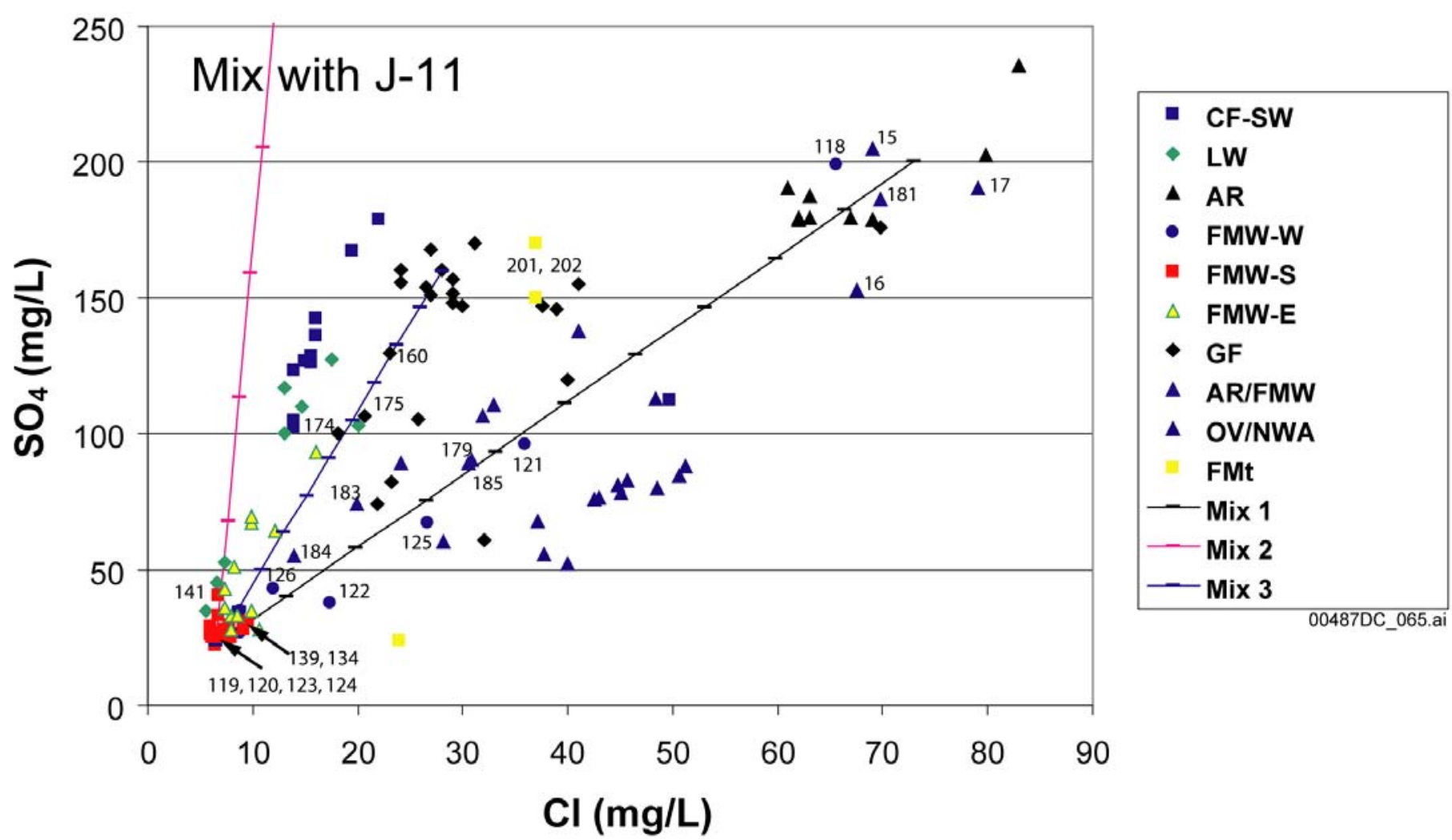

$\mathrm{Cl}(\mathrm{mg} / \mathrm{L})$

Source: Table A6-1.

NOTES: Mixing lines show 10 percent increments. End members for the mixing lines are: dilute end member for all mixing lines is $6.5 \mathrm{mg} / \mathrm{L} \mathrm{Cl}$ and $22 \mathrm{mg} / \mathrm{L}$ $\mathrm{SO}_{4}{ }^{2-}$. Mixing line 1 (Mix 1) upper end member is the average of the AR Group of $73 \mathrm{mg} / \mathrm{L} \mathrm{Cl}{ }^{-}$and $200 \mathrm{mg} / \mathrm{L} \mathrm{SO}_{4}{ }^{2-}$. Mixing line 2 (Mix 2) upper end member corresponds to $\mathrm{Cl}^{-}$and $\mathrm{SO}_{4}{ }^{2-}$ values for J-11 of $17.5 \mathrm{mg} / \mathrm{L}$ and $480 \mathrm{mg} / \mathrm{L}$, respectively. Mixing line 3 (Mix 3) upper end member is the visual average of the tight cluster displayed by the GF Group $\left(\mathrm{Cl}^{-}\right.$and $\mathrm{SO}_{4}{ }^{2-}$ concentration of $28 \mathrm{mg} / \mathrm{L}$ and $160 \mathrm{mg} / \mathrm{L}$, respectively). Mixing lines are drawn by plotting calculated values for $\mathrm{Cl}^{-}$and $\mathrm{SO}_{4}{ }^{2-}$ obtained by the mixing equation: $[\mathrm{Cl}]_{\text {mix }}=\mathrm{F} \cdot[\mathrm{Cl}]_{\mathrm{A}}+(1-\mathrm{F}) \cdot[\mathrm{Cl}]_{\mathrm{B}}$, where $\mathrm{F}$ is the fraction of component $\mathrm{A}$ in the mix. The $\mathrm{SO}_{4}{ }^{2-}$ concentration is determined by substituting values for $\mathrm{SO}_{4}{ }^{2-}$ into the equation.

Figure A6-50. Cross Correlation Plot of Sulfate versus Chloride for Samples in the Amargosa Desert Region 
Samples 119, 120, 123, and 124 are the most dilute groundwaters from the FMW-West grouping. Three of four of these are also the most northeasterly wells of the grouping, furthest from the flow pathway of the AR group groundwater. Samples 118, 121, 122, 125, and 126 are located to the south or southwest of the dilute samples and show variable amounts of mixing with Amargosa River groundwater. This pattern is consistent with southeastward groundwater flow from the vicinity of the AR group. The relative amounts of mixed Amargosa River water are not entirely consistent with geographic position, however. Similar to the FMW-W grouping, the mixing percentages for wells of the AR/FMW group do not correlate with geographic position. In fact, the $\mathrm{Cl}^{-}$and $\mathrm{SO}_{4}{ }^{2-}$ concentrations of samples 118 and 181 are essentially identical to those of the AR group, and these are located adjacent to wells with significantly different anion concentrations. This inconsistency in detailed correlation between hydrochemistry and geographic position may be due to factors that are unknown or poorly understood including well completion, well pumping history, and vertical and horizontal anisotropy in the flow system. The similar hydrochemistry of well 181 compared to that of the AR group suggests a continuous flow pathway between these areas. Doing so, however, isolates sample 179, which clearly plots as a mixed sample with most of this water similar to the dilute water of the FMW-S group, and geographically separates a mixed sample from one of its presumed sources. Again, this inconsistency may be related to vertical heterogeneities or potentially points to another dilute groundwater source in southwestern Amargosa Desert. Although a pristine AR end member groundwater has not been sampled south of well 181, the mixing relationship demonstrated by samples 183 to 185 allows continuation of the flow pathway to the west of these samples.

Groundwater from the Gravity fault group also has a distinct $\mathrm{Cl}^{-}$and $\mathrm{SO}_{4}{ }^{2-}$ concentrations, although the group does show some variability (Figure A6-50). A mixing line between average $\mathrm{Cl}^{-}$and $\mathrm{SO}_{4}{ }^{2-}$ concentrations for the tight cluster of the GF and FMW-S group samples is shown on Figure A6-50 (Mix 3). Groundwaters from the LW and FMW-E groups define an array along, though slightly above, this mixing line. These two groups of wells also lie geographically between the two hydrochemical end-member groups. This relationship suggests that the intermediate chemical compositions of the LW and the FMW-E groups may be due to mixing of variable amounts of dilute water from the Fortymile Wash and groundwater from the GF group. Analysis of other constituents, however, suggests that an additional component may be present. As mentioned, samples of the LW and FMW-E groups plot along but above the mixing line between the GF samples and the FMW-S samples. In fact, these samples plot intermediate between this mixing line (Mix 3) and a mixing line (Mix 2) between the FMW-S samples and well $\mathrm{J}-11$, which has $\mathrm{Cl}^{-}$and $\mathrm{SO}_{4}{ }^{2-}$ concentrations of $17.5 \mathrm{mg} / \mathrm{L}$ and $480 \mathrm{mg} / \mathrm{L}$, respectively (Figures A6-32 and A6-33, Table A6-1). It is possible, given this relationship and the relative geographic position of these well groupings that some groundwater from the vicinity of well $\mathrm{J}-11$ (Site 67) has mixed with these samples. On the plot of $\delta^{34} \mathrm{~S}$ and $1 / \mathrm{SO}_{4}{ }^{2-}$ (Figure A6-51), the few samples from the LW group and the FMW-E group form a trend between the FMW-S samples and groundwater from well J-11. This trend is strongly suggestive of a mixing relationship between these samples. Mixing calculations using $\mathrm{Cl}^{-}, \mathrm{SO}_{4}{ }^{2-}$, and $\delta^{34} \mathrm{~S}$ indicate that a maximum of approximately 20 percent $\mathrm{J}-11$ water is present in one of these samples (site 101-the Desert Farms Garlic Plot well). Sample 141 (FMW-S) contains elevated $\mathrm{SO}_{4}{ }^{2-}$ for the measured $\mathrm{Cl}^{-}$concentration and plots along mixing line 3. The geographic position and hydrochemistry of this sample are consistent with it containing a small percentage of J-11-like 
water. The data plotted in Figure A6-51 do not support the hypothesis that groundwater from the LW and FMW-E groups contains a component of GF water, although the data set for $\delta^{34} \mathrm{~S}$ is incomplete.

Many of the GF samples are also collinear with some samples from FMW-E and LW groups (Figure A6-50). For example, samples 160, 174, and 175 plot intermediate between the tight cluster of GF samples and dilute groundwater of the FMW-S, FMW-E, and LW groups. These samples are also among the more westerly of the GF samples, located geographically between groundwater that defines the tight cluster of GF samples and the FMW-E samples. These samples are also interpreted to be mixtures of GF groundwater and more dilute water of the FMW-E group.

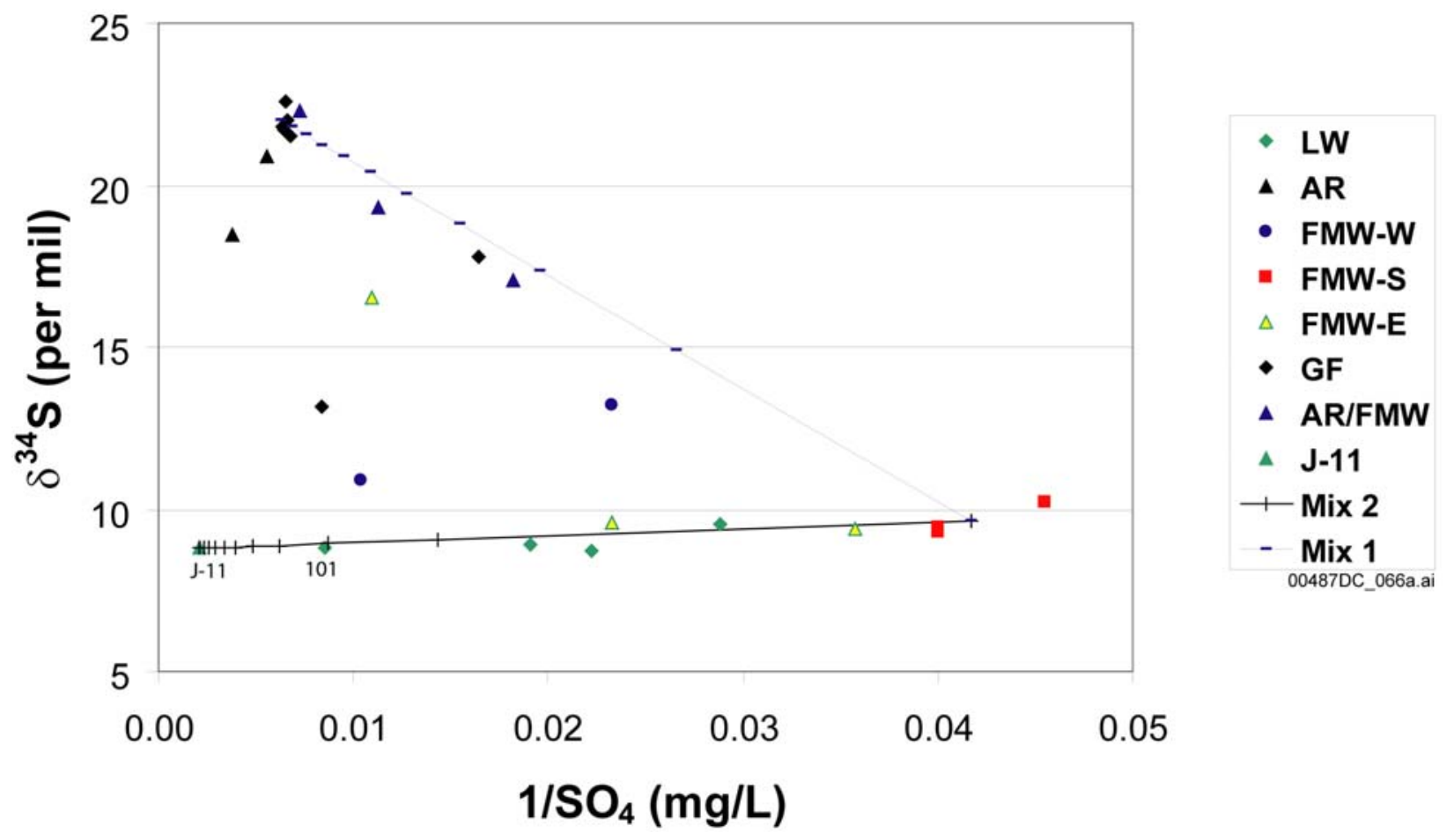

Source: Tables A6-1 and A6-2.

NOTES: On this diagram, a mixture plots as a straight line. Mixing lines show 10 percent increments. End members for the mixing lines are: $24 \mathrm{mg} / \mathrm{L} \mathrm{SO}_{4}{ }^{2-}$ and 9.65 per mil $\delta^{34} \mathrm{~S}$ for the dilute end member. Mixing line 1 (Mix 1) upper end member is the visual average of the AR group samples of $160 \mathrm{mg} / \mathrm{L} \mathrm{SO}_{4}{ }^{2-}$ and 22 per mil $\delta^{34} \mathrm{~S}$. Mixing line 2 (Mix 2) upper end members corresponds to $\mathrm{SO}_{4}{ }^{2-}$ and $\delta^{34} \mathrm{~S}$ values for $\mathrm{J}-11$ of $480 \mathrm{mg} / \mathrm{L}$ and 8.8 per mil, respectively. Mixing lines are drawn by plotting calculated values for $\mathrm{SO}_{4}{ }^{2-}$ and $\delta^{34} \mathrm{~S}$ obtained by the mixing equations: $\left[\mathrm{SO}_{4}{ }^{2-}\right]_{\text {mix }}=F_{\bullet}\left[\mathrm{SO}_{4}{ }^{2-}\right]_{\mathrm{A}}+(1-F) \cdot\left[\mathrm{SO}_{4}{ }^{2-}\right]_{\mathrm{B}}$, where $F$ is the fraction of component $A$ in the mix. Delta sulfur-34 is determined by: $\left[\delta^{34} S\right]_{\text {mix }}=\left(F_{\bullet}\left[\mathrm{SO}_{4}{ }^{2-}\right]_{A} \cdot \delta^{34} \mathrm{~S}_{\mathrm{A}}+\right.$ $\left.(1-F) \cdot\left[\mathrm{SO}_{4}{ }^{2-}\right]_{\mathrm{B}} \cdot \delta^{34} \mathrm{~S}_{\mathrm{B}}\right) /\left[\mathrm{SO}_{4}{ }^{2}\right]_{\text {mix. }}$

Figure A6-51. Scatter Plot of Delta ${ }^{34} \mathrm{~S}$ versus Inverse Sulfate for Samples in the Amargosa Desert Region 


\section{A6.3.8 Groundwater Mixing and Reaction Analyses Using PHREEQC}

In general, the chemical and isotopic composition of groundwater results from the mixing of groundwater from various upgradient locations as well as water-rock interaction along the individual flow paths. Groundwater mixing can occur naturally as a result of hydrodynamic dispersion and can also be induced during groundwater pumping. In either case, however, groundwater mixing can result in real or apparent changes in the composition of even nonreactive chemical and isotopic species in a downgradient direction.

A number of inverse groundwater mixing and reaction analyses were performed to help identify both the upgradient groundwaters that could be present in a downgradient groundwater and the chemical reactions required to explain the downgradient changes in the composition of reactive species. The groundwaters that are considered as potential components in the downgradient groundwater are identified from relatively nonreactive species such as $\mathrm{Cl}^{-}, \mathrm{SO}_{4}{ }^{2-}, \delta \mathrm{D}, \delta^{18} \mathrm{O}$, and $\delta^{34} \mathrm{~S}$. The composition of these species in the downgradient groundwater is assumed to result only from mixing of upgradient groundwaters. The remainder of the chemical and isotopic species, including other major and minor ions, dissolved $\mathrm{SiO}_{2}$, and dissolved carbon isotopes, are considered in these models to result both from mixing and from water-rock interaction. After first determining the mixing fractions of the potential components from the nonreactive species, PHREEQC adjusts the amounts of reactive chemical and isotopic species in the mixture by finding some combination of the allowable reactions that satisfy the mass balance constraints for each chemical and isotopic species. The consideration of reactive species limits the number of potential mixing analyses to those for which plausible chemical reactions can also be found.

The potential groundwater components in the mixture were identified from contour maps of hydraulic heads (Figure A6.5-1) and areal plots and scatterplots between the aforementioned nonreactive chemical and isotopic species. For groundwaters in the volcanic or alluvial aquifers, upgradient groundwater could include recharge as well as groundwater in the carbonate aquifer, which at Yucca Mountain has a higher hydraulic head than groundwater in the volcanic aquifer.

The geographic distribution of one or more nonreactive species in a downgradient direction as shown on maps in Section A6.3.4 suggests an initial combination of groundwaters that may lie along a flow path. In some parts of the Yucca Mountain area where only slight differences in solute concentrations exist among wells, scatterplots of both nonreactive and reactive species were used to suggest possible combinations of groundwaters that may be involved in a mixture (Sections A6.3.6.3 and A6.3.7).

The chemical reactions considered in these PHREEQC; (DTN: MO0309THDPHRQC.000 [DIRS 165529]) mixing and reaction analyses are restricted to those that are consistent with known ion-exchange reactions and mineral saturation indices. Generally, pore-water data from Yucca Mountain (Yang et al. 1996 [DIRS 100194]; 1998 [DIRS 101441]) and Rainier Mesa (White et al. 1980 [DIRS 101166]) indicate that $\mathrm{Ca}^{2+}, \mathrm{Mg}^{2+}$, and $\mathrm{K}^{+}$in solution are exchanged for $\mathrm{Na}^{+}$initially on the exchange sites of minerals. The saturation indices calculated in Section A6.3.5 indicate that Ca-clinoptilolite, Na-clinoptilolite, and smectite may precipitate from groundwater in some areas. Conversely, plagioclase, K-feldspar, calcite, fluorite, kaolinite, and amorphous silica are potentially dissolved by groundwater in certain parts of the Yucca Mountain area. Measurements of $\mathrm{CO}_{2}(\mathrm{~g})$ in the unsaturated zone at Yucca Mountain indicate a 
$\log P_{\mathrm{CO}_{2}}$ of about -3.0 (Yang et al. 1996 [DIRS 100194], Figure 18b). Groundwater with calculated $\log P_{\mathrm{CO}_{2}}$ greater than -3.0 will therefore potentially degas into the overlying unsaturated zone when the $\log P_{\mathrm{CO}_{2}}$ of the groundwater is greater than -3.0 and vice-versa.

A summary of the mineral phases considered in the PHREEQC analyses, their chemical formulas, and any constraints imposed on their precipitation or dissolution is summarized in Table A6-10. Unless otherwise noted in Table A6-12, all mineral phases were considered as potential reactants or products in each PHREEQC analyses discussed in this section.

The inverse analyses identified by PHREEQC are required to simultaneously satisfy mass-balance constraints for $\mathrm{pH}$ and for each element contained in the phases listed in Table A6-10. Where the inverse analyses consider groundwater mixing, the proportions of groundwater from various upgradient wells in the mixture are identified from nonreactive elements or isotopes that, by definition, are not contained in the list of reactive phases. These additional nonreactive elements and isotopes include $\mathrm{Cl}^{-}$and, depending on the model, $\delta \mathrm{D}$ and $\delta^{18} \mathrm{O}$. Many of the inverse models were also required to satisfy mass-balance constraints for $\delta^{13} \mathrm{C}$, which made it necessary to specify values of ${ }^{14} \mathrm{C}$ and $\delta^{13} \mathrm{C}$ for the C-bearing phases in these models (Table A6-10, Note 7).

The groundwater concentrations and isotopic compositions, as well as the isotopic compositions of the gas and mineral phases, are assumed by PHREEQC to be somewhat uncertain because of laboratory analytical error and because of uncertainty associated with the effects of well drilling, completion, and development on groundwater sample compositions. The specified uncertainties varied, depending on the parameter and the model. In general, the specified uncertainties were as follows: $\mathrm{pH}\left(0.05 \mathrm{pH}\right.$ units), ions (10 percent of the measured concentrations), $\delta^{13} \mathrm{C}$ $\left(0.1\right.$ per mil), $\delta^{18} \mathrm{O}(0.1$ per mil), and $\delta \mathrm{D}$ ( 1.0 per mil). These uncertainties determined the amount by which the measured chemical or isotopic parameters in each solution could be adjusted by PHREEQC to obtain mass balance for that parameter. In some cases, however, if no convergent analyses were identified because of a mass imbalance for a single chemical or isotopic species, the specified uncertainties for that species were increased from their typical values until a model, or set of models, could be found. For example, in one set of models, the specified uncertainty for $\delta^{13} \mathrm{C}$ was increased to 0.5 per mil, and in another set, the uncertainty in $\delta^{18} \mathrm{O}$ was increased to 0.4 per mil. In several sets of analyses, it was necessary to increase the uncertainty in $\mathrm{F}^{-}$to 20 percent or more of the measured concentrations, effectively eliminating $\mathrm{F}^{-}$ as a chemical constraint for that set of models. For a subset of models, it was necessary to consider dissolution of kaolinite to balance $\mathrm{Al}^{3+}$ concentrations; generally, however, $\mathrm{Al}^{3+}$ concentrations could be balanced using the other alumino-silicate minerals.

Additional uncertainty associated with these analyses results from the variability in mineral compositions, nonideal chemical compositions for common rock forming minerals like $\mathrm{K}$-feldspar and calcites, and the nonuniqueness of the inverse models themselves. As demonstrated in the following sections, it is often possible to find several combinations of wells and sets of water/rock interactions that can explain the chemical and isotopic composition of groundwater in the downgradient well. 
Table A6-10. Mineral Phases and Exchange Reactions Considered in the PHREEQC Inverse Analyses

\begin{tabular}{|c|c|c|c|}
\hline $\begin{array}{l}\text { Phase or } \\
\text { Exchange } \\
\text { Cation }\end{array}$ & Formula in PHREEQC Analyses ${ }^{1}$ & Constraint & Formula Reference \\
\hline $\begin{array}{l}\text { Carbon } \\
\text { dioxide }^{7}\end{array}$ & $\mathrm{CO}_{2}$ & Exsolution only & $\begin{array}{l}\text { Parkhurst and Appelo, (1999 } \\
\text { [DIRS 159511], Table 55) }\end{array}$ \\
\hline Calcite $^{7}$ & $\mathrm{CaCO}_{3}$ & $\begin{array}{l}\text { Dissolution or } \\
\text { precipitation }^{2}\end{array}$ & $\begin{array}{l}\text { Parkhurst and Appelo, (1999 } \\
\text { [DIRS 159511], Table 55) }\end{array}$ \\
\hline Plagioclase & $\mathrm{Na}_{0.8} \mathrm{Ca}_{0.2} \mathrm{Al}_{1.2} \mathrm{Si}_{2.8} \mathrm{O}_{8}$ & Dissolution only & $\begin{array}{l}\text { Vaniman et al. (1996 [DIRS 105946], } \\
\text { Figure 1.22) }\end{array}$ \\
\hline K-feldspar & $\mathrm{KAISi}_{3} \mathrm{O}_{8}$ & Dissolution only & $\begin{array}{l}\text { Parkhurst and Appelo, (1999 } \\
\text { [DIRS 159511], Table 55) }\end{array}$ \\
\hline Ca exchange & $\mathrm{CaX}_{2}$ & Sorption only & $\begin{array}{l}\text { Parkhurst and Appelo, (1999 } \\
\text { [DIRS 159511], Table 55) }\end{array}$ \\
\hline Mg exchange & $\operatorname{MgX}_{2}$ & Sorption only & $\begin{array}{l}\text { Parkhurst and Appelo, (1999 } \\
\text { [DIRS 159511], Table 55) }\end{array}$ \\
\hline $\mathrm{Na}$ exchange & $\mathrm{NaX}$ & De-sorption only & $\begin{array}{l}\text { Parkhurst and Appelo, (1999 } \\
\text { [DIRS 159511], Table 55) }\end{array}$ \\
\hline K exchange & $\mathrm{KX}$ & None & $\begin{array}{l}\text { Parkhurst and Appelo, (1999 } \\
\text { [DIRS 159511], Table 55) }\end{array}$ \\
\hline $\begin{array}{l}\text { Amorphous } \\
\text { silica }\end{array}$ & $\mathrm{SiO}_{2}$ & Dissolution only & $\begin{array}{l}\text { Parkhurst and Appelo, (1999 } \\
\text { [DIRS 159511], Table 55) }\end{array}$ \\
\hline Kaolinite & $\mathrm{Al}_{2} \mathrm{Si}_{2} \mathrm{O}_{5}(\mathrm{OH})_{4}$ & None $^{3}$ & $\begin{array}{l}\text { Parkhurst and Appelo, (1999 } \\
\text { [DIRS 159511], Table 55) }\end{array}$ \\
\hline Smectite & $\begin{array}{l}\mathrm{K}_{0.1} \mathrm{Na}_{0.02} \mathrm{Ca}_{0.14} \mathrm{Al}_{4.4} \mathrm{Si}_{7.6} \mathrm{O}_{20}(\mathrm{OH})_{4} \cdot 4 \mathrm{H}_{2} \\
\mathrm{O}\end{array}$ & $\begin{array}{l}\text { Precipitation } \\
\text { only }\end{array}$ & $\begin{array}{l}\text { Chipera et al. (1995 [DIRS 100025], } \\
\text { Table 1) }\end{array}$ \\
\hline $\begin{array}{l}\text { Ca- } \\
\text { Clinoptilolite }\end{array}$ & $\begin{array}{l}\mathrm{K}_{2.5} \mathrm{Na}_{1.1} \mathrm{Ca}_{1.2} \mathrm{Al}_{6.0} \mathrm{Si}_{30.0} \mathrm{O}_{72.0} \cdot 26.8 \\
\mathrm{H}_{2} \mathrm{O}\end{array}$ & $\begin{array}{l}\text { Precipitation } \\
\text { only }\end{array}$ & $\begin{array}{l}\text { Chipera and Bish (1997 } \\
\text { [DIRS 105079], Tables 1-2) }\end{array}$ \\
\hline $\begin{array}{l}\text { Na- } \\
\text { Clinoptilolite }^{4}\end{array}$ & $\begin{array}{l}\mathrm{K}_{2.8} \mathrm{Na}_{1.5} \mathrm{Ca}_{0.9} \mathrm{Al}_{6.1} \mathrm{Si}_{29.9} \mathrm{O}_{72.0} \cdot 26.8 \\
\mathrm{H}_{2} \mathrm{O}\end{array}$ & $\begin{array}{l}\text { Precipitation } \\
\text { only }\end{array}$ & $\begin{array}{l}\text { Chipera and Bish (1997 } \\
\text { [DIRS 105079], Tables 1-2) }\end{array}$ \\
\hline Pyrite & $\mathrm{FeS}_{2}$ & Dissolution only & $\begin{array}{l}\text { Parkhurst and Appelo, (1999 } \\
\text { [DIRS 159511], Table 55) }\end{array}$ \\
\hline Biotite & $\mathrm{KMg}_{2} \mathrm{FeAlSi}_{3} \mathrm{O}_{10}(\mathrm{OH})_{2}$ & Dissolution only & $\begin{array}{l}\text { Vaniman et al. (1996 [DIRS 105946], } \\
\text { Figure 1.22) }\end{array}$ \\
\hline Gypsum & $\mathrm{CaSO}_{4} \cdot 2 \mathrm{H}_{2} \mathrm{O}$ & Dissolution only & $\begin{array}{l}\text { Parkhurst and Appelo, (1999 } \\
\text { [DIRS 159511], Table 55) }\end{array}$ \\
\hline Oxygen & $\mathrm{O}_{2}$ & None $^{3}$ & $\begin{array}{l}\text { Parkhurst and Appelo, (1999 } \\
\text { [DIRS 159511], Table } 55\end{array}$ \\
\hline Ferrihydrite & $\mathrm{Fe}(\mathrm{OH})_{3}(\mathrm{a})$ & Precipitation & $\begin{array}{l}\text { Parkhurst and Appelo, (1999 } \\
\text { [DIRS 159511], Table 55) }\end{array}$ \\
\hline
\end{tabular}


Table A6-10. Mineral Phases and Exchange Reactions Considered in the PHREEQC Inverse Analyses (Continued)

\begin{tabular}{|l|l|l|l|}
\hline $\begin{array}{c}\text { Phase or } \\
\text { Exchange } \\
\text { Cation }\end{array}$ & Formula in PHREEQC Analyses & \multicolumn{1}{|c|}{ Constraint } & \multicolumn{1}{c|}{ Formula Reference } \\
\hline Fluorite $^{5}$ & $\mathrm{CaF}_{2}$ & Dissolution only & $\begin{array}{l}\text { Parkhurst and Appelo, (1999 } \\
\text { [DIRS 159511], Table 55) }\end{array}$ \\
\hline Dolomite $^{6,7}$ & $\mathrm{CaMg}\left(\mathrm{CO}_{3}\right)_{2}$ & Dissolution only & $\begin{array}{l}\text { Parkhurst and Appelo, (1999 } \\
\text { [DIRS 159511], Table 55) }\end{array}$ \\
\hline
\end{tabular}

NOTES:

${ }^{1}$ An $\mathrm{X}$ in a formula in this column represents the exchange site.

${ }^{2}$ A dissolution constraint for calcite was imposed for all inverse models except for models involving the Desert Farms Garlic Plot well, for which a precipitation constraint was imposed for calcite.

${ }^{3}$ Although no precipitation (or exsolution) or dissolution constraints were imposed, none of the inverse models required the precipitation of kaolinite or the exsolution of $\mathrm{O}_{2}$. Kaolinite dissolution was considered only in models for wells NC-EWDP-3D, WT-3, and certain depth intervals of NC-EWDP-19D, for which it was necessary to balance $\mathrm{Al}^{3+}$ concentrations in the inverse models. Although groundwaters are assumed to be in equilibrium with kaolinite, kaolinite dissolution can be driven by the precipitation of smectite and clinoptilolite phases from the groundwater.

4 Either Ca-clinoptilolite or Na-clinoptilolite, but not both, were considered in each inverse model. In the inverse models, the relevant clinoptilolite composition was determined by geography, with models for wells having potential upgradient sources in Crater Flat or Solitario Canyon assigned Na-clinoptilolite as a possible secondary phase and inverse models involving wells in central or eastern Yucca Mountain or near Fortymile Wash assigned Ca-clinoptilolite as a potential secondary phase. These choices were based on trends in clinoptilolite composition noted by Broxton et al. (1987 [DIRS 102004], Figure 8).

${ }^{5}$ Fluorite dissolution was considered only in a subset of inverse models, including those models with wells $\mathrm{VH}-1$, WT-3, NC-EWDP-15P, GEXA Well 4, NC-EWDP-3D, and NC-EWDP-1S as the downgradient wells.

${ }^{6}$ Dolomite dissolution was considered only in a subset of inverse models where the proximity to dolomite outcrops or to alluvium derived from these outcrops had a possible influence on groundwater composition. These inverse models included those models with wells VH-1, GEXA Well 4, NC-EWDP-9S, NC-EWDP-3D, or NC-EWDP-1S as the downgradient well.

${ }^{7}$ The inclusion of $\delta^{13} \mathrm{C}$ as a mass-balance constraint requires that the ${ }^{14} \mathrm{C}$ and $\delta^{13} \mathrm{C}$ of carbon-bearing phases $\left(\mathrm{CO}_{2}\right.$, calcite, and dolomite) be defined. The ${ }^{14} \mathrm{C}$ activity of any $\mathrm{CO}_{2}$ de-gassing from groundwater was set equal to the ${ }^{14} \mathrm{C}$ of the groundwater at the downgradient well, and the ${ }^{14} \mathrm{C}$ of the calcite and dolomite (if present) were set to 0 . The $\delta^{13} \mathrm{C}$ of $\mathrm{CO}_{2}$ de-gassing from the groundwater was assumed to be $-18 \pm 2$ per mil, based on measurements of the $\delta^{13} \mathrm{C}$ of $\mathrm{CO}_{2}$ in the unsaturated zone at Yucca Mountain (Yang et al. 1996 [DIRS 100194], Figure 19). Except for the WT-3 models for which $\delta^{13} \mathrm{C}$ was set to $-1 \pm 3$ per mil, the $\delta^{13} \mathrm{C}$ of saturated-zone calcite in the volcanic and alluvial aquifers was set to $-4 \pm 3$ per mil, and the $\delta^{13} \mathrm{C}$ of dolomite was set to $0 \pm 2$ per mil, based on data for SZ calcites contained in Whelan et al. (1998 [DIRS 108865], p. 179 and Figure 2).

\section{A6.3.8.1 Desert Farms Garlic Plot}

The PHREEQC analyses investigated if groundwater at the Desert Farms Garlic Plot (DFGP) well (Site 101) could be produced by a mixture of groundwater from Fortymile Wash at borehole JF-3 (Site 37) and groundwater from Jackass Flats at well J-11 (Site 67). This PHREEQC analyses was motivated by the similar $\delta^{34} \mathrm{~S}$ and $\delta^{13} \mathrm{C}$ ratios and low $\mathrm{HCO}_{3}{ }^{-}$at both $\mathrm{J}-11$ and the DFGP well, and by the mixing relation estimated from $\delta^{34} \mathrm{~S}$ versus $1 / \mathrm{SO}_{4}{ }^{2-}$, which indicated well $\mathrm{J}-11$ and wells from the FMW-S area as potential mixing end members (Figures A6-50 and A6-51). The 6 analyses identified by PHREEQC are of the form:

DFGP well $=X_{1} \mathrm{JF}-3+X_{2} \mathrm{~J}-11-$ calcite + plagioclase $+\mathrm{SiO}_{2}(\mathrm{a})+\mathrm{K}$-feldspar - smectite $-\mathrm{Ca}-$ clinoptilolite + biotite + pyrite $+\mathrm{O}_{2}(\mathrm{~g})-\mathrm{Fe}(\mathrm{OH})_{3}(\mathrm{a})-\mathrm{MgX} 2-\mathrm{KX}+\mathrm{NaX}$ 
where the fraction of well JF-3 groundwater $\left(\mathrm{X}_{1}\right)$ is between 0.76 and 0.77 and the fraction of well J-11 groundwater $\left(\mathrm{X}_{2}\right)$ is between 0.23 and 0.24 . (Note that in these PHREEQC analyses the "+" indicates the phase was taken in solution along the flow path and "-" indicates the phase left the solution along the flow path. The " $X$ " indicates phases on exchange sites.) Subsets of the phases indicated in the preceding reaction were identified in 6 reaction analyses by PHREEQC for this group of wells. Calcite precipitation was considered as a possible reaction because the groundwater at well J-11 is saturated with calcite (Figure A6.3-34). These mixing analyses did not use $\delta^{34} \mathrm{~S}$ as a constraint, but these mixing fractions are nonetheless in good agreement with the mixing fractions for Fortymile Wash area groundwaters and well J-11 groundwater estimated using mixing trends based on $\delta^{34} \mathrm{~S}$ versus $1 / \mathrm{SO}_{4}{ }^{2-}$ (Figure A6-51). However, the PHREEQC analyses could not match groundwater $\mathrm{F}^{-}$or $\delta \mathrm{D}$ data at the DFGP well. The inability to match the $\delta \mathrm{D}$ data could reflect differences in the ages of waters actually mixed to produce the DPGP water. The J-11 water could not be directly mixed with JF-3 because these two wells are kilometers apart. Instead, a water similar to J-11 could have been mixed with a water similar to JF-3 to produce the DFGP water. The actual waters mixed could have been different from J-11 or JF-3 in age. The inability to match the $\mathrm{F}^{-}$data may reflect analytical errors in the $\mathrm{F}^{-}$analyses or water/rock interactions not specified in the PHREEQC calculations (e.g., dissolution of fluorite $\left.\left(\mathrm{CaF}_{2}\right)\right)$.

\section{A6.3.8.2 Well 16S/49E-05acc}

The PHREEQC analyses investigated whether groundwater at the northernmost well in the FMW-S group (well 16S/49E-05acc) (Site 127) could be produced from groundwater in the southern part of the FMW-N group at well J-12 (Site 37). Groundwater from the JF well J-11 (Site 67) was also included as a potential mixing member. The inclusion of well $\mathrm{J}-11$ as a potential mixing member was motivated by the higher $\mathrm{SO}_{4}{ }^{2-}$ of groundwater in the FMW-S group compared to the FMW-N group and the very high $\mathrm{SO}_{4}{ }^{2-}$ at well $\mathrm{J}-11$ (Figure A6-33). However, no PHREEQC analyses were identified that included well J-11 groundwater at well 16S/49E-05acc. The 3 PHREEQC analyses for well 16S/49E-05acc were of the form:

16S/49E-05acc $=\mathrm{J}-12+$ calcite + plagioclase + K-feldspar + gypsum - Ca-clinoptilolite + biotite + pyrite $+\mathrm{O}_{2}(\mathrm{~g})-\mathrm{Fe}(\mathrm{OH})_{3}(\mathrm{a})$

Subsets of the phases indicated in the preceding reaction were identified in 3 reaction analyses by PHREEQC for this pair of wells. The PHREEQC analyses were able to match the $\delta^{13} \mathrm{C}$ at well 16S/49E-05acc but not the $\delta^{18} \mathrm{O}$ and $\delta \mathrm{D}$ values. The $\delta \mathrm{D}$ between the FMW-N and FMW-S groups is significantly different (Figure A6-41). The cause of this difference is probably climate change, which has resulted in the upgradient groundwater in the FMW-N group being of more recent origin compared to the downgradient groundwater in the FMW-S group (Figure A6-41). The groundwater in the FMW-S group is older and contains a greater percentage of cooler Pleistocene recharge, which in turn, has lighter $\delta \mathrm{D}$.

\section{A6.3.8.3 GEXA Well 4}

The groundwater at GEXA well 4 (Site 68) was modeled as a mixture of the groundwater in lower Beatty Wash at well ER-OV-03c (Site 23) and local recharge from surface runoff. Recharge from surface runoff is likely because GEXA well 4 is located in a major drainage in 
northwest Crater Flat (Figure A6-4). Because the chemical and isotopic characteristics of local recharge from surface runoff have not been measured in this area, the chemical and isotopic characteristics of the local recharge represented by groundwater from 29a\#2 (Site 31) in Fortymile Canyon was used. The 9 models identified by PHREEQC were of the form:

GEXA Well $4=X_{1}$ ER-OV-03c $+X_{2}$ recharge from runoff + calcite + dolomite + plagioclase + $\mathrm{SiO}_{2}(\mathrm{a})+\mathrm{K}$-feldspar - smectite $-\mathrm{Na}$-clinoptilolite + pyrite $+\mathrm{O}_{2}(\mathrm{~g})-\mathrm{Fe}(\mathrm{OH})_{3}(\mathrm{a})-\mathrm{CaX}_{2}-$ $\mathrm{MgX}_{2}-\mathrm{KX}+\mathrm{NaX}$

where the fraction of well ER-OV-03c groundwater $\left(X_{1}\right)$ ranged from about 0.68 to 0.79 and the fraction of recharge from surface runoff $\left(X_{2}\right)$ ranged from about 0.21 to 0.32 . Subsets of the phases indicated in the preceding reaction were identified in 9 reaction analyses by PHREEQC for the group of wells. Dolomite was considered a potentially reactive phase due to the presence of Paleozoic dolomites at Bare Mountain. The PHREEQC analyses successfully matched the $\delta^{18} \mathrm{O}$ and $\delta \mathrm{D}$ of groundwater at GEXA well 4 in addition to the ion composition.

\section{A6.3.8.4 Borehole VH-1}

The groundwater at borehole VH-1 (site 69) was modeled as a potential mixture of groundwater from GEXA Well 4 (Site 68) and groundwater from Beatty Wash at well ER-OV-03c (Site 23), Coffer Ranch Windmill Well (CRWW) (Site 22), and ER-EC-07 (Site 24). These wells were chosen as potential mixing components because they are all upgradient from borehole VH-1. Furthermore, these upgradient wells spanned a considerable range in $\mathrm{Cl}^{-}, \mathrm{SO}_{4}{ }^{2-}, \delta^{18} \mathrm{O}$, and $\delta \mathrm{D}$ (Section A6.3.4), which collectively bounded the values in groundwater at borehole VH-1. The 6 analyses identified by PHREEQC were of the form:

VH-1 $=X_{1}$ ER-OV-03c $+X_{2}$ CRWW $+X_{3}$ ER-OV-07 $+X_{4}$ GEXA well $4+$ dolomite + plagioclase $+\mathrm{SiO}_{2}(\mathrm{a})+\mathrm{K}$-feldspar - smectite $-\mathrm{Na}$-clinoptilolite + pyrite $+\mathrm{O}_{2}(\mathrm{~g})-\mathrm{Fe}(\mathrm{OH})_{3}(\mathrm{a})-$ $\mathrm{CaX}_{2}-\mathrm{KX}+\mathrm{NaX}$

where $X_{1}$ is the fraction of groundwater from well ER-OV-03c, $X_{2}$ is the fraction of groundwater from the CRWW, $X_{3}$ is the fraction of groundwater from well ER-OV-07, and $X_{4}$ is the fraction of groundwater from GEXA well 4. Subsets of the phases indicated in the preceding reaction were identified in 6 reaction analyses by PHREEQC for this set of wells. Four of the six analyses were two component-mixing models involving roughly equal amounts of ER-OV-03c and CRWW groundwater. Of the two remaining analyses, one model was a three-component mixing model involving roughly equal amounts of ER-OV-03c $\left(X_{1}=0.34\right)$, CRWW $\left(X_{2}=0.29\right)$, and GEXA well $4\left(X_{4}=0.37\right)$ groundwater, and one model involved about 10 percent of groundwater from ER-EC-07 with subequal amounts of ER-OV-03c $\left(X_{1}=0.39\right)$ and CRWW $\left(X_{2}\right.$ $=0.53$ ) groundwater. The models collectively indicate that most of the groundwater originates from lower Beatty Wash, with at most, a small component from upper Beatty Wash at well EREC-07. In light of the PHREEQC analyses for GEXA well 4 groundwater that indicate a component of local recharge from surface runoff, the groundwater at well VH-1 may also include a small component of local recharge from surface runoff in the northwest corner of Crater Flat. In addition to explaining the ion composition of groundwater at $\mathrm{VH}-1$, the PHREEQC analyses accurately replicate the $\delta^{18} \mathrm{O}$ and $\delta \mathrm{D}$ of groundwater at $\mathrm{VH}-1$. However, 
attempts to simultaneously model the relatively light $\delta^{13} \mathrm{C}(-8.5$ per mil) of groundwater at borehole VH-1 were unsuccessful.

\section{A6.3.8.5 Well NC-EWDP-1S (Composite)}

Groundwater at well NC-EWDP-1S (composite) (Site 77) was evaluated as a potential mixture of groundwater at upgradient wells VH-1 (Site 69) and VH-2 (Site 70). These components were suggested by the hydraulic gradient and fault orientations (Figure A6.5-1) and by the fact that many chemical and isotopic species in groundwater at well NC-EWDP-1S (composite) are very similar in composition to the groundwater at borehole VH-2 (Section A6.3.4). The 9 models identified by PHREEQC were of the form:

NC-EWDP-1S $($ composite $)=X_{1} \mathrm{VH}-1+X_{2} \mathrm{VH}-2+$ dolomite - calcite + Plagioclase $+\mathrm{SiO}_{2}(\mathrm{a})+$ K-feldspar - Na-clinoptilolite - smectite $-\mathrm{KX}+\mathrm{NaX}$

where the fraction of well VH-1 groundwater $\left(X_{1}\right)$ ranged from about 0.14 to 0.16 and the fraction of groundwater from well VH-2 $\left(X_{2}\right)$ ranged from about 0.84 to 0.86 . Subsets of the phases indicated in the preceding reaction were identified in the 9 reaction models by PHREEQC for group of wells. Note that in southwestern Crater Flat, the groundwater is saturated with calcite (Figure A6.3-34), so that calcite precipitation rather than dissolution is likely. In addition to reproducing the ion compositions, the PHREEQC analyses were also able to reproduce the $\delta^{18} \mathrm{O}$ and $\delta \mathrm{D}$ compositions of groundwater at NC-EWDP-1S (composite) with a high degree of accuracy. These models indicate that groundwater at NC-EWDP-1S (composite) originates dominantly from groundwater at well VH-2.

\section{A6.3.8.6 Well NC-EWDP-9SX (Composite)}

Groundwater at well NC-EWDP-9SX (composite) (Site 81) was evaluated as a potential mixture of groundwater at upgradient wells VH-1 (Site 69) and VH-2 (Site 70). These components were suggested by the hydraulic gradient and fault orientations (Figure A6.5-1) and by the fact that many chemical and isotopic species in groundwater at well NC-EWDP-9SX (composite) are intermediate in composition between the groundwaters at boreholes $\mathrm{VH}-1$ and $\mathrm{VH}-2$ (Section A6.3.7.1). The 3 models identified by PHREEQC were of the form:

NC-EWDP-9SX (composite) $=X_{1} \mathrm{VH}-1+X_{2} \mathrm{VH}-2+$ plagioclase $+\mathrm{SiO}_{2}(\mathrm{a})+\mathrm{K}$-feldspar $-\mathrm{Na}-$ clinoptilolite - smectite $-\mathrm{CaX}_{2}-\mathrm{KX}+\mathrm{NaX}$

where the fraction of well VH-1 groundwater $\left(X_{1}\right)$ ranged from about 0.78 to 0.79 and the fraction of groundwater from well VH-2 $\left(X_{2}\right)$ ranged from about 0.21 and 0.22 . Subsets of the phases indicated in the preceding reaction were identified in the 3 reaction models identified by PHREEQC for this group of wells. In addition to reproducing the ion compositions, the PHREEQC analyses were also able to reproduce the $\delta^{18} \mathrm{O}$ and $\delta \mathrm{D}$ compositions of groundwater at NC-EWDP-9SX (composite) with a high degree of accuracy. These models are consistent with the interpretation that groundwater at NC-EWDP-9S originates dominantly from groundwater at well VH-1. 


\section{A6.3.8.7 Well NC-EWDP-3D (Composite)}

Groundwater at well NC-EWDP-3D (composite) (Site 86) was evaluated as a potential mixture of groundwater at upgradient wells VH-1 (Site 69) and WT-10 (Site 42). These components were suggested by the hydraulic gradient and fault orientations (Figure A6.5-1) and by the fact that many chemical and isotopic species in groundwater at well NC-EWDP-3D (composite) are intermediate in composition between the groundwaters at boreholes VH-1 and WT-10 (Section A6.3.4). The 1 model identified by PHREEQC was of the form:

NC-EWDP-3D $($ composite $)=X_{1} \mathrm{VH}-1+X_{2} \mathrm{WT}-10+$ calcite + plagioclase $+\mathrm{SiO}_{2}(\mathrm{a})+\mathrm{K}-$ feldspar + kaolinite $-\mathrm{Na}$-clinoptilolite $-\mathrm{MgX}_{2}+\mathrm{NaX}$

with the fraction of well $\mathrm{VH}-1$ groundwater $\left(X_{1}\right)$ equal to 0.80 and the fraction of groundwater from well WT-10 $\left(X_{2}\right)$ equal to 0.20 . In addition to reproducing the ion compositions, the PHREEQC models were also able to reproduce the $\delta^{18} \mathrm{O}, \delta \mathrm{D}$, and $\delta^{13} \mathrm{C}$ compositions of groundwater at NC-EWDP-3D (composite) with a high degree of accuracy. These models indicate that groundwater at NC-EWDP-3D originates dominantly from groundwater at well VH-1.

\section{A6.3.8.8 Well NC-EWDP-15P}

The groundwater at well NC-EWDP-15P (Site 90) was modeled as a potential mixture of groundwaters from upgradient wells VH-1 (Site 69) and WT-10 (Site 42). The carbonate-aquifer-like groundwater from borehole VH-2 (Site 70) was also considered as a potential component based on head gradients in southern Crater Flat and Yucca Mountain and on mixing trends that suggested a carbonate-aquifer component in the groundwater in this area (see Section A6.3.7.1). The 2 PHREEQC analyses found for well NC-EWDP-15P took the form:

NC-EWDP-15P $=X_{1}$ WT-10 $+X_{2}$ VH-2 $+X_{3} \mathrm{VH}-1+\mathrm{SiO}_{2}($ a) + K-feldspar +gypsum $-\mathrm{Na}-$ clinoptilolite - smectite

where the fraction of well WT-10 groundwater $\left(X_{1}\right)$ was approximately 0.45 to 0.49 , the fraction of carbonate aquifer groundwater from borehole $\mathrm{VH}-2\left(X_{2}\right)$ was 0.05 to 0.06 , and the fraction of groundwater from well $\mathrm{VH}-1\left(X_{3}\right)$ was about 0.45 to 0.49 . The 2 PHREEQC analyses were able to successfully match the $\delta^{18} \mathrm{O}$ and $\delta \mathrm{D}$ at well NC-EWDP-15P with a high degree of accuracy. The $\delta^{13} \mathrm{C}$ of groundwater at NC-EWDP-15P was not estimated by the inverse models because no groundwater $\delta^{13} \mathrm{C}$ data were available from borehole VH-2. The PHREEQC analyses support the hypothesis that groundwater flows from eastern Crater Flat through wells in southern Yucca Mountain.

\section{A6.3.8.9 Borehole WT-3}

The PHREEQC models investigated whether groundwater at borehole WT-3 (Site 65) could have evolved from groundwater in northern Yucca Mountain at borehole WT-24 (Site 44). This possible flow path was suggested by fault orientations and the hydraulic gradient in the northern Yucca Mountain area, the high ${ }^{234} \mathrm{U}^{238} \mathrm{U}$ activity ratio at both boreholes, and the fact that groundwater at borehole WT-24 is the only location upgradient from borehole WT-3 with a 
higher ${ }^{14} \mathrm{C}$ activity. The reaction models for these wells assumed that calcite dissolved along the flow path had a $\delta^{13} \mathrm{C}$ of $-1.0 \pm 3$ per mil because this is a common value measured in saturated zone calcite (Whelan et al., 1998, Figure 3. [DIRS 108865]). The reactions identified by PHREEQC for this flow path were of the general form:

WT-3 = WT-24 + calcite + fluorite $+\mathrm{SiO}_{2}(\mathrm{a})+\mathrm{K}$-feldspar + kaolinite - smectite Ca-clinoptilolite + biotite $+\mathrm{O}_{2}(\mathrm{~g})-\mathrm{Fe}(\mathrm{OH})_{3}(\mathrm{a})-\mathrm{CaX}_{2}-\mathrm{MgX}_{2}$

Subsets of the phases indicated in the preceding reaction were identified in 6 reaction models identified by PHREEQC for this pair of wells. The results of the reactions models confirm this as a plausible flow path.

\section{A6.3.8.10 Well NC-EWDP-19D and -19P}

Groundwater at well NC-EWDP-19D (Sites 92 and 94-98) was sampled from several different zones in alluvium as well as from longer intervals spanning the depth of the alluvium or the entire well. The chemistry and isotopic compositions of these zones exhibited substantial differences in both chemical and isotopic compositions (see Section A6.3.3). Although cation, bicarbonate, and isotope compositions varied substantially among different zones, the groundwater $\mathrm{Cl}^{-}$and $\mathrm{SO}_{4}{ }^{2-}$ compositions within almost all zones are uniformly low. The similarity of groundwater $\mathrm{Cl}^{-}$and $\mathrm{SO}_{4}{ }^{2-}$ compositions in well NC-EWDP-19D and upgradient well WT-3 (Site 65) suggests a flow path between these two wells, in spite of the differences in other chemical and isotopic species. Groundwater at well WT-3 is also the only upgradient groundwater with ${ }^{14} \mathrm{C}$ activity high enough to explain the high ${ }^{14} \mathrm{C}$ activities of some zones in well NC-EWDP-19D. One group of models for well NC-EWDP-19D therefore attempts to explain the compositional difference between wells WT-3 and various zones within well NC-EWDP-19D as the result of water rock interactions along the flow path between the wells. The same set of reactions are applied to varying extents to explain the differences in compositions between various depth intervals in well NC-EWDP-19D:

NC-EWDP-19D (various zones) $=\mathrm{WT}-3+$ calcite $+\mathrm{SiO}_{2}(\mathrm{a})+\mathrm{K}$-feldspar + kaolinite + plagioclase + gypsum - smectite - Ca-clinoptilolite + biotite + pyrite $+\mathrm{O}_{2}(\mathrm{~g})-\mathrm{Fe}(\mathrm{OH})_{3}(\mathrm{a})-$ $\mathrm{CaX}_{2}-\mathrm{MgX}_{2} \pm \mathrm{KX}+\mathrm{NaX}$

Scatter plots (Figures A6-42 to A6-46) show that some groundwaters in the SCW group are similar to groundwater at well NC-EWDP-19D. Although slightly higher in $\mathrm{Cl}^{-}$and $\mathrm{SO}_{4}{ }^{2-}$, groundwater in the SCW group is similar to groundwater at well NC-EWDP-19D with respect to cation compositions, DIC, and $\delta^{13} \mathrm{C}$. However, the groundwater ${ }^{14} \mathrm{C}$ activities in the SCW area are far too low for this groundwater to be the source of groundwater at NC-EWDP-19D unless the SCW groundwater mixes with younger groundwater along its flow path. This younger water is assumed to be local recharge from Yucca Mountain itself, as represented by perched water from borehole SD-7. Some component of local recharge in southern Yucca Mountain is consistent with the hypothesis that much of the groundwater at Yucca Mountain is derived from local recharge (Section A6.3.6). The local recharge represented by perched water from SD-7 
also has lower $\mathrm{Cl}^{-}$and $\mathrm{SO}_{4}{ }^{2-}$ concentrations than the well NC-EWDP-19D, making it a suitable mixing end member. This group of models can be represented as:

NC-EWDP-19D (various zones $)=X_{1}$ WT-10 $+X_{2}$ local recharge $($ SD-7 perched water $)+$ calcite $+\mathrm{SiO}_{2}(\mathrm{a})+\mathrm{K}$-feldspar + kaolinite + plagioclase + gypsum - smectite $-\mathrm{Ca}$-clinoptilolite + biotite + pyrite $+\mathrm{O}_{2}(\mathrm{~g})-\mathrm{Fe}(\mathrm{OH})_{3}(\mathrm{a})-\mathrm{CaX}_{2}-\mathrm{MgX}_{2} \pm \mathrm{KX}+\mathrm{NaX}$

where $X_{1}$ is the fraction of groundwater from SCW well WT-10 (Site 42), $X_{2}$ is the fraction of local recharge (as represented by perched water from borehole SD-7). Similar chemical processes but different sources are invoked in the two sets of PHREEQC models to explain the composition of groundwater within different zones in well NC-EWDP-19D. Both sets of models are able to explain the chemical compositions and $\delta^{13} \mathrm{C}$ values of groundwater in various zones at well NC-EWDP-19D, but neither set of models adequately explains the extremely light $\delta^{18} \mathrm{O}$ and $\delta \mathrm{D}$ compositions in some of these zones.

The PHREEQC analyses for groundwater at well NC-EWDP-19P (Site 93) use the same set of reactions as for -19D but consider groundwater flow from well WT-3 and well JF-3 in the FMW-N group as possible sources of groundwater at well NC-EWDP-19P. The PHREEQC analyses results indicate that 80 to 100 percent of the shallow groundwater in well NC-EWDP-19P originates from the area of well JF-3.

\section{A6.3.9 Evaluation of Groundwater Velocities in the Yucca Mountain Region}

In this section, groundwater velocities are estimated along various flow-path segments using the ${ }^{14} \mathrm{C}$ activities of the groundwater along the flow path. The measured ${ }^{14} \mathrm{C}$ activities at the upgradient well defining the segment are adjusted to account for decreases in the ${ }^{14} \mathrm{C}$ activity that result from water-rock interactions the groundwater undergoes between wells, as identified by the PHREEQC mixing and chemical reaction models described in Section A6.3.8. This adjustment to the initial ${ }^{14} \mathrm{C}$ activity at the upgradient well is necessary to distinguish between the decrease in ${ }^{14} \mathrm{C}$ activity caused by water-rock interaction and the decrease in ${ }^{14} \mathrm{C}$ activity due to transit time between the wells. After determining the transit time between wells, linear groundwater velocities are determined by dividing the distance between the wells by the transit time.

The transit time between wells is calculated from the radioactive decay equation for ${ }^{14} \mathrm{C}$ (Section A6.3.1.2.2). A variety of methods have been used to estimate the value of ${ }^{14} A_{0}$ to use with the radioactive decay law (Clark and Fritz 1997 [DIRS 105738], Chapter 8). One simple method that can be used to correct for the effects of calcite (or dolomite) dissolution in the case where the downgradient groundwater evolves from a single upgradient source is to compare the total DIC in the upgradient well $\left(D I C_{\mathrm{u}}\right)$ with the DIC of the downgradient groundwater $\left(D I C_{\mathrm{d}}\right)$ (Clark and Fritz 1997 [DIRS 105738], p. 209):

$$
q_{\mathrm{DIC}}=\frac{D I C_{\mathrm{u}}}{D I C_{\mathrm{d}}}
$$

where $q_{\text {DIC }}$ represents the fraction of the DIC in the downgradient that originated from the upgradient well, with the remainder acquired from water-rock-gas interactions. Therefore, the 
initial value of ${ }^{14} A_{0}$ is the product of $q_{\text {DIC }}$ and the measured ${ }^{14} \mathrm{C}$ activity at the upgradient well $\left({ }^{14} A_{\mathrm{u}}\right)$ :

$$
{ }^{14} A_{0}={ }^{14} A_{\mathrm{u}} \cdot q_{\text {DIC }}
$$

Several assumptions are made to simplify this calculation. The method assumes that after infiltration reaches the SZ and becomes recharge, the water is effectively isolated from further interaction with carbon dioxide gas in the unsaturated zone, so that any downgradient increases in the DIC of the groundwater are a result of interactions with carbon-bearing minerals. These minerals are assumed to be depleted in ${ }^{14} \mathrm{C}$, which is probably the case because most SZ calcite was formed either during a 10-million-year-old hydrothermal event or under unsaturated conditions at a time when the water table was lower than today (Whelan et al. 1998 [DIRS 108865], p. 180). Thus, although the proportions of dissolved carbon-dioxide gas, bicarbonate, and carbonate may change with $\mathrm{pH}$ as the groundwater interacts with the rock, the total DIC is fixed unless the groundwater reacts with calcite. This method would not account for any interactions between groundwater and calcite once the groundwater had become saturated with calcite (Table A5-1, Assumption 8), nor would it account for the effects of groundwater mixing. This method was applied to obtain a preliminary estimate for the case that the upgradient groundwater was undersaturated with calcite and mixing was not considered an important process based on the PHREEQC inverse analyses.

Additional simplifying assumptions in evaluating transport times based on ${ }^{14} \mathrm{C}$ ages along flow paths include: groundwater flows along the straight-line distance between wells. This is a necessary, though likely inaccurate, assumption since the quantitative data for a particular nonlinear travel path are lacking. Using the straight-line distance yields the highest flow velocity. Also, the effects of matrix diffusion are not accounted for, though they are likely. Matrix diffusion may add older DIC to the groundwater. Corrections to account for this older component would also increase the calculated flow velocity.

For flow path segments in which PHREEQC inverse analyses indicate the downgradient groundwater evolves from a single upgradient well, the value of ${ }^{14} A_{U}$ is simply groundwater ${ }^{14} A$ at the upgradient well and the expression for $q_{\mathrm{DIC}}$ is computed as follows:

$$
q_{\mathrm{DIC}}=\left(D I C_{\mathrm{u}}\right) /\left(D I C_{\mathrm{u}}+D I C_{\text {carbonate }}\right)
$$

where $D I C_{\mathrm{u}}$ is the DIC at the upgradient well and $D I C_{\text {carbonate }}$ is the amount of carbon contributed by water-rock interactions involving carbonate rocks. The denominator in Equation 12 was expressed as $D I C_{\mathrm{u}}+D I C_{\text {carbonate }}$ rather than simply as the measured value of $D I C_{\mathrm{d}}$ to allow for the possibility that the measured DIC concentrations were affected by $\mathrm{CO}_{2}(\mathrm{~g})$ de-gassing either during flow or during sampling.

For flow path segments for which the PHREEQC inverse analyses identified mixing as an important control on the downgradient groundwater chemistry, the values of ${ }^{14} A_{\mathrm{u}}$ and $q_{\text {DIC }}$ were calculated as follows:

${ }^{14} A u=\left(f_{1}{ }^{14} A_{1} D I C_{1}+f_{2}{ }^{14} A_{2} D I C_{2}+\ldots+f_{i}{ }^{14} A_{i} D I C_{i}\right) /\left(f_{1} D I C_{1}+f_{2} D I C_{2}+\ldots+f_{i} D I C_{i}\right)$

(Eq. 6-13) 
and

$$
q_{\mathrm{DIC}}=\left(f_{1} D I C_{1}+f_{2} D I C_{2}+\ldots+f_{i} D I C_{i}\right) /\left(f_{1} D I C_{1}+f_{2} D I C_{2}+\ldots+f_{i} D I C_{i}+D I C_{\text {carbonate }}\right)
$$

where $f_{i}$ is the fraction of upgradient component $i$ in the mixture. The equations do not consider the effects of $\mathrm{CO}_{2}$ degassing or dissolution, or calcite precipitation on ${ }^{14} \mathrm{C}$ activity. This omission is an acceptable simplification because the fractionation factor for ${ }^{14} \mathrm{C}$ is small (Clark and Fritz 1997 [DIRS 105738], inside front cover), and the ${ }^{14} \mathrm{C}$ in the $\mathrm{CO}_{2}$ or calcite exiting the groundwater should leave the ${ }^{14} \mathrm{C}$ in the groundwater relatively unchanged. Gas dissolution by the groundwater should not occur in most instances because the $\log P_{\mathrm{CO}_{2}}$ of the groundwater is higher than that of the overlying unsaturated zone (see Section A6.3.8).

It is important to recognize that the hydrogeologic environment at Yucca Mountain represents a departure from the ideal circumstances under which ${ }^{14} \mathrm{C}$ activities can be reliably used to calculate groundwater velocities. Ideally, the ${ }^{14} \mathrm{C}$ method should be used where recharge is added at a known location and moves through a confined aquifer, isolated from the effects of groundwater mixing or downgradient additions of recharge. The degree of confinement of the aquifers at Yucca Mountain is not known, and mixing and downgradient additions of recharge are possible that could cause conditions to depart from the ideal circumstances. The PHREEQC analyses that have identified groundwater mixing as a process affecting groundwater compositions can, in theory, help to calculate the effects of groundwater mixing on ${ }^{14} \mathrm{C}$ activities, as described in Equations 6-13 and 6-14. However, in the Yucca Mountain area, the calculation of groundwater velocities based on ${ }^{14} \mathrm{C}$ activities is made more complicated by the possible presence of multiple, distributed recharge areas. If relatively young recharge were added along a flow path, the ${ }^{14} \mathrm{C}$ activity of the mixed groundwater would be higher, and the calculated transit times shorter, than for the premixed groundwater without the downgradient recharge. Unfortunately, the chemical and isotopic characteristics of the recharge from various areas at Yucca Mountain may not be sufficiently distinct to identify separate sources of local recharge in the groundwater.

Despite these nonideal conditions, groundwater velocities were calculated for several possible flow paths south of the repository in the Yucca Mountain area. The results of the calculations are described in the following subsections. These results should be viewed in light of the reservations noted above.

\section{A6.3.9.1 Flow-Path Segment from Well WT-3 to Well NC-EWDP-19D}

The PHREEQC inverse analyses (Section A6.3.8) indicate that groundwater sampled from various zones in well NC-EWDP-19D (Sites 92 and 94-98) could have evolved from groundwater at well WT-3 (Site 65). Table A6-11 shows the transit times calculated by using the DIC of groundwater at well WT-3 and PHREEQC estimates of the carbon dissolved by this groundwater as it moves toward various zones at well NC-EWDP-19D (Equation 6-12). The third column of Table A6-11 refers to the transit time estimate made from the measured DIC at well WT-3 and that particular zone in well NC-EWDP-19D. The differences between the transit times based on the PHREEQC analyses results (Table A6-11, Column 2) and the transit times based on the measured differences in DIC concentrations (Table A6-11, Column 3) arise from 


\section{A6.3.9.2 Flow Path Segment from Well WT-24 to Well WT-3}

The transit times calculated by using the DIC of groundwater at well WT-24 (Site 44) and PHREEQC estimates of the carbon dissolved by this groundwater as it moves toward well WT-3 (site 65) averaged $-499 \pm 147$ years. The transit time estimate based on the measured differences in DIC of groundwater at wells WT-24 and WT-3 is 216 years. The differences in the estimates arise from the fact that the PHREEQC analyses allow an uncertainty of 10 percent in the DIC concentrations at each of the wells, which allows a slightly larger amount of calcite to be dissolved in the models (33 to $39 \mathrm{mg} / \mathrm{L}$ in the PHREEQC analyses versus $23 \mathrm{mg} / \mathrm{L}$ based on the measured DIC values). Using the estimate of transit time based on the measured DIC values and a linear distance between wells WT-24 and WT-3 of 10-km results in a linear groundwater velocity of 46-m/year.

\section{A6.3.10 Groundwater Flow Patterns Simulated with the Saturated Zone Flow Model}

The site-scale SZ flow model (Output DTN: LA0304TM831231.002), or simply, the SZ flow model, was used to simulate the movement of a conservative tracer through various features in the model. The location of these features and their numerical designations in the model are shown in Figure 6-5 and Table 6-17. The goal of these simulations was to provide an understanding of where groundwater at any location in the flow system may have originated and to what extent groundwaters originating from various locations may mix. These simulation results are then qualitatively evaluated in the context of the understanding gained from the analysis of the hydrochemical and isotopic data discussed in the previous sections.

The simulations performed with FEHM used the advection-dispersion (trac) macro embedded in that code to simulate the steady-state distribution of a tracer originating from most boundary segments and from Yucca Mountain and Fortymile Wash recharge. In each simulation, an assigned longitudinal dispersivity of $10 \mathrm{~m}$ and a transverse dispersivity of $1 \mathrm{~m}$ were used. Small dispersivities were assumed to better observe the effects of heterogeneities on groundwater mixing and dilution. Nonetheless, as in most simulations that use the advection-dispersion equation, some numerical dispersion due to the mesh discretization may also have affected the tracer simulation results. For this reason, the simulation results are not analyzed quantitatively, and comparisons to the geochemical data are qualitative in nature.

The flow-system behavior illustrated by these simulations is partly the result of the distributions of aquifers and confining units in the model (Figure A6-52). Where an aquifer exists along the boundary of the model, relatively large amounts of water enter the model along that boundary segment and the tracer originating from that segment dominates the character of the downgradient groundwater for a considerable distance. Conversely, where confining units are present along the boundary, groundwater inflow is small, and the tracer originating from that segment is readily diluted by the relatively larger amounts of untraced groundwater entering the model along the neighboring boundary segments.

Two simulations were done for each boundary segment considered. The first simulation for each segment examined the steady-state distribution of inflow along the pre-Tertiary rocks contained within that boundary segment. These pre-Tertiary rocks include the granitic rocks, the Lower Clastic Confining Unit, the Lower Carbonate Aquifer, the Upper Clastic Confining unit, the 
Lower Carbonate Aquifer Thrust, and the Upper Carbonate Aquifer Thrust. The Tertiary rocks (and sediment) include the remainder of the model units shown on Figure A6-52. The Prow Pass tuff, the Bullfrog tuff, and the Tram tuff, although not explicitly identified as aquifers in Figure A6-52, comprise the Lower Volcanic Aquifer of Luckey et al. (1996 [DIRS 100465], Figure 7).

\section{Saturated-zone hydrostratigraphic units}

\begin{tabular}{|l}
\hline Legend \\
\hline Valley-Fill Aquifer \\
Not Used \\
Limestone Aquifer \\
Lava Flow Aquifer \\
U. Volcanic Aquifer \\
U. Volc. Conf. Unit \\
Prow Pass Tuff \\
Bullfrog Tuff \\
Tram Tuff \\
L. Volc. Conf. Unit \\
Older Volc. Aquifer \\
Older Volc. Conf. Unit \\
Valley Fill (undiff.) \\
U. Carbonate Aquifer \\
L Carb. Aquif. Thrust \\
U. Clastic Conf. Unit \\
L. Carbonate Aquifer \\
L. Clastic Conf. Unit \\
Granite \\
\hline
\end{tabular}

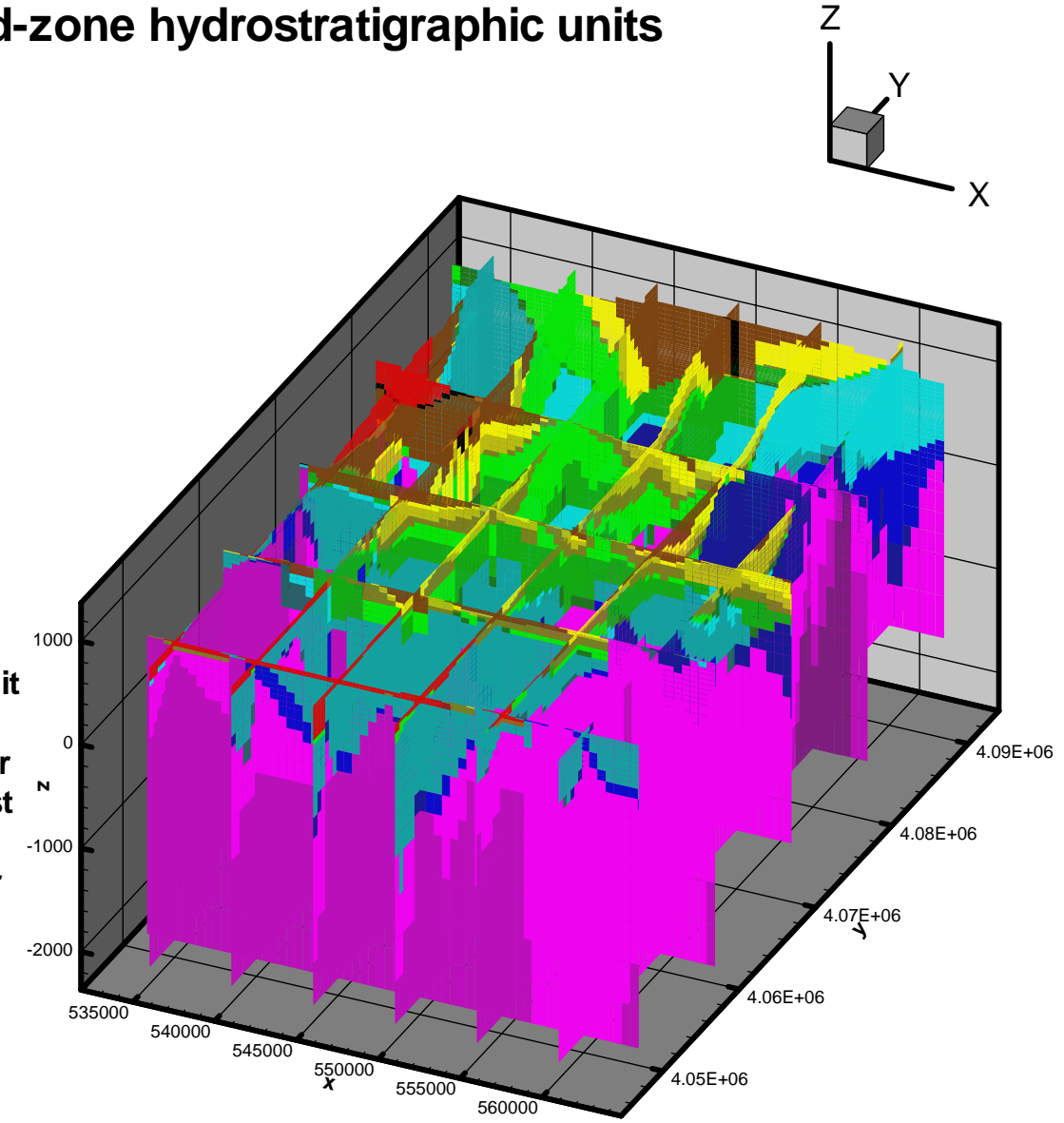

Output DTN: LA0304TM831231.002.

DTN: LA0309EK831231.001 [DIRS 171887].

NOTES: The $X$ and $Y$ coordinates are Universal Trans-Mercator Projection (UTM) coordinates in meters. The $Z$ coordinate is elevation relative to sea level in meters. $X=U T M-E a s t i n g$ and $Y=U T M-N o r t h i n g$.

Figure A6-52. Geologic Units Defined in the Saturated Zone Flow Model 
The first simulation result presented here shows the steady-state distribution of Yucca Mountain recharge in the model (Figure A6-53). Also shown in the figure are the locations of the boreholes that provided head data used in the calibration of the SZ flow model. Some key boreholes that figured prominently in the earlier discussions of the hydrochemistry are labeled in this and subsequent figures. The boreholes extend from ground surface (not shown) through the water table, which in this case, coincides with the top of the model. The length of the boreholes shown in these figures thus approximates the thickness of the UZ at that location.

\section{Steady-state distribution of Yucca Mountain recharge}

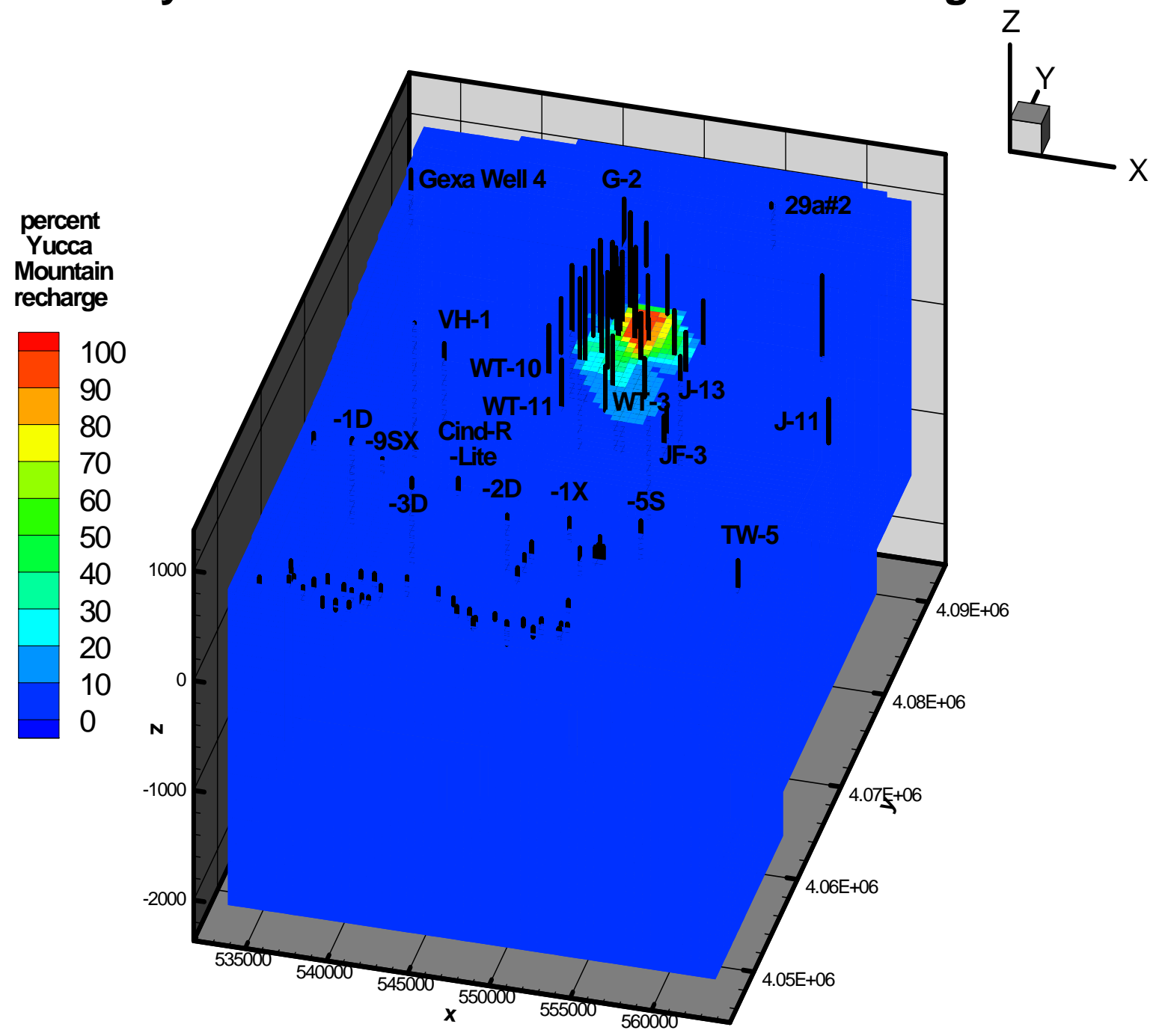

Output DTN: LA0304TM831231.002.

DTN: LA0309EK831231.001 [DIRS 171887].

NOTES: The $X$ and $Y$ coordinates are Universal Trans-Mercator Projection (UTM) coordinates in meters. The $Z$ coordinate is elevation relative to sea level in meters. $X=U T M$-Easting and $Y=U T M-N o r t h i n g$.

Figure A6-53. Steady-State Distribution of the Percentage of Yucca Mountain Recharge in Downgradient Groundwater Calculated Using the Saturated Zone Flow Model 
The longest boreholes are located along Yucca Crest where the unsaturated zone thickness can reach $750 \mathrm{~m}$.

The Yucca Mountain recharge entering the model was tagged with a concentration of 100 units, whereas all other water entering the model was given a tracer concentration of 0 units. The percentage of Yucca Mountain recharge at any location in the model is therefore equivalent to the tracer concentration at that location. The simulation results indicate that Yucca Mountain recharge is substantially diluted by groundwater flowing from adjacent parts of the flow system by the time it passes the Dune Wash area near well WT-3 (Site 65). The percentage of Yucca Mountain recharge in the groundwater is less than 10 percent near well NC-EWDP-2D (Site 91) along U.S. Highway 95. The downgradient decrease in tracer concentrations associated with Yucca Mountain recharge cannot be explained by spreading of the plume due to numerical dispersion because, in this case, the plume tends to become narrower and more focused in the downgradient direction. A more likely explanation is that as Yucca Mountain recharge moves downgradient, it is mixed and diluted by groundwater moving from more active parts of the flow system. These results are consistent with observed hydrochemical patterns and help to explain the difficulty in identifying Yucca Mountain recharge in groundwater near and south of U.S. Highway 95.

The flow entering along the northern boundary of the model (zone 61) in northwest Crater Flat is shown in Figures A6-54 to A6-56. The flow through the pre-Tertiary rocks is predicted to emerge into the shallow part of the flow system in several points of the model, including the central part of Crater Flat near borehole VH-1 (Site 69) and the southern part of Crater Flat near well NC-EWDP-3D (Site 86) and the NC-EWDP-15P well (Site 90). The groundwater at borehole VH-2 (Site 70) in central Crater Flat does appear to have many of the characteristics of groundwater from the carbonate aquifer, and groundwater at well NC-EWDP-3D (Site 86) and the NC-EWDP-15P well (Site 90) were analyzed with the PHREEQC code to be partially derived from the carbonate aquifer, in agreement with these results. The deep groundwater flowing through Crater Flat is apparently forced both upward and to the east by a buried ridge formed by the low-permeability Lower Clastic Confining unit (compare Figures A6-52 and A6-55). The groundwater entering Crater Flat through the undifferentiated Valley Fill in zone 61 dominates the shallow flow system in most of Crater Flat, except for the westernmost part of Crater Flat where the groundwater enters from the western boundary along Bare Mountain. Although most of the groundwater entering the undifferentiated Valley Fill in northwest Crater Flat flows southward from borehole VH-1 (Site 69) to wells NC-EWDP-9SX (Sites 81-85) and NC-EWDP-3D (Site 86), as analyzed with the PHREEQC calculations (Sections A6.3.8.6 and A6.3.8.7), a part of this groundwater flows southeastward past well WT-10 (Site 42) and into southern Yucca Mountain to become a component of the groundwater near the NC-EWDP-15P well (Site 90) and NC-EWDP-2D (Site 91). PHREEQC calculations for these well NC-EWDP-15P and for nearby well NC-EWDP-19D indicated that groundwater from well WT-10 (Site 42) could constitute a significant fraction of the groundwater at these wells (Sections A6.3.8.8 and A6.3.8.10).

Because of the very low permeability of the pre-Tertiary rocks near Zone 62 at Timber Mountain, very little groundwater enters the model from this area and tracer concentrations indicate that inflow from this area exerts little influence on the downgradient water chemistry (figure not shown). The Tertiary rocks from Zone 62 include the relatively permeable upper 
volcanic aquifer, which permits a considerably greater amount of groundwater to enter the model than the pre-Tertiary rocks in this zone. The steady-state distribution of tracer concentrations (Figure A6-57) indicates that groundwater entering through the Tertiary rocks of Zone 62 flows southward through Yucca Mountain and forms a component of the groundwater throughout the Yucca Mountain area, including southeastern Crater Flat at wells WT-10 (Site 42), NC-EWDP-3D (Site 86), the Cind-R-Lite well (Site 89), and wells NC-EWDP-2D (Site 91) and NC-EWDP-19D (Sites 92 and 94-98) in southern Yucca Mountain near Fortymile Wash. The $\delta^{13} \mathrm{C}$ of shallow groundwater in the northernmost part of Yucca Mountain is too light for that groundwater to have originated from groundwater directly to the north at well ER-EC-07 (Site 24) in Beatty Wash. However, the increase in groundwater $\delta^{13} \mathrm{C}$ southward at Yucca Mountain is consistent with an increasing component of groundwater from the area of well ER-EC-07 (Site 24) present in the Yucca Mountain groundwater.

\section{Steady-state distribution of inflow through the pre-Tertiary units of zone 61 (NW Crater Flat)}

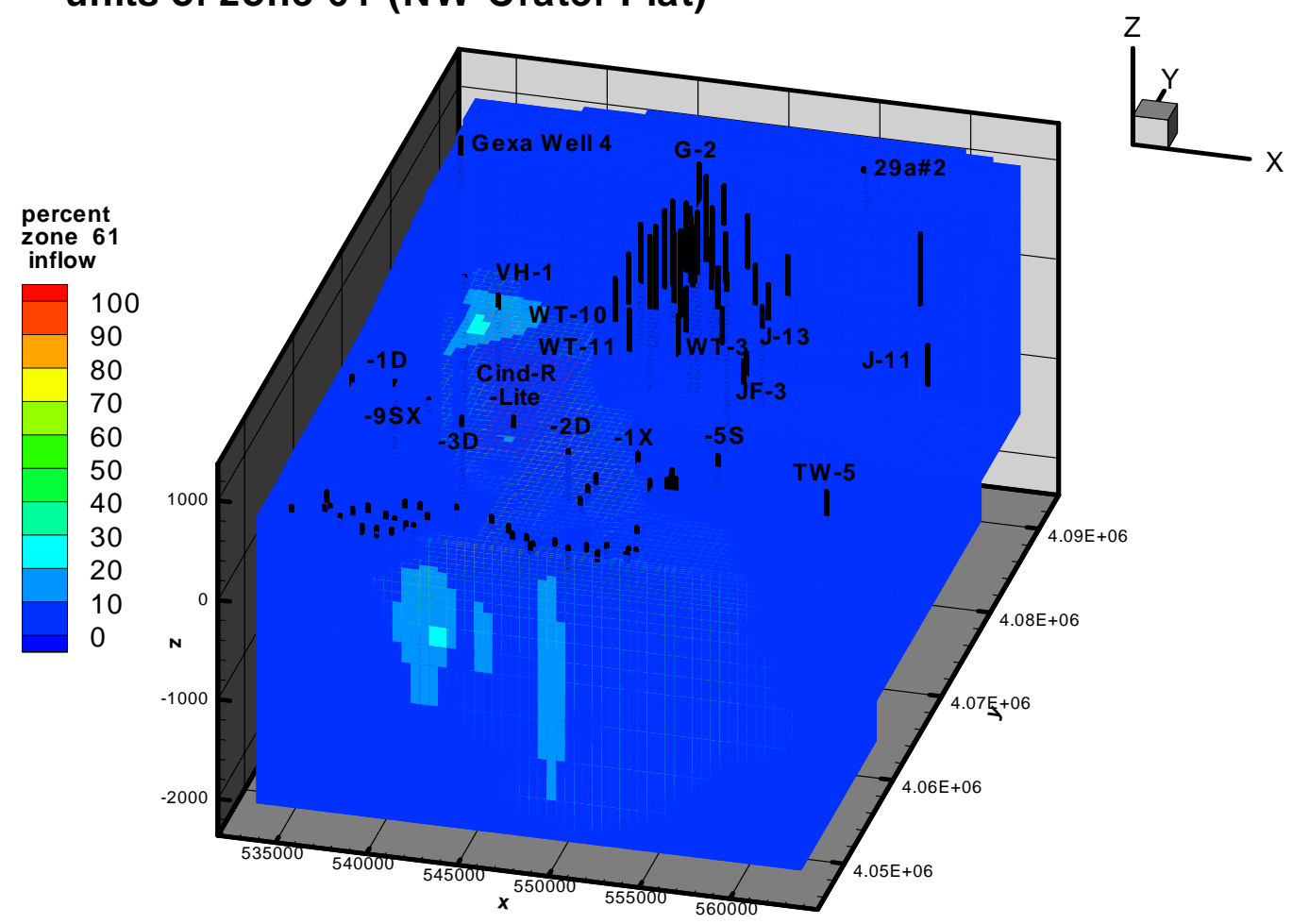

Output DTN: LA0304TM831231.002.

DTN: LA0309EK831231.001 [DIRS 171887].

NOTES: The $X$ and $Y$ coordinates are Universal Trans-Mercator Projection (UTM) coordinates in meters. The $Z$ coordinate is elevation relative to sea level in meters. $X=U T M-E a s t i n g$ and $Y=U T M-N o r t h i n g$.

Figure A6-54. Map View of Steady-State Distribution of the Percentage of Inflow through the Pre-Tertiary Units of Northwest Crater Flat Groundwater Calculated Using the Saturated Zone Flow Model 


\section{Steady-state distribution of inflow through the pre-Tertiary units of zone 61 (NW Crater Flat)}

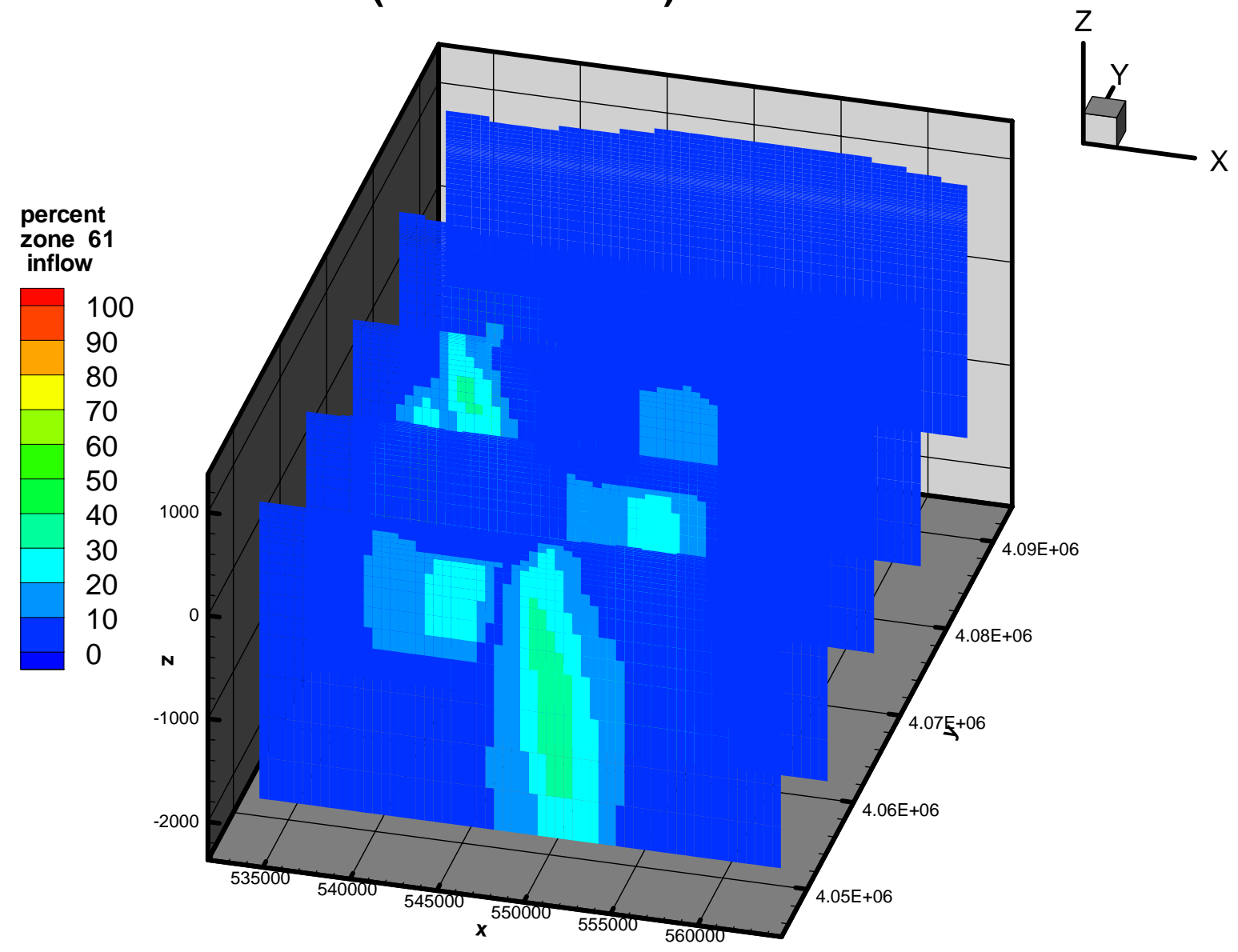

Output DTN: LA0304TM831231.002.

DTN: LA0309EK831231.001 [DIRS 171887].

NOTES: The $X$ and $Y$ coordinates are Universal Trans-Mercator Projection (UTM) coordinates in meters. The $Z$ coordinate is elevation relative to sea level in meters. $X=U T M-E a s t i n g$ and $Y=U T M-N o r t h i n g$.

Figure A6-55. Cross Sectional View of Steady-State Distribution of the Percentage of Inflow through the Pre-Tertiary Units of Northwest Crater Flat Groundwater Calculated Using the Saturated Zone Flow Model 


\section{Steady-state distribution of inflow through Tertiary units of zone 61 (NW Crater Flat)}

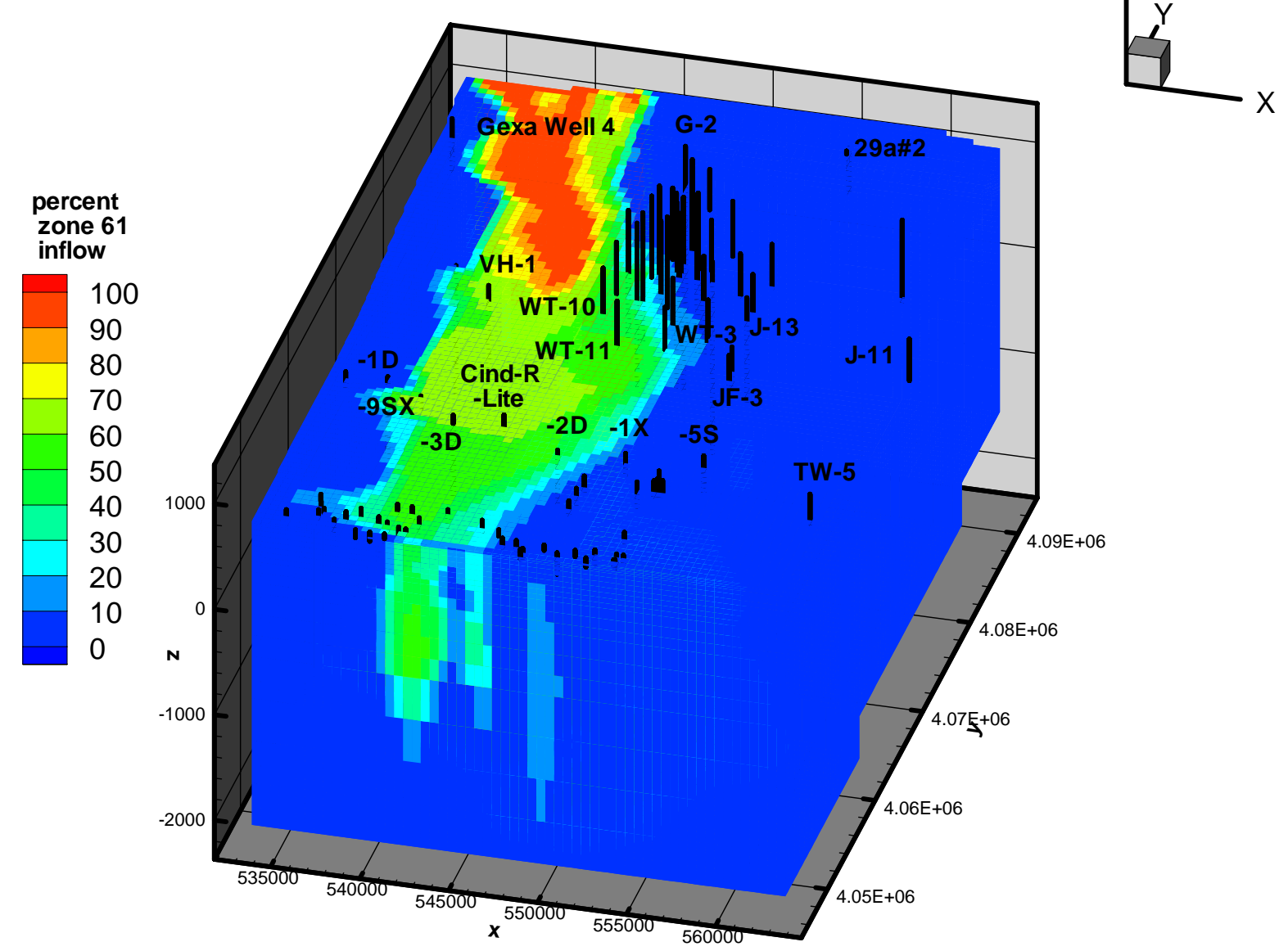

Output DTN: LA0304TM831231.002.

DTN: LA0309EK831231.001 [DIRS 171887].

NOTES: The $X$ and $Y$ coordinates are Universal Trans-Mercator Projection (UTM) coordinates in meters. The $Z$ coordinate is elevation relative to sea level in meters. $X=U T M-E a s t i n g$ and $Y=U T M-N o r t h i n g$.

Figure A6-56. Steady-State Distribution of the Percentage of Inflow through the Tertiary Units of Northwest Crater Flat Groundwater Calculated Using the Saturated Zone Flow Model 


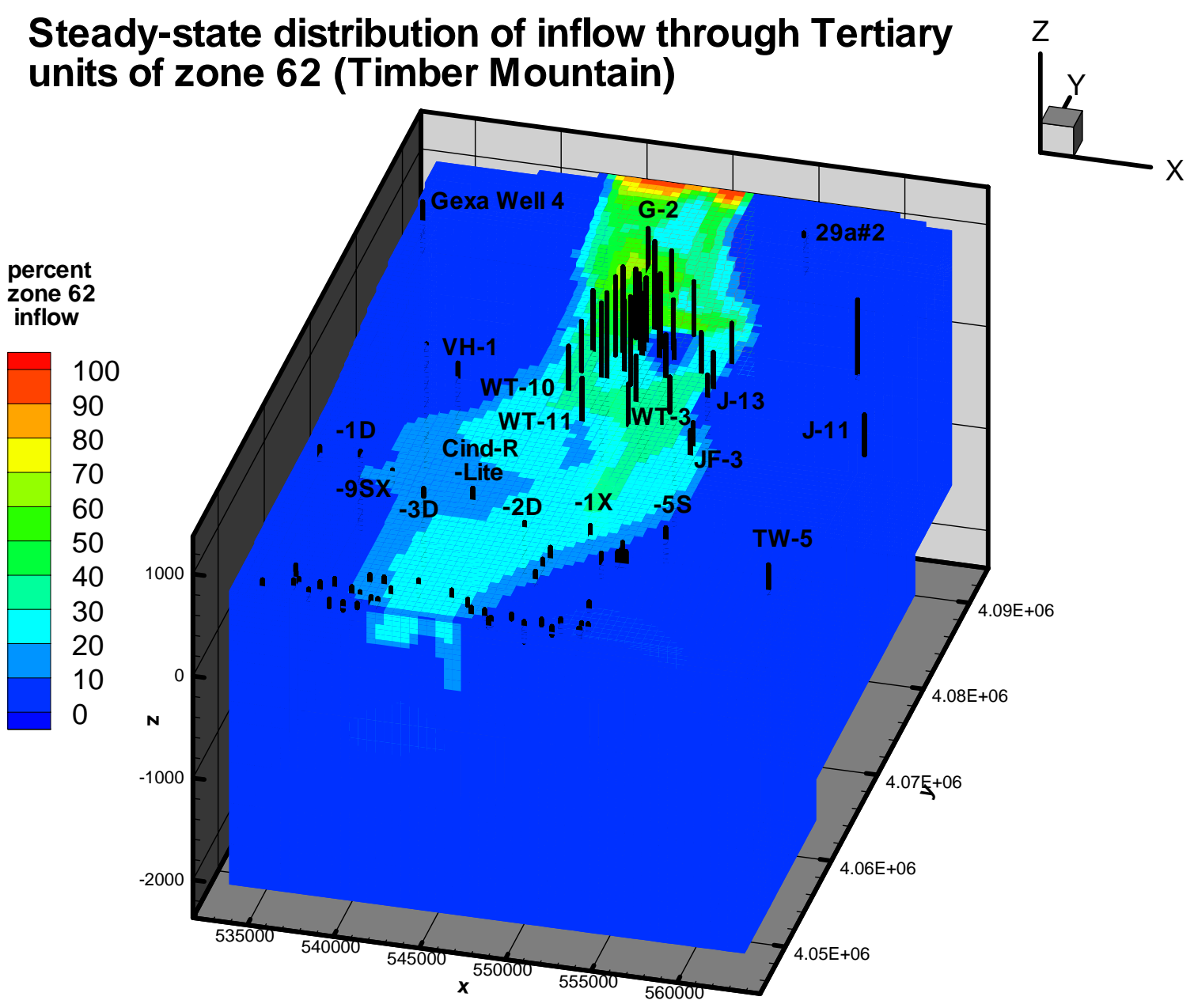

Output DTN: LA0304TM831231.002.

DTN: LA0309EK831231.001 [DIRS 171887].

NOTES: The $X$ and $Y$ coordinates are Universal Trans-Mercator Projection (UTM) coordinates in meters. The $Z$ coordinate is elevation relative to sea level in meters. $X=U T M-E a s t i n g$ and $Y=U T M-N o r t h i n g$.

Figure A6-57. Steady-State Distribution of the Percentage of Shallow Timber Mountain Area

Groundwater through the Tertiary Units Calculated Using the Saturated Zone Flow Model 
Groundwater entering the model domain from the pre-Tertiary rocks of Zone 63 near Fortymile Canyon follows a sinuous pathway through the Fortymile Wash area and western Jackass Flats as it moves southward through the model (Figures A6-58 and A6-59). The sinuous movement of this tracer plume in the model may be related to the deflection of groundwater eastward around the buried ridge of the Lower Clastic Confining unit in the southwestern part of the model (Figure A6-52) and, later, by the large amount of inflow from Zone 81 in the southeast part of the model (see below). Groundwater from the pre-Tertiary rocks of Zone 63 is predicted by the SZ flow model to be a small component of the shallow groundwater at borehole JF-3 (Site 37) and other Fortymile Wash area boreholes in the northern Amargosa Desert and in the Amargosa Valley area. The groundwater from the pre-Tertiary rocks of Zone 63 could be the component of groundwater from western Jackass Flats predicted from an analysis of sulfur isotopes to be present in minor amounts in some LW and FMW-E groundwaters (Figure A6-51).

The steady-state distribution of groundwater entering the Fortymile Canyon area of the model through the Tertiary rocks of Zone 63 indicates that this groundwater is diluted by groundwater from other areas, including Yucca Mountain (Figure A6-60) by the time it has reached well J-13 (Site 35) in Fortymile Wash. The shallow groundwater entering Zone 63 again becomes a small component of the groundwater southward along Fortymile Wash near JF-3 (Site 37) and in southern Yucca Mountain near well NC-EWDP-2D (Site 91), but does not persist as an identifiable part of the groundwater in the FMW-S area wells. Dilution of the shallow inflow from Zone 63 by downgradient recharge along Fortymile Wash is not a plausible explanation for the dilution of the Zone 63 in flow, given the small amount of Fortymile Wash recharge present in the model. The geochemical and isotopic data from the FMW-N and FMW-S wells indicate a much more significant component of inflow from Zone 63, and perhaps of recharge along the wash, than is indicated by the SZ flow model.

Like groundwater from the pre-Tertiary units of Zone 63, the groundwater entering the northern boundary through the pre-Tertiary rocks of Zone 64 beneath Shoshone Mountain follows a sinuous trajectory through western Jackass Flats and emerges into the shallow flow system in the vicinity of well NC-EWDP-5S (Site 154) of the Amargosa Valley area (figure not shown). Some of the groundwater entering the model through Zone 64 leaves the model along its eastern boundary. The model results suggest that the deep groundwater from Zone 64 could also be the component of groundwater from western Jackass Flats identified from $\delta^{34} \mathrm{~S}$ analysis to be present in some of the LW and FMW-E area wells. The Tertiary rocks of Zone 64 are comprised of confining units (Figure A6-52) and virtually no groundwater enters the model through these rocks.

The groundwater in the southeast corner of the model near the Skeleton Hills area is dominated by inflow from pre-Tertiary rocks of Zone 81 (Figure A6-61). The model results are consistent with the geochemical and isotopic data from this area, which suggest that the groundwaters near the Gravity fault, and as far west as NC-EWDP-5S (Site 154) and some LW- and FMW-E area wells, contain a component of groundwater from the carbonate aquifer leaking into the alluvium across the Gravity fault. 


\section{Steady-state distribution of inflow through the pre- Tertiary units of zone 63 (Fortymile Canyon)}

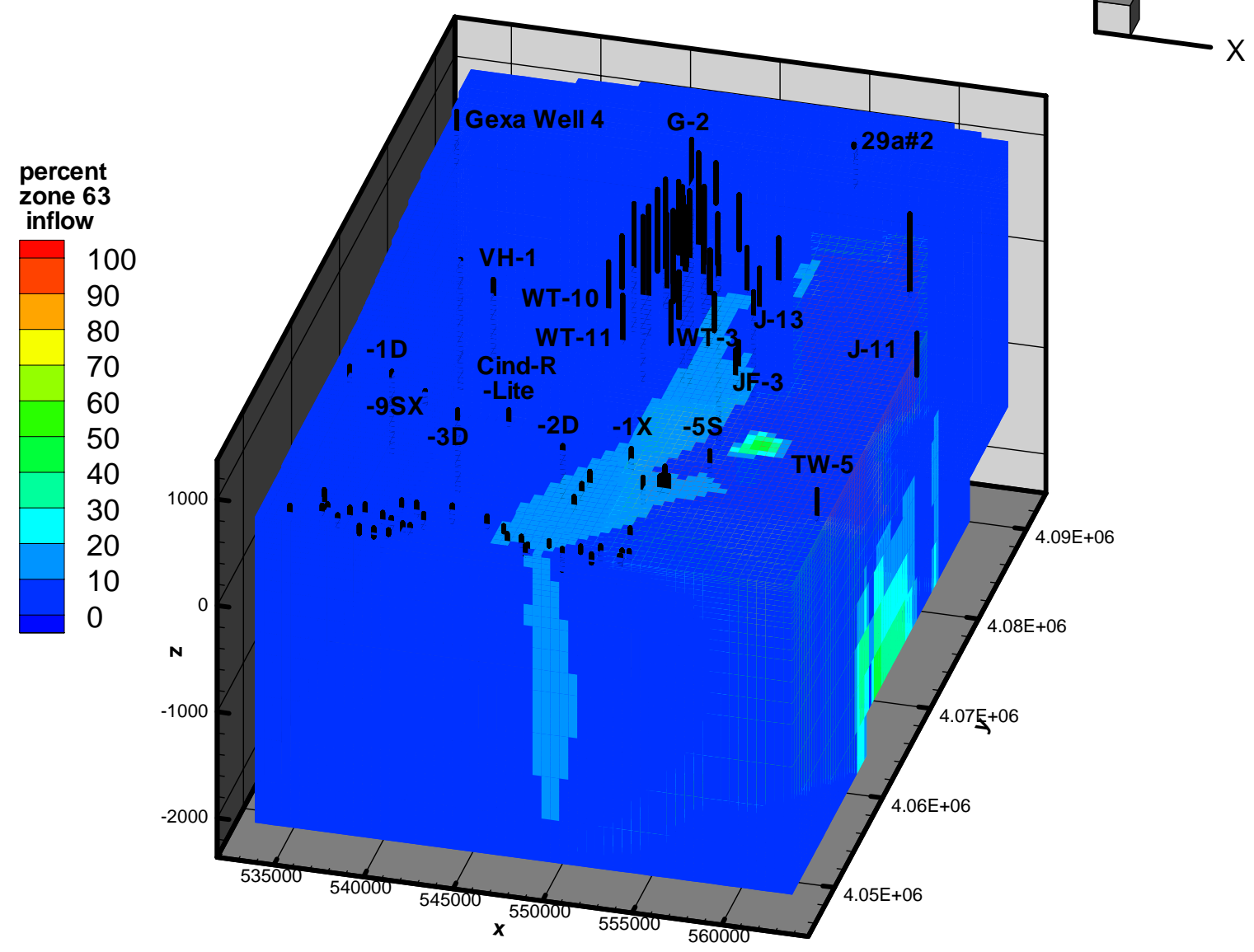

Output DTN: LA0304TM831231.002.

DTN: LA0309EK831231.001 [DIRS 171887].

NOTES: The $X$ and $Y$ coordinates are Universal Trans-Mercator Projection (UTM) coordinates in meters. The $Z$ coordinate is elevation relative to sea level in meters.

Figure A6-58. Map View of Steady-State Distribution of the Percentage of Shallow Upper Fortymile Wash Area Groundwater through the Pre-Tertiary Units Calculated Using the Saturated Zone Flow Model 


\section{Steady-state distribution of inflow through the pre- Tertiary units of zone 63 (Fortymile Canyon)}

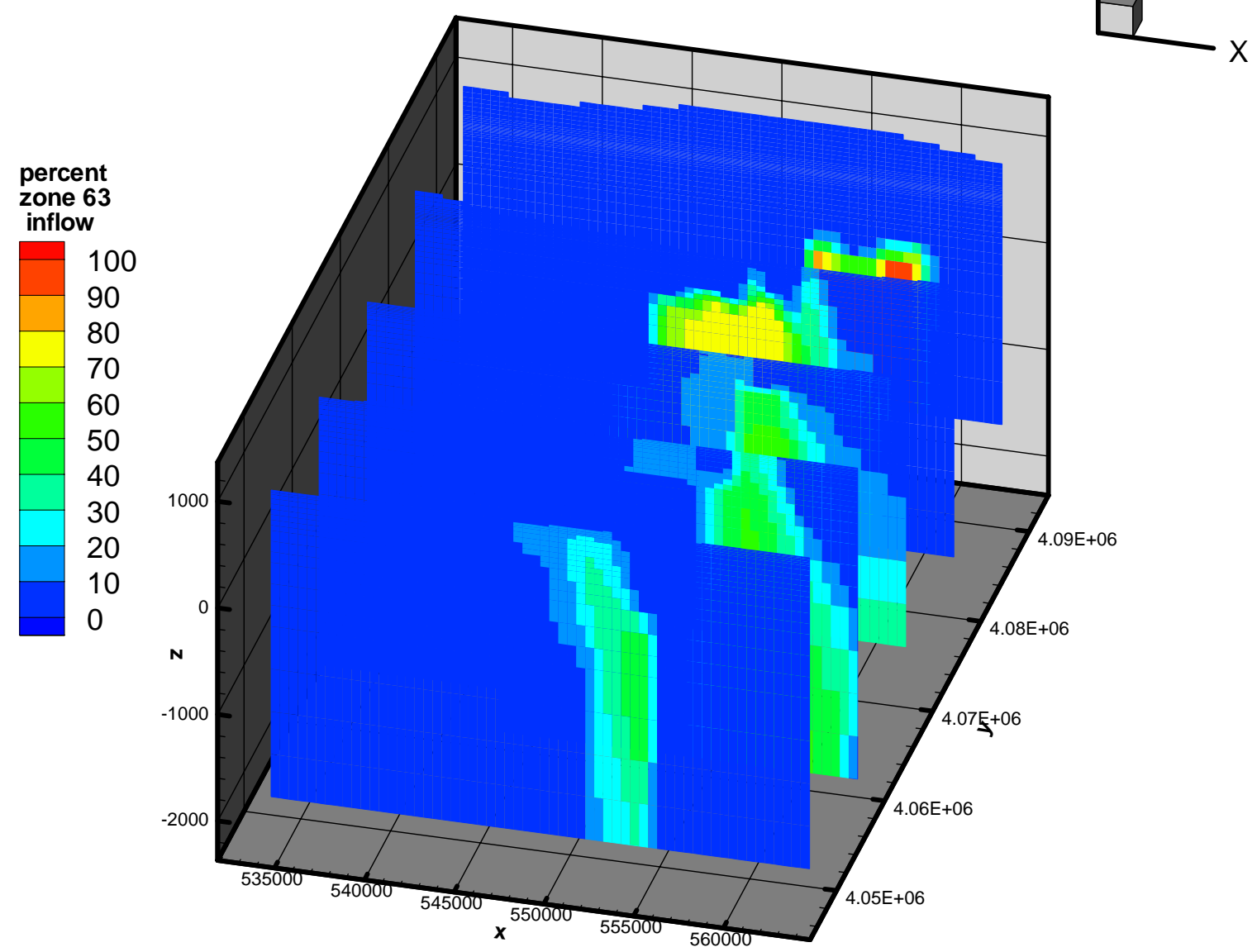

Output DTN: LA0304TM831231.002.

DTN: LA0309EK831231.001 [DIRS 171887].

NOTES: The $X$ and $Y$ coordinates are Universal Trans-Mercator Projection (UTM) coordinates in meters. The $Z$ coordinate is elevation relative to sea level in meters.

Figure A6-59. Cross Sectional View of Steady-State Distribution of the Percentage of Shallow Upper Fortymile Wash Area Groundwater through the Pre-Tertiary Units Calculated Using the Saturated Zone Flow Model 


\section{Steady-state distribution of inflow through Tertiary units along zone 63 (Fortymile Canyon)}

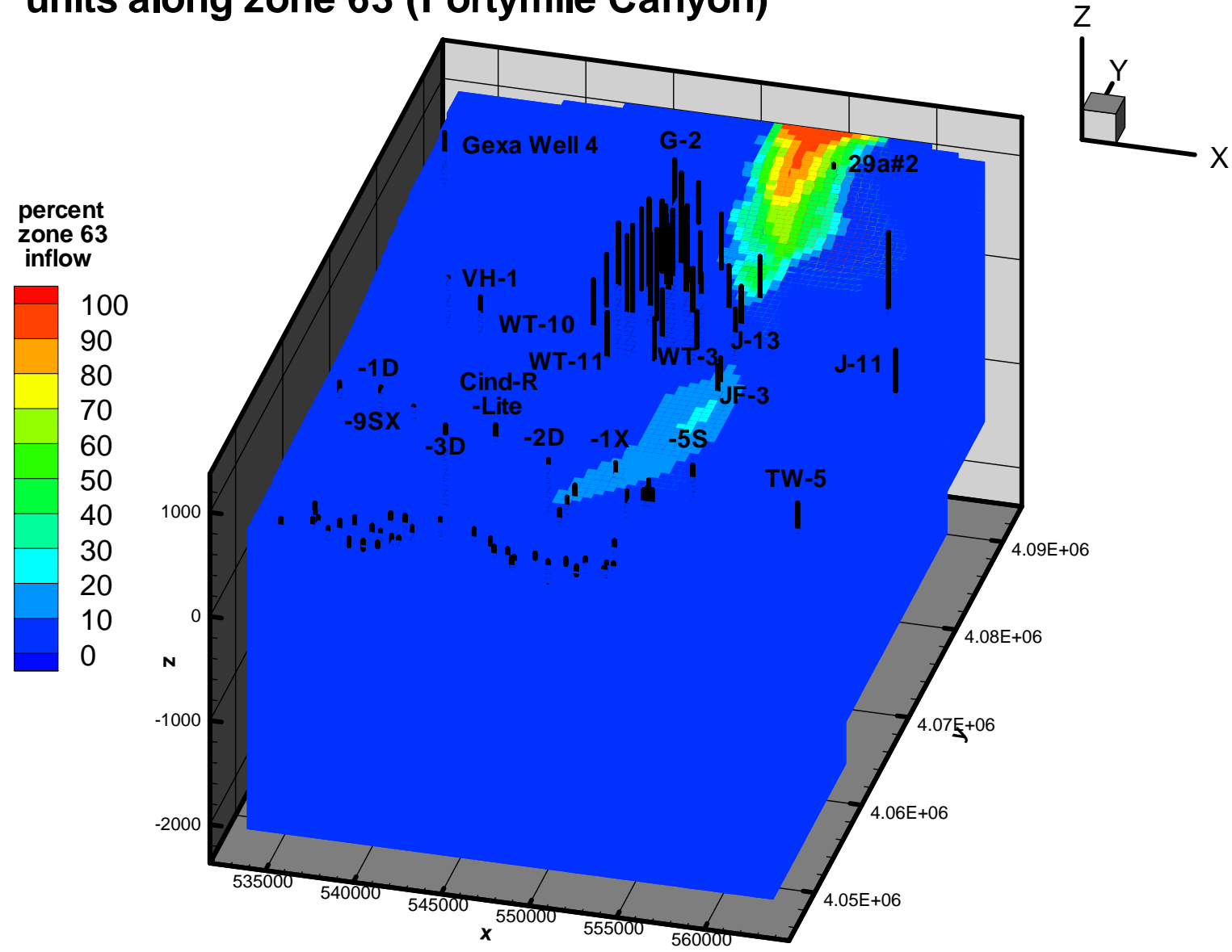

Output DTN: LA0304TM831231.002.

DTN: LA0309EK831231.001 [DIRS 171887].

NOTES: The $X$ and $Y$ coordinates are Universal Trans-Mercator Projection (UTM) coordinates in meters. The $Z$ coordinate is elevation relative to sea level in meters.

Figure A6-60. Steady-State Distribution of the Percentage of Shallow Upper Fortymile Wash Area Groundwater through the Tertiary Units Calculated Using the Saturated Zone Flow Model 


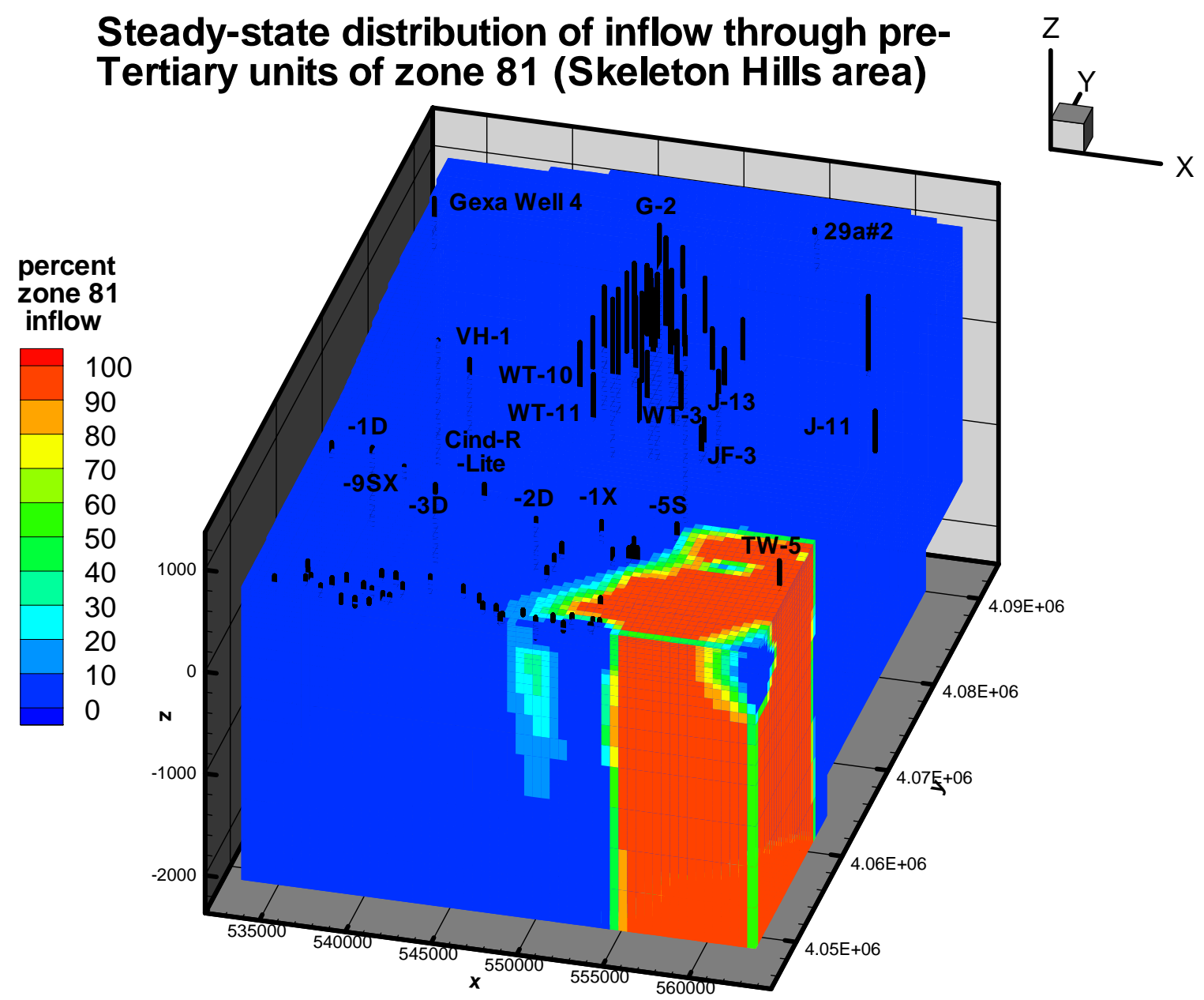

Output DTN: LA0304TM831231.002.

DTN: LA0309EK831231.001 [DIRS 171887].

NOTES: The $X$ and $Y$ coordinates are Universal Trans-Mercator Projection (UTM) coordinates in meters. The $Z$ coordinate is elevation relative to sea level in meters.

Figure A6-61. Steady-State Distribution of the Percentage of Pre-Tertiary Rocks of the Skeleton Hills Area Groundwater Calculated Using the Saturated Zone Flow Model

In summary, the flow patterns and mixing relations identified with the SZ flow model are similar in many ways to the flow patterns and mixing relations inferred from the hydrochemical and isotopic data for the area. Of particular importance are the simulations of movement of recharge from the Yucca Mountain area. These simulations indicate that groundwater from Yucca Mountain may not be easily identifiable in groundwaters south of Yucca Mountain because of dilution by groundwater from other, more active parts of the flow system. The SZ flow model appears to underestimate the quantity of inflow from the Fortymile Canyon area through the Tertiary units. This conclusion is based on the observation that groundwater along Fortymile 
Wash through Jackass Flats and the Amargosa Desert is chemically and isotopically unique compared to the surrounding groundwaters, but the tracer simulations indicate that groundwater inflow from Fortymile Canyon or from downgradient recharge along the wash is present only in dilute amounts along Fortymile Wash. Some of the discrepancy between the simulations and the data for the Fortymile Wash area may be due to recharge of some or most of this chemically distinct groundwater during wetter climate periods.

\section{A6.3.11 Regional Flow Paths Inferred from Hydrochemical Data}

Groundwater flow paths and mixing zones are identified on the basis of the preceding discussions of measured and calculated geochemical and isotopic parameters. The hydraulic gradient shown on the potentiometric surface map (Figure A6-3) is used to constrain flow directions only insofar as groundwater cannot flow from areas of lower hydraulic head to areas of higher hydraulic head. Chemical and isotopic composition of groundwater were then used to locate flow pathways in the context of the hydraulic gradient and considering the possibility that flow paths can be oblique to the potentiometric gradient because of anisotropy in permeability.

The analysis of flow paths that follows assumes that $\mathrm{Cl}^{-}$and $\mathrm{SO}_{4}{ }^{2-}$ values are conservative and that changes to these are due to mixing along flow paths. This same assumption holds for isotopes of hydrogen and oxygen; however, because recharge waters have almost certainly changed over time, it is to be expected that isotopic variability in these constituents will occur in groundwaters of different ages (Benson and Klieforth 1989 [DIRS 104370], Figure 11; Winograd et al. 1992 [DIRS 100094], Figure 2). In spite of the potential reactive nature of $\mathrm{Na}$ and $\mathrm{Ca}$, the contrast in concentrations between some areas is great enough that meaningful inferences about flow directions can be made.

Flow paths can be traced using conservative constituents only where compositional differences exist that allow some directions to be eliminated as possible flow directions. Some chemical and isotopic species in some areas have relatively uniform compositions and, thus, provide no information about flow paths. In other areas, they show more distinct compositional differences and, thus, can be used to infer flow directions. Because no single chemical or isotopic species varies sufficiently to determine flow paths everywhere in the study area, multiple lines of evidence were used to construct the flow paths inferred in this section. This evidence includes the areal distribution of chemical and isotopic species, sources of recharge, groundwater ages and evaluation of mixing/groundwater evolution through scatterplots, and inverse mixing and reaction models as presented in the previous sections.

Flow path 1 (Figure A6-62) traces the movement of groundwater southeastward from Oasis Valley (OV/NWA group) through the Amargosa Desert along the axis of the Amargosa River (AR and AR/FMW groups) to its confluence with Fortymile Wash (FMW-S group). This flow path is identified from areal plots of chloride (Figure A6-15) and scatterplots of $\mathrm{SO}_{4}{ }^{2-}$ versus $\mathrm{Cl}^{-}$(Figure A6-50) that support this flow path. It is inferred from Figure A6-50 that the more dilute groundwater from the Oasis Valley area (OV/NWA group) became concentrated by evapotranspiration (ET) as it moves from the Oasis Valley area into the northwestern Amargosa Desert toward sites 15-17. This inference is based on the common trend of the OV/NWA and AR groups in Figure A6-50, which indicates that the composition of the AR group can be derived by concentrating groundwater from the OV/NWA group through evapotranspiration 
downgradient from the Oasis Valley sample locations. Data contained in White (1979 [DIRS 101165], Table 2, sample sites 28 and 29) corroborate this interpretation. These data show that groundwater exiting Oasis Valley through Beatty Narrows into the NW Amargosa Desert has a $\mathrm{Cl}^{-}$concentration of between 76.9 and $100.0 \mathrm{mg} / \mathrm{L}$ and $\mathrm{SO}_{4}{ }^{2-}$ concentrations of between 183.5 and $249.8 \mathrm{mg} / \mathrm{L}$. The more dilute solute concentration of these two samples is nearly identical to that from Sites 15-17. The data in Figure A6-50 also indicate that groundwater in the CF-SW group has a much lower $\mathrm{Cl}^{-}$concentration than groundwater in the AR group, making it unlikely that groundwater from the CF-SW wells is a major component of groundwater in the AR and FMW-W wells. Groundwater along flow path 1 becomes more dilute in the AR/FMW wells as it becomes increasingly mixed with FMS-S group groundwater near Fortymile Wash (see below). Northwest of this mixing zone, high groundwater ${ }^{14} \mathrm{C}$ activities (Figure A6-28) and variable $\delta \mathrm{D}$ (Figure A6-24) and $\delta^{18} \mathrm{O}$ (Figure A6-25) compositions at the AR wells indicate the presence of relatively young recharge in the groundwater due to runoff or irrigation in the area.

Flow path 2 (Figure A6-62) traces the movement of groundwater from the Fortymile Canyon area southward along the axis of Fortymile Wash into the Amargosa Desert. This flow pathway is drawn on the basis of similar anion and cation concentrations along the flow line and dissimilarities compared to regions to the east and west (see, for example, Figures A6-15, A6-16, and A6-22). Groundwater along the northern part of this flow path (FMW-N groups samples) is distinguished from groundwater at Yucca Mountain by $\delta \mathrm{D}$ and $\delta^{18} \mathrm{O}$ compositions that are heavier and/or more offset from the global meteoric water line $\left(\delta \mathrm{D}=8 \delta^{18} \mathrm{O}+10\right)$ than the groundwater found under Yucca Mountain (Figure A6-48). It is inferred that the groundwater found along the FMW-S wells in the Amargosa Desert is derived, in part, from groundwater flow from the FMW-N wells, based on the similarly dilute $\mathrm{SO}_{4}{ }^{2-}$ (Figure A6-16) and $\mathrm{Cl}^{-}$(Figure A6-15) compositions of these groundwaters. Differences in the $\delta \mathrm{D}$ compositions of the FMW-N and FMW-S groundwaters (Figure A6-24) are attributed to the effects of changing climatic conditions on the $\delta \mathrm{D}$ composition of recharge (see Section A6.3.6.6.1). Groundwater flow from the FMW-N area wells southward into the Amargosa Desert along the axis of the wash is also compatible with expected and observed chemical evolution trends between the two areas, such as downgradient increases in $\mathrm{pH}$ (Figure A6-14), calcite saturation indices (Figure A6-37), and $\mathrm{HCO}_{3}{ }^{-}$(Figure A6-17) and $\mathrm{SiO}_{2}$ (Figure A6-1) concentrations. Some part of the groundwater along Fortymile Wash may also be derived by recharge from overland flow, based on the observation that ${ }^{14} \mathrm{C}$ activities do not decrease systematically southward in either the northern or southern segments of the wash (Figure A6-28). Groundwater flow from the eastern and western parts of the Amargosa Desert toward Fortymile Wash is relatively minor, however, based on the much higher solute contents (Figures A6-15 to A6-17, and A6-34) and distinct isotopic compositions (Figures A6-26 and A6-27) of groundwaters adjacent to the FMW-S area wells. 
Flow path 3 (Figure A6-62) traces the movement of groundwater from Jackass Flats in the vicinity of well J-11 (Site 67) as it moves along the western edge of the Amargosa Valley (LW) area wells and arcs southward through the FMW-E area wells. The identification of groundwater from Jackass Flats in this mixture of groundwaters is possible because the high $\mathrm{SO}_{4}{ }^{2-}$ and low $\delta^{34} \mathrm{~S}$ characteristics of groundwater from well $\mathrm{J}-11$ distinguish it from the high $\mathrm{SO}_{4}{ }^{2-}$ and high $\delta^{34} \mathrm{~S}$ groundwater characteristic of the Gravity fault (GF group) and the low $\mathrm{SO}_{4}{ }^{2-}$ and low $\delta^{34} \mathrm{~S}$ groundwater of the Fortymile Wash area (FMW-S group) on scatterplots of $\delta^{34} \mathrm{~S}$ versus $1 / \mathrm{SO}_{4}{ }^{2-}$ concentration (Figure A6-51). A source for this high $\mathrm{SO}_{4}{ }^{2-}$ groundwater from Jackass Flats rather than the Gravity fault area is also indicated by the similarly light $\delta^{13} \mathrm{C}$ of groundwater along this flow path (Figure A6-27).

Flow path 4 (Figure A6-62) traces the movement of groundwater from the lower Beatty Wash area (southern TM group samples) into northwestern Crater Flat. This groundwater flows predominantly southward in Crater Flat through Sites 69 (borehole VH-1) and Site 86 (NC-EWDP-3D). The chemistry and isotopic composition of this groundwater appears to be a mixture of subequal amounts of groundwater from Sites 22 and 23 in lower Beatty Wash, with much smaller amounts of recharge from local runoff in Crater Flat or groundwater flow from Site 24 (Section A6.3.8.4). Dashed lines are used to illustrate these relationships on Figure A6-62. Groundwater from Site 68 (GEXA Well 4), which may be groundwater from Site 23 modified by recharge from surface runoff (Section A6.3.8.3), also contributes groundwater to this flow path. Scatterplots and PHREEQC inverse models (Sections A6.3.8.3 and A6.3.8.4) show that a mixture of groundwater from Sites 22 and 23 is required to account for both the relatively low $\mathrm{Cl}^{-}$and the light $\delta^{18} \mathrm{O}$ and $\delta \mathrm{D}$ activity ratios characteristic of this flow path, whereas small amounts of recharge from local runoff or flow from Site 24 are needed to decrease the $\delta^{13} \mathrm{C}$ of the lower Beatty Wash groundwater.

Most groundwater at Timber Mountain north of Yucca Mountain (TM group) is characterized by $\delta^{13} \mathrm{C}$ values that are too heavy (-6 to 0 per mil) and ${ }^{14} \mathrm{C}$ values that are too low for it to be a major source of groundwater at Yucca Mountain (Figure A6-45). The absence of significant amounts of Timber Mountain groundwater beneath Yucca Mountain is also indicated by the extremely low $\delta^{87} \mathrm{Sr}$ and high $\mathrm{Sr}^{2+}$ concentration of the Timber Mountain groundwater compared to Yucca Mountain (Figure A6-32 and A6-31). The extremely light $\delta^{13} \mathrm{C}$ (Figures A6-27 and A6-45) and high $\delta^{87} \mathrm{Sr}$ (Figure A6-32) of groundwater in northern Yucca Mountain (YM-CR group) compared to Timber Mountain (TM group) groundwater indicates that groundwater from the Timber Mountain/Beatty Wash area does not flow south through northern Yucca Mountain. One well in upper Beatty Wash (Site 24 - ER-EC-07) has a high ${ }^{14} \mathrm{C}$ activity (Figure A-28), and $\delta^{13} \mathrm{C}$ (Figure A6-27) and $\delta^{87} \mathrm{Sr}$ values (Figure A6-32) similar to those of groundwaters in the Solitario Canyon Wash area (SCW group) and to groundwater south of Drill Hole Wash at Yucca Mountain. Based on Figure A6-45, some groundwater from the area of well ER-EC-07 in upper Beatty Wash could be present in Yucca Mountain groundwater south of Drill Hole Wash (YM-C, YM-SE and YM-S groups) and along Solitario Canyon Wash (SCW group) if sorption on rock removed most of the $\mathrm{Sr}^{2+}$ from the Beatty Wash area along its flow path. 
Flow path 5 (Figure A6-62) traces groundwater with a distinct chemical composition that comprises the SW Crater Flat (CF-SW) Group. Groundwater from site 70 (borehole VH-2) is chemically and isotopically distinct from groundwater that characterizes flow path 4, with higher concentrations of many major ions (Figures A6-15 to A6-17) (but lower concentrations of $\mathrm{F}$ (Figure A6-18) and $\mathrm{SiO}_{2}$ (Figure A6-19)) and relatively high $\delta^{18} \mathrm{O}$ (Figure A6-25) and $\delta \mathrm{D}$ (Figures A6-24 and A6-49) values. The $\delta^{18} \mathrm{O}$ and $\delta \mathrm{D}$ of groundwater from borehole VH-2 is similar to groundwater from Species Spring (Rose et al. 1997 [DIRS 144725]), a perched spring at Bare Mountain, suggesting that groundwater at borehole VH-2 and other CF-SW group wells are derived principally from local recharge and runoff from Bare Mountain. Dashed east and southeast-oriented lines schematically illustrate this flow (Figure A6-62). Groundwater in Oasis valley has some of the lightest groundwater $\delta \mathrm{D}$ and $\delta^{18} \mathrm{O}$ values in the Yucca Mountain area (Figures A6-24 and A6-25), eliminating flow from Oasis Valley under Bare Mountain as a possible source of groundwater in southwest Crater Flat. The similar chemical and isotopic characteristics between groundwater from borehole VH-2 and other southwest Crater Flat boreholes (Section A6.3.4) and PHREEQC models of Sites 77 and 81 (Sections A6.3.8.5 and A6.3.8.6) indicate a dominantly north-south flow along this flow path as far south as these sites. Importantly, the chemically distinct groundwater along this flow pathway is not observed in boreholes to the south in the Amargosa Desert (AR and FMW-S groups) (for example, see Figure A6-50). Mixing relationships discussed in connection with Figure A6-49, and PHREEQC models of Sites 86 and 90 (Sections A6.3.8.7 and A6.3.8.8), suggest that this groundwater likely flows to the east and southeast and mixes with wells from the YM-S group (Figure A6-49).

Flow path 6 (Figure A6-62) traces the movement of groundwater from Site 42 (well WT-10) southward toward Sites 89 (Cind-R-Lite well) and 90 (well NC-EWDP-15P). This flow path is identified from PHREEQC models that indicate that groundwater from well NC-EWDP-15P is formed from subequal amounts of groundwater from Sites 69 (well VH-1) and 42 (well WT-10), with a minor component (5 percent) of groundwater like that from Site 70 (well VH-2) (see Section A6.3.8.8). Mixing trends indicated by plots of $\mathrm{Cl}$ versus $\delta \mathrm{D}$ (Figure A6-49) also suggest leakage from Crater Flat toward the YM-S group in southern Yucca Mountain. Although the predominant direction of flow from the Solitario Canyon (SCW group) area is southward along the Solitario Canyon fault, evidence for the leakage of small amounts of groundwater eastward across the fault is also provided by similarities in the ion concentrations and isotopic values of groundwaters in the SCW and YM-CR area wells (Section A6.3.6.3, Figures A6-42 to A6-46). This chemical and isotopic similarity indicates that groundwater as far east as borehole NC-EWDP-19D may have some component of groundwater from the Solitario Canyon Wash area. The short southeast-oriented dashed lines from Solitario Canyon group wells schematically illustrate this leakage. 


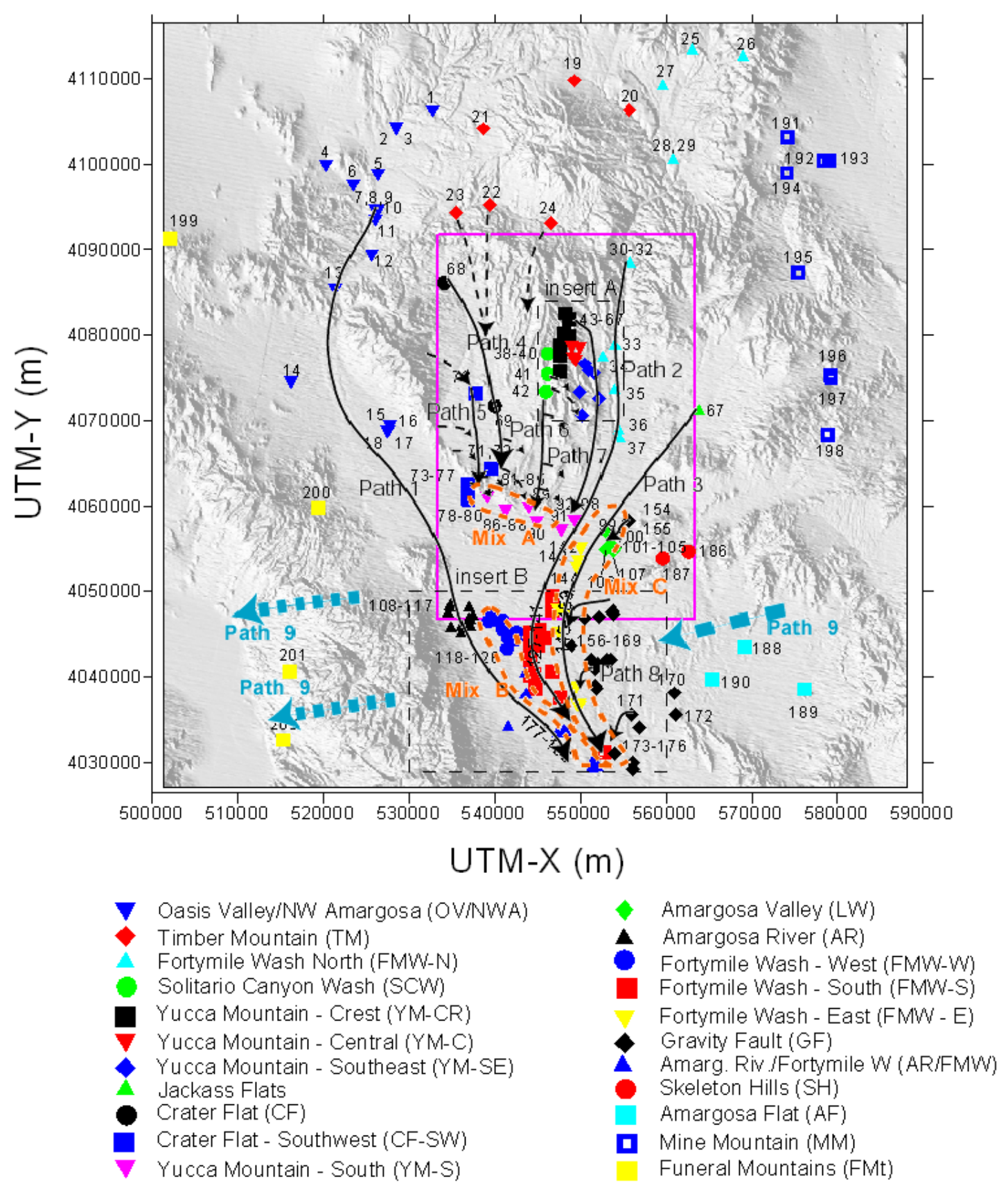

DTN: LA0308RR831233.001 [DIRS 171890].

NOTES: This figure has color-coded data points and should not be read in a black and white version. Solid lines indicate a relatively high degree of confidence in the interpretations; dashed flow paths indicate relatively less confidence. Base map shows borehole designators and inserts; for reference see Figure A6-5 and Table A4-3. UTM-X =UTM-Easting and UTM-Y =UTM-Northing. UTM=Universal Transverse Mercator.

Figure A6-62. Regional Flow Paths Inferred from Hydrochemical and Isotopic Data 
Flow path 7 (Figure A6-62) traces the movement of groundwater from northern Yucca Mountain southeastward toward YM-SE wells in the Dune Wash area and then southwestward along the western edge of Fortymile Wash. The upper segment of this flow path is motivated by the high groundwater ${ }^{234} \mathrm{U} /{ }^{238} \mathrm{U}$ activity ratios found in the northern Yucca Mountain and Dune Wash areas (Figure A6-47). High ${ }^{234} \mathrm{U} /{ }^{238} \mathrm{U}$ activity ratios (greater than 7) typify both perched water and groundwater along and north of Drill Hole Wash but not groundwater along Yucca Crest at borehole SD-6 (Site 50) or perched water at borehole SD-7. Based on the conceptual model for the evolution of ${ }^{234} \mathrm{U} /{ }^{238} \mathrm{U}$ activity ratios described in Section A6.3.6.2, dissolution of thick vitric tuffs that underlie the Topopah Spring welded tuff along Yucca Crest south of Drill Hole Wash would be expected to decrease the ${ }^{234} \mathrm{U} /{ }^{238} \mathrm{U}$ activity ratios of deep unsaturated zone percolation south of the Wash. High ${ }^{234} \mathrm{U} /{ }^{238} \mathrm{U}$ activity ratios are expected only where these vitric tuffs are absent, as in northern Yucca Mountain. Results of a PHREEQC analysis of the evolution of groundwater between site 44 (well WT-24) in northern Yucca Mountain and Site 65 (well WT-3) in the Dune Wash area are consistent with this segment of flow path 7 (Section A6.3.8.9). The southern segment of flow path 7 is based on PHREEQC analyses of groundwater evolution between well WT-3 and various depth intervals of well NC-EWDP-19D (Sites 92 and 94 to 98) (Section A6.3.8.10). Groundwater at well NC-EWDP-19D has low $\mathrm{Cl}^{-}$(Figure A6-15) and $\mathrm{SO}_{4}{ }^{2-}$ (Figure A6-16) concentrations that are characteristic of groundwater at well WT-3. The light $\delta^{18} \mathrm{O}$ and $\delta \mathrm{D}$ values eliminate Fortymile Wash as a possible source of the dilute groundwater at well NC-EWDP-19D (Figures A6-24, A6-25, A6-44 and A6-48). An alternative set of PHREEQC analyses was developed that interprets the groundwater at NC-EWDP-19D to be a result of the mixing of groundwater from well WT-10 and local southern Yucca Mountain recharge, as represented by perched water from borehole SD-7 (Section A6.3.8.10). Both sets of models explain the major-ion chemistry and $\delta^{13} \mathrm{C}$ values of groundwater at NC-EWDP-19D. The arrows leading from flow path 6 toward NC-EWDP-19D (Figure A6-62) reflect this alternative groundwater path. It should also be noted that the $\delta^{18} \mathrm{O}$ and $\delta \mathrm{D}$ values of groundwater at well NC-EWDP-19D are substantially lighter than for groundwater at either wells WT-3 or WT-10, requiring that climate change be invoked as a possible explanation for their differences.

Flow Path 8 (Figure A6-62) schematically illustrates leakage of groundwater from the carbonate aquifer (GF and AF Groups) across the Gravity fault. Hydrogeologists and geochemists have recognized this leakage across the fault for many years (Winograd and Thordarson 1975 [DIRS 101167]; Claassen 1985 [DIRS 101125]). These hypotheses are also compatible with the hydraulic gradient and our understanding of the regional groundwater flow patterns (Lacziak et al. 1996 [DIRS 103012]). The carbonate aquifer component in this groundwater is recognized by many of the same chemical and isotopic characteristics that typify groundwater discharging from the carbonate aquifer at Ash Meadows. These characteristics include high concentrations of $\mathrm{Ca}^{2+}$ (Figure A6-20) and $\mathrm{Mg}^{2+}$ (Figure A6-21), low $\mathrm{SiO}_{2}$ (Figure A6-19), heavy $\delta^{13} \mathrm{C}$ values (Figure A6-27), low ${ }^{14} \mathrm{C}$ activity (Figure 6-28), and comparable $\delta^{18} \mathrm{O}$ and $\delta \mathrm{D}$ values as the Ash Meadows groundwater. Westward seepage of this groundwater mixes with the southward flow of groundwater along path 3 to produce groundwater with compositions intermediate between the two (Section A6.3.7.2). Evidence for these flow paths is best defined in groundwater compositions of some of the more westerly samples of the GF group such as samples 160, 175, and 175 (Figure 6-50). 
Flow path 9 (Figure A6-62) is drawn to schematically illustrate deep underflow of groundwater from the carbonate aquifer, east of and including the GF and AF groups, beneath the Amargosa Desert and Funeral Mountains to the discharge points in Death Valley. The similarity in the chemical and isotopic characteristics of groundwater found in the Gravity fault area and groundwater that discharges from springs at sites 201 (Nevares Spring) and 202 (Travertine Spring) support this interpretation. The dissimilarity in $\mathrm{Cl}^{-}$(Figure A6-15), $\mathrm{Mg}^{2+}$ (Figure A6-21), and $\mathrm{SiO}_{2}$ (Figure A6-19) concentrations in these springs compared to the groundwater from the alluvial aquifer along the Amargosa River suggests that this alluvial groundwater is not the predominant source of the spring discharge in Death Valley.

\section{A6.3.11.1 Mixing Zones}

Figure A6-62 also highlights three zones (Mix A, B, and C) within which there is good evidence for mixing as demonstrated by trends of multiple solutes and isotope ratios on cross-correlation plots. Details of the mixing relations were given in Section A6.3.7.

Mixing zone A is defined by YM-S and CF-SW samples along U.S. Highway 95. The mixing zone is indicated by groundwater compositions of samples 78 to 85,89 , and 90 that are intermediate between the compositionally distinct groundwater of the CF-SW group and dilute groundwater of the YM-S group that is interpreted to have originated in the Yucca Mountain area (see Figure A6-49 and the discussion of flow paths 6 and 7 in Section A6.3.11). The location of the southernmost CF-SW samples coincides with a steep hydraulic gradient (Figure A6-3), which remains steep to the west but decreases to the east. Evidence for the distinct groundwater of the CF-SW group in boreholes to the south in the Amargosa Desert is lacking (for example, Figure A6-50). Thus, hydrochemical data and the hydraulic gradient suggest that southward flow indicated by flow path 5 is effectively blocked to the south. This flow is at least partly diverted to the east where it mixes with more dilute groundwater of the YM-S group to the east.

Mixing zone B consists of samples from the FMW-W and AR/FMW groups and a few samples from the FMW-S groups. The zone highlights groundwater with compositions that are intermediate between the distinct and consistent groundwater compositions of the AR group and the dilute groundwater of the FMW-S group (Figure A6-50). Flow path 1 is drawn to skirt the edge of mixing zone B and to connect the groundwater from the Amargosa River group to sample 181, which has a similar groundwater composition and is interpreted to represent undiluted groundwater from the AR group.

Mixing zone C consists of all samples from the LW and FMW-E groups, a few of the more westerly samples form the GF group, and at least one sample (141) from the FMW-S group. The mixing zone is characterized by small percentages of the distinctively high $\mathrm{SO}_{4}{ }^{2-}$ groundwater from borehole J-11 (Figure A6-51) in groundwater near flow path 3. This distinct hydrochemical signature persists in variable percentages as far south as borehole 150 . Groundwater with this distinctive signature is mixed to variable degrees with dilute water from the FMW-S group to the west or groundwater from the carbonate aquifer (GF Group) to the east. 
An important conclusion derived from identification of these mixing zones is that they qualitatively illustrate the extent of transverse dispersivity along certain flow pathways. The mixing zones also illustrate that, although some flow pathways may remain intact for great distances (e.g., paths 1 and 2), even these most-persistent flow paths eventually loose their distinct character, largely through mixing. This effect is best illustrated in southern Amargosa desert where flow paths 1,2 , and 3 , with contributions from 8 , converge and mix. The distinct end member groundwater of the AR and FMW-S groups, representing flow paths 1 and 2, appears to be absent at the southern boundary of the study area. Whereas it is possible that these end member groundwaters have not yet been sampled, the proximity of mixed groundwater samples in the southern part of the study area (samples 141, 174, 175, 183, 184, and 185) leaves little room for unmixed (end member) groundwater to move through the area. The hydrochemical data are interpreted to indicate that groundwaters from distinct sources that merge in the Amargosa Desert eventually lose their hydrochemically distinct character and flow southward as partially mixed groundwater.

\section{A7. SUMMARY, OUTPUT DATA TRACKING NUMBERS, AND UNCERTAINTIES}

\section{A7.1 SUMMARY}

Hydrochemical data from the saturated zone in the Yucca Mountain region were compiled, documented, and analyzed in this appendix. The hydrochemical data are used together with physical hydraulic data to evaluate the local and regional flow system at Yucca Mountain. This report provides an independent assessment of the flow patterns (Section A6.3.11) and recharge rates (Section A6.3.6) near Yucca Mountain that can be compared with flow paths and recharge rates associated with the Site-Scale SZ flow model documented in Table 6-17. This report also provides an independent basis for calculating groundwater residence times (Section A6.3.9) that can be compared with particle breakthrough curves calculated using the site-scale SZ transport model. Additionally, this appendix contributes to the resolution of technical issues associated with groundwater residence times and flow path lengths in alluvium and tuff, as discussed below. The methods used in this appendix are widely accepted, the data are sufficient and the analysis appropriate for the intended use if this document.

\section{A7.1.1 Summary of Overview Sections (Sections A6.3.1 to A6.3.5)}

Areal distributions of chemical and isotopic data as well as calculated parameters show many consistent patterns throughout the study area. Groundwater that has low concentration of most solutes characterizes groundwater beneath Yucca Mountain and in Fortymile Wash. Dilute groundwaters characterize the northern part of Fortymile Wash as well as the southern part in the Amargosa Desert. Increases in most solute concentrations occur to the west of Yucca Mountain and along the southern margin of Yucca Mountain near U.S. Highway 95. Dilute groundwaters are flanked by less dilute groundwaters to the east and west in the Amargosa Desert. Hydrochemical data presented in these sections provide first-order constraints on flow pathways. Groundwater beneath Yucca Mountain and in Fortymile Wash is characterized by low concentrations of most solutes. 
Section A6.3.3 reveals that some wells display significant hydrochemical variability with depth. An important example is illustrated in the data from wells NC-EWDP-19D and -19P, which show that groundwater in all zones is similar to groundwater from the volcanic aquifer at Yucca Mountain, whereas groundwater in $-19 \mathrm{P}$ is more chemically similar to groundwater in Fortymile Wash. These data illustrate potentially important information regarding flow pathways that may be obscured when only groundwater samples from open boreholes are available, as is the case for most data in this report. In the absence of additional discrete vertical sampling data, the two-dimensional analysis will form the basis of the flow-path analysis described herein.

\section{A7.1.2 Summary of Sources and Evolution of Recharge at Yucca Mountain (Section A6.3.6)}

Particular attention is given to this topic to set the stage for evaluation of flow from Yucca Mountain. Hydrochemistry of perched water is considered a reliable surrogate for potential recharge water. The hydrochemistry of perched groundwater is quite similar to that of groundwater beneath Yucca Mountain. Some perched water and groundwater beneath Yucca Mountain has similarly elevated ${ }^{234} \mathrm{U} /{ }^{238} \mathrm{U}$ activity ratios and relatively small uranium concentrations. Depth-dependent trends in uranium activity ratios of unsaturated-zone pore water and perched water are also consistent with a model for local recharge. Local recharge of groundwater beneath Yucca Mountain is also supported by hydrochemical evaluation of potential upgradient sources of groundwater. Significant hydrochemical differences between most of these waters argue against the possibility that significant percentages of upgradient groundwater are present at Yucca Mountain. It is therefore concluded that much of the water present beneath Yucca Mountain was derived from local recharge.

Estimates of the magnitude of recharge at Yucca Mountain were obtained using the chloride mass balance method. For groundwaters within the immediate vicinity of Yucca Mountain, chloride concentrations range from 5.7 to $10.8 \mathrm{mg} / \mathrm{L}$ (excluding p\#1-v), indicating local recharge rates between 4.7 and $17.9 \mathrm{~mm} /$ year using an average, present-day precipitation rate of $170 \mathrm{~mm} /$ year and an estimated range of $\mathrm{Cl}^{-}$concentrations in precipitation of 0.3 to $0.6 \mathrm{mg} / \mathrm{L}$.

The timing of recharge at Yucca Mountain was evaluated using hydrogen and oxygen isotopes as well as ${ }^{14} \mathrm{C}$ ages. Although the hydrogen and oxygen isotope data do not place an absolute age on the groundwater, they do indicate that the groundwater was recharged under paleoclimatic conditions that existed until the late Pleistocene. Corrected groundwater ${ }^{14} \mathrm{C}$ ages range from 11,430 years at borehole UE-25 WT\#3 to 16 years at borehole UE-25 WT\#12. These calculations are based on the averaged, that is, mixed age, of the groundwater sample. Calculations are also presented to bound the fraction of young water present in Yucca Mountain recharge. Estimates using an age of 1000 years for the young component range from a low of about 0.02 at borehole UE-25 WT\#12 to more than 0.15 at boreholes UE-25 WT\#3 and USW G-4. Smaller fractions of young water would be present if water younger than 1,000-year-old were assumed in the calculations. 


\section{A7.1.3 Summary of Groundwater Flow and Evolution Away From Yucca Mountain (Sections A6.3.7 to A6.3.10)}

Areal distribution plots reveal regions where steep gradients in solute concentrations and isotopic signatures exist. Based on evaluating elemental and isotopic correlation and PHREEQC analyses, it is concluded that mixing does readily explain compositional gradients in some areas. For example, mixing explains the compositional gradient displayed by the Nye County wells along U.S. Highway 95 where dilute groundwater to the southeast mixes with groundwater with high solute concentrations present to the northwest. Mixing also readily accounts for many of the groundwater compositions found in the Amargosa Desert. Here, dilute groundwater present along the Fortymile Wash drainage in the central part of the Amargosa Desert mixes with groundwater to the east and west to produce intermediate compositions. It is also concluded that sulfate-rich groundwater similar to that found in well J-11 is present in the Amargosa Desert. PHREEQC analyses help to confirm mixing relationships and define other components that must be added or removed through water-rock interaction to achieve observed groundwater compositions.

In Section A6.3.9, groundwater velocities are estimated along a selected flow path south of the repository in the Yucca Mountain area. Velocities are estimated by evaluating the ${ }^{14} \mathrm{C}$ activities of the groundwater along the flow path in context with PHREEQC analyses of groundwater evolution. Estimated groundwater velocities along a linear flow path from WT-24 to WT-3 are $46 \mathrm{~m} /$ year or higher. Groundwater velocities were also estimated along a flow path from WT-3 to the various zones sampled at NC-EWDP-19D. These velocities range from approximately $80 \mathrm{~m} /$ year to $5 \mathrm{~m} / \mathrm{year}$. The faster velocities are suggested to indicate that some of the shallow groundwater at well WT-3 moves along major faults such as the Paintbrush Canyon fault.

The site-scale saturated zone flow model (or, simply, SZ flow model) was used to simulate the movement of a conservative tracer from various segments along the boundaries in the model (Section A6.3.10). Flow patterns and mixing relations identified with the SZ flow model were generally consistent with flow patterns and mixing relations inferred from the hydrochemical and isotopic data for the area. Of particular importance are simulations of the movement of recharge from the Yucca Mountain area. These simulations indicate that groundwater from Yucca Mountain may not be easily identifiable in groundwaters south of Yucca Mountain because of dilution by groundwater from other, more active parts of the flow system. This groundwater mixture includes contributions from northwest Crater Flat, Timber Mountain, and Fortymile Canyon. In some other respects, the SZ flow model differs from what is inferred from the geochemical data. For instance, the SZ flow model appears to underestimate the quantity of inflow from the Fortymile Canyon area through the Tertiary units. This conclusion is based on the observation that groundwater along Fortymile Wash through Jackass Flats and the Amargosa Desert is chemically and isotopically unique compared to the surrounding groundwaters, but the tracer simulations indicate that groundwater inflow from Fortymile Canyon or from downgradient recharge along the wash is present only in dilute amounts along Fortymile Wash. Some of the discrepancy between the simulations and the data for the Fortymile Wash area may be due to recharge of some or most of this chemically distinct groundwater during wetter climate periods. 


\section{A7.1.4 Summary of Flow Pathways (Section A6.3.11)}

Flow paths can be traced using areal plots and scatterplots of geochemical and isotopic data, inverse mixing and water/rock interaction analyses involving PHREEQC, and simulations done with the SZ flow model. Because no single chemical or isotopic species varies sufficiently to determine flow paths everywhere in the study area, multiple chemical and isotopic species were considered.

Flow Path 1 (Figure A6-62) shows groundwater moving roughly parallel to the Amargosa River from an area west of Bare Mountain toward the southwest corner of the site model area. Flow Path 2 indicates that groundwater flows parallel to Fortymile Wash to connect upgradient areas in Fortymile Canyon with downgradient areas in the Amargosa Desert. Groundwater following Flow Path 3 flows from central Jackass Flats near well J-11 through the eastern part of the Amargosa Desert. Flow Paths 4 and 5 shows groundwater moving predominantly south-southeast through Crater Flat. Mixing relations and modeling suggest that these groundwaters leak across a region with a steep hydraulic gradient to mix with more dilute groundwaters to the southeast. Flow Paths 6 and 7 show groundwater flow from the Solitario Canyon area to the south. Again, leakage to the southeast across a steep hydraulic gradient coincident with the Solitario Canyon fault is suggested by hydrochemical trends. Groundwater from northern Yucca Mountain is interpreted to flow southeast toward lower Dune Wash and then southwestward toward wells located west of Fortymile Wash near U.S. Highway 95 (Flow Path 7). The location of Flow Path 7 implies that groundwater from the repository area will flow further to the west of this path. Flow Path 8 illustrates leakage to the east across the hydrologic boundary between the carbonate aquifer to the east and the alluvial aquifer in Amargosa Desert. Flow Path 9 schematically illustrates deep underflow of groundwater from the carbonate aquifer, east of and including the GF and AF groups, beneath the Amargosa Desert and Funeral Mountains to the discharge points in Death Valley.

Regions where mixing relations are strongly suggested by hydrochemical data are also shown in Figure A6-62. An important conclusion derived from drawing these mixing zones is that they document and qualitatively illustrate the extent of transverse dispersivity along certain flow pathways. The mixing zones also illustrate that although some flow pathways may remain intact for great distances (e.g., Paths 1 and 2), even these most persistent flow paths eventually lose their distinct character largely through mixing as is demonstrated in southern Amargosa Desert along the southern border of the map area.

\section{A7.2 DATA TRACKING NUMBERS}

Several data tracking numbers (DTNs), generated in this appendix are cited elsewhere in this report where they are used as indirect input. These are listed below in an order that coincides with the structure of the appendix. These results are not qualified and cannot be used as direct input without qualification:

Regional groundwater hydrochemical data: DTNs: LA0309RR831233.001 [DIRS 171890] and LA0309RR831233.002 [DIRS 171890]

Calculated hydrochemical parameters: DTN: LA0310EK831232.001 [DIRS 165995] 
Calculation of corrected and uncorrected groundwater ${ }^{14} \mathrm{C}$ ages: DTN: LA0202EK831231.002 [DIRS 165507]

Calculations of fractions of young water in selected Yucca Mountain groundwaters: Output DTN: LA0202EK831231.004

Groundwater travel-time calculations for selected wells: DTN: LA0310EK831231.001 [DIRS 171889]

FEHM groundwater models of nonreactive tracer transport in the Yucca Mountain area: DTN: LA0309EK831231.001 [DIRS 171887]

A map of groundwater flow paths in the Yucca Mountain area: DTN: LA0308RR831233.001 [DIRS 171890].

\section{A7.3 UNCERTAINTIES AND RESTRICTIONS}

The evaluations and conclusions presented in this appendix are interpretive in nature. The overall uncertainty of these interpretations is a function of the analytical uncertainty of the data on which the interpretations were based, the distribution of data both areally and with depth, the representativeness of these data for various parts of the groundwater system, and the uncertainty in the conceptual models that formed the framework for the interpretations.

Results presented in this appendix are affected to different degrees by each of these uncertainties. The following sections list the key uncertainties associated with each of the DTNs cited in Section A7.2.

\section{A7.3.1 Compilation of Hydrochemical Data}

The uncertainty associated with the DTNs results primarily from the analytical uncertainty associated with the measurements and the representativeness of the data for those parts of the aquifer from which the groundwater samples were taken. Ideally, groundwater samples are taken after the well has been pumped for some time after drilling so that the effects of foreign drilling fluids and borehole cuttings on in situ groundwater compositions have been mitigated. Although this is true of the vast majority of the samples used in this report, a small number of samples used in this report originated from wells in which the samples were bailed prior to a "clean-out" period. This approach may have caused the chemical characteristics of these samples to change somewhat relative to in situ groundwater. In general, bailed samples were used in this report only if later pumped samples were not available from a particular well. The representativeness of sampled groundwater of in situ groundwater compositions is also related to the depth interval over which the sample was taken. Most hydrochemical data reported here are from single-interval boreholes, the hydrochemistry of which will represent an average of the sampled depth intervals. Hydrochemical data for discrete depth intervals are presented in Section 6.7.3.

The representativeness of sampled groundwater of in situ conditions may also be affected by the sampling method. For example, choice of container or prolonged exposure to atmosphere may affect groundwater chemistry. Most sample data presented herein were collected by the United 
States Geological Survey (or by their contractors), who have a long and proven record of groundwater sampling using proven techniques. Furthermore, Yucca Mountain Project Quality Assurance Programs also govern many of these sampling procedures. This program is designed to assure that methods utilized are appropriate for the desired purpose. Thus, the data are accepted to be representative of in situ conditions. All analytical data presented herein have uncertainty associated with the individual values. These uncertainties reflect limits of precision of the analytical technique combined with accuracy of the measurement, which is typically determined by replicate analysis of samples (standards) with known values. The data presented herein were determined using a variety of analytical techniques by a number of laboratories, collected over a span of more than 20 years, during which time analytical techniques and associated uncertainties have changed. In some cases, uncertainties for individual analytes or groups of analytes are presented in the original data sources, however, in other data sets analytical uncertainties are neither given nor discussed. Some examples of stated uncertainties are presented below.

The National Water Quality Laboratory produced many of the data presented herein for the Yucca Mountain Program at the United States Geological Survey and uncertainties are stated in some of the DTNs. For example, accuracy for major anions, cations and strontium concentration is estimated to be better than 10 percent except for fluoride, which is estimated at 15 percent (DTN: GS000308312322.003 [DIRS 149155]). Uncertainty in concentration of major anions and cations as well as strontium concentration is quoted at less than 10 percent in DTN: GS011108312322.006 [DIRS 162911]. This DTN also presents uncertainties for isotopic measurements as follows (all given in per mil): deuterium $3.0,{ }^{18} \mathrm{O} 0.2,{ }^{13} \mathrm{C} 0.2$ and ${ }^{34} \mathrm{~S} 0.2$. In some cases, strontium was determined by isotope dilution, mass spectrometry methods, for which data are more precise (e.g. 0.5 percent, DTN: GS970708315215.008 [DIRS 164674]). Uncertainties for ${ }^{14} \mathrm{C}$ are $0.1 \mathrm{pmc}$ for data presented in DTN: GS011108312322.006 [DIRS 162911]. Uncertainties for uranium concentration are given as better than 1 percent (Paces et al 2002 [DIRS 158817]). Uncertainties in uranium isotope ratios $\left({ }^{234} \mathrm{U} /{ }^{238} \mathrm{U}\right)$ are typically given with each individual analysis in the original data source. For example, uncertainties presented in Paces et al. (2002 [DIRS 158817], Table 2) range from 0.09 percent to 4.5 percent with a mean of 0.73 percent (with the exception of a single analysis of a rainfall sample with small $U$ concentration for which uncertainty in the ${ }^{234} U /{ }^{238} U$ ratio is 9.8 percent). Uncertainties for strontium isotope ratios $\left({ }^{87} \mathrm{Sr} /{ }^{86} \mathrm{Sr}\right)$ are typically quoted at 0.00001 for absolute values (e.g. DTN: GS011108312322.006 [DIRS 162911] and for Nye County wells), which translates to an uncertainty of approximately 0.01 in $\delta^{87} \mathrm{Sr}$ units.

For the purpose of this report, uncertainties assigned to analytical data are based on one or more of the following: (1) stated uncertainties in the original data set; (2) consideration that data produced by the same facility, for which no uncertainties are stated, are likely to have similar uncertainties to data with stated uncertainties; (3) typical uncertainties given in the literature; or (4) the authors' personal experience with typical uncertainties associated for various analytical techniques and analytes. Where uncertainties are not stated, the following uncertainties are assigned to the analytical data: Major anions and anions and strontium concentration: 10 percent; fluoride concentration: 15 percent; stable isotopes of hydrogen, oxygen, sulfur, and carbon (expressed as $\delta \mathrm{H}, \delta \mathrm{O}, \delta \mathrm{S}$, and $\delta \mathrm{C}$ in per mil): 0.2 ; and ${ }^{14} \mathrm{C}: 0.2$ pmc. Uncertainties in uranium concentration and uranium and strontium isotope ratios are given in the original data sets. 
In addition to analytical errors, many of the samples in the portion of the data set that had no prior DTNs may have an additional uncertainty in that they were obtained from a database (geochem02.mdb) that does not represent the primary source of the data. Hence, the possibility of transcription errors is compounded. Where original published sources could be found and checked against that database, some transcription errors in the database were evident. This uncertainty affects only groundwater samples at locations to the west, north, and east of the site model area, outside of the site model area.

It is prudent to point out that most of the evaluations presented herein are based on hydrochemical groupings and general data trends displayed within and among these groupings as opposed to any one analysis or data set from any one sample. Generally, the range of analytical values displayed within a single hydrochemical grouping is greater than the analytical uncertainty for any individual analysis. Hydrochemical groupings and data trends remain valid and essentially unaffected by considerations of analytical uncertainty.

\section{A7.3.2 Calculated Hydrochemical Parameters}

The uncertainty in the calculated hydrochemical parameters reflects the analytical uncertainty of the measurements, the representativeness of these measurements of in situ groundwater conditions, and uncertainty in the solubility constants of the minerals for which saturation indices were calculated. Uncertainty in the applicability of the solubility constants arises from (1) inaccurate, incomplete or inconsistent thermodynamic data, (2) nonstoichiometric or variable mineral compositions, (3) differences in the particle sizes of minerals that produced the thermodynamic data and particle sizes of minerals to which the data were applied, (4) model assumptions and limitations, such as which aqueous complexes are considered in the model, and (5) kinetic effects arising from slow reaction rates relative to groundwater residence times (Langmuir 1997 [DIRS 100051], p. 221). In addition, because solubility constants are a function of temperature, uncertainty in groundwater temperatures affects the calculated saturation indices. Measured groundwater temperatures were used to calculate saturation indices for most wells considered in this report. For a relatively small number of wells in the Yucca Mountain area, groundwater temperatures were estimated from published maps of water table temperatures. Groundwaters in the Amargosa Desert with no temperature data were assumed to be at $25^{\circ} \mathrm{C}$ based on the measured groundwater temperatures of nearby wells. A sensitivity analysis to examine the effect of temperature changes on $\log P_{\mathrm{CO} 2}$ and mineral saturation indices for groundwater from well $\mathrm{J}-13$ indicated the following uncertainties as assumed temperatures were varied by $\pm 5^{\circ} \mathrm{C}$ around $25^{\circ} \mathrm{C}$ : $\log P_{\mathrm{CO} 2}( \pm 0.06), S I_{\text {calcite }}( \pm 0.04), S I_{\text {smectite }}( \pm 1.72), S I_{\text {Ca-clinoptilolite }}$ $( \pm 4.77), S I_{\mathrm{SiO} 2(\mathrm{a})}( \pm 0.04), S I_{\text {fluorite }}( \pm 0.06), S I_{\text {albite }}( \pm 0.28), S I_{\mathrm{K}-\text { feldspar }}( \pm 0.34)$, and $S I_{\text {dolomite }}( \pm 0.14)$. Saturation indices for calcite and dolomite and $\log P_{\mathrm{CO} 2}$ increase with temperature, but the remaining saturation indices decrease with temperature. The saturation indices of smectite and Ca-clinoptilolite are particularly sensitive to temperature because of the large enthalpies estimated for these minerals (Table A6-4); however, groundwaters in the Amargosa Desert are typically very supersaturated with these minerals (Figures A6-38 and A6-39), so that a temperature uncertainty of $\pm 5^{\circ} \mathrm{C}$ does not change the fundamental conclusion that groundwaters in the Amargosa Desert are supersaturated with these minerals. For other minerals, uncertainty in groundwater temperatures of $25 \pm 5^{\circ} \mathrm{C}$ introduces less absolute uncertainty into the calculated saturation indices. 
Another source of uncertainty in the calculated saturation indices of alumino-silicate minerals concerns the assumption that total dissolved $\mathrm{Al}^{3+}$ concentrations are in equilibrium with kaolinite. This assumption was based on an empirical fit to dissolved $\mathrm{Al}^{3+}$ concentrations from a subset of the Yucca Mountain area wells for which dissolved $\mathrm{Al}^{3+}$ data exist (see Section A6.3.5). Estimates of $\mathrm{Al}^{3+}$ concentrations that rely on assumed equilibrium with kaolinite underestimate measured $\mathrm{Al}^{3+}$ concentrations by $-3.0 \pm 2.9 \mathrm{ppb}$. If the actual $\mathrm{Al}^{3+}$ concentrations were approximately $3 \mathrm{ppb}$ higher than was estimated for the Yucca Mountain area, the saturation indices of all Al-bearing minerals would increase. Assuming $\mathrm{Al}^{3+}$ equilibrium with kaolinite, most groundwaters in the Yucca Mountain area are estimated to be saturated with smectite and Ca-clinoptilolite (Figures A6-38 and A6-39). With higher $\mathrm{Al}^{3+}$ concentrations, these groundwaters would be even more supersaturated with these minerals. Groundwaters in the Yucca Mountain area are presently estimated to be both undersaturated and supersaturated with K-feldspar (Figure A6-37). With higher $\mathrm{Al}^{3+}$ concentrations, some groundwaters that are estimated to be undersaturated with K-feldspar might be calculated to be saturated or supersaturated with K-feldspar.

\section{A7.3.3 Calculated ${ }^{14} \mathrm{C}$ Ages}

The calculations of ${ }^{14} \mathrm{C}$ ages used the downgradient increase in the DIC concentrations of selected Yucca Mountain area groundwaters, relative to the DIC concentrations of Yucca Mountain perched waters to estimate the extent of ${ }^{14} \mathrm{C}$ dilution by calcite dissolution in the saturated zone (Section A6.3.6.6.2). The selected groundwater samples were chosen because they, like the perched water samples, had high ${ }^{234} \mathrm{U} /{ }^{238} \mathrm{U}$ activity ratios relative to many Yucca Mountain area groundwaters, thus indicating the likelihood of a common origin. The estimated increases in the DIC concentrations of the groundwaters were then used to reduce the initial ${ }^{14} \mathrm{C}$ activities to below their original atmospheric values to calculate a "corrected" ${ }^{14} \mathrm{C}$ age for the groundwater. The critical assumptions in this analysis are that (1) the perched water itself required no age corrections and (2) that the measured increases in groundwater DIC relative to perched water limit the amount of ${ }^{14} \mathrm{C}$ dilution by calcite. Assumption (1) appears to be valid based on the historic variations of ${ }^{36} \mathrm{Cl} / \mathrm{Cl}$ and ${ }^{14} \mathrm{C}$ activities measured on organic carbon in pack-rat middens and similar relations between ${ }^{36} \mathrm{Cl} / \mathrm{Cl}$ and ${ }^{14} \mathrm{C}$ activities measured for inorganic carbon in perched water. Assumption (2) requires that no reductions in groundwater DIC concentrations take place through exsolution of $\mathrm{CO}_{2}$ during groundwater flow or during sampling. Although $\mathrm{CO}_{2}$ losses from groundwater to the unsaturated zone are estimated to be small because of the low diffusion of $\mathrm{CO}_{2}$ in groundwater, exsolution of $\mathrm{CO}_{2}$ during groundwater sampling may be a more significant effect. However, groundwater at the wells where ${ }^{14} \mathrm{C}$ age corrections were made typically had relatively low $(<7.8) \mathrm{pH}$ values, indicating that the effects of degassing on DIC concentrations during sample collection were minimal.

\section{A7.3.4 Calculations of the Fractions of "Young" Water in Yucca Mountain Groundwaters}

These calculations interpret the measured ${ }^{14} \mathrm{C}$ activities of groundwater beneath Yucca Mountain to result from the mixing of groundwater that has been recharged at different times from the unsaturated zone at Yucca Mountain. Although recharge may have been added continuously over time at varying rates to Yucca Mountain groundwater, the calculations simplify the actual distribution by assuming that the measured ${ }^{14} \mathrm{C}$ activities result from the mixing of an "old" 
component and a "young" component that are widely separated in time. This approach effectively replaces the actual (but unknown) distribution of groundwater ages by a bimodal distribution of ages with the same mean age. This idealized distribution of ages places more emphasis on the very young and very old groundwaters than the actual age distribution would indicate. This method provides upper bounds to the fraction of young groundwater in the mixture, which is the quantity of interest in these calculations.

\section{A7.3.5 PHREEQC Inverse Models of Groundwater Mixing and Water-Rock Interaction}

The PHREEQC inverse models of groundwater mixing and water-rock interaction described in Section A6.3.8 are affected by uncertainties in the accuracy and representativeness of groundwater compositions (see Section A7.3.1), uncertainties in mineral-phase compositions, and uncertainties in the conceptual model. The uncertainties in the accuracy and representativeness of groundwater compositions are accounted for in the PHREEQC models through user-specified uncertainty criteria. Generally, uncertainties specified in the PHREEQC models were 10 percent or less of the measured concentrations for major and minor ions, 0.1 per mil for $\delta^{18} \mathrm{O}, 1.0$ per mil for $\delta \mathrm{D}, 0.1$ per mil for $\delta^{13} \mathrm{C}$, and $0.05 \mathrm{pH}$ units for $\mathrm{pH}$. These uncertainties were intended to reflect not only analytical uncertainty in the measurements (See Section A7.3.1) but also the representativeness of the groundwater samples in light of the chemical and isotopic heterogeneity that exists in groundwaters from closely spaced wells. It was necessary to specify some uncertainty in these models in order to simultaneously satisfy the multiple mass-balance constraints involved in any particular model. There is also some variability in mineral phase compositions from Yucca Mountain and, hence, some uncertainty in specifying a single representative phase composition for the entire area. This variability is particularly true of clinoptilolites, which are known to have east-to-west chemical variations across the Yucca Mountain area (Broxton et al. 1987 [DIRS 102004]). Generally, clinoptilolite compositions used in any particular model were chosen to be representative of the area near the wells considered by that model. For reactions involving the dissolution or precipitation of calcite (or dolomite), it was necessary to specify the $\delta^{13} \mathrm{C}$ composition of the calcite. The $\delta^{13} \mathrm{C}$ compositions are variable in SZ calcites and, therefore, some uncertainty exists in choosing a single representative value. Calcite in the volcanic aquifers was assumed to have $\delta^{13} \mathrm{C}$ values of between $-4 \pm 3$ and $-1 \pm 3$ per mil, whereas calcite in the alluvial aquifers near Fortymile Wash was assumed to be $-4 \pm 3$ per mil. Although the values of $\delta^{13} \mathrm{C}$ used for the volcanic aquifer are in agreement with measured values (Whelan et al. 1998 [DIRS 137305]), the isotopic characteristics of calcite in alluvium have not been measured at Yucca Mountain. The calcite in alluvium was assumed to have isotopic characteristics $\left(\delta^{13} \mathrm{C}=-4\right.$ per mil) similar to pedogenic calcite at the surface of Yucca Mountain (Table A5-1 in Assumption 9).

The specified uncertainty in solution compositions and in the isotopic composition of the minerals is propagated through the PHREEQC inverse models so that, for each model, upper and lower bounds are also estimated for the mixing ratios and amounts of each mineral phase dissolved. However, although quantitative measures of uncertainty are provided for each model discussed in this report (DTN: LA0310EK831232.001 [DIRS 165995]), these uncertainty estimates do not consider the other combinations of mineral reactions and mixing end members present in alternative models identified by PHREEQC. Additionally, these uncertainty estimates do not consider the conceptual model uncertainty. 
Conceptual-model uncertainty includes the choice of mineral phases to be considered in a particular model, any constraints on the precipitation/dissolution or exchange reactions imposed on these phases, and the choice of groundwaters considered in these models as potential mixing components. The rationale behind selection of these various parameters is discussed in Section A6.3.8. It is acknowledged; however, that all possible combinations of these parameters were not exhaustively evaluated. Other combinations of end-member mixing components and reaction history could possibly be modeled to yield a particular downgradient water chemistry. Given all the potential combinations of mixing end members and reaction models, it is impossible to quantify uncertainty related to uncertainties in the conceptual model.

\section{A7.3.6 Groundwater Velocities}

The groundwater velocities calculated in Section A6.3.9 were based on the measured groundwater ${ }^{14} \mathrm{C}$ activities at wells defining a flow path segment, the linear distance between the wells, and the water-rock interactions identified by the PHREEQC models for that flow-path segment. The calculated velocities are, therefore, affected by the accuracy and representativeness of the groundwater ${ }^{14} \mathrm{C}$ measurements (see Section A7.3.1), the assumption that groundwater flows along a straight path between the wells defining the flow-path segment, and the uncertainties associated with the PHREEQC models, as described in Section A7.3.5. An indication of the quantitative uncertainty associated with transit times is provided by the standard deviations associated with transport times based on the PHREEQC models and differences between the means of these estimates and estimates made based on downgradient increases in DIC concentrations (Table A6-11). An additional uncertainty that may impact these calculations concerns the implicit assumption that no additional ${ }^{14} \mathrm{C}$ is added to the groundwater from downgradient recharge as the groundwater moves from the upgradient to downgradient wells defining a flow-path segment. Recharge at Yucca Mountain may not vary enough spatially to guarantee that upgradient and downgradient recharge could be recognized in a mixture.

\section{A7.3.7 FEHM Groundwater Models of Nonreactive Tracer Transport in the Yucca Mountain Area}

The FEHM simulations of nonreactive tracer transport described in Section A6.3.10 used the Yucca Mountain site-scale saturated zone flow model documented in Table 6-17. Uncertainties associated with this flow model are documented therein. An additional uncertainty that pertains to the tracer simulations but not the flow model itself concerns numerical dispersion associated with the advection/dispersion equation. Numerical dispersion would tend to cause greater apparent mixing and dilution than would be present solely because of hydraulic conductivity variations in the model. These effects are likely to have influenced the tracer concentration distributions shown in Section A6.3.10 and, in particular, the relatively dilute concentrations near the edges of these tracer plumes may be an artifact of this numerical dispersion.

\section{A7.3.8 A Map of Groundwater Flow Paths for the Yucca Mountain Area}

The map of groundwater flow paths in the Yucca Mountain area (Figure A6-62) was developed on the basis of areal variations of chemical and isotopic species (Section A6.3.4), scatterplots that indicated mixing between groundwaters from different areas (Section A6.3.7), and PHREEQC models of groundwater mixing and chemical evolution (Section A6.3.8). The 
flow-path map is affected, therefore, by the uncertainties already described for these outputs in Sections A7.3.1, A7.3.2, and A7.3.5.

Possibly, the most important uncertainty in the flow path map relates to the source of the groundwater at well NC-EWDP-19D (Sites 92 and 94-98). Two equally plausible sets of groundwater mixing and reaction models were developed with PHREEQC for groundwater at well NC-EWDP-19D, each of which implies a different direction for groundwater flow from the repository area in southern Yucca Mountain. The first set of models indicates that groundwater from various depths at NC-EWDP-19D originates from groundwater in the Dune Wash area (represented by groundwater from well WT-3) and a set of water-rock-gas reactions. These results are represented on the flow-path map as the southern part of Flow Path 7. Groundwater from the repository area would be constrained by the southern part of Flow Path 7 to move predominantly southward or southwestward through southern Yucca Mountain, thereby avoiding most of the alluvium north of U.S. Highway 95. The second group of PHREEQC models for groundwater from various zones in well NC-EWDP-19D indicated that these groundwaters are a mixture of groundwaters from the Solitario Canyon Wash area (represented by groundwater from well WT-10) and local Yucca Mountain recharge (represented by perched water from borehole SD-7), plus a set of water-rock reactions. This origin for the groundwater at well NC-EWDP-19D indicates that groundwater from the repository area will follow a more southeasterly trajectory and would probably encounter more of the alluvium west of Fortymile Wash than is indicated by Flow Path 7. The leakage of groundwater from the Solitario Canyon area across the Solitario Canyon fault beneath Yucca Mountain is indicated by the southeast-trending arrows originating from Flow Path A6.

\section{A8. RESULTS, LISTED BY DATA TRACKING NUMBER}

These results are not qualified and cannot be used as direct input to models or scientific analyses without qualification:

LA0202EK831231.002 [DIRS 165507] Calculation of Corrected and Uncorrected Groundwater Carbon-14 Ages. Submittal date: 02/25/2002.

LA0202EK831231.004. Calculation of the Maximum Possible Percentage of 1000 Year-old Water Present in Selected Yucca Mountain Area Groundwater Samples. Submittal date: 02/25/2002. (output).

LA0308RR831233.001. Regional Groundwater Flow Pathways in the Yucca Mountain Area Inferred from Hydrochemical and Isotopic Data.. Submittal date: 08/25/2003.

LA0309EK831231.001. SZ Flow and Transport Model, FEHM Files for Tracer Transport. Submittal date: 09/02/2003. 
LA0309RR831233.001. Regional Groundwater Hydrochemical Data in the Yucca Mountain Area Used as Direct Inputs for ANL-NBS-HS-000021, Rev. 01. Submittal date: 05/09/2003.

LA0309RR831233.002. Regional Groundwater Hydrochemical Data in the Yucca Mountain Area Used as Corroborative Data for ANL-NBS-HS-000021, Rev. 01. Submittal date: 05/09/2003.

LA0310EK831231.001. SZ Geochemical Calculations, Groundwater Travel Times for Selected Wells. Submittal date: 10/16/2003

LA0310EK831232.001. SZ Geochemical Models, PHREEQC Files for Selected Groundwater Parameters. Submittal date: 10/02/2003. 


\section{INTENTIONALLY LEFT BLANK}

